\title{
ARQUITECTURA TERAPÉUTICA
}

EL SANATORIO ANTITUBERCULOSO PULMONAR
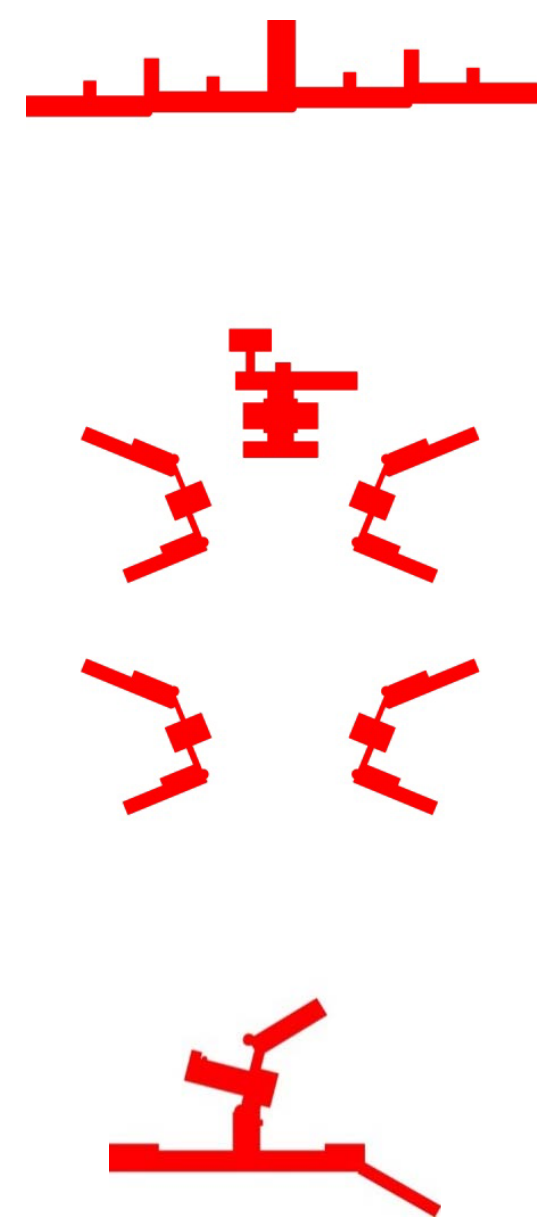

Autora: CECILIA RUILOBA QUECEDO Directora: JOSEFINA GONZÁLEZ CUBERO UNIVERSIDAD DE VALLADOLID ESCUELA TÉCNICA SUPERIOR DE ARQUITECTURA Departamento: TEORÍA DE LA ARQUITECTURA Y PROYECTOS ARQUITECTÓNICOS 


\section{Universidad deValladolid}

Tesis doctoral:

ARQUITECTURA TERAPÉUTICA: EL SANATORIO ANTITUBERCULOSO PULMONAR

Presentada para optar al grado de doctora por:

CECILIA RUILOBA QUECEDO

Directora: JOSEFINA GONZÁLEZ CUBERO

UNIVERSIDAD DE VALLADOLID ESCUELA TÉCNICA SUPERIOR DE ARQUITECTURA Departamento: TEORÍA DE LA ARQUITECTURA Y PROYECTOS ARQUITECTÓNICOS 


\section{Agradecimientos}

Quiero manifestar mi gratitud a todos aquellos que han contribuido a la realización de esta Tesis doctoral.

En primer lugar quisiera dar las gracias a mi directora de tesis la profesora Josefina González Cubero, por su gran generosidad intelectual y académica, sólo superada por la personal. Igualmente, quiero agradecer al Presidente y a todos los demás miembros del Tribunal que hayan aceptado participar en el juicio y valoración de esta investigación.

Quisiera también mostrar mi gratitud al profesor Pedro Iglesias Picazo por sus consejos y por su apoyo al ponerme en contacto con el profesor Jan Molema, quien me acogió desinteresadamente en Holanda y me brindó todos sus conocimientos. A la profesora Luz Estela Carrero Flores por su contribución desde Caracas a la búsqueda de documentación sobre Rafael Bergamín durante su exilio en Venezuela. Además de a los profesores del Departamento de Teoría de la Arquitectura y Proyectos arquitectónicos por su apoyo y su interés, y al resto de profesores y personal de la Escuela Técnica Superior de Arquitectura de la Universidad de Valladolid por los ánimos que me han trasmitido.

Agradezco a la profesora Guillemette Morel-Journel y a Arnaud Dercelles de la Fundación Le Corbusier de París su amabilidad y su ayuda durante mi visita. Al Dr. Ramón Navarro García y a Lourdes Mariño Gutiérrez, miembros del Museo de Sanidad e Higiene Publica, la información obtenida a través de las conversaciones mantenidas y de los documentos facilitados; y a Francisco Fuster de la Mata, Jefe del área de infraestructuras del Instituto Carlos III, su permiso para consultar los archivos de dicha institución. A Susanna Pettersson y a Meria Maino del Alvar Aalto Museo quiero darles las gracias por su imprescindible colaboración para la concesión de la beca de formación que me facilitó viajar a Finlandia; y a Tuija Lind y Marianna Heikinheimo de Helsinki su hospitalidad y su ayuda durante mi estancia. A las Bibliotecas, Archivos y demás organismos nacionales e internacionales consultados reconocer sus importantes aportaciones a la base documental de este trabajo, en particular quisiera dar las gracias a la Biblioteca de Arquitectura de Valladolid y a su personal por su constante ayuda.

Por último a mis amigos, y de una manera especial a Miguel y a mis padres, gracias por cuidarme y apoyarme siempre, por el cariño, la ayuda y la cofianza que me han dado, sin los cuales no hubiera tenido la fuerza necesaria para realizar este trabajo. 
INTRODUCCIÓN. p.3

I. MEDICINA Y ARQUITECTURA

CAPÍTULO 1

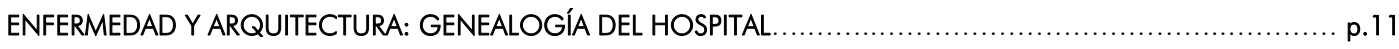

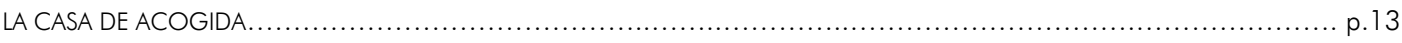

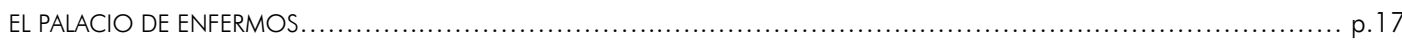

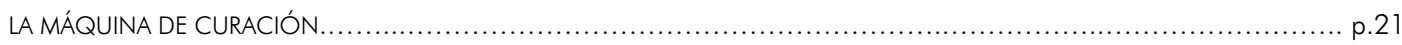

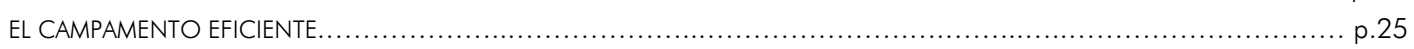

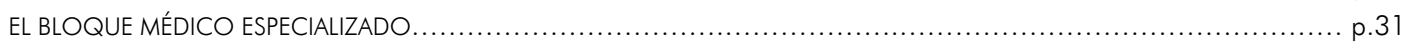

CAPÍTULO 2

MEDICINA Y ARQUITECTURA: TERAPIAS ANTITUBERCULOSAS Y PROPUESTAS EXPERIMENTALES ................... p.37

LA CONSIDERACIÓN DE INCURABLE Y LA ILUSIÓN TERAPÉUTICA: EL ASILO AISLADO ................................... p. 44

LA CURA EN EL LITORAL Y LA CURA DE ALTURA: LA IMPORTANCIA DEL MEDIO ........................................ p. 47

LA TERAPIA DE EJERCICIO Y LA TERAPIA DE REPOSO: LA GALERÍA DE CONVALECENCIA.................................... p. 51

LA VIDA EN EL HOTEL Y LA VIDA EN LA CABAÑA: EL PATRÓN MÉDICO ................................................ p. 63

HELIOTROPISMO PASIVO Y HELIOTROPISMO DINÁMICO: LA SECCIÓN ESCALONADA ................................... p.69

LAS TERAPIAS CLIMÁTICAS Y LA CURA DE TRABAJO: LA CIUDAD SANATORIO ......................................... p. 77

CAPÍTULO 3

LA BÚSQUEDA DE LO ESPECÍFICO: EL SANATORIO ANTITUBERCULOSO PULMONAR .......................... p.83

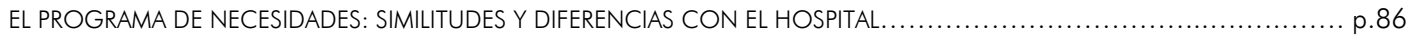

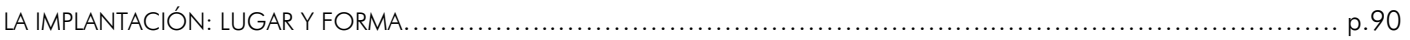

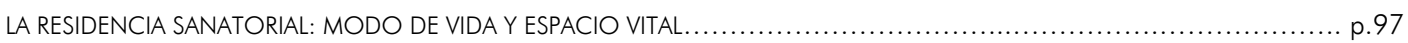

EL DISEÑO INTEGRAL DEL SANATORIO: EL MOBILIARIO Y EL DETALLE.................................................. p. 105

\section{EL SANATORIO ANTITUBERCULOSO PULMONAR Y LA ARQUITECTURA MODERNA}

\section{CAPÍTULO 4}

LA UNIDAD CIENTÍFICA DE LAS PARTES:

EL SANATORIO EN BLOQUE DE LOS MONTALVOS. RAFAEL BERGAMÍN ...................................... p. 115

LA ARQUITECTURA "IIMPIA "DE RAFAEL BERGAMÍN................................................................ p. 117

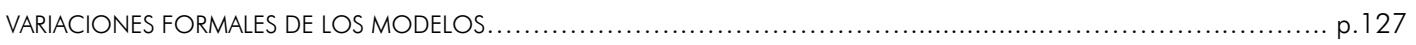

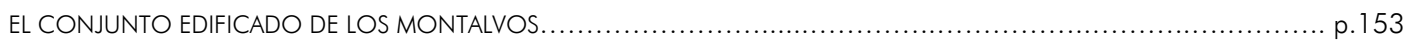

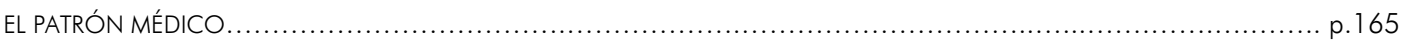

CAPÍTULO 5

LA ESCISIÓN HIGIÉNICA DE LAS PARTES:

EL SANATORIO DE PABELLONES DE ZONNESTRAAL. JOHANNES DUIKER .................................. p.191

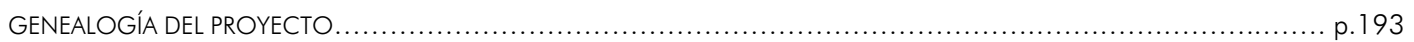

ALTERACIONES CONCEPTUALES DEL TIPO: EL PROYECTO DE ZONNESTRAAL.......................................... p. 214

LAS MODERNAS SALAS DE LA FÁBRICA DE CURAR ENFERMOS.................................................... p. 244

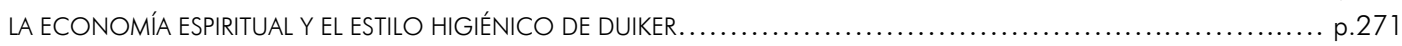

\section{CAPÍTULO 6}

LA AGRUPACIÓN BIOLÓGICA DE LAS PARTES:

EL SANATORIO POLIMÓRFICO DE PAIMIO. ALVAR AALTO .................................................... p.289

LA ESTRUCTURACIÓN EN PARTES Y LA HERENCIA CLASICISTA...................................................... p. 291

LA METAMORFOSIS DEL TIPO ARQUITECTÓNICO: EL PROYECTO DE PAIMIO .......................................... p. 297

EL HOGAR DEL ENFERMO EN EL SANATORIO: LA UNIDAD DE ENFERMERÍA......................................... p.327

EL PROCESO EVOLUTIVO DE LA ARQUITECTURA EN ALVAR AALTO............................................... p.35 


\section{HACIA UNA ARQUITECURA TERAPÉUTICA}

CAPÍTULO 7

ESPACIOS PARA MORIR Y ESPACIOS PARA VIVIR.

p.369

SANATORIOS, BUQUES INSIGNIA DE LA VANGUARDIA ARQUITECTÓNICA .......................................... p.371

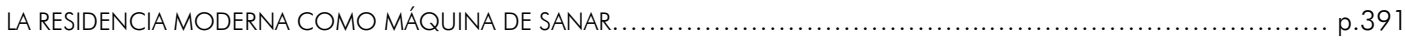

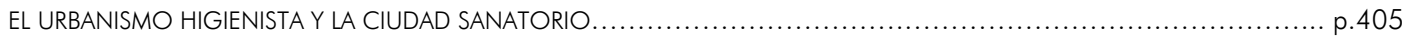

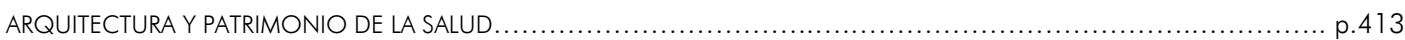

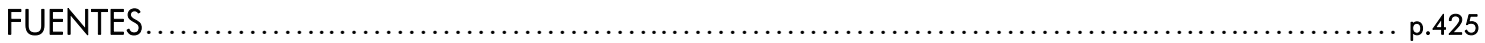

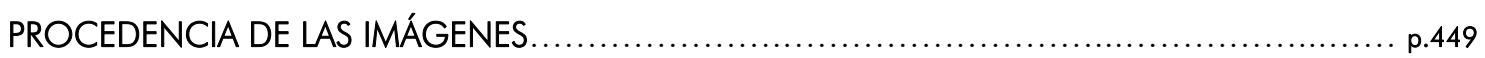




\section{INTRODUCCIÓN}

El presente trabajo de investigación trata de mostrar la influencia que el sanatorio antituberculoso pulmonar ha tenido en la arquitectura, no sólo entre las edificaciones hospitalarias, sino también en otros campos que ésta abarca.

El interés personal por realizar una investigación esencialista y la propuesta de estudiar una arquitectura científica sugerida por parte de la profesora Josefina González Cubero, directora de esta tesis doctoral, se concretan en el estudio de la arquitectura del sanatorio antituberculoso un género hospitalario específico de gran repercusión en la arquitectura del siglo XX.

Una reflexión sobre el tema escogido en términos de utilidad, desataría ciertos interrogantes sobre el interés que puede suscitar hoy el estudio de los sanatorios antituberculosos pulmonares, cuando hace más de medio siglo que, gracias al avance de la medicina, escasean los casos de tuberculosis y los enfermos que aún perduran, pueden ser tratados en hospitales generales y no precisan ya de estos centros especializados.

Incluso, una deliberación más amplia, Ilevaría a cuestionar el valor que tiene investigar sobre los hospitales, un género tan poco trascendente para los críticos e historiadores de la arquitectura moderna, a juzgar por su escasa representación en los manuales de arquitectura'.

Sin embargo, siendo la arquitectura hospitalaria un campo muy especializado, marcado por estrictos condicionantes terapéuticos, se comprueba que éste también participa de los presupuestos de la arquitectura de la época e, incluso, puede ayudar a configurarlos.

La tesis pretende encuadrar al sanatorio antituberculoso pulmonar dentro de la arquitectura de la modernidad europea, estudiando previamente la herencia que le llega. Para ello se plantea un análisis tipológico general del hospital y de cómo van configurándose los centros de infecciosos hasta llegar al estudio específico del sanatorio como hospital de especialización terapéutica del siglo XX.

La relación del sanatorio con la arquitectura moderna y su influencia resulta en ciertos casos evidente si se analiza la trayectoria profesional de los arquitectos que los proyectaron y

\footnotetext{
'Sólo dos obras hospitalarias, el Sanatorio antituberculoso de Paimio de Alvar Aalto y el proyecto del Hospital de Venecia de Le Corbusier, han ocupado un lugar destacado en la historia de la arquitectura del siglo XX.
} 
construyeron; pero también está presente en la obra de otros tantos arquitectos que, tras la Primera Guerra Mundial y pese a no construir sanatorios, trataron de atender a las necesidades de una población destrozada por el conflicto bélico, intentando aportar optimismo a la nueva sociedad emergente de posguerra. Estos arquitectos adoptaron los principios climáticos e higiénicos descritos por los médicos higienistas dado que, como ellos, estaban convencidos de ser capaces de transformar la sociedad al mejorar las condiciones de su entorno ${ }^{2}$; para lograrlo llenaron sus construcciones de luz, sol, aire puro e higiene. De este modo, el sanatorio antituberculoso pulmonar, creado a partir de estas mismas terapias higienistas, se convierte en un referente a imitar $y$, en consecuencia, sus características específicas pasan a estar presentes en la arquitectura de todos los niveles, especialmente en el ámbito residencial. Por otro lado, gracias a la simbiosis médicoarquitectónica que caracteriza al período de entreguerras, se produce una acentuación de este trasvase que pone a la arquitectura de la salud en la primera línea de la experimentación, incrementando el potencial interés por su estudio.

La motivación para el desarrollo de esta tesis doctoral responde al deseo por investigar los proyectos arquitectónicos desde una aproximación objetiva que pueda servir de instrumento para la enseñanza de la arquitectura en el ámbito universitario, siendo consciente de que a todo estudio se le imprime una determinada visión personal.

Se plantea así una investigación centrada en la arquitectura del sanatorio antituberculoso pulmonar por sus particulares características formales, su vinculación ambiental y su relación con el entorno, que pretende seguir el método denominado por R. Moneo como "experimental" ${ }^{2}$, en el que se atiende a reflexiones anteriores sin ser tomadas como postulados doctrinales $y$, consecuentemente, se plantean hipótesis susceptibles de ser completadas y reconsideradas en investigaciones posteriores.

Previamente al inicio de esta investigación se cursa el programa de doctorado del Dpto. de Teoría de la Arquitectura y Proyectos Arquitectónicos de la E.T.S. de Arquitectura de la Universidad de Valladolid Modernidad y Contemporaneidad en la Arquitectura durante los cursos 2003-2004 y 2004-2005, y se presenta el trabajo final correspondiente, que fue

\footnotetext{
2 "L'ambient forma l'individu" en $A C$ Documents d'activitat contemporània n' 25,1937, en AC Documentos de Actividad Contemporánea. Publicados por el GATEPAC entre 1937-1937. Fundación Caja de Arquitectos, Barcelona 2005, pp. 1205-1210

3 "Entendiendo por método experimental aquel que no parte de principios a priori, lo que permite poner en duda las teorías anteriores y hacer planteamientos lícitos mientras no existan pruebas de lo contrario". Rafael MONEO, "A vueltas con la Metodología" en Arquitectura n 82, Madrid 1965, p. 9.
} 
dirigido por la profesora Josefina González Cubero, obteniendo así la suficiencia investigadora.

Para formarse en el encuadre temático de la tesis se realiza posteriormente el Máster universitario en Arquitectura, Organización y Gestión de Infraestructuras Hospitalarias de la Universidad Europea de Madrid y de Especialización Arquitectónica por el Instituto de Arquitectura del Colegio Oficial de Arquitectos de Madrid, durante el curso 2007-2008, y se participa en diversos seminarios y encuentros especializados en arquitectura sanitaria, como el Curso de Arquitectura Hospitalaria organizado por la Fundación del Colegio Oficial de Arquitectos de Madrid (2007), y el Encuentro de Profesionales en el Campo del Diseño Ambiental y la Atención Sociosanitaria, organizado por el Centro de Referencia Estatal de atención a personas con enfermedad de Alzheimer de Salamanca (2010).

Se persigue obtener una aproximación interdisciplinar al sanatorio antituberculoso pulmonar desde diversos campos: medicina, historia, sociología, literatura, cine, arquitectura, para confluir en el análisis arquitectónico del mismo. Con ese fin, durante la investigación se consultan publicaciones vinculadas a diferentes disciplinas como Historia de la Tuberculosis. Ensayos de Fisiología colectiva (1944) de J. y A. Oriol Anguera, The Retreat of Tuberculosis 1850-1950 (1988) de F.B. Smith, y Les Sanatoria: Traitement et Prophylaxie de la Phtisie Pulmonaire (1895) de Sidgard Adolphus Knopf, entre otros.

Para comprender la forma de vida y el ambiente del sanatorio sirven de ayuda publicaciones de otra índole y documentos cinematográficos de la época, entre los que destacan las novelas La montaña mágica (1924) de Thomas Mann, Pabellón de Reposo (1943) de Camilo José Cela y El hombre sin atributos (1930) de Robert Musil, así como en la película del No-Do En estos años de paz (1949) del director Alberto Reig Gozalbes o los documentales $n^{\circ} 226$ (1949) y nº 487 (1954) de la Revista Imágenes.

Respecto a los libros medulares afines al tema se han consultado, además de los tratados generales sobre la arquitectura del siglo XX, las publicaciones especializadas más actuales ligadas a la arquitectura de la salud como Hospitales. La arquitectura del Insalud. 19862000 (2000) de J. F. Isasi, J. L. Paniagua y A. Pieltáin, y The Architecture of Hospitals (2006) editado por Cor Wagenaar que versan sobre los hospitales generales; así como Architecture et Santé, Le temps du sanatorium en France et en Europe (2005) de JeanBernard Cremnitzer, e Historie et Réhabilitation des sanatoriums en Europe (2004) editada por el Docomomo Internacional, especializados en la arquitectura del sanatorio. 
Se destacan por sus aportaciones a este estudio las tesis doctorales publicadas bajo los títulos: Arquitectura hospitalaria gallega de pabellones (2002) de Mercedes Insua Cabanas, Arquitectura para la Sanidad pública en España 1942-1977 (2007) de Alberto Pieltáin Álvarez-Arenas y La habitación del enfermo: Ciencia y arquitectura en los hospitales del Movimiento Moderno (2011) de Pedro Iglesias Picazo.

Durante la investigación se realiza un estudio taxonómico y documental del sanatorio antituberculoso, realizando un inventario por relevancia de ámbito nacional e internacional de las obras y proyectos que permite la recopilación de información y la clasificación de los mismos atendiendo a diversos parámetros: localización, uso y características arquitectónicas. Esta clasificación sirve para la selección de los casos que serán estudiados con más detalle y para el posterior análisis y documentación de los mismos.

En el estudio de los casos seleccionados no se utiliza un método uniforme para todos ellos, sino que el proyecto $u$ obra y sus circunstancias dictan las pautas para establecer el procedimiento. Se busca una contextualización de la obra por medio de un encuadre general de la misma en la trayectoria profesional de su autor; sin embargo, no se persigue realizar un estudio en profundidad de cada arquitecto y de sus distintas obras, sino de una arquitectura en concreto, la del sanatorio antituberculoso pulmonar en diferentes autores.

La dificultad de un estudio comparativo tan amplio y geográficamente tan dispar ha requerido el manejo de fuentes bibliográficas muy diversas, así como la consulta de documentos en archivos nacionales e internacionales.

Se ha investigado en la construcción internacional de hospitales y sanatorios de las distintos períodos de estudio a través de los manuales de la época y de libros recopilatorios, como Hôpitaux Sanatoria (1932) de Roger Poulain, Ospedali (1935) de Bruno Moretti y Terrassen Typ: Krankenhaus, Erholungsheim, Hotel, Bürohaus, Einfamilienhaus, Siedelungshaus, Miethaus und die Stadt (1929) de Richard Döcker, del período de entreguerras; o como Les hôpitaux modernes au XIXe siècle (1894) de Casimir Tollet, Sanatoria for consumptives in various parts of the world (1899) de R. Rufenacht Walters y Edificios hospitalarios en Europa durante diez siglos (1967) de Dankwart Leistikow, vinculados a los períodos históricos.

Además se indaga la presencia de proyectos y obras de sanatorios en las más importantes revistas nacionales e internacionales de arquitectura entre 1920 y 1960. Cabe destacar la existencia de números completos dedicados a la arquitectura hospitalaria como en la revista L'Architecture Vivante (1933) $n^{\circ} 41$, en L'Architecture d'Aujourd'hui (1934) n' 9 o en el $n^{\circ}$ 
33 de la Revista Nacional de Arquitectura (1944) dedicado a sanatorios, prueba del interés real de los arquitectos sobre el tema objeto de estudio ${ }^{4}$.

Estas y otras fuentes se obtienen a través de la biblioteca del Instituto General de Sanidad de Madrid, la biblioteca del Colegio Oficial de Arquitectos de Madrid y de diversas bibliotecas universitarias, además de la biblioteca de la Escuela Técnica Superior de Arquitectura de Valladolid, que ha resultado fundamental para conseguir un gran número de ellas.

También se consulta el material original disponible en archivos nacionales e internacionales. Para el estudio de los sanatorios nacionales se acude al Archivo General de la Administración en Alcalá de Henares, al Archivo del Ministerio de Sanidad y al Archivo General del Ministerio del Interior de Madrid, así como a diversos Archivos Provinciales en busca de información sobre el antiguo Archivo del Patronato Nacional Antituberculoso, donde deberían conservarse los proyectos originales de todos aquellos sanatorios pertenecientes al mismo. Desgraciadamente sólo se obtiene información parcial de ciertas obras en Madrid en los archivos del Instituto de Salud Carlos III, en el Hospital del Rey, y además las memorias e informes del Patronato donde se les menciona, consultadas en la biblioteca del Museo de Sanidad e Higiene Pública.

Se consultan también diversos archivos internacionales como: la Fundation Le Corbusier en París, en relación al supuesto Sanatorio de Zurich (1934) atribuido a Le Corbusier, el Nederlands Architectuurinstituut de Rotterdam y el Internationaal Instituut voor Sociale Geschiedenis de Ámsterdam, para el estudio del Sanatorio de Zonnestraal (1926) de J. Duiker y B. Bijvoet, y los archivos del Museo Alvar Aalto en Jyväskylä para investigar sobre el Sanatorio de Paimio (1929).

Las consultas documentales y archivísticas son la base del conocimiento directo de los proyectos, mientras que la visita posterior a las obras sirve para la comprobación más fehaciente y la experiencia de su arquitectura. Se realizan visitas a varios sanatorios los sanatorios entre ellos el de Los Montalvos en Salamanca, el de Zonnestral en Hilversum, Holanda, y el de Paimio cerca de Turku, Finlandia.

\footnotetext{
${ }^{4}$ Aizpurúa estaba encargado de preparar un número monográfico sobre hospitales para la revista AC. Documentos de Actividad Contemporánea que nunca llegó a publicarse. Carta de Aizpúrua a Torres fechada el 28 de diciembre de 1933. Arxiu Històric COAC. Fons GATCPAC.
} 
La tesis doctoral establece una estructuración tipológica en la que el tipo arquitectónico se entiende como el "concepto que describe una estructura formal", según la definición de C. Martí Arís ${ }^{5}$. La existencia de afinidades formales en la arquitectura no son óbice para la libertad creativa, por lo que la estructuración tipológica aplicada no sólo atiende a la permanencia de ciertas formas esenciales, sino también a la múltiple variedad de sus acepciones.

Esta estructuración realizada surge como resultado de un estudio analítico a posteriori, es decir, a partir de los proyectos de arquitectura y, en el caso de los sanatorios desarrollados más exhaustivamente, del análisis de la obra construida. Así se logra extraer la estructura formal del tipo arquitectónico, en este caso, las de los tipos de los distintos sanatorios antituberculosos pulmonares.

Con el estudio analítico de la documentación gráfica, de los ejemplos destacables de la historia de la arquitectura de la salud, se reconoce la existencia de permanencias y variaciones que descubren el camino de decantación de las diversas clases de tipos sanatoriales $^{6}$. A través de los dibujos sintéticos de los bocetos, las propuestas previas o los proyectos de ejecución de los sanatorios, se desvela un entronque formal que confiere al tipo la posibilidad de ser empleado, no sólo como un método cognoscitivo, sino también como un método operativo aplicable en el proceso de proyecto $^{7}$.

La estructura del trabajo de investigación consta de tres partes: la primera consiste en un amplio estudio de la arquitectura del sanatorio antituberculoso pulmonar, de sus antecedentes, terapias y elementos constituyentes; la segunda se centra en el estudio de tres sanatorios, sus proyectos y su edificación; y la tercera pone de manifiesto la trascendencia de la arquitectura terapéutica en el Movimiento Moderno.

En la primera parte del trabajo se presentan las arquitecturas de la salud que a lo largo de la historia han ido surgiendo, desde el siglo VIII al siglo XX, y las terapias de cura que van a

\footnotetext{
${ }^{5}$ Carlos MARTí ARÍS, Las variaciones de la identidad. Ensayo sobre el tipo en arquitectura. Ediciones del Serbal, Barcelona 1993, p. 16.

6 "La operación que conduce a la individualización del tipo es similar a la de redibujar sobre papeles transparentes obras ya realizadas que tenían caracteres particulares comunes, sobreponerlos, e individualizar todos los elementos coincidentes, descartando todos los que no coincidan". C.G. Argan "Interpretazioni e tendenze tipologiche in architettura", en // fondamento tipologico dell'architettura, Marcello REBECCHINI. Bulzoni, Roma, 1978, p. 92. Citado en: Manuel J. MARTíN HERNÁNDEZ, La tipología en Arquitectura, Tesis Doctoral inédita, Universidad de Las Palmas 1984, p. 89.

7 Tanto Saverio Muratori en Studi per una operante Storia Urbana di Venezia como su discípulo Gianfranco Caniggia en Struttura dello spazio antropico estudian la existencia y aplicación de este método tipológico al proyecto.
} 
generar la presencia de ciertos elementos arquitectónicos significativos que otorgan identidad al sanatorio frente a otras edificaciones hospitalarias; para finalizar, se entra en detalle sobre las características de estas construcciones en cuanto a su programa, implantación, formas de vida y diseño.

La segunda parte del trabajo gira sobre el estudio del Sanatorio de los Montalvos, el Sanatorio de Zonnestraal y el Sanatorio de Paimio. Los criterios de selección de estas obras responden a su divergencia morfológica y a la indiscutible calidad arquitectónica de las mismas. Las tres obras ejemplifican tres organizaciones, resultado de procedimientos de proyecto distintos, cuyas fórmulas revierten en el resto de la arquitectura: la yuxtaposición unitaria de las partes, la separación geométrica de éstas y la agrupación heteróclita ${ }^{8}$ de las mismas.

Con el Sanatorio de los Montalvos se pretende analizar la imitación y la variación formal de los modelos como estrategia de proyecto, así como las formas de enraizamiento de los prototipos arquitectónicos concebidos para ser idénticamente repetibles. Este estudio intenta poner en relieve la importancia de la obra de Rafael Bergamín, en igualdad de consideración que las otras dos obras siguientes estudiadas, enriqueciéndolo con las aportaciones de otros proyectos nacionales e internacionales con los que comparten ciertas similitudes.

En el estudio del Sanatorio de Zonnestraal se pretende ver cómo las actuaciones formales sobre el tipo ejercidas por Duiker y Bijvoet pueden llegar a afectar a su constitución conceptual. A partir de ello, y en base a los documentos consultados, se pretende comprobar el itinerario seguido en la concepción del proyecto durante su dilatada gestación, ante las incertidumbres existentes en estudios precedentes de otros estudiosos o ensayistas.

En el capítulo destinado al Sanatorio de Paimio se estudian los bocetos y el proceso de proyecto seguido por Aalto en el Sanatorio y en otras propuestas suyas de sanatorios para comprobar si éste sigue un método tipológico como indican: Demetri Porphyrios, Rafael Moneo y Carlos Martí Arís, y en qué radica éste.

En la tercera parte y capítulo final de la tesis se intenta establecer cómo la búsqueda de una nueva arquitectura científica lleva a los arquitectos modernos a despojarse del ropaje de los

\footnotetext{
${ }^{8}$ Expresión que hace referencia a los posibles órdenes existentes fuera de la geometría. Michel FOUCAULT, Las palabras y las cosas. Una arqueología de las ciencias humanas (1966). Siglo XXI editores, Madrid 2010, p. 3.
} 
estilos heredados y a defender le creación de una arquitectura terapéutica sobre bases pragmáticas, que va a impregnar la residencia y, por extensión, la ciudad moderna. Finalmente, no se quiere olvidar que aunque en la actualidad el valor de uso del sanatorio antituberculoso pulmonar haya desaparecido éste se ha convertido, por su trascendencia, en un paradigma de la arquitectura del Movimiento Moderno, merecedor de un nuevo destino que garantice la preservación de su valor patrimonial. 
I. MEDICINA Y ARQUITECTURA EN EUROPA

CAPÍTULO 1

ENFERMEDAD Y ARQUITECTURA: GENEALOGÍA DEL HOSPITAL

LA CASA DE ACOGIDA

EL PALACIO DE ENFERMOS

LA MÁQUINA DE CURACIÓN

EL CAMPAMENTO EFICIENTE

EL BLOQUE MÉDICO ESPECIALIZADO 


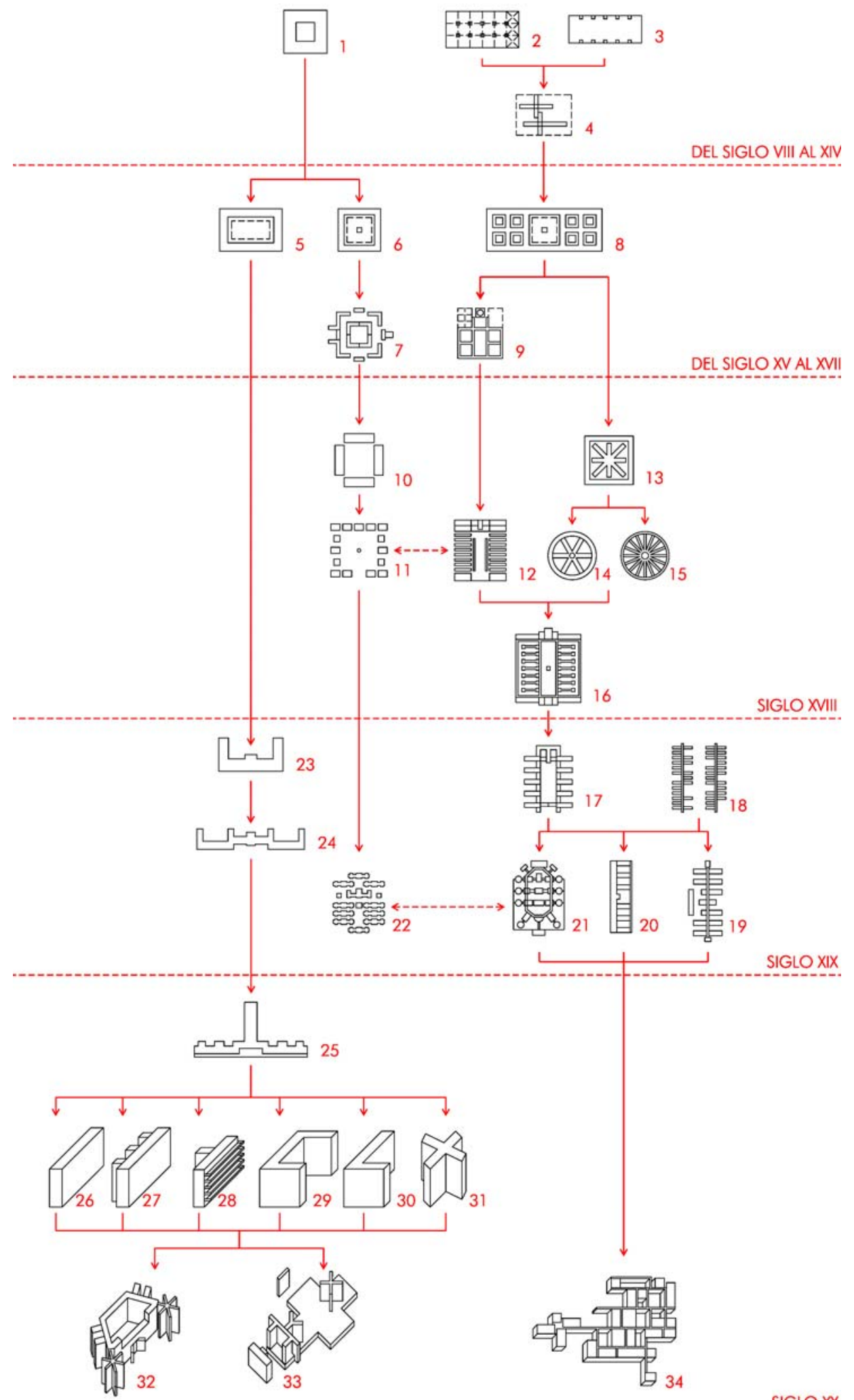

SIGLOXX

1) Hospital de la Abadia de Saint Gall, siglo VIII. 2) Hospital del Rey, Burgos, siglo XIII. 3) Hospital de Tonnerre, 1293-1295. 4) Hospital de Santa Maria La Nuova, 1286.5) Hospital Julios Würrburg, 1676-1685. 6) Lazareto de Milán, 1507. 7) Hospital de San Luis, París, 1607. 8) Hospital Mayor de Milán, 1456-. 9) Hospital de los Inválidos, Paris, 1670. 10) Hospital de San Bartolomé, Londres 1729. 11) Hospital Naval Real de Plymouth, Rovehead 1756-1764. 12) Le Roy. Nuevo Hôtel-Dieu de Paris, 1773. 13) A. Desgodets. Hospital finales del siglo XVII.14) Peftit. Nuevo Hôtel-Dieu de París, 1774.15) Poyet. Nuevo Hôtel-Dieu de Paris, 1786.16) Academia de las Ciencias Francesas. Nuevo Hôtel-Dieu, Paris, 1787.17) Hospital de Lariboisière, Paris, 1846-1854. 18) Hospital de campaña de Renkioki, 1855. 19) Hospital militar Herbert, Woolwich, 1864. 20) Hopsital de Saint Thomas, Londres, 1871. 21) Hospital Stuivemberg, Amberes, 1878-1885. 22) Hospital de Carabanchel Madrid, 1889-1897. 23) Hospital Niuvanniemi, Kuopio, 1881-1885. 24) Hospital Cantonal de Ginebra, 1849.25) Sanatorio Alemán de Davos, principios s.Xx.26) Sanatorio de la Fuenfría, Madrid, 1921.27) Hospital de Colmar, 1936.28) Sanatorio de Marte-de-Janville, Savoya, 1933-1937. 29) Residencia sanitaria de La Coruña, 1950. 30) Clínica de la Cruz Roja, Berlín, 1930-1931.31) Fundación Wesley, Chicago, 1940-1941.32) Ciudad hospitalaria de Lille, 1932-1953. 33) P. Nelson. Ciudad hospitalaria de Lille, 1932. 34) Le Corbusier. Hospital de Venecia, 1964-1965.

1.01 Genealogía de los tipos de hospital (dibujos de la autora). 


\section{ENFERMEDAD Y ARQUITECTURA: GENEALOGÍA DEL HOSPITAL}

El significado del término "hospital", al igual que los diversos nombres con que éste es designado, cambia a lo largo de los siglos a la par que avanza la especialización de las actividades que se albergaban en tales instituciones o edificios'. De este modo, el hospital pasa de ser definido como una casa de acogida, a ser considerado un bloque técnico especializado.

Este cambio semántico es un fiel reflejo del nivel de conocimiento de la ciencia médica en las diversas épocas de la historia, prueba de ello es que a la transformación lingüística del término hospital a lo largo de los siglos, le acompaña un cambio funcional, espacial y formal.

Atendiendo a estas cuestiones, se traza un recorrido por las etapas más significativas de la arquitectura hospitalaria, que pone de relieve los cambios formales que han sufrido los hospitales, cambios que a su vez han consolidado a las diversas tipologías hospitalarias [fig. 1.02].

\section{LA CASA DE ACOGIDA}

Durante el periodo comprendido entre los siglos VIII y XIV, los hospitales se definen como casas de acogida de pobres y peregrinos, no necesariamente enfermos, y carecen de una forma arquitectónica propia. Los hospitales están incluidos dentro de las tipologías claustrales [fig. 1.02] y basilicales [fig. 1.03], pues son las congregaciones religiosas que presiden los conventos e iglesias las que en origen se encargan de regentar estos centros ${ }^{2}$. A partir del siglo XII se establece una tutela compartida entre la sociedad civil y la religiosa en la administración del hospital, que trae en consecuencia la aparición de un nuevo hospital el tipo hall o gran espacio único [fig. 1.04], empleado en las construcciones civiles de la Europa atlántica, en sus edificaciones domésticas, agrícolas y palaciegas, cuya configuración formal asemeja a la de un navío invertido ${ }^{3}$. El hospital tipo hall está constituido por una sala que incorpora en su interior un deambulatorio suspendido a modo de galería que permite visitar y controlar a distancia a los enfermos acogidos.

\footnotetext{
${ }^{1}$ Dankwart LEISTIKOW, Edificios hospitalarios en Europa durante diez siglos. C. H. Boeringer Sohn, Ingelheim am Rehein, Germany 1967, pp. 9-11.

2 Los hospitales, entre los siglos VIII y XIV, solían implantarse en el campo incluidos dentro de los monasterios, aunque también se ubicaban dentro de las ciudades adosados a las iglesias y ocasionalmente aislados, a lo largo de los caminos de peregrinación.

${ }^{3}$ Yago BONET CORREA, La arquitectura del humo. Cuadernos do seminario de Sargadelos no 61. Ediciós do Castro, A Coruña 1994, pp. 31-33.
} 


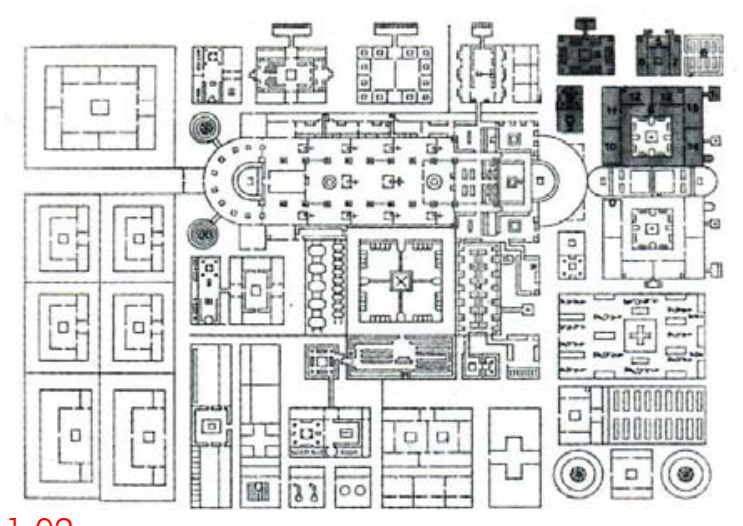

1.02
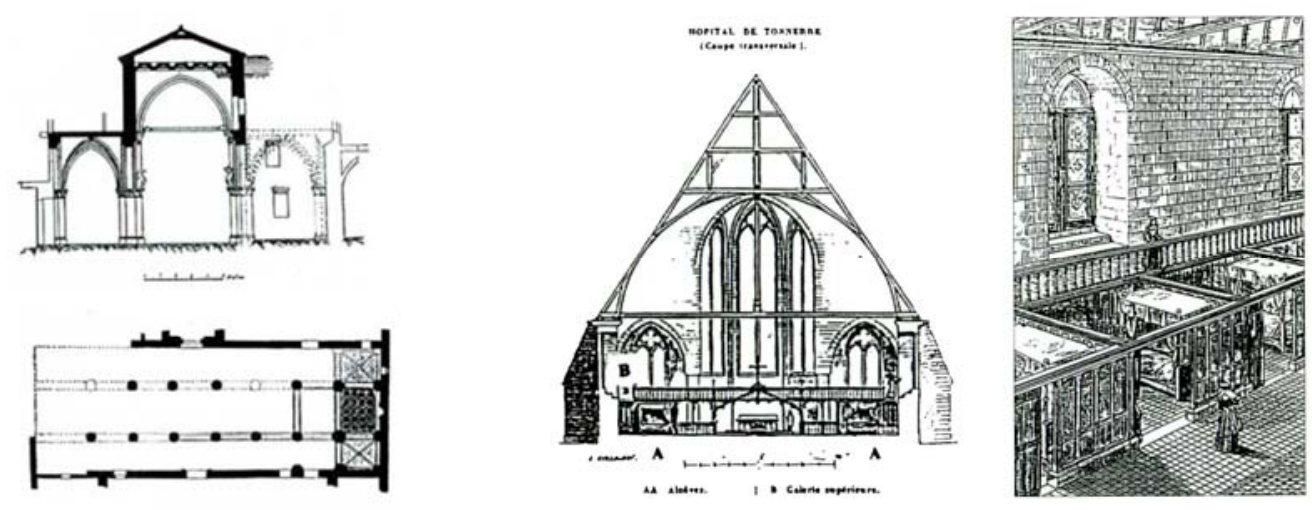

1.03 y 1.04
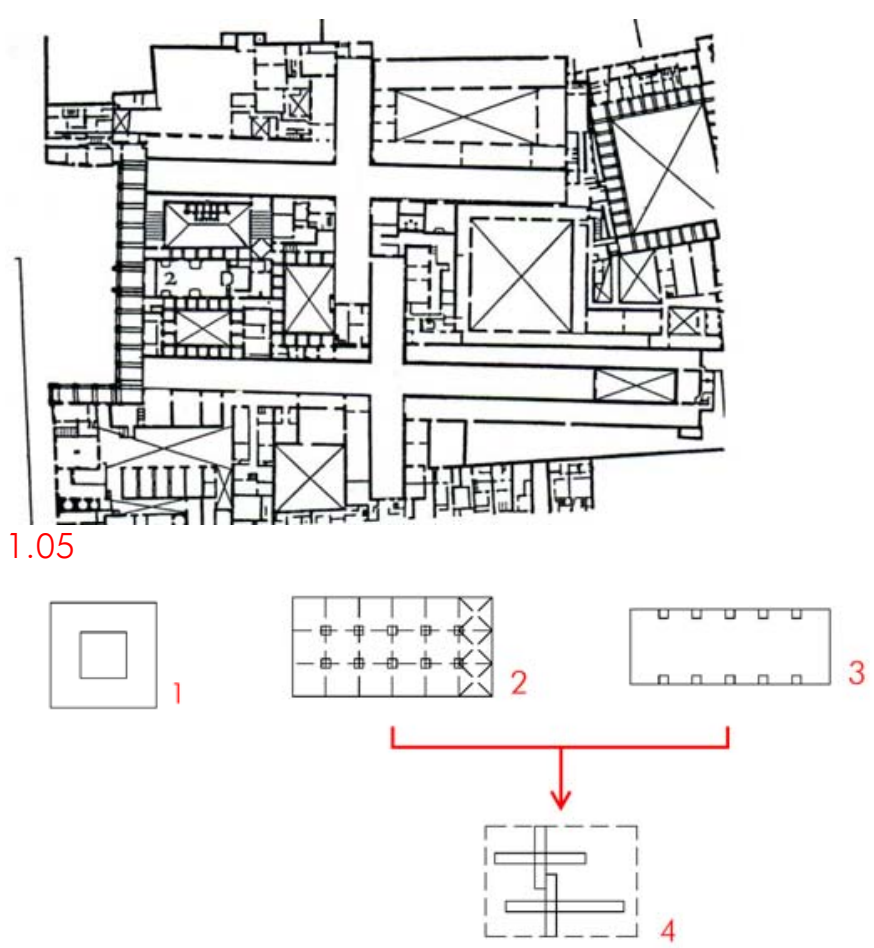

1.06

1.02 Hospital de la Abadía de Saint Gall, siglo VIII.

1.03 Hospital del Rey, Burgos, siglo XIII. Sección transversal y planta.

1.04 Hospital de Tonnerre, 1293-1295. Sección transversal y vista interior.

1.05 Hospital de Santa Maria La Nuova, Florencia, 1286.

1.06 Genealogía de los tipos hospitalarios del siglo VIII al XIV: La casa de acogida 1) Hospital de la Abadía de Saint Gall s. VIII, 2) Hospital del Rey, Burgos s. XIII, 3) Hospital de Tonnerre 1293-1295, 4) Hospital de Santa María La Nuova, Florencia 1286 (dibujos de la autora). 
El hospital tipo hall del poder civil pasa a convivir con el hospital tipo basilical católico formado por una nave tripartita y ambos responden a la misma estructura formal lineal ${ }^{4}$; $\sin$ embargo, de la misma manera que las iglesias se transforman y abandonan la forma basilical para dar paso a la aparición de naves cruciformes, donde se combinan las formas centrales en representación de lo sagrado con las unidireccionales en representación de lo humano ${ }^{5}$, el hospital también altera su estructura formal. En 1286 se construye el primer hospital cruciforme, el de Santa Maria La Nuova en Florencia [fig. 1.05], que presenta dos cruces: una destinada a hombres y otra a mujeres ${ }^{6}$, adelantándose a las nuevas tipologías hospitalarias que se desarrollan durante los siglos XV y XVI principalmente en la Europa mediterránea, cuando se construyen en España hospitales como el de Santa Cruz de Toledo (1504), con planta en forma de cruz latina, o el de Granada (1511) con planta en forma de cruz griega.

La Edad Media es una época marcada por devastadoras epidemias como la de la peste negra de 1348, hecho que lleva a la población a refugiarse en la religión y en la bondad humana para lograr superar tales tragedias. Surge así un predominio de la espiritualidad y de la vida interior que superan a la confianza en la técnica y en la ciencia, aplicadas con bastante precariedad durante esta época en lo concerniente a la medicina. Los médicos se preocupan más del individuo que de la enfermedad y tratan de aliviarlo acercándolo a Dios, con el fin de curar no tanto su cuerpo como su espíritu ${ }^{7}$.

El empleo de la fe en la religión como terapia dentro del hospital se traslada a su arquitectura construyéndose altares en todas las salas. Se considera imprescindible que los acogidos en el hospital puedan escuchar el oficio religioso desde su cama y se sitúa un altar en el extremo. La aparición del hospital cruciforme permite trasladar el altar a la parte central del crucero, pudiendo oficiar misa simultáneamente hacia todas las salas que en él confluyen. Se crea así una nueva tipología de hospital que muestra la misma configuración de las iglesias cruciformes y que responde a una necesidad terapéutica fundamentada en la cura a través de la fe [fig. 1.06].

\footnotetext{
${ }^{4}$ Hay que tener en cuenta que la forma basilical en origen también pertenece a la sociedad civil; en el Imperio romano la basílica podía acoger el mercado o la bolsa, aunque posteriormente fuera utilizada para el culto cristiano. Calos MARTÍ ARÍS, Las variaciones de la identidad. Ensayo sobre el tipo en arquitectura. Ediciones del Serbal, Barcelona 1993, p. 83.

${ }^{5}$ Calos MARTí ARÍS, Las variaciones de la identidad. Ensayo sobre el tipo en arquitectura. Ediciones del Serbal, Barcelona 1993, pp. 59-60.

${ }^{6}$ Dankwart LEISTIKOW, Edificios hospitalarios en Europa durante diez siglos. C. H. Boeringer Sohn, Ingelheim am Rehein, Germany 1967, pp. 68-69.

7 J. y A. ORIOL ANGUERA, Historia de la Tuberculosis. Ensayos de Fisiología colectiva. Salvat Editores, Barcelona, Buenos Aires 1944, pp. 39-50.
} 


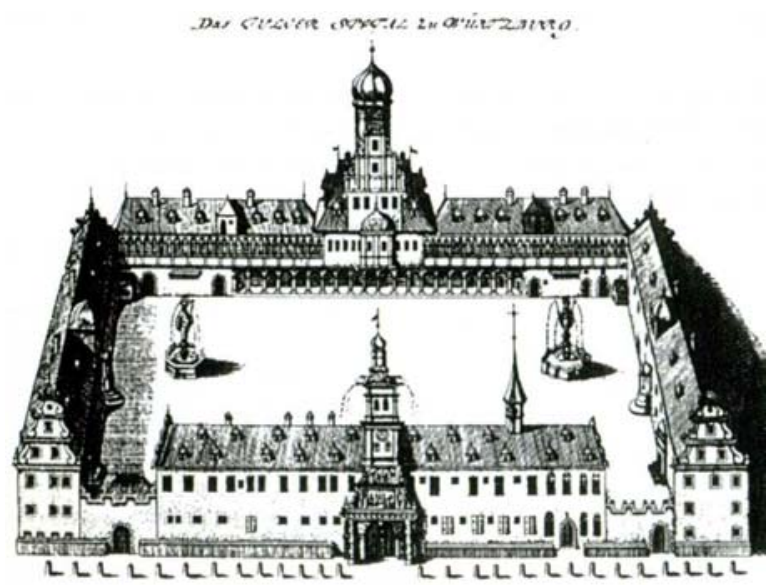

1.07

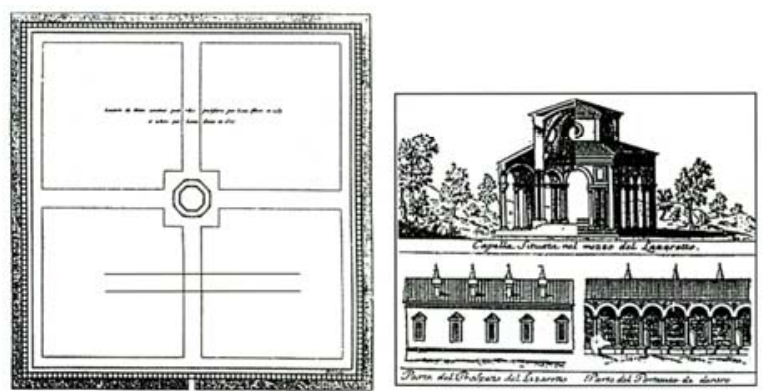

1.08

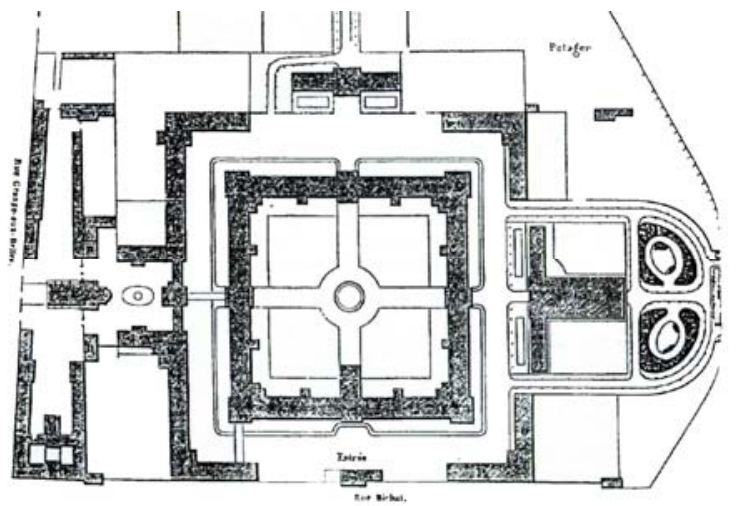

1.09

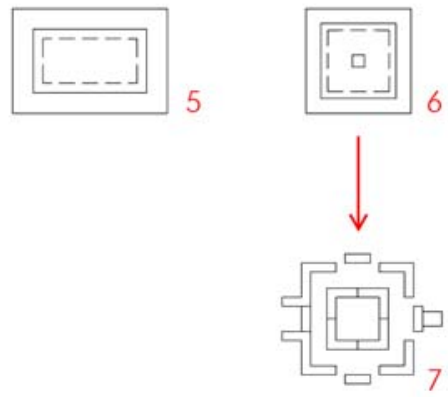

1.07 Hospital Julios Würzburg, 1676-1685.

1.08 Lazareto de Milán, 1507. Planta y alzados de la capilla central y de la enfermería.

1.09 Hospital de San Luis, París, 1607.

1.10 Genealogía de los tipos hospitalarios claustrales del siglo XV al XVII: El palacio de enfermos. 5) Hospital Julios Würzburg 1676-1685, 6) Lazareto de Milán 1507, 7) Hospital de San Luis, París 1607 (dibujos de la autora). 


\section{EL PALACIO DE ENFERMOS}

Durante los siglos XV, XVI y XVII el hospital se transforma en uno de los estandartes del poder civil, que trata de competir con el poder religioso, y adopta las formas palaciegas representativas de la potestad de los nobles. Estas formas arquitectónicas de los palacios renacentistas provienen de las estructuras claustrales de los monasterios de la Edad Media que crecen en amplitud, altura y ornamento, y evolucionan hacia configuraciones rectangulares exentas [fig. 1.07] o más abiertas en forma de C.

Los hospitales que mantienen la tipología claustral de un modo más estricto son los lazaretos y los hospitales de infecciosos [fig. 1.08]. Sin embargo, el riesgo de contagio hace que el hospital tienda a fraccionarse para lograr un mayor aislamiento de cada parte; un ejemplo de esta transformación es el hospital de San Luis de París (1607-1612), construido por el arquitecto Claude Vellefaux entre 1607 y 1612 [fig. 1.09], compuesto por un doble anillo cuadrado. El anillo interior contiene a los enfermos contagiosos en cuatro salas, que no coinciden con sus cuatro lados sino que tienen forma de $L$ y se dividen en dos salas ortogonales más pequeñas. El anillo exterior, parcialmente fragmentado para permitir el acceso al hospital, contiene los servicios asistenciales; de esta manera, por medio del segundo anillo, se aísla aún más al enfermo del ambiente exterior. A través de este fraccionamiento se vislumbra un cambio en la concepción hospitalaria que pasa de la configuración unitaria y claustral a la organización en pabellones [fig. 1.10].

Paralelamente a la lucha de poder mantenida entre nobleza y religión, desde el siglo XV al XVII se van a ir produciendo ciertos avances en la medicina que traen consigo algunos cambios en el concepto de hospital, aunque todavía éste no alcanza a ser la casa de la medicina, sino la del dolor, la pobreza y la beneficencia, el lugar donde los ciudadanos de buena posición jamás acuden ${ }^{8}$. Por primera vez se amplía la definición de hospital y la tradicional casa de acogida pasa a contemplar entre sus diversos fines el cuidado de enfermos 9 . Este cambio tiene como resultado la aparición del primer edificio de la historia que puede ser considerado un hospital, el Ospedale Maggiore de Milano ${ }^{10}$ proyectado por

\footnotetext{
8 J. F. ISASI, J. L. PANIAGUA, A. PIELTÁIN, Hospitales. La arquitectura del Insalud. 1986-2000. Libro 2. Insalud, Madrid 2000, p. 9.

9 Luis Vives define el hospital en el siglo XVI con las siguientes palabras: "Doy el nombre de Hospital a estas instituciones donde los enfermos son atendidos y cuidados, donde se alimenta a un número de necesitados, donde se educa a los niños y niñas,... donde los locos y ciegos pasan su vida". Citado en: Arquitectura hospitalaria gallega de pabellones, Mercedes INSUA CABANAS. Universidad de La Coruña, La Coruña 2002, p. 54.

10 Dankwart LEISTIKOW, Edificios hospitalarios en Europa durante diez siglos. C. H. Boeringer Sohn, Ingelheim am Rehein, Germany 1967, pp. 70.
} 

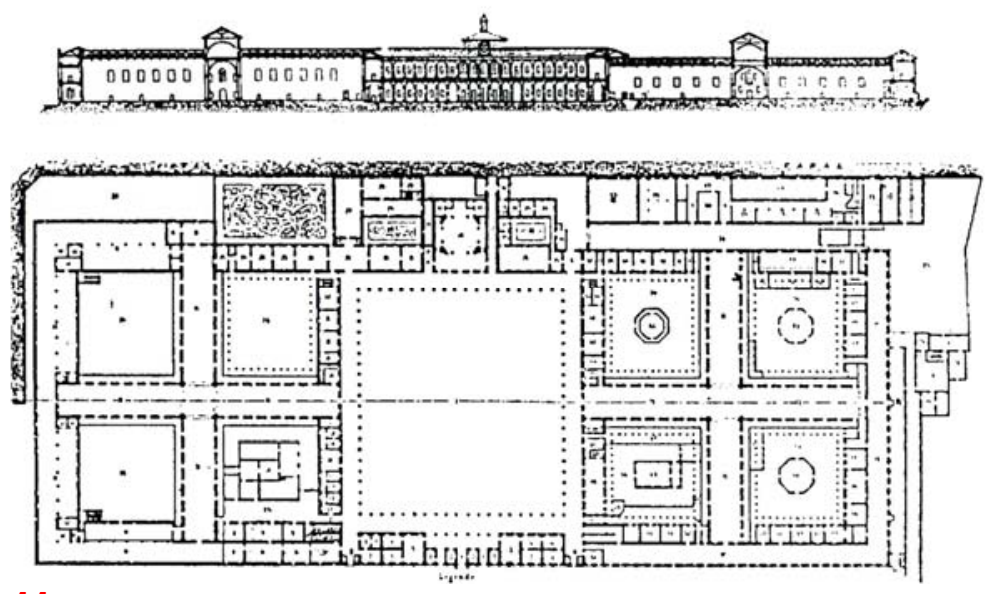

1.11

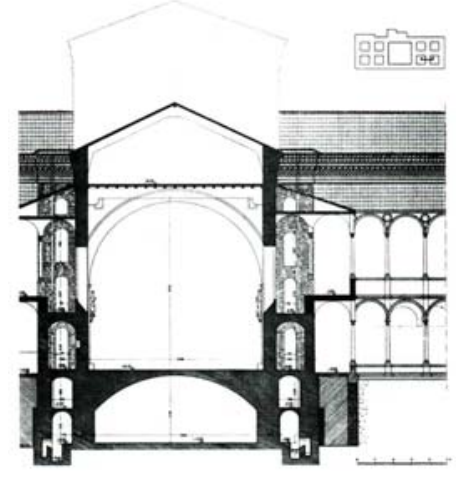

1.12

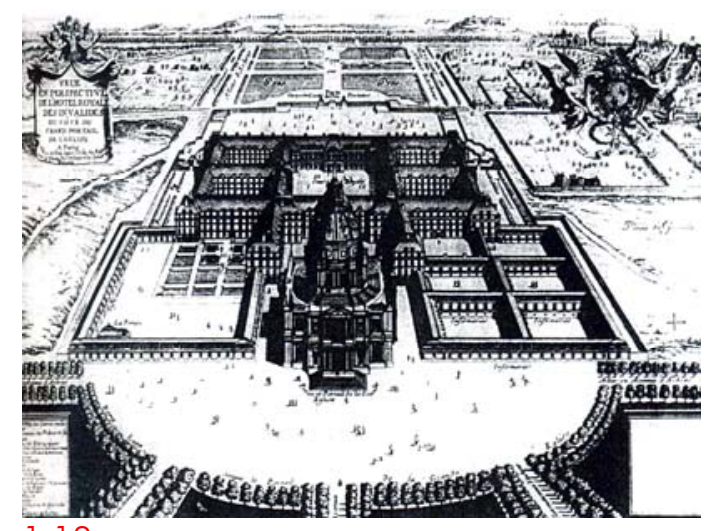

1.13
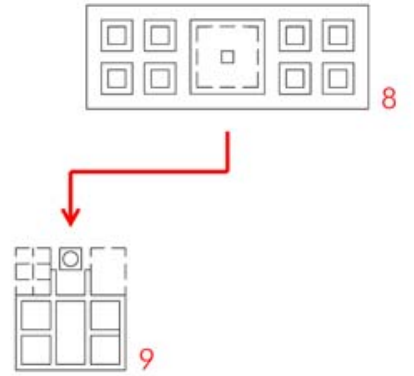

1.14

1.11 Filarete. Hospital Mayor de Milán, 1456-. Planta y alzado.

1.12 Filarete. Hospital Mayor de Milán, 1456-. Sección transversal.

1.13 L. Bruant y J. Hardouin-Mansart. Hospital de los Inválidos, París, 1670.

1.14 Genealogía de los tipos hospitalarios cruciformes del siglo XV al XVII: El palacio de enfermos. 8) Hospital Mayor de Milán 1456-, 9) Hospital de los Inválidos 1607 (dibujos de la autora). 
Filarete, cuya construcción se comienza en 1456 [fig. 1.11]. Su imagen no es novedosa, recuerda a numerosos palacios de la época; tampoco lo son las enfermerías cruciformes que ya habían aparecido con anterioridad en el Hospital de Santa María La Nueva de Florencia a finales del siglo XIII. La condición que le hace diferente radica en la forma y disposición de esos elementos, ya que combina dos tipologías: las cruciformes y las claustrales, y en el diseño de su sección [fig. 1.12]. Contiene soluciones arquitectónicas que por primera vez dan respuesta a problemas de confort e higiene de las personas acogidas. Incorpora forjados elevados para evitar humedades, sistemas de ventilación a través de las paredes laterales de las naves y emplea las logias como elementos de control solar, además de como deambulatorios para las visitas y las cuidadoras, como soluciones que tratan de mejorar el bienestar físico de los enfermos.

La gran belleza formal y la funcionalidad del Hospital Mayor de Milán lo convierten en el modelo que se sigue en toda Italia y el sur de Europa. Su trazado regulador ortogonal y cruciforme se va alterando y multiplicando en función del tamaño del hospital, hasta generar nuevas estructuras formales a modo de retícula, igual al utilizado en el Hospital de los Inválidos de París (1670) construido por Libéral Bruant y Jules Hardouin-Mansart [fig.1.13]. Tales estructuras y sus predecesoras no son exclusivas de la arquitectura hospitalaria, están presentes en numerosos monasterios y palacios de la época, porque la universalidad de la forma permite contener diversas funciones, evidenciando así cómo en cierta medida las formas trascienden al uso concreto que de ellas pueda hacerse ${ }^{11}$.

Respecto a la ubicación del hospital, Alberti y Filarete comparten la opinión de que debe ser "bello y cómodo" lo que obliga a ubicarlo extra-muros pues la ciudad resulta siempre menos conveniente para la cura del enfermo que el campo. Para Alberti: "Los contagiosos no solamente serán excluidos lejos de la ciudad, sino también de la vida pública. Los demás serán mantenidos en la ciudad"12. No hay que olvidar que el hospital era un símbolo de poder religioso y civil, y que pese a la pérdida de bienestar, permitía su emplazamiento dentro la ciudad.

\footnotetext{
11 Ver: Calos MARTí ARÍS, Las variaciones de la identidad. Ensayo sobre el tipo en arquitectura. Ediciones del Serbal, Barcelona 1993, pp. 80-81.

12 Mercedes INSUA CABANAS, Arquitectura hospitalaria gallega de pabellones. Universidad de La Coruña, La Coruña 2002, p. 54.
} 


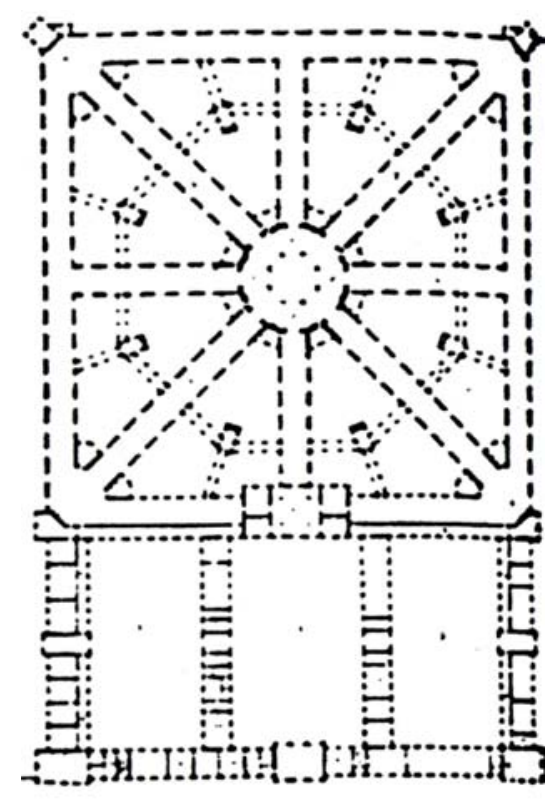

1.15
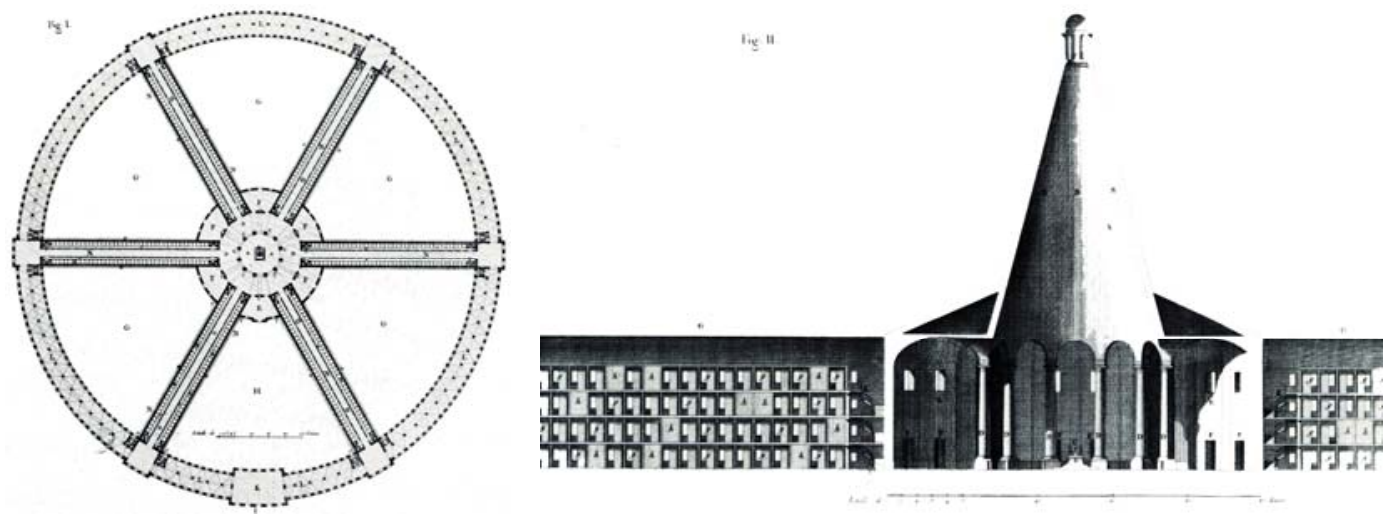

1.16 y 1.17

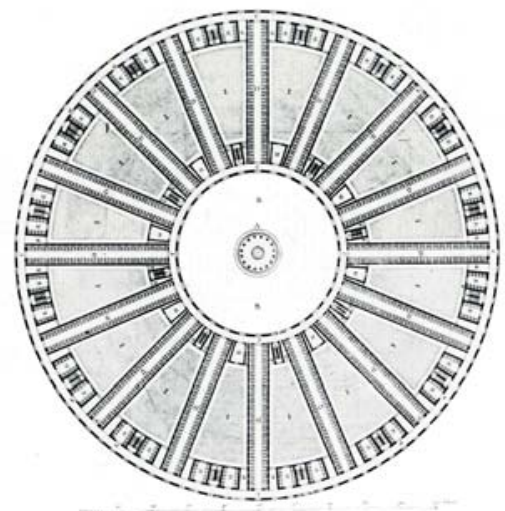

1.18 y 1.19

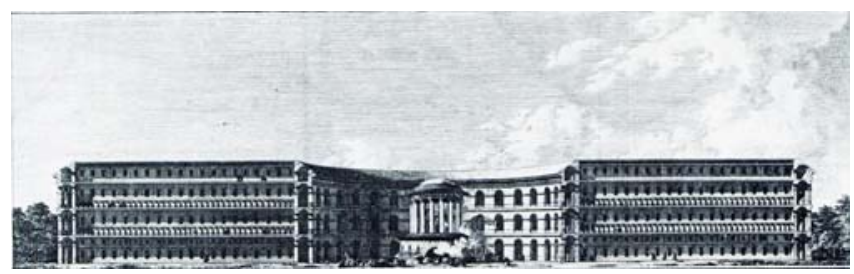

1.15 A. Desgodets. Proyecto de hospital, finales del siglo XVII.

1.16 y 1.17 A. Petit. Proyecto para el nuevo Hôtel-Dieu de París, 1774. Planta y sección.

1.18 y 1.19 B. Poyet. Proyecto para el nuevo Hôtel-Dieu de París, 1786. Planta y sección. 


\section{LA MÁQUINA DE CURACIÓN}

En los siglos XVIII y XIX el hospital se define como un establecimiento convenientemente dispuesto para la estancia de enfermos que necesitan someterse a tratamientos médicos.

El despertar de la medicina y el reconocimiento del derecho a la asistencia médica ${ }^{13}$ hacen que necesariamente en el siglo XVIII surja un nuevo hospital. Ya no representa ni al poder político ni al religioso, el nuevo hospital debe convertirse en una herramienta científica, debe ser una "máquina" que contribuya a la curación. Con este propósito se diseñan las diversas propuestas realizadas para reemplazar el antiguo Hôtel-Dieu de París que había sufrido su segundo incendio en 1772. La analogía la expresa Jean Baptiste Le Roy en la memoria de su proyecto para el nuevo Hôtel-Dieu realizado en 1773, leída ante la Academia de las Ciencias Francesas en 1785: "una sala hospitalaria, si es que está permitido expresarse así, es una verdadera máquina para el tratamiento del enfermo ${ }^{114}$.

El tradicional concepto de máquina descrito por Vitruvio en su Libro X como un instrumento válido para el transporte de cargas, cambia por completo en los siglos XVII y XVIII. La máquina, gracias a la contribución de científicos como Newton con su Principia, es entendida ahora como un mecanismo capaz de transformar la materia original en el producto requerido. De este modo el hospital pasa a ser una "máquina", un instrumento al servicio del hombre que transforma al enfermo en sano.

En aquella época la medicina cree que el origen de la enfermedad reside en el miasma y que la manera de combatir tal efluvio radica en la pureza del aire, convirtiéndose la ventilación en el objetivo prioritario de los hospitales. Bajo este criterio se gestan las secciones de las propuestas para el nuevo Hôtel-Dieu de París de los arquitectos Petit, con su diseño de "cloaca máxima" que presenta una enorme chimenea piramidal sobre la capilla central [fig.1.17], Poyet, con sus plenum de ventilación entre forjados [fig.1.19] y Le Roy, cuyas salas de enfermos desarrolladas en planta baja contienen numerosas chimeneas de extracción [fig.1.22].

En todas ellas la inspiración maquinista no les hace renunciar a consideraciones estéticas, ya que la composición formal y la geometría de los edificios emulan a los templos griegos y al coliseo romano, en definitiva, a las bellas construcciones del pasado, una clara influencia del Neoclasicismo iluminista de Claude-Nicolas Ledoux y Etienne- Louis Boullée existente

\footnotetext{
${ }^{13}$ En 1789 en la declaración de "Derechos del Hombre" se reconoce por primera vez el derecho a ser asistido en caso de enfermedad.

${ }^{14}$ Dankwart LEISTIKOW, Edificios hospitalarios en Europa durante diez siglos. C. H. Boeringer Sohn, Ingelheim am Rehein, Germany 1967, p. 94.
} 

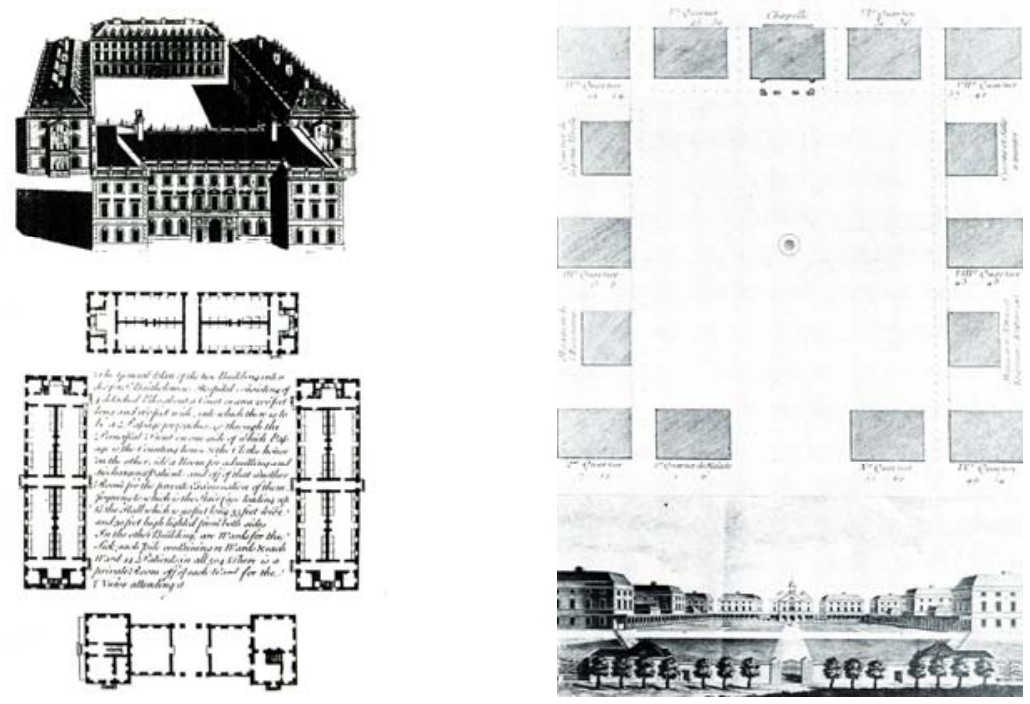

1.20 y 1.21
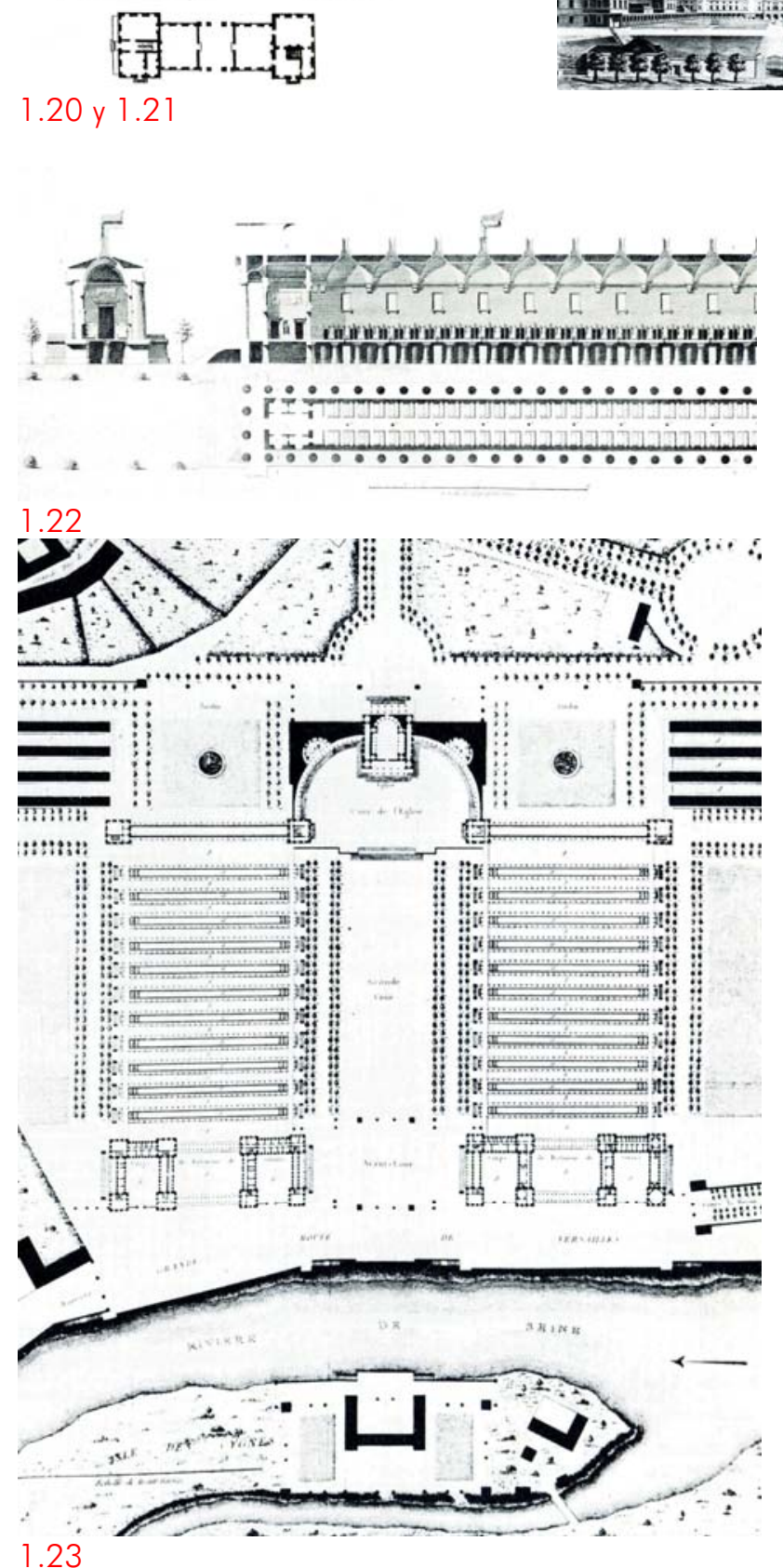

1.20 J. Gibbs. Hospital de San Bartolomé, Londres 1729. Vista general y planta.

1.21 Hospital Naval Real de Plymouth, Rovehead 1756-1764. Planta y vista general.

1. 22 y 1.23 J. B. Le Roy. Proyecto para el nuevo Hôtel-Dieu de París, 1773. Sección y planta. 
en este período.

Las propuestas para el nuevo Hôtel-Dieu de Antoine Petit [fig.1.16] y de Bernard Poyet [fig.1.18] proponen un cambio tipológico basado en el empleo de construcciones panópticas, constituidas por la disposición radial de una serie de salas de enfermos inscritas en un anillo circular perimetral. Esta estructura formal surge al tratar de optimizar los modelos cruciformes al aumentar el número de salas que confluyen en un mismo centro, como ya había propuesto anteriormente Antoine Desgodets en su proyecto de hospital cuadrado y radial de finales del siglo XVII [fig.1.15]. Es obvio que los hospitales radiales desarrollados en varias plantas de altura permiten aumentar considerablemente el número de camas sin ampliar cuantiosamente ni sus servicios ni su superficie.

La propuesta de Le Roy, muy distinta a la de sus colegas Petit y Poyet, es decisiva en la definición final del proyecto que viene impuesta por la Academia de las Ciencias Francesa ${ }^{15}$. Su solución puede considerarse el primer proyecto de hospital longitudinal de pabellones de Francia. En cambio, en Inglaterra ya existen hospitales de pabellones como el Hospital de San Bartolomé de Londres (1729) del arquitecto James Gibbs [fig.1.20], un hospital que aunque sigue un orden claustral está compuesto por cuatro pabellones independientes, o el Hospital Naval Real de Plymoth (1756-1764) construido en Rovehead [fig.1.21], que consta de diez pabellones conectados en planta baja por un corredor cubierto, ordenados también en torno a un patio central. Sin embargo, la propuesta de Le Roy responde a un orden lineal, más próxima tipológicamente a los modelos hospitalarios reticulares que responden a arquetipos direccionales que a los claustrales herederos de las formas centrales ${ }^{16}$ [fig. 1.25].

Está constituido por dos series enfrentadas de salas aisladas de enfermos dispuestas en batería, en una composición axial ordenada a ambos lados del gran patio de acceso rectangular, rematado frontalmente con la iglesia que preside el conjunto [fig.1.23]. La Academia de las Ciencias Francesa no acepta como válida ninguna de las tres propuestas ${ }^{17}$ y plantea sus propias ideas que son interpretadas por el doctor Tenon y por Bernard Poyet, el arquitecto del rey y de la ciudad de París, incorporadas al proyecto definitivo del nuevo

\footnotetext{
${ }^{15}$ Casimir TOLLET, "Le Nouvel Hôtel-Dieu de Paris (1874)" en Les Hopitaux modernes XIX ${ }^{\text {me }}$ siècle. Paris 1894, pp. 15-20.

${ }^{16}$ La configuración formal de la propuesta de Le Roy puede interpretarse como una evolución procedente de tipología reticular de los países del sur de Europa, en donde la retícula se densifica al construir salas de enfermos de una sola planta, reduciéndose la anchura de los patios y provocando la escisión de la misma en pabellones aislados paralelos entre sí.

17 Dankwart LEISTIKOW, Edificios hospitalarios en Europa durante diez siglos. C. H. Boeringer Sohn, Ingelheim am Rehein, Germany 1967, p. 95.
} 


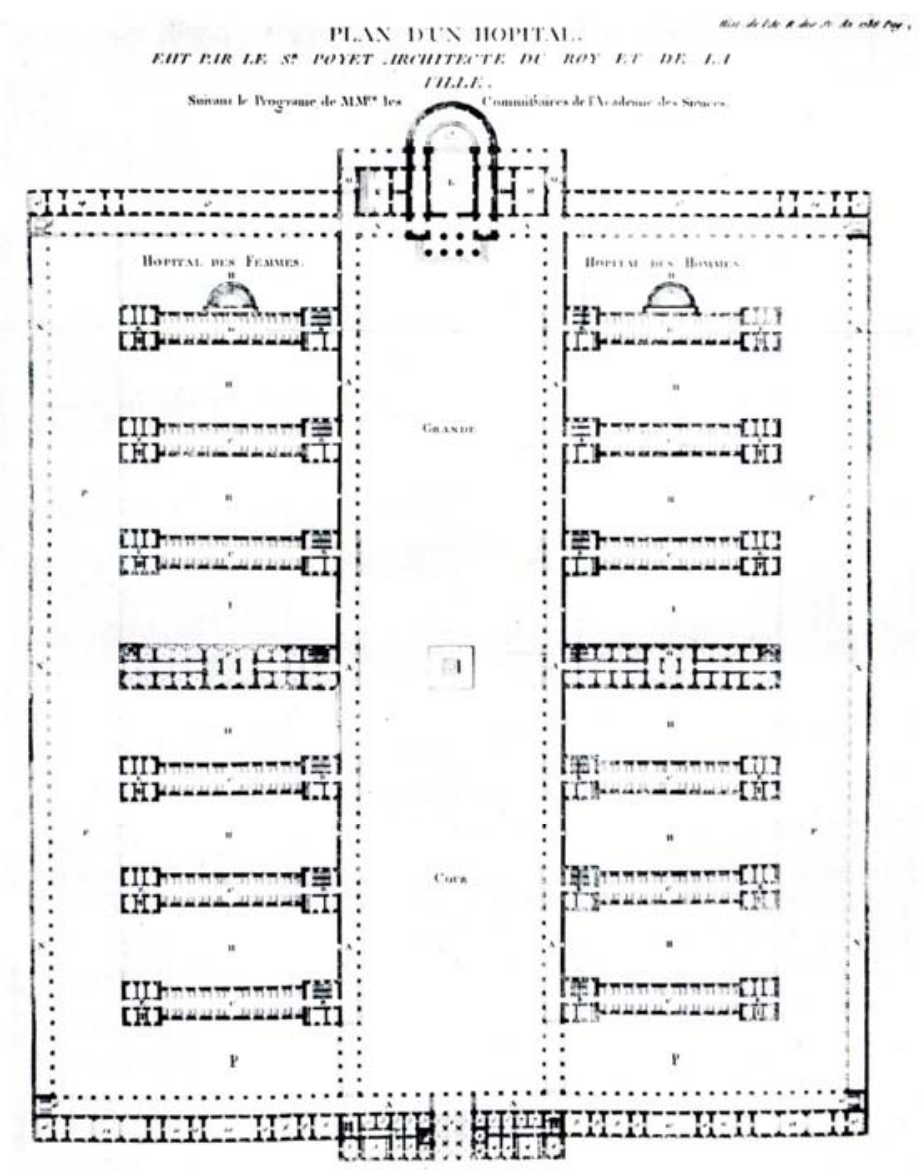

1.24

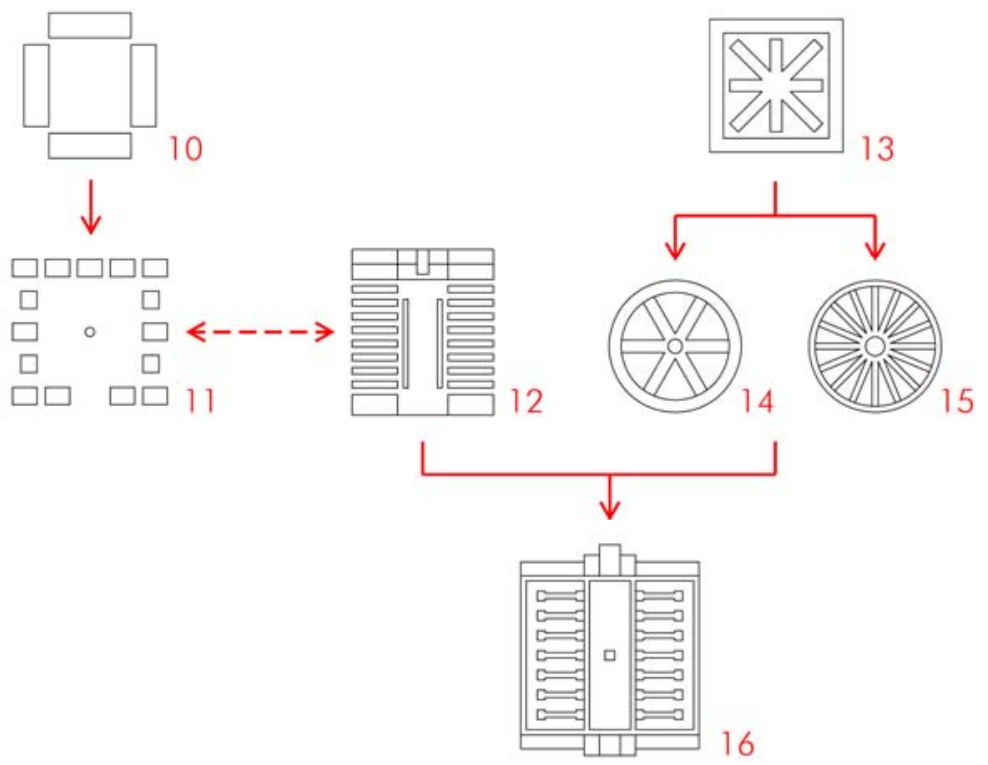

1.24 B. Poyet. Proyecto de la Academia de las Ciencias Francesas para el nuevo Hôtel-Dieu, París, 1787.

1.25 Genealogía de los tipos hospitalarios del siglo XVIII: La máquina de curación. 10) Hospital de San Bartolomé, Londres 1729, 11) Hospital Naval Real de Plymouth, Rovehead 1756-1764, 12) Le Roy. Nuevo Hôtel-Dieu, París 1773, 13) A. Desgodets. Proyecto de hospital de finales del s. XVII, 14) Petit. Nuevo Hôtel-Dieu, París 1774, 15) Poyet. Nuevo Hôtel-Dieu, París 1786, 16) Academia de las Ciencias Francesas. Nuevo Hôtel-Dieu, París 1787 (dibujos de la autora). 
Hôtel-Dieu realizado en $1787^{18}$ [fig.1.24]. Su ubicación no respeta ni las recomendaciones de Antonie Petit, que propone su implantación fuera de la ciudad, sobre un terreno seco y abrigado de los vientos fríos y húmedos ${ }^{19}$, ni la de la Academia de las Ciencias Francesa, que estudia los posibles emplazamientos del nuevo hospital tanto dentro de París y propone tanto su construcción frente a la Isle des Cygnes junto al antiguo Hôtel-Dieu, como en el extrarradio. Al final, la presión del Cabildo de Notre Dame impone su construcción intramuros justo al lado de la catedral ${ }^{20}$.

\section{EL CAMPAMENTO EFICIENTE}

La evidencia del fracaso del hospital, demostrada al comparar las tasas de mortalidad de los solemnes hospitales ingleses del siglo XIX con las de los hospitales militares de campaña, revela la necesidad de un cambio en los modelos hospitalarios. Los precarios barracones temporales, acondicionados con sencillos sistemas de ventilación y de evacuación de residuos, resultaron más eficaces que los grandiosos hospitales de la ciudad de Londres.

La enfermera inglesa Florence Nightingale contribuye considerablemente a lograr tal avance en los hospitales de campaña durante la guerra de Crimea. Es la encargada de trasladar los métodos allí aplicados a las nuevas edificaciones hospitalarias y Nightingale aprende los criterios de higiene y eficiencia del proyecto del ingeniero Isambard Brumel que realiza en 1855 para un hospital de campaña en Renkioki, en la península de Crimea [fig.1.26]. Es un hospital de barracones de madera prefabricados que trata de ser lo más económico y ligero posible [fig.1.27]. Se encuentra ubicado en un terreno con una pendiente gradual hacia el mar que facilita la evacuación de aguas sucias ${ }^{21}$ y con abundantes fuentes de agua potable.

\footnotetext{
${ }^{18}$ La Academia de las Ciencias se inclina por un hospital de pabellones simétricos similar al de Le Roy, con la diferencia de que apila en altura varias salas de enfermos para aislar más los pabellones al aumentar el espacio libre entre ellos. Este mismo esquema se empleó en la construcción de otro de los más importantes hospitales de París, el hospital Lariboisière de 1846-1854, que se adelantó al nuevo Hôtel-Dieu construido en 1876, casi un siglo después de su concepción. Para entonces el modelo de pabellones había evolucionado y la propuesta para el nuevo Hôtel-Dieu había quedado obsoleta, ya que sus pabellones constaban de tres plantas, mientras que desde 1862 la propia Academia de las Ciencias Francesa había recomendado la construcción de pabellones de una sola planta como en su día propone Le Roy.

${ }^{19}$ Antoine PETIT, Memoria sobre la mejor manera de construir un hospital de enfermos, 1774. Citado en: Arquitectura hospitalaria gallega de pabellones, Mercedes INSUA CABANAS. Universidad de La Coruña, La Coruña 2002, p. 87.

${ }^{20}$ Dankwart LEISTIKOW, Edificios hospitalarios en Europa durante diez siglos. C. H. Boeringer Sohn, Ingelheim am Rehein, Germany 1967, p. 92.

21 J. F. ISASI, J. L. PANIAGUA, A. PIELTAIN, Hospitales. La arquitectura del Insalud. 1986-2000. Libro 2. Insalud, Madrid 2000, pp. 25-26.
} 


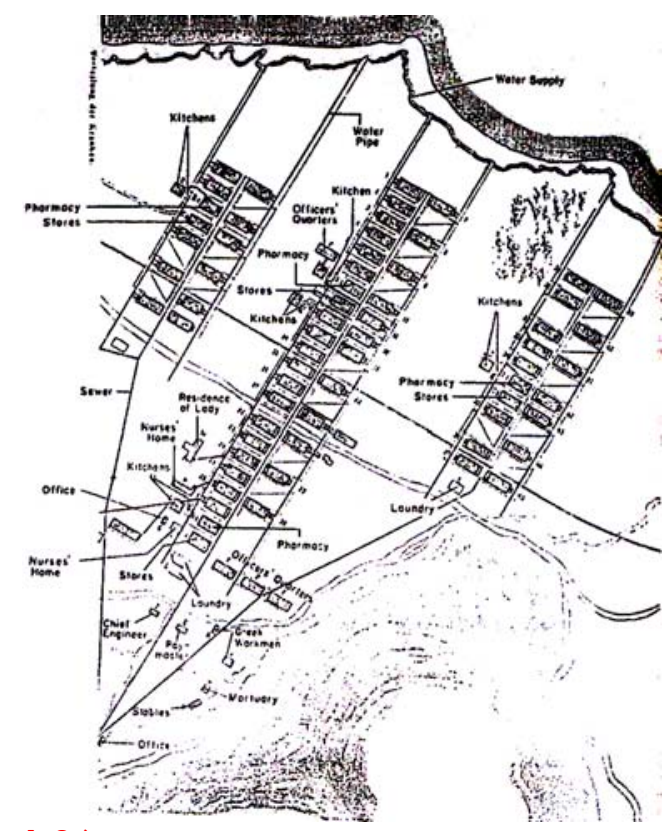

1.26
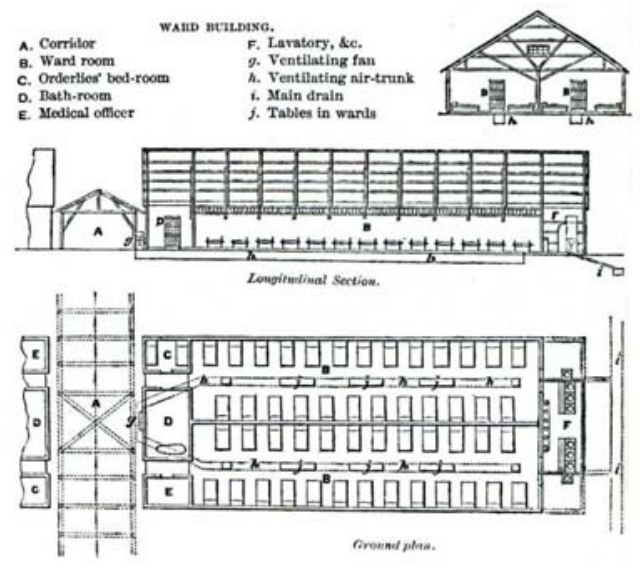

1.27

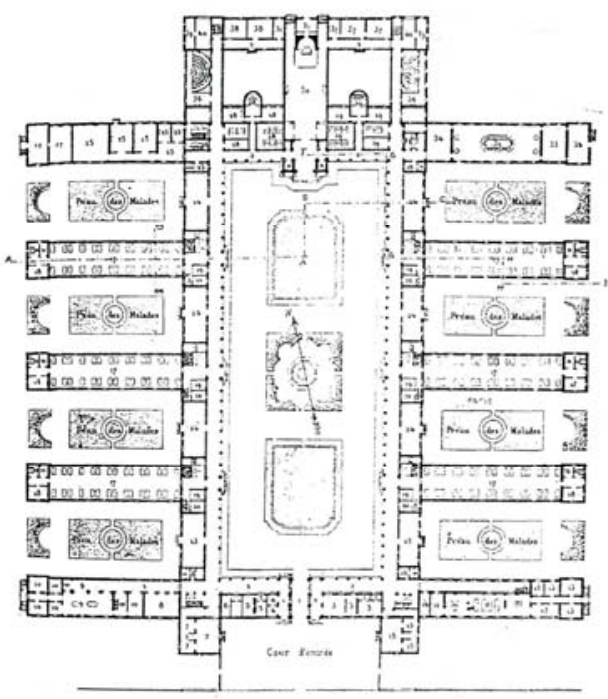

1.26 I. Brumel. Proyecto del hospital de campaña de Renkioki, 1855. Planta general.

1.27 I. Brumel. Proyecto del hospital de campaña de Renkioki, 1855. Planta y sección de los barracones.

1.28 M. P. Gauthier. Hospital de Lariboisière, París, 1846-1854. 


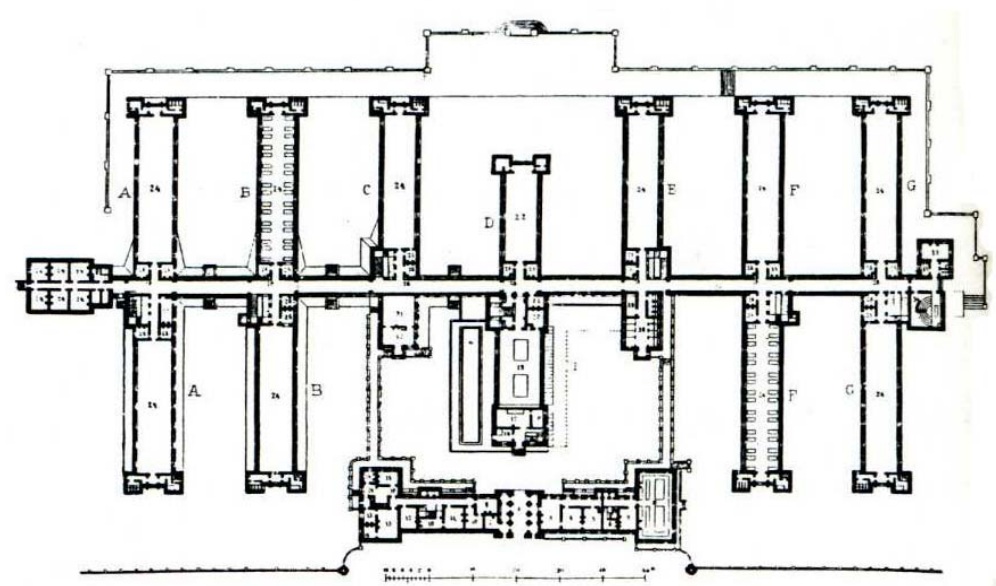

1.29

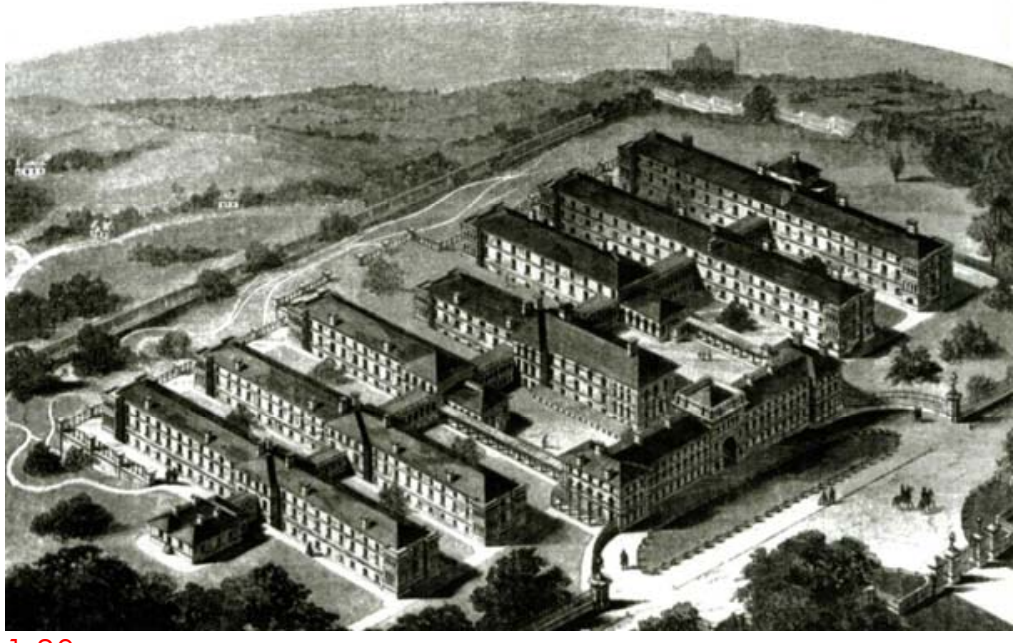

1.30

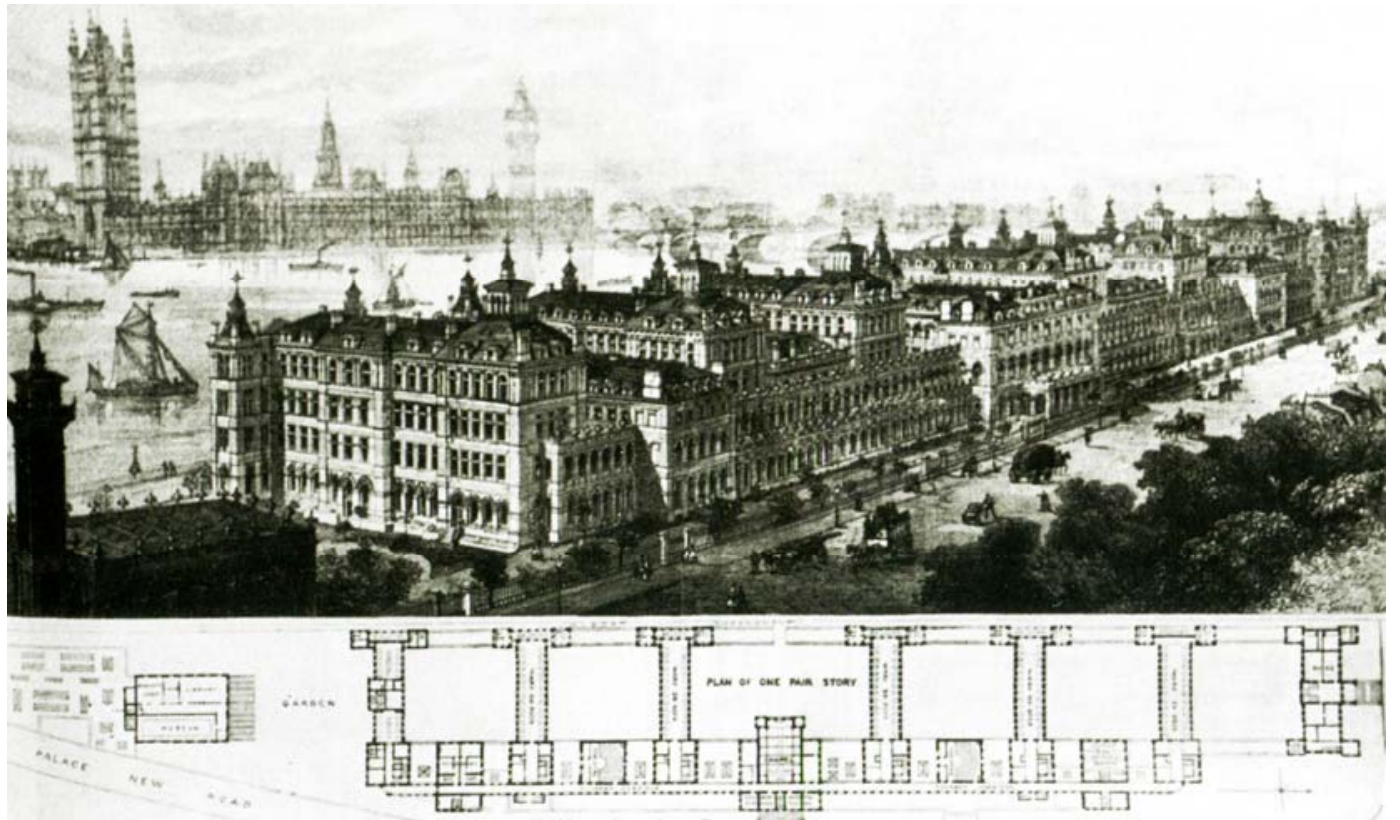

1.29 y 1.30 D. Galton. Hospital militar Herbert, Woolwich, 1864. Planta y vista general.

1.31 H. Currey. Hopsital de Saint Thomas, Londres, 1871. Planta y vista general. 

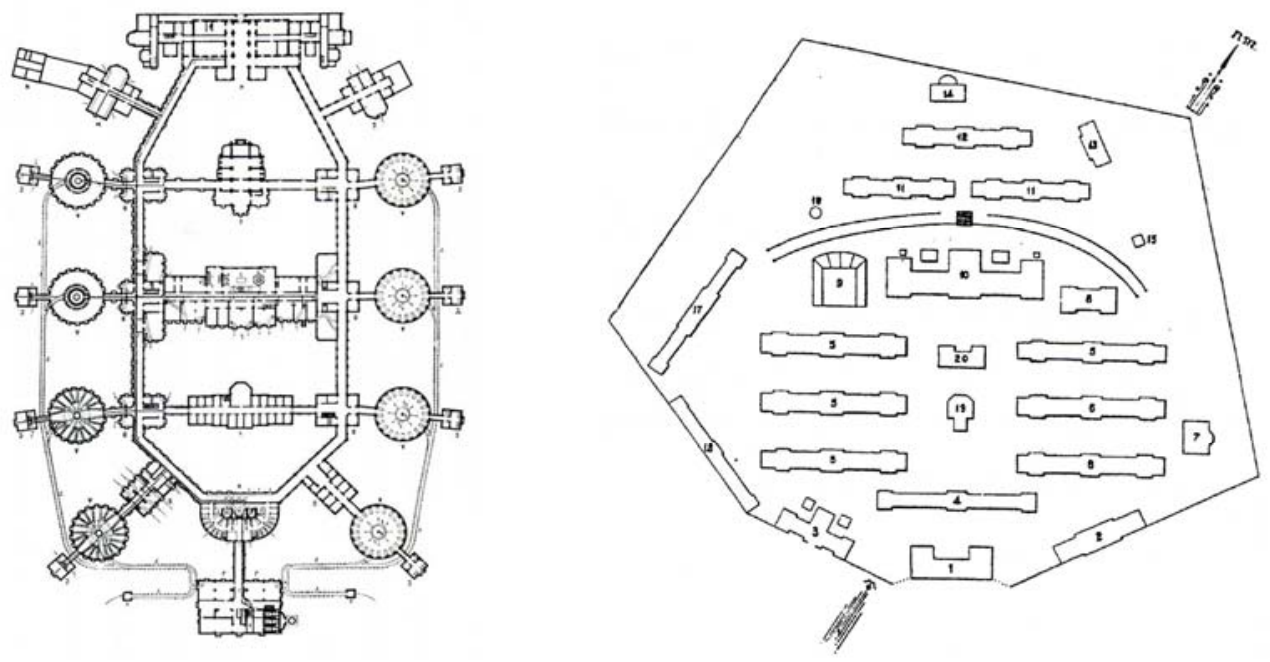

1.32 y 1.33

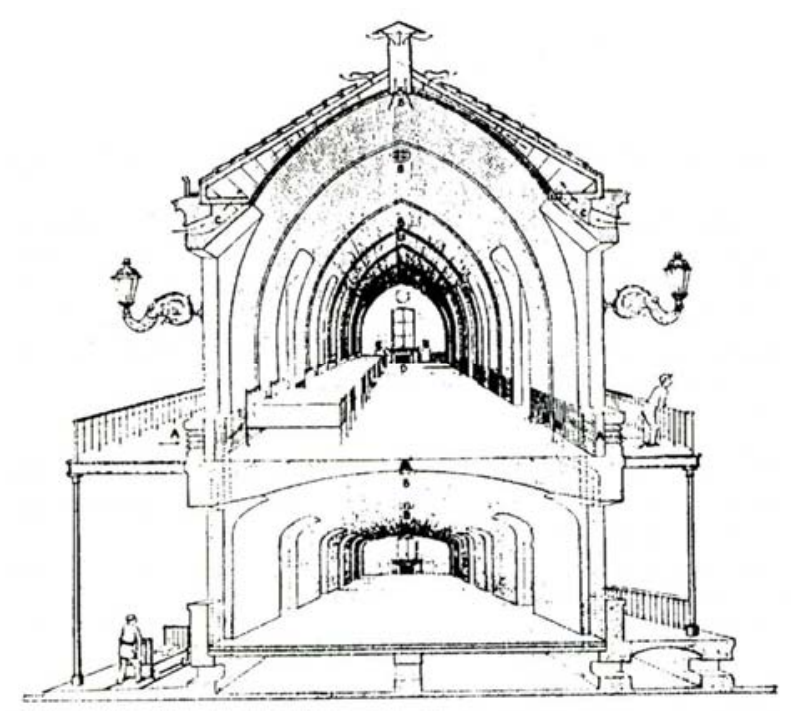

1.34

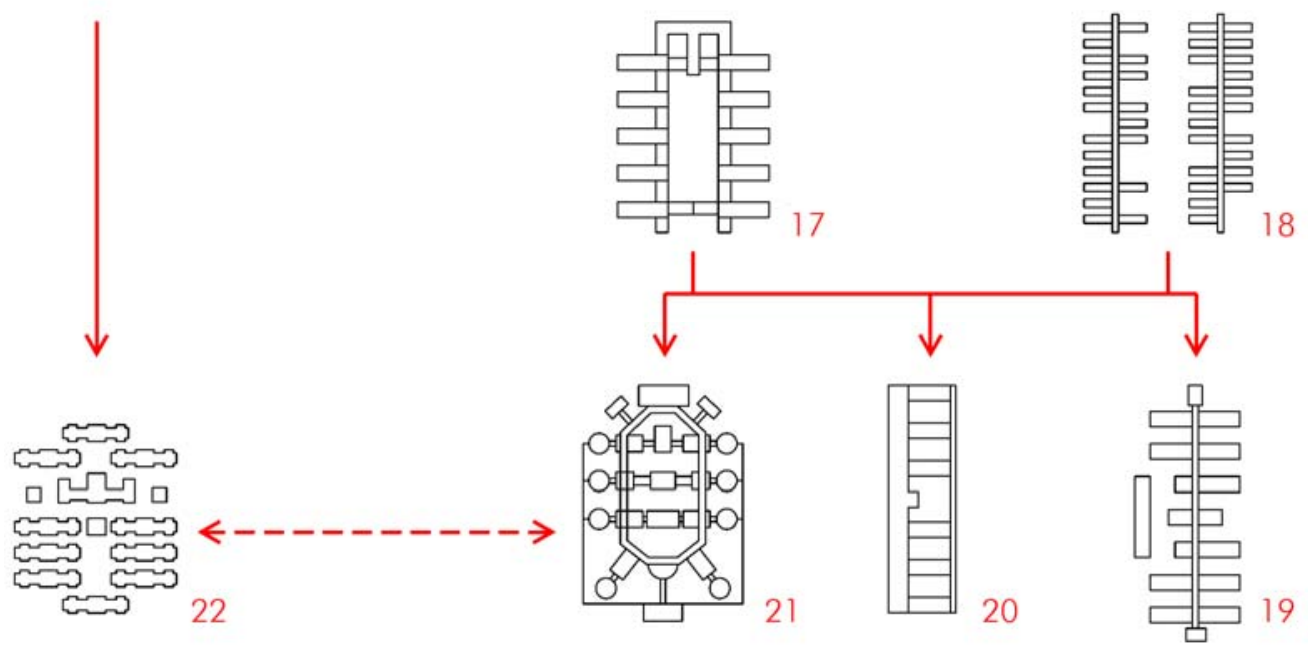

1.35

1.32 Hospital Stuivemberg, Amberes, 1878-1885.

1.33 M. Cano de León. Hospital de Carabanchel Madrid, 1889-1897.

1.34 C. Tollet. Proyecto de modelo de sala de enfermos, 1884.

1.35 Genealogía de los tipos hospitalarios del siglo XIX: El campamento eficiente.17) Hospital Laiboisière, París 1846-1854. 18) Hospital de campaña de Renkioki 1855 19) Hospital militar Hebert, Woolwich 1864, 20) Hospital de Saint Thomas, Londres 1871 21) Hospital Stuivemberg, Amberes 1878-1885, 22) Hospital de Carabanchel, Madrid 1889-1897 (dibujos de la autora). 
Nightingale propone que el hospital sea eminentemente eficiente, de modo que su construcción debe facilitar en todo momento la cura del enfermo, que depende tanto de los criterios higiénicos y de ventilación, pues aún se cree en los miasmas, como de la asistencia médica.

Los avances científicos y médicos del siglo XIX conseguidos por Louis Pasteur (1822-1895) y Robert Koch (1843-1910) en el campo de los gérmenes patógenos, de Charles Robert Darwin (1809-1882) y Gregor Johann Mendel (1822-1884) en el área de la genética, de Rudolf Virchow (1821-1902) y Santiago Ramón y Cajal (1854-1934) en la investigación celular, entre otros, logran por primera vez en la historia que la sociedad confíe en la medicina $^{22}$ y en la ciencia y la antepongan a la creencia en la fe.

La religión aunque resulta reconfortante para muchos, indudablemente por sí sola no es capaz de eliminar la enfermedad, luego no es eficaz. En consecuencia el elemento más representativo del hospital, la capilla o iglesia, que como en el Hospital de Lariboisière ${ }^{23}$ de París (1846-1854) construido por M. P. Gauthier [fig.1.28] preside el conjunto rematando el patio longitudinal de acceso, se acaba sustituyendo por un corredor, un eje de comunicación para el personal médico ${ }^{24}$.

Nightingale trata de eliminar todos aquellos espacios superfluos de los hospitales, en aras de la eficiencia: "Cinco minutos gastados en la limpieza de zonas que no deberían existir, es un tiempo desperdiciado para el servicio y perdido para el enfermo "25. Comienza por sustituir las dobles circulaciones que se generan alrededor de los patios por un único eje de circulación, dando origen a una nueva tipología hospitalaria en "espina de pez". Consiste en una columna de comunicación principal a la que se conectan los pabellones perpendicularmente, adoptada en el Hospital militar Herbert (1864) construido en Woolwich al sur de Londres por Douglas Galton [fig.1.29 y fig.30], o en el Hospital de Saint

\footnotetext{
${ }^{22}$ Lovis Pasteur, descubridor de la vacuna, Robert Koch descubridor del bacilo de Koch germen causante de la tuberculosis. Charles Robert Darwin que con su teoría de la evolución desvela el origen de las especies, y Gregor Johann Mendel que demuestra la llamada herencia genética con sus leyes. Rudolf Virchow muy interesado en la patología, es quien descubre la mitosis celular; y Santiago Ramón y Cajal en su "doctrina de la neurona" muestra la presencia de células individuales en el tejido cerebral.

${ }^{23}$ Casimir TOLLET, "Hôpital Laribisière de Paris (1846-1854)" en Les Hopitaux modernes XIX"Xe siècle. Paris 1894, pp. 5-14.

${ }^{24}$ En un plano para el Hôpital de la Roquette, que no llegó a construirse, la capilla se encuentra en un lateral del patio central, desplazada del eje y en el centro de las salas se proyecta una cabina de cristal para el vigilante. Dankwart LEISTIKOW, Edificios hospitalarios en Europa durante diez siglos. C. H. Boeringer Sohn, Ingelheim am Rehein, Germany 1967, p. 95.

${ }^{25}$ Mercedes INSUA CABANAS, Arquitectura hospitalaria gallega de pabellones. Universidad de La Coruña, La Coruña 2002, p. 125.
} 

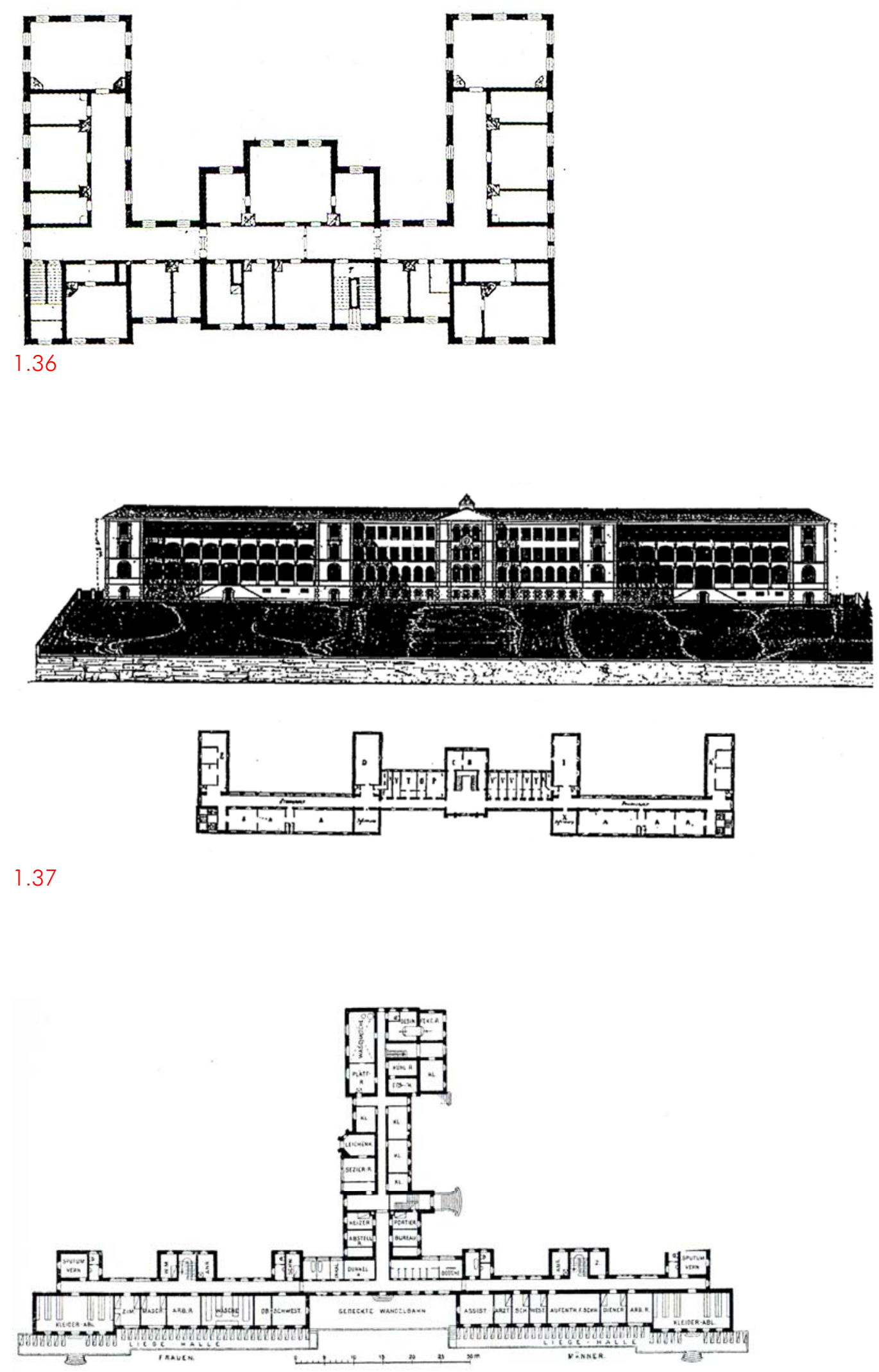

1.36 G. Wilenius. Hospital Niuvanniemi, Kuopio, 1881-1885.

1.37 Hospital Cantonal de Ginebra, 1849.

1.38 Sanatorio Alemán de Davos, principios del XX. 
Thomas de Londres (1871) de Henry Currey [fig.1.31]. Esta nueva tipología en "espina de pez" sufre variaciones formales al articular los corredores en forma de $\mathrm{H}$, o en forma de anillo, como en el Hospital Stuivemberg (1878-1885) de Amberes [fig.1.32] en el que se produce un mestizaje formal entre las estructuras direccionales y las formas centrales 0 radiales [fig. 1.35].

Siguiendo las recomendaciones de la señorita Nightingale, la Academia de las Ciencias Francesa aconseja en 1862 construir hospitales de pabellones de una sola planta que mantengan una proporción de $50 \mathrm{~m}^{3}$ de aire por cama, con salas de entre 15 y 20 camas máximo, provistos siempre de una sala de reserva para poder limpiar y ventilar debidamente las que habitualmente están en uso.

El ingeniero francés Casimir Tollet $^{26}$ en 1884 crea una sala de enfermos sencilla, tecnológica y eficiente donde plantea dos sistemas para evitar la presencia de humedades en la sala ${ }^{27}$ : elevar la planta de enfermería al primer piso dejando libre la planta baja, y ventilar la cubierta introduciendo aire por el alero y expulsándolo por unas piezas especiales situadas junto a la cumbrera ${ }^{28}$ [fig.1.34]. Este modelo se impone en multitud de hospitales de pabellones europeos, en los de tipo "espina de pez" y en los de pabellones exentos como el Hospital de Carabanchel (1889-1897) en Madrid construido por Manuel Cano de León [fig.1.33].

\section{EL BLOQUE MÉDICO ESPECIALIZADO}

En el siglo XX el hospital se concibe como el establecimiento destinado al diagnóstico y al tratamiento de enfermos, donde se practican también la investigación y la enseñanza. Es en este siglo cuando los criterios de la medicina y de la ciencia moderna, aplicados en la construcción de hospitales contagian a los de la arquitectura. Ya no sólo los hospitales tienen que ser higiénicos y eficaces, también las viviendas, las escuelas, las fábricas, etc.,

\footnotetext{
${ }^{26}$ Casimir Tollet escribe el tratado Les Hopitaux modernes XIX ${ }^{\text {me }}$ siècle en 1894 donde plantea un importante estudio de las diversas tipologías hospitalarias existentes y un estudio detallado de su pabellón tipo.

${ }^{27}$ Casimir TOLLET, Les Hopitaux modernes XIX ${ }^{\text {me }}$ siècle. Paris 1894, pp. 217-219.

${ }^{28}$ Se vuelve a una sala de enfermería única, sin plantas superpuestas, tal y como aconseja Nightingale y la Academia de las Ciencias Francesa, de gran altura libre para tener una mayor cantidad de volumen de aire por enfermo. La sala dispone de grandes ventanales enfrentados, como las salas propuestas por Filarete en el Hospital Mayor de Milán, y discretos sistemas de impulsión de aire frío y caliente situados en las partes bajas de las paredes junto a las ventanas. Consta también de orificios de extracción en el techo y de sistemas de renovación y regulación del aire viciado en los extremos de la sala.
} 

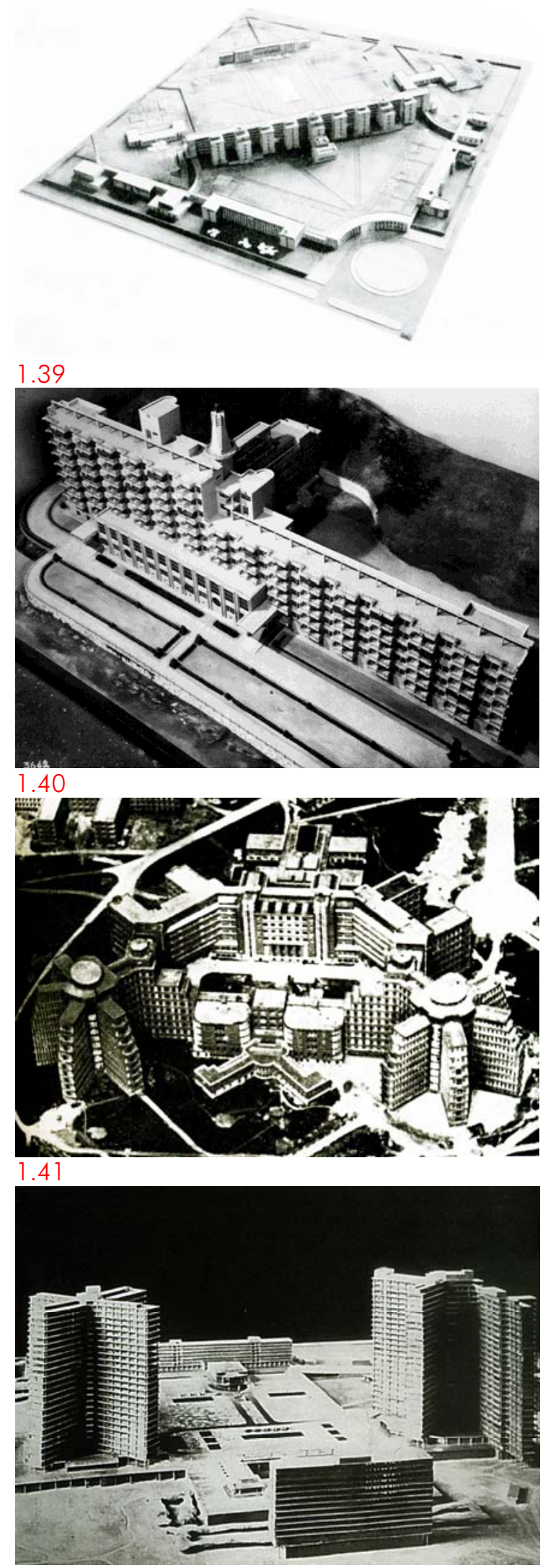

1.42

1.39 W. Vetter, Hospital de Colmar, alrededor de 1936. Maqueta.

1.40 P. Abraham y H. Le Même. Sanatorio de Martel-de-Janville en el Plateau d'Assy, 1933-1937. Maqueta.

1.41 I. Walter. Ciudad hospitalaria de Lille, 1932-1953. Maqueta.

1.42 P. Nelson. Proyecto para la Ciudad hospitalaria de Lille, 1932. Maqueta.

todos los edificios deben serlo. 
Durante la primera mitad de siglo se desarrollan principalmente dos clases de hospitales: el hospital general y el sanatorio antituberculoso pulmonar. Éste último debido a la rápida propagación de la tuberculosis, se convierte en el protagonista de la arquitectura hospitalaria en el período de entreguerras y eclipsa en número al hospital general.

Los sanatorios antituberculosos pulmonares del siglo XX consisten en un bloque lineal, generalmente con planta en forma de $\mathrm{T}$ o de mariposa. Proceden de los hospitales palaciegos del siglo XIX que tienden a adoptar morfologías abiertas en forma de C, como sucede en el Hospital Niuvanniemi de Kuopio en Finladia (1881-1885) construido por Georg Wilenius, con planta rectangular abierta por uno de sus lados [fig.1.36]. Este tipo de hospital en las latitudes Suizas, con el fin de aprovechar al máximo la orientación sur, pierde su estructura claustral y se transforma en una edificación lineal como el Hospital Cantonal de Ginebra (1849) [fig.1.37], cuya estructura formal es muy similar a la de ciertos sanatorios de principios de siglo que incluyen además, como en el Sanatorio Alemán de Davos [fig.1.38], galerías y balcones frente a las habitaciones para facilitar la helioterapia. Surge así el tipo de sanatorio en T que pasará a desarrollarse en altura y extenderse por toda Europa.

Las características de las terapias proporcionadas en el sanatorio requieren prestar una especial atención al bienestar del enfermo, convirtiéndose en una casa de reposo, mientras que el hospital general presenta más restricciones vinculadas al programa. En ambos edificios sanitarios se propone un crecimiento en vertical de la tipología palaciega compacta, contraria a los modelos de hospitales de pabellones de una sola planta desarrollados en épocas anteriores.

El crecimiento en altura surge debido a la necesidad de economía y funcionalidad, aunada al avance tecnológico y constructivo del siglo XX. Al ser más concentrado el edificio, se reduce la superficie de ocupación y los costes del solar de implantación ${ }^{29}$, logrando además rentabilizar mejor los servicios comunes y disminuir los recorridos de circulación dentro del mismo. Por otro lado, el conocimiento médico sobre el contagio y la etiología de las enfermedades permite la superposición de las salas de enfermos en altura, considerándose

\footnotetext{
${ }^{29}$ Según exponen a principios del siglo XX los estadounidenses Albert Oschner y Meyer Sturm en su estudio para un hospital de 500 camas. Albert J. OSCHNER y Meyer J. STURM, The Organization, Construction and Management of Hospitals. Cleveland Press, Chicago 1907.
} 


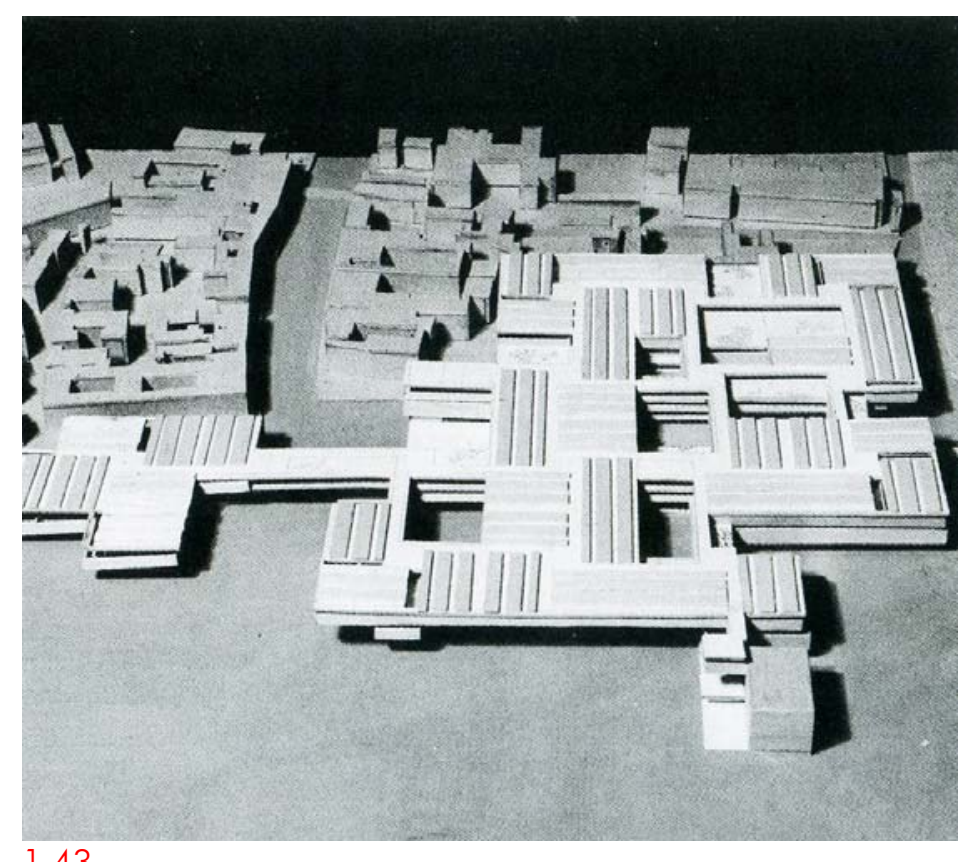

1.43
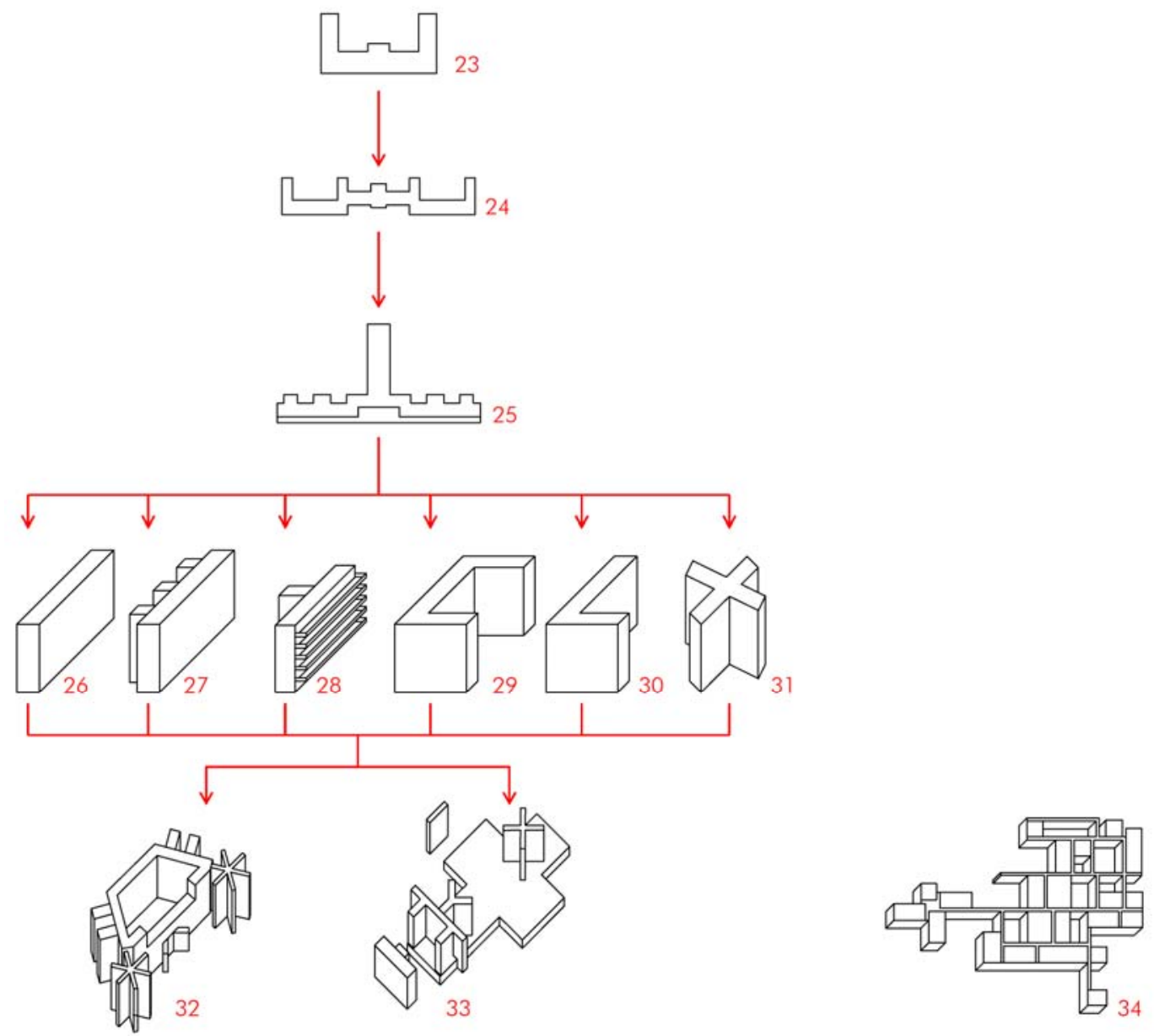

1.44

1.43 Le Corbusier y J. de la Fuente. Proyecto de Hospital de Venecia (1964-1965). Maqueta.

1.44 Genealogía de los tipos hospitalarios del siglo XX: El bloque médico especializado 23)Hospital Niuvanniemi, Kuopio 1881-1885, 24) Hospital Cantonal de Ginebra 1849, 25) Sanatorio Alemán de Davos, principios s. XX, 26) Sanatorio de la Fuenfría, Madrid 1921, 27) Hospital de Colmar 1936, 28) Sanatorio de Martel-de-Janville, Savoya 1933-1937, 29) Residencia sanitaria de La Coruña 1950, 30) Clínica de la Cruz Roja, Berlín 1930-1931, 31) Fundación Wesley, Chicago 1940-1941, 32) Ciudad hospitalaria de Lille 1932, 33) P. Nelson, Proyecto de Ciudad hospitalaria de Lille 1932, 34) Le Corbusier, Proyecto de Hospital de Venecia 1964-1965 (dibujos de la autora). 
igualmente higiénico y saludable el nuevo hospital vertical frente al tradicional hospital de pabellones en una sola planta.

En origen el hospital vertical consta de un bloque compacto que puede presentar una morfología muy diversa: en peine como el Hospital de Colmar de William Vetter construido alrededor de 1936 [fig.1.39], en forma de C, L, X ○ T, como el Sanatorio de Martel-deJanville en el Plateau d'Assy en Francia (1933-1937), construido por Pol Abraham y Henry Le Même [fig. 1.40], etc. La proliferación de tantas variaciones es porque tratan de adaptarse al programa de necesidades del hospital.

El avance de la ciencia y de la enseñanza de la medicina modifica el programa de necesidades del hospital, disminuyendo la parte residencial y aumentando la de servicios generales, quirófanos, salas de curas, áreas de investigación y diagnóstico, etc. Esta circunstancia se refleja en la complejidad formal que va adquiriendo el hospital cuyo exponente máximo es el tipo poli-bloque, como en la Ciudad hospitalaria de Lille (19321953) construida por I. Walter [fig.1.41] donde el programa se reparte en las múltiples torres conectados entre sí que definen el enorme complejo hospitalario.

Otra variante del hospital vertical es el tipo torre y base, en el que los servicios comunes se distribuyen en un edificio extenso desarrollado en planta baja, concentrándose el programa residencial en las construcciones en altura, tipología que propone Paul Nelson para la ya mencionada Ciudad Hospitalaria de Lille (1932) [fig.1.42].

La inmensa dimensión que va adquiriendo el hospital general obliga a ubicarlo en la periferia de las ciudades, lugares donde difícilmente encajan los grandes edificios verticales y son más aconsejables las construcciones de poca altura. Surge así otro tipo de hospital el tipo bloque horizontal, de crecimiento expansivo que facilita la transición entre la alta densidad edificatoria de la ciudad y las dispersas poblaciones del campo. Le Corbusier se enfrenta a este problema en el singular borde urbano de la ciudad de Venecia con el proyecto de hospital realizado junto a Julián de la Fuente (1964-1965). Diseña un edificiotapiz o matt-building que dialoga con la ciudad y con el agua [fig.1.43]. En esta nueva tipología horizontal se mezclan los arquetipos centrales presentes en las partes que lo componen y los longitudinales formando una retícula de perímetro irregular.

Este recorrido tipológico sirve para contextualizar el sanatorio dentro de la genealogía del hospital y para mostrar cómo el valor del análisis tipológico no reside en la invariabilidad 
de las estructuras ${ }^{30}$, sino en el constante proceso formativo al que éstas están sometidas. Tras sucesivas y lentas transformaciones de los prístinos hospitales claustrales se decantan los hospitales articulados y compactos desarrollados en altura y los conjuntos unitarios de pabellones aislados, de la misma manera que de los hospitales basilicales y tipo hall se derivan los hospitales en tipo de bloque horizontal y extensivo. Sin embargo, la transformación formal no transgrede totalmente las leyes características de las estructuras originales. Tanto en los hospitales verticales como en los conjuntos de pabellones se conserva el carácter unitario de las formas claustrales, mientras que en el hospital extensivo de bloque horizontal se sigue manteniendo la direccionalidad, cualidad característica del hospital tipo hally del tipo basilical.

De este análisis podemos considerar que los tipos hospitalarios no son fruto de la invención "ex novo" ni de la mímesis literal de modelos existentes aplicados en otros programas religiosos o residenciales, sino que no son más que variaciones aplicadas sobre tipos preexistentes que generan nuevos tipos edificatorios, de manera que, como afirma C. Martí Arís: "Toda arquitectura puede ser vista entonces como el resultado de una serie de transformaciones operadas sobre otras arquitecturas ${ }^{\prime 31}$.

\footnotetext{
${ }^{30}$ Entendiendo por estructura la definición dada por Jean Piaget en su libro Le Structuralisme : "un sistema de transformaciones que posee sus propias leyes en tanto que sistema y que se conserva 0 enriquece mediante el juego mismo de sus transformaciones, sin que éstas le conduzcan más allá de sus propias fronteras". Citado en: Las variaciones de la identidad. Ensayo sobre el tipo en arquitectura, Calos MARTí ARÍS. Ediciones del Serbal, Barcelona 1993, p. 114.

${ }^{31}$ Calos MARTÍ ARÍS, Las variaciones de la identidad. Ensayo sobre el tipo en arquitectura. Ediciones del Serbal, Barcelona 1993, p. 115.
} 
MEDICINA Y ARQUITECTURA:

TERAPIAS ANTITUBERCULOSAS Y PROPUESTAS EXPERIMENTALES

LA CONSIDERACIÓN DE INCURABLE Y LA ILUSIÓN TERAPÉUTICA: EL ASILO AISLADO LA CURA EN EL LITORAL Y LA CURA DE ALTURA: LA IMPORTANCIA DEL MEDIO LA TERAPIA DE EJERCICIO Y LA TERAPIA DE REPOSO: LA GALERÍA DE CONVALECENCIA LA VIDA EN EL HOTEL Y LA VIDA EN LA CABAÑA: EL PATRÓN MÉDICO HELIOTROPISMO PASIVO Y HELIOTROPISMO DINÁMICO: LA SECCIÓN ESCALONADA LAS TERAPIAS CLIMÁTICAS Y LA CURA DE TRABAJO: LA CIUDAD SANATORIO 


\section{MEDICINA Y ARQUITECTURA: TERAPIAS ANTITUBERCULOSAS Y PROPUESTAS EXPERIMENTALES}

A finales del siglo XVIII y principios del XIX la tuberculosis, o la más tarde llamada "peste blanca", arrasa el continente europeo y llega a principios del XX a ser la primera causa de mortandad en toda Europa. No es hasta trascurrida la Primera Guerra Mundial cuando se elaboran y aplican en profundidad los Planes de Lucha Antituberculosa que se traducen en un surgimiento masivo de sanatorios.

La tuberculosis es una antigua conocida de los médicos. Hipócrates en el siglo IV a.C. describe y trata la tisis y más tarde, ya en el siglo XVI, Paracelso la incluyó junto con la gota y la epilepsia en el grupo de las "enfermedades incurables". Frans de le Boë en el siglo XVII establece la relación entre escrófula y y tisis. La escrófula consiste en la inflamación fría de los ganglios linfáticos principalmente cervicales; se considera una enfermedad endémica y contagiosa, identificada con la fase purulenta de los tubérculos². La tisis por su parte es calificada como un tipo de escrófula que afecta al pulmón. Hasta la segunda mitad del XVII no se acuña el término de "tuberculosis pulmonar", que trata de sustituir al de tisis sin demasiado éxito. El Dr. Morton dictamina que la tuberculosis es el mal que precede a cualquier caso de tisis y llega a detallar hasta catorce tipos diferentes de tisis: la hemoptoica, la escrofulosa, la melancólica, la asmática, etc. en su libro Phtisiología, sui exercitationes de phtisi (1689).

Mientras tanto en Inglaterra aumenta la popularidad del Dr. Thomas Sydenham, conocido como el "Hipócrates inglés" quien, convencido de la necesidad de observar al enfermo para poder reconocer y ordenar los síntomas de las enfermedades y de que dichas enfermedades eran fruto del aire, los alimentos, el ejercicio y las emociones, establece que el método para combatirlas reside en la naturaleza, creando terapias higiénico-dietéticas de cura $^{3}$. También determina que las epidemias y las enfermedades contagiosas están

\footnotetext{
'Escrófula, enfermedad similar a la tisis descrita por Andrés du Laurens en su obra De mirabili strumas sanadi vi solis Gallice Regibus hristianissimis divintus concessa liber unus. Et de strumorum natura, differentiis, cauais, curatione, quoe fit arte et industria medica (1609). J. y A. ORIOL. Historia de la Tuberculosis. Ensayos de Fisiología colectiva. Salvat Editores S.A., Barcelona-Buenos Aires 1944, p. 92.

${ }^{2}$ Los tubérculos asociados a la Medicina son definidos por la Real Academia de la Lengua como productos morbosos, de color ordinariamente blanco amarillento, redondeados, duros al principio en la época de evolución llamada de crudeza y que adquiere en la de reblandecimiento el aspecto y la consistencia del pus.

${ }^{3}$ El Dr. Thomas Sydenham fue también conocido como "Láudano de Sydenham" por haber creado el remedio "útil para todas las edades y en todas las enfermedades. El laudanun nostrum". Era un compuesto de vino español, opio, azafrán, polvo de canela y polvo de clavos calentado al baño María durante tres días, que garantizaba la paz de los enfermos moribundos. J. y A. ORIOL, Historia
} 
asociadas a fenómenos inflamatorios o flogísticos y que su tratamiento debe consistir en la aplicación de productos refrescantes o antiflogísticos. Comienzan aquí las primeras contradicciones terapéuticas cuando el Dr. Morton sostiene que enfermedades como la tuberculosis pulmonar deben tratarse propiciando la calentura, la inflamación y la fiebre.

En el siglo XVIII el Dr. Lavoisier revoluciona la medicina a través de la química desmintiendo la existencia del citado flogisto y define la fisiología del aparato respiratorio estableciendo las bases de la neumología moderna. Un siglo después el Dr. Laennec transforma la práctica clínica con un sencillo instrumento de diagnóstico: el estetoscopio. Es también el descubridor de la "materia tuberculosa" ${ }^{4}$ y un defensor de que la tuberculosis es una enfermedad curable y, a pesar de la opinión popular y la de muchas doctrinas médicas anteriores, escasamente contagiosa. El Dr. Villemin retoma la teoría del contagio ${ }^{5}$ y desvela que la aparición de la materia tuberculosa es consecuencia de un agente específico, un virus o miasma único que se desconoce. Habrá que esperar algún tiempo hasta que el Dr. Robert Koch lo descubra.

La guerra de Crimea a mediados del siglo XIX demuestra que es mayor el número de soldados que mueren tras haber sido ingresados y tratados en el hospital que el de los heridos que se niegan a ello. Estos datos avivan la sospecha de Villemin sobre la presencia del miasma, un efluvio maligno desprendido a través del hedor de los cuerpos enfermos del hospital que antecede al descubrimiento de la existencia de los microbios. Es el Dr. Pasteur quien describe a este ser vivo infinitamente pequeño que acompaña a toda fermentación previa a la putrefacción, pero no puede dar respuesta a cómo se originan; le parece que son hijos de otros microbios que preexisten en el medio, postulando la etiología ambiental de las enfermedades.

de la Tuberculosis. Ensayos de Fisiología colectiva. Salvat Editores, Barcelona, Buenos Aires 1944, p. 93.

${ }^{4}$ La materia tuberculosa según Laennec, y como se conoce hoy en día, solía desarrollarse en el pulmón aunque también podía desarrollarse en otros órganos, siempre bajo dos aspectos posibles, bien como tuberculitos o como masa o infiltración que al cabo de un tiempo acaba por reblandecerse y licuarse, generando una cavidad en el órgano dañado. J. y A. ORIOL, Historia de la Tuberculosis. Ensayos de Fisiología colectiva. Salvat Editores, Barcelona, Buenos Aires1944, pp. 179-182.

${ }^{5}$ Los sabios de la Academia de las Ciencias Francesa se negaban a creer que la tuberculosis fuera contagiosa, ya que tal afirmación pondría en crisis todo el sistema médico establecido y los tísicos deberían ser aislados de la sociedad y de sus familias, por eso: "Aunque en realidad la tisis fuera contagiosa deberíamos decirlo en voz baja" afirmaban los miembros de la Academia. J. y A. ORIOL, Historia de la Tuberculosis. Ensayos de Fisiología colectiva. Salvat Editores, Barcelona, Buenos Aires 1944, p. 197. 
A finales del siglo XIX, el 24 de marzo de 1882, el Dr. Koch lleva a cabo uno de los descubrimientos más importantes en la historia médica de la tuberculosis al identificar al microbio causante de esta enfermedad, conocido como "bacilo de Koch". Ahora ya sólo es preciso lograr eliminarlo, y es en este proceso cuando reaparece Pasteur con su descubrimiento de la vacuna, de modo que el Dr. Koch sólo tiene que arrebatar la virulencia al bacilo para poder inocularlo a los sanos, haciéndoles inmunes al mal.

Tras múltiples intentos en 1890 surge la "tuberculina" pero no llega a funcionar como se espera, no obstante su inoculación contribuye a detectar la enfermedad ${ }^{6}$. La pronta detección de la enfermedad resulta un hecho determinante para el futuro del enfermo, y la obtención de la primera radiografía en 1895 por el Dr. Wilhelm Conrad Röntgen, consigue revolucionar los métodos de diagnóstico de la tuberculosis. Los aparatos de rayos-x, el estetoscopio y la prueba de la tuberculina son los elementos de diagnóstico de los tisiólogos, pero se precisa de un remedio eficaz para acabar con el bacilo porque hasta el momento la única forma de combatirlo reside en crear un ambiente hostil para su desarrollo.

Se sabe que el microbio por sí sólo no es perjudicial, precisa del medio adecuado para su crecimiento y en él se centra el médico. La tuberculosis se considera una "enfermedad ambiental", y el médico procura cambiar su entorno para curar al enfermo. En Inglaterra surgen los primeros "tratamientos ambientales". Los médicos higienistas de finales del siglo $\mathrm{XVIII}$ están convencidos de que el origen de la enfermedad radica en los miasmas provocados por los modos de vida insalubres de las ciudades y que su contagio se produce a través del ambiente. En base a ello, el doctor inglés George Bodington defiende en 1840

\footnotetext{
${ }^{6}$ Francis Barrymore SMITH, The Retreat of Tuberculosis 1850-1950. Croom Helm, New York 1988, p. 58.

7 "En Europa, desde la publicación en 1790 de la obra del médico vienés J.P. Frank, titulada La miseria del pueblo, madre de enfermedades, otros higienistas como Turner Thackrah, Arnold, Chadwick, Villermé o Virchow contribuyeron con sus estudios a refundar la higiene, que entonces formaba parte junto con la medicina legal de la llamada medicina pública, como ciencia profiláctica y disciplina médica independiente de aquellas, dotándola de un cuerpo doctrinario propio que la situó en primera línea de la lucha por la erradicación de enfermedades como el la fiebre amarilla o el cólera-morbo, afecciones que se desarrollaban con más frecuencia en el medio urbano y que afectaban a la mayor parte de la población, especialmente aquella conformada por las clases más bajas, trabajadores, obreros y sus familias, cuyas insalubres condiciones de vida y de trabajo se convertían en focos de enfermedad permanentes". Rafael ALCALDE GONZÁLEZ, "La introducción y el desarrollo del Higienismo en España durante el siglo XIX. Precursores, continuadores y marco legal de un proyecto científico y social" en Scripta Nova. Revista Electrónica de Geografía y Ciencias Sociales n 50, Universidad de Barcelona, 15 de octubre de 1999.
} 
el tratamiento de la tuberculosis mediante la cura de aire puro en un ambiente sano alejado de la ciudad ${ }^{8}$.

La higiene abarca todos los ámbitos y se convierte en una disciplina médico-social de modo que los médicos higienistas traspasan la pura praxis clínica convirtiéndose en auténticos "médico-arquitectos" y "médico-urbanistas" como fundamento de sus terapias.

En Estados Unidos entre 1860 y 1905 se desarrolla un modelo terapéutico basado en la vida al aire libre y el reencuentro con la naturaleza o Wilderness, que consiste en la práctica de ejercicio al aire libre, la estancia en entornos naturales, las travesías en crucero ${ }^{10}$, etc. para combatir la tuberculosis.

Los tisiólogos alemanes y suizos apoyan también la cura al aire libre o Freiluftkur promulgada por el Dr. Brehmer, director del primer sanatorio en altura para tísicos construido en Görbersdorf en Silesia en 1859, y la cura de reposo Liegekur o Ruheluftkur promovida más tarde por el Dr. Dettweiler, discípulo de Brehmer y director del Sanatorio de Falkenstein en Alemania, también defendida por el Dr. Spengler establecido en Davos en su ensayo "médico-climatológico"1 1 . Sin embargo, los médicos suizos amplían los métodos de curación e incluyen la helioterapia como tratamiento de la tuberculosis. Los doctores helvéticos Roller y Bernhart consideran que la exposición del cuerpo del enfermo a los rayos ultra-violetas, junto con la cura de aire puro y reposo, son los mejores remedios para eliminar la tuberculosis.

Todas estas terapias configuran el programa sanatorial desarrollado en la primera mitad del siglo XX y definido en el Congreso Internacional de la Tuberculosis celebrado en Berlín en

\footnotetext{
${ }^{8}$ Francis Barrymore SMITH, The Retreat of Tuberculosis 1850-1950. Croom Helm, New York 1988, p. 97.

9 El Dr. T. Pritgin Teale fue uno de los "médicos arquitectos" que realizan una serie proyectos de casas sanas en 1861, así como el Dr. Benjamin Ward Richardson, quien en su libro Hygeia, a city of health, proyecta una ciudad utópica con el más bajo índice de mortalidad posible. Anne-Marie ADAMS Corpus sanum in domo sano, The Architecture of the Domestic Sanitation Movement 1870 1914. Centre Canadian d'Architecture, Montréal 1991, p.10.

${ }^{10}$ A principios del siglo XX el médico francés Dr. Achille Edom, secundado por la compañía naviera alemana Nord-Deutsche Lloyd, propone la construcción de sanatorios flotantes o "barcos de la salud". En su libro Tuberculose et sanatoriums flottants (1906), los barcos-sanatorios tienen cabinas acristaladas en cubierta que permiten la exposición al sol y a la brisa. Se posibilita practicar la cura de aire en pleno mar abierto en aquellas regiones del océano donde las condiciones meteorológicas sean las más propicias para el enfermo. Este proyecto de sanatorio flotante apenas tuvo repercusión, tan sólo persistieron los sun deck o barcos con cubiertas solárium que iban recorriendo las costas.

${ }^{11}$ Sigard Adolphus KNOPF, Les sanatoria, traitement et prophylaxie de la phtisie pulmonaire. Carré et Naud, Paris 1900, p. 264.
} 
1899 ${ }^{12}$. La cura sanatorial suministrada en los sanatorios antituberculosos consiste en llevar una vida sana y reposada, fuera de las sucias ciudades, basada en el aire puro, el reposo y la sobrealimentación. Contribuye además a controlar la propagación de la enfermedad y a evitar el contagio, ya que los sanatorios se ubican en lugares apartados de los núcleos de población, lo que favorece el aislamiento del enfermo y protege a la población sana del contagio.

Este tipo de tratamiento y el lugar de emplazamiento prevalecen, con leves diferencias, en todos los sanatorios antituberculosos europeos. La aplicación masiva en niños de la vacuna BCG, Bacilo Calmette-Guérin ${ }^{13}$, utilizada por primera vez en seres humanos en 1921, junto con el descubrimiento en 1944 por los doctores Waksman, Schatz y Bugie del primer antibiótico eficaz contra la tuberculosis: la estreptomicina, logran ir erradicando paulatinamente la enfermedad hasta que, en torno a 1950 se considera innecesaria la existencia de sanatorios antituberculosos.

Para poder entender la trascendencia social del sanatorio, que va más allá de la cura de la enfermedad, hay que conocer cómo se establece la "Lucha Antituberculosa", nacida en la primera posguerra y practicada hasta mediados del siglo XX. La tuberculosis se combate en varios frentes: el sanatorio, los dispensarios y los preventorios o colonias infantiles. Si atendemos al número de enfermos curados en estos establecimientos quizás nos resulten poco eficaces, pero el valor de su actividad es incalculable. En palabras del Dr. Robert Koch:

"Considero a los dispensarios de lucha antituberculosa, no como uno de los poderosos medios de lucha, sino como el más útil, y creo que cuando cubran una estrecha red todos los países estarán llamados a ejercer una actividad extraordinariamente rica en frutos ${ }^{\prime 14}$.

La enfermedad afecta principalmente a la clase obrera, y los diversos estudios epidemiológicos realizados por los médicos higienistas demuestran que su origen está

\footnotetext{
12 Terapias y síntomas que son mostrados en el cine en películas como "Robert Koch, el vencedor de la muerte", "Sangre y Vino", en adaptaciones literarias como "Emile Brönte y Jane Eyre", etc. Ver: José Elias GARCÍA-SÁNCHEZ, María José FRESNADILLO, Enrique GARCÍA-SÁNCHEZ, "El cine en la docencia de las enfermedades infecciosas y la microbiología clínica" en Enfermedades Infecciosas y Microbiología Clínica n²0, 2002, pp.403-405.

${ }^{13}$ La vacuna BCG fue bautizada con el nombre de sus inventores, el microbiólogo Charles Calmette y el veterinario Jean-Marie Camille Guérin, ambos miembros del Instituto Pasteur.

14 B. BENITTEZ FRANCO. Información sobre la lucha antituberculosa en España y Memoria correspondiente al año 1944. Patronato Nacional Antituberculoso, Madrid 1945, p. 35.
} 
relacionado con las malas condiciones de vida, la alimentación insuficiente, las largas jornadas de trabajo, las viviendas insalubres y un salario insuficiente para cubrir las necesidades básicas de la población. A todo ello se añaden los malos hábitos populares como el alcoholismo o la promiscuidad que contribuyen a su propagación y a la degeneración del ser humano ${ }^{15}$.

Por ello, para acabar con la tuberculosis no basta con curar a los enfermos, hay que proteger a los sanos; es necesario cambiar las condiciones ambientales que propician la propagación de la enfermedad y eso significa terminar con la miseria social y con ciertos hábitos como la falta de higiene y la mala alimentación. La medicina es incapaz de zanjar los problemas salariales, pero sí está a su alcance educar a la sociedad en nuevos modos de vida más higiénicos y saludables.

Las estancias de los enfermos en los sanatorios antituberculosos, preventorios y colonias, así como sus visitas a los dispensarios, no sólo sirven para sanarlos, también contribuyen a la educación del enfermo y de su familia en nuevos hábitos. Se logra así ir transformando la sociedad, estableciendo la higiene, la vida sana y la buena alimentación como un patrón de comportamiento capaz de prevenir y fortalecer frente a las enfermedades venideras. La lucha antituberculosa parece movida por la misma creencia que Le Corbusier cuando dictamina: "No curéis más a los enfermos, cread hombres sanos"16.

\section{LA CONSIDERACIÓN DE INCURABLE Y LA ILUSIÓN TERAPÉUTICA: EL ASILO AISLADO}

Hasta mediados del siglo XX, gracias a la aparición de los medicamentos, se desconocen remedios eficaces para la erradicación de la tuberculosis. La alta tasa de mortandad que provoca esta enfermedad fuerza a que se desarrollen terapias de cura basadas en conocimientos empíricos y en técnicas y creencias poco científicas, a menudo contradictorias, que en ciertos casos son determinantes en la localización y la definición formal de los sanatorios.

Pese a ser tachada de incurable, las primeras terapias antituberculosas se remontan al siglo IV a. C. y consisten en remedios genéricos basados en dietas y purgas que tratan de

\footnotetext{
15 Jorge MOLERO MESA, "Los sanatorios para tuberculosos" en A. GONZÁLEZ DE PABLO y J. MARTÍNEZ PÉREZ (coord.) Historia de los hospitales. Revista El Médico. Insalud, Dirección provincial de Madrid, p. 326.

${ }^{16}$ LE CORBUSIER, Précisions sur un état présent de l'architecture et de l'urbanisme. Crés, Paris 1930, p. 263.
} 
expulsar el mal del cuerpo enfermo, como aconseja Hipócrates ${ }^{17}$. Posteriormente se utilizan las sangrías, muy eficaces para cualquier tipo de enfermedad según el Dr. Broussais ${ }^{18}$. La única particularidad terapéutica asociada a la tuberculosis se debe al carácter contagioso de la enfermedad que aconseja el aislamiento del enfermo, lo que provoca que el tuberculoso comparta lecho con leprosos y otros desahuciados en lazaretos y leproserías.

Durante los siglos XVI y XVII se desarrolla la extraña creencia en el poder curativo de la escrófula y de la tisis de los reyes de Francia. Francisco I, Carlos IX, Enrique IV y Luis XIV, entre otros, presumen de poseer el don de curar estas dos enfermedades, doctrina que defienden en su día importantes médicos de la época, entre ellos el Decano de la Facultad de Medicina de París. Como describe el Dr. Du Laurens, bajo las palabras: "El rey toca y Dios te cura", al restregar su mano sobre la cara del enfermo de arriba a abajo y de izquierda a derecha haciendo la señal de la cruz, el monarca suministraba la milagrosa curación ${ }^{19}$.

En consecuencia surge en 1645 en Reims, ciudad en que se celebra la coronación de los soberanos franceses y a donde éstos acuden en las celebraciones religiosas importantes en las que tienen lugar los actos curativos de los reyes, el primer hospital específico para tísicos y escrofulosos: el Hospital de Saint Marcoul. Es un lugar de asilo y aislamiento fundado por Marguerite Rousselet con el fin de acoger a los enfermos que acuden al milagroso "toque regio" y no sanan.

A este primer centro hospitalario específico para tuberculosos, carente de peculiaridad arquitectónica alguna pese a su especificidad programática, le siguen otros similares por toda Europa, hasta que a mediados del siglo XIX comienzan a consolidarse las teorías higienistas.

\footnotetext{
17 Dijo Hipócrates: "En sus comienzos la tisis puede curarse. Es entonces cuando se deberán administrar purgantes tales como el eléboro, y más tarde la decocción de lentejas y leche. En ciertos casos, es aconsejable la leche sola: leche de vaca, de burra o de cabra, cruda o hervida, cortada con agua y miel y adicionándole orégano al tercio". J. y A. ORIOL, Historia de la Tuberculosis. Ensayos de Fisiología colectiva. Salvat Editores, Barcelona, Buenos Aires 1944, p. 29.

${ }^{18}$ Para Broussais no existían las enfermedades sino una única enfermedad cuyo origen residía en la irritación de los tejidos que provocaba su inflamación. J. y A. ORIOL, Historia de la Tuberculosis. Ensayos de Fisiología colectiva. Salvat Editores, Barcelona, Buenos Aires 1944, p. 166.

19 J. y A. ORIOL, Historia de la Tuberculosis. Ensayos de Fisiología colectiva. Salvat Editores, Barcelona, Buenos Aires 1944, pp. 98-103.
} 


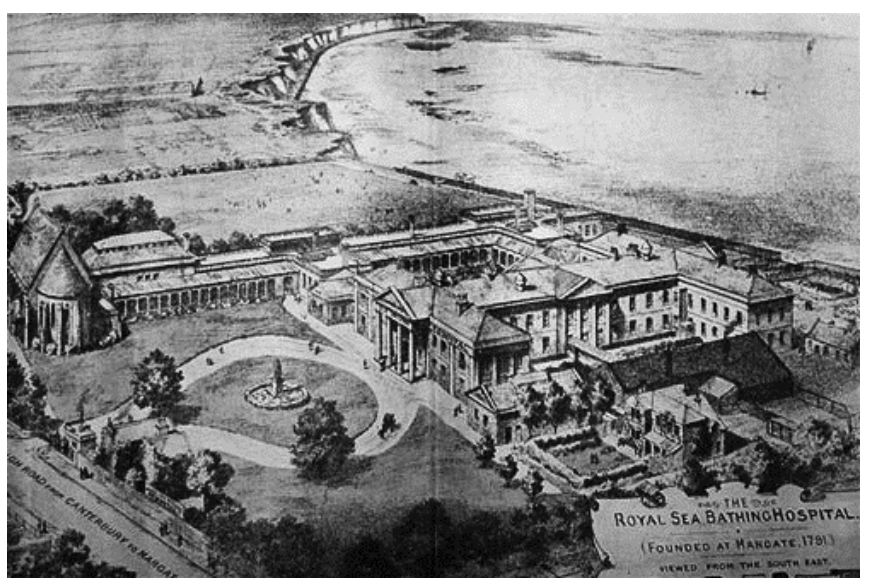

2.01
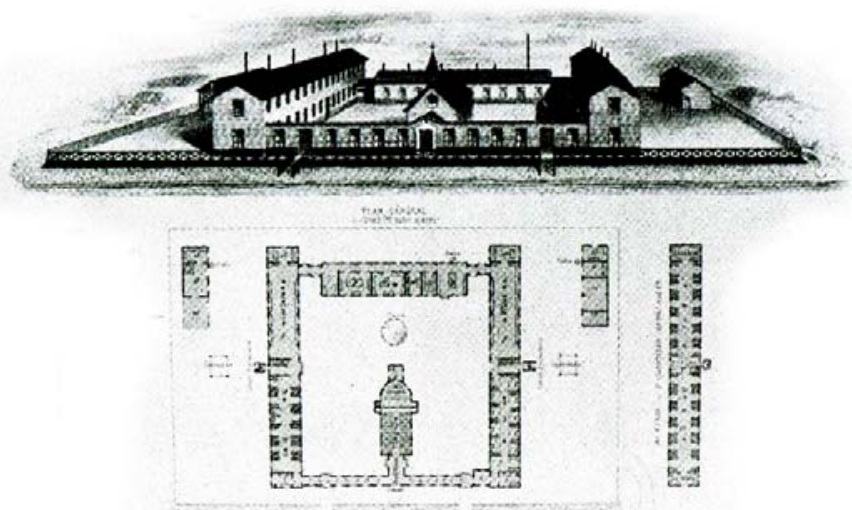

2.02

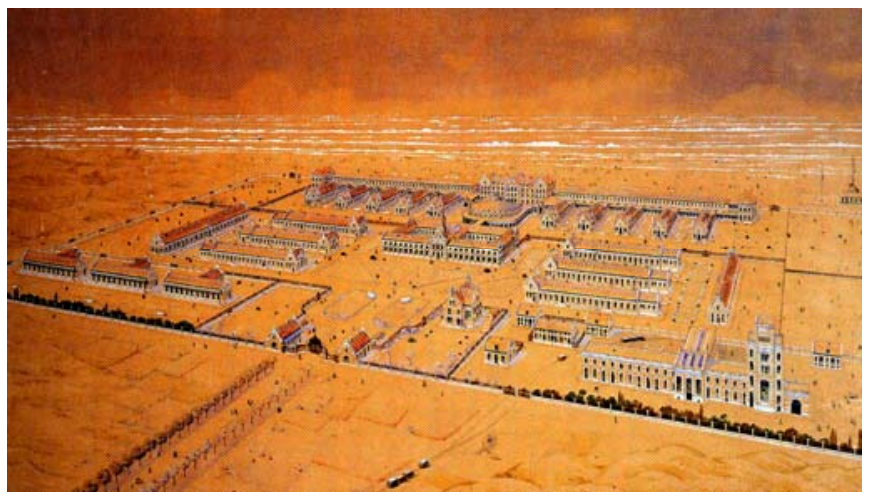

2.03

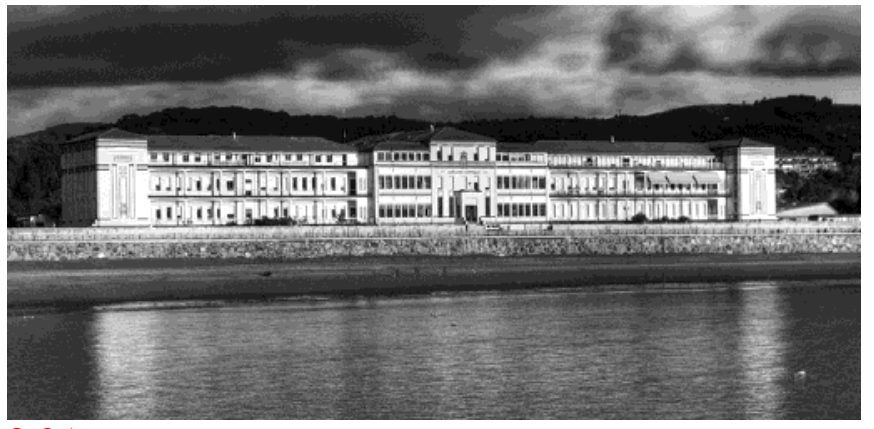

2.04

2.01 Royal Sea Bathing Infirmary for Scrofula, Margate, 1791.

2.02 Gran Hospital Marítimo de Berck, 1869.

2.03 Sanatorio de Zuydcoote, 1910.

2.04 Sanatorio de Górliz, 1919. 


\section{LA CURA EN EL LITORAL Y LA CURA DE ALTURA: LA IMPORTANCIA DEL MEDIO}

Frente a los hospitales antituberculosos de asilo y aislamiento surgen otros nuevos establecimientos que intentan proporcionar un tratamiento terapéutico basado en la cura al aire libre, según las teorías de los médicos higienistas europeos de finales del siglo XVIII. A ellos se unen las de los médicos naturistas del XIX, como el Dr. Rikli quien afirma que: "hay que devolver el hombre a su verdadero estado, la vida libre, de la cual se encuentra alejado por exigencias de la civilización $n^{\prime \prime 2}$. Este regreso a la vida al aire libre se aplica en función de ciertos principios terapéuticos climáticos como la cura en el litoral o la cura de altura.

En 1791 surge en la costa Margate de Inglaterra el primer modelo documentado de una institución específica para el tratamiento al aire libre de la tuberculosis, la Royal Sea Bathing Infirmary for Scrofula [fig. 2.01], dirigida por el Dr. Lettson y orientada a la cura de niños tuberculosos de familias de escasos recursos. Debe tanto su ubicación como los métodos terapéuticos aplicados en el sanatorio a la confianza de su fundador en las cualidades curativas del clima marítimo. El Dr. Lettson, tras observar que los pescadores no sufrían de escrófula, se convierte en defensor de la "inmunidad escrofular del litoral" y funda este centro que sirve de modelo a otros tantos sanatorios marítimos que van poblando las costas europeas, como el Gran Hospital Marítimo de Berck (1869) construido en Francia bajo el patronato de la emperatriz Eugenia [fig. 2.02], el inmenso Sanatorio de Zuydcoote (1910) también francés [fig. 2.03], o el Sanatorio de Górliz (1919) construido en Vizcaya [fig. 2.04]. Sus estructuras formales coinciden respectivamente con los diversos tipos hospitalarios: claustrales en el Sanatorio de Berck, de pabellones en el Sanatorio de Zuydcoote y palaciegos en el caso de Gorliz; dado que la terapia climática aplicada en ellos no afecta a su arquitectura.

También pasan a ser consideradas beneficiosas para la cura de la tuberculosis las aguas termales. Surge así en Rusia el primer establecimiento para la cura de la tuberculosis del país, una estación termal fundada por el Dr. N.V. Postnikov en $1858^{21}$. Lo mismo sucede en Suiza donde a principios del siglo XIX existe un renacimiento de ciudades termales como

\footnotetext{
${ }^{20}$ Dr. AREILZA, El Sanatorio de Górliz. Excma. Diputación Provincial de Vizcaya, Bilbao 1921, p. 16.

${ }^{21}$ El zar Pedro el Grande en 1718 pone en marcha un estudio para la localización de nuevas fuentes termales por todo su imperio, que más tarde ampliará Catherina II en la región de Cáucaso. Danilo UDOVICKI-SLEB "Les constructivistes face à Staline. Sanatoriums méconnus des années 1930 de Moscou au Caucase" en Histoire et Réhabilitation des Sanatoriums en Europe, Les réseaux de la modernité au XXe siècle/l. Docomomo International, Paris 2008, p.52.
} 


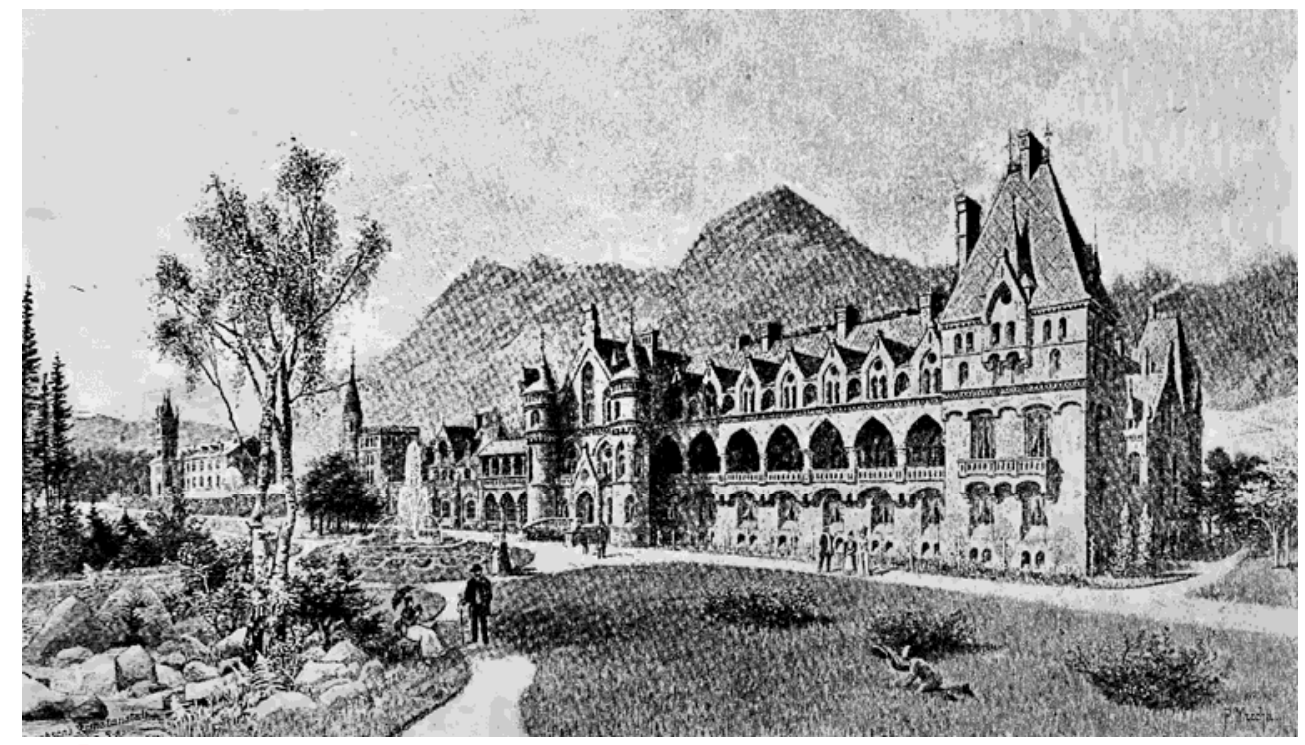

2.05

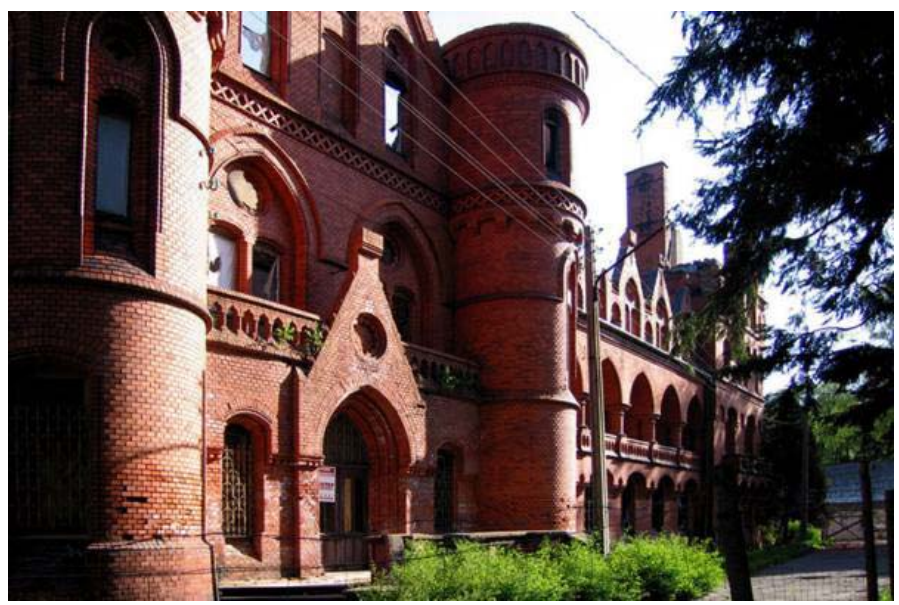

2.06

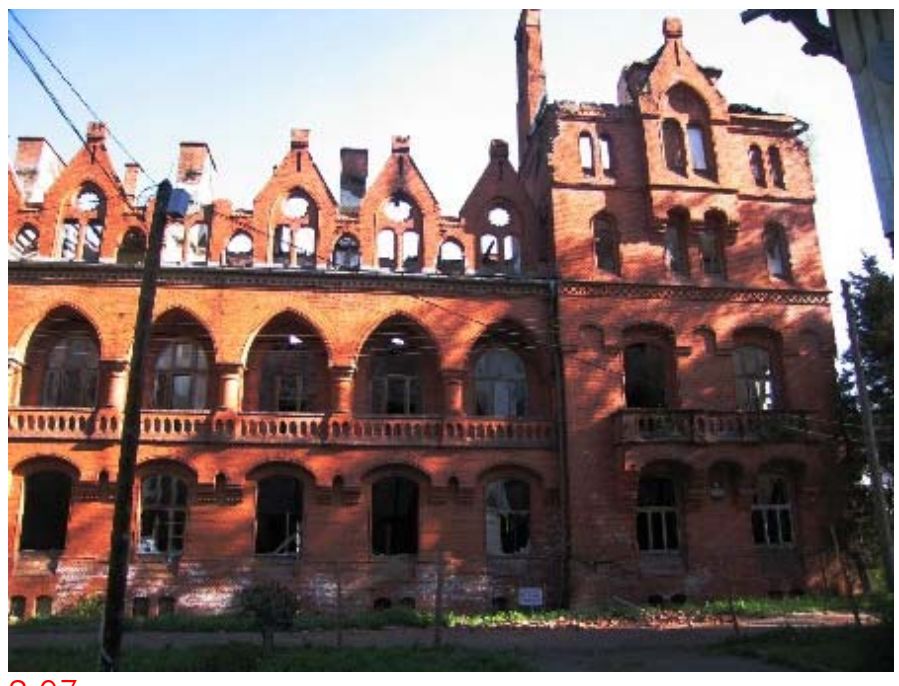

2.07

2.05 Dr. Brehmer. Sanatorio de Görbersdorf, 1859.

2.06 y 2.07 Dr. Brehmer. Sanatorio de Görbersdorf, 1859. Estado actual. 
Baden, Loèche, Yverdon, etc. ${ }^{22}$, despertándose un gran interés por las terapias naturistas que hacen de Suiza un país orientado al turismo de la salud.

A la terapia de "inmunidad escrofular del litoral" le sigue, por contradictorio que parezca, la creencia en la "inmunidad tísica de las alturas". La diferencia entre el clima montañoso y el marítimo y la correspondiente respuesta terapéutica experimentada por los diferentes tipos de enfermos tuberculosos, hace que se considere adecuada la cura en el litoral únicamente para los tuberculosos óseos y la cura en altura para los pulmonares, y que dichos enfermos jamás deban intercambiar sanatorios, como se acuerda en el Congreso para el Estudio de la Tuberculosis en el Hombre y en los Animales celebrado en $1891^{23}$.

Previamente a la celebración del Congreso en Görbersdorf, una localidad perteneciente a la región prusiana de Silesia, el médico alemán Hermann Brehemer funda en 1859 el primer sanatorio antituberculoso pulmonar, a 500 metros de altitud. El Sanatorio aplica una terapia de cura específica de la tuberculosis, "la cura de altura". La terapia parte de la hipótesis de equilibrio entre latitud y altitud, de manera que a mayor latitud se precisa menor altura, de este modo 500 m. de altitud en Silesia equivalen a 1500 m. en Suiza ${ }^{24}$.

La tesis doctoral del Dr. Brehemer, que llevaba por título Acerca de las leyes que atañen al inicio y progresión de la tuberculosis en los pulmones, se basa en cuatro principios, apoyados en experiencias personales y en datos recogidos a través de autopsias ${ }^{25}$ :

$1^{\circ}$. La tuberculosis es una enfermedad curable, ya que en numerosas autopsias de enfermos fallecidos por causas ajenas a este mal se han detectado lesiones tuberculosas curadas.

$2^{\circ}$. La altura es beneficiosa para los enfermos tuberculosos, idea que es trasmitida al Dr. Brehmer por el profesor Johann Lukas Schoenlein y por el explorador Alexander von Humboldt, quienes afirman que esta enfermedad no existe en países montañosos.

$3^{\circ}$. La tuberculosis es el resultado de una circulación pulmonar deficiente. Conclusión obtenida al comprobar en las autopsias el gran tamaño que presentan los pulmones de

22 Rudolf MOSSE, Bäder-Almanach; reports of spas, climatic stations and sanatoria in Germany, Austria-Hungary, Switzerland and adjoing countries, for physicians and patients (1910). Published Rudolf Mosse, Berlin 1912, pp. 87-166.

${ }^{23}$ Actas del Congreso de 1891. Intervención del Dr. Charles Roux el 30 de julio de 1891. Citado en: Jean-Bernard CREMNITZER, Architecture et Santé : Les temps du sanatorium en France et en Europe. Picard, Paris 2005, p. 17.

${ }^{24}$ Jean-Bernard CREMNITZER, Architecture et Santé: Les temps du sanatorium en France et en Europe. Picard, Paris 2005, p. 17.

${ }^{25}$ Adolphus KNOPF, "The centenary of Brehmer's birth" en The American review of tuberculosis, vol. 13, August 1926, pp. 207-210. 
muchos de los enfermos en comparación con la dimensión de su corazón, lo que provoca una disminución del riego pulmonar.

$4^{\circ}$. El tratamiento de la tuberculosis, se obtiene con la práctica de ejercicio en territorios altos y con una alimentación abundante, pues la menor presión atmosférica de estas zonas provoca un aumento de la función cardiaca y la mejora del metabolismo.

El Sanatorio de Görbersdorf (1859) originalmente ocupa una pequeña edificación pintoresca con la administración y los servicios médicos, después se amplía en distintas épocas con dos edificios anexos ubicados a ambos lados de la misma, conectados entre sí a través de pasajes y galerías acristaladas dispuestas linealmente ${ }^{26}$ [fig. 2.05].

La primera ampliación se construye en 1862 y consiste en un edificio cuadrado con una torre que se sitúa a la derecha de la edificación original; la segunda se realiza dieciséis años después por el arquitecto Hanovre Ediwin Oppler, discípulo de Viollet-le-Duc. Se trata de una construcción de aspecto gótico que parece un castillo, con tres plantas de altura y 88 habitaciones con 104 camas en sus dos plantas superiores. Las habitaciones del primer piso presentan una galería corrida a modo de logia decorada con arcadas ${ }^{27}$, mientras que las de la planta segunda tienen ventanas abuhardilladas [fig. 2.06 y fig. 2.07].

El Sanatorio se complementa con tres pabellones aislados dentro de un parque de 110 hectáreas, recorrido por un paseo de 9 millas equipado con unos 300 bancos y 200 sillas ${ }^{28}$, junto a pequeñas construcciones de madera para facilitar la terapia de cura al aire libre o Freiluftkur que incluye la cura de ejercicio. Brehmer escoge este lugar de implantación por considerarlo óptimo para desarrollar sus caminatas terapéuticos que exigen un esfuerzo gradual adaptable a la gravedad y a las carencias cardiacas de los pacientes.

El Sanatorio posee también dos grandes invernaderos o jardin d'hiver destinados al paseo en las épocas de mal tiempo, para aunar los beneficios de la naturaleza y el confort de la arquitectura $^{29}$. Dispone de biblioteca, salas de conciertos, de hidroterapia e incluso ascensor para enfermos, signo de la modernidad y del nivel de bienestar enarbolado por el

\footnotetext{
${ }^{26}$ Frederick RUFENACHT WALTERS, Sanatoria for consumptives in various parts of the world. Swan Sonnenschein, London 1899, p.151.

${ }^{27}$ Sigard Adolphus KNOPF, Les sanatoria, traitement et prophylaxie de la phtisie pulmonaire. Carré et Naud, Paris 1900, p. 145-152.

28 Anne-Marie CHÂTELET, "1860-1902 La naissance du sanatorium en Europe" en Histoire et Réhabilitation des Sanatoriums en Europe, Les réseaux de la modernité au XX e siècle/l. Docomomo International, Paris 2008, p.19.

29 Sigard Adolphus KNOPF, Les sanatoria, traitement et prophylaxie de la phtisie pulmonaire. Carré et Naud, Paris 1900, pp. 145-152.
} 
sanatorio; la misma pretensión tiene el sofisticado sistema de calefacción por impulsión de aire que permite controlar la humedad del ambiente interior del mismo ${ }^{30}$. Este desarrollo tecnológico contrasta con los rudimentarios métodos terapéuticos basados en cinco comidas copiosas al día y numerosos paseos ${ }^{31}$.

La terapia de cura en altura del doctor Brehmer se extiende por Europa, creándose numerosas instituciones privadas dirigidas a una clientela adinerada ${ }^{32}$ para las que el Sanatorio de Görbersdorf es todo un referente ${ }^{33}$.

La necesidad de espacios libres equipados junto al sanatorio para ejercer las terapias de cura hace que los arquitectos paisajistas encargados de estas áreas tengan un papel destacado en la definición del sanatorio. El trazado del jardín y de los paseos terapéuticos son claves en la organización de su entorno. Queda pues definida una de las características fundamentales del sanatorio antituberculoso: la importancia que en estas construcciones tienen las condiciones climáticas y ambientales del lugar de ubicación así como la naturaleza que circunda al edificio, es decir, la necesaria vinculación que en el sanatorio debe existir entre la arquitectura y el entorno en función de las características terapéuticas.

\section{LA TERAPIA DE EJERCICIO Y LA TERAPIA DE REPOSO: LA GALERÍA DE CONVALECENCIA}

En oposición a la teoría de la cura de ejercicio del Dr. Brehemer surge en 1874, de mano de su ayudante y antiguo paciente el Dr. Dettweiler, el primer sanatorio antituberculoso concebido para la cura de reposo ${ }^{34}$ en Falkenstein; construido a $400 \mathrm{~m}$. de altitud en la región de los montes Taunus cerca de Frankfurt. El Dr. Dettweiler no considera importante ni la altitud ni el ejercicio para la cura de la tuberculosis, su terapia consiste en el reposo y en la exposición del paciente al aire puro junto a un riguroso control médico y a la práctica de hábitos higiénicos. Es precisamente esta terapia la que origina el nacimiento del primer

\footnotetext{
${ }^{30}$ Frederick RUFENACHT WALTERS, Sanatoria for consumptives in various parts of the world. Swan Sonnenschein, London 1899, p.151.

${ }^{31}$ Frederick RUFENACHT WALTERS, Sanatoria for consumptives in various parts of the world. Swan Sonnenschein, London 1899, p.152.

${ }^{32}$ Rudolf MOSSE, Bäder-Almanach; reports of spas, climatic stations and sanatoria in Germany, Austria-Hungary, Switzerland and adjoing countries, for physicians and patients (1910). Published Rudolf Mosse, Berlin 1912, pp. 166-230.

${ }^{33}$ En Suiza, donde era habitual la visita de enfermos y turistas a principios de verano a los hoteles de montaña, entre los que se encontraban los afectados de tuberculosis. A partir de 1865 los tuberculosos acuden también durante el invierno, lo que obliga a la construcción de los Kurhaus o casas de cura. Edificios de concepción clásica y composición simétrica idénticos a los hoteles de viajeros y turistas veraniegos, dado que la terapia de aire puro y ejercicio se lleva a cabo fuera del edificio, pero éstos a diferencia de los hoteles habituales están debidamente calefactados y acondicionados para el invierno.

${ }^{34}$ Aunque no se inaugura hasta dos años más tarde en 1876.
} 


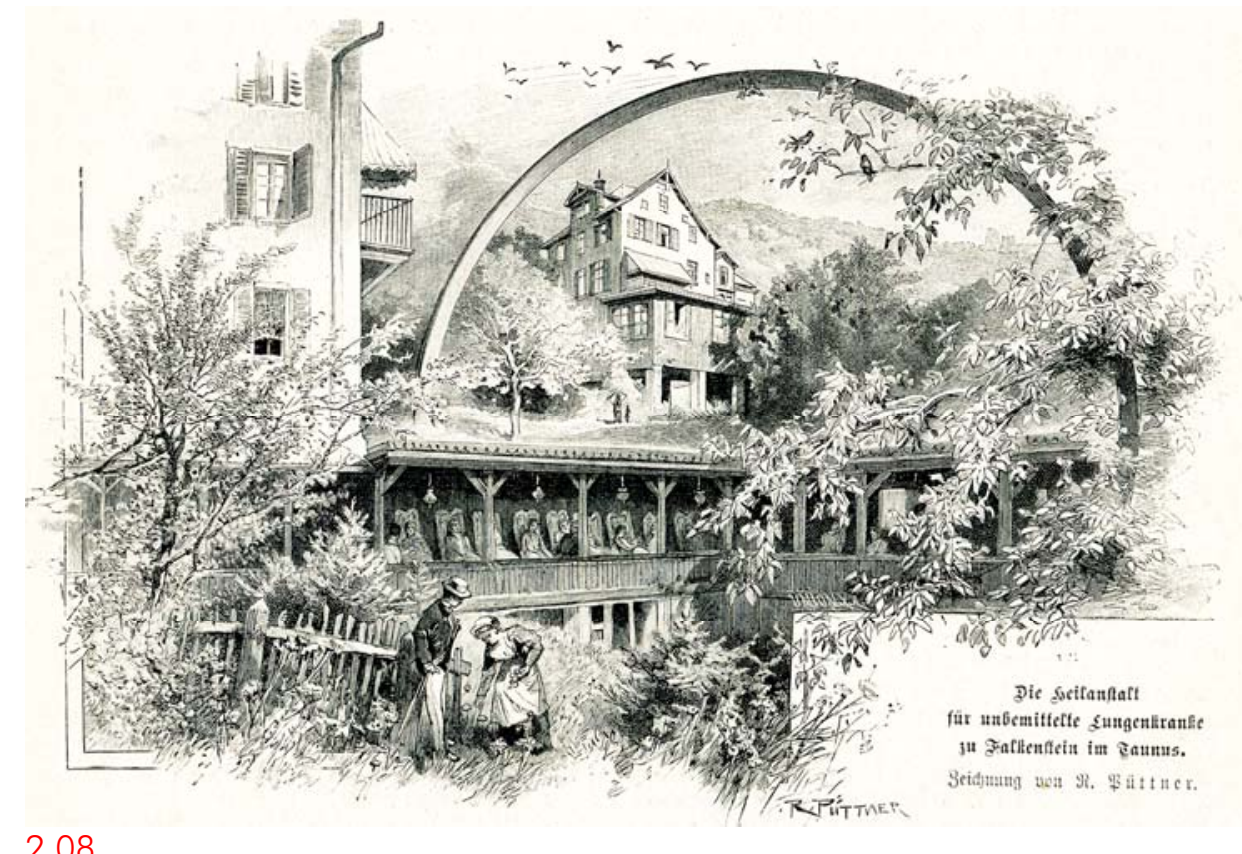

2.08

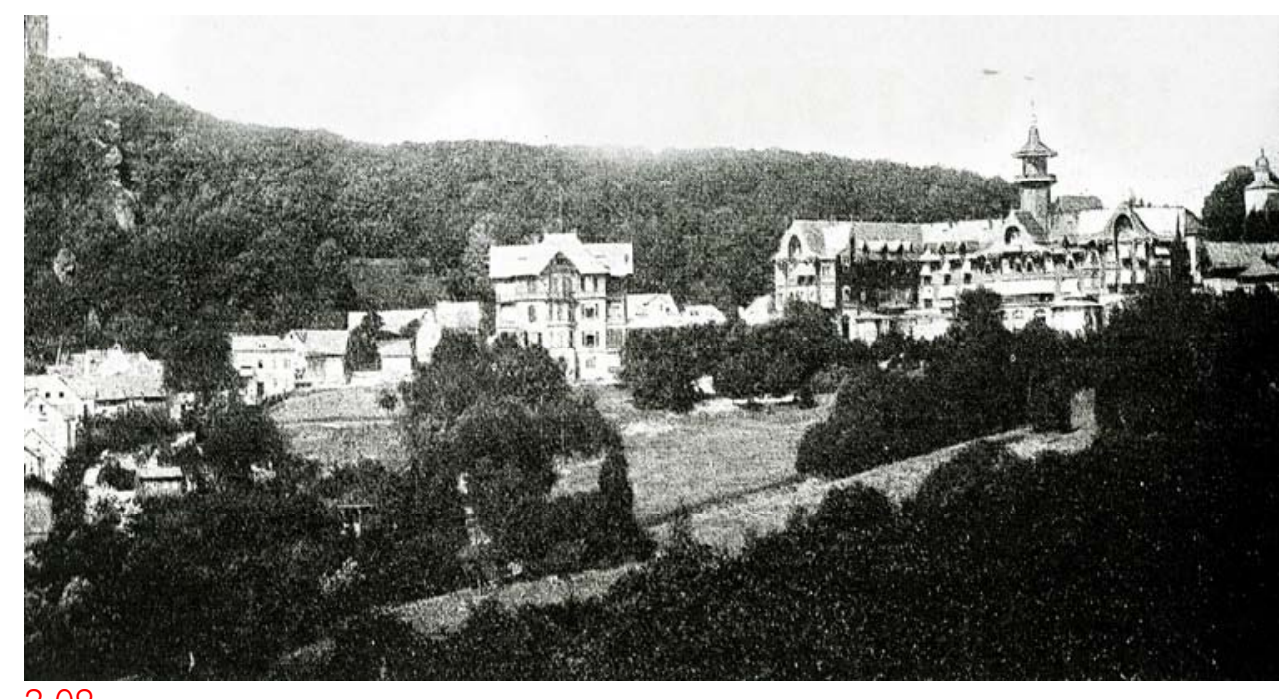

2.09

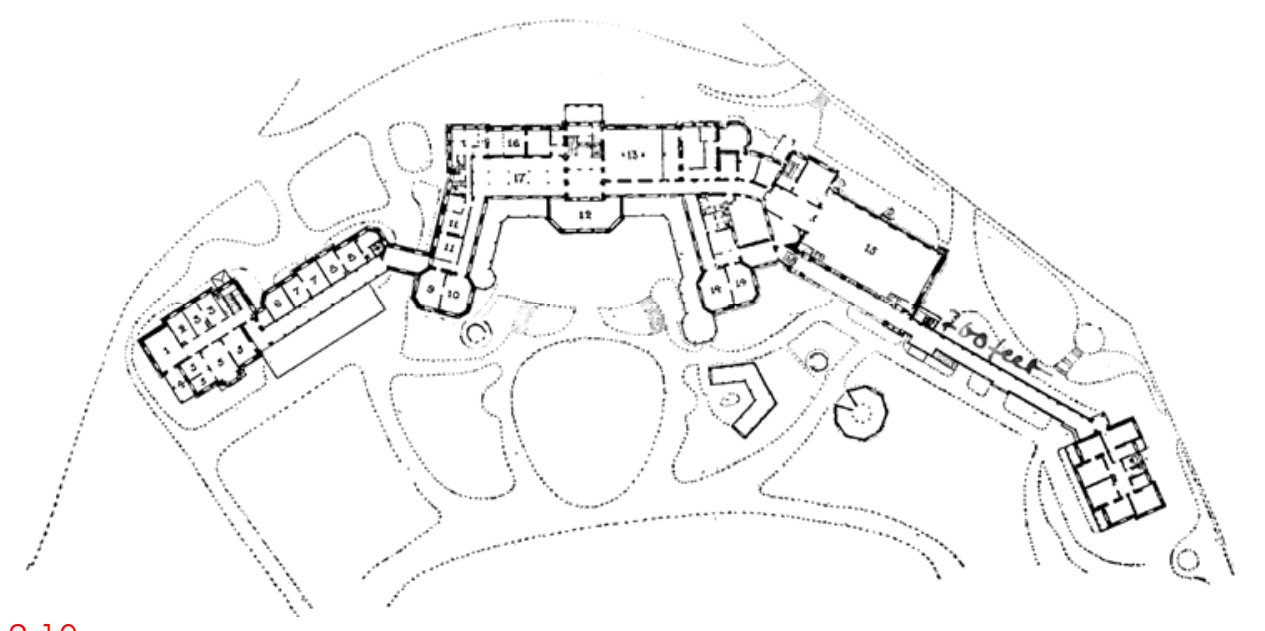

2.10

2.08 Dr. Dettweiler. Sanatorio de Falkenstein, 1874.Galería de cura.

2.09 Dr. Dettweiler. Sanatorio de Falkenstein, 1874. Alzado.

2.10 Dr. Dettweiler. Sanatorio de Falkenstein, 1874. Planta. 
espacio arquitectónico específico para el tratamiento de la tuberculosis, la terraza cubierta de cura común donde los enfermos reposen y respiren aire puro, la denominada liegehalle o galería de cura [fig. 2.08].

Mientras el Sanatorio de Görbersdorf del Dr. Brehemer se puede considerar desde un punto de vista médico el primer sanatorio antituberculoso pulmonar, ya que es el primero creado para aplicar una terapia concreta vinculada a esta enfermedad ${ }^{35}$, el de Falkenstein [fig. 2.09] puede ser considerado desde el punto de vista arquitectónico el primer sanatorio antituberculoso pulmonar, al ser el primero que plantea soluciones arquitectónicas particulares para el tratamiento.

En efecto, el diseño arquitectónico de Falkenstein, donde se atiende a la orientación solar de las habitaciones y por primera vez aparecen las galerías de cura, sirve de modelo arquitectónico a todos los sanatorios posteriores, convirtiéndose en palabras del Dr. Sigard Adolphus Knopf en "La Meca de los tisiólogos" 36 .

Se desconoce el nombre del arquitecto encargado de su construcción, pero no el del arquitecto paisajista que diseña el parque que le circunda, Heinrich Siesmayer (18171900), lo que ratifica la importancia que adquiere el paisajismo en el conjunto de estos edificios. El parque cuenta con numerosos jardines y paseos, entre los que se erigen pabellones de madera giratorios en busca de la orientación más adecuada para el reposo de los enfermos ${ }^{37}$.

Igual que Görbersdorf, Falkenstein se constituye por la agregación de partes. Consta de un edificio principal simétrico con forma de $\mathrm{C}$ situado en el centro del conjunto y abierto al sur, con sus brazos laterales girados entre sí divergiendo hacia el paisaje. A él se le añaden, siguiendo un orden lineal que permite mantener la orientación al mediodía, varias construcciones a cada lado conectadas con el cuerpo principal mediante oblicuos corredores cubiertos ${ }^{38}$. Los brazos del cuerpo principal delimitan en planta baja una terraza abierta al sur y protegida del viento, con profundas verandas en su perímetro utilizadas también para la cura de reposo [fig. 2.10].

\footnotetext{
${ }^{35}$ La cura marítima y termal aunque se aplica a la tuberculosis no es una terapia específica de esta enfermedad.

${ }^{36}$ Sigard Adolphus KNOPF, Les sanatoria, traitement et prophylaxie de la phtisie pulmonaire. Carré et Naud, Paris 1900, p.133.

37 Anne-Marie CHÂTELET, "1860-1902 La naissance du sanatorium en Europe" en Histoire ef Réhabilitation des Sanatoriums en Europe, Les réseaux de la modernité au XX e siècle/l. Docomomo International, Paris 2008, p. 20.

${ }^{38}$ Frederick RUFENACHT WALTERS, Sanatoria for consumptives in various parts of the world. Swan Sonnenschein, London 1899, p.178.
} 

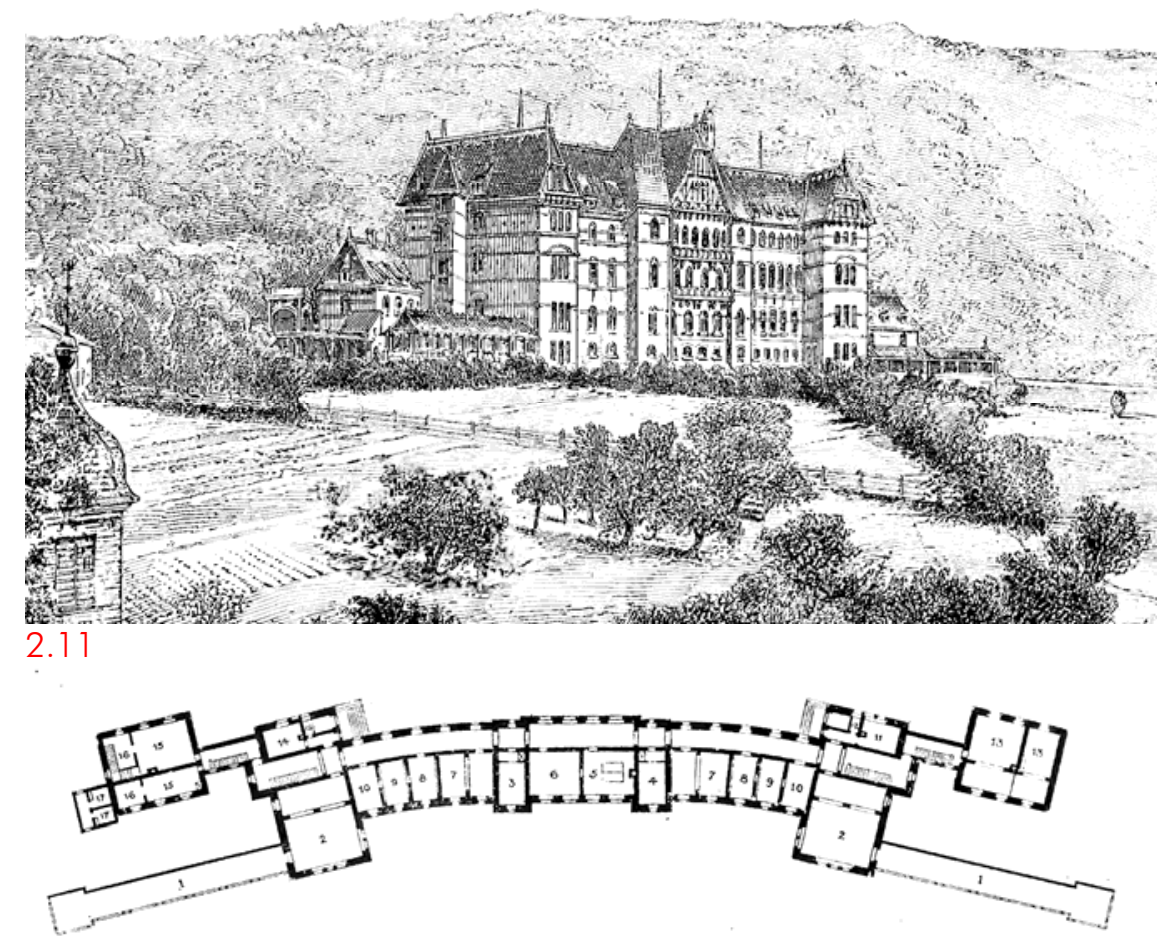

2.12
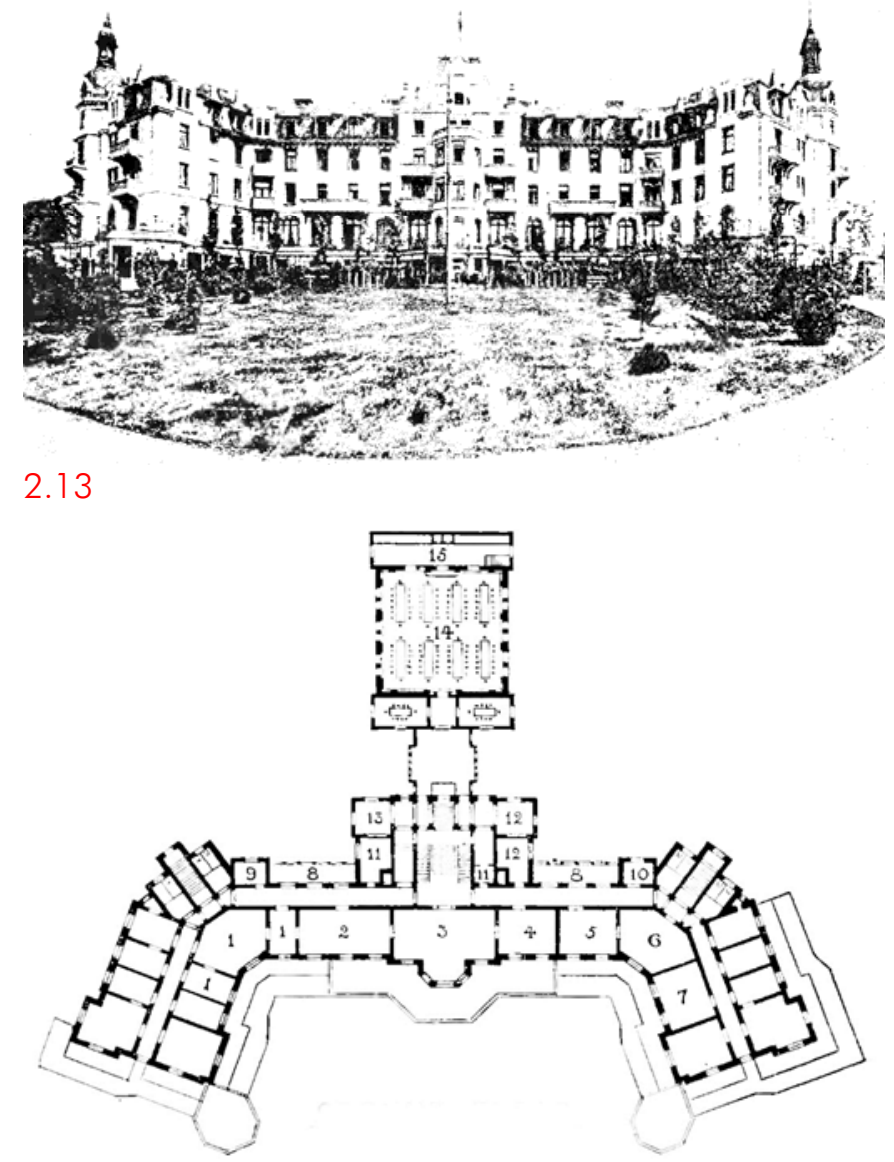

2.14

2.11 Sanatorio de Ruppertshain, Königstein, Görbersdorf, 1895. Perspectiva.

2.12 Sanatorio de Ruppertshain, Königstein, Görbersdorf, 1895. Planta.

2.13 Sanatorio Hohenhonnef, Bonn, 1892. Imagen.

2.14 Sanatorio Hohenhonnef, Bonn, 1892. Planta. 
Fruto de la terapia de Falkenstein se crean las sillas o tumbonas reclinables, muebles que se convierten en auténticos referentes del diseño del siglo XX. Con su ergonomía facilitan la respiración del enfermo tumbado proporcionándole un apacible descanso y es motivo de alabanza por Thomas Mann en La Montaña Mágica: "nada podía garantizar el feliz reposo del cuerpo mejor que aquella excelente tumbona "39. Surge también allí un objeto fundamental para evitar los contagios ${ }^{40}$, la escupidera portátil e individual de cada enfermo, "una botellita plana de cantos redondeados de cristal azul con tapón de metal"41.

En el Sanatorio el programa común se distribuye en planta baja; el cuerpo principal alberga la administración y los diversos salones, que incluyen la biblioteca, una sala de billar y varios invernaderos o jardin d'hiver. Al este, junto al cuerpo central y en un volumen rectangular independiente se encuentra el comedor que, por su tamaño, resulta difícil integrarlo en volumen principal. El extremo lo ocupa un edificio con estancias para enfermos, comunicado con el cuerpo central a través de un largo corredor abierto que se emplea como galería de cura. En el lateral oeste, junto al edificio principal está un cuerpo rectangular con los laboratorios y la morgue en planta baja, los baños y duchas en un nivel inferior y las dependencias de los médicos en otro superior, y en el extremo en un cuerpo de planta más cuadrada se ubican las dependencias del personal y las de las visitas.

La mayor parte de los 112 pacientes del Sanatorio residen en el edificio principal, en habitaciones de 4 por 4,5 metros orientadas al sur, algunas de las cuales disponen de chimenea y de balcón ${ }^{42}$.

El Dr. Dettweiler, consciente de la necesidad de crear sanatorios para las clases más necesitadas, construye en 1892 también Falkenstein, un sanatorio para atender a enfermos sin recursos y propone crear un gran número de ellos ubicados en las proximidades de las ciudades destinados a la clase obrera ${ }^{43}$. La modesta casa-sanatorio para pobres de Falkenstein se traslada a una población cercana; se construye al lado de Königstein el Sanatorio de Ruppertshain para tuberculosos de escasos recursos [fig. 2.11], cuya

\footnotetext{
${ }^{39}$ Thomas MANN, La Montaña Mágica (Berlín, 1924). Edhasa, Barcelona 2005, p. 149.

${ }^{40}$ Para preservar la higiene, el uso de los pañuelos en el sanatorio llega a estar prohibido, al igual que las alfombras, y tanto en Görbersdorf como en Falkenstein los suelos son de linóleo.

${ }^{41}$ Thomas MANN, La Montaña Mágica (Berlín, 1924). Edhasa, Barcelona 2005, p. 15.

${ }^{42}$ Frederick RUFENACHT WALTERS, Sanatoria for consumptives in various parts of the world. Swan Sonnenschein, London 1899, p.179.

${ }^{43}$ Anne-Marie CHÂTELET, "1860-1902 La naissance du sanatorium en Europe" en Histoire et Réhabilitation des Sanatoriums en Europe, Les réseaux de la modernité au XX siècle/7. Docomomo International, Paris 2008, p. 21.
} 
disposición formal trata de imitar a Falkenstein, y se amplía en 1895 gracias a la Asociación de Convalecientes de Frankfurt.

El Sanatorio de Ruppertshain consiste en un único bloque lineal ligeramente curvo y perfectamente simétrico donde todas las estancias, a excepción de ciertas dependencias de servicio, se orientan al sur y donde existen dos galerías de cura comunes situadas en sus extremos. Dispone de cuatro plantas; en el basamento se encuentran los servicios comunes flanqueados por las galerías de cura y en las demás plantas del bloque lineal están las habitaciones, dispuestas en hilera a ambos lados del cuerpo central, ocupado en planta baja por los servicios médicos y en el resto de plantas por un comedor que invade el pasillo y fragmenta el edificio en dos mitades idénticas. Esta fragmentación contribuye a separar por sexos las casi 100 habitaciones de una, tres y cinco camas, que posee el edificio [fig. 2.12].

Una peculiaridad del Sanatorio consiste en que al ser para pobres carece de los adornos superfluos de los sanatorios de lujo, de manera que su imagen resulta más limpia y austera, acorde con sus pacientes.

En 1892, el mismo año en que Dettweiler construye en Falkenstein el primer sanatorio para enfermos pobres, su discípulo el Dr. Meissen construye también en los montes Taunus un sanatorio privado, el Sanatorio Hohenhonnef cerca de Bonn [fig. 2.10], que trata de imitar también a Falkenstein en su terapia y en su arquitectura.

A diferencia de Ruppertshain, donde predomina el carácter lineal del modelo original, el Sanatorio Hohenhonnef reproduce la disposición compacta y simétrica de su edificio principal en forma de $C$, con sus brazos ligeramente más cerrados entre sí pero abiertos hacia el jardín, sin embargo, en planta baja acaba por generar una configuración en T, estructura formal considerada prototípica en la arquitectura del sanatorio [fig. 2.14].

El Hohenhonnef con cinco plantas de altura mantiene una estricta simetría en su organización, pese a que en él no existe una separación de los pacientes por sexos. Sus estancias se distribuyen idénticamente a ambos lados del cuerpo central que contiene el núcleo de comunicación principal en el que se incluye un ascensor. Estas estancias se organizan en una única hilera orientada al sur en la parte central, y en dos hileras en los brazos laterales. El Sanatorio dispone de amplias galerías de cura, tanto al norte como al sur; las orientadas al norte se utilizan para la cura de reposo en períodos calurosos, y se 
localizan a partir de la primera planta en la parte central del edificio; la orientada al sur, en cambio, recorre el perímetro del edificio y se ubica en el basamento.

Sus 88 habitaciones de $4 \mathrm{~m}$. de ancho cada una, con chimenea y doble ventana, se distribuyen a partir de la primera planta y en la planta baja, mientras que en el basamento se concentran los servicios comunes.

Como en Falkenstein, la gran dimensión del comedor no encaja dentro del bloque en $\mathrm{C}$ y pasa a situarse ahora en la parte norte en el eje de simetría del edificio, definiendo la planta en forma de T. Se consigue así una edificación más compacta y elevada que Falkenstein, debido a las necesidades espaciales del programa, en la que se desvirtúa la estructura palaciega en $C$ pero se siguen manteniendo sus leyes compositivas.

Desde 1865 el doctor Alexandre Spengler, defensor de la teoría de la "inmunidad tísica de la altura", acoge masivamente a enfermos de tuberculosis en Davos en los Kurhaus, hoteles veraniegos que se habilitan para utilizarse todo el año. Al mismo tiempo en esta localidad y en toda Suiza se inicia el desarrollo de un tratamiento para la tuberculosis basado en tomar el sol.

La cura de sol o helioterapia, que inicialmente se prescribe para la tuberculosis de tipo ósea y para la cura de ciertas heridas, comienza a ser recomendada a principios del siglo XX en los casos agudos de tuberculosis pulmonar.

En 1889 el Dr. Karl Turban funda en Davos un sanatorio antituberculoso, siguiendo las teorías de reposo del Dr. Dettweiler, conocido como la Estación Terapéutica Alemana, según los planos del arquitecto de Brunswich Erdmann Hartig, y construido por el arquitecto de Davos, Gaudenz Issler ${ }^{44}$. Se trata de una institución donde los enfermos siguen una estricta disciplina durante la cura de reposo al sol que suele oscilar entre 5 y 7 horas, no permitiendo al paciente acceder al edificio salvo para comer y dormir, anteponiendo las cuestiones médicas a las condiciones de confort.

El Sanatorio consta de un edificio principal compuesto por cuatro construcciones que siguen una disposición lineal, conectadas entre sí por corredores cubiertos, y una villa aislada

${ }^{44}$ Anne-Marie CHÂTELET, "1860-1902 La naissance du sanatorium en Europe" en Histoire et Réhabilitation des Sanatoriums en Europe, Les réseaux de la modernité au XX siècle/1. Docomomo International, Paris 2008, p. 20. 


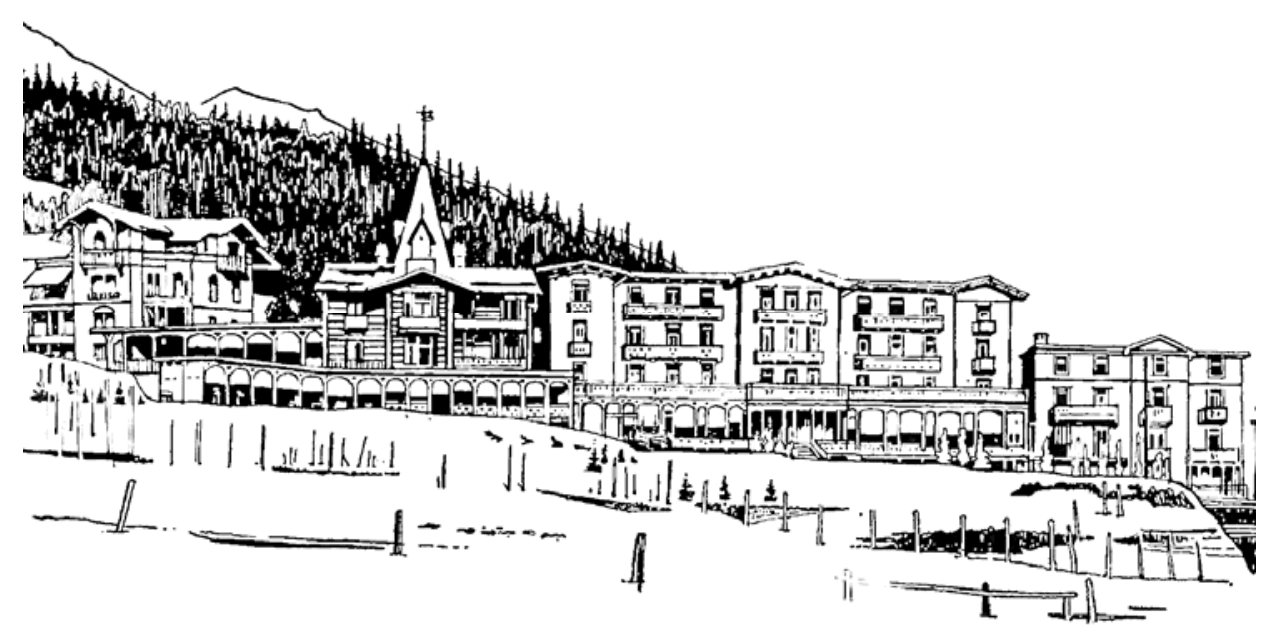

2.15
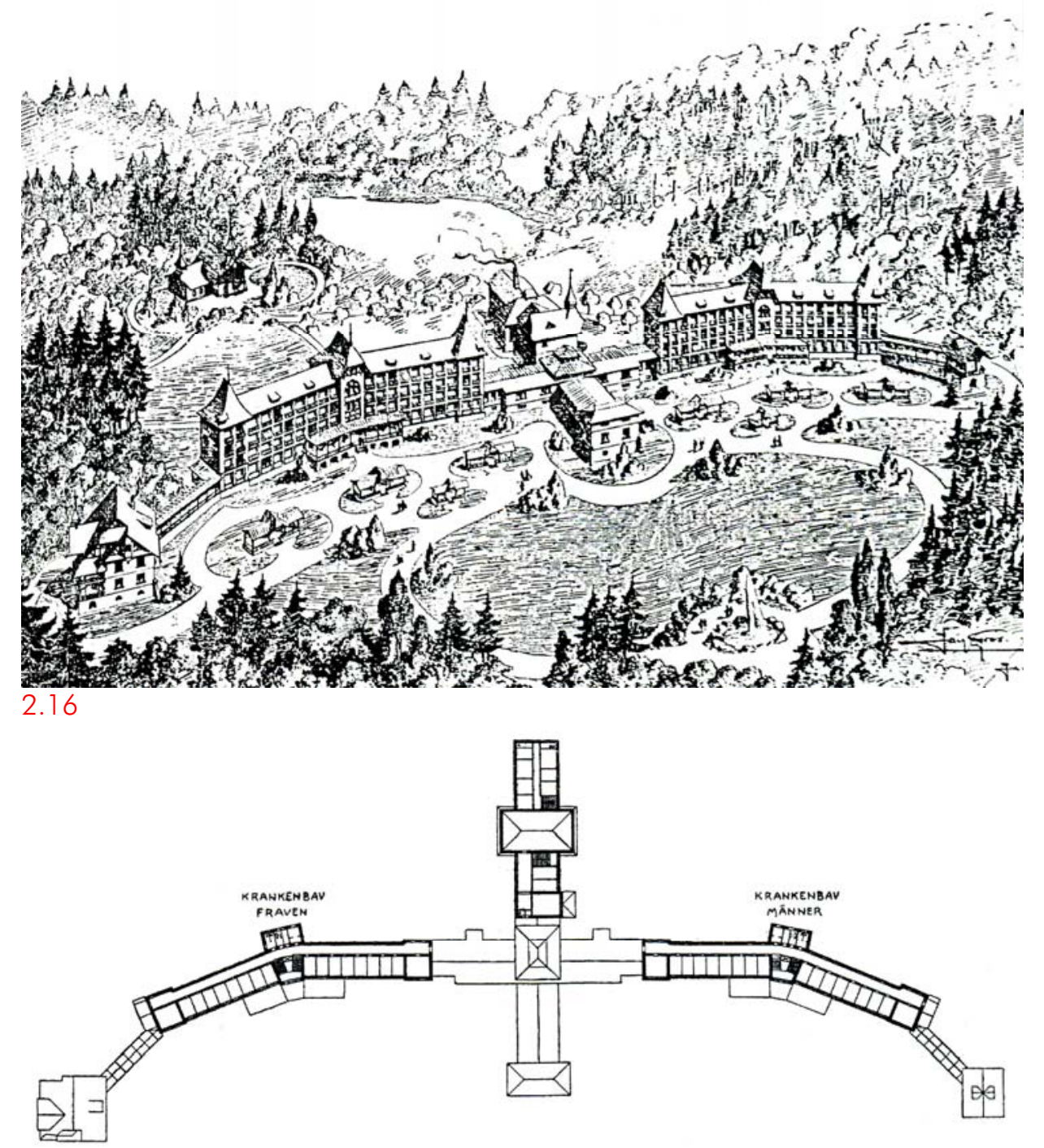

2.17

2.15 Dr. Turban Estación Terapéutica Alemana, Davos, 1889. Perspectiva.

2.16 Dr. Turban. Proyecto de Sanatorio modelo para Inglaterra, 1902. Perspectiva.

2.17 Dr. Turban. Proyecto de Sanatorio modelo para Inglaterra, 1902. Planta. 
donde residen el médico jefe y el director ${ }^{45}$. El edificio principal con cuatro plantas de altura tiene una anchura aproximada de 8,5 metros y un único frente de habitaciones en hilera orientadas al sur a las que se accede a través de un corredor con numerosas ventanas orientadas al norte, facilitando la creación de corrientes de aire entre los dos frentes.

En planta baja se sitúan las zonas comunes y la extensa galería de cura que recorre la fachada donde se lleva a cabo la cura de reposo y de sol en la tumbona o chaise-longue, cura que también se recibe en las cabañas de madera dispuestas en las 7 hectáreas de parque que circundan el sanatorio. En las tres plantas superiores de habitaciones existen balcones parcialmente corridos en sus fachadas, empleados también para la cura de reposo y sol, cuya colindancia con la habitación posibilita el traslado de los enfermos encamados al exterior; por consiguiente, las galerías de cura de la planta baja pasan a trasladarse a toda la fachada sur del edificio [fig. 2.15].

Este mismo modelo de edificio es asumido por el Dr. Turban en el proyecto del arquitecto Jacques Gros, para el concurso convocado en 1902 por el rey Eduardo VII con el propósito de construir un sanatorio modelo en Inglaterra [fig. 2.16 y fig. 2.17]. El proyecto supera los límites de altura establecidos debido al estrechamiento del edificio para favorecer la ventilación cruzada entre sus dos frentes, y obliga a incorporar ascensores en su interior. Su estrechez fuerza a que los programas comunes que precisan de una mayor dimensión se desarrollen en un cuerpo independiente y ortogonal a las edificaciones residenciales. Éste se instala sobre el eje de simetría del edificio, reproduciendo la distribución en planta en forma de T propuesta en Hohenhonnef que facilita la separación de enfermos por sexos.

En esta propuesta para el modelo de sanatorio inglés el Dr. Turban, preocupado por la captación solar, sustituye los balcones de las habitaciones, al considerar que restan luz al interior y dificultan la ventilación, por una pared de vidrio móvil que transforma la habitación en una logia, resolviendo así el problema del traslado de los enfermos encamados a las galerías.

Casi simultáneamente, el doctor Berlinois Wilhelm Dosquet desarrolla una idea similar y crea en 1905 su famoso sistema Dosquet de cerramiento acristalado, empleado en numerosos sanatorios. La diferencia entre ambos mecanismos estriba en que, mientras Turban propone la apertura del frente a través de una serie de puertas de vidrio plegables

\footnotetext{
${ }^{45}$ Frederick RUFENACHT WALTERS, Sanatoria for consumptives in various parts of the world. Swan Sonnenschein, London 1899, p. 289.
} 

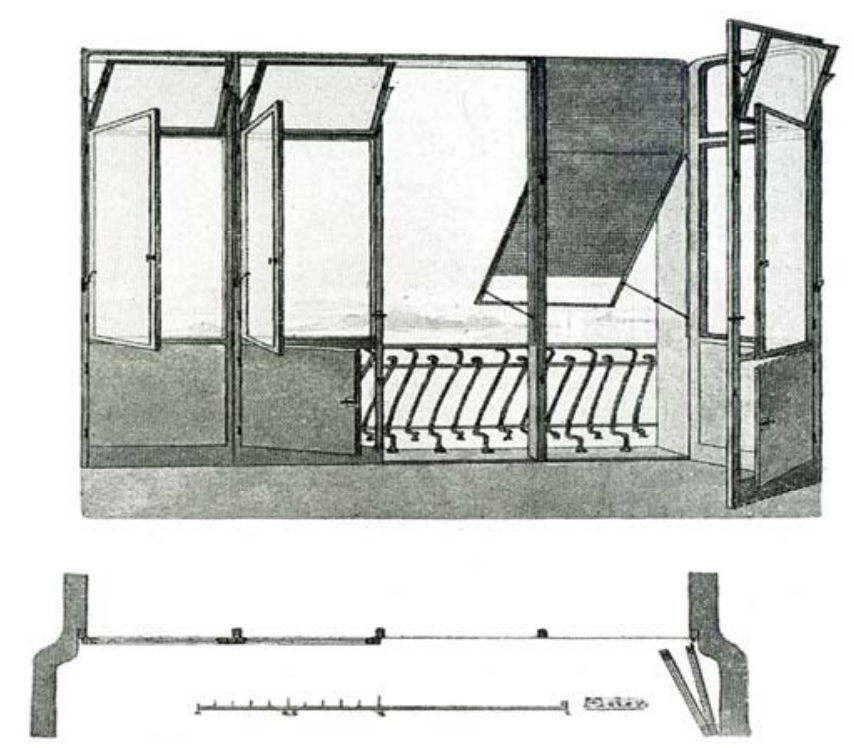

2.18
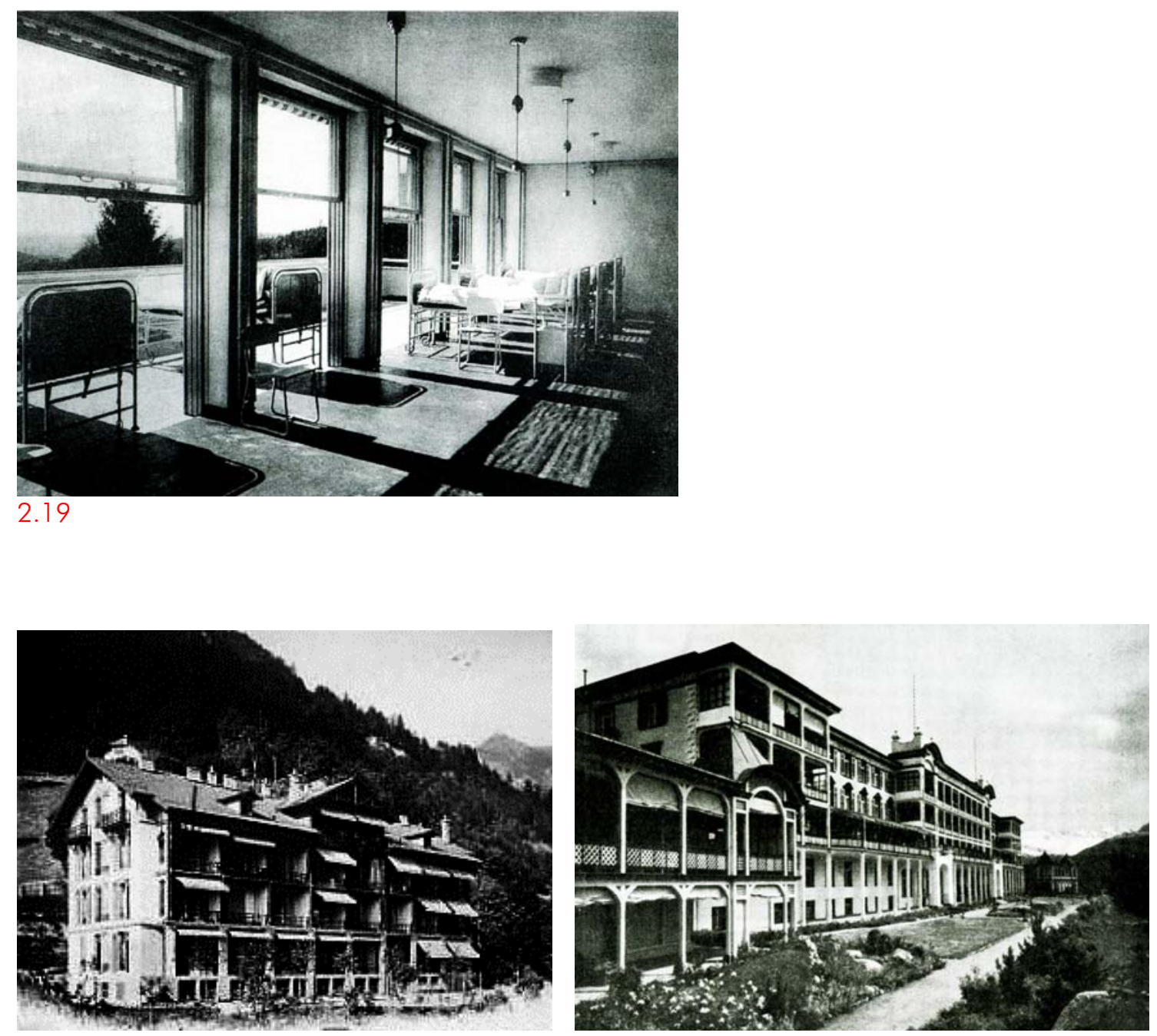

2.20 y 2.21

2.18 Dr. Turban. Cerramiento de vidrio móvil, 1902.

2.19 Dr. Dosquet. Cerramiento de vidrio móvil, 1905.

2.20 Sanatorio La Colline, Montreux, 1898.

2.21 Pfleghard y Haefeli. Sanatorio Schatzalp, Davos, 1900. Galerías de cura 1912. 
que se recogen en las paredes laterales de la habitación [fig. 2.15], Dosquet sugiere un sistema de apertura horizontal mediante una ventana de guillotina que se eleva 1,80 m. y se desliza sobre un vidrio fijo ubicado en la parte superior del frente de la habitación [fig. 2.19].

Las directrices arquitectónicas esgrimidas por Turban van más allá de la definición del cerramiento; guiado por su espíritu higienista y espartano, propone la construcción de un mobiliario sencillo construido mediante tubos metálicos lacados y una composición de fachada sobria y sin adornos, pues defiende que: "Los muros deben de ser lisos, sin cavidades, para no albergar miasmas ni bacilos" ${ }^{\prime \prime 6}$.

Sin embargo en Davos, una ciudad convertida en un centro de turismo de salud, no siempre se aplica la estricta disciplina que propone el Dr. Turban. En el Sanatorio de Schatzalp (1900), en el que se inspira Tomas Mann para escribir La Montaña Mágica, "la comida era tan excelente como copiosa" 47 y los enfermos gozan de: "música en vivo en la terraza, pues cada dos semana acudía una banda" ${ }^{48}$.

En estos sanatorios el confort es prioritario; en ellos no sólo se mantienen las galerías de cura en las fachadas sino que éstas pasan a independizarse. Se crea así: "una terraza corrida y sólo cortada por mamparas de cristal que, sin llegar del todo hasta la barandilla, marcaban la subdivisión de los distintos cuartos" ${ }^{\prime 4}$ y se otorga una mayor autonomía a la célula de la habitación y una mayor intimidad al paciente.

La galería de cura permite además controlar mejor al enfermo mientras realiza la cura de reposo y se emplea también como un corredor de comunicación exterior para los médicos, como relata Thomas Mann:

"Estaba medio traspuesto cuando, sobresaltándose, se dio cuenta de que el médico ayudante estaba alli, en su habitación sin haber cruzado la puerta, pues se dirigía hacia él desde la galería exterior. No había venido desde el pasillo, sino por las terrazas, de modo que parecía como si hubiera llegado volando" ${ }^{50}$.

El primer ejemplo de sanatorio con galerías de cura individualizadas por habitación se encuentra en el Sanatorio La Colline [fig. 2.20], construido en 1898 en Territet, encima de

\footnotetext{
${ }^{46}$ Dave LÜTHI, "1870-1950 Le sanatorium en Suisse. Du Kurhaus à la clinique pneumologie", en Histoire et Réhabilitation des Sanatoriums en Europe, Les réseaux de la modernité au XX e siècle/l. Docomomo International, Paris 2008, p. 44.

${ }^{47}$ Thomas MANN, La Montaña Mágica (Berlín, 1924). Edhasa, Barcelona 2005, p. 111.

${ }^{48}$ Thomas MANN, La Montaña Mágica (Berlín, 1924). Edhasa, Barcelona 2005, p. 159.

${ }^{49}$ Thomas MANN, La Montaña Mágica (Berlín, 1924). Edhasa, Barcelona 2005, p. 58.

50 Thomas MANN, La Montaña Mágica (Berlín, 1924). Edhasa, Barcelona 2005, pp. 274 y 275.
} 

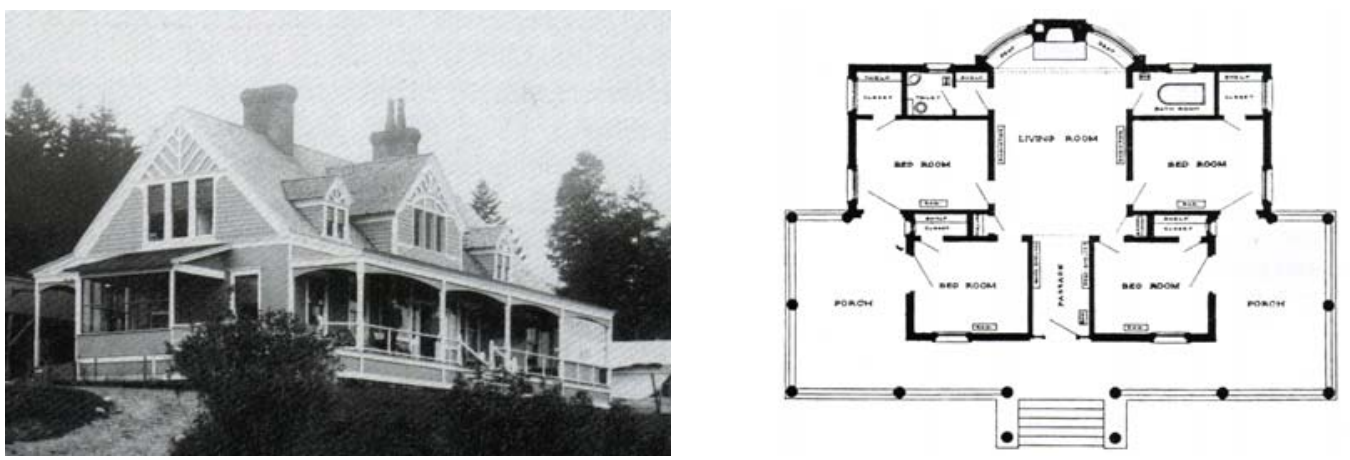

2.22 y 2.23
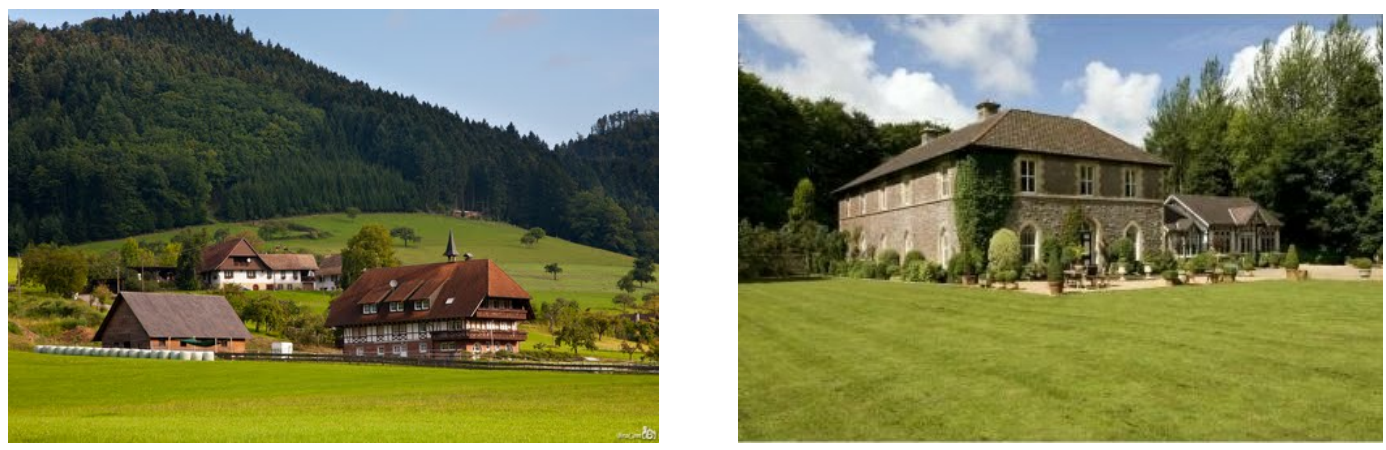

2.24 y 2.25
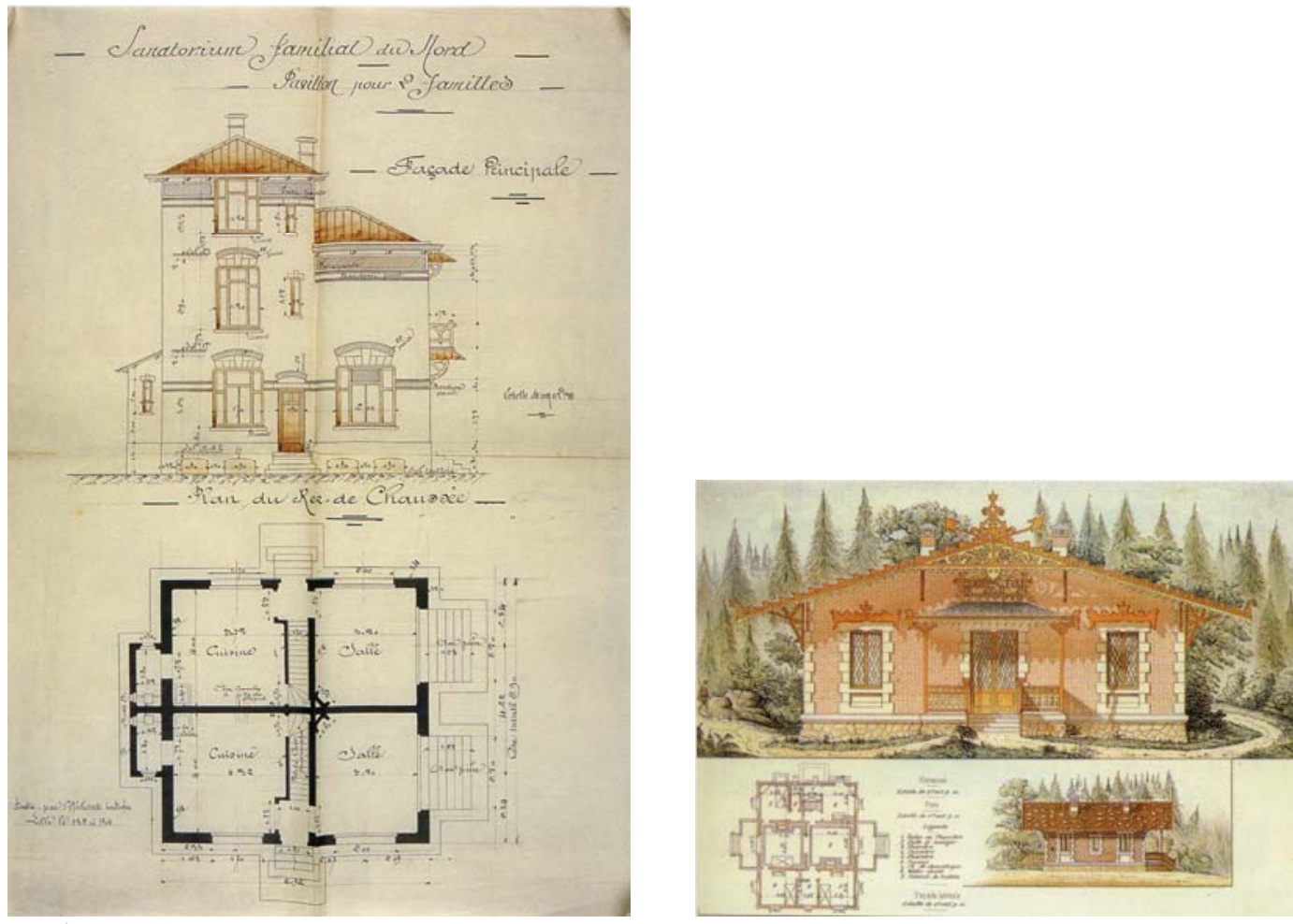

2.26 y 2.27

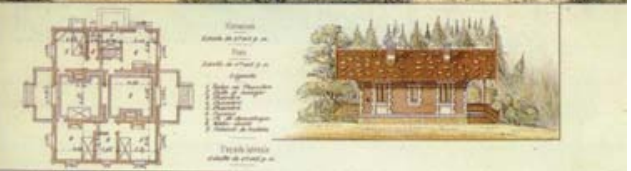

2.22 y 2.23 Dr. Trudeau. Sanatorio de Adrionack, Nueva York, 1884. Imagen y planta.

2.24 Dr. Otto Walther. Colonia de Nordrach Dosquet, Selva Negra, 1888.

2.25 Sanatorio Nordrach-on-Mendip, Somerset, 1899.

2.26 L. Hainez. Sanatorio de Montigny-en-Ostrevent ,1904.

2.27 M. Ormières. Villas higiénicas de invierno, Arcachon, 1896. 
Montreux, Suiza, obra del arquitecto Jules $\mathrm{Clerc}^{51}$. Contiene balcones corridos formando nichos, divididos por elementos móviles que coinciden con los soportes estructurales de cada habitación. Las galerías de cura corridas, independizadas o no, se implantan en todos los sanatorios suizos, principalmente en la región de Leysin, llegando a ser descritos los sanatorios con galerías como "tipo Leysin". Se añaden incluso en aquellos que como Schatzalp carecen de ellas en origen [fig. 2.21], incorporándose en sus fachadas estas protuberancias de madera o albañilería con sus esbeltos soportes.

A partir del siglo XX la galería de cura y la transparencia se convierten en los elementos arquitectónicos característicos del sanatorio antituberculoso pulmonar que para Thomas Mann consiste en: "un edificio alargado con la fachada principal orientada hacia el suroeste y una torre en forma de cúpula, el cual, de tantos balcones que tenía, de lejos parecía agujereado y poroso como una esponja ${ }^{\prime \prime 2}$.

\section{LA VIDA EN EL HOTEL Y LA VIDA EN LA CABAÑA: EL PATRÓN MÉDICO}

Los resultados arquitectónicos de los sanatorios antituberculosos de finales del siglo XIX y principios del $X X$, aunque responden a terapias similares, formalmente son muy diferentes entre sí. A partir de 1884, en Estados Unidos se aplica como método terapéutico contra la tuberculosis una cura basada en la vida en la naturaleza en estado puro o Wilderness, promovida por el Dr. Edward Livingston Trudeau, un antiguo enfermo de tuberculosis que funda el Sanatorio de Adrionack en Saranac Lake en Nueva York ${ }^{53}[$ fig. 2.22]. El Sanatorio está constituido por una serie de tiendas de campaña y unas 18 casas unifamiliares de madera, acondicionadas con habitaciones individuales donde residen los enfermos. En las casas cada estancia tiene dos ventanas y las puertas no tocan ni el suelo ni el techo para favorecer la ventilación ${ }^{54}$. Todas ellas cuentan con amplios porches para llevar a cabo la cura de aire y de reposo [fig. 2.23]. Las viviendas se agrupan formando el conjunto

\footnotetext{
${ }^{51}$ Dave LÜTHI, "1870-1950 Le sanatorium en Suisse. Du Kurhaus à la clinique pneumologie", en Histoire et Réhabilitation des Sanatoriums en Europe, Les réseaux de la modernité au XX ${ }^{e}$ siècle/l. Docomomo International, Paris 2008, p. 44.

${ }^{52}$ Thomas MANN, La Montaña Mágica (Berlín, 1924). Edhasa, Barcelona 2005, p. 16.

${ }^{53}$ En 1918 los Estados Unidos contaban con más de 600 sanatorios de pabellones. Bernard TOULIER "Les sanatoriums en Europa. Architecture éphémère et reconversión" en Histoire et Réhabilitation des Sanatoriums en Europe, Les réseaux de la modernité au XXe siècle/l. Docomomo International, Paris 2008, p. 8.

${ }^{54}$ Anne-Marie CHÂTELET, "1860-1902 La naissance du sanatorium en Europe" en Histoire et Réhabilitation des Sanatoriums en Europe, Les réseaux de la modernité au XX siècle/1. Docomomo International, Paris 2008, p.21.
} 
heterogéneo y disperso de construcciones que constituye el Sanatorio de Adrionack, que nada tiene que ver con los sanatorios compactos de Alemania y Suiza.

El modelo germano-suizo entra en cierta crisis con el descubrimiento del bacilo de Koch en 1882, debido a la concentración de gérmenes producida por la reunión de pacientes en un único edificio. Comienza así a desarrollarse en Alemania sanatorios como el estadounidense de Adrionack, constituidos por pabellones aislados; éste es el caso de la Colonia de Nordrach fundada en 1888 por el Dr. Otto Walther y su esposa la Dra. Hope Bridges Adams en la Selva Negra, para la que se reutiliza una antigua fábrica de vidrio abandonada que había pasado a mano de los monjes Benedictinos ${ }^{55}$.

Se trata de un área con una extensión de 1840 metros cuadrados que llega a contar con 40 edificios. Los servicios comunes y los comedores se concentran en los edificios principales y en el resto se distribuyen los pacientes. Existe una residencia de enfermos con capacidad para unas 20 camas y los demás se distribuyen en las pequeñas casas de madera, anteriormente ocupadas por los trabajadores de la fábrica, en donde residen en higiénicas habitaciones. Son de dos pisos o menos y todas ellas con baño propio. El Sanatorio carece de galerías de cura, ya que se aplica una terapia de ejercicio afín a la propuesta por el Dr. Brehmer, además de una sobrealimentación, un estricto control de la fiebre y una constante exposición al aire libre con el fin de robustecer el cuerpo, como defiende el Dr. Trudeau, estando prohibido en varias zonas del Sanatorio cerrar las ventanas $^{56}$ [fig. 2.24].

Este tipo de sanatorio no tiene prácticamente repercusión en Alemania, pero sí en otros países europeos como en Francia en donde el arquitecto M. Ormières construye las Villas higiénicas de invierno de Arcachon (1896) [fig. 2.27], y donde se crea el Sanatorio de Montigny-en-Ostrevent (1904) del arquitecto Léonce Hainez [fig. 2.26], constituido por pequeños pabellones de viviendas higiénicas de grandes ventanales.

Sin duda es en Inglaterra donde este tipo de sanatorio tuvo más arraigo; sus tisiólogos seguidores de las teorías de los médicos higienistas de finales del XVIII, se muestran partidarios de los sanatorios constituidos por casas de campo o cottage y tratan de aplicar el modelo de Nordrach en su país. La influencia de esta colonia alemana es tal que incluso varios sanatorios en el Reino Unido llevan su nombre, como el Nordrach-on-Mendip (1899)

\footnotetext{
${ }^{55}$ Frederick RUFENACHT WALTERS, Sanatoria for consumptives in various parts of the world. Swan Sonnenschein, London 1899, p. 190.

${ }^{56}$ Francis Barrymore SMITH, The Retreat of Tuberculosis 1850-1950. Croom Helm, New York 1988, p. 98.
} 
en Somerset [fig. 2.25], el Nordrach-on-Dee (1900) en Escocia y el Nordrach-on-Wales (1900) en Pedyffryn en Caernarvonshire ${ }^{57}$, llegando a conocerse la cura de ejercicio del Dr. Brehmer como Nordarch Cure ${ }^{58}$.

La diversidad tipológica existente entre los sanatorios y la variedad de terapias de cura derivan en la necesidad de unificar criterios y, con tal fin, se celebra en Berlín del 24 al 27 de mayo de 1899 el primer Congreso Internacional de la Tuberculosis. Se perfila definitivamente el programa sanatorial germano-suizo, basado en la cura de reposo, aire puro y sobrealimentación como el método terapéutico más conveniente. En cuanto a la arquitectura se rechazan los sanatorios de pabellones y se apuesta por el sanatorio tipo Kurhaus, constituidos por un único edificio alargado y compacto con planta en forma de Ty con galerías de cura en la fachada sur, que definen el tipo de sanatorio a aplicar.

En el congreso se apuesta por la eficacia del sanatorio frente a los dispensarios o preventorios. Con él desaparecen las restricciones de altitud propias de la "inmunidad tísica de la altura" o las climáticas ligadas a la "inmunidad escrofularia del litoral" y pasan a ser considerados fundamentales otros aspectos en la implantación del sanatorio: la pureza del aire y la existencia de un clima seco y templado. Se renuncia además a la cura de ejercicio forzado y a la helioterapia más severa, en pos del reposo y de los paseos al aire libre, considerando los baños de sol más beneficiosos por sus propiedades asépticas que curativas.

A la difusión de la tipología arquitectónica establecida en el Congreso de Berlín contribuye la Exposición Universal de París de 1900, en la que se presentan los principales sanatorios alemanes en el Palacio de la Higiene. Junto a los sanatorios de Görbersdorf y Falkenstein se exponen también los planos de los Sanatorios de Ruppertshain y Hohenhonnef, entre otros. Los edificios descritos en la exposición se convierten en paradigmas del programa sanatorial, ratificados como tales en el Congreso Internacional de la Tuberculosis celebrado

57 Anne-Marie CHÂTELET, "1860-1902 La naissance du sanatorium en Europe" en Histoire ef Réhabilitation des Sanatoriums en Europe, Les réseaux de la modernité au XXe siècle/l. Docomomo International, Paris 2008, p.21.

58 West London Medical Journal, British sanatoria for the open-air treatment of tuberculosis. John Bale, Sons \& Danielsson, Ltd., London 1899, p.24. 


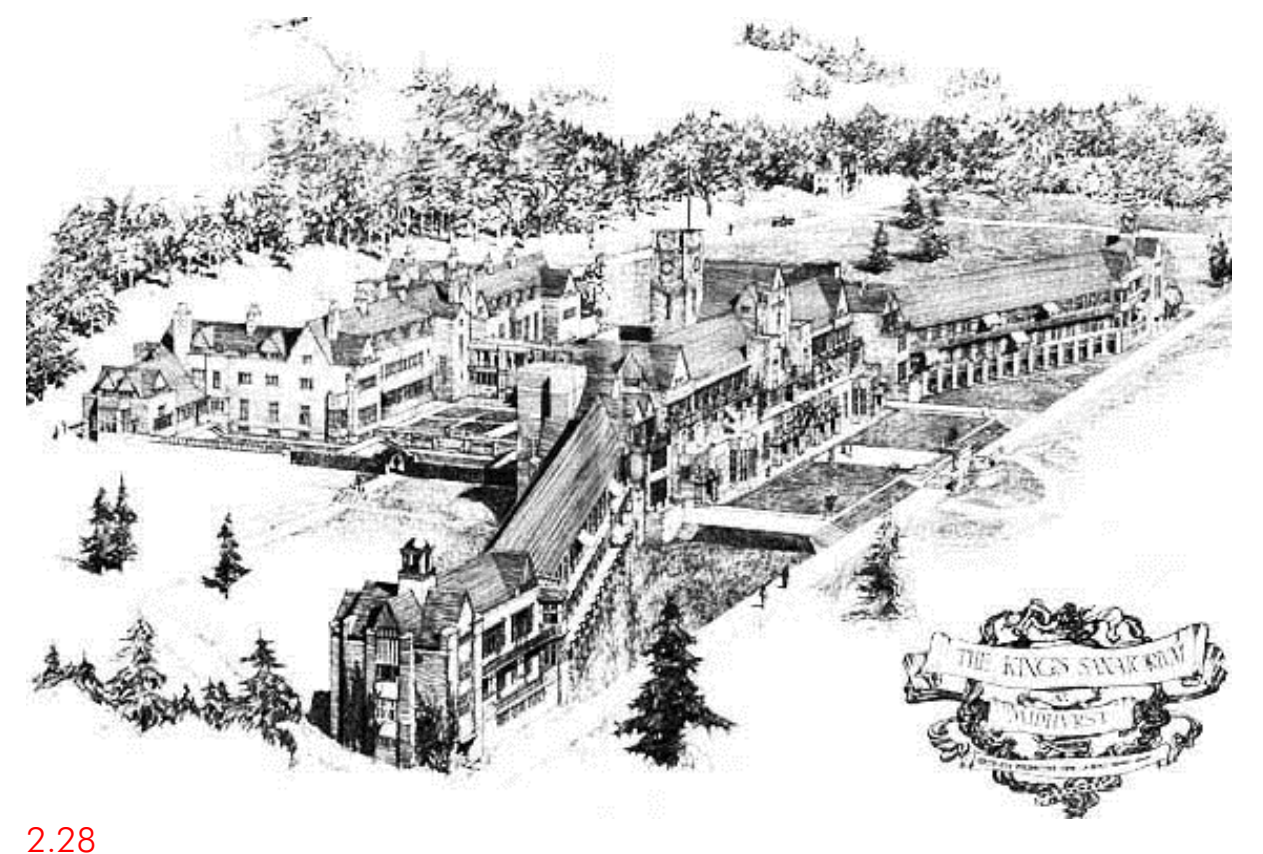

2.28

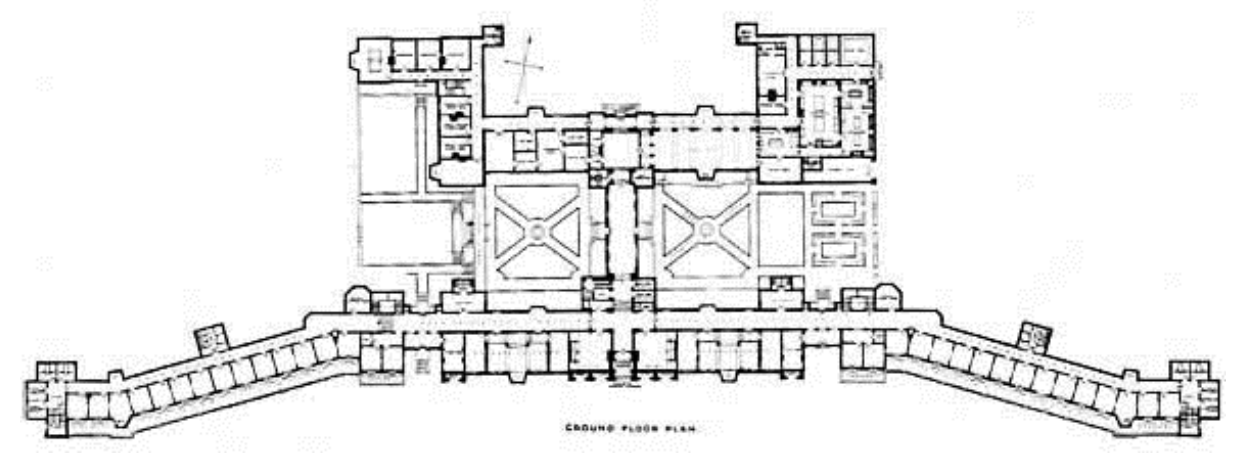

2.29

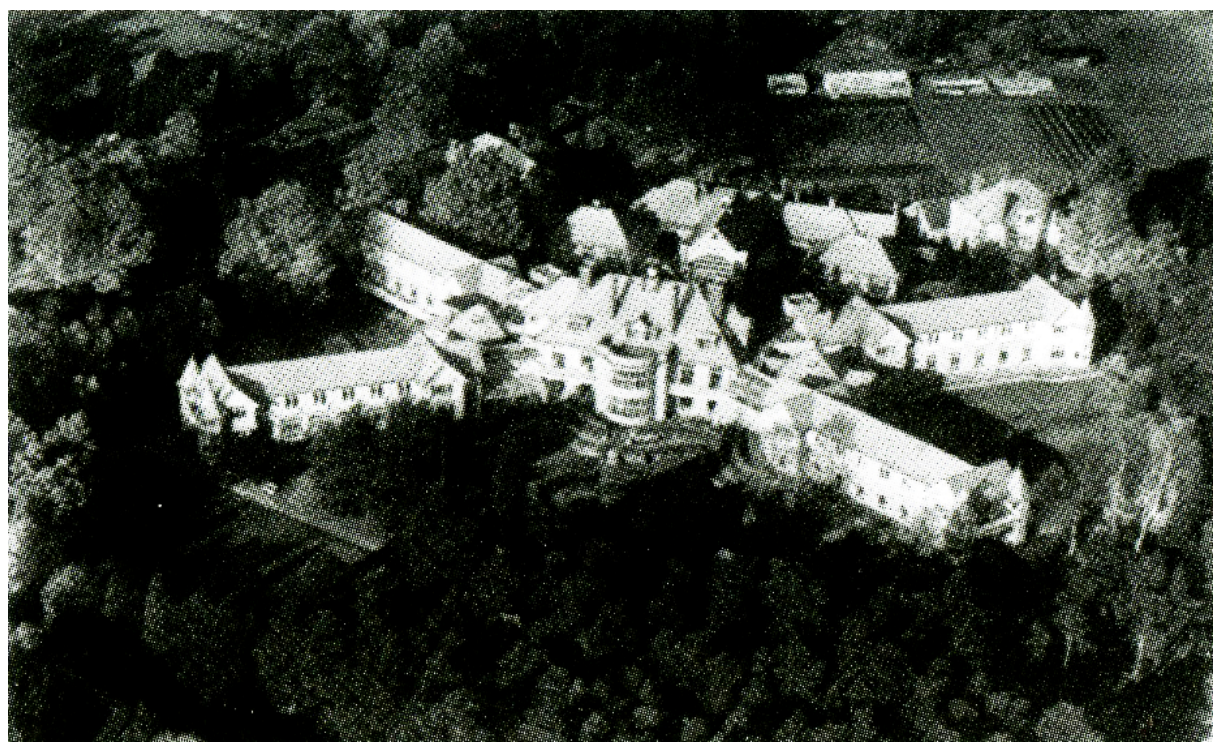

2.30

2.28 y 2.29 P. Adams y C. Holden. Sanatorio de Midhurst, Sussex, 1903-1906. Perspectiva y planta baja.

2.30 Brompton Hospital Sanatorium de Firmley, Surrey, 1904. 
en Londres un año más tarde ${ }^{59}$.

En 1902 tiene lugar el concurso internacional de ideas para la construcción de un sanatorio modelo en Inglaterra, impulsado por el rey Eduardo VII. Como resultado del concurso se construye entre 1903 y 1906 el Sanatorio de Midhurst en Sussex [fig. 2.28], obra de los arquitectos Percy Adams y Charles Holden. Está inscrito en un terreno de 60 hectáreas en las que la paisajista Gertrud Jekyll se encarga de diseñar el jardín y los trazados de los paseos terapéuticos de dificultad progresiva ${ }^{60}$. El Sanatorio de Midhurst constituye el primer sanatorio inglés concebido bajo el concepto sanatorial definido en el Congreso Internacional de Berlín.

Es un edificio simétrico con planta en forma de doble $T$ o mejor aún de mariposa, que consta de un cuerpo central con la administración y los servicios comunes, perpendicular al bloque de habitaciones de enfermos longitudinal. Todas sus habitaciones están orientadas al sureste y al suroeste, separadas en dos alas una de hombres y otra de mujeres, ligeramente giradas entre sí y abiertas hacia el jardín [fig. 2.29].

A este sanatorio le siguen otros de similar estructura formal como el Brompton Hospital Sanatorium de Firmley (1904) construido en Surrey [fig. 2.30], y el Sanatorio Benedin (1907) en Kent ${ }^{61}$, los dos con planta en forma de mariposa, es decir, una variación de la forma en T.

La revista francesa L'Architecture anuncia el concurso del rey de Inglaterra bajo el título "Concurso internacional de arquitectura entre médicos. ¿̇Cuándo un concurso entre arquitectos sobre el mejor modo de operar la apendicitis? "62. Una evidencia más del protagonismo del médico en la definición arquitectónica del sanatorio y del hospital, terreno que no es conquistado por los arquitectos hasta pasada la Primera Guerra Mundial.

\footnotetext{
59 Después del Congreso de Londres se crea el Comité Internacional de la Tuberculosis, encargado de organizar los siete congresos siguientes celebrados antes de la Primera Guerra Mundial, el de Berlín en 1902, París en 1903, Copenhague en 1904, París en 1905, La Haya en 1906, Washington en 1908 y Roma en 1912. Anne-Marie CHÂTELET, "1860-1902 La naissance du sanatorium en Europe", en Histoire et Réhabilitation des Sanatoriums en Europe, Les réseaux de la modernité au XXe siècle/7. Docomomo International, Paris 2008, p.22.

60 Anne-Marie CHÂTELET, "1860-1902 La naissance du sanatorium en Europe" en Histoire et Réhabilitation des Sanatoriums en Europe, Les réseaux de la modernité au XX e siècle/1. Docomomo International, Paris 2008, p.21.

${ }^{61}$ Bernard TOULIER "Les sanatoriums en Europa. Architecture éphémère et reconversion", en Histoire et Réhabilitation des Sanatoriums en Europe, Les réseaux de la modernité au XX e siècle/l. Docomomo International, Paris 2008, p. 9.

${ }^{62}$ L'Architecture, 25 janvier 1902, p.32.
} 
Schoma für sin

Terransen-canaterimm.

(eier ismohokel.)

nath System Dr. D. Satasotz.

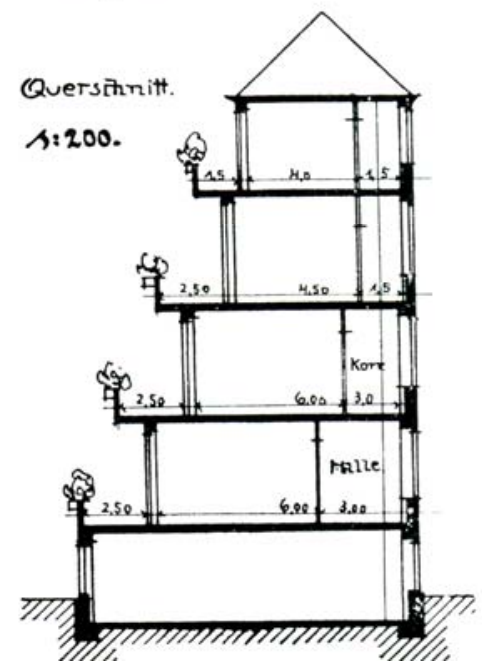

2.31
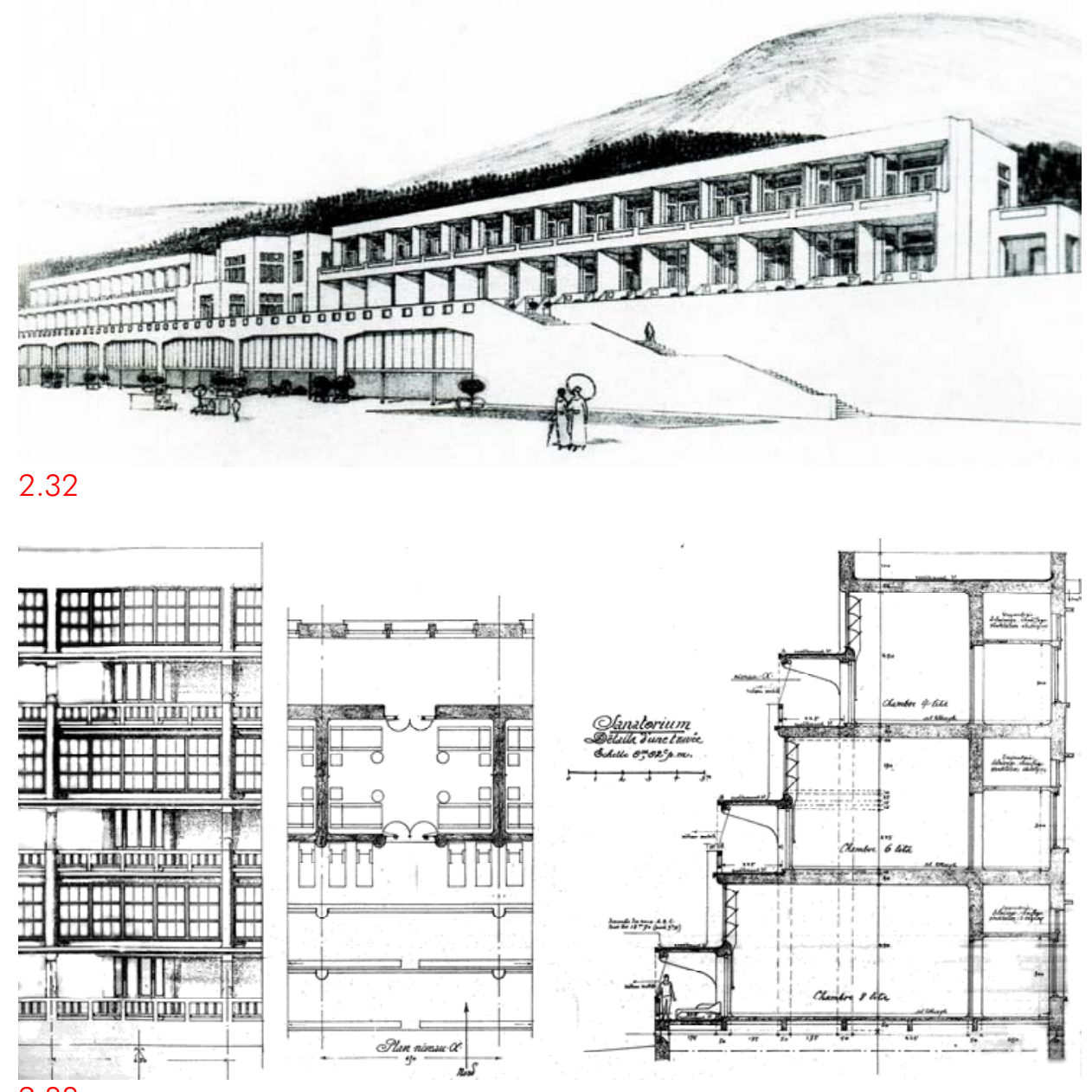

2.33

2.31 Dr.Sarason. Esquema de sanatorio de sección escalonada, 1900.

2.32 T. Garnier. Proyecto de Establecimiento Sanitario de Helioterapia para la Ciudad Industrial de Lyon , 1904.

2.33 T. Garnier. Proyecto de Sanatorio Franco-Americano, 1917. 


\section{EL HELIOTROPISMO PASIVO Y EL HELIOTROPISMO DINÁMICO: LA SECCIÓN ESCALONADA}

A principios del siglo XX, pese a las indicaciones sobre el escaso beneficio terapéutico de la exposición solar prolongada para la cura de la tuberculosis, el Dr. Bernhardt en St. Moritz ${ }^{63}$ y el Dr. Roller en Leysin desarrollan las teorías helioterapéuticas. Como consecuencia en Suiza se altera la estructura formal del sanatorio tipo al incorporar azoteas solarios en la cubierta y escalonar el frente de habitaciones, trasformando las galerías de cura cubiertas en terrazas. Estas terrazas permiten que el enfermo pueda realizar la cura de sol sin desplazarse de su habitación y favorecen que la luz y el aire penetren más fácilmente en el interior de las estancias. Es un médico alemán David Sarason quien diseña, alrededor del año 1900, junto al arquitecto G. Bärhr ${ }^{64}$ el primer esquema de sanatorio con sección escalonada. Su sección consta de cuatro plantas de habitaciones con galerías de cura de 2,5 metros de ancho, cuyo frente sur se va retranqueando en altura, dejando las galerías semi-cubiertas, y disminuyendo progresivamente la profundidad del bloque de habitaciones [fig. 2.31].

Este modelo tuvo una gran acogida internacional. Es divulgado en Francia por el Dr. Camille Savoire en su conferencia pronunciada en la Escuela de Bellas Artes de París en 1902, y en 1903 a través del artículo "Luz y Salud" publicado en el Bulletin de la S.A.D.G., el Boletín de la Sociedad del Gobierno de Arquitectos Diplomados ${ }^{65}$.

En 1904, un año después de la publicación del artículo, Tony Garnier, quien ya ha proyectado dos sanatorios ${ }^{66}$, diseña el Establecimiento Sanitario de Helioterapia para la Ciudad Industrial de Lyon (1904-1907) [fig. 2.32]. Un gran bloque lineal escalonado de tan sólo dos plantas de habitaciones, recorridas por largas galerías de cura adosadas a su fachada sur.

Este mismo esquema se repite en su proyecto para el Sanatorio Franco-Alemán realizado en 1917 [fig. 2.33]. Proyecta una elaborada sección escalonada en la que se aprecia un cuidado interés por el control solar. Consta de tres plantas de habitaciones con las terrazas ahora completamente cubiertas por un elemento horizontal, que sobresale del plano de

\footnotetext{
${ }^{63}$ Francis Barrymore SMITH, The Retreat of Tuberculosis 1850-1950. Croom Helm, New York 1988, p. 100.

64 Jean-Bernard CREMNITZER, Architecture et Santé : Les temps du sanatorium en France et en Europe. Picard, Paris 2005, p. 50.

${ }^{65}$ François LOYER, Hélène GUÉNÉ, Henri Sauvage. Les immeubles a gradins. Mardaga, Liège Bruxelles 1987, p.35.

${ }^{66}$ Tony Garnier proyecta el Sanatorio para una alta estación en los Alpes (1895) con el que consigue el segundo puesto del Gran Premio de Roma, y el Sanatorio para oficiales y soldados convalecientes de la armada de tierra y mar (1896) inspirado en el anterior, en donde propone un aterrazamiento del bloque de habitaciones para adaptarse al terreno.
} 

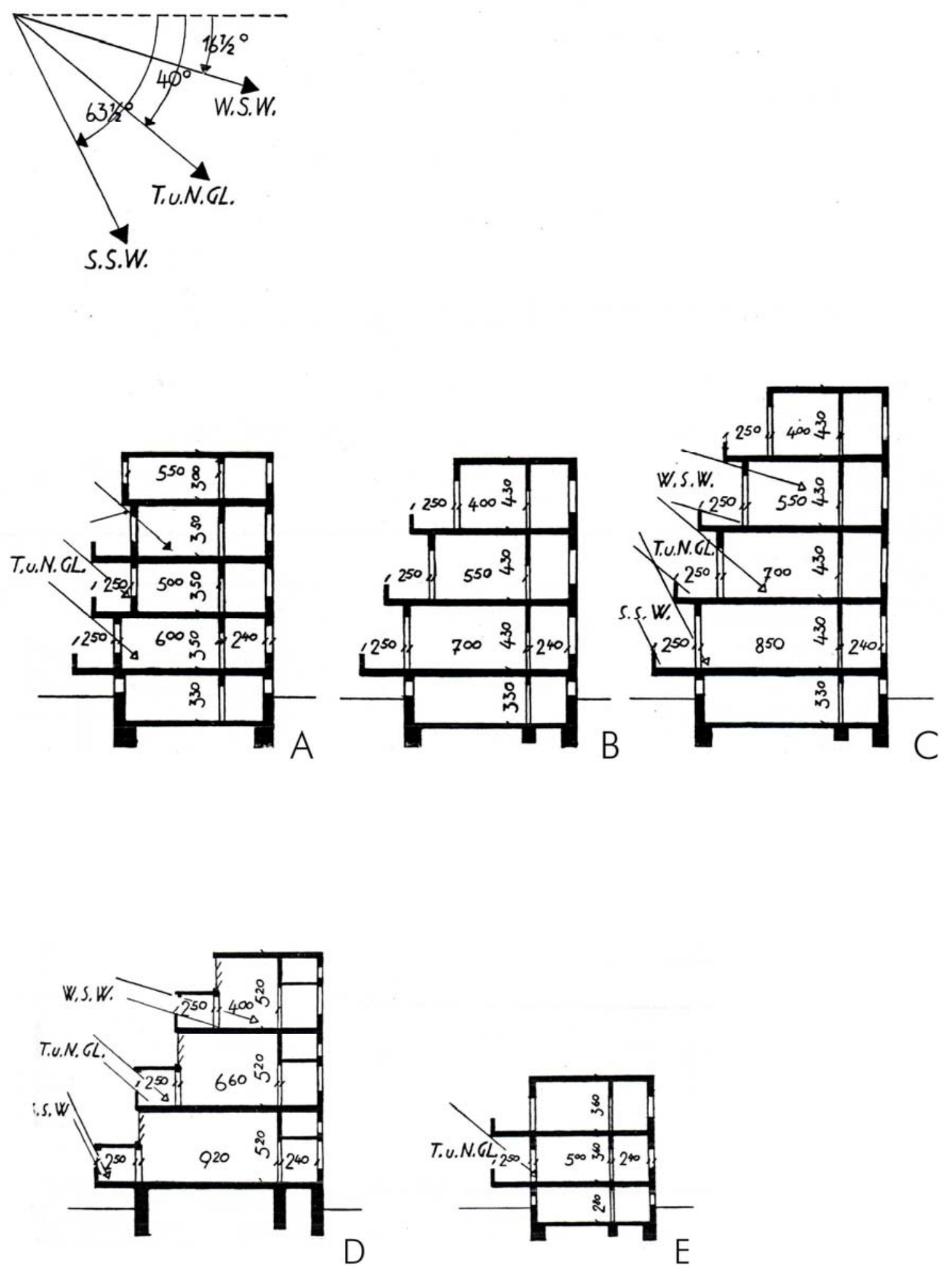

2.34 R. Döcker. Esquemas de sanarorios escalonados Terrassen Typ, 1929. 

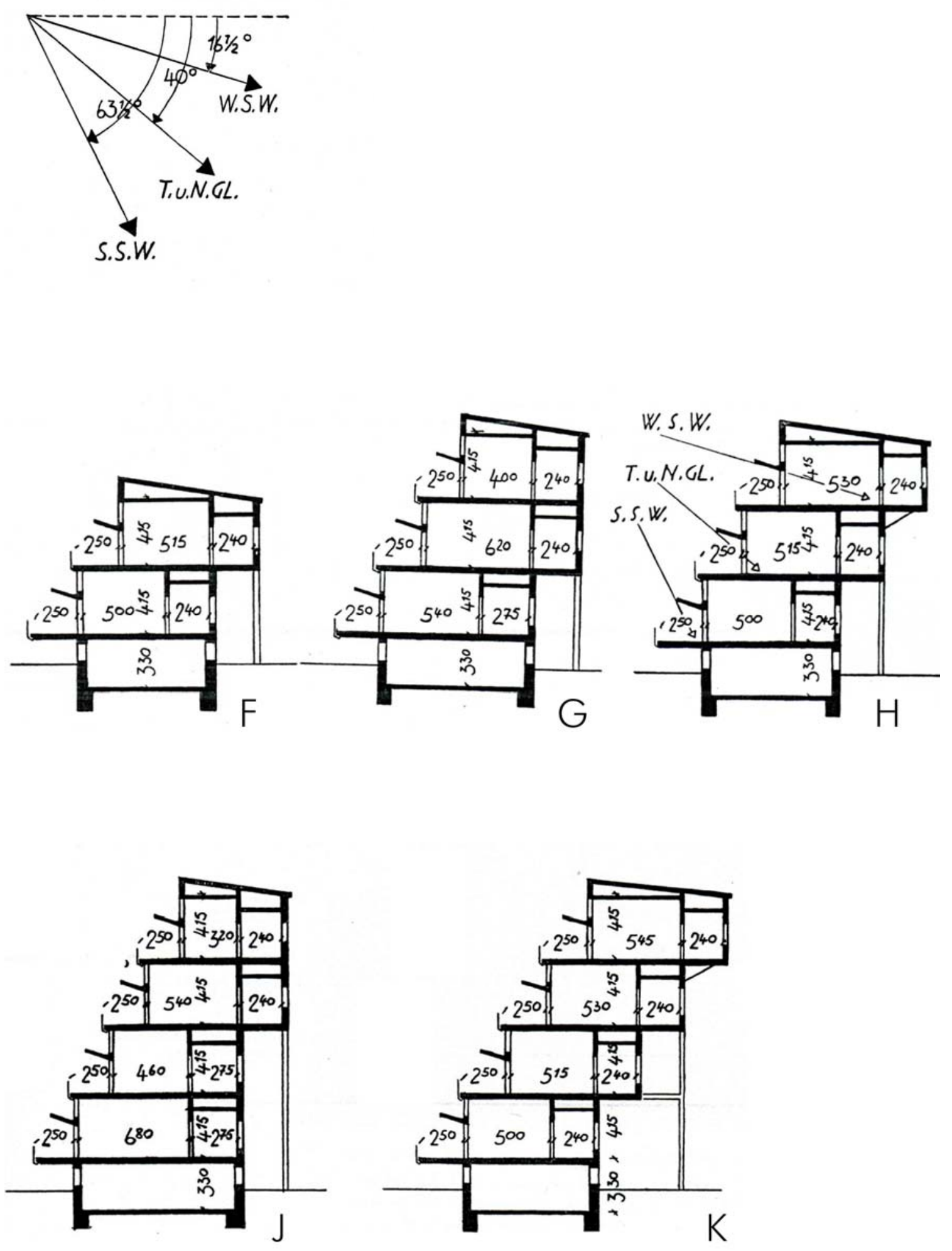

2.34 R. Döcker. Esquemas de sanarorios escalonados Terrassen Typ, 1929. 


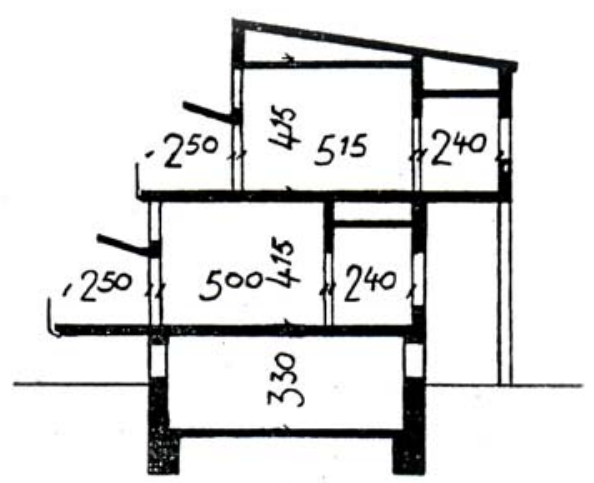

2.35
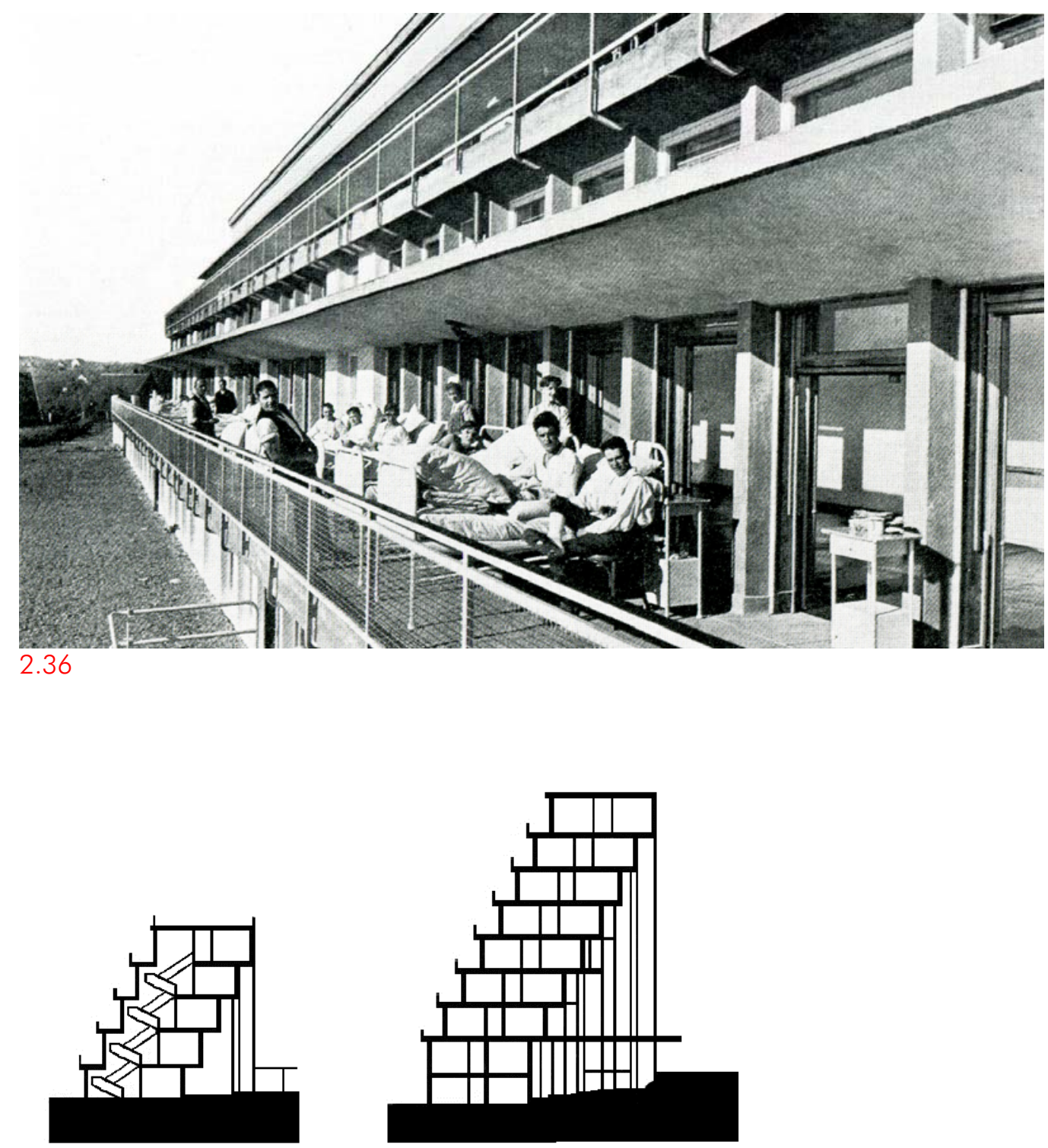

2.35 y 2.36 R. Döcker. Sanatorio de Waiblingen, 1926-1929. Sección tipo e imagen.

2.37 Marcel Breuer y Hassenpflug. Proyecto de Sanatorio con 1.100 camas, Elberfeld, 1928-1929. Secciones. L'Architecture vivante, automne \& hiver $n^{\circ} 33-34,1931$. 
fachada de cuyo extremo pende un toldo enrollable. A pesar de cubrir las terrazas, el escalonamiento de la fachada contribuye a que el sol y el aire penetren en la habitación a través del acristalamiento superior, ubicado sobre la visera horizontal que divide el frente de la habitación de 4,90 m. de altura en dos franjas. La inferior de unos 2,3 metros de altura, totalmente ciega a excepción de la puerta de acceso a la galería que es de cristal, y la superior totalmente acristalada compuesta por un friso de pequeñas ventanas horizontales con un mecanismo de apertura común, que facilitan la ventilación y la entrada de luz en la estancia $^{67}$.

En 1907 el Dr. Sarason publica el libro Ein Neves Bauprinzip (Terrasen-System) Für Krankenanstalten und wohnhaüser en el que incluye su propuesta escalonada de sanatorio. Esta obra probablemente sirve de inspiración a otro arquitecto, Richard Döcker, el gran proyectista y constructor de numerosos sanatorios antituberculosos por toda Alemania ${ }^{68}$. Döcker en 1929 publica su libro Terrassen Typ: Krankenhaus, Erholungsheim, Hotel, Bürohaus, Einfamiliënhaus Siedlungshaus, Miethaus und die Stadt, un verdadero manifiesto internacional donde, como ya propuso Sarason, se analiza la aplicación del sistema escalonado a diversos programas arquitectónicos: hospitalarios, hoteleros, edificios de oficinas, viviendas unifamiliares ${ }^{69}$, en bloque, etc., e incluso en ciudades.

El Sanatorio antituberculoso de Waibling en Alemania (1927-1929) puede considerarse la obra sanitaria más relevante de Richard Döcker. Este edificio consiste en un bloque lineal de dos plantas de altura que presenta sus dos fachadas escalonadas, tanto la sur con las habitaciones como la norte con el corredor [fig. 2.35]. El frente de las habitaciones está completamente acristalado, cerrado mediante ventanas de guillotina según el sistema Dosquet, e incluye una estrecha visera inclinada que protege parcialmente la galería de cura y el interior de la habitación de la incidencia de los rayos solares en los meses de verano o en las horas del mediodía [fig. 2.36].

La sección del Sanatorio de Waiblingen aparece recogida en el apartado hospitalario del libro Terrasen Typ. A través del análisis de las secciones de diversos proyectos de sanatorios

${ }^{67}$ En el corredor la altura libre se reduce a 3 metros, ocultándose a través de un falso techo los conductos de instalaciones que también se ventilan al exterior.

${ }^{68}$ En 1925 Richard Döcker amplía el Sanatorio de Urach ya existente. Entre 1926 y 1928 construye el Sanatorio antituberculoso de Waiblingen y, entre 1927 y 1929, el Sanatorio antituberculoso de Maulbronn. Proyectó además otros dos sanatorios que no llegaron a ser construidos, uno entre 1925 y 1926, y otro más en 1927, todos ellos de sección escalonada.

${ }^{69}$ Como las que construye en la Weissenhofsiedlung de Stuttgart, celebrada en 1928 y coordinada por Mies van der Rohe, año en que es nombrado miembro de los CIAM y de la asociación alemana Werkbund. 
se estudian en el libro las proporciones óptimas entre el vuelo de las terrazas, la altura libre de las habitaciones y la profundidad de las mismas, atendiendo a la inclinación solar del solsticio de verano y de invierno, y del equinoccio de otoño y primavera. Pretende controlar con ello la exposición solar del enfermo, ya que un exceso de sol es molesto e incluso puede llegar a ser perjudicial para los tuberculosos pulmonares. El estudio es un claro exponente de que al mismo tiempo que se busca la captación de sol, se investiga sus sistemas de control [fig. 2.34].

Entre las secciones de sanatorios que analiza Richard Döcker en su libro Terrassen Typ se encuentran las de sus predecesores el Dr. Sarason (esquema B) y Tony Garnier (esquema D). Todas ellas poseen entre dos y cuatro plantas de habitaciones, elevadas del terreno para evitar humedades ${ }^{70}$. También en todas, la galería de cura tiene una anchura de 2,5 m., como establece el Dr. Sarason, una medida que permite colocar la cama o tumbona de cura y dejar un paso libre de circulación; y en la mayoría, la anchura del corredor de acceso es de 2,4 m.

Los esquemas de las secciones presentadas por R. Döcker se pueden clasificar en dos grupos. En el primero sólo se escalona el frente de habitaciones y el frente de los corredores mantiene la verticalidad (esquemas A, B, C, D y E), y en el segundo se escalonan los dos frentes del sanatorio (esquema F, que coincide con la sección del Sanatorio de Waiblingen; G, H y J que coinciden con la sección propuesta por R. Döcker para un proyecto de sanatorio en 1926 que no se llega a construir y K).

En el primer grupo ( $A, B, C, D$ y E) los escalonamientos o retranqueos en fachada son constantes y varían de $1 \mathrm{~m}$., en los sanatorios que tienen las habitaciones más pequeñas, a 2,6 m., a excepción del esquema $\mathrm{E}$ que no presenta retranqueos. El ancho del corredor se mantiene siempre constante mientras varía la profundidad de las habitaciones en cada planta, a medida que la sección del sanatorio se escalona, oscilando entre los $4 \mathrm{~m}$. y los 9,2. La altura libre en las plantas de habitaciones permanece constante dentro de cada sanatorio y oscila entre 3,5 y 5,2 m. Se establece una proporción entre la altura y la profundidad para lograr una mayor captación solar, de modo que los sanatorios que presentan las habitaciones más profundas son los más altos. El inconveniente surge al

\footnotetext{
${ }^{70}$ El recurso de elevar las habitaciones sobre el terreno para evitar posibles humedades es recurrente; había aparecido ye en la sección del Hospital Mayor de Milán de Filarete en el siglo XV, en el proyecto para el Hôtel- Dieu de París del arquitecto Le Roy en el siglo XVIII y en la sección modelo de la sala de enfermos proyectada por el ingeniero C. Tollet en el siglo XIX.
} 
mantener constante la altura en todas las plantas siendo su profundidad variable, llegando a obtener habitaciones más altas que largas ${ }^{71}$.

La visera horizontal presente en la sección del Sanatorio Franco-Americano de Tony Garnier (esquema D) sirve de referente para los esquemas del segundo grupo, (F, G, H, J y K) incluido el proyecto del Sanatorio de Waiblingen de Döcker. Las secciones de este grupo presentan un sistema de protección horizontal similar, pero en ellas la visera no cubre completamente la galería y presenta una ligera inclinación de unos 16 grados, que coincide con la inclinación de los rayos solares en el solsticio de invierno, lo que permite una mayor iluminación tanto dentro de la habitación como en la galería y, un menor deslumbramiento cuando el sol es más bajo.

El escalonamiento o retranqueo de las plantas en este grupo de esquemas $(F, G, H$, J y K $)$ oscila entre los 2,2 y los 2,4 m., acompañado del desplazamiento de la fachada trasera, que implica la aparición de la estructura de apoyo vista para soportar las plantas. Mientras el escalonamiento del frente sur es constante, en cambio, el del frente norte presenta saltos que corresponden a varias plantas ( $G$ y J).

Todas las habitaciones de este grupo tienen una altura libre constante de 4,15 m. y una profundidad que oscila entre los 3,2 y los 6,8 m. Destaca entre las distintas propuestas el modelo de cuatro plantas escalonadas, tanto en la fachada sur como en la fachada norte, soportado por una estructura de vigas y pilares vistos en la parte trasera (K). Este mismo esquema es adoptado por Marcel Brever y Hassenpflug en 1930, en su proyecto para la construcción de un sanatorio de 1.100 camas [fig. 2.37].

Antes de que aparecieran las galerías de cura anexas a las fachadas de los sanatorios, el tratamiento de reposo, aire puro y de sol, se realizaba en el exterior. A principios del siglo XX existen principalmente en Inglaterra pequeñas cabañas de madera dispuestas en los jardines de los sanatorios, como las del Mount Pleasant Sanatorium de Ventmor en la isla de Wight ${ }^{72}$, y en las casas. Su cometido es para descansar al aire libre y para tomar el sol. Estas cabañas se perfeccionan y se hacen giratorias [fig. 2.38] para conseguir una mejor

${ }^{71}$ En la última planta del esquema de Tony Garnier para el Sanatorio Franco-Americano la habitación de cuatro camas tiene 4,25 m. de anchura interior y 4,9 de altura libre.

72 British sanatoria for the open-air treatment of tuberculosis. West London Medical Journal, John Bale Sons \& Danielsson, London 1899, pp.17-20. 


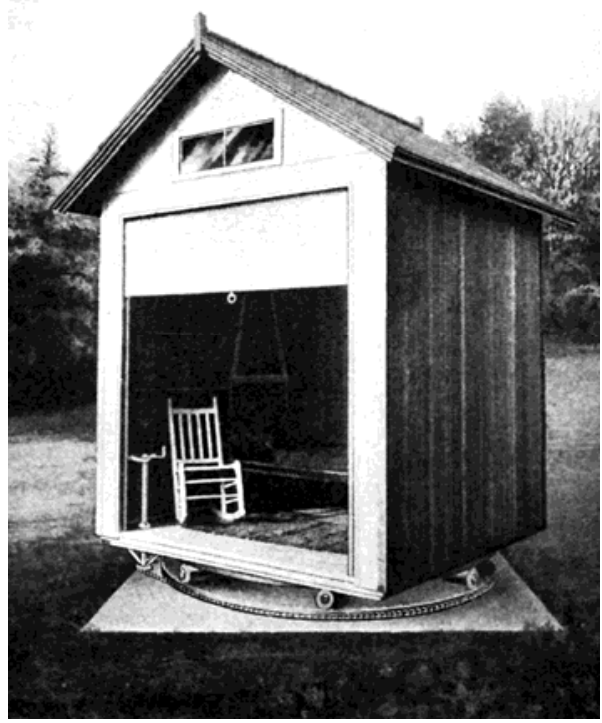

2.38
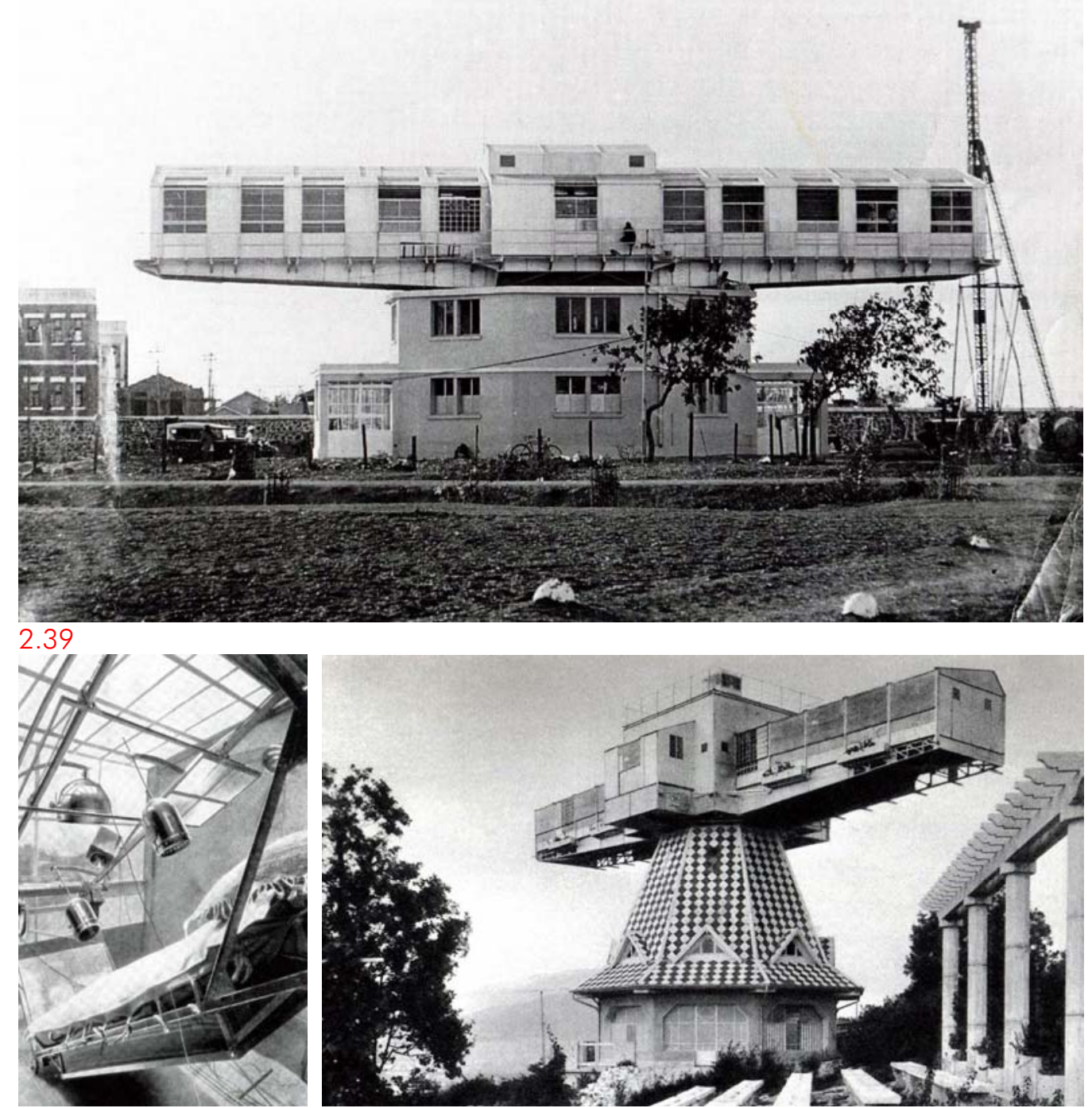

2.40 y 2.41

2.38 Cabaña giratoria para la cura de reposo, sol y aire puro. Principios del siglo XX

2.39 Dr. Saidman. Sanatorio-solárium de Jamnagar, 1935.

2.40 Dr. Saidman. Interior de una cabina de insolación.

2.41 Dr. Saidman. Sanatorio-solárium de Aix-les-Bains, Savoya, 1928. 
orientación a lo largo del día ${ }^{73}$, llegando incluso a convertirse treinta años después en sanatorios completos, auténticos artefactos de insolar inspirados en el fototropismo natural. La construcción de estos artefactos surge en el Instituto de Actinología, encargado del estudio de los efectos químicos y biológicos de las radiaciones ultravioletas de la luz solar en los organismos, fundado por el Dr. Jean Saidman en 1926, orientado no sólo hacia la cura de la tuberculosis sino también hacia la cura de enfermedades cutáneas y del raquitismo ${ }^{74}$.

Son construcciones más mecánicas que arquitectónicas, cuyo movimiento circular recuerda al desplazamiento de las hélices de un helicóptero [fig. 2.39]. Constan de una sala-solario prismática y acristalada, equipada interiormente con espejos reflectores y con lámparas para los días de escaso sol, que contiene camillas colgadas orientables para conseguir que los rayos solares incidan directamente sobre el enfermo, [fig. 2.40]. La sala-solario está soportada en su centro por un pie vertical que contiene los mecanismos giratorios que permiten la rotación de la estancia según el desplazamiento solar [fig. 2.41].

El Dr. Saidman implanta cabinas giratorias de este tipo en las cubiertas de algunos de los más importantes sanatorios antituberculosos, como la Estación Terapéutica Alemana de Davos en 1915, y construye varios sanatorios-solarios entre los que se encuentran el de Savoya en Aix-les-Bains (1928), el de la Còte d'Azur en Vallauris (1931) y el de la India en Jamnagar (1934), el único que aún se conserva. Proyecta incluso la creación de una serie de Actinópolis o ciudades solares dedicadas a la investigación sobre la acción biológica del sol, proyectos y construcciones que le consiguen fama internacional ${ }^{75}$.

\section{LAS TERAPIAS CLIMÁTICAS Y LA CURA DE TRABAJO: LA CIUDAD SANATORIO}

Después de la Primera Guerra Mundial se desarrolla una germanofobia que lleva a rechazar cualquier idea procedente de este país y, pese a que Alemania sigue manteniéndose como lugar de peregrinación de los tisiólogos, el elevado índice de fallecimientos a causa de los contagios, provoca que se despierte un movimiento en contra del programa sanatorial establecido en 1899 en el Congreso Internacional de Berlín y se pone en duda tanto su eficacia curativa como su conveniencia social.

\footnotetext{
${ }^{73}$ Thomas Spees CARRINGTON, Fresh air and how to use it. National Association for the Study and Prevention of Tuberculosis, New York 1912, pp.160-162.

${ }^{74}$ Jean-Bernard, Cremnitzer. Architecture et Santé. Le temps du sanatorium en France et en Europe. Picard, París 2005, p. 111.

${ }^{75}$ Jean-Bernard, Cremnitzer. Architecture et Santé. Le temps du sanatorium en France et en Europe. Picard, Paris 2005, p. 114.
} 

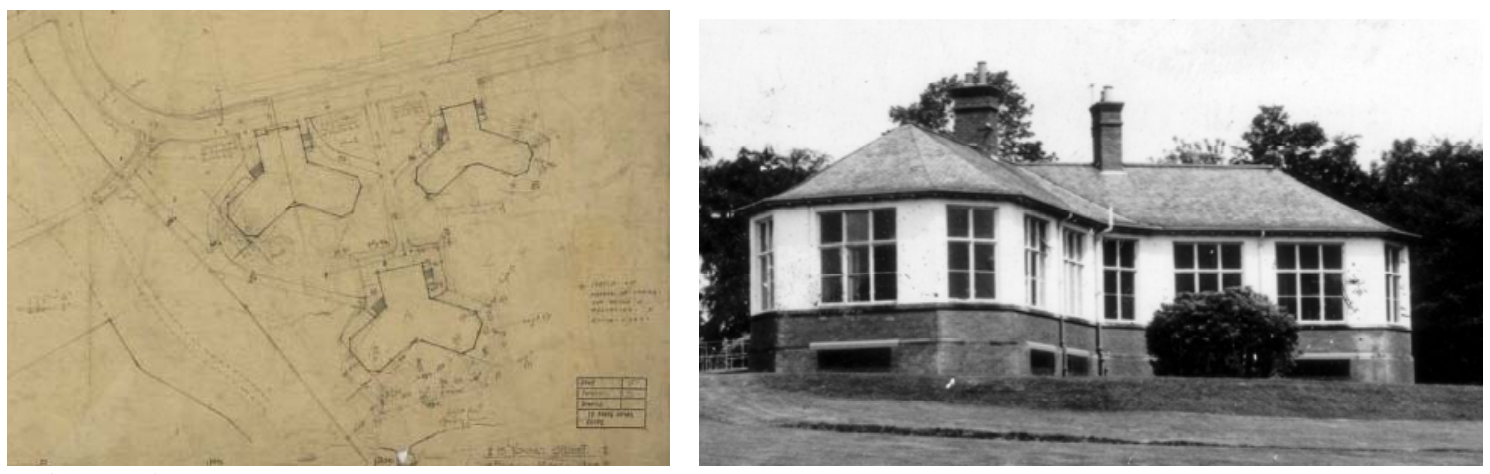

2.42 y 2.43
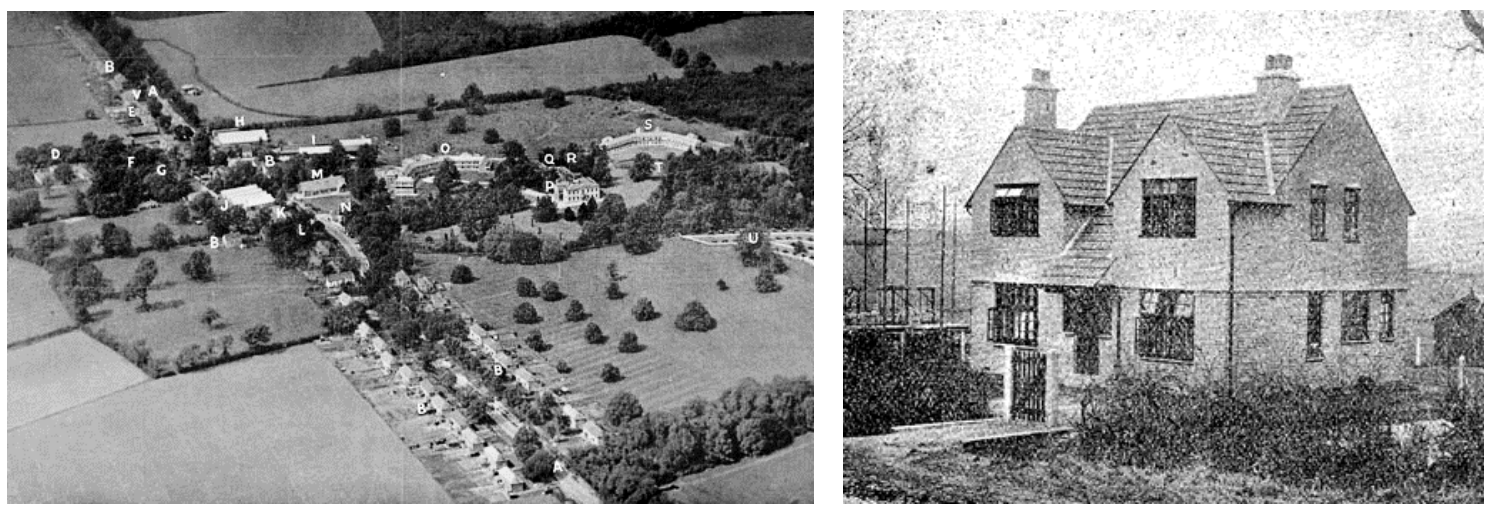

2.44 y 2.45

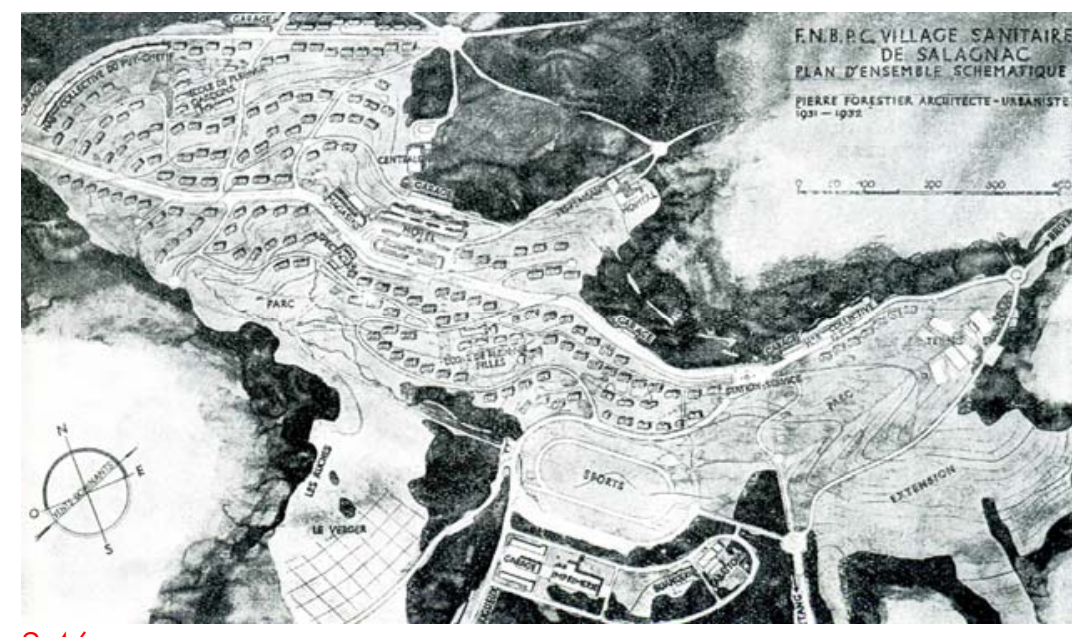

2.46

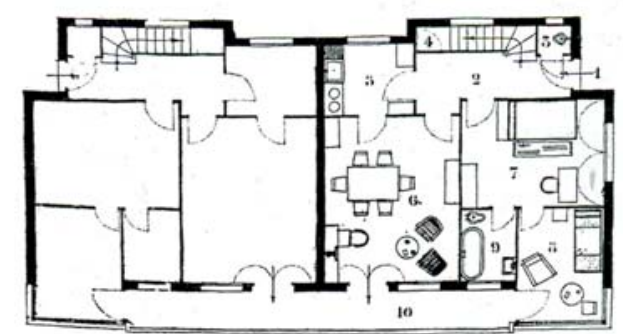

2.47

2.42 y 2.43 Dr. R. Philip. Royal Victoria Hospital, Edimburgo, 1894. Plano de 1907 e imagen de un pabellón.

2.44 y 2.45 Dr. P. C. Varrier-Jones. Colonia de Papworth, 1915. Imagen de conjunto y de una vivienda.

2.46 y 2.47 Pierre Forestier. Ciudad Sanatorial de Clairvivre, Salagnac, 1930-1933. Plano de situación y planta tipo de una vivienda. 
La tuberculosis es ya considerada una enfermedad de masas y, como explica el Dr. VarrierJones, debe tener tratamiento con amplios fines: "Los principios del tratamiento sanatorial son buenos. Es su método de aplicación el que falla. Este método para poder dar sus frutos, debe tener en cuenta, junto a la atención a los fines médicos, los fines morales y sociales ${ }^{\prime \prime 76}$. La mayor ambición se encuentra motivada por la insuficiencia de la cura sanatorial que debe combinarse con la cura en los dispensarios y preventorios.

El ingreso del enfermo en el sanatorio supone un aislamiento de su entorno ${ }^{77}$ y un abandono de su actividad profesional. La precaria situación de la clase obrera, provoca un gran problema que afecta a su recuperación física y a su reinserción laboral posterior El doctor inglés Sir Robert Philip, atendiendo a estas cuestiones sociales, crea en su propia casa en $1887^{78}$ el primer dispensario antituberculoso para dar la posibilidad al enfermo leve de recuperar la salud, permanecer en su hogar y mantener su trabajo.

A finales del siglo XIX existen en Inglaterra teorías que defienden el trabajo del obrero como método de cura para la tuberculosis pulmonar. Según éstas, la auto-inoculación leve de tuberculina suministrada a través de la vida en la casa insalubre del enfermo sumada al esfuerzo físico que realiza en la fábrica, hacen que éste desarrolle gradualmente anticuerpos que le vuelven inmune al germen ${ }^{79}$.

Robert Philip no confía en que el trabajo por sí solo, sea un remedio curativo, pero tampoco cree en la reclusión inactiva del enfermo en el sanatorio. Bajo estas creencias establece en Edimburgo en 1894 la primera colonia de convalecencia, también conocida como "colonia de reeducación", el Royal Victoria Hospital, donde se combinan la cura de reposo y la cura de trabajo. Cuatro años después de su inauguración, el 23 de julio de 1898, el British Medical Journa/ recoge:

\footnotetext{
76 "Les príncipes du traitament sanatorial sont bons. C'est la méthode suivant laquelle on les applique qui est en défaut. Cette méthode, pour porter ses fruits, doit tenir compte, à côté du but medical à atteindre, des buts moral et social." Robert WOLFSOHN, Las Villages de Tuberculeux en Anglaterra (Papworth, Preston Hall, Barrowmore Hall). Thèse pour le doctorat en Médicine, Faculté de Médecine de Paris, Paris 1924, p. 11.

77 La desvinculación con el entorno cotidiano es tan grande que en ciertos casos, como nos retrata Thomas Mann en su novela, el enfermo una vez curado es incapaz de retomar su vida: "(...) cuando se recuperó (pues, en efecto, a veces se cura uno aquí arriba) no quería marcharse de ninguna manera. Rogó encarecidamente al médico jefe que la retuviese aquí, le dijo que no podía ni quería irse a casa, que esta era su casa y que aquí se sentía feliz". Thomas MANN, La Montaña Mágica (Berlín, 1924). Edhasa, Barcelona 2005, p. 127.

${ }^{78}$ Francis Barrymore SMITH, The Retreat of Tuberculosis 1850-1950. Croom Helm, New York 1988, p. 66.

79 Robert WOLFSOHN, Las Villages de Tuberculeux en Anglaterra (Papworth, Preston Hall, Barrowmore Hall), Thèse pour le doctorat en Médicine, Faculté de Médecine de Paris, Paris, 1924, pp.12-15.
} 
"En este sanatorio, establecido bastante antes de esta fecha bajo la dirección de Sir Robert Philip, la experiencia parece indicar en primer lugar que la desaparición completa de los síntomas de la tuberculosis pulmonar no podía obtenerse por la cura sanatorial, incluso cuando era considerablemente prolongada, en segundo lugar, que un trabajo exactamente dosificado, lejos de oponerse a la curación, podía útilmente secundarla ${ }^{\prime \prime 80}$.

Así el Royal Victoria Hospital de Edimburgo se convierte en un modelo de sanatorio imitado en toda Inglaterra. Consta de un edificio principal que contiene los servicios comunes y una serie de pabellones de enfermos, idénticos entre sí, cuyo número va creciendo a medida que aumentan los ingresados en el centro. Constituyen en 1907 un conjunto disperso y ordenado de 5 pabellones de enfermos con forma de $Y$ [fig. 2.42 y fig. 2.43] contenidos dentro de un amplio recinto arbolado.

La unión de su terapia laboral y las teorías urbanas de los médicos higienistas ingleses fomentan la aparición en el Reino Unido de numerosas colonias de reeducación o convalecencia, como la Colonia Tuberculosa de Papworth fundada en 1915 por el doctor Sir Pendrill Charles Varrier-Jones ${ }^{81}$.

Se trata de una villa de la salud constituida por una comunidad de casas unifamiliares de madera congregadas en torno a un hospital antituberculoso, donde conviven y trabajaban los enfermos junto a sus familiares. Papworth cuenta con escuelas, negocios, huertos, talleres, etc. [fig. 2.44]; allí los casos prácticamente curados completan la terapia de recuperación con la cura de trabajo progresivo. El enfermo cobra un salario en función de la actividad realizada con el que paga su tratamiento, el alquiler de la vivienda en la que reside junto a su familia y los gastos de manutención, y una vez curado tiene la opción de seguir trabajando y viviendo en la colonia [fig. 2.45].

Con estos mismos criterios se establecieron en el Reino Unido la colonia de Preston Hall (1919) o Barrowmore Hall (1921), y otras tantas ciudades sanatoriales más tardías que se desarrollan en Europa. En Francia se crean también varias de ellas en los años 30. La

\footnotetext{
80 "Dans ce sanatorium, placé avant et bien après cette date sous la direction de Sir Robert Philip, l'expérience semblait indiquer en premier lieu que la latence complete des symptoms de tuberculose pulmonaire ne pouvait des symptoms de tuberculose pulmonaire ne pouvait très souvent pas être obtenue par la cure sanatoriale, meme considérablement prolongée et, en second lieu, qu'un travail exactement dose, loin de s'opposer à la guérison, pouvait utilement la seconder." Robert WOLFSOHN, Las Villages de Tuberculeux en Anglaterra (Papworth, Preston Hall, Barrowmore Hall). Thèse pour le doctorat en Médicine, Faculté de Médecine de Paris, Paris 1924, p. 14.

${ }^{81}$ Francis Barrymore SMITH, The Retreat of Tuberculosis 1850- 1950. Croom Helm, New York 1988, p. 86.
} 
Ciudad Sanatorial de Clairvivre con capacidad para 55.000 habitantes es un ejemplo. Construida en Salagnac (1930-1933) por el arquitecto Pierre Forestier, discípulo de August Perret, está destinada a las víctimas de la Primera Guerra Mundial enfermas de tuberculosis. Se ubica en las montañas de Salagnac en Dordoña, en una parcela de 43 hectáreas de bosque, y se proyecta para contener 124 pabellones de dos apartamentos cada uno ${ }^{82}$ [fig. 2.46]. Cada apartamento quiere ser una "casa-sanatorio" en la que el enfermo puede disfrutar de toda la asepsia del hospital en un ambiente familiar. El enfermo dispone en la casa de una habitación individual muy ventilada con baño completo, conectada con una sala de estar acristalada donde llevar a cabo la terapia de cura de reposo en invierno y con una terraza para la cura en verano, estando la terraza y la galería orientadas al Sur [fig. 2.47].

Clairvivre consta de dos edificios hospitalarios. Uno es un gran "hotel-sanatorio" de 200 camas con amplios salones de reunión, biblioteca, cine, etc., donde residen los enfermos de tuberculosis sin familia; el otro es el "hospital-dispensario" con capacidad para 40 enfermos. Dispone además de otras construcciones de uso general: escuelas, centro comercial, campos deportivos, áreas industriales, etc ${ }^{83}$. Toda la ciudad se implanta sin un orden geométrico claro; se desarrolla longitudinalmente jalonando una vía principal que transcurre en la dirección Este-Oeste y se va adaptando a los desniveles topográficos. La principal peculiaridad en su disposición responde a la búsqueda de la orientación sur y las vistas sobre el paisaje. Este hecho fomenta un crecimiento disperso con tendencia a crear una configuración lineal de la ciudad. En ella se aprecia un cierta zonificación; en el centro se instalan las áreas comerciales y las viviendas de baja densidad, y en la periferia el hospital, las industrias y los bloques residenciales que conviven con las áreas deportivas, los colegios y los grandes parques.

En teoría la ciudad-sanatorio plantea una magnífica solución a los problemas médicos y sociales del enfermo de tuberculosis, pero en la mayoría de los casos no se obtienen los resultados esperados y estos macro-complejos sanitarios son abandonados enseguida. Al ser lugares de residencia tan aislados en la montaña, pese a las posibilidades de trabajo y de reinserción social, los pacientes y sus familias no se establecen de forma permanente en estos complejos.

\footnotetext{
${ }^{82}$ Jean-Bernard Cremnitzer, Architecture et Santé : Les temps du sanatorium en France et en Europe. Picard, Paris 2005, p. 100.

${ }^{83}$ Jean-Bernard Cremnitzer, Architecture et Santé : Les temps du sanatorium en France et en Europe. Picard, Paris 2005, p. 102.
} 
Se comprueba a lo largo de este recorrido cómo tras siglos de terapias y de arquitectura, así como tras la ampliación de los métodos terapéuticos propuestos en los Planes de Lucha Antituberculosa desarrollados después de la Primera Guerra Mundial que incluyen la cura en los dispensarios y preventorios, el aislamiento forzoso o voluntario del enfermo de tuberculosis, bien hacinado en un asilo o bien en su higiénica vivienda dentro de una saludable ciudad, se sigue manteniendo en el tiempo hasta alcanzar la erradicación completa de la enfermedad a mediados del siglo XX. 


\section{CAPÍTULO 3}

\section{LA BÚSQUEDA DE LO ESPECÍFICO: EL SANATORIO ANTITUBERCULOSO}

PULMONAR

EL PROGRAMA DE NECESIDADES: SIMILITUDES Y DIFERENCIAS CON EL HOSPITAL

LA IMPLANTACIÓN: LUGAR Y FORMA

LA RESIDENCIA SANATORIAL: MODO DE VIDA Y ESPACIO VITAL

EL DISEÑO INTEGRAL DEL SANATORIO: EL MOBILIARIO Y EL DETALLE 


\section{LA BÚSQUEDA DE LO ESPECÍFICO: EL SANATORIO ANTITUBERCULOSO PULMONAR}

Del análisis histórico y tipológico de la arquitectura hospitalaria se deduce que las formas que adoptan los hospitales son las mismas que las de los claustros de los monasterios, las basílicas de los templos cristianos, los palacios del poder civil, los barracones de las milicias, etc., e incluso el hospital de pabellones aislado, que surge siguiendo principios higiénicos y para evitar contagios no difiere de otras construcciones de la época ajenas al programa hospitalario, como la de los pabellones del jardín de Marly (1695) de Charles Le Brun inspirados en las Metamorfosis de Ovidio.

Resulta innegable que la arquitectura hospitalaria se encuadra dentro de la de su época, y pese a la complejidad de su programa, al que dar respuesta supone en ocasiones un auténtico reto constructivo, nunca pierde el equilibrio vitruviano que debe poseer una obra arquitectónica entre: firmitas, utilitas y venustas. Alberti dice que el hospital debe ser "bello y confortable" adjetivos necesariamente compatibles en la arquitectura. Haciendo un inmenso salto cronológico, siglos más tarde Aizpurúa refiriéndose a la construcción del hospital de San Sebastián" critica a la "arquitectura que queriendo ser funcional, racional, y demás tópicos modernos no es lo único que puede ser la arquitectura: ARQUITECTURA"2.

Sin embargo, resulta necesario plantear la evolución de la arquitectura hospitalaria en paralelo a la evolución de la propia ciencia médica para entender las transformaciones formales experimentadas a lo largo de la historia en los edificios hospitalarios que, sin dejar de ser arquitectura, responden a los avances terapéuticos del momento, ya que ciencia y arquitectura siempre han convivido en el hospital.

Es a partir de la Primera Guerra Mundial cuando la fusión entre arquitectura y ciencia supera al programa hospitalario abarcando todos los campos arquitectónicos, y cuando el sanatorio antituberculoso, por sus peculiares características arquitectónicas, se transforma en un referente para muchos otros programas. Como Alvar Aalto describe en Noviembre de 1940:

\footnotetext{
${ }^{1}$ Carta-manifiesto sin fecha, probablemente de octubre de 1933, escrita por Aizpurúa a Torres Clavé para su publicación en la revista $A C$, con motivo del fallo del jurado del concurso de anteproyectos de un Hospital en San Sebastián al que se presentó el equipo formado por Sánchez Arcas, Lagrande, Labayen y el propio Aizpurúa, en el que quedaron clasificados en segundo lugar. Arxiu Històric Collegi d'Arquitectes de Catalunya.

${ }^{2}$ José Ángel SANZ ESQUIDE, La tradición de lo nuevo en el País Vasco. La arquitectura de los años 30. Tesis doctoral dirigida por Josep María Rovira i Gimeno. Universidad Politécnica de Cataluña, Barcelona 1988, pp. 340-341.
} 
"Durante las últimas décadas la arquitectura se ha comparado a menudo con la ciencia, y se han hecho esfuerzos para hacer sus métodos más científicos, incluso para hacerla una ciencia pura. Pero la arquitectura no es una ciencia. Todavía es el mismo gran proceso sintético de combinación de miles de funciones humanas definidas, y continúa siendo "arquitectura". Su propósito todavía es armonizar el mundo material y la vida humana. Hacer arquitectura más humana significa mejor arquitectura, y esto quiere decir un funcionalismo mucho más amplio que el meramente técnico. Esta meta sólo puede alcanzarse con métodos arquitectónicos, con la creación y combinación de diferentes elementos técnicos, de tal modo que faciliten la más armoniosa vida al ser humano"3.

Esta preocupación por el ser humano se manifiesta de manera singular en el sanatorio antituberculoso pulmonar en su programa, en la meticulosa selección de su lugar de implantación, en las necesidades específicas de los enfermos para los que se construye y en las soluciones y detalles arquitectónicos que responden a las terapias de cura sanatoriales practicadas en estos hospitales, que hacen del sanatorio antituberculoso pulmonar una edificación especial, diferente del resto de la arquitectura.

\section{EL PROGRAMA DE NECESIDADES: SIMILITUDES Y DIFERENCIAS CON EL HOSPITAL}

A finales del siglo XIX y principios del XX reconocidos tisiólogos escriben numerosos textos para indicar las reglas de organización espacial y los requerimientos de equipamiento técnico que precisan los sanatorios ${ }^{4}$. Pero es tras la redacción de la Ley Honnorat en 1920, cuando se legisla la necesidad de presentar, junto a la documentación técnico constructiva del proyecto, una memoria descriptiva de las actividades terapéuticas a desarrollar en el sanatorio previamente a su construcción y cuando se definen, de manera general, los programas de necesidades aplicables en la edificación de sanatorios antituberculosos ${ }^{5}$.

El término "programa de necesidades" es acuñado por los arquitectos como consecuencia del carácter social de las construcciones más frecuentes y emblemáticas de la posguerra

\footnotetext{
3 Alvar AALTO, "La Humanización de la Arquitectura" ("The Humanizing of Architecture"), The Techonology Review, Nov.1940, en Göran SCHILDT, Alvar Aalto de palabra y por escrito (Alvar Aalto. In his own words, 1997). El Croquis Editorial, Madrid 2000, p. 143.

${ }^{4}$ Como la obra del Dr. Thomas Spees Carrington Tuberculosis Hospital and Sanatorium Constraction (1911).

${ }^{5}$ El primer decreto de la Ley Honnorat, que lleva el nombre del Ministro de Educación pública y de Bellas Artes de París, data del 10 de agosto de 1920, pero va a ser modificado en numerosas ocasiones durante 12 años debido a los cambios terapéuticos ligados a la cura de la tuberculosis, que se traducen en cambios en los equipamientos de los mismos.
} 
como escuelas, sanatorios, viviendas de bajo coste, etc., que logran cambiar la tradicional forma de pensar y organizar los espacios en base a los "requerimientos de uso" por este nuevo concepto de "programa de necesidades", manifestando que el primer cometido del arquitecto es satisfacer las necesidades del cliente, siendo su cliente con carácter general la sociedad.

El procedimiento para establecer el programa de necesidades es coherente con el carácter científico de la época. Se basa en definir y organizar las funciones que debe cumplir el edificio para satisfacer las necesidades del enfermo. Debido a la diversidad de usos que convergen en el hospital, el programa de necesidades en este tipo de edificios se transforma en lo que actualmente se conoce como "plan funcional".

Este modelo de organización, basado en la función, permite validar con cierto rigor científico el edificio, de modo que la mejor arquitectura será la que más se ajuste al programa de necesidades, sin olvidar su función principal la "capacidad de conmover" al que la experimenta, según argumenta Le Corbusier en su artículo "Où en est l'architecture" (¿Dónde está la arquitectura?) publicado en 1927 en la revistas L'Architecture vivanté6.

El programa de necesidades de principios del siglo XX parte de las actividades básicas de un hospital y de cómo estas se relacionan entre sí, adjudicando una dimensión y relación de posición adecuada a los espacios asociados con cada una de ellas.

Aquí comienzan a desvelarse ciertas peculiaridades del sanatorio antituberculoso frente al hospital general ya que, mientras en el hospital es la clínica la actividad más importante, en el sanatorio antituberculoso lo es la función residencial, al margen de que un posterior avance de la cirugía torácica provoque una densificación de la actividad clínica dentro del sanatorio.

El peso de la parte residencial acerca al arquitecto a la labor de proyectar los sanatorios, ya que desde siempre este uso ha estado ligado a su profesión; las necesidades clínicas, sin embargo, le son ajenas y deben venir especificadas por los verdaderos conocedores del medio, los médicos. Por otro lado, al tratarse de un hospital de larga estancia, el programa residencial exige unas normas de aplicación para el control del modo de vida en el sanatorio, donde se suele exigir la separación por sexos de los enfermos. Esta condición implica una disposición formal simétrica de muchos ellos, donde los enfermos se reparten

6 Juan José LAHUERTA "Ex quo symetria efficitur" en L'Architecture vivante: el documento arquitectónico del movimiento moderno. Colegio Oficial de Arquitectos de Aragón, Zaragoza 2004, p. 20. 
en dos cuerpos idénticos, separados entre sí por un cuerpo central con los servicios comunes.

En el programa de necesidades del sanatorio se incluyen además indicaciones sobre las condiciones del entorno para la localización del mismo y la superficie de parcela mínima exigible para su implantación ${ }^{7}$. Dado que las terapias de cura se aplican tanto dentro como fuera del mismo, el sanatorio precisa de una amplia parcela para llevar a cabo la cura de reposo y de ejercicio, convirtiéndose su diseño en un proyecto tanto de edificación como de paisajismo.

Otra condición particular del sanatorio vinculada a la terapia radica en la presencia de las galerías de cura y de amplios ventanales. Queda así definida la imagen abierta de hormigón y cristal característica de los sanatorios en los años 30.

A excepción de estas particularidades, en los sanatorios y en los hospitales se mantienen los mismos criterios de higiene y asepsia, recomendándose el empleo de linóleo y de cerámica en los revestimientos interiores y las mismas reglas de organización y dimensionamiento de espacios basados en la economía y eficiencia.

Para dimensionar el programa se fijan los mínimos necesarios para el adecuado funcionamiento de cada espacio y se aplican fórmulas o estándares matemáticos en función del número de camas; ya que la cama, que representa al enfermo, pasa a considerarse la unidad de referencia del sanatorio y del hospital ${ }^{8}$. De este modo la superficie de los servicios médicos de un sanatorio antituberculoso es de 1,30 $\mathrm{m}^{2}$ por cama, la de la lencería de $0,25 \mathrm{~m}^{2}$ por cama, etc. ${ }^{9}$

\footnotetext{
${ }^{7}$ Los sanatorios deben situarse en el campo, distanciados de las carreteras frecuentadas y de las aglomeraciones humanas (excepto en las estaciones climatológicas de cura), emplazados en lugares soleados y protegidos por obstáculos naturales de los vientos dominantes (...), deben de contar con un parque o estar en la proximidad de un bosque (...), con al menos 15 hectáreas cada 100 camas. Les prescriptions d'hygiène et techniques à observer pour la construction d'un sanatorium. Citado en : Architecture et Santé. Le temps du sanatorium en France et en Europe, de J.B. CREMNITZER. Picard, París 2005, p. 86.

8 Programa del proyecto de sanatorio ganador del equipo de Ernesto Ripollés ganador del concurso de anteproyectos de sanatorios antituberculosos de 200, 300 y 400 camas: "El reparto de las camas en los dormitorios que llamamos en común será de seis, cuatro y dos camas, con los porcentajes de 50, 25 y 12 por 100, más los reservados para los aislados en la proporción del 6 por 100. Nosotros, además, hemos considerado imprescindible prever locales para graves (...). En las habitaciones de seis camas se proyectan, por lo tanto, dos filas de 3 camas, separadas entre sí 2,20 metros, a cuya dimensión corresponde un núcleo central de 1,30 metros para la circulación general y una zona de 0,45 metros a cada lado de la cama". Bartolomé BENÍTEZ FRANCO, Información sobre la lucha antituberculosa en España y memoria correspondiente al año 1944. PNA, Madrid 1945, p. 128.

9 Bartolomé BENÍTEZ FRANCO, Información sobre la lucha antituberculosa en España y memoria correspondiente al año 1944. PNA, Madrid 1945, p. 134.
} 
Respecto a las dimensiones generales del sanatorio antituberculoso se considera conveniente un hospital de alrededor de 200 camas $^{10}$, cantidad que generalmente es sobrepasada, donde las habitaciones que las albergan están distribuidos en las plantas superiores del sanatorio, ya que en la planta baja se suelen disponer los accesos y los servicios comunes.

En España el Patronato Nacional Antituberculoso establece en 1944 que la capacidad de cada unidad de enfermería por planta debe ser de aproximadamente de 60 camas, 30 de hombres y 30 de mujeres, reservando en los extremos del ala pabellones para albergar al $10 \%$ de enfermos infantiles y de maternidad. Determina además que las habitaciones de enfermos sean de seis, cuatro, dos y una camas, para facilitar su clasificación y aislamiento y que todas ellas dispongan de galerías de curas con orientación sur ${ }^{11}$.

El principal problema del programa funcional de los sanatorios antituberculosos, al igual que en el resto de edificaciones hospitalarias, es su permanente trasformación. Los constantes avances en los métodos terapéuticos dificultan la definición de un programa y de un modelo arquitectónico duradero, motivo por el cual el Dr. Douady y el arquitecto Sarge, en su artículo "La cellule du malade" publicado en la revista Téchniques Hospitalières en 1946 afirman: "Un sanatorio, como un barco o un avión, caduca rápidamente. Por consiguiente, el edificio será ventajosamente concebido bajo la forma de una envolvente completamente vacía dividida interiormente en pisos", apostando por la aplicación de una arquitectura racionalista de tipo monobloque en el sanatorio.

Sin embargo, a pesar de la existencia de un programa funcional predefinido y de la problemática inherente a la constante mejora terapéutica del hospital, las innovaciones espaciales y técnicas que plantean los arquitectos de este período de entreguerras que se ocupan de la construcción de sanatorios, de la que anteriormente han sido siempre responsables los médicos, superan el mero cumplimiento del mismo mediante vinculaciones espaciales que relacionan al enfermo con el paisaje y mejoran el confort interior de los espacios gracias al diseño y a la poética que emana de la propia arquitectura, como

\footnotetext{
10 La dimensión recomendada estaría entre 100 y 150 camas por el Dr. Léopold Berl en su Tesis doctoral Importance de L'aménagement architectural dans le rendement thérapeutique d'un sanatorium (1936), o entre 150 y 300 por el Dr. Julius Grober en su libro Das Deutsche Krankenhaus (1932), ampliable por elementos modulares, aunque en España el Patronato Nacional Antituberculoso recomienda la construcción de sanatorios de entre 200 ó 300 camas en Información sobre la Lucha Antituberculosa en España y Memoria correspondiente al año 1944.

"Bartolomé BENIITEZ FRANCO, Información sobre la Lucha Antituberculosa en España y Memoria correspondiente al año 1944. PNA, Madrid 1945, p. 126.
} 
consecuencia de prestar una especial atención a las necesidades particulares de los enfermos. Alvar Aalto es consciente de ello cuando sugiere que:

"Si tenéis que construir un sanatorio, por ejemplo, o un hospital, recurrís a los pacientes $-y$ en este caso los pacientes son vuestros clientes reales, no la persona de turno o el comité que os lo encarga-para estudiar la particular sensibilidad de la vida humana, demandando el conjunto una solución diferente" ${ }^{12}$.

\section{LA IMPLANTACIÓN: LUGAR Y FORMA}

Los criterios de implantación del sanatorio antituberculoso, estrechamente ligados a la terapia de cura, divergen de los del hospital general. Mientras la ubicación más recomendable para los hospitales de los años 30 se basa en la proximidad al paciente, y en función de esta pauta se recomienda su implantación dentro de las ciudades y núcleos de población, en cambio, el criterio general que rige la implantación del sanatorio radica en el aislamiento y en las condiciones ambientales, si bien éstas cada vez resultan menos estrictas. La doble función del sanatorio, que por un lado sirve para proteger a la sociedad sana del contagio y por otro aísla al enfermo de los focos de infección que suponen las ciudades y las aglomeraciones proporcionándole una cura ambiental a través de las propiedades del entorno natural donde se implanta el sanatorio, son determinantes de la ubicación del mismo en lugares aislados fuera de los núcleos de población.

Las terapias climáticas experimentales que determinan su ubicación en el litoral o en las altas montañas a medida que avanza la medicina se van desechando y, en el Congreso Internacional de la Tuberculosis celebrado en París en 1900, se establecen la pureza y "un clima moderadamente frío y seco, relativamente estable ${ }^{13}$ como los factores ambientales determinantes para la implantación del sanatorio.

La preocupación por el bienestar no sólo físico sino también psicológico del paciente lleva a proponer la construcción de auténticas ciudades sanatoriales donde el enfermo convive con su familia, que precisan de una vasta superficie de implantación que implica generalmente que su sitúen en lugares cada vez más aislados. Por otro lado, se plantea también la

\footnotetext{
12 Alvar AALTO, "Villa Mairea" ("The home of a rich art collector"), discurso pronunciado en la Universidad de Yale, 9 de Mayo de 1939,( Arkkitethi n 9, 1939), en Göran SCHILDT, Alvar Aalto de palabra y por escrito (Alvar Aalto. In his own words, 1997). El Croquis Editorial, Madrid 2000, p. 311.

${ }^{13}$ Tal y como sostenía el médico americano Daniel Drake a mediados del siglo XIX, quien funda en 1840 un sanatorio hecho con cabañas en la Caverna del Mamut en Kentucky.
} 
posibilidad de establecer una red de dispensarios dentro de las ciudades, que permita al enfermo permanecer en su casa mientras la enfermedad no sea extremadamente grave ${ }^{14}$.

Ante tan contrarias soluciones, la distancia del sanatorio a los núcleos de población pasa a considerarse un factor determinante para la implantación del mismo. Como recoge la Memoria del Patronato Nacional Antituberculoso de 1944, la proximidad de los sanatorios a las ciudades facilita la visita de sus familiares y la llegada de abastecimientos al mismo, lo que reduce su dimensión ya que éste deja de ser autosuficiente y no precisa de granjas, molinos, silos, etc.; incluso el personal médico no se ve forzado a residir dentro del recinto. Estas razones, junto con otras de carácter más técnico ${ }^{15}$, hacen que el distanciamiento del sanatorio con los núcleos de comunicación se reduzca aunque siga estando aislado y ubicado en un medio natural ${ }^{16}$.

La manera de vincularse el sanatorio con el lugar de implantación varía en función del tipo de edificación y de las características orográficas del mismo. En todos ellos se mantiene la orientación sur en las habitaciones y en las salas comunes de los pacientes, con el fin de poder combatir las bajas temperaturas a las que están expuestos, dada la ventilación constante de las estancias y los largos períodos a la intemperie que pasan los enfermos durante la cura de reposo y de aire puro. Este hecho favorece la aparición de edificios lineales con un gran frente de fachada orientado al sur con planta en forma de $T$, o al sureste y al suroeste para captar mejor los rayos solares más bajos del invierno con planta en forma de $Y$ de escasa altura.

La implantación en terrenos escarpados de las zonas de montaña obliga a reducir la extensión del mismo, generando un desarrollo del sanatorio más compacto y en altura [fig. 3.01] que, junto a la aparición del hospital vertical ubicado en la gran ciudad, determina la selección del modelo de sanatorio monobloque con planta en forma de T o planta de avión de gran longitud y altura, cuya morfología se impone en al paisaje [fig.3. 02]. Incluso llegan a desarrollarse propuestas de sanatorios lineales y asimétricos compuestos por varios brazos ortogonales yuxtapuestos a un elemento lineal, como el proyecto del Sanatorio de

\footnotetext{
${ }^{14}$ Este hecho contribuye a un cambio en los hábitos higiénicos de la sociedad y en las necesidades residenciales de la misma, porque la familia del tuberculoso se convierte en su equipo de enfermería y su casa en su sanatorio.

${ }^{15}$ Razones como la facilidad de captación de personal para realizar las obras de construcción, para el suministro de los materiales, el abastecimiento de las redes de suministro, etc.

16 Tal y como se recoge en las bases del concurso abierto de anteproyectos de sanatorios antituberculosos convocado por el Ministerio de la Gobernación en la Orden del 11 de agosto de 1942, publicada en el Boletín Oficial del estado n² 233, pp. 6300-6301.
} 

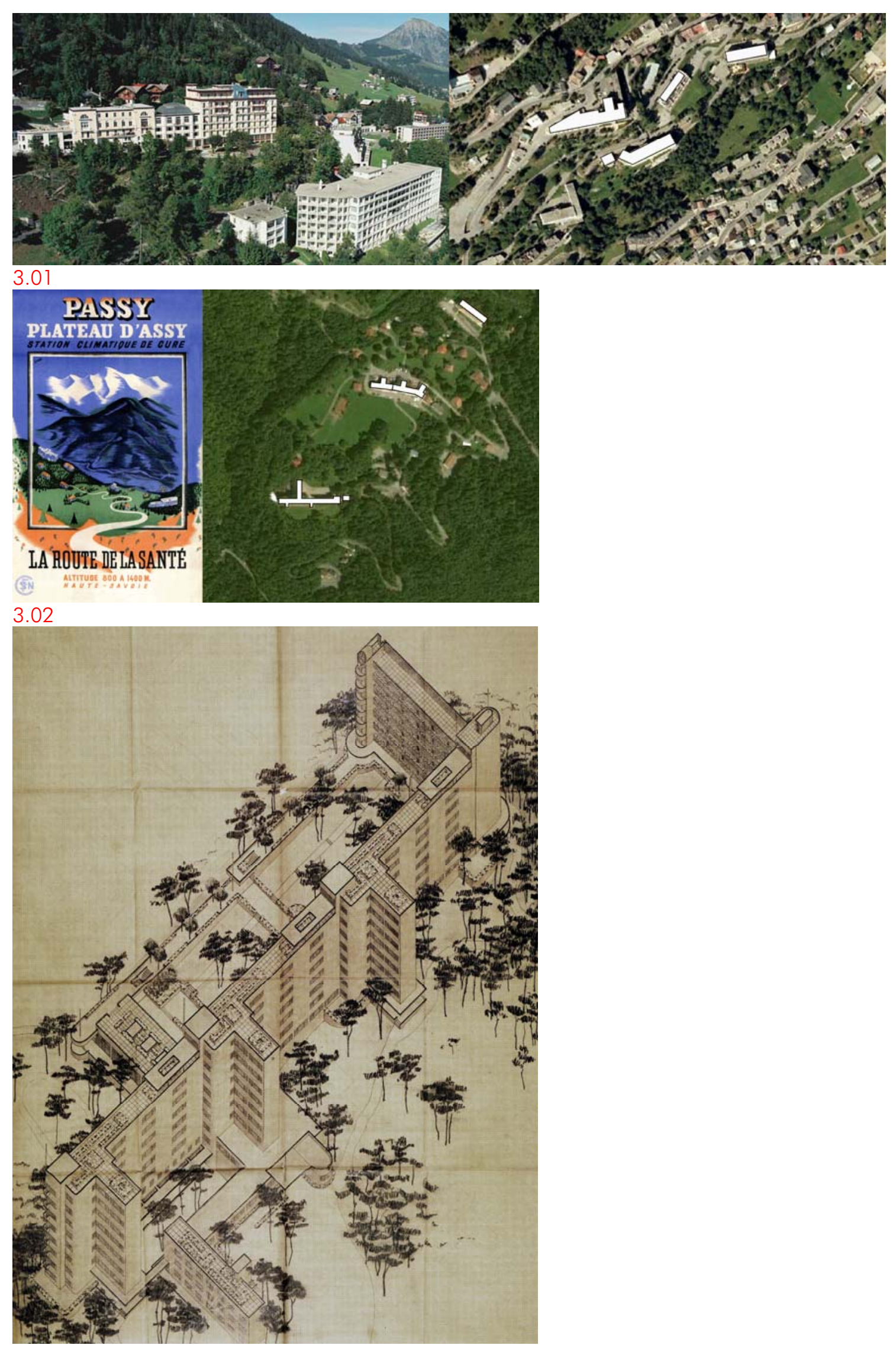

3.03

3.01 Sanatorios de Leysin. Imágenes panorámicas (representaciones de la autora).

3.02 Sanatorios de la Ruta de la Salud del Plateau D'Assy. Cartel e imagen panorámica en planta (representaciones de la autora).

3.03 A. Lurçat. Proyecto de Sanatorio de Durtol, 1929. Perspectiva. 


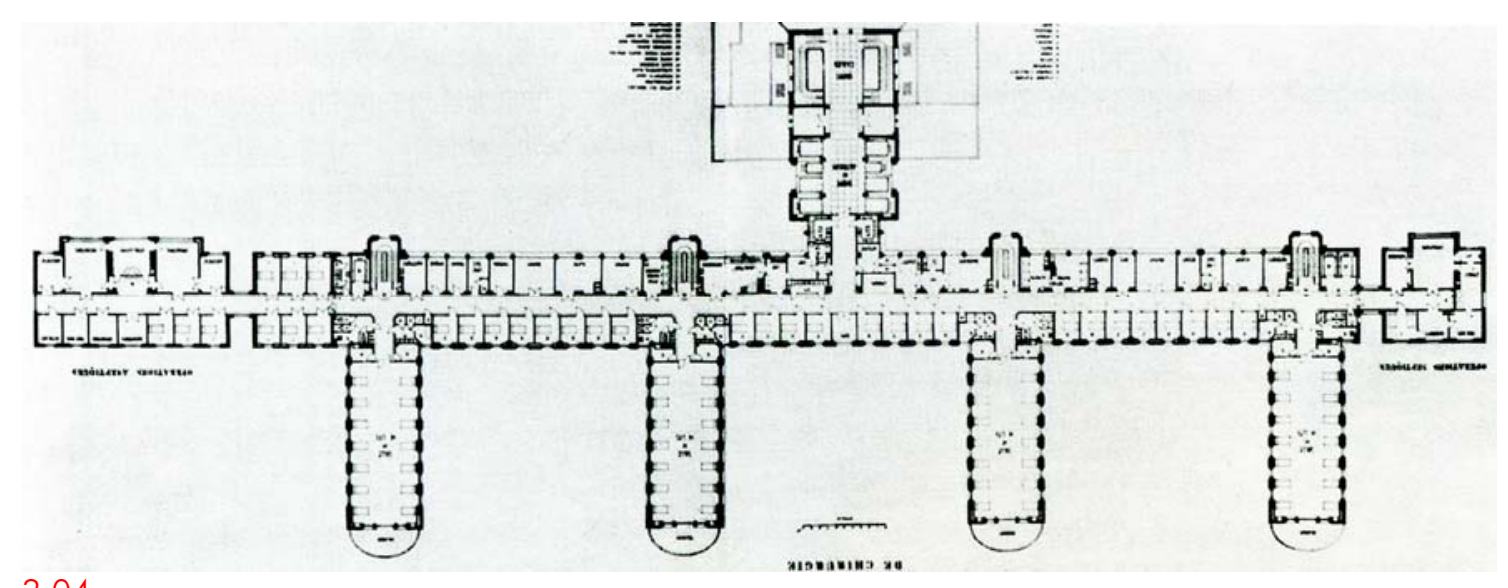

3.04

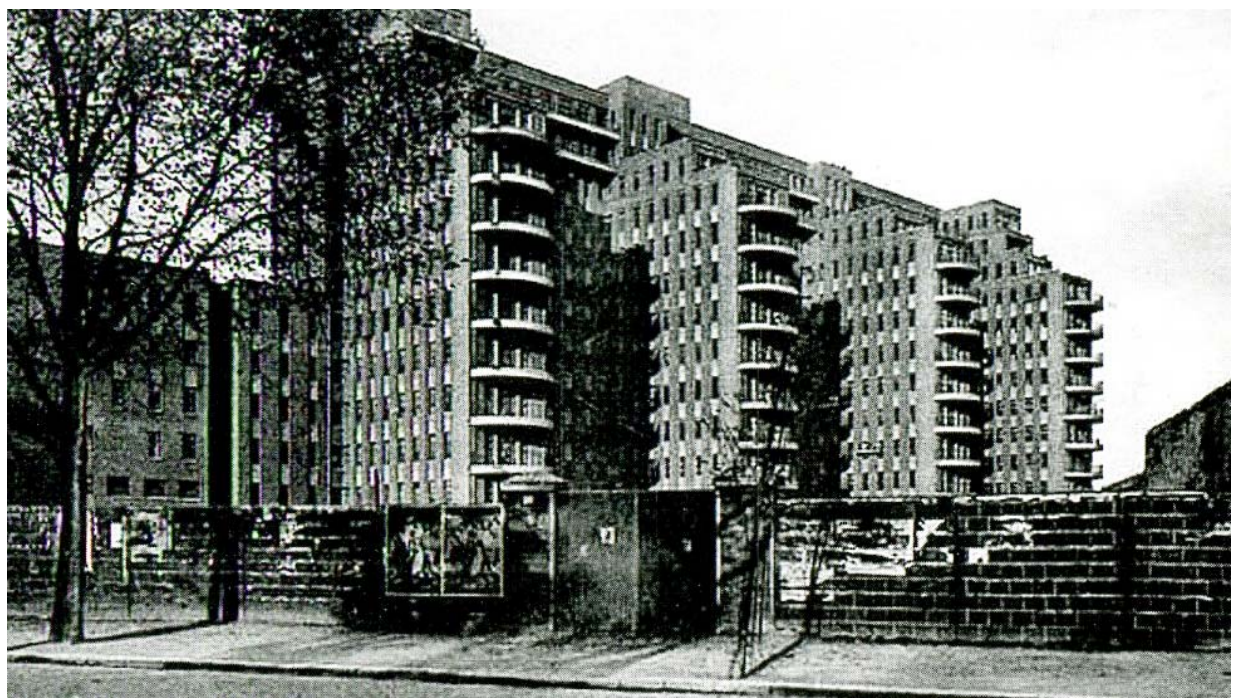

3.05
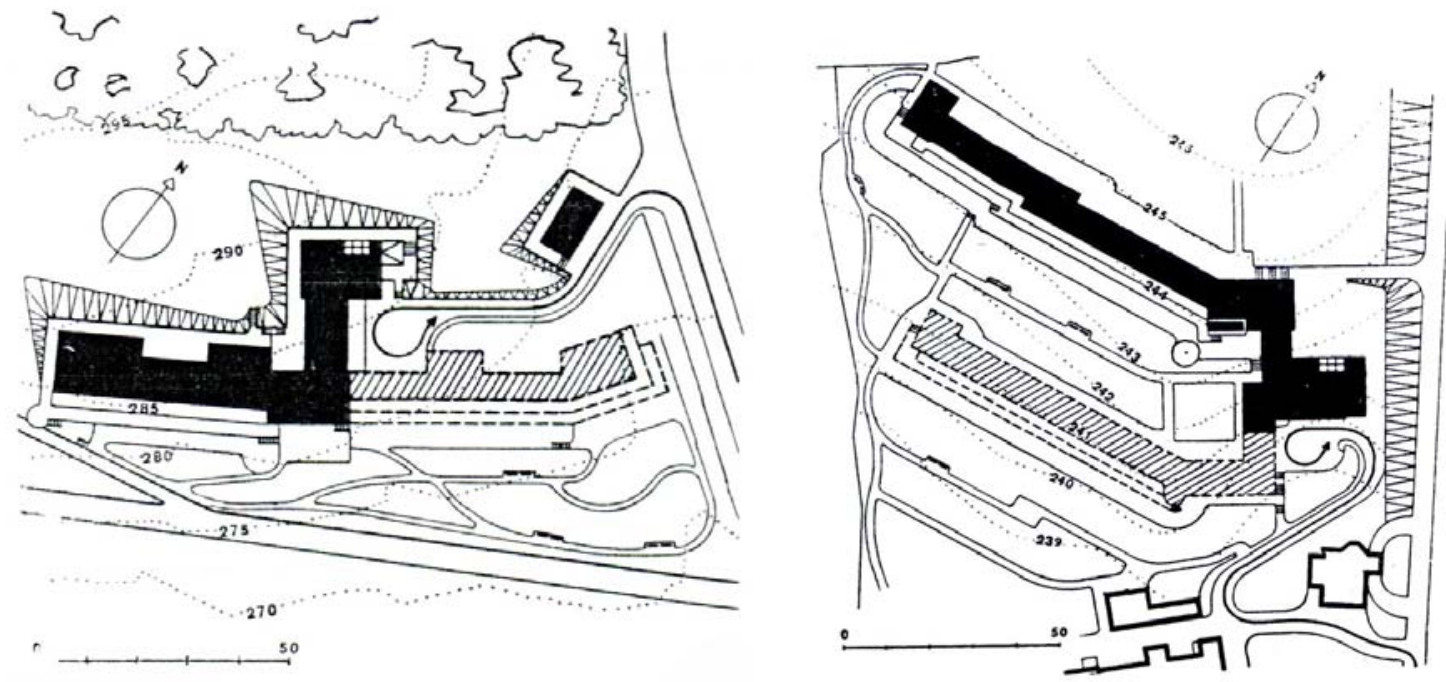

3.06 y 3.07

3.04 y 3.05 Plousen, Cassan y Walter. Hospital de Beaujon de París, 1933. Planta tipo y perspectiva.

3.06 R. Döcker. Sanatorio de Waiblingen, 1926-1928. Planta de situación.

3.07 R. Döcker. Sanatorio de Maulbroon, 1927-1929. Planta de situación. 

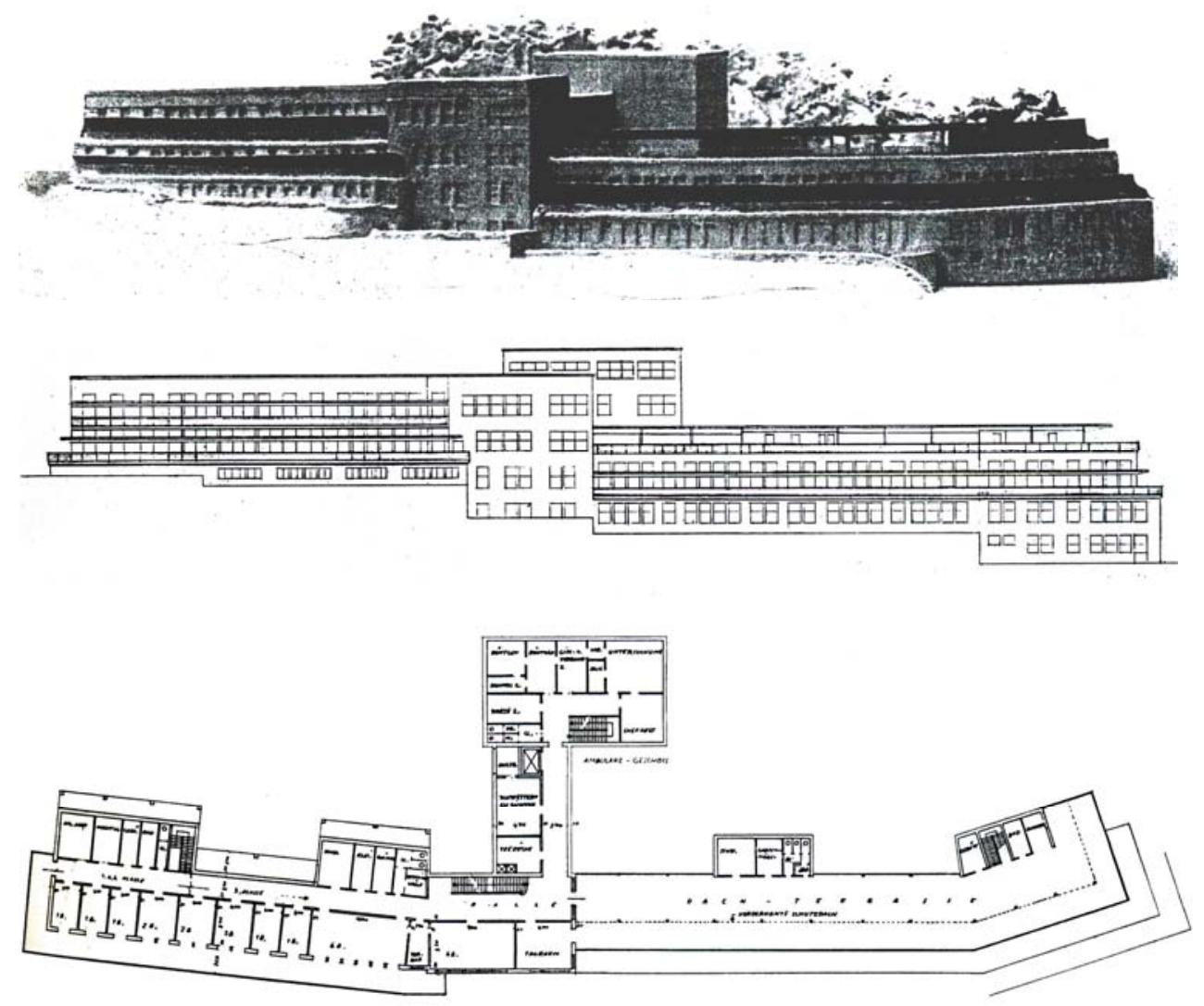

3.08
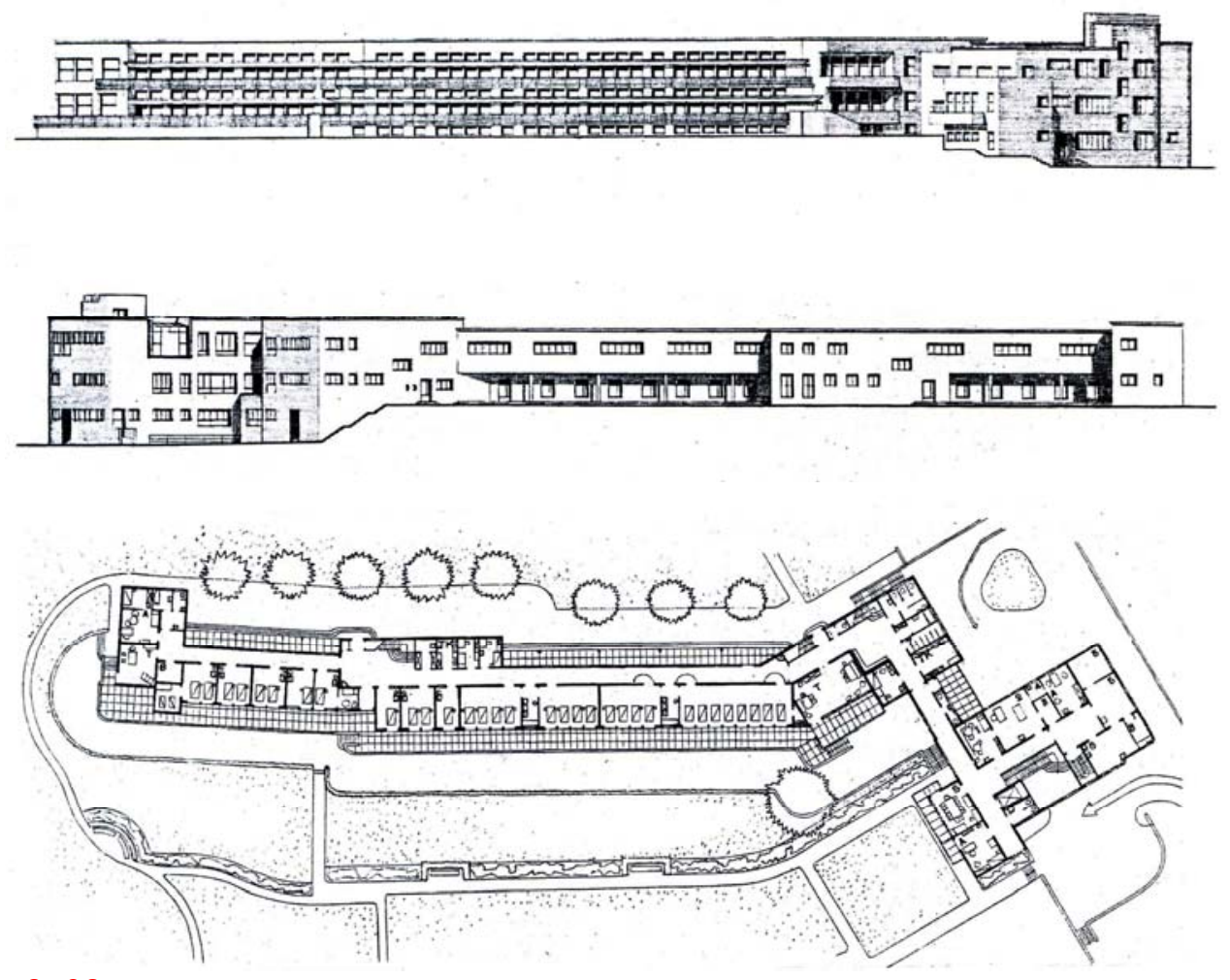

3. 09

3.08 R. Döcker. Sanatorio de Waiblingen, 1926-1928. Maqueta, alzado sur y planta tipo.

3.09 R. Döcker. Sanatorio de Maulbroon, 1927-1929. Alzados y planta tipo. 
Durtol (1929) de André Lurçat, donde las habitaciones individuales de enfermos se reparten en la "barra" principal y el resto de dependencias en los cuerpos transversales [fig. 3.03], sanatorio que por su forma y extensión resulta más adecuado en un entorno urbano que natural. De hecho su morfología se aproxima a la de los hospitales generales urbanos con planta en forma de peine desarrollados en vertical, como el más tardío Hospital de Beaujon de París (1933), construido por los arquitectos Plousen, Cassan y Walter [fig. 3.04 y fig.3.05]. Es un hospital simétrico que está constituido por una espina principal con las habitaciones individuales, que tiene una mayor anchura que la del Sanatorio de Durtol al contener además los servicios de enfermería, a la que se adosan perpendicularmente las dotaciones generales y las salas de enfermos comunes.

Por el contrario, existen también otros sanatorios compactos que reproducen en su arquitectura la topografía del terreno, como sucede con los sanatorios construidos en Alemania por Richard Döcker, el Sanatorio de Waiblingen (1926-1928) [fig. 3.06] y el Sanatorio de Maulbroon (1927-1929) [fig. 3.07].

En el Sanatorio de Waiblingen con planta en forma de T, no del todo simétrica, su perfil se escalona en dos alturas de tal manera que la cubierta de una mitad del bloque de habitaciones se convierte en una terraza solárium que coincide con la penúltima planta de la otra mitad [fig. 3.08]. Un recurso similar se emplea en el Sanatorio de Maulbronn donde el bloque de habitaciones abierto al sur se fragmenta en dos partes que, en vez de estar alineadas formando una planta en $T$, son paralelas entre sí. La pendiente pronunciada sobre la que se implanta permite que, a pesar de la disposición paralela de los dos bloques de habitaciones, no se dificulte la captación de luz y vistas entre sí, dado que la cubierta del bloque inferior coincide con la planta baja del bloque superior [fig. 3.09]. Ambos sanatorios presentan leves giros y quiebros en sus plantas y un perfil fragmentado que favorece su integración en el paisaje.

Por su parte, los sanatorios antituberculosos de pabellones, con un crecimiento más extensivo y de menor altura, se relacionan mejor con el entorno natural.

Los que se construyen en el período de entreguerras son fruto de la influencia de los modelos sanatoriales norteamericanos, basados en terapias naturistas, especialmente de aquellos que fueron expuestos en el VI Congreso Internacional de la Tuberculosis celebrado en Whasington en 1908, donde se presentan entre otros el Sanatorio antituberculoso pulmonar de Saranac Lake construido por el Dr. Trudeau en 1884. 

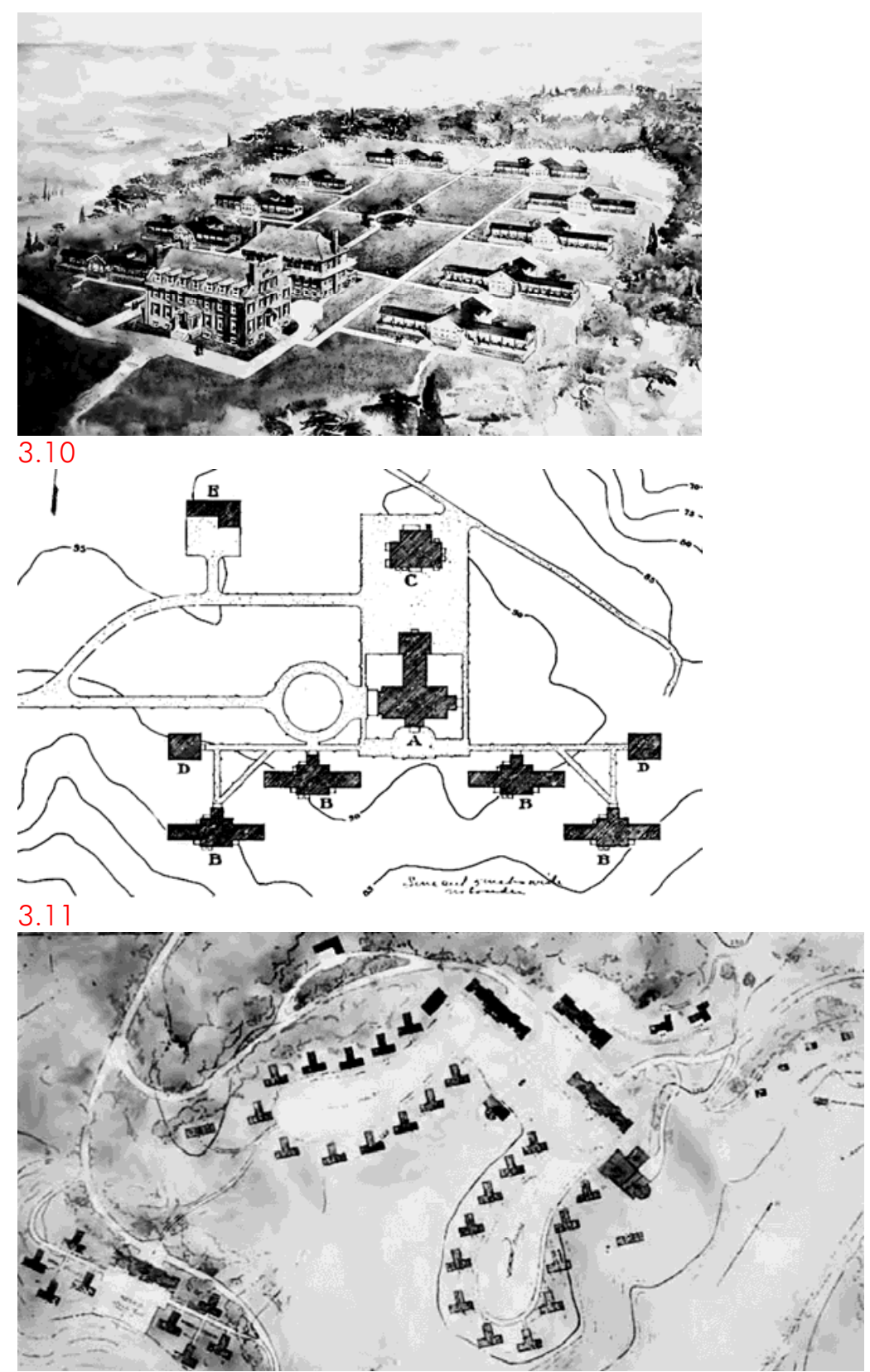

3.12

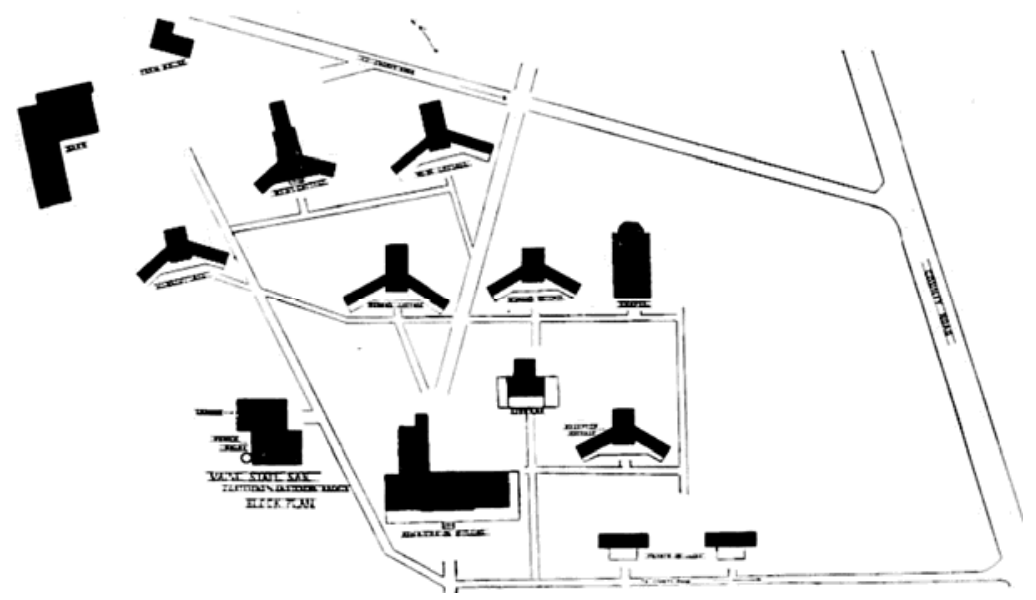

3.10 Wyatt y Nolting. Sanatorio de Maryland, Sabillasville. Perspectiva.

3.1 1 Scopes \& Feustmann y W.W. Judell. Preventorio infantil, Farmingdale. Planta general.

3.12 Scopes \& Feustmann y W. W. Judell. Sanatorio Estatal de Georgia, Alto. Planta general.

3.13 T.C. Stevens y J.H. Stevens.Sanatorio Estatal de Maine, Hebron. Planta general. 
El problema de la implantación de los sanatorios de pabellones radica en las vistas y la orientación, como demuestran las diversas propuestas de sanatorios estadounidenses de principios de siglo. Una organización compacta y simétrica de los mismos provoca que se acaben enfrentando las fachadas de los pabellones residenciales entre sí como sucede en el Sanatorio de Maryland construido por los arquitectos Wyatt y Nolting en Sabillasville [fig. 3.10], siendo más conveniente la disposición lineal al tresbolillo o alterna de los mismos. Esta solución se adopta en el Preventorio de Farmingdale [fig. 3.11], donde existe un desplazamiento lineal y en profundidad de los pabellones, describiendo una $V$, que consigue liberar más espacio alrededor de cada pabellón. El problema de este sistema de implantación radica en la prolongación excesiva de los recorridos entre sus distintas partes. Para evitarlo se crean agrupaciones más heterogéneas que siguen directrices curvas como la propuesta en el Sanatorio Estatal de Georgia en Alto [fig. 3.12], proyectado por el mismo equipo de arquitectos del Preventorio de Farmingale constituido por la firma Scopes \& Feustmann y Walter W. Judell, donde los pabellones residenciales con forma de $T$ se ordenan describiendo dos herraduras.

Sin embargo, la solución más sensata para lograr una cierta concentración en los recintos que configuran, sin renunciar a una buena orientación y a las vistas sobre el paisaje, pasa por variar la geometría del pabellón residencial articulándolo en forma de $Y$, como sucede en el Royal Victoria Hospital de Edimburgo y como se plantea en el Sanatorio Estatal de Maine en Hebron [fig. 3.13]. En ellos, los giros relativos de los brazos de habitaciones que definen cada pabellón facilitan su agrupación sin obstaculizar las vistas, logrando incorporar el entorno natural en el interior del edificio pues, como relata Thomas Mann: " $A$ través de los arcos de la galería, el paisaje - árido y desnudo pero soleado - parecía un cuadro dentro de un marco"17.

\section{LA RESIDENCIA SANATORIAL: MODO DE VIDA Y ESPACIO VITAL}

El sanatorio antituberculoso es fundamentalmente un hospital de larga estancia, caracterizado por un régimen disciplinario establecido para la aplicación de las terapias de cura.

En el sanatorio antituberculoso privado, más próximo a un establecimientos hotelero que a un hospital descrito por Rafael Alberti en sus poemas de Marinero en tierra como: "hotel de

\footnotetext{
17 Thomas MANN, La Montaña Mágica (Berlín, 1924).Edhasa, Barcelona 2005, p. 99.
} 
azules perdidos" 18 , se mantiene un régimen sanatorial muy poco estricto. Son centros mixtos, en los que se permite el consumo de alcohol, se organizan conciertos, excursiones en grupo, etc., y, a pesar de tener un completo plan de actividades que permite controlar al paciente en todo momento del día, impera siempre un ambiente amable y relajado entre los enfermos: "La mayoría estaban de buen humor, sin una razón concreta, probablemente sólo porque no tenían ningún problema inmediato y se veían reunidos en gran número" ${ }^{19}$.

Bien diferentes son los sanatorios antituberculosos públicos, considerados "instituciones totales" al igual que las prisiones, cuarteles, manicomios o conventos ${ }^{20}$. Lugares en donde los enfermos están constantemente vigilados y en los que el incumplimiento del régimen es duramente sancionado con la expulsión del centro. En ellos está totalmente prohibido el consumo de alcohol y de tabaco y, por supuesto, la relación entre hombres y mujeres. En el caso de ser sanatorios mixtos se establece una separación entre ambos sexos por niveles, o por alas en los sanatorios en T, llegando incluso a separar los tiempos de paseo para evitar que coincidan ${ }^{21}$.

A pesar de sus diferencias, tanto en los sanatorios antituberculosos públicos como privados la vida de los enfermos está marcada por una constante rutina. La carencia de medicamentos eficaces obliga a que el método de curación radique en la forma de vida que el enfermo desarrolla en él, lo que se traduce en un control absoluto de las acciones del mismo mediante el establecimiento de un horario de actividades que abarca toda la

\footnotetext{
${ }^{18}$ Rafael ALBERTI, "Balcón del Guadarrama" en Marinero en tierra (1945). Editorial Losada, Buenos Aires 1990, p. 39.

${ }^{19}$ Thomas MANN, La Montaña Mágica (Berlín, 1924).Edhasa, Barcelona 2005, p. 68.

20 Instrucciones generales para los enfermos de los sanatorios antituberculosos: $1^{\circ}$ No se les permitirá fumar, ni en la habitación ni fuera de ella. $2^{\circ}$ No se escupirá más que en las escupideras; ni en el suelo del edificio, ni en el monte ni en el pañuelo. $3^{\circ}$ No se permitirán otros juegos, labores, ejercicios o entretenimientos que los que señale el Director para cada enfermo. $4^{\circ}$ Tomarán un baño general de limpieza al ingresar y los repetirán con la frecuencia que se les ordene. $5^{\circ}$ No se tolerará que reciban ni tomen medicamentos y alimentos, que no sean los prescritos en el Sanatorio. $6^{\circ} \mathrm{A}$ los enfermos que sepan y deseen leer se les facilitarán publicaciones y se les señalará la duración de la lectura y la hora y sitio en que deben efectuarla. $7^{\circ}$ Todas las publicaciones que se reciban para los enfermos y que se consideren inapropiadas para la vida sanatorial serán retiradas. En el dormitorio: $8^{\circ}$ Se tendrá constantemente abierto incluso de noche; más o menos, según la temperatura exterior. $9^{\circ}$ Antes de acostarse se lavarán la boca detenidamente. $10^{\circ} \mathrm{Al}$ levantarse harán la limpieza cuidadosa de manos, uñas, cabeza y cuello.En las galería de curas: $11^{\circ}$ Permanecerán en ella el tiempo exacto que se les índice y en la posición que se les prescriba. $12^{\circ}$ No podrán, sin prescripción expresa, pasear por ella ni reunirse unos con otros. $13^{\circ}$ No deberán hacer ningún esfuerzo respiratorio (hablar muy alto, cantar, silbar, levantar cuerpos pesados, etc.) En total se detallan hasta 22 normas, ver: Jorge MOLERO MESA "Los sanatorios para tuberculosos" en El médico. Historia de los hospitales. Revista publicada por el Insalud, Madrid, p. 330.

${ }^{21}$ Ver las 22 instrucciones generales para los enfermos en los sanatorios antituberculosos en: Jorge MOLERO MESA "Los sanatorios para tuberculosos" en El médico. Historia de los hospitales. Revista publicada por el Insalud, Madrid, p. 327.
} 
jornada y que permite conocer en cada momento el lugar y la labor que está desarrollando el paciente ${ }^{22}$.

Se crean así pequeñas sociedades aisladas, constituidas por hombres y mujeres enfermos a los que se les trata de inculcar nuevos estilos de vida saludables y estructurados, totalmente ajenos a los del mundo de los sanos, convirtiendo al sanatorio en un "condensador social" ${ }^{23}$ donde la arquitectura es un instrumento médico más que contribuye a transformar al individuo.

El paso de millones de enfermos por los sanatorios supone un adiestramiento en la importancia de la salud, la higiene y la vida al aire libre que contribuye a un cambio social del que surge una nueva cultura del territorio, que muestra un claro interés por la conquista de lugares vírgenes en el litoral y en la montaña, y una mayor demanda sobre las condiciones de higiene, luz y ventilación que deben cumplir las viviendas.

Pero esta no es la única consecuencia del paso del enfermo por el sanatorio; la reiteración constante de las mismas actividades junto a su aislamiento crea en él una permanente rutina que le provoca la sensación de que en el sanatorio el tiempo, como Thomas Mann describe, "no pasa de ningún modo, aquí no hay tiempo, no hay vida" 24 . Ante tal situación debe reaccionar el arquitecto, pues como el Dr. Blanco Soler indica años más tarde: "Muchas veces el enfermo necesita más poesía que medicina y el arquitecto tendrá que tenerlo en cuenta en su trabajo" 25 .

La importancia que cobra el bienestar psíquico del enfermo en el sanatorio antituberculoso conlleva diversas transformaciones en la concepción arquitectónica del mismo. Al mismo tiempo que se mantienen las edificaciones colectivas y compactas tipo bloque, se trata de potenciar cada vez más el cuidado individual del paciente otorgándole, dentro de la colectividad preponderante, una cierta autonomía. En consecuencia, las habitaciones de enfermos con 8, 6 ó 4 camas tienden a individualizarse, de modo que el sanatorio se convierte en un gran complejo formado por la agrupación de unidades o células de

\footnotetext{
${ }^{22}$ Francis Barrymore SMITH, The Retreat of Tuberculosis 1850-1950. Croom Helm, New York 1988, pp. 101-102.

${ }^{23}$ Paolo SICA, Historia del urbanismo: El siglo XX. Instituto de Estudios de Administración Local, Madrid 1981, p. 281.

${ }^{24}$ Thomas MANN, La Montaña Mágica (Berlín, 1924).Edhasa, Barcelona 2005, p. 25.

${ }^{25}$ Carlos BLANCO SOLER "Comentarios de un médico", en Arquitectura año III, n 19, Julio 1960, p. 5.
} 


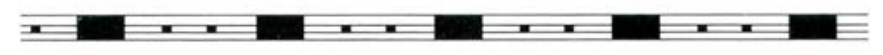

COULOIR

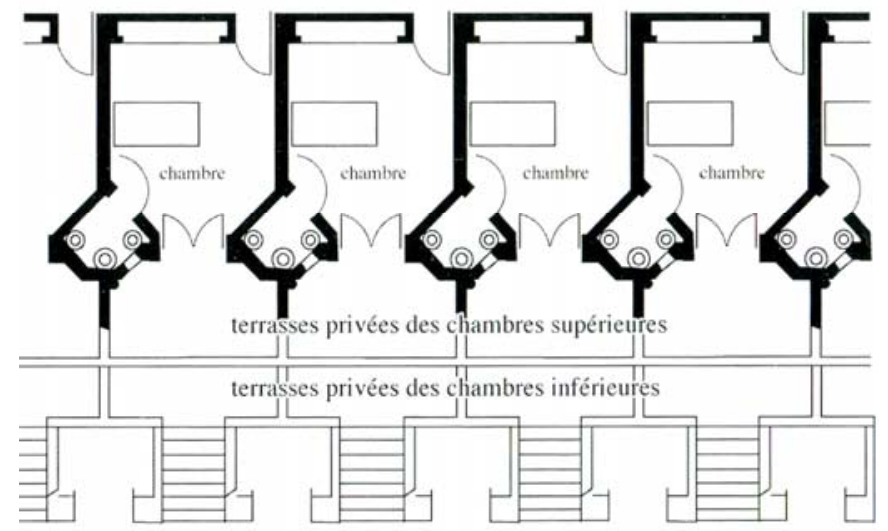

3.14

GRANDE TERRASSE
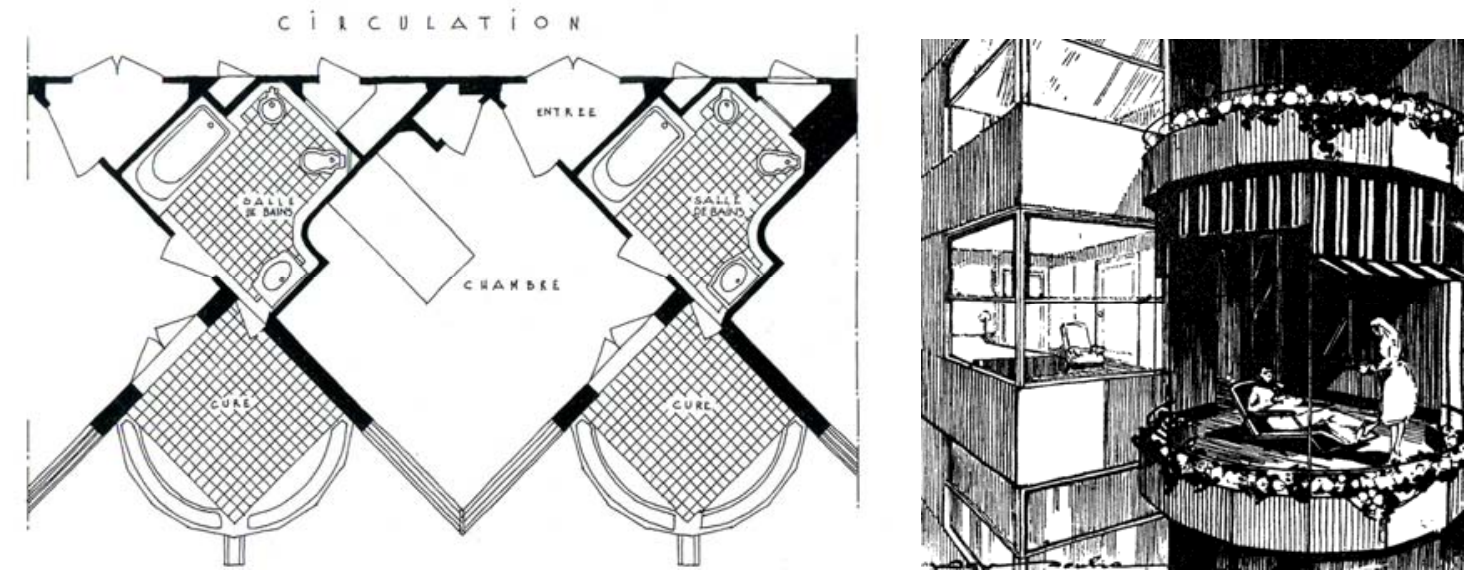

3.15 y 3.16

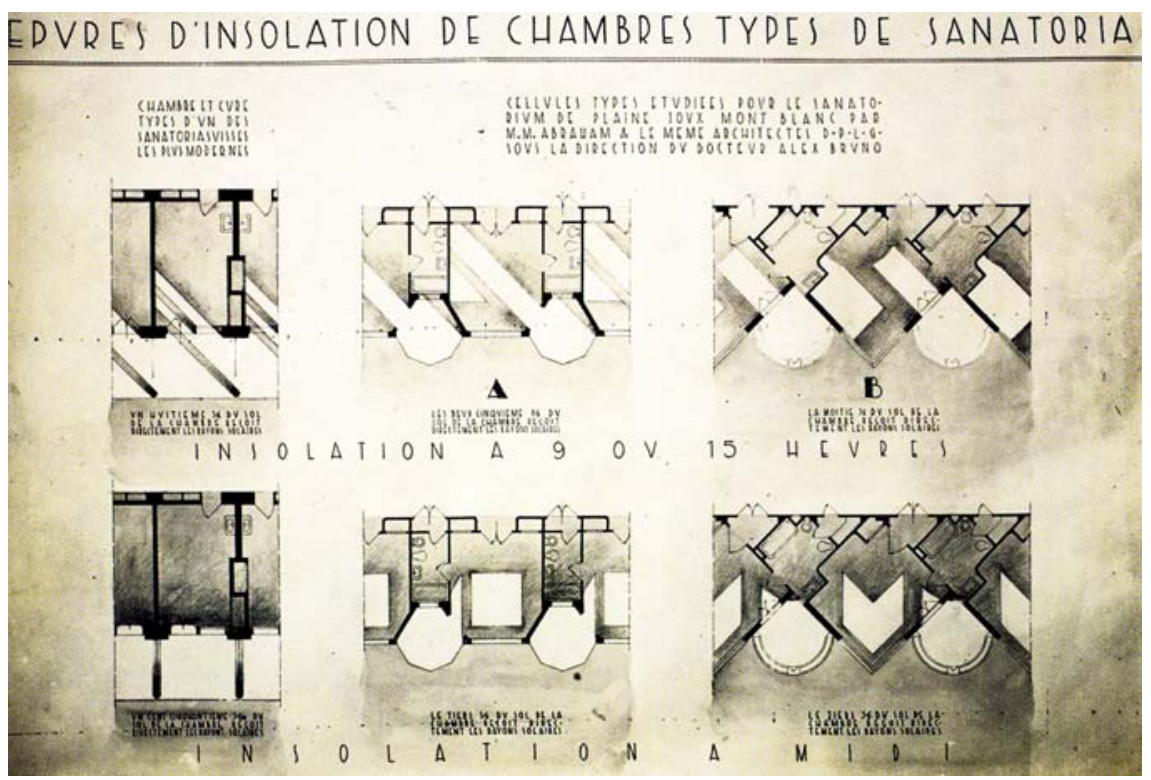

3.17

3.14 T. Garnier. Proyecto de Establecimiento Sanitario de Helioterapia, Lyon, 1904. Planta.

3.15 y 3.16 P. Abraham y H.-J. Le Même. Sanatorio Plaine-Joux, Plateau d'Assy, 1927. Planta y perspectiva.

3.17 P. Abraham. Estudio de soleamiento en distintos tipos de habitaciones de sanatorios, 1929. 
habitación como Pol Abraham afirma: "La arquitectura del sanatorio está dominada por la 'célula-tipo'"'26.

Esta "célula-tipo" está formada según P. Abraham por la habitación y el baño, constitución que no siempre será así. En origen los servicios higiénicos en los sanatorios se ubican en el basamento, alejados de las plantas de habitaciones. Paulatinamente éstos pasan a incorporarse en las mismas plantas y provocan un ensanchamiento puntual de la profundidad de la barra residencial, ya que los servicios higiénicos comunes se ubican en el frente norte del bloque de habitaciones junto al corredor que le atraviesa lateralmente, hasta que éstos se individualizan y se trasladan al interior de la habitación cuando éstas también lo han hecho.

Tony Garnier en el proyecto para el Establecimiento Sanitario de Helioterapia de la Ciudad Industrial de Lyon (1904-1907) las habitaciones son individuales y poseen un pequeño aseo contenido en un cuadrado girado $45^{\circ}$, integrado en ellas. Su forma y su posición permiten que el aseo esté ventilado al exterior sin restar excesiva iluminación ni espacio en el interior [fig. 3.14].

La habitación del enfermo se convierte en un elemento independiente y privado que contiene todo lo necesario para procurar el bienestar y cura al enfermo, a la par que se segrega la galería de cura también. Desaparece así de la fachada sur del sanatorio este elemento corrido y en vuelo tan representativo del mismo y se cambia por una seriación de balcones individuales pertenecientes a cada habitación que le dan una imagen más doméstica.

Pol Abraham y Henry-Jacques Le Même experimentan con la disposición de balcones individuales en su proyecto para el Sanatorio Plaine-Joux en el Plateau d'Assy (1927) que no llega a ser construido. En la habitación, como en el proyecto de Garnier, el cuarto higiénico se incluye en un cuadrado girado $45^{\circ}$ y ventilado al exterior, aunque ahora se trata de un baño completo y no de un aseo [fig. 3.15]. La estancia principal también es cuadrada y está girada $45^{\circ}$; posee una ventana en esquina, situada en el centro de la habitación que ilumina toda la estancia, y un balcón circular independiente contenido entre los picos de la habitaciones para no alterar las vistas ni impedir la penetración de aire y de sol en el interior de las mismas [fig. 3.16].

\footnotetext{
${ }^{26}$ Pol ABRAHAM "L'architecture et la lutte contre la tuberculose", entrevista de Jean-Louis Simian con Pol Abraham, La Petite Gironde, 8 oct. 1932 en Pol Abraham Architect. Collection Centre Pompidou, Musée National d'Art Moderne, Paris 2005, p. 152.
} 


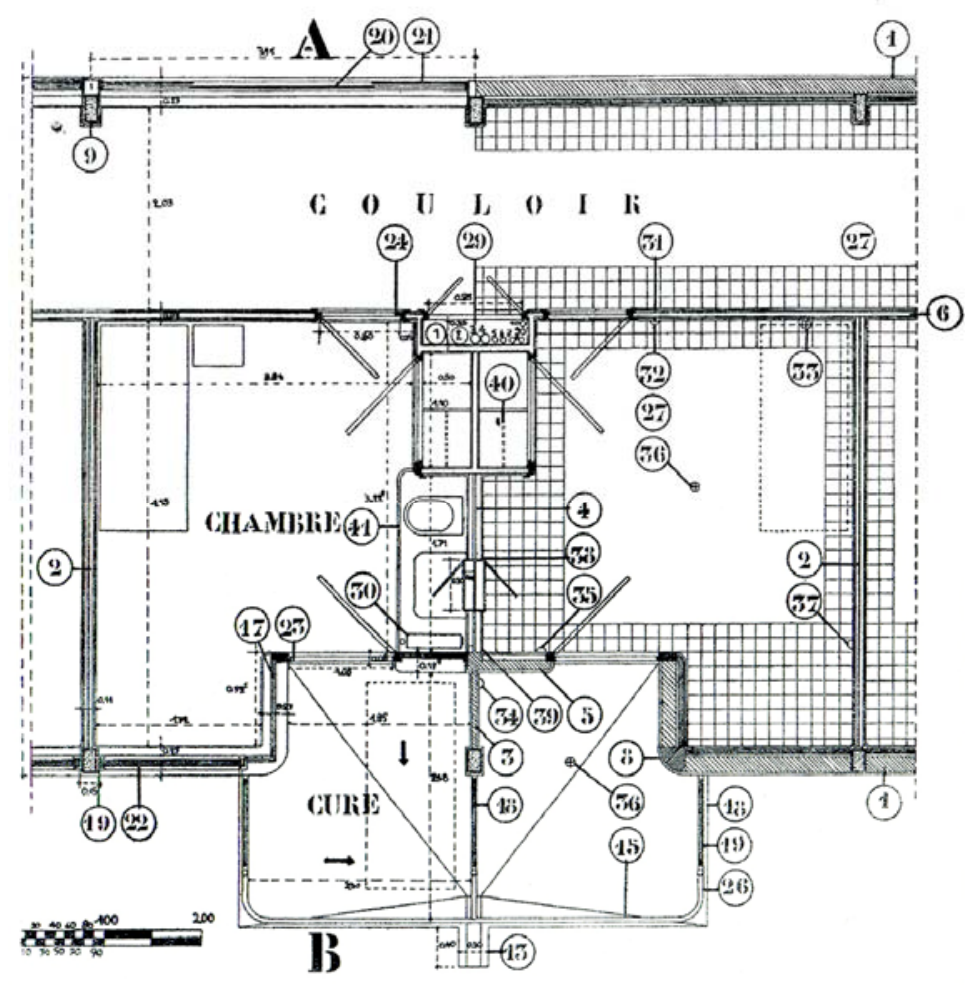

3.18

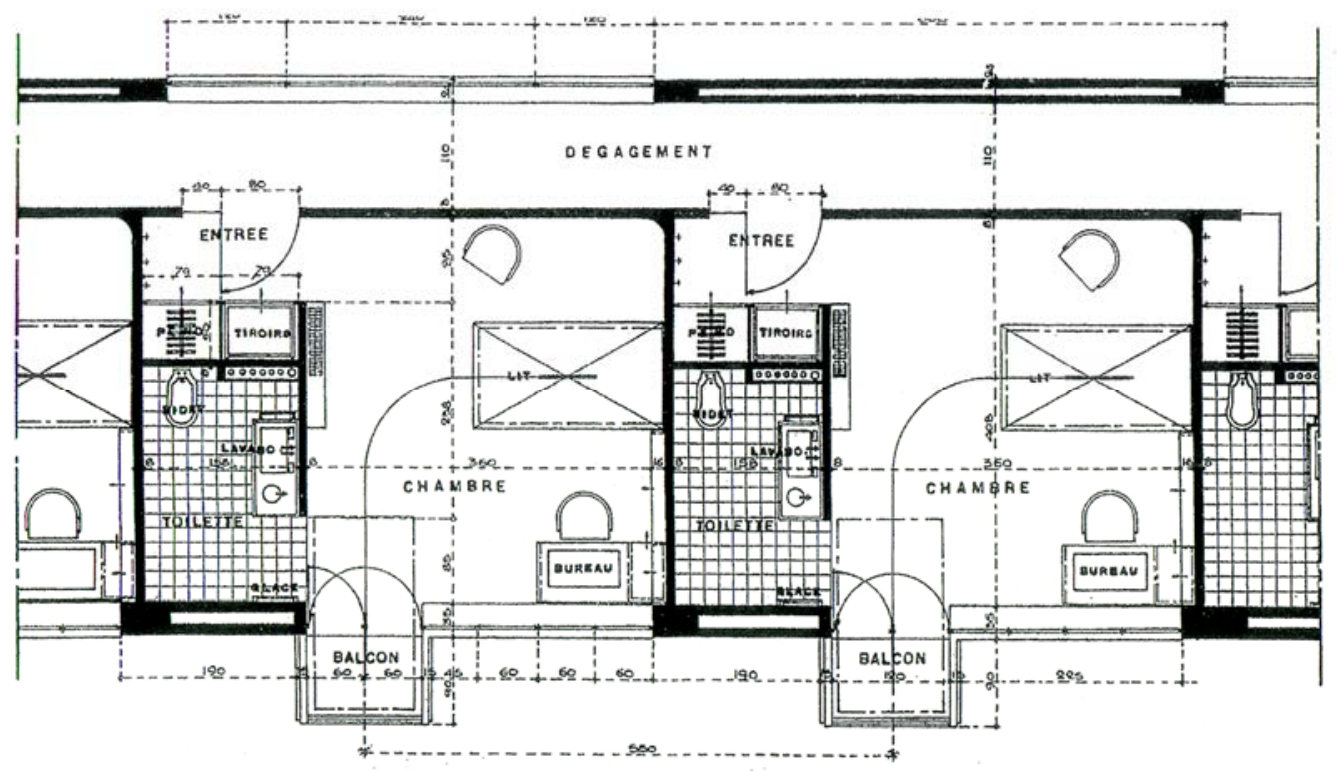

3.19

3.18 P. Abraham y H.-J. Le Même. Sanatorio de Martel de Janville, Plateau d'Assy, 1933-1937. Planta de la habitación.

3.19 A. Lurçat. Proyecto de Sanatorio de Durtol, 1929. Planta de la abitación. 
La "célula-tipo" de la habitación del sanatorio se somete a un estudio pormenorizado y a una racionalización espacial como consecuencia de las reflexiones ergonómicas de médicos y arquitectos [fig. 3.17]. Realizan detallados diseños de habitaciones pensados para su construcción en serie, dando pie a la estandarización del bloque residencial y, por ende, de todo el sanatorio.

Así, Pol Abraham y Henry-Jacques Le Même, proyectan un diseño exhaustivo de la habitación del Sanatorio de Martel de Janville (1933-1937), también en el Plateau d'Assy, donde los elementos sanitarios y los armarios se concentran en una banda transversal interpuesta entre habitaciones con el fin de liberar más espacio dentro de cada una. La banda se remata con un amplio balcón, algo remetido hacia el interior, de dimensión suficiente para albergar longitudinalmente una cama [fig. 3.18]. André Lurçat, en su proyecto para el Sanatorio de Durtol (1929), propone un diseño similar. La habitación se organiza en dos partes, una más grande y cuadrada sólo para la cama y un pequeño escritorio junto a la ventana, y otra más alargada adosada a una de sus paredes medianeras, que contiene en una banda transversal un amplio aseo ventilado a fachada y los armarios empotrados enfrentados a la puerta de acceso para generar un pequeño vestíbulo que puede utilizarse también como vestidor y así liberar un mayor espacio en la zona de descanso. Aquí el balcón se reduce al mínimo, un pequeño vuelo de 1,20 m. de ancho y 0,9 m. de largo pensado para asomar parcialmente la cama al exterior [fig. 3.19]. En los dos proyectos quedan perfectamente acotados y definidos todos los elementos de la habitación que la integran para poder ser construidos en serie.

Estos mismos procesos de estandarización se aplican no sólo a la habitación del sanatorio sino a todos los edificios hospitalarios, de tal manera que a mediados del siglo XX existen auténticos manuales de procedimiento que indican las dimensiones de cada ámbito del hospital y de cada uno de los elementos que lo constituyen, sus características técnicas y su disposición más conveniente. Se fijan sobre estándares preestablecidos con el fin de optimizar los procesos constructivos y de hacer más científico el método de proyecto aplicado al sanatorio y al hospital. 


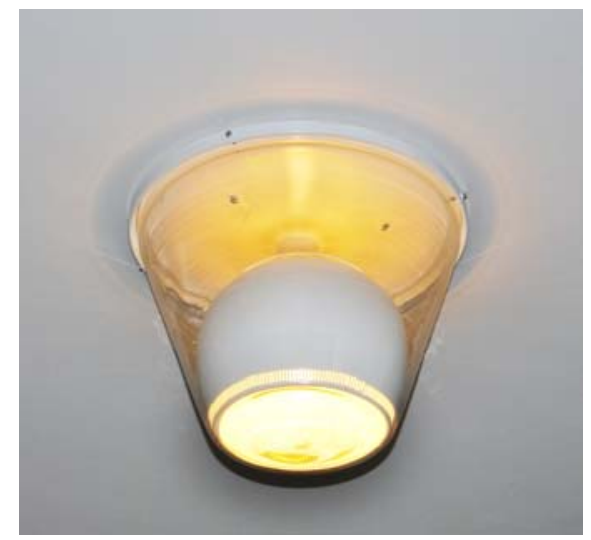

3.20
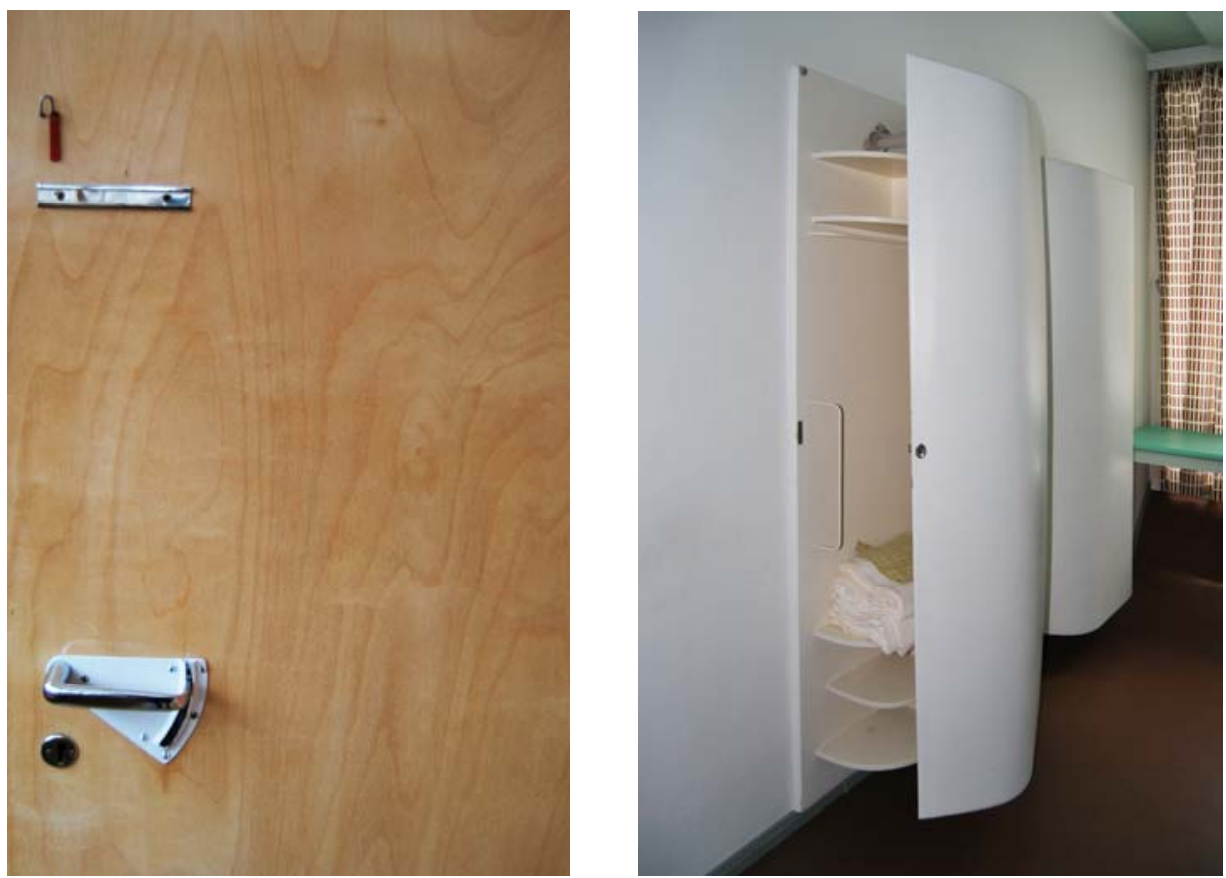

3.21 y 3.22

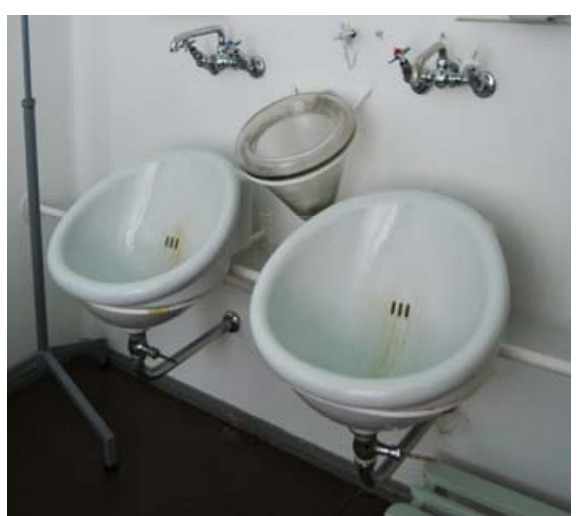

3.23

3.20 A. Aalto. Sanitario de Paimio, Turku, 1928-1933. Lámpara del vestíbulo (fotografía de la autora).

3.21 A. Aalto. Sanitario de Paimio, Turku, 1928-1933. Puerta y manilla de las habitaciones (fotografía de la autora).

3.22 A. Aalto. Sanitario de Paimio, Turku, 1928-1933. Armario de la habitación (fotografía de la autora).

3.23 A. Aalto. Sanitario de Paimio, Turku, 1928-1933. Lavabos de la habitación (fotografía de la autora). 


\section{EL DISEÑO INTEGRAL DEL SANATORIO: EL MOBILIARIO Y EL DETALLE}

Como indica la inscripción del Dr. Brehmer en el Sanatorio de Görbersdorf: "La mejor ocupación para el enfermo es trabajar para alcanzar buena salud "27, y este trabajo consiste exclusivamente en el cumplimiento de la terapia.

Durante años se piensa que la mejor manera de alcanzar la salud en el sanatorio consiste en el reposo del enfermo recostado sobre una tumbona o silla reclinable, que facilita su descanso, al permitir estirar el cuerpo en horizontal al mismo tiempo que mantiene el pecho erguido para facilitar la respiración. La tumbona surge como resultado de combinar dos acciones, la de sentarse erguido en una silla y la de tumbarse relajado en una cama. Es una patente inglesa del siglo XVII destinada a los inválidos que precisaban guardar cama, ya que este mueble, al igual que muchos otros: "surge en circunstancias en que el cuerpo requiere especial atención: entre los enfermos y los inválidos" ${ }^{28}$, como relata Siegfried Giedion en su libro La mecanización toma el mando.

En el siglo XIX la técnica se pone al servicio del mobiliario aplicado a la medicina y a otros oficios $^{29}$, se crean así muebles móviles y funcionales como los sillones reclinables de dentista, las mesas de operaciones, las sillas adaptables de barbero, los asientos-cama de los vagones de ferrocarril, etc. Sin embargo, tras la Primera Guerra Mundial, surge en Europa un interés por emplear esta movilidad para alcanzar el confort en el mobiliario doméstico y porque el mueble deje de ser una herramienta funcional ligada a un oficio y pase a convertirse en un bello objeto de diseño.

Un cambio en las concepciones artísticas hace que tanto el edificio como su contenido sean considerados una misma unidad dominada por el arquitecto y que los nuevos diseños de muebles, dejen de ser anónimos. En sus creaciones buscan el confort y la estética para alcanzar un diseño integral de muebles e inmueble. Los arquitectos proyectan tanto el edificio como sus lámparas, pensadas para no retener polvo [fig. 3.20]; los tiradores de las puertas, diseñados para evitar que las mangas de la ropa queden enganchadas en la

\footnotetext{
${ }^{27}$ Sigard Adolphus KNOPF, Les sanatoria, traitement et prophylaxie de la phtisie pulmonaire (1895). Carré et Naud, Paris 1900, p. 151.

${ }^{28}$ Siegfried GIEDION, La mecanización toma el mando (Mechanization takes command, 1948). Gustavo Gili, Barcelona 1978, pp. 417-427.

${ }^{29}$ En el siglo XVIII surgen los lechos-máquina, una derivación de las sillas-cama que atienden más a cuestiones de espacio que de posición del enfermo, donde el colchón se divide en tres piezas, una para las piernas, otra para los muslos y otra para la espalda, de forma que se pueden convertir los asientos en cama. En el siglo XIX, al tiempo que se desarrollan los asientos más tecnológicos ligados a los oficios, la búsqueda de un mueble híbrido a medio camino entre una cama y una silla toma una nueva dimensión ajena a la técnica o a la funcionalidad. Estas nuevas sillas con forma de sofás o canapés dejan de ser retráctiles para retornar a su carácter estático.
} 

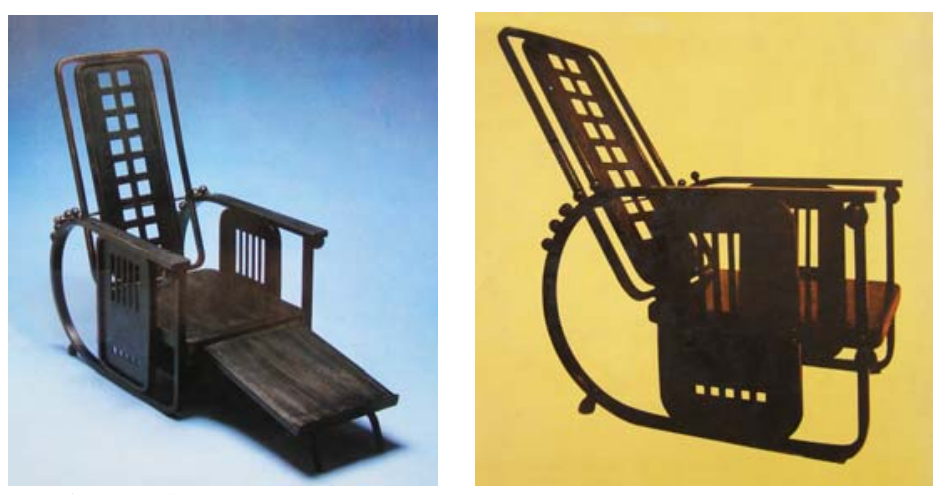

3.24 y 3.25

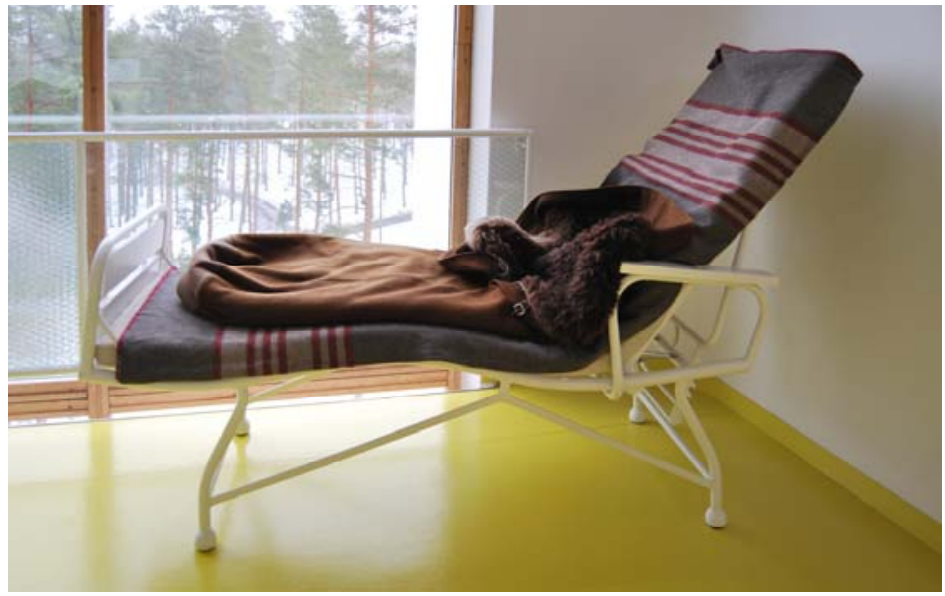

3.26

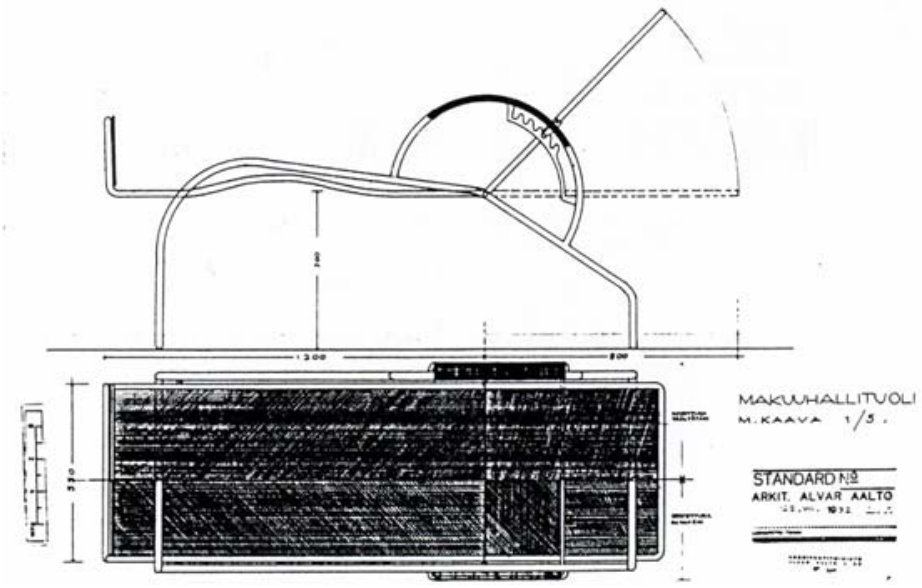

3.27
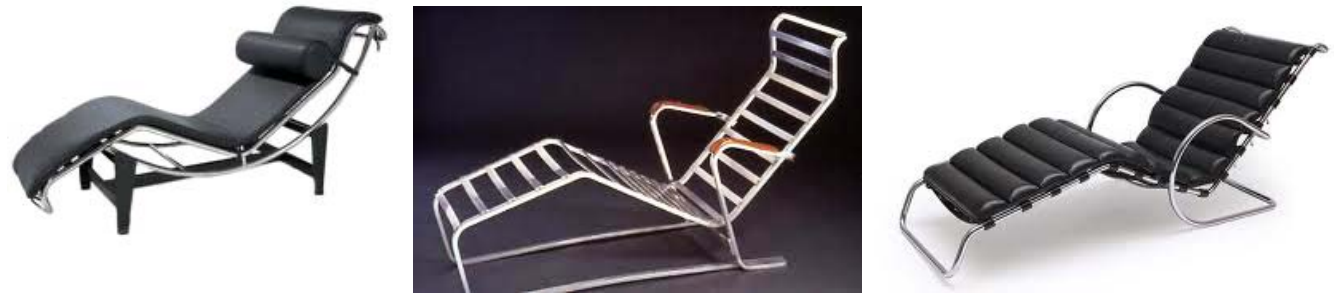

$3.28,3.29$ y 3.30

3.24 y 3.25 J. Hoffmann. Sanatorio de Purkersdorf, Viena, 1904-1905.

3.26 y 3.27 A. Aalto. Sanitario de Paimio, Turku, 1928-1933. Tumbona imagen (fotografía de la autora) y plano (50/209).

3.28 C. Perriand. Chaise-longue Basculante, 1928.

3.29 M. Brever. Tumbona, 1932.

3.30 L. Mies van der Rohe. Tumbona, 1932. 
manilla [fig. 3.21], los armarios, elevados del suelo y sin esquinas para facilitar su limpieza [fig. 3.22], los lavabos, que no salpican para evitar el ruido [fig. 3.23], etc., tal y como Alvar Aalto consigue en el Sanatorio de Paimio (1928-1933). Entre todos los elementos diseñados destacan las tumbonas y las sillas de reposo como los muebles más característicos del sanatorio.

Las sillas y tumbonas creadas "ad hoc" para los sanatorios alcanzan su máximo reconocimiento en los diseños de grandes arquitectos. Nombres como Josef Hoffmann y su silla para el sanatorio de Purkersdorf [fig. 3.24 y fig. 3.25] o Alvar Aalto [fig. 3.26 y fig. 3.27] se preocupan por dar una cualidad estética a objetos que conservan aún hoy un gran valor como muestra de la evolución cultural del siglo XX.

Estas sillas de reposo, además de higiénicas y ligeras, tienen que resultar extremadamente cómodas para reconfortar al enfermo, "casi mágicas" como relata Thomas Mann:

"(...) aquellas sensaciones tan desagradables eran compensadas por lo cómodo que se sentía, por las cualidades difíciles de analizar y casi mágicas de la tumbona, que Hans Castrop de nuevo constataba con sumo placer. ¿̇ería por la calidad del colchón, por la idónea inclinación del respaldo, por la altura y anchura ideales de los brazos, o sencillamente por la consistencia de la almohada? En cualquier caso, nada podía garantizar el feliz reposo del cuerpo mejor que aquella excelente tumbona ${ }^{\prime \prime 30}$.

Para conseguir tales cualidades los arquitectos tratan de conferir cierta elasticidad al mueble de modo que el enfermo pueda mantener el cuerpo relajado gracias a la posibilidad de pequeñas variaciones de postura, conseguidas por sistemas sencillos como la charnela o el pivote, sin necesidad de recurrir a complejos mecanismos. Las investigaciones sobre el mobiliario se trasladan al diseño doméstico general. La pérdida de rigidez en las sillas del hogar se resuelve en 1927, cuando el arquitecto holandés Mart Stam diseña su silla Cantilever [fig. 3.32], mejorada poco tiempo después por Marcel Brever con su diseño del modelo Cantilever elástico [fig. 3.33] compuesta por una estructura tubular continua que hace de muelle para conferir a la silla cierta motilidad. Esta búsqueda de movimiento en los muebles trajo consigo el desarrollo de la sorprendente Chaise-longue Basculante [fig. 3.28], diseñada en 1928 por Charlotte Perriand en el taller de Le Corbusier y Pierre Jeanneret. Una bella tumbona que consta de una base fija y una estructura móvil curva, pero que obliga a incorporarse para poder cambiar de posición.

\footnotetext{
30 Thomas MANN, La Montaña Mágica (Berlín, 1924). Edhasa, Barcelona 2005, p. 149.
} 

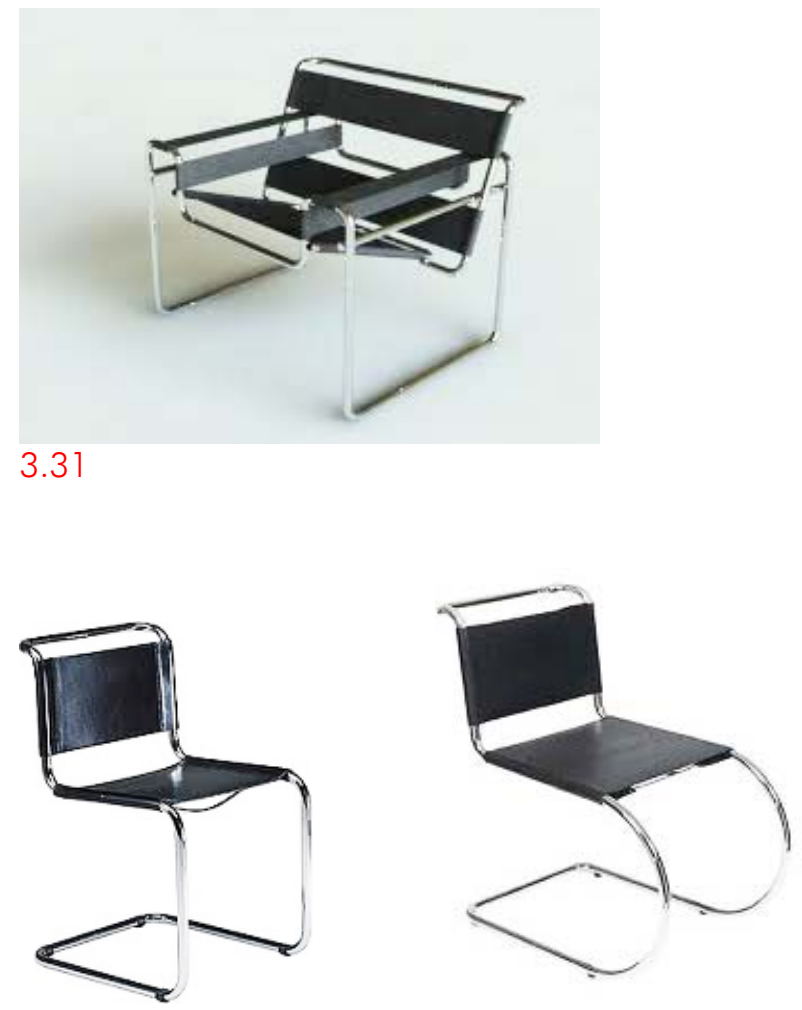

3.32 y 3.33

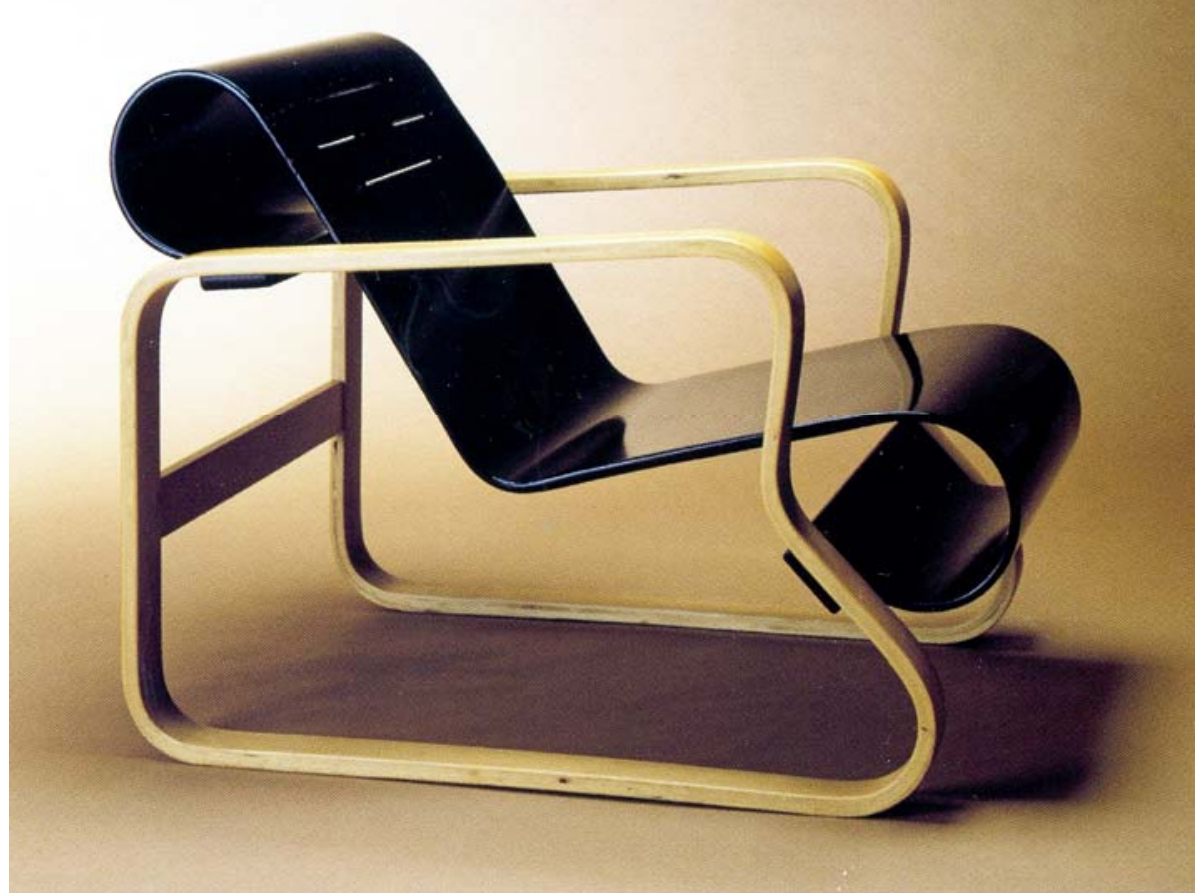

3.31 M. Brever. Silla Wassilly, 1925.

3.32 M. Stam. Silla Cantilever, 1927.

3.33 M. Brever. Silla Cantilever elástico, 1927.

3.34 A. Aalto. Sanitario de Paimio, Turku, 1928-1933. Silla de reposo. 
En 1928 en la Bauhaus, se trata de aprovechar la elasticidad de la madera curvada para conseguir este grado de flexibilidad en los asientos. Artistas como Laszlo MoholyNagy y arquitectos como Alvar Aalto investigan sobre las posibilidades de este material que, por sus propiedades táctiles y por su flexibilidad, acaba por sustituir al tubo metálico [fig. 3.34] como se aprecia en la silla de reposo diseñada para el Sanatorio de Paimio:

"El mobiliario de madera curvada es resultado de otros experimentos realizados en el Sanatorio de Paimio. Al mismo tiempo que dichos experimentos se llevaban a cabo, el primer mueble de tubo de acero cromado se construía en Europa. Las superficies tubulares y de cromo son buenas soluciones técnicas, pero no son materiales psicológicamente adecuados para el ser humano. El sanatorio necesitaba muebles ligeros, flexibles, fáciles de limpiar, etc. Después de muchas pruebas con la madera se descubrió el sistema curvado, y por tanto, un método y un material que combinados para producir mobiliario daban como resultado un mejor tacto para el ser humano; y como material más conveniente en general para la larga y dolorosa vida en un sanatorio" ${ }^{\prime \prime 1}$.

El empleo de los tubos metálicos en el mobiliario no era nuevo, se usaba en Inglaterra en 1830 en la construcción de camas y en Francia en sillas pintadas y decoradas, pero no es hasta 1925, cuando Marcel Brever construye su primera silla de metal cromado visto, la silla Wassilly [fig. 3.31], cuando cobra una verdadera relevancia. No se parece a ninguna silla jamás contemplada. En ella los tubos describen una estructura espacial tridimensional muy ligera y transparente, que recuerda a los cuadros de las bicicletas o a piezas mecánicas de origen industrial, con un soporte de tela elástico para el asiento y el respaldo. Un mueble innovador que como reconoce Wirtold Rybczynski:

"Incluso sesenta años después sigue pareciéndose más a una máquina de hacer ejercicio que a una butaca. De ahí que la primera reacción al sentarse en la silla Wassily sea favorable; resulta sorprendente que sea posible sentarse en absoluto en este extraño montaje de tubos y de planos que se intersectan ${ }^{\prime \prime 2}$.

Los muebles del sanatorio, al igual que la silla Wassily, resultan extraños e inapropiados para una habitación, su aspecto metálico e industrial les hacía poco elegantes para formar

\footnotetext{
${ }^{31}$ Alvar AALTO, "La Humanización de la Arquitectura" ("The Humanizing of Architecture"), The Techonology Review, Nov.1940, en Göran SCHILDT, Alvar Aalto de palabra y por escrito (Alvar Aalto. In his own words, 1997). El Croquis Editorial, Madrid 2000, pp. 145-146.

${ }^{32}$ Wirtold RYBCZYNSKI, La Casa, Historia de una idea (1989). Nerea, San Sebastián 2006, p.208.
} 

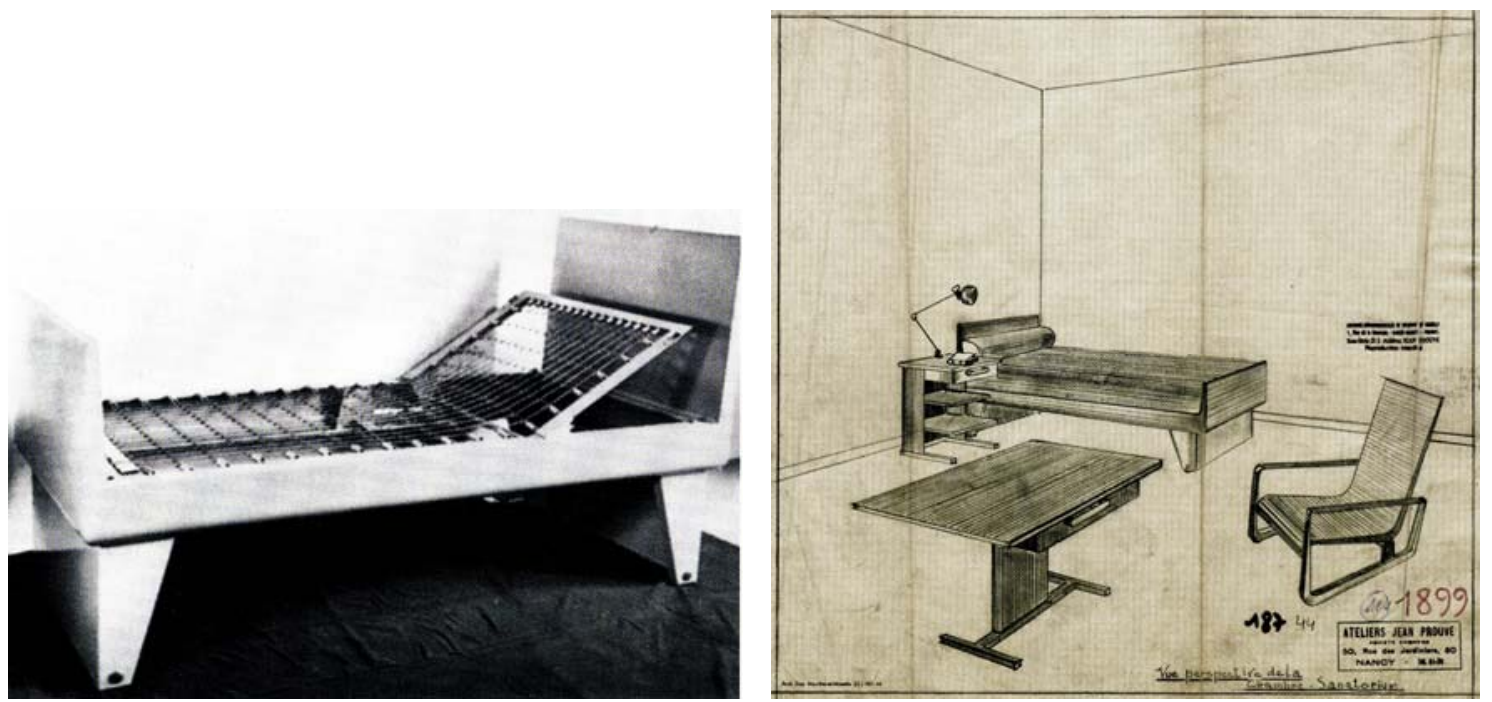

3.35 y 3.36

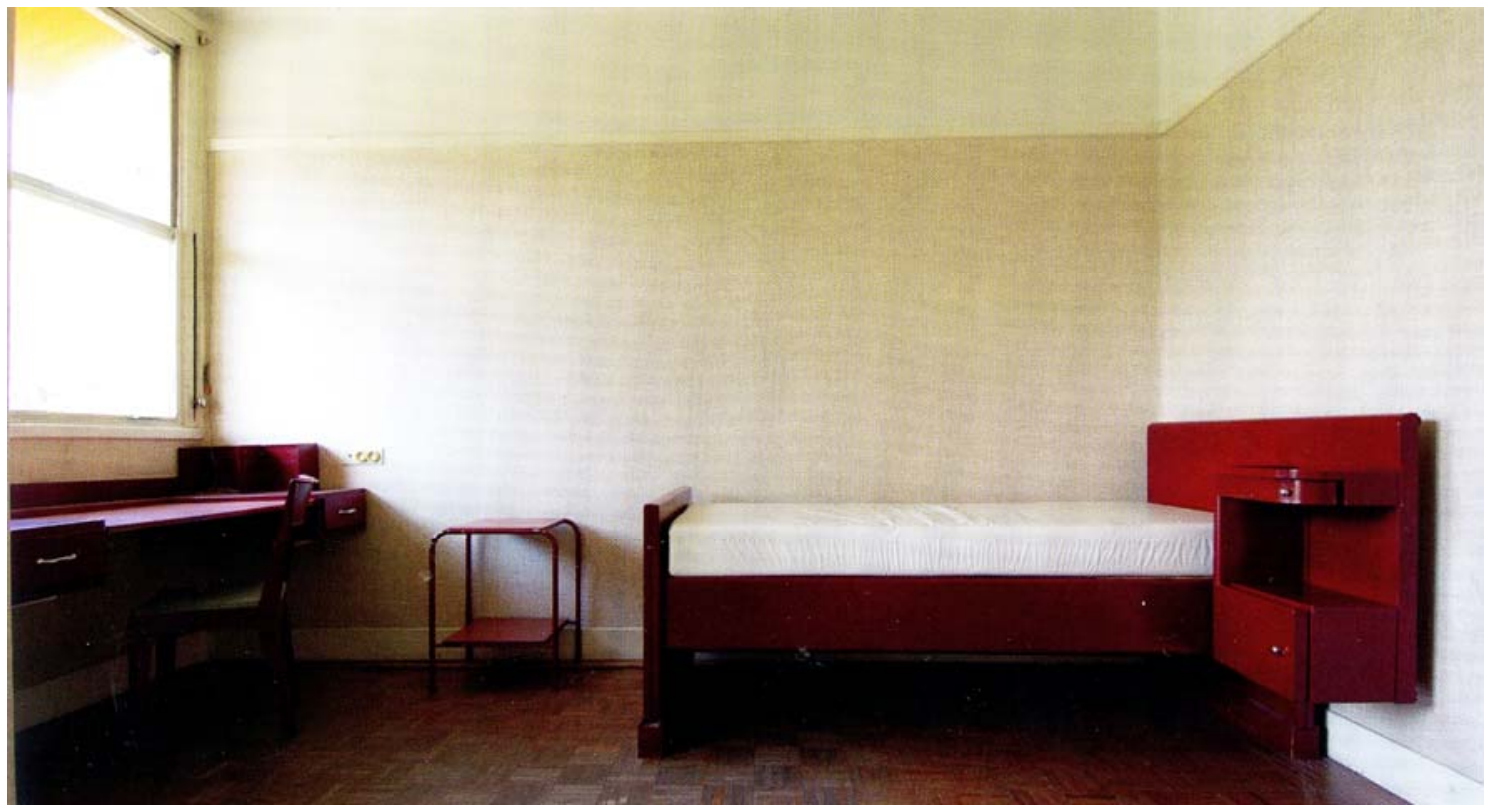

3.37
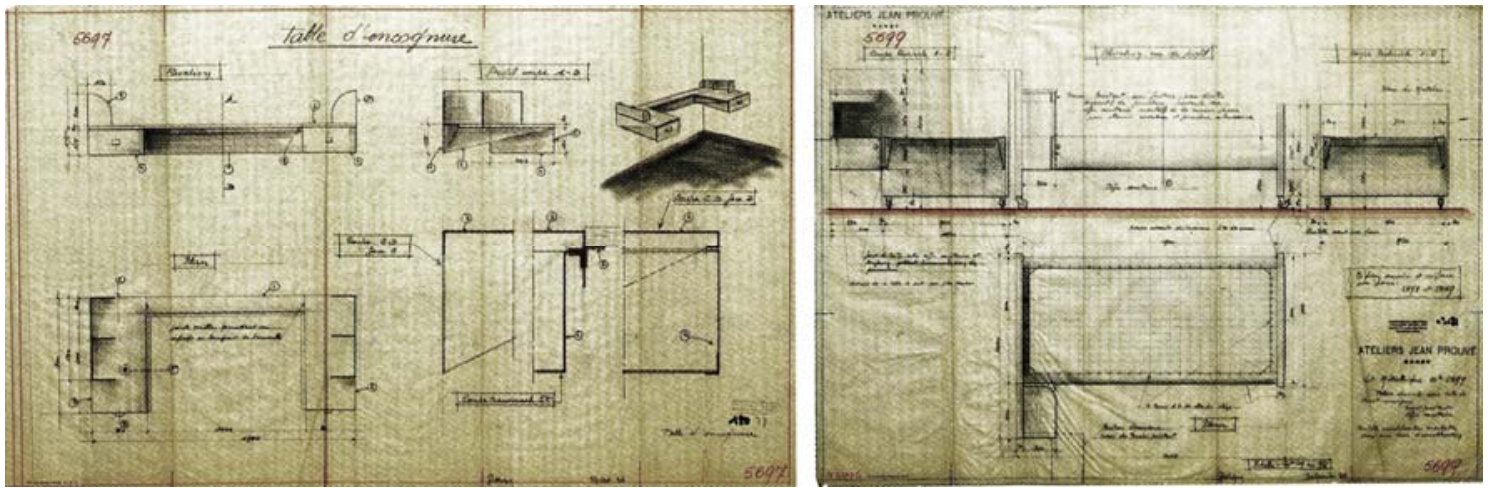

3.38

3.35 y 3.36 P. Abraham y H.-J. Le Même. Sanatorio de La Clairière, Plateau d'Assy, 19301933. Mobiliario de la habitación de Jean Prouvé. Imagen de la cama y perspectiva de la habitación.

3.37 y 3.38 P. Abraham y H.-J. Le Même. Sanatorio de Martel de Janville, Plateau d'Assy, 1933-1937. Mobiliario de la habitación de Jean Prouvé. Imagen y planos de detalle de la mesa y de la cama. 
parte de un salón o de un dormitorio, pero en este caso la higiene justifica su uso y los enfermos los aceptan e incluso comienzan a apreciarlos. Thomas Mann describe la asepsia y pulcritud del ambiente de la habitación con gran precisión:

"Joachim había encendido la lámpara del techo y, a su luz temblorosa, la habitación daba la sensación de ser alegre y tranquila, con sus muebles blancos y funcionales, su papel de la pared también blanco, fuerte y lavable, su suelo de linóleo limpio y brillante y sus cortinas de lino adornadas con bordados sencillos y agradables, de gusto moderno" ${ }^{\prime 3}$.

Lo mismo sucede con el mobiliario de metal lacado diseñado por Jean Prouvé para la habitación del Sanatorio de La Clairière (1930-1933), obra de P. Abraham y H.-J. Le Même, inspirado en sus muebles para la ciudad universitaria de Nancy. Su monolítica cama de metal pintada en blanco, reclinable y de esquinas redondeadas, resulta higiénica y funcional [fig.3.36], igual que el mueble de escritorio y la butaca de la habitación construidos con chapas plegadas y tubos huecos de metal lacados en rojo [fig.3.37]. Jean Prouvé se encarga también del diseño del mobiliario de las habitaciones de otro sanatorio de estos mismos arquitectos, el de Martel de Janville (1933-1937), también lacado en rojo, aunque el resto del mobiliario y de la decoración se encargan a Jules Leleu ${ }^{34}$.

Todos los muebles de la estancia están en vuelo, a excepción de la cama, para facilitar así la limpieza del suelo. Consta de un escritorio, formado por una chapa plegada con un cajón en cada extremo que ocupa todo el frente de la habitación y que se sujeta a ambos lados de la pared, y de una cama con una mesilla integrada en el cabecero. La cama de sencillos planos rectos posee un cabecero que se prolonga en horizontal del que queda suspendido un mueble de cuatro baldas con una tapa pivotante, de exquisito diseño, que hace las funciones de mesilla [fig.3.38]. Este mueble diseñado "ex profeso" entre 1933 y 1934 será un modelo posteriormente comercializado bajo el nombre Martel-deJanville ${ }^{35}[$ fig. 3.39].

Es probable que, en cierta medida, el sanatorio contribuya al proceso de aceptación social de este nuevo mobiliario, utilizado anteriormente tan sólo en barberías o en quirófanos, propiciando el diseño de muebles metálicos y tumbonas para uso doméstico como las que

\footnotetext{
${ }^{33}$ Thomas MANN, La Montaña Mágica (Berlín, 1924). Edhasa, Barcelona, 2005, p. 20.

${ }^{34}$ Pol Abraham Architect. Collection Centre Pompidou, Musée National d'Art Moderne, Paris 2005, p. 141.

${ }^{35}$ Bernard TOULIER "Les sanatoriums en Europa. Architecture éphémère et reconversión", en Histoire et Réhabilitation des Sanatoriums en Europe, Les réseaux de la modernité au XX e siècle/l. Docomomo International, Paris 2008, p. 13.
} 
diseñan Marcel Brever [fig. 3.29] o Mies van der Rohe [fig. 3.30] en el año 1932. Lo mismo sucede con ciertos aparatos como las aspiradoras o los frigoríficos fabricados originariamente para los sanatorios y hospitales, y que fueron popularizándose entre otros medios a través de las campañas higiénicas de prevención antituberculosa, hasta pasar a incorporarse a la vida doméstica.

Pero en el sanatorio, el diseño no sólo atañe al mobiliario sino que se hace extensivo a todos sus elementos pues el bienestar del enfermo depende de ellos, incluso de los que tradicionalmente se tratan de ocultar: calderas, conductos de ventilación, chimeneas, etc., sin embargo, ahora pasan a ser protagonistas, y el sanatorio adquiere por esta vía también una imagen tecnológica y moderna más acorde con su función.

Las características terapéuticas de los sanatorios obligan a una experimentación técnica constante para dar respuesta a las necesidades de soleamiento y ventilación requeridas en la cura, lo cual lleva a plantear soluciones constructivas que permitan abrir grandes huecos en fachada y a emplear nuevos materiales de construcción como el hormigón armado, para poder ejecutar los vuelos de los balcones y las galerías.

Las duras condiciones climáticas de los lugares habitualmente escogidos para la implantación de los sanatorios, sometidos a bajas temperaturas y en ocasiones a grande saltos térmicos a lo largo del día, fuerzan a innovar en los materiales de aislamiento y a desarrollar nuevos sistemas de calefacción y de acristalamiento que impidan las pérdidas de calor, llegando incluso a soluciones de vidrios triples.

De este modo el programa sanatorial por su complejidad terapéutica y su vinculación con el enfermo llega a convertirse en un importante campo de experimentación arquitectónico y técnico que comienza a ser conocido y muy apreciado por el arquitecto. Alvar Aalto reconoce implícitamente este campo de acción como el lugar donde fructifica la respuesta de arquitectura moderna:

"El arquitecto que hasta ahora ha encontrado sus tareas más "valiosas" en edificios decorativos de signo tradicional y en proyectos monumentales acordes con los viejos conceptos, empieza a percibir con creciente agudeza que los cometidos más difíciles, atractivos y al mismo tiempo más positivos, se hallan allí donde los modos de vida 
por las exigencias actuales, requieren nuevas y culturalmente positivas soluciones técnicas" ${ }^{36}$.

Con este estudio de las características específicas del sanatorio antituberculoso pulmonar se intenta encuadrar de manera general las particularidades arquitectónicas del sanatorio, que serán analizadas a continuación a través del análisis de tres obras en concreto: El Sanatorio de los Montalvos de Rafael Bergamín (1934-1948), el Sanatorio de Zonnestraal de Johannes Duiker (1919-1928) y el Sanatorio de Paimio de Alvar Aalto(1928-1933), en los capítulos de la segunda parte de este trabajo de investigación.

Estos tres ejemplos sintetizan las múltiples soluciones arquitectónicas que ha adoptado el sanatorio antituberculoso pulmonar moderno, al tiempo que el estudio de sus proyectos pone de manifiesto las variaciones tipológicas que éste ha experimentado desde los prístinos modelos lineales con una sencilla forma de $T$, hasta las edificaciones articuladas mucho más complejas, pasando por los sanatorios de pabellones aislados.

\footnotetext{
36 Alvar AALTO, "Sobre las últimas tendencias en arquitectura" ("Uusimmista virtauksista rakennustaiteen alalla"), artículo publicado en el periódico Uusi Aura el 1 de Enero de 1928, en Göran SCHILDT (edit.), Alvar Aalto de palabra y por escrito (Alvar Aalto. In his own words, 1997). El Croquis Editorial, Madrid 2000, p.85.
} 


\section{EL SANATORIO ANTITUBERCULOSO PULMONAR Y LA ARQUITECTURA MODERNA}

\section{CAPÍTULO 4}

LA UNIDAD CIENTÍFICA DE LAS PARTES:

EL SANATORIO EN BLOQUE DE LOS MONTALVOS, RAFAEL BERGAMÍN

LA ARQUITECTURA "LIMPIA"DE RAFAEL BERGAMÍN

VARIACIONES FORMALES DE LOS MODELOS

EL CONJUNTO EDIFICADO DE LOS MONTALVOS

EL PATRÓN MÉDICO 

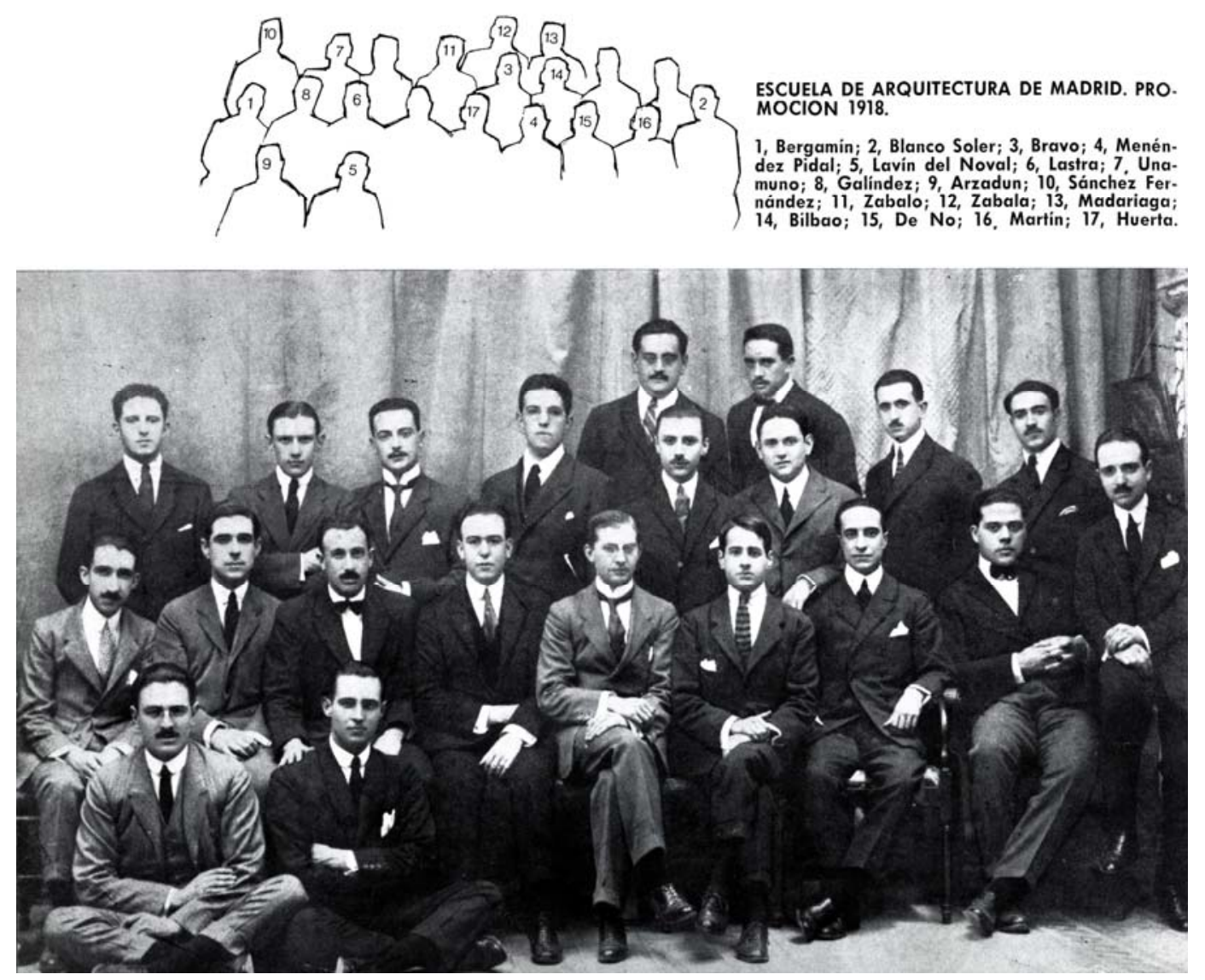

4.01

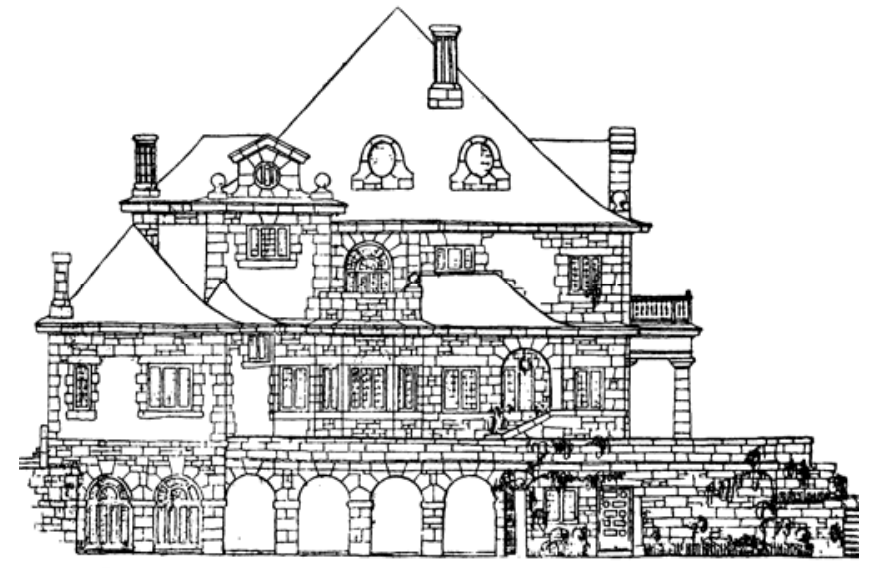

4.02

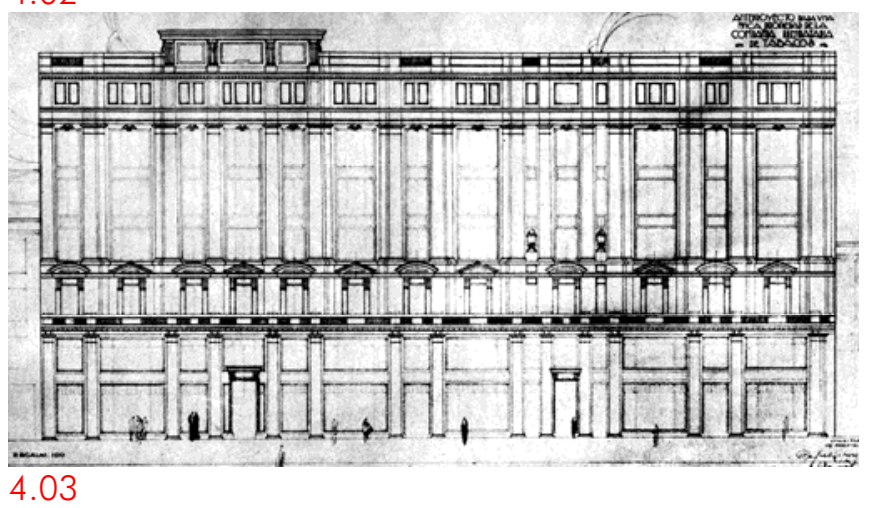

4.01 Promoción del año 1918 de la Escuela de Arquitectura de Madrid.

4.02 R. Bergamín. Proyecto del concurso para la Sociedad Central de Arquitectos, Madrid, anterior a 1919.

4.03 R. Bergamín y L. Blanco Soler. Proyecto de Tabacalera, Madrid, 1925. 


\section{LA ARQUITECTURA "LIMPIA" DE RAFAEL BERGAMÍN}

El proyecto del sanatorio antituberculoso de Los Montalvos de Salamanca se encarga en 1934 por la Dirección General de Sanidad a uno de sus arquitectos más relevantes, Rafael Bergamín. A sus cuarenta y tres años se encuentra en una etapa de madurez profesional, lleva dieciséis trabajando para Sanidad y, paralelamente, ha construido algunas de las más trascendentes obras residenciales de la época', a menudo en colaboración con el arquitecto Blanco Soler ${ }^{2}$, miembros los dos del grupo conocido como la "generación de $1925^{\prime \prime 3}$ [fig. 4.01].

Rafael Bergamín, malagueño de nacimiento, había estudiado Arquitectura en Madrid a la vez que Ingeniería de Montes en El Escorial, obteniendo el título de licenciado en Ingeniería en 1917 y en Arquitectura un año después.

Durante sus estudios de arquitectura recibe una formación academicista y regionalista, como se manifiesta en el proyecto realizado para el concurso convocado por la Sociedad Central de Arquitectos entre los alumnos de Proyectos de las Escuelas de Barcelona y Madrid. El concurso consistía en el diseño de una casa de campo para un propietario acomodado, "debiendo especificar los concursantes- decía la convocatoria- la región para la que esos proyectos son imaginados ${ }^{\prime \prime}$, forzando así a los estudiantes al empleo de elementos pintorescos en sus propuestas [fig. 4.02].

\footnotetext{
1 Rodolfo UCHA DONATE, Cincuenta años de Arquitectura Española / (1900-1950). Adir Editores, Madrid 1980, pp. 165-168.

${ }^{2}$ Bergamín y Blanco Soler son compañeros de promoción y comienzan a trabajar juntos en 1921. Ese mismo año se presentan al concurso del Teatro Ciudad de Barcelona, en 1924 lo harán al del Palacio Central de la Exposición de Barcelona de 1929 y en 1925 al de la construcción del edificio de La Tabacalera en Madrid. Dos años más tarde comienzan su andadura por el Norte de África y participan en el concurso de la Ciudad Satélite Loma Larga en Ceuta, a partir del cual les nombran asesores técnicos de la Dirección de Marruecos y Colonias y reciben una serie de encargos entre los que se encuentran una iglesia con residencia para los franciscanos en Larache, el edificio del consulado de España, un grupo escolar en Casablanca y otro en Tánger. Juntos proyectan también la Residencia de Estudiantes Hispanoamericanos, Fundación del Amo (1928-1930) en la Ciudad Universitaria de Madrid, y en 1929 se presentan al que será su último concurso juntos, el del aeropuerto de Barajas, al que le siguen la realización del proyecto de los apartamentos Gaylord's (1930) y la participación en la Cooperativa de Casas Económicas Residencia (1931). "Rafael Bergamín, De la 'gran borrasca' y el exilio a la evanescente figura del arquitecto en Venezuela" en Entre rayas, la revista de Arquitectura, $\mathrm{n}^{\circ} 84$, Caracas 2010, pp.44-47.

${ }^{3}$ La designación de "generación de 1925" fue utilizada por primera vez por Carlos Flores y agrupaba a los jóvenes arquitectos vanguardistas titulados en la Escuela de Arquitectura de Madrid entre 1918 y 1925; a ella también pertenecen Fernando García Mercadal, Casto Fernández-Shaw y su compañero de despacho Luis Blanco Soler, entre otros tantos arquitectos como Lacasa, Sánchez Arcas, Arniches, Gutiérrez Soto, De los Santos, Aguirre, Domínguez, etc. Carlos FLORES, "1927: Primera Arquitectura Moderna en España" en Hogar y Arquitectura n 70, 1967, p. 37.

${ }^{4}$ Leopoldo TORRES BALBÁS, "El Concurso de proyectos de la Sociedad Central", en Arquitectura n ${ }^{\circ}$ 12, Sociedad Central de Arquitectos, Madrid 1919, pp. 103-105.
} 

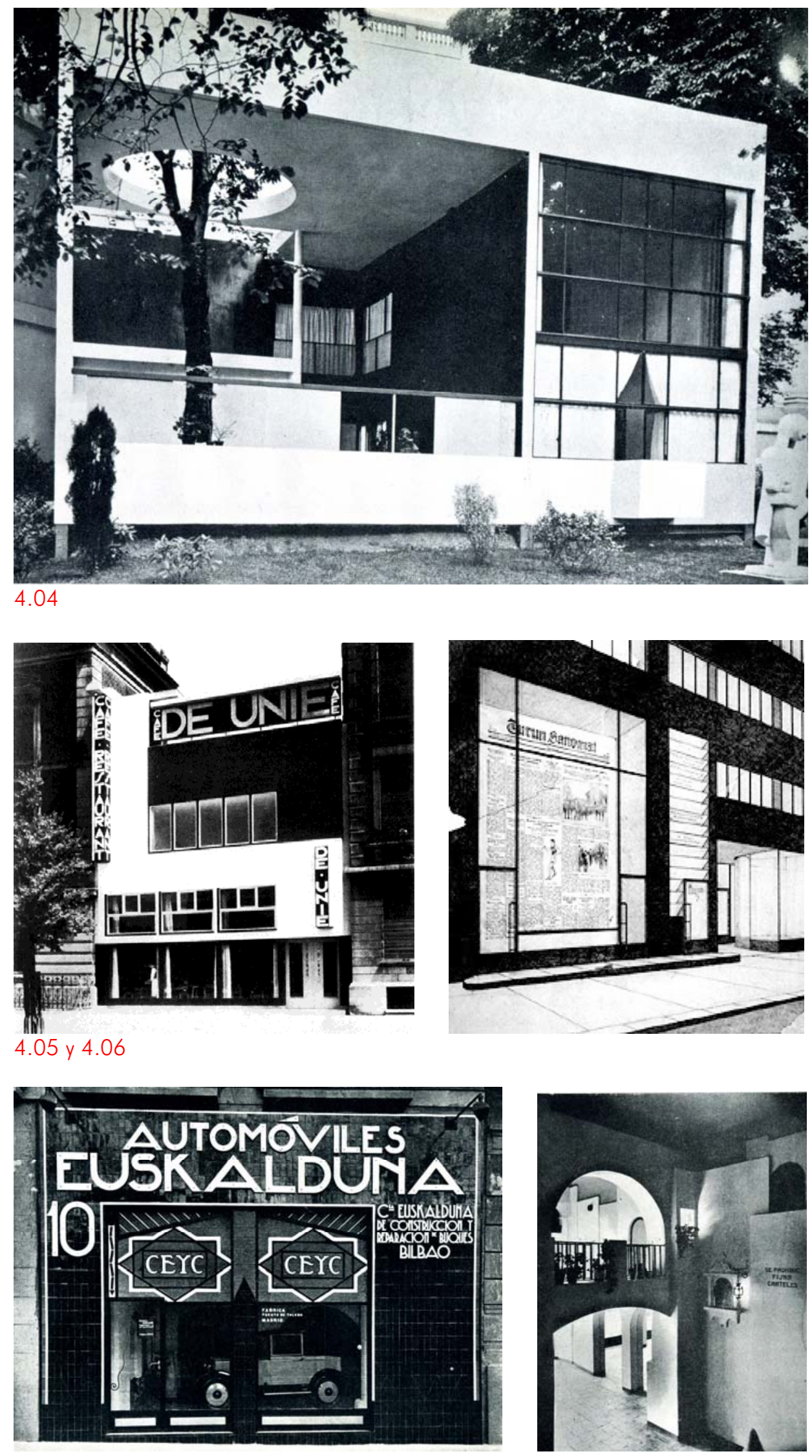

4.07 y 4.08

4.04 Le Corbusier. Pabellón de L’Esprit Nouveau. Exposición de Artes Decorativas, París, 1925.

4.05 J.J.P. Oud. Café De Unie, Rotterdam, 1925.

4.06 A. Aalto. Periódico Turum Sanomat, Turku, 1928.

4.07 R. Bergamín. Tienda de automóviles Euskalduna, Madrid, 1927. Fachada.

4.08 R. Bergamín. Tienda de automóviles Euskalduna, Madrid, 1927. Interior. 
Estas influencias estuvieron muy presentes en los comienzos de su carrera, como se aprecia en el proyecto para el concurso del edificio de La Tabacalera, en la esquina de la calle Sevilla con Arlabán en Madrid, realizado en el año 1925 junto a Blanco Soler, en el que obtuvieron el segundo premio ${ }^{5}$ [fig. 4.03]. En él, ambos arquitectos apuestan por una arquitectura clasicista, decorada con pilastras, capiteles y frontones, totalmente ajena a la de la Casa del Marqués de Villora realizada tan sólo dos años más tarde, en 1927, que es considerada por Carlos Flores como una de las obras más significativas de los orígenes de la arquitectura moderna en España ${ }^{6}$.

¿A qué se debió tal cambio? No es posible saber con certeza cuál es la causa exacta, pero es innegable la influencia que tuvo su visita a la Exposición de Artes Decorativas celebrada en París en 1925, que reconoce años más tarde en una entrevista:

"La Exposición de Artes Decorativas. Lo descubrimos todo, desde Hoffmann a L'Esprit

Nouveau. Los holandeses... Todo lo que intuíamos durante largos años. A partir de entonces vemos nuestro camino ${ }^{\prime \prime}$.

También es muy importante la relación con su hermano José Bergamín, escritor de profesión. Él es quien le introduce en las tertulias literarias y artísticas de la época, celebradas en los concurridos cafés madrileños Pombo, Lyon y la Granja El Henar. Sus miembros se confiesan devotos de los ballets rusos y de las nuevas músicas, sumergiéndose en un ambiente donde "la voluntad de renovación común a todos, la expresaba cada uno a su manera "8, en palabras de Bergamín. De este modo se ve inmerso en las vanguardias plásticas y artísticas, casi antes que en las arquitectónicas, y su interés por la cultura le conduce a participar en la fundación de varias revistas de diferentes ámbitos como España Forestal, Arquitectura, o Sociedad de Antistas Ibéricos?. Esta amplitud de conocimientos favorece su rápida asimilación de conceptos ante las nuevas arquitecturas europeas ${ }^{10}$

\footnotetext{
5 "El Concurso de La Tabacalera", en Arquitectura n 80, Sociedad Central de Arquitectos, Madrid 1925, p. 315-316.

${ }^{6}$ Carlos FLORES, "1927: Primera Arquitectura Moderna en España", en Hogar y Arquitectura n 70 1967, p. 37.

7 Eduardo AMANN, "Paseo por 'El Viso' madrileño del brazo de Bergamín", en El Inmueble n 2, 1966, p. 19.

${ }^{8}$ Eduardo AMANN, "Paseo por 'El Viso' madrileño del brazo de Bergamín", en El Inmueble n², 1966, p. 19

9 Henry Vicente GARRIDO (dir.), Arquitecturas desplazadas. Arquitecturas del exilio español. Ministerio de Vivienda, Madrid 2007, p. 180.

${ }^{10}$ De las obras expuestas en París Bergamín reconoce que las que más le impactaron fueron los de los arquitectos nórdicos, especialmente el pabellón de Finlandia, y J. Hoffman. "Mesa redonda con Rafael Bergamín, Fernando García Mercadal y Casto Fernández-Shaw", en Hogar y Arquitectura n 70,1967, p. 39.
} 
presentes en la exposición parisina y su pronta adhesión a la arquitectura moderna [fig. 4.04].

Una clara manifestación de este cambio es notoria en la imagen vanguardista que ofrece la tienda de automóviles Euskalduna construida en 1927 [fig. 4.07], pese a que en su interior presenta un reconocible "estilo español" 11 [fig. 4.08]. En ella, al igual que en los más modernos edificios europeos del momento como el Café De Unie de Rotterdam (1925) del arquitecto J.J.P. Oud ${ }^{12}$ [fig. 4.05] o, de una manera más evidente, en la editorial del periódico Turum Sanomat en Turku (1928) del arquitecto Alvar Aalto [fig. 4.06], se reconoce cómo la imagen del edificio, es decir su fachada, se convierte en un gran anuncio publicitario: "La portada: es el cartel que grita al público de la calle la marca del auto que se vende dentro" ${ }^{13}$, y lo hace por medio de sus letreros, del vehículo expuesto y, sobre todo, a través del telón de foro de la fachada que ofrece una imagen integral de la tienda: mecánica, industrializada y moderna. En contraste su interior apuesta por un mundo bien distinto; Bergamín construye la escenografía de una calle típica española, con sus farolillos, rejas y arcos, en la que se exponen los coches como si estuvieran en circulación; una recreación de estilo andaluz que sigue las corrientes regionalistas imperantes en el panorama arquitectónico y que son aprendidas durante su formación universitaria.

Es en 1928 con la Casa del Marqués de Villora, su obra más destacada, cuando despoja a la arquitectura de todo ropaje clasicista o pintoresco. Ésta carece de un estilo al uso, lo que provoca que sea descrita como: "'esa cosa tan tonta', 'que le falta algo'" por parte de algunos de sus compañeros ${ }^{14}$. La casa cambia la habitual apariencia regionalista a favor de una más abstracta y prismática, formada por paños lisos de ladrillo, libres de cornisas y de aleros, sobre los que se recortan los huecos de sus fachadas [fig. 4.12]. Unas características que recuerdan a la nueva arquitectura holandesa que tanto le interesa ${ }^{15}$, totalmente inusual en España ${ }^{16}$.

\footnotetext{
${ }^{11}$ Rafael BERGAMíN, "La tienda de Automóviles Euskalduna. El problema estético de una tienda de 'estilo español'", en Arquitectura n 99, Sociedad Central de Arquitectos, Madrid 1927, p. 261.

${ }^{12}$ Obra que es muy probable que conozca e incluso que pudo haberla visitado durante su estancia en Holanda alrededor de 1925. "Rafael Bergamín, De la 'gran borrasca' y el exilio a la evanescente figura del arquitecto en Venezuela" en Entre rayas, la revista de Arquitectura n84, Caracas 2010, p.45.

13 Rafael BERGAMÍN, "La tienda de Automóviles Euskalduna. El problema estético de una tienda de "estilo español", en Arquitectura n 99, Sociedad Central de Arquitectos, Madrid 1927, p. 261.

${ }^{14}$ Rafael BERGAMín, "Casa del Marqués de Villora en Madrid", en Arquitectura n ${ }^{\circ}$ 113, Sociedad Central de Arquitectos, Madrid 1928, p. 288.

${ }^{15}$ Bergamín comenta en una entrevista: "Yo hice varios viajes por Europa, especialmente con motivo del concurso del aeropuerto de Barajas. La arquitectura holandesa de ladrillo causó en mí gran
} 
Bergamín describe la Casa de Villora como una "arquitectura limpia "17, una cualidad propia de la arquitectura sanitaria, que deja patente la influencia que tiene su trabajo en la Dirección General de Sanidad, donde ejerce desde su licenciatura, en el resto de sus obras $^{18}$. La influencia se muestra tanto en la carencia de estilo, ya que la arquitectura sanitaria "era un mundo en el que sobraban la moldura y el pastiche. Un mundo de volúmenes limpios y espacios lógicos"19, como en la concepción arquitectónica porque: "la geometría o las formas simples fueron la reacción obligada para la 'limpieza' de la arquitectura $^{\prime 20}$, una depuración formal que exige un sentido riguroso del orden, siendo éste para Bergamín la mejor característica y enseñanza de la arquitectura racionalista ${ }^{21}$.

Otra característica de la Casa de Villora consiste en la preocupación de Bergamín por el bienestar y la economía:

"No hay en ella más pretensión que la de proporcionar a sus moradores el máximo de 'confort' con el mínimo gasto, procurando cumplir exactamente el programa de necesidades impuesto por el propietario" 22 .

Son características propias de la arquitectura sanitaria, cuya aplicación al ámbito residencial privado en España supone una innovación, máxime tratándose de la lujosa vivienda de un marqués ${ }^{23}$.

impresión". "Mesa redonda con Rafael Bergamín, Fernando García Mercadal y Casto FernándezShaw", en Hogar y Arquitectura n 70, 1967, p. 39.

${ }^{16}$ Tanto es así que Bergamín se vio en apuros al cubrir aguas en la vivienda y verse obligado a dar parte al Ayuntamiento de Madrid de haber llegado a la cornisa, pese a que tal cornisa no existiera. Rafael BERGAMíN, "Casa del Marqués de Villora en Madrid", en Arquitectura n ${ }^{\circ} 113$, Sociedad Central de Arquitectos, Madrid 1928, p. 288.

${ }^{17}$ Rafael BeRGAMíN, "Casa del Marqués de Villora en Madrid", en Arquitectura n ${ }^{\circ} 113$, Sociedad Central de Arquitectos, Madrid 1928, p. 286.

18 La arquitectura de Bergamín guarda también una gran vinculación con otra arquitectura residencial ligada a la sanidad como la arquitectura higienista inglesa desarrollada desde los siglos XVII y XVIII, preocupada por la salud, el confort y la funcionalidad.

19 "Rafael Bergamín", en Conarquitectura, Conarquitectura Ediciones, Madrid 2004, pp. 89-96.

20 Rafael BERGAMíN en Eduardo AMANN, "Paseo por 'El Viso' madrileño del brazo de Bergamín", El Inmueble $\mathrm{n}^{\circ} 2,1966$, p. 20.

${ }^{21}$ Rafael BERGAMÍN en Eduardo AMANN, "Paseo por 'El Viso' madrileño del brazo de Bergamín", El Inmueble n 2, 1966, p. 20.

22 Rafael BERGAMín, "Casa del Marqués de Villora en Madrid" en Arquitectura n 113, Sociedad Central de Arquitectos, Madrid, 1928, p. 282

${ }^{23}$ En Inglaterra sin embargo el concepto de austeridad y contención formal llevaba siglos imperando. Hace ya más de cuatrocientos años Francis Bacon dijo: "Houses are built to live in, not to look at" ("Las casas están hechas para vivir en ellas, no para mirarlas") en Hermann MUTHESIUS, The English House, (Das englische Haus. Wasmuth, Berlin 1904). Crosby Lockwood Staples, London 1979, p. 149. 


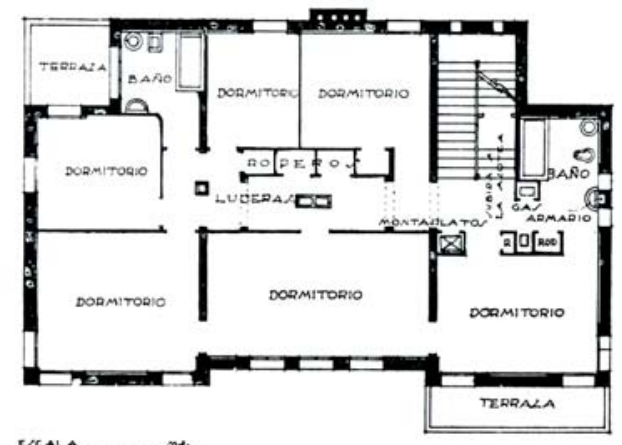

45
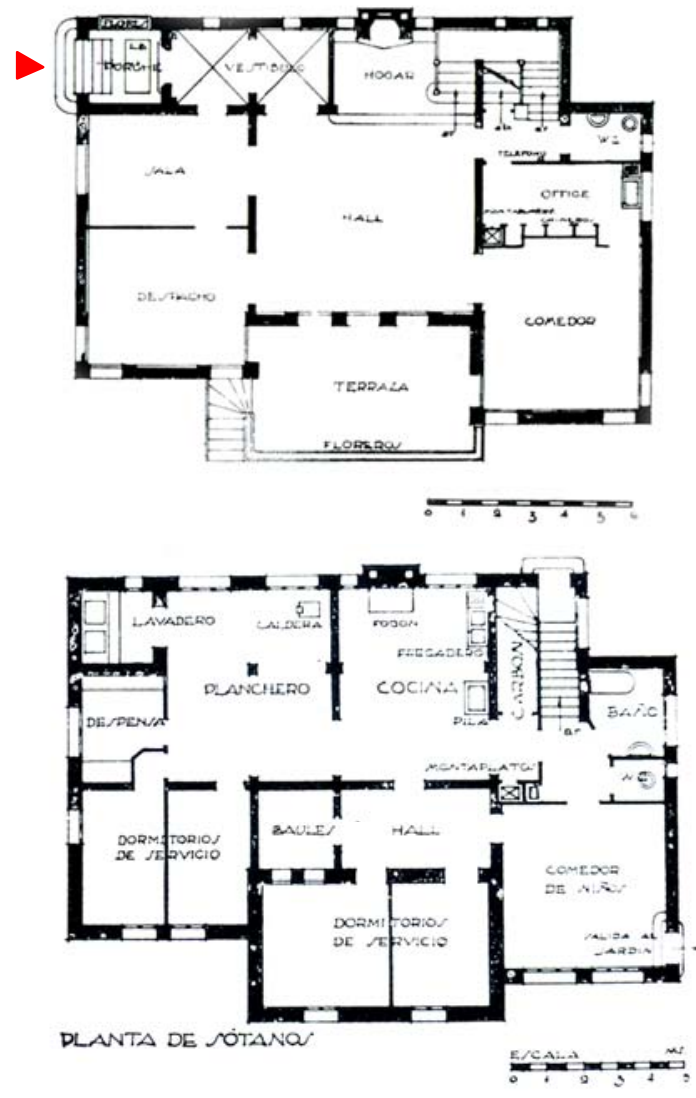

4.09
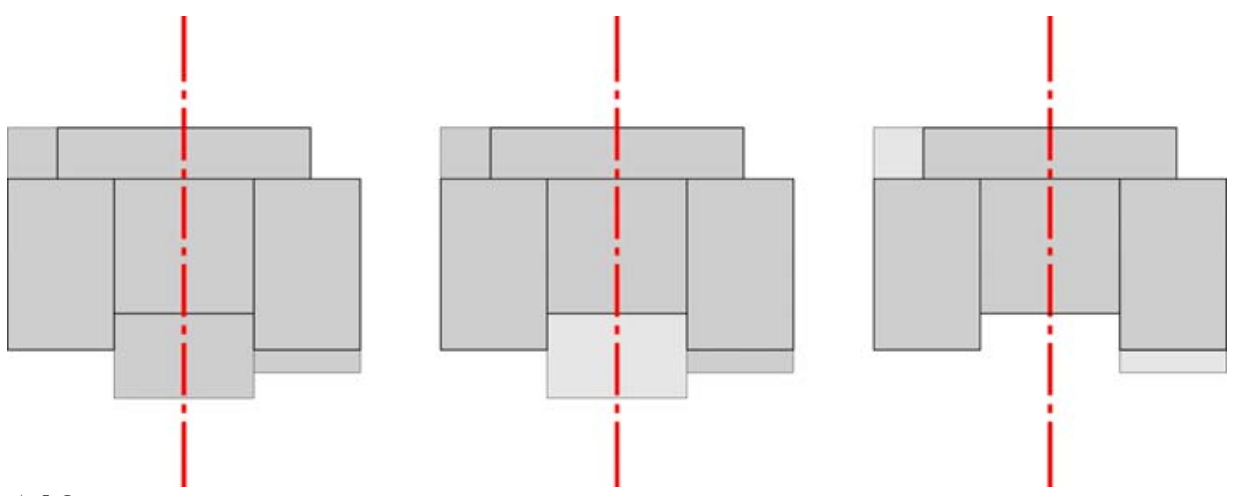

4.10

4.09 R. Bergamín. Casa del Marqués de Villora, Madrid, 1927-1928. Plantas semisótano, baja y primera.

4.10 Matrices geométricas de las plantas (dibujos de la autora). 
La sobriedad exterior de una cierta apariencia loosiana, aloja una planta compacta en tres alturas: semisótano, planta baja y primera [fig. 4.10] y presenta un orden tripartito y simétrico, clásico de las viviendas inglesas y americanas ${ }^{24}$. Consta de un hall cuadrado y abierto al sur en planta baja como elemento central, con el hogar al fondo y en su frente una terraza. Éste aparece flanqueado por dos crujías longitudinales que sobresalen ligeramente del plano de fachada y por una crujía transversal adosada a las otras tres, alargada y estrecha, que contiene el acceso en la esquina noroeste, a continuación el vestíbulo, el hogar y la escalera principal de la vivienda ${ }^{25}$.

La planta primera mantiene una volumetría simétrica mientras que el resto de plantas presentan ciertas extensiones de las crujías, convertidas en terrazas en los niveles superiores, que alteran el orden de la composición. De este modo, en la planta baja, el cuerpo situado al este del hall crece hacia el sur para poder albergar el oficio y el comedor; por su lado el volumen situado al norte se extiende hacia el oeste generando un porche que protege el umbral de entrada. En la planta semisótano es la crujía central la que se extiende hacia el sur para albergar dos dormitorios de servicio, creando así la terraza de la planta primera [fig. 4.11].

La distribución del programa viene condicionada por la captación solar, orientándose el mayor número de estancias posible al mediodía e incluyendo una terraza solárium en la $a_{z o t e}{ }^{26}$. Lo mismo sucede con el tamaño de los huecos, en las que se supeditan las cuestiones compositivas a los criterios de soleamiento, provocando una pérdida de carácter en la fachada principal de acceso:

"(...) está orientada a poniente y de propósito no se ha resuelto como una 'fachada principal', pues esto hubiera llevado consigo la modificación radical de la distribución por plantas y del criterio seguido al estudiar los muros y tamaño de los huecos' ${ }^{\prime 27}$. Los criterios arquitectónicos aplicados por Bergamín dan como resultado volúmenes depurados que, a su juicio, proporcionan una "arquitectura un poco 'seca'" 28 , que precisa

\footnotetext{
24 Juan Antonio CORTÉS, El racionalismo madrileño. Colegio Oficial de Arquitectos de Madrid 1992, p.160-161.

${ }^{25}$ La organización de la Casa Villora es muy similar a ciertas residencia inglesas como el Raynham Hall de Norfolk (1635), o a la más tardía Lord Windsor's house de Londres (1899).

${ }^{26}$ Rafael BeRGAMíN, "Casa del Marqués de Villora en Madrid" en Arquitectura no 113, Sociedad Central de Arquitectos, Madrid, 1928, p. 286

${ }^{27}$ Rafael BERGAMíN, "Casa del Marqués de Villora en Madrid" en Arquitectura n 113 , Sociedad Central de Arquitectos, Madrid, 1928, p. 282.

${ }^{28}$ Bergamín describe así la arquitectura de las viviendas de El Viso en las que aplica los mismos criterios que en la Casa del Marqués de Villora. José de CASTRO ARINES, "Rafael Bergamín y su arquitectura madrileña" en Temas de Arquitectura y Urbanismo n 138, 1970, p. 2.
} 


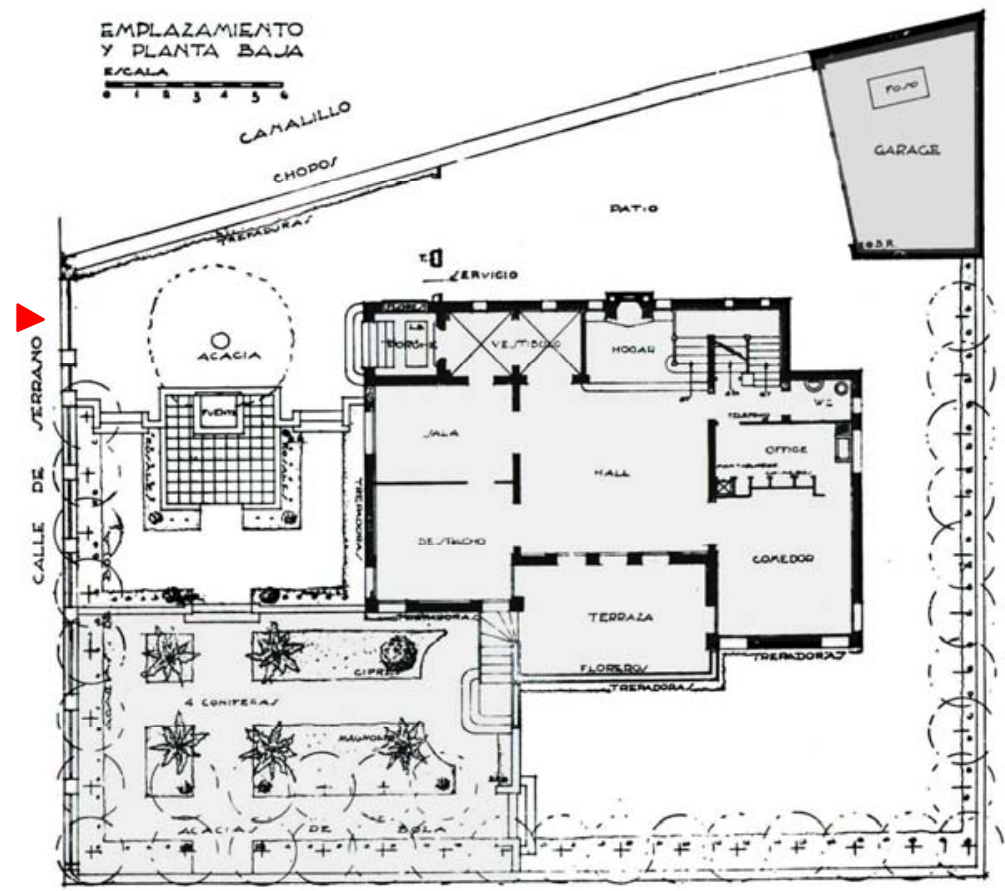

(1)

4.11
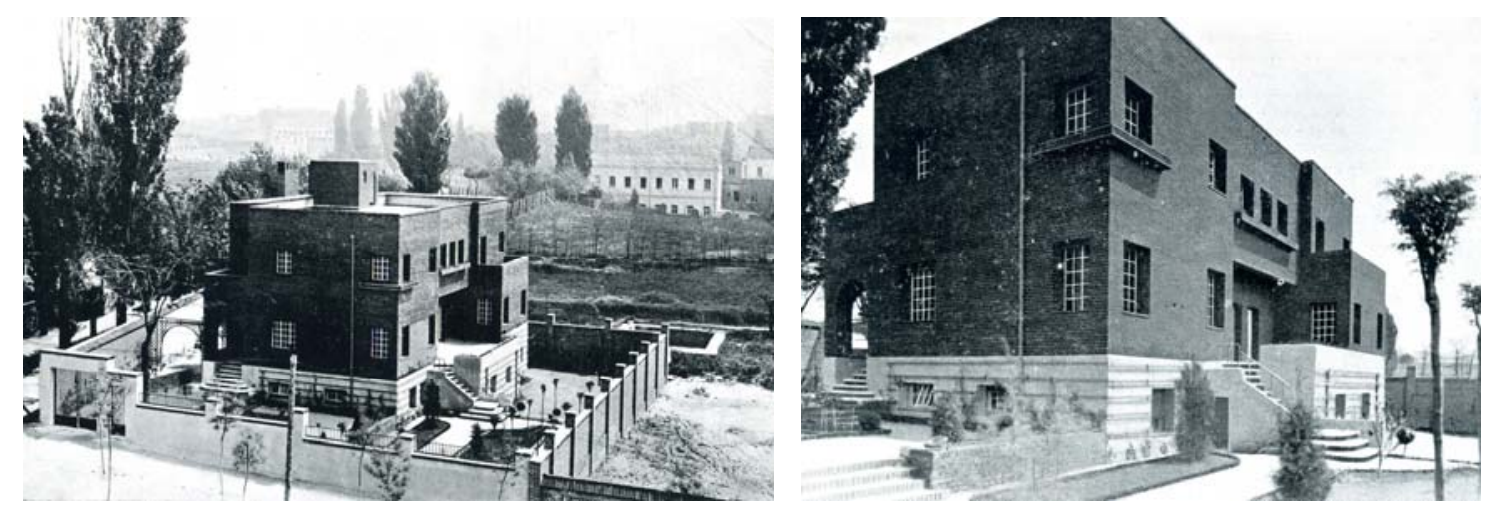

4.12 y 4.13
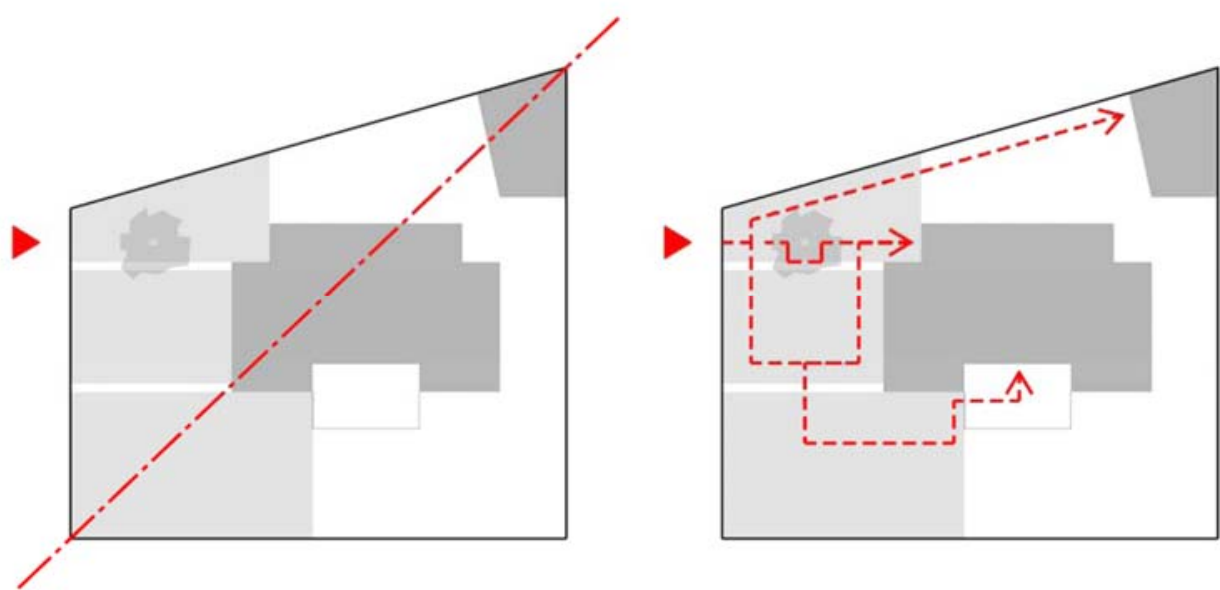

4.14

4.11 R. Bergamín. Casa del Marqués de Villora, Madrid, 1927-1928. Planta del conjunto.

4.12 y 4.13 R. Bergamín. Casa del Marqués de Villora, Madrid, 1927-1928. Vistas del conjunto y de la casa desde el jardín.

4.14 Organización del recinto en diagonal y relaciones establecidas a través del jardín (dibujos de la autora). 
ser compensada con la presencia de vegetación [fig. 4.13 $]^{29}$.

Su formación como ingeniero de Montes se ve reflejada en la Casa de Villora, donde diseña un jardín en el que llega incluso a definir cada una de las especies que lo forman ${ }^{30}$. Un jardín compuesto de tres plataformas escalonadas ubicadas en el lateral de acceso a la parcela. La plataforma más definida y arbolada se sitúa en la esquina, entre el cierre perimetral y la fachada sur de la vivienda. Ésta conecta a través de una escalera con la terraza y, en ella, la disposición geométrica de la vegetación que delimita los recorridos y la vinculación con la vivienda hace que se incorpore como una estancia más a la casa.

El garaje se ubica en la esquina opuesta al jardín y completa una secuencia de elementos ordenados en diagonal dentro del recinto trapezoidal de la parcela, que evita la percepción frontal de las fachadas de la vivienda, especialmente la sur, es decir, la que más evidencia su génesis simétrica. Con esta disposición se potencia la percepción de las esquinas de la misma, hacia las que Bergamín arrastra los huecos de las ventanas para forzar la percepción diedro y la comprensión volumétrica de la casa [fig. 4.14].

En el recinto de la propiedad destaca la presencia de un gran árbol, una acacia enfrentada a la entrada principal, que se convierte en un hito visual. Años más tarde durante su exilio en Caracas escribe:

\section{"No creo que exista un solo Arquitecto en el mundo que no considere el árbol como su mejor amigo y colaborador. El gran Arquitecto francés Le Corbusier llegó a construir en la Exposición de París, de 1925, una casa alrededor de un árbol, que pasaba a través de unos círculos abiertos en el 'concreto' en cada piso y salía victorioso por encima de la cubierta". ${ }^{31}$}

Estos recuerdos ponen de manifiesto, además de su respeto por la naturaleza, la huella imborrable que guarda Bergamín de su visita a la Exposición de Artes Decorativas de París de 1925.

Este viaje a París, su contacto con las vanguardias artísticas de Madrid y su formación como experto forestal son los factores más influyentes en la definición de la arquitectura residencial y sanitaria de Bergamín, uno de los más importantes impulsores del racionalismo en España.

\footnotetext{
${ }^{29}$ En el Viso se apoyará también en el color para romper con la "sequedad" descrita.

30 Una acacia grande junto a la entrada, cuatro coníferas, un ciprés, un magnolio y una fila de acacias perimetral cerrando la parcela.

${ }^{31}$ Rafael BERGAMín, 20 años en Caracas: 1938-1958. Gráficas Reunidas, Madrid 1959, p. 21.
} 

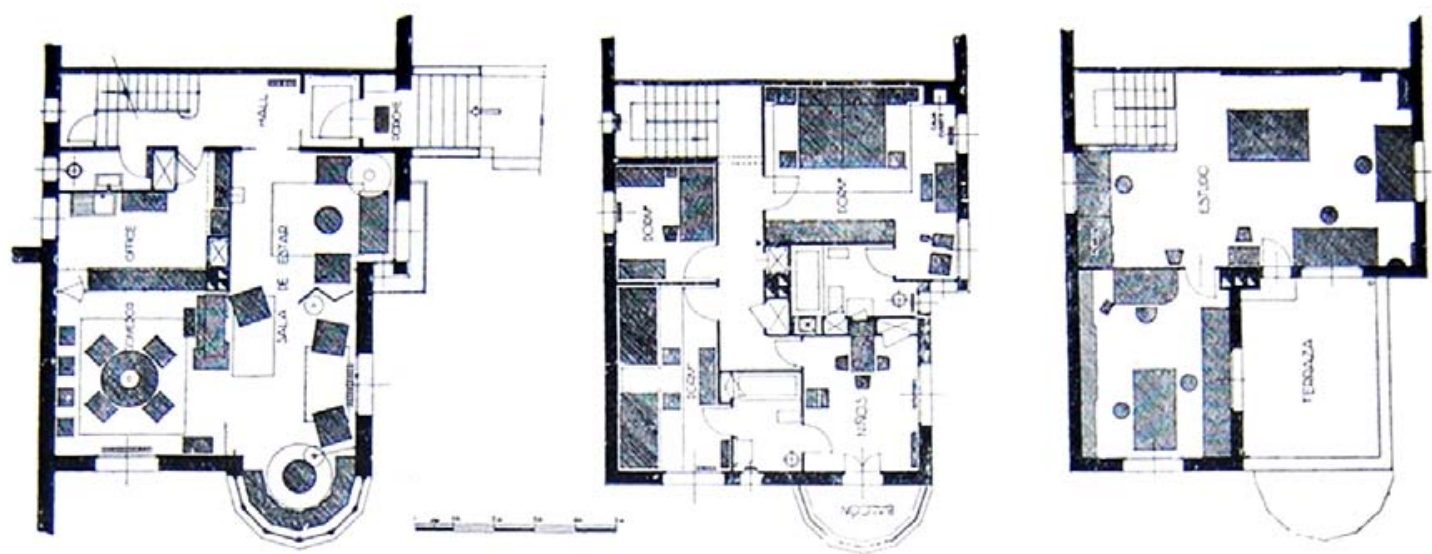

4.15
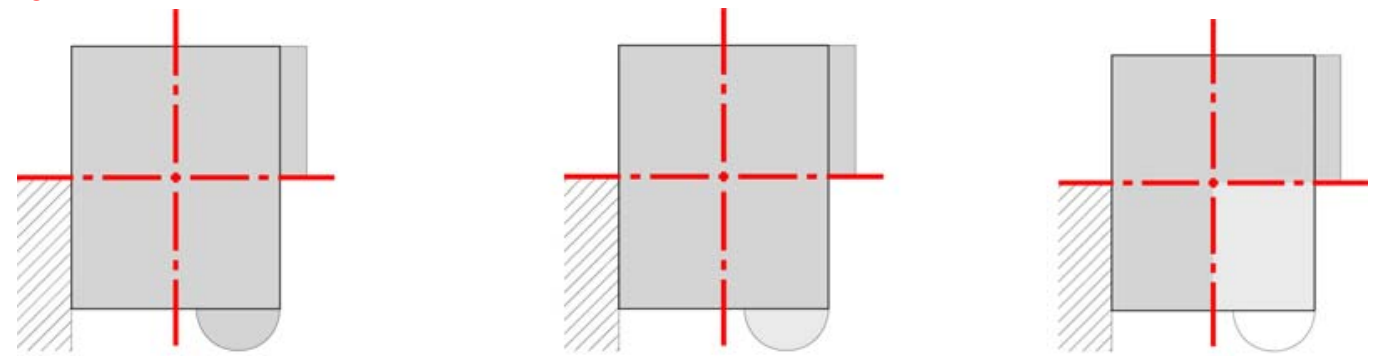

4.16
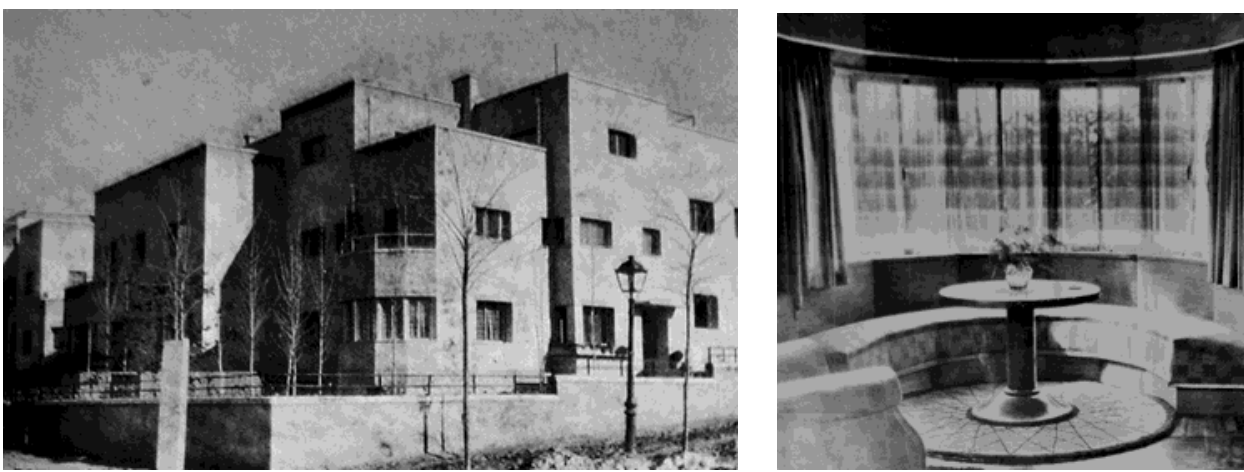

4.17 y 4.18
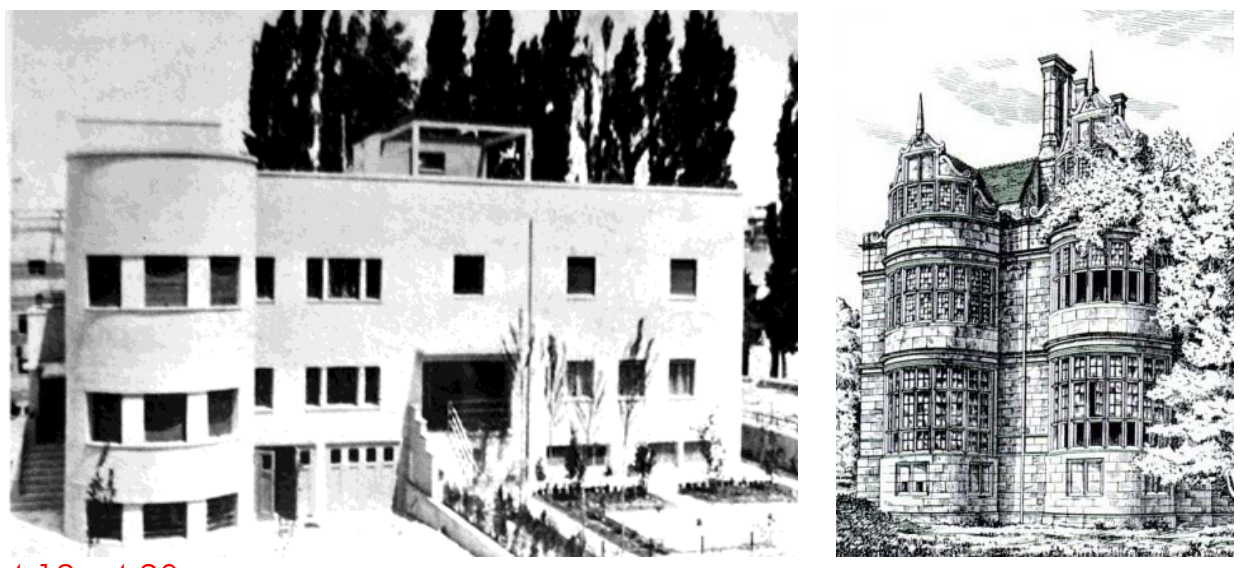

4.19 y 4.20

4.15 R. Bergamín. Vivienda de la colonia Residencia, Madrid, 1933. Planta baja, primera y segunda. 4.16 Matrices geométricas de las plantas (dibujos de la autora).

4.17 y 4.18 R. Bergamín. Vivienda de la colonia Residencia, Madrid, 1933. Imagen exterior e interior del mirador.

4.19 F. Salvador. Vivienda de la colonia Residencia, Madrid, 1933.

4.20 Kirby Hall, Northamptonshire, 1570-75. Bow-window (mirador curvo). 


\section{VARIACIONES FORMALES DE LOS MODELOS}

A principio de los años treinta Bergamín comienza su participación en varias sociedades para la construcción de colonias residenciales. Entre 1931 y 1933 junto a Luis Blanco Soler, Javier Gómez de la Serna y Gregorio Iturbe, forma parte de la Cooperativa de Casas Económicas Residencia, conocida como Colonia Parque Residencia, construida en Madrid en la barriada del hipódromo. Consta de un grupo de viviendas en hilera en su mayoría, aunque también las hay aisladas, rodeadas de una gran cantidad de nuevos árboles ${ }^{32}$. La colonia tiene 69 viviendas en total, con un lenguaje formal próximo a las Siedlung alemanas, aunque no se construyen viviendas mínimas para las clases obreras, sino que se trata de casas unifamiliares de unos 150 ó $200 \mathrm{~m}^{2}$ cada una destinadas a familias de profesionales liberales de clase media alta.

Las propuestas residenciales de Bergamín en la Colonia Parque Residencia mantienen ciertas características de la Casa del Marqués de Villora. Parten de una matriz geométrica compacta de la planta a la que se le aplican extensiones puntuales [fig. 4.16] y su aspecto presenta también volúmenes puros y desornamentados, aunque aquí se sustituye el ladrillo visto por el revoco de mortero [fig. 4.17].

A cada planta se asigna un uso diferente: las dependencias de servicio incluido el garaje en semisótano, en planta baja los salones y el comedor, y en la primera planta las habitaciones y baños; sobre ella se añade un nivel más para la zona de trabajo [fig. 4.15].

En uno de sus proyectos realizados para la Colonia Parque Residencia destaca la presencia de un volumen poligonal orientado al sur, casi semicircular, dependiente del salón para ampliar las vistas y la captación solar [fig. 4.18]. Esta pieza aparece en planta baja y se convierte en una terraza en la planta primera.

Pero, no sólo él incluye volúmenes curvos en la Colonia, también aparecen en las viviendas de los arquitectos Luis Blanco Soler ${ }^{33}$ y Fernando Salvador Amós. Este último es más radical y realiza un proyecto de dos viviendas pareadas, en una de las cuales presenta medio cilindro de tres plantas de altura en una de sus fachadas ${ }^{34}$ [fig. 4.19]. Se recuperan así los

32 "(...) simultáneamente con la construcción se ha previsto la obra de jardinería, habiéndose plantado unos 1.500". "La Colonia Residencia en la Barriada del Hipódromo, en Madrid", en Viviendas: revista del hogar $\mathrm{n}^{\circ} 8,1933$, p. 6.

33 "La Colonia Residencia en la Barriada del Hipódromo, en Madrid", en Viviendas: revista del hogar n० 8, 1933, p. 21.

34 "La Colonia Residencia en la Barriada del Hipódromo, en Madrid", en Viviendas: revista del hogar nº 8,1933, p. 22 y 23. 

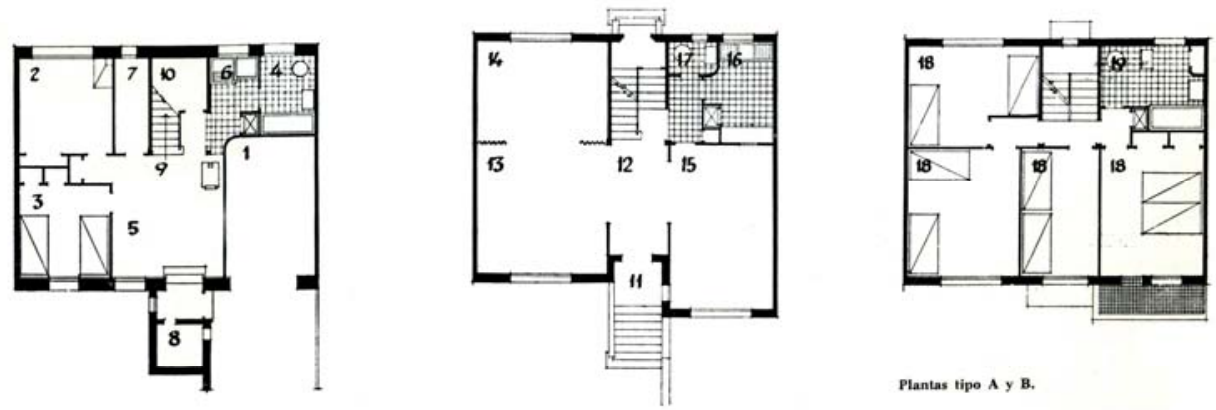

Plantas tipo A y B.
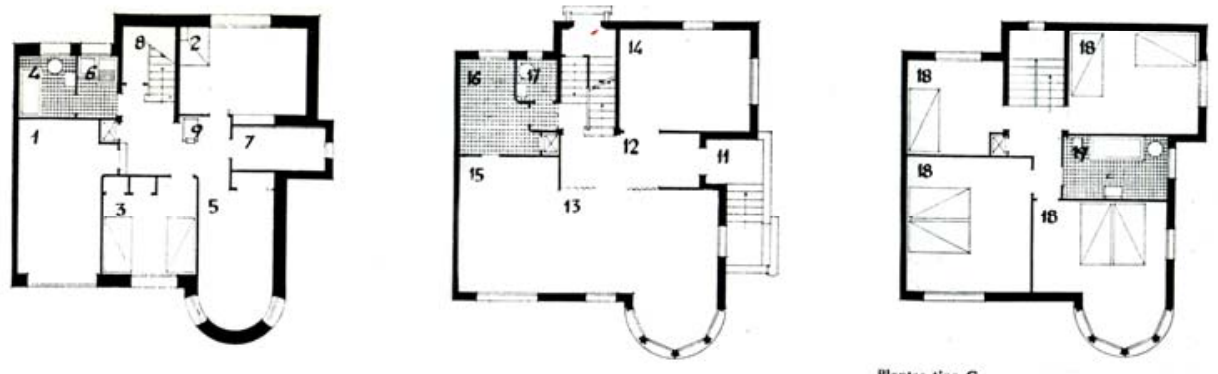

4.21

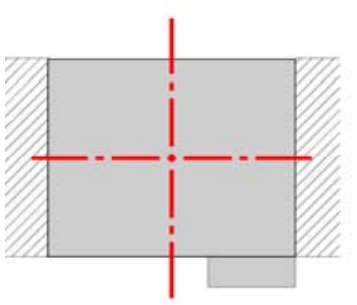

TIPO A y B 250 m $^{2}$ centro 4.22
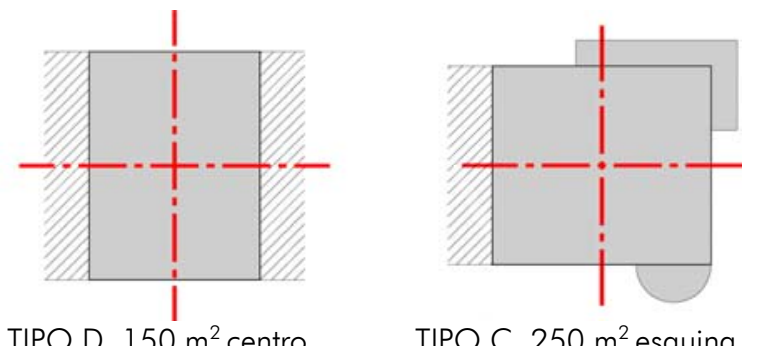

TIPO C $250 \mathrm{~m}^{2}$ esquina

\section{M.VII "EL VISO"}
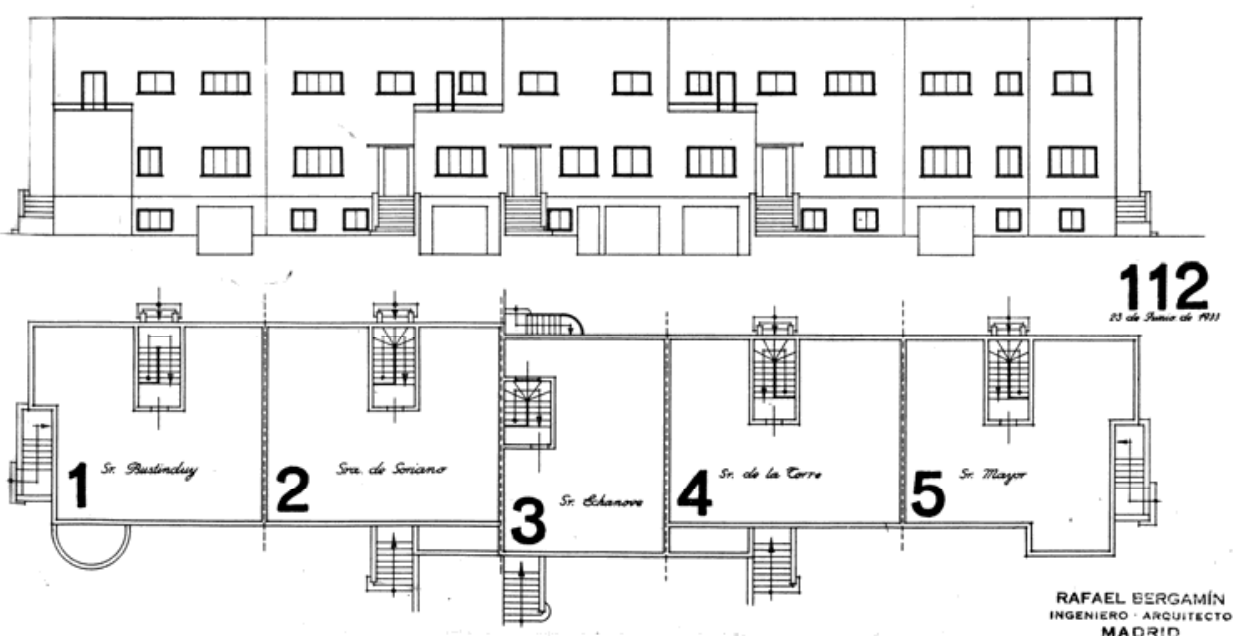

4.23

4.21 R. Bergamín y L. Blanco Soler. Viviendas de la colonia El Viso, Madrid, p.1933-36 o.1958. Viviendas tipo.

4.22 Matrices geométricas de planta (dibujos de la autora).

4.23 R. Bergamín y L. Blanco Soler. Viviendas de la colonia El Viso, Madrid, p.1933-36 o.1958. Agrupación de viviendas en hilera. 
miradores curvos ingleses del siglo $\mathrm{XVI}^{35}$, indispensables en las casas de campo isabelinas ${ }^{36}$ [fig. 4.20].

Tras el éxito de la sociedad en la Colonia Parque Residencia, Bergamín repite la experiencia en el barrio residencial de El Viso, proyectado entre los años 1933 y 1936 junto al arquitecto Blanco Soler y a Gregorio Iturbe como promotor, sin embargo, Blanco Soler no llegó a participar en el proyecto. Las obras se vieron truncadas por la Guerra Civil y por el exilio de Bergamín a Venezuela en 1938, obligando a que sea su sobrino Luis Felipe de Vivanco quien concluya la construcción en $1953^{37}$.

Las viviendas de El Viso son una continuación, con ciertas variaciones, de las propuestas residenciales de la Colonia Parque Residencia, aunque aquí desaparece la planta segunda con el despacho profesional. En ellas se mantienen los mismos criterios de orden en las plantas y de orientación en las estancias, y se parte de una geometría unitaria casi cuadrada a la que se aplican extensiones y sustracciones de prismas y cilindros [fig. 4.21].

A pesar de la uniformidad exterior que presentan las 242 viviendas de El Viso, que en origen se ajustan a cuatro modelos ${ }^{38}$, la variedad es mucho mayor. Bergamín acaba adaptando el modelo correspondiente a las necesidades del cliente y diseña a cada propietario una vivienda distinta ${ }^{39}$ manteniendo las características del modelo de partida [fig. 4.23].

En sus viviendas aisladas y de mayor programa coetáneas a la Colonia, como la Casa del Sr. Bergua Oliván en Zaragoza (1933) [fig. 4.24 y 4.25], la Casa para fin de semana construida cerca de Madrid (1934) conocida como Casamarilla, con la que Bergamín alcanza un reconocimiento internacional al ser publicada en el libro de Raymond McGrath Twentieth-Century Houses (1934) ${ }^{40}$ [fig. 4.26 y 4.27], o la Casa del Barco, en la calle Joaquín Costa de Madrid (1935) situada en un escarpado solar en pendiente [fig. 4.28 y 4.29 ], se

${ }^{35}$ Hermann MUTHESIUS, The English House, Volume: // Layout and Construction, (Das englische Haus. Wasmuth, Berlin 1904). Frances Lincoln Ltd., London 2007, p. 193.

${ }^{36}$ Este elemento también había sido utilizado por su amigo García Mercadal en varias ocasiones anteriores, en su proyecto de un chalet mediterráneo (1924) y en su famosa obra el Rincón de Goya en Zaragoza (1928).

37 Henry Vicente GARRIDO (dir.), Arquitecturas desplazadas. Arquitecturas del exilio español. Ministerio de Vivienda, Madrid 2007, p. 80.

${ }^{38}$ Existían dos modelos, el $\mathrm{A}$ y el $\mathrm{B}$, de $200 \mathrm{~m}^{2}$ ubicados en el centro del boque, el modelo $\mathrm{C}$ de los extremos, y el D de $150 \mathrm{~m}^{2}$. Antón CAPITEL (ed.) Arquitectura de/ siglo XX: España. Tanais Ediciones, Madrid 2000, p. 96.

39 Rafael AMAT, "Colonia El Viso-Madrid 1934", en Arquitectura n 204 y 205, Colegio Oficial de Arquitectos, Madrid 1977, pp. 50-56.

40 "Rafael Bergamín, De la 'gran borrasca' y el exilio a la evanescente figura del arquitecto en Venezuela" en Entre rayas, la revista de Arquitectura, n84, Caracas 2010, p.47. 

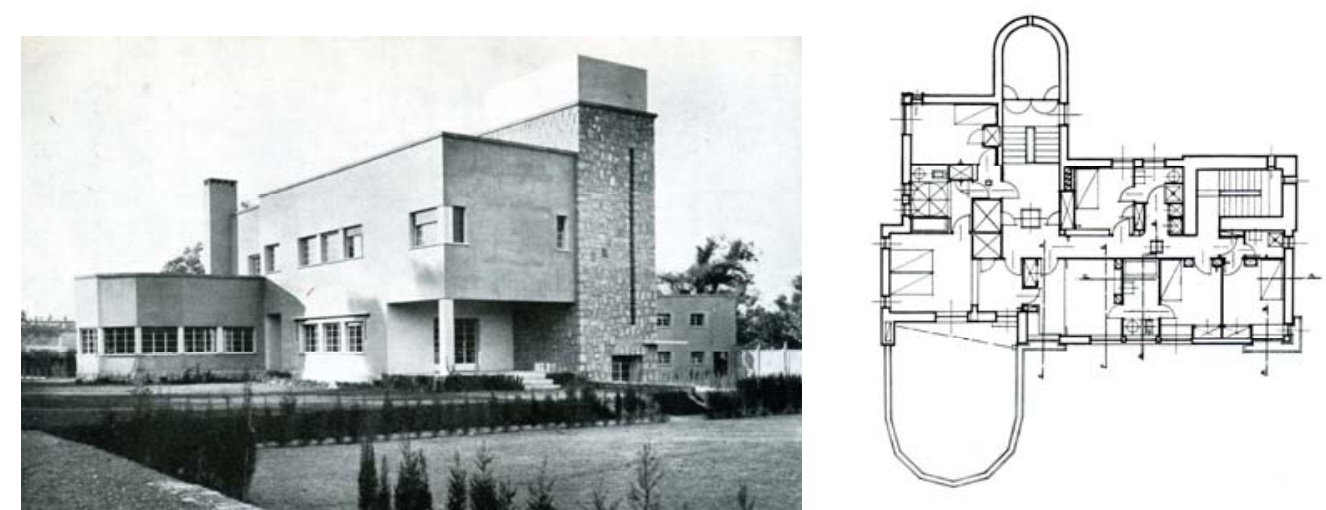

4.24 y 4.25
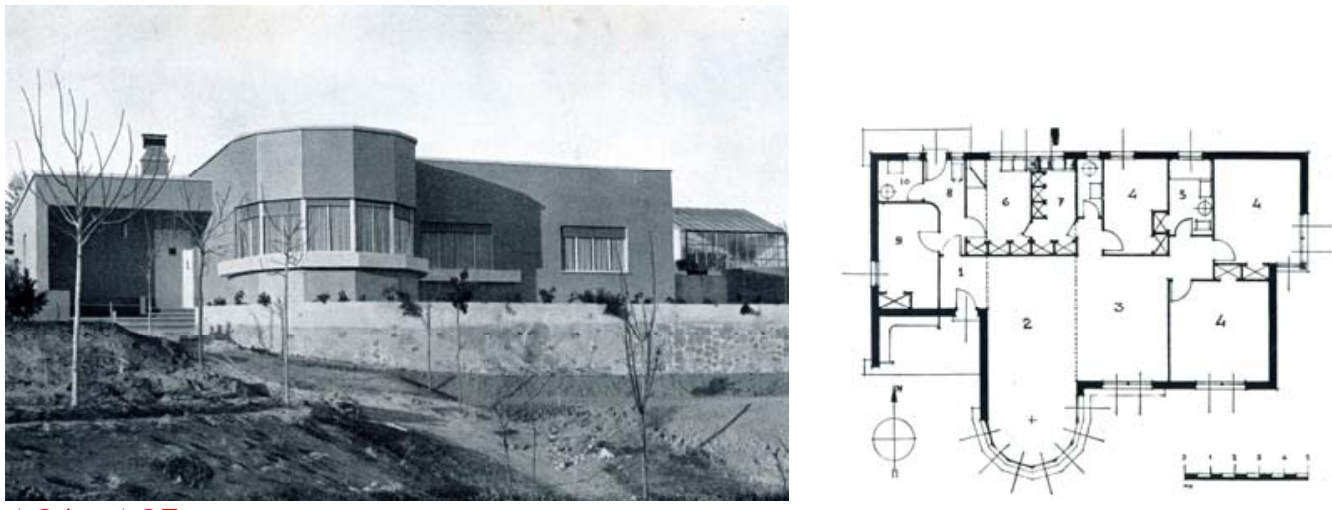

4.26 y 4.27
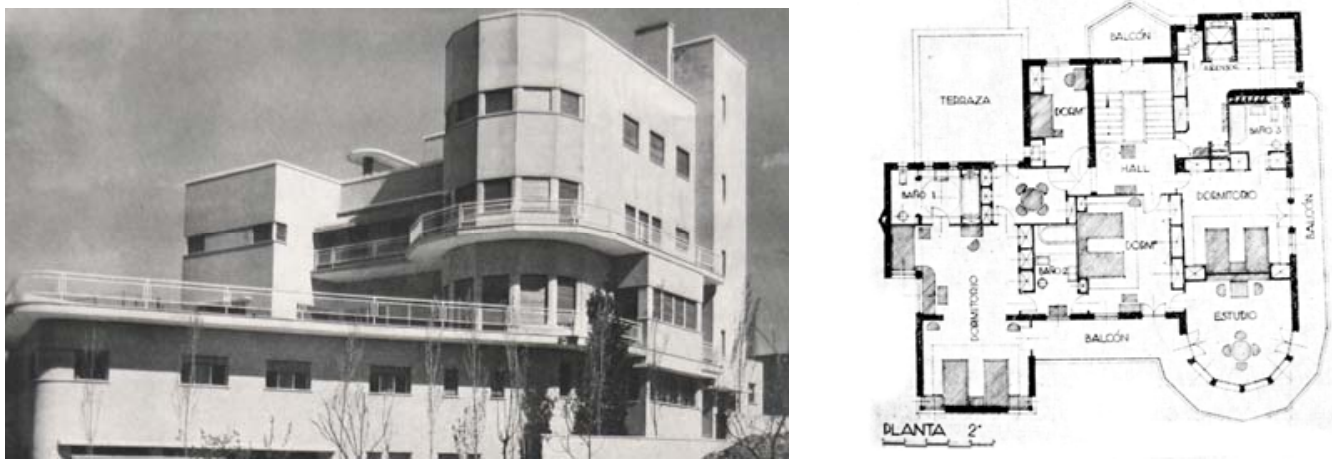

4.28 y 4.29
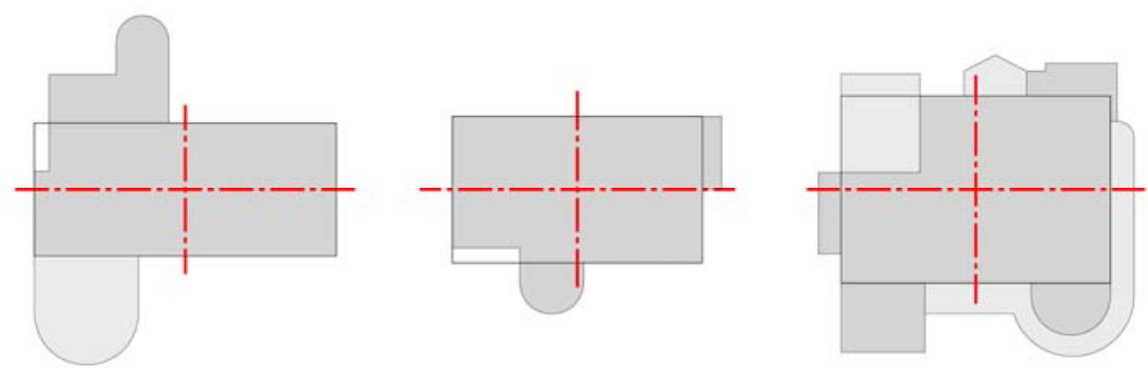

4.24 y 4.25 R. Bergamín. Casa del Sr. Bergua Oliván, Zaragoza, 1933. Exterior y planta primera.

4.26 y 4.27 R. Bergamín. Casa para fin de semana, Madrid, 1934. Exterior y planta baja.

4.28 y 4.29 R. Bergamín. Casa del Barco, Madrid, 1935. Exterior y planta segunda.

4.30 Matrices geométricas de cada casa (dibujos de la autora). 
aprecian similares constantes organizativas y formales ya existentes en sus propuestas residenciales en hilera. Todas parecen ser variantes de un mismo modelo de vivienda que parte de una matriz geométrica unitaria a la que se le quita o añade volúmenes menores para adaptarse a las necesidades del programa y a las condiciones topográficas de implantación al tiempo que se imprime una mayor dinámica a la forma [fig. 4.30].

Lo mismo sucede en el ámbito sanitario con los sanatorios antituberculosos que proyecta, los cuales resultan ser alteraciones de un mismo modelo de sanatorio en forma de T.

En torno a los años treinta Bergamín participa no sólo en cooperativas para la construcción de viviendas sino también para la construcción de sanatorios, como la Sociedad del Sanatorio Medio. Una organización "con cierto espíritu filantrópico"41 que, junto a Julio Blanco, Carlos Padrós y el ingeniero Jose Luis Grasset, se constituye con el fin de construir sanatorios antituberculosos pulmonares para los enfermos de clase media y baja que no pueden costearse la estancia en sanatorios privados, viéndose avocados a engrosar las infinitas listas de espera de los hospitales del estado. De este modo, por un precio módico pueden ser atendidos en modernas instituciones debidamente acondicionadas para $\operatorname{tal} \mathrm{fin}^{42}$. El primer proyecto de sanatorio que realiza la Sociedad es el Sanatorio antituberculoso La Solana, ubicado en la sierra de Guadarrama en la finca Prado Bardal del municipio de San Lorenzo del Escorial [fig. 4.31]. Consta de un edificio principal con planta en forma de T y de un pabellón de enfermeras rectangular, que recuerda a la Escuela Residencia de Enfermeras construida en 1933 en el Hospital del Rey en Madrid, también obra de Bergamín.

Se desconoce la fecha exacta en que se concibe el proyecto de La Solana, no obstante, en el $n^{\circ} 17$ de la revista Cortijos y Rascacielos del año 1934 se publica una perspectiva axonométrica del mismo ${ }^{43}$ [fig. 4.32], aunque los planos definitivos del proyecto difieren en ligeros aspectos del dibujo publicado y están datados en el año $1935^{44}$.

\footnotetext{
41 "Hospital Comarcal de El Escorial" en Arquitectura y Desarrollo Urbano. Comunidad de Madrid zona Oeste) Tomo V. Colegio Oficial de Arquitectos, Madrid 1998, p. 340.

${ }^{42}$ En los sanatorios de la Sociedad del Sanatorio Medio, aunque el orden de admisión coincidía con el orden de solicitud, la posesión de acciones en la Sociedad suponía una condición de prioridad para el ingreso. "Hospital Comarcal de El Escorial" en Arquitectura y Desarrollo Urbano. Comunidad de Madrid zona Oeste) Tomo V. Colegio Oficial de Arquitectos, Madrid 1998, p. 340.

${ }^{43}$ Perspectiva publicada posteriormente en la revista Nueva Forma n ${ }^{\circ} 68,1971$.

${ }^{44}$ En la perspectiva el sanatorio constaba de una terraza solárium protegida por una ligera cubierta soportada sobre pilares, que reproducía los retranqueos curvos de la planta del cuerpo residencial, cubrición que dejará de estar presente en el proyecto definitivo del sanatorio La Solana de 1935.
} 


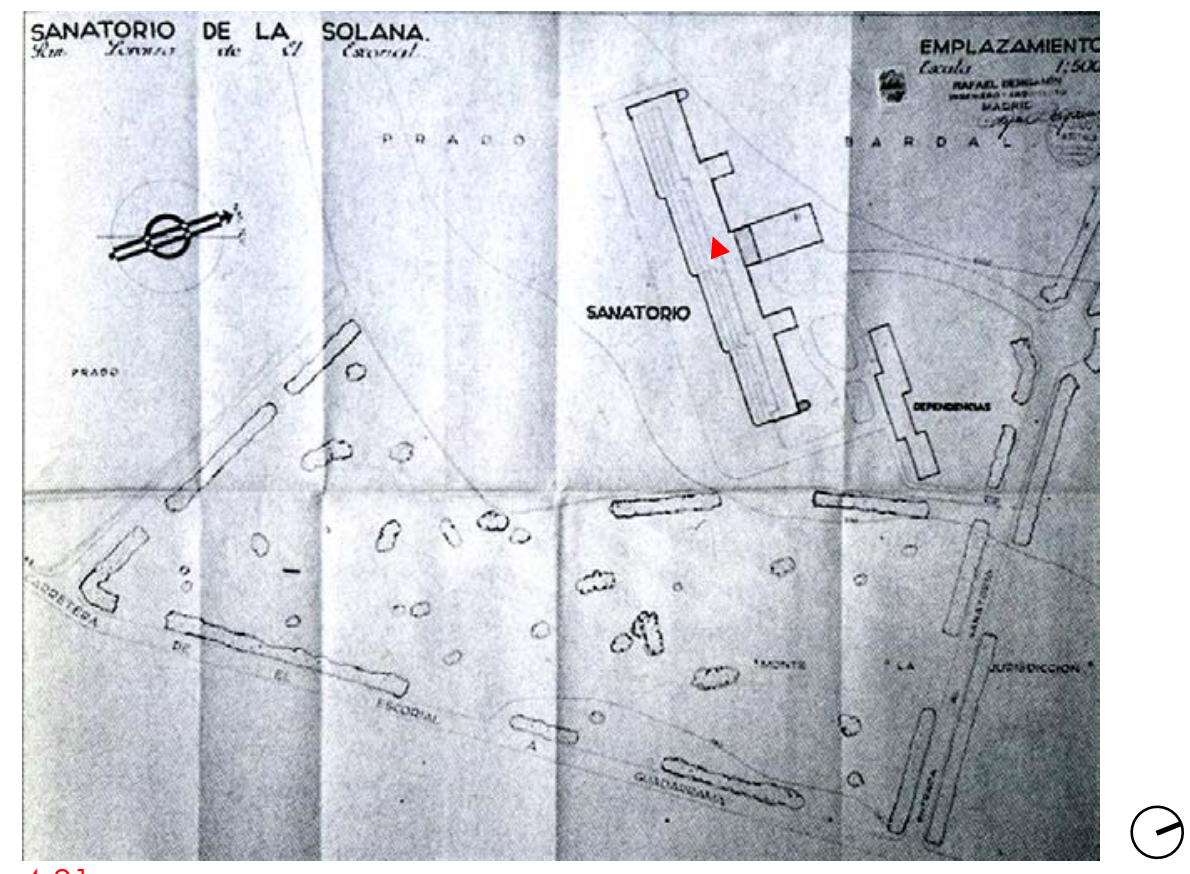

4.31

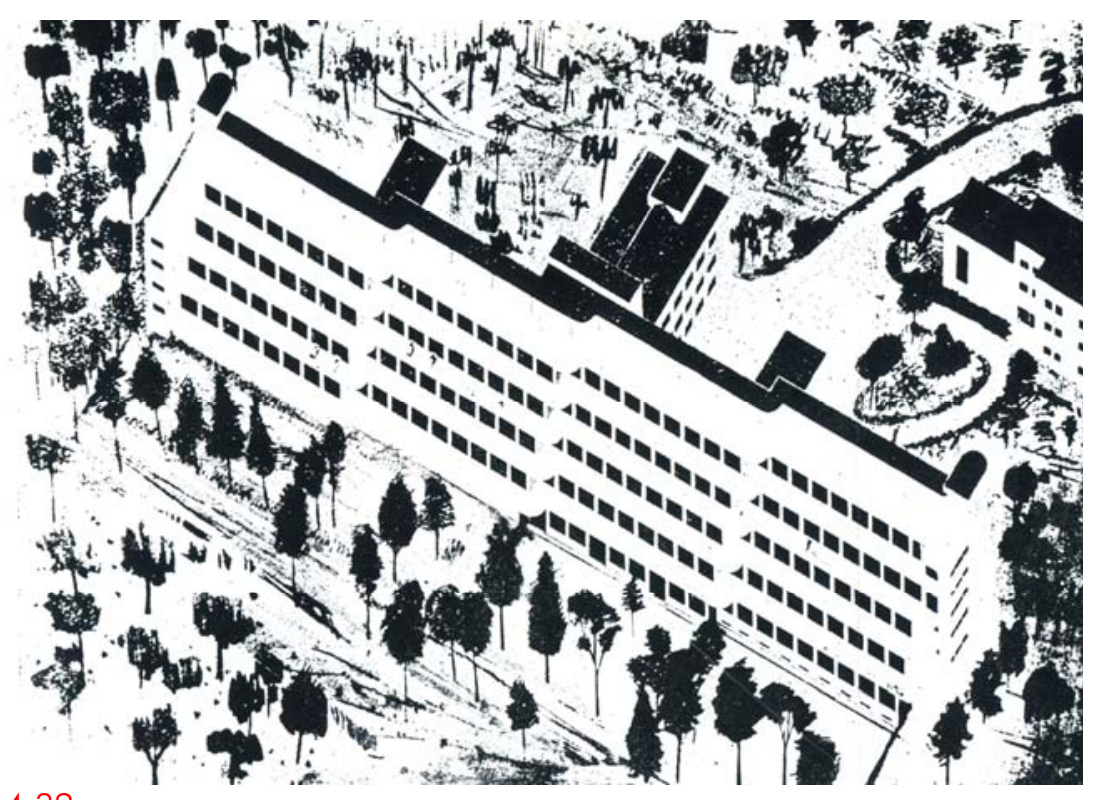

4.31 R. Bergamín. Proyecto Sanatorio La Solana, El Escorial, 1934-35. Plano de situación (1935).

4.32 R. Bergamín. Proyecto Sanatorio La Solana, El Escorial, 1934-35. Axonometría (1934). 
El proyecto de La Solana se distingue del resto de sanatorios de similar disposición en planta por su peculiar configuración del bloque residencial, fragmentado en cuatro partes o unidades de habitación que se van desplazando transversalmente en la dirección oeste-este hasta formar un bloque quebrado.

A resultas del desplazamiento volumétrico, la fachada sur adopta una composición dinámica, reforzada por las esquinas redondeados de las terrazas voladas de las galerías de cura. En la fachada norte pasan más desapercibidos dichos desplazamientos al incorporar varios cuerpos perpendiculares al bloque lineal residencial, son los denominados "martillos" que acogen los servicios comunes. Se localizan estratégicamente articulando los quiebros, y coinciden con las unidades de enfermos en que se divide el bloque de habitaciones [fig. 4.33-fig.4.34].

Así pues, la matriz unitaria con forma de $T$ en planta se descompone en planos en profundidad al introducir la "diagonalización" de la misma, [fig. 4.37], otorgando una sensación de movimiento en la fachada sur [fig. 4.38, fig. 4.39(a)]. A ésta se contrapone la composición más estática y simétrica descrita por los cuerpos dominantes de la fachada norte: un cuerpo central mayor, dos cuerpos intermedios y equidistantes, y dos prismas menores rematados en semicilindros ubicados en los testeros [fig. 4.39 (b)].

Sin embargo, la "diagonalización" y la fragmentación de la planta no son las mayores peculiaridades del proyecto de La Solana, éstas residen en sus secciones escalonadas que siguen en vertical las mismas pautas de desplazamiento diagonal [fig. 4.39(c)]. Bergamín adopta con tan singular sección, una solución similar a la propuesta por Richard Döcker en el sanatorio de Waiblingen, construido en Alemania en 192945, que aparece recogida en su libro Terrasen Typ publicado ese mismo año y en el $n^{\circ} 41$ de la revista L'Architecture Vivante publicada 1933. Las secciones de La Solana recuerdan también a las del hospital Louis Pasteur de Colmar, Francia ${ }^{46}$, escalonado y de seis plantas de altura, obra de M. W. Vetter que será publicado en el $n^{\circ} 9$ de la revista L'Architecture d'aujourd'hui en diciembre de 1934, número dedicado íntegramente a la arquitectura hospitalaria que pudo haber consultado.

La superposición de niveles en vuelo obliga a utilizar una estructura exterior de pilares para soportar la última planta en los tramos que no tienen martillos transversales. Se propone un escalonamiento de los dos frentes del bloque de habitaciones y de este modo, el dinamismo

\footnotetext{
${ }^{45}$ Bruno MORETTI, Ospedali. Ulrico Hoepli, Milano 1935, pp.59-62.

${ }^{46}$ Bruno MORETTI, Ospedali. Ulrico Hoepli, Milano 1935, pp.40-43.
} 


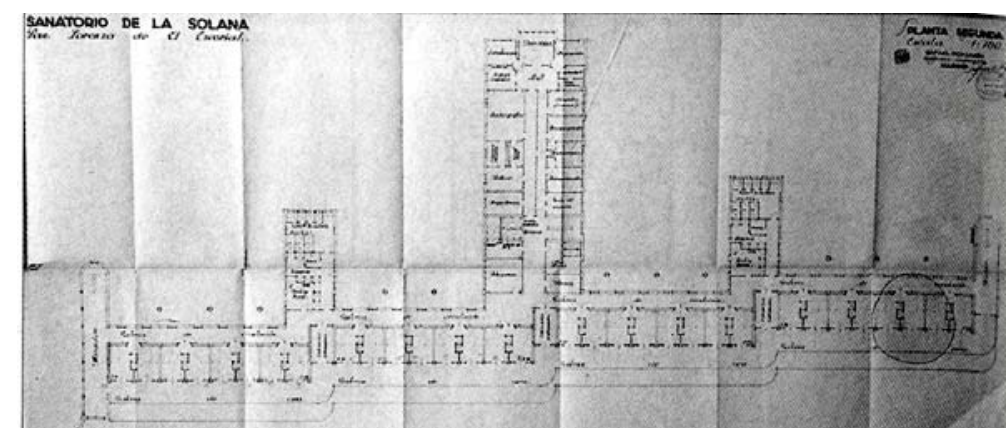

4.33

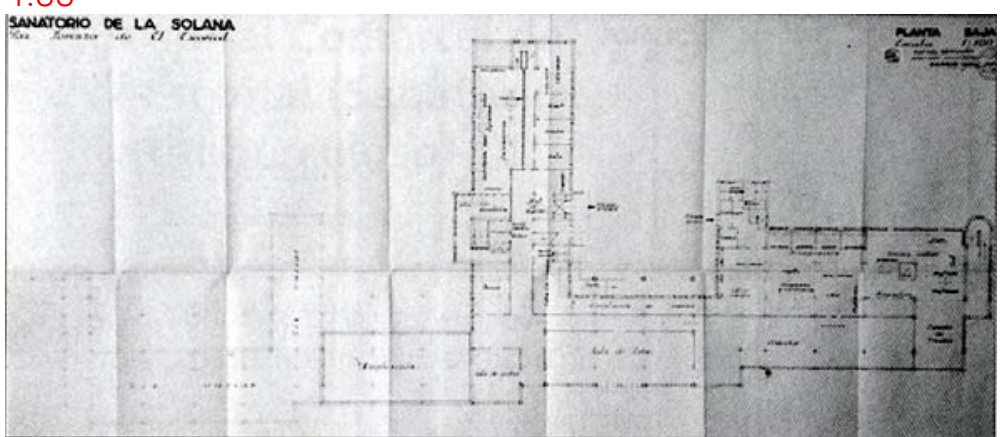

4.34

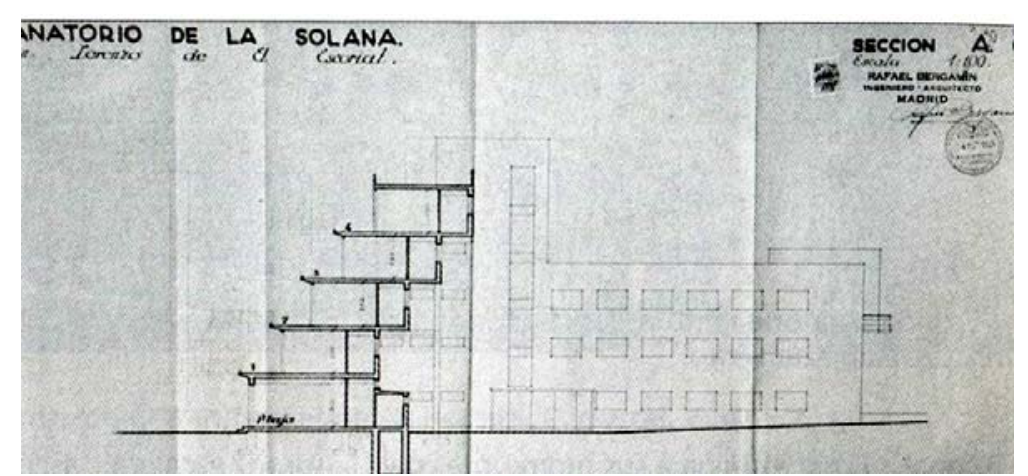

4.35

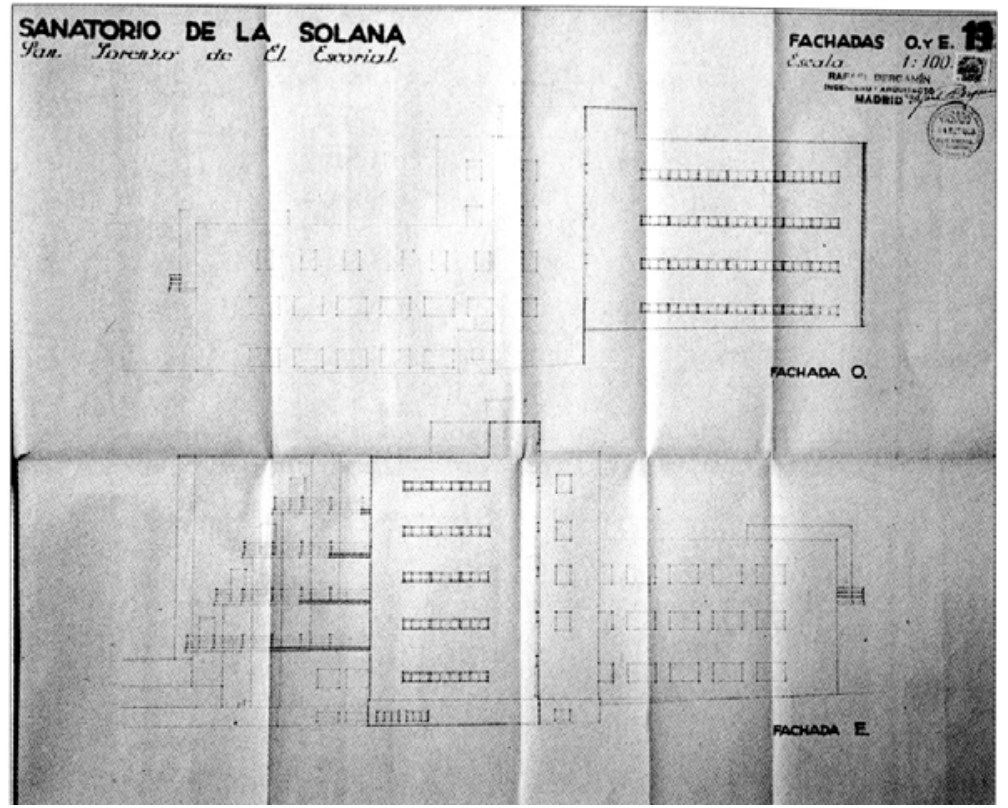

4.36

4.33 y 4.34 R. Bergamín. Proyecto Sanatorio La Solana, El Escorial, 1934-35. Planta tipo y baja (1935).

4.35 y 4.36 R. Bergamín. Proyecto Sanatorio La Solana, El Escorial, 1934-35. Sección y alzados oeste y este (1935). 


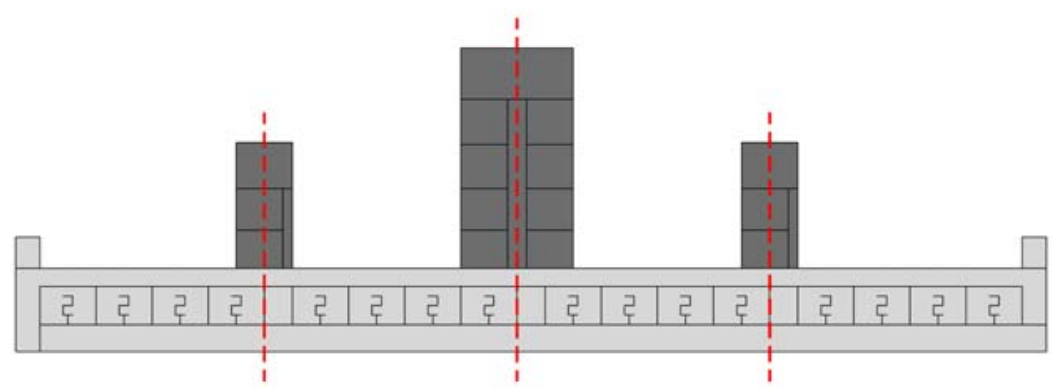

a) modelo en $T$

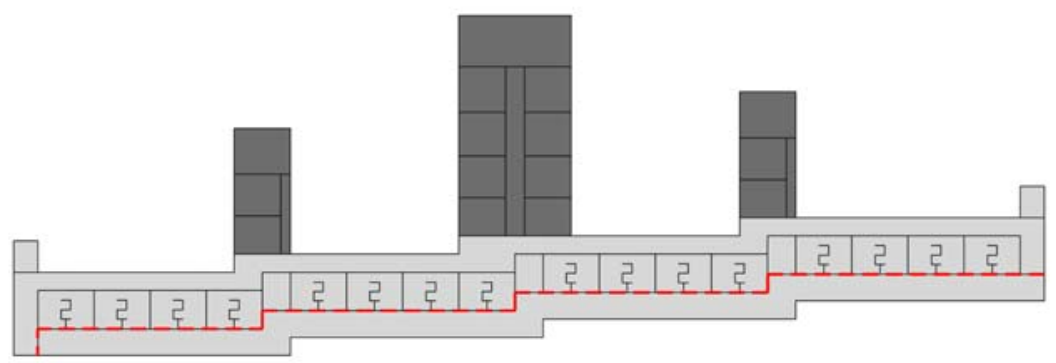

b) desplazamiento horizontal

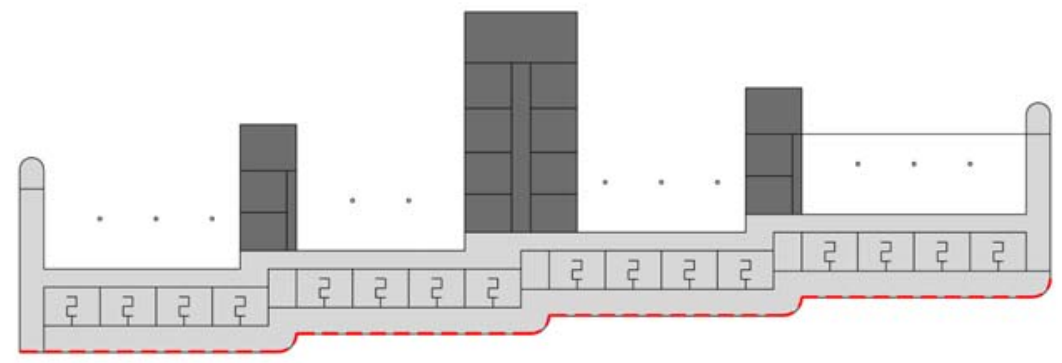

c) curvatura

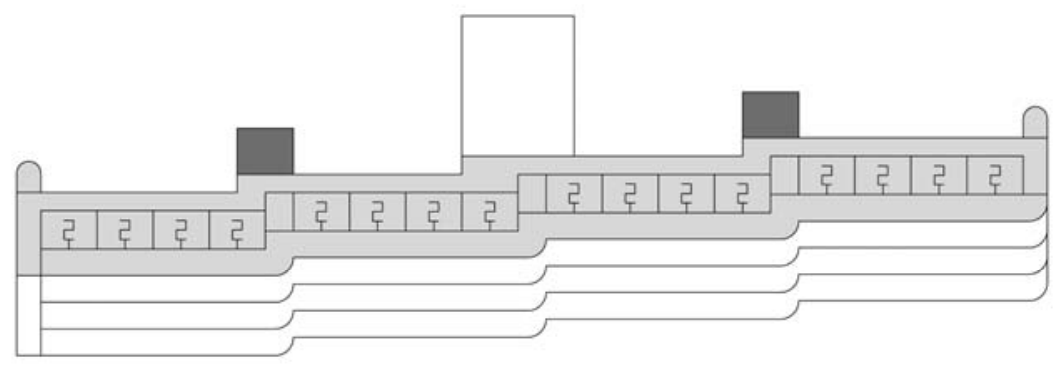

d) desplazamiento vertical

servicios comunes

habitaciones

4.37. Sanatorio La Solana procedimiento de generación (dibujos de la autora). 


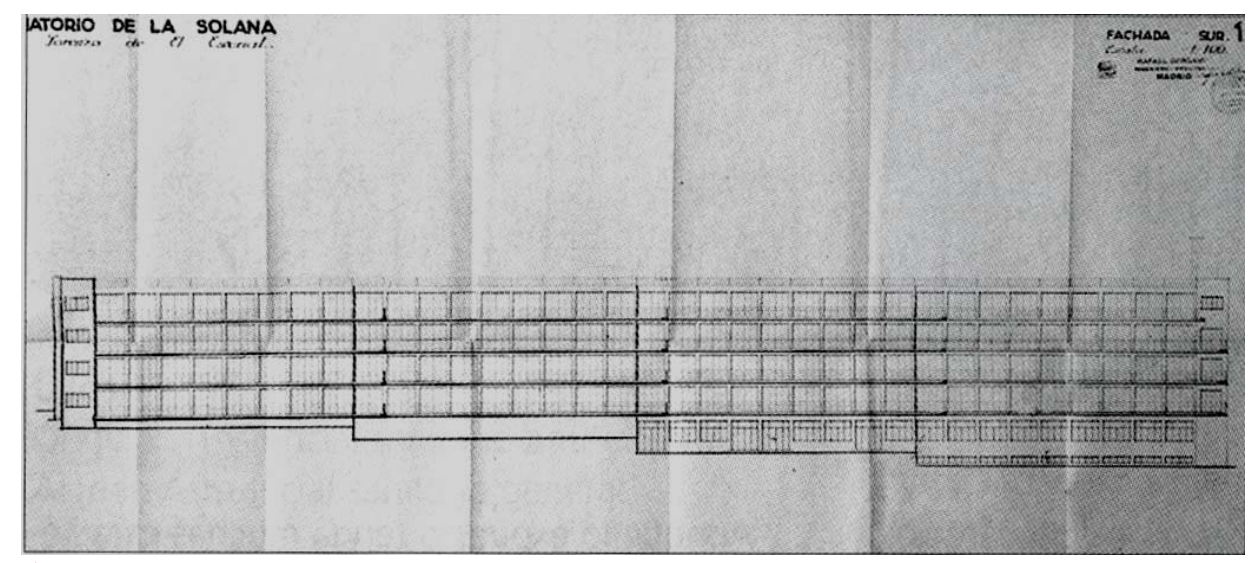

4.38

a)

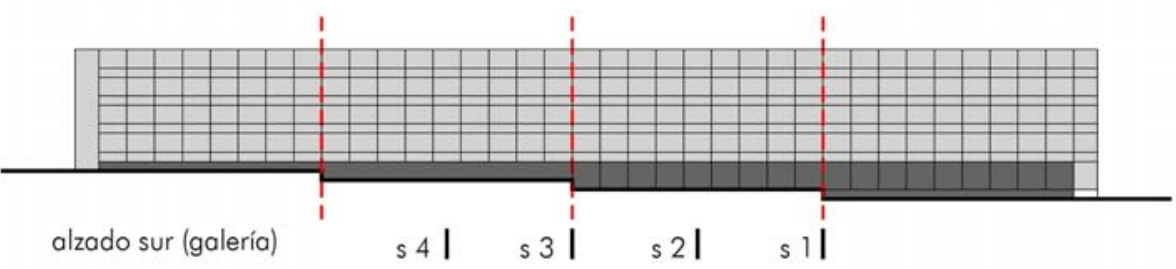

b)

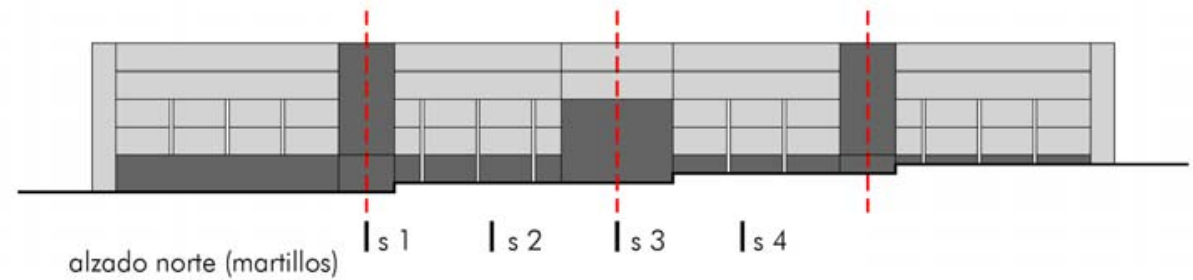

c)
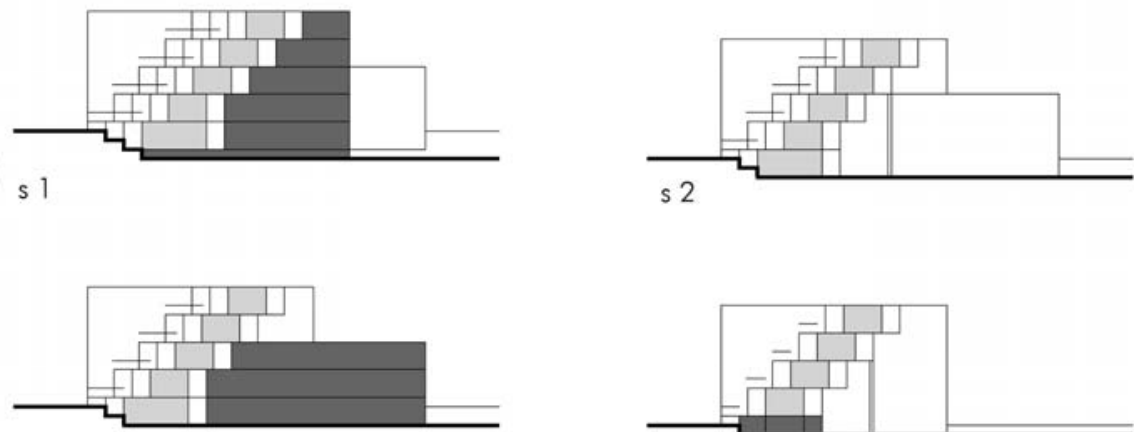

s 3

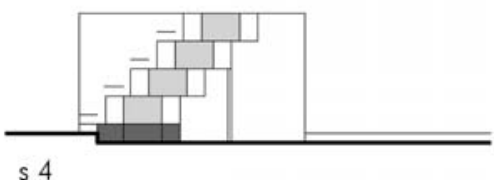

habitaciones

servicios comunes

4.39

4.38 R. Bergamín. Proyecto Sanatorio La Solana, El Escorial, 1934-35. Alzado sur (1935). 4.39. Sanatorio La Solana desarrollo en sección (dibujos de la autora). 
de los desplazamientos horizontales de la planta [fig. 4.37(b)], se hace presente en el perfil a través del desplazamiento en vertical de los pisos [fig. 4.37(d)], y el mismo principio de composición se aplica a los alzados y a las secciones, es decir, tridimensionalmente.

Sobre la división cuatripartita del gran bloque residencial se adosan las terrazas en vuelo que constituyen las galerías de cura, con el voladizo afilado para favorecer que los rayos solares del invierno penetren hasta el fondo de la habitación, proporcionando mayor ligereza al alzado [fig. 4.35].

Los testeros del edificio principal del Sanatorio se flanquean por dos volúmenes prismáticos que conectan las galerías de cura con los corredores interiores del bloque de habitaciones, cerrando un anillo de circulación continuo y perimetral en torno a las habitaciones que permite obtener una visión completa del paisaje circundante y relacionar con mayor fluidez circulaciones exteriores e interiores [fig. 4.46]. El testero oeste del edificio se remata con un volumen cerrado que abarca las fachadas anterior y posterior escalonadas, protegiendo a las terrazas del sanatorio de los vientos laterales. En el lado este, en cambio, las terrazas en vuelo abrazan al volumen del testero, dando la vuelta y asomándose sobre el costado.

La circulación continua a través de los corredores interiores y de las galerías de cura exteriores definiendo un anillo, se emplea con anterioridad en otros sanatorios y hospitales nacionales y extranjeros. En el polémico concurso de anteproyectos del hospital de San Sebastián celebrado entre marzo y junio de 193347, del que Rafael Bergamín fue miembro del jurado, también está presente. El pabellón de enfermos de tuberculosis del proyecto ganador realizado por Francisco Urcola y Domingo Aguirrebengoa que consiste en la macla de un prisma de laterales semicirculares con otro de base rectangular. Este último está penetrado por un corredor que se conecta con los salones semicirculares del otro prisma y crea una servidumbre de paso a través de ellos al enlazar las terrazas y cerrar el anillo de circulación [fig. 4.40 y 4.41 ].

Este sanatorio sigue el mismo trazado que el Hospital para la maternidad y la infancia de Berna, Suiza, proyectado por el profesor O. R. Salvisberg (1929-1930). Está formado por dos volúmenes adosados, un prisma de esquinas redondeadas rodeado por un anillo

\footnotetext{
${ }^{47}$ En el no 11 de la revista $A C, 1933$, se publica el artículo "Un fallo lamentable. El concurso de anteproyectos para un nuevo hospital en San Sebastián" donde se critica la decisión del jurado y se propone como justo ganador el proyecto realizado por Sánchez Arcas, Lagarde, Labayen y Aizpurúa.
} 

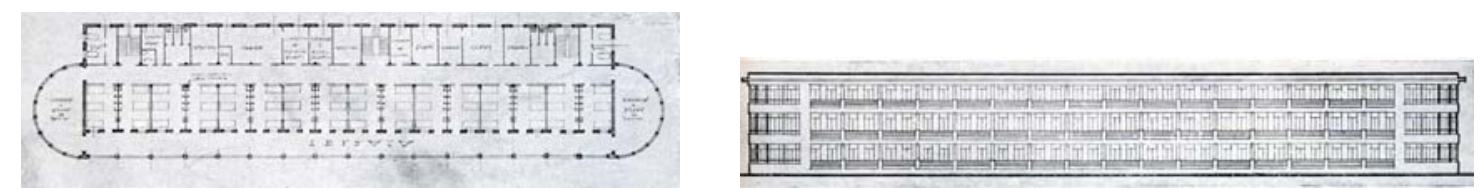

4.40 y 4.41
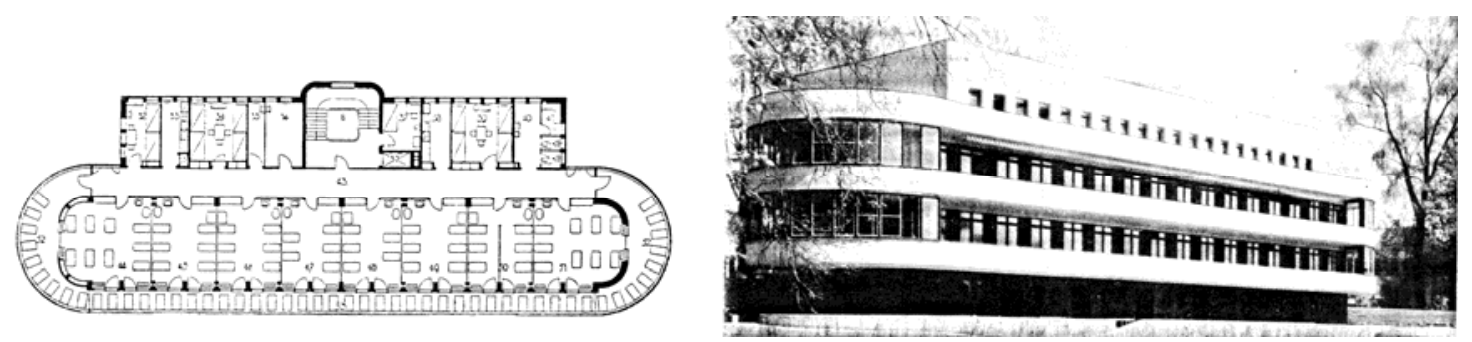

4.42 y 4.43
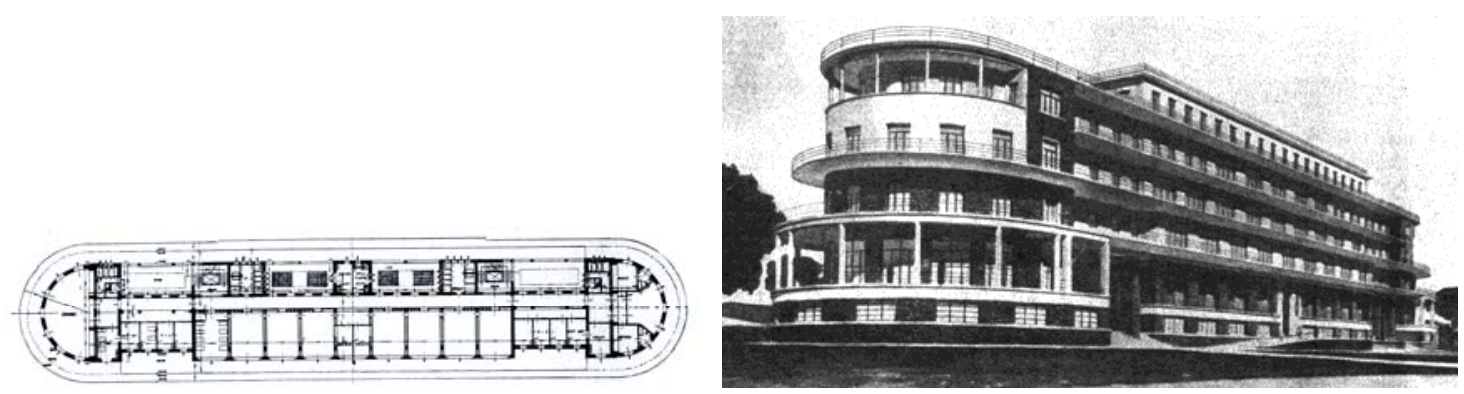

4.44 y 4.45

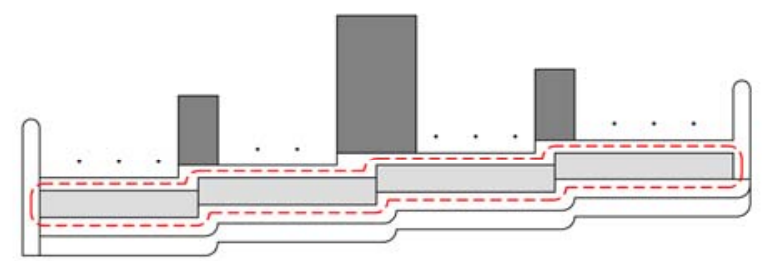

Sanatorio La Solana

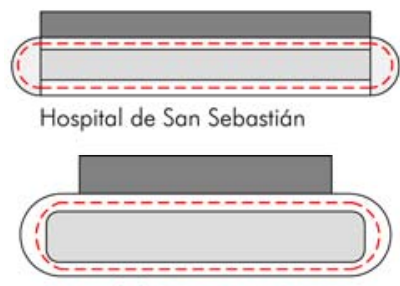

Hospital de Berna

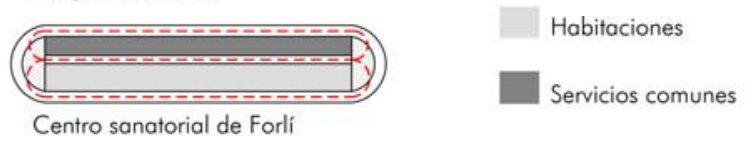

4.46

4.40 y 4.41 F. Urcola y D. Aguirrebengoa. Proyecto del pabellón de tuberculosos del Hospital de San Sebastián, 1933. Planta tipo y alzado

4.42 y 4.43 O. R. Salvisberg. Hospital para la maternidad y la infancia de Berna, 1929-30. Planta tipo y vista exterior.

4.44 y 4.45 Istituto Nacionale Fascista della Previdenza Sociale. Centro Sanatorial de Forlí, 1934. Planta tipo y vista exterior.

4.46 Anillo de circulación (dibujos de la autora). 
perimetral de circulación y un prisma recto de menor tamaño agregado a su espalda ${ }^{48}$ [fig. 4.42 y 4.43$]$.

El pabellón infantil del Centro Sanatorial de Forlít en Italia realizado por el Istituto Nacionale Fascista della Previdenza Sociale (1934) contiene tres circuitos anulares posibles [fig. 4.44 y 4.45]. Se trata de un edificio de volumen unitario, un prisma de esquinas semicirculares atravesado por un corredor interior y rodeado por una terraza perimetral, ambos conectados a través de los salones situados en los extremos. Gracias a la terraza perimetral se consigue obtener, como sucede en el edificio principal del Sanatorio de La Solana, una visión completa del paisaje circundante desde el edificio [fig. 4.46], mientras que el corredor interior favorece una variedad de recorridos que enlazan con el anillo exterior de las terrazas.

La distribución del programa en las plantas del edificio principal del Sanatorio de La Solana sigue criterios funcionales. En los "martillos" se agrupan los servicios comunes y se libera el bloque longitudinal para las habitaciones en las plantas superiores y las zonas comunes en la planta baja. El "martillo" central de tres plantas de altura contiene en planta baja los servicios médicos y administrativos, a los que se accede a través de la entrada principal del sanatorio ubicada en el lateral este; en planta primera se encuentran los laboratorios, las zonas de plancha y el ropero, y en planta segunda los quirófanos. Los dos "martillos" adyacentes contienen los baños y los servicios de enfermería de cada planta de habitaciones.

Los salones de reunión, las salas de visitas y los comedores, a los que se adosan la cocina y las instalaciones con un acceso independiente, se sitúan en la planta baja que, debido a la pendiente del terreno, no abarca la longitud total del bloque. Sobre esta planta y en los cuatro niveles superiores se distribuyen las habitaciones individuales que albergan las 128 camas de las que dispone el sanatorio.

Los enfermos se distribuyen por sexos, las dos plantas superiores se destinan a mujeres y las otros dos inferiores a hombres. Los quiebros del corredor interior, que replican los retranqueos de la fachada y evitan la visión de una fuga infinita e intimidatoria, compartimentan la planta en unidades de enfermos, e instalan en cada quiebro una sala de enfermeras.

\footnotetext{
${ }^{48}$ Bruno MORETTI, Ospedali. Ulrico Hoepli, Milano 1935, p. 190.

${ }^{49}$ Bruno MORETTI, Ospedali. Ulrico Hoepli, Milano 1935, p.133.
} 


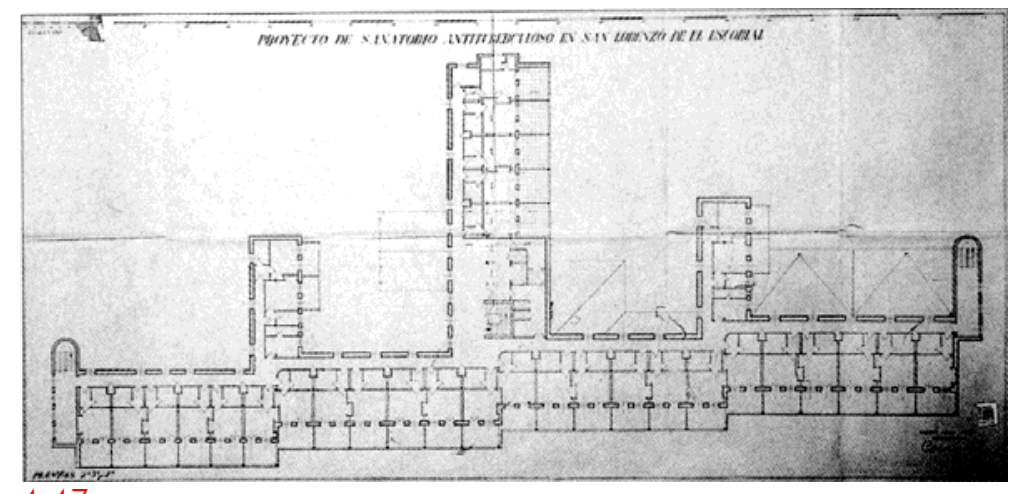

4.47
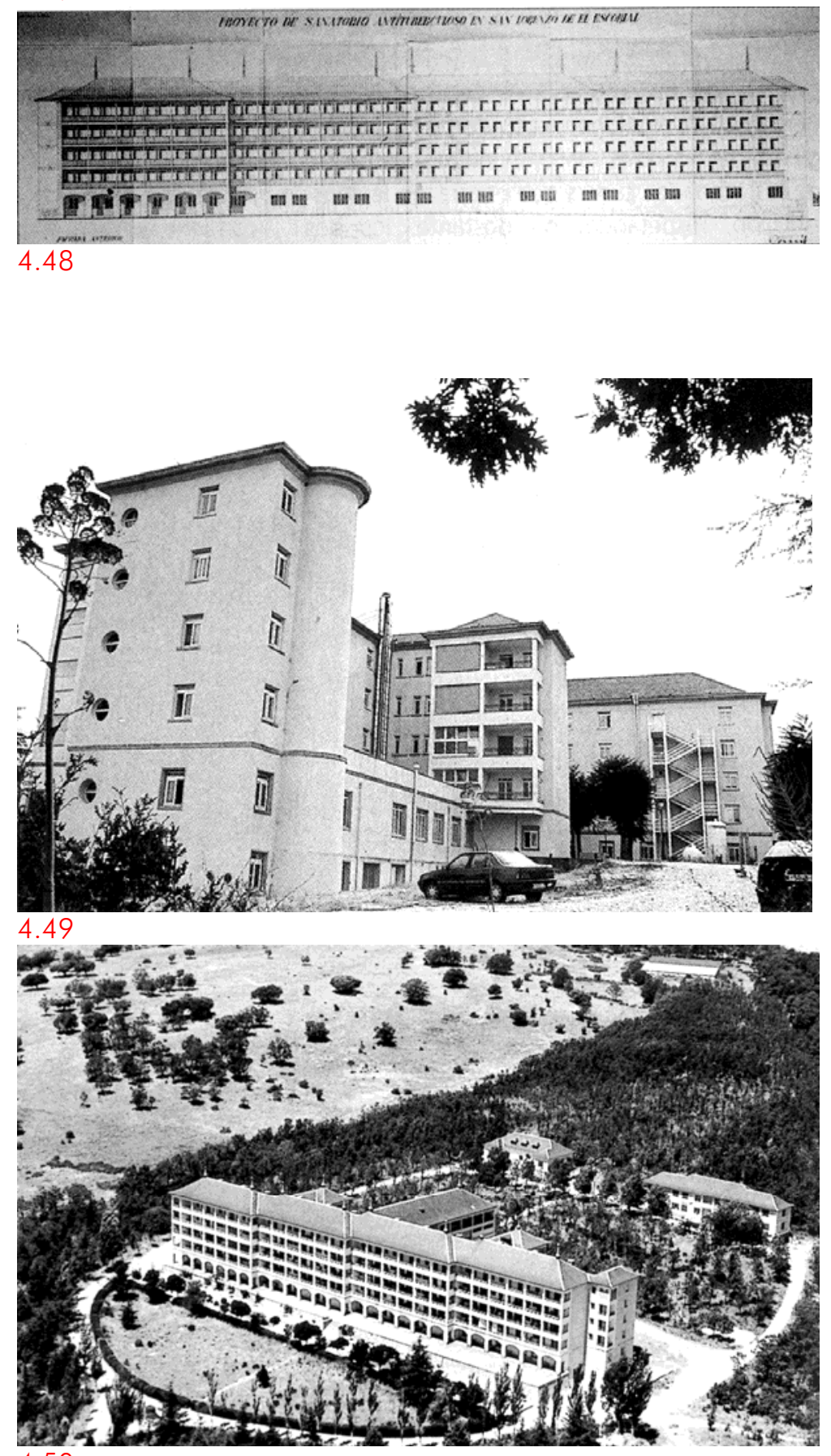

4.50

4.47 y 4.48 Sanatorio El Pinar, El Escorial, 1947. Planta tipo y alzado sur.

4.49 y 4.50 Hospital Comarcal de El Escorial, 1951. Fachada norte y vista del conjunto. 
A las habitaciones se accede por un pequeño vestíbulo común, que recoge las puertas de entrada de dos dependencias contiguas, y su interior se abre hacia la galería mediante un frente completamente acristalado en el que se incorporan las puertas de conexión ${ }^{50}$. Las habitaciones son individuales y tienen un tamaño muy reducido que hace que resulten económicas. En ellas se utilizan como elementos separadores dos armarios empotrados contrapeados, uno para cada habitación.

Las obras del sanatorio de La Solana comienzan en 1936, pero en breve se ven paralizadas a consecuencia del comienzo de la Guerra Civil, y no son reanudadas hasta el 2 de enero de 1948, momento en el que la Sociedad Comercial de Hierros Compañía Anónima compra la finca con las obras ya empezadas ${ }^{51}$. Esta sociedad había elaborado en 1947 un proyecto de reforma para transformar el sanatorio de La Solana de las clases medias en el sanatorio privado de El Pinar, destinado a las clases más acomodadas. En la reforma al edificio principal se le incorporan una serie de volúmenes que rompen con la claridad formal del proyecto original, del que sólo se conservan los quiebros del bloque residencial. Las plantas se ensanchan para incluir un baño particular en cada habitación, desaparece el escalonamiento de la sección y las galerías de cura se fragmentaron en terrazas individuales.

La imagen del edificio se tiñe además de un marcado estilo regionalista: la azotea-solárium se cambia por una cubierta de pizarra a dos aguas rematada con pináculos, se introduce una arquería de sillares de piedra en planta baja, se añaden monumentales porches de acceso de estilo escurialense y los frentes completamente acristalados de las habitaciones se sustituyeron por puertas de cristal inscritas en muros ciegos, haciendo bastante irreconocible el proyecto original [fig. 4.47 y 4.48$]$.

Este proyecto tampoco llega a ser construido. En 1951 la Administración Institucional de la Sanidad Nacional AISNA adquiere de nuevo la propiedad con las obras avanzadas del Sanatorio El Pinar, que pasa a convertirse en el Sanatorio del Estado de Nuestra Señora de la Asunción y a depender del Patronato Nacional Antituberculoso.

Las habitaciones pasan ahora a contener tres camas cada una y a carecer de baño y las terrazas vuelven a ser corridas, mientras se siguen añadiendo cuerpos incoherentes con el volumen del edificio principal que desvirtúan aún más el proyecto original [fig. 4.49 y 4.50 ].

\footnotetext{
${ }^{50}$ El acristalamiento de la fachada recuerda al alzado sur del sanatorio de Leza proyectado por Pablo Zabalo Ballarín en 1930 y construido en 1935.

51 "Hospital Comarcal de El Escorial" en Arquitectura y Desarrollo Urbano. Comunidad de Madrid zona Oeste) Tomo V. Colegio Oficial de Arquitectos, Madrid 1998, p. 345.
} 


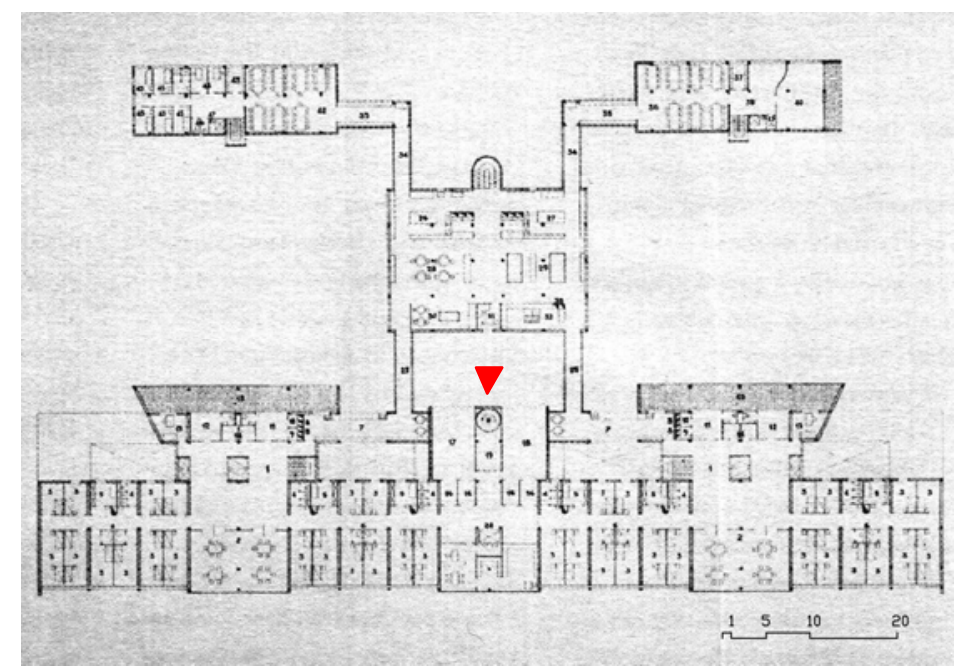

4.51

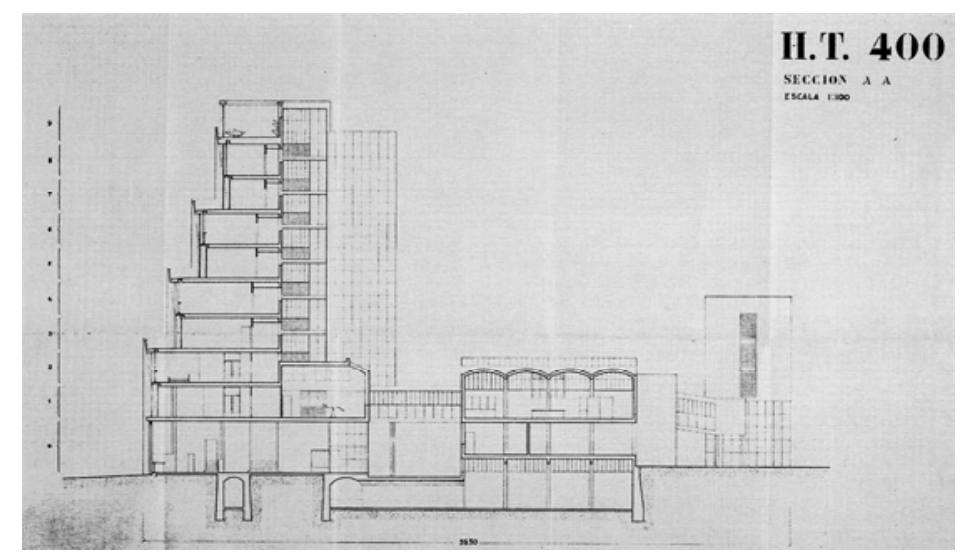

4.52
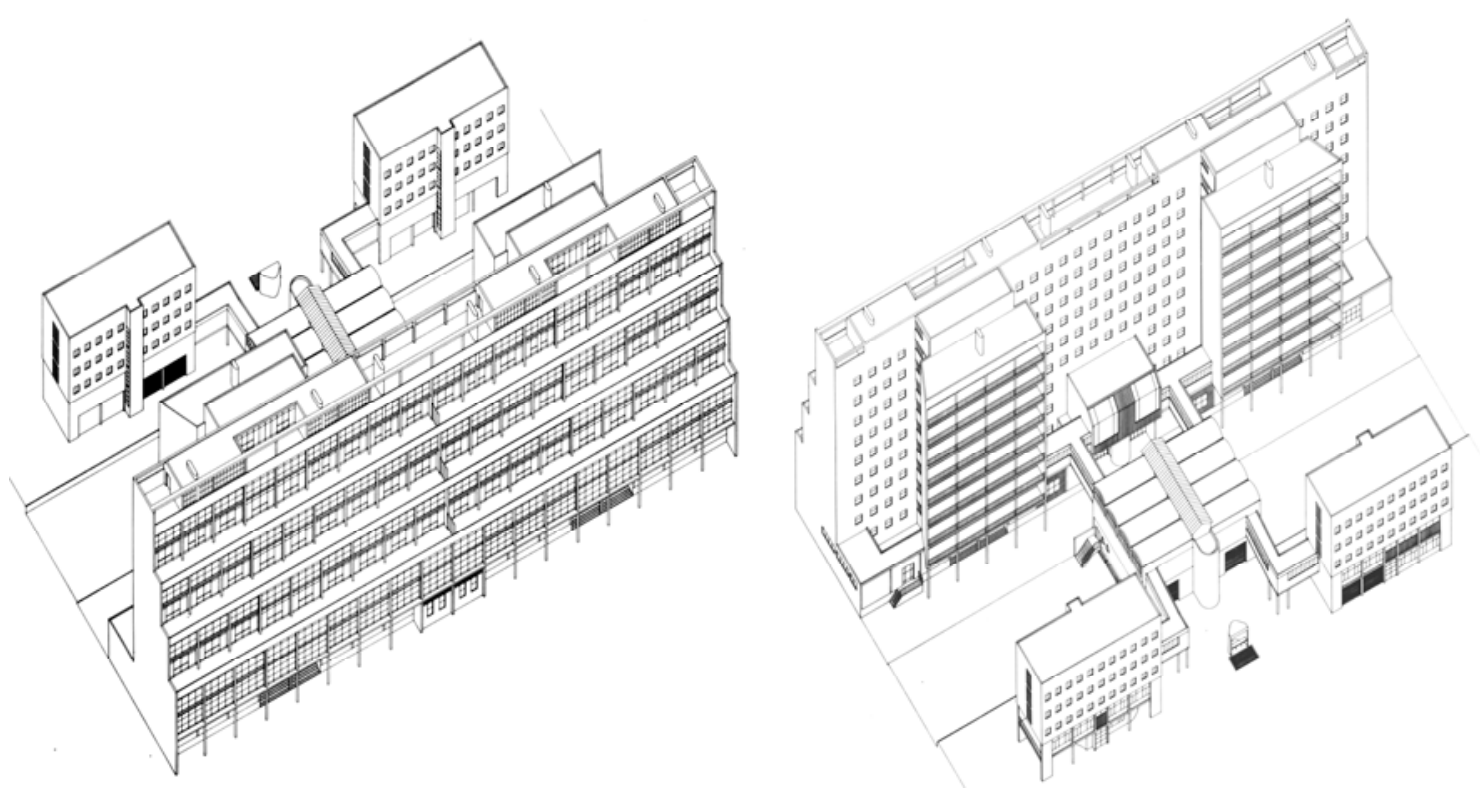

4.53 y 4.54

4.51 y 4.52 J. L. Sert y J. Torres Clavé. Sanatorio tipo de 400 camas HT 400, Barcelona, 1936. Planta tipo y sección.

4.53 y 4.54 J. L. Sert y J. Torres Clavé. Sanatorio tipo de 400 camas HT 400, Barcelona, 1936. Axonometría de la fachada sur y de la fachada norte. 
La Solana se convierte en un ensayo de soluciones arquitectónicas como la fragmentación y el desplazamiento diagonal de la planta que más tarde retomará Bergamín en el Sanatorio de Los Montalvos donde sin embargo, abandona la idea de escalonar la sección.

En el mismo año 1936 en el que dan comienzo las obras del sanatorio de La Solana José Luis Sert y José Torres Clavé elaboran para Cataluña un proyecto de sanatorio tipo de 400 camas que guarda relación con el proyecto de Rafael Bergamín, precisamente por su planteamiento en sección, ya que la planta, que sigue también el modelo en T, no es tan compacta y se articula en varios volúmenes independientes conectados entre sí [fig. 4.51].

Cabe la posibilidad de que Sert y Torres Clavé conocieran la propuesta de Bergamín para el Sanatorio de La Solana, no sólo a través de su publicación Cortijos y Rascacielos de 1934, sino también a través del G.A.T.E.P.A.C. ${ }^{52}$. Bergamín nunca llegó a formar parte de esta agrupación a cuya sección catalana, el G.A.T.C.P.A.C. ${ }^{53}$, pertenecían Sert y Torres Clavé, pero su amigo Fernando García Mercadal, con quien viaja a París a visitar la Exposición de Artes Decorativas" ${ }^{54}$, hace de puente entre la "generación del 1925" madrileña a la que ambos pertenecen y el más tardío G.A.T.E.P.A.C. ${ }^{55}$, sobre todo en los primeros años de formación de este grupo ${ }^{56}$.

En cualquier caso Sert y Torres Clavé están al tanto a través de la revista L'Architecture Vivante de Jean Badovici de los sanatorios de sección escalonada y cuentan con la experiencia de haber trabajado junto a Subirana en los proyectos del Dispensario Central Antituberculoso de Barcelona (1933) y del Hospital Comarcal Tipo de 100 camas (1934). Subirana, por encargo de la Generalitat en abril de 1933, ha estado viajando por Francia, Italia, Suiza y Alemania en busca de modelos de hospitales y sanatorios apropiados para su aplicación en Lucha Antituberculosa de Cataluña ${ }^{57}$.

El encargo del sanatorio antituberculoso tipo de 400 camas, designado como H.T. 400, surge a raíz del congreso de Esquerra Republicana de Catalunya de 1932, en el que se

\footnotetext{
52 Grupo de Arquitectos y Técnicos Españoles para el Progreso de la Arquitectura Contemporánea.

${ }^{53}$ Grupo de Arquitectos y Técnicos Catalanes para el Progreso de la Arquitectura Contemporánea.

${ }^{54}$ En compañía de Casto Fernández-Shaw según se recoge en el artículo. "Mesa redonda con Rafael Bergamín, Fernando García Mercadal y Casto Fernández-Shaw", en Hogar y Arquitectura n 70,1967, p. 39.

${ }^{55}$ Del que sí parecían tener conocimiento era del sanatorio antituberculoso de Leza, construido por Pablo Zabalo en 1934. Antonio PIZZA, Josep Maria ROVIRA GIMENO, G.A.T.C.P.A.C. 1928-1939, Una nueva arquitectura para una nueva ciudad. Colegio de Arquitectos de Cataluña, Barcelona 2006, p. 235

56 Sofía DIÉGUEZ PATAO, La generación del 25. Primera Arquitectura Moderna en Madrid. Cuadernos de Arte Cátedra, Madrid 1997, pp. 37-38.

57 Antonio PIZZA, Josep Maria ROVIRA GIMENO, G.A.T.C.P.A.C. 1928-1939, Una nueva arquitectura para una nueva ciudad. Colegio de Arquitectos de Cataluña, Barcelona 2006, p. 194.
} 


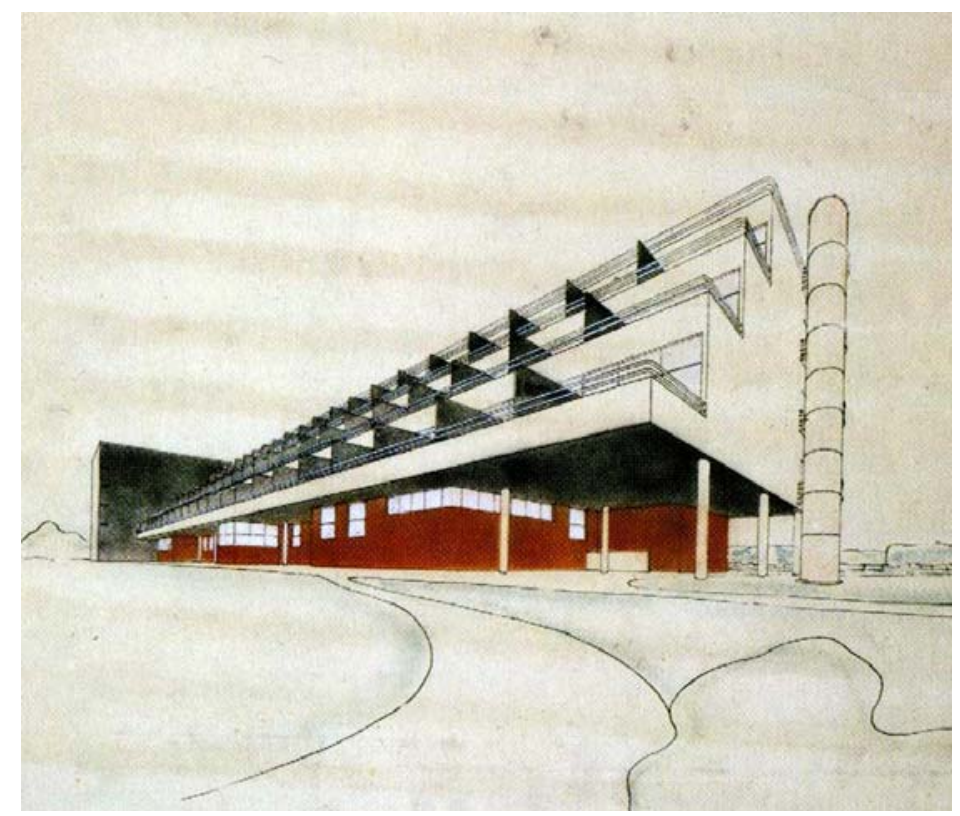

4.55
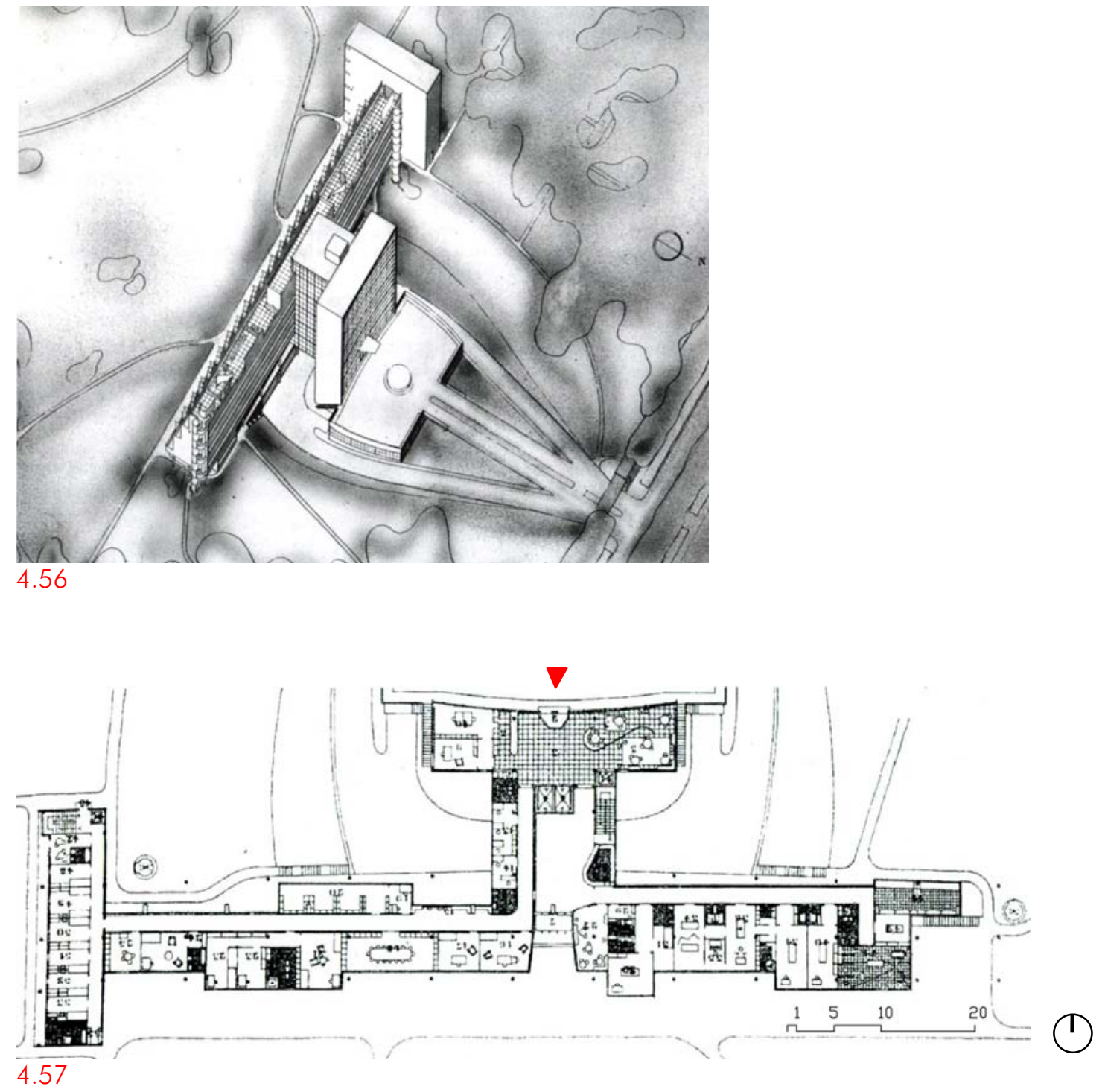

4.55, 4.56 y 4.57 Paul Nelson. Maison de Santé Minimum, 1932. Cónica de la fachada sur, axonometría de la fachada norte y planta baja. 
aprueba un plan para la construcción de una serie de sanatorios y dispensarios con el fin de controlar la tuberculosis en Cataluña ${ }^{58}$.

Fruto de este congreso, Subirana, Sert y Torres Clavé, reciben el encargo del Dispensario Central de Barcelona y un año después gracias a la aprobación de la Ley de bases para la organización de los servicios de Sanidad y Asistencia Social de Cataluña, se acuerda la creación de una red comarcal de hospitales tuteladas por la Generalitat que revierte en el encargo a Subirana de la remodelación y ampliación de un gran número de ellos ${ }^{59}$, así como la realización del proyecto de un Hospital Comarcal Tipo de 100 camas $^{60}$, H.T. 100, predecesor del citado sanatorio antituberculoso tipo de 400 camas, H.T. 400, del que se encargan sólo Sert y Torres Clavébl.

El proyecto de este sanatorio presenta una sección escalonada similar a la del sanatorio de La Solana [fig. 4.52] aunque con el doble de plantas, nueve en total, además de una terraza solario. El escalonamiento se produce aquí cada dos pisos a partir de la planta baja, quedando ésta enrasada con las dos superiores, y se manifiesta sólo en el frente sur de las galerías de cura siendo el frente norte plano, de manera que las plantas de habitaciones se acortan a medida que el sanatorio crece en altura. La fachada inclinada abierta al mediodía se acristala, convirtiéndose el sanatorio por su tectónica, su forma y orientación en una "gran placa solar", como Xavier Monteys describe en su artículo de 1980 "Una actitud de Modernidad. A propósito del Hospital de Sert y Torres Clavé"62 .

La misma sección inclinada había sido aplicada en la construcción de varios sanatorios franceses como en el de la Ciudad Sanatorial de Guébriant-La Clairière construido en 1933

\footnotetext{
${ }^{58}$ Dentro del plan se planteó construir un hospital fuera de la ciudad de Barcelona destinado a enfermos graves de tuberculosis pulmonar, dos sanatorios, uno en la playa y otro en la montaña, cuatro dispensarios, uno en cada capital de provincia, además de la creación de una organización similar al "Instituto de Clínica Quirúrgica de la ciudad de Moscú". Antonio PIZZA, Josep Maria ROVIRA GIMENO, G.A.T.C.P.A.C. 1928-1939, Una nueva arquitectura para una nueva ciudad. Colegio de Arquitectos de Cataluña, Barcelona 2006, p. 190.

59 Los de Igualada, Manresa, Viella, Vic, Palafrugell y Badalona. Antonio PIZZA, Josep Maria ROVIRA GIMENO, G.A.T.C.P.A.C. 1928-1939, Una nueva arquitectura para una nueva ciudad. Colegio de Arquitectos de Cataluña, Barcelona 2006, p. 198.

60 Antonio PIZZA, Josep Maria ROVIRA GIMENO, G.A.T.C.P.A.C. 1928-1939, Una nueva arquitectura para una nueva ciudad. Colegio de Arquitectos de Cataluña, Barcelona 2006, pp. 197. 198.

${ }^{61}$ Este sanatorio debería constituir el comienzo de la futura ciudad sanitaria del Valle de Hebrón, en Barcelona. Antonio PIZZA, Josep Maria ROVIRA GIMENO, G.A.T.C.P.A.C. 1928-1939, Una nueva arquitectura para una nueva ciudad. Colegio de Arquitectos de Cataluña, Barcelona 2006, p. 235.

${ }^{62}$ Xavier MONTEYS, "Una actitud de modernidad. A propósito del Hospital de Sert y Torres Clavé", en 2 Construcción de la ciudad. Josep Torres Clavé arquitecto y revolucionario, $n^{\circ} 15-16$, mayo 1980 , pp. 58-61.
} 


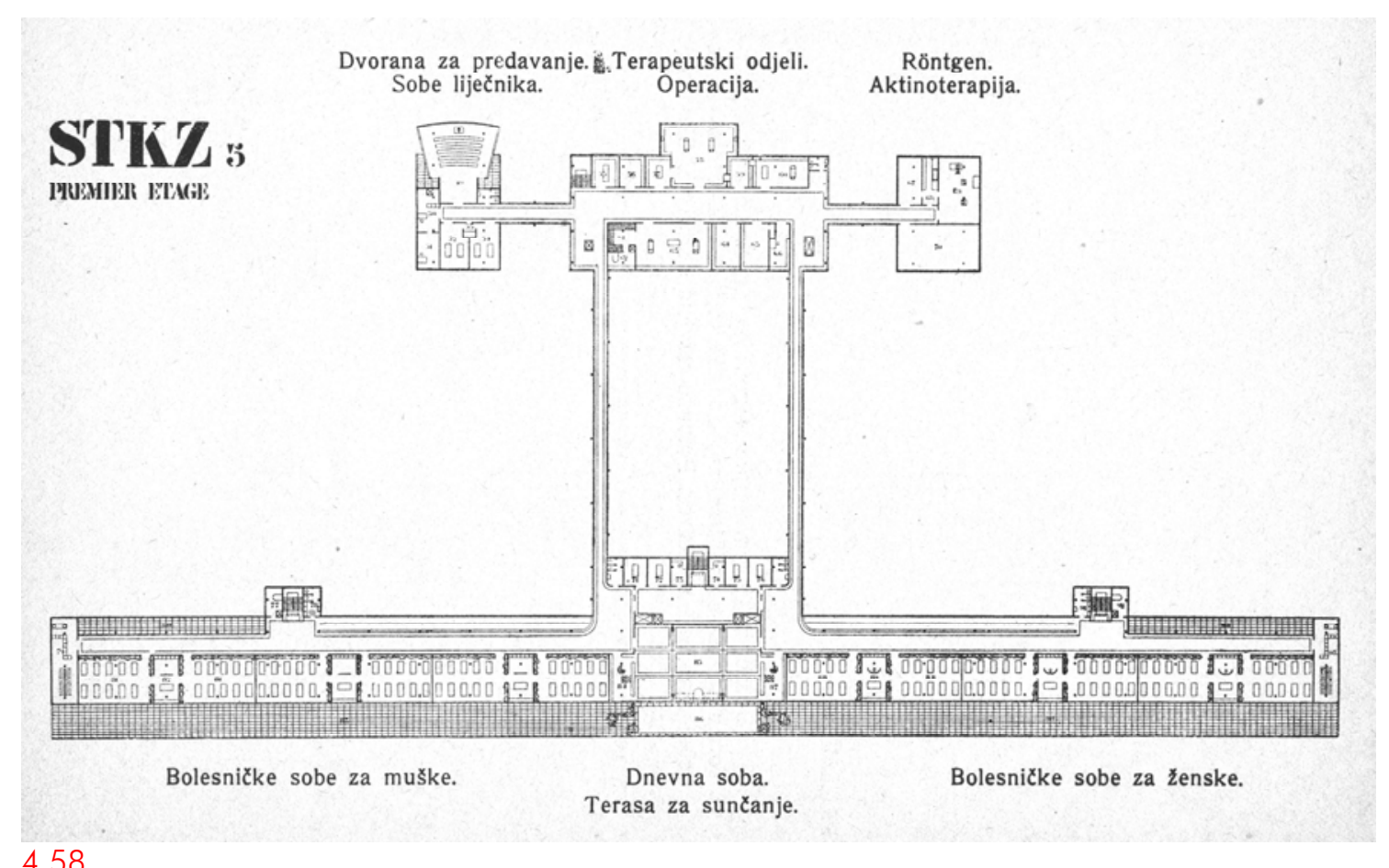

4.58

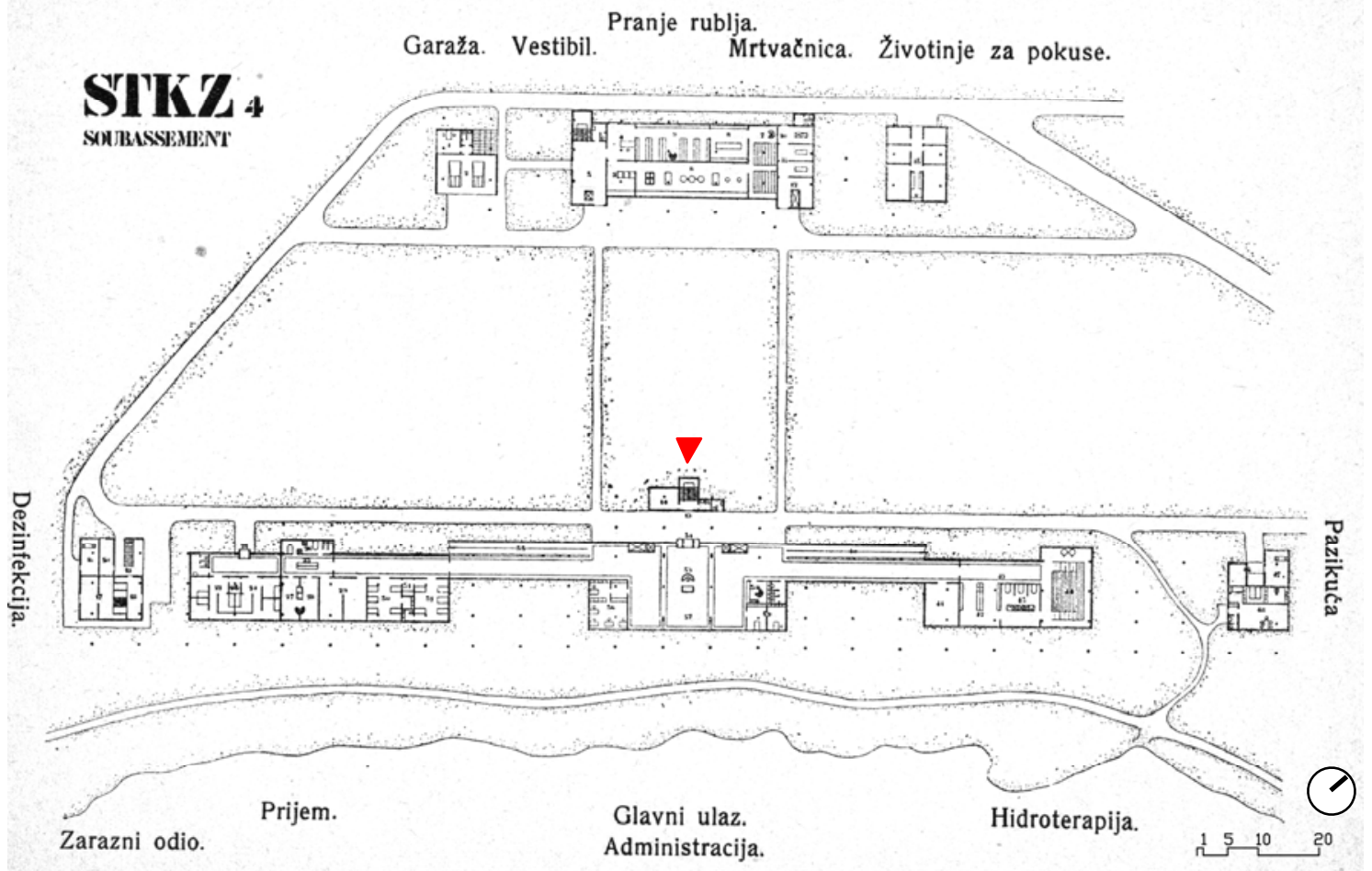

4.59

4.58 y 4.59 Ernest Weissmann. Proyecto de Sanatorio antituberculoso para Zagreb, STKZ, 1930 (Atribuido a Le Corbusier como el Sanatorio antituberculoso, Zúrich, 1934). Planta primera, planta baja. 
por Pol Abraham y Henry Le Meme, en el Plateau d'Assy ${ }^{63}$, o en el Instituto de Helioterapia de Vallauris, dirigido por el doctor Saidman y construido por Pierre Souzy en 1934, afines a las propuestas de sanatorios escalonados de principios del siglo XX realizadas por el Dr.

Sarason y Tony Garnier ${ }^{64}$.

El proyecto de sanatorio H.T. 400, que no llega a ser construido, guarda también un parecido formal por su sección y por su composición en planta con otro proyecto de hospital tipo, la "Maison de Santé Minimum" realizada por Paul Nelson en 1932.

En la "Maison de Santé Minimum" se observa una matización de la simetría, gracias al desplazamiento relativo entre corredores y la adhesión de un prisma de remate en el extremo oeste de habitaciones, así como una articulación volumétrica del cuerpo central en varios volúmenes yuxtapuestos [fig. 4.56 y 4.57], produciéndose un desplazamiento de la simetría hacia la asimetría y un desmembramiento del modelo más compacto y unitario de partida ${ }^{65}$.

Volviendo al proyecto del sanatorio H.T. 400, aunque mantiene la simetría, la fragmentación del cuerpo central se acentúa. Detrás del bloque escalonado de habitaciones en sección se sitúan dos prismas rectos que contienen los núcleos de comunicación vertical, a los que se adosan otros cuerpos prismáticos, de menor altura y base trapezoidal, con los servicios generales de cada planta ${ }^{66}$ [fig. 4.54].

Del mismo modo, al bloque residencial de 10 alturas se conectan tres volúmenes más bajos. Los tres pabellones se ordenan simétricamente. En el centro se ubica la cocina en un volumen de planta casi cuadrada rematado con una cubierta construida con bóveda catalana. Consta de tres plantas, semisótano, baja y primera, y se conecta con el pabellón residencial a través del subsuelo y por dos pasarelas elevadas en la planta primera.

Detrás y en ambos lados de la cocina se disponen otros dos pabellones de geometría prismática y 5 plantas de altura, prácticamente idénticos entre sí, que contienen las dependencias del personal. A un lado está el pabellón de los médicos y al otro el de los empleados, conectados a través de sendas pasarelas en la primera planta primera que

\footnotetext{
${ }^{63}$ Bruno MORETTI, Ospedali. Ulrico Hoepli, Milano 1935, p. 153.

${ }^{64}$ También a los proyectos de Henri Sauvage más tardíos, para la construcción de su quartier à gradins (1920) comentados en un capítulo anterior.

${ }^{65}$ Pedro IGLESIAS PICAZO, La habitación del enfermo. Ciencia y arquitectura en los hospitales del Movimiento Moderno. Arquia/tesis n³2 Fundación Caja de Arquitectos, Barcelona 201 1, p. 249.

${ }^{66}$ La geometría de estas dos agrupaciones de elementos se asemeja a la del martillo central de la "Maison de Santé Minimum" de P. Nelson, compuesto por una torre casi cuadrada y un bloque prismático de gran altura a los que se yuxtapone otro volumen rectangular más extenso y más bajo.
} 


\section{STKZ $z$}
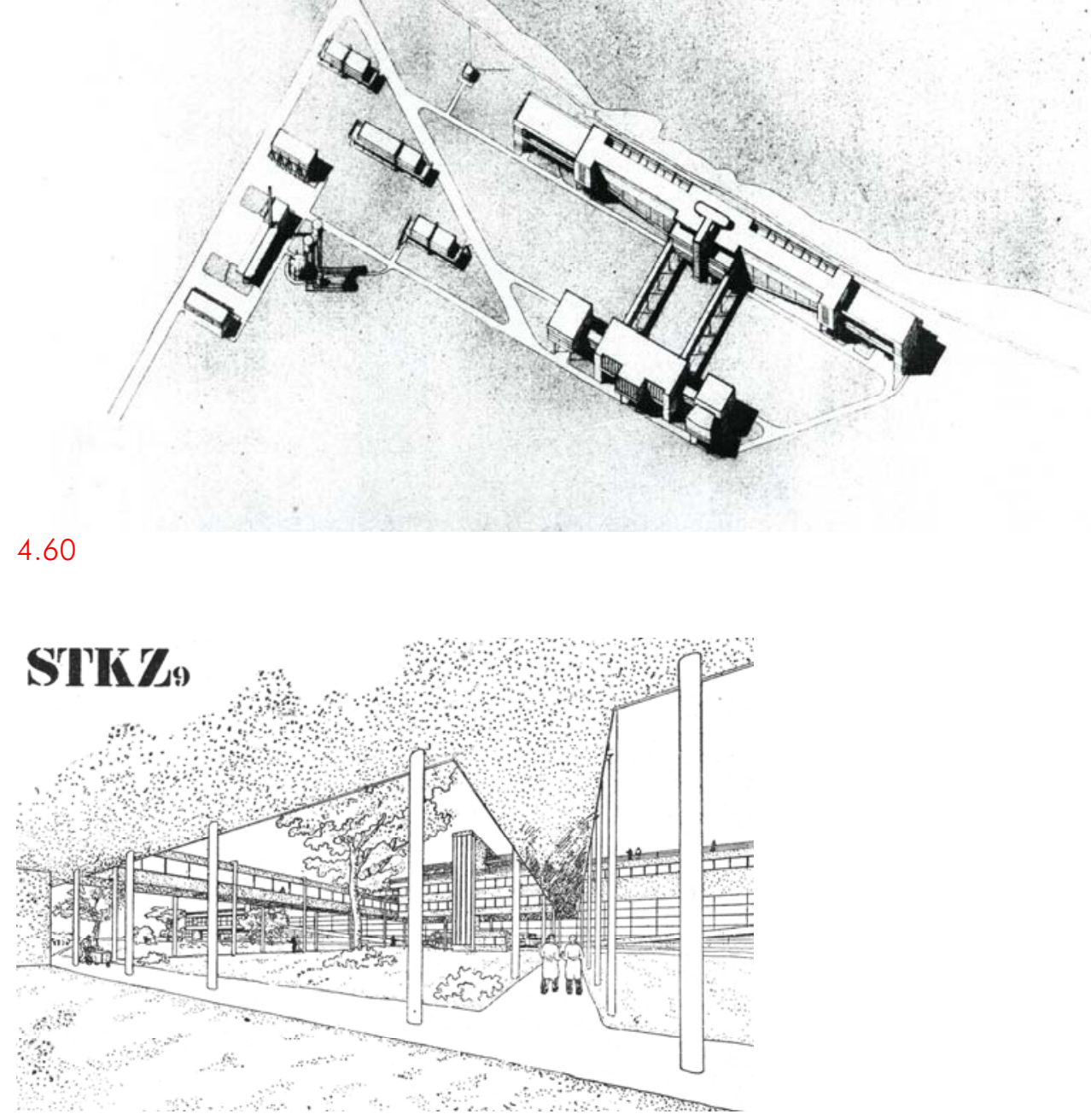

4.61

\section{STKZ}

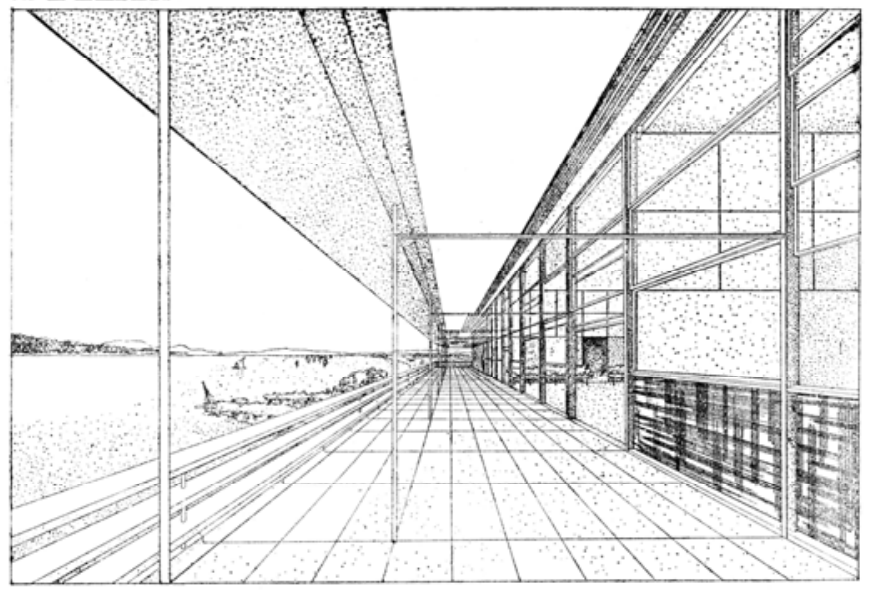

4.62

4.60, 4.61 y 4.62 Ernest Weissmann. Proyecto de Sanatorio antituberculoso para Zagreb, STKZ, 1930 (Atribuido a Le Corbusier como el Sanatorio antituberculoso, Zúrich, 1934). Axonometría del conjunto, cónica exterior desde el vacío central y cónicas interior desde la galería de curas. 
atraviesan por los costados del cuerpo central de cocina y continúan hacia al pabellón residencial [fig. 4.54].

Así, el modelo compacto con planta en forma de T se fragmenta y se hace poroso en su frente norte transformando la unidad en un conjunto ordenado y heterogéneo de partes [fig. 4.51].

Esta escisión del cuerpo central en pabellones conectados entre sí, ordenados siguiendo la forma en $T$ de los sanatorios compactos, había sido utilizada en el proyecto de Ernest Weissmann en 1930 para el Sanatorio de Zagreb, Croacia [fig. 4.60], proyecto que durante años y aún hoy ha sido atribuido erróneamente a Le Corbusier y está designado como el Sanatorio antituberculoso de Zúrich (1934) ${ }^{67}$.

Se desconocen las causas de tal confusión, pero la semejanza de grafismo y rotulación existente en los planos de este proyecto con los de otros muchos procedentes del estudio del maestro pudo inducir a tal error. El equívoco resulta comprensible porque el verdadero autor del proyecto, Ernest Weissmann, estuvo trabajando durante años en el estudio de Le Corbusier $^{68}$.

Las siglas STKZ que aparecen en los planos corresponden a los términos croatas Sanatorij Tuberkuloze Kosti i Zglobova, Sanatorio Antituberculoso Óseo y Articular, probablemente fueron las que llevaron a describirlo como un proyecto de sanatorio antituberculoso realizado por Le Corbusier para Zúrich, ya que varios proyectos suyos para Suiza se designan con siglas similares como el Inmueble locatif (1932) con las siglas S.ZCH o el Inmueble pour ouvriers en Zurich (1934) Z.ch.A. La fecha de la atribución 1934 puede deberse a que proyectos como Inmueble pour ouvriers, que sigue un trazado simétrico y en doble T similar al del sanatorio, al igual que Etude T CIAM que contiene un edificio en bloque con planta en forma de T, fueron diseñados ese mismo año.

\footnotetext{
${ }^{67}$ La propia Fundación Le Corbusier incluye en su base de datos este proyecto de sanatorio como suyo, al igual que numerosas publicaciones como Le Corbusier Buildings and Projects, 1933-1937. Garland Publishing, New York, 1983, o en recopilaciones de su obra más recientes como Xavier MONTEYS, Le Corbusier. Obras y Proyectos. Gustavo Gili, Barcelona, 2005. Sólo en la versión digital de sus archivos Le Corbusier plans publicados en formato DVD por la Fundación (2005) se expresan ciertas dudas sobre la autoría del proyecto.

La visita a los archivos de la Fundación Le Corbusier de París, ha servido a esta tesis para averiguar que los estudios realizados por Tamara Biazic Klarin sobre el arquitecto Ernest Weissmann corroboran que el proyecto no es obra de Le Corbusier. Tras una consulta posterior a la Fundación, ésta confirmó la autoría del proyecto con el envío de una breve publicación del mismo realizada en el año 1930 donde se describe perfectamente cómo se trata de un proyecto de sanatorio realizado por el arquitecto Ernest Weissmann junto al Dr. Miroslav Delic para Zagreb en ese año y no de un sanatorio para Zurich.

${ }^{68}$ Tamara BJAZIC KLARIN, "Radna grupa Zagreb - osnutak i javno djelovanje na hrvatskoj kulturnoj sceni Zagreb Group - Foundation and Public Activities in Croatian Cultural Context", en Prostor $\mathrm{n}^{\circ} 13,2005$, p. 41.
} 

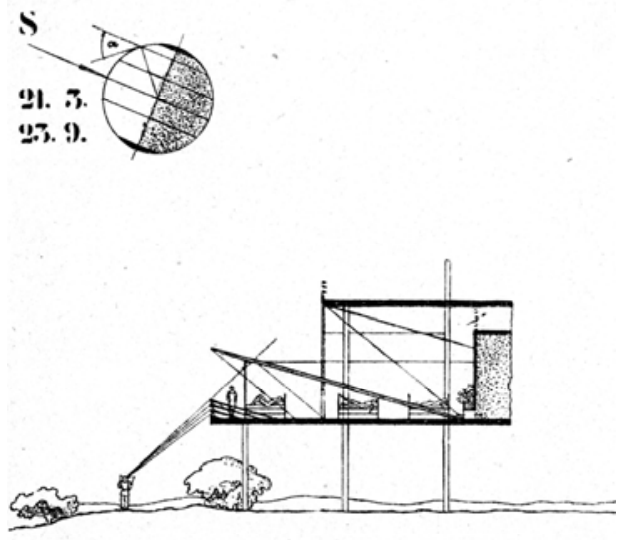

STKY/2

4.63
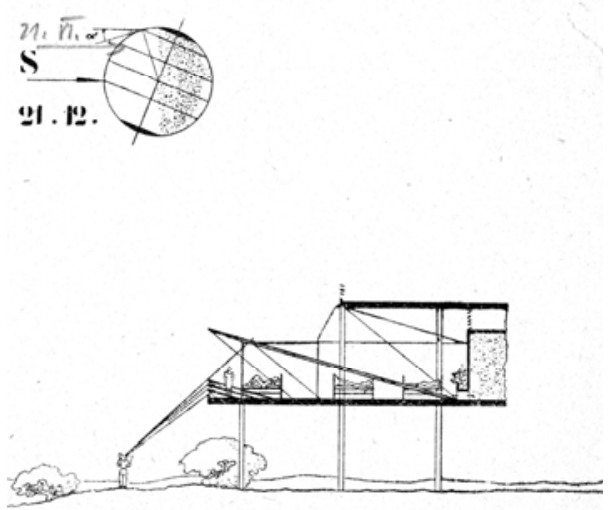

S'IKZM

\section{S'IKZ}
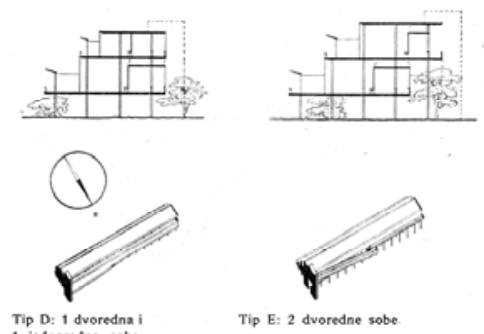

SEMA TIPOVA BOLNICE MAKSIMALNE INSOLACIE

S'IIL/
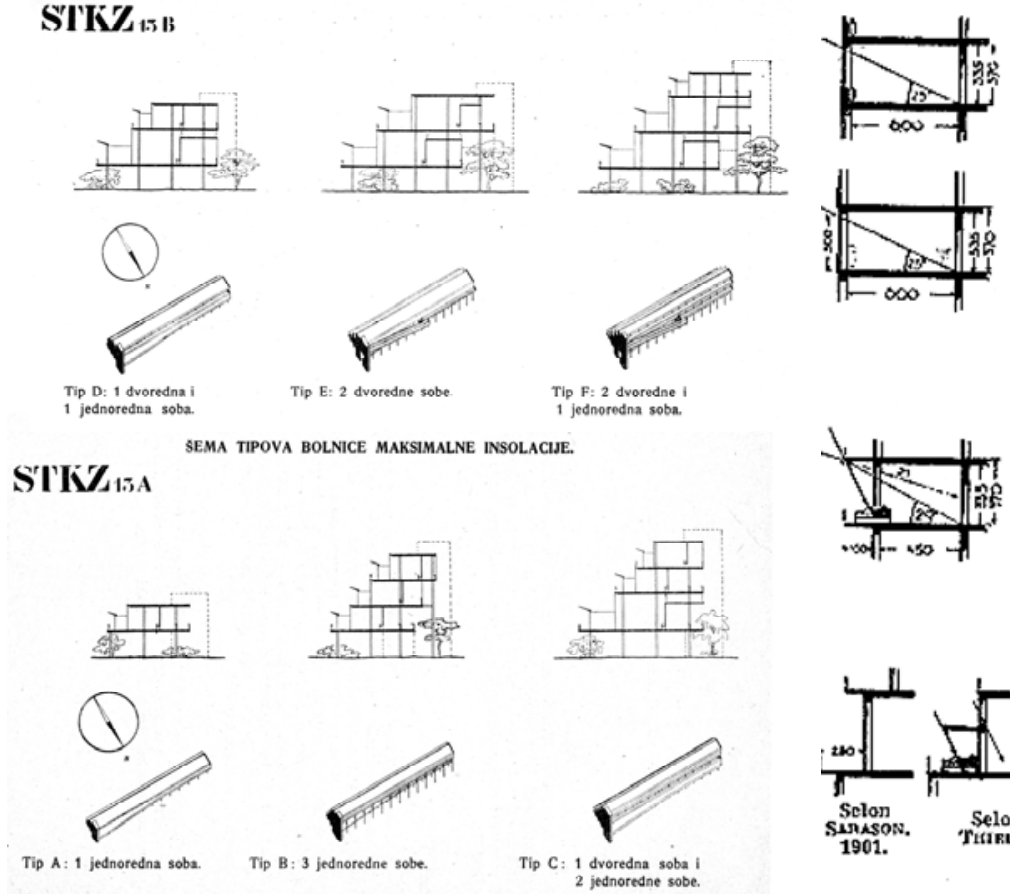

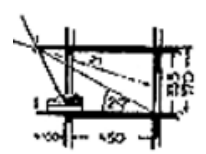

VENETRE ORDINAIRE, Dispositton colntmode des apparetls tie chautfape sols
la fentere. Ius de factilté de fes fer-

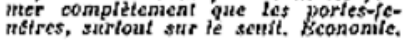
PORXB-FBNETRE avec appuls, ie pitce pett etre transformio en lerrvesse de repos pour le trattement par le prond Dosqunt 1905. Bonne infruence an solell et de l'air frats sur les maiades de loutes sortes. Le sentiment dit rep. est preciert atssi du point de vie

PORTE-YCNETRE AVIC BAI.CON. SUr ces baicons les maladies transportes quitse du baicont les prottge contre ta tutic et l'trdettr dut soleil d'Ate. Cepen-

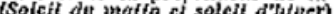
m. So dic propondear et $\mathrm{m}, 70$ de cauteur d'etage et une satille de balcon cin. so on wa pas linconounten de ta piace gui se tronve au-dessous sturtont st celle-el a des grandes fenetres. Le datcon est ie moyten le plas

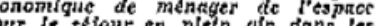
tlages stiperieurs.

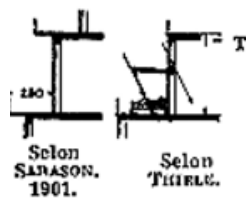

BRRASSES A GRADINS, La largeur des your la tongueur des lts tsans atsombrtr les ptoces en dessous). Incontvenientes : difficutteds pour un plan ra-

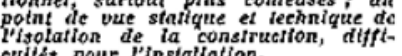

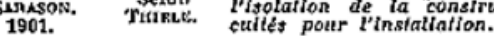

4.63 y 4.64 E. Weissmann. Proyecto de sanatorio antituberculoso para Zagreb, STKZ, 1930 (atribuido a Le Corbusier). Secciones, cónica de la galería de cura y del exterior, y estudio de secciones tipo.

4.65 B. Schachner. Esquemas de secciones propuestas en el artículo "Directrices para la construcción de Hospitales", L'Architecture Vivante n4 1, 1933. 
De la variedad de soluciones de sección que plantea Ernest Weissmann en su proyecto de Sanatorio para Zagreb STKZ, se deduce que pretende desarrollar un sanatorio-modelo [fig. 4.64]. Sus propuestas podrían ser una reinterpretación de las secciones de sanatorios escalonados realizado por Richard Döcker en su libro Terrasen Typ (1929). También se aproximan a los diseños de Benno Schachner presentes un su artículo publicado en 1931 en la revista Baumeistery bajo el título "Directrices para la construcción de Hospitales" en la revista L'Architecture Vivante, en el año $1933^{69}$ [fig. 4.65].

La sección tipo del sanatorio combina la descrita por Schachner como Porte-fenêtre avec balcon, puerta-ventana con balcón, y Terrases à gradins, terrazas escalonadas ${ }^{70}$, pero la sección del sanatorio de Zagreb resulta aún más compleja. Weissmann incluye en la parte superior de la pared norte de la habitación un cerramiento de lamas para generar una ventilación cruzada y trata de preservar la privacidad del enfermo al proyectar una barandilla de lamas horizontales para la galería de cura de la planta primera, que impide que los enfermos puedan ser vistos por los visitantes que recorren sus inmediaciones [fig. 4.63].

El proyecto en planta sigue la morfología en T pero no la unidad entre sus partes como los descritos anteriormente [fig. 4.58 y 4.59]. Está compuesto por un prisma recto que contiene las habitaciones a partir de la planta primera repartidas por sexos. En cada planta el ala masculina se sitúa al oeste y el ala femenina al este, separados por una terraza solárium ubicada en el centro de la planta primera y por el comedor en la segunda. En planta baja el prisma se fragmenta en cinco partes dispuestas simétricamente: dos aisladas situadas en los extremos, que están ocupadas por los enfermos infecciosos el del oeste y por el vigilante el del este, mientras que las tres del centro conectadas por un corredor común albergan la recepción al oeste, la entrada principal y la administración en el centro, y la zona de hidroterapia al este.

Dos pasarelas cubiertas y paralelas entre sí parten de la planta primera del pabellón residencial y lo conectan con los servicios médicos y centrales dispuestos en tres pabellones paralelos independientes situados al norte, en la parte posterior, que se intercomunican a través de pasarelas. En el pabellón central se halla el vestíbulo, la lavandería y el depósito de cadáveres en la planta baja, y en la primera los departamentos terapéuticos. Al lado este

69 Antonio PIZZA, Josep Maria ROVIRA GIMENO, G.A.T.C.P.A.C. 1928-1939, Una nueva arquitectura para una nueva ciudad. Colegio de Arquitectos de Cataluña, Barcelona 2006, p. 192.

${ }^{70}$ En Zagreb, a diferencia del artículo de Schachner, la galería tiene mayor profundidad y, en vez de poseer un alero continuo apoyado a media altura en la fachada, tiene un parasol oblicuo completamente separado del frente de la habitación. 

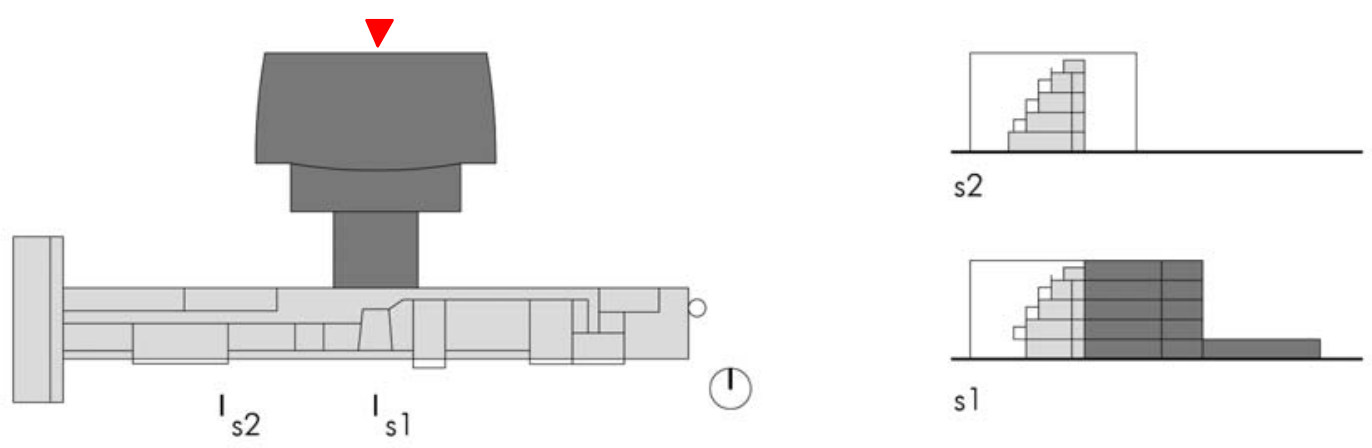

a)

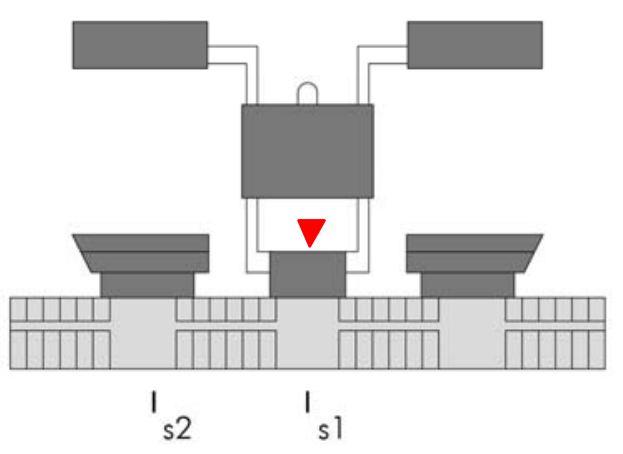

(1)

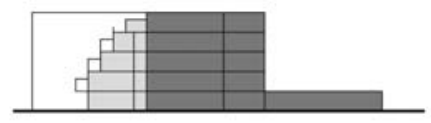

s1
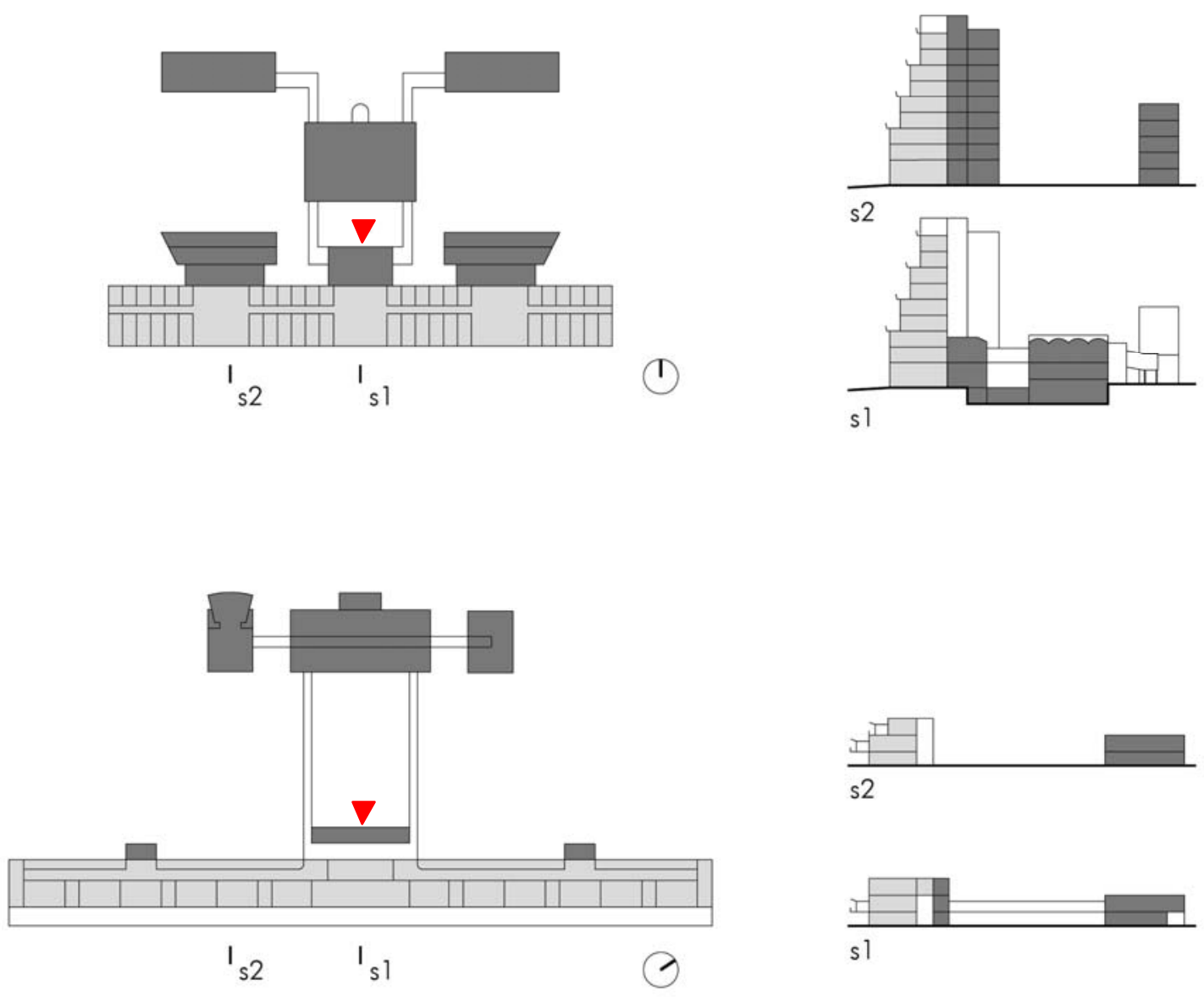

habitaciones

servicios comunes

4.66

4.66 Evolución tipológica del sanatorio compacto al de pabellones dentro de la morfología en T:

a) Paul Nelson. Maison de Santé Minimum

b) J. L. Sert y J. Torres Clavé. HT 400, Sanatorio de 400 camas-STKZ

c) Ernest Weissmann. Sanatorio antituberculoso para Zagreb

(dibujos de la autora).

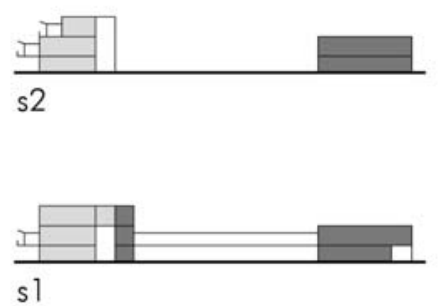


se ubica un pabellón con el animalario en planta baja y con las salas de rayos $x$ y actinoterapia en la primera, y al oeste otro con el garaje en planta baja y la sala de conferencias y los despachos médicos en primera.

De este modo, las edificaciones se organizan en dos bandas paralelas y se conectan perpendicularmente quedando en el centro del sanatorio un gran vacío [fig. 4.63], un patio de honor que recoge la entrada principal.

Así la forma en T asociada a los sanatorios compactos se combina ahora con un sanatorio de pabellones, como se aprecia al observar el conjunto de edificaciones de todo el recinto. Está integrado por una serie de edificaciones aisladas, en su mayoría paralelas entre sí, localizadas junto a las vías ortogonales y diagonales de circulación que lo atraviesan, cada una destinado a una actividad diferente [fig. 4.60]. La introducción de estos pabellones parece ejercer una potente atracción dirigida a disgregar el cuerpo central primitivo de las originarias plantas en T y a hacerlo más esponjoso.

Al comparar estos tres sanatorios anteriormente mencionados: la Maison de Santé Minimum de Paul Nelson, el Sanatorio HT 400 de J. L. Sert y J. Torres Clavé y el Sanatorio de 400 camas-STKZ de Ernest Weissmann, se aprecia cómo las funciones que anteriormente se concentraban y se repartían dentro de la propia edificación de los sanatorios compactos con forma de $T$ en planta, tienden a independizarse volumétricamente y a segregarse [fig. 4.66], de manera que el sanatorio deja de ser un único edificio y se convierte en un conjunto de construcciones diseminadas dentro de un ámbito abierto pero aglutinado, sin perder los vínculos compositivos de atado por sus relaciones geométricas.

En este marco compositivo se encuentra el Sanatorio antituberculoso de Salamanca proyectado por Rafael Bergamín entre 1934 y 1935, que puede interpretarse como una variación desde el predecesor Sanatorio de La Solana, hacia uno de pabellones aislados, el principal y cuatro más. A medida que el modelo unitario se articula y crea un conjunto, la vinculación del proyecto a las condiciones físicas del lugar de implantación aumenta, surgiendo así la especificidad del mismo y, en consecuencia, el enraizamiento local del modelo universal.

\section{EL CONJUNTO EDIFICADO DE LOS MONTALVOS}

El sanatorio antituberculoso de Salamanca debe su creación al empeño personal del Dr. Filiberto Villalobos, que quiso dotar a la provincia y a su localidad natal de estos servicios. 


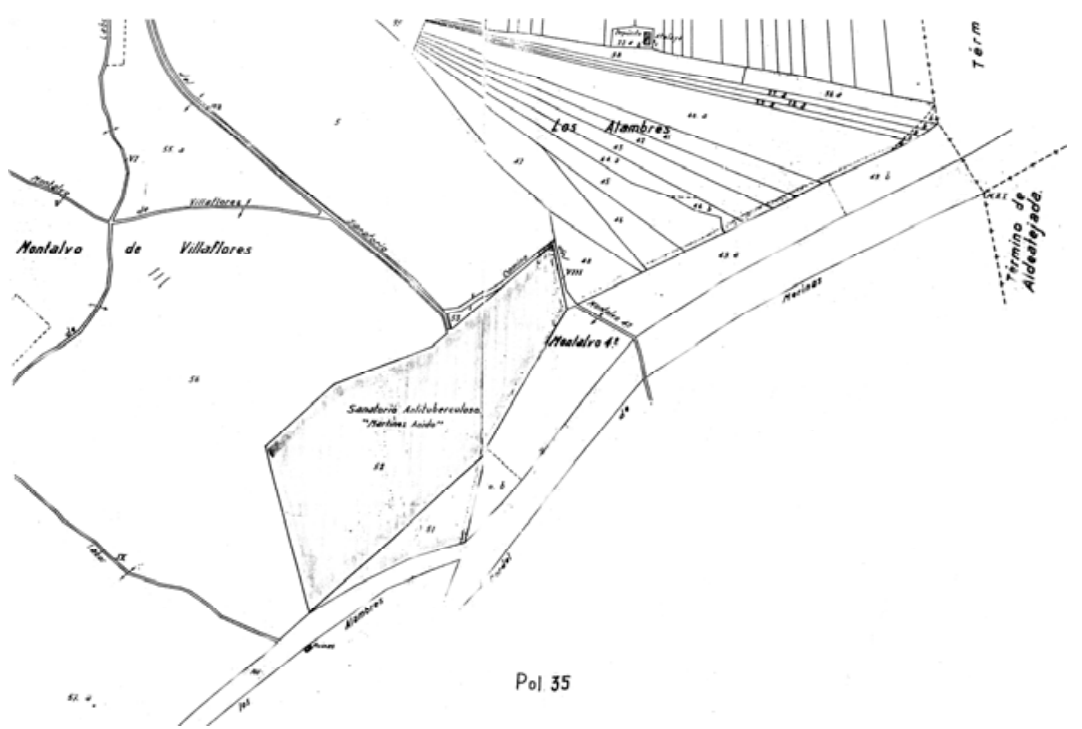

4.67

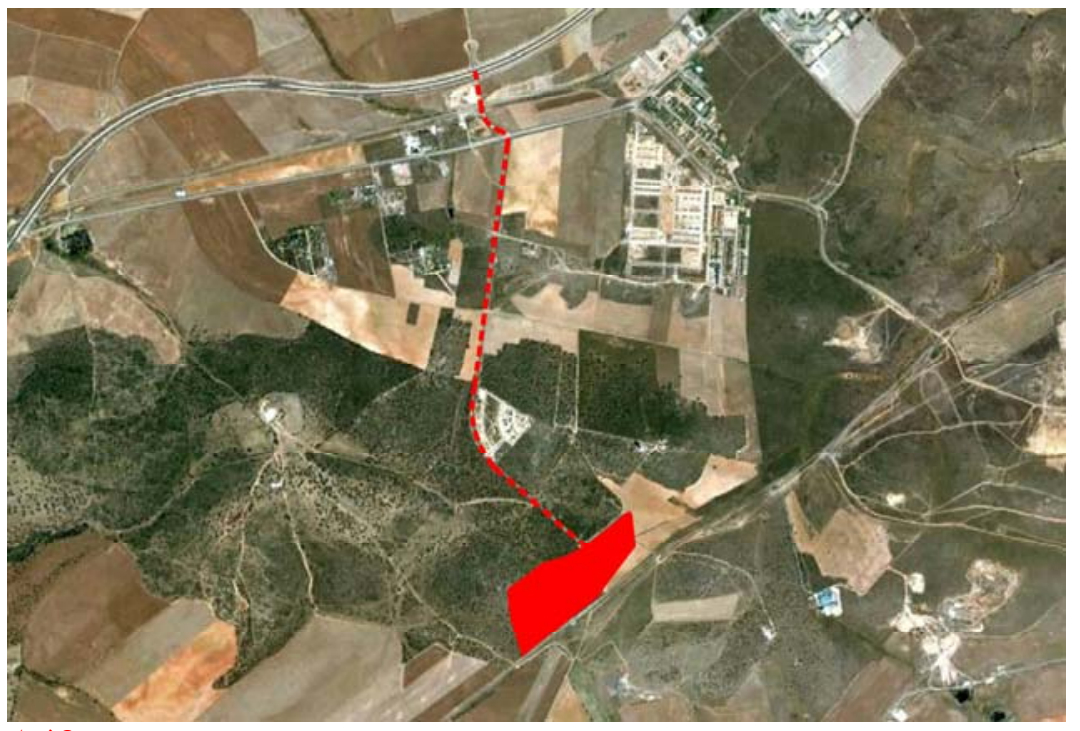

4.68

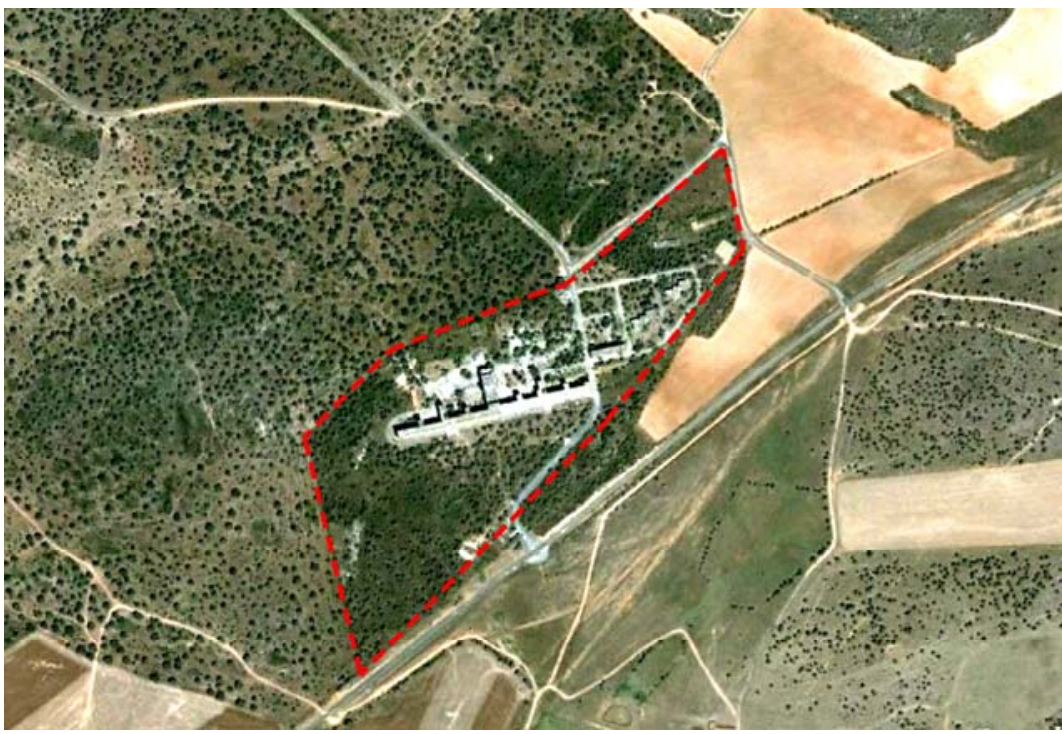

4.67, 4.68 y 4.69 R. Bergamín. Sanatorio antituberculoso Los Montalvos, Salamanca, p. 1934-35 o. 1948. Finca, localización y perímetro (dibujos de la autora). 
En Salamanca en el año 1927 no existe ningún sanatorio público y los enfermos de tuberculosis son acogidos en el Hospital de la Santísima Trinidad, con el que la Diputación Provincial tiene concertadas un determinado número de camas $^{71}$. Ese año, el Dr. Bustos propone a la Diputación de Salamanca la creación de un sanatorio, idea que retoma un año después el Dr. Villalobos, director de la asociación "Los amigos de la escuela y de los niños" que se ofrece a cofinanciar su construcción ${ }^{72}$.

El sanatorio antituberculoso que se pretende construir tiene capacidad para unos 60 ó 100 enfermos pobres y de clase media y se quiere implantar en la Sierra de Tonda, en un lugar recogido y con buen clima, perteneciente a Salvatierra de Tormes, localidad de la que es natural el Dr. Villalobos, dotando a sus habitantes de las ventajas sanitarias y económicas que su construcción reportaría.

El proyecto sigue adelante hasta el año 1931, momento en que se proclama la Segunda República, y se reanuda en 1934 cuando el Dr. Villalobos es nombrado Ministro de Instrucción Pública y Bellas Artes. En ese momento Villalobos se reúne con su colega el Ministro de Trabajo, Sanidad y Previsión José Estadella, quien aprueba la propuesta y le recomienda que el sanatorio: "se realizase con uno de los proyectos modelo de su ministerio para así darle mayor celeridad" ${ }^{\prime 73}$; es así cómo Rafael Bergamín, arquitecto de la Dirección General de Sanidad, recibe en septiembre de 1934 el encargo de elaborar un proyecto para el sanatorio de Salamanca, mucho más ambicioso que el inicial, ya que debe constar de 500 camas, de hecho, en el momento de su inauguración es el más grande de España ${ }^{74}$ y uno de los más grandes de Europa.

Tan sólo un mes después del encargo el Ministro Estadella es sustituido por José Oriol Anguera de Sojo, enemigo político del Dr. Villalobos, que elige para lugar de implantación del mismo la finca del Montalvo $n^{\circ} 3$, ubicada a unos 10 kilómetros de la capital en los

\footnotetext{
71 Antonio MEDINA ALARCÓN, Historia del sanatorio de "Los Montalvos" (1935-1986), Tesis doctoral inédita del Dpto. de Psiquiatría, Psicología Médica, Medicina Legal e Historia de la Medicina. Facultad de Medicina de la Universidad de Salamanca, Salamanca 1992, p. 24.

${ }^{72}$ Antonio MEDINA ALARCÓN, Historia del sanatorio de "Los Montalvos" (1935-1986), Tesis inédita del Dpto. de Psiquiatría, Psicología Médica, Medicina Legal e Historia de la Medicina. Facultad de Medicina de la Universidad de Salamanca, Salamanca 1992, pp. 23-48.

${ }^{73}$ Antonio MEDINA ALARCÓN, Historia del sanatorio de "Los Montalvos" (1935-1986), Tesis inédita del Dpto. de Psiquiatría, Psicología Médica, Medicina Legal e Historia de la Medicina. Facultad de Medicina de la Universidad de Salamanca, Salamanca 1992, p. 35.

${ }^{74}$ A partir de la construcción de la Ciudad Sanatorial de Tarrasa en 1952, con capacidad para 1500 camas, el sanatorio de Los Montalvos pasó a ser el segundo más grande de España.
} 


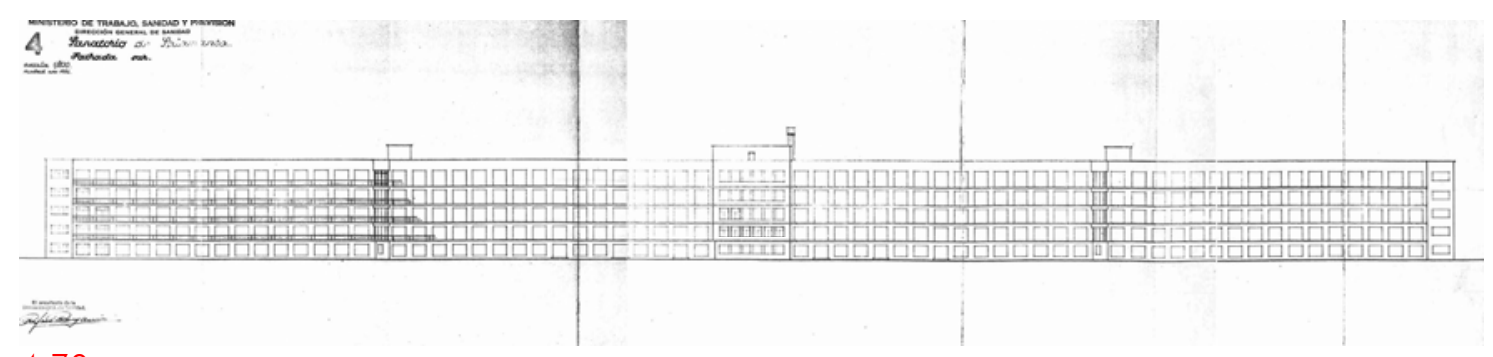

4.70

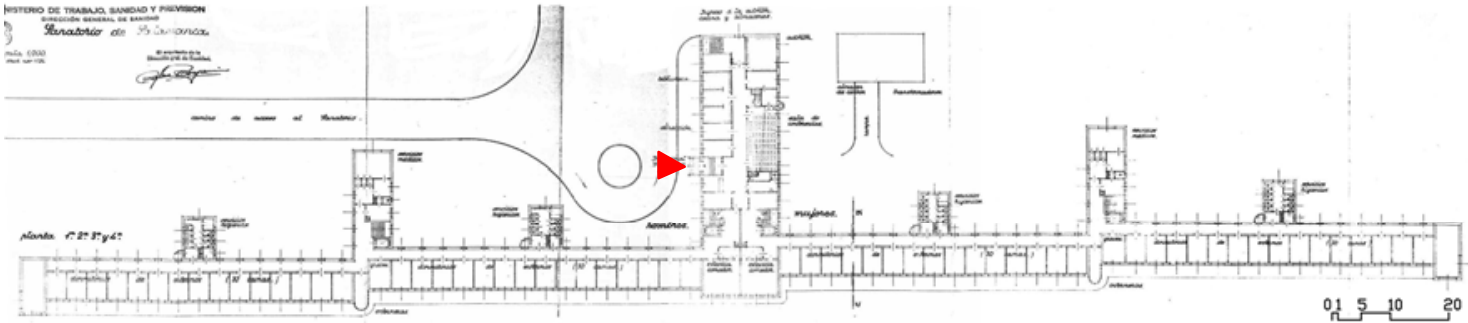

4.71

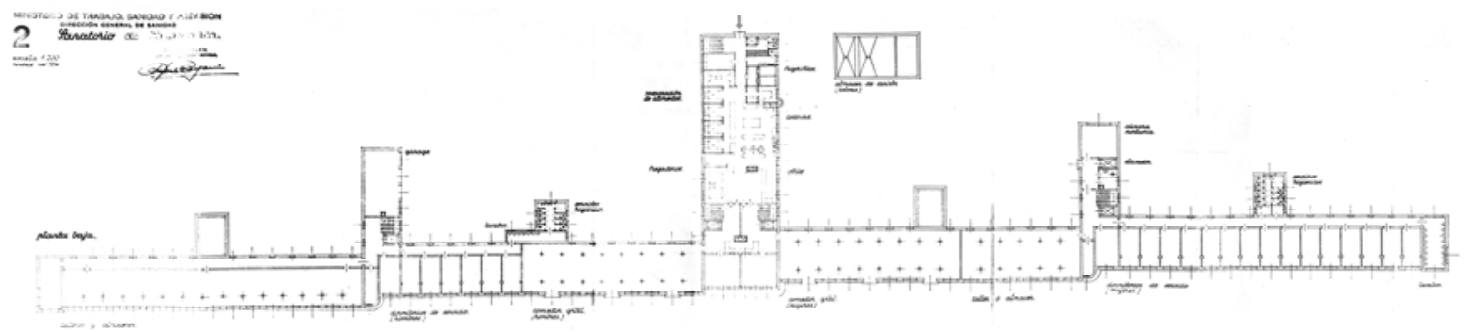

4.72

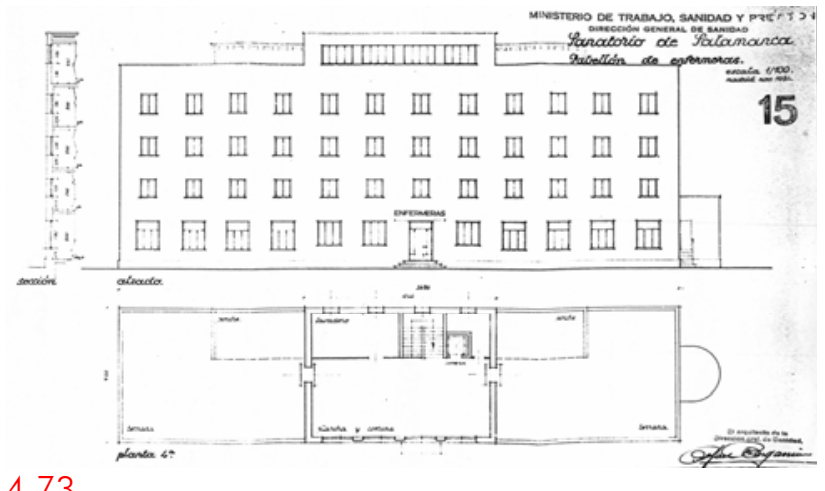

4.73

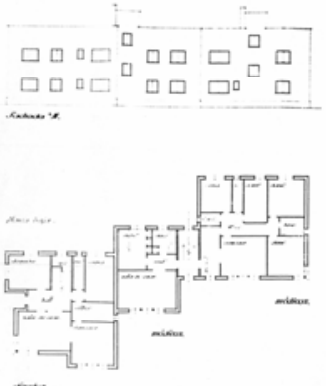

$=$
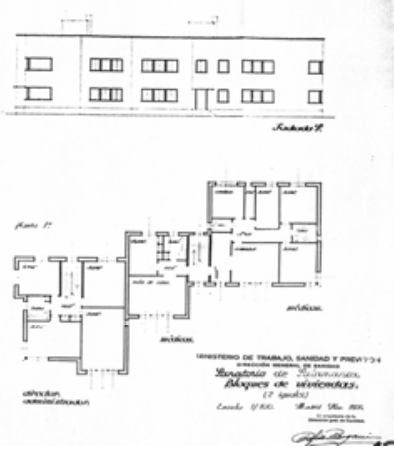

4.74

4.70, 4.71 y 4.72 R. Bergamín. Sanatorio antituberculoso Los Montalvos, Salamanca, p. 1934-35 o. 1948. Pabellón principal, planta primera, baja y alzado (proyecto de 1934).

4.73 R. Bergamín. Sanatorio antituberculoso Los Montalvos, Salamanca, p. 1934-35 o. 1948. Pabellón de enfermeras y (proyecto de 1934).

4.74 R. Bergamín. Sanatorio antituberculoso Los Montalvos, Salamanca, p. 1934-35 o. 1948. Pabellón de administradores y médicos (proyecto de 1934). 
terrenos del Montalvo de Villaflores, perteneciente a la localidad de Carrascal de Barregas ${ }^{75}$ [fig. 4.67].

El proyecto del sanatorio se presenta en noviembre de 1934. Ese mismo mes, no sabemos con certeza si antes o después de presentar el proyecto, Rafael Bergamín junto a las autoridades y el arquitecto salmantino Genaro de Nó, antiguo compañero suyo de promoción y futuro responsable de las obras ${ }^{76}$, visitan el entorno donde éste debe edificarse.

La finca tiene una extensión aproximada de 14 hectáreas que descienden en una suave ladera rodeada de un monte de encinas. Está ubicada a $920 \mathrm{~m}$. de altitud protegida de los vientos del norte y disfruta de clima seco y templado, donde no son frecuentes ni las nieblas ni los cierzos. Posee abundante agua, condición muy importante para garantizar la higiene en el sanatorio ${ }^{77}$, y excelentes vistas sobre el paisaje que permiten contemplar a lo lejos la sierra de Béjar, la Peña de Francia y la sierra de Gredos. A ella se accede desde la carretera que une Salamanca con Ciudad Rodrigo, a través de un camino cuyo trazado quebrado y en pendiente fuerza a que el sanatorio resulte prácticamente imperceptible hasta las proximidades de la puerta de acceso, quedando sus casi 20.000 metros cuadrados ocultos tras el bosque de encinas ${ }^{78}$ [fig. 4.68 y 4.69 ].

El proyecto inicial realizado en noviembre de 1934 para el sanatorio [fig. 4.70-4.74], según describe J. González Cubero, es el mismo que Bergamín presenta para el sanatorio de Húmera, Madrid, aclarando en la memoria descriptiva del primero, que debería adaptarse a los condicionantes del lugar de implantación definitivo ${ }^{79}$.

En él se definen por separado tres de los cuatro pabellones del sanatorio: el edificio principal de hospitalización, el pabellón de enfermeras y dos bloques de viviendas idénticos

\footnotetext{
${ }^{75}$ Contentando así a la Junta del Paro Obrero salmantina que exigía que su construcción se llevara a cabo en las proximidades de la capital, para aliviar las tasas de desempleo, y contrariando la voluntad de Villalobos que siempre quiso construir el sanatorio en su localidad de origen.

${ }^{76}$ El Director General de Sanidad el Dr. Villoria, el Inspector Provincial de Sanidad el Dr. Prada y un representante de $D^{a}$. María Antonia Díaz, la propietaria de la finca.

77 Antonio MEDINA ALARCÓN, Historia del sanatorio de "Los Montalvos" (1935-1986), Tesis inédita del Dpto. de Psiquiatría, Psicología Médica, Medicina Legal e Historia de la Medicina. Facultad de Medicina de la Universidad de Salamanca, Salamanca 1992, p. 40 y p. 63.

78 La propietaria de la finca, María Antonia Díaz, puso como condición en el contrato de compraventa que el sanatorio no resultara visible desde la carretera a Ciudad Rodrigo para no devaluar con su presencia las fincas colindantes de las que era también propietaria. Antonio MEDINA ALARCÓN, Historia del sanatorio de "Los Montalvos" (1935-1986), Tesis inédita del Dpto. de Psiquiatría, Psicología Médica, Medicina Legal e Historia de la Medicina. Facultad de Medicina de la Universidad de Salamanca, Salamanca 1992, p. 410.

79 Josefina GONZÁLEZ CUBERO, "Arquitectura hospitalaria de Rafael Bergamín: El Sanatorio de los Montalvos", en José ALTÉS BUSTELO (ed.), Arquitectura Moderna en Salamanca. Colegio de Arquitectos de León, Delegación en Salamanca, Salamanca 1998, pp. 36-37.
} 

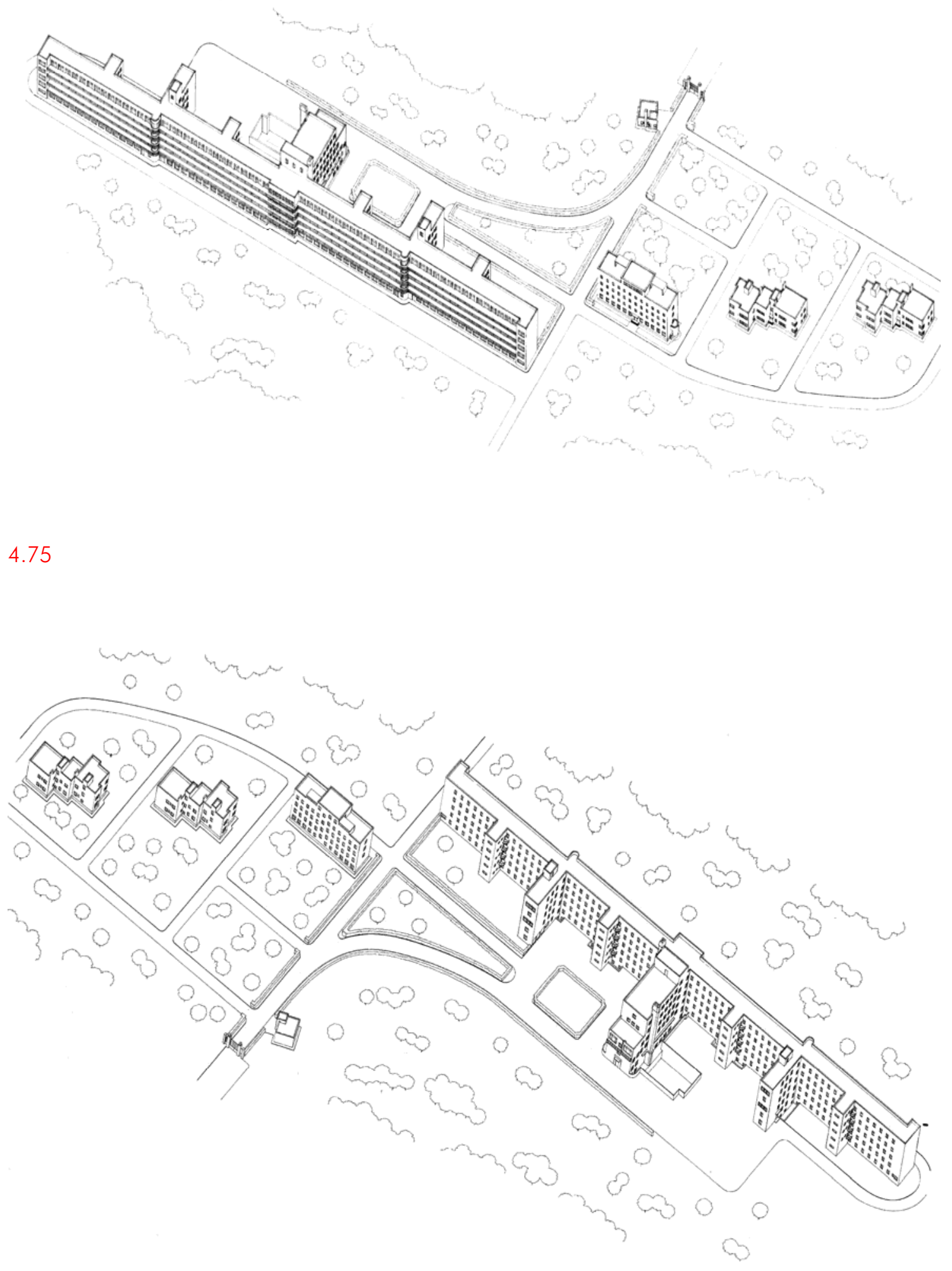

4.76

4.75 y 4.76 R. Bergamín. Sanatorio antituberculoso Los Montalvos, Salamanca, p. 1934-35 o. 1948. Axonometría del conjunto desde la fachada sur y desde la fachada norte (dibujos de la asignatura de Elementos de Composición. Curso 1993-1994. Departamento de Teoría de la Arquitectura y Proyectos arquitectónicos. Escuela de Arquitectura de Valladolid curso 1993-94). 
para los administradores y los médicos. En el proyecto inicial no se describe la posición de cada uno de ellos en la finca, que se concreta después en el proyecto definitivo realizado por Bergamín en 1935, donde se mantienen prácticamente idénticos los pabellones anteriormente descritos y se incluye otro más, el de la residencia del guarda.

Los únicos cambios importantes que se producen en el proyecto de 1935 con respecto al de 1934 responden a la variación de la posición de la entrada al edificio. En el proyecto inicial el acceso al edificio principal se produce a través de una vía paralela al mismo que discurre desde el oeste por su fachada posterior orientada al norte, hasta alcanzar el "martillo" central, en cuyo lateral se sitúa la puerta principal [fig. 4.70], mientras que en el proyecto de 1935 la vía de acceso parte del norte y se aproxima hacia el "martillo" central por su cara este, quedando situada la puerta de entrada al contrario del proyecto anterior y provocando por arrastre una alteración simétrica en la distribución del programa.

La gran extensión de la finca, más amplia en la dirección este-oeste, propicia la organización de las construcciones lineales dentro del recinto, lo que permite disponer con la mejor orientación y vistas sobre el paisaje, a excepción de la vivienda del guarda que se localiza junto al acceso, algo alejada del resto de edificaciones.

Al este y ligeramente retrasado del edificio de hospitalización, se ubica el pabellón de enfermeras. Junto a él, y también desplazado en profundidad, se encuentra uno de los dos pabellones de médicos y administrativos del Sanatorio y a continuación el otro repitiendo el mismo desplazamiento. Los cuatro pabellones describen un trazado diagonal ${ }^{80}$ que logra acortar las distancias entre ellos y evita la configuración de un frente edificado continuo, favoreciendo el entrelazado de los edificios con la vegetación. Así Bergamín, quien considera que: "Todo el valor de la moderna arquitectura, con su sobriedad y sus planos lisos, viene realzado por la línea graciosa y espontánea trazada por la Naturalezd"81, ve cumplido aquí su propósito en toda su dimensión [fig. 4.75 y 4.76 ].

Con esta disposición se establece una reducción progresiva del tamaño de las construcciones que propicia la consideración de un orden jerárquico de reminiscencias biológicas, donde el edificio principal, lineal y compacto, define la cabeza del mismo y el conjunto discontinuo de los otros tres pabellones desplazados entre sí forman la cola. De

\footnotetext{
${ }^{80}$ Ya en la casa del Marqués de Villora se detecta esta organización en diagonal de los elementos de la parcela, sugerida por la posición del garaje en una de las esquinas, la vivienda principal en el centro y el jardín en la esquina contraria.

${ }^{81}$ Rafael BERGAMíN, 20 años en Caracas 1938-1958. Gráficas Reunidas, Madrid 1959, p. 21.
} 

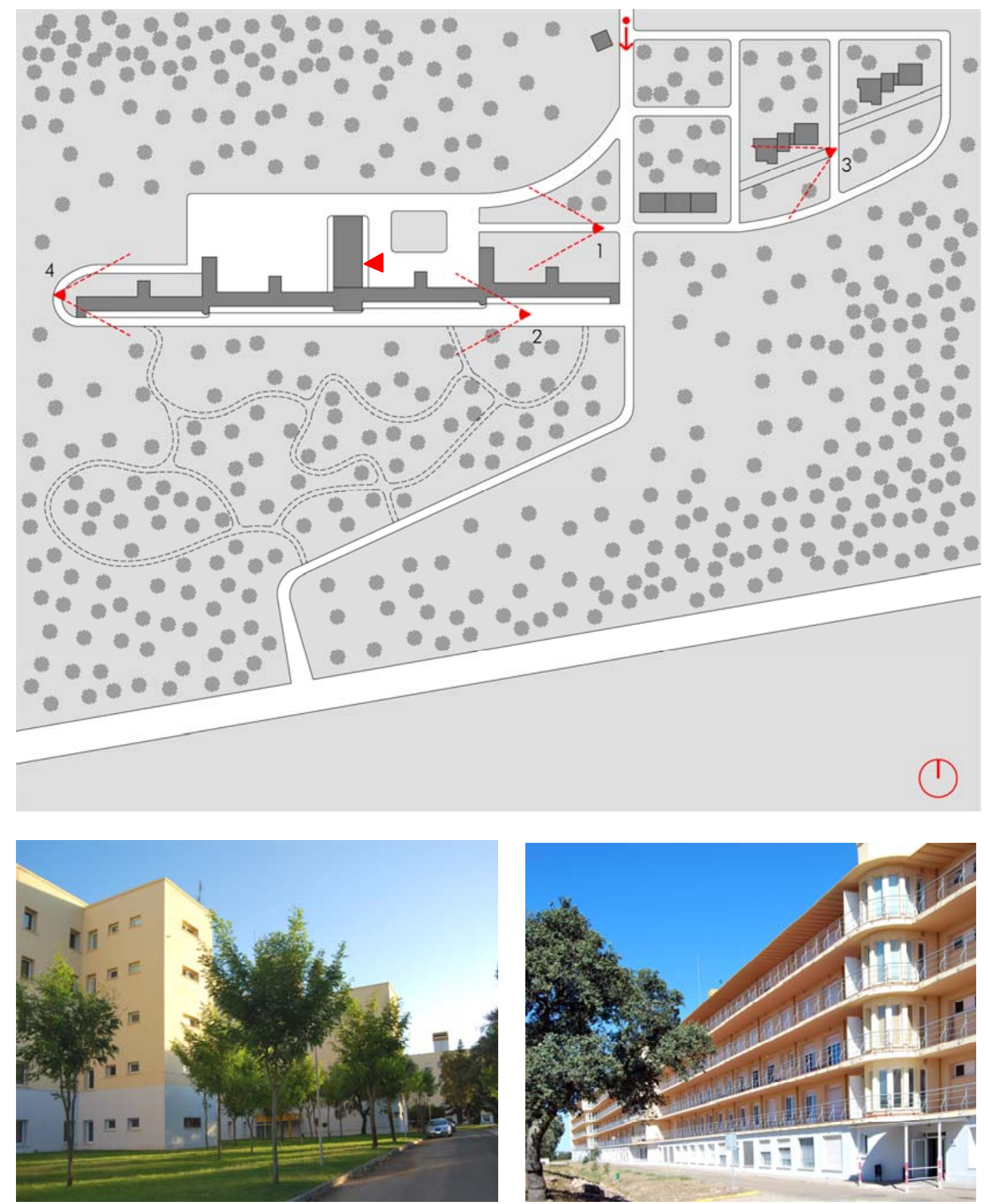

VISTA 1 y VISTA 2
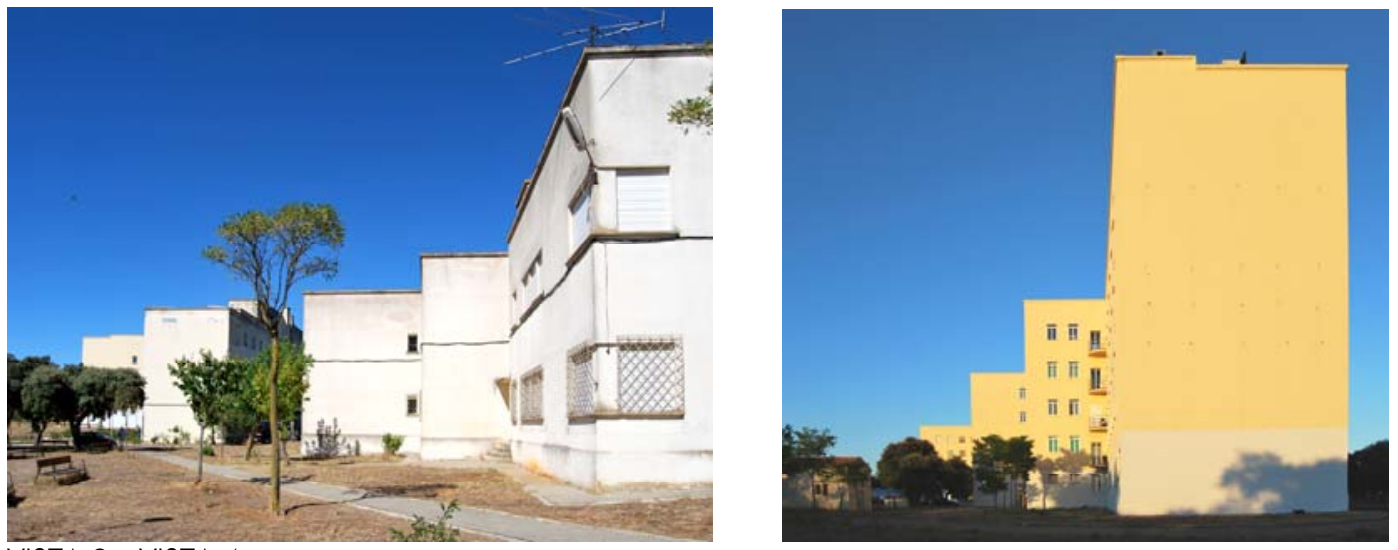

4.77

4.77 Vistas exteriores del sanatorio de Los Montalvos (dibujo y fotografías de la autora). 
este modo, todo el conjunto de edificaciones de Los Montalvos acaban definiendo una cierta unidad orgánica.

Lo que era la matriz unitaria de la planta del bloque lineal residencial del modelo en T aquí se estructura en cuatro fragmentos que se desplazan en profundidad, al igual que los otros tres pabellones aislados del recinto que se desplazan hacia el norte y hacia el este, describiendo una diagonal ${ }^{82}$. De este modo se reconoce una similitud entre la disposición diagonal empleada en el edificio principal y en la ordenación del conjunto.

Estas relaciones formales existentes en el conjunto del Sanatorio se ven reforzadas por el trazado curvo y diagonal de los caminos que lo atraviesan [fig. 4.77]. Años más tarde, durante su exilio en Venezuela, Bergamín relata su rechazo a las ordenaciones en cuadrícula porque considera entre otras desventajas que aumentan los recorridos hasta en un $40 \%{ }^{83}$, y se pregunta: "¿Por qué no hay calles curvas? ¿Por qué esa disciplina en donde la libertad hubiera dado siempre mejores soluciones?" 84 . Calles como las que él propone en el Sanatorio ${ }^{85}$, cuyos recorridos evitan la visión frontal de las edificaciones y propician las visiones en escorzo de sus volúmenes.

La localización de la puerta de acceso del edificio principal en un lateral del "martillo" central, desplazada de su eje de simetría, favorece que el recorrido de acceso desde la entrada al recinto hasta ella no coincida tampoco con este eje, evitando la percepción del inmenso frente del edificio en su totalidad y propiciando una visión sesgada del mismo donde se aprecia la secuencia de tres de sus seis "martillos". En la fachada sur de galerías de cura, Bergamín también evita la frontalidad mediante la creación de un camino paralelo a la misma que fuerza una visión en escorzo de los pliegues curvos de su cambiante perfil. Los caminos diagonales que conectan peatonalmente los pabellones anexos al edificio principal hacen posible también una visión más dinámica del conjunto, pues gracias a sus quiebros y a sus desplazamientos los pabellones se van concatenando entre sí definiendo una misma unidad. De este modo, tanto el inmenso sanatorio compacto como los

\footnotetext{
${ }^{82}$ La fragmentación del bloque residencial era un recurso habitualmente empleado para resolver sanatorios de gran tamaño, como sucede en el proyecto realizado por Marcel Brever y Hassenpflug en torno a 1930 para un sanatorio con capacidad para 1.100 camas; el gran bloque lineal se fragmenta en 7 unidades que van desplazándose en profundidad, pero a diferencia del Sanatorio de Los Montalvos el resto de las edificaciones del conjunto siguen un orden ajeno a este desplazamiento.

${ }^{83}$ Rafael BERGAMíN, 20 años en Caracas 1938-1958. Gráficas Reunidas, Madrid 1959, p. 17.

${ }^{84}$ Rafael BERGAMÍN, 20 años en Caracas 1938-1958. Gráficas Reunidas, Madrid 1959, p. 17.

${ }^{85}$ En el sanatorio de La Solana Bergamín también emplea trazados curvos en su viario y, en el proyecto de sanatorio de Zagreb de Weissmann, una vía diagonal atraviesa el recinto, dando acceso a través de ella a los pabellones adyacentes al edificio principal.
} 
pabellones anexos de mucho menor tamaño transmiten una imagen recurrente de deslizamientos, estableciéndose entre ellos relaciones visuales y formales que superan la mera construcción de un modelo sanatorial en forma de $T$, meramente útil o funcional. Las palabras de Adolf Behne subrayan este propósito de Bergamín: "Procurar que las cosas entren en relación, y ver si lo hacen, no es nunca una cuestión de utilidad. Si renunciamos a la exigencia de unidad, ya no podemos hablar propiamente de configuración" $" 86$.

El recinto del sanatorio se completa con el parque terapéutico ubicado al sur, atravesado por caminos serpenteantes entre las encinas para realizar la cura de ejercicio de los enfermos. Acondicionado con bancos para su descanso y para llevar a cabo la cura de aire puro y sol fuera del edificio principal, tiene una organización similar que se disuelve entre las masas arboladas.

El conjunto del sanatorio responde así a una configuración de ciudad moderna con edificaciones en altura entre amplias zonas verdes, nunca antes proyectada por él, ya que sus colonias residenciales de baja densidad se aproximan más a la ciudad-jardín ${ }^{87}$.

En 1938 Bergamín publica varios artículos sobre el urbanismo de Caracas donde expone su apuesta por esta nueva concepción urbana:

"(...) viene al caso recordar las palabras del gran Arquitecto, del maestro Walter Gropius: ¿Puede uno imaginarse la extensión racional de una ciudad cuando todos los ciudadanos habitan una casa con jardín? ¿̇s esta forma de habitación solamente la que puede dar a sus habitantes la garantía de un sano desarrollo corporal e intelectual?. NO. La construcción baja no es el remedio para todos los males, para el saneamiento de la civdad" 88 .

Emplea, para solucionar los problemas de hacinamiento de esa ciudad, las directrices aplicadas en sus sanatorios, de modo que:

"(...) las construcciones se desarrollan solamente en líneas según la mejor orientación. Todos los locales tienen iluminación y ventilación directas. Desde todas las ventanas se dominan amplias perspectivas" ${ }^{\prime \prime 9}$.

De hecho, en una conferencia dada en el Colegio de Ingenieros de Caracas en 1942, muestra unas maquetas con sus propuestas, donde se observa una serie de bloques lineales

\footnotetext{
${ }^{86}$ Adolf BEHNE, 1923 La construcción funcional moderna (Der moderne Zweckbau, 1926). Ediciones del Serbal, Barcelona 1994, p. 80.

${ }^{87}$ Blanco Soler renunció a la construcción de El Viso debido al aumento de densidad propuesto por Bergamín y por el promotor de la obra.

${ }^{88}$ Rafael BERGAMÍN, 20 años en Caracas 1938-1958. Gráficas Reunidas, Madrid 1959, p. 30.

${ }^{89}$ Rafael BERGAMíN, 20 años en Caracas 1938-1958. Gráficas Reunidas, Madrid 1959, p. 25.
} 
escalonados con terrazas corridas que podrían ser sanatorios ${ }^{90}$. Busca la imbricación entre la naturaleza y la arquitectura al concebir lo que él llama una "ciudad cultivada" o un "campo civilizado"191. Urbes donde el número de habitantes se limita a unos doscientos o cuatrocientos mil, rodeadas de parques, espacios arbolados "(...) con sus quebradas llenas de sombra acogedora, como lugares de reposo sabiamente espaciados por la Naturalezd"92. Ciudades donde el verde esté presente "sobre la tierra y sobre los techos, con el fin de que la Naturaleza sea diaria, no dominical solamente" ${ }^{\prime \prime 3}$; donde los árboles y la vegetación sirven para amortiguar los ruidos de la ciudad, "sirviendo también de pantalla contra humos y olores' ${ }^{\prime \prime 4}$, mejorando así la calidad de vida de los ciudadanos, ya que para él:

"Urbanizar es hacer vivible una ciudad, es hacerla grata a la vida del hombre, es hacerla sana y alegre; es, en fin, hacer que el trabajo diario y obligado sea compatible con el aire puro y el contacto directo con la Naturalezd" ${ }^{\prime 15}$.

De modo que los principios aprendidos en la arquitectura sanitaria pasan de la unidad al conjunto, y no sólo son aplicados en su arquitectura residencial sino que alcanza a toda la ciudad y al urbanismo, pues según Bergamín "sin urbanismo no hay sanidad; pero...sin sanidad no hay urbanismo..."196

En esta traslación, la arquitectura debe de impregnarse de las condiciones del entorno y de las relaciones que suscita la multiplicidad, para que el conjunto, la ciudad, no sea una mera agrupación de edificios saludables y en ellos se siga identificando un cierto carácter unitario ligado a los principios de la Gestalt: proximidad, continuidad y cerramiento ${ }^{97}$, como sucede en el conjunto de pabellones del Sanatorio de Los Montalvos donde, además de perseguir los " 'placeres esenciales': sol, espacio y vegetación" ${ }^{198}$ definidos por Le Corbusier, algo más que la mera suma de edificios sobre la naturaleza pero que no consigue

\footnotetext{
90 Trata de trasladar la galería de cura tanto a sus bloques residenciales como a toda la ciudad, proponiendo la creación de arcadas o soportales sobre las aceras. Rafael BERGAMíN, 20 años en Caracas 1938-1958. Gráficas Reunidas, Madrid 1959, p. 17.

${ }^{91}$ Rafael BeRGAMíN, 20 años en Caracas 1938-1958. Gráficas Reunidas, Madrid 1959, p. 123.

92 Rafael BERGAMín, 20 años en Caracas 1938-1958. Gráficas Reunidas, Madrid 1959, p. 131.

${ }_{93}$ Rafael BERGAMÍN, 20 años en Caracas 1938-1958. Gráficas Reunidas, Madrid 1959, p. 30.

${ }^{94}$ Rafael BERGAMÍN, 20 años en Caracas 1938- 1958. Gráficas Reunidas, Madrid 1959, p. 25.

${ }^{95}$ Rafael BERGAMíN, 20 años en Caracas 1938-1958. Gráficas Reunidas, Madrid 1959, p. 132.

${ }^{96}$ Rafael BERGAMíN, 20 años en Caracas 1938-1958 Gráficas Reunidas, Madrid 1959, p. 24.

97 Christian NORBERG-SCHULZ, Los principios de la arquitectura Moderna (Principles of Modern Architecture, 2000). Reverté, Barcelona 2005, p. 159.

${ }_{98}$ Christian NORBERG-SCHULZ, Los principios de la arquitectura Moderna (Principles of Modern Architecture, 2000). Reverté, Barcelona 2005, p. 156.
} 


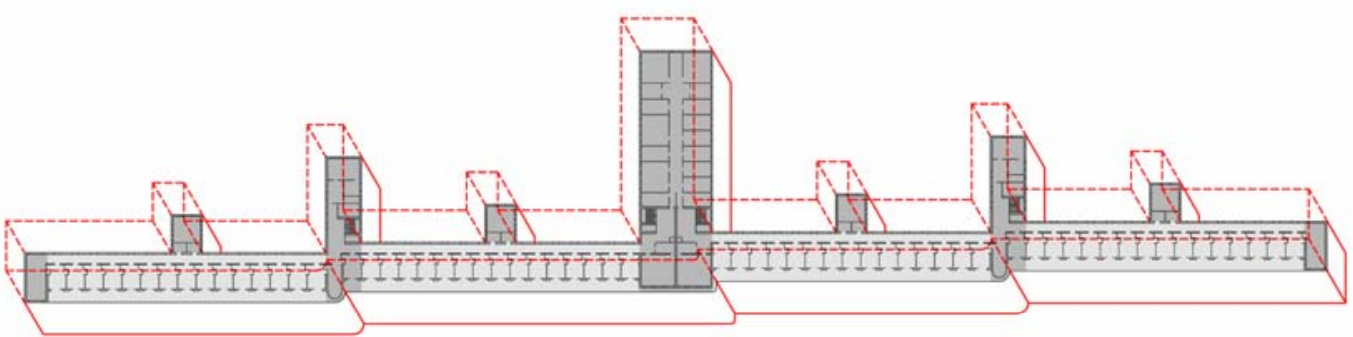

sanatorio en T

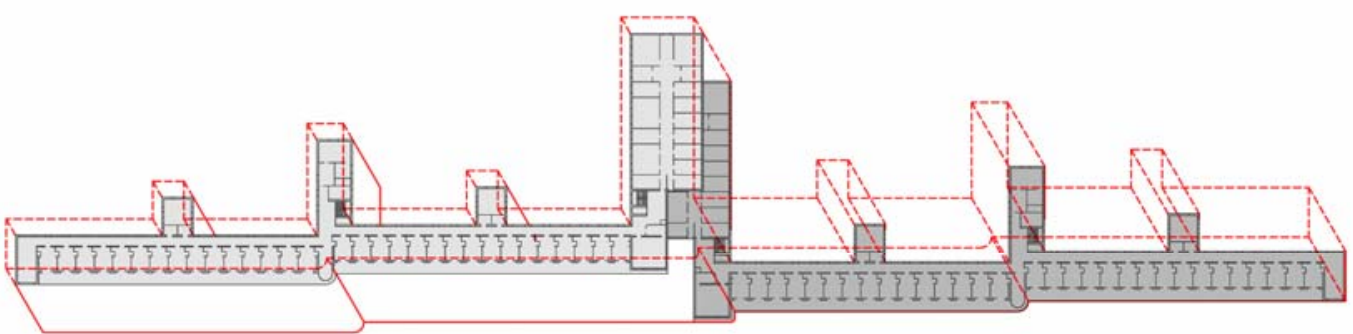

distribución en L por sexos

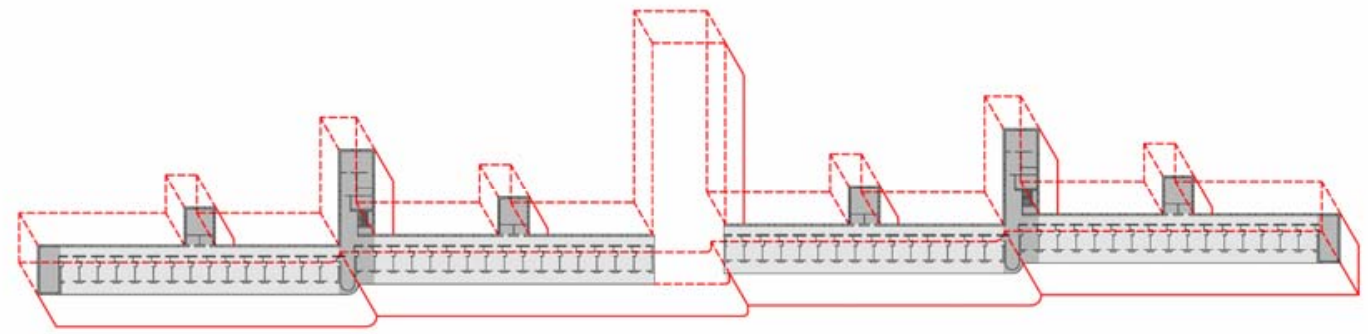

alas independientes en T (masculina y femenina)

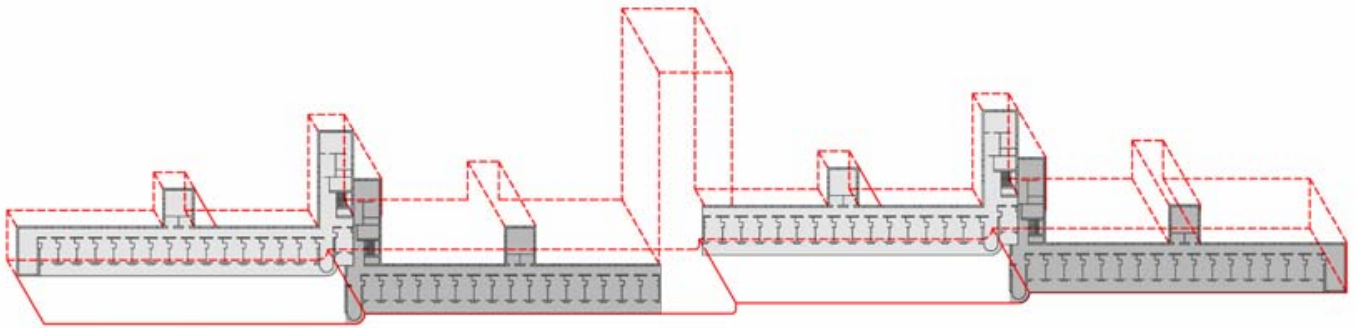

disribución en L en cada ala (masculina y femenina)

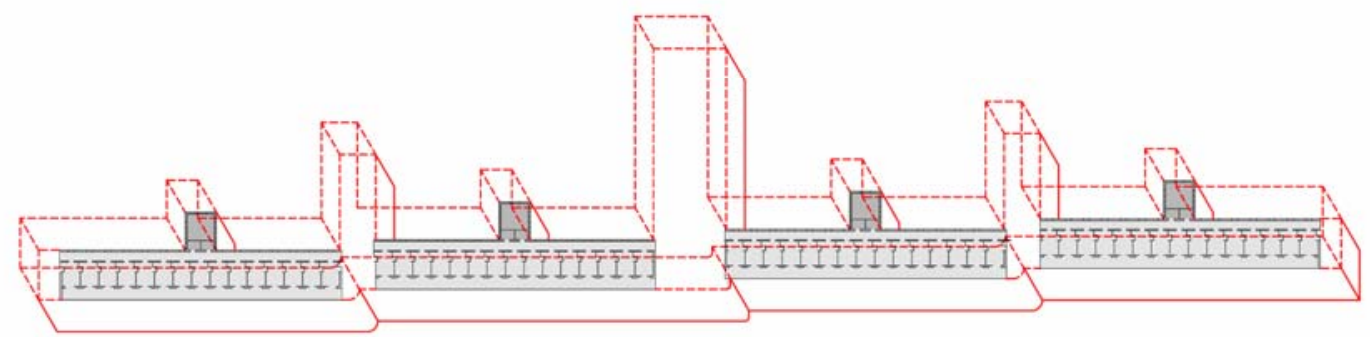

unidades de enfermería en T

4.78 Sanatorio de los Montalvos, distribución funcional (dibujos de la autora). 
esclarecer. En los mismos términos ambiguos Richard Döcker, el arquitecto de sanatorios explica:

"Edificio, hombre, sol, paisaje, forman un complejo de relaciones mutuas. Del mismo modo que la obra única, en tanto que orgánica y creada por estas relaciones, recibe una fisonomía y un cuerpo formados, el conjunto edificado en tanto que composición urbanística general de un organismo complicado debe satisfacer las exigencias múltiples y heterogéneas de un entorno para recoger, incorporar y subordinar en la unidad determinada por la idea de conjunto, la personalidad de los organismos particulares elaborados en lo impersonal, que sólo juntos adquieren valor y significado, y llegan a ser lo que cada uno quiere ser"

\section{EL PATRÓN MÉDICO}

La configuración del edificio principal del sanatorio de Los Montalvos de Salamanca, de casi 250 metros de fachada, sigue el patrón o "pattern"100 establecido en 1899 por los médicos y tisiólogos presentes en el Congreso Internacional de la Tuberculosis celebrado en Berlín, donde se determina que la cura de reposo, sol y aire puro en el sanatorio, por encima de las colonias de convalecencia y trabajo o los dispensarios, es el remedio más eficaz para acabar con la tuberculosis. A raíz de esta consideración se proponen los modelos de sanatorios compactos constituidos por un bloque lineal de habitaciones orientado al sur con sus galerías de cura, y un cuerpo transversal en el centro con los servicios comunes yuxtapuestos en la fachada norte, que acaba por definir la planta en $T$ característica de los sanatorios.

En el Sanatorio de Los Montalvos, además de poseer un "martillo" central con los servicios comunes alberga otros seis simétricos de menor tamaño, a ambos lados del primero, que recorren sus cinco plantas y el semisótano en vertical ${ }^{101}$. Contienen los servicios comunes necesarios para atender a los 500 enfermos que están repartidos a partir de la planta primera, es decir, aquella que coincide con el nivel de acceso, en habitaciones dobles

\footnotetext{
99 Richard DÖCKER, Volkswohnung, 10 julio de 1923. Citado en: Adolf BEHNE, 1923 La construcción funcional moderna (Der moderne Zweckbau, 1926). Ediciones del Serbal, Barcelona 1994, pp. 79-80.

100 Según la interpretación de Christopher Alexander que considera a los "patterns" como soluciones empíricas compartidas por toda una comunidad.

101 Este recurso era habitual en la época en los hospitales de gran tamaño como el Hospital Luis Pasteur de Colmar, Francia, de M. W. Vetter de 740 camas, con ocho martillos y el central.
} 

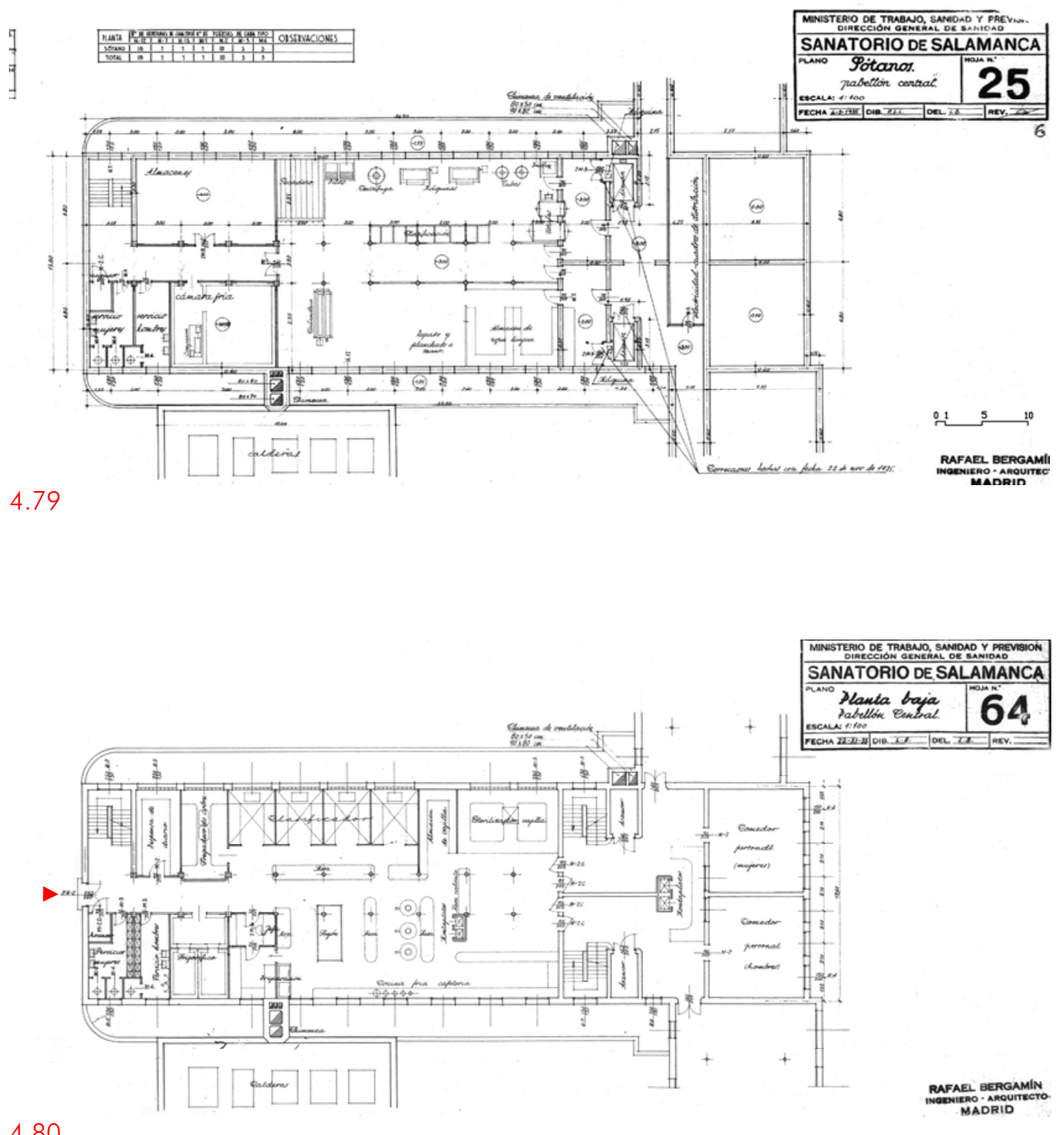

4.80

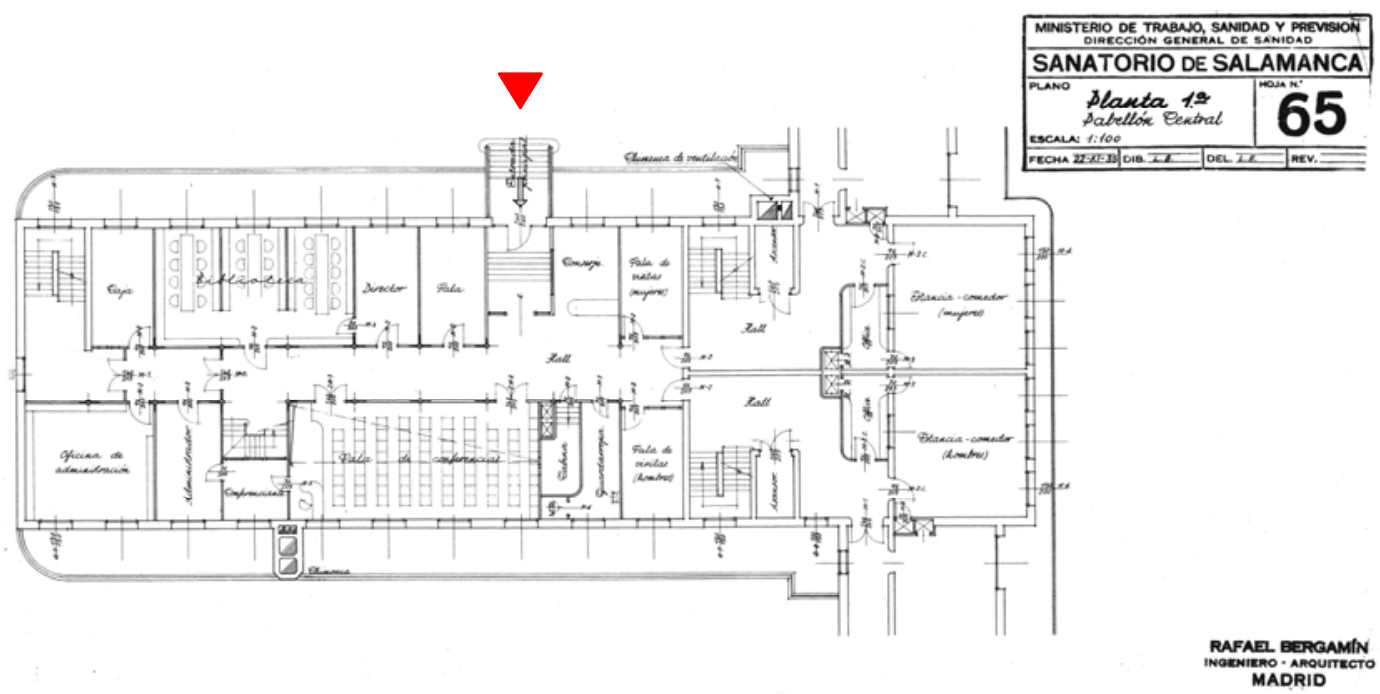

4.79, 4.80 y 4.81 R. Bergamín. Sanatorio antituberculoso Los Montalvos, Salamanca, p. 1934-35 o. 1948. "Martillo" central plantas sótano, baja o semisótano y primera (planos del proyecto de 1935). 

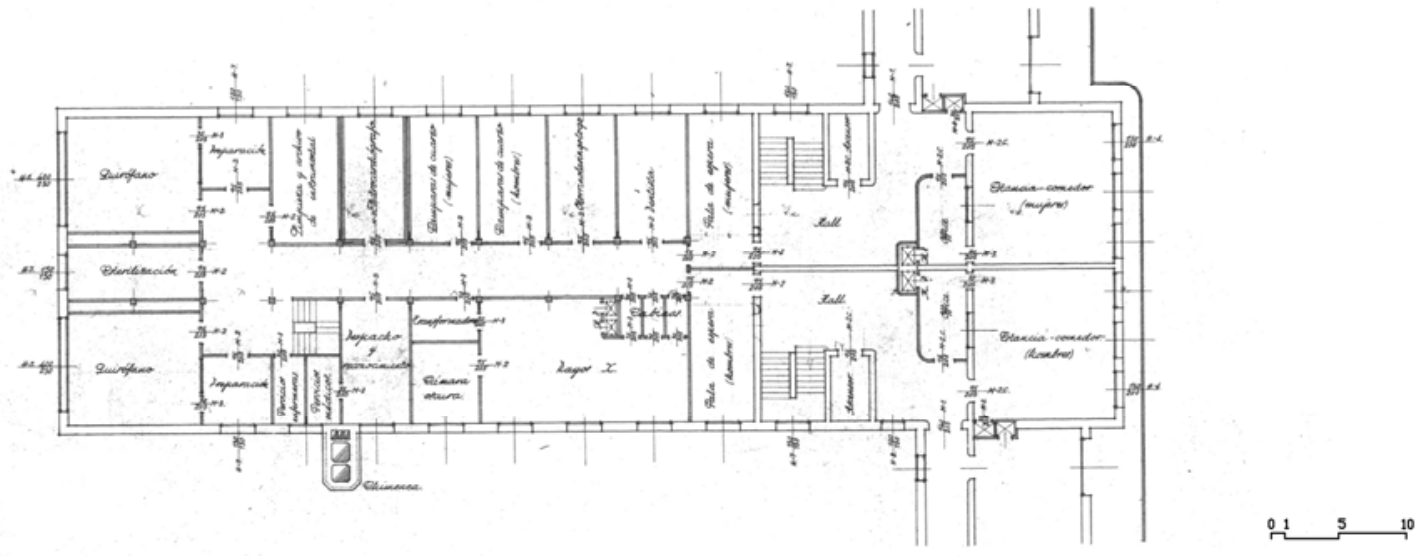

4.82
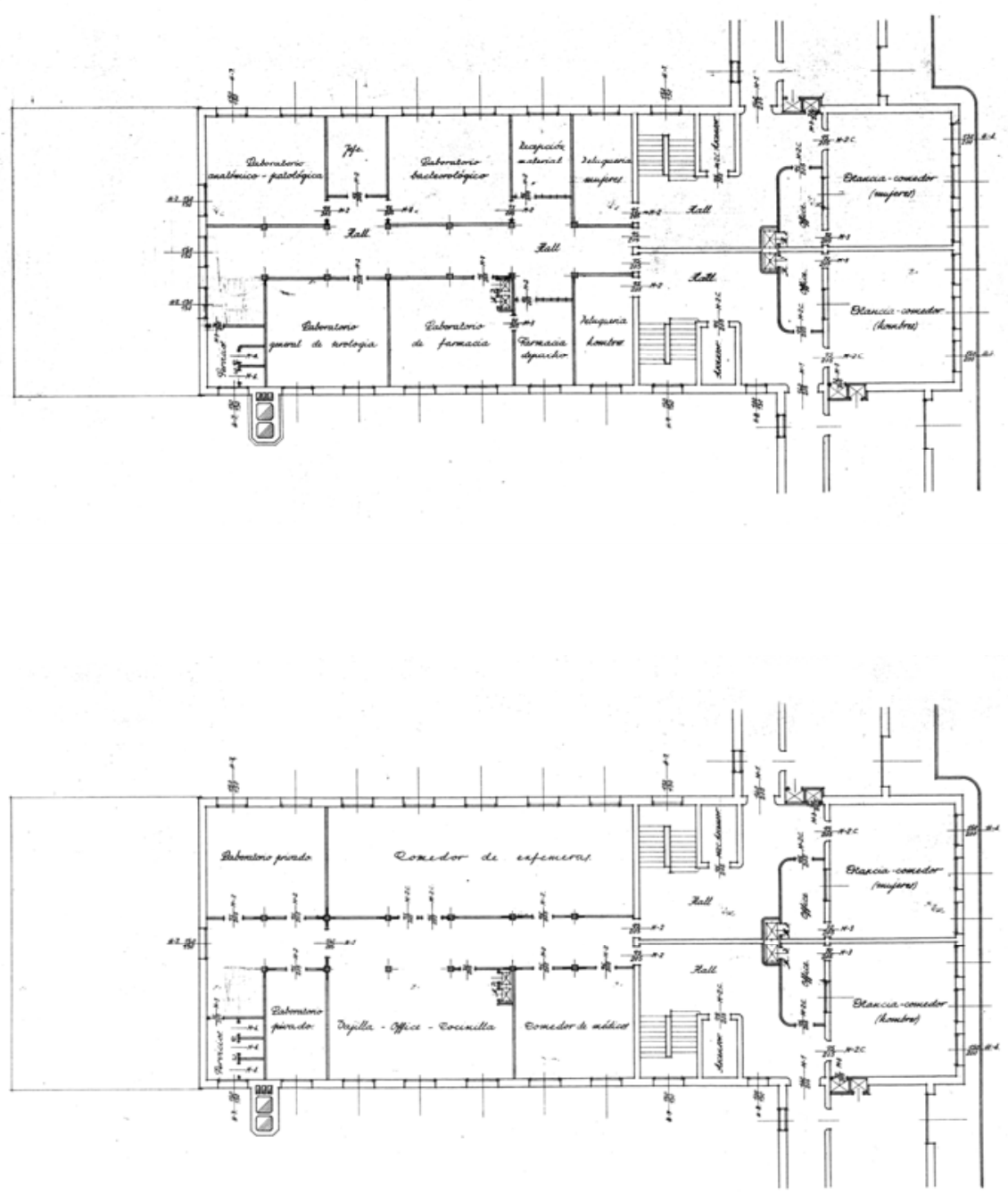

4.82, 4.83 y 4.84 R. Bergamín. Sanatorio antituberculoso Los Montalvos, Salamanca, p. 1934-35 o. 1948. "Martillo" central plantas segunda, tercera y cuarta (planos de c. 1970). 


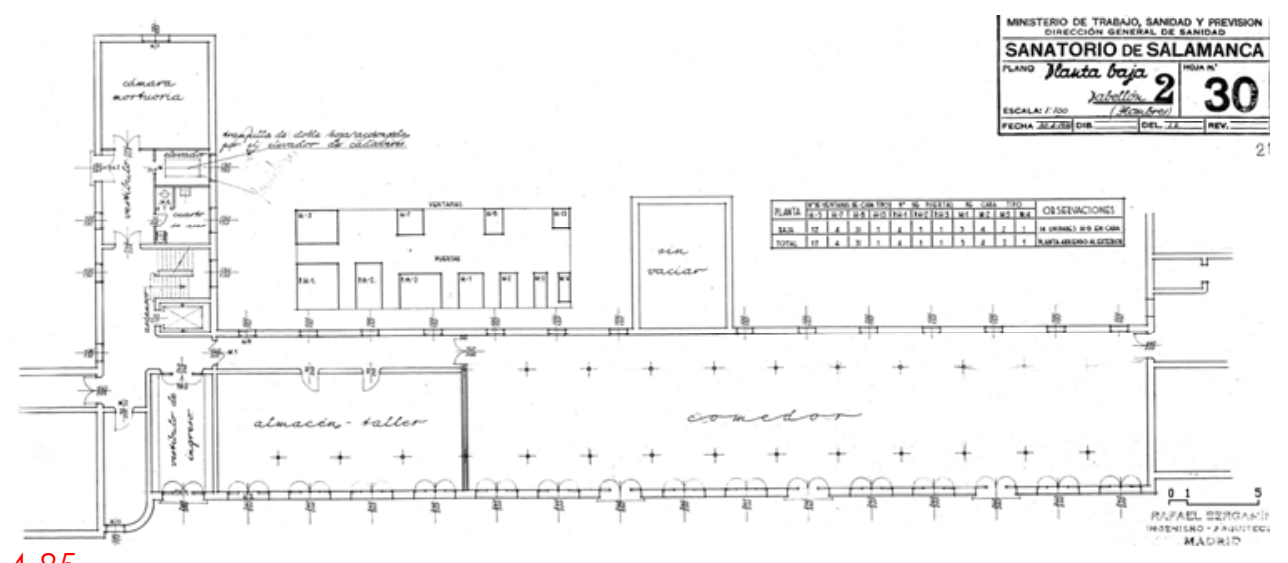

4.85
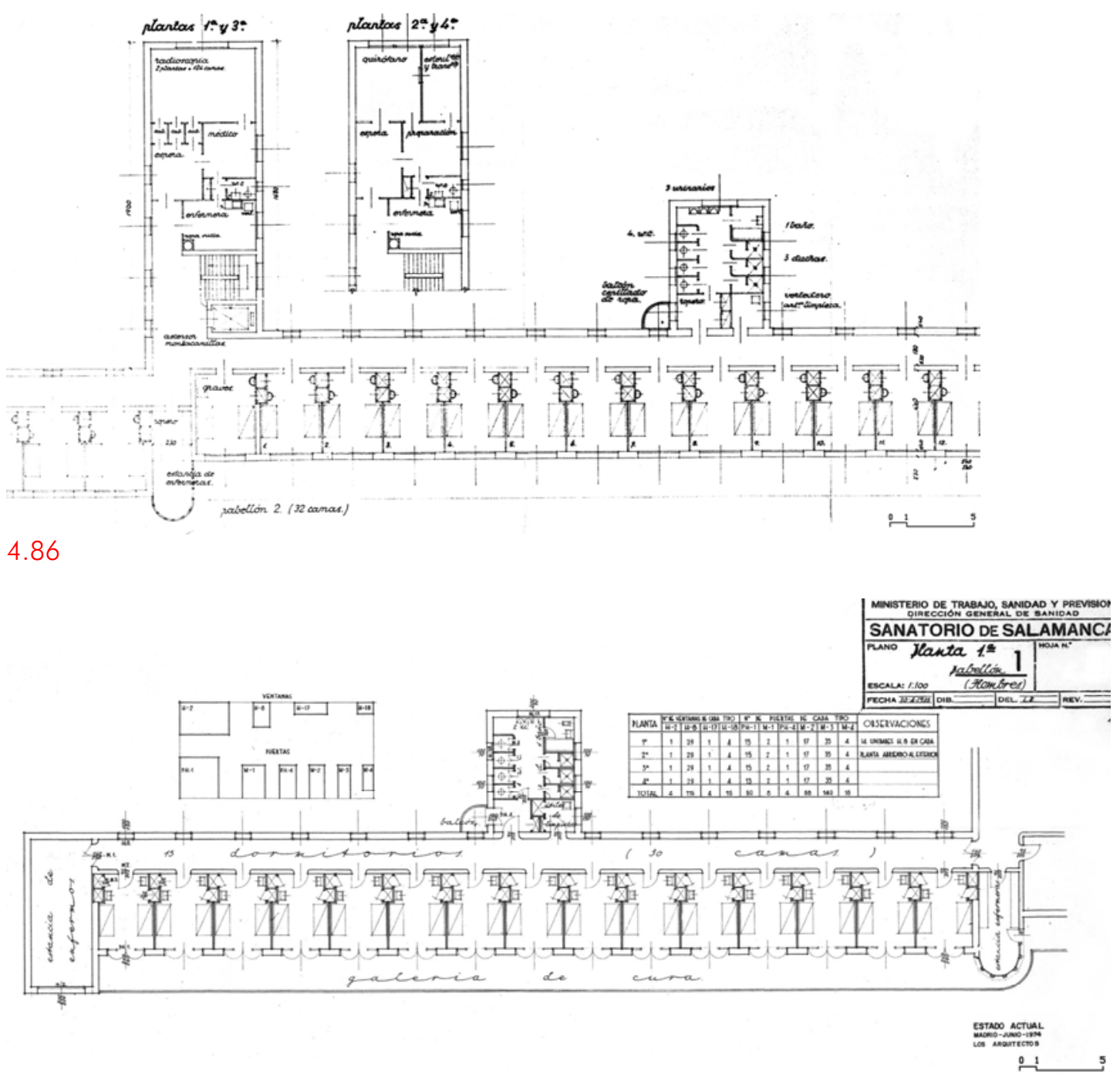

4.87

4.85 R. Bergamín. Sanatorio antituberculoso Los Montalvos, Salamanca, p. 1934-35 o. 1948. Fragmento en $\mathrm{L}$ del ala oeste del bloque de habitaciones con el comedor, planta baja (plano del proyecto de 1935).

4.86 R. Bergamín. Sanatorio antituberculoso Los Montalvos, Salamanca, p. 1934-35 o. 1948. Fragmento en $L$ del ala oeste de habitaciones plantas $1^{a}$, con las $3^{a}, 2^{a}$ y $4^{a}$ de su "martillo" central (plano del proyecto de 1934).

4.87 R. Bergamín. Sanatorio antituberculoso Los Montalvos, Salamanca, p. 1934-35 o. 1948. Unidad de habitaciones (plano del proyecto de 1935). 
organizadas por sexos. Se trata de un sanatorio mixto donde los enfermos no se distribuyen por niveles horizontales, como tiene el proyecto del Sanatorio de La Solana, sino que la distribución se produce en vertical.

Cada planta del bloque residencial se divide en dos mitades, y cada una la ocupan enfermos del mismo sexo. En el centro se colocan los comedores o salas de estar, que sirven de barrera entre ambas mitades, divididos a su vez por un muro que separa el área de mujeres de la de hombres. El comedor asoma sobre el plano de fachada impidiendo ver desde la galería de cura del ala masculina situada al oeste, la galería femenina al este, y viceversa.

Con esta configuración cada ala de enfermos funciona como una unidad independiente junto con los servicios higiénicos, de enfermería y comedores propios, transformándose el sanatorio en $T$ en dos sanatorios en $L$ que tienen en común parte de los servicios del "martillo" central [fig. 4.78].

El "martillo" central, al igual que el edificio principal del Sanatorio, mantiene también una organización simétrica donde las estancias que lo integran se ordenan a ambos lados de un pasillo central. En él se ubican en planta sótano, e iluminados a través de un patio inglés, la lavandería y las instalaciones, conectadas con el resto del edificio a través de los ascensores principales y de una escalera de servicio [fig. 4.79].

En planta baja o semisótano se localiza la cocina, a unos 90 centímetros por debajo de la cota de acceso, que dispone de una entrada directa en la fachada norte coincidiendo con el eje principal de simetría del edificio. Por este punto se accede tanto a la cocina como a la escalera de servicio que baja a la lavandería y sube a la planta primera. En el extremo opuesto, junto al bloque lineal, arrancan las escaleras principales del sanatorio repartidas en dos núcleos independientes y enfrentados, situados junto a los ascensores, separados por el muro divisorio de las dos alas de enfermos masculina y femenina [fig. 4.80].

En la planta primera del "martillo" central se sitúa la puerta de acceso en el lateral este del mismo. La entrada se produce a través de una escalera dividida en dos tramos; uno asoma al exterior como un puente tendido sobre el patio inglés que ilumina el semisótano o planta baja y el sótano, y un segundo tramo interior que desemboca en el vestíbulo [fig. 4.81].

En la planta primera se ubican la administración, los despachos de dirección, la biblioteca y la sala de conferencias, repartidos a ambos lados del pasillo central, y en su extremo más 
próximo al cuerpo de habitaciones se encuentran las salas de visitas, una para hombres y otra para mujeres ${ }^{102}$.

La planta segunda alberga los quirófanos, la sala de rayos- $X$, varias consultas médicas y salas de tratamiento, a las que los enfermos acceden una vez traspasado el filtro de las salas de espera anexas al pabellón residencial, también independizadas por sexos [fig. 4.82].

Las plantas tercera y cuarta son de menor longitud que las anteriores. En la tercera se emplazan los laboratorios generales, la farmacia y dos peluquerías, de caballeros y de señoras. En la última planta, dos laboratorios privados y un núcleo de aseos, además del comedor de médicos separado del de enfermeras, ambos abastecidos por una pequeña cocina conectada a través de un montaplatos con la cocina central de la planta baja [fig.

\subsection{3 y 4.84$]$.}

Como el bloque residencial carece de sótano, en planta baja se encuentran los almacenes, los dormitorios del personal de servicio, también separados por sexos, y los grandes comedores generales de enfermos en el centro como en el resto de plantas [fig. 4.85].

En Los Montalvos las dependencias de la cocina y su vinculación con los comedores cobran una particular transcendencia. La cocina que ocupa toda la planta baja del "martillo" central se ubica junto a los comedores generales. A partir de esta planta los comedores de los enfermos se van distribuyendo en altura, lo que obliga a crear pequeños oficios previos en cada planta con un montaplatos en cada uno que les conecta de manera sencilla y eficaz con la cocina.

El esfuerzo organizador sobre el equipamiento del sanatorio deja huella en su arquitectura doméstica y llega a reconocer que:

"La cocina y su anexo el 'pantry', que debe quedar en directa relación con el comedor, como ya dijimos, son a mi juicio, los locales de la casa que mayor atención exigen en el proyecto y en la ejecución. Son los que mejor aprovechado deben tener el espacio en beneficio de la eficacia más que de la economía" ${ }^{103}$. Sus cocinas se transforman en una especie de quirófanos de las viviendas en donde: "todos los utensilios y aparatos para cocinar deben de tener su lugar previsto y determinado" 104.

102 En los proyectos residenciales Bergamín también suele elevar la planta principal de acceso creando un semisótano donde se localizan los espacios de servicio, cocina, lavandería etc.; así lo plantea entre otras en la Casa del Marqués de Villora o en sus viviendas del Viso.

${ }_{103}$ Rafael BERGAMíN, 20 años en Caracas 1938-1958. Gráficas Reunidas, Madrid 1959, p. 41.

104 Rafael BERGAMín, 20 años en Caracas 1938-1958. Gráficas Reunidas, Madrid 1959, p. 41. 
La primacía de los criterios de uso por encima de los de economía se advierten en la organización estructural de la cocina y del resto de plantas del "martillo" central [fig. 4.79fig. 4.84], donde sus 14 metros de anchura se resuelven en tres pórticos de pilares cada 3 m., que salvan luces de 5,55 m. en los extremos y de 2,5 m. en el centro. Esta distribución antieconómica se ajusta al funcionamiento espacial interior porque mantiene una espina central por la que se accede a las estancias laterales, las cuales se ajustan al módulo de $3 \mathrm{x}$ 5,5 m. definido por la disposición de los pilares.

Gracias a la configuración modular y simétrica de las plantas, éstas se vuelven más versátiles y permiten alterar el orden del programa si es menester, sin trastocar la morfología del edificio. Esto sucede por ejemplo al variar la posición de la vía de acceso y la puerta del edificio principal del Sanatorio, que pasa de situarse en el lateral oeste del "martillo" central en el proyecto de 1934 al del este en el proyecto definitivo de 1935, invirtiéndose la distribución de las estancias de ambos lados del corredor central. Lo mismo ocurre en los "martillos" más pequeños del sanatorio, principalmente en los que ocupan la posición central de cada ala residencial, los cuales, debido a los cambios en la posición del acceso, pasan a intercambiarse sus usos en planta baja ${ }^{105}$ [fig. 4.85].

Otras estancias fundamentales para Bergamín en Los Montalvos son las habitaciones de los enfermos, como se ha dicho, distribuidas a partir de la planta primera en dos alas idénticas para cada sexo, cada una a su vez con forma de T. El ala se divide en dos unidades de enfermería que comparten los servicios del "martillo" central de ala y están comunicadas por el corredor interior quebrado aunque mantienen galerías de cura independientes, separadas por la sala de enfermeras que asoma sobre ellas interrumpiendo el paso. Junto a la mencionada sala de enfermeras, semicircular y acristalada, aparece una habitación de aislamiento común, orientada al sur, y frente a ella en la parte norte se localizan los servicios médicos contenidos en los "martillos" centrales de ala, comunicados verticalmente por un montacamillas y una escalera. En las plantas primera y tercera de estos "martillos" están las salas de radioscopia y en la segunda y cuarta los quirófanos particulares para cada ala, coincidiendo con los quirófanos generales del Sanatorio dispuestos en la segunda planta [fig. 4.86].

\footnotetext{
${ }^{105}$ En el proyecto de 1934, el garaje se encuentra en el "martillo" central del ala oeste y la sala de autopsias en el del este. Con el cambio de posición de la entrada ambos usos se intercambian para evitar que la morgue esté junto al acceso principal.
} 


\section{IIIIIIIIIIIII}
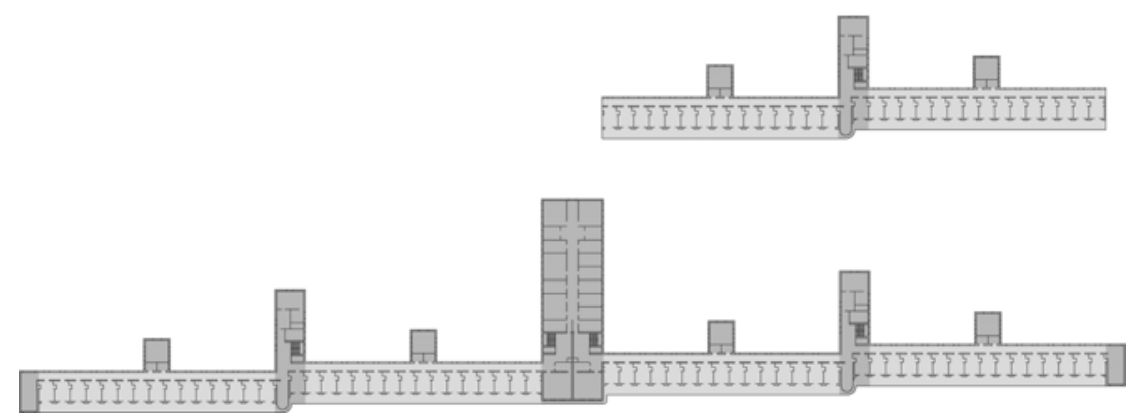

4.88

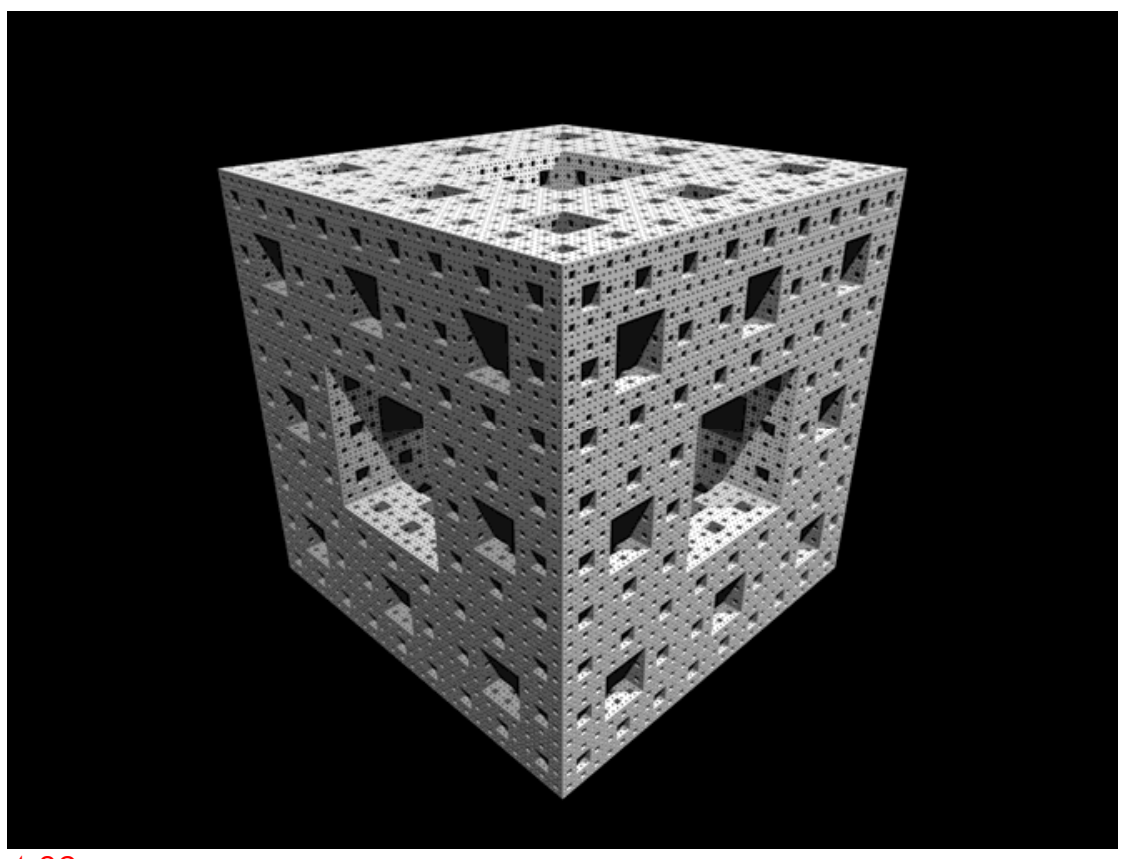

4.89

4.88 Sanatorio antituberculoso Los Montalvos generación por autosemejanza (dibujos de la autora). 4.89 Esponja de Menger. 
La distribución y los tamaños de las estancias de las salas de radioscopia y de los quirófanos son muy similares, lo que facilita que sus usos sean fácilmente intercambiables según las necesidades del sanatorio. Por tanto, debido al orden y a la modulación de las áreas de servicios generales se logra aumentar la capacidad de transformación de los mismos.

Las dos unidades de enfermería de cada ala también están moduladas [fig. 4.87], siendo la habitación el módulo de referencia. Cada unidad consta de 15 habitaciones dobles y de un "martillo" central que contiene los servicios higiénicos.

El análisis de la configuración del bloque residencial del Sanatorio muestra la existencia de una ley de generación por autosemejanza entre los tres elementos en que se fragmenta: las unidades de enfermería con 15 habitaciones en cada una, las alas de enfermos con 30 y las plantas constituidas por 60 habitaciones, manteniéndose en todas ellas el mismo esquema formal en T [fig. 4.88]. Esta autosemejanza tiene similitudes con las teorías de los objetos fractales definidas por Mandelbrot, y está reflejada en el proceso que se ha venido describiendo en el análisis anterior de las partes y el todo [fig. 4.89].

Cada módulo de habitación es de 3,60 m. de ancho, medido a ejes de tabiques, y 4,60 m. de largo, medido a las caras interiores. Las habitaciones son dobles y como la disposición de los elementos que las integran están adosados a sus paredes laterales, pueden fácilmente ser compartimentadas en dos dormitorios de uso individual ${ }^{106}$.

Dentro de la habitación el lavabo, el armario y la cama del enfermo se sitúan en paredes enfrentadas, dejando una distancia que libera el centro de la estancia y creando una zona amplia de paso que contribuye a evitar el contagio de los enfermos. Los armarios de las habitaciones son empotrados; existen dos en cada habitación y ocupan la cavidad interior del tabique quebrado que separa las estancias, contrapeándose sus aperturas entre ellos, de manera que, cuando en una de las habitaciones hay una puerta, en la vecina hay un tabique sobre el que se apoya el lavabo y viceversa.

Para Bergamín "el cuarto de dormir sólo deberá servir para eso, y entonces parecerá lógico que para dimensionarlo sirviera de base o módulo la cama"107. La colocación del armario

\footnotetext{
106 La disposición de habitaciones dobles en los sanatorios públicos no era habitual en España ni en la Europa mediterránea, ya que los ejemplos italianos propuestos por el Istituto Nazionale Fascista della Previdenza Sociale también carecían de ellas. Contaban con estancias de unas seis camas mínimo, a excepción de las habitaciones de aislamiento. La individualización de la asistencia sanitaria existente de los países centroeuropeos, sólo solía darse en España en los sanatorios privados, siendo Los Montalvos revolucionario en ese sentido.

107 Rafael BERGAMíN, 20 años en Caracas 1938-1958. Gráficas Reunidas, Madrid 1959, p. 41.
} 

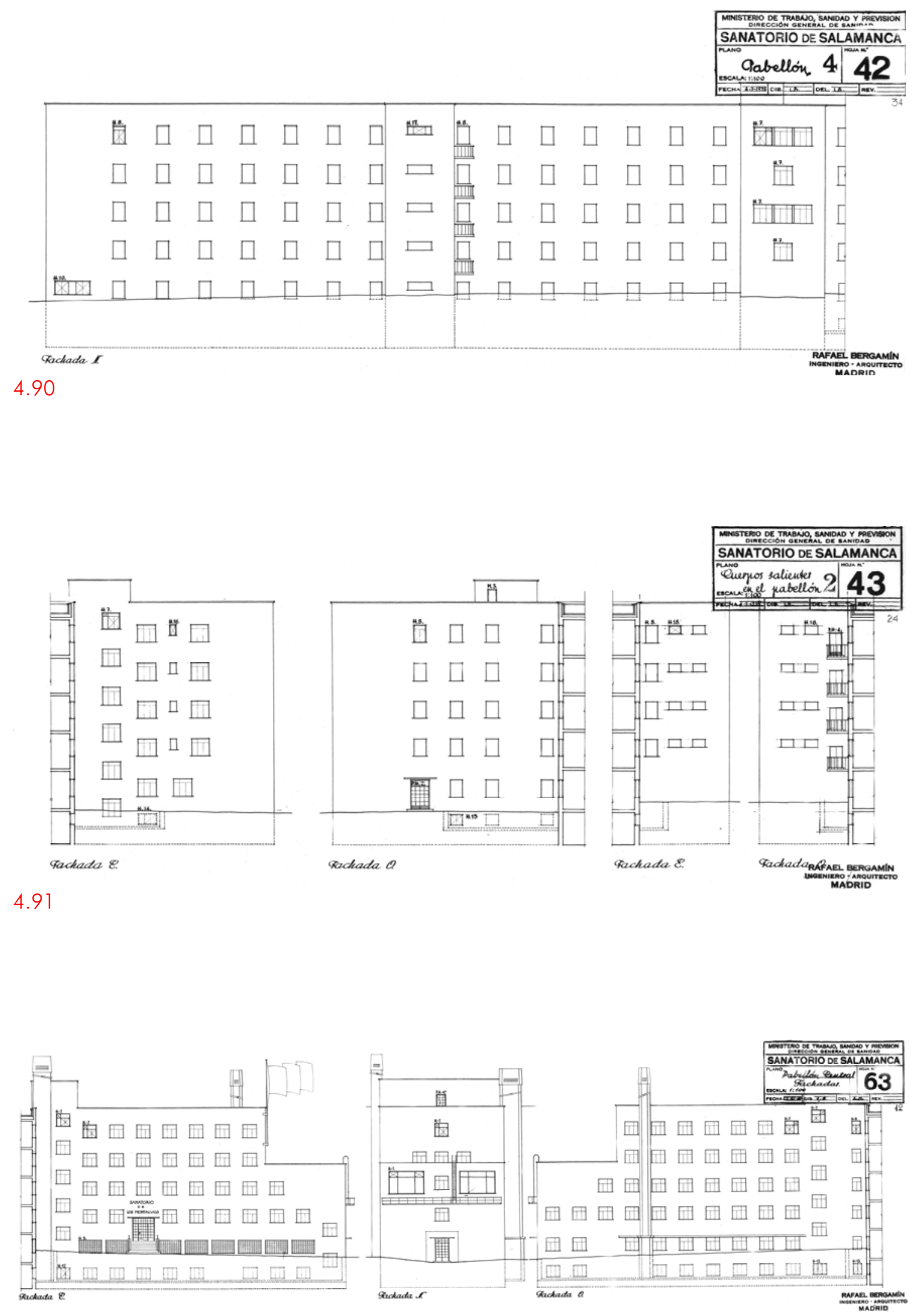

4.90, 4.91 y 4.92 R. Bergamín. Sanatorio antituberculoso Los Montalvos, Salamanca, p. 1934-35 o. 1948. Fragmento del alzado norte, alzados laterales de los "martillos" de las alas, alzados del "martillo" central. 
y del lavabo junto a la puerta de entrada libera al espacio de la cama de estorbos. Ésta se sitúa más próxima a la fachada, favoreciendo la exposición del enfermo a la luz solar y al aire puro que penetra desde la galería a través de una doble puerta acristalada de 1,20 m. de ancho, situada en el centro de la fachada de la habitación. La anchura entre ejes de las habitaciones resulta ser cuatro veces el ancho de una cama estándar de $90 \mathrm{~cm}$.

La galería de cura tiene una anchura libre de 2,30 m., dimensión que permite la disposición de tumbonas en el exterior y protege al enfermo del exceso de sol en verano o del agua en época de tormentas. Se resuelve en voladizo y está apoyada en el muro de carga de la fachada de $40 \mathrm{~cm}$. de espesor, formado probablemente por dos hojas de ladrillo entre las que se incluye una lámina de aislamiento de corcho, solución comúnmente empleada por Bergamín en la construcción de sus viviendas ${ }^{108}$.

Frente a la galería, al fondo de la habitación, se ubica el corredor de distribución interior de 1,80 m. de ancho, separado de ésta por un muro de $30 \mathrm{~cm}$. de espesor con las esquinas redondeadas para facilitar la limpieza. El espesor excesivo de este muro contrasta con el de los tabiques de separación entre las habitaciones que no alcanzan los $10 \mathrm{~cm}$. Su grosor se debe a una cuestión estructural, ya que, con su posición parte en dos vanos la distancia total entre los ejes de las fachadas que es de 7,10 m. ${ }^{109}$. Además con este espesor se contribuye a aislar el pasillo calefactado de las habitaciones sin calefactar. Es probable que el origen de la decisión de no calefactar las habitaciones recayera en una recomendación médica, puesto que los enfermos de tuberculosis debían permanecer casi constantemente con las ventanas de las habitaciones abiertas ${ }^{110}$, o que, aprovechando esta terapia responda a una cuestión de ahorro. En cualquier caso, el resto del edificio sí dispone de calefacción. El "martillo" central se acondiciona con radiadores, mientras que los pasillos y los "martillos" adyacentes están calefactados por paneles radiantes, alojados en el suelo y en el techo, denominados "plafones calientes" que fueron instalados por primera vez en

\footnotetext{
${ }^{108}$ En la casa de la calle Joaquín Costa llega incluso a utilizar el corcho no sólo como aislante sino como revestimiento interior, forrando de corcho las paredes del vestíbulo de acceso.

${ }^{109}$ Tanto este muro de carga interior de $30 \mathrm{~cm}$. como el de la fachada sur de $40 \mathrm{~cm}$., se trasforman en dos filas de pilares en planta baja en las zonas de los comedores generales, que ocupan el ancho total del pabellón residencial de 9,80 m. medidos a haces exteriores, consiguiéndose así una mayor diafanidad en la sala.

110 Antonio MEDINA ALARCÓN, Historia del sanatorio de "Los Montalvos" (1935-1986), Tesis inédita del Dpto. de Psiquiatría, Psicología Médica, Medicina Legal e Historia de la Medicina. Facultad de Medicina de la Universidad de Salamanca, Salamanca 1992, p. 72.
} 

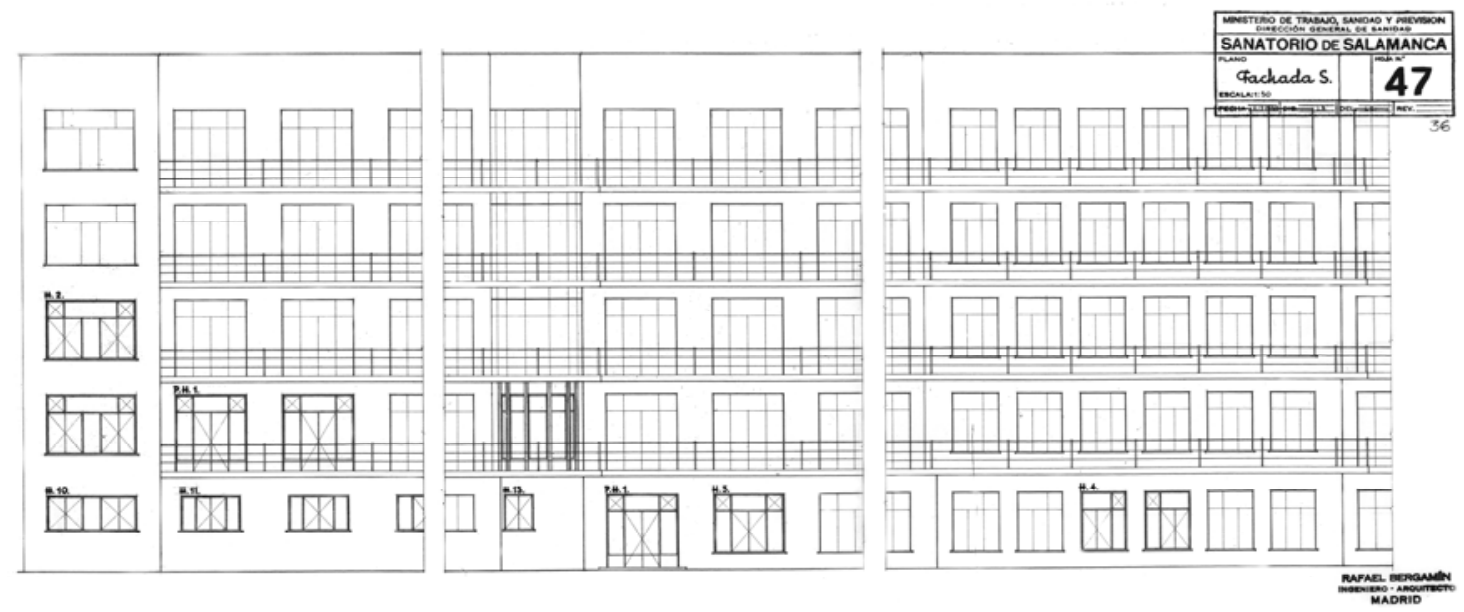

4.93
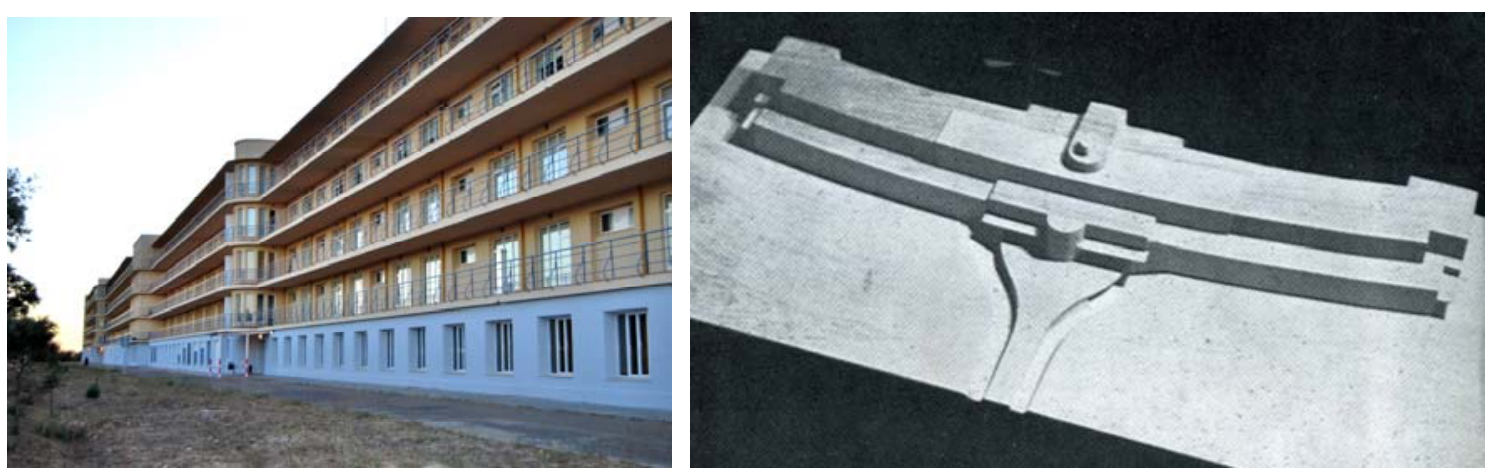

4.94 y 4.95
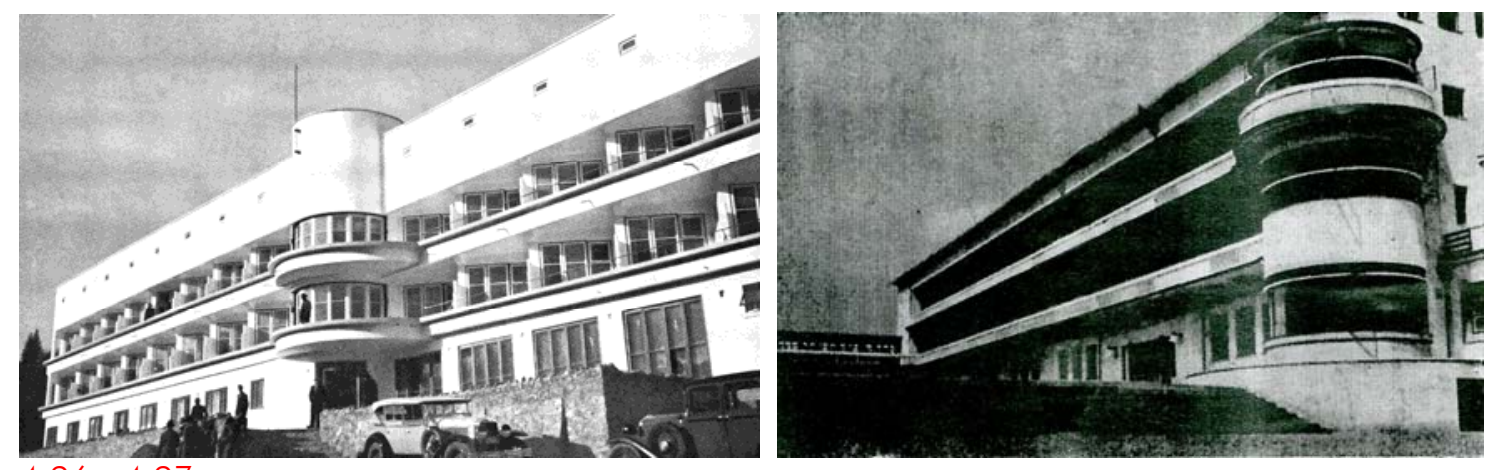

4.96 y 4.97

4.93 R. Bergamín. Sanatorio antituberculoso Los Montalvos, Salamanca, p. 1934-35 o. 1948. Alzado norte (plano del proyecto de 1935).

4.94 R. Bergamín. Sanatorio antituberculoso Los Montalvos, Salamanca, p. 1934-35 o. 1948. Fachada sur (fotografía de la autora).

4.95 R. Bergamín y L. Blanco Soler. Proyecto para el concurso del aeropuerto de Madrid, 1929. Maqueta.

4.96 M. lanco y J. lanco. Sanatorio en Predeal, 1936. Fachada sur.

4.97 Schwelthelm. Sanatorio para niños de Haggerode, ca. 1932. Fachada sur. 
España en este edificio ${ }^{111}$.

Al exterior el sanatorio tiene dos frentes muy diferenciados, cuyo contraste destaca J. González Cubero por el "predominio de la horizontalidad y suavidad de los quiebros de las superficies como contrapunto a la rigidez y sequedad de los muros y sus adiciones volumétricas ortogonales ${ }^{\prime \prime 1} 12$. En cada uno se aprecia el empleo reiterado de un mismo tipo de hueco algo que Bergamín hace explícito: "La repetición de elementos es, a mi entender, repito, lo que da belleza, armonía y hasta grandeza al conjunto arquitectónico"ll13.

En el frente norte, más masivo y ortogonal, predomina una seriación continua de huecos verticales que corresponde a las ventanas de los pasillos, de 1,2 m. de ancho por 1,6 m. de alto [fig. 4.90]. Sólo en los "martillos" transversales cambia este tipo de hueco. En los más pequeños que contienen los servicios higiénicos se cortan por ventanas horizontales de 60 centímetros de anchura y, en los que contienen los servicios médicos, se disponen ventanas más grandes y casi cuadradas de 1,60 m. de alto por 1,80 m. de ancho en uno de sus frentes ajustando su dimensión al uso [fig. 4.91]. Las ventanas del "martillo" central son cuadradas de 1,8 m. de lado, siendo este matiz el único que distingue el cuerpo principal del resto y una cualidad apenas perceptible dentro de la uniformidad de todo el frente norte del edificio [fig. 4.92].

A la fachada donde se ubica la puerta principal de acceso le sucede lo mismo que a la de la Casa del marqués de Villora porque: "sólo la puerta principal da a esta fachada distinto carácter que a las otras $" 114$. La falta de ornamento aunada a su posición asimétrica en el este del martillo central hacen que la fachada "principal" del sanatorio carezca de la monumentalidad propia de los edificios públicos, y que sólo la puerta y la escalera de acceso sean las piezas que discretamente destacan dentro del zócalo, generado por una fila de ventanas rectangulares protegidas por una celosía que se disponen en la planta baja.

En la fachada sur del bloque residencial, donde dominan las geometrías curvas y la horizontalidad, existe una reiteración idéntica de huecos en alzado que van de suelo a

11 Antonio MEDINA ALARCÓN, Historia del sanatorio de "Los Montalvos" (1935-1986), Tesis inédita del Dpto. de Psiquiatría, Psicología Médica, Medicina Legal e Historia de la Medicina. Facultad de Medicina de la Universidad de Salamanca, Salamanca 1992, p. 72.

112 Josefina GONZÁLEZ CUBERO, "Arquitectura hospitalaria de Rafael Bergamín: El Sanatorio de los Montalvos" en José ALTÉS (ed.), Arquitectura Moderna en Salamanca. Colegio de Arquitectos de León, Delegación en Salamanca, Salamanca 1998, p. 39.

113 Rafael BERGAMíN, 20 años en Caracas 1938-1958. Gráficas Reunidas, Madrid 1959, p. 65.

114 Rafael BERGAMÍN, "Casa del Marqués de Villora en Madrid", en Arquitectura n ${ }^{\circ} 113$, Sociedad

Central de Arquitectos, Madrid 1928, p. 282. 
techo salvo en la planta baja, donde las ventanas no llegan al suelo y configuran un zócalo continuo, materialmente más denso, sobre el que se disponen las galerías [fig. 4.93].

La ventana de cada habitación presenta cuatro particiones verticales de 60 centímetros de ancho, abriéndose las dos del centro ${ }^{115}$. El hueco completo se aproxima a un cuadrado con una altura de unos $2,60 \mathrm{~m}$. y una anchura de $2,40 \mathrm{~m}^{1{ }^{16}}$.

Entre ellas se insertan los miradores semicilíndricos de las unidades de enfermería que funcionan como torres de vigilancia porque, debido a su posición adelantada sobre el plano de fachada, permiten controlar las galerías de cura de los dos tramos de habitaciones, siendo estas piezas las rótulas que articulan dichas unidades. Estas columnas vidriadas asociadas a las infinitas terrazas solárium, potencian la estética naval y recuerdan la cubierta de los trasatlánticos [fig. 4.94], una imagen perseguida por las vanguardias arquitectónicas modernas a causa de su fascinación por los nuevos inventos de la época: los aviones, los automóviles y los grandes barcos.

Los miradores ya habían sido empleados por Bergamín en sus proyectos residenciales como ampliación de los salones, e incluso también como elementos de vigilancia en el proyecto realizado junto a Blanco Soler en 1929 para el concurso del aeropuerto de Madrid, ganador del segundo premio, en el que la cabina de control semicircular y acristalada, situada en el eje de simetría, sobresale del cuerpo longitudinal [fig. 4.95].

Con la posición en proa central también aparecen los miradores semicilíndricos en otros sanatorios europeos de la época como el Sanatorio en Predeal, Rumanía (1936) obra de Marcel y Juliu lanco ${ }^{117}$ [fig. 4.96], y con una localización en esquina en una obra anterior, el Sanatorio para niños de Haggerode en Alemania del arquitecto Schwelthelm publicado en 1932 en el no 8 de la revista Der Baumister reproducido ese mismo año en L'Architecture $d^{\prime}$ Avjourd'hui ${ }^{118}$ [fig. 4.97] publicación que quizás Bergamín pudo haber contemplado.

Es probable que antes de realizar el proyecto de La Solana y de Los Montalvos conociera también el proyecto de Fritz Berke para una residencia de ancianos en Frankfurt que

\footnotetext{
$115 \mathrm{El}$ módulo de $60 \mathrm{~cm}$. domina la fachada sur. Está presente en la zona central de los comedores donde las ventanas no llegan a tocar el suelo y tienen una anchura de 1,80 m. También en los extremos, donde se ubican la estancia de las enfermeras, con ventanales de 3 m.de ancho (5 módulos de $60 \mathrm{~cm}$.), en las salas de enfermeras con los miradores curvos fragmentados en cristaleras verticales de $60 \mathrm{~cm}$. de anchura y en las puertas-ventana de las habitaciones de enfermos.

116 En el proyecto que finalmente se construye, estas ventanas se protegen con contraventanas plegables de lamas de madera, cuya posición, abierta o cerrada, produce importantes cambios en la apariencia del alzado.

117 AA.W. Functional architecture: the international style 1925-1940. Benedikt Taschen, Köln 1990, p. 287.

118 "Allemagne" en L'Architecture d'Aujourd'hui n6, 1932, p. 98.
} 
aparece publicado en el libro monográfico Hôpitaux Sanatoria de Roger Poulain en 1932. Este proyecto, al igual que los sanatorios de Bergamín, consiste en un bloque lineal con una serie de martillos transversales, cuyas habitaciones se agrupan en unidades que se desplazan en diagonal incluyendo en el punto de desplazamiento unos miradores acristalados de aspecto cilíndrico como en Los Montalvos ${ }^{119}$ [fig. 4.98- fig. 4.99]. Los posibles condicionantes urbanos del proyecto de Frankfurt obligan al pliegue de sus extremos, un constreñimiento del que Los Montalvos carece. La libertad en el paisaje es asumida por Bergamín manteniendo la linealidad del bloque por razones compositivas y ventajas terapéuticas.

Frente a la bipolaridad destacada de las fachadas, el elemento unificador del volumen es el cromatismo general del sanatorio. Las fachadas se pintan de un tono sepia anaranjado, similar al de la tierra del lugar que, en el transcurso del día con los cambios experimentan matizaciones cromáticas tiñéndose de amarillo en el ocaso y de tonos rosáceos al mediodía ${ }^{120}$ [fig. 4.94]. Bergamín rechaza el higiénico color blanco, comúnmente empleado como color-manifiesto de la arquitectura hospitalaria y residencial por algunos arquitectos modernos. Considera que la pigmentación en los edificios y la vegetación contribuyen a suavizar la sequedad formal ${ }^{121}$. Sequedad manifestada en los muros ciegos que definen sus testeros, que tenían aperturas en el primer proyecto realizado en 1934. Tan radical decisión obedece a permitir una futura ampliación lateral del mismo si fuera necesaria.

En el resto de edificaciones del Sanatorio se aprecian las mismas características compositivas basadas en la repetición de huecos y en la desnudez de ornamento. El pabellón de enfermeras [fig. 4.101] y la vivienda del guarda [fig. 4.103] destacan por su pureza geométrica en comparación con el resto de construcciones que son más articuladas. El pabellón de enfermeras consiste en un edificio prismático prácticamente simétrico, salvo por un leve desplazamiento de la puerta principal de acceso y por la inclusión de la cabina de proyección, un cuerpo independiente y semicircular en planta baja que se adosa a un

\footnotetext{
119 Carmen Jordá propone que Bergamín pudo haberse inspirado en la fachada posterior del conjunto berlinés de Woga de Mendelshon. AA. W., Equipamientos I. Lugares públicos y nuevos programas. Registro DOCOMOMO ibérico, 1925-1965. Fundación Caja de Arquitectos, Barcelona 2010, p. 19.

${ }^{120}$ Los arquitectos franceses P. Abraham y H.-J. Le Même, constructores de sanatorios en el Plateau d'Assy, también solían pintar sus sanatorios en tonos similares con el fin de que en invierno fueran perceptibles entre la nieve.

${ }^{121}$ Por esta razón, en la colonia El Viso las viviendas fueron pintadas en tonos verdes, ocres, azules, grises, amarillos, para matizar con el color su limpia volumetría, como anteriormente haría Le Corbusier con sus viviendas en Pessac cuando trata de dar profundidad en las fachadas a través del color.
} 

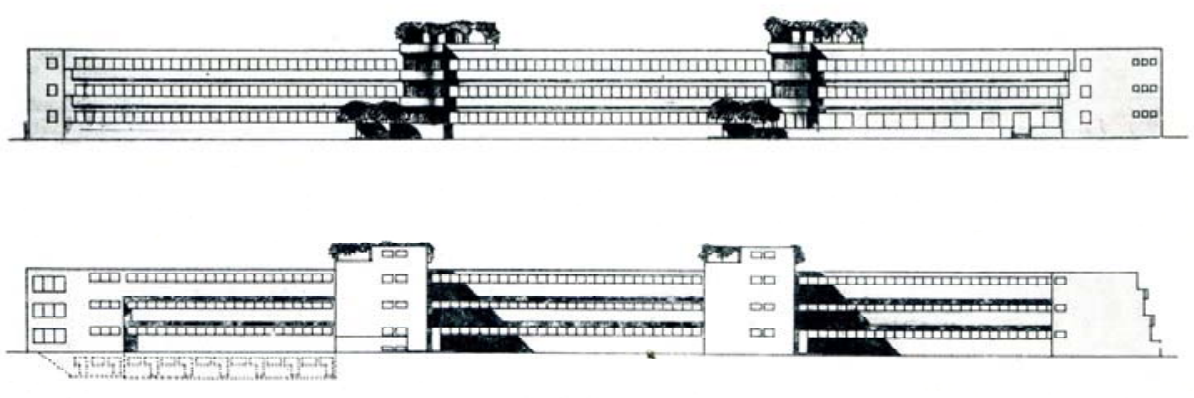

4.98

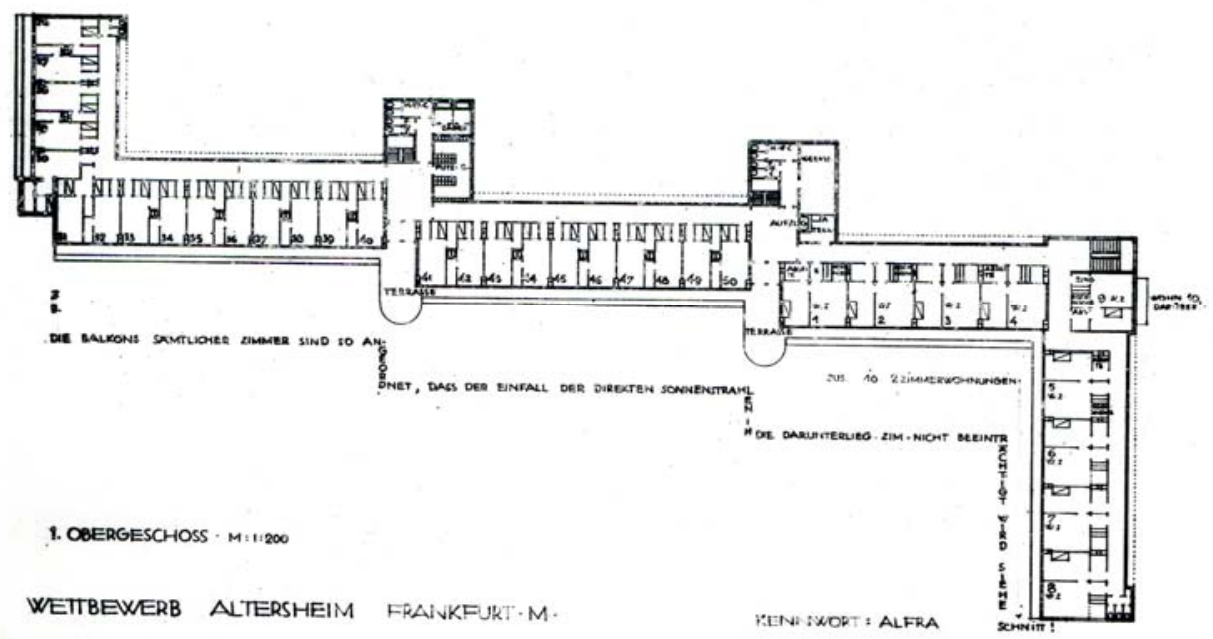

4.99

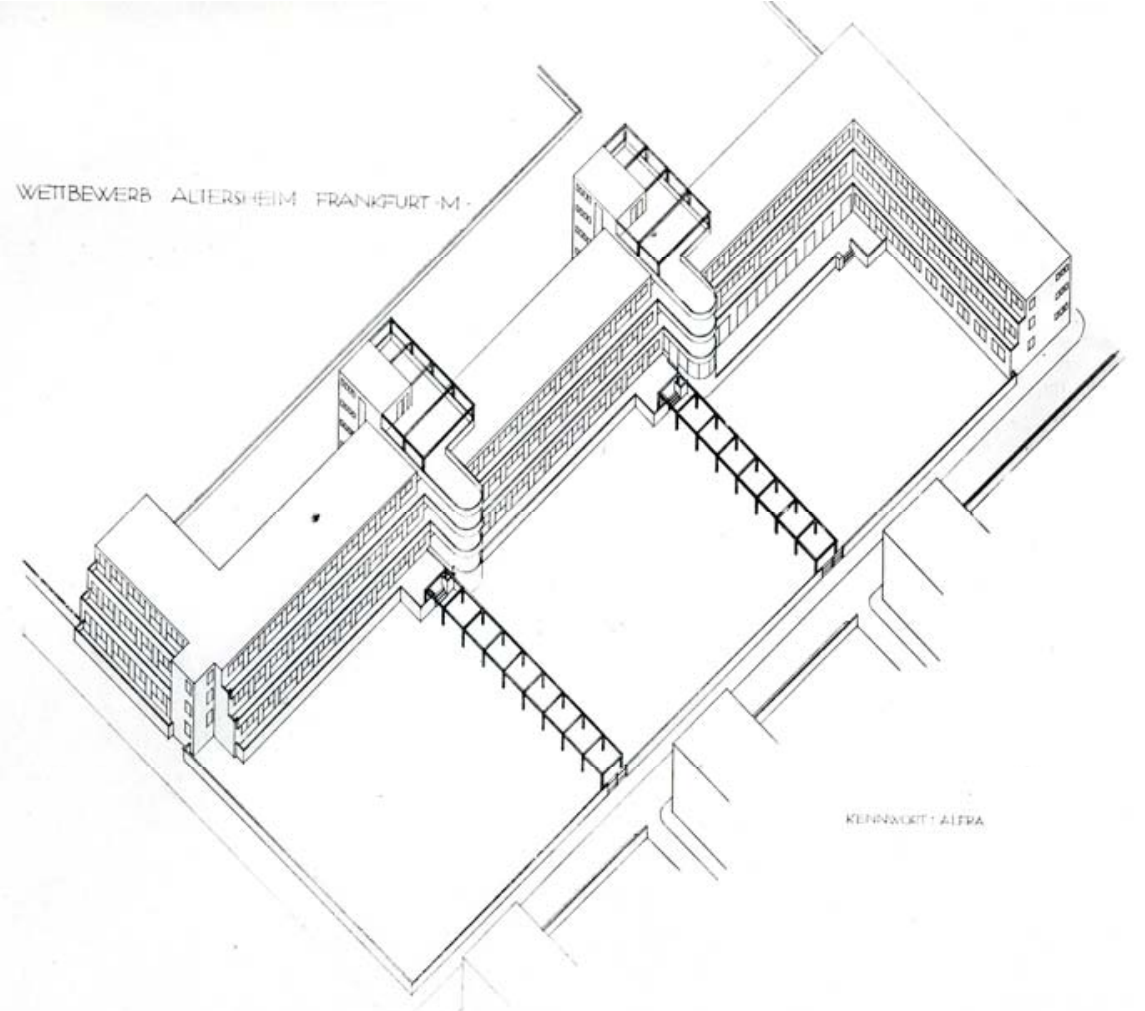

4.100

4.98 F. Berke Bergamín. Proyecto de Residencia de Ancianos, Frankfurt, a. 1932. Alzados.

4.99 F. Berke Bergamín. Proyecto de Residencia de Ancianos, Frankfurt, a. 1932. Plantas.

4.100 F. Berke Bergamín. Proyecto de Residencia de Ancianos, Frankfurt, a. 1932. Perspectiva. 


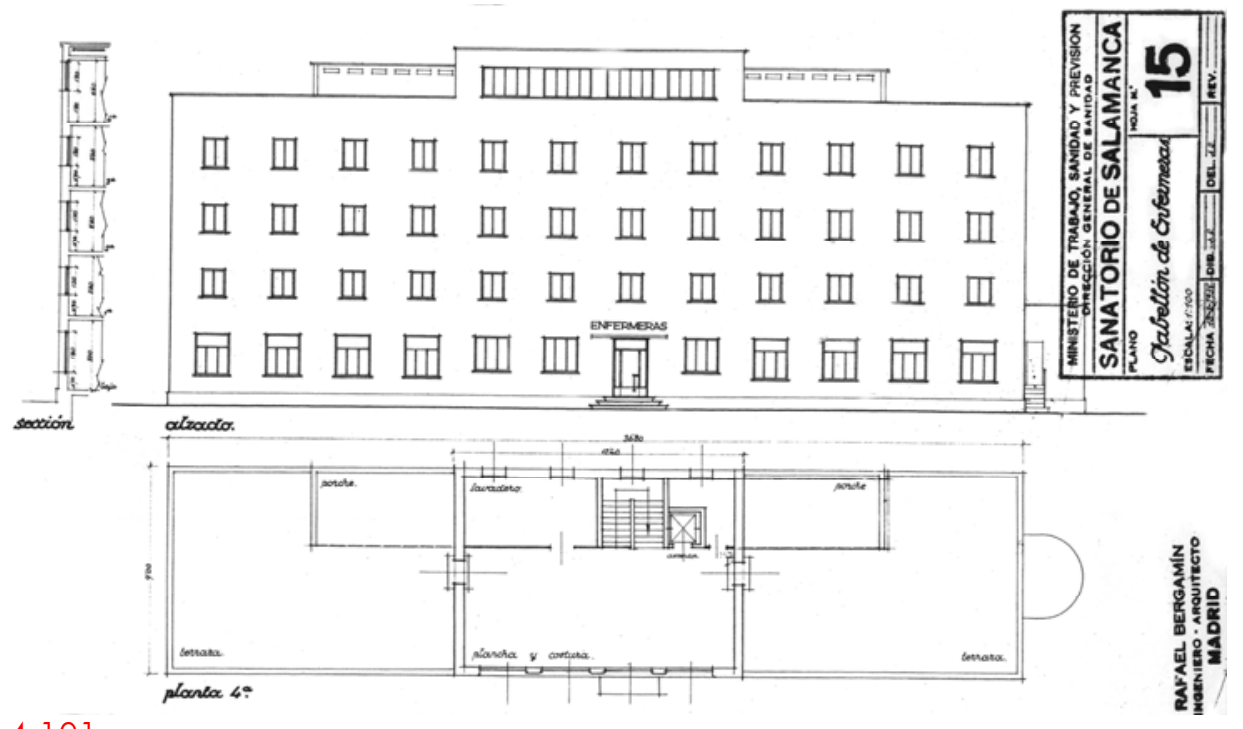

4.101
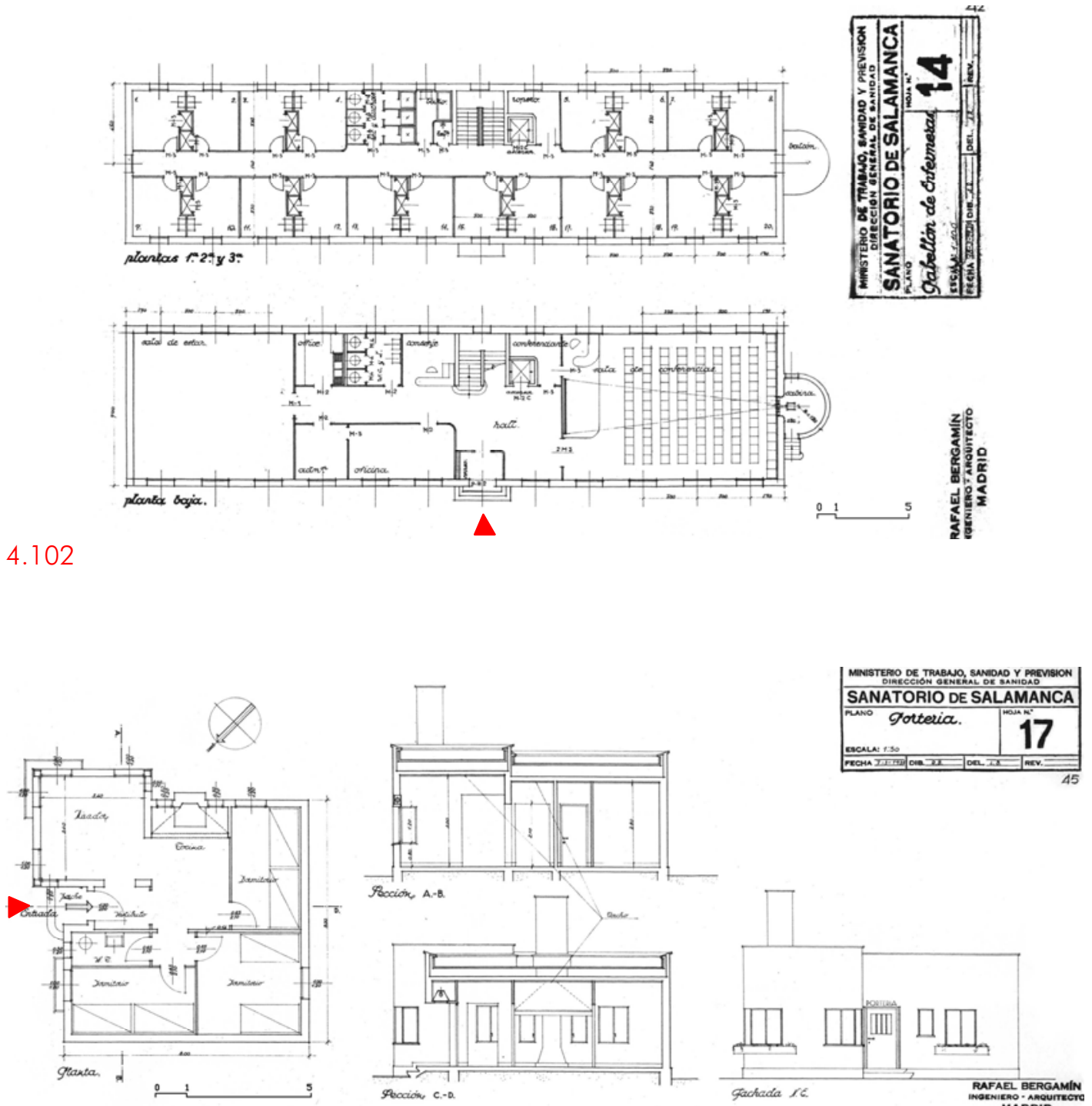

4.103

4.101 y 4.102 R. Bergamín. Sanatorio antituberculoso Los Montalvos, Salamanca, p. 1934-35 o. 1948. Pabellón de enfermería alzado y planta.

4.103 R. Bergamín. Sanatorio antituberculoso Los Montalvos, Salamanca, p. 1934-35 o. 1948.

Pabellón de la vivienda del guarda. 


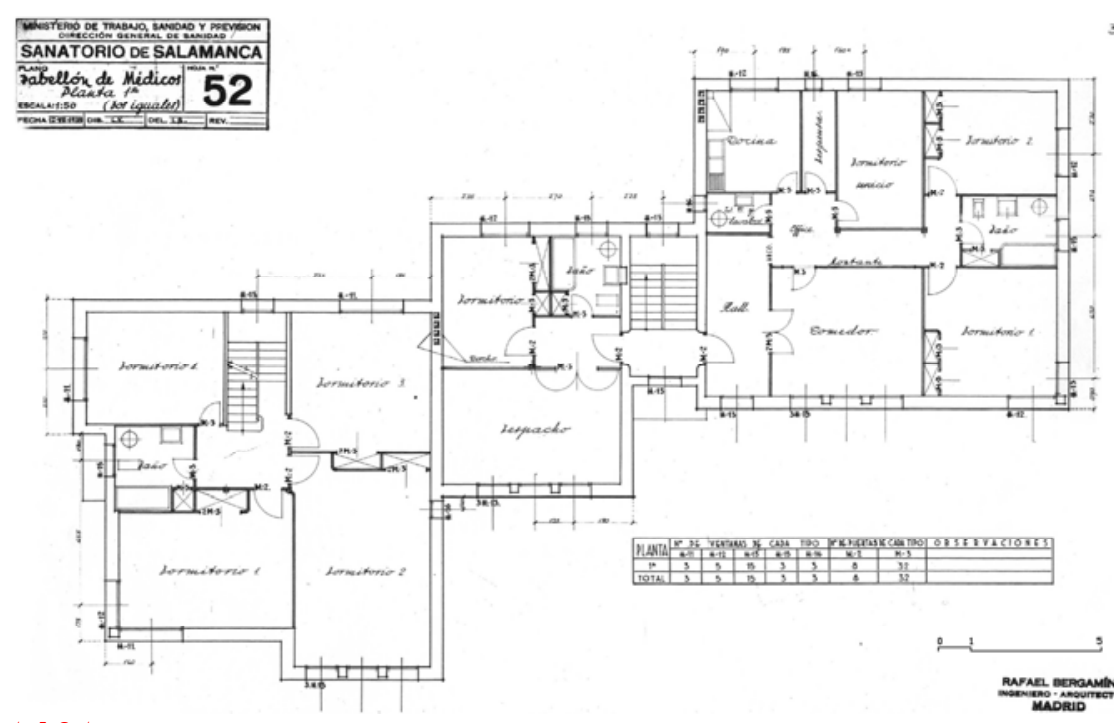

4.104

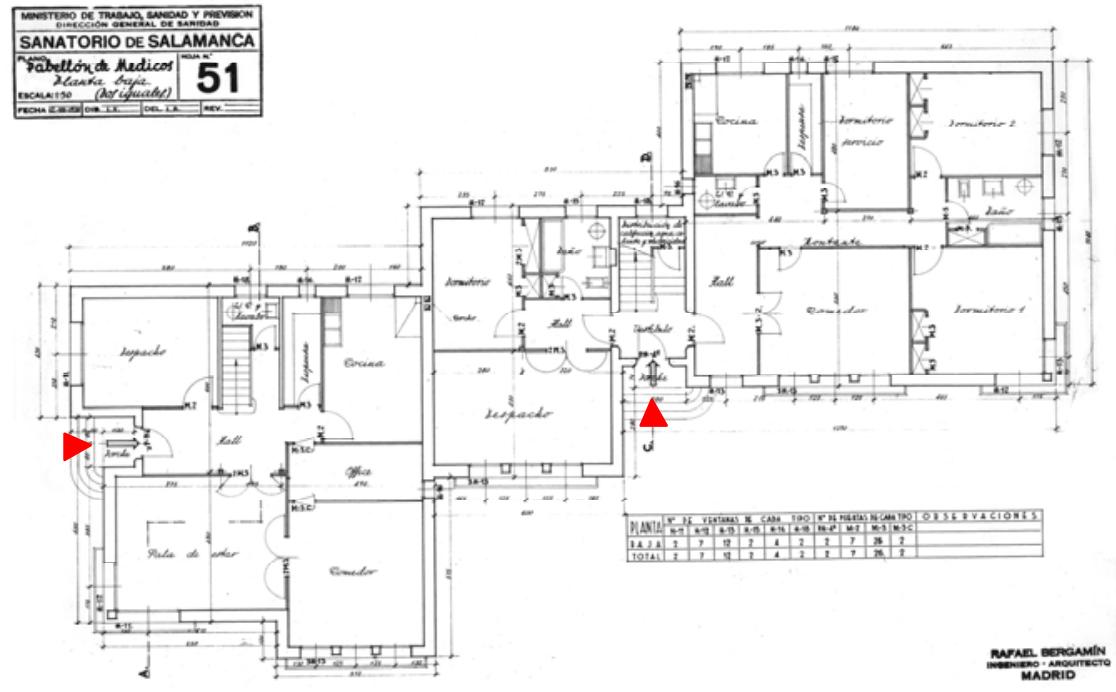

4.105
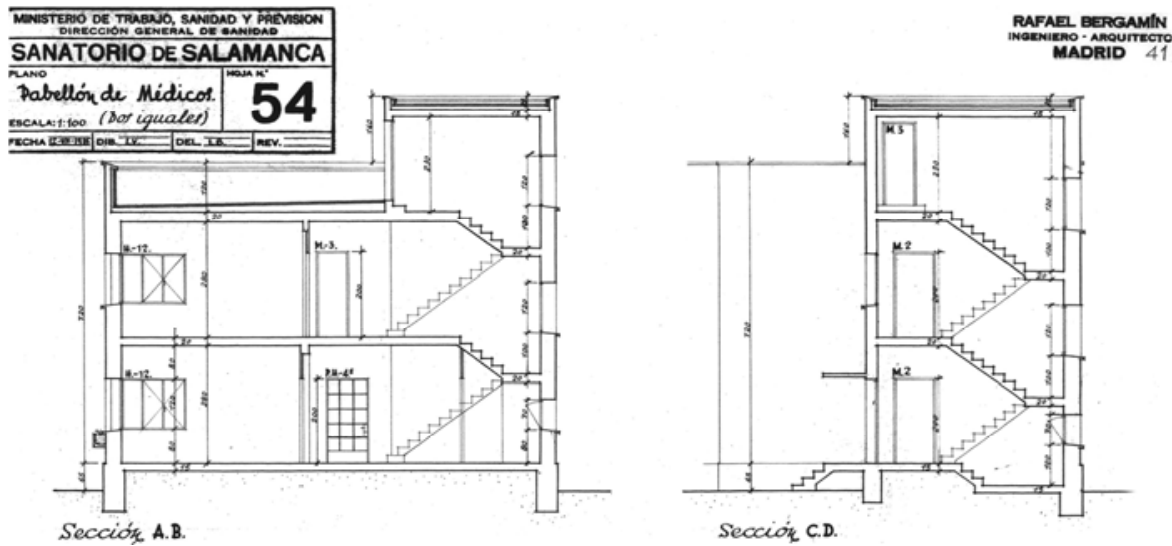

4.106

4.104, 4.105 y 4.106 R. Bergamín. Sanatorio antituberculoso Los Montalvos, Salamanca, p. 193435 o. 1948. Pabellón de médicos y administradoes. Plantas primera y baja y sección por la vivienda del administrador. 
lateral del mismo [fig. 4.102]. Consta de una planta baja con las dependencias comunes y tres plantas de habitaciones individuales. Las habitaciones presentan una distribución muy similar a las de los enfermos del Sanatorio, y están ubicadas a ambos lados del corredor central.

Los dos edificios de viviendas, idénticos entre sí, contienen cada uno una vivienda para el director o para el administrador, de dos plantas de altura, y dos viviendas y dos despachos más para los médicos.

El edificio está compuesto por tres cuerpos yuxtapuestos, el de la vivienda del administrador, el de los dos despachos y el de las dos viviendas de los médicos. Los tres con una forma en planta casi cuadrada, desplazados en profundidad siguiendo un trazado diagonal, como las unidades de enfermos del edificio principal del Sanatorio [fig. 4.104 - 4.106]. En la organización de las viviendas se aprecia la tipología compacta aplicada por Bergamín en sus proyectos residenciales anteriores, que parten de un cuerpo unitario al que se aplican ciertas extensiones y desplazamientos de sus partes. Con el desplazamiento diagonal de los volúmenes del edificio de viviendas, comúnmente ordenados en hilera, Bergamín permiten aumentar el frente de fachada y aprovechar mejor la orientación sur y este [fig. 4.107] sin llegar a independizar o segregar cada cuerpo.

Este procedimiento trata de aplicarlo a las bloques de vivienda en su proyecto para la urbanización de la zona de San Francisco (1962), en la Puerta de Toledo, Madrid, realizado junto a Fernando Higueras y Manuel Ortiz de la Torre, tras su regreso del exilio en 1958. Consiste en una serie de bloques lineales cuyas fachadas principales se quiebran formando una secuencia de picos, a través de los cuales se intenta proporcionar luz a las estancias y evitar la orientación norte [fig. 4.108].

Tony Garnier en el concurso de la Fundación Rothschild celebrado en París en 1905 ya había propuesto los quiebros diagonales en las fachadas de sus bloques residenciales donde ninguna de sus estancias podía carecer de una ventana al sur [fig. 4.109], y lo consigue separando los bloques de viviendas de la alineación de la calle y ordenándolas siguiendo un trazado diagonal, quebrando las fachadas para obtener la mejor orientación y la mayor superficie de fachada.

Garnier utiliza los desplazamientos en profundidad siguiendo un trazado diagonal en su proyecto para el Sanatorio Franco-Americano de Lyon (1917) [fig. 4.110], como hace después Bergamín en Los Montalvos [fig. 4.111], tanto en cada uno de sus edificios con planta en forma de $\mathrm{V}$ como en la ordenación del conjunto. 

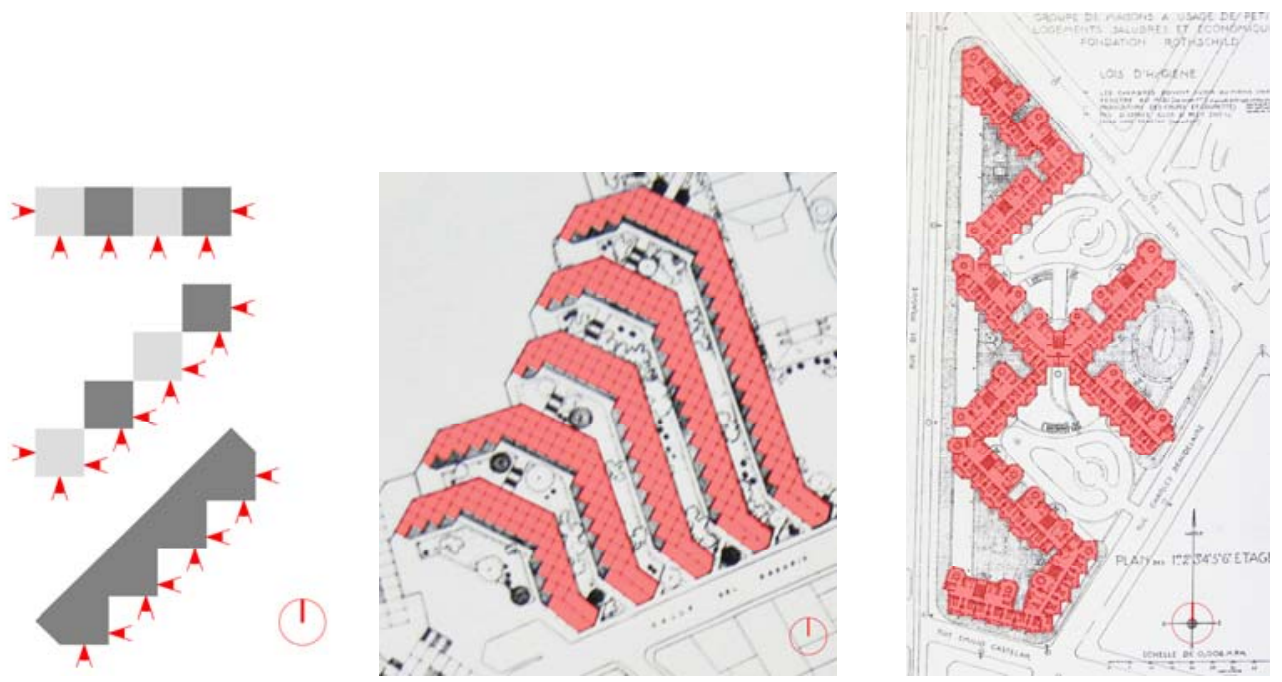

$4.107,4.108$ y 4.109

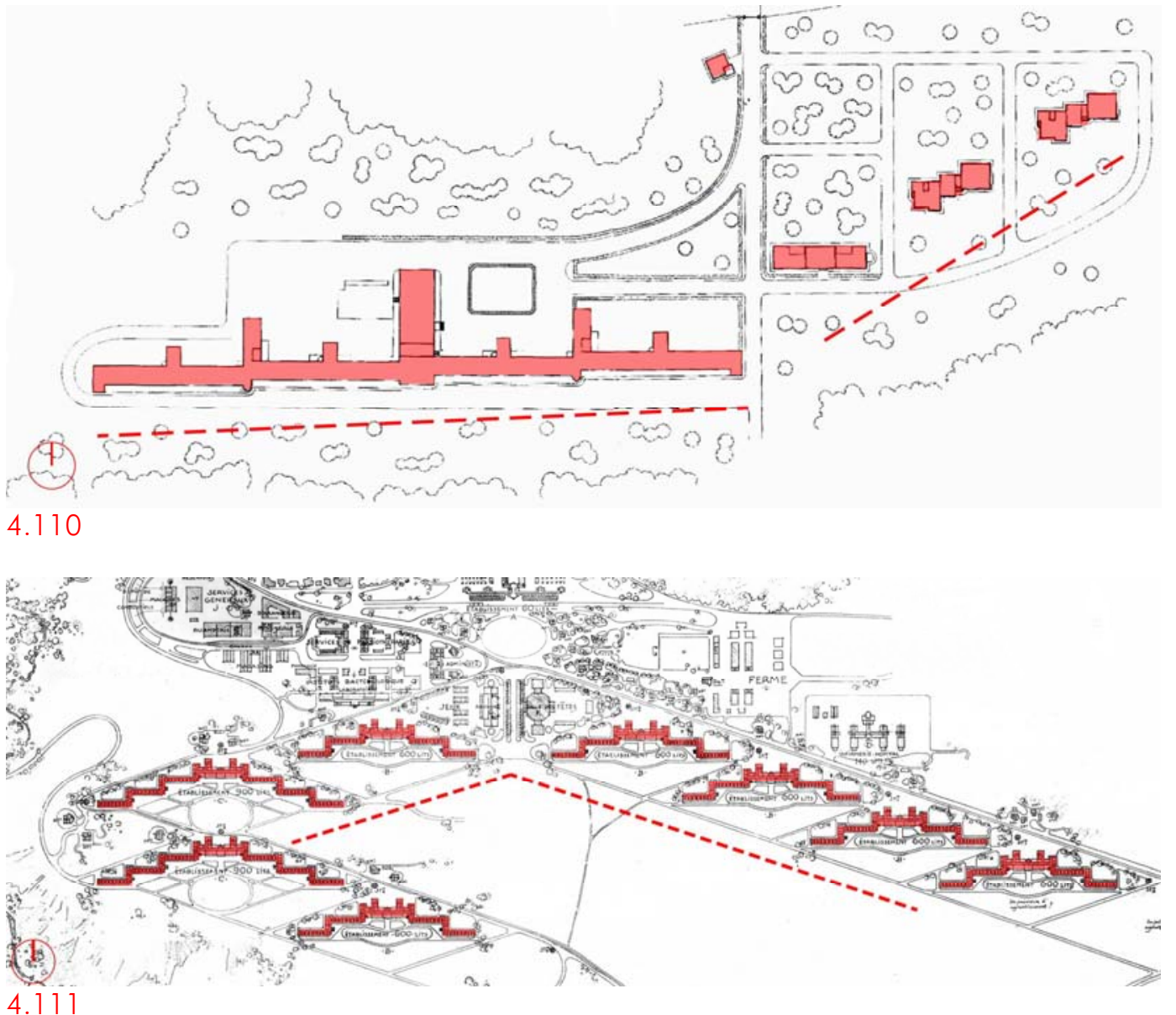

4.107 Paso de las viviendas desplazadas en hilera al bloque con el frente quebrado (dibujos de la autora).

4.108 R. Bergamín, F. Higueras y M. Ortiz de la Torre. Proyecto para la urbanización de la zona de San Francisco en la Puerta de Toledo, Madrid, 1962 (análisis de la autora)

4.109 T. Garnier. Proyecto para el concurso de la Fundación Rothschild, París, 1905 (análisis de la autora).

4.110 R. Bergamín. Sanatorio antituberculoso Los Montalvos, Salamanca, p. 1934-35 o. 1948. Desplazamiento diagonal del conjunto (análisis de la autora).

4.111 T. Garnier. Proyecto para el sanatorio Franco-Americano, Lyon, 1917. Desplazamiento diagonal del conjunto (análisis de la autora). 
Las edificaciones de Los Montalvos se completan con un pequeño pabellón que contiene la vivienda del portero. Consiste en un cuadrado de $8 \mathrm{~m}$. de lado girado unos $30^{\circ}$ con respecto al resto de construcciones, evitando que sus frentes queden orientados al norte. En uno de sus vértices, un cuadrante del mismo se desplaza del perímetro y crece hacia el exterior configurando un mirador desde el que se vigila la entrada [fig. 4.110 y fig. 4. 103]. Bergamín propone así una caracterización de los elementos de vigilancia al proporcionarles una geometría más singular, dado que tanto el cuadrado girado de la vivienda del guarda, como los semicilindros acristalados de las salas de enfermeras, destacan formalmente dentro de la composición general del proyecto del Sanatorio.

Sus obras comienzan el año 1935 y son dirigidas por Genaro de Nó. Un año después estalla la Guerra Civil y pasan a depender del Patronato Nacional Antituberculoso creado por el General Francisco Franco. Las obras continúan con lentitud hasta 1938, cuando se paralizan a causa de la falta de recursos económicos y se obtiene una dotación de 350 nuevas camas para tuberculosos en Salamanca a raíz de la transformación de la colonia veraniega Llano Alto en sanatorio. Se reanudan los trabajos en 1941 por el Patronato, que decide cambiarle el nombre por Sanatorio Martínez Anido en honor a su antiguo presidente recién fallecido, el General Severiano Martínez Anido. Se concluye la construcción en 1948, en pleno desarrollo del "Plan de Construcciones del Patronato Nacional Antituberculoso para la Lucha contra la Tuberculosis".

Antes de la consolidación del Plan de Construcciones del Patronato, es decir, previamente a la concepción de Los Montalvos por Bergamín, los escasos sanatorios antituberculosos existentes en España, privados en su mayoría, siguen generalmente los trazados de los hospitales de infecciosos. Son edificios aislados, de planta rectangular, atravesados por un corredor central o lateral, con las habitaciones de los enfermos con más recursos orientadas al sur y con los servicios comunes y las estancias más económicas al norte ${ }^{122}$. Así se organizan entre otros el Sanatorio de La Fuenfría de Antonio Palacios (1921) [fig. 4.113] y el Real Sanatorio del Guadarrama de Alfredo Echegaray (1917) [fig. 4.114], donde Camilo José Cela estuvo ingresado ${ }^{123}$ y en cuyas vivencias se inspira su novela El pabellón de Reposo. En ella relata, a través de las desgracias de sus personajes, la distinción económica

\footnotetext{
122 El sanatorio de Lago construido en 1924 en la sierra de Guadarrama, concebido para ser un sanatorio privado aunque luego pasa a ser público, es uno de los pocos de aquella época que presenta una disposición en $T$.

${ }^{123}$ Camilo José CELA, "El Real Sanatorio del Guadarrama" en ABC Madrid, 25 de feb. 1995, p.1 1.
} 

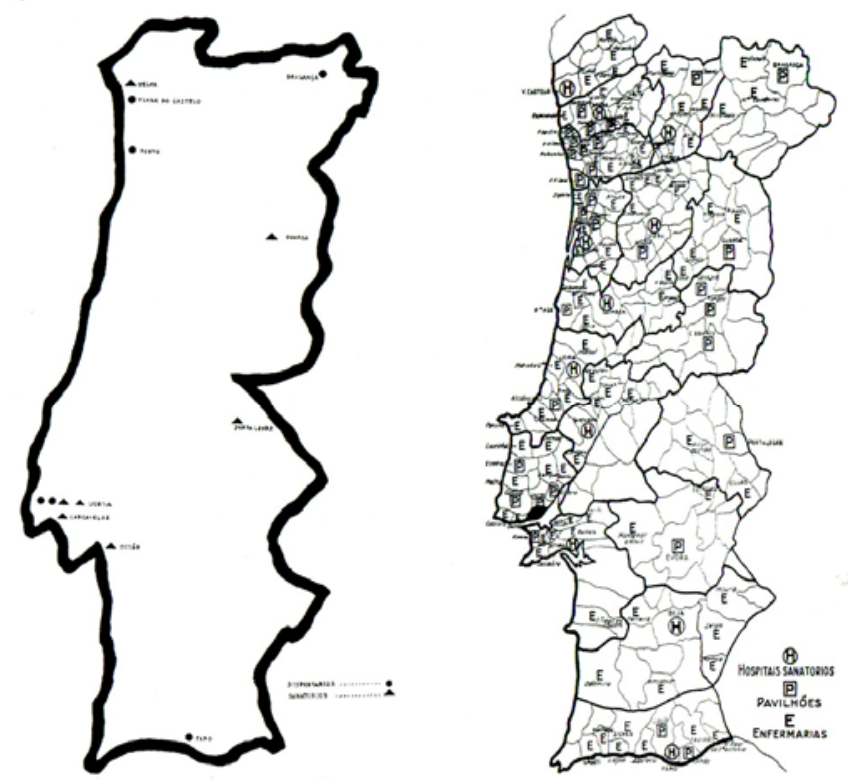

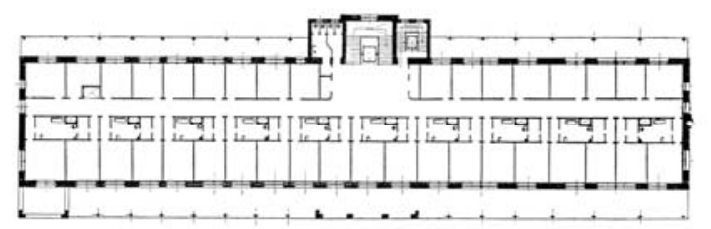

4.113 y 4.114
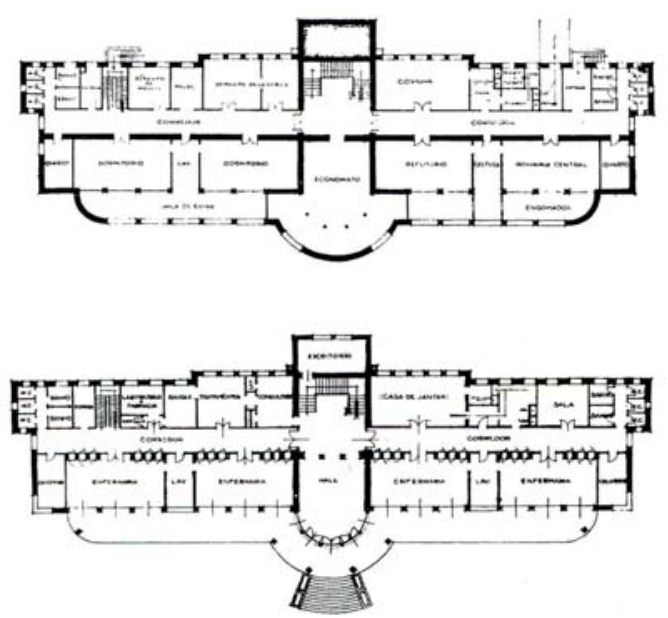
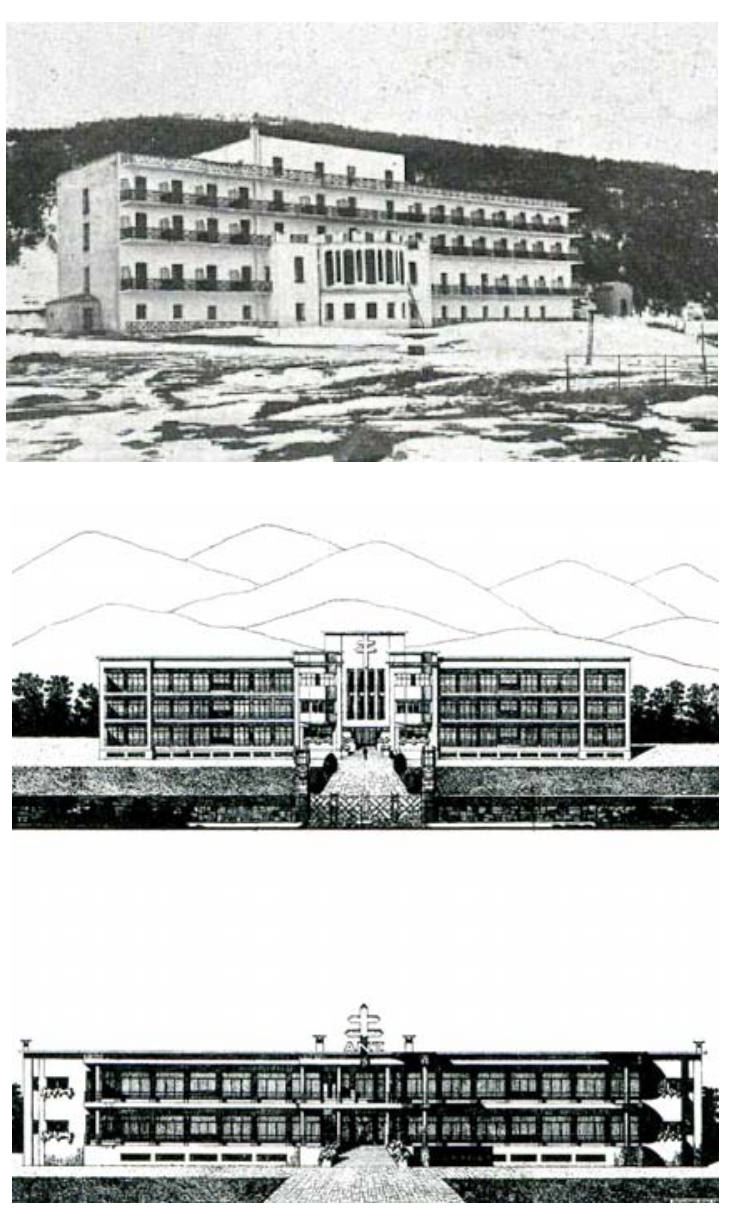

4.115 y 4.116

4.112. Plan de Construcciones de la Assistência Nacional aos Tuberculosos de Portugal, ANT. Distribución de sanatorios.

4.113 A. Palacios. Sanatorio de La Fuenfría, Madrid, 1921. Plantas $1^{a}$ y $2^{a}$.

4.114 A. Echegaray. Real Sanatorio del Guadarrama, Madrid, 1917. Fachada principal.

4.115 V. Regaleira. Proyecto de sanatorios-tipo, 1934. Plantas.

4.116 V. Regaleira. Proyecto de sanatorios-tipo, 1934. Alzados. 
establecida en las estancias: "Se gastó sus ahorros para morirse. Como no era rica, murió en el Pabellón del Norte" $" 124$.

Este tipo de sanatorio rectangular se mantuvo, con un ropaje más racionalista, hasta los comienzos de la Guerra Civil Española, siguiendo una configuración similar a los modelos de "sanatorio-tipo" proyectados en 1934 por Vasco Regaleira para la A.N.T. la Assistência Nacional aos Tuberculosos de Portugal ${ }^{125}$ [fig. 4.112]. Los "sanatorios-tipo" eran pabellones rectangulares y simétricos, de dos o tres plantas de altura, constituidos también por un pasillo central que distribuía al norte los servicios comunes y al sur las habitaciones con sus galerías de cura. El acceso solía ubicarse en el centro de la fachada Sur y, en algunos casos, estaba contenido en un cuerpo circular y acristalado que remarcaba la simetría del conjunto $^{126}$ [fig. 4.115 y fig. 4.116 ].

Es en el año 1942 cuando el Patronato Nacional Antituberculoso, con el Dr. Benítez Franco como Secretario General, pone en marcha el "Plan de Construcciones del Patronato Nacional Antituberculoso para la Lucha contra la Tuberculosis" amparado en la Ley del 23 de Noviembre de 1940. Dicha Ley autoriza la creación de una serie de nuevos sanatorios con carácter de urgencia ${ }^{127}$, para aumentar así el reducido número de camas públicas existentes, unas 5.400 en todo el país, y combatir a las 30.000 muertes anuales que provoca la tuberculosis ${ }^{128}$ [fig. 4.117]. Este plan sigue las mismas directrices que el /stituto Nazionale Fascista della Previdenza Sociale había planteado en 1927 ante una situación similar y trata de construir 20.000 nuevas camas para tuberculosos, distribuidas por todo el país al dotar al menos de un sanatorio a cada provincia ${ }^{129}$. Igual que los italianos el Patronato intenta definir una serie de modelos o prototipos de sanatorios, reproducibles en

\footnotetext{
${ }^{124}$ Camilo José CELA, Pabellón de reposo (1943). Destino, Barcelona 2011 , p. 27.

125 André TAVARES, Arquitectura Antituberculose. Trocas e tráficos na construção terapéutica entre Portugal e Suiça. Faculdade de Arquitectura da Universidade do Porto, Poto 2005, p. 21 1-220.

126 Entre los múltiples sanatorios antituberculosos construidos en Portugal destacan la Clínica Heliântia de Francelos (1929) y el Sanatorio Marítimo do Norte en Valadares (1919-1933), ambos en Vila Nova de Gaia y concebidos por Francisco Oliveira Ferreira.

127 Alberto PIELTÁIN ÁLVAREZ-ARENAS, Arquitectura para la sanidad pública en España 1942-1977. INGESA, Madrid 2007, p. 18.

${ }^{128}$ Ramón NAVARRO GARCÍA, Análisis de la Sanidad en España a lo largo del siglo XX. Ministerio de Sanidad y Consumo, Instituto de Sanidad Carlos III, p. 223.

129 El Istituto Nazionale Fascista della Previdenza Sociale en 1927 precisa construir 20.000 camas para hacer frente al creciente número de enfermos de tuberculosis del país. Para ello el gobierno italiano crea el seguro obligatorio contra la tuberculosis, con el fin de recaudar el medio millón de liras necesario para llevar a cabo su construcción, y define una serie de modelos o prototipos de sanatorios creados para ser reproducibles en regiones de características similares que adoptan la configuración en T, con la peculiaridad de fragmentar el programa residencial por sexos.
} 

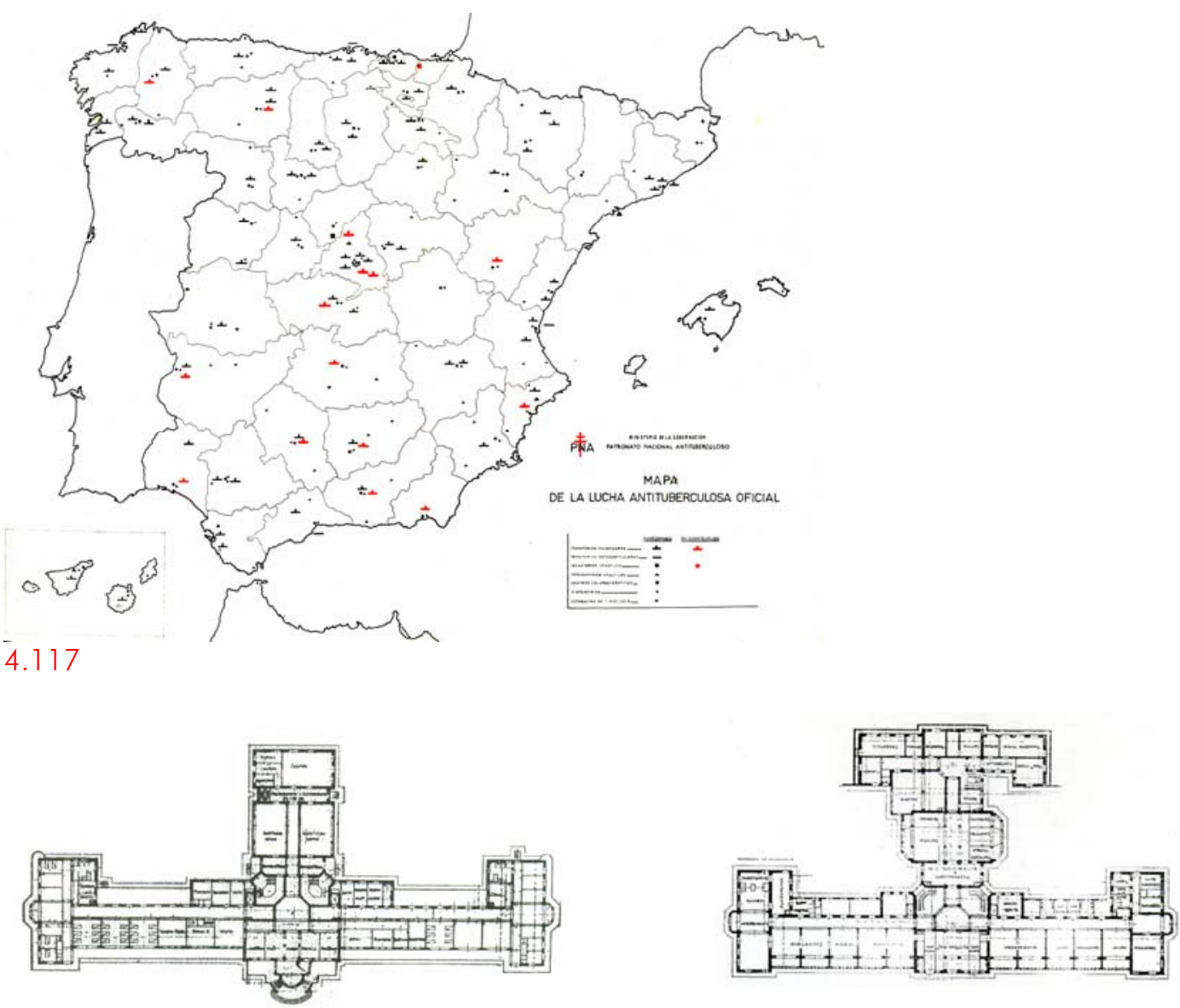

4.118 y 4.119

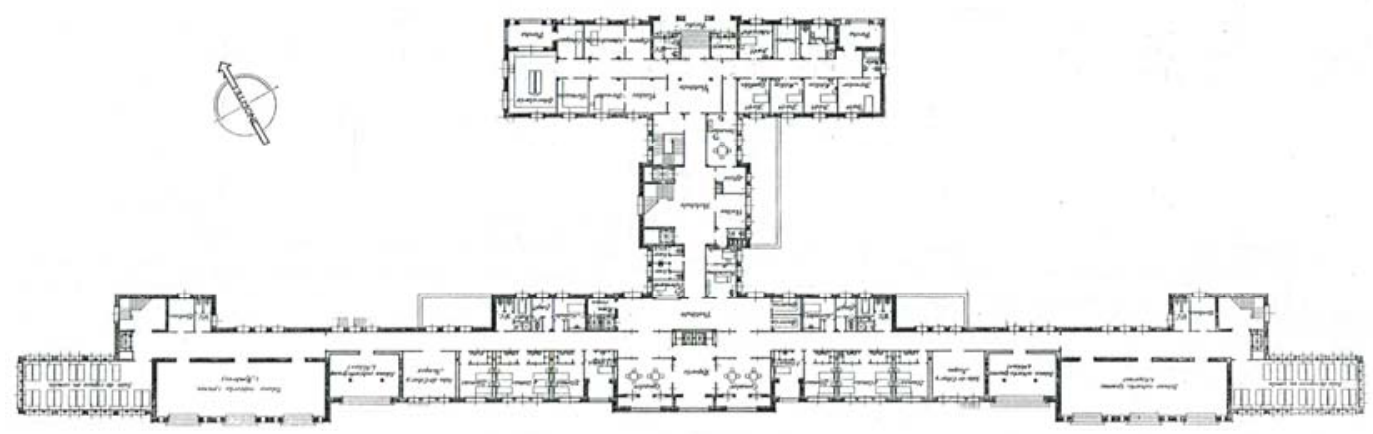

4.120

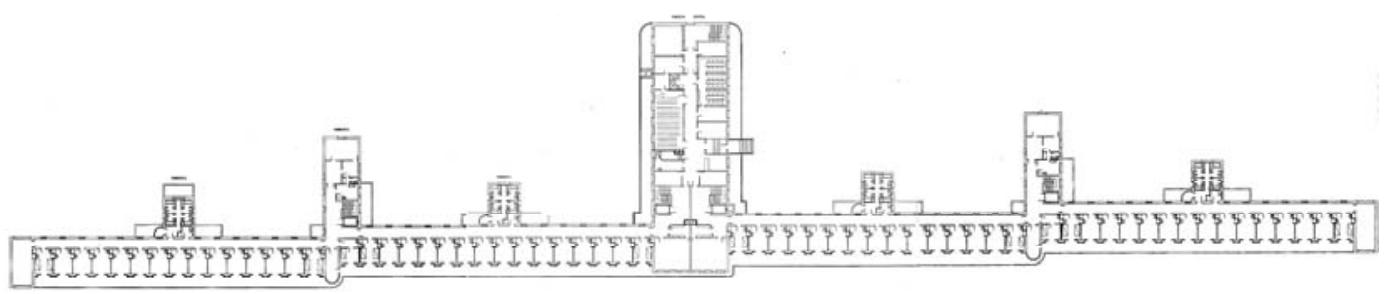

4.121

4. 1 17. Plan de Construcciones de la Lucha Antituberculosa, PNA. Distribución de sanatorios.

4.118 y 4.119 Istituto Nazionale Fascista della Previdenza Sociale. Sanatorio de Tápani "Tipo sud" y sanatorio de Lucca "Tipo Nord".

4.120 E. Ripollés. Proyecto ganador del concurso de anteproyectos de sanatorios antituberculosos de 200,300 y 4001942.

4.121 R. Bergamín. Sanatorio antituberculoso Los Montalvos, Salamanca, p. 1934-35 o. 1948 (dibujo de la asignatura de Elementos de Composición. Curso 1993-1994. Departamento de Teoría de la Arquitectura y Proyectos arquitectónicos. Escuela de Arquitectura de Valladolid curso 1993-94). 
las diferentes regiones de España, según recogen los informes sobre la Lucha Antituberculosa de 1944:

"No basta, sin embargo, con resolver en cada caso el problema y proyectar, por tanto, cada Sanatorio con absoluta independencia de los demás, aunque se ajuste a las mismas normas; es indispensable que exista entre todos ellos una identidad de criterio en su concepción que mejore no sólo sus condiciones, sino la vida futura de los Centros y su administración, por unificarse instalaciones, tipo de material, etc., lo que redunda además en beneficio del Patronato al abaratarse las diversas unidades de su repetición" 130 .

De este modo se pretenden resolver los mismos problemas con las mismas formas arquitectónicas, a partir de la definición de una serie de modelos ${ }^{131}$. Para obtenerlos el Patronato convoca el "Concurso de Anteproyectos de Sanatorios Antituberculosos de 200, 300 y 400 camas", donde el equipo ganador dirigido por Ernesto Ripollés, propone un modelo de sanatorio en doble T [fig. 4.120], muy similar al "Tipo Nord" italiano [fig. 4.118 y fig. 4.119]. Con esta elección, se abandonan en España los modelos de sanatorios con forma de prisma rectangular, tipo pabellón, y se opta por al patrón de sanatorio compacto en T y orientado al sur definido en Berlín por los tisiólogos a finales del siglo XIX.

La rotundidad formal asociada a este patrón, con su matriz geométrica en $T$, facilita que el tipo, que había sido aplicado ya hacía ocho años en la concepción del Sanatorio de Los Montalvos [fig. 4.121], se convierta en prototipo y que éste pase a ser reproducido en todos aquellos sanatorios de nueva planta construidos por el Patronato Nacional Antituberculoso en las distintas provincias españolas ${ }^{132}$ entre 1936 y 1958, fecha en la que la tuberculosis se considera erradicada en España.

\footnotetext{
${ }^{130}$ Bartolomé BENITEZ FRANCO, Información sobre la Lucha Antituberculosa en España y Memoria correspondiente al año 1944. Patronato Nacional Antituberculoso, Madrid, 1945, p. 126.

131 Rafael MONEO, "On typology", Oppositions n'13, 1978. Traducido en J. Rafael MONEO, J. Antonio CORTÉS, Sobre el concepto de tipo en Arquitectura. Catedra de Composición. Escuela Técnica Superior de Arquitectura, Madrid 1984, p. 192.

132 El patrón de Los Montalvos fue aplicado en el Sanatorio de El Caubet en Palma de Mallorca, el del Doctor Novoa Santos de El Ferrol en La Coruña, el de Ciudad Real, el de Fuentes Bermejas de Burgos, el de Virgen del Valle en Toledo, el de Linares en Jaén y el de Almería. También en los sanatorios del Patronato de entre 300 y 350 camas como el Sanatorio Monte San Isidro en León, el de Calde en Lugo, El Piñor en Orense, el de Liencres en Cantabria, el Generalísimo Franco en Vizcaya, El Escorial en Madrid, el Sanatorio Nuestra Señora de los Llanos en Albacete, General Alonso Vega en Huelva, Los Morales en Córdoba, Puerto Real en Cádiz y el de Campanillas en Málaga. Y también en los de entre 400 ó 450 camas como el Sanatorio Royo Villanova en Zaragoza, el de San Pedro en Logroño, el de Monte Naranco en Oviedo, La Magdalena en Castellón, el de Soria y en la Ciudad Sanatorial de Tarrasa.
} 


\section{CAPÍTULO 5}

\section{LA ESCISIÓN HIGIÉNICA DE LAS PARTES:}

EL SANATORIO DE PABELLONES DE ZONNESTRAAL, JOHANNES DUIKER

GENEALOGÍA DEL PROYECTO

ALTERACIONES CONCEPTUALES DEL TIPO: EL PROYECTO DE ZONNESTRAAL

LAS MODERNAS SALAS DE LA FÁBRICA DE CURAR ENFERMOS

LA ECONOMÍA ESPIRITUAL Y EL ESTILO HIGIÉNICO DE DUIKER 


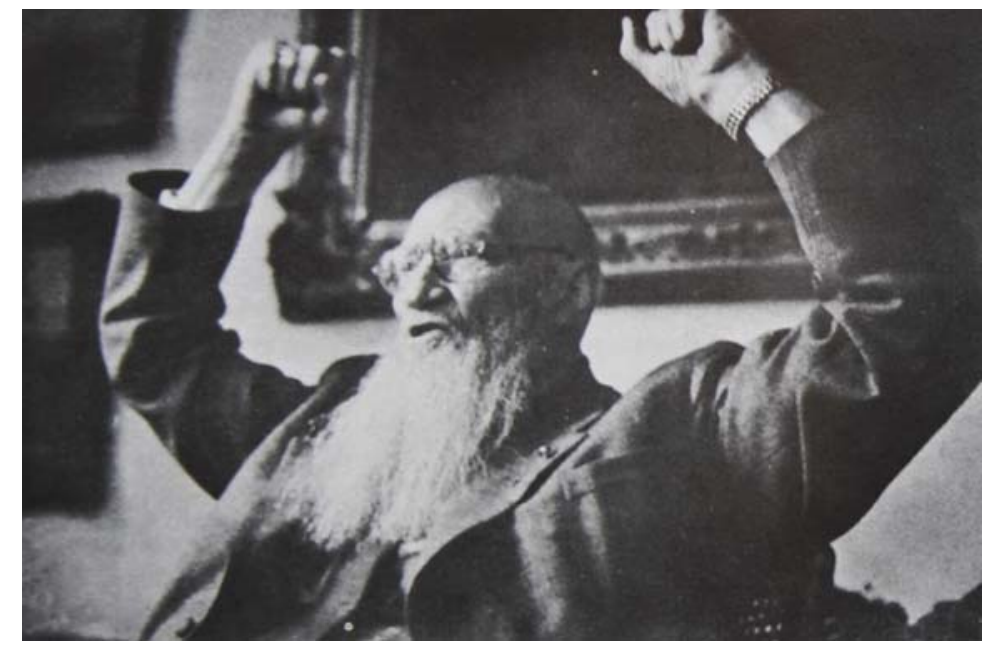

5.01

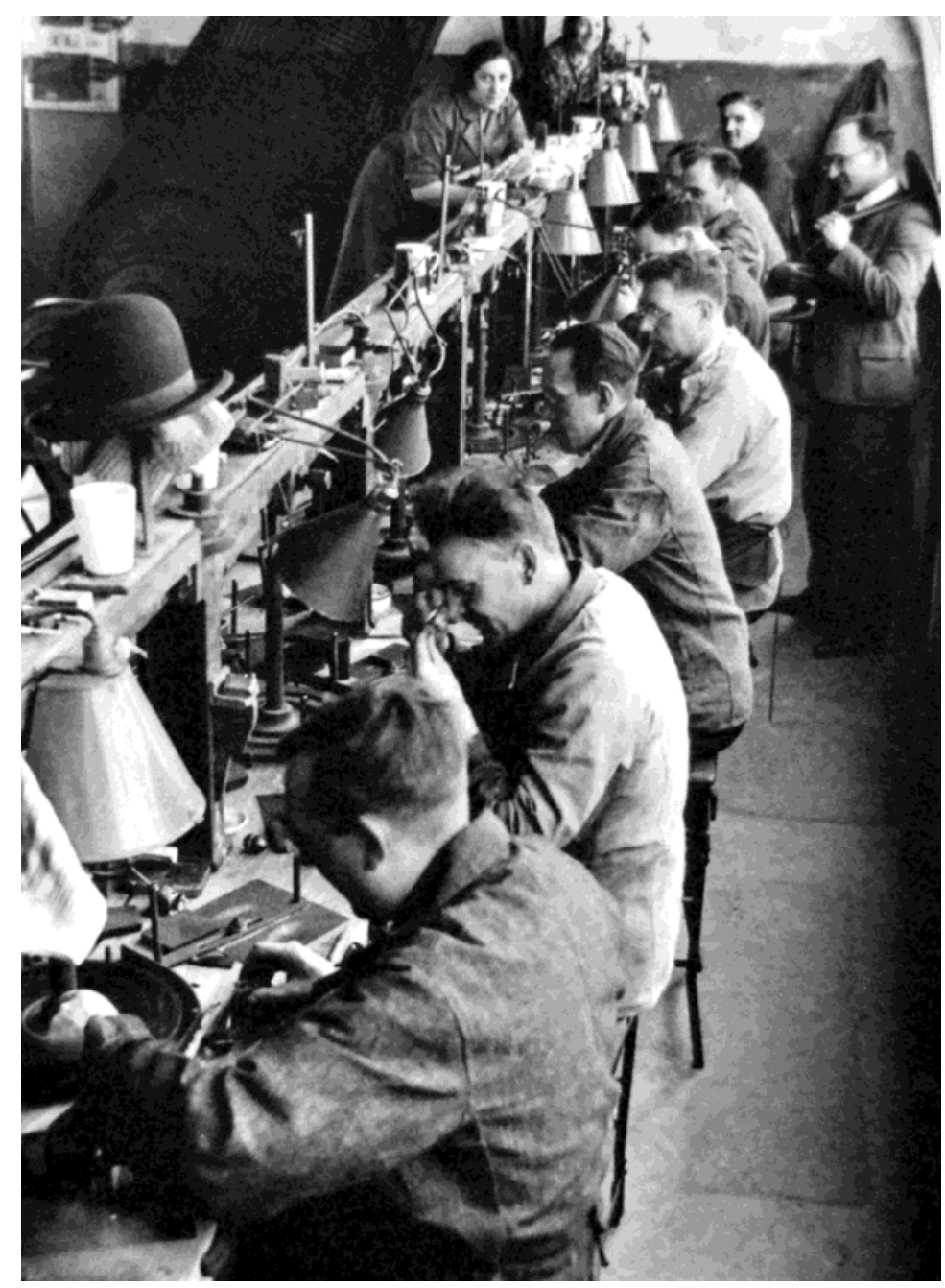

5.02

5.01 Jan van Zutphen o Ome Jan, tío Jan.

5.02 Trabajadores del diamante en los talleres de pulido. 


\section{GENEALOGÍA DEL PROYECTO}

En el año 1905 el secretario del Sindicato Holandés de los Trabajadores del Diamante, Algemene Nederlandsche Diamantbewerkers Bond -ANDB-, Jan van Zutphen familiarmente conocido como Ome Jan (tío Jan) [fig. 5.01] propone la creación de una fundación para la construcción de un sanatorio que sirva como centro de convalecencia y reinserción laboral, para los trabajadores del diamante afectados de tuberculosis ${ }^{1}$.

El aire respirado en los talleres de pulido, contaminado por las partículas de polvo desprendidas en el perfilado del diamante, hace sufrir a los trabajadores frecuentes afecciones respiratorias que fomentan el desarrollo de la tuberculosis pulmonar [fig. 5. 02]. En este tiempo, la seguridad social de los Países Bajos está obligada a hacerse cargo de los enfermos graves de tuberculosis hasta que la enfermedad remita, pero no de atenderlos hasta su completa recuperación, motivo por el que resulta crucial la creación de centros de convalecencia ${ }^{2}$. Para promover su construcción Jan van Zutphen propone a los trabajadores la creación de la Fundación de los Fondos de los Manguitos de Cobre, Koperen Stelen Fonds -KSF-. Los patrones de la industria del diamante permiten a sus empleados que se queden con las piezas de cobre deterioradas que habían sido utilizadas para sujetar los diamantes durante el proceso de pulido y que, debido al rozamiento, acababan desgastándose y rompiéndose. Con el dinero obtenido de la venta del cobre, los trabajadores solían salir a beber todos juntos un día a la semana, actividad que "tío Jan" propone cambiar con la creación de la citada Fundación KSF³.

Al dinero recaudado por la venta del cobre se suma el procedente de la venta del polvo de diamante, utilizado posteriormente en los diversos procesos de tallado y pulido del mismo ${ }^{4}$. Con este capital y el recaudado a través de las campañas populares organizadas por la fundación, además del procedente de las donaciones particulares, la Fundación KSF logra adquirir en 1919 para la construcción del sanatorio una propiedad al noroeste de Hilversum conocida como Pampahoeve ${ }^{5}$ [fig.5. 03]. Se trata de una finca inmensa de más

\footnotetext{
' Ronald ZOETBROOD, Jan Duiker en het sanatorium Zonnestraal. Van Gennep, Amsterdam 1984, p. 24.

2 Pedro IGLESIAS PICAZO, La habitación del enfermo. Ciencia y arquitectura en los hospitales del Movimiento Moderno. Fundación Caja de Arquitectos, Barcelona 2011 , p. 85.

${ }^{3}$ Ton IDSINGA, Zonnestraal Een nieuwe tijd lag in het verschiet. Uitgeverii De Arbeiderspers Stichting Wonen, Amsterdam 1986, pp. 39-40.

${ }^{4}$ Su obtención fue posible gracias a Henri ter Meulen, químico y profesor de la universidad de Delft, quien en el año 1917 inventa una máquina centrifugadora capaz de extraer el polvo de diamante de los uniformes de los trabajadores.

${ }^{5}$ Pedro IGLESIAS PICAZO, La habitación del enfermo. Ciencia y arquitectura en los hospitales del Movimiento Moderno. Fundación Caja de Arquitectos, Barcelona 2011 , p. 85.
} 

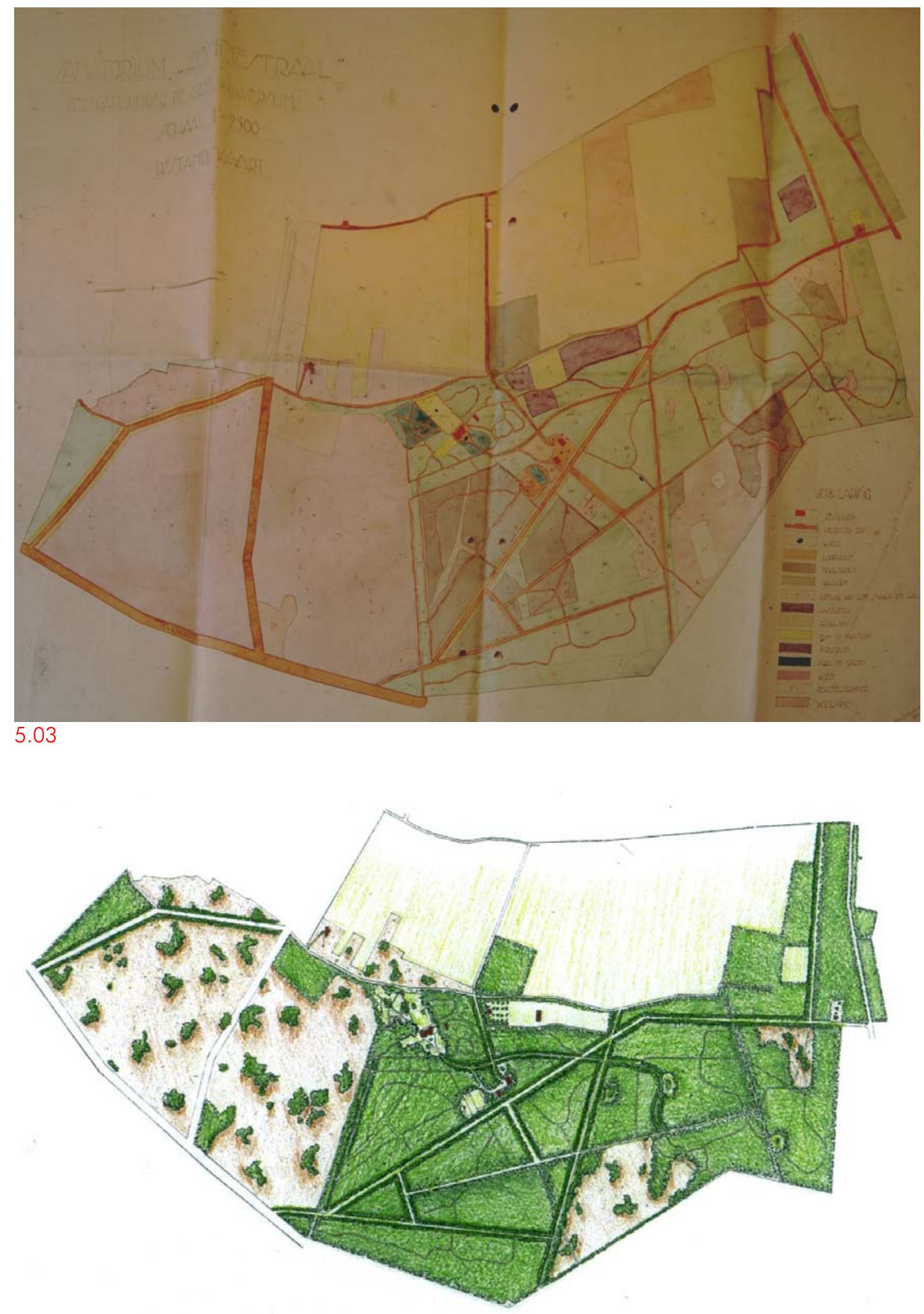

5.04

5.03 Finca de Zonnestral antes de 1919 (IISG)

5.04 Finca de Zonnestraal antes de 1919, vegetación. 
de ciento diez hectáreas de extensión fragmentada por una serie de vías y caminos que la atraviesan. Ésta dispone de dos áreas naturales diferenciadas, una constituida por un denso bosque sombrío y la otra por una extensión de brezo, más soleada y expuesta al aire puro ${ }^{6}$ [fig. 5. 04].

El mismo año de la adquisición Jan van Zutphen encarga a su amigo Hendrik Petrus Berlage [fig. 5. 05], miembro del partido socialdemócrata Sociaal Democratische Arbeiders Partij-SDAP-, la construcción del sanatorio. Berlage ya había trabajado para el sindicato ANDB con la construcción de su sede en Ámsterdam (1898-1900) [fig. 5.06], sin embargo, en esta ocasión rechaza el encargo a pesar de acabar de rescindir un importante contrato con la familia Kröller-Müller ${ }^{7}$. En su lugar recomienda para la elaboración del proyecto a dos jóvenes arquitectos-ingenieros -bouwkundig ingenieur- de la universidad de Delft, Johanes Duiker y Bernad Bijvoet que acaban de ganar el concurso para la construcción de la Academia de Artes Plásticas de Ámsterdam, Rijksacademie [fig. 5. 07], del que Berlage ha sido miembro del jurado.

El concurso había sido convocado en 1917 por la Academia Estatal y tenía como objetivo principal crear una "solución arquitectónica bella"8.

La propuesta de Duiker y Bijvoet con claras influencias de la arquitectura de Frank Lloyd Wright ${ }^{9}$ tanto en su imagen exterior y su organización en planta, muy similares a las del Hotel Imperial de Tokio concebido un año antes (1916-1922) [fig. 5.08], como en el diseño de su interior [fig. 5.09], que recuerda a la Unity Church (1905-1907) [fig. 5.10], logra

\footnotetext{
6 Según Annette Koenders, la finca había pertenecido desde 1911 a Frederik Smidt, cónsul de profesión y gran viajero, quien designa la finca con un evocador nombre argentino y manda construir una villa de madera de estilo inglés, con un jardín de inspiración oriental y otro de estilo romántico con caminos serpenteantes que conducen a sorprendentes espacios naturales, como el pequeño lago artificial con una isla o como la montaña que manda construir, en recuerdo de los paisajes contemplados en sus viajes. Annette KOENDERS, "Centuries-old landscape. History of the design of the Zonnestraal Estate", en Paul MEURS, Mare-Thérèse VAN THOOR (ed.), Zonnestraal, the history and restoration of modern monument. NAi, Rotterdam 2010, pp. 66-70.

7 H.P. Berlage trabajaba en exclusiva para la familia Kröller-Müller desde el año 1913, siendo el encargado del departamento de arquitectura de la compañía Wm. H. Müller \& Co. Durante este periodo construye su sede en Londres, conocida como Holland House, y un gran pabellón de caza para la familia en la finca Hoge Veluwe. Desde 1917 había elaborado sin éxito varias versiones de una casa-pabellón para la Sra. Hélène Müller, donde expondría su colección de arte moderno, vivienda que finalmente es construida por el arquitecto Henry Van de Velde. Sergio POLANO, Hendrik Petrus Berlage. Opera Completa. Electra, Milan 1987, pp. 23-27.

${ }^{8}$ Así queda recogido en el programa mismo. Jan MOLEMA, Duiker, arquitecto de una nueva era. $\mathrm{TH}$ Delft, Delft 1985, p. 48.

9 La relación entre la arquitectura de Duiker y Bijvoet con la de Wright ha sido ampliamente estudiada. Ver: Gabriele MILELLI, Zonnestraal. I/ sanatorio de Hilversum. Universale di architettura, Torino 2000, p.83; Kenneth FRAMPTON/Jan MOLEMA en Jan MOLEMA, Jan Duiker (Rotterdam 1989). Gustavo Gili, Barcelona 1996, p.6 y p.13.
} 


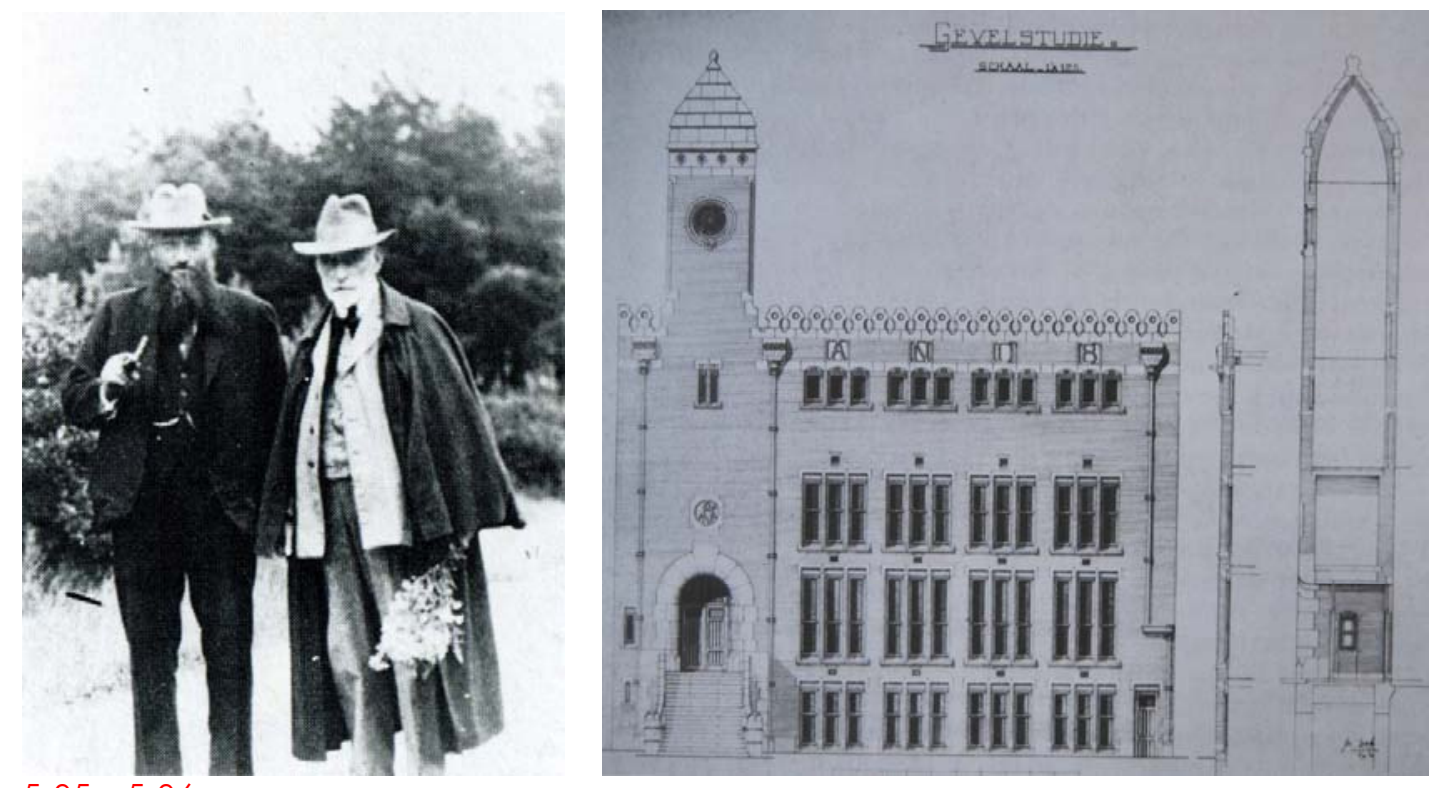

\subsection{5 y 5.06}
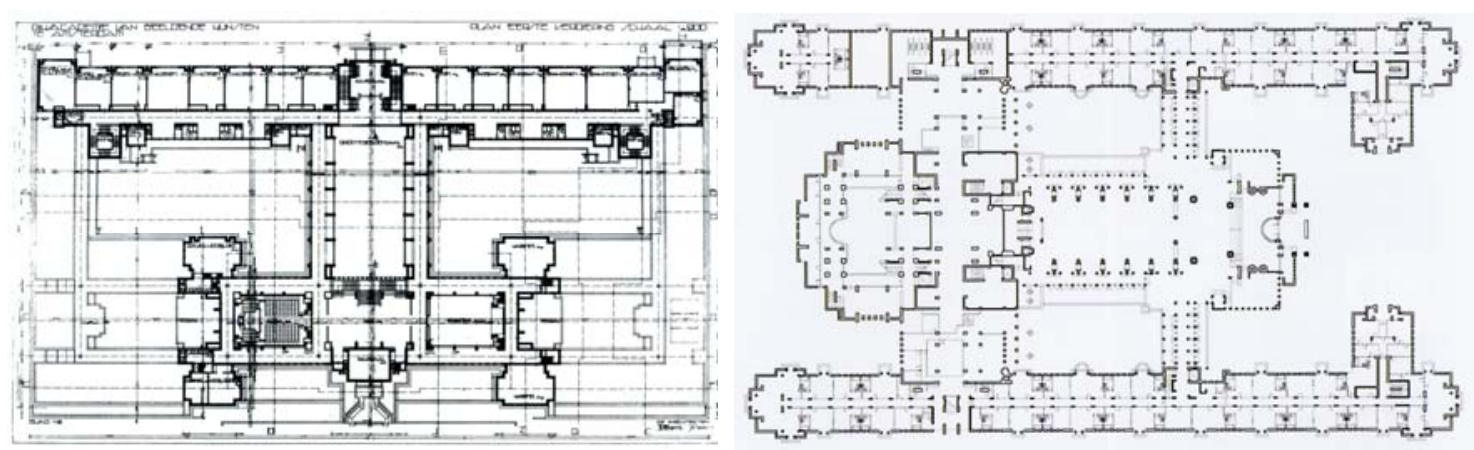

5.07 y 5.08
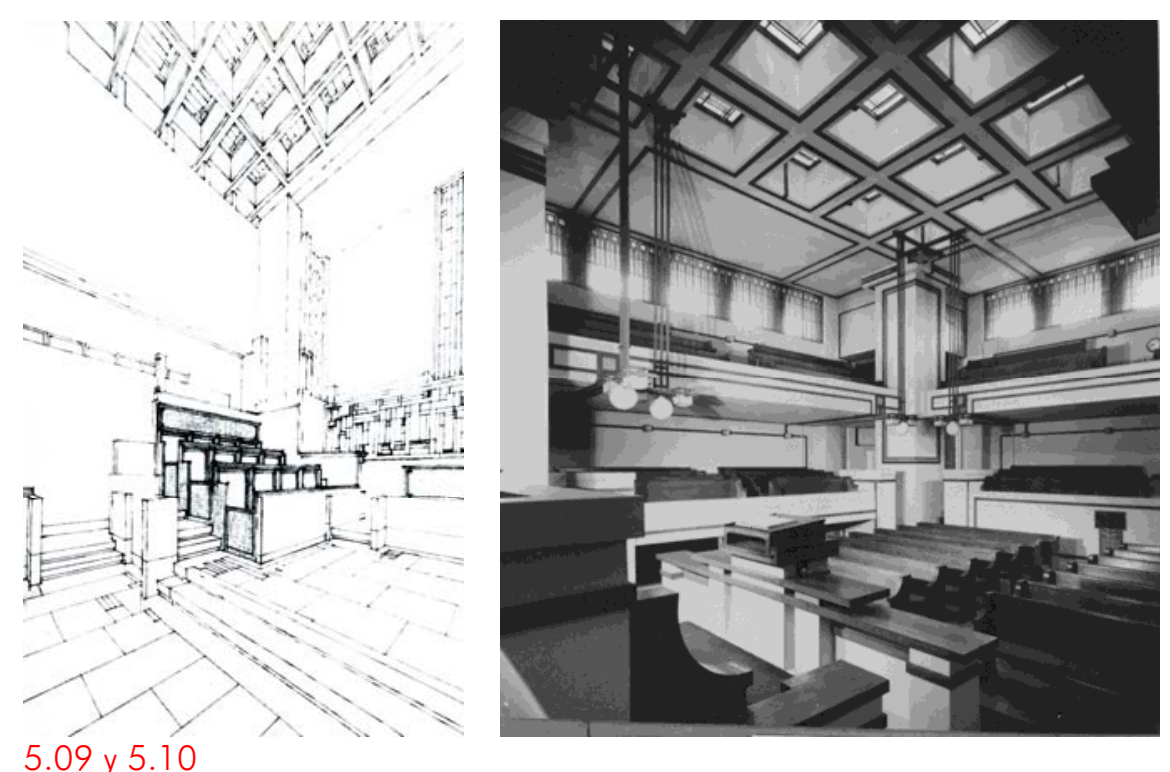

5.09 y 5.10

5.05 Jan van Zutphen (tío Jan) y Hendrik Petrus Berlage.

5.06 H.P. Berlage. Oficinas del sindicato del diamante ANDB, Ámsterdam, 1898-1900

5.07 J. Duiker y B. Bijvoet. Proyecto del Concurso para la Academia de Artes Plásticas de Ámsterdam, 1917. $1^{\text {er }}$ Premio.

5.08 Frank. Lloyd Wright. Hotel Imperial de Tokio, 1916.

5.09 J. Duiker y B. Bijvoet. Proyecto del Concurso para la Academia de Artes Plásticas de Ámsterdam, 1917. $1^{\text {er }}$ Premio.

5.10 F. LI. Wright. Unity Church, Oak Park, Illinois, 1908. 
convencer a los miembros del jurado y en particular a Berlage, que no duda en recomendarlos ${ }^{10}$, para la construcción del sanatorio, así como también a Jan Van Zutphen, quien les concede el encargo bajo la supervisión de un comitéll formado por varios médicos y por Berlage ${ }^{12}$. De este modo, Duiker y Bijvoet se convirtieron en los arquitectos del sanatorio de la Fundación KSF que recibirá el nombre de "rayo de sol" o Zonnestraal. Casualmente, al primer concurso que ganan, un complejo residencial para ancianos "Karenhuis", en Alkmaar, Holanda (1916-1917), se presentan bajo el lema "Zon", que significa sol, un presagio de la futura designación del sanatorio.

Duiker y Bijvoet habían creado su propio estudio en La Haya hacía tan sólo tres años ${ }^{13}$ y nunca antes se han enfrentado a un encargo de tal complejidad y trascendencia social, quizás por ello durante el dilatado proceso de proyecto del Sanatorio éste pasara por numerosas propuestas formalmente muy distintas.

La mayoría de los planos donde se describen estas propuestas carecen de fecha, por lo que resulta difícil establecer un orden secuencial entre ellas. Tan sólo en uno de los planos se data con "Diciembre 1919", hecho que ha motivado que un gran número de estudiosos lo hayan considerado como la primera propuesta del sanatorio de Zonnestraal, pese a que la agrupación de ciertos elementos que la componen generando una cabeza principal con dos brazos oblicuos [fig. 5.11], se aproxime más a los pabellones de enfermos finalmente

\footnotetext{
${ }^{10}$ Según Molema puede que entre los tres, Berlage, Duiker y Bijvoet, existiera además una relación personal, ya que vivieron en el mismo barrio The Huge, se movieron en los mismos ámbitos sociales dada su profesión, y tenían las mismas inclinaciones políticas afines al partido socialdemócrata SDAP. Jan MOLEMA, "The Zonnestraal commission" en Paul MEURS, Mare-Thérèse VAN THOOR (ed.), Zonnestraal, the history and restoration of modern monument. NAi, Rotterdam 2010, pp. 6266.

11 Ton IDSINGA, Zonnestraal Een nieuwe tijd lag in het verschiet. Uitgeverii De Arbeiderspers Stichting Wonen, Amsterdam, 1986, p. 59.

${ }^{12}$ Berlage tuvo una participación muy activa en el comité, quiso viajar al Reino Unido en el primer viaje de estudios que realizaron Duiker, su esposa y el Dr. Sajet en torno a 1919 para analizar las diversas soluciones arquitectónicas planteadas para la cura de la tuberculosis pulmonar. Jan MOLEMA, "The Zonnestraal commission" en Paul MEURS, Mare-Thérèse VAN THOOR (ed.), Zonnestraal, the history and restoration of modern monument. NAi, Rotterdam 2010, p. 66.

${ }^{13}$ La relación entre Duiker y Bijvoet trasciende el plano profesional. Los dos arquitectos-ingenieros han sido compañeros en la universidad de Delft, han trabajado juntos en el estudio de su profesor H.J. Evers y comparten la misma pasión por la música.
} 


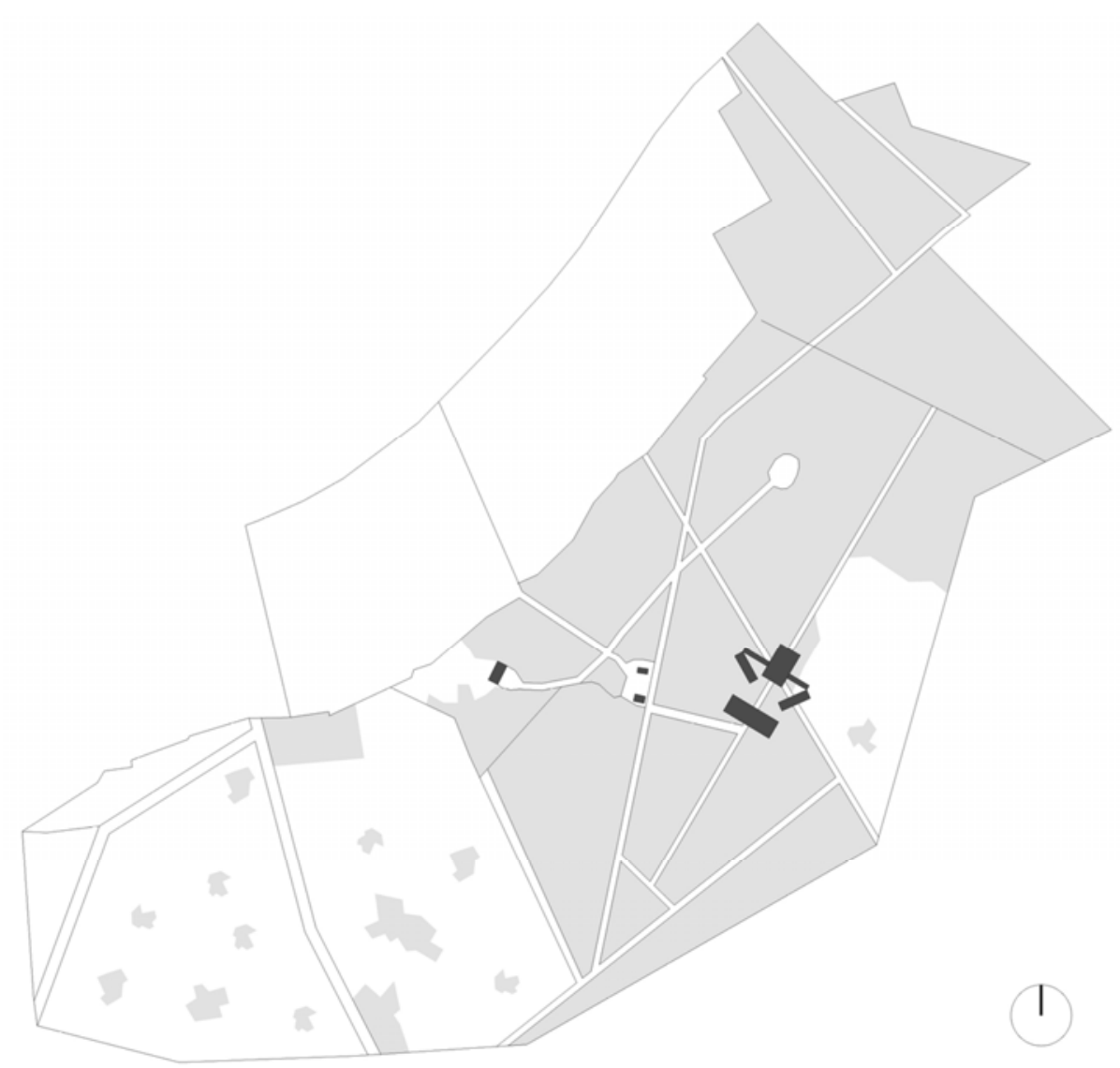

5.11

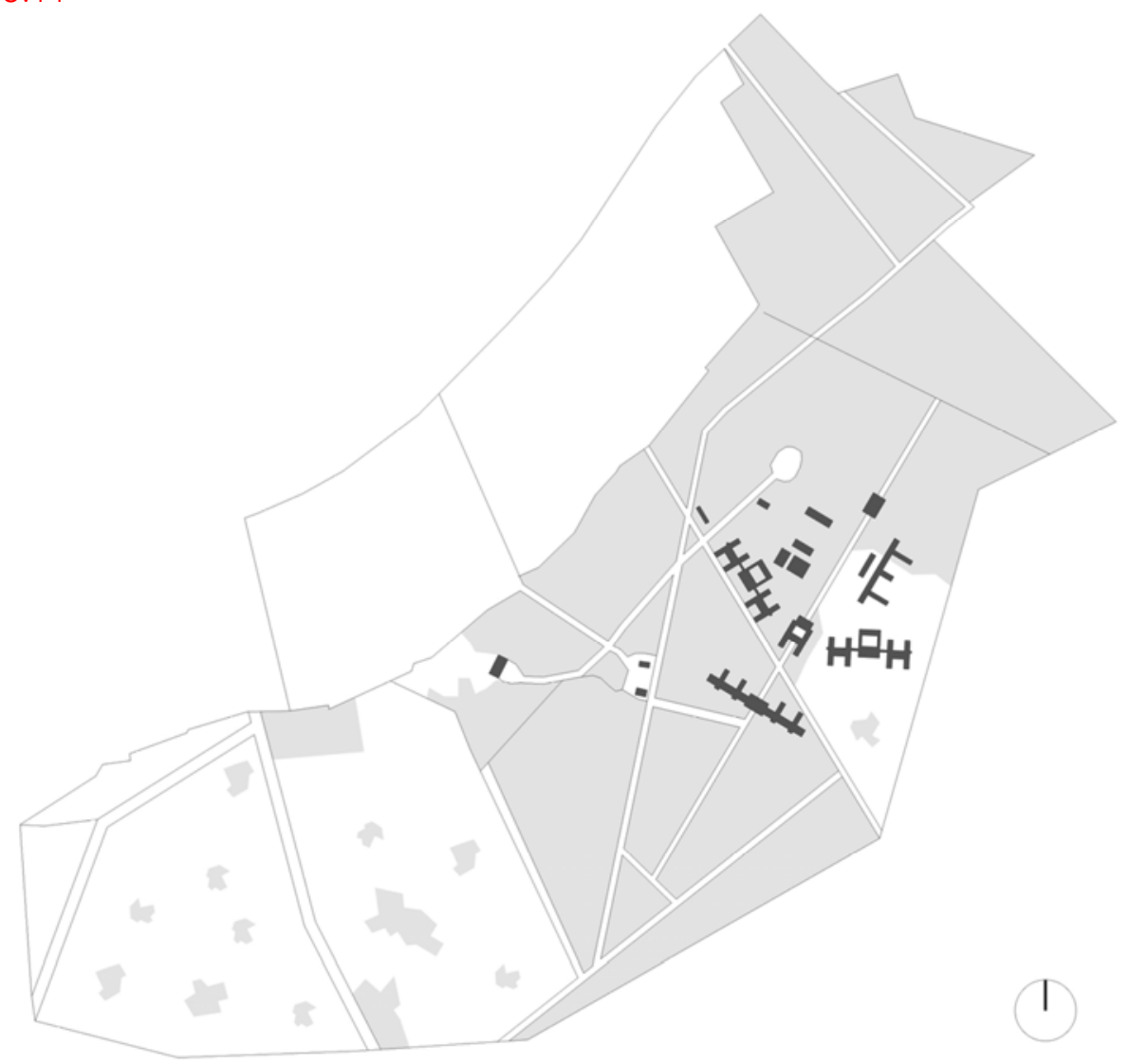

5.12

5.11 J. Duiker y B. Bijvoet. Propuesta para el Sanatorio de Zonnestraal datada en Diciembre de 1919 (dibujo de la autora).

5.12 J. Duiker y B. Bijvoet. Propuesta para el Sanatorio de Zonnestraal sin datar (dibujo de la autora). 
construidos que a otras propuestas previas ${ }^{14}$.

A diferencia de esta asunción generalizada, considero también como primera propuesta del Sanatorio de Zonnestraal una distinta a la citada, la misma que atribuye Ronald Zoetbrood en su libro Jan Duiker en het sanatorium Zonnestraa/ publicado en $1984^{15}$ [fig. 5.12], tanto por su tamaño, ya que es la más grande y ambiciosa de todas las descritas en las diversas soluciones de Duiker y Bijvoet ${ }^{16}$, como por su arquitectura, más afín y concordante con la del resto de propuestas previas.

La solución que corroboro como primera propuesta está reflejada en dos dibujos de conjunto en planta: un croquis [fig. 5.13] y un dibujo delineado a escala 1:100 [fig. 5.14]. Consiste en un conjunto arquitectónico de gran tamaño formado por varios edificios desarrollados sólo en planta baja, organizados en torno a un eje longitudinal central que recorre el complejo en la dirección sureste-noroeste. Consta de un edificio principal de hospitalización presidiendo el conjunto, que se sitúa al sur del mismo, con planta en forma de T. A continuación, centrado en el eje se ubica un edificio más pequeño organizado en torno a un patio central y, a ambos lados de éste otros dos edificios de hospitalización, simétricos y girados 30 grados respecto al eje. Aparecen después otro gran pabellón de

14 En el capítulo "Sanatorium 'Zonnestraal', Hilversum", del libro Duiker Bouwkundig Ingenieur. Constructeur in stuc en staal, (1982) Wessel de Jonge describe el citado plano como: "Eerste Voorontwerp' voor een sanatorium op het terrain, December 1919", "Primer proyecto' del sanatorio en el terreno. Diciembre 1919". En una publicación posterior Sanatorium Zonnestraal, the history and restoration of modern monument (2010), Herman van Bergeijk en el artículo "Architecture an d 'spiritual' economy" describe el mismo plano como: "The only dated preliminary design for Zonnestraal, December 1919", "El único diseño preliminar de Zonnestraal datado, diciembre 1919". $Y$ en el capítulo "The Zonnestraal Aftercare Colony. Design and Buildings", de ese mismo libro, escrito por Wessel de Jonge y Paul Meurs aparece escrito en el texto: "The surviving preliminary designs are variations on a grouping of low-rise buildings around a central main axis, based on British examples", "Los diseños preliminares que han sobrevivido son variaciones sobre un grupo de edificios de poca altura alrededor de un eje principal central, basados en ejemplos británicos". Descripción que coincide con la propuesta definida en el libro de Jan Molema Duiker Bouwkundig Ingenieur. Constructeur in stuc en staal por de Jonge como "Segundo Proyecto".

${ }^{15}$ En la página 27 del libro de Ronald Zoetbrood, Jan Duiker en het sanatorium Zonnestraal, se publica un croquis descrito como: "B. Bijvoet, J. Duiker, Eerste ontwerp voor het sanatorium van het Koperen Stelen Fonds, Hilversum ca. 1919, coll. Nederlans Documentatiecentrum voor de Bouwkunst, Amsterdam", "B. Bijvoet, J. Duiker, primer croquis del sanatorio del Fondo de los Manguitos de Cobre, Hilversum ca. 1919, col. Centro de Documentación Holandés del Arte de la Construcción, Ámsterdam". Sin embargo, el mismo documento aparece recogido en el artículo "The Zonnestraal Aftercare Colony. Design and Buildings" escrito por Wessel de Jonge y Paul Meurs en el libro Sanatorium Zonnestraal, the history and restoration of modern monument (2010) con la descripción: "J.Duiker y B. Bijvoet. Design studies for Zonnestraal, ca. 1920", "J.Duiker y B. Bijvoet. Estudios del diseño de Zonnestraal, ca. 1920".

${ }^{16}$ El Dr. Sajet describe en su biografía que en el año 1920 Duiker y Bijvoet ya habían realizado varias propuestas y que éstas iban decreciendo en tamaño. Jan MOLEMA, Duiker Bouwkundig Ingenieur. Constructeur in stuc en staal. Stichting Bouw, Rotterdam 1982, p. 94. 


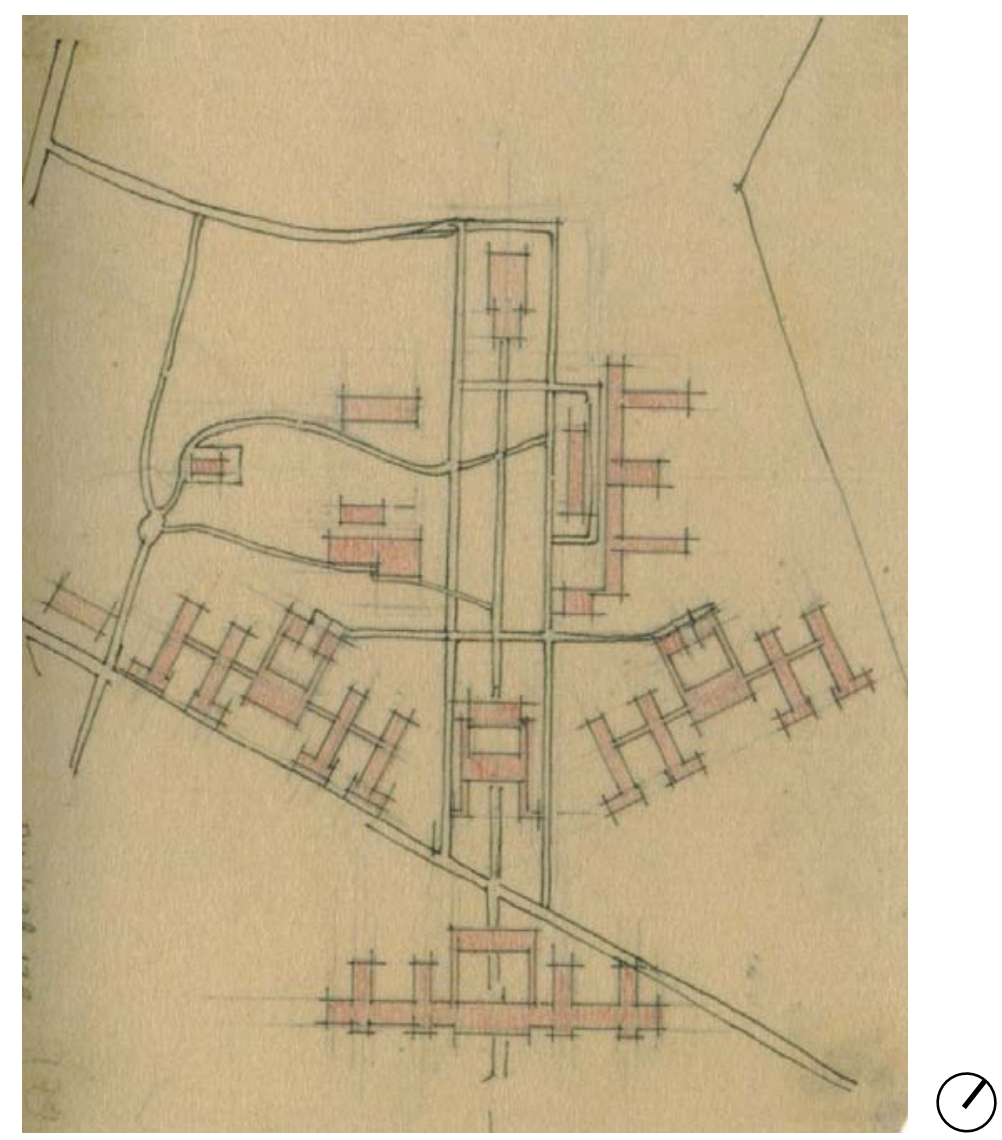

5.13

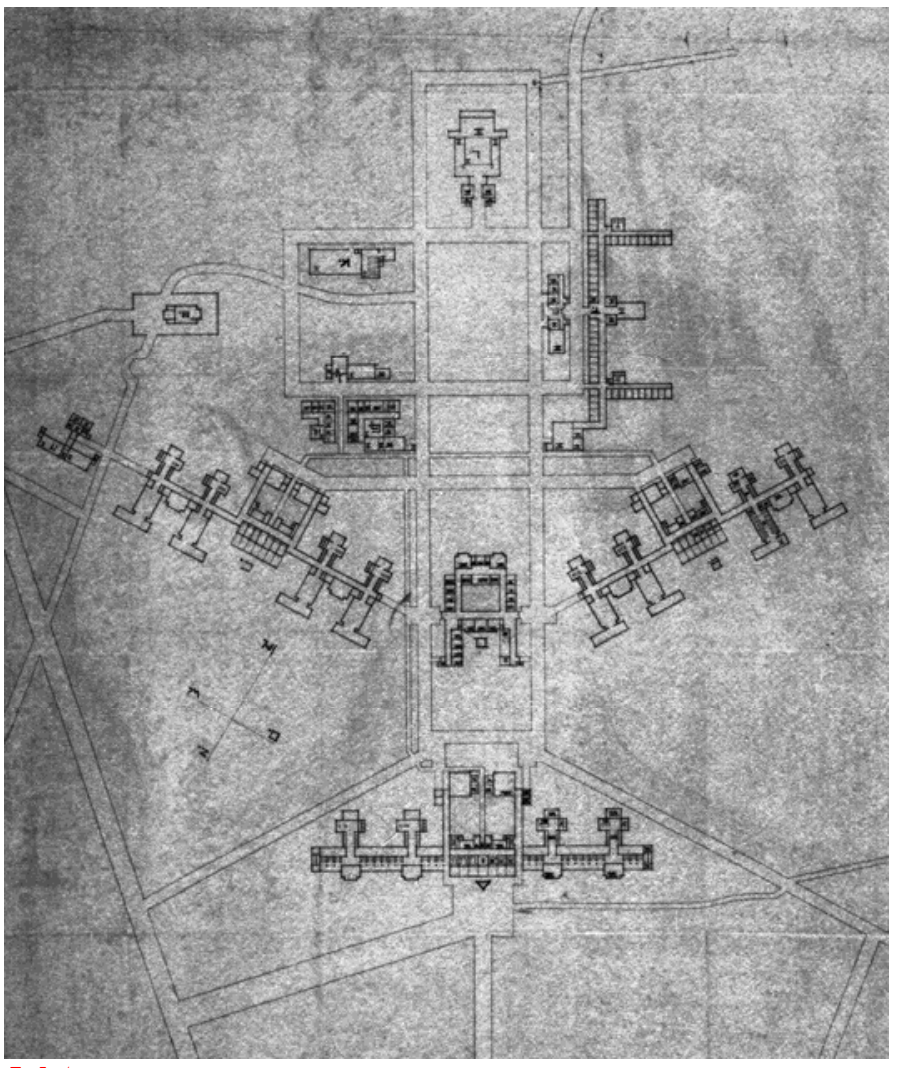

5.14

5.13 J. Duiker y B. Bijvoet. Primera propuesta para el Sanatorio de Zonnestraal ca. 1919. Croquis de planta.

5.14 J. Duiker y B. Bijvoet. Primera propuesta para el Sanatorio de Zonnestraal ca. 1919. Planta e $1: 100$. 
habitaciones desplazado del eje y paralelo al mismo organizado en peine, y varias construcciones anejas de menor tamaño.

Aun desconociendo el uso de las edificaciones, dada la escasa documentación existente, parece que el edificio principal sigue grosso modo el modelo tradicional de sanatorio en $T$, y está constituido por dos frentes diferenciados. El frente meridional orientado al sureste con las habitaciones abiertas a las galerías de cura comunes, en el que excepcionalmente se intercalan las salas de estar o de reunión, una cada 25 camas aproximadamente, y el frente norte, con los servicios higiénicos y otras dependencias comunes contenidos en varios "martillos" transversales en forma asimilable a la de una cruz griega y enfrentadas a las salas de estar. En el cuerpo central del bloque se sitúa una serie de estancias, con galerías de cura independientes, que deben destinarse a los enfermos más graves.

Es probable que este edificio fuera un sanatorio masculino y que los siguientes girados fueran sanatorios femeninos e infantiles ${ }^{17}$, los cuales mantienen una composición muy similar a la del edificio principal, con el mismo cuerpo central y dos alas laterales simétricas. En este caso, cada ala hacia el sur no está constituida por una hilera de habitaciones continua, sino por dos pabellones transversales con capacidad para unas 10 camas cada uno, rematados por una galería de cura común. Además los pabellones se conectan entre sí por un corredor junto al que se incorpora la sala de estar. Hacia el norte se repiten los mismos "martillos" frente a los pabellones conteniendo los servicios higiénicos y estancias comunes descritos en el edificio principal.

La manera de organizar el conjunto de edificios en torno a un eje longitudinal y la forma de los supuestos sanatorios femenino e infantil, constituidos por la agrupación de pabellones conectados entre sí, recuerdan, como describe Jan Molema, al proyecto norteamericano de la Colonia Tuberculosa Cook Country Infirmary de Oak Forest de los arquitectos Holabird y Roche, Richard E. Schmidt, Garden y Martin [fig. 5.15], publicado el 22 de junio de 1916 en el artículo "Amerikaansche Ziekenhuizen", "Hospitales Americanos", de la revista holandesa de arquitectura Vademecum der Bouwvakken, la cual es muy probable que Duiker y Bijvoet

\footnotetext{
17 Según Ton Idsinga, al principio se pensaba construir en Zonnestraal un gran complejo constituido por cuatro sanatorios uno para hombres, otro para mujeres, otro para niños y otro para pacientes quirúrgicos, además de una escuela al aire libre al sur de Zonnestraal, en Zonneheide. Ton IDSINGA, "In their own hands. A social and medical history of Zonnestraal", en Paul MEURS, MareThérèse VAN THOOR (ed.), Zonnestraal, the history and restoration of modern monument. NAi, Rotterdam 2010, p. 55.
} 


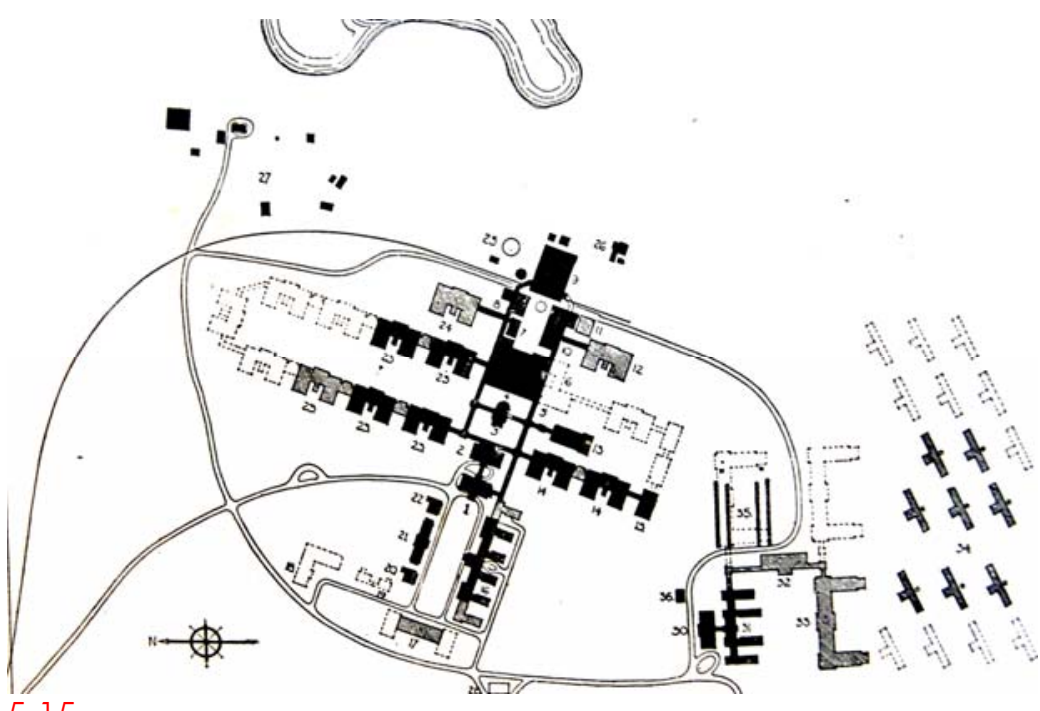

5.15
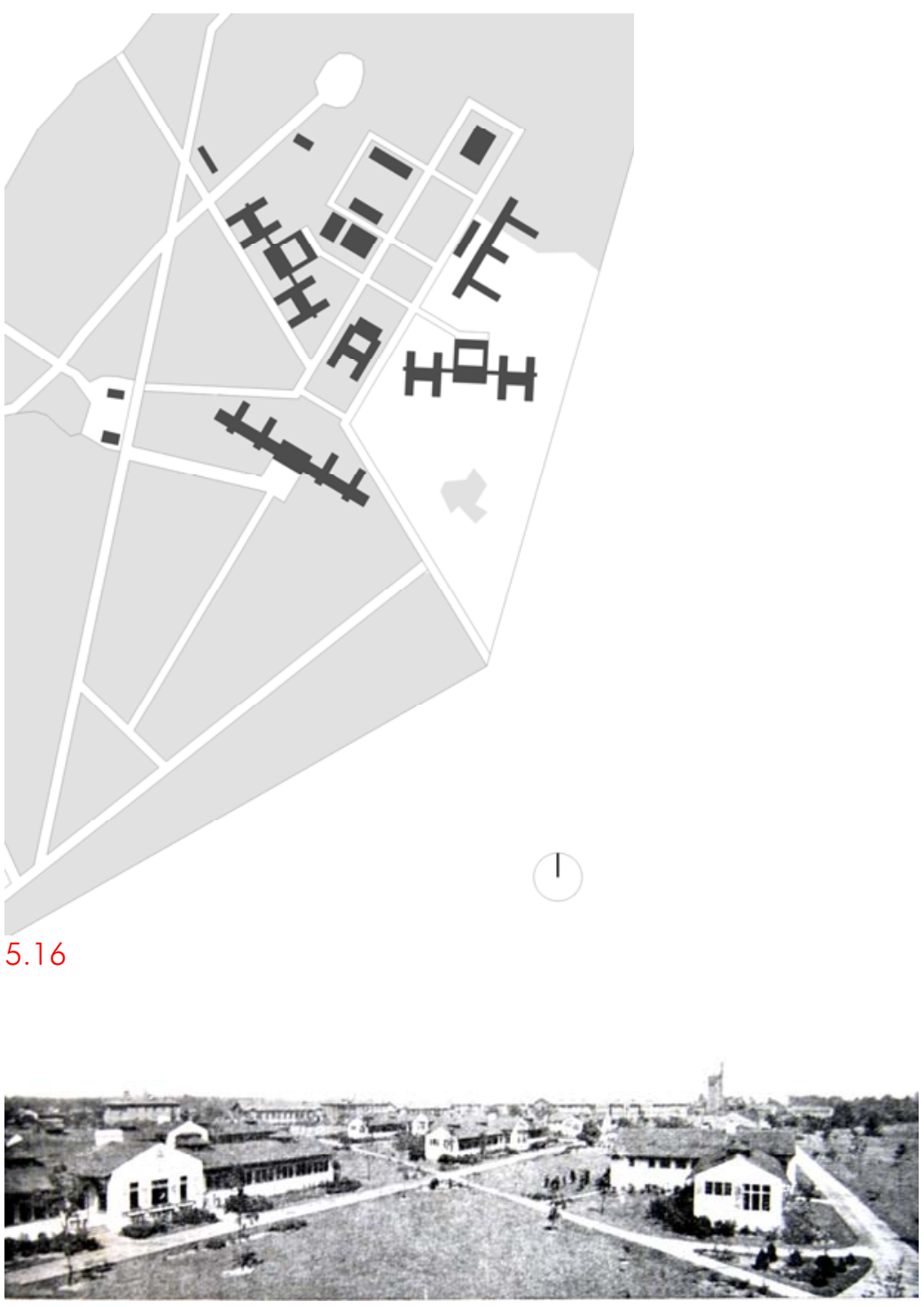

5.17

5.15 Holabird y Roche, Richard E. Schmidt, Garden y Martin. Cook Country Infirmary, Oak Forest, a. 1916. Planta de situación.

5.16 J. Duiker y B. Bijvoet. Primera propuesta para el Sanatorio de Zonnestraal ca. 1919. Croquis de planta.

5.17 W.A. Otis y E.H. Clarck .Colonia de enfermos de tuberculosis, Chicago, a. 1916 
conocieran y consultaran, según Molema ${ }^{18}$.

De hecho, el plano de esta primera propuesta parece una adaptación de la planta de la Colonia de Oak Forest a la finca de Zonnestraal, acoplándose al cruce de vías que se produce dentro de una zona parcialmente boscosa situada al este de la propiedad, junto a la avenida principal que conduce a la villa de Pampahoeve, posición que no coincide con la del proyecto definitivo [fig. 5.16]. La mayor diferencia existente entre ambos proyectos responde al giro de 30 grados que presentan ciertos edificios.

En el mismo artículo de la revista también se muestra otro sanatorio norteamericano formado por edificios girados entre sí, se trata de la Colonia de enfermos de tuberculosis de Chicago de los arquitectos W.A. Otis y E.H. Clarck [fig. 5.17]. Dada la presencia que en el croquis inicial de la propuesta cobra el trazado del camino oblicuo en el que se apoya uno de los edificios inclinados, los giros de 30 grados de dos de los bloques del sanatorio parecen obedecer más al interés por el soleamiento, la búsqueda de la orientación sur y suroeste respectivamente, y a la adaptación del conjunto a los trazados de los viales preexistentes, que a una cuestión formal.

Alrededor de 1920, Duiker, su esposa y el Dr. Ben Sajet, el médico que va a estar al frente del sanatorio, viajan al Reino Unido para visitar los sanatorios y colonias de convalecencia ingleses. Se desconoce el itinerario seguido en el viaje pero, a juzgar por la arquitectura descrita en la propuesta que considero que corresponde con la segunda realizada del sanatorio de Zonnestraal ${ }^{19}$, designada por Duiker y Bijvoet como Hulpsanatorium Zonnestraal, Sanatorio de ayuda o de convalecencia de Zonnestraal [fig. 5.18 y fig. 5.19], resulta fácil pensar que visitaron el Sanatorio de King Edward VII en Sussex, construido en 1906, uno de los primeros y más famosos de Inglaterra [fig. 5.20].

Se trata de un edificio compacto con planta simétrica con forma de doble $T$, conocida también como planta de mariposa, con un frente principal quebrado que consta de un tramo central recto y dos alas laterales ligeramente inclinadas. El sanatorio presenta una peculiar capilla al aire libre separada del edificio principal, que está constituida por dos

\footnotetext{
18 Jan MOLENA, "The Zonnestraal comisión", en Paul MEURS Mare-Thérèse VAN THOOR (ed.) Zonnestraal, the history and restoration of modern monument. NAi, Rotterdam 2010, pp. 62-66.

19 Esta propuesta del sanatorio está considerada por algunos autores como la cuarta, según la descripción de Wessel de Jonge en el libro Duiker Bouwkundig Ingenieur. Constructeur in stuc en staal (1982), donde se data alrededor de 1924, la misma fecha que le otorga Ton Idsinga en su libro Zonnestraal, Een nieuwe tijd lag in het verschiet (1986). Sin embargo, en los libros de Ronald Zoetbrood, Jan Duiker en het sanatorium Zonnestraal (1984), y Zonnestraal, the history and restoration of modern monument (2010) el proyecto aparece datado en torno a1920, tal y como hemos considerado en este texto.
} 


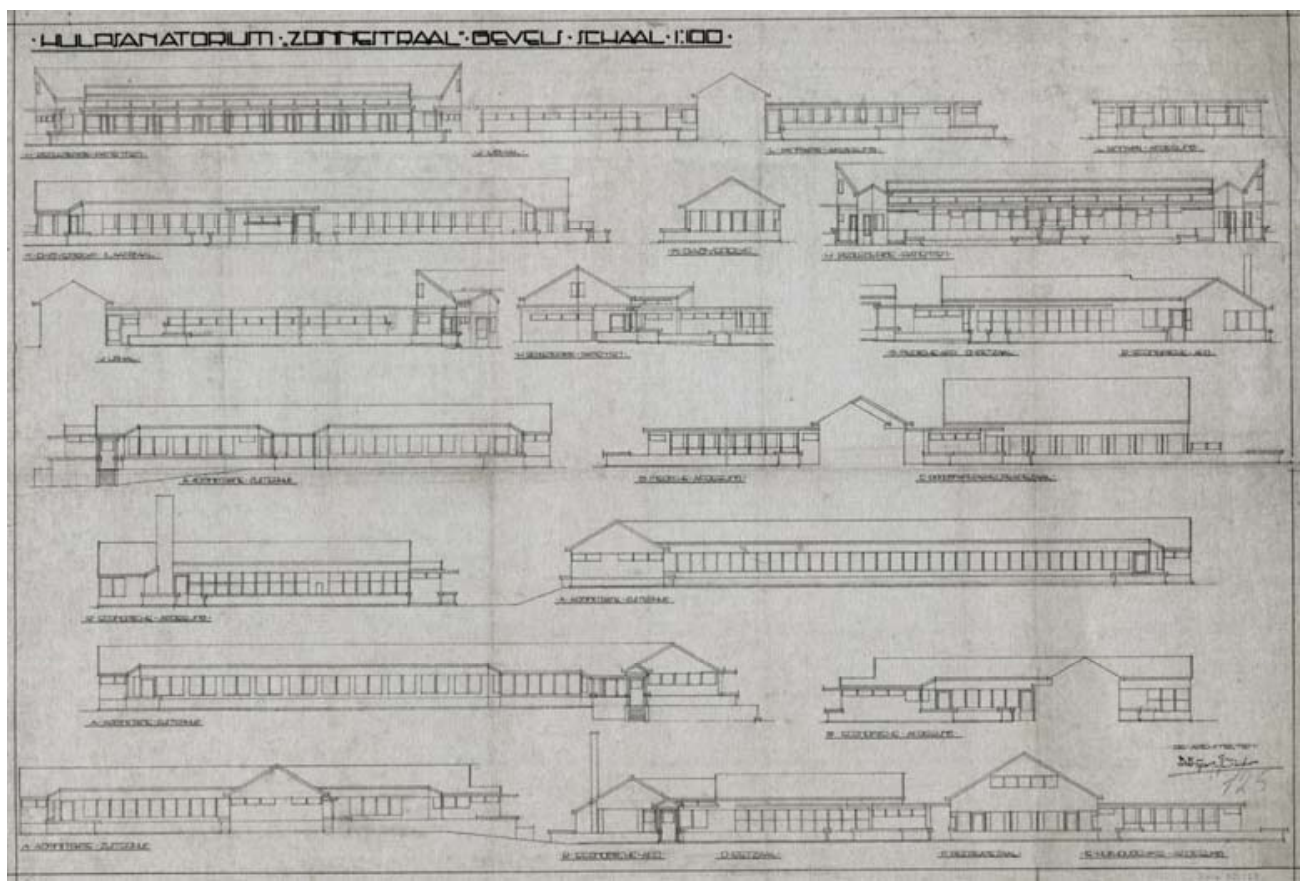

5.17

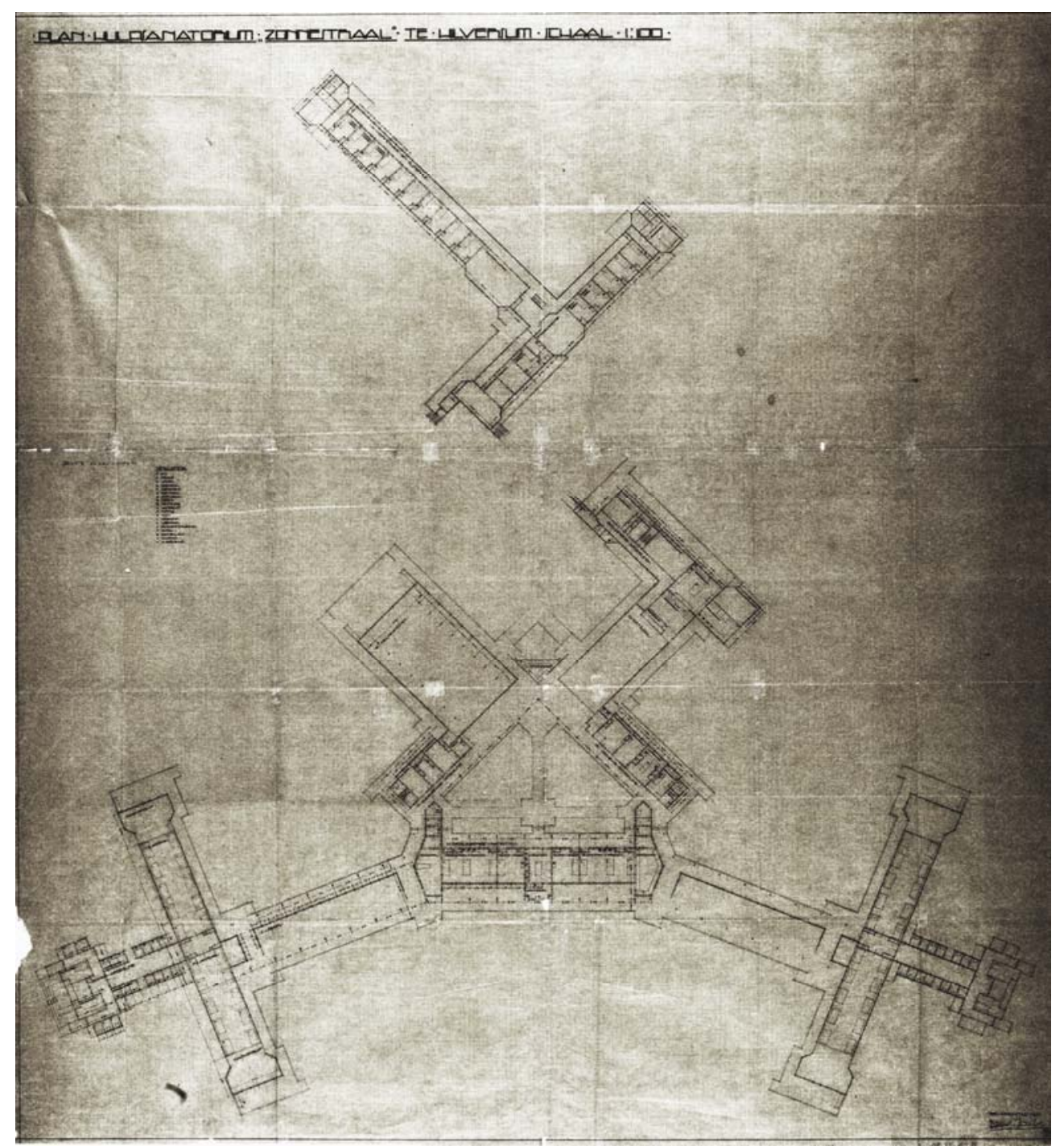

5.18

5.17 J. Duiker y B. Bijvoet. Sanatorio de Zonnestraal. Segunda propuesta, ca. 1920. Alzados. 5.18 J. Duiker y B. Bijvoet. Sanatorio de Zonnestraal. Segunda propuesta, ca. 1920. Planta. 
naves ortogonales entre sí, giradas 45 grados con respecto al sanatorio.

Esta segunda propuesta de Duiker y Bijboet de la que se conoce la planta y los alzados pero no la ubicación, aunque presumiblemente coincide con la del edificio principal de la propuesta anterior, muestra una considerable similitud con el Sanatorio King Edward VII e indica su datación posterior al viaje a Reino Unido, mientras que la primera propuesta previa a ésta, por su diferencia con los sanatorios ingleses, se dataría antes de 1920.

En ella el sanatorio consiste en un único edificio principal al sur y otro menor adyacente al norte. El primero, compacto y casi simétrico, con su fachada principal facetada orientada al mediodía, es un bloque lineal articulado en tres tramos, uno central recto y dos laterales oblicuos atravesados perpendicularmente por dos cuerpos rectangulares que contienen las habitaciones de enfermos. Como su predecesor, el tramo central alberga a los enfermos graves, flanqueado por los tramos oblicuos con las galerías de cura y los servicios higiénicos separados por los cuerpos de habitaciones. Cada uno contiene veinte camas de enfermos, repartidas en dos salas de diez camas en cuyos extremos se incluye un espacio común de reunión con un gran porche.

Adosados a la espalda del bloque por su parte central se instalan dos cuerpos perpendiculares entre sí y girados 45 grados que generan un patio triangular, cuya posición recuerda a la capilla del Sanatorio King Edward VII. A ellos se acoplan perpendicularmente los servicios médicos contenidos en un volumen en $L$ y un gran comedor rectangular.

Separado del Sanatorio se encuentra un edificio con planta en T, para la administración y las estancias del personal, girado también 45 grados respecto al edificio principal.

La solución adoptada, de mantener la misma ubicación que las propuestas anteriores, resulta bastante ilógica desde el punto de vista clínico, ya que las habitaciones de los enfermos pierden la orientación sur y pasan a estar abiertas hacia el este y el oeste. La propuesta más bien parece ser fruto del esfuerzo por conseguir una forma predeterminada que el resultado de una reflexión sobre las necesidades del programa [fig. 5.21].

Ésta no es tampoco la propuesta definitiva, ya que la crisis mundial de 1920 afecta también al sector del diamante y paraliza por completo la búsqueda de la adecuada organización. La difícil situación provoca que la finca de Zonnestraal pase a convertirse en un lugar de empleo de los trabajadores del diamante desocupados, que se encargan de su cuidado y explotación. Con tal fin Duiker y Bijvoet proyectan y construyen una serie de edificaciones 


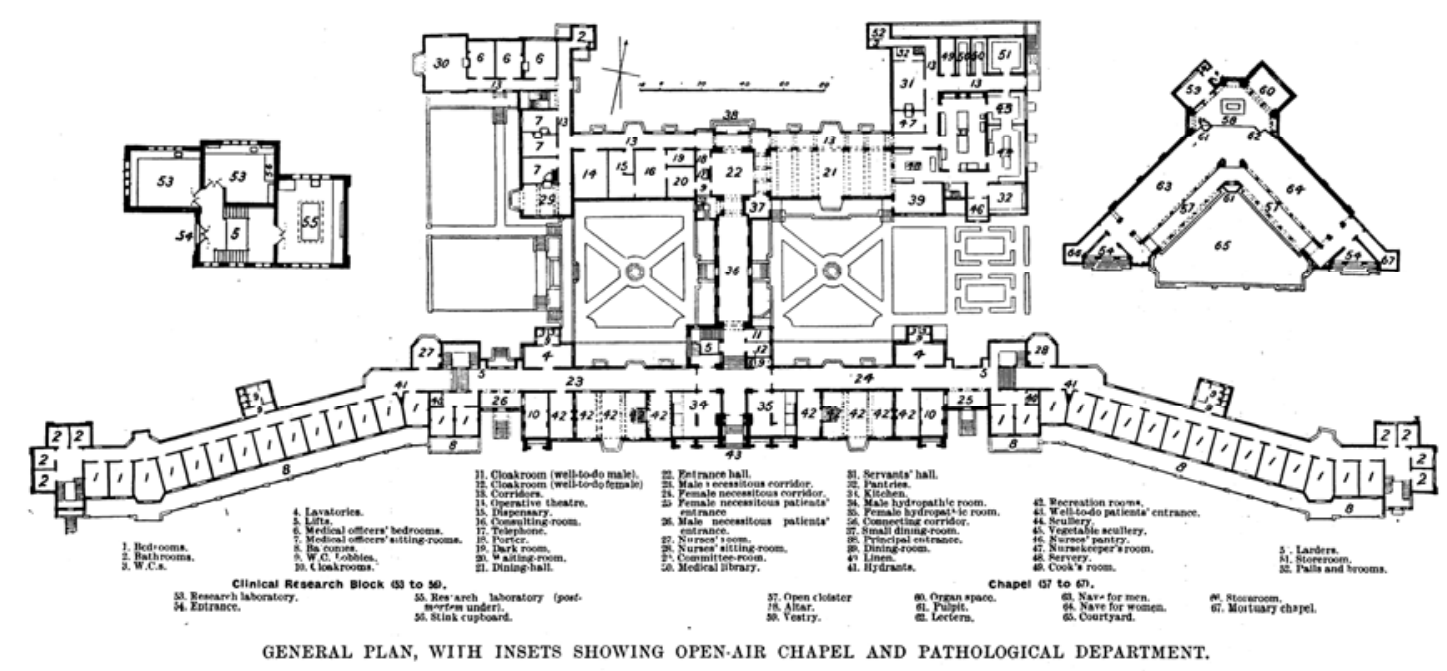

5.19

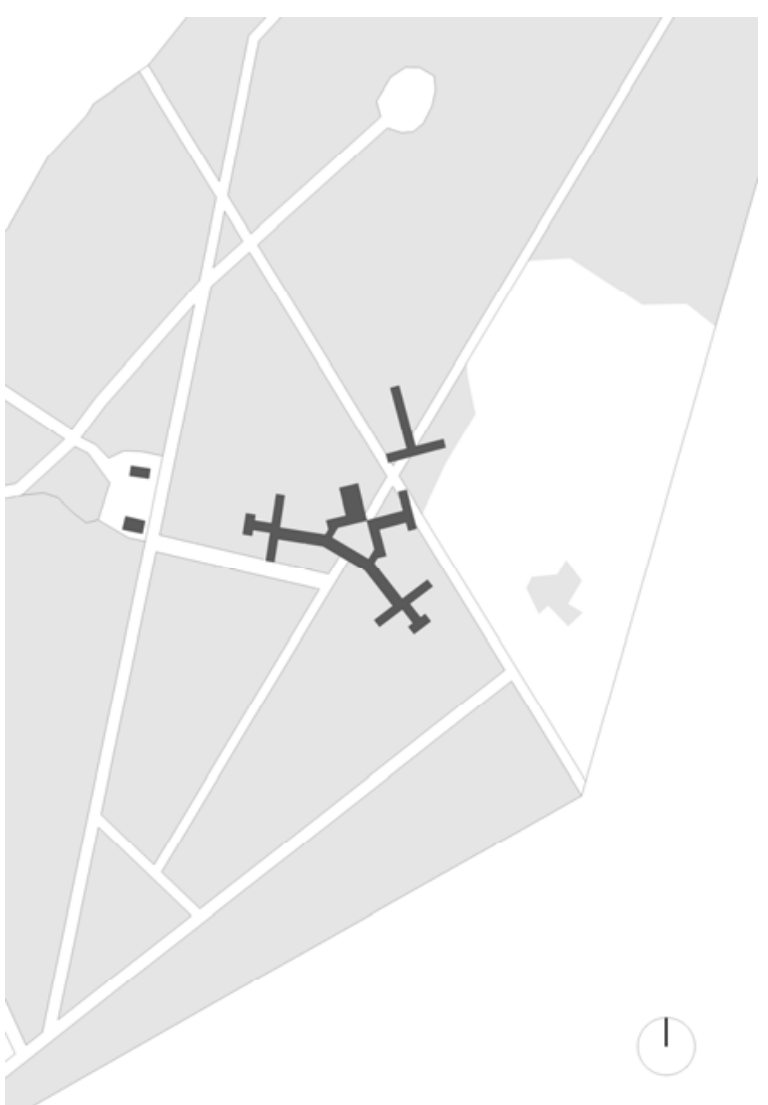

5.20

5.19 Sanatorio King Edward VII, Sussex, 1906. Planta general.

5.20 J. Duiker y B. Bijvoet. Sanatorio de Zonnestraal. Segunda propuesta, ca. 1920. Plano de la supuesta situación (dibujo de la autora). 

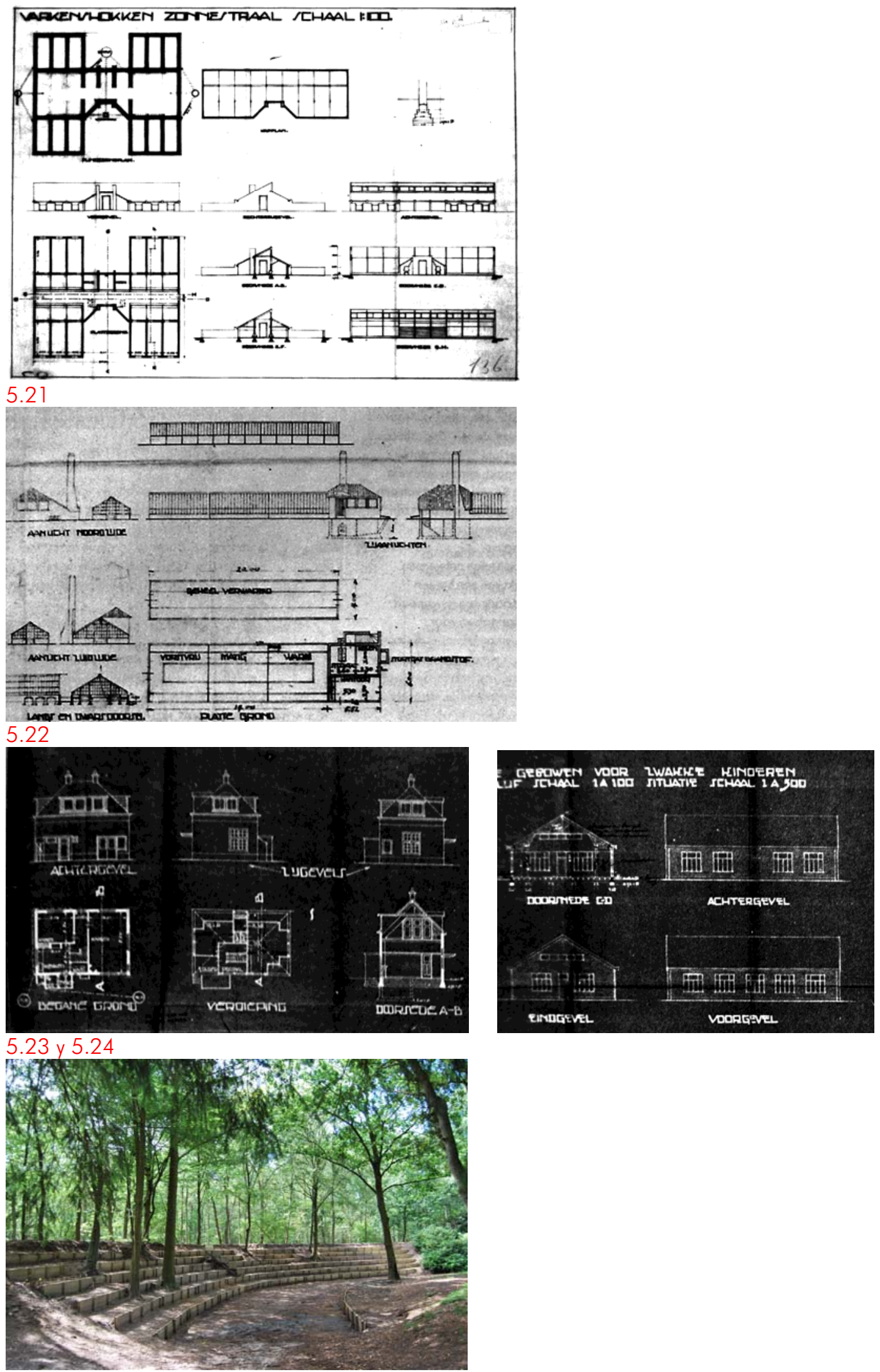

5.25

5.21 J. Duiker y B. Bijvoet. Sanatorio de Zonnestraal, ca. 1919. Porquerizas.

5.22 J. Duiker y B. Bijvoet. Sanatorio de Zonnestraal, ca. 1920. Vivero.

5.23 J. Duiker y B. Biivoet. Sanatorio de Zonnestraal, ca. 1920. Reforma de la casa del portero

5.24 J. Duiker y B. Bijvoet. Sanatorio de Zonnestraal, ca. 1920. Refugio temporal para niños.

5.25 J. Duiker y B. Bijvoet. Sanatorio de Zonnestraal, 1921-1922.Teatro al aire libre (fotografía de la autora). 


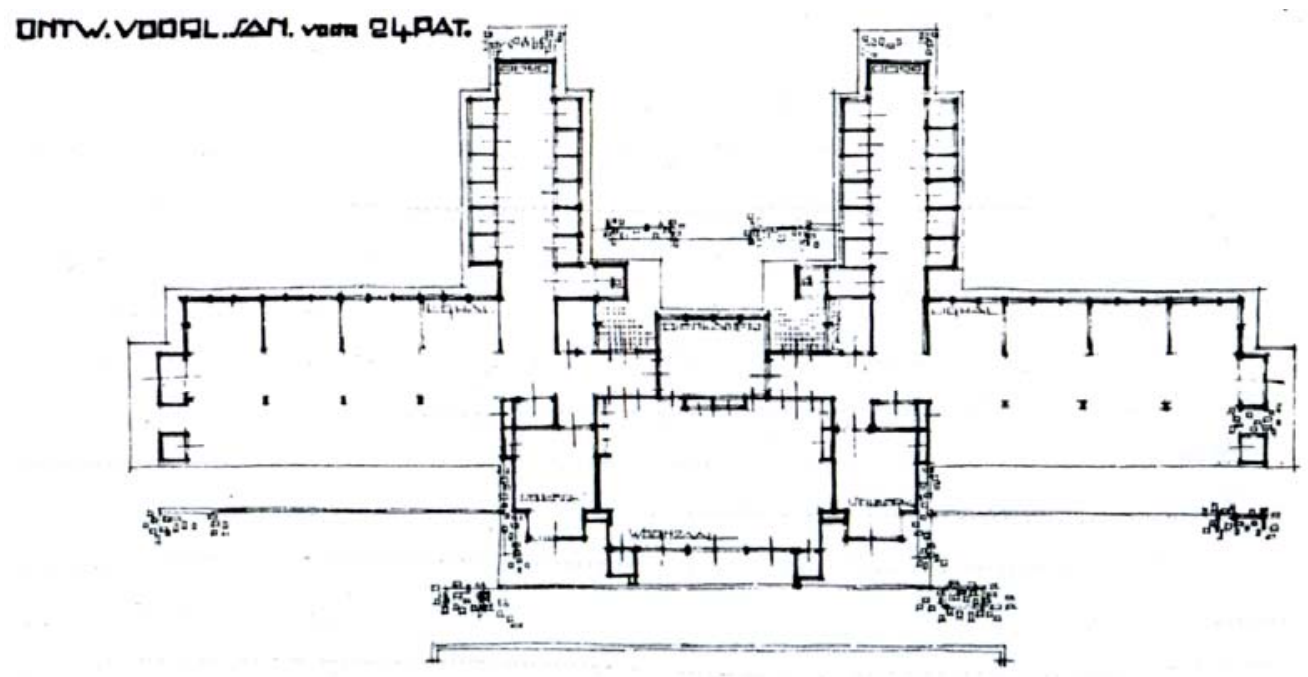

DLMAITEEW.K.J.F. "NIEUWE-LEVETKRDALUT"

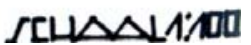
5.26
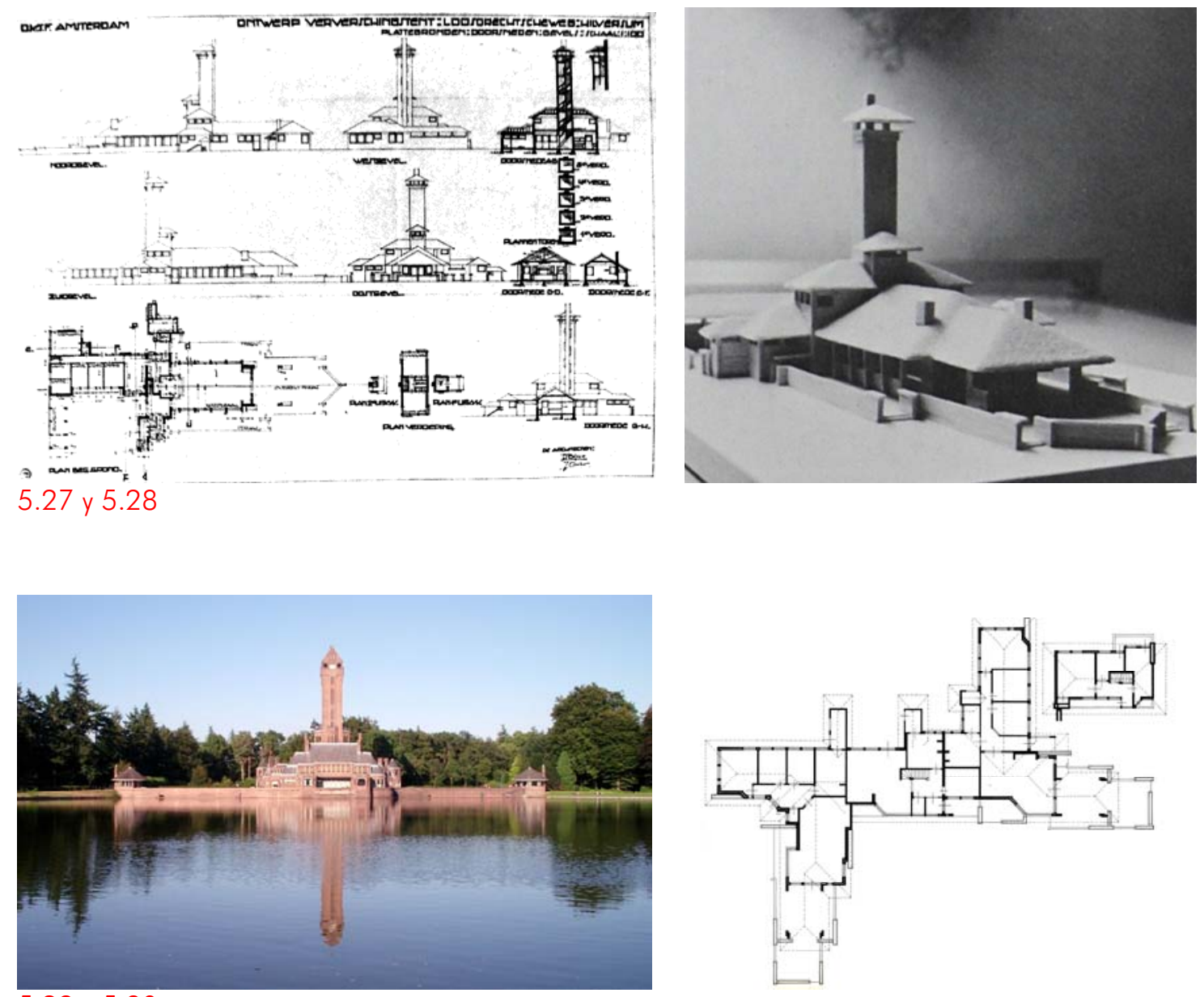

5.29 y 5.30

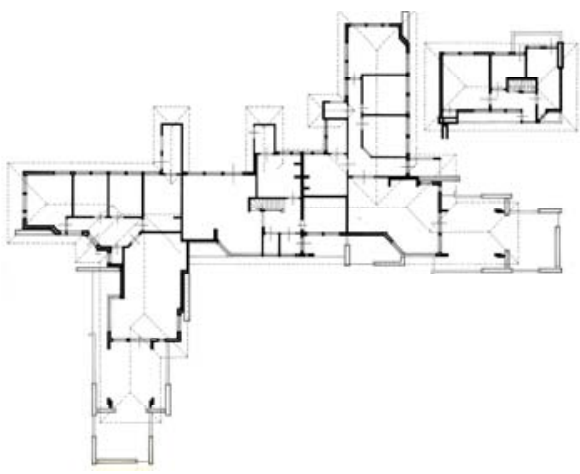

5.26 J. Duiker y B. Bijvoet. Sanatorio de Zonnestraal. Tercera propuesta ca. 1921.

5.27 J. Duiker y B. Bijvoet. Sanatorio de Zonnestraal, ca.1921. Pabellón de refrescos.

5.28 J. Duiker y B. Bijvoet. Sanatorio de Zonnestraal, ca.1921. Pabellón de refrescos. Maqueta

5.29 H.P. Berlage. Pabellón de caza Hubertus, Otterlo, 1914.

5.30 J. Duiker y B. Bijvoet. Vivienda urbanización Kijkduin, La Haya, 1921-1923. 
menores orientadas a la explotación agrícola y pecuaria: porquerizas [fig. 5.22], casetas con paneles para la apicultura y un vivero [fig. 5.23], entre otros. También remodelan la casa del portero [fig. 5.24], y proyectan un pequeño refugio temporal para unos 20 niños enfermos de tuberculosis [fig. 5.25], aunque no consta con seguridad que se llegara a construir ${ }^{20}$.

Los trabajadores del diamante son empleados en la construcción de un jardín terapéutico, dentro de una red de caminos en forma de tela de araña que, con su diversidad, trata de evitar la monotonía que puede provocar a los enfermos el paseo reiterado por un único recorrido. Estos caminos se enlazan con los del exótico jardín preexistente en Pampahoeve. Dentro del jardín terapéutico se incluye un teatro al aire libre realizado entre 1921 y 1922, con asientos escalonados de tierra compactada contenida por tablazones [fig. 5.26].

Es probable que en esta época, en torno a 1921 Duiker y Bijvoet realicen otro proyecto de sanatorio con capacidad para tan sólo 24 pacientes tuberculosos, del que sólo se conoce una planta, y es muy similar a las propuestas anteriores ${ }^{21}$. Se trata de un edificio simétrico que consta de un bloque lineal de estancias abiertas y galerías de cura, en cuyo centro se incrusta la sala de reunión común acristalada, y un par de habitaciones para los enfermos graves ubicados a ambos lados de ésta, todo orientado al sur; en la parte norte se disponen los servicios higiénicos, contenidos en dos "martillos" perpendiculares e idénticos [fig. 5.26]. Lamentablemente este pequeño sanatorio tampoco llega a ser construido, lo mismo que el coetáneo proyecto para el majestuoso pabellón de refrescos diseñado por Duiker y Bijvoet [fig. 5.27 y fig. 5.28], cuyo alzado con la torre recuerda al pabellón de caza Hubertus (1914) de Berlage, para el matrimonio Kröller-Müller [fig. 5.29]; sin embargo, su planta se acerca más a las de las viviendas para la urbanización Kijkduin (1921-1923) de los mismos arquitectos, por la organización ortogonal cruciforme, los porches y aleros en vuelo [fig. 5.30], características más propias de la arquitectura de Wright.

\footnotetext{
${ }^{20}$ Según aparece descrito en el libro Zonnestraal, the history and restoration of modern monument, se proyectan sanatorios provisionales para niños que no llegan nunca a construirse. Mientras que en el libro, Duiker arquitecto de una nueva era, se menciona que probablemente la obra se realiza pero fue derribada a los 5 años. Ver: Paul MEURS, Mare-Thérèse VAN THOOR (ed.), Zonnestraal, the history and restoration of modern monument. NAi, Rotterdam, 2010, p.79; MOLEMA Jan, Duiker, arquitecto de una nueva era, constructor en estuco y acero. Equipo de trabajo Duiker, TH Delft, Delft, 1986, p. 15.

${ }^{21}$ Este proyecto está recogido en el artículo de Wessel de Jonge en Duiker Bouwkundig Ingenieur (1982) se define como el tercer proyecto, y está fechado en torno a 1921. En el plano aparece una inscripción "Nieuwe levens kracht", "Nueva fuerza de vida". Wessel de JONGE "Sanatorium 'Zonnestraal', Hilversum" en MOLEMA Jan, J. Duiker bouwkundig ingenieur. Constructeur in stuc en staal. Stichting Bouw, Rotterdam, 1982, p.95.
} 


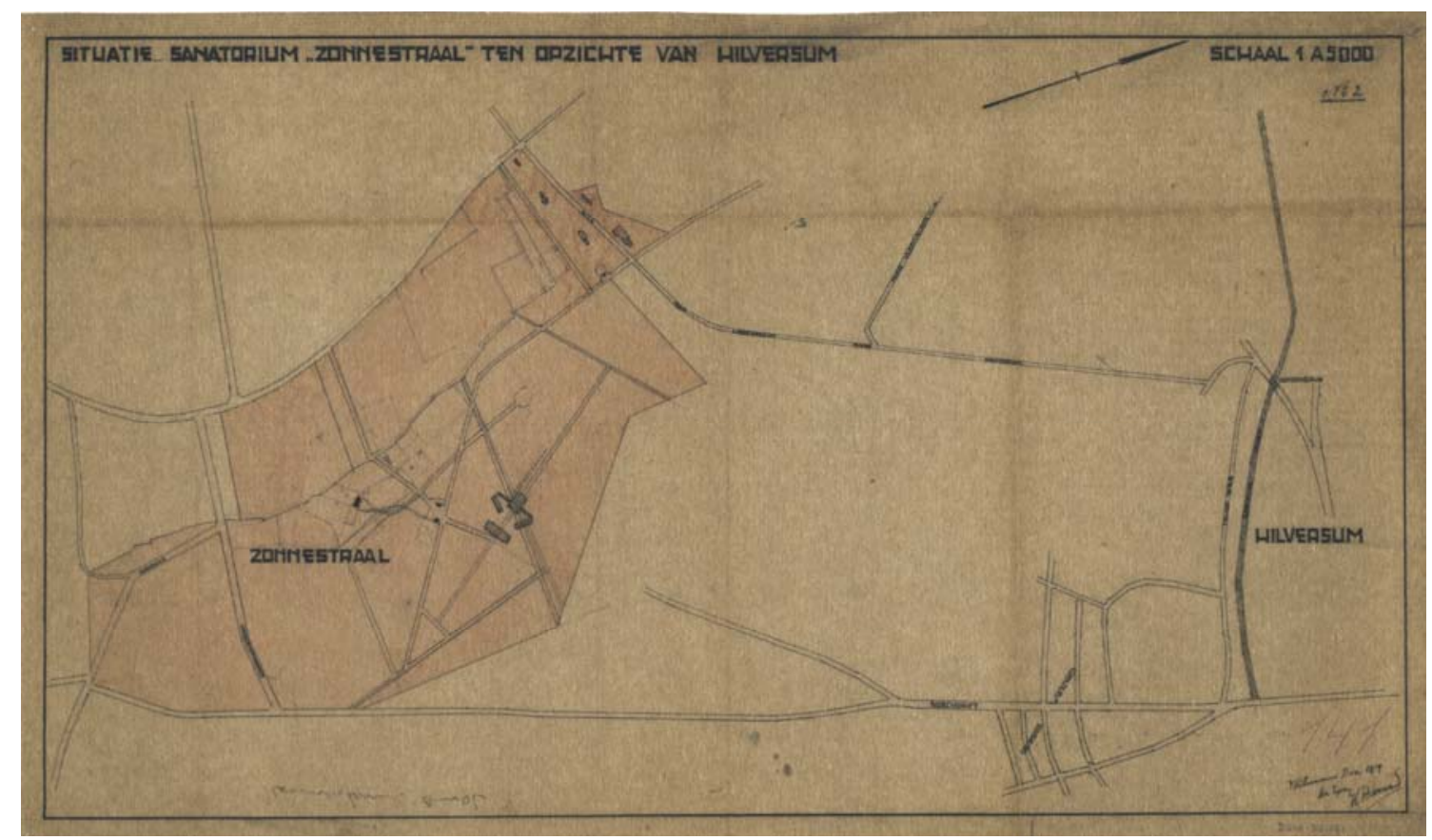

5.31
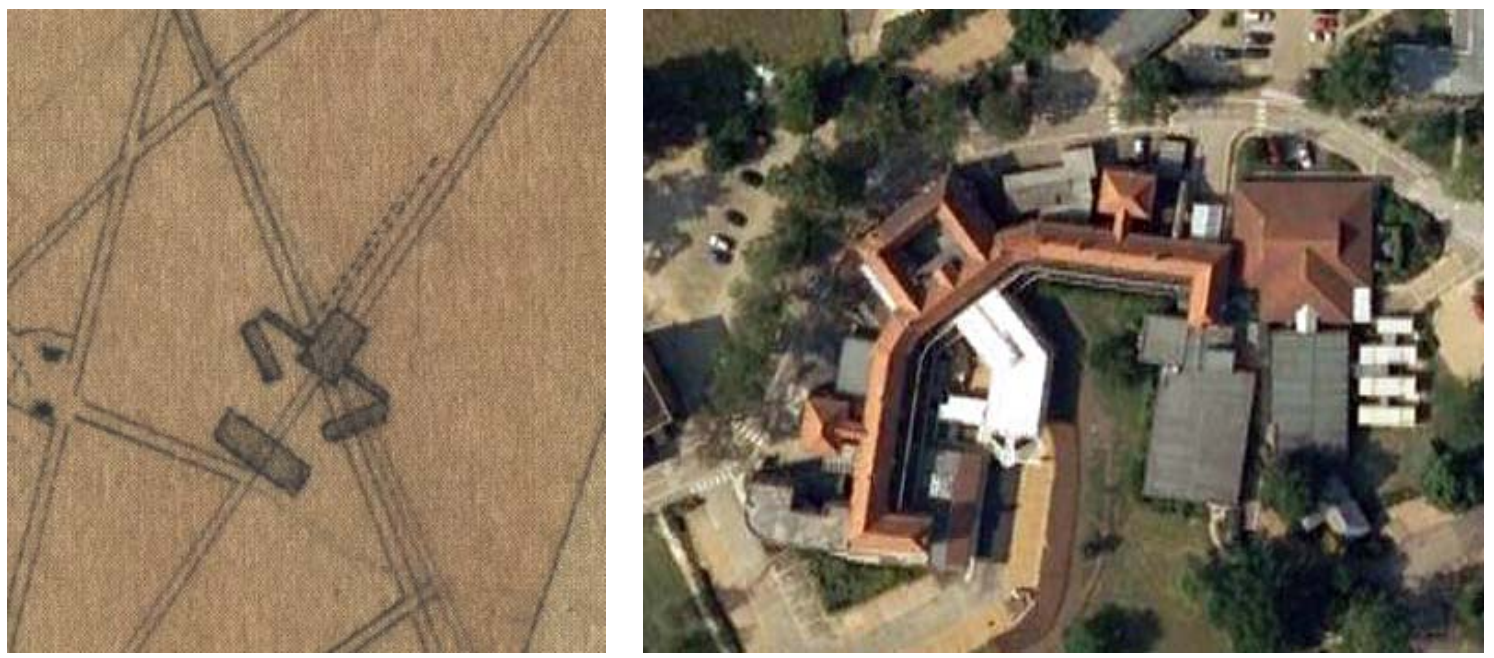

5.32 y 5.33
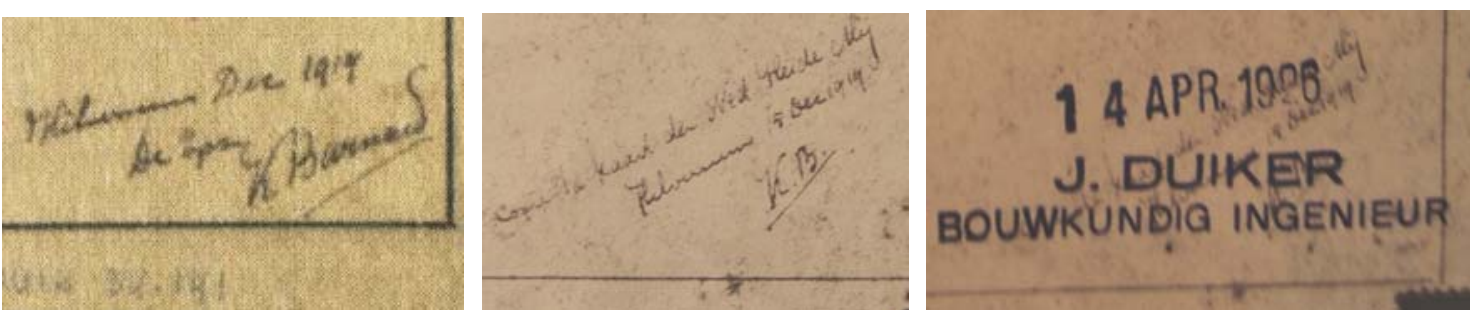

$5.34,5.35$ y 5.36

5.31 J. Duiker y B. Bijvoet. Sanatorio de Zonnestraal. Cuarta propuesta, ca. 1924. Planta de situación.

5.32 J. Duiker y B. Bijvoet. Sanatorio de Zonnestraal. Cuarta propuesta, ca. 1924.

5.33 Sanatorio de Papworth. Hospitales.

5.34 Firma del capataz K. Barnard del plano de la Cuarta propuesta.

5.35 y 5.36 Firma del capataz K. Barnard en varios planos del Sanatorio de Zonnestraal (Caja 40,

Carpeta 401926 1927, IISG). 
Una ligera reactivación económica experimentada en 1923 por el sector del diamante, alienta a la Fundación de los Fondos de los Manguitos de Cobre -KSF- a la creación de una nueva comisión para la construcción del sanatorio; constituida por varios médicos de la Cruz Roja holandesa, entre otros su director el Dr. H.C. Dresselhuys, ya que esta organización participa muy activamente en la definición del proyecto. Con el nuevo comité se programa un segundo viaje al Reino Unido para visitar principalmente varias colonias de reinserción laboral ${ }^{22}$.

Una de ellas es la Colonia antituberculosa de Papworth en Cambridgeshire y, muy probablemente, el escocés Royal Victoria Hospital de Edimburgo ${ }^{23}$, la primera colonia europea de convalecencia ${ }^{24}$.

Tras el regreso del viaje Duiker escribe, en enero de 1924, una carta a los miembros de la comisión de la Cruz Roja con la idea de construir un sanatorio más compacto que los cottages o pabellones dispersos propios de las colonias de convalecencia inglesas. Su propuesta consiste en un edificio principal con los servicios comunes, comedores y cocinas, además de habitaciones para 40 pacientes, y de 3 edificios más de convalecencia. Cada uno albergaría a 20 pacientes, repartidos en dos grupos de diez habitaciones individuales, con una sala de reunión común. El recinto se completa con 3 ó 4 talleres y una docena de cabañas para la cura de reposo y aire libre ${ }^{25}$.

La descripción del sanatorio en la carta coincide con la reflejada en el plano fechado en diciembre 1919 [fig. 5.31 y fig. 5.32], que considero como la cuarta propuesta. Se trata de un plano de situación a escala 1:5.000 en el que aparecen dibujados un edificio principal de mayor tamaño y tres más longitudinales de dimensiones similares, implantados en el mismo lugar que la primera.

La disposición de los edificios guarda una estrecha relación con el Hospital de la Colonia de Papworth [fig. 5.33]. Ambos están constituidos por un cuerpo central prácticamente

${ }^{22}$ También participan el Dr. Sajet, Duiker y Bijvoet. Ton IDSINGA, "In their own hands. A social and medical history of Zonnestraal" en Paul MEURS, Mare-Thérèse VAN THOOR (ed.), Zonnestraal, the history and restoration of modern monument. NAi, Rotterdam 2010, p. 55.

${ }^{23}$ Gabrielle Milelli describe que entre 1920 y 1924 se realizaron dos viajes de estudio a Inglaterra y Escocia, pero sin especificar el momento de cada uno de ellos. Gabriele MILELLI, Zonnestraal. II sanatorio de Hilversum. Universale di architettura, Torino, 2000, p. 26.

${ }^{24}$ El Royal Victoria Hospital de Edimburgo es creado por Sir Robert Philip bajo las premisas de que: "(...) un trabajo exactamente dosificado, lejos de oponerse a la curación, podía útilmente secundarla", como recoge el British Medical Journal, el 23 de julio de 1898. Citado en: Robert WOLFSOHN, Las Villages de Tuberculeux en Angleterre (Papworth, Preston Hall, Barrowmore Hall), Thèse pour le doctorat en Médicine, Faculté de Médecine de Paris, Paris 1924, p.14.

${ }^{25}$ Wessel DE JONGE, Paul MEURS "The Zonnestraal Aftercare Colony. Design and Buildings" en Paul MEURS, Mare-Thérèse VAN THOOR (ed.), Zonnestraal, the history and restoration of modern monument. NAi, Rotterdam 2010, p. 79. 

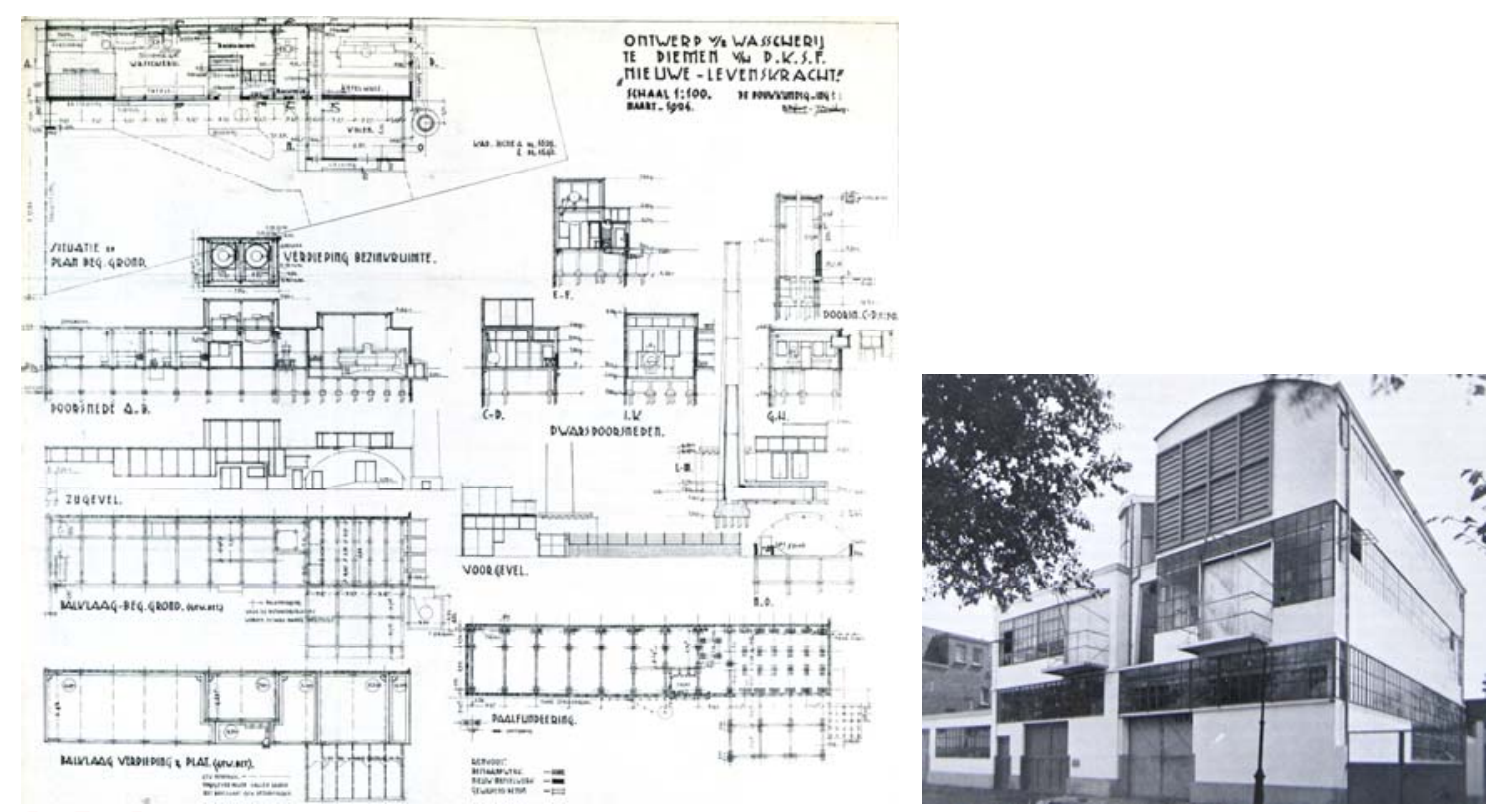

5.37 y 5.38
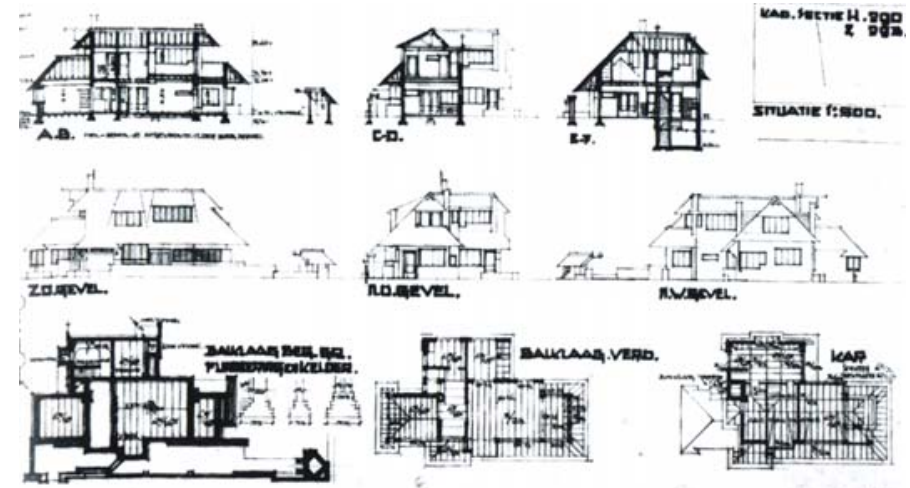

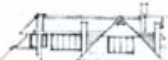

gever.

5.39 y 5.40
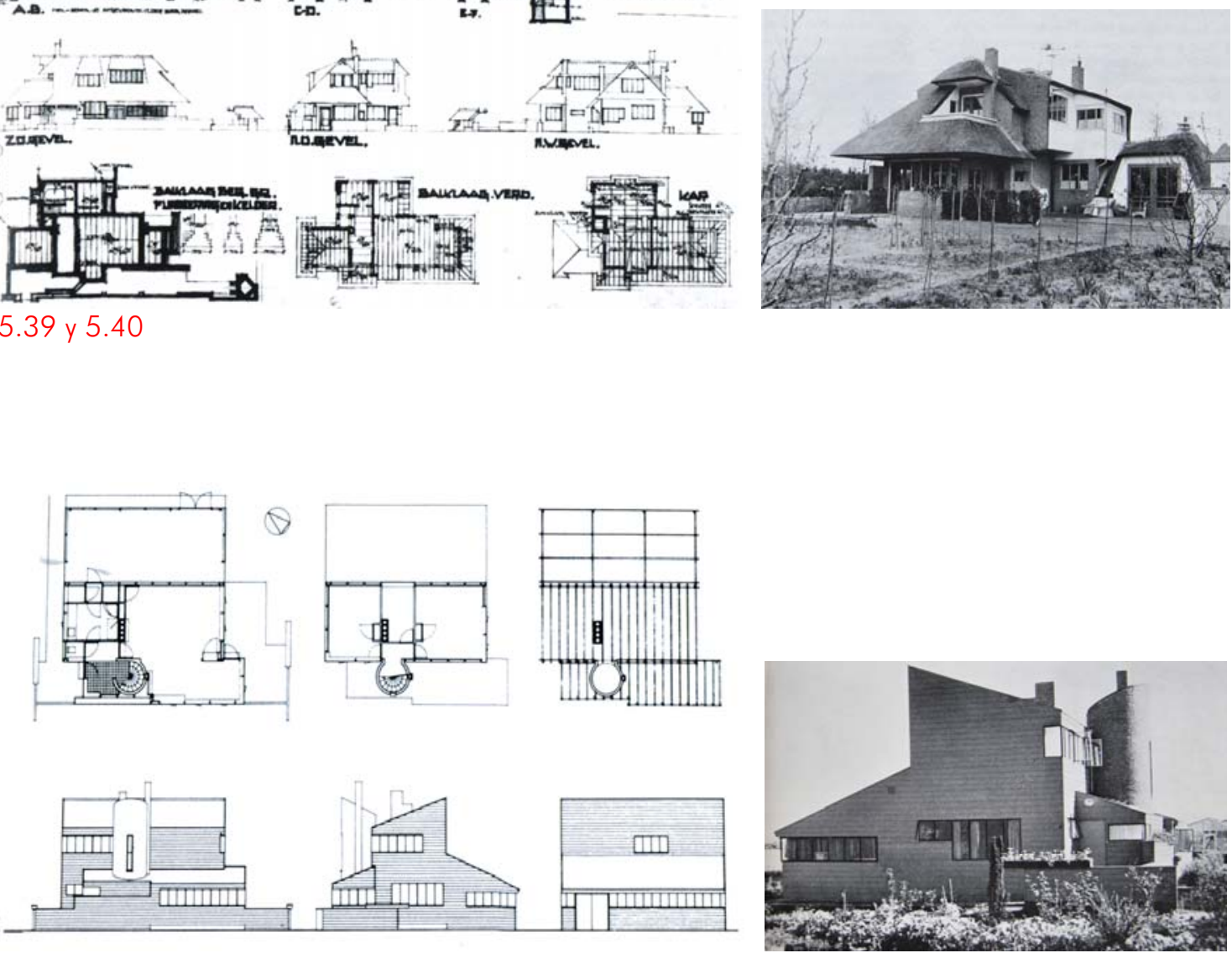

5.41 y 5.42

5.37 y 5.38 J. Duiker y B. Bijvoet. Lavandería del ANDB, Diemen, 1924-1925. Proyecto e imagen.

5.39 y 5.40 J. Duiker y B. Bijvoet. Villa Doelzicht en Hilversum, 1924. Proyecto e imagen.

5.41 y 5.42 J. Duiker y B. Bijvoet. Casa de un horticultor, Aalsmeer, 1924-1925. Proyecto e imagen. 
cuadrado flanqueado por dos brazos de habitaciones oblicuos. Sin embargo, en la propuesta de Duiker y Bijvoet los edificios residenciales de los laterales no se inclinan simétricamente formando ángulos obtusos iguales como en Papworth, de manera que las habitaciones se abran al sur y se miren entre sí y los corredores queden orientados al norte, sino que sus ángulos son agudos y los corredores son los que se miran entre sí y quedan orientados al norte, mientras las habitaciones se orientan al sur abriéndose hacia el paisaje.

Por la relación entre esta cuarta propuesta y Papworth, resulta lógico pensar que fue realizada después de visitar por segunda vez el Reino Unido y no en el año 1919, como consta en el plano. A ello se puede añadir otro argumento más. A lo largo de la investigación documental que he realizado en Amsterdam en los archivos del Internationaal Instituut voor Sociale Geschiedenis -IISG-, Instituto Internacional de Historia Social pude comprobar que existen varios planos originales de Zonnestraal con la misma fecha 1919 y la misma firma, distintas a la de Duiker y Bijvoet, que contienen el diseño de la parcela de base y que posteriormente han sido modificados [fig. 5.35 y fig. 5.36]. Están fechados el 15 de diciembre de 1919 y firmados tan sólo con las iniciales del autor "K. B.", que corresponden al capataz K. Barnard, escritas con el mismo trazo que en el plano de la propuesta [fig. 5.34]. En uno de ellos, sobre la firma y fecha preexistente, se estampa un sello con otra fecha "14 de abril de 1926" y otra inscripción, "J. Duiker Bouwkundig Ingenieur" [fig. 5.36]. Este procedimiento puede explicar por qué en el plano de 1919 la propuesta descrita no corresponde con la fecha sino con una posterior, ya que el levantamiento base del entorno pudo ser realizado en ese momento y sobre él, alrededor de 1924, haberse redibujado la cuarta propuesta ${ }^{26}$.

En ese mismo año 1924, Duiker y Bijvoet reciben otros dos encargos también del sindicato del diamante ANDB. En marzo llega el primero para la construcción de una lavandería en Diemen [fig. 5.37 y fig. 5.38], con el cometido de extraer el polvo de diamante de los uniformes de los empleados, pues el dinero obtenido con su venta va destinado una parte al fondo de pensiones del sindicato ANDB y la otra a la Fundación KSF ${ }^{27}$. La lavandería se aloja en un edificio industrial preexistente que se intenta conservar para abaratar costes.

\footnotetext{
${ }^{26}$ En varios documentos consultados en el IISG de Ámsterdam, se aprecia cómo Duiker y Bijvoet suelen utilizar planos de base sobre los que se borra parte y dibujaban encima, o sobre los que se pegan textos y luego reproducen, generando así nuevos documentos. Los diversos planos con fecha 15 de Diciembre de 1919, son reproducciones de una misma base que han sido pintados, al parecer en torno a 1926, con acuarelas de colores para identificar la leyenda.

${ }^{27}$ Jan MOLEMA, Duiker, arquitecto de una nueva era. TH Delft, Delft 1985, p. 54.
} 
Plantean una estructura de pilares de hormigón perfectamente modulada ${ }^{28}$ y una fachada ligera, como consecuencia de un necesario refuerzo estructural provocado por el peso de las máquinas de lavado y el aumento de altura de los forjados en algunas zonas. La estructura perimetral de pilares a unos 50 centímetros de separación aligera los cerramientos que dejan de tener función resistente. Además, la estructura reduce la sección de las vigas y ahorra material, al compensar con el vuelo de ellas sus momentos flectores. La solución estructural hace posible mantener el cerramiento preexistente de ladrillo en ciertas zonas y suplementarlo con otro más ligero que contiene grandes huecos para la carga y descarga de la ropa, y ventanales corridos. Duiker y Bijvoet experimentan en esta obra con los métodos constructivos y compositivos que después utilizan en Zonnestraal, incluso se atreven a pintar el edificio de blanco con las carpinterías metálicas en azul29.

Como compensación al tiempo y al esfuerzo invertido en la incesante búsqueda de la correcta organización del Sanatorio, en septiembre les llega el segundo encargo de la mano de Jan van Zutphen con la villa Doelzicht en Hilversum [fig. 5.39 y fig.5.40], una casa pabellón para su esposa, la señora B. J. Greger de Van Zutphen. Aunque conocen sobradamente los nuevos sistemas constructivos, los arquitectos optan por una residencia tradicional con una pronunciada cubierta vegetal inclinada, que recuerda a la de la villa inglesa de Pampahoeve, y una geometría compleja e irregular, opuesta a la estricta modulación de la lavandería en Diemen. Sin embargo, en ella se observan ciertas apuestas experimentales al combinar frentes pintados de blanco con muros de ladrillo visto y al disponer las ventanas en función de las necesidades interiores de la vivienda, como ya emplearon ese mismo año en la casa de un horticultor de Aalsmeer [fig. 5.41 y fig. 5.42], rompiendo así con el estricto orden horizontal presente en otros proyectos suyos ${ }^{30}$.

\section{ALTERACIONES CONCEPTUALES DEL TIPO: EL PROYECTO DE ZONNESTRAAL}

Por fin en 1925, la Cruz Roja nacional proporciona financiación suficiente para avanzar en el proyecto del Sanatorio de Zonnestraal. El 16 de septiembre se crea la Asociación Holandesa para la creación de Colonias Laborales destinada a pacientes con tuberculosis, a la que se adscribirá Zonnestraal cuando deje de ser un centro exclusivo para el sector del

\footnotetext{
${ }^{28}$ Duiker y Bijvoet, junto a Wiebenga, ya han planteado anteriormente una estructura de hormigón en su proyecto para la Academia de las Artes Plásticas de Ámsterdam.

${ }^{29}$ La lavandería de Diemen que fue terminada en el año 1925, experimentó una gran cantidad de reformas, hasta su demolición durante la Segunda Guerra Mundial.

${ }^{30}$ La villa Doelzicht desapareció tras un bombardeo durante la Segunda Guerra Mundial.
} 
diamante y se convierta en un sanatorio general; la asociación poco después se llamará Zonnestraal y estará presidida por Jan van Zutphen ${ }^{31}$. Se reanudan así las deliberaciones de la comisión médica sobre el modelo de sanatorio a seguir y la adecuación de los proyectos realizados hasta la fecha.

Duiker y Bijvoet se separan este mismo año y el primero traslada el estudio a Ámsterdam, una vez que Bijvoet se instala en París para trabajar con Pierre Chareau ${ }^{32}$ en la construcción de la casa estudio del Dr. Dalsace conocida como Maison de verre ${ }^{33}$.

Es precisamente durante este período temporal, entre1925 y 1926, cuando se fragua el proyecto definitivo del Sanatorio, momento en el que Bernard Bijvoet vive en París y en el que Duiker empieza a colaborar con el ingeniero civil Jan Gerko Wiebenga ${ }^{34}$, con el que ya han trabajado años atrás en la estructura para el proyecto de la Academia de Artes Plásticas de Ámsterdam, que nunca llegó a ser construida. Duiker y Wievenga también han trabajado juntos en 1923 en el desarrollo de un sistema constructivo estandarizado aplicable a la construcción de viviendas pareadas y en hilera, obteniendo la patente en 1926. Este mismo año es cuando, tras regresar Wiebenga a los Países Bajos de su estancia en Estados Unidos, Duiker se pone en contacto con él para encargarle el diseño de la estructura de Zonnestraal. La ausencia de fechas en los planos impide aclarar el grado de implicación de Bijvoet y de Wiebenga en el proyecto definitivo, dado que Duiker tiene un gran empeño en justificar la participación de Bijvoet en el mismo ${ }^{35}$, pues suele firmar los

\footnotetext{
${ }^{31}$ Ton IDSINGA, "In their own hands. A social and medical history of Zonnestraal", en Paul MEURS, Mare-Thérèse van THOOR (ed.), Zonnestraal, the history and restoration of modern monument, NAi, Rotterdam 2010, p. 55.

${ }^{32}$ Bijvoet conoce a Chareau durante el Salón de Otoño de 1919.Pedro IGLESIAS PICAZO, La habitación del enfermo. Ciencia y arquitectura en los hospitales del Movimiento Moderno. Fundación Caja de Arquitectos, Barcelona 201 1, p. 102.

${ }^{33}$ En 1925 Duiker se divorcia de su esposa y se casa con Lucy Küpper, una arquitecta alemana que pasa a colaborar en su estudio. Poco después su ex-mujer, H.B. Barendina Valken, con sus dos hijos se trasladan a París se alojan en la residencia de Bijvoet y su esposa. Años más tarde Barendina Valken acaba casándose con Bijvoet. Gabriele MILELLI, Zonnestraal // sanatorio di Hilversum. Universale di architettura, Torino 2000, p.45.

${ }^{34}$ Duiker no pierde el contacto con Bijvoet pese a que éste se establece en París; al parecer viajan para encontrarse y mantienen comunicación. Puede que por ello, además de por la amistad que los une y por el vínculo sentimental entre la ex-mujer y los hijos de Duiker con Bijvoet, Duiker trate siempre de mantener la autoría conjunta del proyecto del sanatorio de Zonnestraal. Incluso llega a incluir el nombre de su antiguo socio en planos realizados en 1926, ya en la época que colaboraba con J. G. Wiebenga, cuyo nombre no se refleja en ningún documento gráfico del proyecto. (Existen varias copias de planos originales en el IISG de Ámsterdam y en los archivos del NAi de Rotterdam con fecha: 27-9-26 y firma: B.Bijvoet-J. Duiker, escritos a mano con la misma letra).

35 Incluso en el no 30 (1928) de la revista Bouwkundig Weekblad aparece una rectificación debido a que en el número anterior atribuyen Zonnestraal sólo a Duiker. Pedro IGLESIAS PICAZO, La habitación del enfermo. Ciencia y arquitectura en los hospitales del Movimiento Moderno. Fundación Caja de Arquitectos, Barcelona 201 1, p. 102.
} 

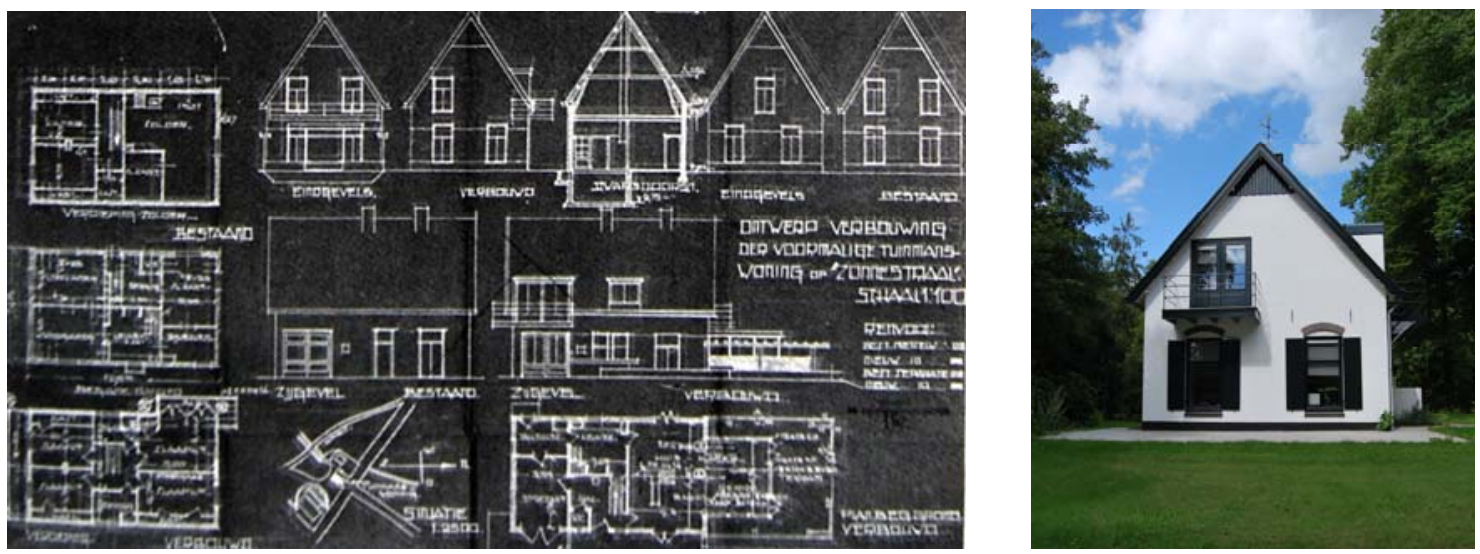

5.43 y 5.44

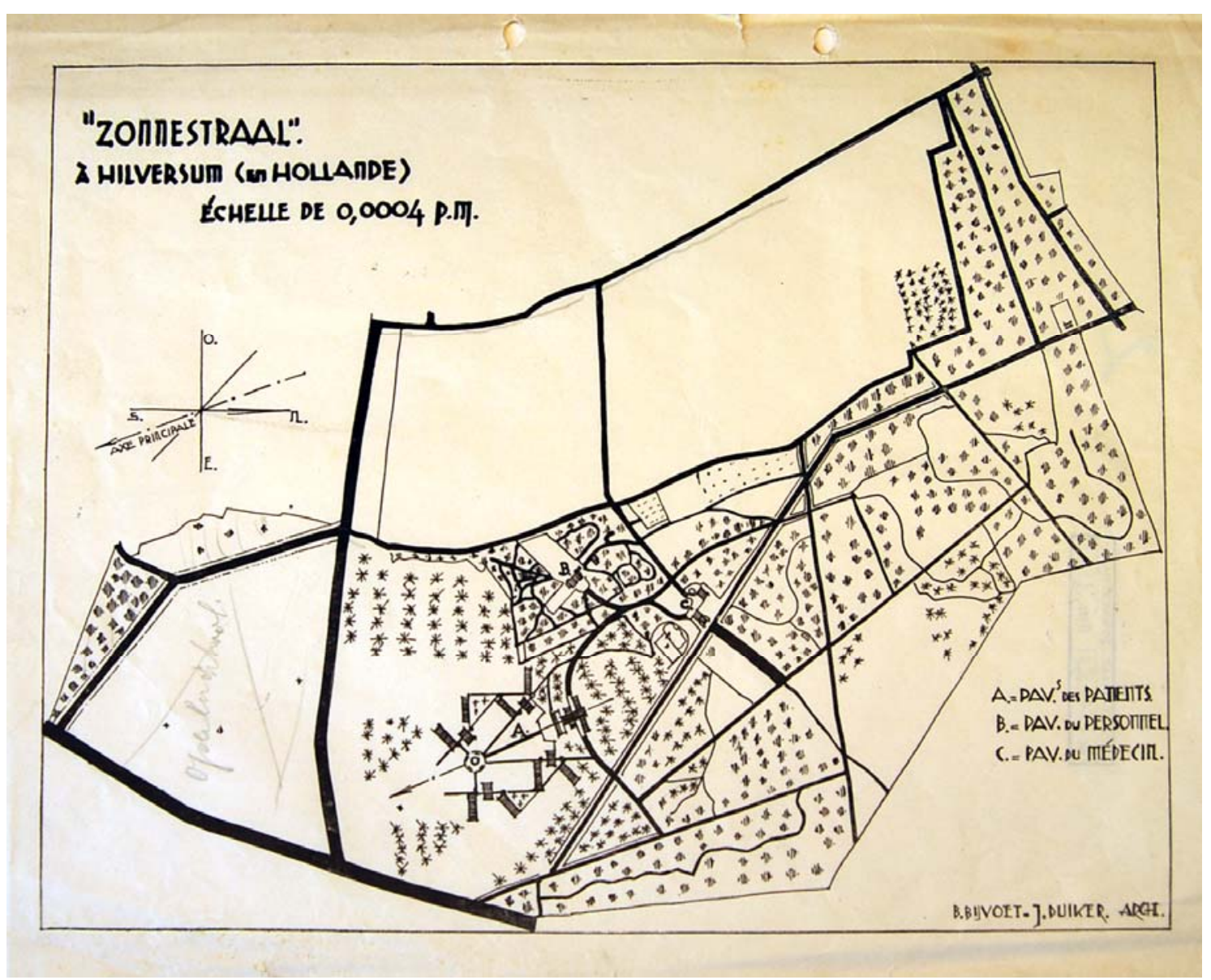

5.45

5.43 y 5.44 J. Duiker y B. Bijvoet. Sanatorio de Zonnestraal. Transformación de la vivienda del jardinero en la del médico 1926. Proyecto e imagen (fotografía de la autora).

5.45 J. Duiker y B. Bijvoet. Sanatorio de Zonnestraal. Situación con la quinta propuesta. Verano 1926 (Caja 40, Carpeta 40 19261927 (209), IISG) 
planos del proyecto con el nombre de los dos.

Según Ronald Zoethbrood, el proyecto de Zonnestrasl se realiza durante la primera mitad de 1926, bajo la supervisión de una comisión de la que forma parte el Dr. Van Lier, futuro director médico del sanatorio, obteniéndose un primer diseño en el verano ${ }^{36}$. El razonamiento encaja con el cambio de método proyectual utilizado en el proyecto definitivo, cambio en el que pueden haber influido las teorías que triunfan en América sobre el taylorismo y el fordismo buscando sobre todo la eficacia, y que Wiebenga puede haber traído consigo.

La primera gran decisión que marca la forma definitiva del sanatorio de Zonnestraal, en este caso ajena a los arquitectos, consiste en renunciar a los modelos de sanatorios compactos en favor de los cottages o edificios aislados ${ }^{37}$. Coincide con un cambio de implantación del sanatorio, probablemente debido a la necesidad de una mayor extensión de terreno despejada de árboles. El sanatorio abandona el bosque y se instala en una parte de la finca cubierta de brezo que se emplea como coto de caza, lo que favorece la captación de sol y de aire puro para los pacientes, y deja la zona arbolada para sus paseos.

La reforma de la vivienda del jardinero para convertirse en la del médico [fig. 5.43 y fig. 5.44] es uno de los primeros pasos que se dan en enero de 1926 para la adecuación del conjunto arquitectónico definitivo al lugar, el cual se organiza en tres áreas: la de pacientes en la zona de brezo más soleada, la de personal en la villa de Pampahoeve y la del médico algo más alejada. Así se recoge en un plano conservado en el archivo del IISG de Ámsterdam [fig. 5.45] que, dada la propuesta que contiene, puede corresponder al verano de 1926. Coincide con el plano de la que podía considerarse la quinta y penúltima propuesta del Sanatorio, en donde se aprecia cómo el conjunto consta de un edificio principal con planta en forma de cruz latina soportada por varios volúmenes transversales en planta baja, y de otros cuatro más, con una sala de reuniones común y dos bloques de habitaciones cada uno [fig. 5.46]. La solución se ajusta a la descrita por Duiker en una carta consultada en los archivos IISG de Ámsterdam para esta investigación, escrita el 13 de julio

\footnotetext{
${ }^{36}$ Ronald ZOETBROOD, Jan Duiker en het sanatorium Zonnestraal. Van Gennep, Amsterdam 1984, p. 34.

${ }^{37}$ El 26 de enero de 1926, cuando todavía no hay un proyecto definitivo, la comisión médica decide adoptar en Zonnestraal el modelo del Dr. Varrier Johnes en Papworth que incluye casas para los enfermos y las familias. Ronald ZOETBROOD, Jan Duiker en het sanatorium Zonnestraal, Van Gennep, Amsterdam 1984, pp.32-33.
} 

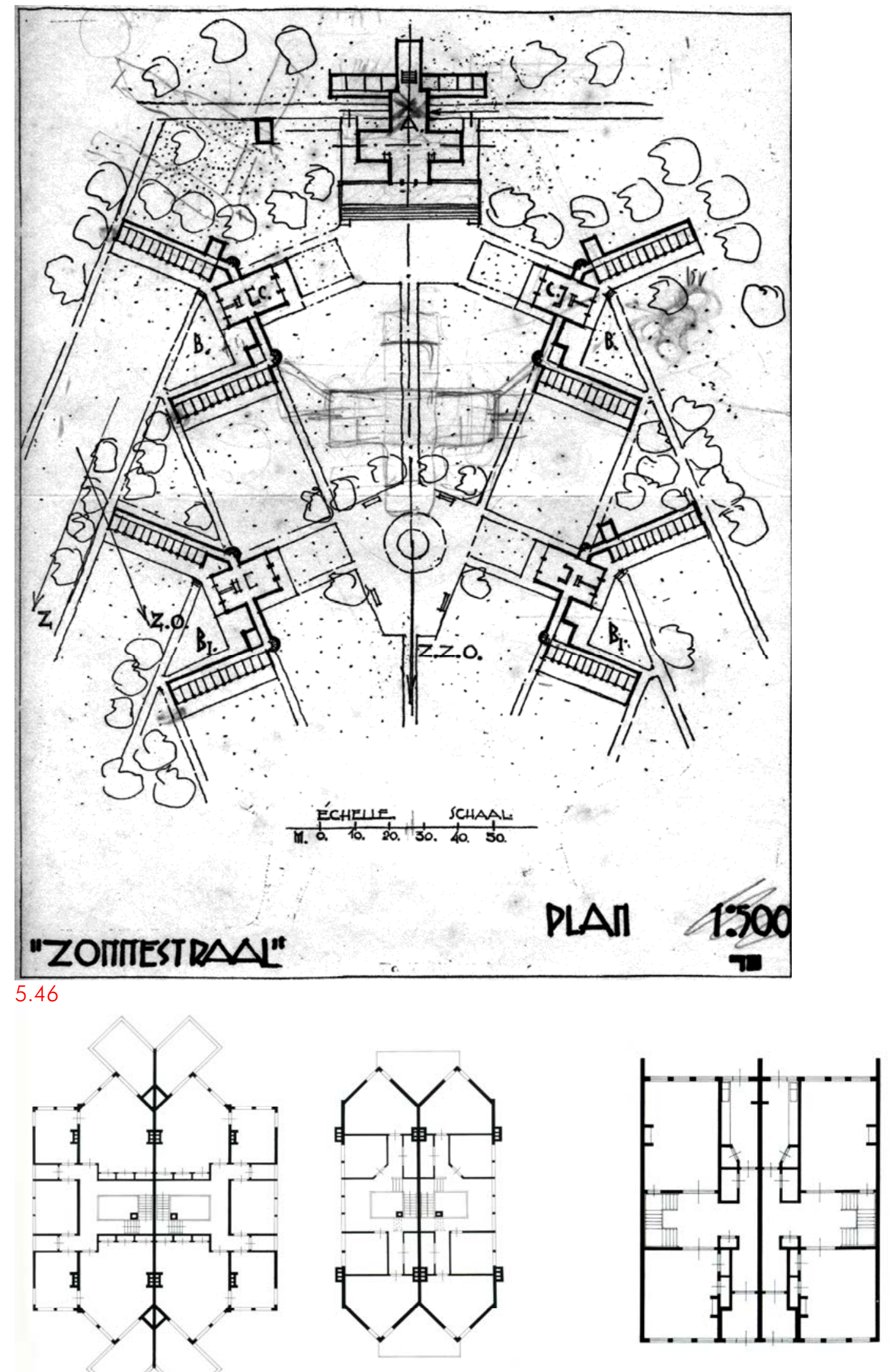

5.47 y 5.48

5.46 J. Duiker y B. Bijvoet. Sanatorio de Zonnestraal. Quinta propuesta, verano 1926. Planta 5.47 J. Duiker y B. Bijvoet. Viviendas Stadhoulerslaan, La Haya, 1918. Planta.

5.48 J. Duiker y B. Bijvoet. Viviendas Eikstraat, La Haya, Países Bajos 1920-1921. Planta. 
de $1926^{38}$ al tesorero de la sociedad Zonnestraal, G.H. Sanders. Explica que el sanatorio consta de un edificio principal con la administración, las consultas médicas y las instalaciones, al que se le superpone el salón-comedor, conectado a través de escaleras y plataformas con el suelo de la finca; también menciona los edificios de enfermos, cada uno con dos bloques de 24 pacientes repartidos en dos plantas ${ }^{39}$.

La disposición en cruz y la pureza geométrica del edificio principal recuerdan a proyectos anteriores de viviendas de Duiker y Bijvoet, especialmente a dos proyectos de casas pareadas en La Haya, las viviendas Stadhoulerslaan (1918) [fig. 5.47] y las casas de Eikstraat (1920-1921) [fig. 5.48]. Vistas cada pareja como unidad, la planta alberga una estructuración cruciforme.

Resulta más insólita la solución formal de los pabellones de enfermos y principalmente su disposición en la parcela, que Duiker justifica en un informe escrito a máquina adjunto a la mencionada carta [fig. 5.49] que incluye varios croquis hechos a mano, los únicos que se conocen del proyecto ${ }^{40}$ [fig. 5.50]. En el informe en primer lugar se exponen una serie de consideraciones para la construcción del Sanatorio, después se explican las diversas propuestas estudiadas y concluye con un resumen económico de las mismas.

Entre las diez consideraciones iniciales para la construcción del Sanatorio de Zonnestraal destacan: la común preocupación por la orientación de los edificios al sur, la búsqueda de amplias vistas sobre el paisaje y la reducción al máximo del frente de fachada. Se establece

38 El plano de la que hemos llamado quinta propuesta está reproducido en el libro Duiker Bouwkundig Ingenieur (1982) con la descripción: "Die vermoedelijk is vervaardigd voor de Wereldtentoonstelling te Pariis in 1925", "Presumiblemente realizado para la Exposición Universal de París de 1925", lo que implicaría que el plano debía haber sido realizado antes del 14 de abril de 1925, fecha en que se inaugura la exposición. Jan MOLEMA, Duiker Bouwkundig Ingenieur, Duiker Bouwkundig Ingenieur, constructeur in stuc en staal. TH Delft, Delft 1982, p. 98.

Sin embargo, en libro Zonnestraal, the history and restoration of modern monument (2010), aparece el mismo proyecto junto a la descripción: "Duiker did the drawing for a lectura in French by Van Lier in the summer of 1926", "Duiker hizo el diseño en el verano de 1926 para una lección en francés de Van Lier". Paul MEURS, Mare-Thérèse VAN THOOR (ed.), Zonnestraal, the history and restoration of modern monument. NAi, Rotterdam 2010, p.73.

Esta aproximación temporal coincidiría con las fechas de la carta en que se describe el proyecto, y dataría el plano de situación con las tres áreas, también escrito en francés, y el plano del proyecto en el mismo período, el verano del 1926, ya que el idioma empleado en sus leyendas permite suponer que ambos documentos fueron creados con el mismo fin.

39 Ronald ZOETBROOD, en su libro Jan Duiker en het sanatorium Zonnestraal (1984), recoge el mismo texto, pero la carta va dirigida el Sr. Roodenburg, otro miembro de la Sociedad Zonnestraal, de lo que deducimos que la misma carta fue enviada a varios miembros de la citada Sociedad.

${ }^{40}$ Consultado en el IISG, donde el informe posee el mismo número de legajo $\left(n^{\circ} 126\right)$ que la carta con fecha 13 de julio de 1926, por lo que supongo que el informe se adjuntaría a la carta y tienen ambos la misma fecha. El mismo informe aparece recogido en el libro de Jan Molema Duiker Bouwkundig Ingenieur, sin especificar la fecha del mismo, salvo la aclaración de que es posterior al 18 de marzo de 1924. Jan MOLEMA, Duiker Bouwkundig Ingenieur, constructeur in stuc en staal. TH Delft, Delft 1982, pp.93-94. 

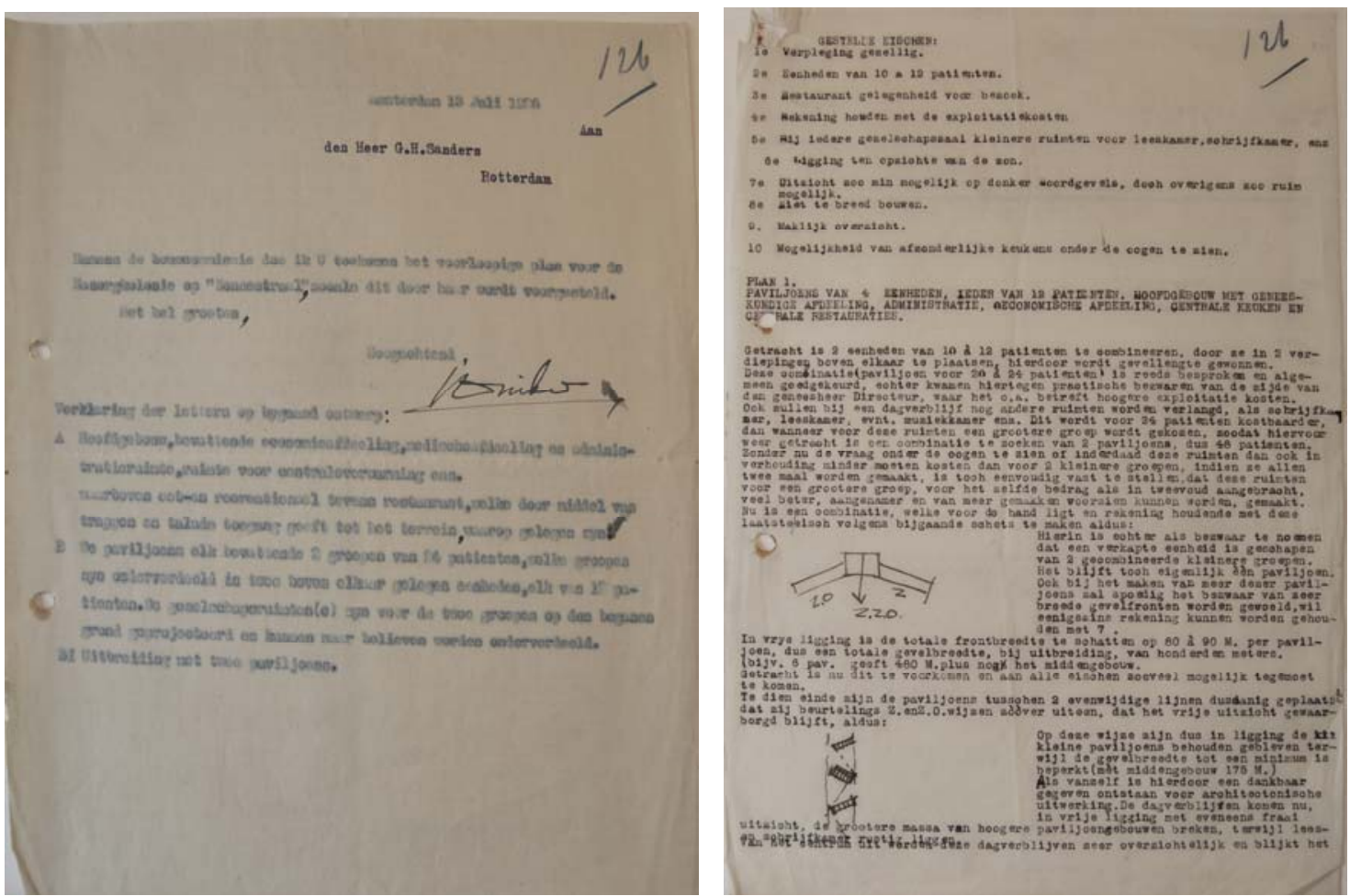

5.49 y 5.50
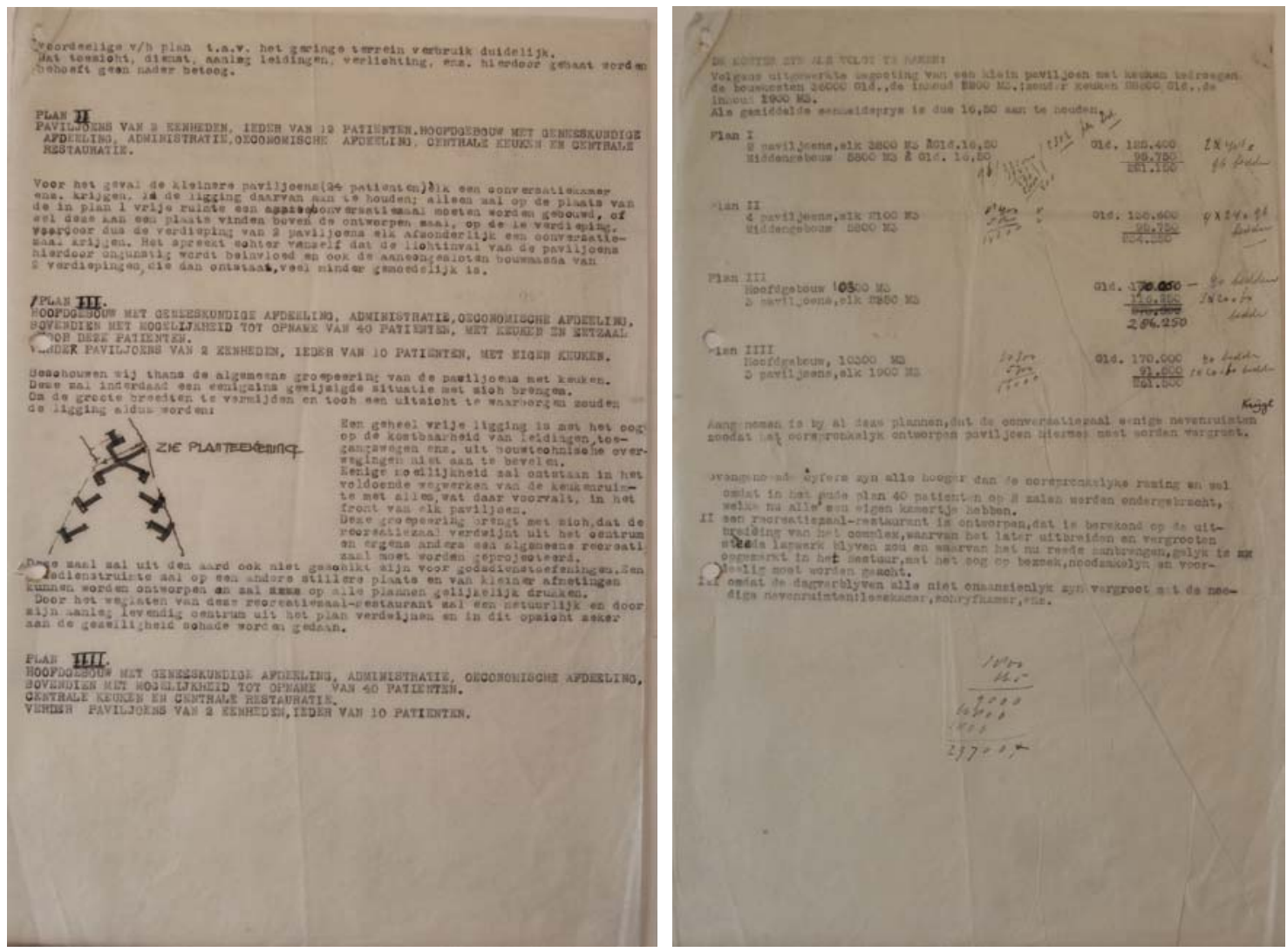

5.49 J. Duiker. Carta del 13 de julio de 1926 (IISG, Caja 40, Carpeta 4019261927 (126)) 5.50 J. Duiker Informe al Comité de la Sociedad Zonnestraal. pp. 1, 2, 3. (IISG, Caja 40, Carpeta $4019261927(126))$ 
además que cada unidad de hospitalización esté ocupada por 10 ó 12 pacientes, que en ellas exista un restaurante para las visitas y espacios más íntimos para leer o escribir incluidos en las salas de reunión, así como la posibilidad de disponer de cocina.

Sobre la base de estas consideraciones en el informe se comparan cuatro soluciones posibles:

En la primera, designada por Duiker como "PLAN I", acompañada de dos bocetos explicativos [fig. 5.51 y fig. 5.52], se describe un edificio principal con los servicios comunes y otros cuatro residenciales independientes de una sola planta con unidades de 10 ó 12 habitaciones cada uno [fig. 5.53 (a)]. La organización se considera anti-económica por ser demasiado dispersa, y se decide apilar las unidades en altura en tan sólo dos edificios de 20 ó 24 pacientes y una sala de reuniones en cada uno [fig. 5.53 (b)]. A su vez, para reducir el número de salas, se agrupan los dos edificios en uno, de manera que exista una sala común para 48 pacientes [fig. 5.53 (c)]. Se diseña el edificio residencial en forma de T, muy similar al del sanatorio compacto de King Edward VII [fig. 5.19], y se incluye su croquis en el informe [fig. 5.51]; consiste en un cuerpo central con la sala de reunión común y dos bloques laterales ligeramente inclinados, orientados al sur y al sureste, de dos plantas de altura.

El inconveniente de esta solución radicaba en la dificultad de crecimiento sin aumentar la altura. Para poder mantener la orientación y vistas favorables en las habitaciones es necesario extender los brazos. El gran frente de fachada resultante se quiere evitar, ya que hace más difícil el cuidado y el control de los enfermos e incrementa el gasto de explotación, a la vez que dota al edificio de una monumentalidad contraria al cobijo y confort de las residencias más pequeñas y domésticas. Para evitarlo se propone una ley de ordenación de los edificios residenciales que permite limitar su frente edificado a unos 175 metros máximo y mantener las vistas y la orientación, sistema que explica con otro boceto a través de una variante en la que aparecen dos líneas paralelas que acotan la longitud de cada bloque residencial con 10 ó 12 habitaciones, colocados en zig-zag tres de ellos [fig. 5.52]. Si un bloque está orientado al sureste el siguiente, ubicado fuera del campo de visión del anterior y dándole la espalda, al sur y así sucesivamente. Estos giros entre los edificios residenciales existen en los brazos de los pabellones del Sanatorio Royal Victoria Hospital de Edimburgo, que tienen forma de $Y$, de tal modo que las salas de enfermos se inclinen 30 grados en sentidos opuestos respecto a la perpendicular al eje de simetría, formando sus tres brazos ángulos obtusos de 120 grados entre sí [fig. 5.54]. 

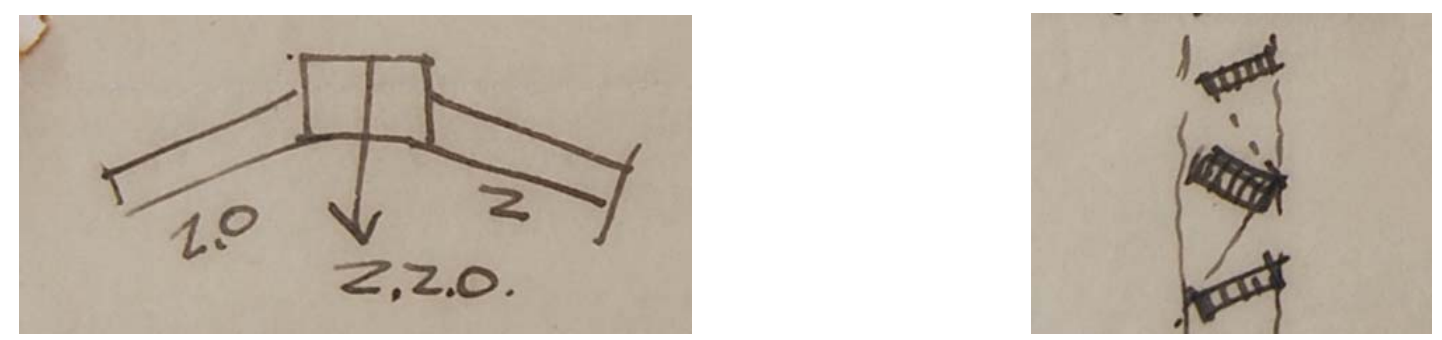

5.51 y 5.52

a)
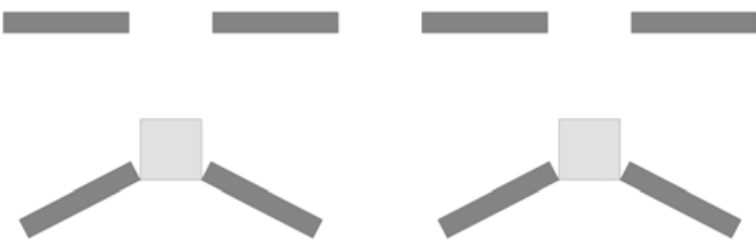

b)

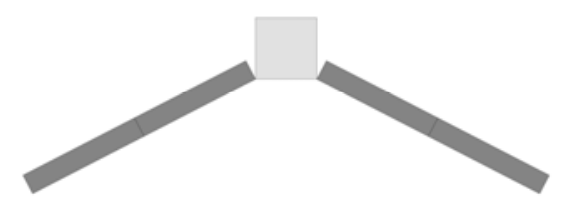

c)

d)

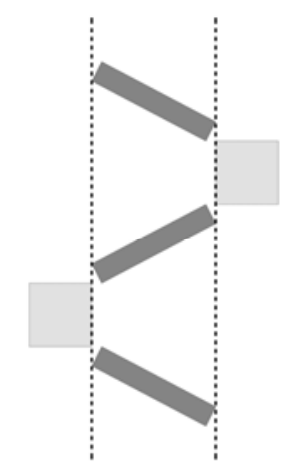

5.53

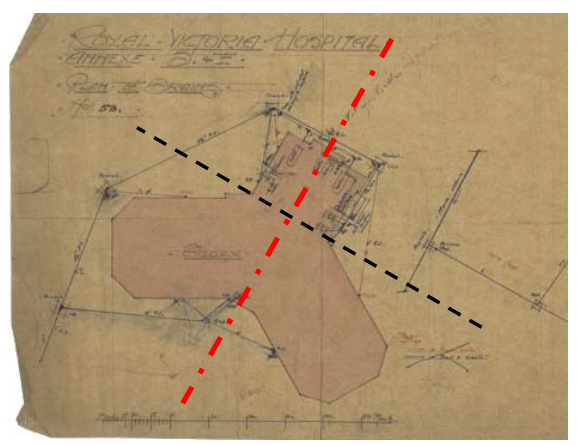

5.54
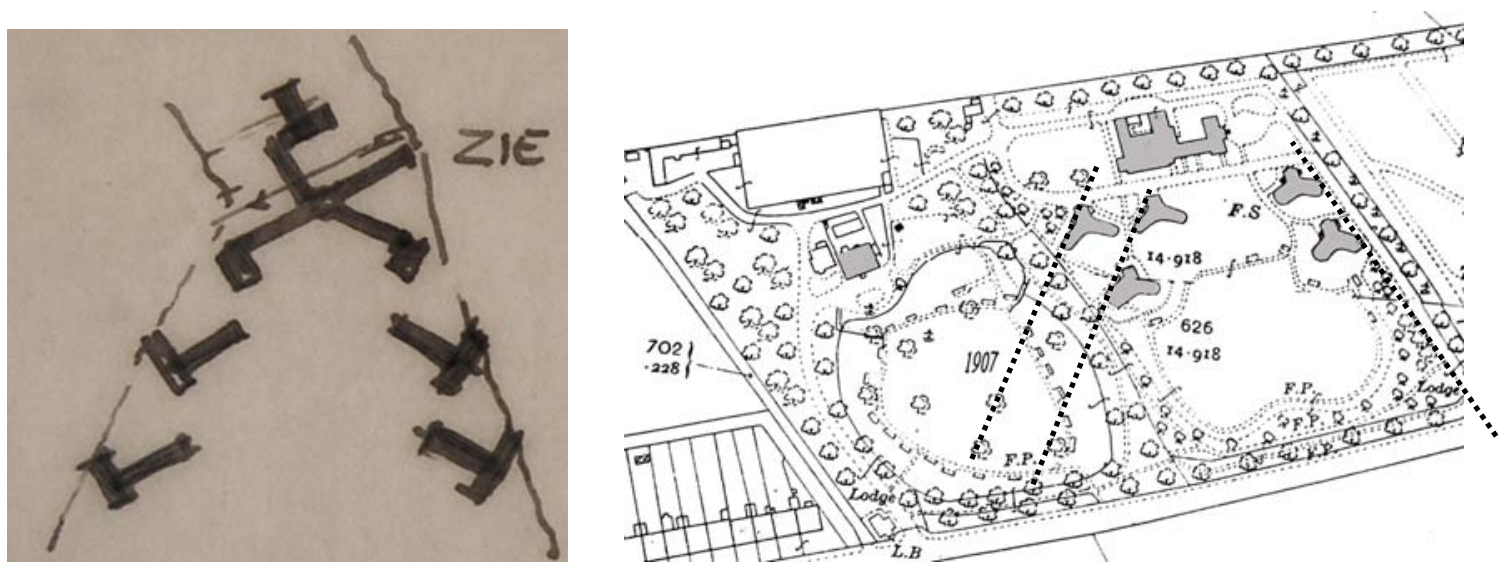

5.55 y 5.56

5.51 y 5.52 J. Duiker. Informe al Comité de la Sociedad Zonnestraal. Croquis "Plan I" (IISG).

5.53 J. Duiker. Informe al Comité de la Sociedad Zonnestraal. Croquis Plan I. a) 4 edificios residenciales de 10 ó 12 enfermos; b) 2 edificios residenciales de 20 ó 24 enfermos y una sala común; c) 1 edificio residencial con una sala común y 48 enfermos; d) posible posición de los edificios residenciales (esquemas de la autora).

5.54 Sanatorio Royal Victoria Hospital, Edimburgo, 1907. Pabellón residencial.

5.55 J. Duiker. Informe al Comité de la Sociedad Zonnestraal. Croquis "Plan II" (IISG).

5.56 Sanatorio Royal Victoria Hospital, Edimburgo, 1907. Plano de situación. 
Recuérdese que Duiker ya ha planteado giros similares en la supuesta segunda propuesta [fig. 5.18] donde dos de los edificios residenciales y el principal se agrupan formando un triángulo. El esquema estudiado en esta variante del "PLAN I" es la que más se aproxima a la forma final adoptada, donde los dos brazos de cada edificio residencial giran para orientarse al sur y al sureste, o al sur y al suroeste, dependiendo de la posición del mismo respecto al eje de la ordenación del conjunto[fig. 5.53 (d)].

La segunda solución, designada como "PLAN II", no incluye bocetos y es una variación de la anterior. Contempla la posibilidad de disponer en los edificios residenciales de una sala de recreo cada dos unidades de habitaciones, en vez de cada cuatro, lo cual implica bien un aumento del número de edificios residenciales y una consecuente disminución del espacio libre, a lo que se opone la comisión, o bien una superposición en altura de éstas, a lo que se opone el arquitecto porque considera que afecta a la entrada de luz y crea una atmósfera menos agradable en las habitaciones.

En la tercera solución o "PLAN III" acompañada de un croquis [fig. 5.55], crece el edificio principal, que contiene los servicios comunes y 40 camas, disminuyendo el tamaño de los edificios residenciales integrados por unidades de 10 habitaciones cada uno, además de una cocina y un comedor particular que configuran su forma en L. En el croquis de ordenación del conjunto que se incluye se observa cómo la ubicación de los edificios residenciales facilita la captación de sol y vistas sin formar un frente continuo. Su disposición presenta también concomitancias con el Royal Victoria Hospital [fig. 5.56] donde las residencias se ordenan al tresbolillo en vez de con la frecuente ortgonalidad propia de los hospitales de pabellones.

La cuarta solución o "PLAN IIII", sin aclaraciones gráficas, coincide con la anterior excepto que ahora las cocinas y comedores se concentran en el edificio principal central y por último, la estimación económica aportada al final del informe considera la primera solución como la más ventajosa, la cual es finalmente llevada a cabo aunque el proyecto definitivo sea una combinación de varios aspectos descritos en cada una de ellas.

Como dice Jan Wils en el n¹2 (1926) de la revista Het Bouwbedriff:

"La arquitectura de Duiker y Bijvoet se caracteriza por profundizar en el problema que debe ser resuelto. Para cada proyecto es primordial plantear el problema" ${ }^{41}$.

${ }^{41}$ Jan WILS, "Verbouwing apotheek te Zandvoort. Architecten Irs. Duiker en Bijvoet" Het Bouwbedriif $n^{\circ} 12,1926$, p. 388, en Pedro IGLESIAS PICAZO, La habitación del enfermo. Ciencia y arquitectura en los hospitales del Movimiento Moderno. Fundación Caja de Arquitectos, Barcelona 201 1, p. 134. 

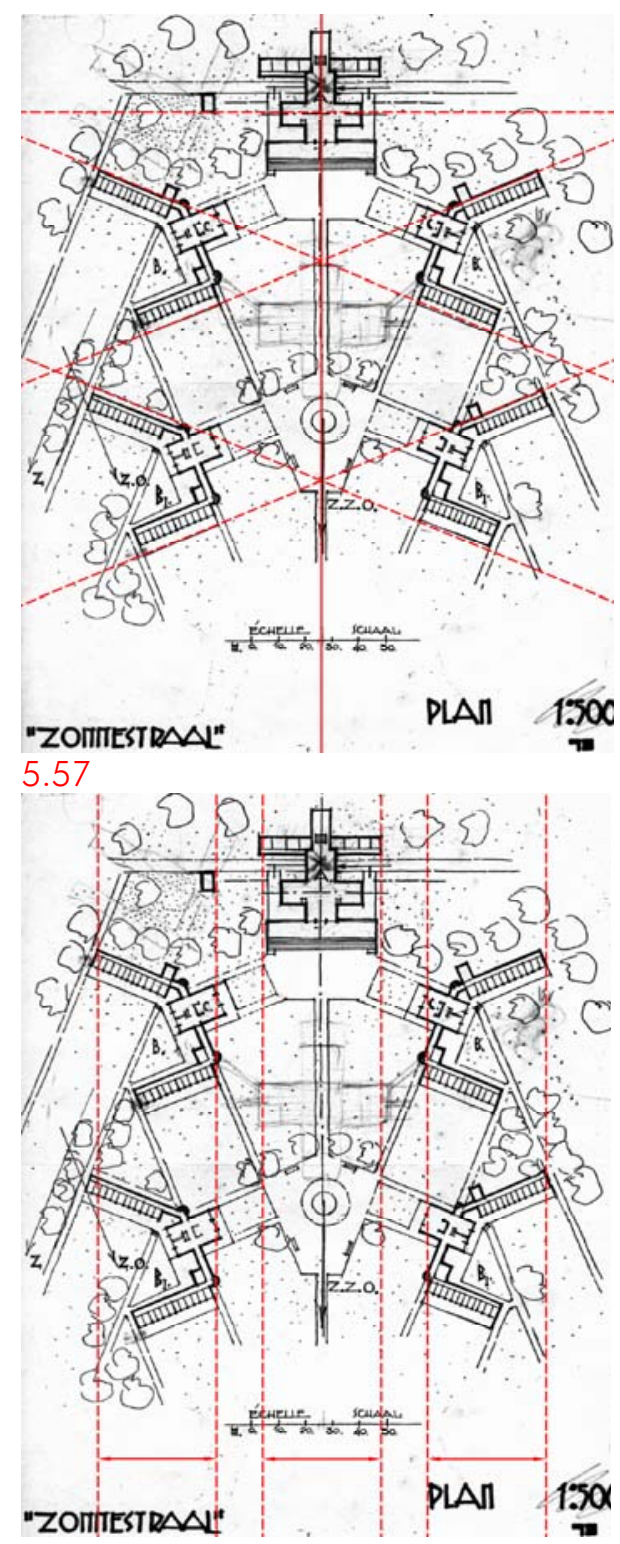

5.58

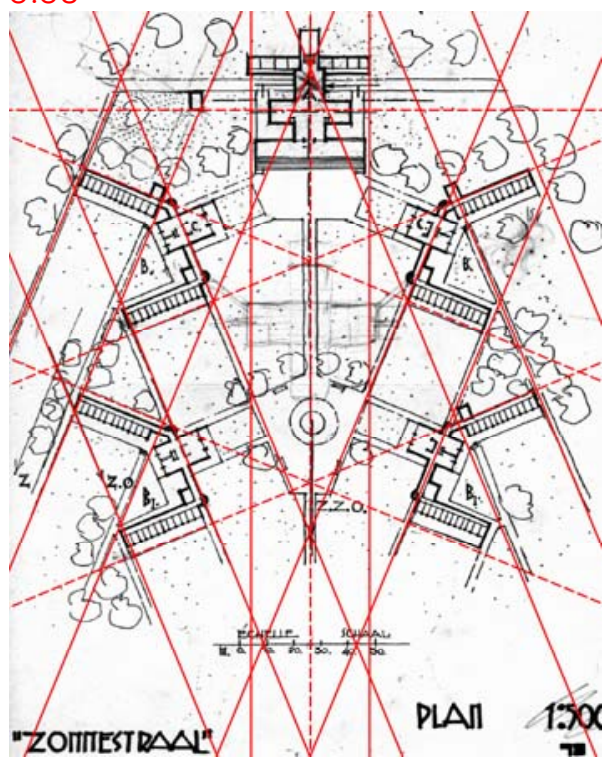

5.59

5.57 Centros del Sanatorio (representaciones de la autora).

5.58 Haces paralelos que limitan los frentes de fachada (representaciones de la autora).

5.59 Trama reguladora (representaciones de la autora). 
Se puede considerar que el informe describe el proceso seguido por Duiker para la elaboración del proyecto definitivo del Sanatorio, en el que a partir de un análisis de las necesidades del programa y de las intenciones que se persiguen, se establecen las premisas de partida a las que se debe ajustar el proyecto. Plantea así diversas soluciones basadas en modelos de sanatorios conocidos que no duda en alterar para obtener la solución formal que más se ajuste a las restricciones de partida que debe resultar además la más razonable económicamente. Ésta será la que finalmente se construya.

En la definición formal del Sanatorio de Zonnestraal, Duiker se apoya en la geometría para dar respuesta a los problemas requeridos en el programa de necesidades. Crea un conjunto simétrico y radial constituido por varios centros a lo largo del eje [fig. 5.57]. El primero se halla en el edificio principal y coincide con el centro de su salón-comedor, de planta en forma de cruz, soportada en planta baja por un tamiz de tres bloques transversales con los servicios comunes. El segundo se crea por la intersección de la prolongación de las fachadas exteriores de los bloques de los dos edificios residenciales. Estas direcciones se ajustan a las orientaciones este-oeste, y nordeste-suroeste, permitiendo que las habitaciones puedan orientarse hacia el sur y el sureste, y los pasillos al norte o al noroeste. El tercer centro se forma idénticamente al segundo pero más alejado del edificio principal ${ }^{42}$. La disposición radial de los bloques de los edificios residenciales con la que se logra una orientación óptima de las habitaciones y que otorga la calificación de "estupendo abanico" con la que Bruno Zevi describe al Sanatorio ${ }^{43}$, se combina con el orden de ciertos haces paralelos entre sí que, como las líneas de un pentagrama ${ }^{44}$, limitan la posición de los mismos para evitar que crezcan demasiado de este modo, como se pedía en el informe, el frente de los edificios residenciales no supera al del edificio principal [fig. 5.58]. A estos trazados se superpone además una trama ortogonal surgida como resultado del intento de preservar las vistas, que acaba por definir el trazado que ordena el conjunto [fig. 5.59].

Si se prolongan las líneas que limitan la fachada del edificio principal se establece el área que debe quedar libre de edificaciones para mantener las vistas [fig. 5. 60]. La misma

\footnotetext{
${ }^{42}$ Estos centros se desajustan levemente al adquirir el proyecto final las dimensiones definitivas, pero se sigue manteniendo la misma disposición abierta y radial y la misma orientación en las habitaciones.

${ }^{43}$ Bruno ZEVI, Historia de la arquitectura moderna (Storia dell'architettura moderna, 1950). Editorial Poseidon, Barcelona 1980, p. 133.

${ }^{44}$ Término empleado por Erik Mattie para describir la organización de Zonnestraal en su libro Functionalism in the Netherlands, quien reconoce en esta obra numerosas referencias teosóficas. Jan DERWIG, Erik MATTIE, Functionalism in the Netherlands. Architectura \& Natura, Amsterdam 1995, p. 31.
} 


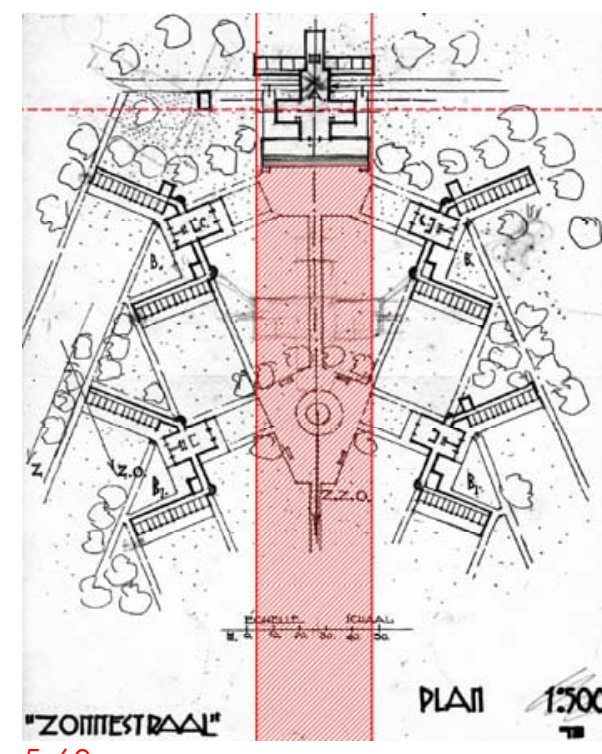

(1)
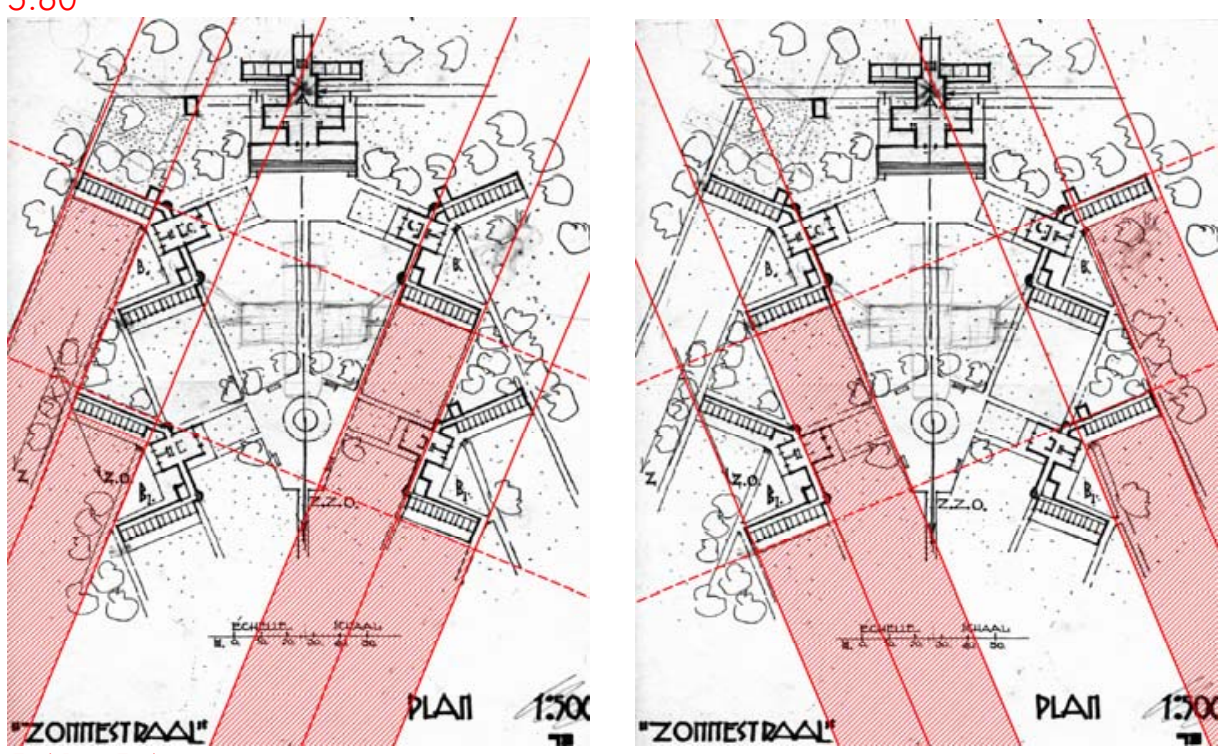

5.61 y 5.62

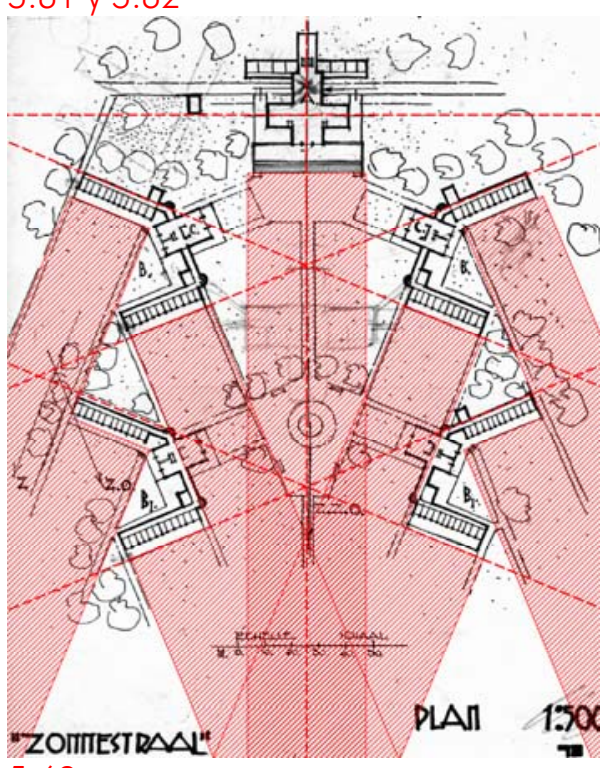

5.63

5.60 Área libre para preservar las vistas desde el edificio principal (representaciones de la autora).

5.61 y 5.62 Área libre para preservar las vistas desde los edificios residenciales orientados al sur y al sureste (representaciones de la autora).

5.63 Orientación y vistas (representaciones de la autora). 
operación se repite con los bloques de los edificios residenciales [fig. 5.61 y fig. 5.62]; se genera así un trazado regulador definido por la posición exacta de los edificios y de sus distintas partes, con el que se logra mantener la buena orientación y los frentes de las fachadas despejados favoreciendo tanto las vistas como la captación de aire puro [fig. 5. 63].

Esta organización definitiva del Sanatorio por partes provoca una fragmentación volumétrica de los usos que alberga, y una diferenciación formal de los elementos de conexión de las mismas más próxima a la cuarta propuesta que a la primera; dado que en la cuarta, el edificio principal y dos de los edificios residenciales se conectan por elementos claramente independientes, mientras que en la primera los elementos de conexión coinciden con las direcciones principales de los edificios integrándose en los mismos.

Por otro lado, en la primera y cuarta propuestas existe un orden simétrico y radial en el conjunto presente también en el proyecto definitivo, donde los edificios residenciales que en sí mismos carecen de simetría se organizan radialmente en relación a los centros que ordenan el conjunto. Los edificios residenciales de la primera propuesta no son radiales aunque sí simétricos, mientras que en la cuarta, la unión del edificio principal y de dos de los edificios residenciales crea una agrupación prácticamente simétrica y radial, cuyo centro coincide con el que ordena el conjunto, aproximándose más a la solución definitiva.

Como se aprecia en el informe la arquitectura de Zonnestraal se ve influida por los conocimientos arquitectónicos adquiridos durante el proceso de gestación; no responde a una mímesis formal, a través de la geometría se propone una arquitectura generativa o "diagramática", en términos de Josep Maria Montaner, ya que en el Sanatorio al igual que en esas arquitecturas: "el programa, se convierte en organigrama y éste en diagrama que se mantiene como base esencial del proyecto " $" 45$.

Las decisiones y formas surgidas del análisis del programa se modulan y se ajustan a una geometría estricta que define la forma final del proyecto, en la que el módulo mínimo es el de la habitación, un cuadrado de 3 metros de lado. La agrupación de 12 habitaciones constituye un módulo superior, la unidad de enfermos. Cuatro unidades de enfermos, 48 habitaciones, ordenadas en torno a una sala de reuniones constituyen el edificio residencial,

45 Josep Maria MONTANER, Sistemas arquitectónicos contemporáneos (2008). Gustavo Gili, Barcelona 2009, p. 198. 


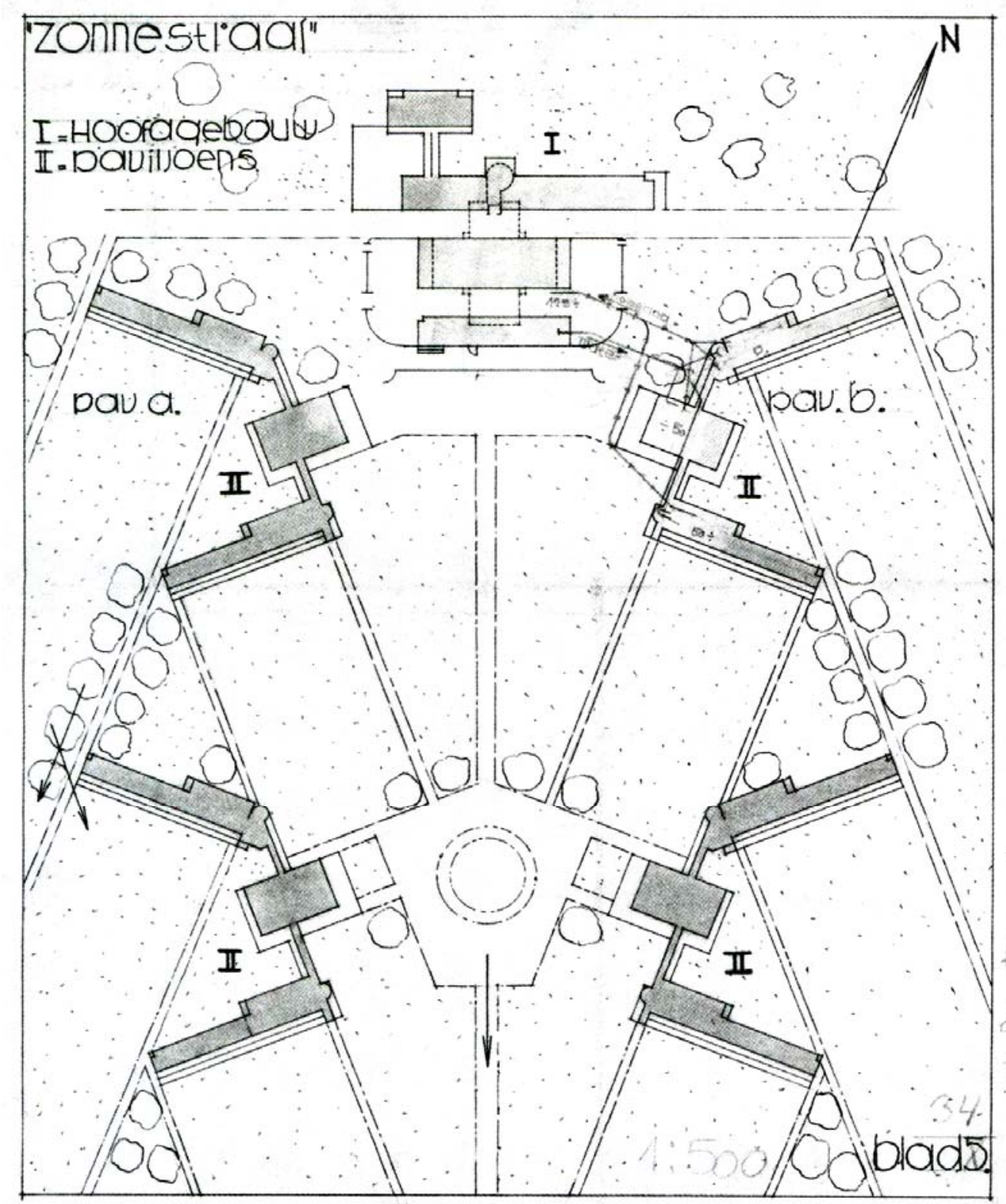

5.64
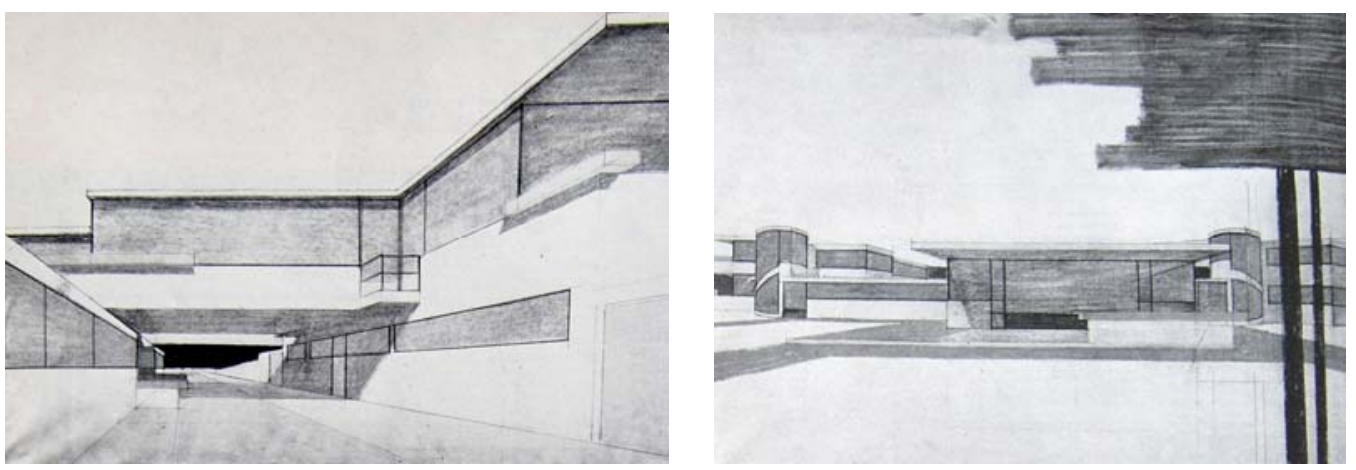

5.65 y 5.66

5.64 J. Duiker y B. Bijvoet. Sanatorio de Zonnestraal. Sexta y última propuesta, 1926. Planta 5.65 y 5.66 J. Duiker y B. Bijvoet. Sanatorio de Zonnestraal, 1926. Perspectivas. 
y cuatro de ellos debidamente dispuestos, que junto con el edificio principal con los servicios comunes acaban por definir el sanatorio de Zonnestraal con 192 habitaciones.

En octubre de 1926 queda definido el sexto y último proyecto de Zonnetraal prácticamente idéntico al anterior, en él se mantiene el módulo de la habitación, pero aumenta el número total de habitaciones por edificio residencial de 48 a 50, que se distribuyen en una unidad de 12 habitaciones individuales de dos plantas de altura y otra de 13 habitaciones individuales de otras dos plantas. Como se ha dicho, con este incremento se alteran las dimensiones de ciertos edificios desvirtuándose la pureza geométrica inicial pero manteniendo las mismas leyes generativas. El edificio principal presenta también ligeras alteraciones; junto a los tres bloques de planta baja destinados a servicios médicoadministrativos, cocinas e instalaciones se incluye un cuarto para enfermos graves, y la gran sala cruciforme de la planta primera depura su geometría adoptando forma de cruz griega [fig. 5.64].

En el itinerario del proyecto se manifiesta el procedimiento higiénico, funcional y científico, seguido en la definición del mismo.

Higiénico, porque aunque originalmente se parta de un modelo compacto, en el proyecto final de pabellones se establece una segregación de usos que contribuye a evitar los contagios $^{46}$.

Funcional, porque el resultado formal de cada parte de los edificios, responde a la conveniencia al uso que alberga, estableciéndose dos tipos formales: el lineal y el central. El primero, resultado de la agrupación de elementos, está presente en los bloques de habitaciones de enfermos, el médico-administrativo, el de las cocinas y también en el bloque de instalaciones. El central, que corresponde a las salas comunes aparece en la gran sala cruciforme del edificio principal y en las salas de reunión de los pabellones de enfermos.

Científico, porque la configuración final del conjunto, la dimensión y posición exacta de las partes del mismo, responden a una ley geométrica basada en la modulación estricta de las superficies y en el establecimiento de un orden preciso que combina disposiciones radiales y ortogonales.

Los procedimientos empleados resultan propios de aquellos que el Sr. H.J. Evers, profesor de Duiker y Bijvoet, llama: "iArquitectos-ingenieros que dibujan con lápices duros!" 47.

\footnotetext{
${ }^{46}$ Aunque la higiene no aparece mencionada explícitamente entre las condiciones del Sanatorio los principios higiénicos están implícitos en el siglo XX en todo complejo hospitalario.
} 
Profesionales que proyectan basándose en el orden y la geometría, a través de dibujos en planta, perfectamente modulados, en los que se aprecia una gran preocupación por la técnica y las cualidades tectónicas de sus edificios [fig. 5.65 y fig. 5.66]. Siendo precisamente esta cualidad tectónica del sanatorio de Zonnestraal, un edificio de vidrio convertido en un contenedor de rayos de sol, una de las características más sorprendente y atractiva del mismo.

El día 12 de junio de 1928, cuando se inaugura el sanatorio de Zonnestraal, aún sin finalizar, ya que en ese momento sólo estaban construidos el edificio principal y uno de los pabellones ${ }^{48}$, se pudo apreciar la magnitud de esta cualidad.

Si se habla de la obra construida, se observan en la pureza volumétrica influencias de su maestro Berlage, gran defensor de la geometría y de los sistemas modulares quien, en una entrevista publicada en 1908, afirma: "El tiempo transforma la moda (...) pero lo que está fundado en la geometría y en la auténtica ciencia permanece siempre" 49.

También Wright está presente en el sanatorio, al igual que en muchas otras obras de Duiker y Bijvoet $^{50}$, en su intento por evitar la frontalidad al plantear los accesos laterales, en sus composiciones simétricas, en las alteraciones espacio temporales que plantea en sus recorridos donde se sale y se vuelve al eje de simetría y en su intento por expandir los límites de la edificación mediante la prolongación de las cubiertas en vuelo y la creación de extensos muros que diluyen el perímetro del edificio, en busca de una fusión del interior con el exterior. Frank Lloyd Wright explica en su libro The Natural House : "Empecé a entender principalmente la vivienda no como una cueva, sino como un amplio refugio al aire libre, relacionado con las vistas, las de fuera y las de dentro" ${ }^{51}$.

A este intento por diluir los límites Duiker contribuye con la transparencia y la desmaterialización de sus fachadas, logrando transformar los espacios interiores en un exterior continuo. Dado que, como explica en su artículo publicado en la revista 8 en Opbouw en el año 1932:

\footnotetext{
${ }^{47}$ E. J. JELLES, C. A. ALBERTS, Duiker 1890- 1935. Recopilación del n 5 y nº del volumen 22 de la revista Forum, Amsterdam 1972, p. 2.

${ }^{48}$ Edificio designado con el nombre del profesor Henri ter Meulen, inventor de la centrifugadora para la extracción del polvo de diamante.

49 Entrevista a Berlage "Grundlagen und Entwicklung del Architektur", "Base y desarrollo de la arquitectura", Giovanni FANELLI, Architettura edilizia urbanística. Citado en: Pedro IGLESIAS PICAZO, La habitación del enfermo. Ciencia y arquitectura en los hospitales del Movimiento Moderno. Fundación Caja de Arquitectos, Barcelona 2011 , p. 88.

${ }^{50}$ Como se aprecia en el rascacielos presentado para el concurso del Chicago Tribune (1922), o en los dibujos de las primeras propuestas para los apartamentos Nirwana (1927).

${ }^{51}$ Frank Lloyd WRIGHT, The Natural House. Horizont Press, Nueva York 1954, p. 16.
} 
"Como todos los grandes arquitectos Wright tuvo sus seguidores especialmente en Holanda, que después de 1910 llevó adelante una mayor evolución. Entonces fue muy útil, enseñó a ver de forma diferente. Pero sólo los que ampliaron sus principios y los ligaron más intensamente a nuestras actuales posibilidades técnicas y nuestra nueva óptica aprendieron realmente de Wright" ${ }^{52}$.

La transparencia de las fachadas del sanatorio, le proporcionan una gran apertura espacial y un mayor dinamismo que altera las cualidades propias de los espacios centrales o longitudinales establecidos. Sin embargo, la apertura no sólo se consigue a través del material, sino también por la adopción de formas abiertas, mediante configuraciones radiales y centrífugas.

Durante la realización del proyecto de Zonnestraal (1925-1926) Duiker proyecta una Escuela al aire libre para el Sanatorio en donde pone de manifiesta una apertura formal [fig. 6.67 y fig. 6.68]. El edificio consta de un pabellón principal orientado al norte y de una serie de pabellones con aulas. Todos ellos se ordenan alrededor de un patio circular siguiendo una disposición radial donde la arquitectura, como los dedos de una mano, se expande hacia el paisaje circundante, dado que en los seis pabellones de aulas sus ejes longitudinales coinciden con los radios del patio.

Duiker seguirá experimentando en el sanatorio con las organizaciones radiales. Un año después, en 1927, adopta una solución parecida al diseñar cinco talleres de carpintería para los enfermos convalecientes de Zonnestraal siguiendo la misma disposición radial que, en este caso describe una semicircunferencia [fig. 6.69 y fig. 6.70]. El centro se ocupa con una chimenea vinculada a un sistema subterráneo de aspiración de las virutas y del polvo producido en los talleres, con el fin de crear un ambiente lo más saludable posible ${ }^{53}$.

En ese año 1927, pero fuera del Sanatorio, Duiker esta vez junto a Wiebenga, proyectan otro edificio constituido por pabellones que también siguen un orden radial, para participar en el concurso de la sede de la Sociedad de las Naciones. Sin embargo, ahora la apertura radial es menor, ya que en el perímetro se incluyen otros pabellones que cierran la figura y evitan su expansión [fig. 6.71 y fig. 6.72].

\footnotetext{
52 "Manifiesto de Frank Lloyd Wright" en 8 en Opbow (8+O), 1932 p. 177-184, en Rafael GARCÍA GARCíA, "Tres Artículos de Duiker", Cuaderno de Notas n 3,1995, p. 42.

53 Dos de los cinco talleres fueron construidos durante ese mismo año por los propios enfermos, siguiendo las instrucciones descritas por Duiker en los planos de montaje, con la intención de que el trabajo de su construcción sirviera como parte de la terapia. En su construcción se reutilizan las vigas de madera retiradas del edificio industrial de Diemen, donde se construyó la lavandería en 1924.
} 

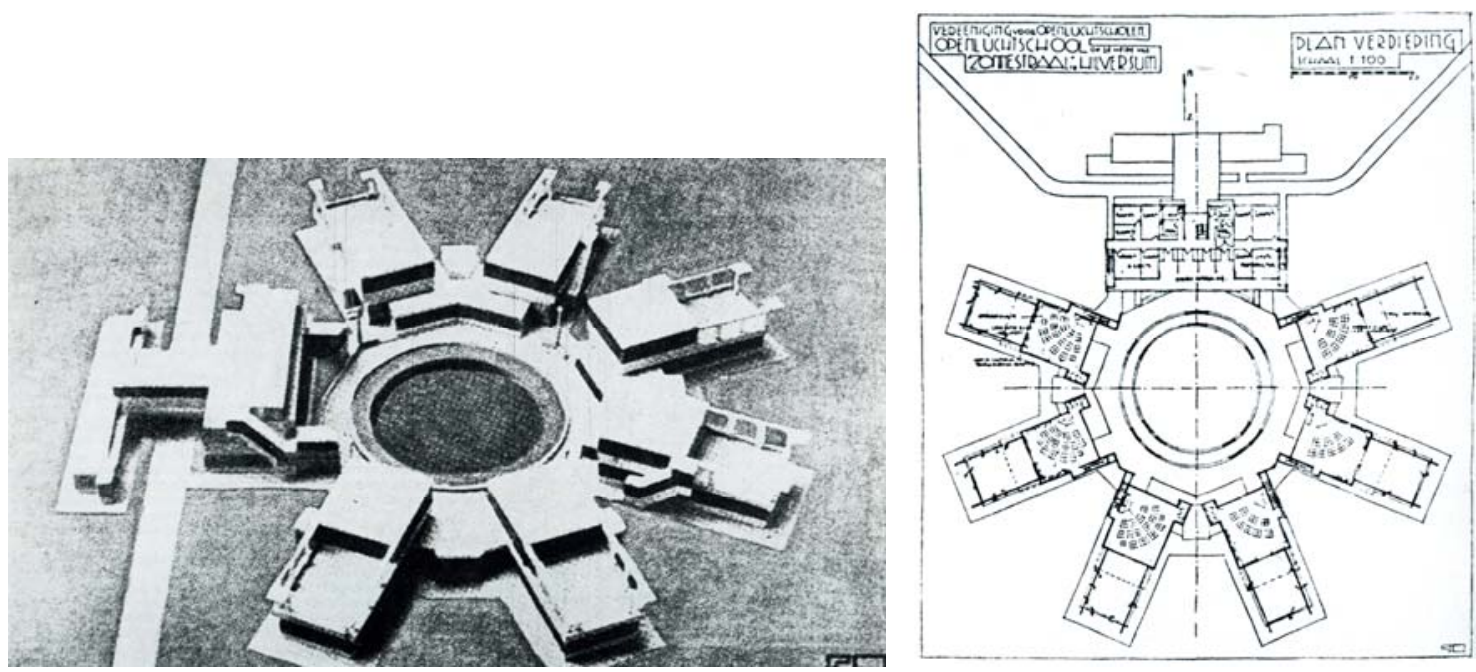

5.67 y 5.68
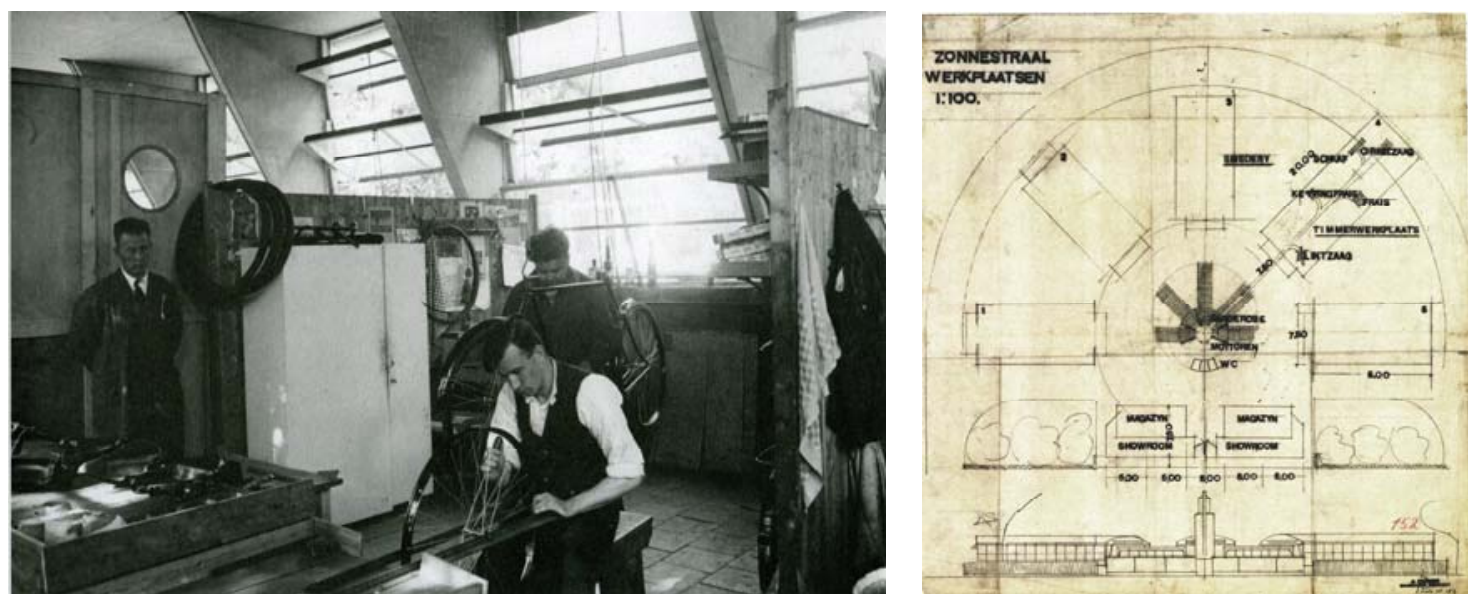

5.69 y 5.70
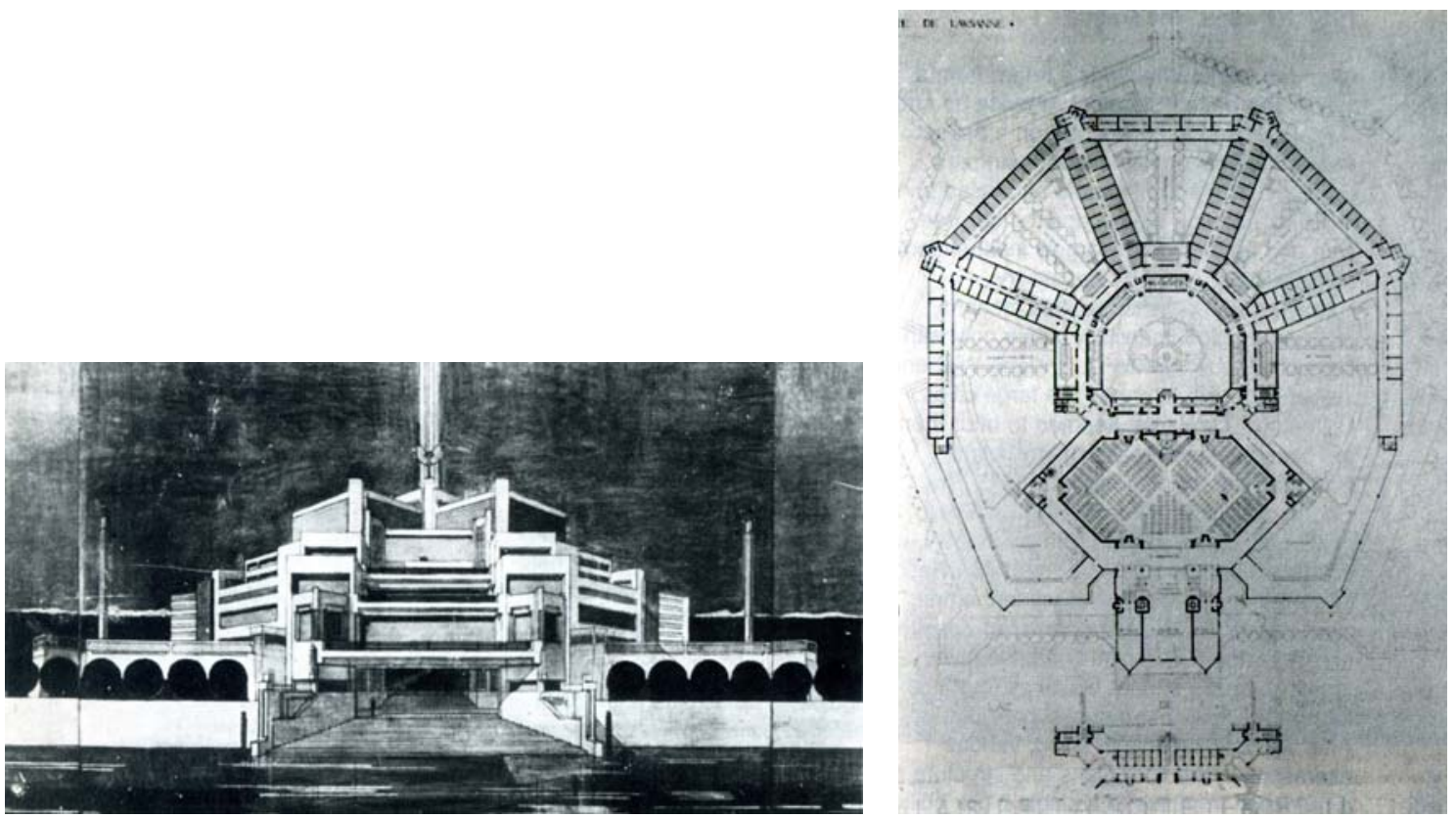

5.71 y 5.72

5.67 y 5.68 J. Duiker y B. Bijvoet. Zonnestraal. Escuela al aire libre 1925-1926. Maqueta y planta. 5.69 y $5.70 \mathrm{~J}$. Duiker y B. Bijvoet. Zonnestraal. Talleres de carpintería, 1927. Imagen del interior y planta.

5.71 y 5.72 J. Duiker y J. G. Wiebenga. Concurso del Palacio de las Naciones, 1927. Alzado y planta. 

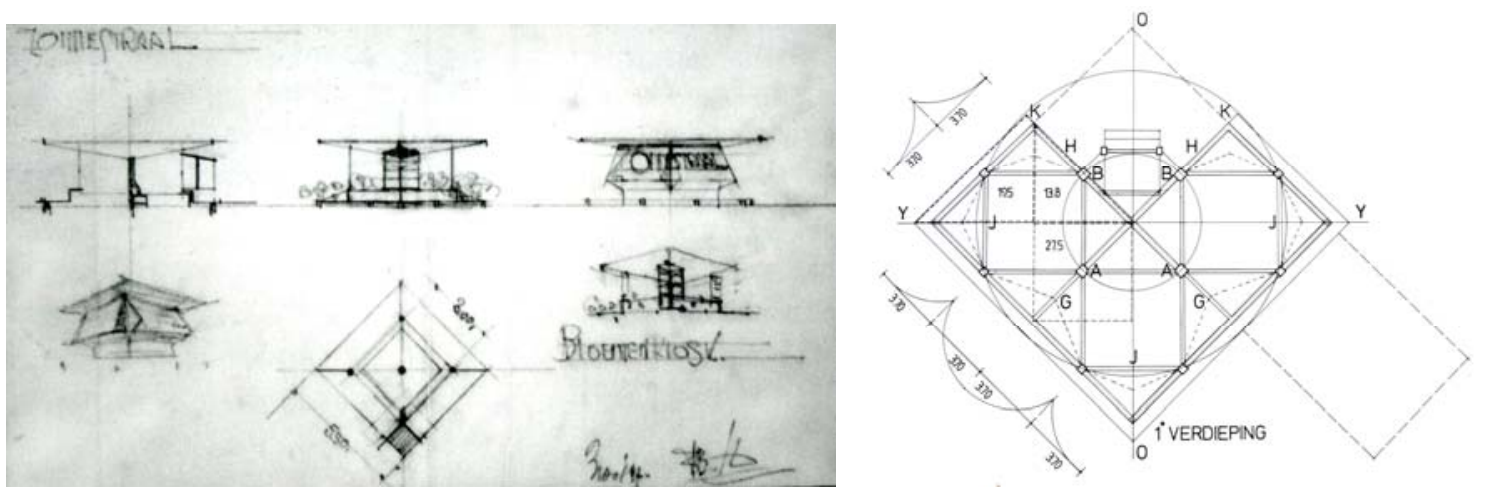

5.73 y 5.74
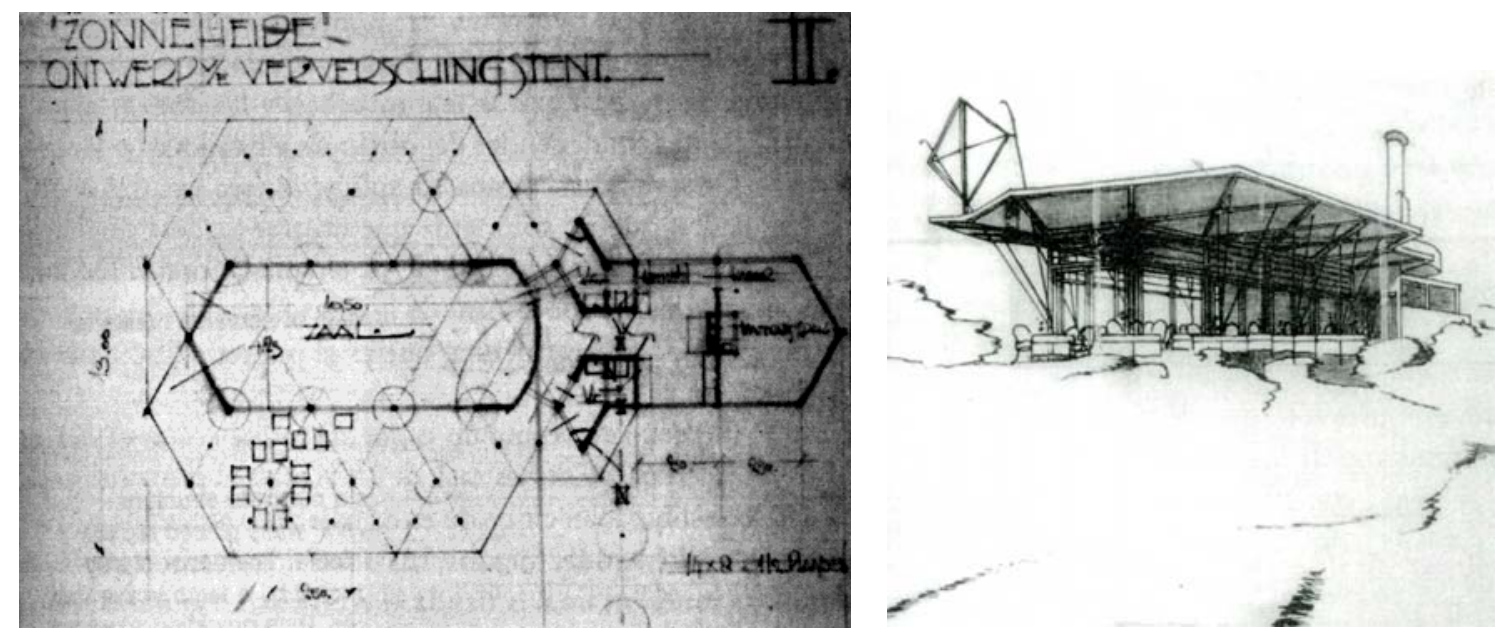

5.75 y 5.76

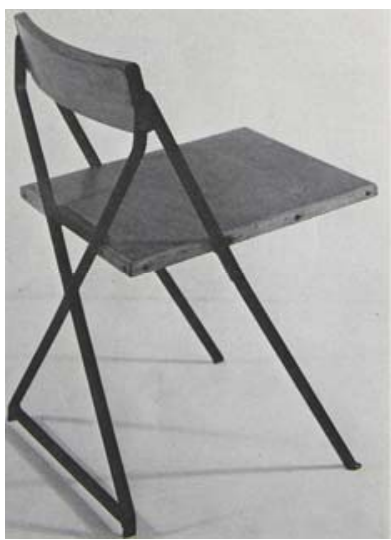

5.77 y 5.78
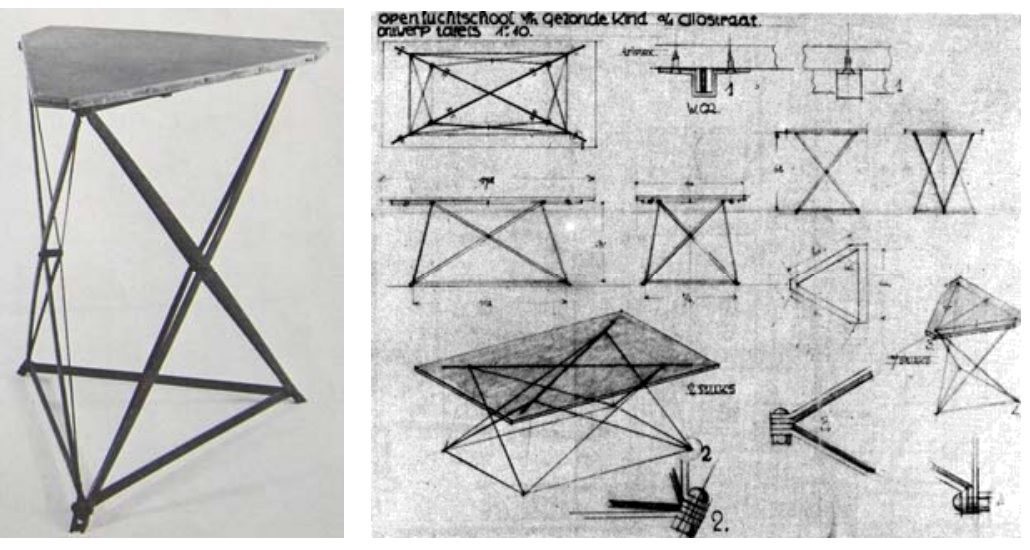

5.73 J. Duiker y B. Biivoet. Zonnestraal. Proyecto de kiosco de flores, 1927.

5.74 J. Duiker y B. Bijvoet. Escuela al aire libre Cliostraat, Ámsterdam 1927-1928. Planta de estructuras.

5.75 y 5.76 J. Duiker y B. Bijvoet. Zonnestraal. Proyecto del pabellón de refrescos, 1927 -

1930.Planta y perspectiva

5.77 y 5.78 J. Duiker y B. Bijvoet. Escuela al aire libre Cliostraat, Ámsterdam 1927-1928. Mobiliario imagen y plano. 


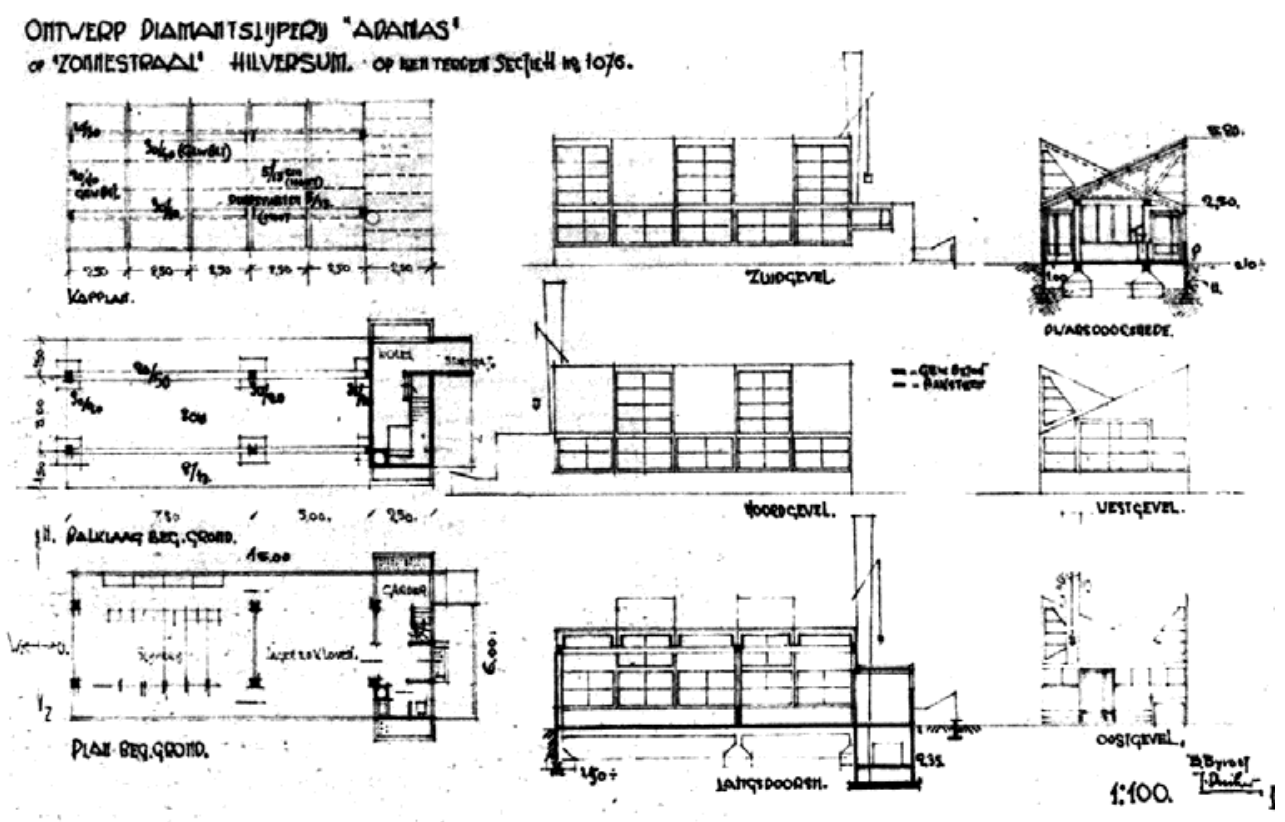

5.79
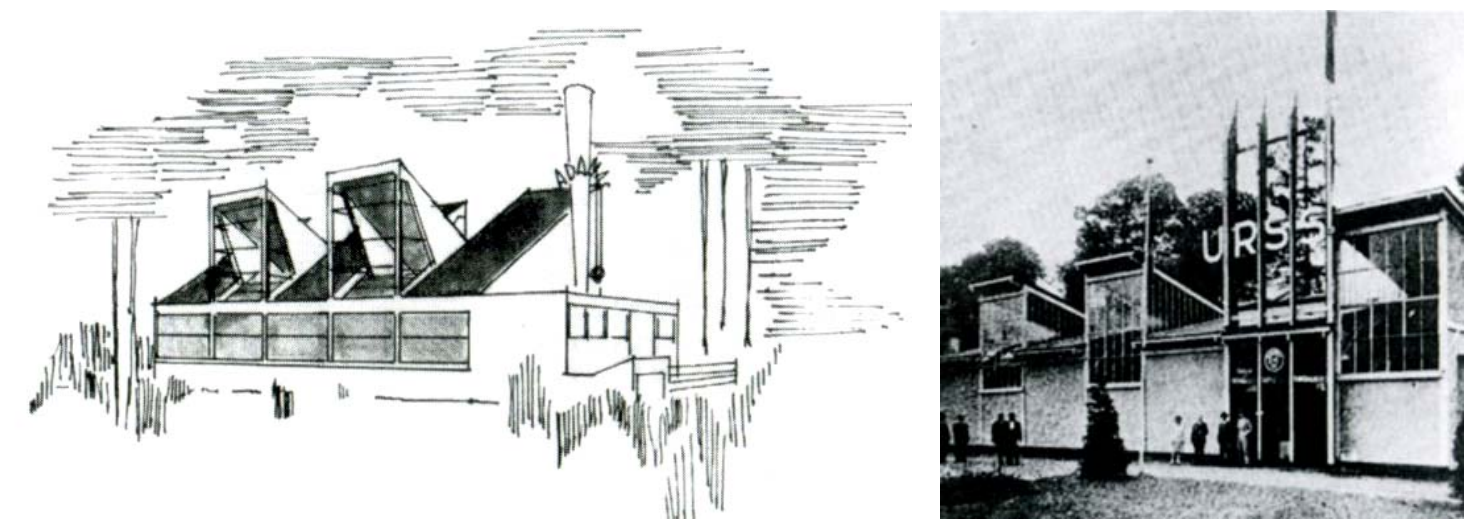

5.80 y 5.81
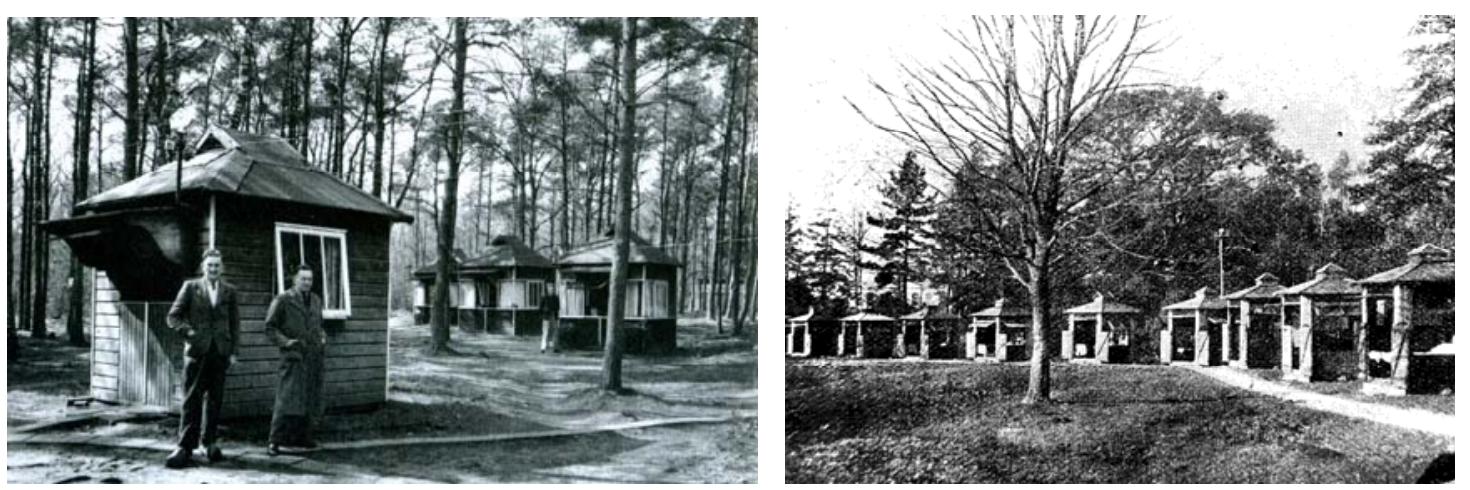

5.82 y 5.83

5.79 y 5.80 J. Duiker y B. Bijvoet. Zonnestraal. Proyecto del taller Adamas de pulido de diamante. Plano y perspectiva

5.81 Lubetkin. Pabellón ruso de la feria de Burdeos, 1931.

5.82 J. Duiker y B. Bijvoet. Zonnestraal. Cabañas de reposo, 1929.

5.83 Sanatorio de Papworth, ca. 1917. Cabañas de reposo. 
El deseo de Duiker por alcanzar la máxima apertura en las construcciones del Sanatorio de Zonnestraal se aplica al material mediante el empleo del vidrio, a la forma y a las soluciones estructurales. En varios proyectos no construidos para el Sanatorio, Duiker emplea estructuras metálicas extremadamente ligeras, y sistemas atirantados para la sustentación de livianas superficies de cubrición. De este modo Zonnestraal se convierte en un laboratorio arquitectónico del que surgirán propuestas arquitectónicas presentes en obras posteriores.

Uno de estos proyectos experimentales fue el kiosco de flores [fig. 6.73], realizado en el año 1927. Consiste en un cuadrado girado de 3 metros de lado, con una cubierta en vuelo también cuadrada de 5,50 metros de lado, soportada por un pilar central y por cuatro vigas dispuestas en diagonal cuya sección va disminuyendo desde el pilar central hasta el extremo, otorgando una gran sensación de ligereza a la edificación.

Una solución estructural similar fue aplicada en la construcción de la Escuela al aire libre de Cliostraat (1927-1928) [fig. 6.74], cuya planta de aulas define un gran cuadrado girado en planta que, al igual que en el kiosco de Zonnestraal, carece de pilares en los vértices llevando al límite la desmaterialización de la esquina.

También en este período, entre 1927 y 1930, se proyecta en Zonnestraal un interesante pabellón de refrescos [fig. 6.75 y 6.76], muy distinto al primero, realizado para el Sanatorio en el año 1922. Consiste en una sala acristalada rectangular con dos amplias terrazas a ambos lados, que Duiker trata de cubrir con una superficie sustentada por la menor cantidad de soportes verticales posible, mediante el empleo de elementos atirantados y superficies trianguladas, para conseguir estabilidad sin perder ligereza. Estas propuestas estructurales están presentes a mucha menor escala en el diseño del mobiliario llevado a cabo por Duiker en la Escuela al aire libre de Cliostraat [fig. 6.76 y fig. 6.77], donde el respaldo y el asiento de las sillas, así como los tableros triangulares de las mesas, están soportados por delgadas estructuras tubulares que evitan la transmisión de cargas en vertical, buscando la estabilidad mediante estados de equilibrio.

Mientras Duiker realiza estos proyectos, en febrero de 1928 se paraliza la construcción de otro proyecto suyo realizado para el Sanatorio, el taller Adamas para el pulido de

diamantes [fig. 6.78] que se quería construir para que los trabajadores, prácticamente curados, se fueran incorporando paulatinamente a las rutinas de su vida anterior. El taller, de planta rectangular, presentaba una estructura unidireccional en el centro, constituida por 
dos filas de pilares de hormigón de unos 2,50 metros de altura, y un cerramiento ligero de madera. Los pilares soportaban dos vigas longitudinales sobre las que se apoyaban una serie de cerchas triangulares que daban forma a la singular cubierta del mismo. Ésta tenía una fuerte inclinación a un agua, con la peculiaridad de que cada 2,50 metros se iba alternando el sentido de la pendiente, creando una imagen muy dinámica al exterior y una sección con grandes diferencias de altura en el interior. Duiker aprovechaba estos saltos de altura para introducir luz a través de las paredes laterales y de los frentes de la irregular cubierta [fig. 6.79]. La solución de la cubierta recuerda a la construida por Lubetkin en el pabellón ruso de la feria de Burdeos celebrada en $1931^{54}$ [fig. 6.81], aunque la inclinación de los faldones del tejado y la cubrición en madera evocan también a la vivienda para un horticultor, ya mencionada, proyectada en 1924 por Duiker y Bijvoet en Aalsmeer. Este será el primer proyecto de ambos construido en seco, en donde, a excepción de la escalera circular hecha de ladrillo, el resto de la vivienda estaba completamente edificada en madera, imitando a los sistemas constructivos empleados en la edificación de invernaderos.

Los mismos sistemas que utilizará Duiker en sus cabañas de reposo [fig. 6.82] proyectadas para el Sanatorio en el año 1929, siguiendo el modelo tradicional de las cabañas de Papworth [fig. 6.83]. Diseña los planos de montaje de un sistema modular que permita su auto-fabricación por parte de los enfermos y que su construcción sea también parte de la terapia.

Un año después, en torno a 1930, sigue investigando en el sanatorio sobre los sistemas constructivos en seco, pero cambia la madera por el acero y el vidrio. En esa época realiza su segundo proyecto para una escuela al aire libre en Zonnestraal [fig. 6.84 y 6.85], cuya configuración en forma de bloque lineal resulta totalmente opuesta a la composición radial de su proyecto anterior, realizado en 1926. El bloque que definía la escuela constaba de dos plantas, en la planta baja se ubicaban los porches o galerías abiertas, y en la superior las aulas, a las que se accede por un núcleo de escaleras independiente dispuesto cada dos aulas, eliminando así la necesidad de incluir un pasillo de conexión común. Los alzados de la escuela están constituidos por un frente continuo de vidrio que recuerda a la solución adoptada por Jan Gerko Wiebenga en las escuelas técnicas de Groninga construidas en 1922, en cuyo proyecto colaboró también el arquitecto Van der Vlugt, obra que es considerada el primer edificio funcionalista de los Países Bajos.

\footnotetext{
${ }^{54}$ Jan MOLEMA, Duiker Bouwkundig Ingenieur, constructeur in stuc en staal. TH Delft, Delft 1982,
} p. 135. 
Pese a haber sido elaborado después, Duiker empleará el esquema organizativo de este proyecto como punto de partida del proceso evolutivo que explica la definición formal de la Escuela al aire libre de Cliostraat en Ámsterdam ${ }^{55}$, esquema que consiste en la agrupación lineal de las aulas [fig. 6.89].

Otro proyecto para una escuela al aire libre, el realizado el 12 de mayo de 1927 en un emplazamiento teórico en Ámsterdam, representaría un siguiente paso en el proceso [fig. 6.86 y fig. 6.87]. En él la longitud del bloque lineal se reduce al distribuir las aulas en altura pero, para su resolución, es preciso incluir varios núcleos de escaleras o pasillos.

La escuela al aire libre de Cliostraat, representa la solución más compacta y eficaz, resuelta con un único núcleo de comunicación y sin pasillos. Consiste en una torre cuadrada con una disposición diagonal de las aulas [fig. 6. 88].

La misma disposición radial estará presente en la residencia de enfermeras de Zonnestraal proyectada y construida por Duiker entre 1930 y 1931 [fig. 6.90]. Un pequeño pabellón casi cilíndrico, con un dodecaedro de base y dos plantas de altura, construido en acero y vidrio. Aquí las escaleras no ocupan una posición central, como sucede en la Escuela al aire libre de Cliostraat o en los apartamentos Nirwana proyectados por Duiker y Wiebenga. El centro del pabellón está vacío e iluminado por un lucernario que emerge en la cubierta. Las escaleras tampoco constituyen un elemento independiente, tal y como Duiker llegó a plantear en uno de los estados intermedios del proyecto en el que la escalera era exterior [fig. 6.91], sino que se ubica en uno de los doce espacios interiores en que se compartimenta cada planta del pabellón.

El edificio recuerda al proyecto realizado por H.P. Berlage en el año 1915 para la construcción de un Panteón para la Humanidad, de planta también radial y de apariencia curva [fig. 6.93]. Pero, a diferencia del Panteón donde las particiones radiales coinciden con los ángulos del octaedro base, en la residencia de enfermeras los tabiques separadores de las habitaciones coinciden con los lados del dodecaedro base, de este modo, el tabique es ortogonal a la pared dando más amplitud a la habitación y facilitando su amueblamiento [fig. 6.94].

En un proyecto previo se diferencia formalmente la ubicación de la entrada y de la escalera rehundiendo ligeramente la fachada [fig. 6.92]. Sin embargo, en el proyecto definitivo se

55 Jan DUIKER: "De Openluchtschool voor het gezonde kind aan de Cliostraat in Amsterdam" en Zonnestaal $n^{\circ}$ 2, 1930 en E. J. JELLES, C. A. ALBERTS, Duiker 1890-1935. Recopilación del n5 y n6 del volumen 22 de la revista Forum, Amsterdam 1972, p. 24. 


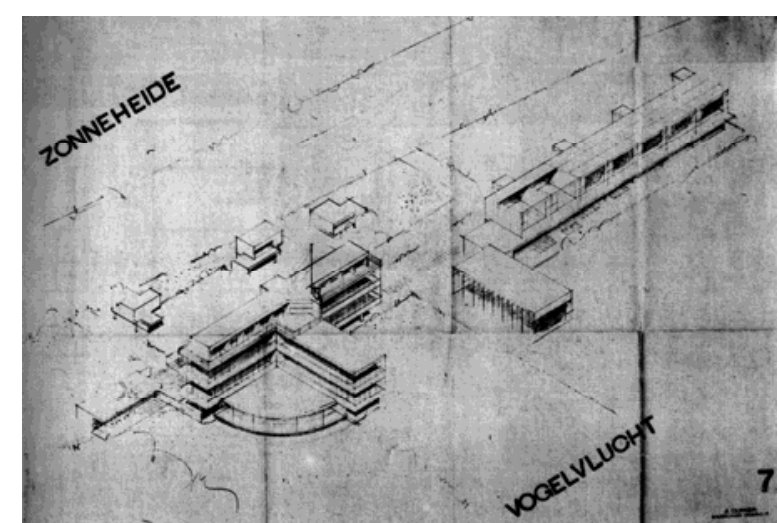

5.84 y 5.85

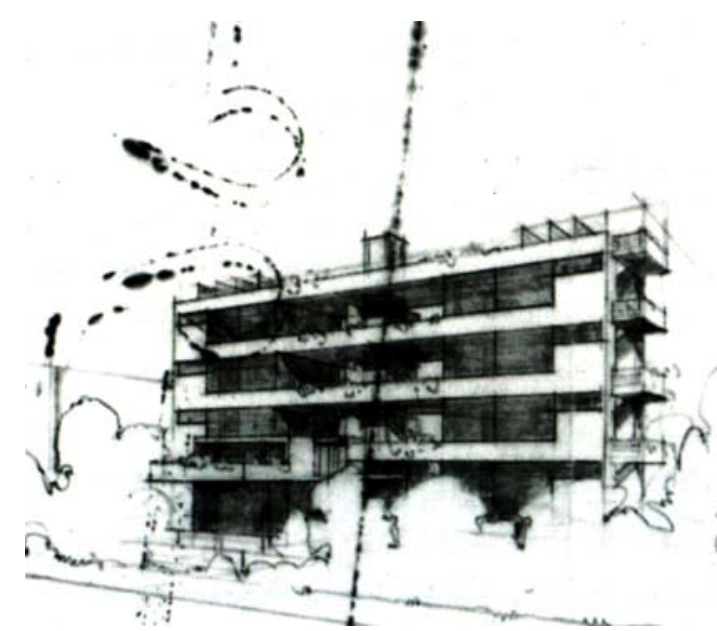

5.86 y 5.87
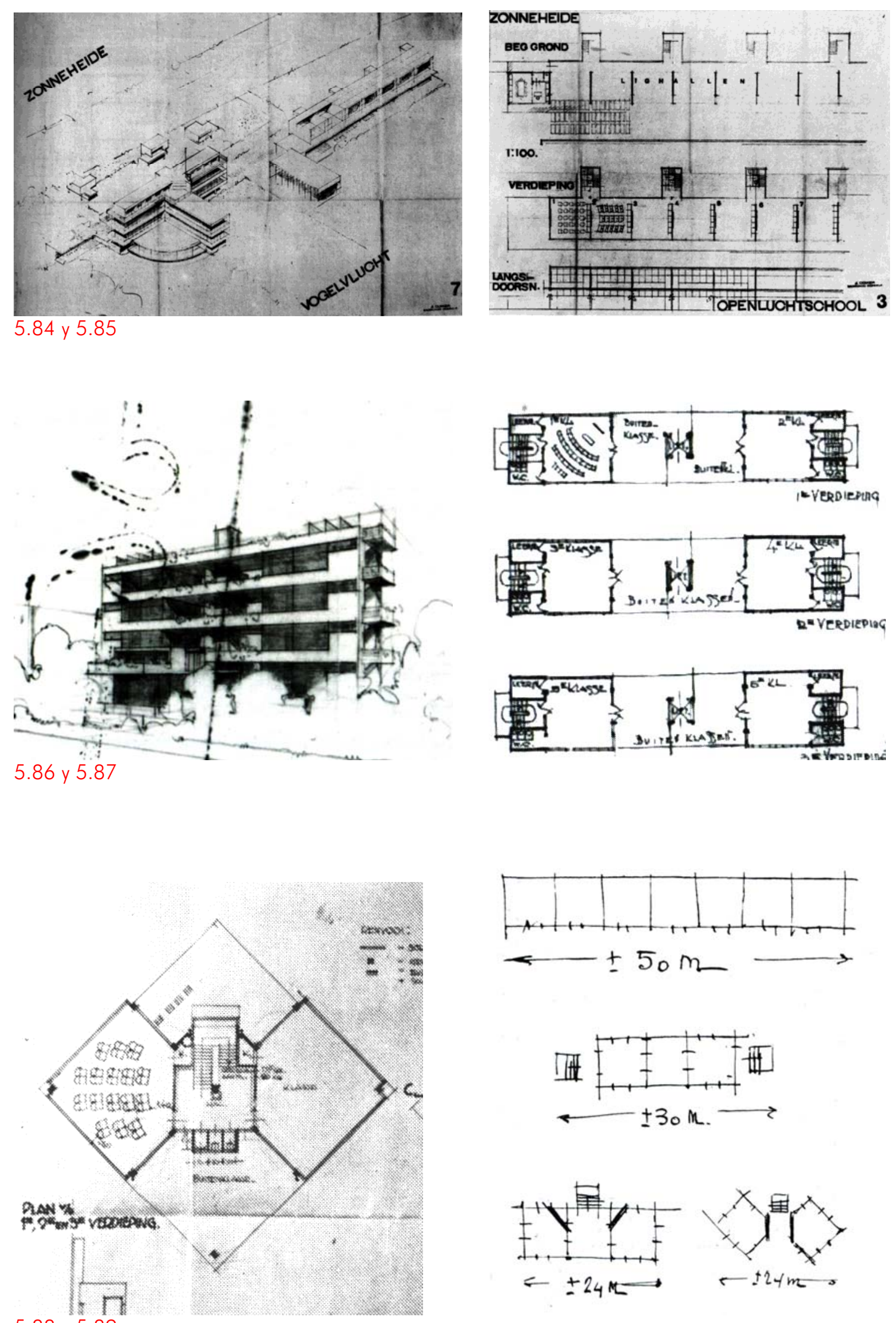

5.88 y 5.89

5.84 y 5.85 J. Duiker y B. Bijvoet. Zonnestraal. Proyecto de egunda escuela al aire libre, ca. 1930. Perspectiva y plantas.

5.86 y 5.87 J. Duiker y B. Bijvoet. Proyecto de Escuela al aire libre en un emplazamiento en Ámsterdam, 1927. Perspectiva y plantas.

5.88 y 5.89 J. Duiker y B. Bijvoet. Escuela al aire libre Cliostraat, Ámsterdam 1927-1928. Plano de planta y croquis explicativos. 
desecha la idea y se opta por una solución de gran rotundidad formal, donde se eliminan incluso los aleros existentes en propuestas anteriores para reforzar su prístino volumen. La centralidad hace del pabellón un objeto ajeno a la orientación y a las condiciones del lugar, susceptible de ser ubicado en cualquier entorno. Todo lo contrario de lo que sucede con los edificios residenciales de Zonnestraal, también ordenados en torno a un centro, pero que responden a las condiciones de orientación y a las vistas sobre el paisaje.

La búsqueda de una apertura espacial y de una óptima orientación, así como la de una eficiencia formal y material conduce a Duiker a experimentar con organizaciones radiales más compactas que las lineales y a su vez más abiertas, y con sistemas estructurales ligeros construidos en seco.

Frente a la isotropía de las organizaciones lineales donde todos los elementos que las componen pueden presentar idénticas cualidades de vistas y orientación, las organizaciones radiales son anisótropas y requieren de una mayor precisión en su uso. Cuando éstas adoptan formas circulares completas traicionan a los principios generadores de dicha ordenación haciendo un uso de la geometría más compositivo que funcional, como el que ya hicieron los iluministas y que retoman ciertos arquitectos del siglo XX, tal y como Antón Capitel explica en su libro La arquitectura compuesta por partes ${ }^{56}$.

El mismo año, 1931, en que se construye la residencia de enfermeras se inaugura el segundo edificio residencial de Zonnestraal, el pabellón Dresselhuys, designado con el nombre del director de la Cruz Roja holandesa, institución que colaboró activamente en la financiación del sanatorio de Zonnestral. Debido al aumento de los casos de tuberculosis, Zonnestraal dejó de funcionar sólo como centro de convalecencia para casos leves, y pasó a atender a enfermos de mayor gravedad. Este hecho obligó a que en el nuevo pabellón se incluyera en los extremos de los bloques de habitaciones dos montacamillas, uno en cada bloque, para facilitar el traslado de los enfermos encamados con escasa movilidad [fig. 5. 95 y 5.96]. Junto a ellos se construyeron también las escaleras de servicio que, a diferencia de las principales, no se acristalan por completo en la parte baja pasando más

\footnotetext{
56 "Y si bien es cierto que los instrumentos racionalistas - la geometría radical, la simplicidad, la repetición- pueden traicionar en buena medida sus objetivos funcionales para convertirse en nuevos mecanismos compositivos - como los grandes arquitectos iluministas pondrán de manifiesto-, también es verdad que fueron y son el medio de una transformación moderna, funcional, formal y material, que tendrá una gran importancia como bien sabemos; esto es, la gran revolución arquitectónica llamada moderna, la del siglo XX". Antón CAPITEL, La arquitectura compuesta por partes. Editorial Gustavo Gili, Barcelona 2009, p. 83.
} 


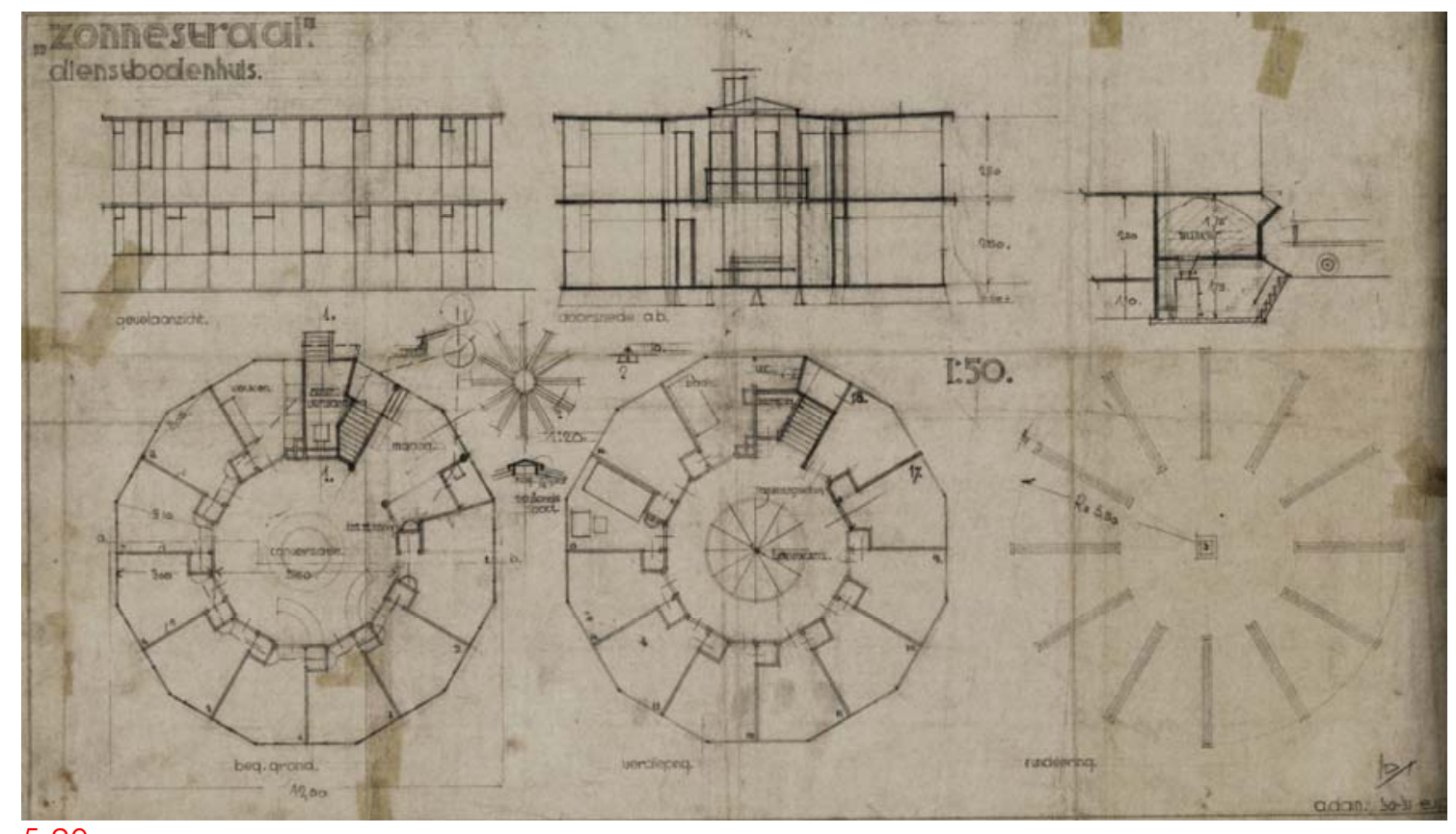

5.90
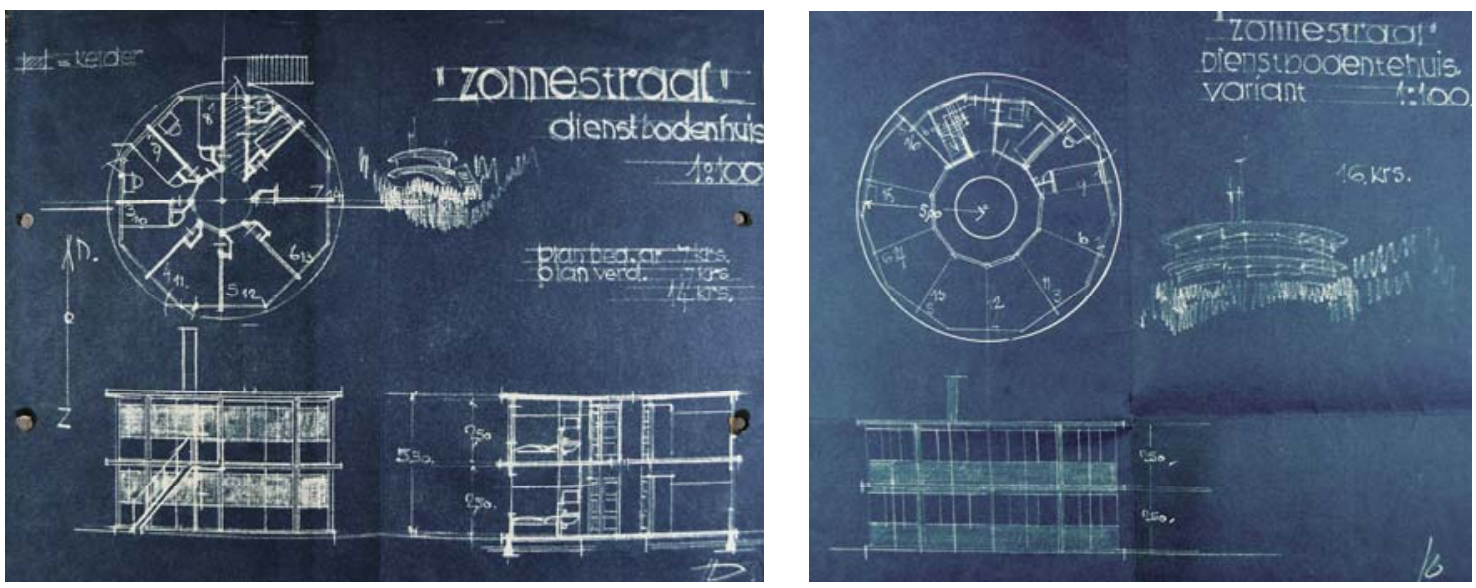

5.91 y 5.92
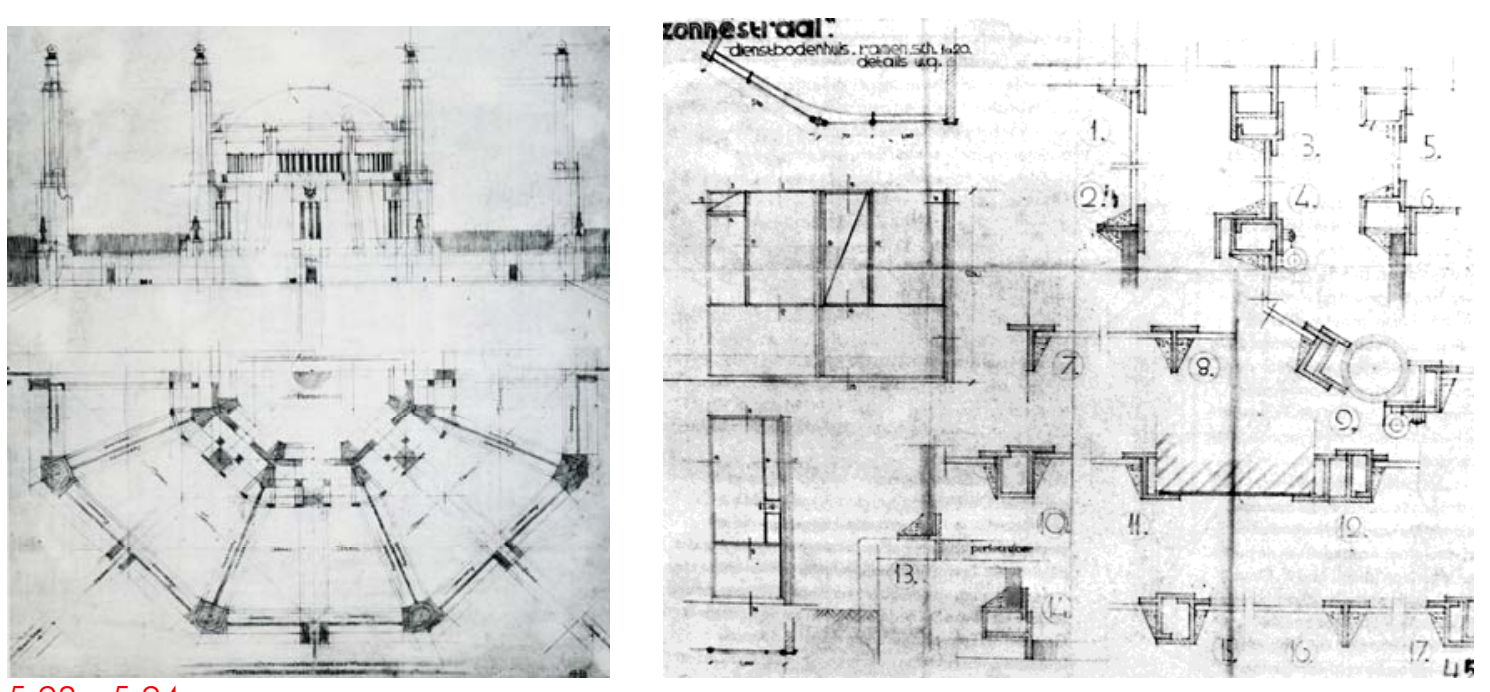

5.93 y 5.94

5.90 J. Duiker y B. Bijvoet. Zonnestraal. Pabellón de enfermeras, 1930-1931. Proyecto definitivo. 5.91 y 5.92 J. Duiker y B. Bijvoet. Zonnestraal. Pabellón de enfermeras, 1930-1931. Propuestas previas (Caja 43, carpeta 43_Bouwoen inrichting-Dunstbodehuis en kantina 1931-1933, IISG).

5.93 H. P. Berlage. Proyecto de Panteón para la Humanidad, 1915.

5.94 J. Duiker y B. Bijvoet. Zonnestraal. Pabellón de enfermeras, 1930-1931. Detalle. 


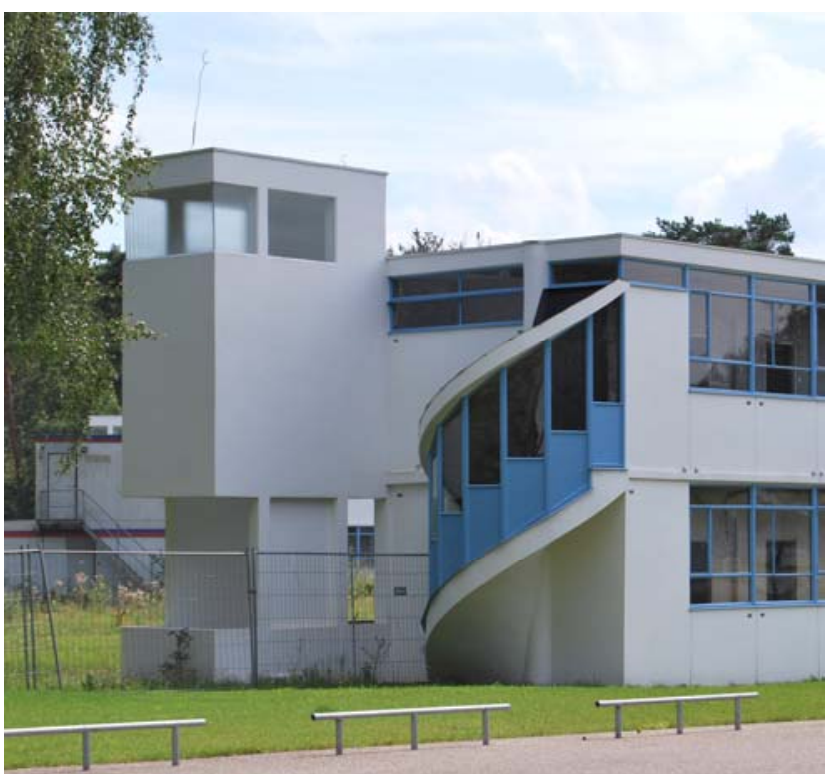

5.95 y 5.96

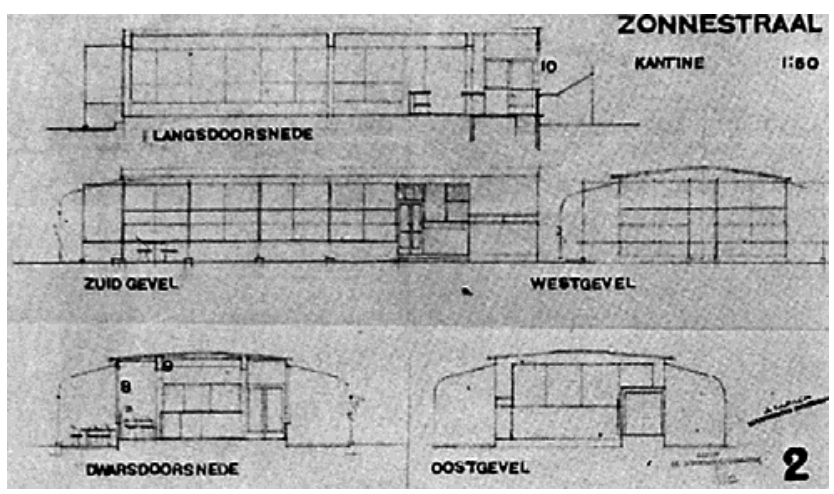

5.97
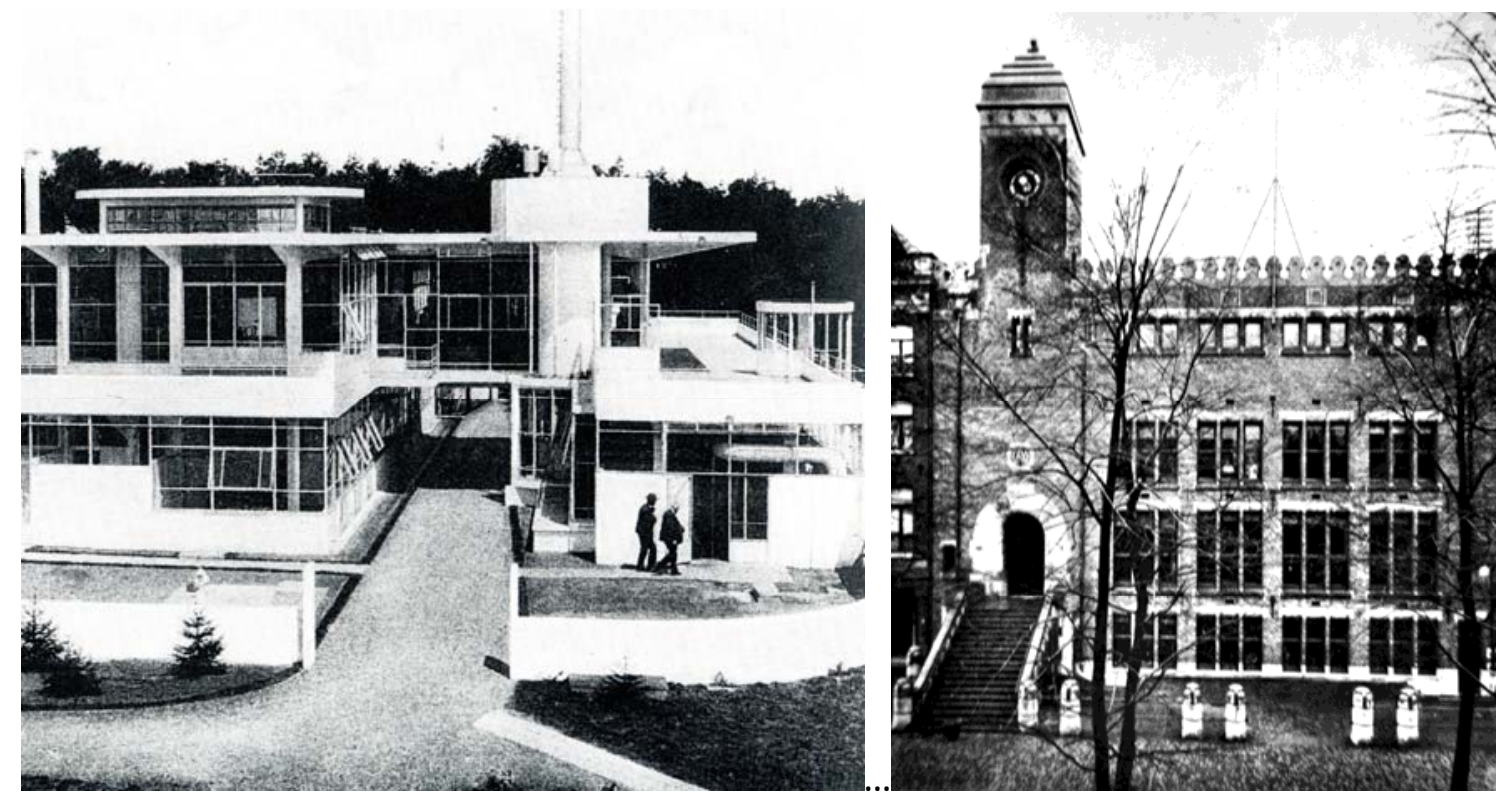

5.98 y 5.99

5.95 y 5.96 J. Duiker y B. Bijvoet. Zonnestraal. Pabellón Dresselhuys. Escalera y montacamillas (fotografía de la autora) y planta.

5.97 J. Duiker. Zonnestraal. Proyecto de cantina, 1932.

5.98 J. Duiker y B. Bijvoet. Zonnestraal. Pabellón principal, 1919-1928 (fotografía de la autora).

5.99 H. P. Berlage. Oficinas del sindicato holandés del diamante ANDB, 1898-1900. 

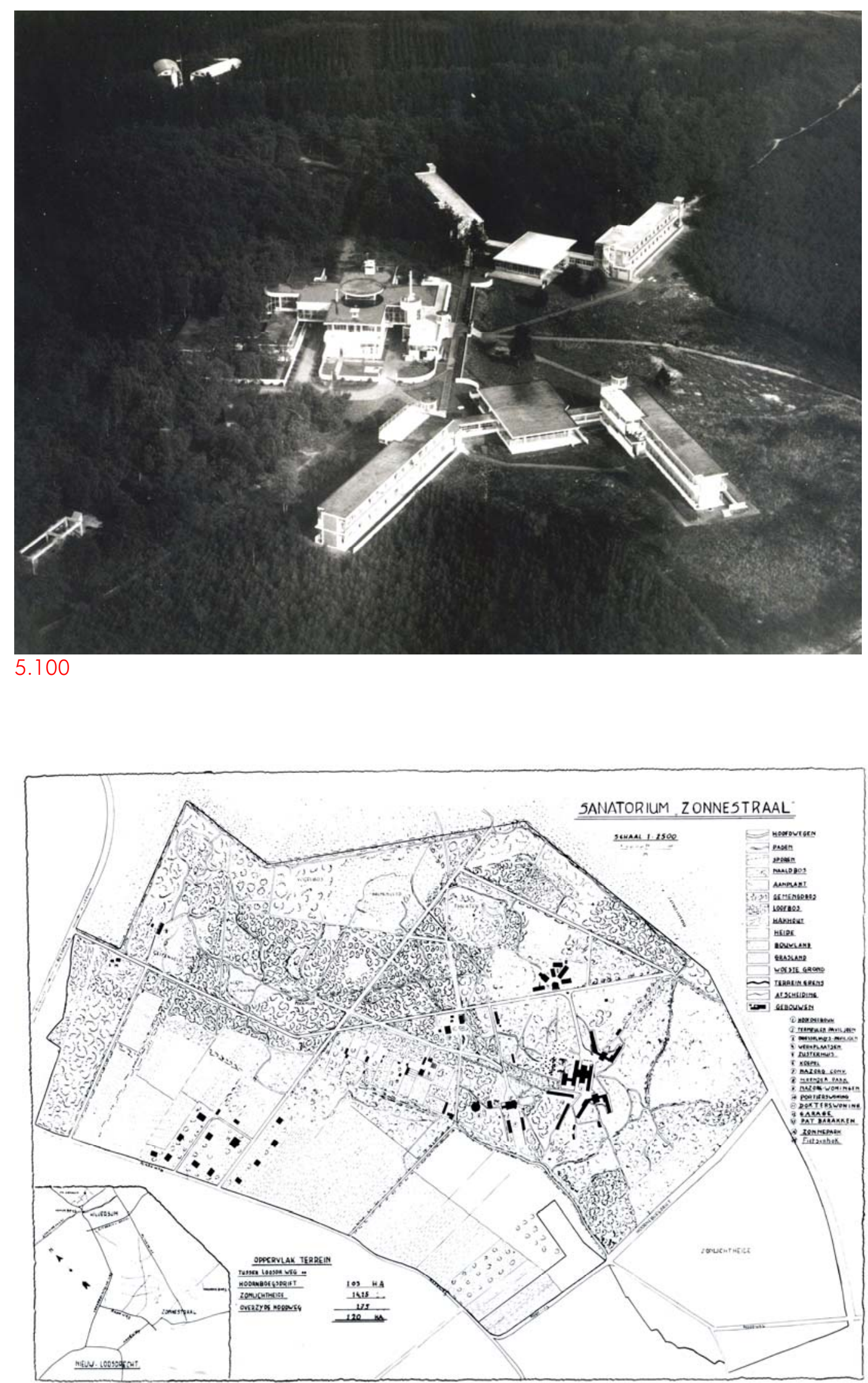

5.101

5.100 J. Duiker y B. Bijvoet. Sanatorio de Zonnestraal. Imagen 1931.

5.101 J. Duiker y B. Bijvoet. Sanatorio de Zonnestraal. Planta de situación 1940. 
desapercibido su arranque desde el suelo ${ }^{57}$.

La construcción del pabellón Dresselhuys permite realizar una versión mejorada del Henri ter Meulen, incorporando ciertas soluciones constructivas que sin variar el diseño original, incrementarán la durabilidad del edificio. Todo lo contrario de lo que sucede con el último proyecto realizado por Duiker para el Sanatorio en el año 1932. A petición de la Sociedad Zonnestraal, transforma el taller Adamas en cantina aprovechando la estructura que ya estaba construida, pero sustituye su singular proyecto de la cubierta, por otro curvo mucho más convencional [fig. 5.97]. Tres años más tarde, en 1935, fallece Johannes Duiker, ese mismo año se construyen el tercer y el cuarto taller de carpintería, siendo el quinto realizado por Bijvoet en el año 1940. Terminan así sus actuaciones en el Sanatorio de Zonnestraal, una obra eternamente inconclusa, pues nunca se construyeron los cuatro edificios residenciales proyectados en 1926, y a la que Duiker dedicó más de la mitad de su de vida profesional ${ }^{58}$.

Antes de su muerte, en el año 1932, el mismo en que Duiker realiza su último proyecto para Zonnestraal, Hendrik Petrus Berlage, su maestro y mentor, expresa públicamente su rechazo a la arquitectura con que al final éstos habían resuelto la obra:

"El nuevo funcionalismo con su tendencia capitalista está también regido al igual que la producción racionalizada por una idea: tan rápido y barato como sea posible. Los sindicatos no pueden aceptar un estilo sin consideraciones sentimentales como suyo propio. No pueden funcionar sin sentimiento" ${ }^{\prime 59}$.

Berlage, muestra su decepción ante la arquitectura funcional de Zonnestral [fig. 5.98], que deja muy atrás el lirismo wrightiano y la búsqueda de la belleza formal que Duiker y Bijvoet manifestaron en el proyecto de la Academia de Artes Plásticas de Ámsterdam que tanto emocionó a Berlage, características aún presentes en las primeras propuestas del Sanatorio cuando éste formaba parte aún del comité de supervisión; y cómo no, en la arquitectura

\footnotetext{
${ }^{57}$ Las escaleras resultaban necesarias para poder hacer uso del ascensor, ya que éste funcionaba manualmente a través de un mecanismo de poleas. Las enfermeras depositaban al enfermo en la plataforma elevadora, para después subir por la escalera de servicio y desde el piso superior accionar las poleas que hacían ascender la camilla.

58 Duiker dedicó 13 años, de los 20 que duró su carrera, a realizar proyectos para el sanatorio de Zonnestraal, desde el año 1919, momento en que recibe el encargo, hasta el año 1932 en el que elabora su último proyecto. La carrera de Duike, que había comenzado en 1915 con su licenciatura como arquitecto-ingeniero por la universidad de Delft, concluye con su muerte en 1935 en un exitoso momento profesional en el que estaba trabajando en el proyecto de varios cines y en el del Hotel Gooiland, que tras su fallecimiento concluirá su amigo, antiguo socio y el padrastro de sus hijos, Bernard Bijvoet.

59 Jan DUIKER, "Dr. Berlage y la Nueva Objetividad" en 8 en Opbow (8+O), 5, 1932 p. 43-59, en Rafael GARCÍA GARCÍA, "Tres Artículos de Duiker", Cuaderno de Notas n³, 1995, p. 34.
} 
neorromántica que él mismo empleó al construir las oficinas del sindicato del diamante, ANDB, en Ámsterdam [fig. 5.99].

La arquitectura generativa y modular aplicada por Duiker en el proyecto del Sanatorio trae consigo esa pérdida de representatividad o carácter que Berlage describe como "estilo sin consideraciones sentimentales ", lo que Sigfried Gideon explica en su artículo "Die architektonische Front", publicado en la revista 8 en Opbow en ese mismo año 1932 como: "el lenguaje de la forma ha quedado obsoleto; hoy en día la forma es sólo un medio con el que trabajamos y no un fin $^{\prime 60}$.

De este modo, el tradicional bloque lineal compacto, con planta simétrica y ortogonal en forma de T, o algo más radial en forma de "mariposa", presente en las tres primeras propuestas del Sanatorio Zonnestraal, pierde su forma y se fragmenta para definir el conjunto abierto de pabellones aislados que constituye el Sanatorio de Zonnestraal; simétrico y radial, organizado en torno a tres centros localizados en el eje donde, a través de la geometría, las partes de los edificios residenciales se ordenan para obtener el óptimo resultado formal que garantice las condiciones terapéuticas de higiene, luz y vistas que exige el programa del que sólo se llegan a construir dos de sus cuatro edificios residenciales [fig. 5.100 y fig. 5.101].

\section{LAS MODERNAS SALAS DE LA FÁBRICA DE CURAR ENFERMOS}

El proyecto definitivo del Sanatorio antituberculoso de Zonnestraal de 1926 pasa a disponer de una cabeza con el edificio principal y de cuatro edificios residenciales. El edificio principal se compone en planta baja, de un tamiz formado por cuatro bloques paralelos entre sí: el de enfermos graves en el extremo norte, seguido del bloque administrativo, del de las cocinas y del bloque de instalaciones en el extremo sur, y de una gran sala cruciforme sobrepuesta en la planta primera [fig. 5.102 y fig. 5.103]. Los edificios residenciales también poseen una sala común de conversación con una geometría casi cuadrada a la que se conectan a través de corredores independientes los bloques de las habitaciones de enfermos [5.104 y fig. 5.105].

Al mismo tiempo en que se gesta el proyecto definitivo, entre1925 y 1926, se elabora el proyecto de la factoría Van Nelle de tabaco, café y té de Róterdam [fig. 5.106] de J. A.

60 Jan DUIKER, "Manifiesto de Frank Lloyd Wright" en 8 en Opbow (8+O), 5, 1932 p. 177-184, en Rafael GARCÍA GARCÍA, "Tres Artículos de Duiker", Cuaderno de Notas n³, 1995, p. 41. 
Brinkman $^{61}$ y Van der Vlugł (1926-1930), una de las obras más emblemáticas de la arquitectura moderna holandesa y, en ambos proyectos, interviene el ingeniero civil Jan Gerko Wiebenga ${ }^{62}$.

Las fábricas modernas se han convertido en símbolos del progreso y del avance de la tecnología del momento. La arquitectura acristalada de las nuevas factorías supera el ámbito industrial y se adopta en otras obras, incluso en el campo sanitario como sucede en el sanatorio de Zonnestraal, dada la fascinación por la máquina de los arquitectos modernos, a la que se suman Duiker y Bijvoet:

"(...) productos tales como los vehículos de motor, los barcos de vapor, los yates, la ropa de caballero, la de deporte, los elementos eléctricos y sanitarios, los utensilios de cocina, etc., son expresión pura de su tiempo, contienen inherentemente los elementos de una estética y pueden ser considerados como puntos de partida para la apariencia exterior de un nuevo arte"63.

Con la construcción del Hôtel Dieu de París en el siglo XVIII, el hospital se define como una "máquina de curar" ${ }^{64}$, pero nunca antes, como sucede ahora en Zonnestraal, había asumido en él la estética de la máquina.

Esta adscripción atiende tanto a sus características formales como a su poder simbólico, ya que representa la ciencia y ésta encarna la fuente de esperanza del enfermo para su cura, convirtiéndose el sanatorio en una auténtica "fábrica de sanación".

Las primeras imágenes que se perciben al acercarse al Sanatorio son las de las chimeneas. La de ventilación de los talleres de carpintería, situada junto a la vía de acceso [fig. 5.107] y la chimenea-depósito de agua ${ }^{65}$ del edificio principal que emerge del bloque de

\footnotetext{
${ }^{61}$ Los trabajos preparatorios del proyecto los realiza su padre Michiel Brinkman en 1925, año en el que éste fallece, y se hace cargo de la obra su hijo. Rafael GARCÍA GARCÍA, Arquitectura Moderna en los Países Bajos 1920-1945. Akal, Madrid 2010, p. 192.

62 Rafael GARCíA GARCÍA, Arquitectura Moderna en los Países Bajos 1920-1945. Akal, Madrid 2010, pp. 104-109.

${ }^{63}$ Duiker y Bijvoet, "De nieuwe nijverheidsscholen te Groningen", BW 55 (1924) p. 22-25, en Rafael GARCÍA GARCÍA, Arquitectura Moderna en los Países Bajos 1920-1945. Akal, Madrid 2010, p. 221.

${ }^{64}$ Mercedes INSUA CABANAS, Arquitectura hospitalaria gallega de pabellones. Universidade da Coruña, A Coruña 2002, p. 99.

${ }^{65} \mathrm{Al}$ igual que ocurría en la vivienda de Aalsmeer (1924), donde el cilindro vertical que atraviesa la casa tiene una doble función, contiene la escalera y un depósito de agua en la cubierta; en Zonnestraal, la sobredimensionada chimenea se emplea también como depósito de agua, una solución bastante común en Holanda, con problemas de presión dada la horizontalidad de su orografía.
} 


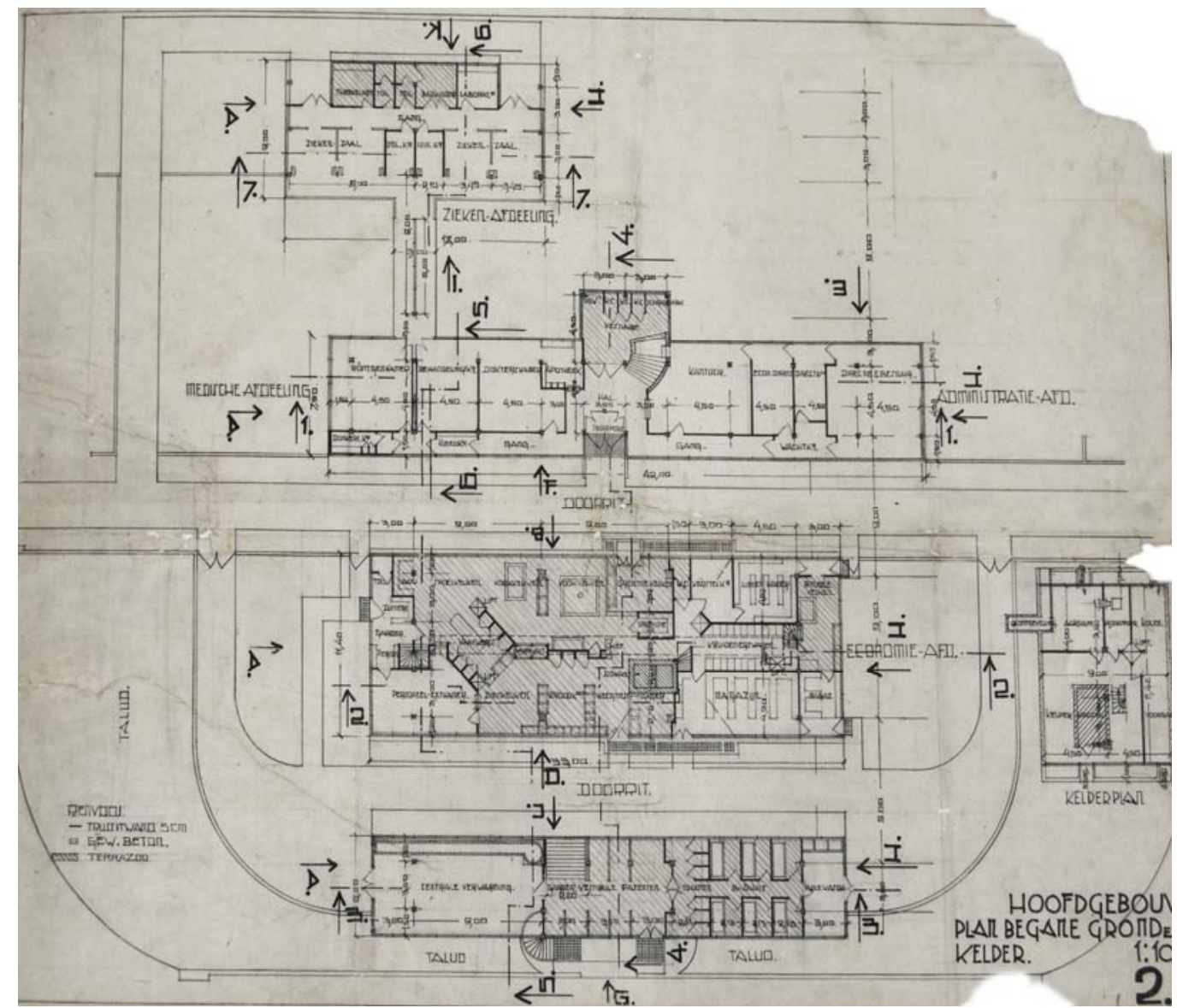

5.102

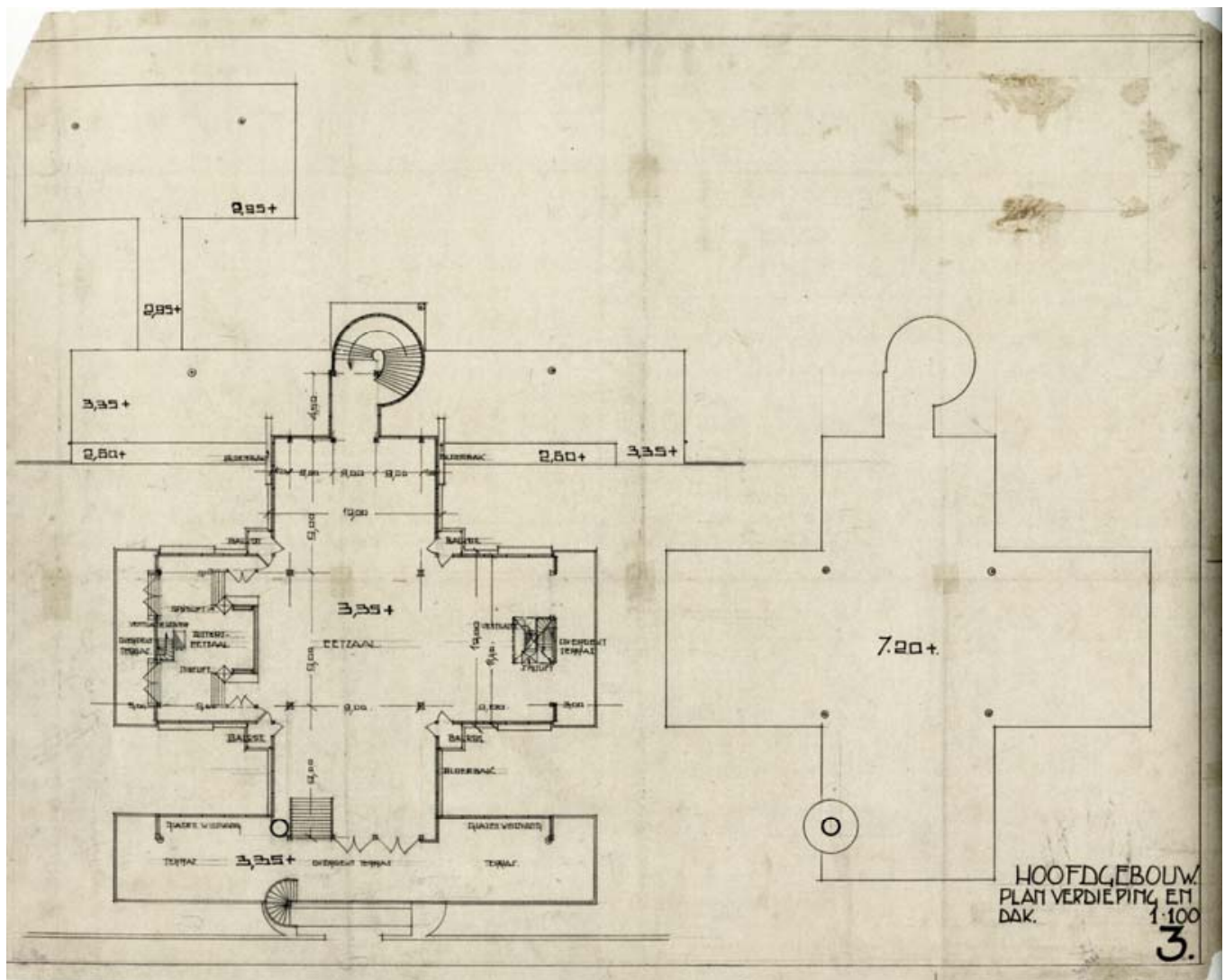

5.103

5.102 J. Duiker y B. Bijvoet. Zonnestraal. Edificio principal. Proyecto de 1926.Planta baja. 5.103 J. Duiker y B. Bijvoet. Zonnestraal. Edificio principal. Proyecto de 1926.Planta primera. 


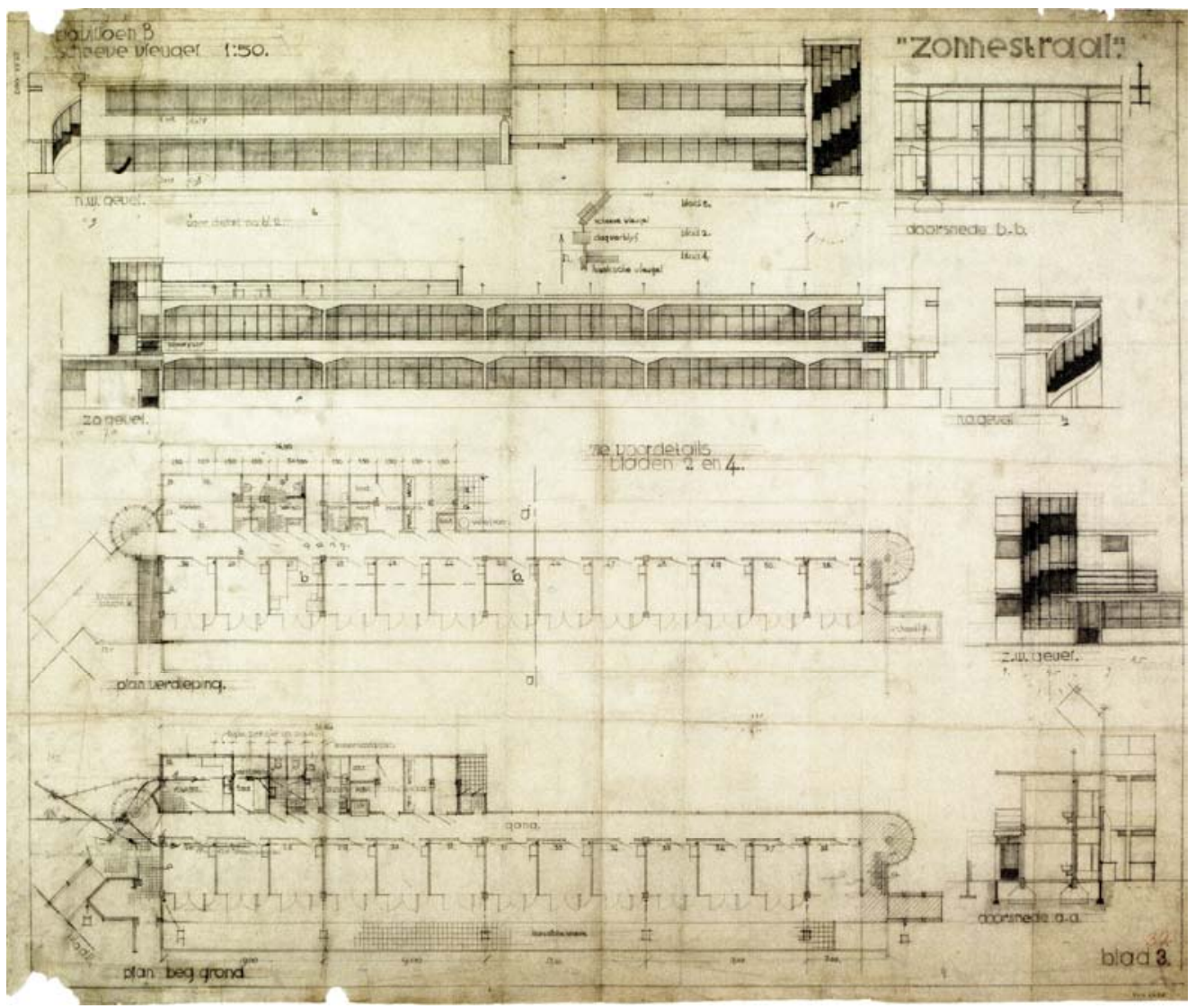

5.104

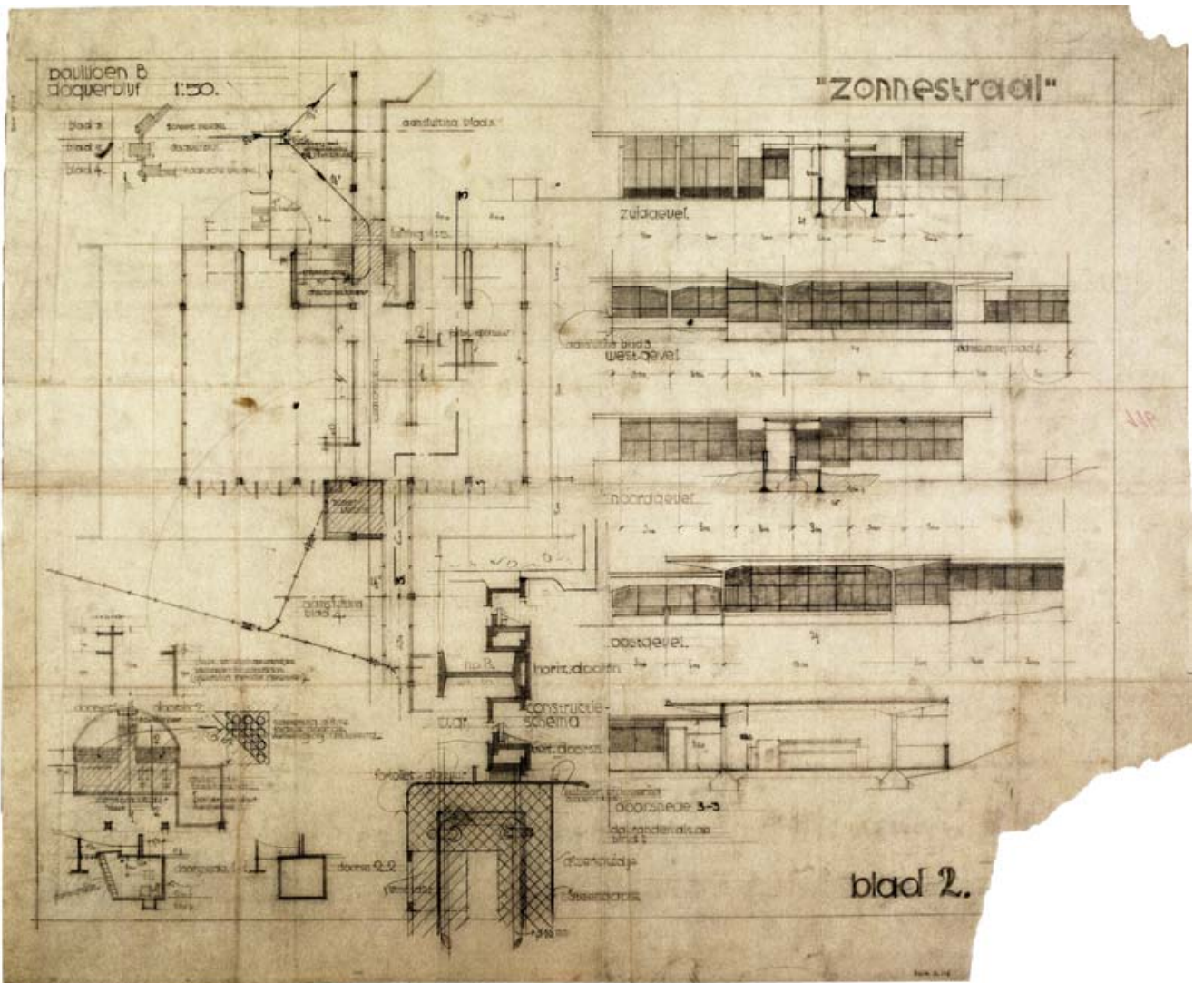

5.105

5.104 J. Duiker y B. Bijvoet. Zonnestraal. Edificio residencial. Pabellón Dresselhuys 1928. Bloque de habitaciones.

5.105 J. Duiker y B. Bijvoet. Zonnestraal. Edificio residencial. Pabellón Dresselhuys 1928. Sala de conversación. 


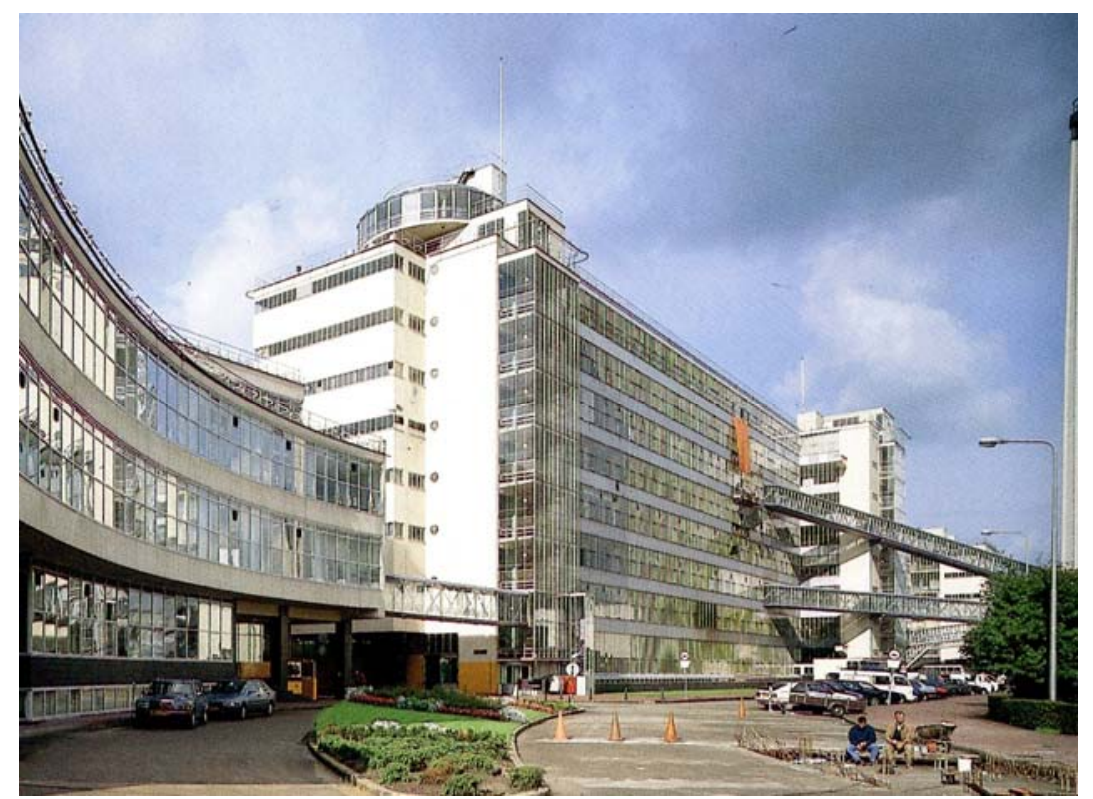

5.106

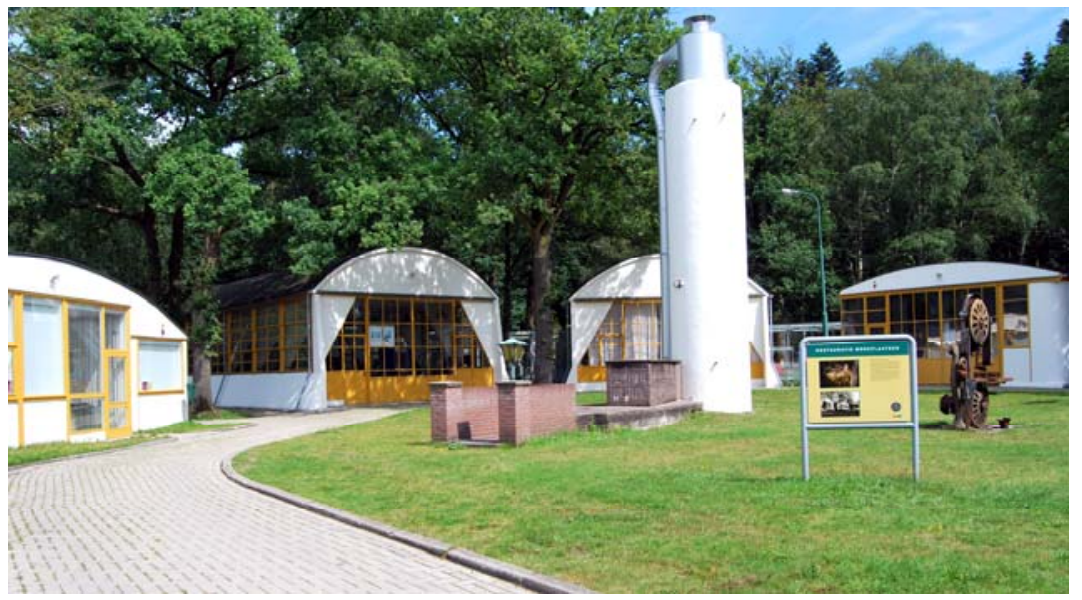

5.107

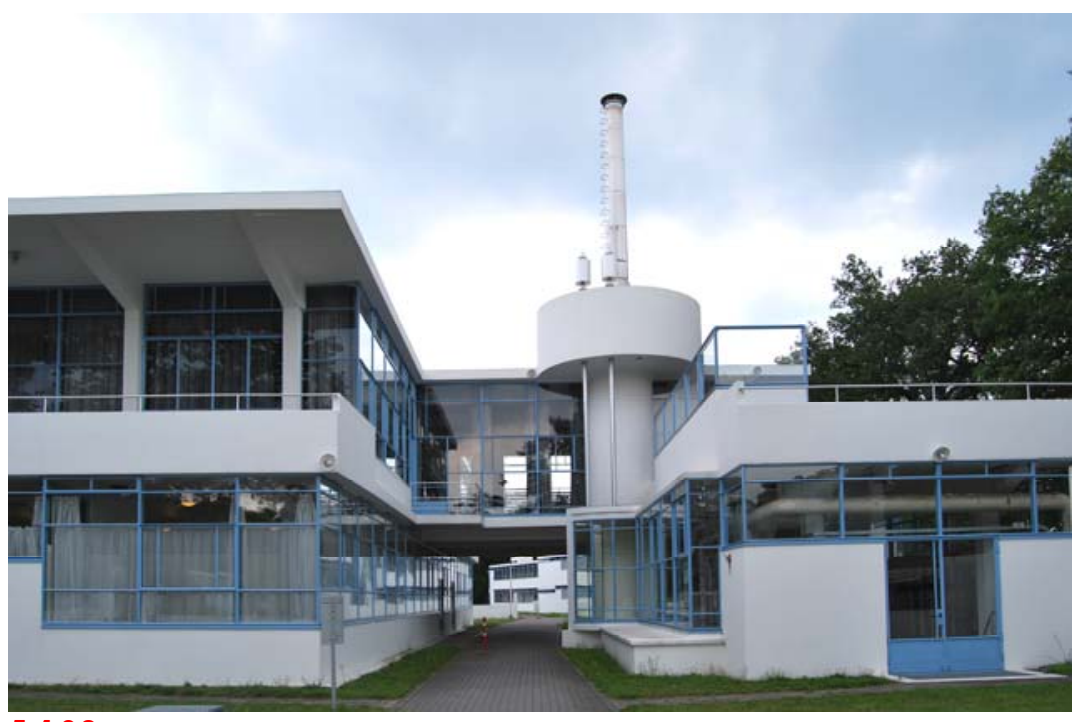

5.108

5.106 J. A. Brinkman y Van der Vlugt. Fábrica Van Nelle, Rotterdam 1926-1930.

5.107 J. Duiker y B. Bijvoet. Sanatorio de Zonnestraal. Talleres de carpintería (fotografía de la autora).

5.108 J. Duiker y B. Bijvoet. Sanatorio de Zonnestraal. Edificio principal (fotografía de la autora). 


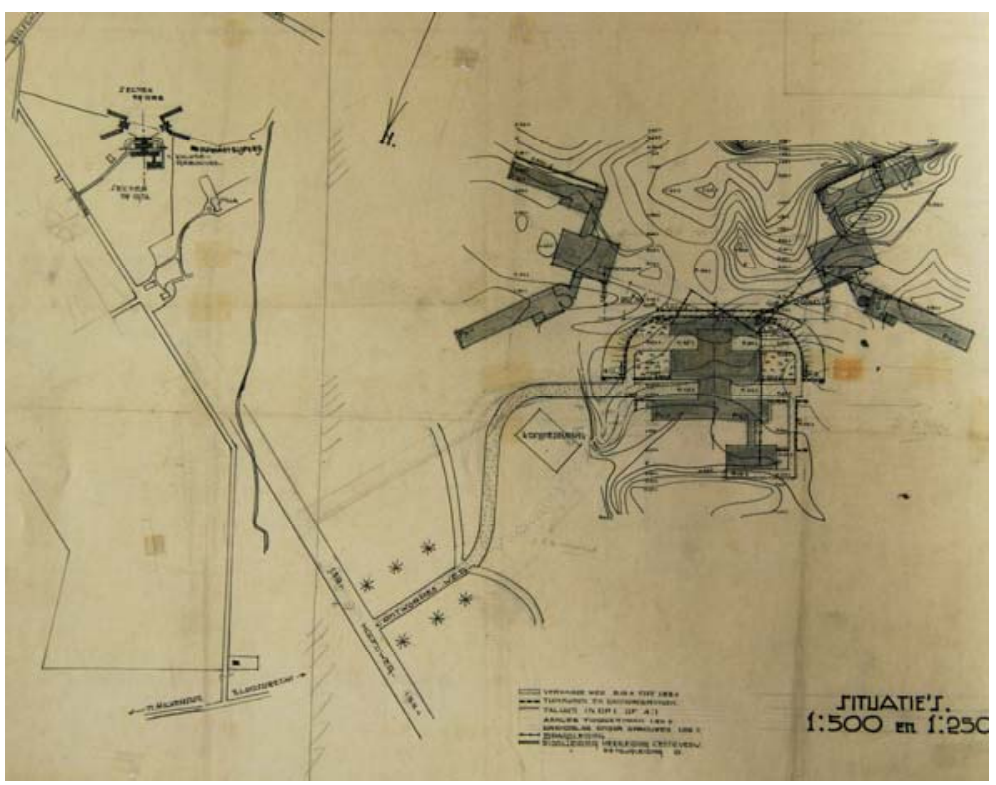

5.109

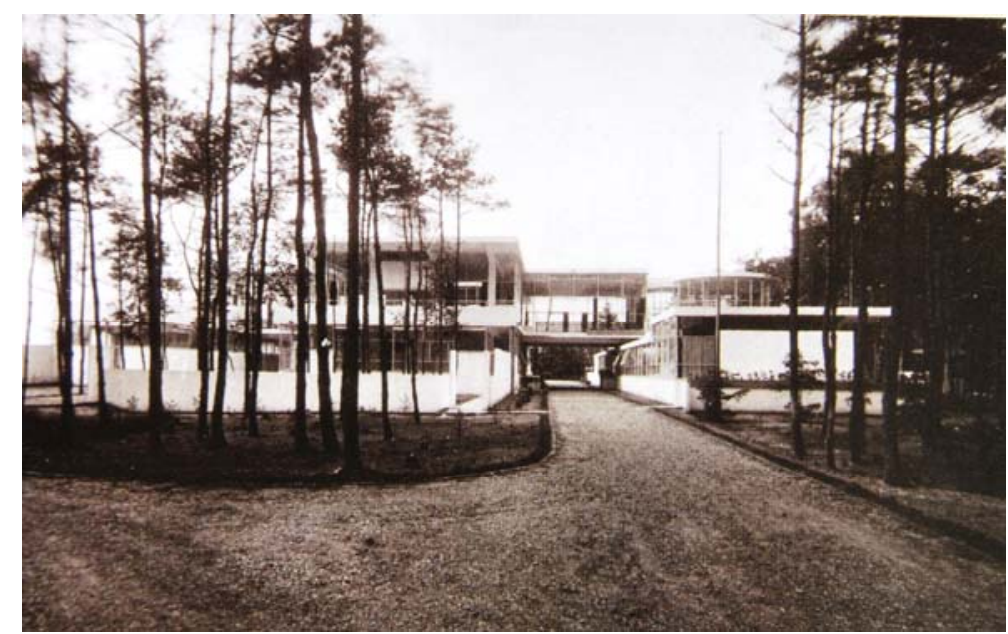

5.110

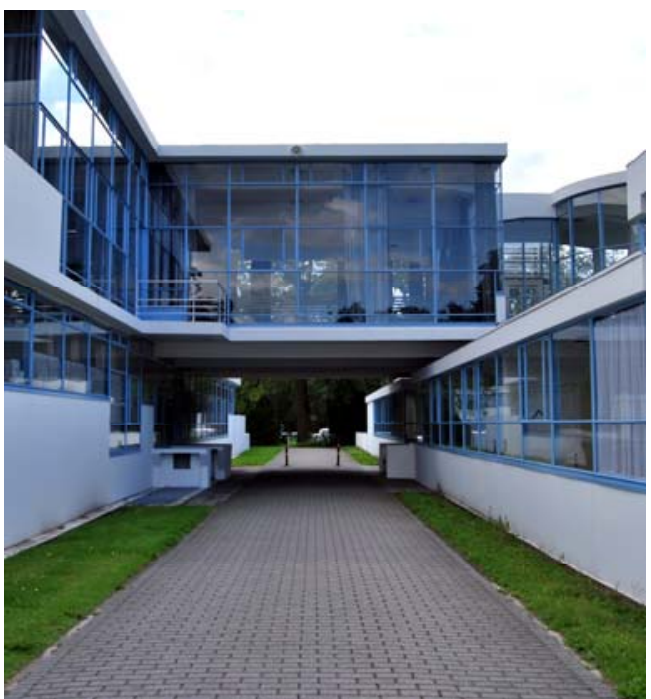

5.111

5.109 J. Duiker y B. Biivoet. Zonnestraal,1926. Plano de acceso al Sanatorio.

5.110 J. Duiker y B. Bijvoet. Sanatorio de Zonnestraal. Edificio principal, acceso.

5.111 J. Duiker y B. Bijvoet. Sanatorio de Zonnestraal. Edificio principal, vía de acceso (fotografía de la autora). 


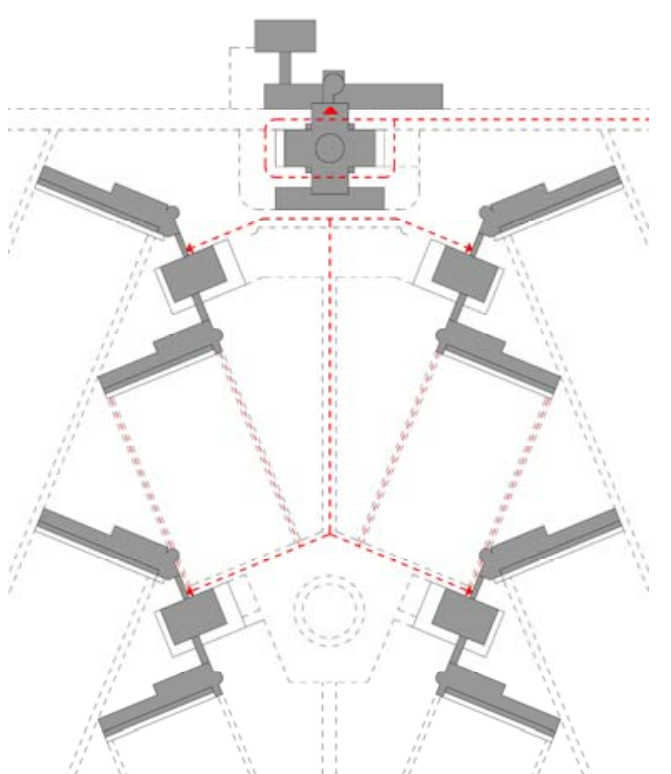

5.112
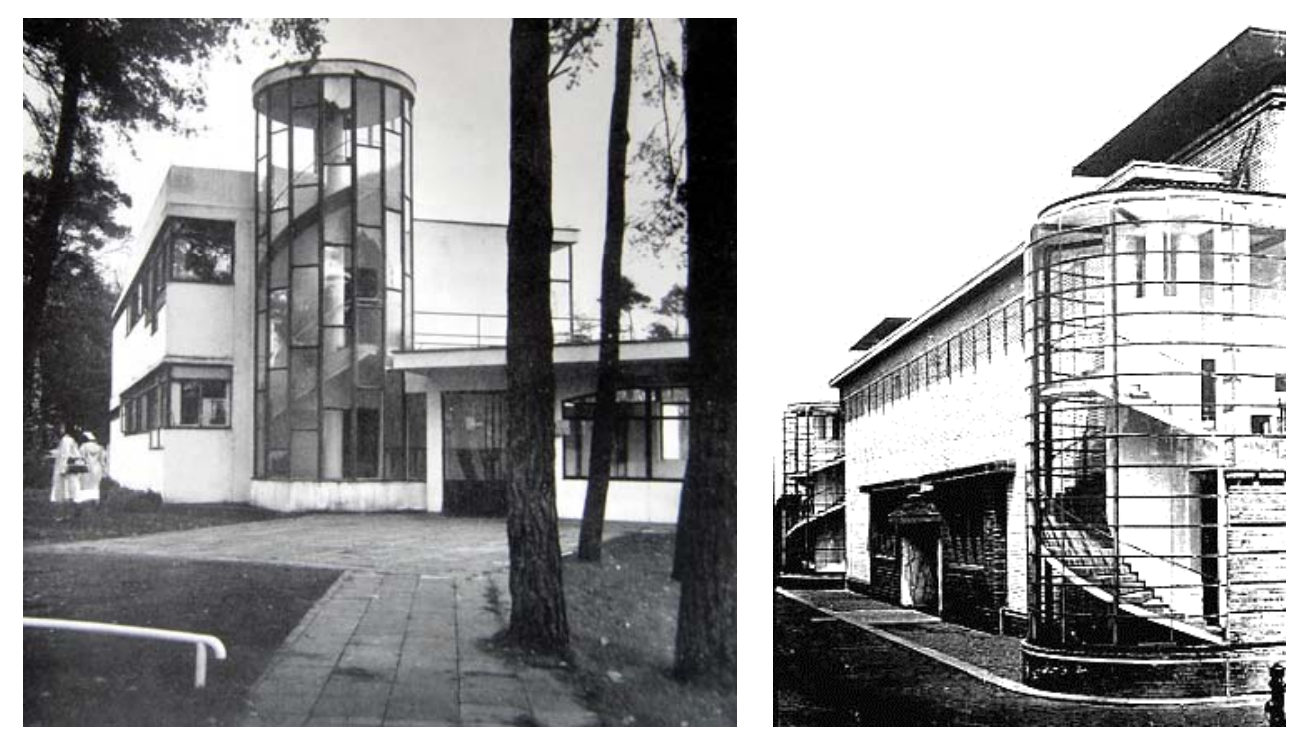

5.113 y 5.114
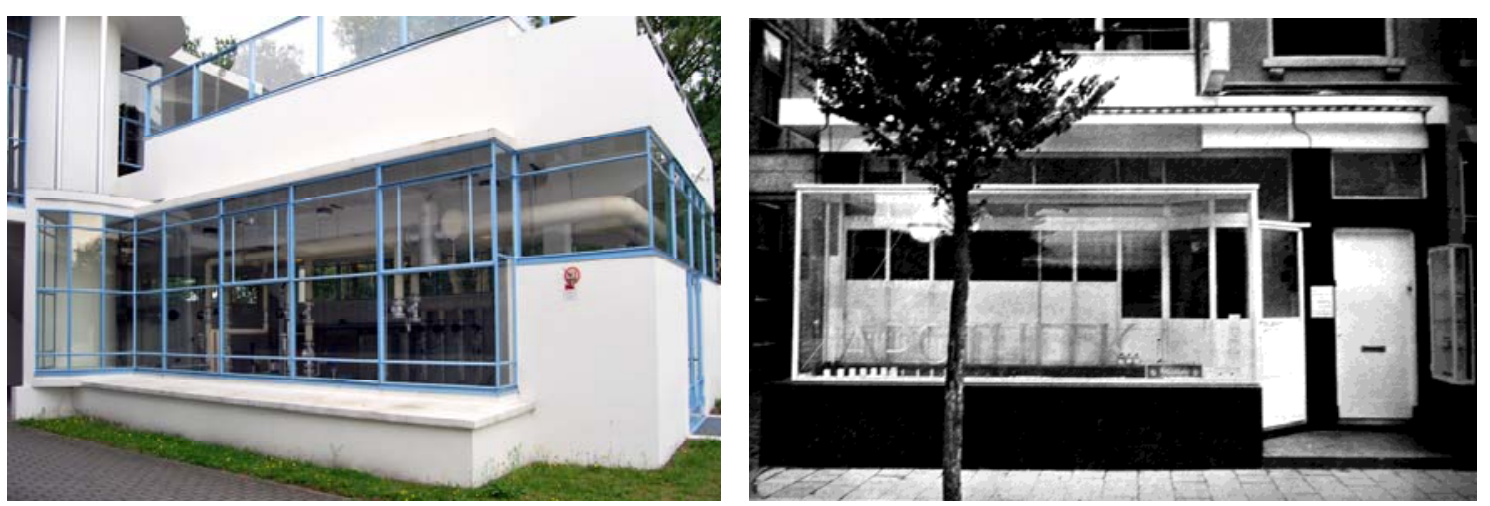

5.115 y 5.116

5.112 J. Duiker y B. Bijvoet. Zonnestraal. Recorridos principales (dibujo de la autora). 5.113 J. Duiker y B. Bijvoet. Zonnestraal 1919-1928. Escalera del edificio residencial. 5.114 W. Gropius. Factoría Fabrik. Exhibición de Werkbund Colonia, 1914.

5.115 J. Duiker y B. Bijvoet. Zonnestraal 1919-1928. Bloque de instalaciones (fotografía de la autora).

5.116 J. Duiker y B. Bijvoet. Farmacia de Zandvoort, 1925. 
instalaciones. Son los hitos verticales y símbolos que le proporcionan la identidad fabril [fig. $5.108]$.

La vía de acceso rodado y peatonal atraviesa la planta baja del pabellón principal. Proviene de la zona de talleres situada al este y rodea el bloque de la cocina formando un anillo; discurre entre éste y el bloque de los servicios médico-administrativos en dirección de entrada, y entre el bloque de instalaciones y el de la cocina en dirección salida [fig. 5.109]. En el proyecto original la masa arbórea situada junto a ambos lados de la carretera de acceso encuadra las vistas hacia el paso cubierto del pabellón principal ${ }^{66}$ [fig. 5.110]. gran dintel formado por el comedor de la planta primera montado sobre los tres bloques de planta baja define las puertas de entrada y salida del sanatorio [fig. 5.111].

Los bloques de servicios médico-administrativos, cocinas e instalaciones, al secundar la dirección de la vía, suponen un límite físico que impide el contacto visual entre el mundo de los sanos y el mundo de los enfermos. El cobijo del enfermo se encuentra en el pequeño pabellón para los graves situado al norte y en los pabellones para todos los demás ubicados al sur. Estos últimos están conectados por vías peatonales, la principal coincide con ele eje de simetría y las secundarias son perpendiculares a los brazos de los edificios residenciales [fig. 5.112]. Se crea así una trama de recorridos oblicuos que dirigen al viandante hacia los accesos de los edificios focalizando los cilindros acristalados que encierran las escaleras de caracol [fig. 5.113], nuevos hitos verticales que, como la chimenea del pabellón principal, tienen también reminiscencias fabriles y recuerdan a las escaleras diseñadas por Walter Gropius en 1914 para la factoría Fabrik [fig. 5.114]; aquellas que a Sigfred Giedion le: "parecían adquirir un movimiento como aprisionado e inmovilizado en el espacio" ${ }^{\prime \prime 67}$. Junto a ellas se ubican las puertas de entrada a los pabellones residenciales, fuera de la sala de conversación central, donde habitualmente se solían encontrar en los sanatorios unitarios con planta en forma de T o mariposa.

La búsqueda de intimidad frente al acristalamiento provoca un distanciamiento de Zonnestraal con la fábrica Van Nelle y otras construcciones racionalistas cuyo uso no es residencial, donde el vidrio se emplea de una manera indiscriminada, como plantean los

\footnotetext{
${ }^{66}$ En la actualidad la vegetación de uno de los lados de la carretera de acceso ha desaparecido al construirse un aparcamiento junto a la entrada del pabellón principal, de modo que al acceder al Sanatorio se ve en primer término la espalda del pabellón Dresselhuys.

${ }^{67}$ Sigfried GIEDION, Espacio, tiempo y arquitectura (Space, time and architecture, 1941). Editorial Dossat, Madrid 1982, p. 508.
} 
seguidores de la Neve Sachlichkeit (Nueva Objetividad) que quieren imponer una nueva manera de mirar que va más allá de la apariencia ${ }^{68}$. En el Sanatorio el nivel de acristalamiento se adapta al uso y a la privacidad de cada espacio, sin por ello impedir que la luz homogénea procedente de varios frentes o de grandes ventanales, y la sensación de apertura estén presentes en todo el edificio. Como describe Van der Steur, en Zonnestraal: "Se ve el interior de la sala de calderas, de la cocina - se puede decir que sólo las habitaciones y los cuartos de baño están cerrados a las vistas desde el exterior, ipero hasta el umbral del WC está abierto!"69.

El frente de la sala de calderas contenida en el bloque de instalaciones está compuesto por una caja de vidrio que se despega de la fachada [fig. 5.115], muy similar al escaparate de la farmacia de Zandvoort realizado por Duiker y Bijvoet en 1925 [fig. 5.116]. Tras él se exhiben las máquinas y conductos de calefacción estratégicamente expuestos a los ojos del visitante, al estar ubicada junto a la vía de salida del Sanatorio remarcando así el carácter tecnológico y fabril del mismo.

Junto a la sala de calderas se ubica el guardarropa ocupando la parte central del bloque de instalaciones; a través de él se accede por una escalera de un solo tramo a la sala principal de la planta primera y está comunicado con una sala de aseos y baños [fig. 5.117 y fig. 5.118]. Los conductos que parten de la sala de calderas y proporcionan agua caliente a los baños son aprovechados para calentar y secar los abrigos de los enfermos, colgados en los percheros, al traspasar serpenteando el guardarropa ${ }^{70}$.

Al norte del bloque de instalaciones se ubica el que contiene la cocina, que coincide con uno de los brazos del salón-comedor de la planta primera, con el que se comunica a través de varias escaleras de servicio y montaplatos. La cocina está constituida por una amplia zona diáfana a la que se accede a través de los laterales este y oeste, además está conectada con el exterior por un muelle de carga y descarga enfrentado a la entrada principal del sanatorio [fig. 5.119]. Contiene, entre otros espacios, una zona de

${ }^{68}$ G.F. HARTLAUB. Carta a Alfred H. Barr Jr., julio de 1929: "La expresión Neve Sachlichkeit en realidad la acuñé yo en 1924. Un año después se celebró la exposición de Mannheim que llevaba el mismo nombre. La exposición debía aplicarse realmente como etiqueta de ese nuevo realismo que tenía cierto sabor socialista. (...) el lado positivo se expresa en el entusiasmo por la realidad inmediata como resultado de un deseo de tomarse las cosas de un modo completamente objetivo, apoyándose en fundamentos materiales y sin asignarles inmediatamente unas implicaciones ideales. En Alemania, ésta sana desilusión tiene su mejor expresión en la arquitectura". Citado en: Kenneth FRAMPTON. Historia crítica de la arquitectura moderna. Gustavo Gili, Barcelona 2009 (Modern Architecture: A Critical History, 1980), p. 132.

${ }^{69}$ Van der STEUR, "Zonnestraal" en Bouwkundig Weekbladn²9, 1928, p.228.

${ }^{70}$ Esta misma idea se aplicará en la Escuela al aire libre de Cliostraat, en Ámsterdam, donde Duiker diseña un perchero cuyos soportes son los tubos de calefacción. 
almacenamiento, unida a través de una escalera con un sótano inferior, y un comedor para los trabajadores con acceso independiente.

Hacia el norte y en paralelo está el bloque de administración y servicios, conectado con el bloque de enfermos graves por un corredor exterior cubierto, atravesado por un muro de cristal que unifica las fachadas y cierra el recinto [fig. 5.120]. Es algo más estrecho que el de las cocinas y más largo que todos los demás y contiene un corredor longitudinal situado en la fachada sureste que distribuye las estancias. En la mitad del bloque se ubica la entrada principal con la gran escalera de caracol que da acceso al comedor [fig. 5.121]. Al lado este de la entrada están los despachos de dirección con la sala de juntas y, en el opuesto, frente al pabellón de enfermos graves, se desarrolla la escueta área médica que consta tan sólo de un despacho, una sala de curas [fig. 5.122] y otra de rayos $X$, ya que se trataba de un sanatorio de convalecencia ${ }^{71}$.

Por último, en la posición más septentrional, se encuentra el bloque de enfermos graves, ordenado en torno a un corredor longitudinal central con las habitaciones orientadas al sureste y con el acceso y los espacios de servicio, que incluyen una pequeña cocina y un laboratorio, abiertos al noroeste.

Sobre la cubierta del bloque meridional de instalaciones hay una terraza previa a la sala principal [fig. 5.123], la cual se cierra al norte con una pared de vidrio soportada sobre un peto de hormigón [fig. 5.124]. Se crea así una continuidad con la fachada acristalada de los pabellones que proporciona a la terraza un mayor carácter de espacio interior, aun siendo una antesala abierta protegida del viento del norte que dificulta al enfermo asomarse hacia el mundo de los sanos, hacia la vía de salida que discurre en planta baja junto a ese frente. La sala principal cruciforme incluye en los cuatro rincones de su planta cuatro pequeños balcones, desde los que los enfermos individualmente se pueden asomar sobre las vías de acceso y salida del sanatorio.

En el centro de la sala se añadió durante la ejecución de la obra un lucernario que no aparecía inicialmente en el proyecto, con el fin de iluminar esta zona más sombría. El lucernario, también cuadrado y con paredes de cristal, se apoya sobre un recorte del forjado del techo con forma de cruz, y se cubre con una losa de hormigón circular, tanto por el alero curvo, como por las esquinas interiores del recorte del techo, los rayos solares se paraban, antes o después del lucernario [fig. 5.125].

\footnotetext{
${ }^{71}$ Llama la atención la posición diagonal de las puertas de la sala de rayos $X$ y de consulta, que recuerda a soluciones adoptas desde en sus primeros proyectos, de Karenhuis o en la Rijksacademie.
} 


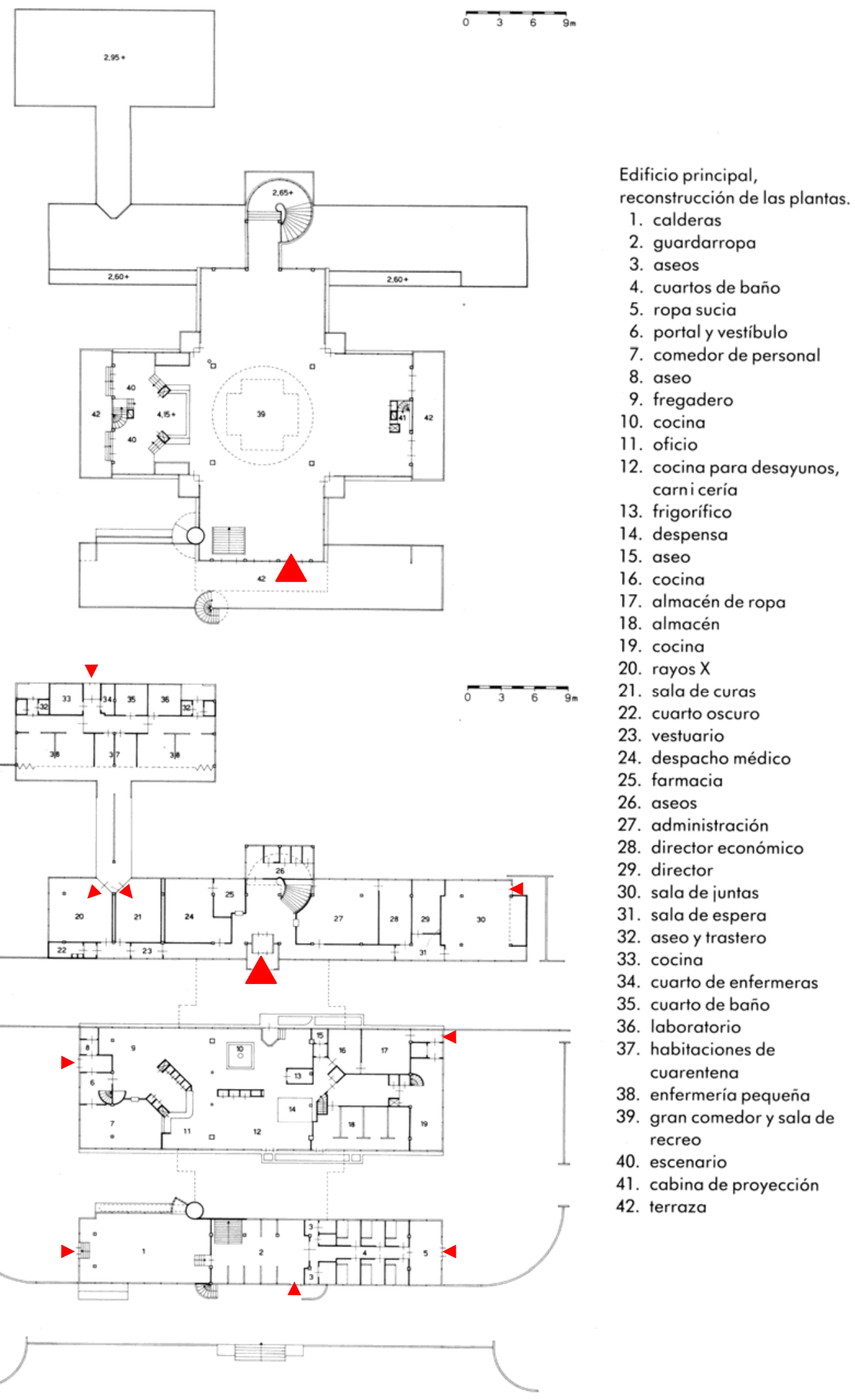

5.117

5.1 17 J. Duiker y B. Bijvoet. Zonnestraal. Programa y plantas del edificio principal, 1928. Planta baja y primera. (Duikergroep 1982). 

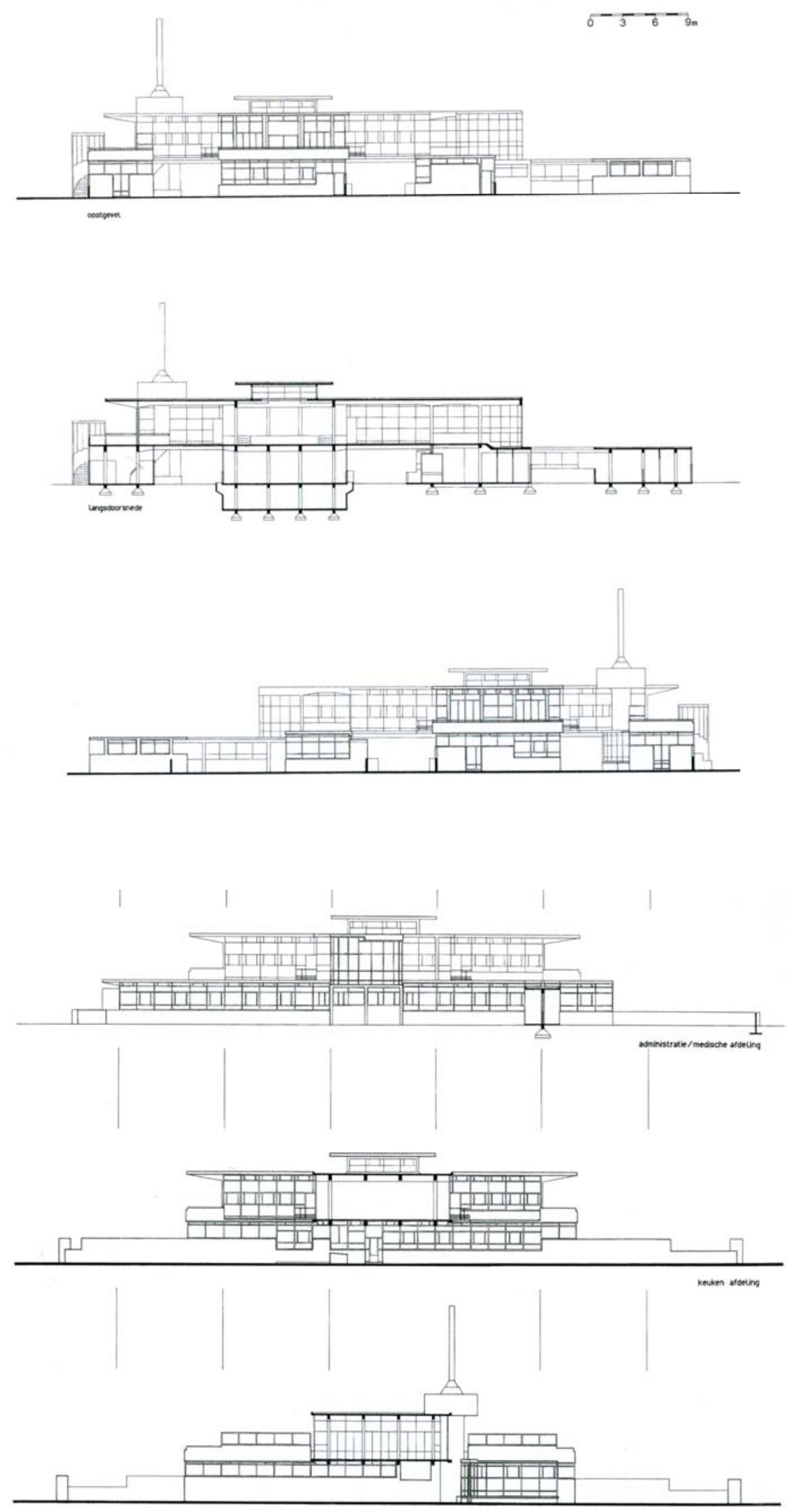

5.118 J. Duiker y B. Bijvoet. Zonnestraal. Alzados y secciones del edificio principal, 1928. Alazdo principal, sección transversal, alzado trasero. Alazdo norte, sección longitudinal por la vía de entrada y sección longitudinal por la vía de salida (Duikergroep 1982). 

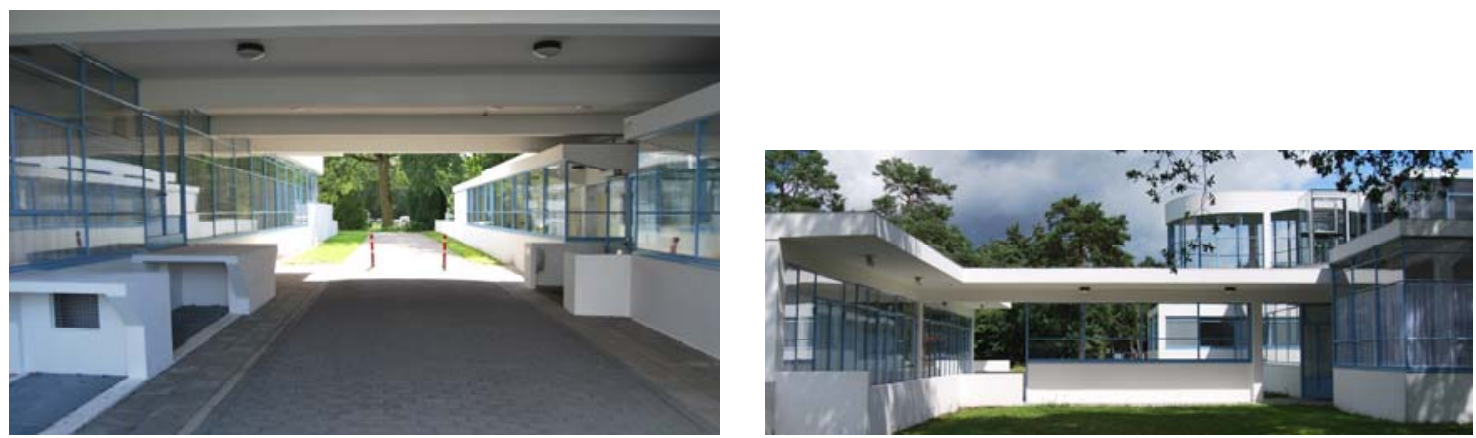

5.119 y 5.120
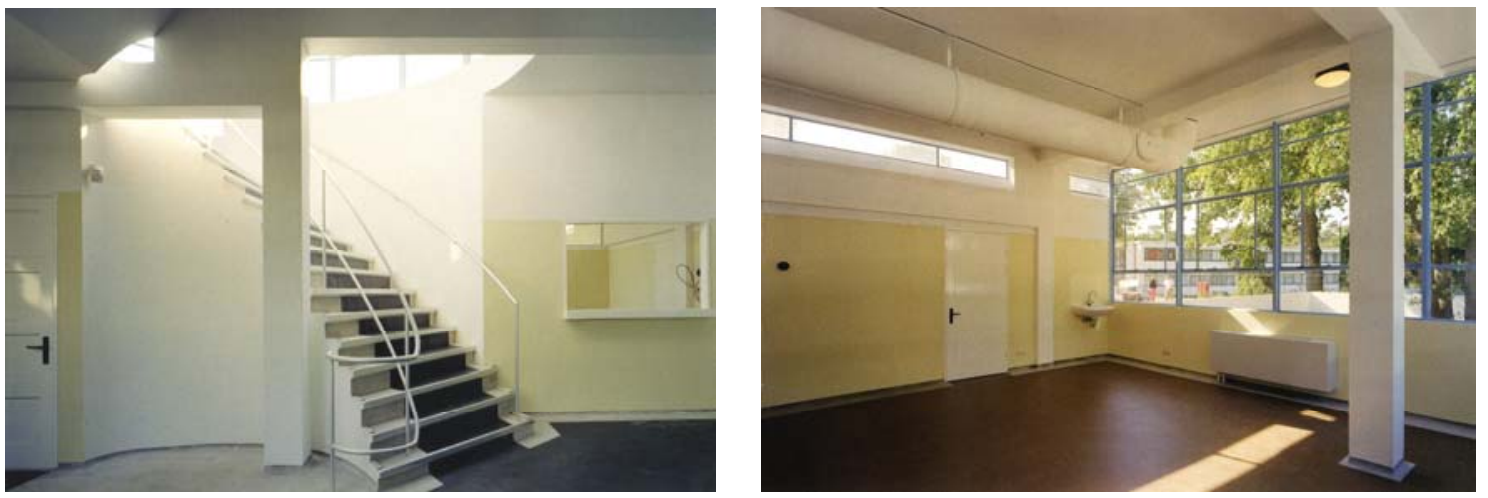

5.121 y 5.122
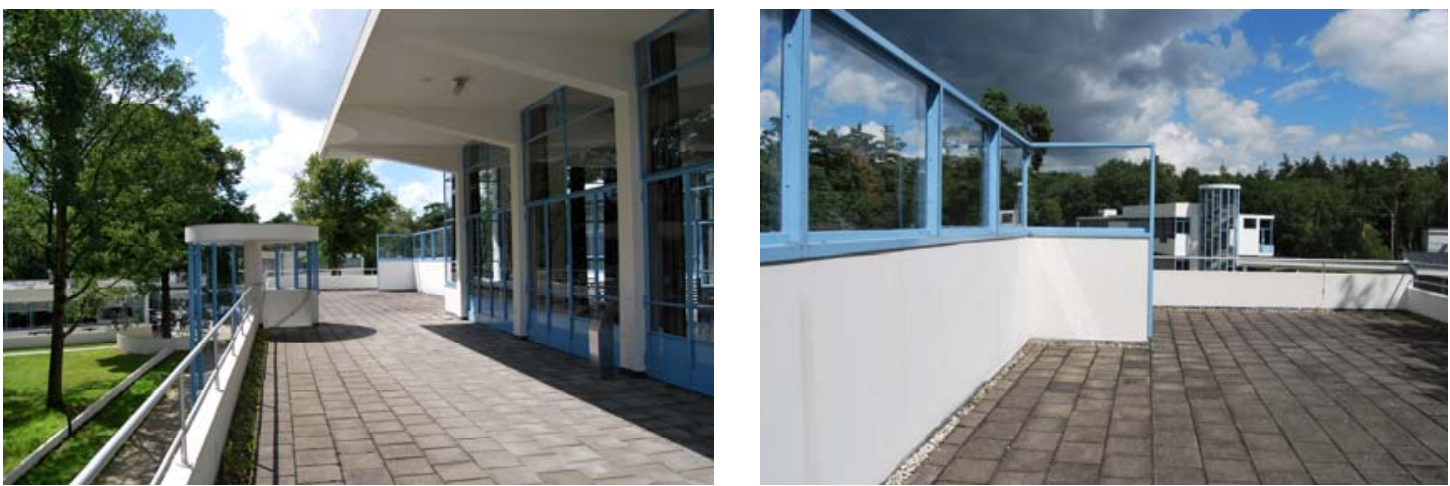

5.123 y 5.124
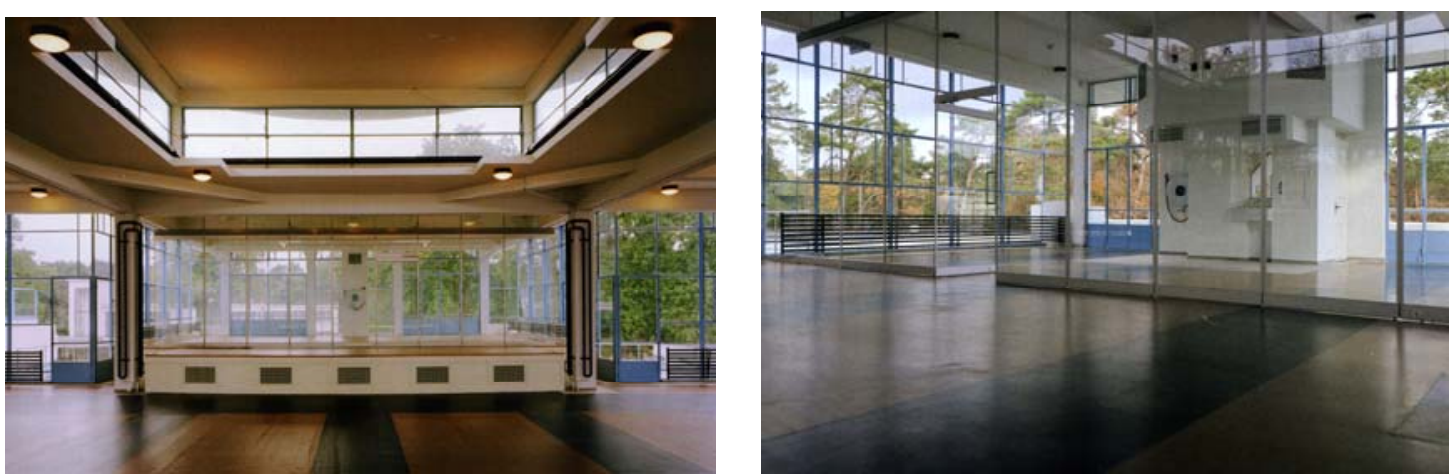

5.125 y 5.126

5.119 y 5.120 Entrada principal y conexión entre el bloque administrativo y el de enfermos graves (fotografías de la autora).

5.121 y 5.22 Interior del bloque administrativo.

5.123 y 5.24 Terraza previa a la gran sala del edificio principal (fotografías de la autora).

5.125 y 5.126 Interior de la gran sala del edificio principal. 
En el fondo de la sala se encuentra la amplia escalera de caracol acristalada que conecta con el acceso principal del sanatorio en la parte interior, por la que circula el personal médico y las visitas. De este modo, Duiker proyecta dos accesos independientes y enfrentados ubicados en el eje norte-sur, uno para sanos desde esa escalera, y otro para enfermos, desde la terraza exterior o a través de la escalera interior que parte del guardarropa situado en el bloque de instalaciones. La peculiar disposición contribuye a separar las circulaciones de ambos mundos a través del distanciamiento de los elementos de comunicación.

En el extremo oeste de la dirección transversal se coloca una plataforma que puede ser utilizada como escenario y al este la cabina de proyección [fig. 5.126] enfrentada a la anterior, pudiéndose convertir la sala en un eventual auditorio o en un cine.

La geometría cruciforme de la sala permite la compartimentación de usos y espacios manteniendo la diafanidad. Esta articulación volumétrica aleja la arquitectura del Sanatorio de las propuestas más racionalistas que buscan una mayor pureza formal, a la que pertenecen aquellas construcciones proyectados desde la repetición idéntica de una estructura encerrada dentro de un volumen exterior compacto, generalmente de vidrio, que define la imagen del edificio. Arquitectura que fue magníficamente interpretada por Duiker en el proyecto de los grandes almacenes Winter de Ámsterdam, realizado en el año 1934, donde la regularidad estructural y la rigidez volumétrica del exterior desaparecen gracias a su troquelado espacio interior, con dobles y triples alturas [fig. 5.127 y fig. 5.128].

En el Sanatorio de Zonnestraal, en cambio, las plantas del pabellón principal alteran su geometría de un nivel a otro [fig. 5.129 y fig. 5.130] poniendo de manifiesto una composición por estratos horizontales, probablemente fruto del resultado de proyectar desde la planta, y que revela la modernidad del proyecto con respecto a la composición frontal del alzado propia de la arquitectura histórica.

La variación formal del edificio principal, aunque pueda partir de condicionantes higiénicos y funcionales, al tratar de segregar los usos en cada planta para mejorar así la ventilación y evitar los contagios, y al compactar los espacios comunes para fomentar el ahorro; proporciona una volumetría irregular que enfatiza las cualidades estéticas del material de cerramiento, el vidrio. Material que provoca un juego de veladuras y reflejos cambiantes que se ve multiplicado al aplicarse sobre formas complejas y horadadas. A través de la trasparencia, la arquitectura logra materializar las nuevas relaciones espacio-temporales tan 

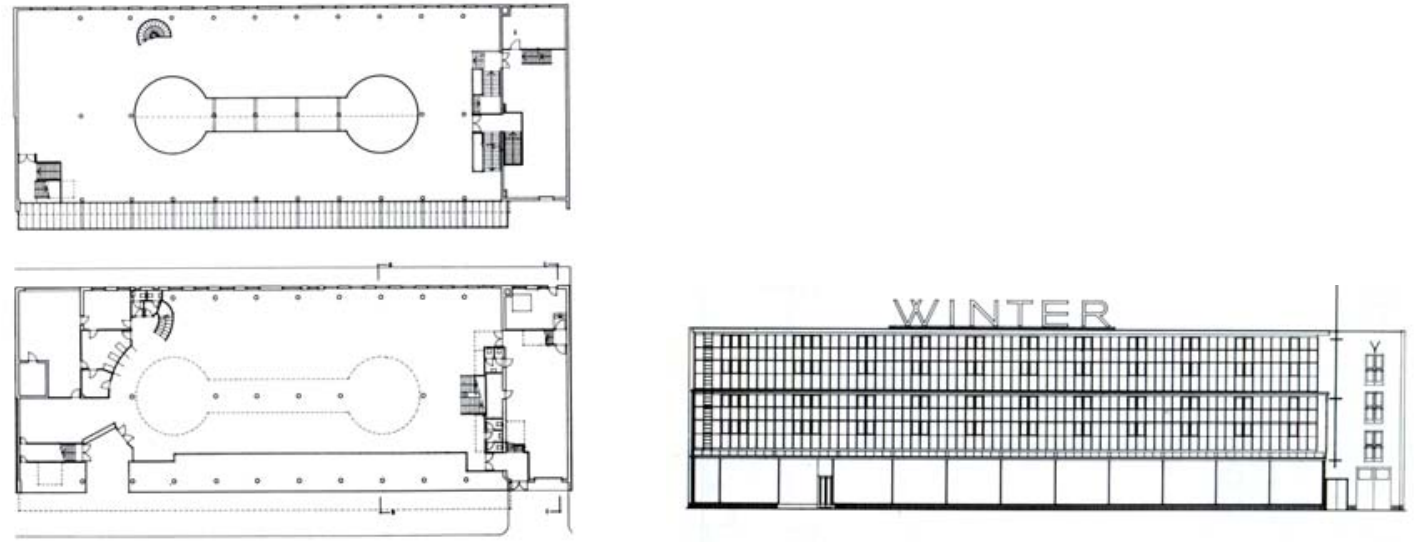

5.127 y 5.128
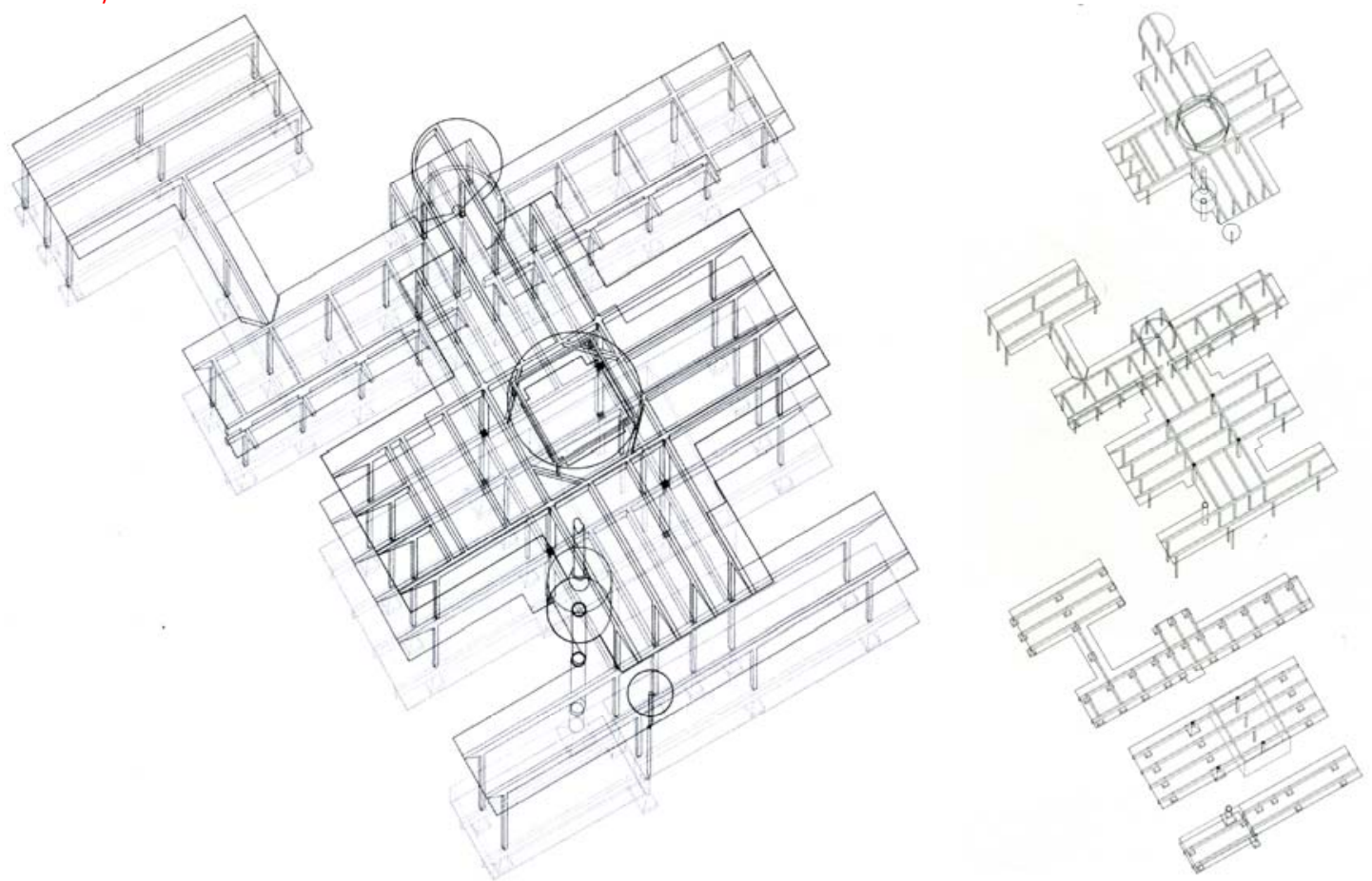

5.129 y 5.130
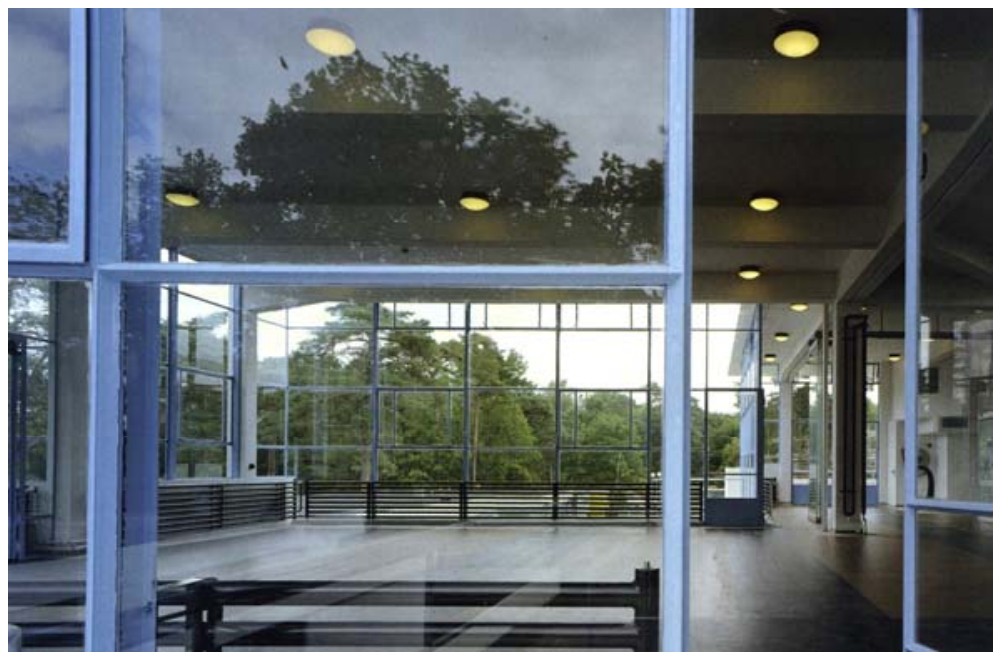

5.131

5.127 y 5.26 J. Duiker. Almacenes Winter, Ámsterdam 1934. Plantas y alzado.

5.128 y 5.29 Zonnestraal.Pabellón principal. Axonometría estructural completa y por plantas.

5.131 Doble visión de la naturaleza real y de la reflejada en el frente de la sala del pabellón principal. 
perseguidas por las vanguardias artísticas del siglo XX que Gyorgy Kepes explica en su Lenguage of Vision:

"Si vemos dos o más figuras que se sobreponen, y cada una de ellas reclama para sí la parte superpuesta que les es común, nos encontramos ante una contradicción de las dimensiones espaciales. Para resolverla debemos asumir la presencia de una nueva cualidad óptica. Las figuras en cuestión están provistas de transparencia: es decir, pueden interpretarse sin que se produzca una destrucción óptica de ninguna de ellas. Sin embargo la transparencias implica algo más que una mera característica óptica, implica un orden espacial mucho más amplio. La transparencia significa la percepción simultánea de distintas locaciones espaciales. El espacio no sólo se retira sino que fluctúa en una actividad continua. La posición de las figuras transparentes tiene un sentido equívoco puesto que tan pronto vemos las figuras distantes como próximas" $" 72$.

La simultaneidad de imágenes se acrecienta en el Sanatorio por la uniformidad de las fachadas de tal manera que, gracias a la fragmentación volumétrica los vidrios de las fachadas muestran a la vez dos imágenes idénticas: la real y la reflejada de la fachada. Algo similar sucede al mirar a través de ciertas paredes acristaladas donde la naturaleza real que a través de ellas se percibe se confunde con la imagen de la naturaleza que en ellas se refleja [fig. 5.131].

De este modo en el sanatorio, lo tangible y lo irreal se diluyen procurando una gran emoción poética propia de aquellos "arquitectos holandeses y alemanes seguidores de la Nueva Objetividad" que Le Corbusier considera "arquitectos sutiles e ingeniosos, artistas plásticos, cuyas palabras ocultan una pasión por la arquitectura bella"73.

Desde la definición inicial del proyecto en 1926, hasta su construcción definitiva en 1928, el pabellón principal sufrió una serie de importantes alteraciones ligadas a la topografía de la parcela y al modo de implantación en el terreno, como consecuencia del desnivel entre la cota del acceso principal del sanatorio y la de los pabellones que Duiker trata de salvar vinculando, a través de escaleras y terraplenes, la sala principal al entorno.

${ }^{72}$ Colin ROWE, Robert SLUTZKY, "Transparencia: Literal y fenomenal" (redactado en 1955-1956 y publicado por primera vez en Perspecta, 1963), en Colin ROWE, Manierismo y arquitectura moderna y otros ensayos. Editorial Gustavo Gili, Barcelona 1978, p.156.

${ }^{73}$ Le Corbusier, Decorative Ant 1929. Citado en: Jan MOLEMA, Duiker, arquitecto de una nueva era. TH Delft, Delft 1985, p. 9. 


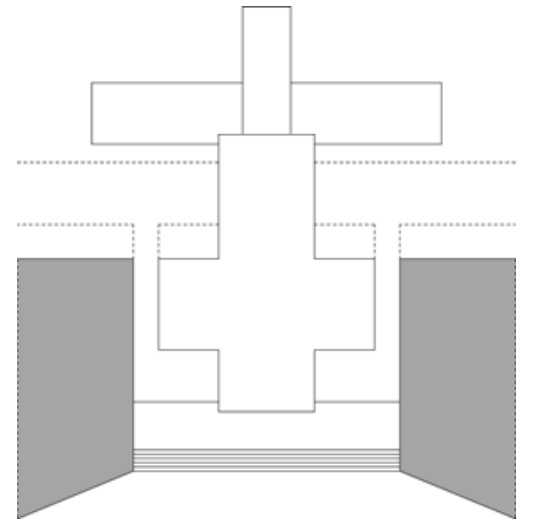

5.132 y 5.133

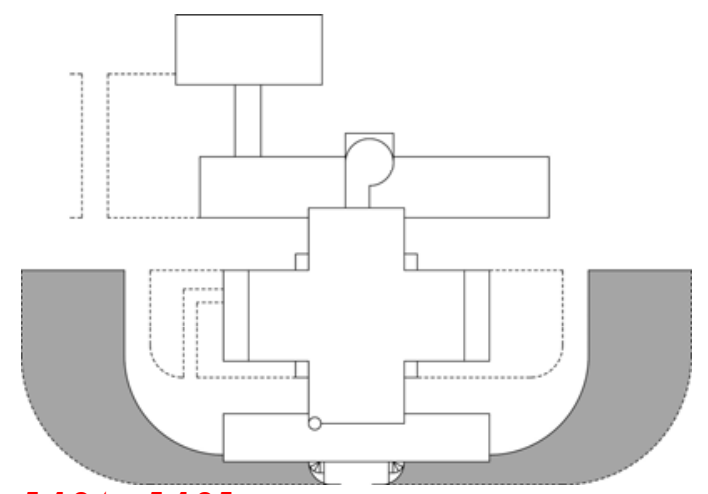

5.134 y 5.135

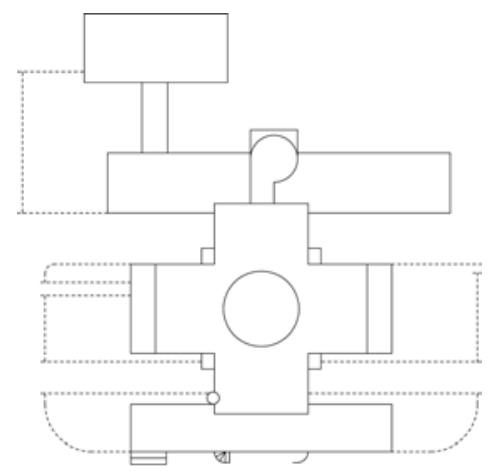

5.136 y 5.137
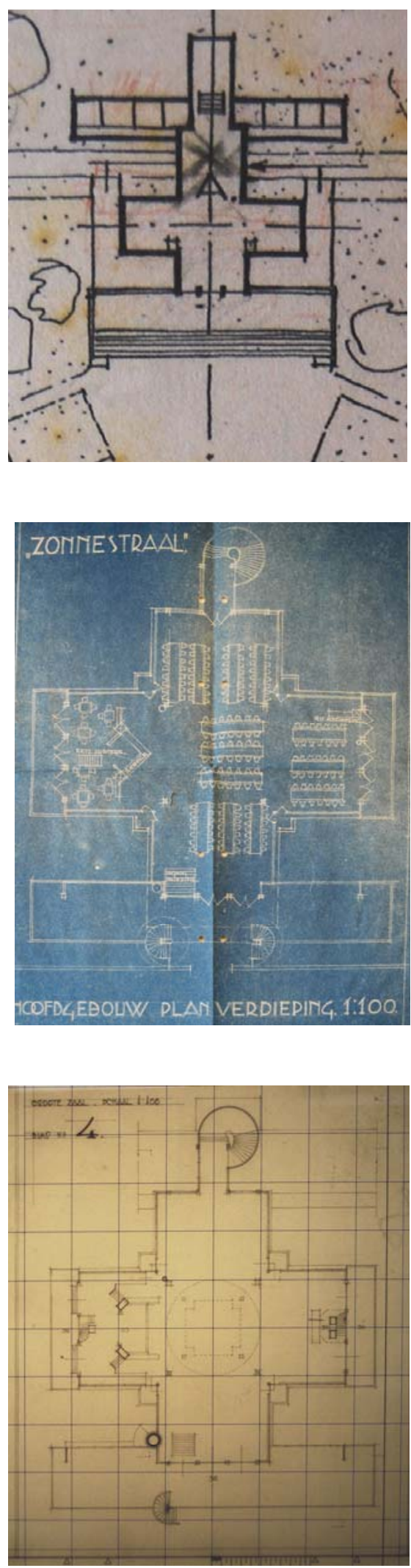

5.132 y 5.133 Edificio principal primera propuesta. Dibujo de la autora y fragmento de planta de la quinta propuesta (IISG, Caja 64, Carpeta 64﹎._Bouwtechningen Bijvoet \& Duiker 1926-1931).

5.134 y 5.135 Edificio principal propuesta previa. Dibujo de la autora y planta sin datar (IISG, Caja 40, Carpeta 40_1926-1929).

5.136 y $5.137^{-}$Edificio principal propuesta definitiva. Dibujo de la autora y planta sin datar (NAi, Zonnestraal, Hilversum, 51). 


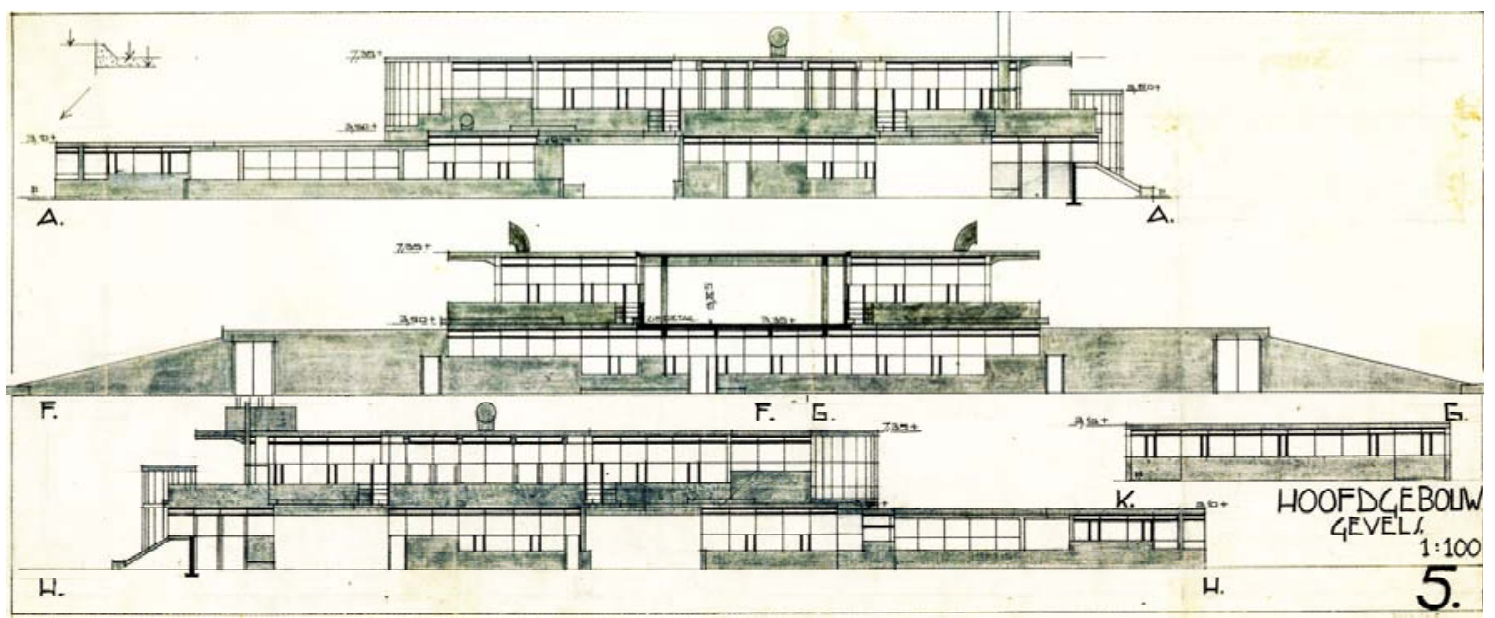

5.138
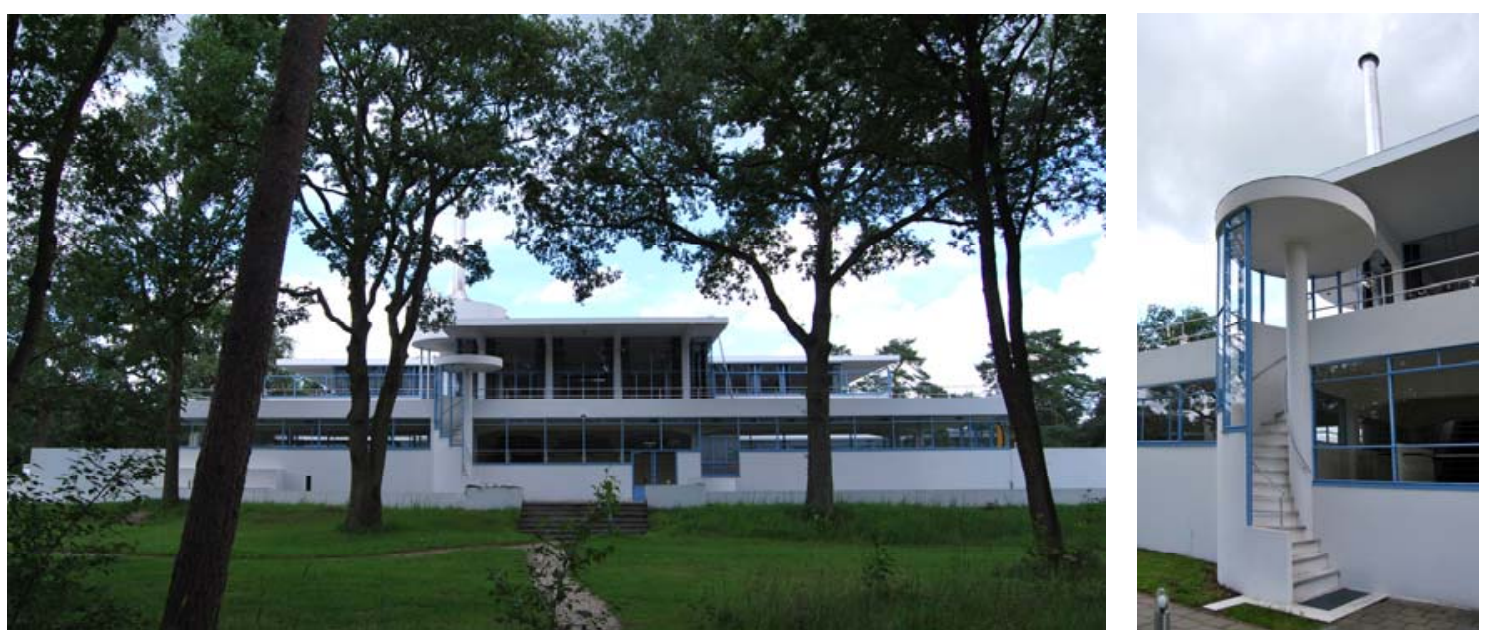

5.139 y 5.140

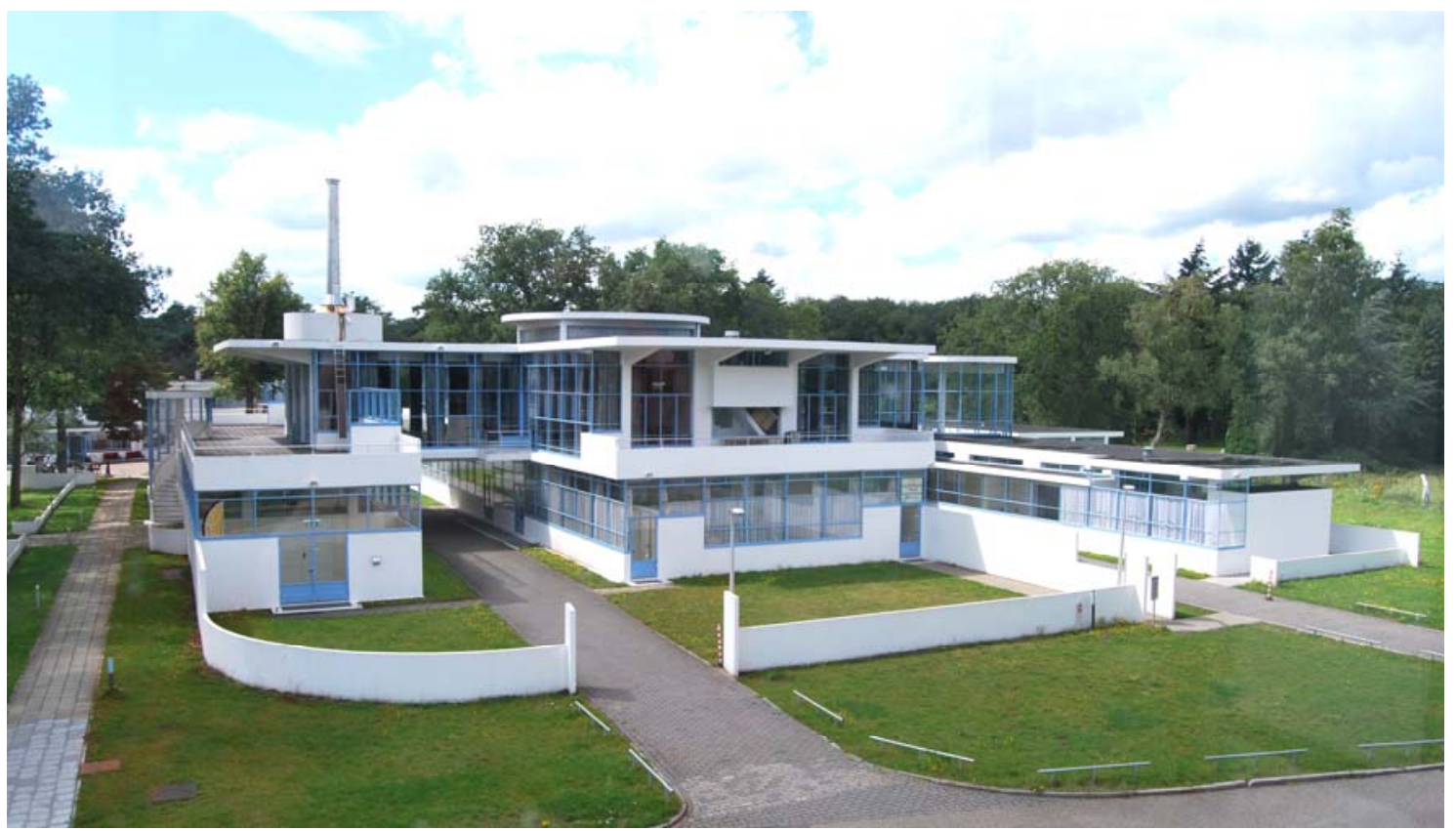

5.141

5.138 Edificio principal propuesta previa. Alzados sin datar.

5.139 y 5.140 Escaleras de acceso a la sala del edificio principal. Escalera de caracol de subida a la terraza del edificio principal (fotografías de la autora).

5.141 Gran sala del edificio principal (fotografía de la autora). 

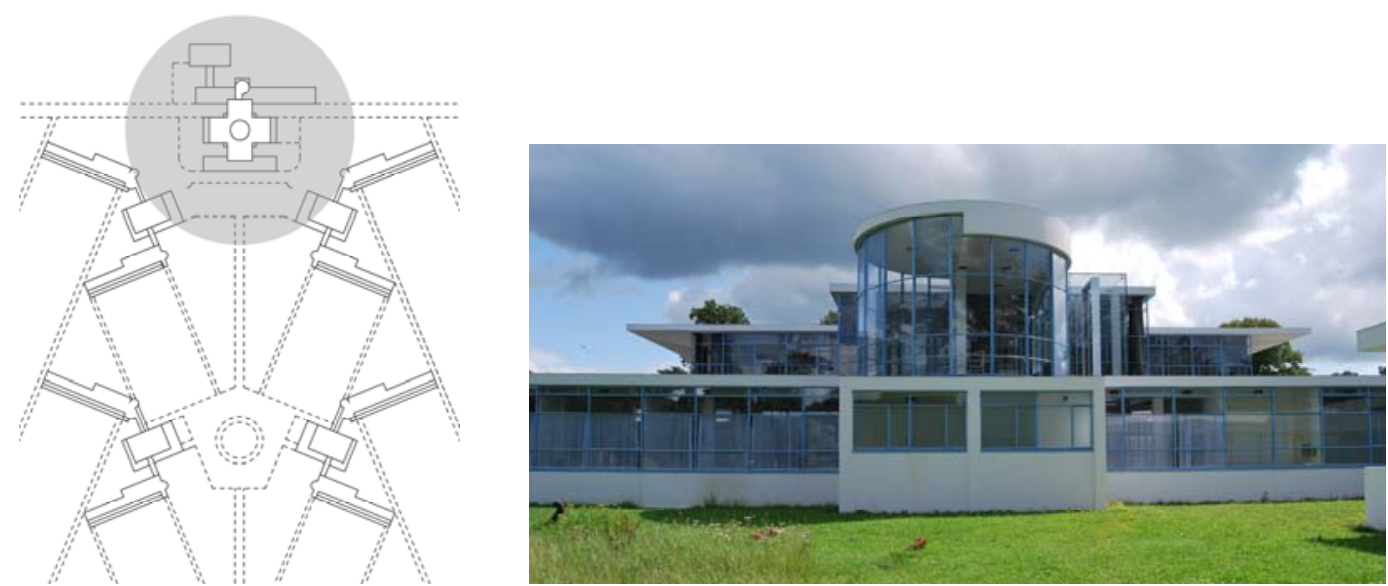

5.142 y 5.143

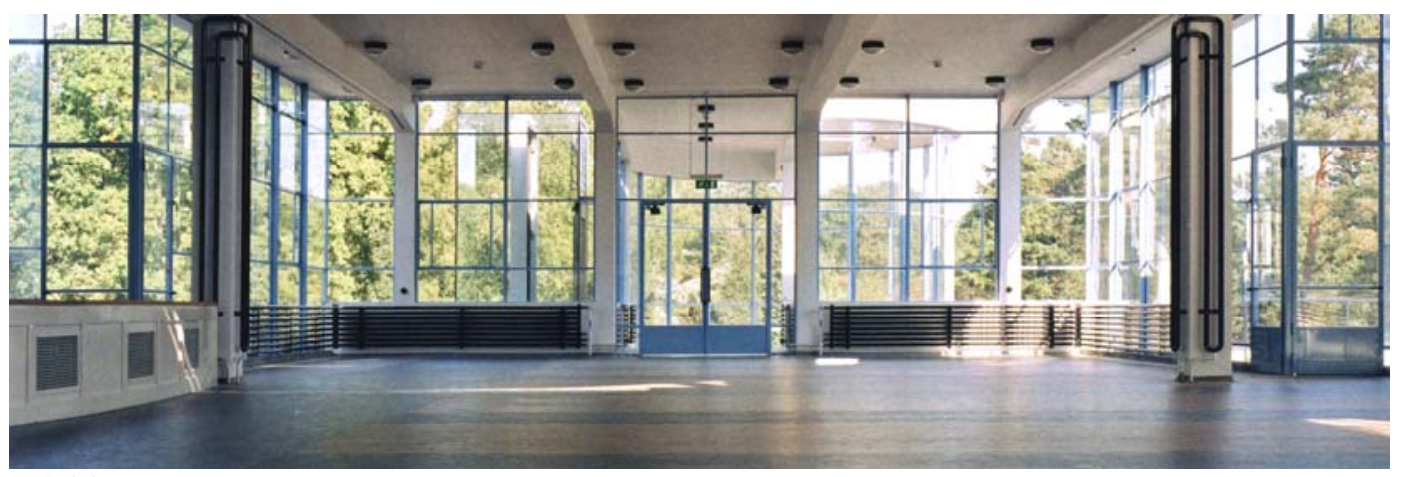

5.144
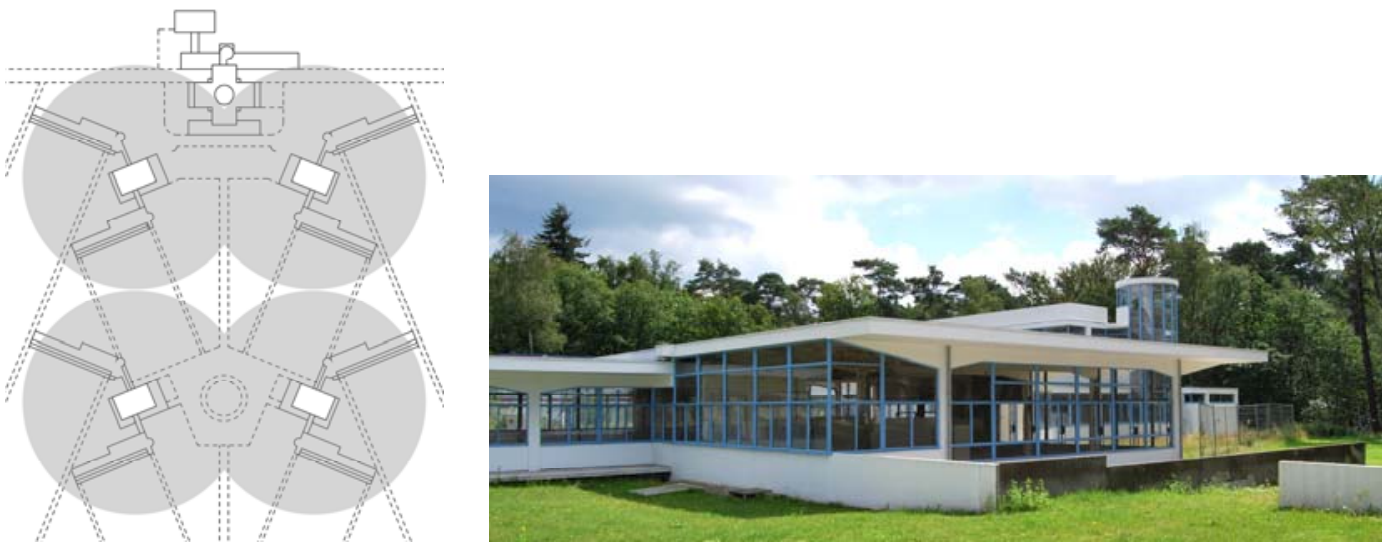

5.145 y 5.146

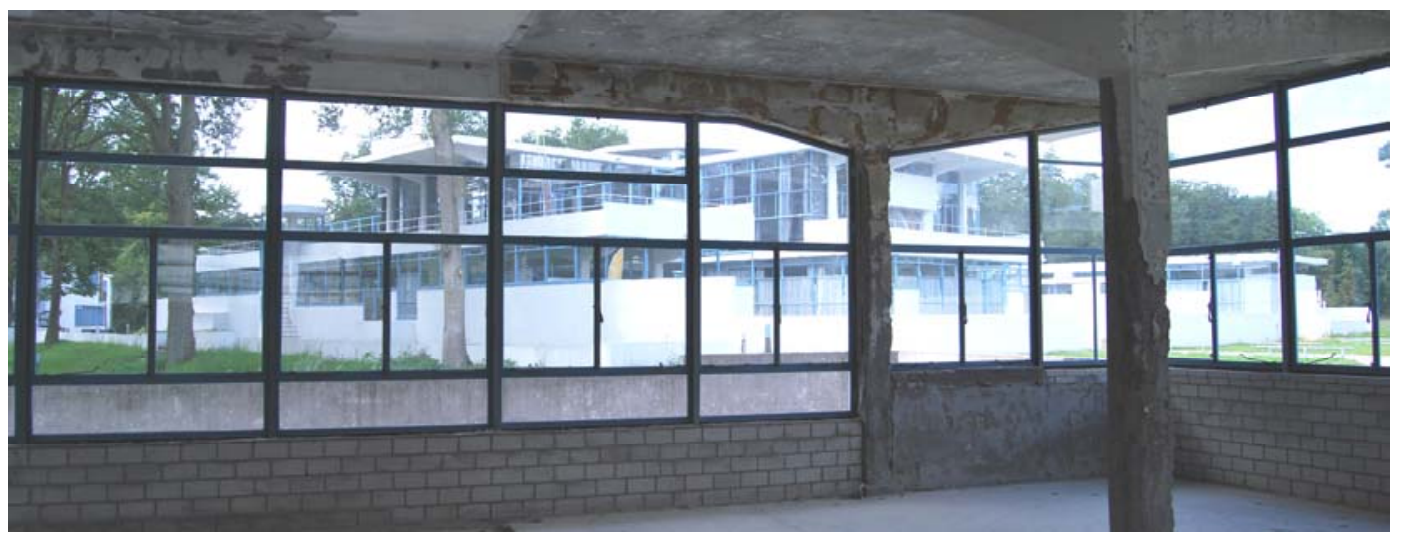

5.147

$5.142,5.143$ y 144. Sala edificio principal. Dibujo e imagen exterior de la autora e imagen interior. $5.145,5.146$ y 5.147 Sala edificio residencial. Dibujo e imagen exterior e interior de la autora. 
En los primeros bocetos del proyecto definitivo el acceso a la sala principal desde los pabellones de enfermos se producía a través de una terraza común sobre la cubierta del bloque de instalaciones de la que partía una escalinata que ocupaba todo su largo. De este modo, se formaba una cascada volumétrica entre la sala y el entorno que descendía construyendo una topografía artificial ajustada a la natural [fig. 5.132 y fig. 5.133].

En la propuesta siguiente la escalinata desaparece y se sustituye por un terraplén vegetal que cubre parcialmente la pared trasera del bloque de instalaciones, en cuya parte baja se absorbe el desnivel. Esta disposición del terreno, que no llega hasta la cota de la cubierta, permite incorporar ventanas en la parte superior del frente sur del bloque de instalaciones [fig. 5.138], y cambia el sistema de accesos a la gran sala cruciforme, ahora se produce a través de una gran escalera de un solo tramo interior, o por medio de dos escaleras de caracol, cubiertas y acristaladas, adyacentes a la fachada [fig. 5.134 y fig. 5.135].

En el proyecto definitivo [fig. 5.136 y fig. 5.137], las dos escaleras de caracol, que reforzaban la simetría y la monumentalidad del edificio principal $^{74}$ se reducen a una, la más próxima a la chimenea ${ }^{75}$, remarcando su verticalidad; aunque se mantiene aún el pequeño muro curvo sobre el que se debería haber construido la otra escalera, que sirve ahora para definir el umbral de acceso al bloque de instalaciones con el ropero y los baños. El terraplén adyacente a la fachada se desplaza hacia adelante y pasa a configurar un pequeño talud en la parcela con una escalera en el centro que resuelve la diferencia de cota existente entre las distintas partes del Sanatorio [fig. 5.139 y fig. 5.140]. Se libera así completamente el frente sur del bloque de instalaciones. A él se adhiere una jardinera escalonada, vestigio de soluciones pasadas, bajo la que se coloca parte de la sala de calderas que precisa un mayor espacio.

A pesar de los cambios experimentados en el edificio principal, la gran sala cruciforme que preside el Sanatorio se ha concebido desde el origen como un espacio que responde a la idea de Norberg-Schulz de una "sala moderna" [fig. 5.141]:

"Para empezar, repitamos que la sala transparente es una de las grandes imágenes públicas de nuestra época. Entrar en un espacio grande y luminoso, aparentemente

\footnotetext{
${ }^{74}$ En una propuesta anterior a la definitiva, sobre la cubierta de la sala principal, coincidente con el bloque de la cocina, asomaban dos conductos curvos, que asemejaban, por su forma, a las chimeneas de los barcos de vapor, enfatizando la simetría del edificio.

${ }^{75}$ La cubierta de la escalera de caracol exterior tiene muy poca altura, hecho que puede deberse al intento de que ésta no obstaculice demasiado las vistas desde la gran sala.
} 


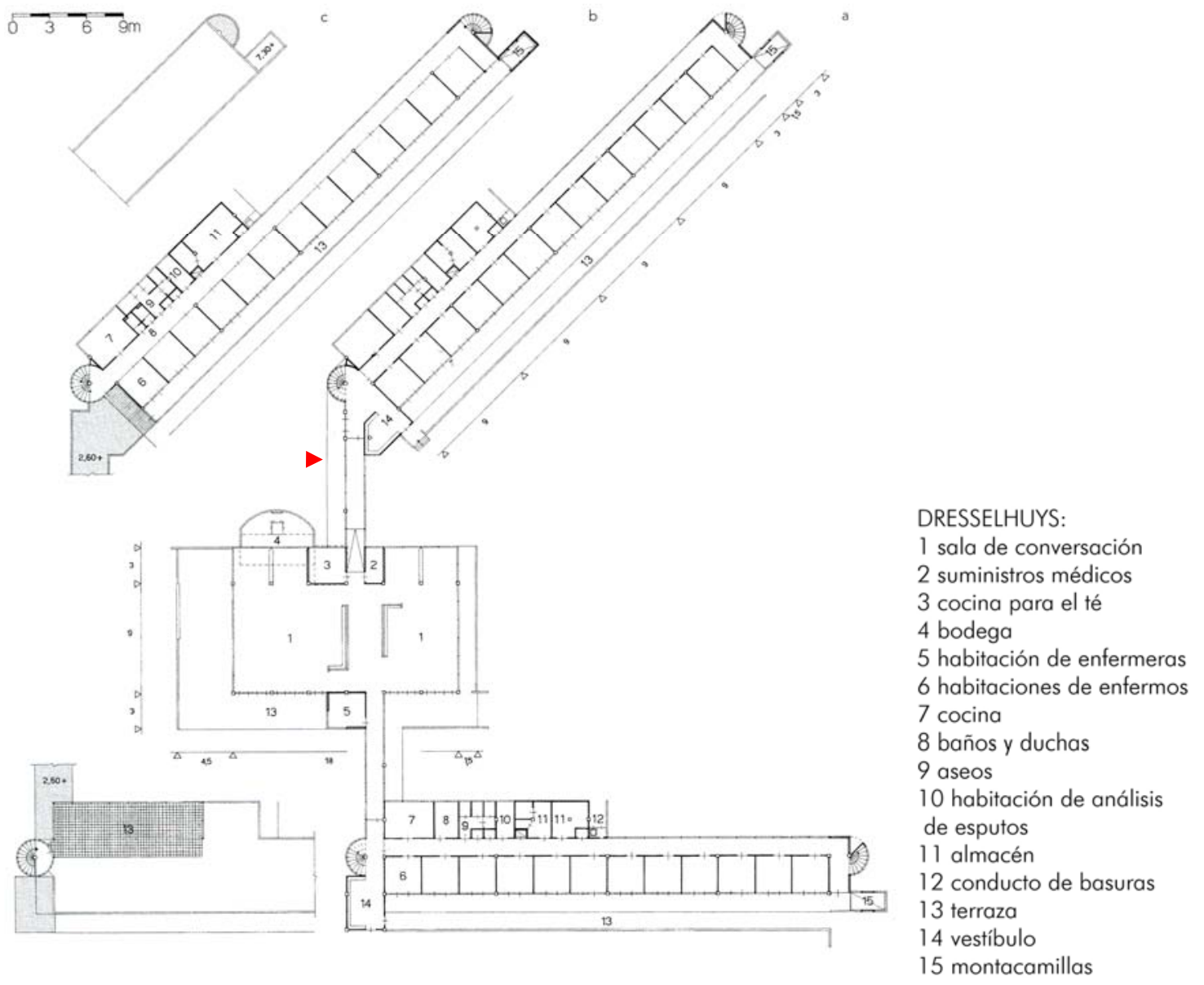

5.148

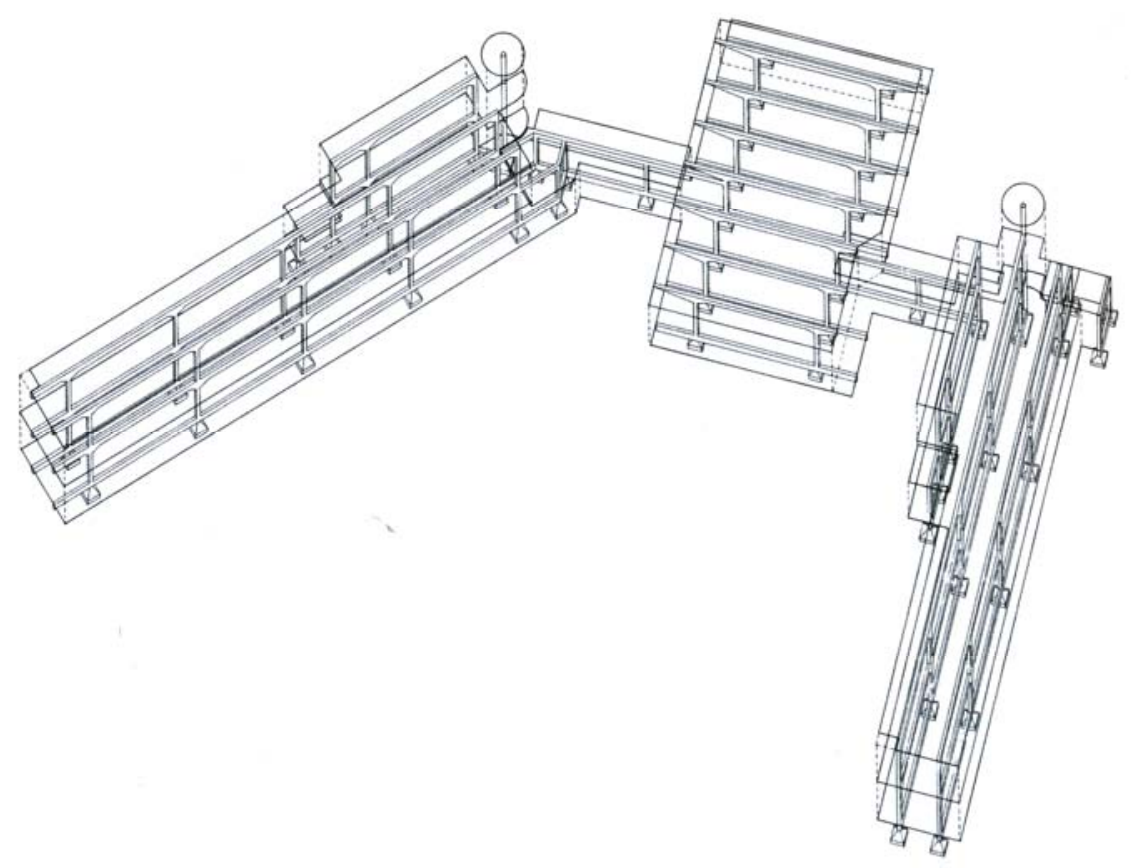

5.149

5.148 J. Duiker y B. Bijvoet. Zonnestraal. Programa y plantas de los edificios residenciales, 1928 y 1931. Planta baja del pabellón Henri ter Meulen 1928 y plantas baja y primera del pabellón Dresselhuys 1931 (Duikergroep 1982).

5.149 J. Duiker y B. Bijvoet. Zonnestraal. Perspectiva del edificio residencial. 

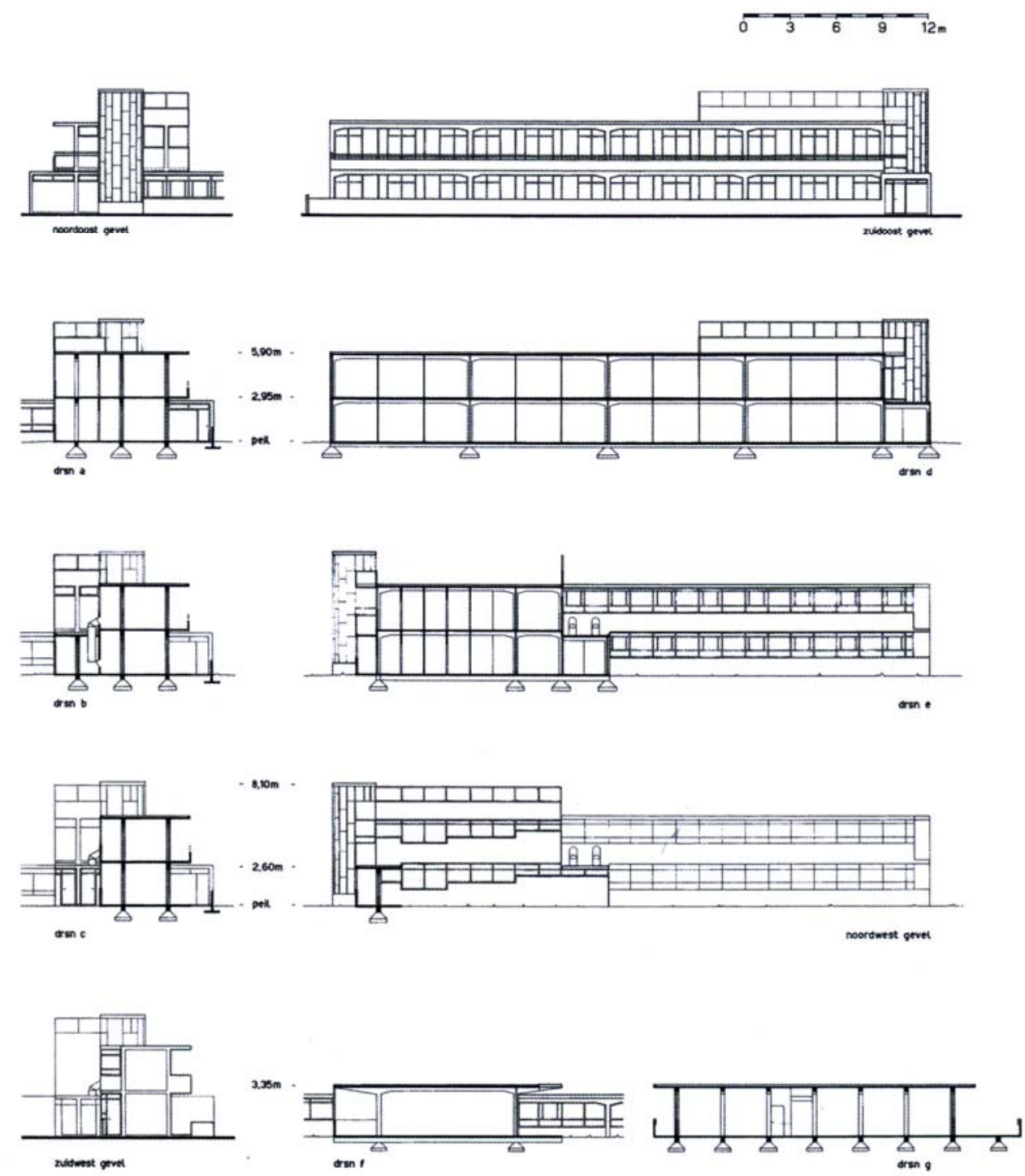

5.150

5.150 J. Duiker y B. Bijvoet. Zonnestraal. Alzados y secciones del edificio residencial, 1928. Plabellón Henri ter Meulen (Duikergroep 1982). 


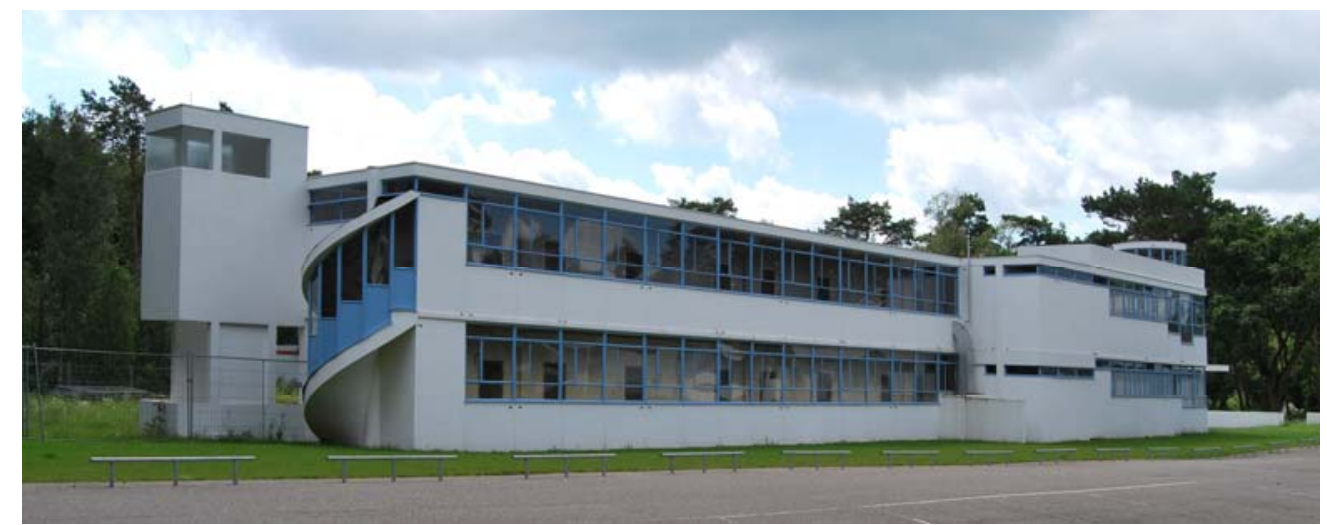

5.151
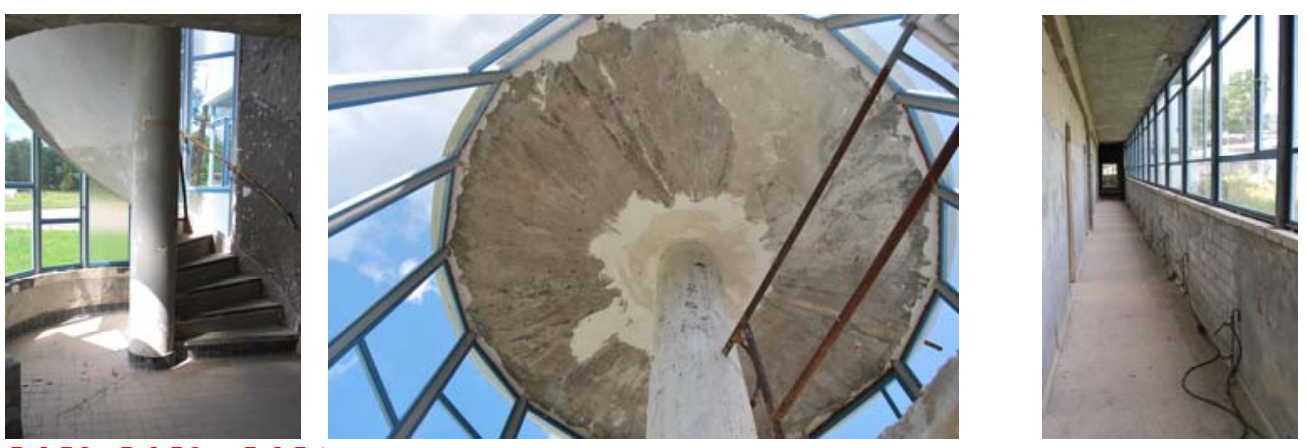

$5.152,5.153$ y 5.154
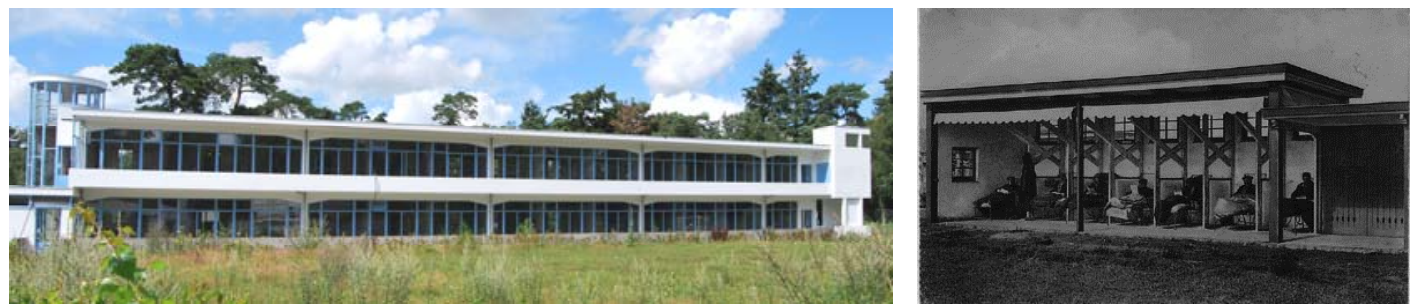

5.155 y 5.156
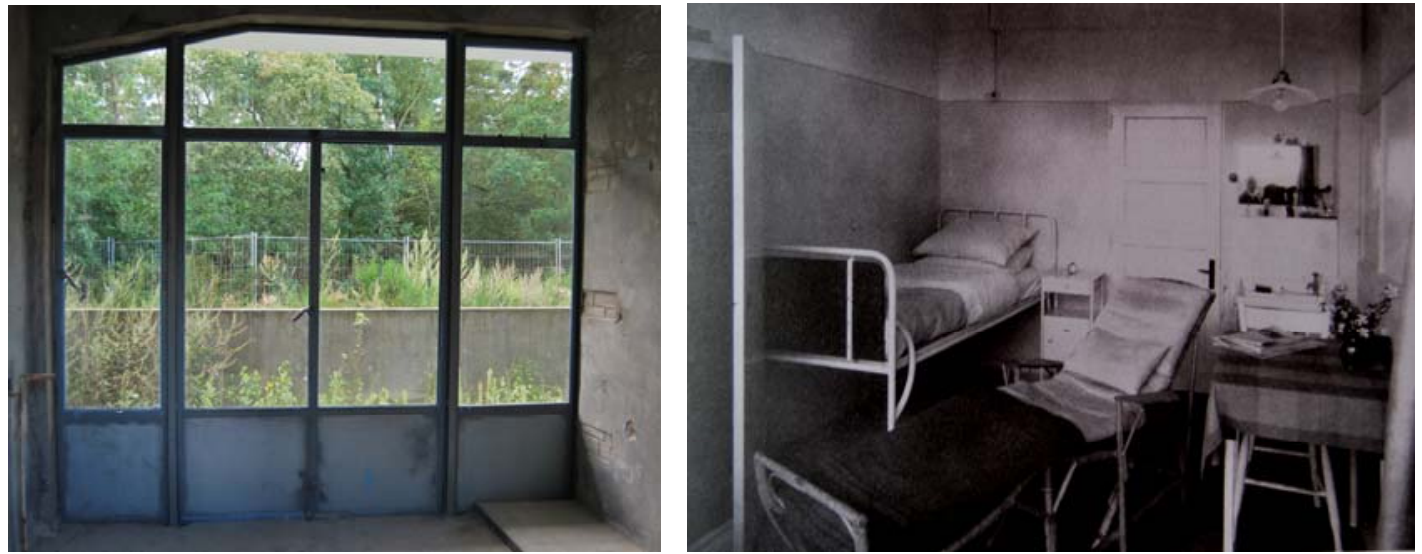

5.157 y 5.158

5.151 Edificio Dresselhuys vista exterior del corredor (fotografía de la autora).

$5.152,5.153$ y 5.154 Edificio Dresselhuys vista interior del corredor. Arranque de escalera, escalera y fondo del pasillo (fotografías de la autora).

5.155 Edificio Dresselhuys vista exterior de las habitaciones (fotografía de la autora).

5.156 Sanatorio De Mick, Brasschaat. Lighal (habitación al aire libre).

5.157 y 5.158 Edificio Dresselhuys vista desde la habitación hacia el exterior (fotografía de la autora) y hacia el interior. 
sin límites fijos y donde gran número de personas pueden reunirse e interactuar, es efectivamente una de las experiencias 'modernas' básicas ${ }^{176}$.

En los hospitales de pabellones tradicionales se solía ubicar la capilla en el centro o en el inicio del eje longitudinal de simetría, siendo esta pieza la que ordenaba y presidía el conjunto. En Zonnestral la capilla es sustituida por la gran sala de reunión destinada a enfermos y a sanos que se ubica en la parte más elevada del sanatorio, la que tiene las mejores vistas y domina el paisaje [fig. 5. 142-5.144]. Su apertura es completa de $360^{\circ}$, de manera que la vista abarca todas las direcciones constituyendo un panóptico sobre el paisaje $^{77}$. El lucernario del centro de la sala marca la cabeza física del sanatorio a partir de la cual nace la composición del conjunto ${ }^{78}$.

Los edificios residenciales también constan de salas modernas de conversación acristaladas por todos sus frentes, que presentan una cierta direccionalidad ${ }^{79}$ [fig. 5. 145-5.147]. En dos de sus laterales opuestos, el norte y el sur, convergen los corredores que comunican con los bloques de habitaciones, mientras que sus otras dos fachadas quedan convertidas en dos pantallas panorámicas hacia la visión exterior, de modo que el espacio queda compartimentado en dos ámbitos, uno abierto hacia el conjunto del sanatorio y otra hacia el espacio contenido entre los dos bloques de habitaciones, un recinto abierto en forma de U más privado ${ }^{80}$.

Sus dos frentes están limitados, al igual que las galerías de cura, por muros perimetrales de baja altura. En el frente abierto hacia fuera, los muros son una prolongación de las fachadas y definen una terraza semicubierta de estancia común, más amplia que la galería de cura del frente de las habitaciones ${ }^{81}$ [fig. 5. 148].

Los bloques de habitaciones de los pabellones de enfermos en cambio, presentan dos frentes diferenciados: uno más cerrado y expuesto a las miradas que está orientado al norte

${ }^{76}$ Christian NORBERG- SCHULZ, Los principios de la arquitectura Moderna (Principles of Modern Architecture, 2000). Editorial Reverté, Barcelona 2009, p. 130.

77 Un panóptico opuesto al de los hospitales radiales del siglo XVIII donde el objetivo de las salas centrales era la vigilancia del enfermo.

${ }^{78}$ Existen dibujos donde se aprecia cómo Duiker plantea la posibilidad de trasladar el edifico principal al centro real del recinto rompiendo la organización jerárquica y lineal de los elementos.

${ }^{79}$ Las salas comunes del sanatorio son completamente diáfanas, las articulaciones espaciales se producen a través de la propia geometría o mediante el empleo de muebles bajos que sirven de alacenas y para separar espacios.

${ }^{80}$ El único bloque de habitaciones de enfermos en el que las galerías de cura asoman hacia el recinto en $U$ está girado $135^{\circ}$ respecto a la dirección principal de la sala de conversación, de modo que, sólo se llega a obtener una visión sesgada del mismo desde su interior.

${ }^{81}$ Los muros que rodean la sala de reunión común de los pabellones de enfermos sirven tanto para ampliar los límites de la edificación como para absorber los desniveles del terreno. 
y contiene los espacios servidores y los corredores, y el otro orientado al sur o sureste totalmente acristalado de las habitaciones [fig. 5. 150].

La secuencia continua de ventanas laterales, presente en los corredores que distribuyen las habitaciones diluye la direccionalidad de los mismos. La apertura que se produce al desplazarse horizontalmente contemplando ininterrumpidamente el paisaje [fig. 5.151] no altera la intimidad del paciente encamado ya que, como las ventanas no llegan al suelo, se impide la visión de camillas y de sillas de ruedas empleadas para desplazar a los enfermos más graves. El efecto de apertura se repite con más intensidad al desplazarse verticalmente por la escalera de caracol acristalada que conecta las dos plantas de habitaciones. La trayectoria helicoidal del recorrido y el completo acristalamiento perimetral de la escalera genera un movimiento centrífugo y continuo que acrecienta la sensación de apertura y la contemplación del entorno [fig. 5.152 y fig. 5.153]. Se abren también los fondos de los corredores ampliando el espacio en su dirección lineal aportando una diafanidad poco frecuente en los corredores de los sanatorios [fig. 5.154].

El frente sur de las habitaciones se acristala en mayor medida que los corredores [fig. 5.155]. Cada pórtico estructural está ocupado por tres habitaciones, éstas son una trasformación de las profundas galerías de cura presentes en los primeros diseños de Duiker y Bijvoet, auténticas habitaciones al aire libre o lighal [fig. 5.156] que ahora pasan a estar compartimentadas y cerradas por un frente de cristal con cuatro particiones practicables de vidrio. Las dos del centro funcionan como puertas de paso a la galería exterior y sus contiguas son ventanas de una hoja con un mecanismo de fijación que permite crear una corriente continua de aire en el interior de la habitación [fig. 5.157 y fig. 5.158].

Frente a la cristalera de la habitación se sitúa un pequeño muro de hormigón o antepecho blanco que define, incluso en planta baja, la galería de cura cubierta. Los planos horizontales del suelo y cubierta, y el muro bajo perimetral, atrapan este espacio exterior inmediato y lo incluye en la pequeña habitación cuadrada de tan sólo 3 metros de lado, aumentando la espacialidad de la misma, y transformando el muro en un delimitador del campo, como explica F. LI. Wright en su libro The Natural House:

"Mi noción de "muro" ya no era el lado de un caja; era la delimitación del espacio proporcionando protección frente a las tormentas y el calor sólo cuando era necesario. Pero también consistía en introducir el mundo exterior en la casa y dejar 
que el interior de la casa saliese fuera. En ese sentido, estaba deshaciendo el muro como muro y dándole la función de una pantalla (...)"

El cerramiento acristalado de la habitación proporciona una vista profunda hacia la naturaleza debido a la estudiada disposición de los bloques de habitaciones en planta, liberando al enfermo de la sensación de reclusión y aislamiento que provoca la permanencia en el sanatorio, todo un deber moral para Duiker:

"Vemos aquí un nuevo impulso espiritual: la liberación del hombre; también el funcionalismo en arquitectura es el único medio para obtener esta libertad; no un seudofuncionalismo que se cierra en sí mismo y juega con materiales de alta calidad como hierro, cristal y cemento, regalos de nuestra época, sino un "funcionalismo" de alta conciencia moral que encuentra sus posibilidades en la inmaterialización de la arquitectura de acuerdo con la ley cósmica de la economía, para proporcionar al hombre de la sociedad futura, la necesaria luz solar y las alegrías de la naturaleza en su inmediato entorno, de los que se le ha privado desde las épocas oscuras"

Para lograr esta liberación confía en la técnica y en los nuevos sistemas tectónicos que proporcionan ese lenguaje fabril al Sanatorio propio de una arquitectura despojada de todo artificio, con los muros pintados de blanco y las pantallas de vidrio; anteponiendo los logros higiénicos a las cuestiones estéticas. En 1933 escribe en "de 8 en Opbouw":

"Ahora lo hemos conseguido: tenía que nacer una ciencia arquitectónica, una ciencia que contuviera además de las materias corrientes, técnicas, matemáticas y físicas, las médicas, filosóficas, económicas, biológicas, etcétera, (...). Aunque todavía podrían decir: "no me parece bonito", esta afirmación nos importaría tan poco como la del enfermo al que no le gusta su medicina, pero que sin embargo no se atreve a renunciar al médico" ${ }^{\prime 84}$.

Sin embargo, la fría apariencia de la fábrica de Zonnestraal se domestica en su interior, el lugar donde la intimidad del enfermo se protege, al ocultarlo de las miradas del resto, y el paisaje natural circundante contemplado a través de las ventanas cobra una especial presencia.

\footnotetext{
${ }^{82}$ Frank Lloyd WRIGHT, The Natural House. Horizont Press, Nueva York 1954, p.33.

${ }^{83}$ Duiker y Bilvoet, "Dr. Berlage y la Nueva Objetividad", De 8 en Opbow (8+O), 5, 1932, p. 43 59, en Rafael GARCÍA GARCíA, "Tres Artículos de Duiker", Cuaderno de Notas n 3, 1995, p. 38. 84 Jan MOLEMA, Duiker, arquitecto de una nueva era. TH Delft, Delft 1985, contraportada.
} 

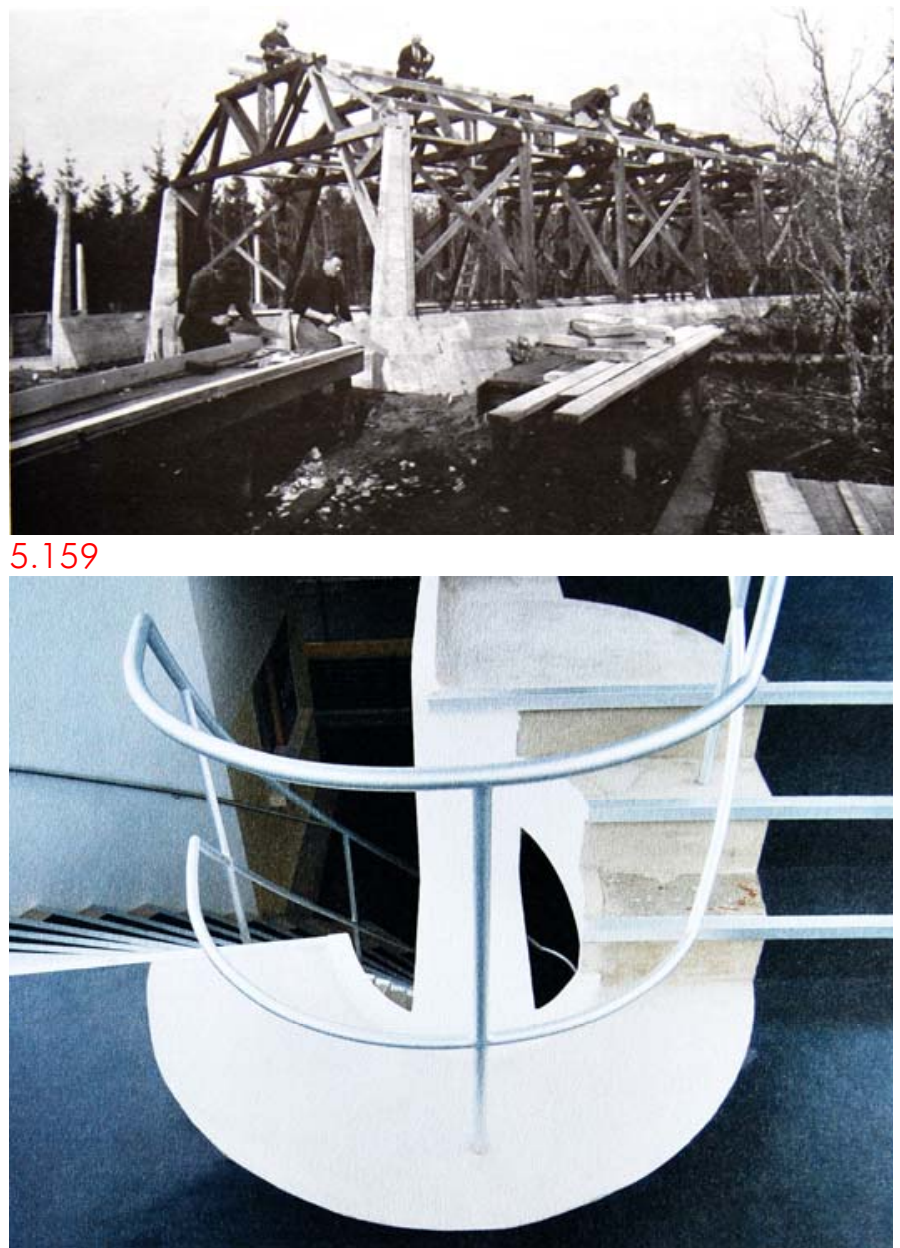

5.160
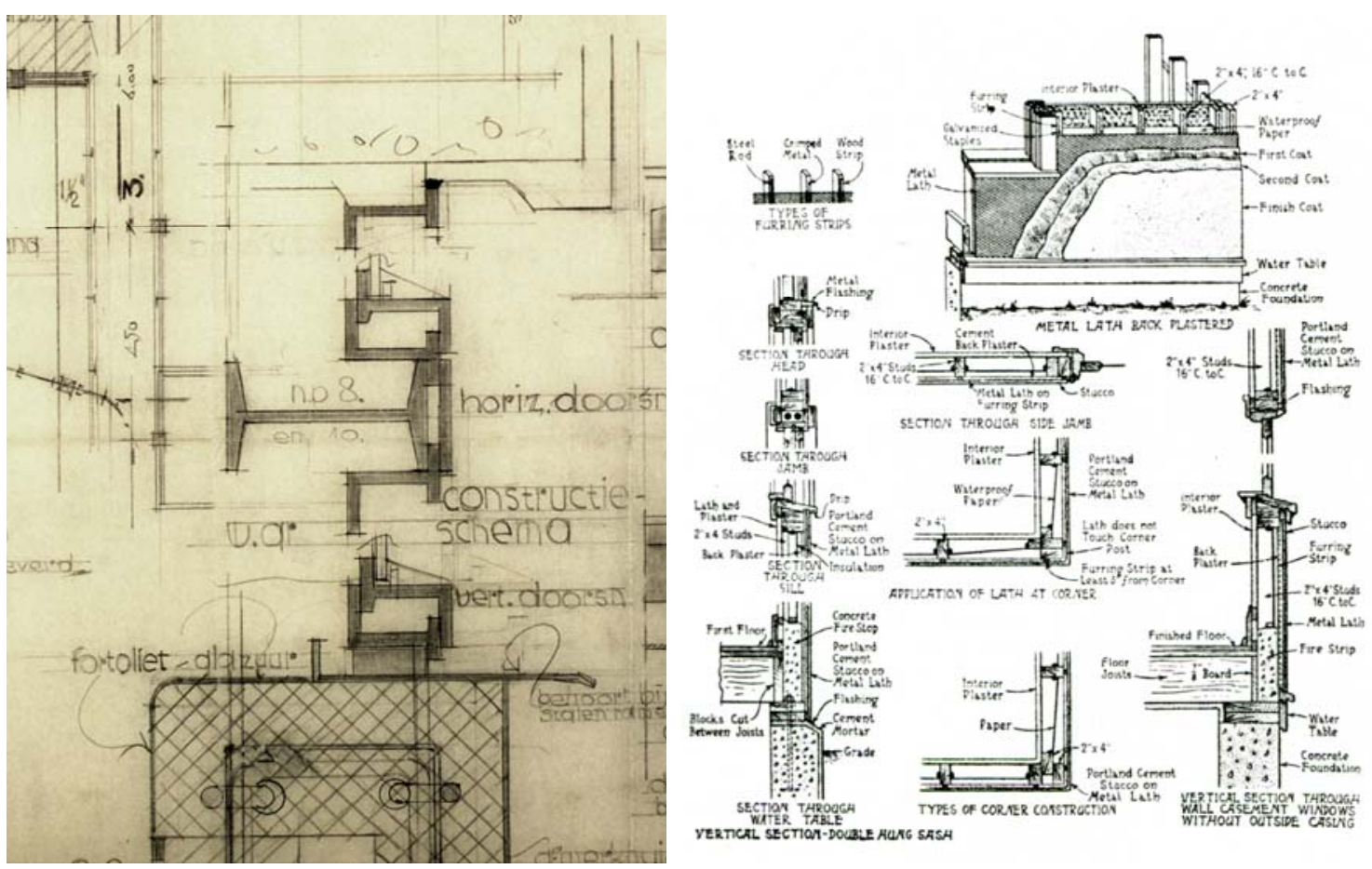

5.161 y 5.162

5.159 J. Duiker y B. Bijpoet. Zonnestraal. Estructura reutilizada del taller de carpintería.

5.160 J. Duiker y B. Bijvoet. Zonnestraal. Interior del edificio principal, 1928.

5.161 J. Duiker y B. Bijvoet. Zonnestraal. Detalle del cerramiento de la sala de conversación del edificio residencial, 1928.

5.162 Wiebenga. Detalles de paneles de cerramiento construidos en seco, 1926. 
Así el sanatorio de Zonnestraal, la fábrica tecnológica e higiénica de sanar enfermos, es capaz de generar en su interior un ambiente acogedor que suministra al enfermo sus necesarias dosis de bienestar. Un lugar donde el blanco aséptico de las paredes se combina con suaves tonos ocres, y donde los pavimentos se pintan de verde y de marrón haciendo que el suelo natural, al igual que los rayos del sol, penetren en el Sanatorio convirtiendo el interior en un exterior continuo.

\section{LA ECONOMÍA ESPIRITUAL Y EL ESTILO HIGIÉNICO DE DUIKER}

Las características terapéuticas del sanatorio de Zonnestraal, la búsqueda de sol y de aire puro, son las que determinan la concepción del mismo. Sin embargo, existen otros condicionantes que también influyeron en su definición: como la precariedad económica, dada la escasa financiación con la que desde el inicio había contado la construcción de esta obra, promovida a base de donaciones, así como la consideración, por parte de la comisión médica, de que esta enfermedad se erradicaría en un período de entre 30 ó 50 $a_{n}{ }^{85}{ }^{85}$. Por tales motivos el sanatorio debía ser una construcción barata que podría tener una durabilidad limitada.

Estos condicionantes traen consigo un ahorro de material, ya que la mano de obra resultaba barata al contar con la colaboración de los enfermos en la construcción del mismo, por lo que se emplean materiales reutilizados de otras obras [fig. 5.159], se restringe el uso de acabados costosos como el linóleo a las zonas estrictamente necesarias [fig. 5.160], y se limita la altura de los pilares a tres metros ${ }^{86}$. Se investigan también sistemas prefabricados de construcción en seco, que debían resultar económicos dada la estandarización del proceso seguida en su construcción, llegándose a construir unos de los primeros paneles prefabricados de hormigón de Europa, basados en la superposición de capas de mortero sobre rejillas metálicas ${ }^{87}$ [fig. 5.161], según el método descrito por

85 Wessel de JONGE, "Zonnestraal. Restauration d'une architecture transitoire", en Jean-Bernard CREMNITZER, Bernard TOULIER, Histoire et Réhabilitation des Sanatoriums en Europe, Les réseaux de la modernité au XX siècle/l. Docomomo International, Paris 2008, p.62.

${ }^{86}$ El linóleo sólo se situó en los corredores y escaleras en las partes centrales, en bandas de 1 metro de ancho para aprovechar al máximo el material. Los tres metros de altura de los pilares responden a la normativa holandesa establecida en 1918 que permite desencofrar tras sólo una semana de fraguado estructuras que no superen los tres metros de altura. De este modo se logra abaratar y acelerar el proceso constructivo. Wessel de JONGE, "Zonnestraal. Restauration d'une architecture transitoire", en Bernard TOULIER, Jean-Bernard CREMNITZER, Histoire et Réhabilitation des Sanatoriums en Europe, Les réseaux de la modernité au XX siècle/l. Docomomo International, Paris 2008, p.69 y p.64.

87 Consistían en piezas prefabricadas de arcilla, armadas interiormente con una malla de hierro y barras de refuerzo de acero de 6 milímetros de diámetro, recubiertas con varias capas de yeso por 
Wiebenga en la revista americana Gewapend Beton publicada en $1926^{88}$ [fig. 5.162]. Con este sistema de cerramiento Duiker busca tanto las mejoras económicas como técnicas, pues la superposición de capas debería procurar un mayor aislamiento térmico, según él explica:

"Eliminad el peso de las ropas y componer el material aislante con telas ligeras y porosas que absorben la humedad en verano cuando transpiramos y permiten el aislamiento en invierno por sus pequeñas celdas de aire en un tejido fino" ${ }^{\prime 99}$.

Estos nuevos sistemas experimentales de cerramiento, "rápidos y baratos" Berlage resultaban poco duraderos, sin embargo, esta cuestión no es un inconveniente para el comité médico dado el carácter efímero del sanatorio, ni tampoco para Jan Duiker porque está convencido de que un edificio sólo tiene sentido mientras perdura su función, de modo que proyecta soluciones perecederas y extremadamente livianas. Emplea acero no galvanizado en las carpinterías, lo que obliga a un mayor trabajo de mantenimiento que, por otro lado, formaría parte de la terapia de cura laboral de los enfermos del sanatorio. En las ventanas del edificio principal del Sanatorio y en las del primer edificio residencial o pabellón Henri ter Meulen, construidos ambos en 1928, se emplean carpinterías de acero de un espesor de 25 milímetros que van colocadas directamente sobre un marco perimetral continuo que recorre toda la fachada, sin elementos de sustentación vertical, a excepción

ambas caras, alcanzando un espesor total de 50 milímetros. Los paneles se fijaban en vertical a los perfiles IPE 8 de las carpinterías, soldando las barras de refuerzo de 6 milímetros del panel a los perfiles, y sellando las juntas con material bituminoso, finalmente se pintaban y se conseguía así una superficie opaca tersa y uniforme, propia de los productos industrializados. El primer intento de fabricación de estos paneles fue llevado a cabo en el pabellón Henri ter Meulen, inaugurado en 1928, y consistía en una malla anclada a los marcos de las ventanas que se iba cubriendo de abajo a arriba con cemento; posteriormente se plegaba hacia el interior y se macizaba con yeso para dar consistencia al conjunto. Su aspecto final era muy similar al de los paneles prefabricados, pero en su construcción se seguía un proceso totalmente artesanal. Este mismo proceso se emplea también en la construcción de los tabiques y particiones interiores. Wessel de JONGE, "Zonnestraal. Restauration d'une architecture transitoire", en Bernard TOULIER, Jean-Bernard CREMNITZER, Histoire et Réhabilitation des Sanatoriums en Europe, Les réseaux de la modernité au XX siècle/l. Docomomo International, Paris 2008, pp.61-70.

${ }^{88}$ En el sistema de Wiebenga los soportes de las telas metálicas son de madera e incluyen láminas de papel resistente al agua, en su interior. Wessel de JONGE, "Nieuwe Bouwen in practice", en Paul MEURS, Mare-Thérèse VAN THOOR (ed.), Zonnestraal, the history and restoration of modern monument. NAi, Rotterdam 2010, p. 117.

89 Jan DUIKER, "Hoe is het met onze kleeding?" ("¿̇ué pasa con nuestras ropas?"), 8 en Opbow (8+O), 1932 p. 166, en C.A., ALBERTS y E.J., JELLES, Duiker 1890-1935. Recopilación del n5 y n6 del volumen 22 de la revista Forum, Amsterdam 1972, p. 136.

${ }^{90}$ Berlage critica la arquitectura funcionalista por estar regida por la idea: "tan rápido y barato como sea posible". Jan DUIKER "Dr. Berlage y la nueva objetividad" Duiker y Bilvoet, "Dr. Berlage y la Nueva Objetividad", De 8 en Opbow (8+0), 5, 1932, p. 43-59, en Rafael GARCÍA GARCÍA, "Tres Artículos de Duiker", Cuaderno de Notas n 3, 1995, p. 34. 
de las particiones de los vidrios fijos y practicables de las mismas o en los encuentros con tabiques $^{91}$ [fig. 5.163].

La inestabilidad del conjunto y la dificultad constructiva del sistema empleado, obligan a incluir en la construcción del segundo pabellón de habitaciones en 1931, Dresselhuys, una delgada subestructura sustentante constituida por perfiles INP $8^{92}$, y a aumentar el espesor de las carpinterías a 37 milímetros [fig. 5.164]. Todos estos elementos que constituyen las carpinterías de las ventanas fueron pintados en azul para que se confundieran con el color del cielo ocultando aún más su presencia.

Al margen de las condiciones de durabilidad, para Duiker la economía se convierte en la ley imperante en la arquitectura desde sus orígenes:

"El estilo griego muestra la evolución a partir de la forma más simple de construcción: dinteles de piedra sobre columnas de piedra; pero este desarrollo evolutivo se basa únicamente en un creciente ahorro de material: columnas más esbeltas, mayores vanos.

La arquitectura medieval se caracteriza por formas constructivas más elevadas. La bóveda de piedra transforma este elemento, desde el más bajo sistema romano de construcción masiva, en algo impresionante, en la edificación de piedra más alta posible: la bóveda de arista con un análisis en nervadura, plementos, arcos y contrafuertes. (...) el crecimiento fue, siguiendo leyes de economía, hacia una mayor amplitud, hacia la utilización de menos material"193.

La estructura del sanatorio de Zonnestraal de Duiker y Wiebenga es un reflejo de la aplicación de esta ley. Proyectada en hormigón por ser considerado más higiénico y agradable al tacto que el acero, además de ser más económico por necesitar menor mano de obra para su manipulación. En ella la sección de pilares y forjados se reducen al máximo, llegándose a proyectar losas de tan sólo 8 centímetros de espesor. En las vigas los cantos se van recortando según la gráfica de momentos, empleando el material sólo y exclusivamente donde es necesario, creando así una estructura muy ligera despojada de cualquier retórica innecesaria.

91 Wessel de JONGE, "Zonnestraal. Restauration d'une architecture transitoire", en Bernard TOULIER, Jean-Bernard CREMNITZER, Histoire et Réhabilitation des Sanatoriums en Europe, Les réseaux de la modernité au XXe siècle/7. Docomomo International, Paris 2008, p.64.

92 El perfil INP 8, descrito en centímetros, equivaldría aproximadamente a un IPN 80.

93 Jan DUIKER, "Dr. Berlage y la Nueva Objetividad", De 8 en Opbow (8+0), 5, 1932, p. 43-59, en Rafael GARCÍA GARCÍA, "Tres Artículos de Duiker", Cuaderno de Notas n 3, 1995, p. 36. 
original main building sills.

The sloping plastered window

sill was finished on the inside

with concrete enamel so that

condensation could run away

through small holes in the

lower sill.

1 INP 8 steel profile,

cc's $1500 \mathrm{~mm}$

2 single drawn glass

3 steel frame, depth $25 \mathrm{~mm}$

4 steel frame depth $25 \mathrm{~mm}$

heabing)

heating)

5 plastered Trussit mesh

6 mineral plaster

7 concrete enamel

8 non ventilated

cavity wall

main building façade before

restoration.

1 inside wall: plastered

Trussit mesh

2 INP 8 steel profile,

cc's $1500 \mathrm{~mm}$

3 concrete enamel laid to falls

4 single drawn glass

5 steel frame, depth $25 \mathrm{~mm}$

6 steel drip rail
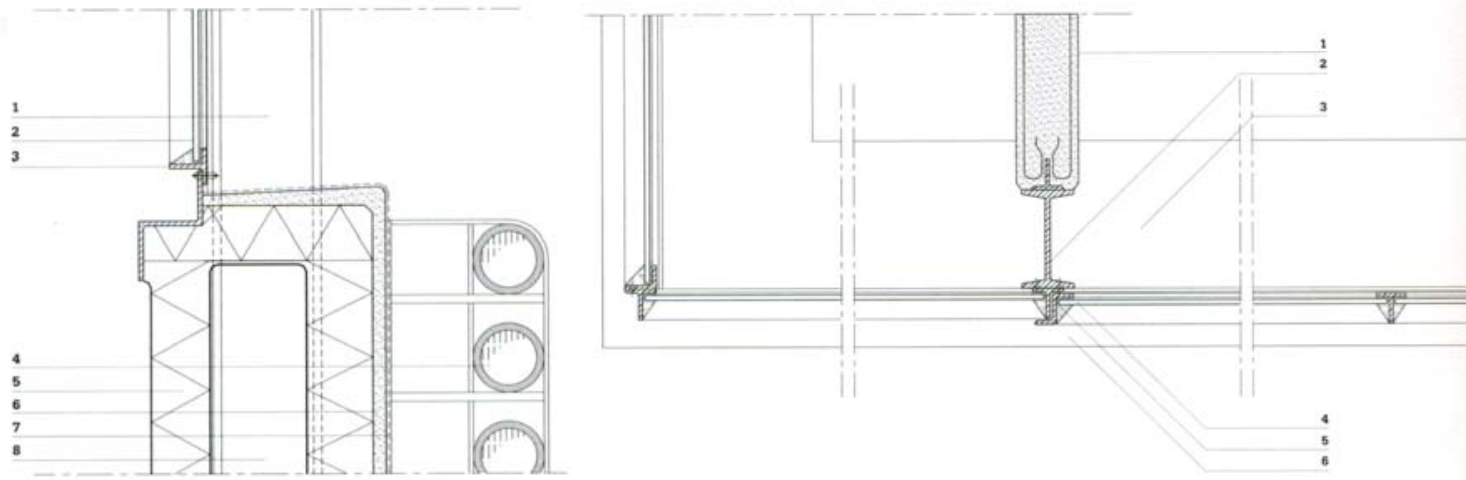

5.163

original façade of Dresselhuys

Pavilion.

1 mineral plaste

2 cement-bonded plaster

3 steel strip ca. $40 \times 5 \mathrm{~mm}$

4 column INP 8

5 steel façade frame $40 \mathrm{~mm}$

6 single drawn glass

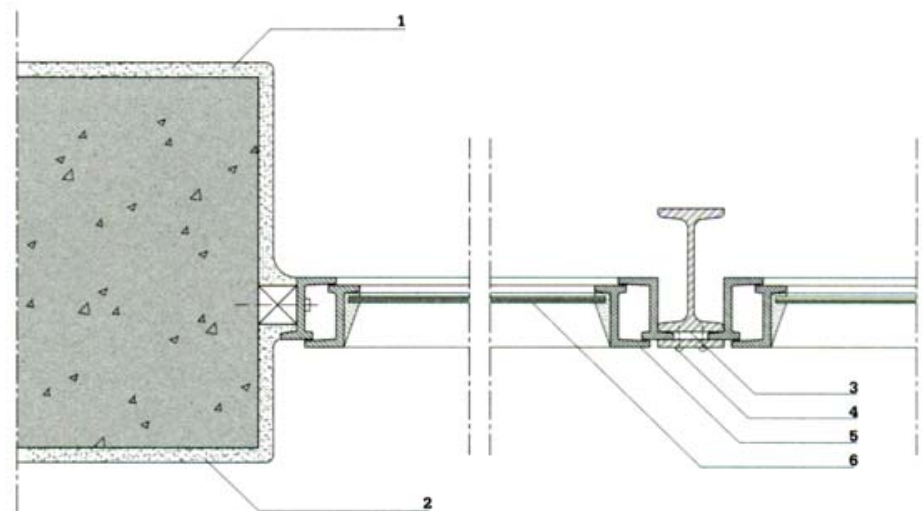

5.164

5.163 J. Duiker y B. Bijvoet. Zonnestraal. Pabellón principal, detalles en sección y en planta, 1928. 5.164 J. Duiker y B. Bijvoet. Zonnestraal. Pabellón de habitaciones Dresselhuys, detalle en planta, 1931. 
La estructura principal de los bloques de habitaciones [fig. 5.149 y fig. 5.150] está constituida por dos pórticos paralelos distanciados 3 metros, coincidiendo con el cerramiento exterior e interior de las habitaciones. Cada pórtico dispone de 5 pilares distanciados 9 metros entre sí, en los que se albergan 3 habitaciones por cada vano, quedando los forjados de la galería de curas y del corredor interior en vuelo, los cuales asoman 1,5 metros sobre los dos pórticos. Los pórticos pasan a ser 3 en las zonas de aseos y espacios servidores ubicadas junto al pasillo.

La sala de conversación del edificio residencial se constituye, en cambio, por 7 pórticos distanciados 3 metros entre sí. Cada pórtico está constituido por dos pilares, separados 9 metros, que soportan una viga de hormigón de 15 metros de longitud y de sección variable, que vuela 3 metros a cada lado del pilar de tal manera que, los momentos flectores se compensan con los vuelos, permitiendo reducir la sección de la viga al alejarse del nudo producido en el encuentro de ésta con el pilar.

El método estructural empleado recuerda al descrito por Mies van der Rohe para la construcción de edificios de oficinas donde:

"La división funcional del espacio de trabajo determina la profundidad del edificio:

16 metros. Se encontró que el sistema más económico es una doble hilera de columnas separadas 8 metros, con 4 metros en voladizo a cada lado. Las jácenas están separadas cada 5 metros. Esas jácenas sostienen las losas del piso que, al final del voladizo, se levantan perpendicularmente formando la piel exterior del edifcio" ${ }^{94}$.

En el sanatorio, también las losas en vuelo se levantan para definir los petos de remate de las terrazas y galerías de cura, petos que además poseen una función portante de manera que la estructura de hormigón se convierte en el esqueleto del edificio [fig. 5.165 y fig. 5.166], mientras que el cerramiento pasa a ser una delgada piel transparente que lo envuelve y que, como en una radiografía, permite ver a través de ella la estructura sustentante de su interior. Viene a colación, la descripción que Thomas Mann pone en boca de su protagonista como si del sanatorio hablase:

"Hans Castorp vio miembros: manos y pies, rodillas, muslos, piernas, brazos y caderas. Sin embargo, los redondeados contornos de aquellos fragmentos del cuerpo humano no eran más que una sombra borrosa; una niebla extraña, un fantasmagórico halo que envolvía un núcleo perfectamente reconocible, nítido y de

\footnotetext{
${ }^{94}$ Ludwig MIES VAN DER ROHE, "Bürohaus", G, 1923, en Escritos, diálogos y discursos, Colección Arquitectura $\mathrm{n}^{\circ} 1$, Colegio Oficial de Aparejadores y Arquitectos Técnicos de la región de Murcia, Murcia 2005, p. 26.
} 

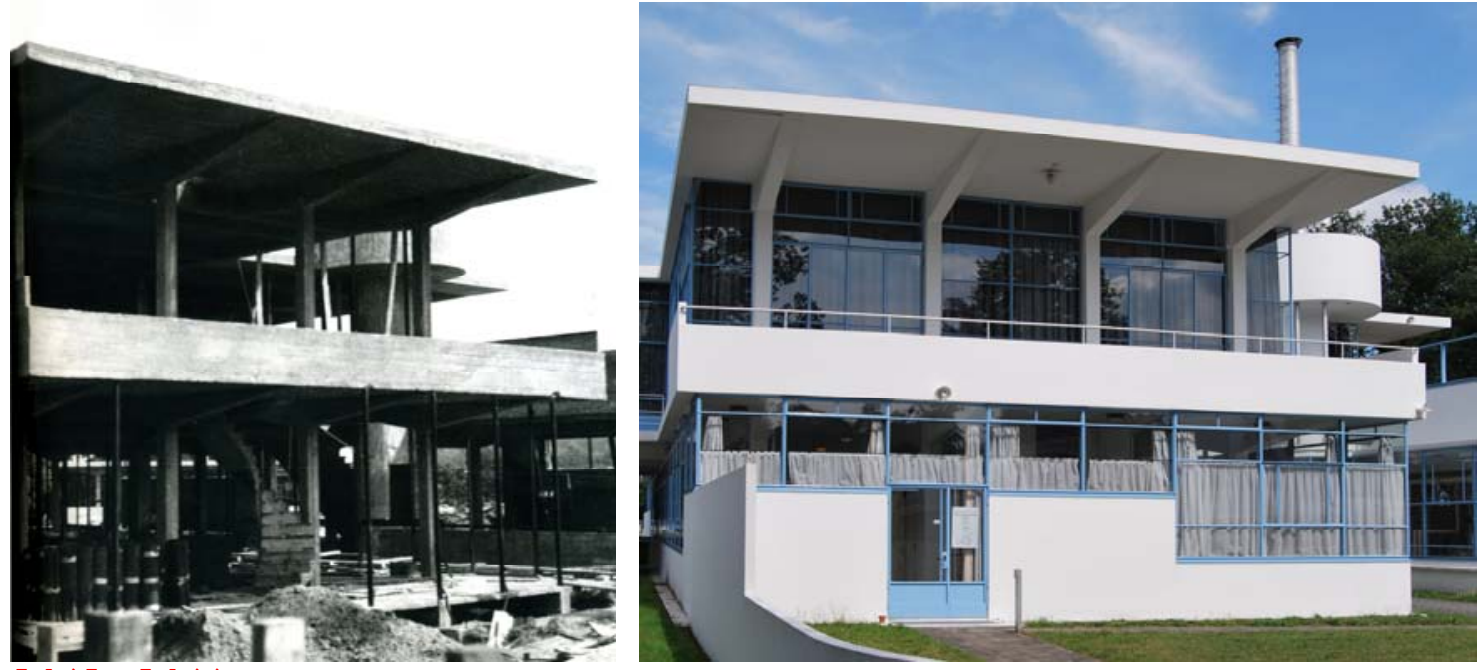

5.165 y 5.166
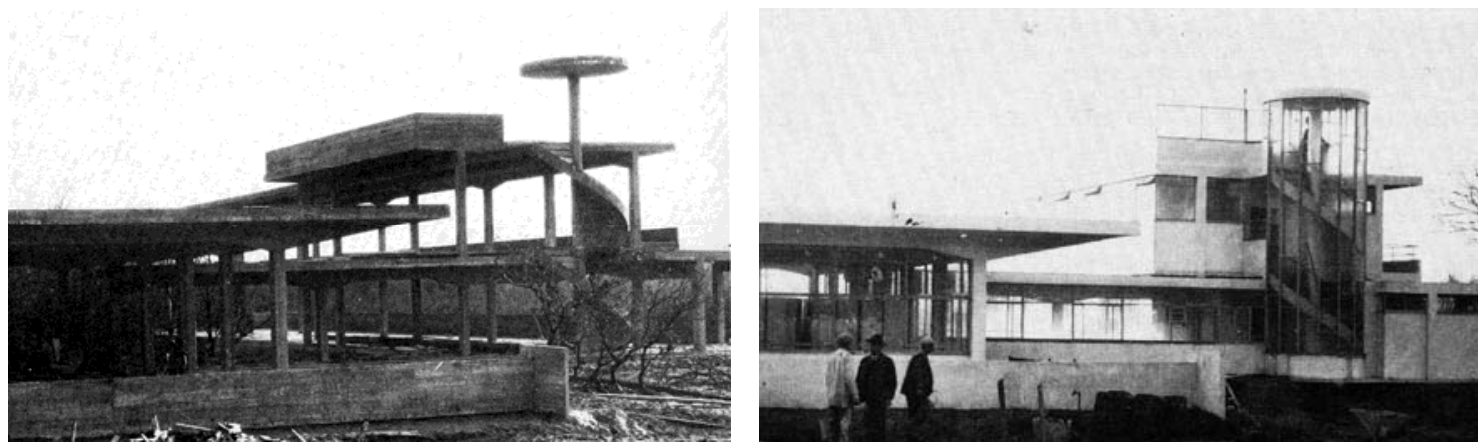

5.167 y 5.168

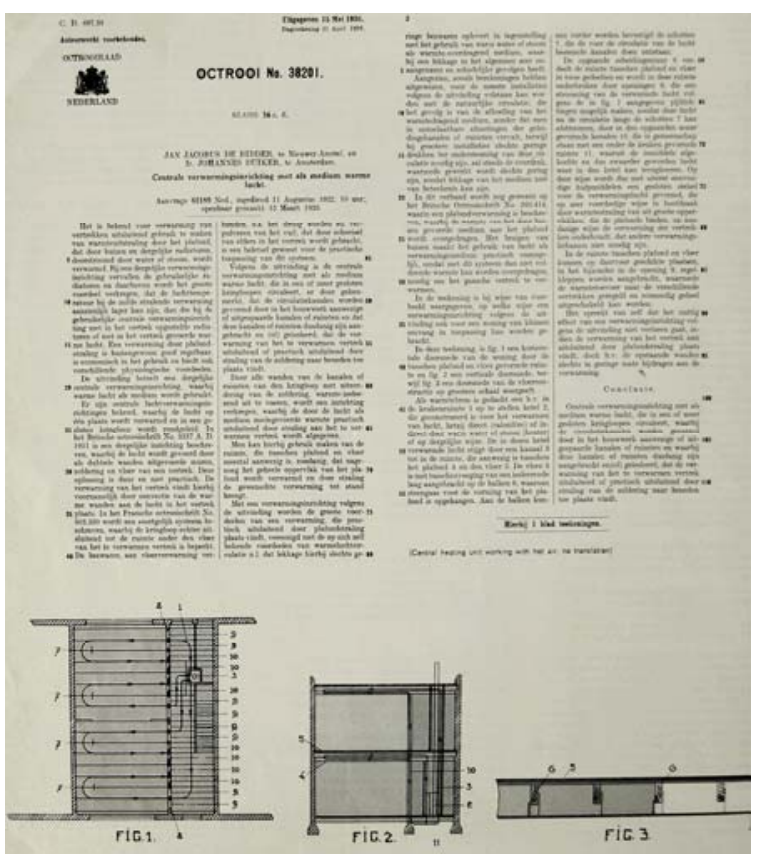

5.169

5.165 y 5.166 J. Duiker y B. Bijvoet. Zonnestraal. Edificio principal estructura y edificio acabado (fotografía de la autora)

5.167 y $5.168 \mathrm{~J}$. Duiker y B. Bijvoet. Zonnestraal. Edificio residencial estructura y edificio acabado. 5.169 J. Duiker. Patente de climatización mediante "techo radiante". 
un blanco refulgente: el esqueleto" 95.

De este modo, Duiker y Wiebenga proponen en Zonnestral una arquitectura desnuda y esencial, sin a penas materia, construida en vidrio y hormigón; según Mies van der Rohe: "Las estructuras de hormigón armado son esqueletos por naturaleza. No tartas. Ni fortalezas. Columnas y jácenas eliminan paredes de carga. Es construcción de piel y huesos ${ }^{\prime \prime} 96$.

La propia estructura es el elemento definidor de la forma del edificio ${ }^{97}$, como se aprecia en 1928 cuando se inaugura la primera fase de Zonnestraal, con el edificio principal y uno de los pabellones de habitaciones acabados mientras que el pabellón Dresselhuys se encontraba aún en fase de estructura y presentaba una configuración formal completa

[fig. 5.167 y fig. 5.168].

El fin último de esta economía material reflejada en la estructura donde, como Mies explica, se trata de "crear la forma desde la esencia del problema con los medios de nuestra época" obteniendo el "máximo rendimiento con mínimos medios"198, alcanza en Duiker cotas más elevadas al perseguir con ella la máxima apertura, desarrollando el concepto de "economía espiritual" definido por Duiker, que alejándose de la "economía financiera" tiende "hacia la inmaterialización y la espiritualidad"99. Apoyándose en la tecnología y en los nuevos materiales, además de en las formas arquitectónicas abiertas, radiales y centrífugas, se busca la apertura espacial como fuente de bienestar físico y mental. Así pues, la arquitectura higiénica y saludable propia del sanatorio se convierte en un modelo a seguir en el resto de programas, llegando incluso a definir un estilo, que Duiker describe como "estilo higiénico", donde la luz y el aire son los verdaderos protagonistas:

\footnotetext{
95 Thomas Mann, La Montaña Mágica (Berlín, 1924).Edhasa, Barcelona 2005, p. 310.

${ }^{96}$ Ludwig MIES VAN DER ROHE, "Bürohaus", G, 1923, en Escritos, diálogos y discursos, Colección Arquitectura $n^{\circ} 1$, Colegio Oficial de Aparejadores y Arquitectos Técnicos de la región de Murcia, Murcia 2005, p. 26.

97 Peter BLUNDELL JONES Modelos de la Arquitectura Moderna (Modern architecture through case studies, 2002). Editorial Reverté, Barcelona, 2011 , pp. 139-140.

${ }^{98}$ Ludwig MIES VAN DER ROHE, "Bürohaus", G, 1923, en Escritos, diálogos y discursos, Colección Arquitectura $n^{\circ} 1$, Colegio Oficial de Aparejadores y Arquitectos Técnicos de la región de Murcia, Murcia 2005, p. 25.

99 "Si el principio del funcionalismo de la obra de Berlage tiene algún valor cultural, se debe a que no tiene ninguna relación con la economía financiera sino sólo con la economía espiritual. Esta economía espiritual nos conduce a una construcción de lo estrictamente posible, dependiendo del material usado, y se desarrolla más allá hacia la inmaterialización y la espiritualidad" Jan DUIKER, "Dr. Berlage y la Nueva Objetividad", De 8 en Opbow (8+O), 5, 1932, p. 43-59, en Rafael GARCÍA GARCÍA, "Tres Artículos de Duiker", Cuaderno de Notas n³ 3, 1995, p. 36.
} 

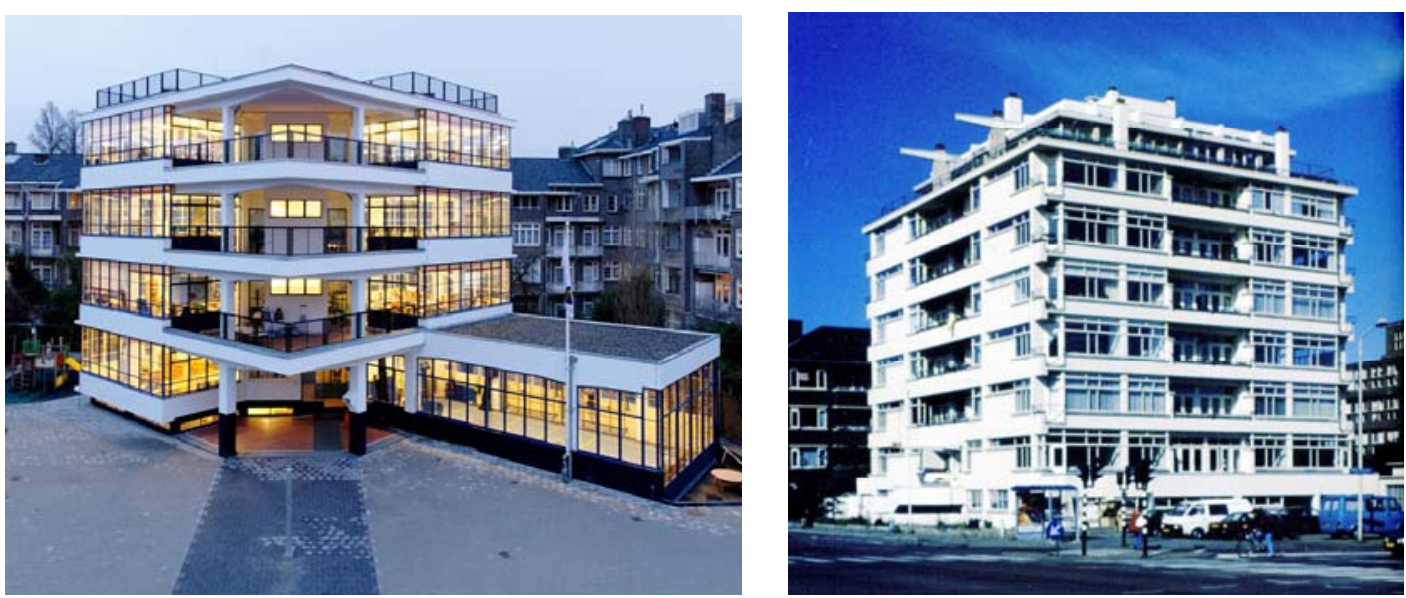

5.170 y 5.171
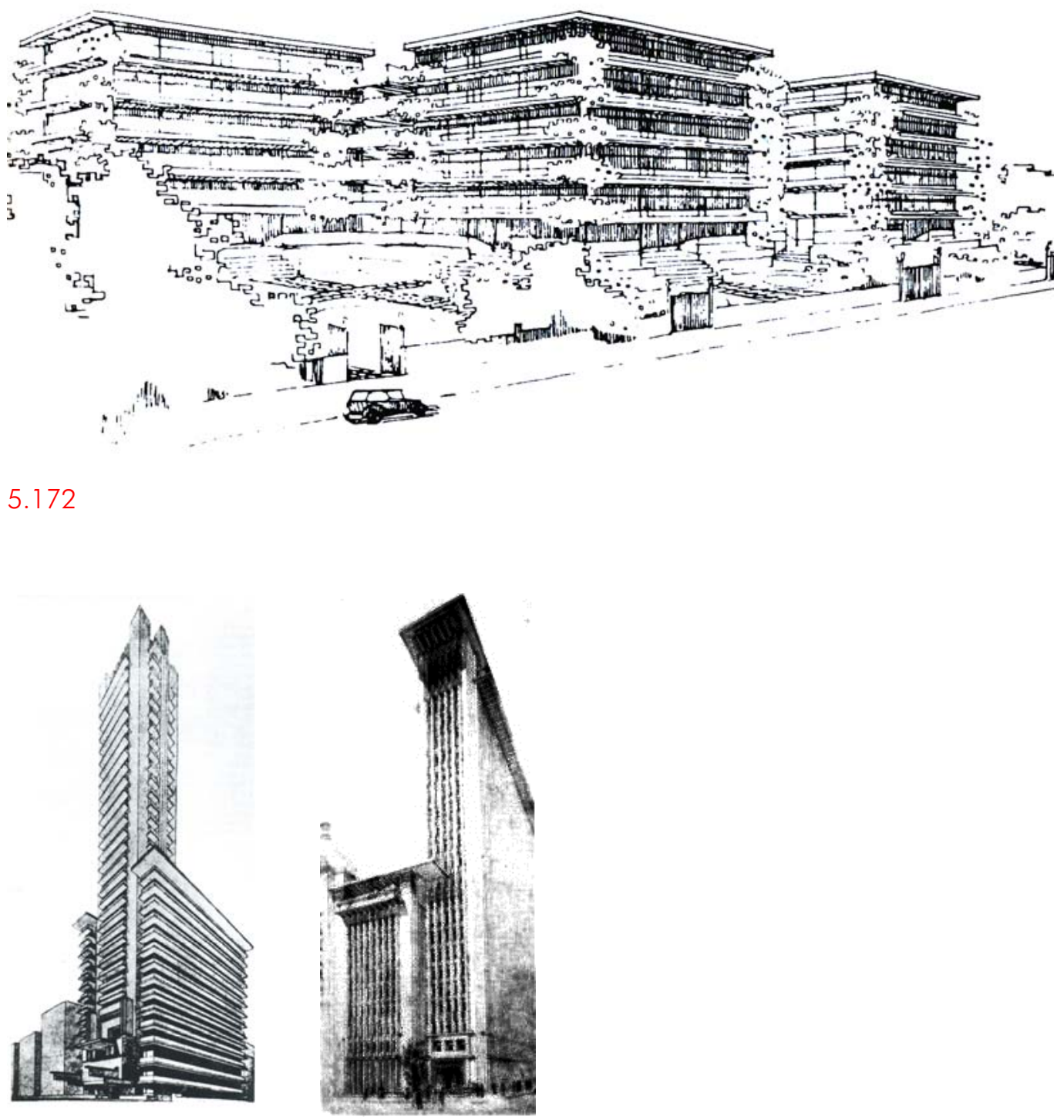

5.173 y 5.174

5.170 J. Duiker y B. Biivoet. Escuela al aire libre Cliostraat, Ámsterdam, 1930.

5.171 J. Duiker y J.G. Wiebenga. Apartamentos Nirwana, La Haya, 1928.

5.172 J. Duiker y J.G. Wiebenga. Proyecto previo. de los apartamentos Nirwana, La Haya, 1928.

5.173 J. Duiker y B. Biivoet. Proyecto para el concurso del Chicago Tribune, 1922.

5.174 F. LI. Wright. Proyecto del Press Building de San Francisco, 1912. 
"(...) Porque el nivel de la cultura higiénica de una vivienda semejante para una familia con tuberculosis no consiste en la presencia de escupideras desinfectantes, ni en la colocación de láminas de vidrio entre las camas. No, el nivel de la cultura higiénica se consigue mediante la construcción de un alojamiento que:

-tenga un soleamiento completamente satisfactorio;

-permita a los pacientes respirar la suficiente cantidad de aire; y

-sea "higiénico" en su construcción básica, ejecución y posterior adecuación interior.

Tales construcciones realmente no existen, por lo menos, aún no. Llegarán seguramente con el tiempo, no hay duda de ello, pero entonces no serán casas para familias tuberculosas sino casas para todo aquel que valore el bienestar físico y mental ${ }^{\prime \prime 100}$.

Sin embargo, una de las principales críticas que suscitaba el "estilo higiénico" consistía en el elevado gasto en calefacción que conllevaba su uso, debido a las pérdidas de calor que el empleo indiscriminado del vidrio podía llegar a producir. Para solucionarlo Duiker patenta varios sistemas de calefacción apropiados para este material, uno de ellos consiste en los "techos radiantes" [fig. 5.169] que sustituyan los convencionales sistemas de calentamiento por convección:

"Un problema técnico importante de la instalación higiénica de un edificio es la calefacción. Se puede hacer de dos formas: reemplazando el aire frío por el caliente o por radiación. (...) se recomienda el calor por radiación. Se pueden ensayar diferentes situaciones para la colocación de la fuente de calor. La más eficiente parece ser la instalación de la fuente en el techo del local. (...) En el sistema tradicional, la instalación de los emisores en el techo sería impracticable. Cuando se usa calor radiante, no existe tal dificultad ya que las capas de aire no se mueven. (...) el calor radiará directamente hacia abajo en todas las direcciones. Con el calor radiante se eliminan las objeciones contra las grandes superficies de vidrio porque el calor de radiación no atraviesa el vidrio sino que es reflejado, un fenómeno en el que se basan los invernaderos" ${ }^{\prime 101}$.

\footnotetext{
100 Jan DUIKER, "Een gezonde school voor het gezonde kind" ("Una escuela sana para niños sanos"), De Opbow (8+0), 1932 p. 88-92 en C.A., ALBERTS y E.J., JELLES. Duiker 1890-1935. Recopilación del n ${ }^{\circ} 5$ y nº del volumen 22 de la revista Forum, Amsterdam 1972, p. 60.

101 Jan DUIKER, "De Nieuwe Zakelijkheid in zomer en Winter", ("El nuevo funcionalismo en verano y en invierno"), De Opbow (8+0), 1932 p. 140-143 en C.A., ALBERTS y E.J., JELLES. Duiker 18901935. Recopilación del n5 y n6 del volumen 22 de la revista Forum, Amsterdam 1972, p. 135.
} 

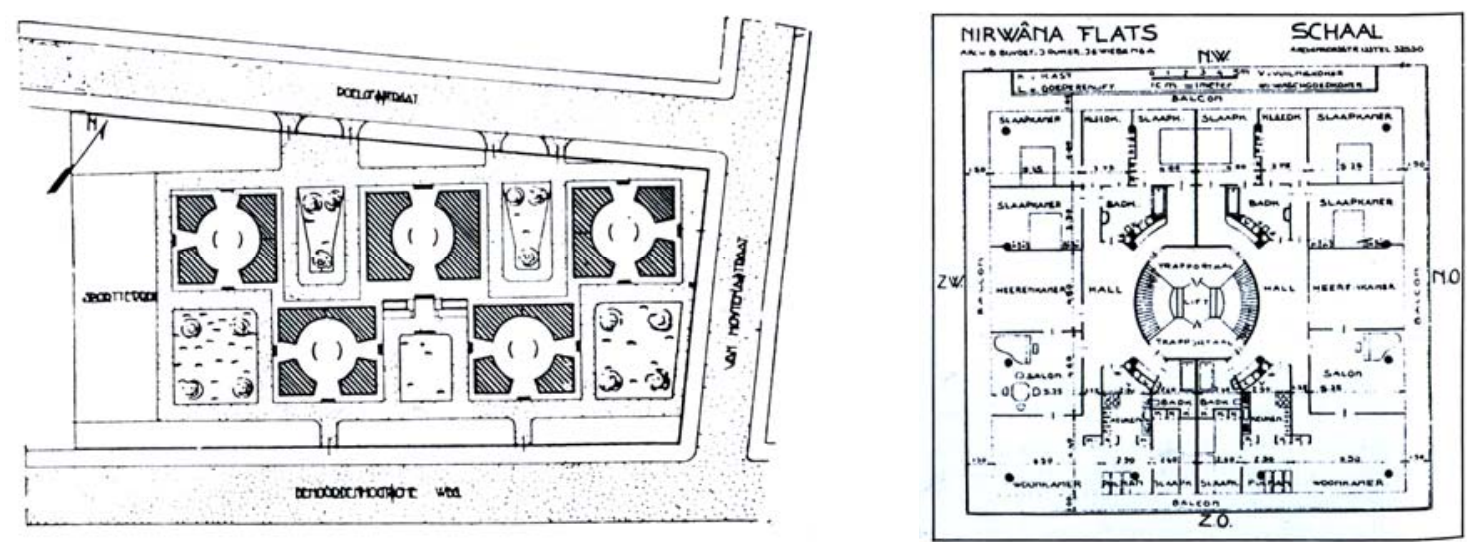

5.175 y 5.176
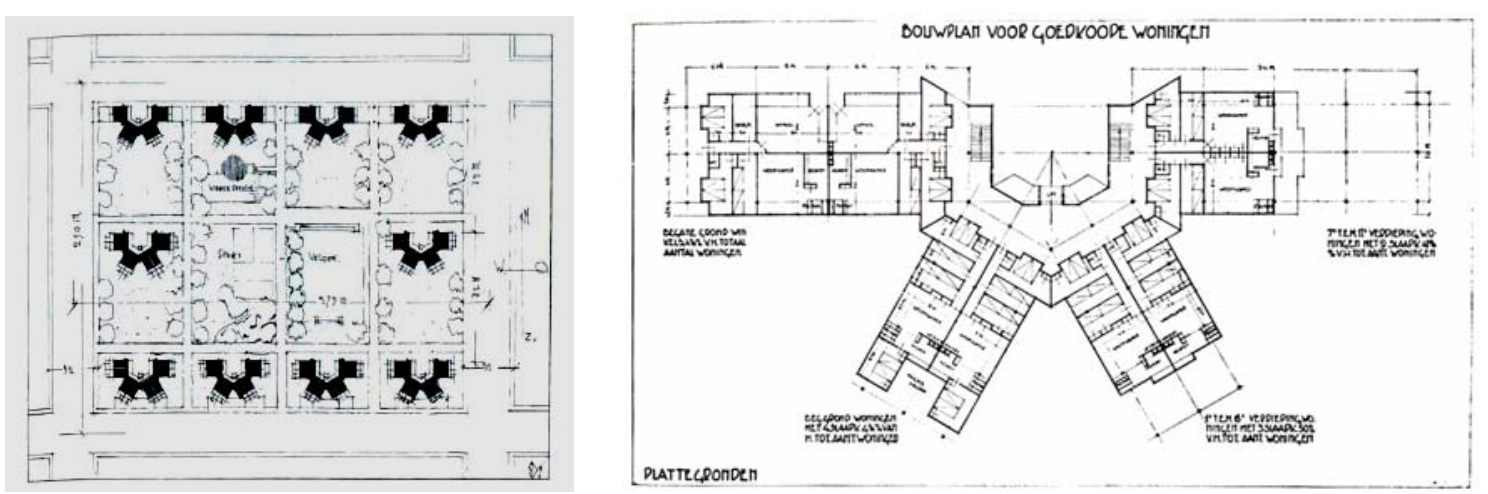

5.177 y 5.178
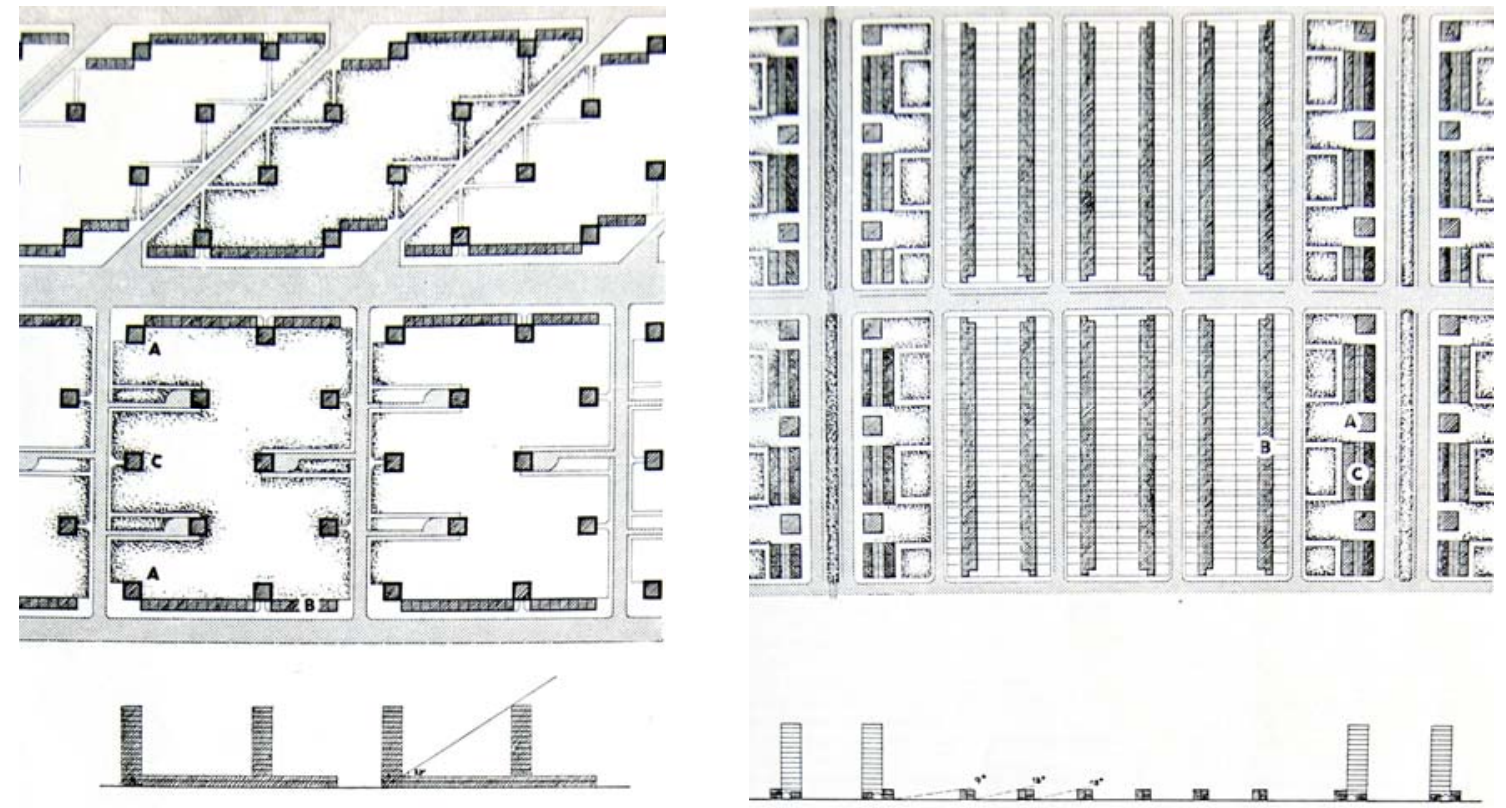

5.179 y 5.180

5.175 y 5.176 J. Duiker y J.G. Wiebenga. Apartamentos Nirwana, La Haya 1928. Ordenación y planta tipo.

5.177 y 5.178 J. Duiker y J.G. Wiebenga. Proyecto de viviendas publicado en su libro Hoogbouw, 1930. Ordenación y planta tipo.

5.179 y 5.180 J. Duiker. Esquemas publicados en Rationelle Bebauungsweisen: Ergebnisse des 3. Internationalen kongresses für neves baven, 1930. 
Los resultados de sus patentes de calefacción no tuvieron mucho éxito, como demuestra el sistema de climatización diseñado por Duiker para el Cineac (1933), que nunca llegó a obtener los resultados esperados, pero manifiesta su afán investigador y su interés por resolver los problemas, llegando incluso a obtener una patente póstuma, en el año 1936, de un nuevo sistema de calefacción.

También la higiene y la salud pasan a protagonizar la obra de Duiker en dos de sus construcciones más próximas al proyecto de Zonnestraal. La primera es la Escuela al aire libre de Cliostraat [fig. 5.170] en Ámsterdam, proyectada entre 1927 y 1928 en teoría por Duiker y Bijvoet, ya que ambos firman los planos, y construida un año más tarde entre 1929 y 1930. La segunda son los apartamentos Nirwana [fig. 5.171], proyectados junto a Wiebenga en el año 1927 y construidos en La Haya en 1928. En ambas obras, al igual que en Zonnestraal, se busca la máxima apertura espacial mediante el empleo del vidrio y la incorporación de terrazas. Se tiene especialmente en cuenta la orientación en la distribución de los espacios y en la ordenación del recinto, y se emplean los mismos materiales, hormigón en la estructura y vidrio en el cerramiento. Se plantea también en las dos una organización centrífuga aunque compacta, cuyos centros están ocupados por el núcleo de las escaleras y el perímetro por las estancias abiertas al entorno.

En los apartamentos Nirwana Duiker y Wiebenga adoptan al principio una solución que consiste en la disposición de cinco torres cuadradas, conectadas entre sí a través de corredores perimetrales abiertos que, a modo de calles superpuestas en altura, van comunicando las diversas plantas de las viviendas [fig. 5.172]. La superposición de bandejas horizontales recuerda el proyecto de la torre realizado por Duiker y Bijvoet para el concurso del Chicago Tribune (1922) [fig. 5.173] con reminiscencias compositivas del proyecto de Wright para el Building Press de San Francisco (1912), aunque en éste impera un orden vertical $^{102}$ [fig. 5.174]. Gracias al crecimiento compacto en altura de las torres se libera más espacio a su alrededor y, mediante su disposición en damero, no se obstaculizan las vistas entre ellas. Se mantiene la máxima captación de luz sin perder la buena orientación solar, y se traslada al programa residencial las necesidades terapéuticas desarrolladas en el proyecto del sanatorio de Zonnestraal [fig. 5.175 y fig. 5.176].

Los mismos planteamientos higiénicos de generar espacios libres y viviendas soleadas están presentes en los proyectos teóricos desarrollados por Duiker y Wiebenga entre 1928 y 1929

102 Pedro IGLESIAS PICAZO, La habitación del enfermo. Ciencia y arquitectura en los hospitales del Movimiento Moderno. Fundación Caja de Arquitectos, Barcelona 2010, p. 113. 
para la construcción de viviendas sociales en altura, descritas en 1930 en su libro Hoogbouw, Construcción en altura. Los proyectos analizan distintas opciones para distribuir una densidad de 154 viviendas por hectárea en viviendas en altura. Una de las propuestas consiste en la construcción de 10 torres, de 12 plantas cada una, constituidas por cuatro bloques dispuestos radialmente que recuerdan a los sistemas de organización aplicados en el proyecto de la escuela al aire libre y en los talleres de Zonnestraal [fig. 5.177 y fig. 5.178]. Este trabajo fue citado por Walter Gropius en su presentación "¿̇Edificación baja, media o alta?", en el III CIAM celebrado en Bruselas en el año 1930103, donde a través de esquemas gráficos o diagramas que pasarán a ser internacionalmente conocidos, claramente inspirados en los diseñados por Duiker, se explican las ventajas de la edificación compacta y vertical frente a la ciudad jardín. Los esquemas originales de Duiker serán publicados en el libro Rationelle Bebauungsweisen: Ergebnisse des 3. Internationalen kongresses für neves baven (1930), un resumen del congreso que incluía 56 propuestas, siendo las $n^{\circ} 52$ y $n^{\circ} 53$ las suyas [fig. 5.179 y fig. 5.180]. Son un reflejo del método de proyecto basado en los análisis de los problemas y en las demostraciones científicas de las soluciones arquitectónicas, método ya presente en los informes elaborados por Duiker para el comité de Zonnestraal y que aplicará en proyectos ulteriores.

Resulta sorprendente la importante repercusión de ciertas reflexiones y métodos desarrollados por Duiker en Zonnestraal frente a la escasa trascendencia internacional que tuvo esta obra en los manuales de arquitectura. Giedion no la menciona en Espacio Tiempo y Arquitectura (1941) pese a comentar otros sanatorios como el de A. Perret de Francia o el Sanatorio Bella-Lui en Suiza; tampoco aparece en El estilo internacional: Arquitectura desde 1922 (1932), de Hitchcock y Jhonson. Sin embargo en el año 1929 J.J.P. Oud incluye en la segunda edición de su libro Holländische Architektur una imagen de Zonnesstraal ${ }^{104}$. Oud, casi 30 años más tarde realizará entre 1952 y 1960 un centro de reeducación para niños parapléjicos Bio-Herstellingsoord en Arnheim. El complejo está constituido por una serie de pabellones singulares situados en el eje con el edificio principal en la cabeza y

\footnotetext{
103 Carlos MARTí ARÍS (ed.), Las formas de la residencia en la ciudad moderna. Vivienda y ciudad en la Europa de entreguerras (1991).Ediciones UPC, Barcelona 2000, p. 37 y 99.

104 En ese mismo año Bruno Taut en su libro Modern Architecture describe a Zonnestral como "quizás el mejor de los logros más recientes" en Holanda, y, tres años más tarde Alberto Sartoris en Gli Elementi dell'architettura funzionale, publicado en 1932, describe la obra de Zonnestraal y la incluye entre "las más significativas obras de la civilización mecánica". Barry BERGDOLL, "Zonnestraal as icon of the Modern Movment. A short history of reception" en Paul MEURS Mare-Thérèse VAN THOOR (ed.), Zonnestraal, the history and restoration of modern monument. NAi, Rotterdam 2010, pp. 10-12.
} 
otros edificios residenciales repetidos, separados y girados respecto al eje longitudinal de la composición. Su ordenación general guarda ciertas similitudes con el proyecto de Zonnestraal por su orden jerárquico, su desarrollo longitudinal y la presencia de edificaciones giradas [fig. 5.181]; además el edificio de instalaciones que contiene la vivienda del guarda también recuerda por su geometría y su distribución radial a la residencia cilíndrica de enfermeras del Sanatorio [fig. 5.182].

El tardío resurgir de Zonnestraal alrededor de los años 60 se debe a Peter y Alison Smithson, exaltadores de la arquitectura de principios de los años 30, la de su llamado "periodo heroico". Peter Smithson en un artículo monográfico sobre Zonnestraal publicado en 1962 en la revista Forum, escribe:

"Uno se imagina que el sueño constructivista era crear una arquitectura capaz de hacer frente a cada tipo de problemas sólo con materiales comunes: acero, hormigón, vidrio launque sean materiales que en ese momento estuvieran acusados de un vigor más poético), y fueron la suerte y el genio de Duiker los que hicieron la un poco loca pero bastante real poesía de la máquina de estas cosas ordinarias, no en la Santa Rusia en la Holanda Burguesa. (...) Ninguna añadidura convencional fue usada en sus diseños, ninguna apropiación histórica les apuntalaba. iQué invención y coraje debe haber exigido! Zonnestraal y Cieneac son obras maestras, que con la casa Rietveld Schroeder y Van Nelle forman los cuatro pilares de logro holandés"105.

En cambio, en los años 30 Zonnestraal apenas fue mencionado en las revistas de arquitectura internacionales, ni tan si quiera aparece en el número dedicado a hospitales de la revista de L'Architecture d'Aujourd'hui publicado en 1934 ${ }^{106}$, aunque sí lo hace en la revista L'Architecture Vivante un año antes, en 1933, en el número específico de arquitectura hospitalaria.

Pese a la escasa difusión internacional, la obra no pasa inadvertida a los grandes maestros de la arquitectura. En el verano de 1928, justo antes de comenzar el proyecto del Sanatorio

\footnotetext{
105 Peter SMITHSON, "Duiker" en Forum, no 1, 1962, p. 1. Texto original: "One imagines that the Constructivist dream was to create an architecture capable of dealing with just such problems in the most ordinary of materials - steel, concrete, glass (albeit materials which at that time were charged with a most poetic vigor), and it was Duiker's luck and genius to make a slightly mad but quite real machine poetry from this ordinary stuff, not in Holy Russia but in Bourgeoise Holland. (...) No conventional aids were used in designing them, no history propped them up. What invention and courage this must have demanded! Zonnestraal and Cieneac are masterpieces, which with the Rietveld-Schroeder House and Van Nelle form the four cornerstones of Dutch achievement."

${ }^{106}$ En esta revista incluso se llega a publicar una imagen del sanatorio Sant Joan de Déu de Manresa, Barcelona, obra del arquitecto Rodríguez Arias.
} 

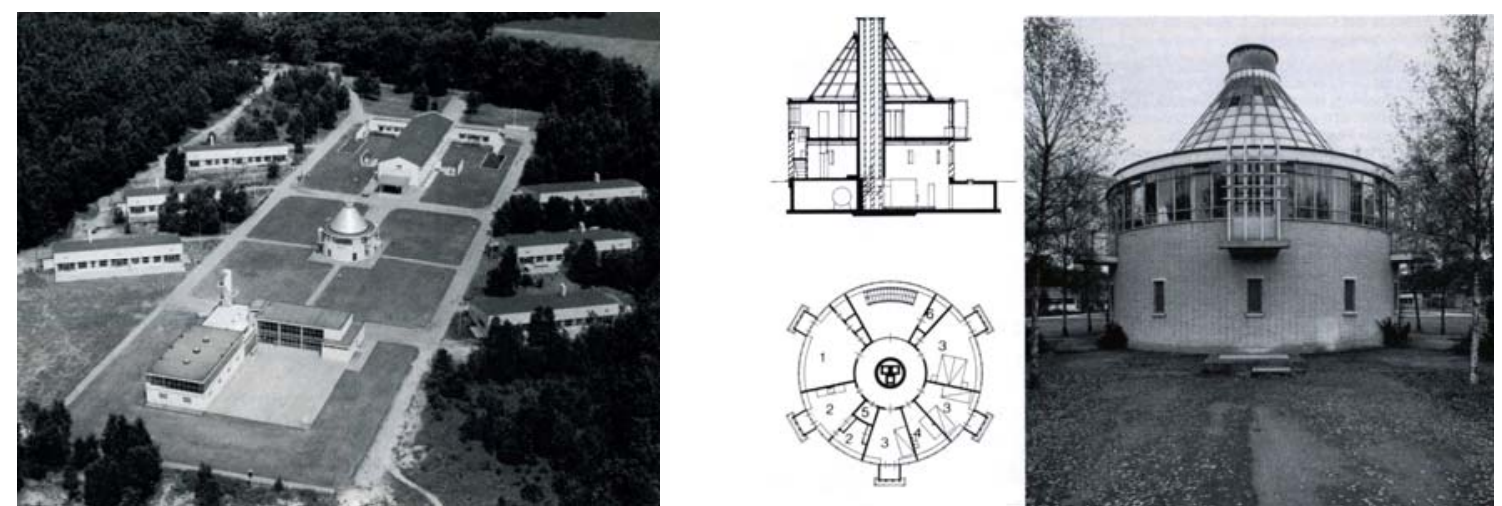

5.181 y 5.182
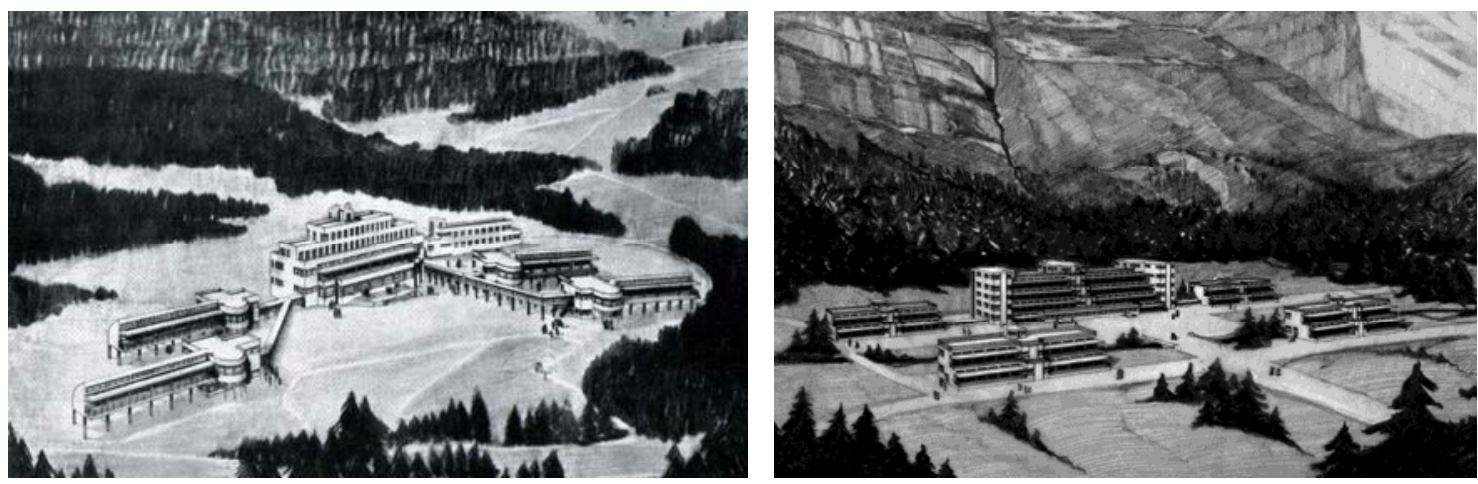

5.183 y 5.184
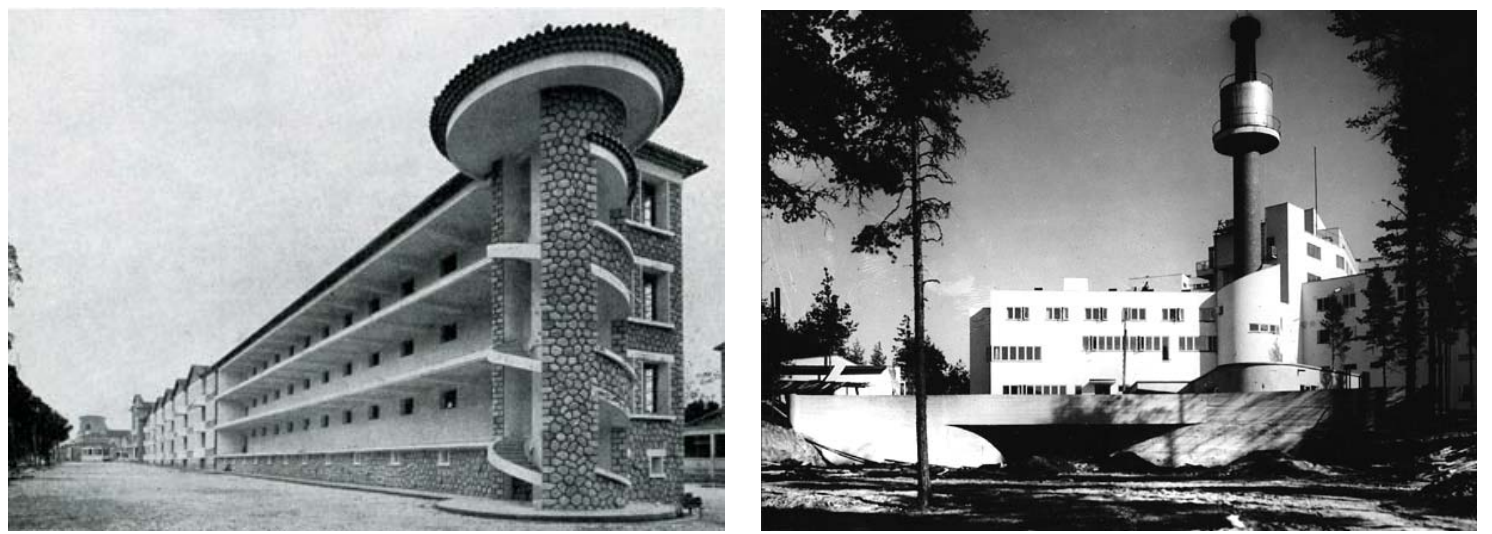

5.185 y 5.186

5.181 y 5.182 J.J.P. Oud. Centro para niños parapléjicos Bio-Herstellingsoord, Arnheim 1960. Ordenación general y casa del guarda.

5.183 P. Abraham y H.J. Le Même. Sanatorio Roc des Fisz, Plateau d'Assy, 1932. Perspectiva del conjunto.

5.184 P. Abraham y H.J. Le Même. Sanatorio La Clairière o Guébriant, Plateau d'Assy, 1933. Perspectiva del conjunto de una propuesta previa.

5.185 G. Castel. Sanatorio Bouches-du-Rhône, Aix-en-Provence, 1934.

5.186 A. Aalto. Sanatorio de Paimio, Turku, 1933. (AA Mav 5317, AAA) 
de Paimio, Alvar Aalto visita Zonnestraal ${ }^{107}$ durante su estancia en Holanda de camino a París junto a su esposa Aino, donde se encontrará con André Lurçat quien conoce y valora Zonnestraal ${ }^{108}$. Años más tarde, en el invierno de 1932, será Le Corbusier quien lo visite ${ }^{109}$, embarcado en ese momento en una transición entre la arquitectura funcional hacia una más lírica.

La influencia de Zonnestraal se hará patente en ciertos sanatorios antituberculosos de pabellones como en los sanatorios de Roc des Fisz (1930-1932) [fig. 5.183] y en el sanatorio La Clairière (1930-1933), conocido actualmente como sanatorio Guébriant [fig. 5.184], los dos construidos en el Plateau d'Assy, Francia, obra de los arquitectos Paul Abraham y Henry-Jacques Le Même. Estos sanatorios siguen el mismo planteamiento que Zonnestraal al estar constituidos por un edificio principal y varios pabellones de habitaciones en los que se persigue conseguir, a través de su implantación, las condiciones óptimas de soleamiento y las mejores vistas sobre el paisaje. Sin embargo, a causa de la irregularidad orográfica del terreno en que se implantan, resulta difícil aplicar un orden geométrico inalterado que organice el conjunto como sucede en el sanatorio holandés.

En otros ejemplos de sanatorios la relación con Zonnestraal es más parcial y se vincula más a la presencia de ciertos elementos significativos del mismo, como sucede en el sanatorio des Bouches-du-Rhône en Aix-en-Provence, Francia, del arquitecto G. Castel construido en 1934 [fig. 5.185], cuyos pabellones resultan una copia pintoresca de sus bloques de habitaciones y de sus remates de escaleras circulares, o en el sanatorio de Paimio de Aalto donde su enorme chimenea recuerda a la de Zonnestraal [fig. 5.186].

Las similitudes demuestran la importancia de la obra en el campo hospitalario, pero es quizás la trasposición que Duiker plantea de los conceptos higiénicos desarrollados en el Sanatorio de Zonnestraal a la arquitectura en general, el valor más trascendente de su obra:

\footnotetext{
107 Paul David PEARSON, Alvar Aalto and the International Style, Mitchell, London 1989, p. 84.

${ }^{108}$ André Lurçat, incluye en su libro Architecture publicado el año 1929 el sanatorio de Zonnestraal. Citado en: Barry BERGDOLL, "Zonnestraal as icon of the Modern Movment. A short history of reception" en Paul MEURS Mare-Thérèse VAN THOOR (ed.), Zonnestraal, the history and restoration of modern monument. NAi, Rotterdam 2010, p. 11.

109 Un año después de su visita, en 1933, Duiker escribe en la revista L'Architecture d'Aujourd'hui, sobre Le Corbusier destacando el carácter higiénico de su arquitectura. En su artículo incluye una cita al respecto del Dr. Pierre Winter: "Médicos, no médicos de prescripciones, sino auténticos técnicos higiénicos le ofrecerán a Le Corbusier colaborar en planes de regularización total de la sociedad donde los equipamientos para la salud van a ser concebidos por fin cuidadosamente" Citado en: Barry BERGDOLL, "Zonnestraal as icon of the Modern Movment. A short history of reception" en Paul MEURS Mare-Thérèse VAN THOOR (ed.), Zonnestraal, the history and restoration of modern monument. NAi, Rotterdam 2010, p. 11.
} 


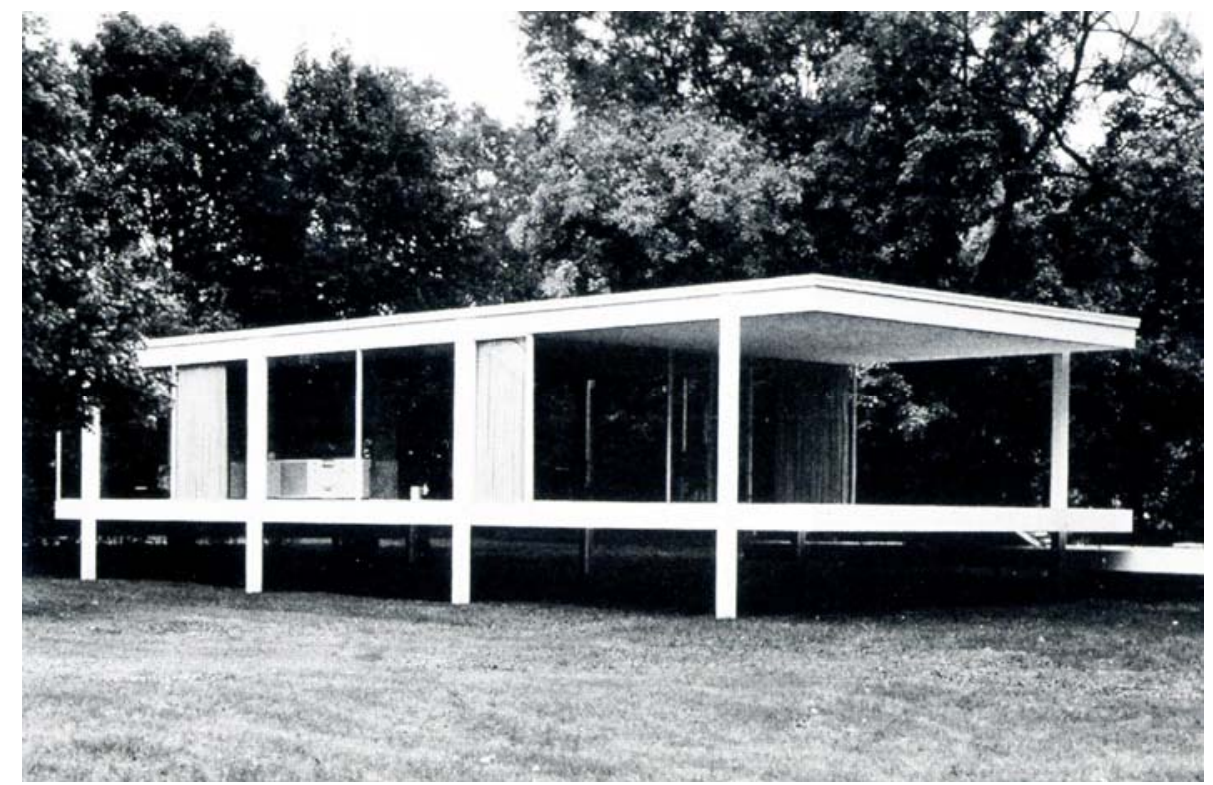

5.187

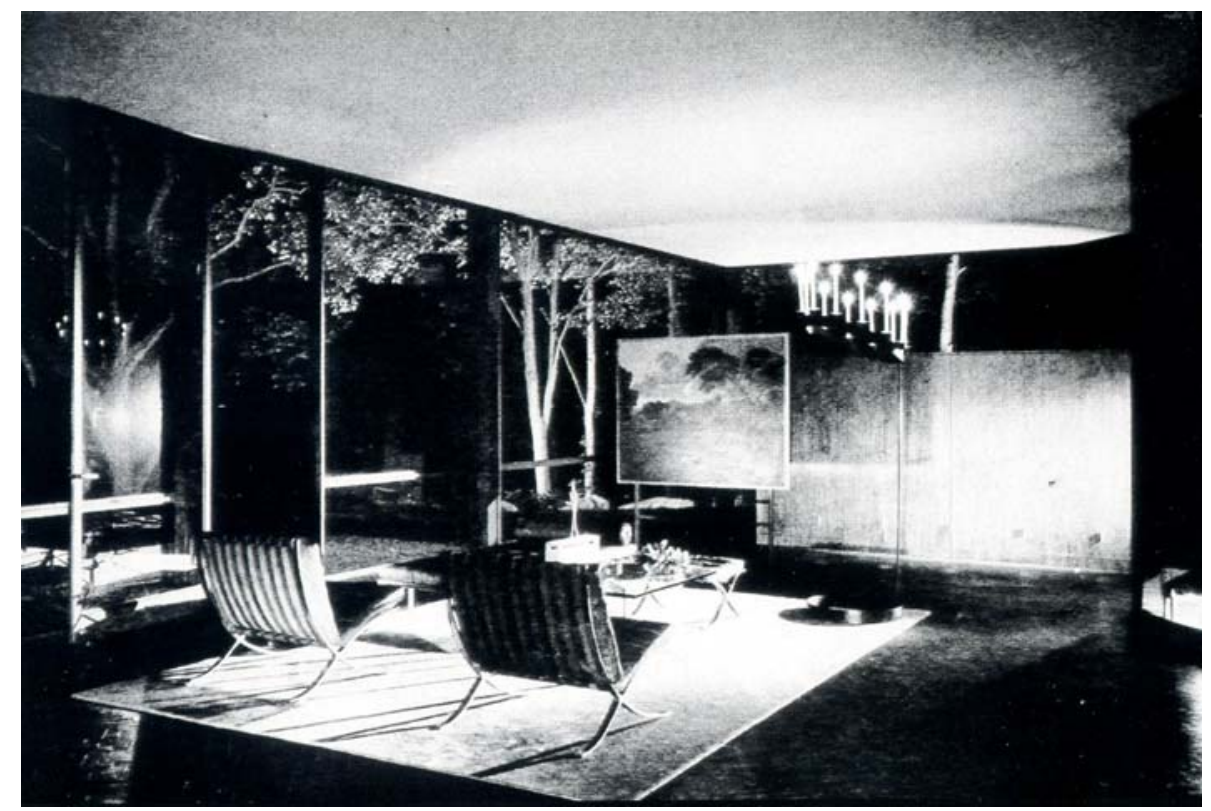

5.188

5.187 Ludwig Mies Van der Rohe. Casa Farnsworth, Plano, 1951. Exterior.

5.188 Philip Johnson. Casa de cristal, New Canaan, 1949. Interior. 
"Si observamos el desarrollo de los últimos años, podemos razonablemente aceptar que, a pesar de la oposición, la apariencia impersonal de los espacios higiénicos de nuestras casa se extenderá a la totalidad de nuestras viviendas y espacios de trabajo.

Es este fuerte potencial higiénico el que está influenciando nuestra vida; que se convertirá en un estilo, iel estilo higiénico!" 110.

La búsqueda de la esencia en la relación entre forma y construcción se aleja de la ideología y se refugia exclusivamente en la forma en arquitectos que se van a Estados Unidos como Mies. Éste mantiene la inquietud por una arquitectura sucinta de piel y huesos, que se apoya en el desarrollo de la tecnología americana, desprovista de las complejidades teóricas de sus homólogas europeas.

Esto favorece que su búsqueda adopte en los años 50 como moderno el "estilo higiénico" que invade las residencias americanas y llega, en ciertos casos, a ser forzado hasta el extremo a costa del "bienestar físico y mental" a que debe su origen.

La vieja aspiración expresionista alemana de alcanzar el edificio de cristal viaja hasta otro continente donde se edifican completos pabellones de vidrio para residencias, como la famosa Casa Farnsworth de Ludwig Mies Van der Rohe (1945-1951), en Plano, Illinois [fig. 5.187], fuente de inspiración de la Casa de cristal de Philip Johnson (1947-1949) construida en New Canaan, Connecticut [fig. 5.188]. Una casa que resulta "inhabitable"111, totalmente expuesta a las miradas y ajena a las condiciones ambientales ligadas al clima y a la orientación. Una casa sin ventanas que carece de aire y de sombra, contraria, pese a su apariencia, a los principios imperantes en la arquitectura de los sanatorios, ya que, como Edith Farnsworth comenta: "Corre ya el rumor local que es un sanatorio de tuberculosis" 112.

\footnotetext{
110 Jan DUIKER, "Een gezonde school voor het gezonde kind" ("Una escuela sana para niños sanos"), en De 8 en Opbow (1932) en C.A., ALBERTS y E.J., JELLES, Duiker 1890-1935. Recopilación del n5 y $n^{\circ} 6$ del volumen 22 de la revista Forum, Amsterdam 1972, p. 60.

111 Así es descrita la casa en la denuncia contra Mies interpuesta por la propietaria. James MARSTON FITCH, "Mies van der Rohe y sus viviendas platónicas", en Escritos, diálogos y discursos, Colección Arquitectura $n^{\circ}$ 1, Colegio Oficial de Aparejadores y Arquitectos Técnicos de la región de Murcia, Murcia 2005, p. 17.

112 Edith Farnsworth, "Memoirs" (manuscrito inédito). Citado en: Beatriz COLOMINA, La Domesticidad en Guerra, Actar, Barcelona 2006, p. 154.
} 
LA AGRUPACIÓN BIOLÓGICA DE LAS PARTES:

EL SANATORIO POLIMÓRFICO DE PAIMIO, ALVAR AALTO

LA ESTRUCTURACIÓN EN PARTES Y LA HERENCIA CLASICISTA

LA METAMORFOSIS DEL TIPO ARQUITECTÓNICO: EL PROYECTO DE PAIMIO

EL HOGAR DEL ENFERMO EN EL SANATORIO: LA UNIDAD DE ENFERMERÍA

EL PROCESO EVOLUTIVO DE LA ARQUITECTURA EN ALVAR AALTO 


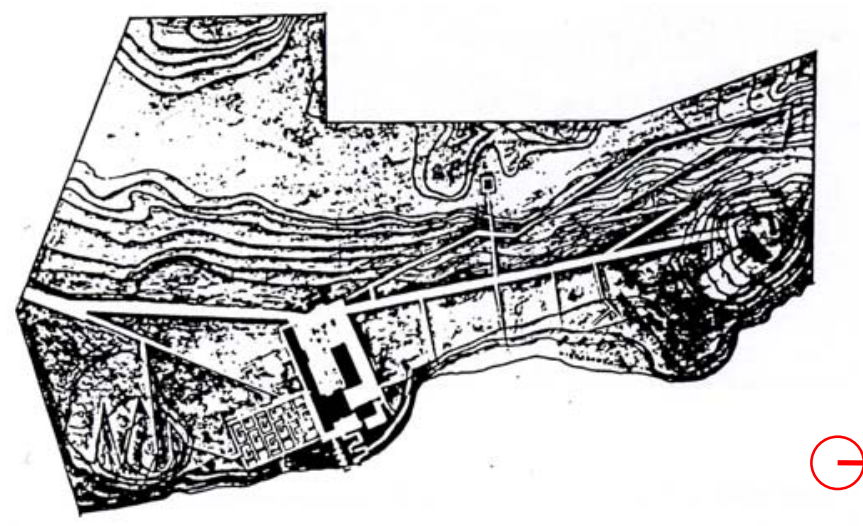

6.01
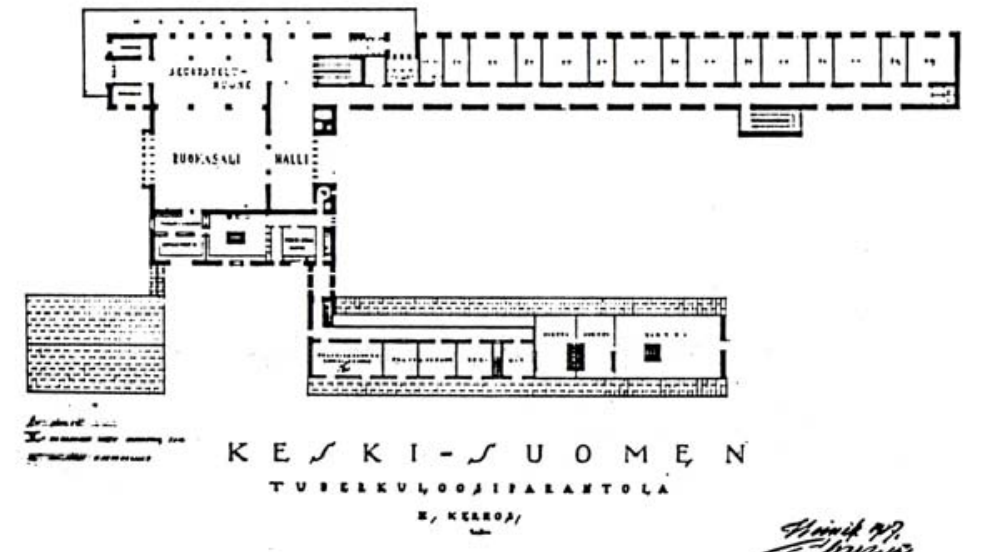

6.02
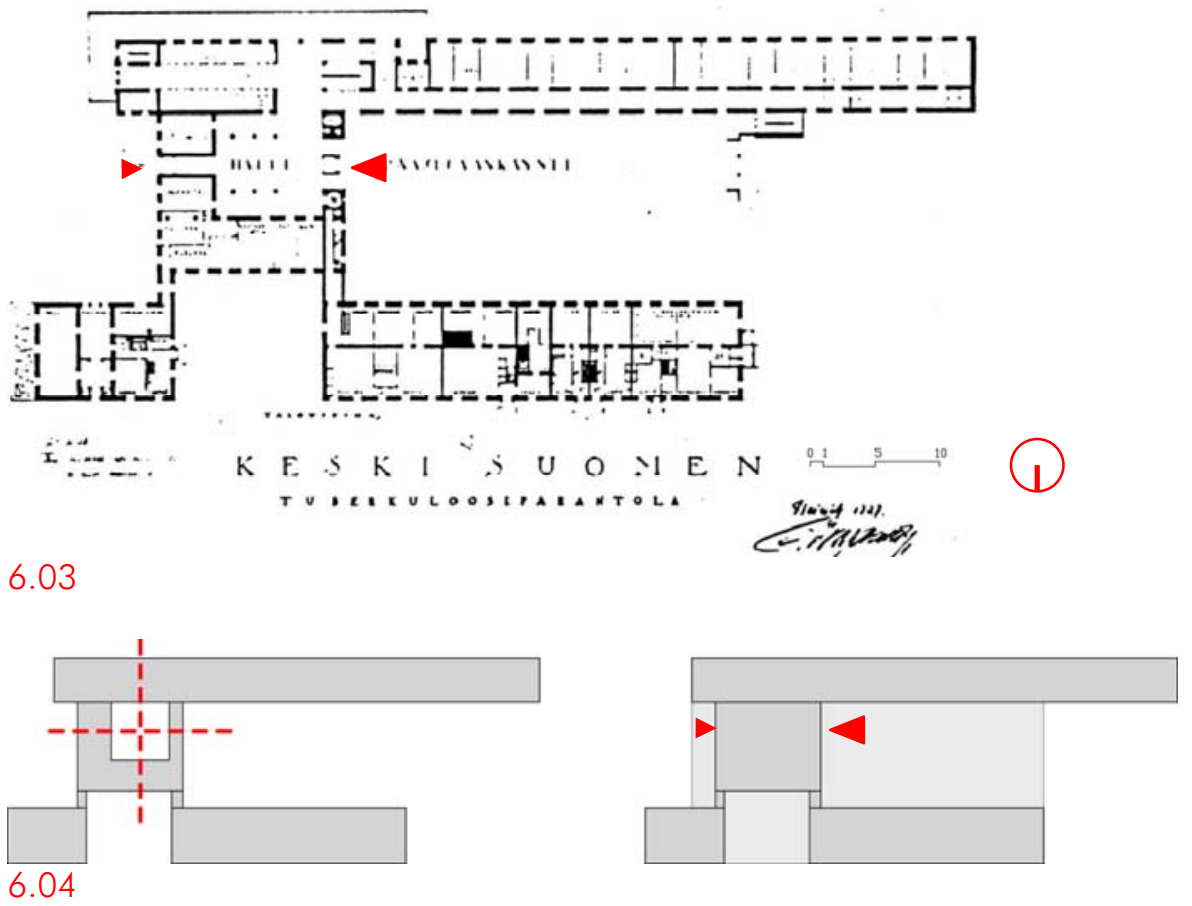

6.01 A. Aalto. Proyecto del sanatorio de Kinkomaa, Murame Kinkomaa 1927. Plano de situación (50/23.1).

6.02 A. Aalto. Proyecto del sanatorio de Kinkomaa, Murame Kinkomaa 1927. Planta primera (50/23.2).

6.03 A. Aalto. Proyecto del sanatorio de Kinkomaa, Murame Kinkomaa 1927. Planta baja (50/23.3). 6.04 Sanatorio de Kinkomaa. Organización de las partes en torno al vestíbulo central. Accesos principales y recintos (dibujos de la autora). 


\section{LA ESTRUCTURACIÓN EN PARTES Y LA HERENCIA CLASICISTA DE ALVAR AALTO}

Alvar Aalto ya conoce el programa del sanatorio antes de proyectar Paimio. Un año antes, en 1927, participa sin éxito en el concurso del sanatorio de Kinkomaa, junto al lago Päiiënne en Muurame Kinkomaa, a 8 kilómetros de Jyväskylä, su ciudad natal [fig. 6.01].

Según afirma Göran Schildt, el planteamiento de Aalto para el concurso del sanatorio de Kinkomaa "fue el primero en revelar claramente su 'conversión' al Funcionalismo". Adhesión que había sido esbozada, tal vez inconscientemente, en su artículo para la organización del centro de Jyväskylä "Kaupunkikulttuuri", "Cultura Urbana", publicado el 12 de diciembre de 1924, poco tiempo después de haber contraído matrimonio con su primera mujer Aino Marsio ${ }^{2}$ y de regresar de su viaje de luna de miel por Italia ${ }^{3}$.

En este texto afirma que la ubicación y el lenguaje formal de los edificios que constituyen la ciudad deben estar relacionados con la función que desempeñan, disponiendo así: "Cada cosa en su sitio, en ambientes que correspondan a su función" con "una estética propia para cada cual" ${ }^{\prime 4}$.

El sanatorio de Kinkomaa se proyecta siguiendo una estructuración de sus funciones por partes y aplicando estos criterios a cada una de ellas. Se articula en cuatro bloques conectados entre sí, cada uno con un uso, una forma y una imagen diferente, que se ubican atendiendo a la orientación, a las vistas y a la vinculación con el entorno. Se crea así un conjunto abierto de tres partes entrelazadas con el cuerpo central de acceso, que se ordenan generando una gran plaza pública de entrada y varios recintos abiertos [fig. 6.04].

\footnotetext{
1 "Aalto's plan was the first to clearly reveal his "conversion" to Functionalism". Göran SCHILDT, Alvar Aalto The Decisive Years, Rizzoli International Publications, Inc., New York, 1986, p. 34.

${ }^{2}$ Aino Marsio fue la compañera sentimental y profesional de Alvar Aalto desde 1924 hasta 1949, año en que ésta fallece, además de la madre de sus dos hijos. Tres años más tarde, en 1952, Aalto contrajo matrimonio con la también arquitecta Elissa Mäkiniemi con quien compartió también vida y profesión hasta el día de su muerte, el 11 de mayo de 1976, fecha en la que el arquitecto fallece a los 78 años de edad. Ver Göran SCHILDT (ed.), Alvar Aalto de palabra y por escrito (Alvar Aalto. In his own words, 1997) El Croquis Editorial, Madrid, 2000, p.13.

${ }^{3}$ Este viaje influyó notablemente en Aalto, como lo demuestran sus escritos. En textos como "Una ciudad en la colina"("Kukkulakaupunki") de 1924, o "La Arquitectura en el paisaje de Finlandia Central" ("Keskisuomalainen maiseman rakennustaide") publicado en 1925, al igual que "El templo de la Sauna en la colina de Jyväskylä" ("Jyväskylän harjum saunatemppeli") o "El sermón del Abad Coignard" de ese mismo año, Alvar Aalto ensalza la belleza del paisaje meridional, con sus pueblos sobre las colinas, y expone su empeño de trasladarlo a su propio país, tratando de convertir Jyväskylä, en una "nueva Florencia" (Schildt, 1986, p. 1 1). Los textos aparecen recogidos y traducidos al castellano en Göran SCHILDt (ed.), Alvar Aalto de palabra y por escrito (Alvar Aalto. In his own words, 1997), El Croquis Editorial, Madrid 2000.

${ }^{4}$ Alvar AALTO, "Cultura urbana" ("Kaupunkikulttuuri") publicado en el periódico Sisä-Suomi el 12 de Diciembre de 1924, en Göran SCHILDT (ed.), Alvar Aalto de palabra y por escrito (Alvar Aalto. In his own words, 1997), El Croquis Editorial, Madrid 2000, p.32.
} 

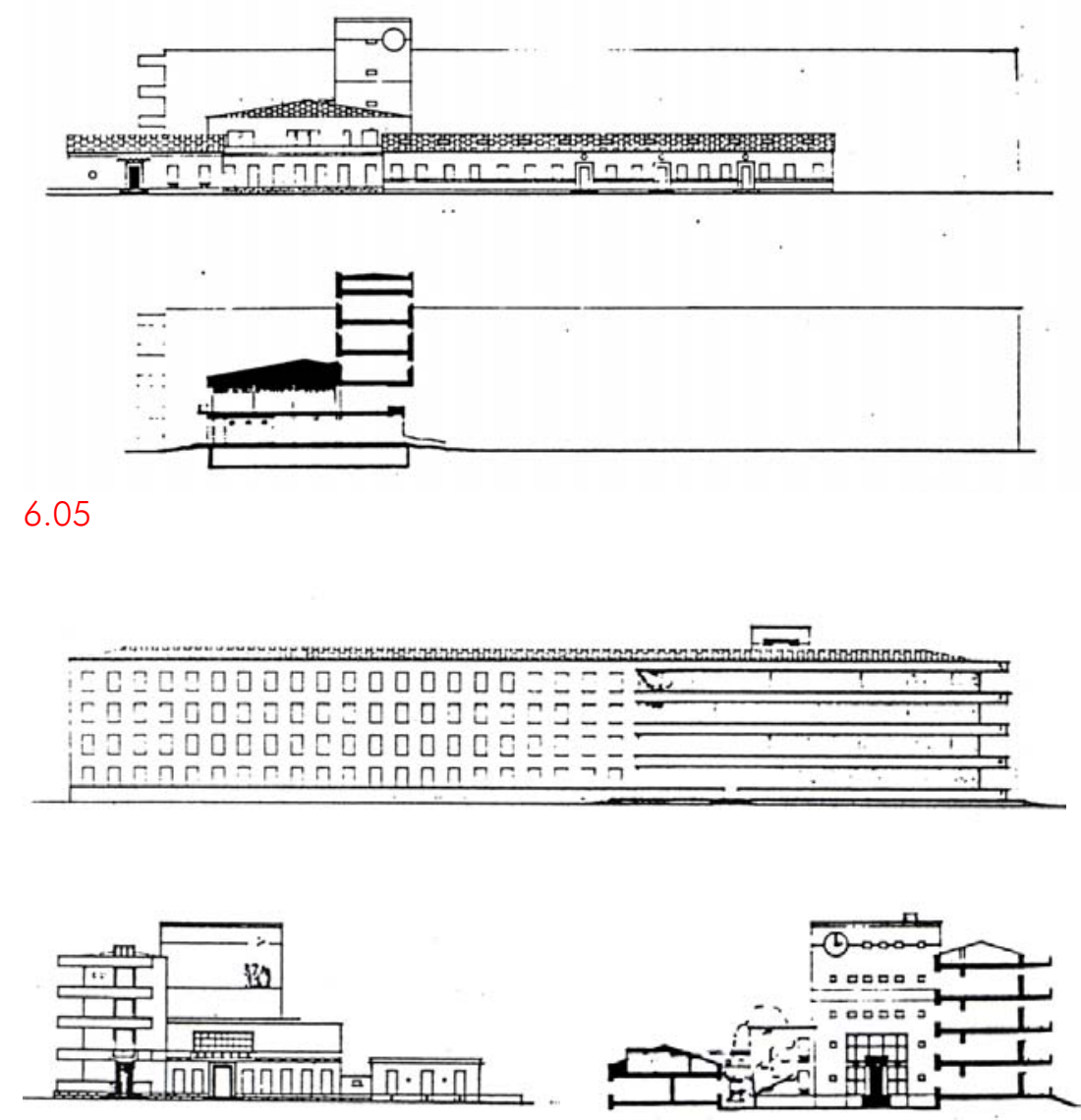

6.06 y 6.07

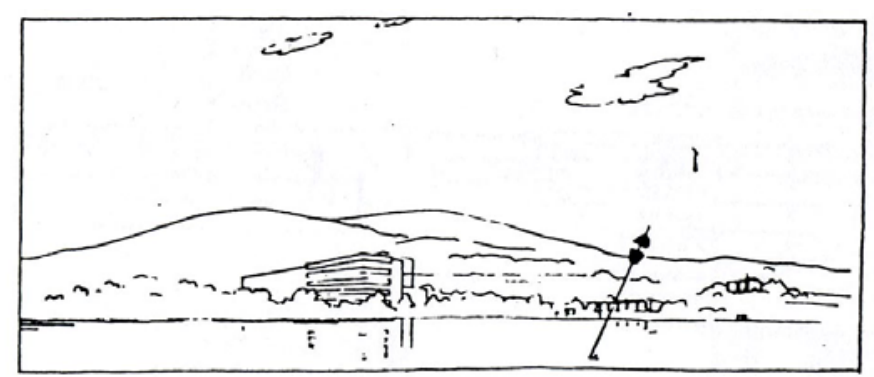

6.08
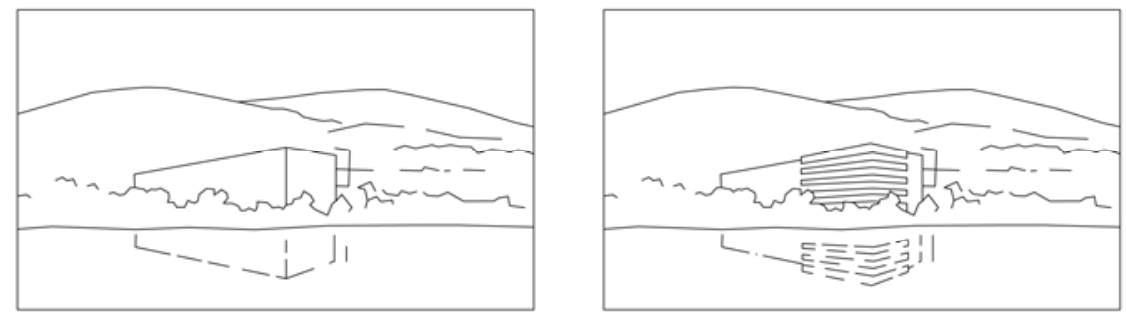

6.09

6.05 A. Aalto. Proyecto del sanatorio de Kinkomaa, Murame Kinkomaa 1927. Alzado norte y sección por el cuerpo principal (50/23.8).

6.06 y 6.07 A. Aalto. Proyecto del sanatorio de Kinkomaa, Murame Kinkomaa 1927. Alzados sur y este (50/23.7) y alzado principal oeste (fragmento 50/23.4).

6.08 A. Aalto. Proyecto del sanatorio de Kinkomaa, Murame Kinkomaa 1927. Vista panorámica desde el lago (50/23.1).

6.09 Sanatorio de Kinkomaa. Vista del sanatorio sin y con galería (dibujos de la autora). 
Al cuerpo principal de planta cuadrada, diversificado en altura a través de una torre de cinco plantas sobre el vestíbulo y un comedor de dos, se adosa en su frente sur un brazo rectangular de cuatro plantas de altura con las habitaciones de los enfermos, y se conecta al norte, a través de corredores longitudinales que parten de sus esquinas, con otros dos brazos rectangulares paralelos al residencial. El de mayor tamaño de los dos alberga los servicios generales, las oficinas y las habitaciones del personal, y cierra un recinto ortogonal en forma de $U$ que define la plaza de entrada, constituido por tres elementos distintos en volumen y composición [fig. 6.02 y 6.03]. El más pequeño contiene la casa del médico desarrollada en planta baja y, gracias a su posición, crea un pequeño patio abierto ubicado entre la casa y el edificio de servicios generales, así como también un ámbito previo a un acceso secundario del cuerpo principal ubicado al este. En todas las situaciones se repite la misma variedad volumétrica del acceso principal [fig. 6.05 y 6.06 ].

En Kinkomaa Aalto desvela a través de la fragmentación de la planta su adhesión al funcionalismo, ya que su diversidad responde a un diseño específico de cada parte por separado, tal y como repetirá en el Sanatorio de Paimio. Con la diferenciación compositiva de sus partes muestra también su vinculación con el llamado "nuevo realismo":

"El 'nuevo realismo', (...) estudia, por el contrario, los mismos fenómenos estéticos y su clasificación, considerando la estimación de la efectividad de los objetos y el correcto aprecio de su contenido como únicos puntos de partida a la hora de crear formas.

Por lo tanto, no podemos concebir una nueva forma si no existe antes un nuevo contenido. No deberíamos construir una iglesia como si fuera una obra de arte total en sí, una muestra magistral de la cultura del año 1927; no se puede crear una iglesia moderna, ya que su contenido -el servicio religioso-, para cuyo marco se crean las formas, pertenece a la vida tradicional y carece de una espiritualidad adecuada a nuestro tiempo" ${ }^{\prime \prime}$.

Esta teoría, abandonada en breve por Aalto ${ }^{6}$, aún perdura en el proyecto del sanatorio. La imagen tradicional de la casa del médico y del edificio de servicios comunes [fig. 6.05]

5 Alvar AALTO, "Sobre las últimas tendencias en arquitectura" ("Uusimmista virtauksista rakennustaiteen alalla"), artículo publicado en el periódico Uusi Aura el 1 de Enero de 1928, en Göran SCHILDT (ed.), Alvar Aalto de palabra y por escrito (Alvar Aalto. In his own words, 1997), El Croquis Editorial, Madrid 2000, pp.82-83.

${ }^{6}$ El clasicismo del proyecto de la Iglesia de Taulumaäki realizado en 1927 lo demuestra. Mientras que las formas plásticas de la planta y la sección del proyecto para el concurso de la lglesia de Vallila, realizado dos años más tarde en 1929, o la abstracción de la fachada del proyecto para la Iglesia de Tehtaanpuisto en 1930, avalan su posterior rechazo. 
contrasta con la modernidad de los alzados del cuerpo principal de acceso y del volumen de habitaciones del sanatorio, especialmente con las galerías de cura del extremo sureste [fig. 6.06 y 6.07$]$.

El dibujo de la vista panorámica desde el lago Päijënne mirando hacia esta esquina de las galerías del sanatorio [fig. 6.08] subraya un aspecto clave en su arquitectura, el incesante intento de valorar el paisaje a través de las edificaciones, intención que se agudiza tras su viaje a Italia:

"Un habitante de Jyväskylä que haya recorrido la Toscana, la Riviera o el Tirol, se habrá fijado seguramente en cómo un edificio en lo alto de las colinas y los montes vigoriza las ciudades, proporcionándoles escala adecuada" $"$.

El cuerpo residencial del sanatorio de Kinkomaa rematado con las galerías que bordean la esquina, constituidas por terrazas voladas protegidas con antepechos de hormigón, sirve para ensalzar la belleza del entorno. Sus reiterados vuelos horizontales diluyen la esquina del prisma, otorgando una imagen menos monolítica, más fragmentada y dinámica del bloque lineal. El protagonismo de la configuración en estratos superpuestos de las galerías y la disminución del volumen por la fuga en perspectiva evocan con su contorno el perfil de las montañas, realzados por su reflejo en el lago, acentuando con la edificación las formas pregnantes del paisaje [fig. 6.09]:

"Nuestros edificios no deben solamente cumplir con unas cuantas normas de belleza, tienen también que ubicarse en el paisaje con naturalidad, realzando las líneas del entorno (...) la naturaleza pura y original, con toda su fuerza fascinante, no puede sustituir a la visión de un paisaje en el que la 'impronta humana' ha insertado una pieza que acentúe su armonía".

La manera de implantar el sanatorio de Kinkomaa sobre una plataforma rectangular que interrumpe la vía de acceso principal resulta artificial y forzada [fig. 6.01], sin embargo, las rectilíneas galerías de cura que asoman ingrávidas sobre los frondosos bosques y las redondeadas colinas, dibujados en la nítida panorámica con la que Aalto describe el

\footnotetext{
${ }^{7}$ Alvar AALTO, "El templo de la sauna en la colina de Jyväskylä"("Jyväskylä harjum saunatemppeli"), Keskisuomalainen, 21 de Enero de 1925, en Göran SCHILDT (ed.), Alvar Aalto de palabra y por escrito (Alvar Aalto. In his own words, 1997), El Croquis Editorial, Madrid 2000, p.28.

8 Alvar AALTO, "La arquitectura en el paisaje de Finlandia Central", título original "Keskisuomalainen maiseman rakennustaide", Sisä-Suomi, 26 de Junio de 1925, en Göran SCHILDT (ed.), Alvar Aalto de palabra y por escrito (Alvar Aalto. In his own words, 1997), El Croquis Editorial, Madrid 2000, p.34.
} 
proyecto, ilustra las reflexiones sobre el paisaje y la arquitectura desarrolladas por el arquitecto en sus viajes en barco por Finlandia?

"Cuando el barco se desliza por los lagos Päijënne o Keitele, adentrándose en profundas ensenadas de orillas magníficamente cultivadas, me resulta grato imaginar cómo se podría llevar a cabo pequeñas mejoras de los edificios circundantes. En ocasiones, resuelvo el problema con unos arreglos mínimos, corrigiendo la forma de las cubiertas -en el centro de Finlandia deben ser lo más planas posible-; otras veces, en cambio, estudio el matiz de los colores de los pueblos, o planto un árbol aquí y otro allá -un árbol se destaca en los campos cultivados de la provincia casi tanto como los chopos en los países meridionales-. En ocasiones, me apetecería contemplar una iglesia erigiéndose en medio de las casas, entonces pongo junto a su entrada una plaza porticada, o elevo la altura de la torre" ${ }^{10}$.

Aalto trata de guiar la mirada por el paisaje con su arquitectura reforzando su interés plástico. Sus dibujos en perspectiva le ayudan a estudiar la percepción de los proyectos en conjunto, poniendo de manifiesto su preocupación por embellecer el entorno y por la aprehensión del mismo dentro de los edificios.

El dibujo en perspectiva del interior de la galería de cura del sanatorio [fig. 6.11], donde están representados el enfermo tumbado, la vista sobre el lago y la cubierta remarcada por una mancha negra lo describen. Se ve cómo se establece la unión del ser humano, la arquitectura y el paisaje, imprescindible en los sanatorios antituberculosos donde la cura se fundamenta en factores ambientales, pero que Aalto resuelve con especial destreza técnica en las terrazas en vuelo que exigen de un necesario conocimiento constructivo [fig. 6.10] pues "el arquitecto debe dominar el aspecto técnico de su profesión, mucho más exigente que la de pintor, y que ocupa un papel muy importante en su arte creativo". ${ }^{1}$

\footnotetext{
${ }^{9}$ La importancia que Alvar Aalto otorga al paisaje puede proceder de la vinculación del arquitecto con el oficio de su padre, agrimensor o topógrafo, al que de niño observó trabajar junto a sus colaboradores en la gran "mesa blanca". "La Mesa Blanca" tiene un carácter simbólico para Alvar Aalto, representa la raíz de su trabajo basado en el conocimiento y la creatividad. Además es el título del texto que pretendía fuese la introducción de su "testamento espiritual" y que jamás llegó a escribir. Göran SCHILDT (ed.), Alvar Aalto de palabra y por escrito (Alvar Aalto. In his own words, 1997), El Croquis Editorial, Madrid 2000, p.16.

10 Alvar AALTO, "La arquitectura en el paisaje de Finlandia Central" ("Keskisuomalainen maiseman rakennustaide"), Sisä-Suomi, 26 de Junio de 1925, en Göran SCHILDT (ed.), Alvar Aalto de palabra y por escrito (Alvar Aalto. In his own words, 1997), El Croquis Editorial, Madrid 2000, p.35.

11 Alvar AALTO, "Pintores y albañiles"("Maalarit ja Muurarit"), Jousimies, 1921, en Göran SCHILDT (ed.), Alvar Aalto de palabra y por escrito (Alvar Aalto. In his own words, 1997), El Croquis Editorial, Madrid 2000, p.47.
} 


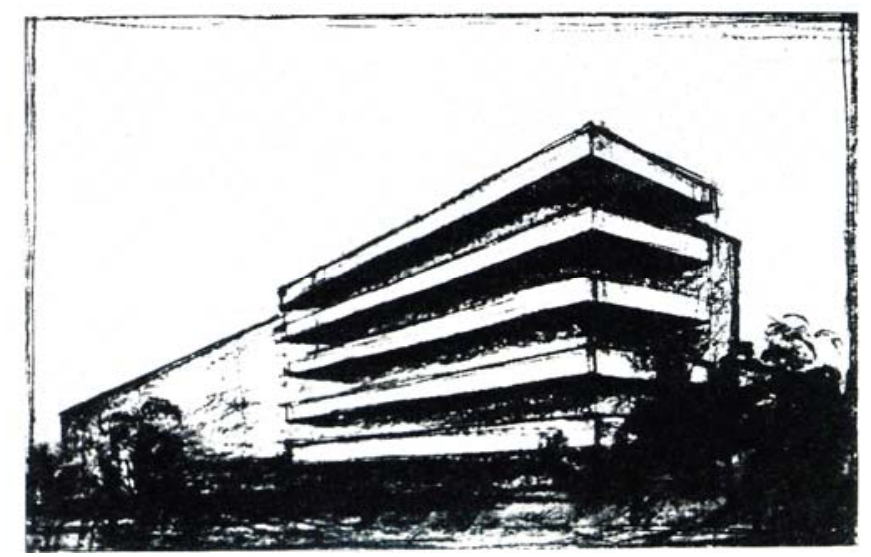

6.10

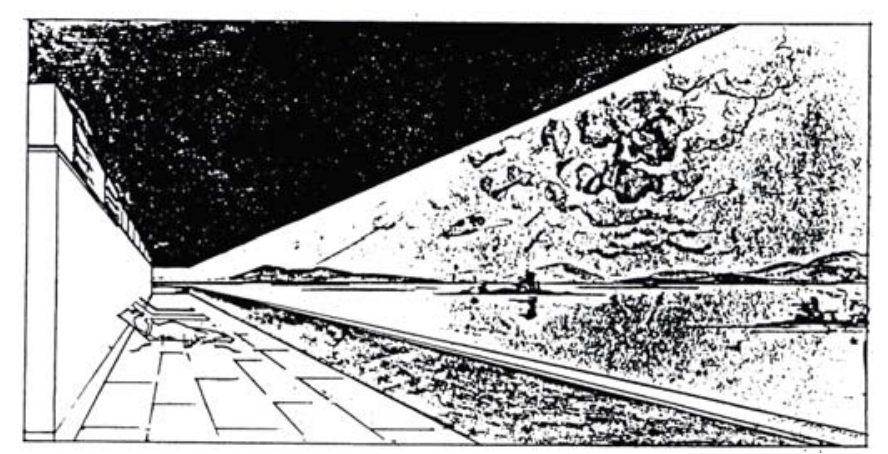

6.11

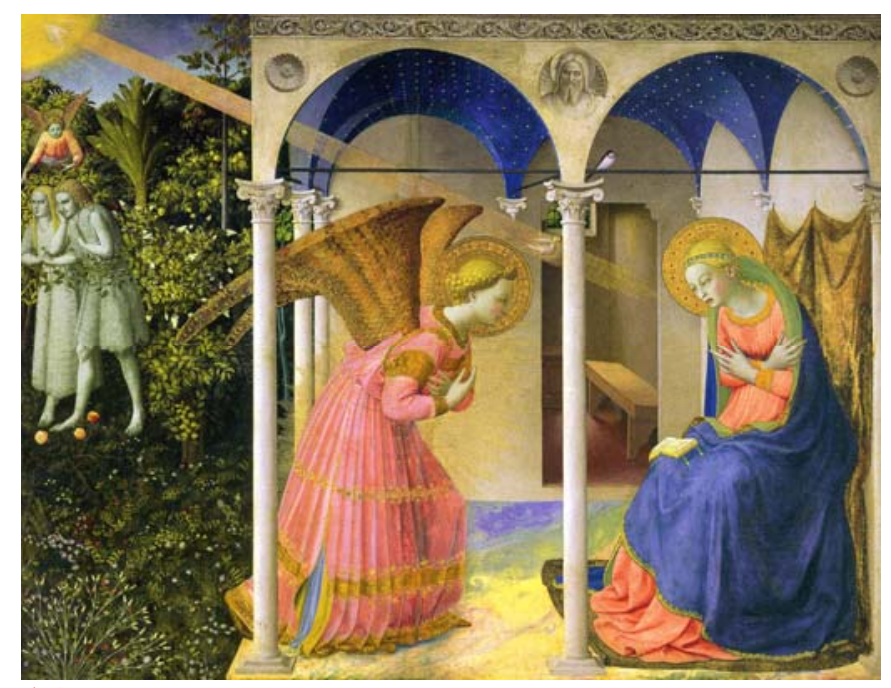

6.12
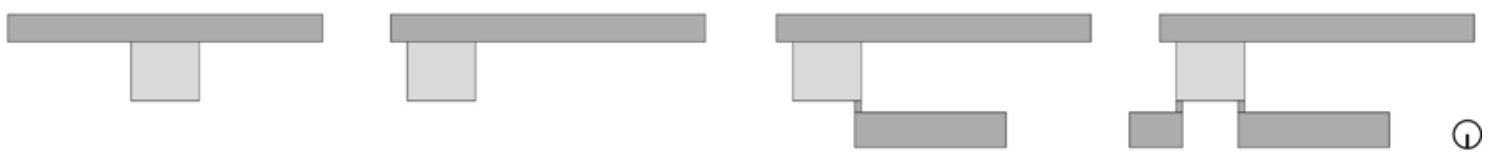

6.13

6.10 A. Aalto. Proyecto del sanatorio de Kinkomaa, Murame Kinkomaa 1927. Perspectiva exterior de la galería de cura (50/23.6).

6.11 A. Aalto. Proyecto del sanatorio de Kinkomaa, Murame Kinkomaa 1927. Perspectiva interior de la galería de cura (50/23.5).

6.12 Fra Angelico. L'Annunciazione 1425-1428.Templete y oro sobre tabla, 194x194 cm. Museo del Prado, Madrid.

6.13 Sanatorio de Kinkomaa. Evolución de la estructura formal (dibujos de la autora). 
Esta imagen resulta comparable a la del cuadro L'Annunciazione de Fra Angélico que Aalto escoge para describir la unidad plástica del hombre y el entorno [fig. 6.12].

"Es un ejemplo idóneo de 'entrada a una habitación'. La trinidad patente que domina la pintura -ser humano, habitación, jardín- nos ofrece una imagen ideal e inalcanzable del hogar. La misma tierna sonrisa que se dibuja en la cara de la Virgen se pierde en los delicados detalles del edificio y en las flores resplandecientes del jardín. Todo el conjunto expresa nítidamente dos cosas: la unidad entre la habitación, la fachada y el jardín, y el modo en que el diseño de estos elementos hace resaltar el ser humano, reflejando sus sentimientos. Quien sea capaz de comprender los secretos en este cuadro de Fra Angélico, puede ceder a otro la lectura de este texto, sin remordimiento alguno"12.

Con este proyecto Aalto ensaya una mayor apertura espacial a través de las galerías de cura y de la articulación de su planta en partes, abandonando las formas compactas y claustrales propias del clasicismo nórdico imperantes en su obra hasta el momento. En su composición se puede apreciar la existencia de una estructura formal inicial que coincide con el sanatorio tipo en T que se va fragmentando en partes [fig. 6.13], sentando las bases para el que, según A. Capitel es "su primer proyecto moderno significativo, y con él, la composición por elementos o partes de un modo pleno"13 en su futuro proyecto para el concurso del sanatorio antituberculoso de Paimio.

\section{LA METAMORFOSIS DEL TIPO ARQUITECTÓNICO: EL PROYECTO DEL SANATORIO DE PAIMIO}

El concurso del Sanatorio antituberculosos de Paimio se convoca en noviembre de 1928, con un plazo máximo para elaborar la propuesta de tres meses, que concluye el 31 de enero de 1929. Antes de la convocatoria del sanatorio, durante el verano de 1928, Aalto y su mujer Aino hacen un viaje en aeroplano desde Turku hasta París. En las diversas escalas del vuelo aprovechan para visitar obras de arquitectura y para contactar con los más renombrados diseñadores ${ }^{14}$ y arquitectos del momento.

\footnotetext{
12 Alvar AALTO, "De los escalones de entrada al cuarto de estar" ("Porraskiveltä arkihuoneeseen"), Aitta, 1926, en Göran SCHILDT (ed.), Alvar Aalto de palabra y por escrito (Alvar Aalto. In his own words, 1997), El Croquis Editorial, Madrid 2000, pp.69-70.

${ }^{13}$ Antón CAPITEL, La arquitectura compuesta por partes. Gustavo Gili, Barcelona 2009, p.167.

${ }^{14}$ Entre otros visitan al diseñador de lámparas danés Poul Henningsen. Göran SCHILDT, Alvar Aalto The Decisive Years, Rizzoli International Publications, New York 1986, p. 55.
} 


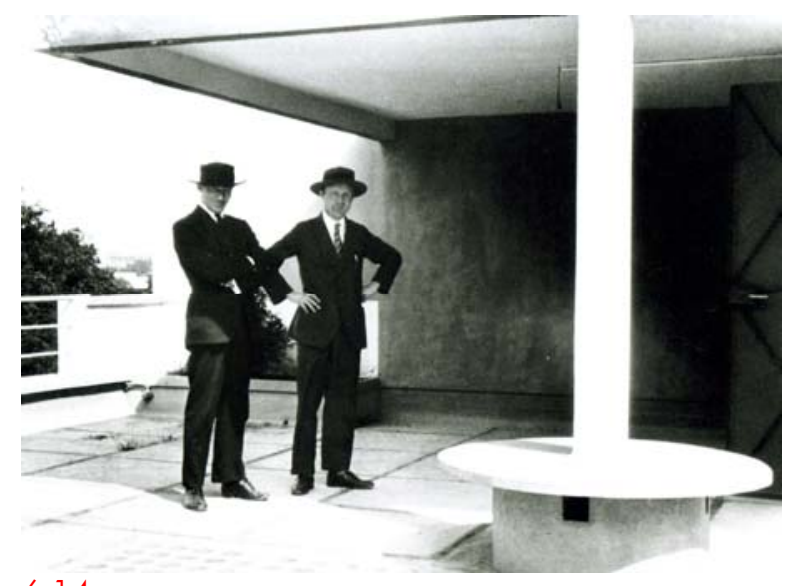

6.14
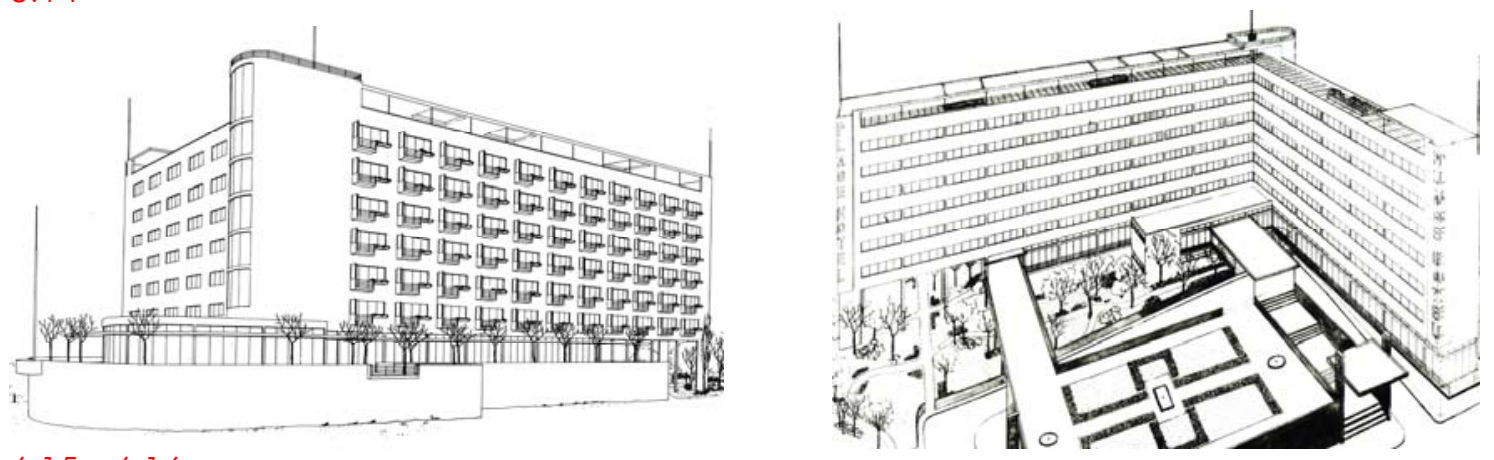

6.15 y 6.16

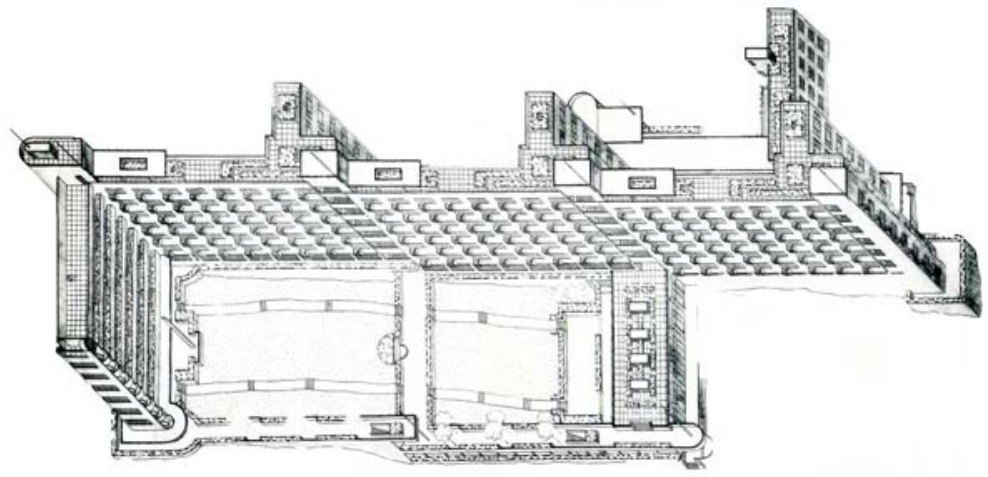

6.17
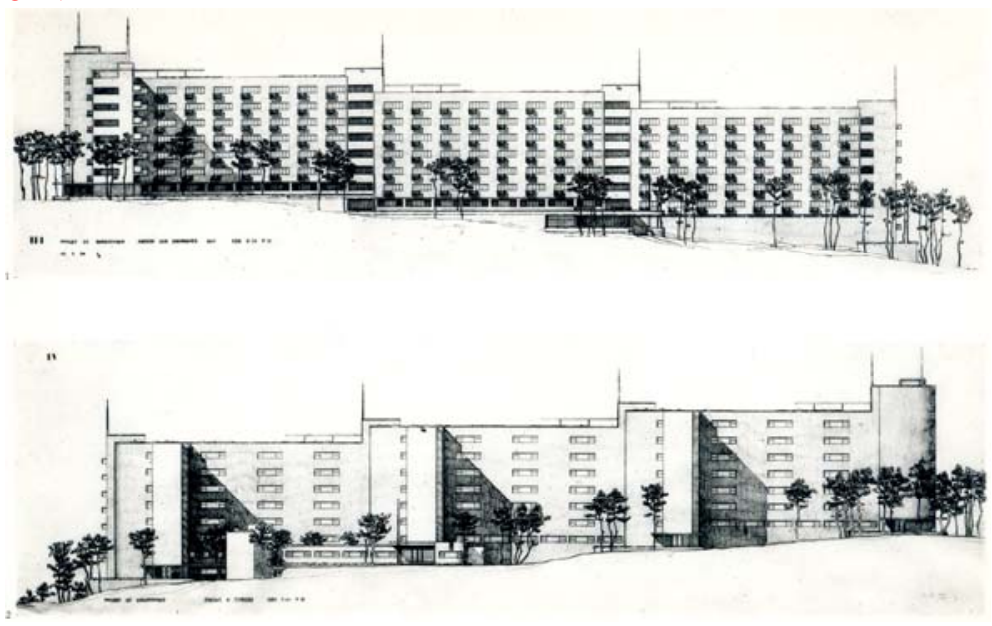

6.18

6.14 Alvar Aalto y André Lurçat en su visita a la Villa Stein, 1928. Fotografía realizada por Aino Aalto.

6.15 y 6.16 A. Lurçat. Proyecto del Plage- Hôtel, 1928. Perspectiva desde la calle y desde el patio del interior.

6.17 y 6.18 A. Lurçat. Proyecto del sanatorio de Durtol, 1929. Axonometría y alzados. 
Hacen escala en Holanda donde contactan con Johannes Duiker ${ }^{15}$ y visitan el sanatorio de Zonnestraal" en Hilversum, obra que Göran Schildt, "fuvo un cierto impacto en su planta para el Sanatorio de Paimio, comenzada pocos meses después", 17 aunque para este autor "los edificios anexos de trabajadores del sanatorio de Paimio indican, sin embargo, que fue más receptivo a la arquitectura de Oud que a la de Duiker en su visita a los Países Bajos"18. En este sentido, P. D. Pearson reconoce una influencia mucho mayor ${ }^{19}$ llegando a afirmar que: "el esquema de Paimio es una variante del sanatorio antituberculoso de Zonnestraal de Duiker ${ }^{\prime 20}$.

Cuando llegan a Paris intentan conocer a Le Corbusier, pero les resulta imposible ya que en aquel momento se halla en Moscú. Allí se encuentran con André Lurçat que ejerce de cicerone. Años más tarde, Aalto define a Lurçat como un arquitecto científico:

"Es, indiscutiblemente, uno de los pocos que no se pierde en los vericuetos del formalismo. (...) Si se entiende correctamente la afirmación de que la arquitectura es ciencia -hecho que supone que no debe comenzar con muletillas tipo 'me parece', o 'según mi punto de vista'-, Lurçat es un científico" ${ }^{21}$.

Junto a Lurçat visitan la Villa Stein en Garches de Le Corbusier [fig. 6.14], y una de sus obras más reciente, la Villa Guggenbuhl, que se ha terminado de construir el verano anterior. También les muestra los proyectos en los que está trabajando y Aalto queda "particularmente impresionado por la ventana de arriba a abajo con forma de L diseñada por Lurçat para un hotel "22, modelo que más tarde aplica en el proyecto del concurso del

\footnotetext{
${ }^{15}$ Alvar Aalto. Architect 1898-1976, The Alvar Aalto Fundation, Tempere 1999, p. 18.

${ }^{16}$ Paul David PEARSON, Alvar Aalto and the international style (1978). Mitchell, London 1989, p.84.

17 "It seems probable that he met Duiker and saw his Zonnestraal Sanatorium, and that this meeting had a certain impact on his plan for Paimio Sanatorium, begun a few months later. "Göran SCHILDT, "Travelling in 1928", en Alvar Aalto The Decisive Years, Rizzoli International Publications, Inc., New York 1986, p. 56.

18 "The free-standing staff buildings al Paimio indicate, however, that he was more receptive to the architecture of Oud than to that of Duiker on his visit to the Netherlands." Göran SCHILDT, "Travelling in 1928", en Alvar Aalto The Decisive Years, Rizzoli International Publications, Inc., New York 1986, p. 56.

${ }^{19}$ La influencia de Zonnestral sí resulta significativa. Los giros de las partes presentes en el sanatorio de Paimio, inexistentes en el sanatorio de Kinkomaa y en obras anteriores de Aalto, son una peculiaridad del sanatorio de Zonnestraal.

20 "The scheme is a variant of Duiker's Zonnestraal Tuberculosis Sanatorium". Paul David PEARSON, Alvar Aalto and the international style (1978), Mitchell, London 1989, p. 84.

${ }^{21}$ Alvar AALTO, "Entrevista de una entrevista. André Lurçat en Finlandia" ("Erään haastattelun haastattelu André Lurçat Suomessa"), Tekniikan Ylioppilas n 2, 1934, en Göran SCHILDT (ed.), Alvar Aalto de palabra y por escrito (Alvar Aalto. In his own words, 1997), El Croquis Editorial, Madrid 2000, p.116.

22 "(...) was particularly impressed by a window in upside-down L shape designed by Lurçat for a hotel". Göran SCHILDT, "Travelling in 1928", en Alvar Aalto The Decisive Years, Rizzoli International Publications, Inc., New York 1986, p. 57.
} 
sanatorio de Paimio [fig. 6.15]. Se trata de las ventanas de las habitaciones de turistas del Plage- Hôtel, organización que André Lurçat vuelve a utilizar en 1929 para el sanatorio de Durtol [fig. 6.17 y fig. 6.18] pensado "desde un punto de vista eminentemente residencial"23. Las conversaciones que mantiene Aalto y las visitas que realiza durante su viaje a París ratifican ciertas convicciones arquitectónicas que había comenzado a adquirir, contrarias a sus planteamientos iniciales, que se hacen explícitas después del sanatorio de Kinkomaa ${ }^{24}$. En enero de 1928, antes del viaje, publica un artículo en el periódico Uusi Aura en el que comenta:

"La 'nueva arquitectura' ha nacido más bien del esfuerzo de trasplantar las experiencias estéticas a una base más real, sacándolas de quiméricas manifestaciones lúdicas. (...) No pretende ser tampoco una especie de árbitro entre lo tradicional y lo moderno, sino que se posiciona por encima de ambos. (...) Equiparemos la estatua de un dios de la antigüedad a la pieza de una máquina moderna: ambas poseen la misma aspiración por proporcionar una forma perfectamente elaborada a un contenido con significado y eco reales en su propio tiempo". 25

Con este convencimiento aplica una arquitectura moderna a todos los programas, a los más recientes y a los heredados, primando así, por encima de cualquier vestigio clasicista, la intención de dar una respuesta arquitectónica acorde con su tiempo"26: "Una obra maestra arquitectónica debe llevar, ante todo, el sello característico de su época" ${ }^{27}$, sin negar por ello sus orígenes y tradiciones:

"(..) nuestro país debe asumir su propia historia, pues ahora ningún estilo europeo o teoría personal (Morris o van de Velde) puede absorbernos en su corriente. Saldremos, por nuestra propia voluntad, hacia aguas más despejadas. Viendo cómo

23 Jean-Louis COHEN, André Lurçat. 1894-1970 autocritica di un maestro moderno (1995), Electra, Milano 1998, p.109.

24 El Plage-Hôtel a orillas del Mediterráneo tiene dos alas de habitaciones distintas, una con estancias más confortables con vistas al mar, destinadas a los turistas que permanecían varias jornadas en el hotel, con las ventanas en L, y otra, con las habitaciones pensadas para los viajeros que sólo pernoctaban una noche, con ventanas rectangulares más sencillas.

25 Alvar AALTO, "Sobre las últimas tendencias en arquitectura", ("Uusimmista virtauksista rakennustaiteen alalla") artículo publicado en el periódico Uusi Aura, el 1 de Enero de 1928, en Göran SCHILDT (ed.), Alvar Aalto de palabra y por escrito (Alvar Aalto. In his own words, 1997), El Croquis Editorial, Madrid 2000, p.80-82.

${ }^{26}$ Desde niño Alvar Aalto soñaba con ser maquinista y siempre le habían fascinado los inventos modernos, como el automóvil, los aviones o el cine. En su pasión por los avances tecnológicos influyó posiblemente su abuelo materno quien, en 1880, publicó el Libro de Inventos. Göran SCHILDT, Alvar Aalto The Decisive Years, Rizzoli International Publications, New York 1986, p. 13.

${ }^{27}$ Alvar AALTO, "Pintores y albañiles" ("Maalarit ja Muurarit"), Jousimies, 1921, en Göran SCHILDT (ed.), Alvar Aalto de palabra y por escrito (Alvar Aalto. In his own words, 1997), El Croquis Editorial, Madrid 2000, p. 47. 
nuestros antepasados fueron capaces de ser internacionales y carentes de prejuicios, manteniendo fidelidad a lo propio, estamos ahora en condiciones de recibir influencias, con los ojos bien abiertos, de la vieja Italia, España y de la nueva América. Aún así, nuestros ancestros continúan siendo nuestros maestros".28

Con este bagaje ${ }^{29}$ se enfrenta al concurso del sanatorio de Paimio, en cuyas bases queda definido su programa de necesidades [fig. 6.19]. El sanatorio debe tener capacidad suficiente para 184 pacientes repartidos en habitaciones dobles, triples o cuádruples distribuidas en cuatro áreas independientes, reservando al menos dos habitaciones individuales por área, y cada una de ellas dispone de un mínimo de $25 \mathrm{~m}^{3}$ por paciente. Además el sanatorio debe estar provisto de todos los espacios generales necesarios para la atención médica y el cuidado de los enfermos ${ }^{30}$.

Cuenta también con una serie de edificaciones anexas: la residencia del médico jefe, la del médico adjunto y la del administrador, un edificio de viviendas para empleados que puede formar parte de las dependencias de enfermeras situadas dentro del propio sanatorio y un edificio auxiliar.

En el concurso del sanatorio participan trece candidatos, ocultos tras sus respectivos lemas, de entre ellos, tres fueron premiados y el cuarto seleccionado. Esta última propuesta seleccionada fue la del arquitecto Erick Bryggman, el tercer premio recayó en el proyecto de los arquitectos R. Ypyä y A. Pernaja, el segundo lo obtuvo la propuesta de K. Borg y $\bigcirc$.

\footnotetext{
${ }^{28}$ Alvar AALTO, "Motivos de tiempos pasados" ("Menneiden aikojen motiivit") Arkkitehti, n², 1922, en Göran SCHILDT (ed.), Alvar Aalto de palabra y por escrito (Alvar Aalto. In his own words, 1997), El Croquis Editorial, Madrid, 2000, p.51.

${ }^{29}$ El bilingüismo de Alvar Aalto que hablaba finés y sueco, la lengua natural de su madre, le acercó a arquitectos como Gunnar Asplund o Sven Markelius y, a través de éstos, logró aproximarse más tarde a la Bauhaus, al movimiento holandés De Stijl y a la figura de Le Corbusier. Nicholas RAY, Alvar Aalto, Yale University Press, London 2005, p.20.

${ }^{30}$ Espacios generales del sanatorio de Paimio:

A. Espacio de despacho y reconocimiento: destinado a los servicios médicos.

B. Dependencias de cada departamento: destinadas a las enfermeras de guardia y a los medios auxiliares de atención a los pacientes.

C. Dependencias comunes para los pacientes: comedor, biblioteca, sala de estar, guardarropas, etc.

D. Dependencias de la sección de cocina.

E. Dependencias de las enfermeras: para el médico auxiliar, alumnos, enfermeras e invitados. Las dependencias podían estar fuera del sanatorio en un edificio anexo.

F. Dependencias de carácter general: contiene los pasillos e instalaciones.

G. Departamento de enfermedades contagiosas: con dos habitaciones para pacientes y una para la enfermera al cargo.

Mateo CLOSA, F. Javier BIURRUN, Alfred LINARES, "Programa del concurso de proyectos para el sanatorio para tuberculosos de Varsinais-Suomi (Paimio)", en El sanatorio de Paimio, 1929-1933, Alvar Aalto. La arquitectura entre la naturaleza y la máquina. Servei de Publicacions de la UPC, Barcelona 1991, pp.18-20.
} 


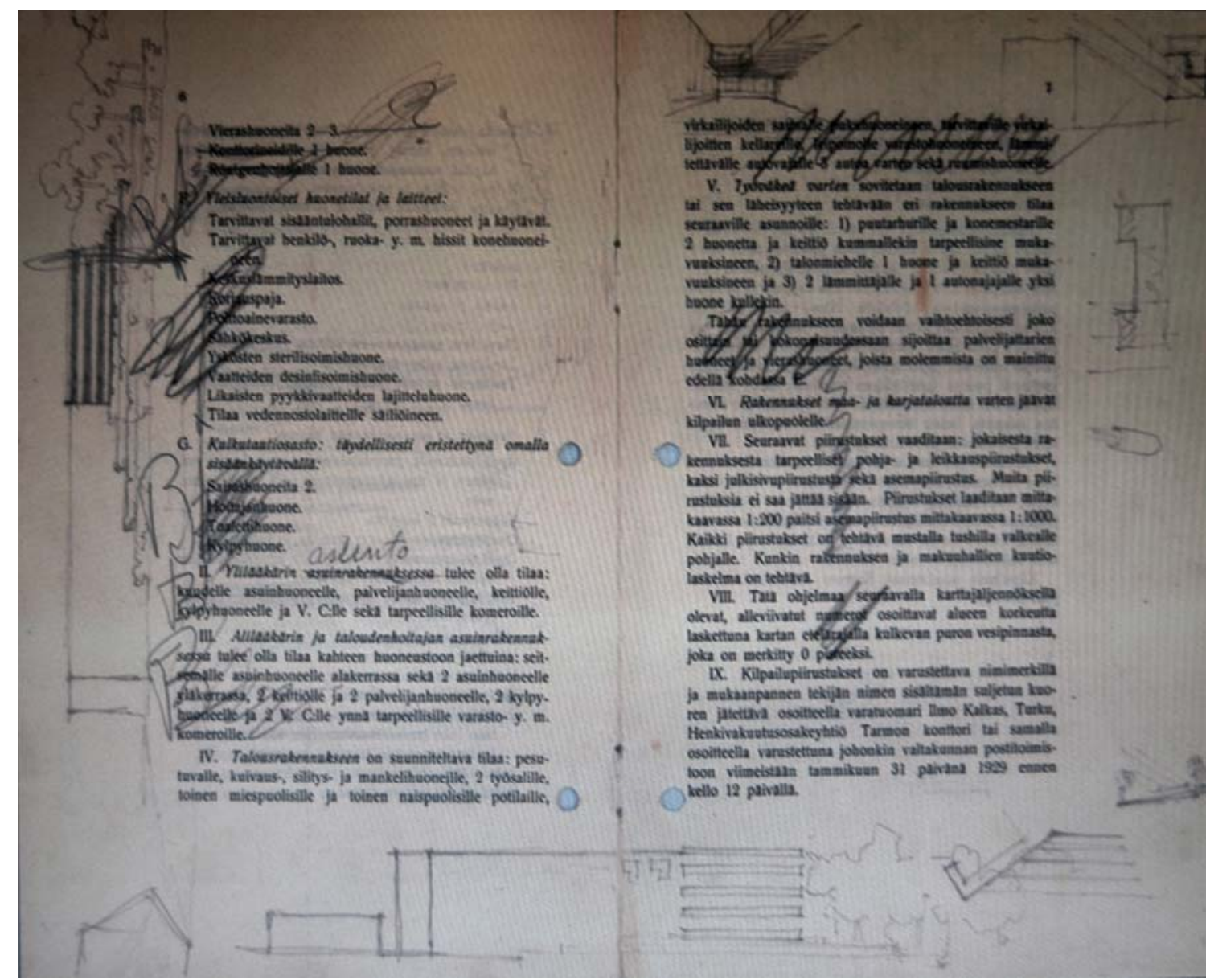

6.19

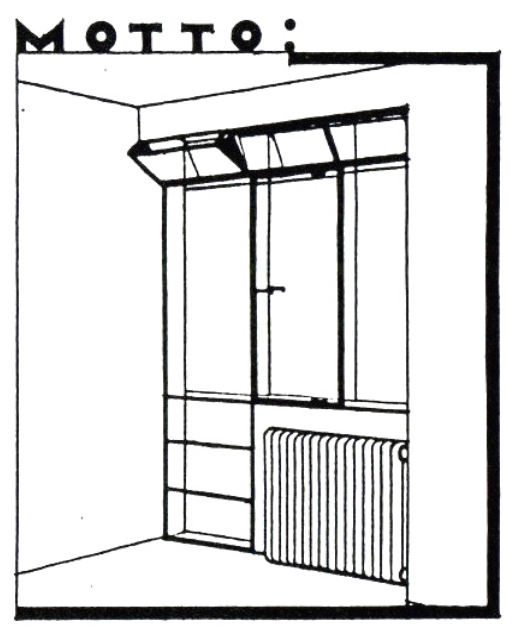

6.20

6.19 Programa del concurso del sanatorio de Paimio con bocetos de A. Aalto, 1928 (AAA 50/35). 6.20 A. Aalto. Proyecto del concurso del sanatorio de Paimio, Turku, 1929. Lema dibujado (50/34). 


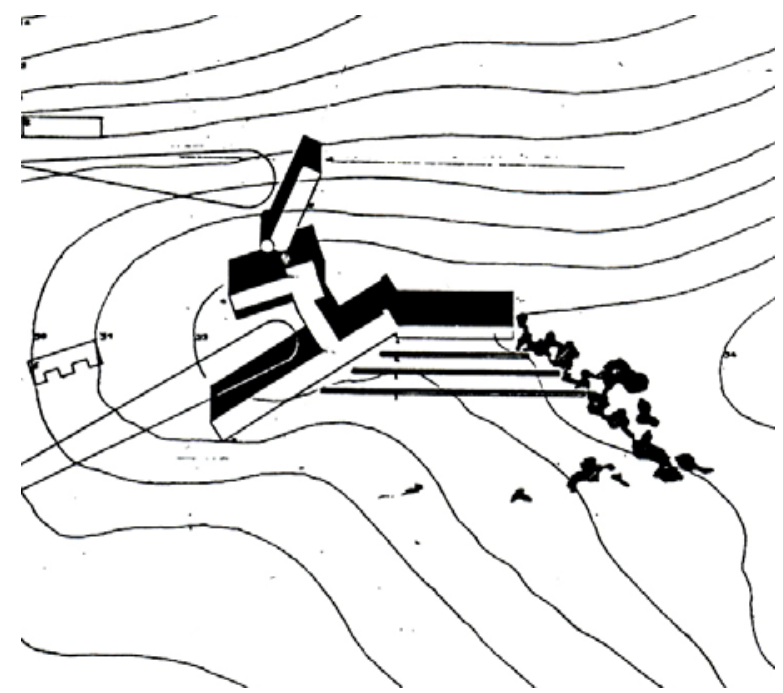

6.21
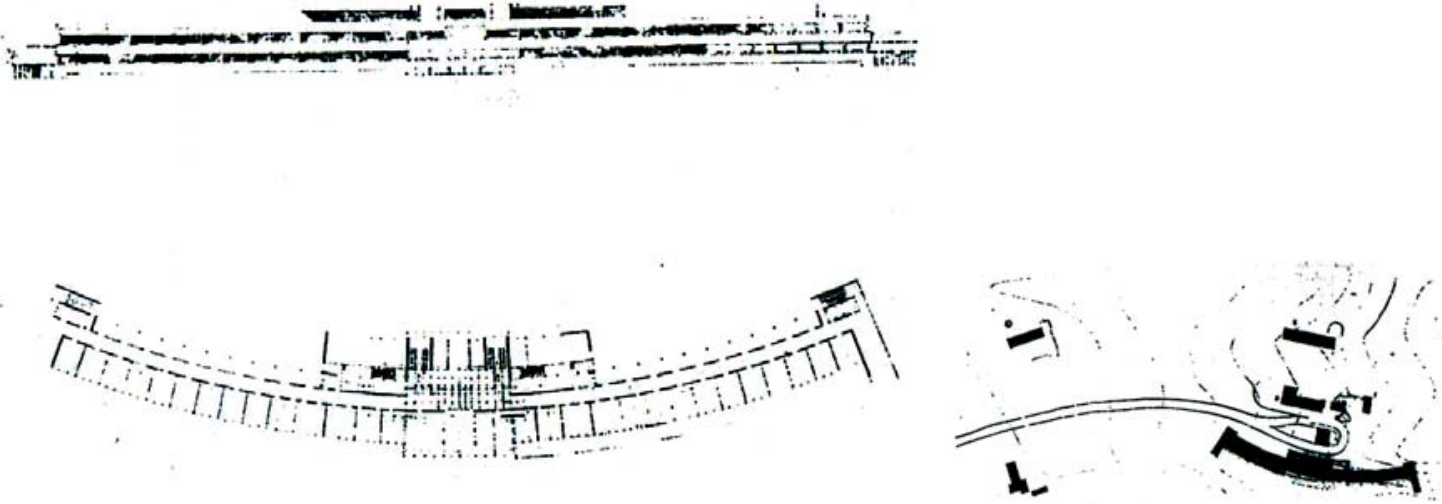

6.22

6.21 A. Aalto. Proyecto del concurso del sanatorio de Paimio, Turku, 1929. Planta de situación (50/24).

6.22 E. Bryggman. Proyecto del concurso del sanatorio de Paimio, Turku, 1929. Propuesta seleccionada. 

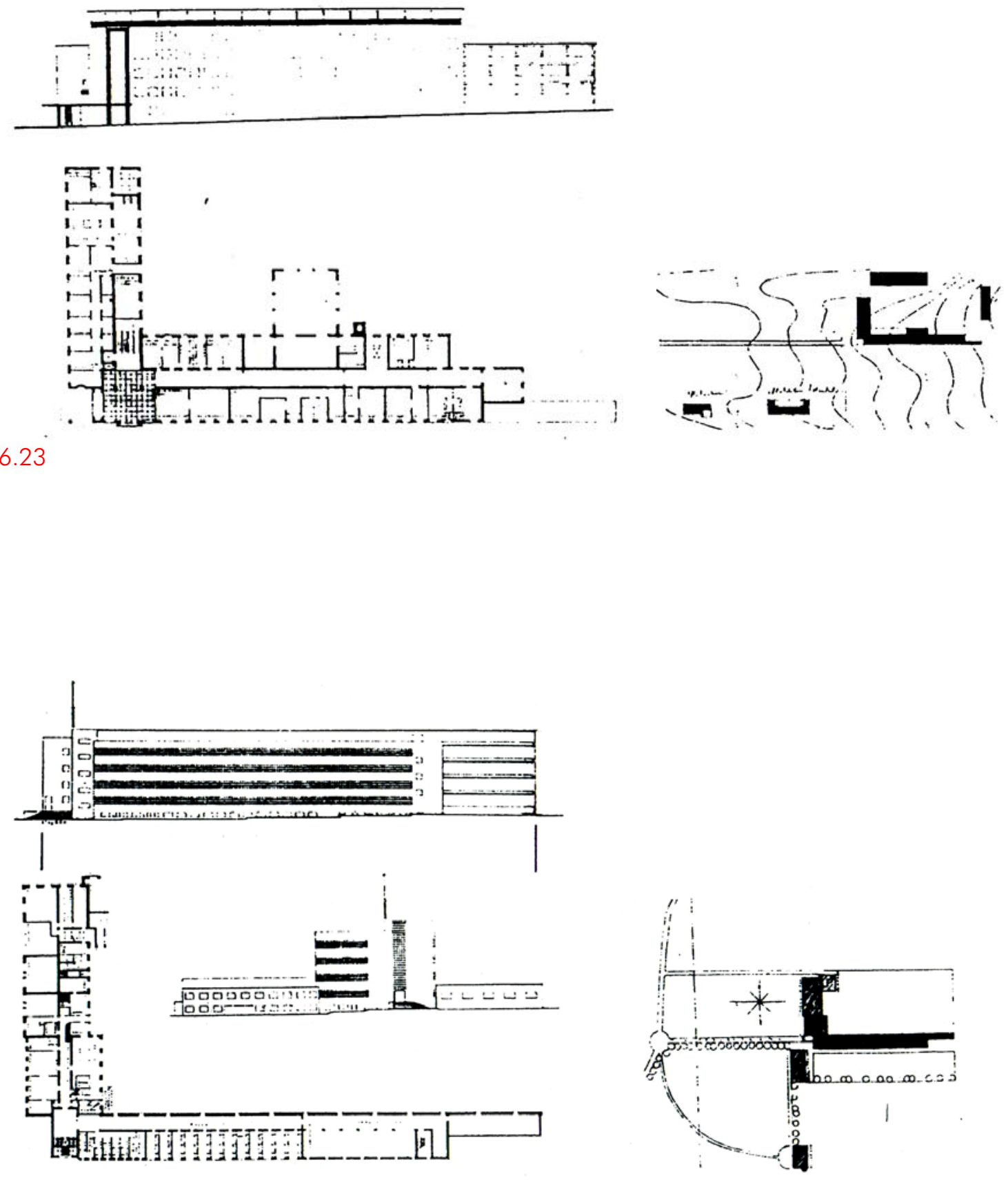

6.24

6.23 K. Borg, O. Flodin y P. Hansten. Proyecto del concurso del sanatorio de Paimio, Turku, 1929. Segundo premio.

6.24 A. Pernaja y R. Ypyä. Proyecto del concurso del sanatorio de Paimio, Turku, 1929. Tercer premio. 
Flodin, y Alvar Aalto fue el arquitecto ganador con su proyecto representado bajo un lema dibujado en vez de escrito, designado por los miembros del jurado como "Piirretty ikkuna", "ventana dibujada" [fig. 6.20]. Su lema consiste en la perspectiva interior de un ángulo de la habitación de hospitalización que muestra la ventana en L, inspirada en la que André Lurçat había proyectado para el hotel Plage-Hôtel. Tanto el lema como la propuesta resultan del todo insólitas para los miembros del jurado que la describen como: "arquitectónicamente interesante, pero en conjunto algo intranquila y poco natural "31. En la concesión de los premios resulta decisiva la opinión de dos de los miembros del jurado, los arquitectos Jussi Paatela y Väinö Vähäkallio, defensores de las últimas tendencias arquitectónicas, que apuestan por el novedoso proyecto.

La irregularidad formal de la planta del sanatorio propuesto por Alvar Aalto contrasta con la rigidez geométrica del resto de proyectos premiados. La propuesta seleccionada de Erick Bryggman, arquitecto con el que Aalto había colaborado en varias ocasiones, sigue el modelo tradicional simétrico y compacto con planta en forma de $T$ de frente curvo [fig. 6.22] y las propuestas ganadoras del segundo y tercer premio plantean un sanatorio articulado en forma de L [fig. 6.23 y fig. 6.24], donde un brazo está destinado a las habitaciones y galerías de cura y el otro contiene los servicios generales.

Sin embargo, su propuesta no responde a un orden axial o geométrico característico de los edificios del positivismo moderno [fig. 6.21], sino más bien a un orden más complejo que Demetri Porphyrios describe como "heterotopía": "aquel peculiar sentido de orden en el cual fragmentos de un determinado número de coherencias posibles brillan por separado, sin una ley común que los unifique" 32 y al que Aalto se refiere como "armonía":

"El concepto de arte que encuentra belleza sólo en formas aisladas y sueltas con finalidad en sí mismas - un pensamiento muy común en nuestras artes industriales de hoy -, no es precisamente de gran ayuda a la hora de salvarnos de la barbarie de formas actual y de crear una armonía más universal para nuestro tiempo, meta que debería ser común a todas las aspiraciones culturales" ${ }^{\prime \prime 3}$.

\footnotetext{
${ }^{31}$ Acta del jurado que falla el concurso de Paimio, publicadas en la revista Arkitehtti en el 1929. Citado en Mateo CLOSA, F. Javier BIURRUN, Alfred LINARES, El sanatorio de Paimio, 1929-1933, Alvar Aalto. La arquitectura entre la naturaleza y la máquina. Servei de Publicacions de la UPC, Barcelona 1991, pp. 20-22.

32 Demetri PORPHYRIOS, "Heterotopía: Un estudio sobre la sensibilidad ordenada de la obra de Alvar Aalto", en David DUNSTER (ed.), Architectural Monographs 4, "Alvar Aalto", Academy Editions, Londres 1978, p. 66.

33 Alvar AALTO, "Sobre las últimas tendencias en arquitectura" ("Uusimmista virtauksista rakennustaiteen alalla"), Uusi Aura, 1928, en Göran SCHILDT, Alvar Aalto de palabra y por escrito (Alvar Aalto. In his own words, 1997), El Croquis Editorial, Madrid 2000, p.85.
} 

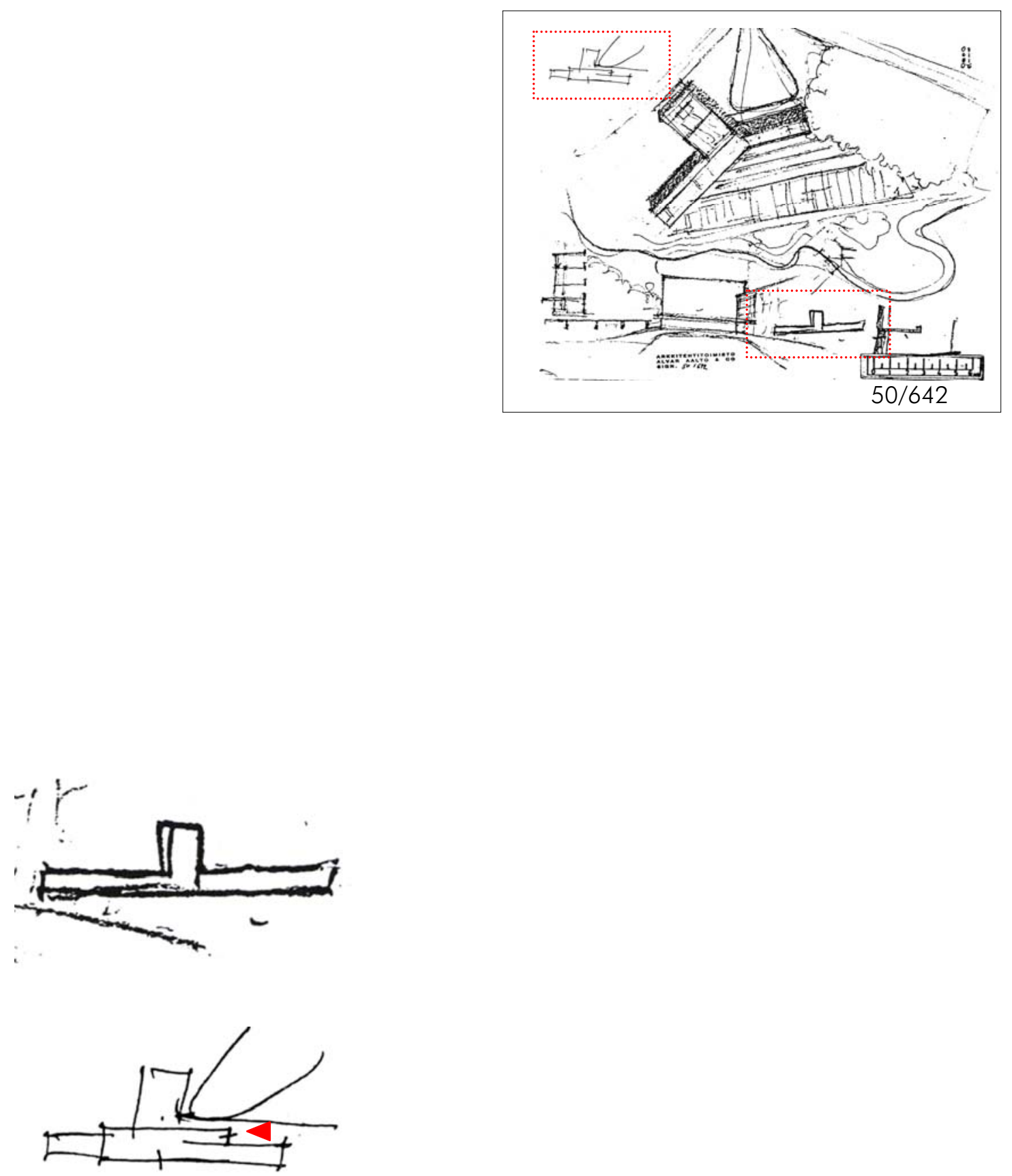

6.25

6.25 A. Aalto. Proyecto del concurso del sanatorio de Paimio, Turku, 1929. Fragmentos del boceto 50/642. Estructura formal en $T$. 
Durante un discurso pronunciado en la Universidad de Yale, seis años más tarde de haber concluido la obra de Paimio, el 9 de mayo de 1939 Aalto expone bajo su peculiar regla de la " $p$ " los cuatro factores determinantes para un arquitecto en el momento de enfrentarse a un proyecto: "programa, propósito, persona y pago" ${ }^{34}$ y destaca la crucial importancia que de entre ellos posee el programa. Su transcendencia no consiste en cumplirlo, es decir, en tratar de generar una forma arquitectónica capaz de contener una serie de usos, dictados a menudo por un cliente ajeno al propio proyecto, sino en ampliarlo:

"El principal problema para el arquitecto es averiguar qué es lo que realmente está detrás del programa: si podéis utilizad los deseos particulares de vuestro cliente de tal manera que el resultado de vuestro trabajo no solamente satisfaga esos especiales deseos, sino que continúe teniendo valor social y utilidad general para todos los seres vivos $^{\prime \prime 35}$.

Pero żcómo consigue Aalto dar una respuesta universal a un programa?

Al analizar la colección de dibujos realizados por él para el concurso del Sanatorio de Paimio $^{36}$ se observa que el proyecto se inicia a partir de una estructura formal que responde a tipo de sanatorio en $T$, procedente de los modelos tradicionales germano-suizos [fig. 6.25]. El interés por esta estructura formal ${ }^{37}$ puede deberse a su intento por crear un "tipo universal".

Un mes antes de que se convocara el concurso de Paimio publica el artículo "Rationell biografi", "Un cine racional", donde describe cómo construir un "tipo universal de salas de cine ${ }^{\prime \prime 38}$ :

"Nos ceñiremos a comenzar por lo esencial del problema, y a descartar las cuestiones comunes a todos los locales de reunión y no exclusivas de las salas de cine.

34 Alvar AALTO, "Villa Mairea" ("The home of a rich art collector"), discurso pronunciado en la Universidad de Yale, 9 de Mayo de 1939; Arkkitethi n9, 1939, en Göran SCHILDT (ed.), Alvar Aalto de palabra y por escrito (A/var Aalto. In his own words, 1997), El Croquis Editorial, Madrid 2000, p. 310 .

${ }^{35}$ Alvar AALTO, "Villa Mairea" ("The home of a rich art collector"), discurso pronunciado en la Universidad de Yale, 9 de Mayo de 1939, Arkkitethi n9, 1939, en Göran SCHILDT (ed.), Alvar Aalto de palabra y por escrito (Alvar Aalto. In his own words, 1997), El Croquis Editorial, Madrid 2000, p. 310.

${ }^{36}$ Alvar AALTO, The architectural drawings of Alvar Aalto, 1917-1939 Vol.4, Paimio Tuberculosis Sanatorium, Cty of Turku 700th Anniversary Exhibition, Standard Furniture, and other buildings and projects 1929-1930, Garland, New York London 1994, pp.137-149.

${ }^{37}$ Se deduce que este esquema formal inicial está presente también en el sanatorio de Kinkomaa a pesar de no disponer de lo bocetos previos del proyecto para comprobar la conjetura.

${ }^{38}$ El artículo "Un cine racional" ("Rationell biografi"), fue publicado en Octubre de 1928 en Kritisk Revy, la revista cultural que apenas duró dos años, de 1926 a 1928, dirigida por el diseñador Poul Henningsen, a quien Aalto había conocido durante su viaje a París realizado ese mismo verano. 

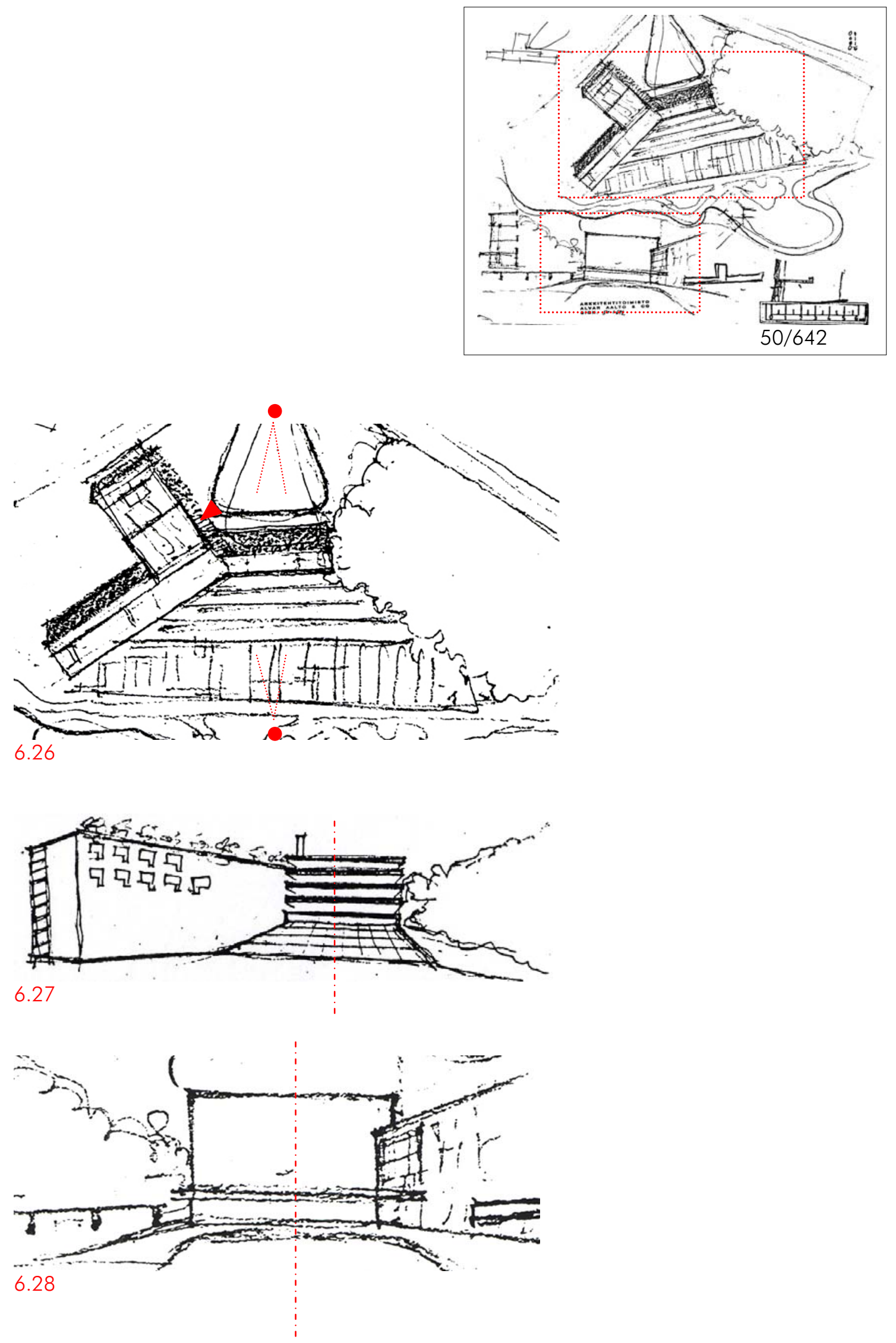

6.26 A. Aalto. Proyecto del concurso del sanatorio de Paimio, Turku, 1929. Fragmento del boceto 50/642. Planta de 3 partes.

6.27 A. Aalto. Proyecto del concurso del sanatorio de Paimio, Turku, 1929. Fragmento del boceto 50/641. Alzado del jardín escalonado

6.28 A. Aalto. Proyecto del concurso del sanatorio de Paimio, Turku, 1929. Fragmento del boceto 50/642. Vista principal de acceso, trasera de la galería de cura. 


\section{(...) Y si queremos que las salas de cine encuentren un tipo universal, el problema ha} de solucionarse con un tipo arquitectónico básico que tenga en cuenta lo variable, lo mutable, lo no monumental, cualidades todas ellas inherentes al cine" ${ }^{\prime \prime 39}$.

Para Aalto el "tipo universal" es el resultado de dar soluciones concretas a problemas específicos del programa, no es tanto una forma sino más bien un "sistema", tal y como él lo define, de manera que puede ser aplicado o reproducido en numerosas ocasiones, como las tiras de celuloide:

"(...) una tira de celuloide pertenece a otra familia, a un tipo objetivo que permite copias ilimitadas. Representa menos una forma que un sistema; y es ejemplo ideal de lo que entendemos por un producto representativo de nuestro tiempo". ${ }^{40}$

Este sistema aflora en el proyecto definitivo del sanatorio en el que, para Antón Capitel: "La planta tipo nos muestra el diseño ad hoc de las piezas" ${ }^{\prime \prime 1}$. Con la intención de encontrar "el sistema" para lograrlo no duda en alterar la estructura en forma de $T$ inicial del tipo habitual de sanatorio antituberculoso y generar un conjunto polimórfico regido por criterios funcionales y sensitivos, cuyo proceso generativo de la forma sigue su más tarde conocido como "principio biológico de la construcción" ${ }^{42}$. El principio consiste en fragmentar el programa en las unidades básicas de cada parte y en tratar de agruparlas.

Aplica así al sanatorio "la tendencia de las células a agruparse - en eso consiste el principio biológico de la construcción - ${ }^{443}$. Lo explica en la memoria del proyecto:

"La forma básica del Sanatorio deriva del intento de tratar por separado cada parte diferente de este tipo de establecimiento, de tal modo que las estancias y espacios similares se agrupan para formar un brazo. (...) Siempre que ha sido posible se ha tratado de conseguir que cada brazo contenga un solo 'tipo de estancias' lo grupos

\footnotetext{
39 Alvar AALTO, "Un cine racional" ("Rationell biografi"), Kritisk Revy, 1928, en Göran SCHILDT (ed.), Alvar Aalto de palabra y por escrito (Alvar Aalto. In his own words, 1997), El Croquis Editorial, Madrid 2000, pp. 91 y 97.

40 Alvar AALTO, "Un cine racional" ("Rationell biografi"), Kritisk Revy, 1928, en Göran SCHILDT (ed.), Alvar Aalto de palabra y por escrito (Alvar Aalto. In his own words, 1997), El Croquis Editorial, Madrid 2000, p. 91.

${ }^{41}$ Antón CAPITEL, La arquitectura compuesta por partes. Gustavo Gili, Barcelona 2009, p.170.

${ }^{42}$ La primera vez que Aalto describe su "principio biológico" lo plantea en la configuración de las ciudades y su idea de crecimiento formando barrios, pequeños agrupaciones de unidades residenciales o "células". Sin embargo, esta agrupación de unidades básicas de similares características ya está presente en el ámbito arquitectónico, en sus proyectos de sanatorios constituidos por partes.

${ }^{43}$ Alvar AALTO, "Geografía del problema de la vivienda" ("Arkitektur och samhälle"), Prisma, 1932, en Göran SCHILDT (ed.), Alvar Aalto de palabra y por escrito (Alvar Aalto. In his own words, 1997), El Croquis Editorial, Madrid 2000, p.123.
} 

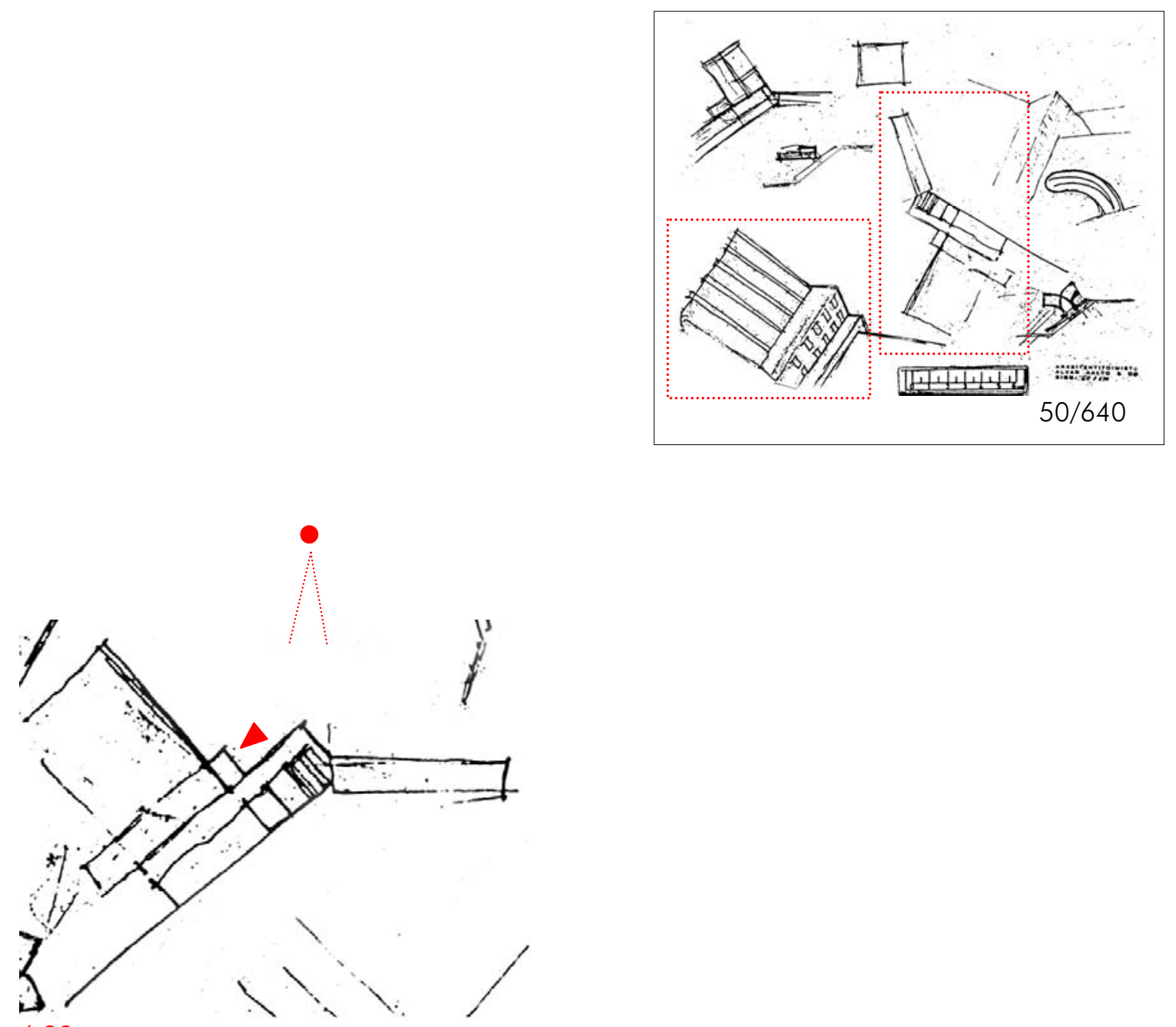

6.29

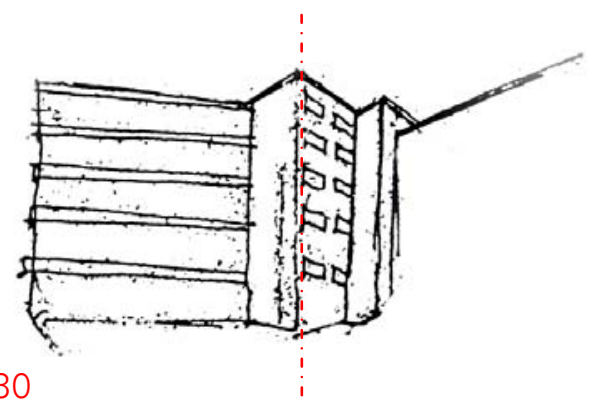

6.29 A. Aalto. Proyecto del concurso del sanatorio de Paimio, Turku, 1929. Fragmento del boceto 50/640. Planta de tres partes con el cuerpo principal en posición central.

6.30 A. Aalto. Proyecto del concurso del sanatorio de Paimio, Turku, 1929. Fragmento del boceto 50/640. Vista principal de acceso, esquina del cuerpo de habitaciones. 
de estancias, donde son similares los requisitos de la luz solar y vistas, etc.) ${ }^{\prime 44}$.

Por consiguiente, se puede suponer que su primera decisión consiste en articular el sanatorio en tres partes rectangulares e interconectadas, cada una destinada a un uso diferente como se aprecia en el boceto 50/642 [fig. 6.26]. La más estrecha orientada al sur contiene la galería de curas; otra más grande y cuadrada alberga los servicios comunes, y una tercera perpendicular a la anterior y conectada por su extremo sur con las dos anteriores constituye el ala de habitaciones abierta al sureste. Esta disposición contribuye a que el enfermo desde la habitación pueda recibir mejor los rayos solares, más bajos y tendidos durante el prolongado invierno nórdico. Además, al eliminar las galerías del cuerpo de habitaciones, el sol incide directamente en la ventana y se evitan las sombras que provocan sus vuelos.

En el boceto de esta solución se aprecia como Aalto enraíza su propuesta con el entorno al dibujar los caminos preexistentes y nuevos, así como la vegetación. Proyecta con la naturaleza y utiliza el bosque como límite, de manera que el cuerpo de habitaciones, la galería y el propio bosque definen un recinto abierto en el que diseña un jardín aterrazado, pieza clave de Paimio que se mantiene en el proyecto definitivo. Con el escalonamiento del jardín se enfatiza la topografía, que tiene una ligera pendiente, y se genera un gran vacío frente a la fachada del edificio de habitaciones, que preserva unas buenas condiciones de iluminación y de circulación del aire, al tiempo que se fomenta la imbricación del edificio y el entorno. La galería de cura, el elemento más plástico y significativo del sanatorio, se sitúa al fondo ocupando el centro de la composición. Se halla flanqueada por la fachada del cuerpo de habitaciones con sus ventanas en $L$ y por la pared vegetal definida por el bosque que focaliza su presencia [fig. 6.27]. Como describe J.M. Montaner: "Cuando Alvar Aalto (1898-1976) proyectó conjuntos de edificios demostró la máxima sensibilidad por el espacio abierto, con la voluntad de que el fondo se convintiera en figura. En sus obras, el espacio abierto articula las diversas partes del conjunto, fusionando objeto y contexto" ${ }^{45}$.

\footnotetext{
44 "The Sanatorium's shape of plan derives from the attempt to handle separately each dissimilar part in this kind of establishment, so that similar rooms and spaces are grouped together to form wing.(...)Wherever possible each wing contains only "one kind of room" (or groups of rooms, where the requirements of sunshine and view etc. are similar)". Alvar AALTO, "Tuberculosis Sanatorium at Paimio/Paimio Hospital" (1933), en Alvar AALTO, Tuberkuloosiparantola, Paimio, Alvar AaltoMuseo Jyväskylä 2004.

45 Josep María MONTANER, Sistemas arquitectónicos contemporáneos. Editorial Gustavo Gili, Barcelona 2009, p. 81.
} 

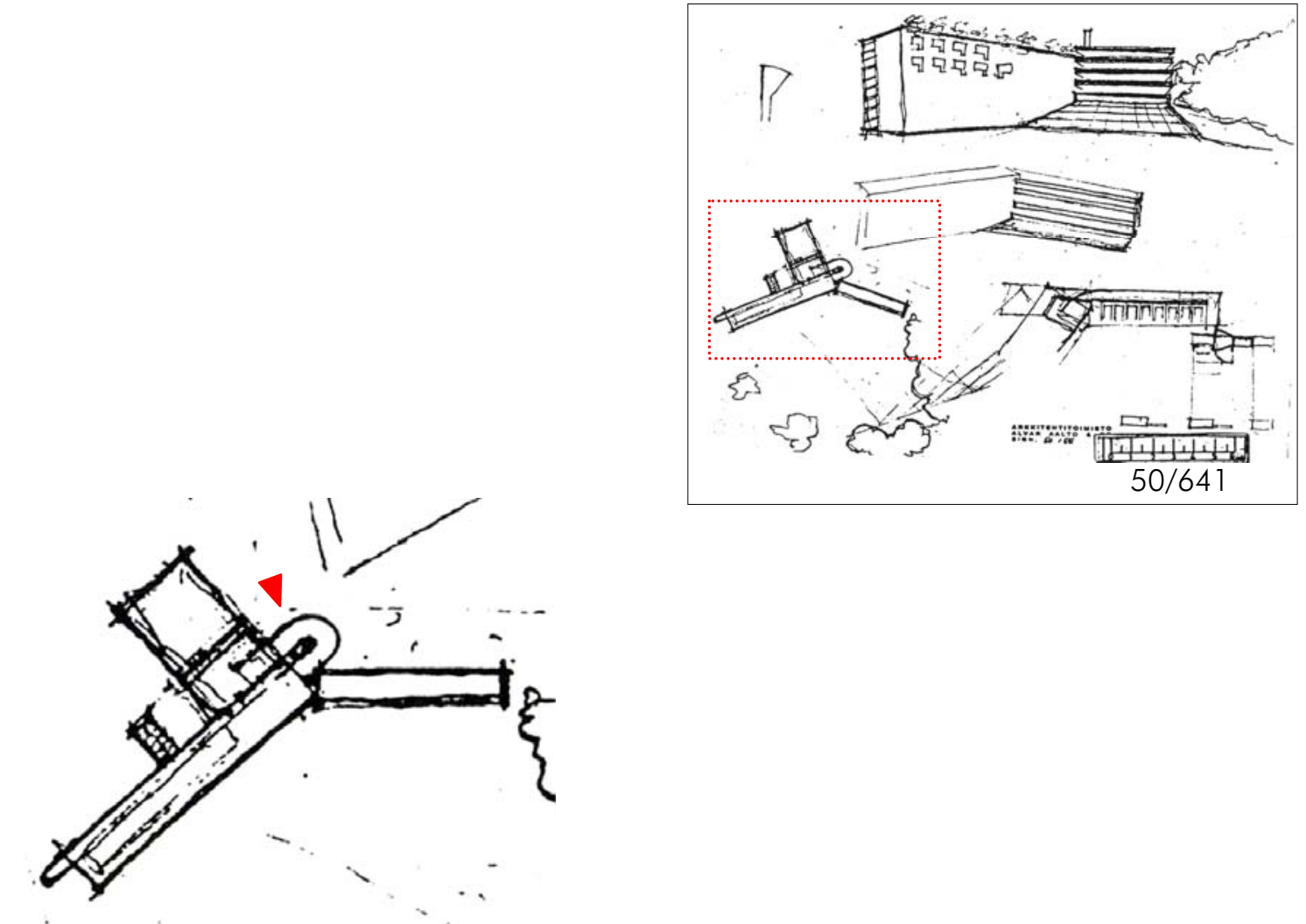

6.31
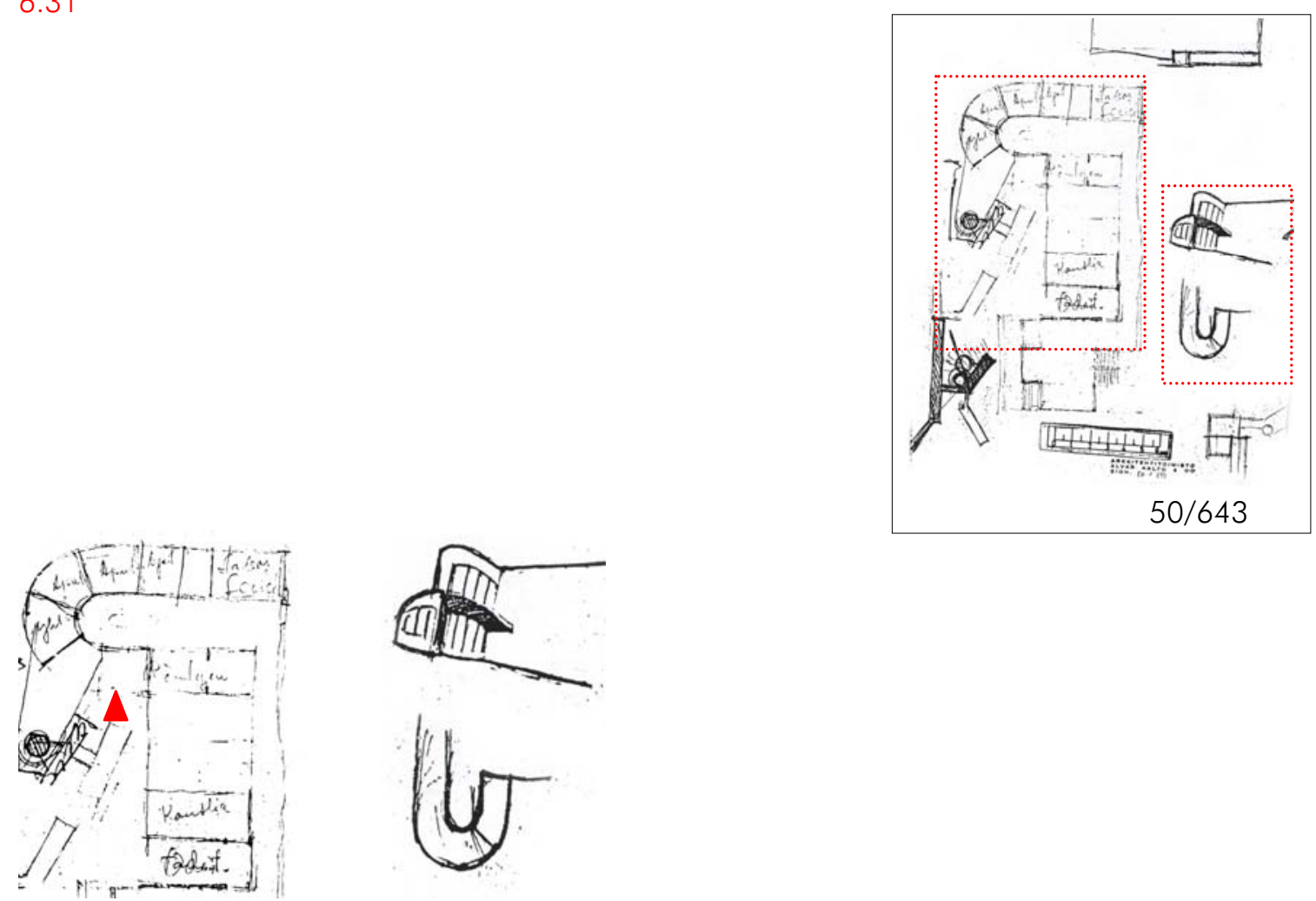

6.32

6.31 A. Aalto. Proyecto del concurso del sanatorio de Paimio, Turku, 1929. Fragmento del boceto 50/641. Vestíbulo circular.

6.32 A. Aalto. Proyecto del concurso del sanatorio de Paimio, Turku, 1929. Fragmento del boceto 50/643. Vestíbulo circular. 

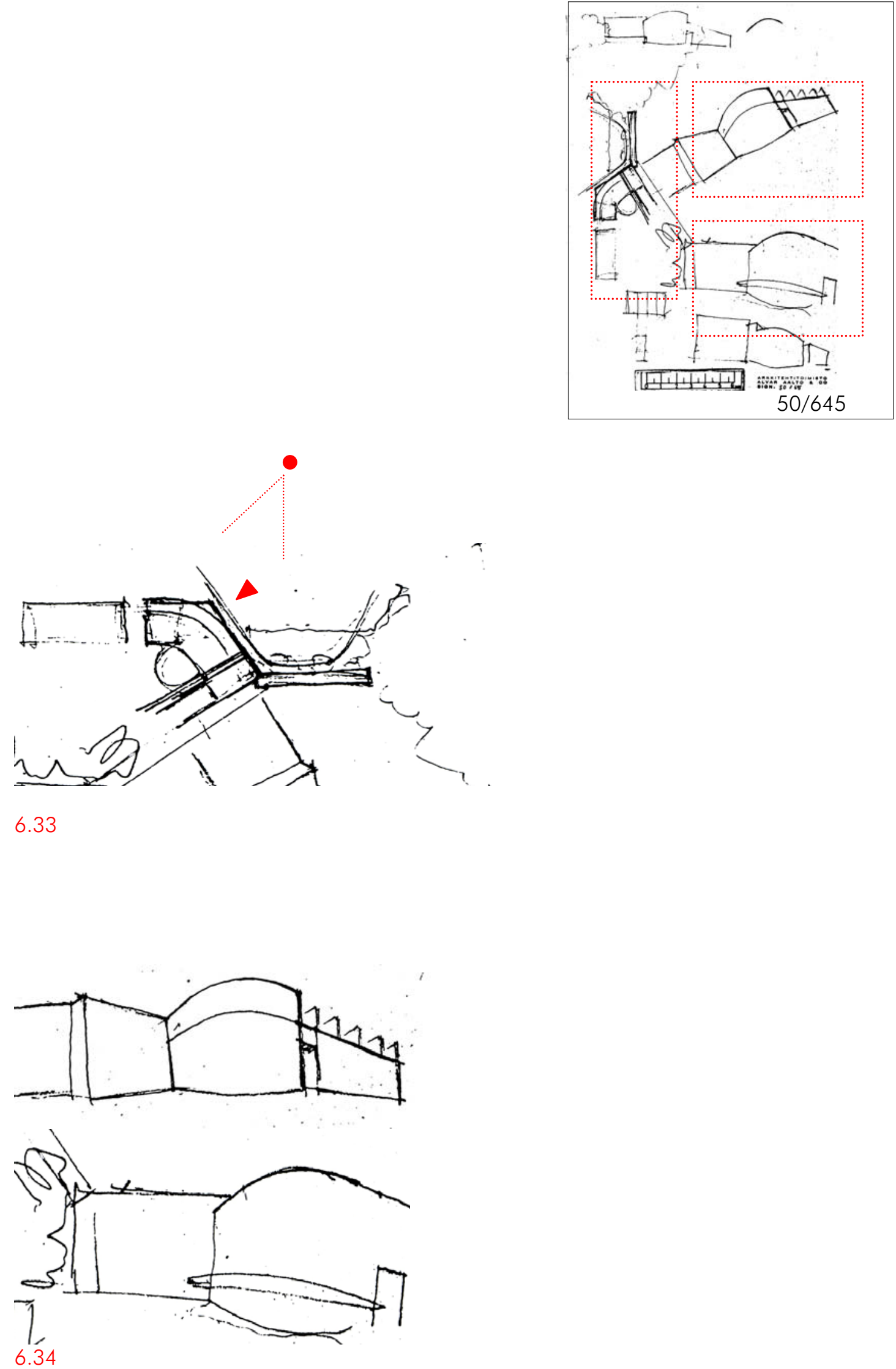

6.33 A. Aalto. Proyecto del concurso del sanatorio de Paimio, Turku, 1929. Fragmento del boceto 50/645. Cuerpo central circular planta

6.34 A. Aalto. Proyecto del concurso del sanatorio de Paimio, Turku, 1929. Fragmentos del boceto 50/645. Cuerpo central circular vistas. 


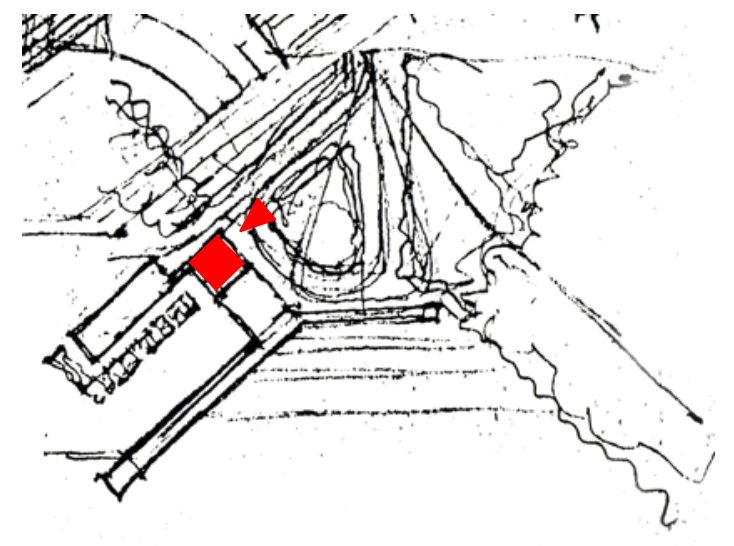

6.35
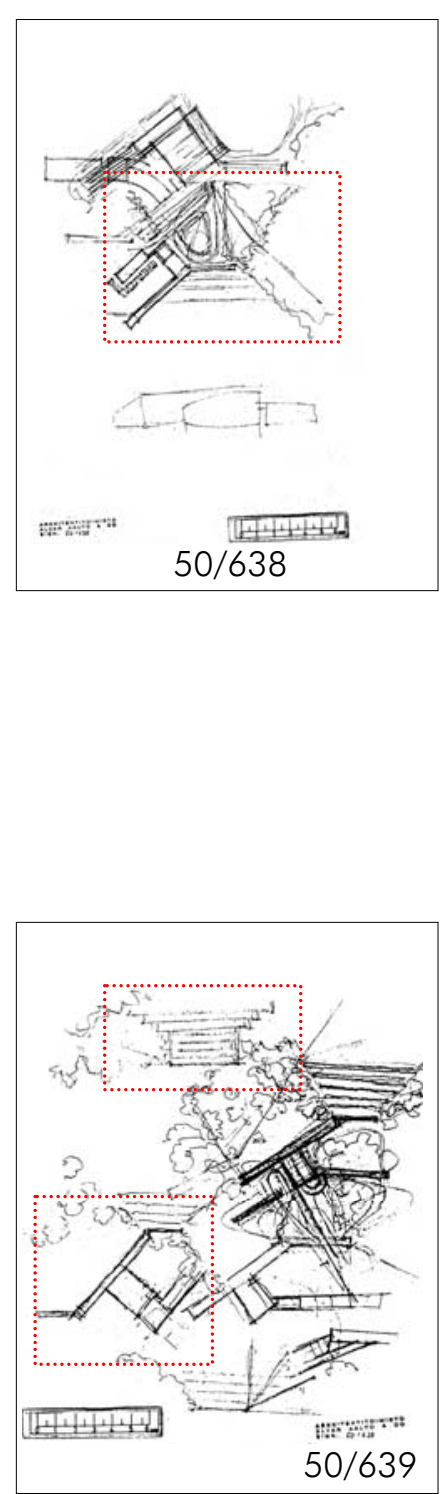

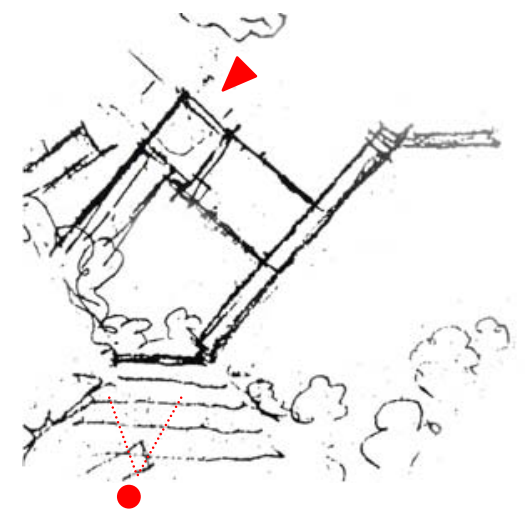

6.37 y 6.38

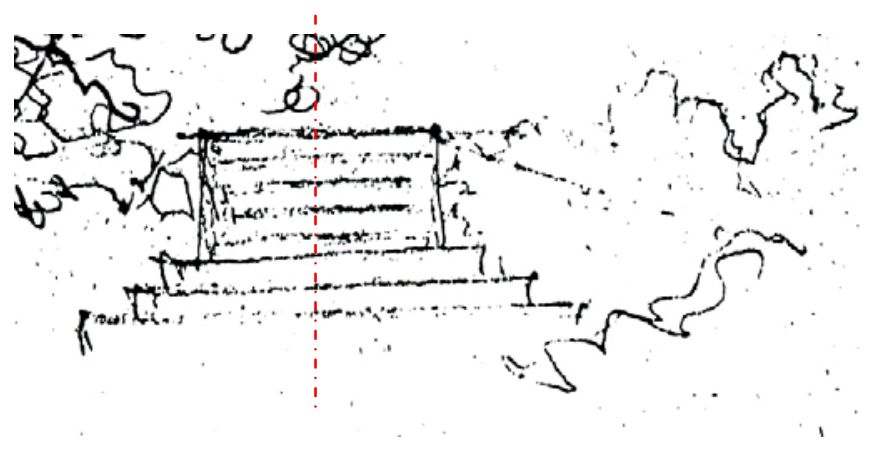

6.35 A. Aalto. Proyecto del concurso del sanatorio de Paimio, Turku, 1929. Fragmento del boceto 50/638. Planta de cuatro partes con el cuerpo principal en el extremo y el vestíbulo al norte. 6.36 y 3.37 A. Aalto. Proyecto del concurso del sanatorio de Paimio, Turku, 1929. Fragmento del boceto 50/639. Descripción de la simetría central entre las galerías y de la planta de cuatro partes con el cuerpo principal en el centro y el vestíbulo al norte.

6.38 A. Aalto. Proyecto del concurso del sanatorio de Paimio, Turku, 1929. Fragmento del boceto 50/639. Vistas de la galería de curas. 
En esta propuesta el acceso al sanatorio se ubica en la fachada noreste del cuerpo de servicios comunes de tal manera que la espalda de la galería de curas pasa a convertirse en la primera imagen que se percibe del mismo [fig. 6.28]. La visión frontal del enorme muro ciego, tan sólo interrumpido por una marquesina lineal que dirige al visitante hacia la puerta, no le convence. Trata de reducir su rotundidad desplazando el cuerpo de servicios comunes y separándolo de la galería, se libera así la esquina del bloque de habitaciones que pasa a convertirse en la primera imagen del sanatorio, más dinámica y menos monumental que la anterior [fig. 6.29]. Plantea también la posibilidad de abrir la galería al norte mostrando sus bandejas a ambos frentes y de crear un cuerpo rectangular de acceso maclado al cuerpo de servicios comunes y al de habitaciones, como muestra el boceto 50/640 [fig. 6.30].

Esta solución tampoco le resulta del todo satisfactoria y prueba a combinar geometrías para otorgar por contraste un mayor carácter al acceso. Incluye elementos curvos a través de marquesinas, mediante un volumen semicilíndrico adosado a la fachada [fig. 6.31 y fig. 6.32] e incluso curva el cuerpo de servicios comunes [fig. 6.33 y fig. 6.34], soluciones que más adelante acabaran plasmándose en la volumetría curva del vestíbulo y en la marquesina de acceso, que por el momento se desecha para intentar resolver el problema cambiando la posición de la entrada y el trazado de los recorridos de llegada.

En el boceto 50/638 traslada el vestíbulo al extremo norte del cuerpo central, permitiendo fragmentar el programa de los servicios comunes en dos cuerpos independientes conectados a través del mismo [fig. 6.35]. Se supone que éste se escinde en dos volúmenes, uno con las dependencias del personal e instalaciones y otro con las consultas y las salas comunes de los enfermos, aportando una mayor privacidad al ámbito de enfermería al alejarlo de las zonas de servicio. Con esta solución se recupera la visión frontal del sanatorio y no de un cuerpo en esquina. Aalto dirige la vía de acceso hacia la fachada principal del cuerpo de servicios comunes, mientras que la espalda de la galería de cura sólo se percibe lateralmente. Se crea además un recinto abierto en forma de $U$ detrás del cuerpo de servicios comunes integrando la naturaleza en el edificio.

Las dificultades surgen al ponderar la conveniencia de ubicar el cuerpo de servicios comunes en un extremo del residencial, aumentando considerablemente los recorridos. En el boceto 50/639 Aalto lo traslada al centro del mismo recuperándose así la estructura simétrica del modelo en $T$, reforzada al duplicar las galerías ubicadas en los extremos del bloque de habitaciones estableciendo una simetría central entre ambas [fig. 6.36]. Esta 
posición permite rodear completamente de vegetación al menos a una de ellas, que se percibe exenta y envuelta por el paisaje, valorando su presencia mediante dos límites vegetales que confluyen en su frente [fig. 6.37 y fig.6.38]. El ritmo horizontal de sus losas, reforzado por el contraste entre el blanco de la construcción y el negro de las sombras que arroja, resulta ser, igual que en las plazas porticadas, "un potente elemento rítmico que contrasta con el paisaje ondulante" ${ }^{46}$.

Se mantiene aún el problema del acceso y de la imagen principal del sanatorio. Aalto los intenta resolver aplicando recursos ya experimentados, como el empleo de formas curvas, el cambio de posición de ciertas partes del conjunto y de los trazados de las vías de acceso, así como el uso de la vegetación como límite de los recintos exteriores. En el boceto 50/639 propone independizar el vestíbulo separándolo del cuerpo de servicios comunes y de instalaciones y fragmentando el programa en seis partes, si se considera el vestíbulo circular como una parte más.

En sus bocetos se vislumbra el intento de crear un recinto en $L$ en cuya intersección se ubica la entrada [fig. 6.39], e incluso una disposición más simétrica en $U$, como la que acabará finalmente eligiendo, empleando de nuevo la vegetación como uno de los límites del mismo [fig. 6.40].

En este momento el proyecto alcanza un punto de inflexión provocado por la alteración formal y el cambio de posición de una de sus partes, ya que Aalto asegura: "(..) con sólo ubicar el vestíbulo en un lugar acertado en relación con las otras habitaciones, el jardín y el patio, lograremos un resultado óptimo" ${ }^{47}$.

En el boceto 50/643 el vestíbulo ubicado dentro del cuerpo de servicios comunes, concebido como el centro no siempre físico pero sí topológico del sanatorio, se independiza y transforma en un elemento longitudinal de conexión [fig. 6.41]. De este modo la organización central en torno a un elemento principal convive con una distribución lineal en torno a un eje, produciéndose un "mestizaje tipológico"48 en el que se mantiene el carácter

\footnotetext{
${ }^{46}$ Alvar AALTO, "La arquitectura en el paisaje de Finlandia Central" ("Keskisuomalainen maiseman rakennustaide" ), Sisä-Suomi, 1925, en Göran SCHILDT (ed.), Alvar Aalto de palabra y por escrito (Alvar Aalto. In his own words, 1997), El Croquis Editorial, Madrid 2000, p. 35.

${ }^{47}$ Alvar AALTO, "De los escalones de entrada al cuarto de estar" ("Porraskiveltä arkihuoneeseen"), Aitta, 1926, en Göran SCHILDT (ed.), Alvar Aalto de palabra y por escrito (Alvar Aalto. In his own words, 1997), El Croquis Editorial, Madrid 2000, p. 72.

${ }^{48}$ Carlos MARTí ARÍS, Las variaciones de la identidad. Ensayos sobre el tipo en arquitectura, Serbal, Barcelona 1993, pp. 58-80.
} 
del centro, y explica que "Las alas están conectadas unas a otras por el elemento central del edificio, donde los servicios comunes, como escaleras, ascensores, etc., se agrupan" ${ }^{49}$.

El sanatorio se configura en cinco partes rectangulares constituidas por la galería de curas, el cuerpo de habitaciones, el vestíbulo, las salas comunes y el cuerpo de instalaciones, que se ordenan siguiendo una disposición radial, como en Zonnestral. Dos de las partes, la galería y los salones comunes, coinciden en el mismo eje este-oeste y junto a una tercera, la del cuerpo de instalaciones, definen un orden radial [fig. 6.42] en el que se aprecia una doble simetría parcial respecto a dos ejes ortogonales donde tres de las partes coinciden con los radios. Sólo el cuerpo de habitaciones no coincide con ningún radio siendo éste paralelo a uno de los ejes principales [fig. 6.43]. Los giros empleados en la ordenación del conjunto recuerdan a la obra de Duiker, al igual que la escalera circular situada en la esquina del cuerpo de instalaciones que aparece representada en el mismo boceto.

Sin embargo, la configuración radial se disipa al ubicar los servicios comunes de nuevo en el centro del brazo de habitaciones y al perder la alineación en la dirección este-oeste de las salas comunes, como se muestra en el boceto 50/646 a. Desaparecen así las relaciones simétricas del conjunto creándose dos ámbitos disociados con configuraciones prácticamente simétricas en cada uno, pero sin relación entre ellos [fig. 6.44]. Se constituye de esta manera un sanatorio con una disposición de las partes en forma de mariposa que recuerda a los sanatorios ingleses de principios del siglo XX, como el de King Edward VII de Sussex, al que se le adosa un brazo con las galerías de cura. La disposición favorece la creación de recintos abiertos en forma de $U$ en torno al perímetro del sanatorio y la naturaleza penetra en el contorno del edificio [fig. 6.45].

La similitud icónica entre Paimio y Zonnestraal aumenta. Aalto conecta el brazo de los salones comunes y el de instalaciones mediante un elemento puente, como los que existen en el pabellón principal del sanatorio de Duiker, y transforma la escalera en una enorme chimenea cilíndrica [fig. 6.47]. Introduce dos accesos independientes [fig. 6.46], el principal enfrentado al vestíbulo proveniente del suroeste [fig. 6.48] y el de servicio en un extremo del mismo que discurre por el noroeste [fig. 6.47]. En la vista del acceso principal, muy similar a la definitiva, se aprecia una regularidad en el tipo de huecos que después desaparece. En el proyecto definitivo la variedad de soluciones adoptadas es tal que Göran Schildt lo describe

\footnotetext{
49 "The wings are then linked to each other by the central part of the building, where the common functions, like stairs, lifts etc. are grouped". Alvar AALTO, "Tuberculosis Sanatorium at Paimio/Paimio Hospital", "Varsinais-Suomen Tuberkuloosiparantola. Rakennusteknillinen selostus" (1933), en Tuberkuloosiparantola, Paimio, Alvar Aalto- Museo, Jyväskylä 2004.
} 

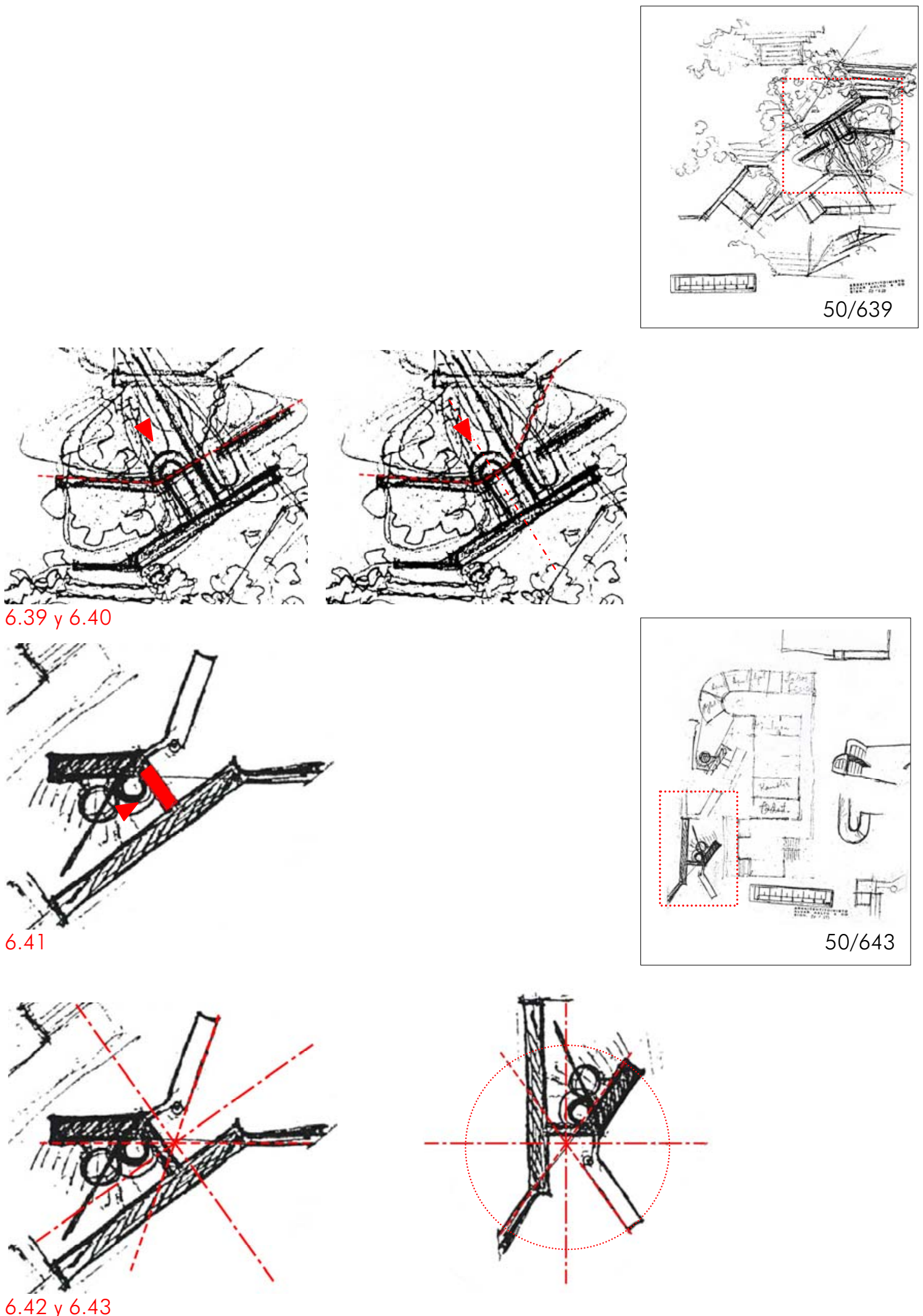

6.42 y 6.43

6.39 y 6.40 A. Aalto. Proyecto del concurso del sanatorio de Paimio, Turku, 1929. Fragmento del boceto 50/639. Planta de seis partes, recinto en $\mathrm{L}$ de acceso y recinto en $U$.

6.41 A. Aalto. Proyecto del concurso del sanatorio de Paimio, Turku, 1929. Fragmento del boceto 50/643. Planta de cinco partes con el vestíbulo longitudinal al sur.

6.42 y 6.43 A. Aalto. Proyecto del concurso del sanatorio de Paimio, Turku, 1929. Fragmento del boceto 50/643. Organización radial de tres de las partes y esquema de las simetrías a eje polar y a eje de 90 grados de las mismas. 

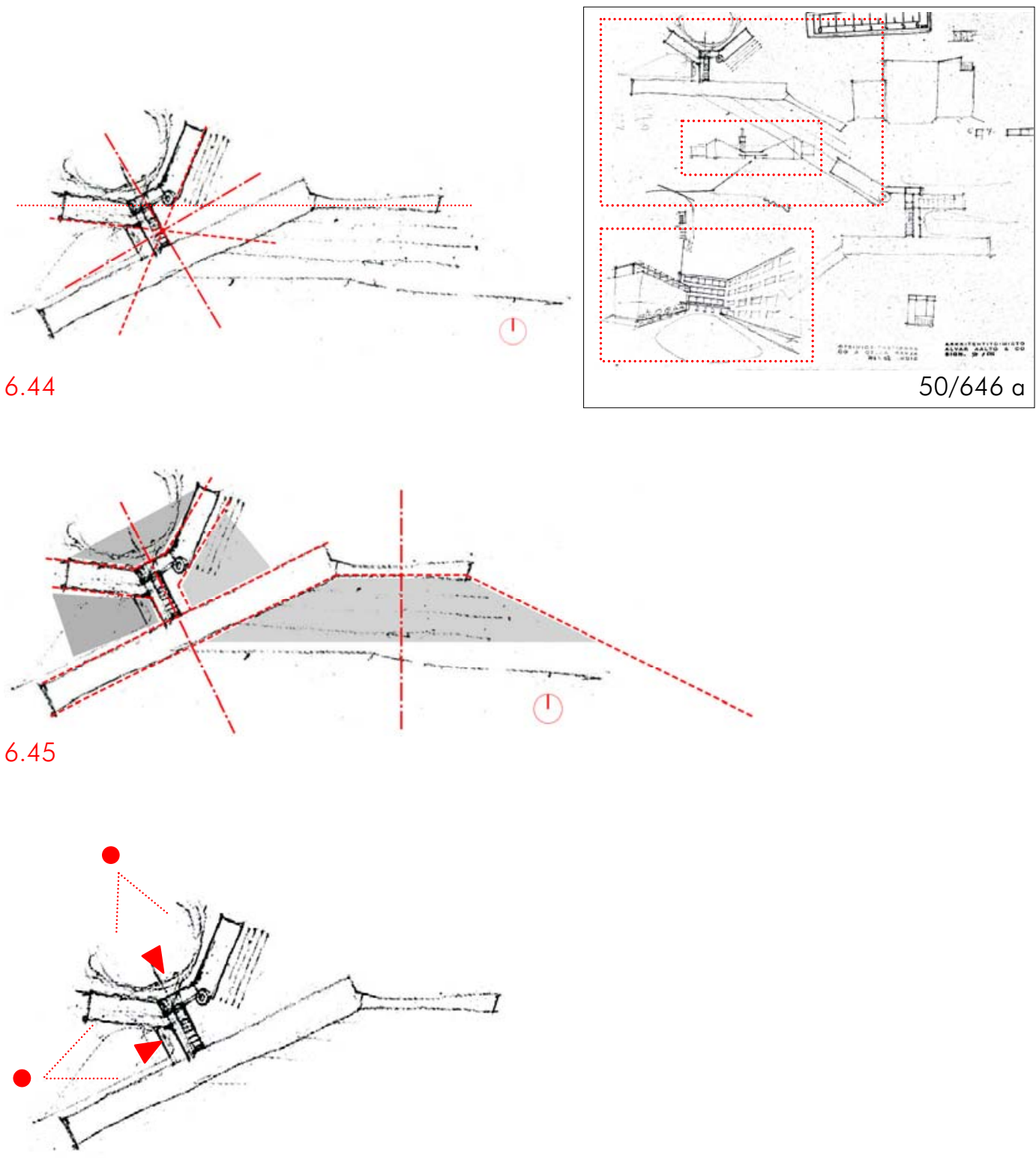

6.46
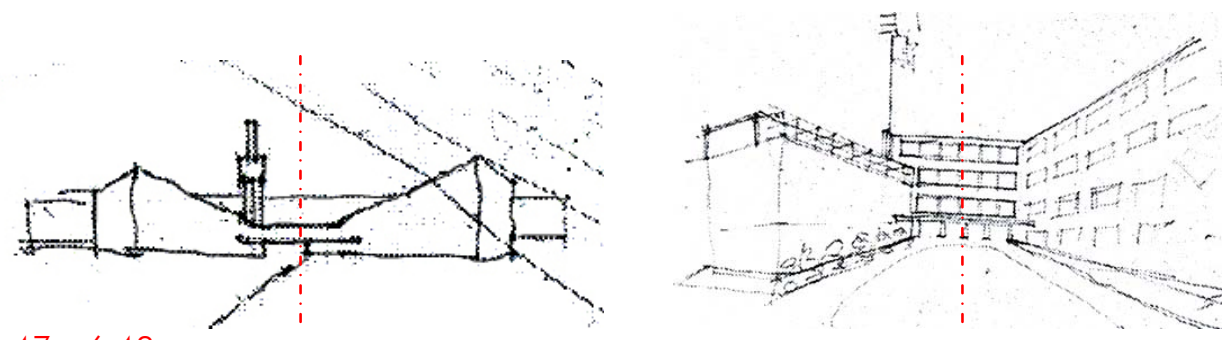

6.47 y 6.48

6.44 A. Aalto. Proyecto del concurso del sanatorio de Paimio, Turku, 1929. Fragmento del boceto $50 / 646$ a. Pérdida del centro y de la simetría del conjunto.

6.45 A. Aalto. Proyecto del concurso del sanatorio de Paimio, Turku, 1929. Fragmento del boceto 50/646 a. Análisis morfológico.

6.46 A. Aalto. Proyecto del concurso del sanatorio de Paimio, Turku, 1929. Fragmento del boceto 50/646 a. Planta.

6.47 y 6.48 A. Aalto. Proyecto del concurso del sanatorio de Paimio, Turku, 1929. Fragmento del boceto 50/646 a. Vistas del acceso de servicio y del acceso principal. 

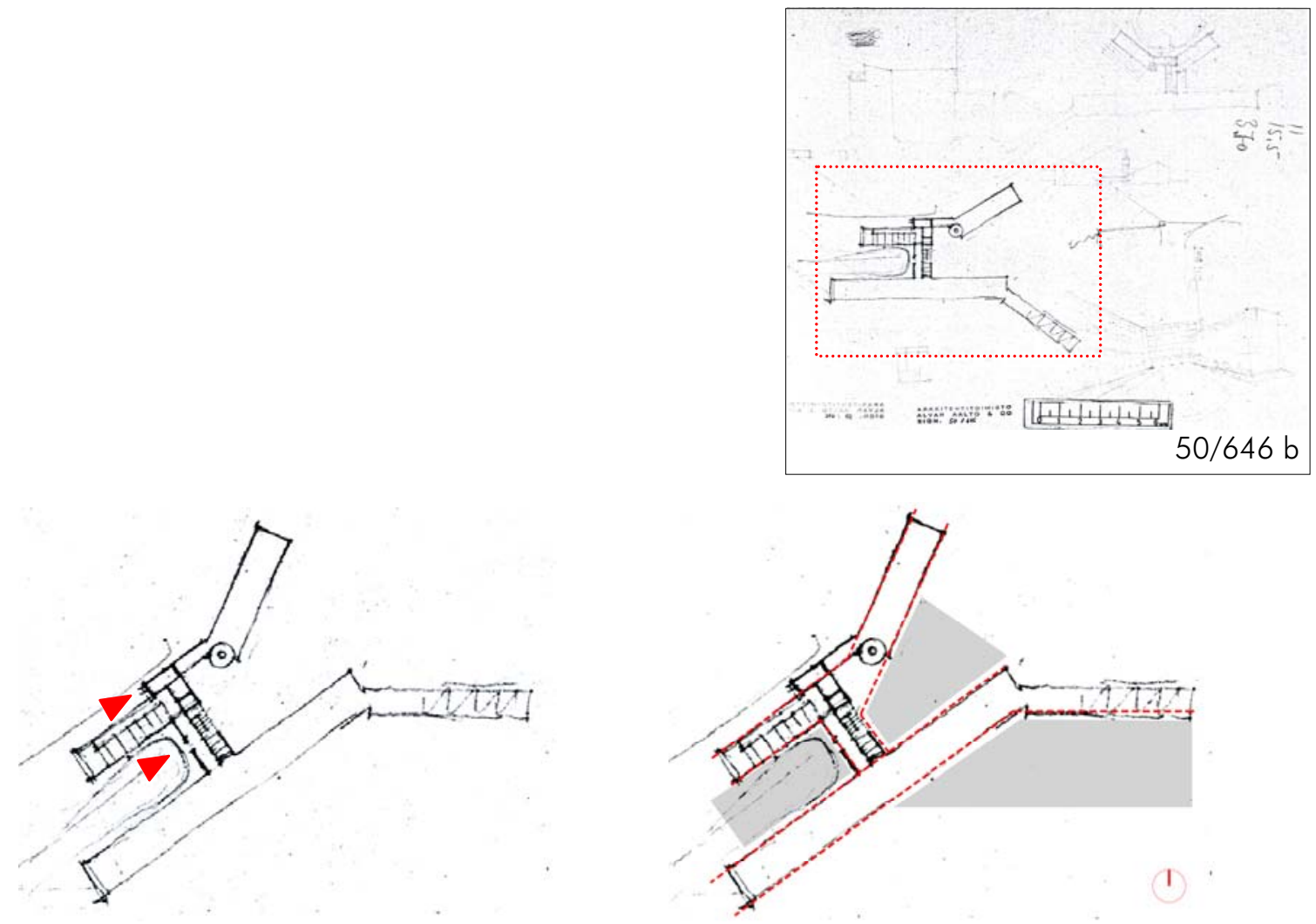

6.49 y 6.50
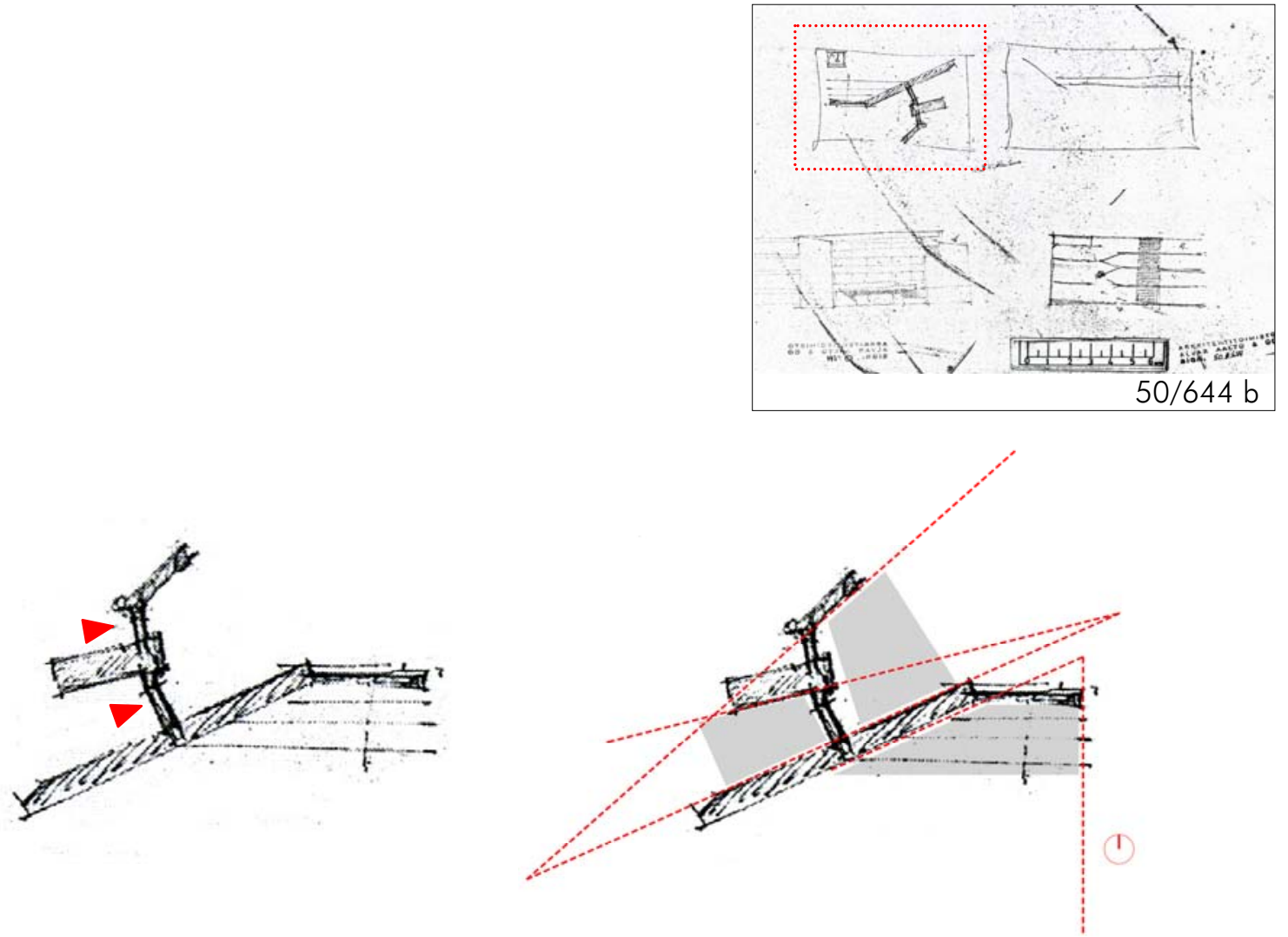

6.51 y 6.52

6.49 y 6.50 A. Aalto. Proyecto del concurso del sanatorio de Paimio, Turku, 1929. Fragmento del boceto 50/646 b. Planta y análisis morfológico.

6.51 y 6.52 A. Aalto. Proyecto del concurso del sanatorio de Paimio, Turku, 1929. Fragmento del boceto 50/644 a. Planta definitiva y análisis morfológico. 
como "un ejemplo de arquitectura analítica, un conglomerado de distintas soluciones de detalles $^{\prime \prime 50}$ que otorga al edificio un cierto carácter pintoresco según Le Corbusier ${ }^{51}$.

De nuevo, como muestra el boceto 50/646 b, el estudio de los accesos conduce a alterar la posición relativa de las partes. El cuerpo de las salas comunes pasa a ser paralelo al cuerpo de habitaciones; esta localización consigue que las dos vías de acceso discurran en paralelo y partan del suroeste, disminuyendo la longitud del recorrido hacia el acceso de servicio [fig. 6.49]. El cambio de posición acaba con la simetría de la disposición en mariposa, aproximando el sanatorio a los modelos hospitalarios más ortogonales en forma de $\mathrm{H}$ y eliminando el recinto abierto en forma de $\mathrm{U}$ creado en el acceso de servicio que tampoco se mantiene en el proyecto definitivo [fig. 6.50].

Al dimensionar cada una de las partes y estudiar particularmente las condiciones de orientación y de vistas sobre el paisaje más convenientes, el paralelismo, la simetría y el orden radial previamente establecidos desaparecen, diluyéndose las relaciones geométricas de conjunto [fig. 6.51].Tal y como Aalto describe en la memoria del proyecto " $A$ cada ala diferente se le asigna una posición especial en el paisaje, de acuerdo a las demandas de las estancias. (...) Por consiguiente, la dirección de cada una de las alas ha sido exactamente definida" ${ }^{\prime 52}$.

Analiza así un conjunto edificado constituido por partes que se agrupan en recintos divergentes, cuyas posiciones de los focos de convergencia no sigue ninguna alineación ni responde a ningún orden jerárquico o beuxartiano [fig. 6.52].

Para resolver los giros sin alterar la forma de cada parte quiebra los elementos de comunicación que los ata [fig. 6.53], una solución ya adoptada en el siglo XIX en ciertos hospitales de tipo espina de pez como el Hospital Stuivemberg de Amberes (1878 y 1885) constituido por elementos girados [fig. 6.54]. Así, el proyecto del sanatorio de Paimio que inicialmente parte de una estructura unitaria en forma $T$ se va aproximando a modelos opuestos propios de los sanatorios de pabellones, al ser éste un conjunto articulado de

${ }^{50}$ Göran SCHILDT (ed.), Alvar Aalto de palabra y por escrito (Alvar Aalto. In his own words, 1997), El Croquis Editorial, Madrid 2000, p. 98.

${ }^{51}$ Antón CAPITEL, La arquitectura compuesta por partes, Gustavo Gili, Barcelona 2009, p. 167.

52 "Each different wing has been given a special position in the landscape, according to the demands of the rooms. (...) Consequently, the direction of each wing has been exactly defined". Alvar AALTO, "Tuberculosis Sanatorium at Paimio/Paimio Hospital", "Varsinais-Suomen Tuberkuloosiparantola. Rakennusteknillinen selostus"(1933), en Tuberkuloosiparantola, Paimio, Alvar Aalto- Museo Jyväskylä, 2004. 

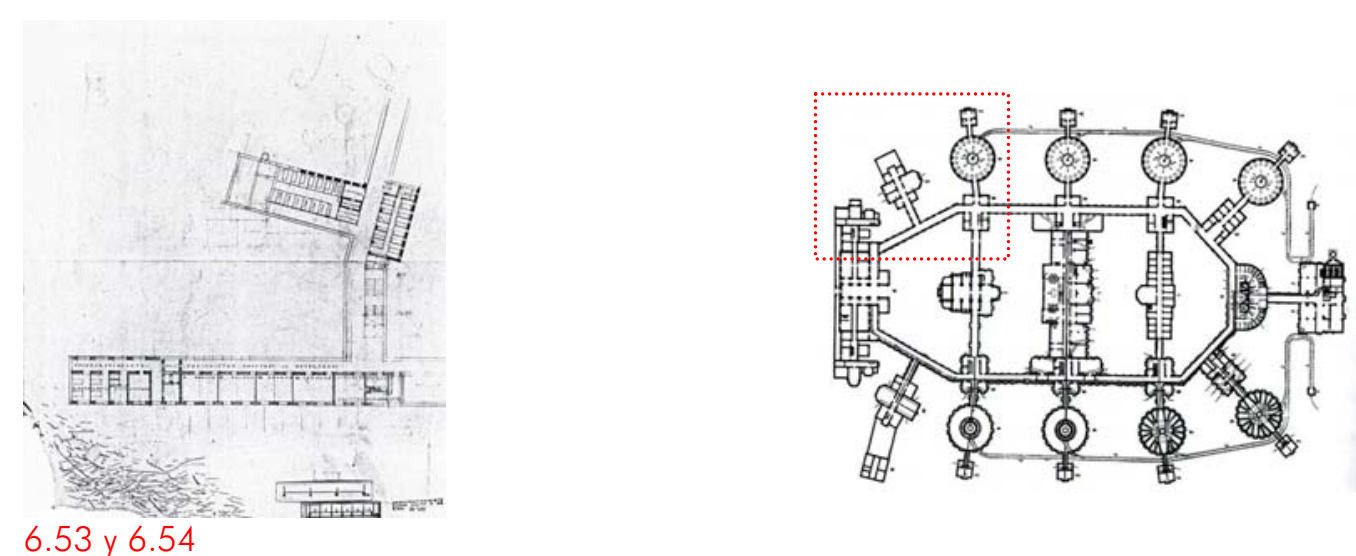

6.53 y 6.54
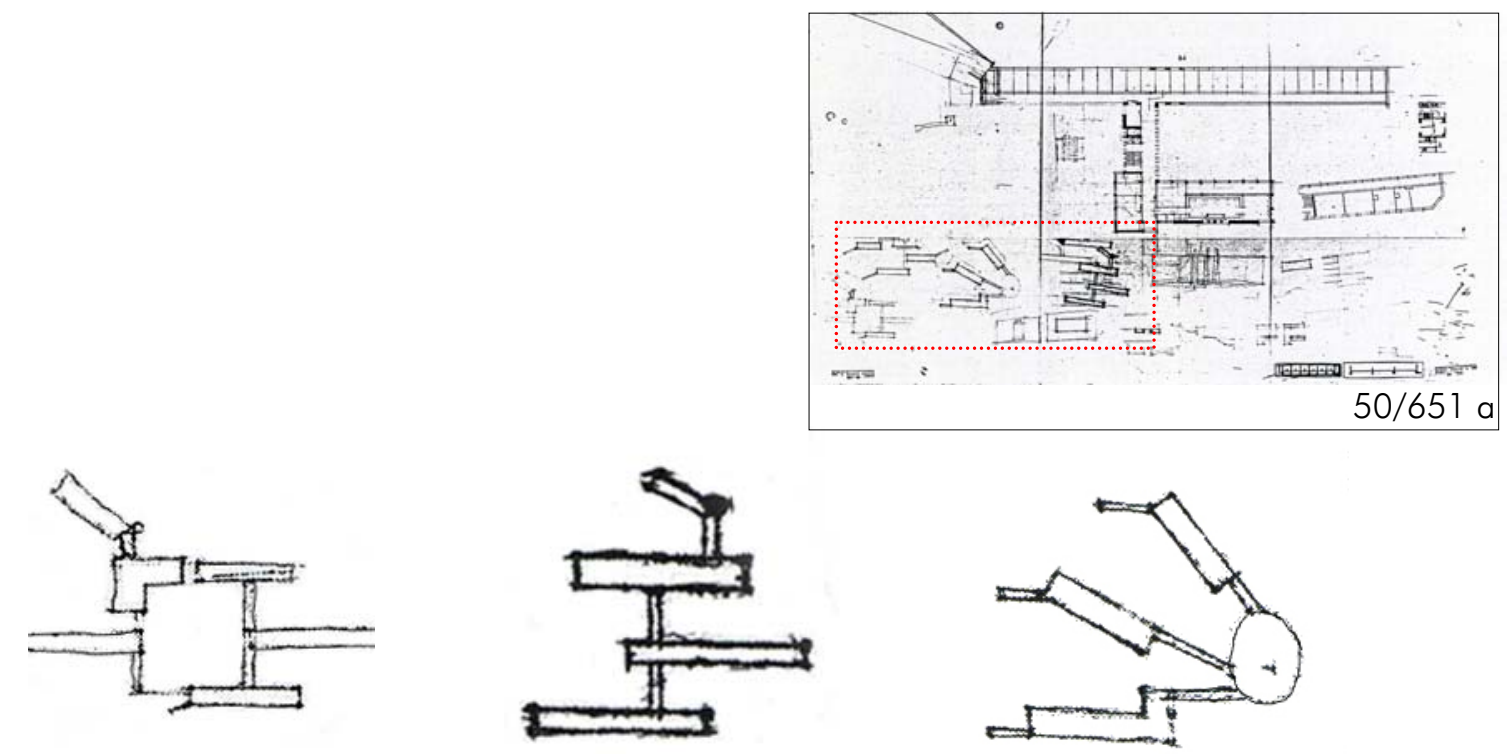

\subsection{5}
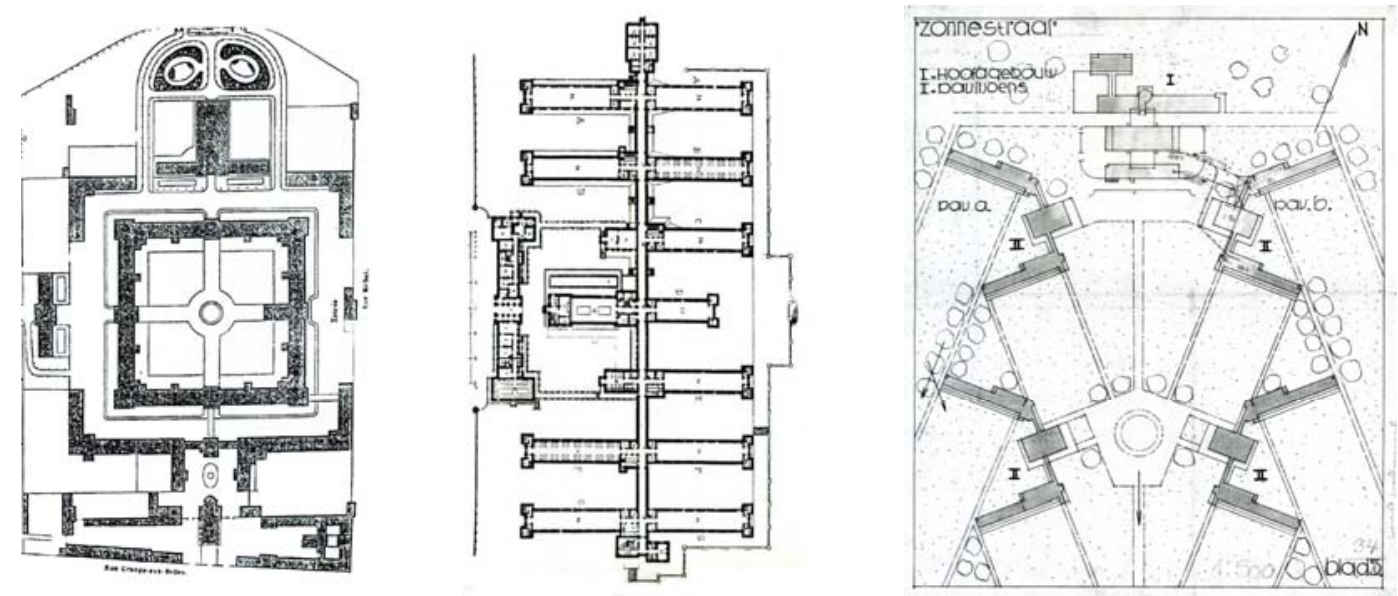

$6.56,6.57$ y 6.58

6.53 A. Aalto. Proyecto del concurso del sanatorio de Paimio, Turku, 1929 (50/647). Detalle en planta de la articulación de las partes.

6.54 Hospital Stuivemberg, Amberes, 18781885.

6.55 A. Aalto. Proyecto del concurso del sanatorio de Paimio, Turku, 1929. Fragmento del boceto

$50 / 651$ a. Tipologías direccionales, centrales y radiales aplicadas a la construcción por partes.

6.56 C. de Chastillon y C. Villefaux. Hospital Saint Louis, París, 1607.

6.57 Hospital Herbert, Londres, 1864.

6.58 J. Duiker y B. Bijvoet. Sanatorio de Zonnestraal, Hilversum, p. 1926 o. 1931. 
partes independientes giradas entre sí y ensartadas por un corredor ${ }^{53}$.

Aalto reflexiona gráficamente en sus bocetos sobre las organizaciones espaciales prístinas, descritas por C. Martí Arís como: "Direccionalidad y centralidad, camino y lugar "54 siguiendo las interpretaciones de Norberg-Schulz sobre el espacio existencial y los esquemas elementales de organización ${ }^{55}$, y trata de aplicar similares principios a su estructuración arquitectónica de partes.

La organización central y por partes se había aplicado a la arquitectura hospitalaria en el siglo XVII en el hospital francés Saint Louis de 1607 [fig. 6.56] donde el modelo claustral se fragmenta manteniendo su configuración central. Del mismo modo, la organización longitudinal aplicada a un conjunto de partes o barracones había provocado la aparición de los hospitales de pabellones ingleses tipo espina de pez como el Hospital Herbert de 1864 [fig. 6.57]. Duiker, en cambio, en Zonnestraal [fig. 6.58] propone un nuevo orden central al pasar del claustro a la forma abierta mediante la organización radial, organización que Aalto asume inicialmente en el proyecto de Paimio y que se mantiene, gracias a sus recintos fugados en forma de $U$, que pese a estar abiertos conservan parte de su identidad claustral.

Ante dicha disposición Paimio puede ser entendido como el resultado de la unión de las partes agrupadas en recintos abiertos que convergen en distintos focos. Su forma procede de primar, por encima del establecimiento de un orden geométrico general, las necesidades arquitectónicas específicas de los programas desarrollados en cada una de sus cinco partes y las relaciones compositivas de la arquitectura y el paisaje en cada uno de sus tres recintos [fig. 6.61].

La evolución formal descrita en el proceso seguido por Aalto en la definición de la forma definitiva del proyecto del sanatorio de Paimio [fig. 6.59] confirma la teoría biológica con que describe el acto de proyectar:

"(...) la arquitectura y sus detalles pertenecen, de algún modo, a la Biología. Tal vez se parecen, por ejemplo, a un gran salmón o a una trucha. No nacen adultos, (...).

${ }^{53}$ Göran Schildt dice que: "en aquellos tiempos, Aalto estaba tan convencido del valor de las soluciones parciales que pensaba escribir un libro sobre "la arquitectura no-sintética'". Göran SCHILDT (ed.), Alvar Aalto de palabra y por escrito (Alvar Aalto. In his own words, 1997), El Croquis Editorial, Madrid 2000, p. 98.

${ }^{54}$ Carlos MARTÍ ARÍS, Las variaciones de la identidad. Ensayos sobre el tipo en arquitectura, Serbal, Barcelona 1993, p. 58.

${ }^{55}$ Christian NORBERG-SCHULZ, Existencia, Espacio y Arquitectura. Editorial Blume, Barcelona 1975, p. 20. 


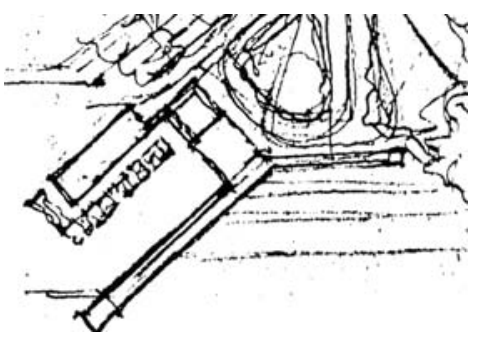

f.) $50 / 638$
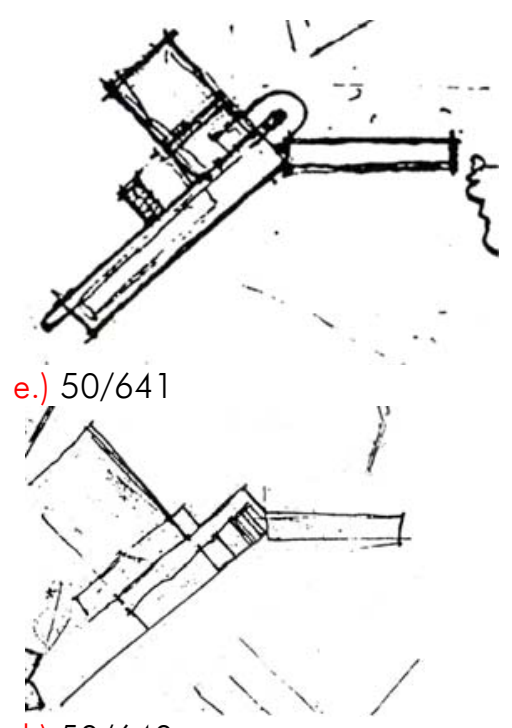

d.) $50 / 640$
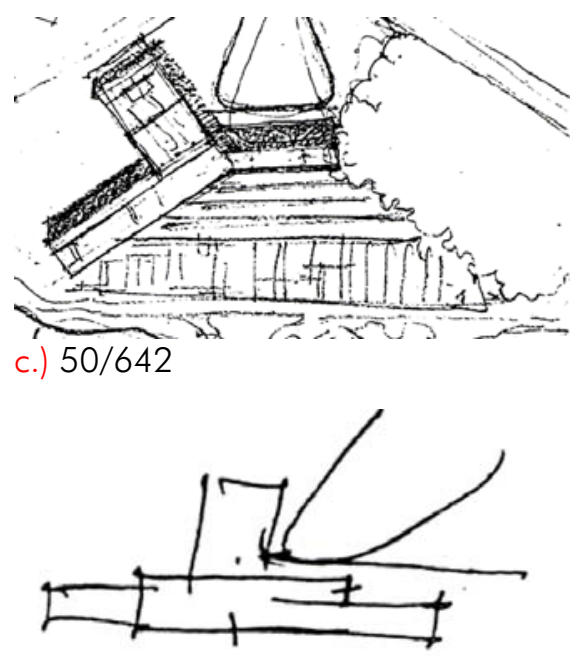

b.) $50 / 642$

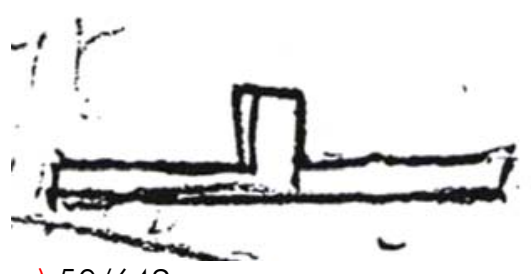

a.) $50 / 642$

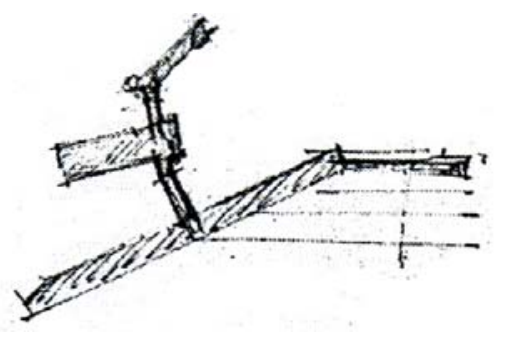

I.) $50 / 644 \mathrm{~b}$

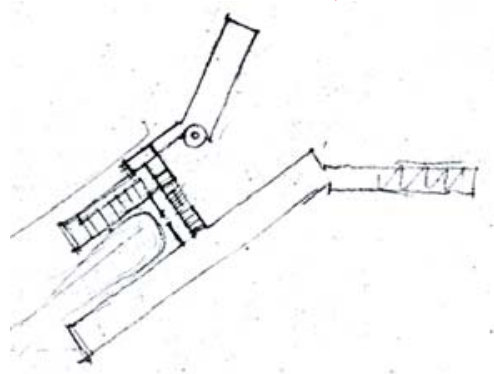

k.) $50 / 646$ b

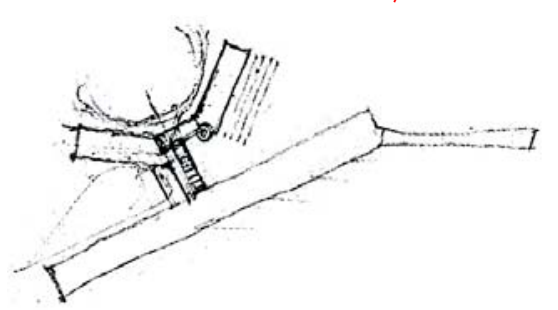

i.) $50 / 646 a$

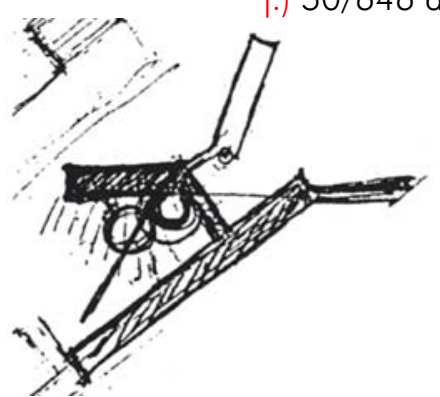

i.) $50 / 643$

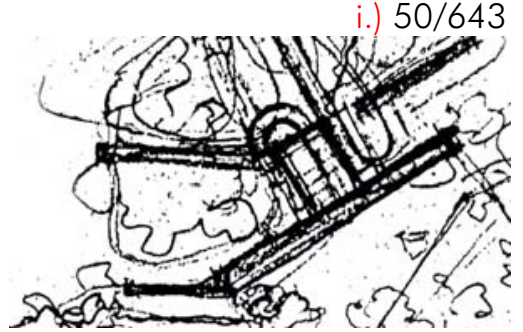

h.) $50 / 639$

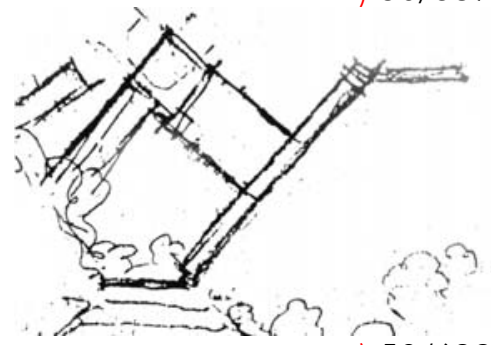

g.) $50 / 639$ 
De igual forma que el desarrollo de una minúscula hueva en un organismo adulto toma su tiempo, se precisa tiempo para todo lo que evoluciona y cristaliza en nuestra mente. La arquitectura necesita aún más tiempo que otras labores creativas. De mi propia experiencia personal puedo mencionar cómo de un juego aparente con las formas ha resultado, inesperadamente, después de largo tiempo, la germinación de una forma arquitectónica práctica" ${ }^{56}$

A pesar de su entronque tipológico, en Paimio no se asume ninguna configuración a priori. Su forma final compuesta por partes responde a un "tipo universal", ya que es el resultado de la aplicación de un método de proyecto o "sistema" aplicable a cualquier programa y época, en el que se trata de resolver las necesidades específicas del mismo por separado, como ya se propuso en el primer sanatorio antituberculoso pulmonar para la cura de reposo, el Sanatorio de Falkenstein del Dr. Dettweiler proyectado en 1874, edificio también compuesto por partes. Quizás, como expone A. Capitel:

"Podría pensarse que la composición por partes o elementos es connatural al proyecto arquitectónico, ya que responde de forma inmediata a la satisfacción de un programa; de ser así, este sistema habría estado presente en muchos períodos de la historia (...), y también se podría creer que dicho método subsistiría para siempre" ${ }^{\prime \prime 7}$.

De ser así habría que añadir que la forma de Paimio responde además al "principio biológico de la construcción" de Aalto, pues está constituida por unidades básicas de similares características, o células, que se agrupan formando partes independientes; no obstante, éstas a su vez se conectan entre sí siguiendo una ley de crecimiento acumulativo, inspirada en el mundo natural. Se representan aquí dos conceptos antagónicos de la biología aplicados a la arquitectura, por un lado la fragmentación del programa en unidades y por otro la agrupación del mismo en pos de una cierta continuidad, como Frederick Kiesler explica en su artículo "L'architecture comme biotechnique" en Architectural Record (1939): "La naturaleza y el ser humano están sometidas a dos principios diferentes: la construcción por división celular pero con el propósito de continuidad; no se puede

\footnotetext{
${ }^{56}$ Alvar AALTO, "La trucha y el torrente de montaña" ("Taimen ja tunturipuro") Arkkitehti n ${ }^{0}$ 7/10 (1948), en Göran SCHILDT (ed.), Alvar Aalto de palabra y por escrito (Alvar Aalto. In his own words, 1997), El Croquis Editorial, Madrid 2000, p. 150.

${ }^{57}$ Antón CAPITEL, La arquitectura compuesta por partes. Gustavo Gili, Barcelona 2009, p.7.
} 


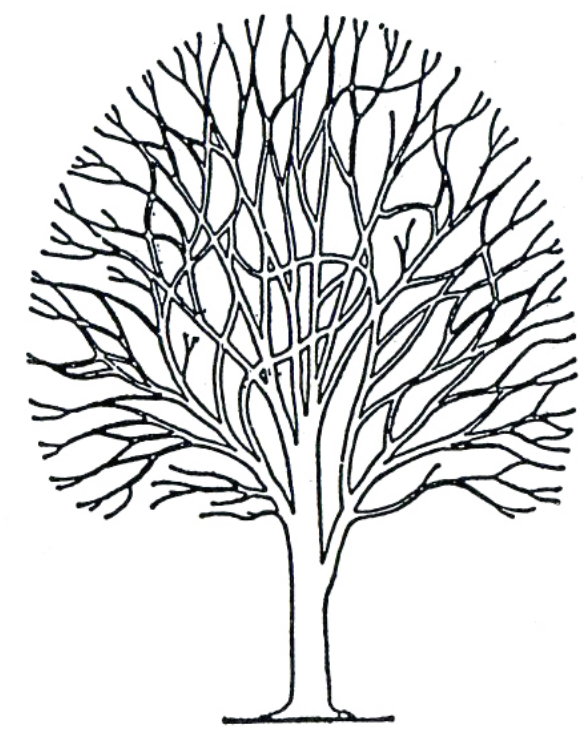

6.60

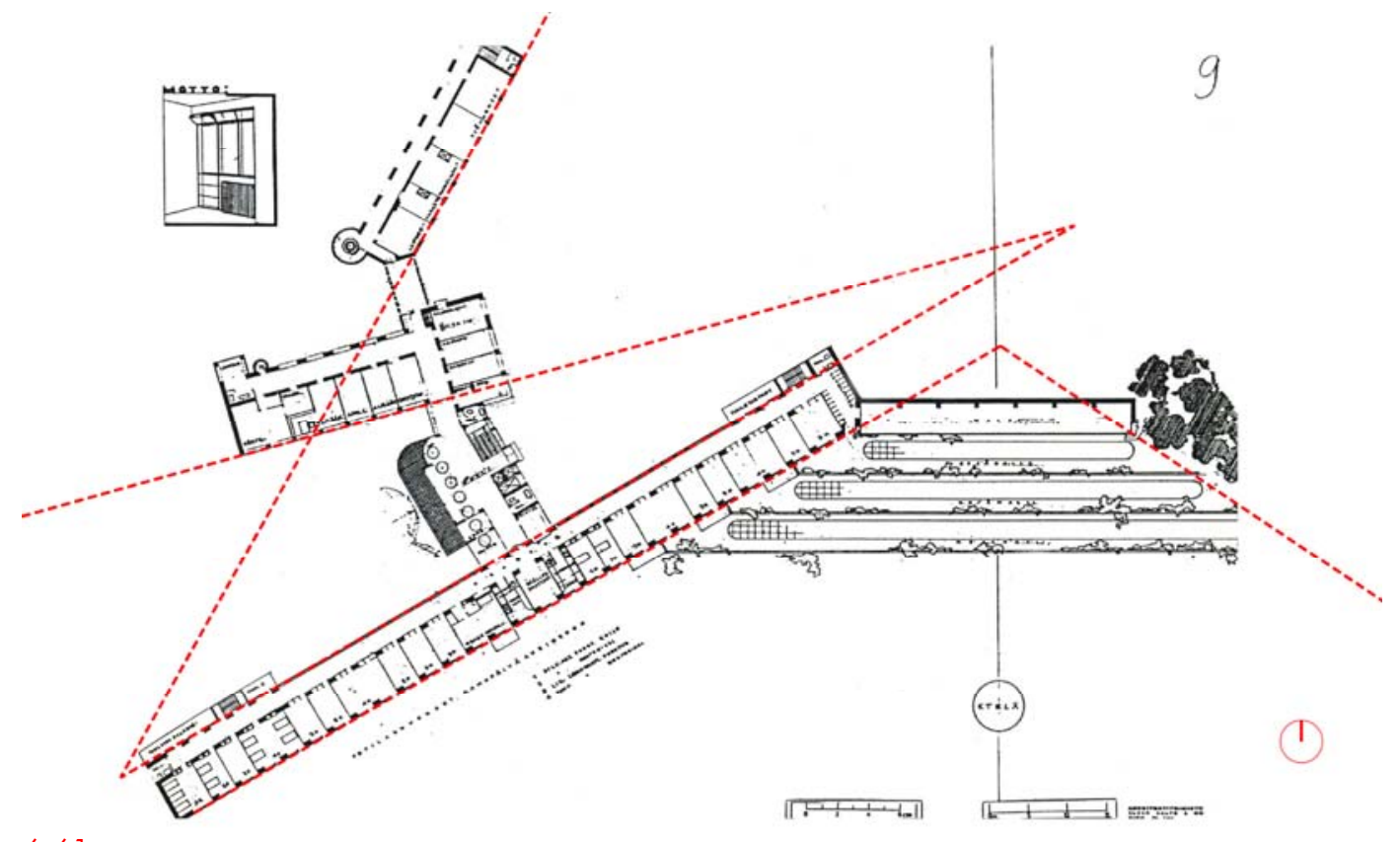

6.60 A. L. Kroeber. Árbol de la filogenia cultural, 1923.

6.61 A. Aalto. Proyecto del concurso del sanatorio de Paimio, Turku, 1929. Planta baja del proyecto presentado a concurso (análisis de la autora). 
construir el hombre sin la reunión de partes en una estructura única, sin continuidad" 58 .

Se obtiene con ello un conjunto heteróclito, resultado de un proceso creativo en el que se produce un mestizaje tipológico, donde los trazados reguladores de las partes que lo integran [fig. 6.61], como las ramas del árbol de la filogenia cultural de Alfred L. Kroeber ${ }^{59}$ [fig. 6.60], "se mezclan y entrecruzan, divergen para luego converger nuevamente y restituyen una figura laberíntica que simboliza los mecanismos de la creación humana" ${ }^{60}$.

\section{EL HOGAR DEL ENFERMO EN EL SANATORIO: LA UNIDAD DE ENFERMERÍA}

Durante su primer viaje a Italia, Aalto llega a desarrollar una auténtica obsesión por la forma de implantación de las ciudades italianas sobre las colinas:

"La 'ciudad ascendente' ha llegado a significar para mí algo parecido a una religión, una enfermedad o una locura. La ciudad de las colinas, con sus vivas líneas onduladas, siguiendo una insospechada trayectoria, desconocida hasta para los matemáticos, es para mí la encarnación de la diferencia entre la mecanización brutal de la vida -cuya plasmación en el mundo moderno es la fealdad imperante- y la belleza religiosa." ${ }^{61}$

Aalto durante la elaboración de los planos del proyecto del concurso estudia la localización del Sanatorio de Paimio y no duda en ubicarlo en lo alto de una pendiente, no en la cima, sino en una meseta natural situada en el centro de la parcela a una cota de $32 \mathrm{~m}$. por encima de la ribera existente al sur de la finca [fig. 6.62]. Al asentar el Sanatorio elevado, la edificación se adapta a las irregularidades del terreno, cumpliendo la premisa de que "Todo lo nuevo que añadamos a nuestro suelo patrio ha de hacerse de manera que no deteriore sino, al contrario, que ennoblezca nuestro paisaje nunca antes dañado" 62 [fig. 6.63-fig. 6.65].

58 "La nature et l'homme relèvent de deux principes différents: la construit par division cellulaire dans un but de continuité; l'homme ne peut construire que par la réunion de parties en une structure unique, sans continuité". Citado en Jaen-Pierre CHUPIN, Analogie et Théorie en Architecture. De la vie, da la ville et de la conception, même. Infolio, Genève 2010, p.101.

59 Alfred L. KROEBER, Antrpology. Race, language, cultura, psycology, prehistory (London, 1923). Harcourt, New York 1948, p. 260.

60 Carlos MARTÍ ARÍS, Las variaciones de la identidad. Ensayos sobre el tipo en arquitectura. Ediciones del Serbal, Barcelona 1993, p. 53.

${ }^{61}$ Alvar AALTO, "Geografía del problema de la vivienda" ("Arkitektur och samhälle"), Prisma, 1932, en Göran SCHILDT (ed.), Alvar Aalto de palabra y por escrito (Alvar Aalto. In his own words, 1997), El Croquis Editorial, Madrid 2000 El Croquis Editorial, Madrid, 2000, pp.67-68.

62 Alvar AALTO, "La arquitectura en el paisaje de Finlandia Central" ("Keskisuomalainen maiseman rakennustaide"), Sisä-Suomi, 26 de Junio de 1925, en Göran SCHILDT, Alvar Aalto de palabra y por escrito (Alvar Aalto. In his own words, 1997), El Croquis Editorial, Madrid 2000 El Croquis Editorial, Madrid, 2000, p.34. 


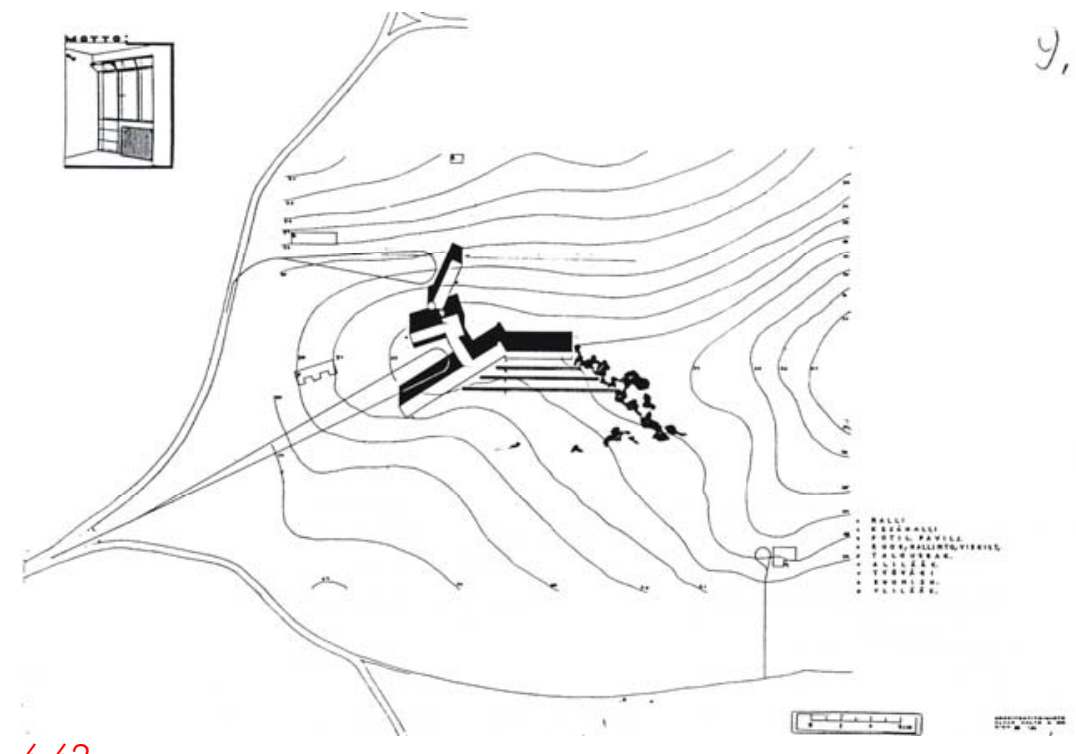

6.62
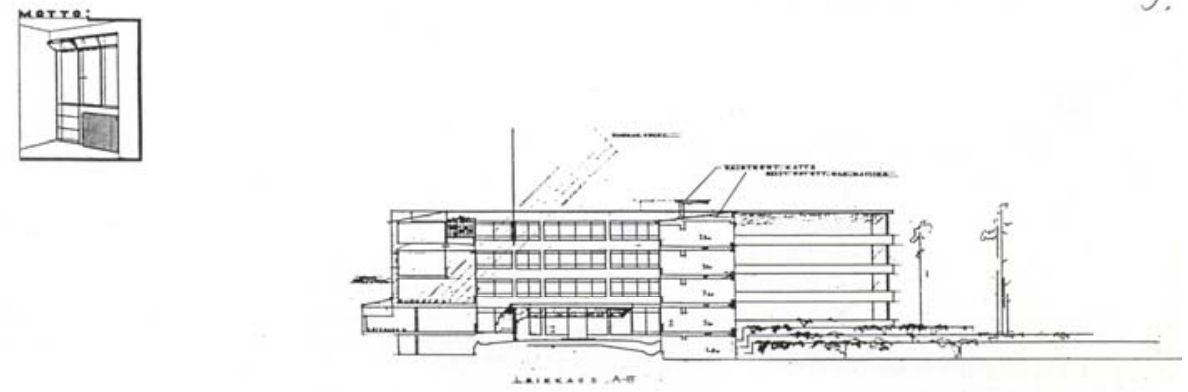

6.63
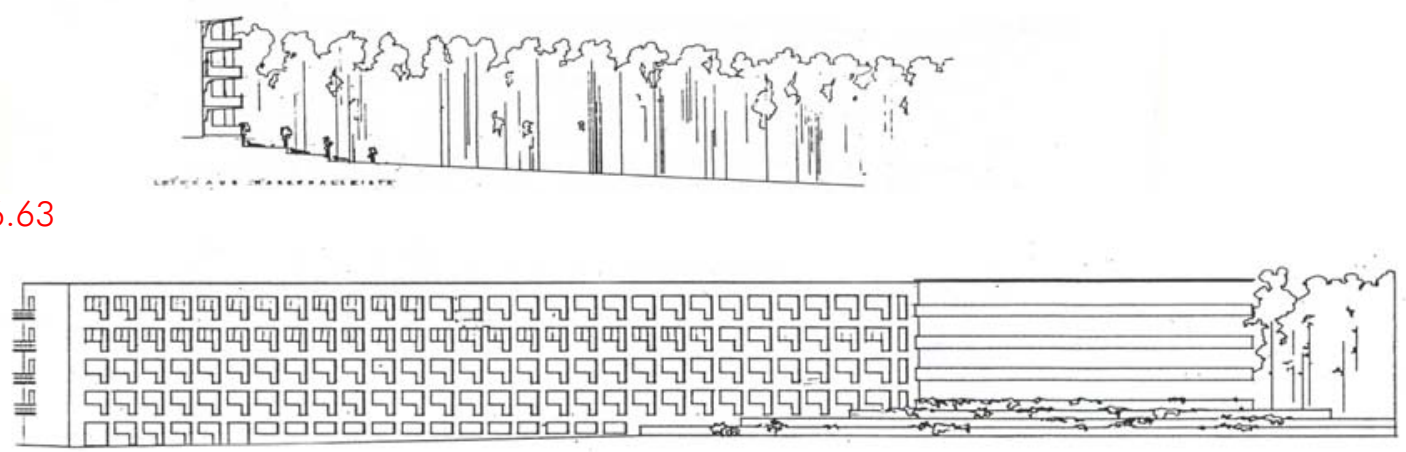

6.64

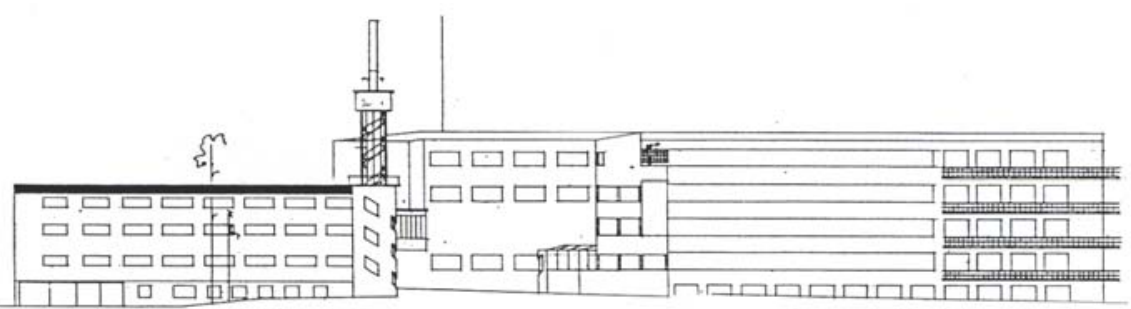

6.65

6.62 A. Aalto. Proyecto del concurso del Sanatorio de Paimio, Turku, 1929. Plano de situación (50/24).

6.63 A. Aalto. Proyecto del concurso del Sanatorio de Paimio, Turku, 1929. Alzado principal y sección por la galería de curas (50/29).

6.64 A. Aalto. Proyecto del concurso del Sanatorio de Paimio, Turku, 1929. Alzado sureste, bloque de habitaciones (50/231).

6.65 A. Aalto. Proyecto del concurso del Sanatorio de Paimio, Turku, 1929. Alzado noroeste, volumen de instalaciones (50/230). 


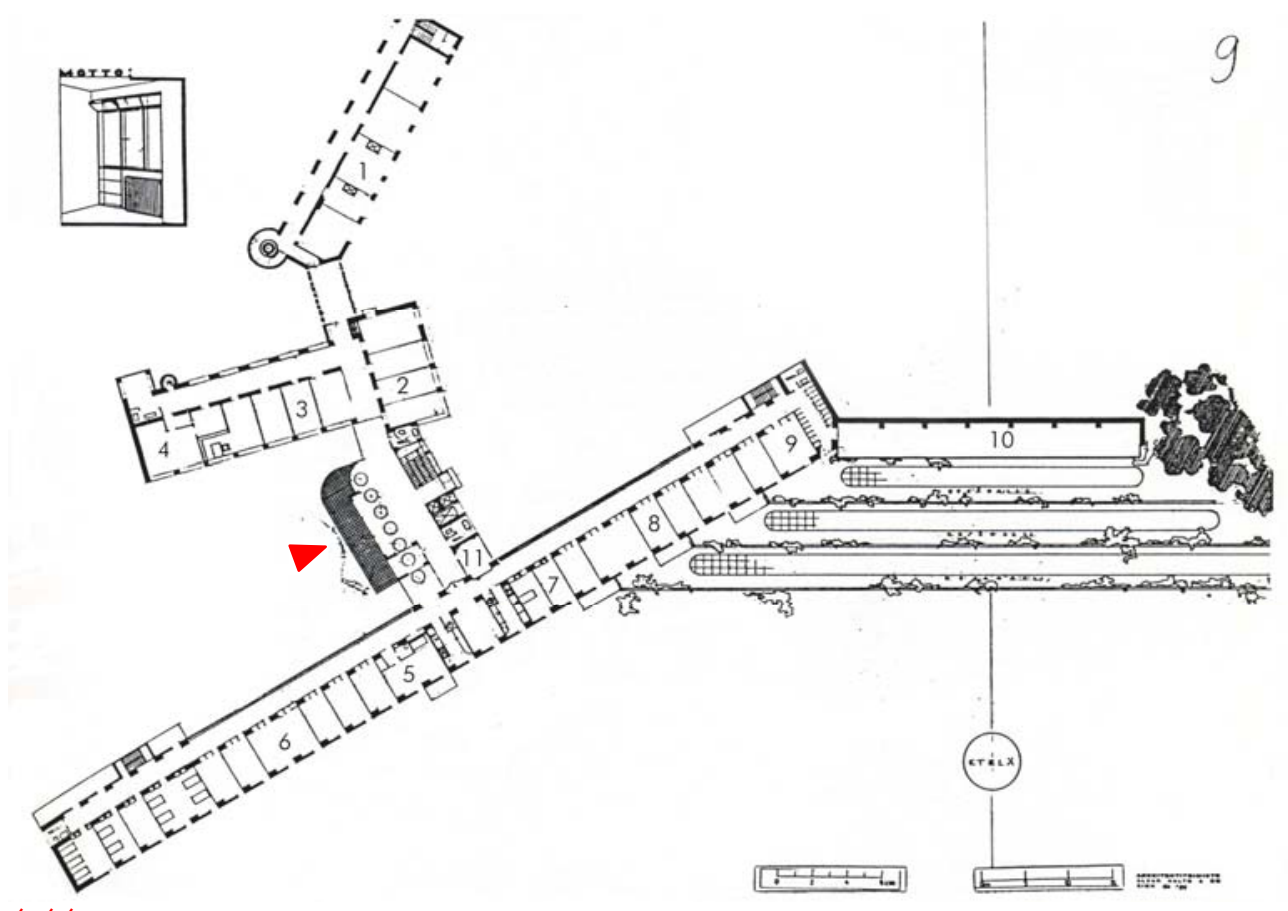

6.66

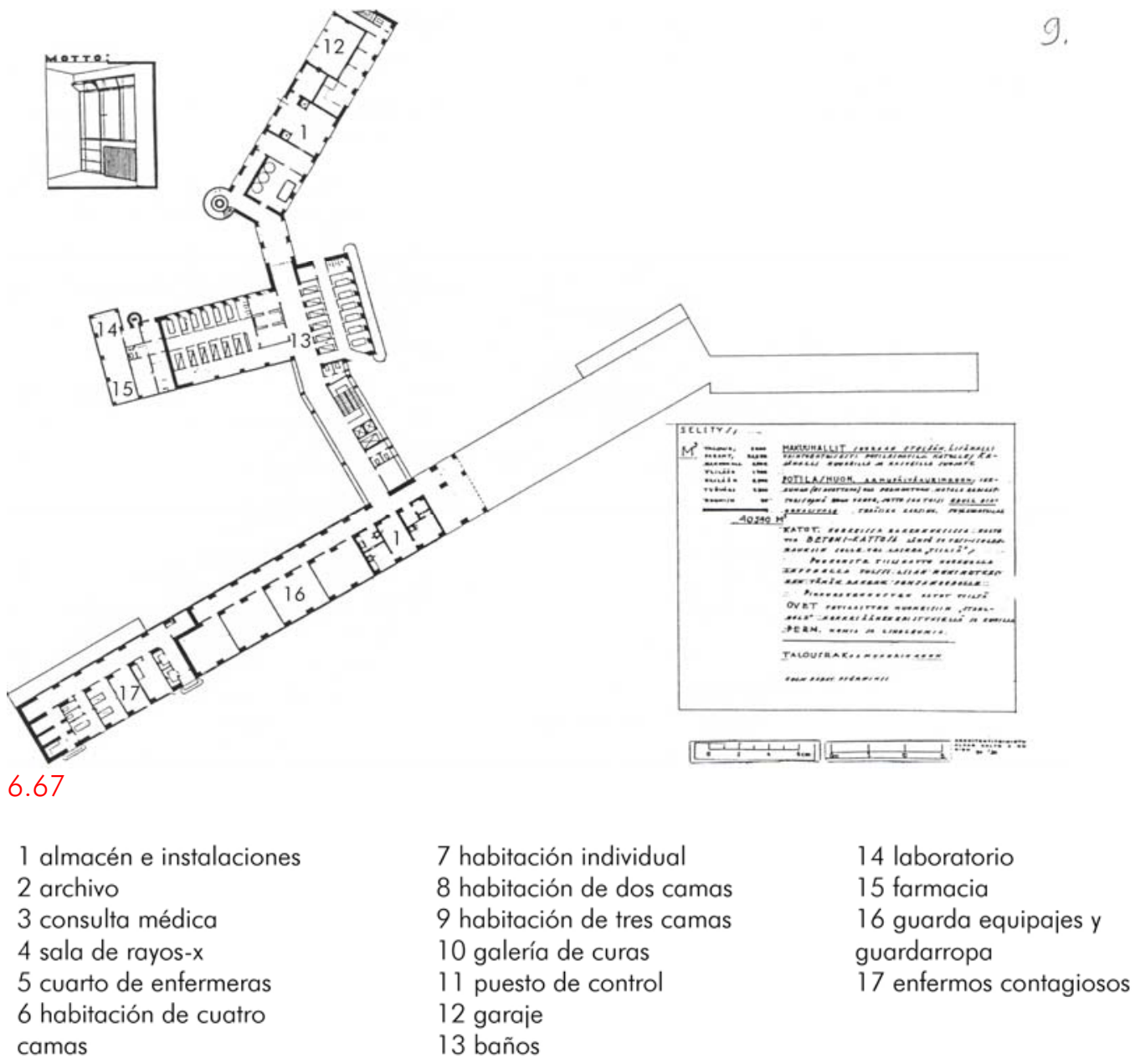

6.66 A. Aalto. Proyecto del concurso del Sanatorio de Paimio, Turku, 1929. Planta baja (50/25).

6.67 A. Aalto. Proyecto del concurso del Sanatorio de Paimio, Turku, 1929. Planta del primer sótano $(50 / 26)$. 

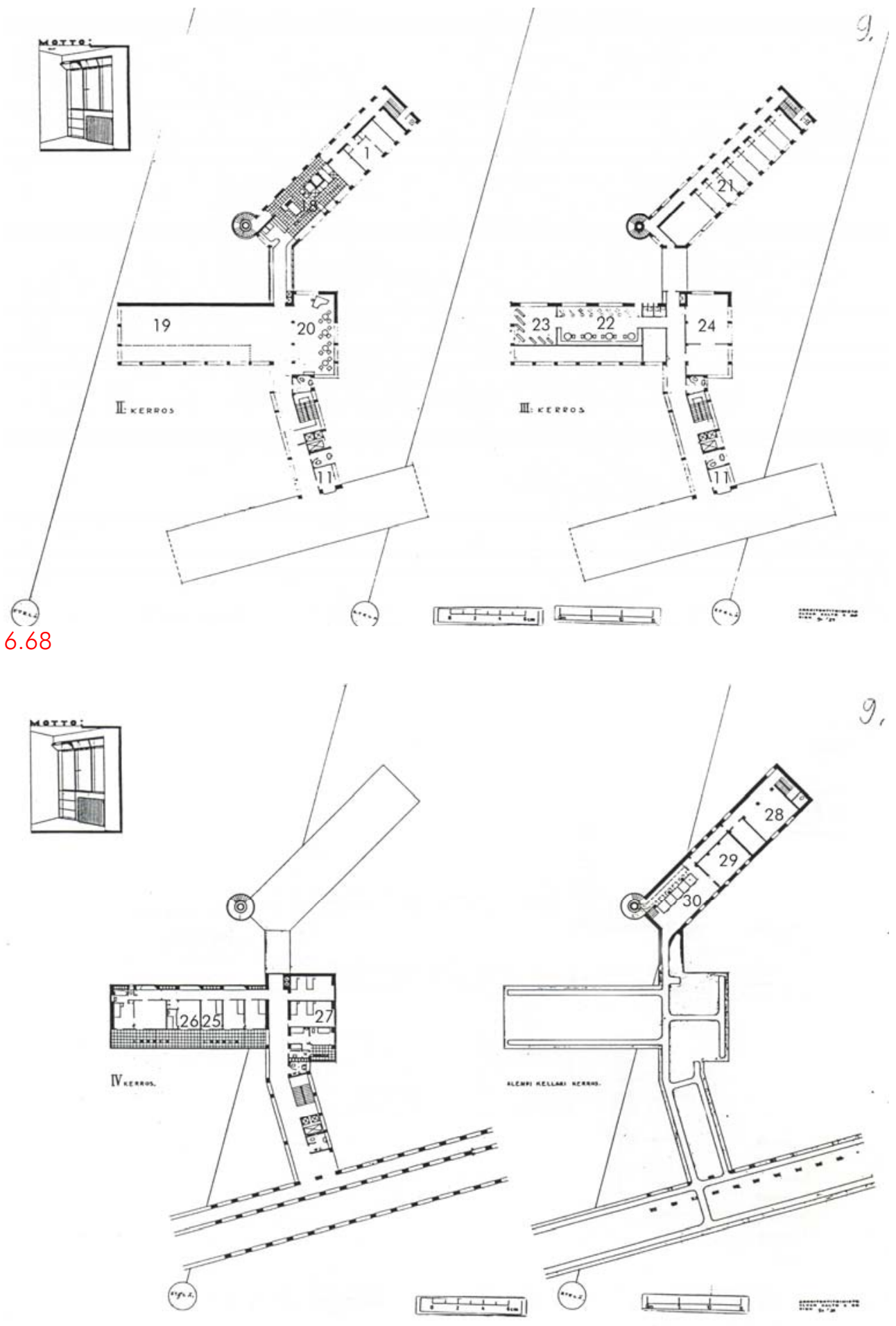

6.69

1 almacén e instalaciones

11 puesto de control

18 cocina

19 comedor

20 salón de enfermos

21 habitaciones de personal
22 sala de lectura

23 biblioteca

24 comedor de enfermeras

25 enfermeras de guardia

26 médico de guardia
27 habitaciones de estudiantes

28 taller de reparación

29 combustible

30 calderas

6.68 A. Aalto. Proyecto del concurso del Sanatorio de Paimio, Turku, 1929. Plantas primera y segunda (50/27).

6.69 A. Aalto. Proyecto del concurso del Sanatorio de Paimio, Turku, 1929. Plantas tercera y segundo sótano (50/28). 
En cada parte que constituye el edificio principal la cota de implantación varía. El volumen de acceso consta de cuatro plantas de altura y un sótano; junto a él se adosa el cuerpo de habitaciones y la galería de curas situados al sureste con la misma altura, sin embargo, la galería de curas carece de sótano y el sótano del cuerpo residencial se convierte en semisótano, incluso en planta baja por la caída del terreno en el que residen los enfermos más graves y en aislamiento.

Al otro lado del acceso se sitúa el volumen de servicios comunes con tres plantas y un semisótano que contiene los baños de los enfermos, entre otras dependencias. Las consultas y la administración se disponen dentro de éste volumen en la planta baja, el comedor en la primera, la biblioteca y la sala de lectura en la segunda y las habitaciones del personal de guardia en la última. Los servicios comunes se conectan con el cuerpo de instalaciones tan sólo en dos niveles, a través del semisótano mediante un paso subterráneo y por una pasarela que comunica el comedor y la cocina en la planta primera.

El cuerpo de instalaciones consta de tres plantas y un semisótano que pasa a transformarse en planta baja, además de un sótano con la sala de calderas. En el semisótano, o planta baja, se localizan parte de las instalaciones y el garaje, la planta superior contiene también almacenes e instalaciones y la siguiente la cocina conectada con el comedor, sobre ella, se encuentran las habitaciones del personal [fig. 6.66-fig. 6.69].

Tras ganar el concurso y firmar el contrato el 28 de junio de $1929^{63}$ [fig. 6.70 y fig. 6.71], el proyecto de Paimio sufre una serie de modificaciones hasta llegar al proyecto definitivo en 1931 y construirse en 1933. El número de camas del sanatorio aumenta de 184 a 296, provocando un crecimiento en altura del cuerpo de habitaciones que pasa de cuatro plantas a seis, además de una séptima planta en la que se incluye una cubierta solario. Crece también la altura de la galería de cura y del vestíbulo, acrecentándose la desigualdad volumétrica de las distintas partes del mismo, de manera que como indica $\mathrm{S}$. Gideon: "Desde cualquier punto de vista el observador halla siempre aspectos nuevos que fortalecen la concepción de 'espacio-tiempo' de este conjunto" ${ }^{64}$ [fig. 6.72].

A causa de las recomendaciones de los miembros del jurado del concurso es preciso llevar a cabo otra serie de cambios. Piensan que los ascensores y la escalera principal son demasiado estrechos, por lo que se amplían y se cambia su posición en el proyecto de

${ }^{63}$ Según los documentos consultados en los archivos de Aalto en Jyväskylä en la Caja Paimio Parantola Dokumentit II.

${ }^{64}$ Sigfried GIEDION, Espacio tiempo y arquitectura (1941). Dossat, Madrid 1982, p.611. 


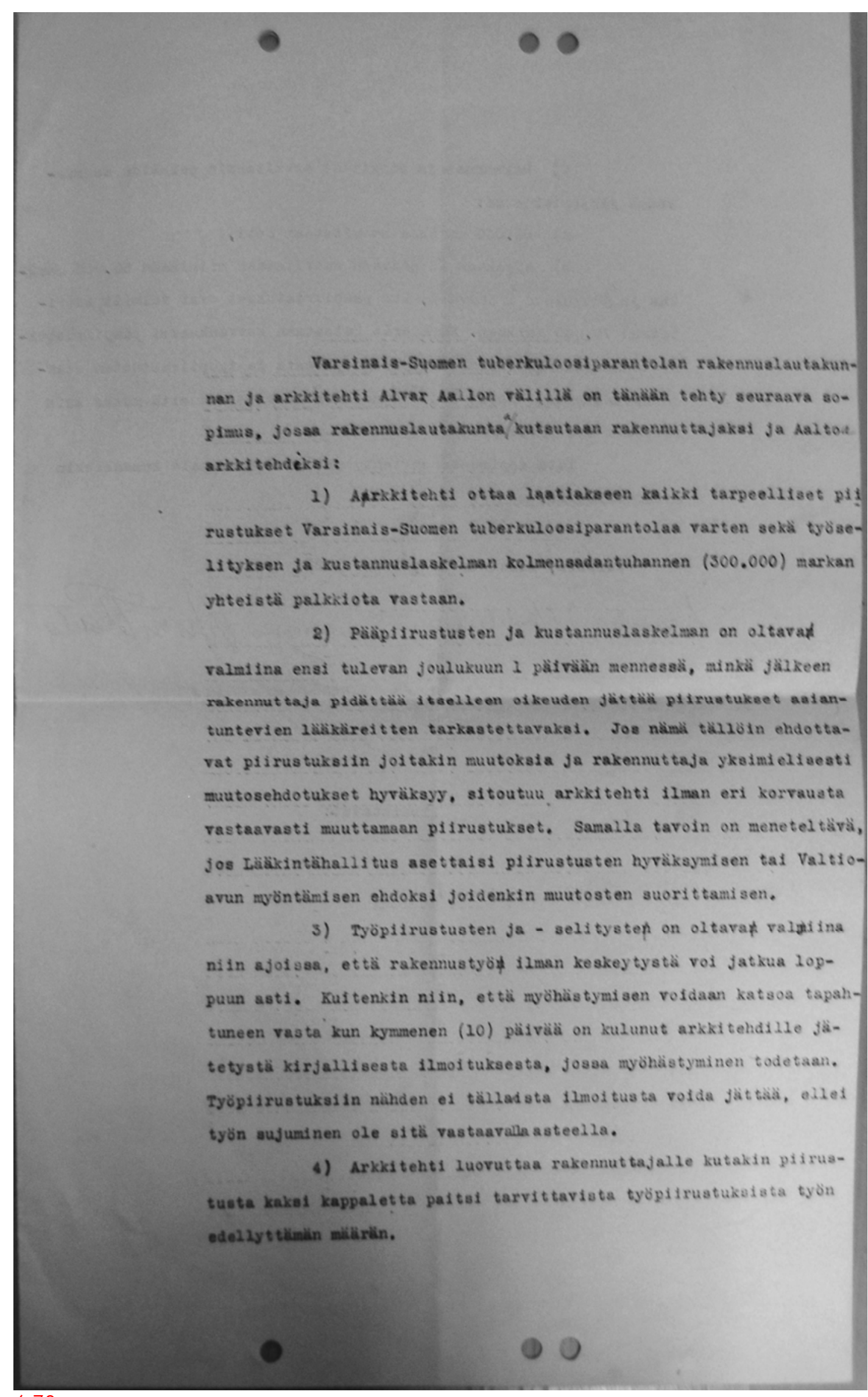

6.70

6.70 Contrato del Sanatorio de Paimio, 1929. (Caja: Paimio Parantola Dokumentit II, Kontrakt, AAA) 


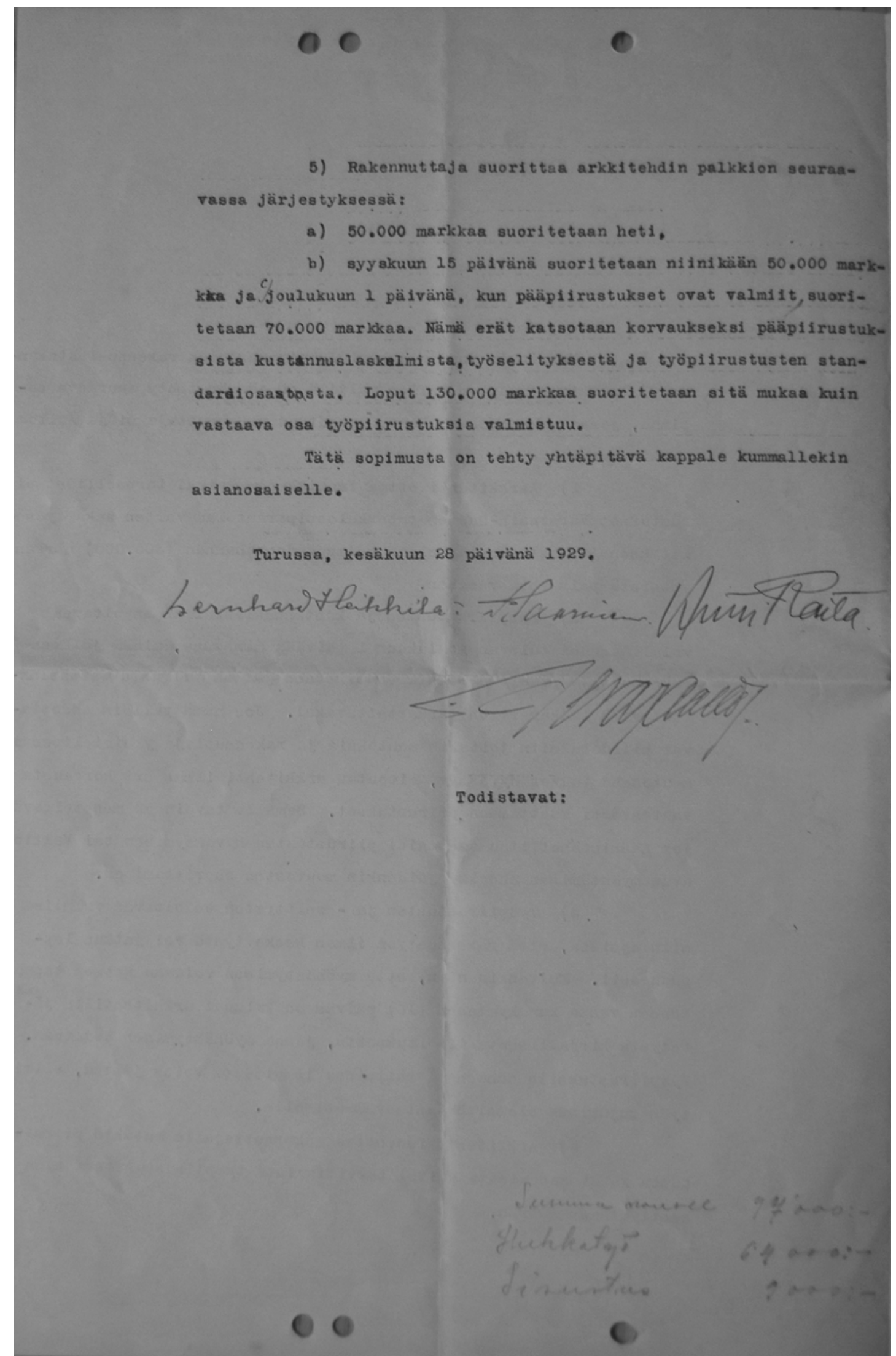

6.71

6.71 Contrato del Sanatorio de Paimio, 1929. (Caja: Paimio Parantola Dokumentit II, Kontrakt, AAA) 

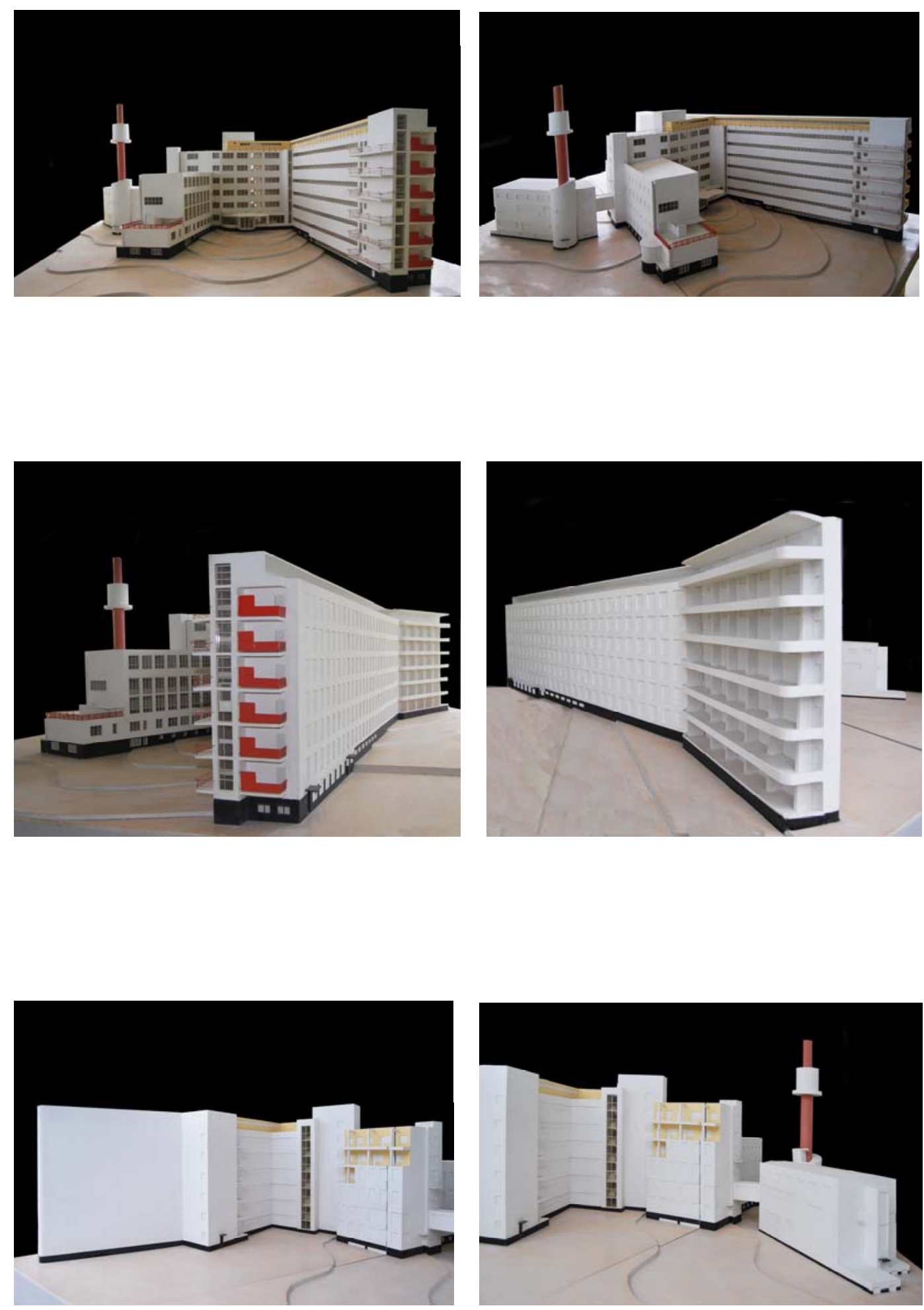

6.72

6.72 A. Aalto. Proyecto del Sanatorio de Paimio, Turku, 1928-1932. Maqueta. 
1931; los baños del semisótano del bloque de servicios comunes son demasiado grandes y se reduce su tamaño; y la farmacia y los laboratorios ubicados en esa misma planta están mal resueltos por lo que son trasladados a la planta baja. En el sanatorio construido en 1933 se incluye un sexto volumen inexistente en el proyecto del concurso, que contiene una central térmica, localizado junto al cuerpo de instalaciones [fig. 6.73].

Dentro del vestíbulo [fig. 6.74], enfrentados a la entrada, Aalto pone dos ascensores de gran tamaño y al lado una escalera de dos tramos que recorre todo el edificio. En el interior del hall hay dos muebles exentos con función de zapatero o taquillero con forma semicircular y de $\mathrm{H}$, y otro más con forma de $\mathrm{L}$ adosado a la pared ${ }^{65}$ que no llegan al techo y dejan ver la secuencia lineal de lucernarios circulares que recorre el vestíbulo en planta baja [fig. 6.75]. En el exterior proyecta una marquesina con forma de ameba y con un corte oblicuo en su extremo que representa, según el personal del hospital, un pulmón cortado o enfermo, convirtiéndose en un cartel por analogía que anuncia la entrada a un sanatorio antituberculoso pulmonar ${ }^{66}$.

El cuerpo de habitaciones anexo es un bloque lineal orientado al sureste compuesto por un corredor lateral, en cuyos extremos se ubican las escaleras de servicio, y una serie de habitaciones, en su mayoría de dos camas, agrupadas en hilera. Cada habitación de dos camas consta de un lavabo para cada enfermo y una escupidera común adosados a la pared que separa la estancia del corredor. Las dos camas se emplazan en sentido transversal mirando a la pared de enfrente donde se encuentran dos armarios independientes uno para cada paciente y, al fondo, enfrentada a la puerta, se sitúa una mesa corrida junto a la ventana. En el extremo oeste del bloque de habitaciones, el más próximo a la vía de acceso, se ubica en cada planta una dependencia para las enfermeras con una pequeña terraza. Aalto proyecta junto a la terraza, situado detrás de la escalera [fig. 6.76], un ascensor panorámico contenido en un volumen acristalado que emerge en la fachada y aporta dinamismo al testero, el cual, al ser el frente más adelantado del Sanatorio se convierte en la primera imagen del mismo que se percibe en la llegada [fig. 6.77]. Una imagen tecnológica y moderna, afín a la estética maquinista defendida por los constructivistas rusos, que recuerda al proyecto del concurso para el periódico Pravda de los

\footnotetext{
${ }^{65}$ Dicho mobiliario en la actualidad se ha modificado y se ha incluido una sala de control acristalada que llega hasta el techo.

${ }^{66}$ Esta marquesina sustituye a una propuesta que había sido realizada anteriormente, presente en el proyecto presentado a concurso, que consiste en un fragmento de anillo tangente a la fachada cuya parte cóncava se despega de la misma.
} 


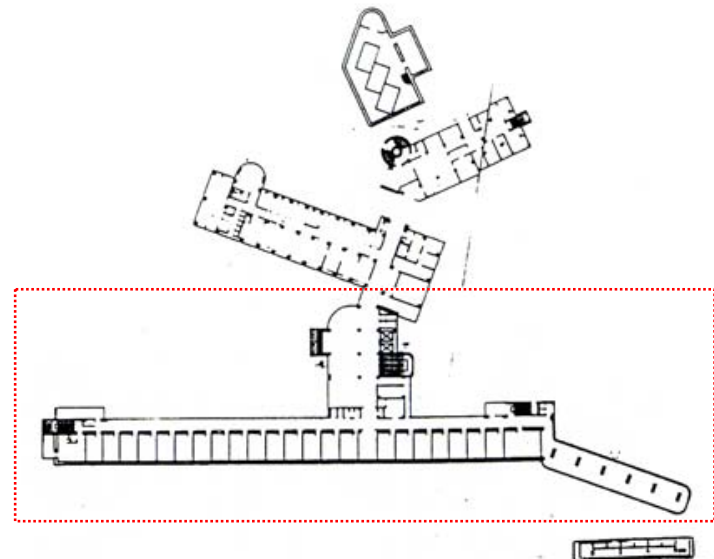

6.73

एक्षक्य

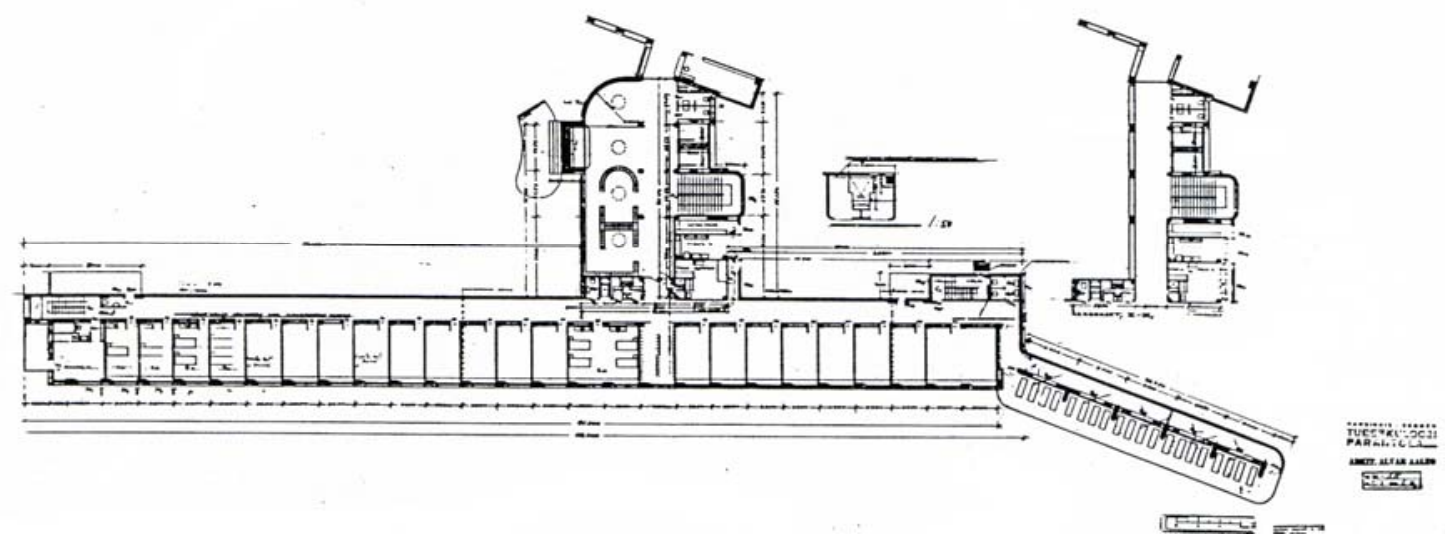

6.74

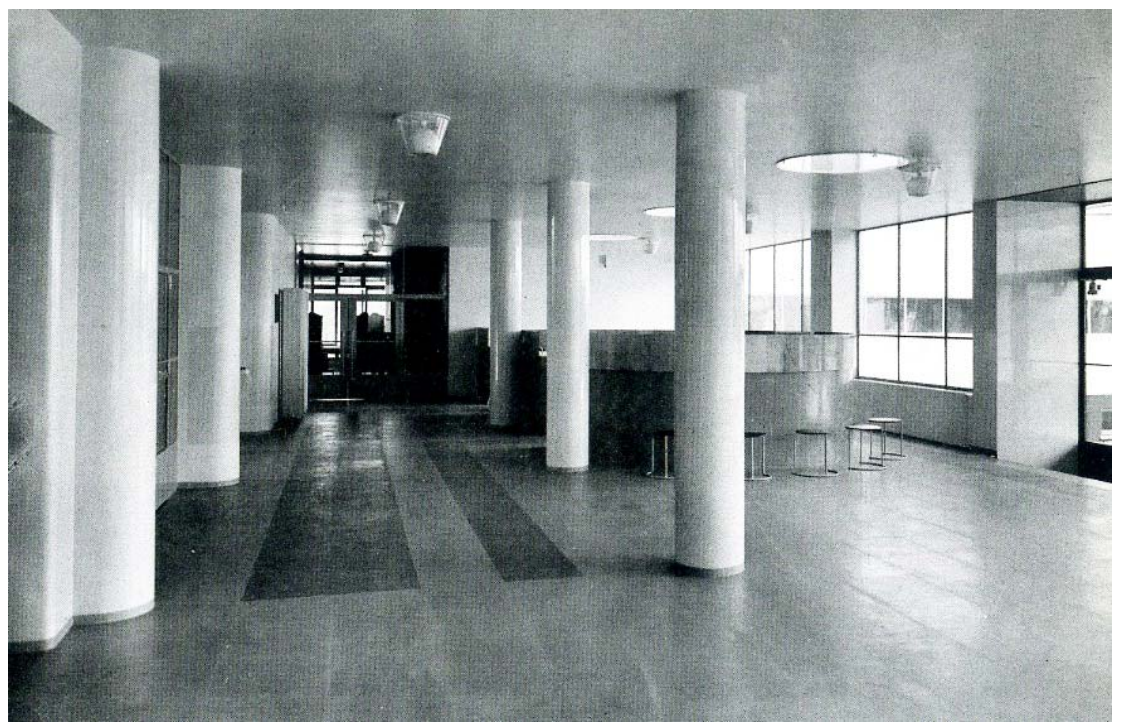

6.75

6.73 A. Aalto. Sanatorio de Paimio, Turku, p. 1928-1932. Plano de situación (50/57).

6.74 A. Aalto. Sanatorio de Paimio, Turku, p. 1928-1932. Planta baja 1930 (50/59).

6.75 A. Aalto. Sanatorio de Paimio, Turku, p. 1928-1932. Vestíbulo. 

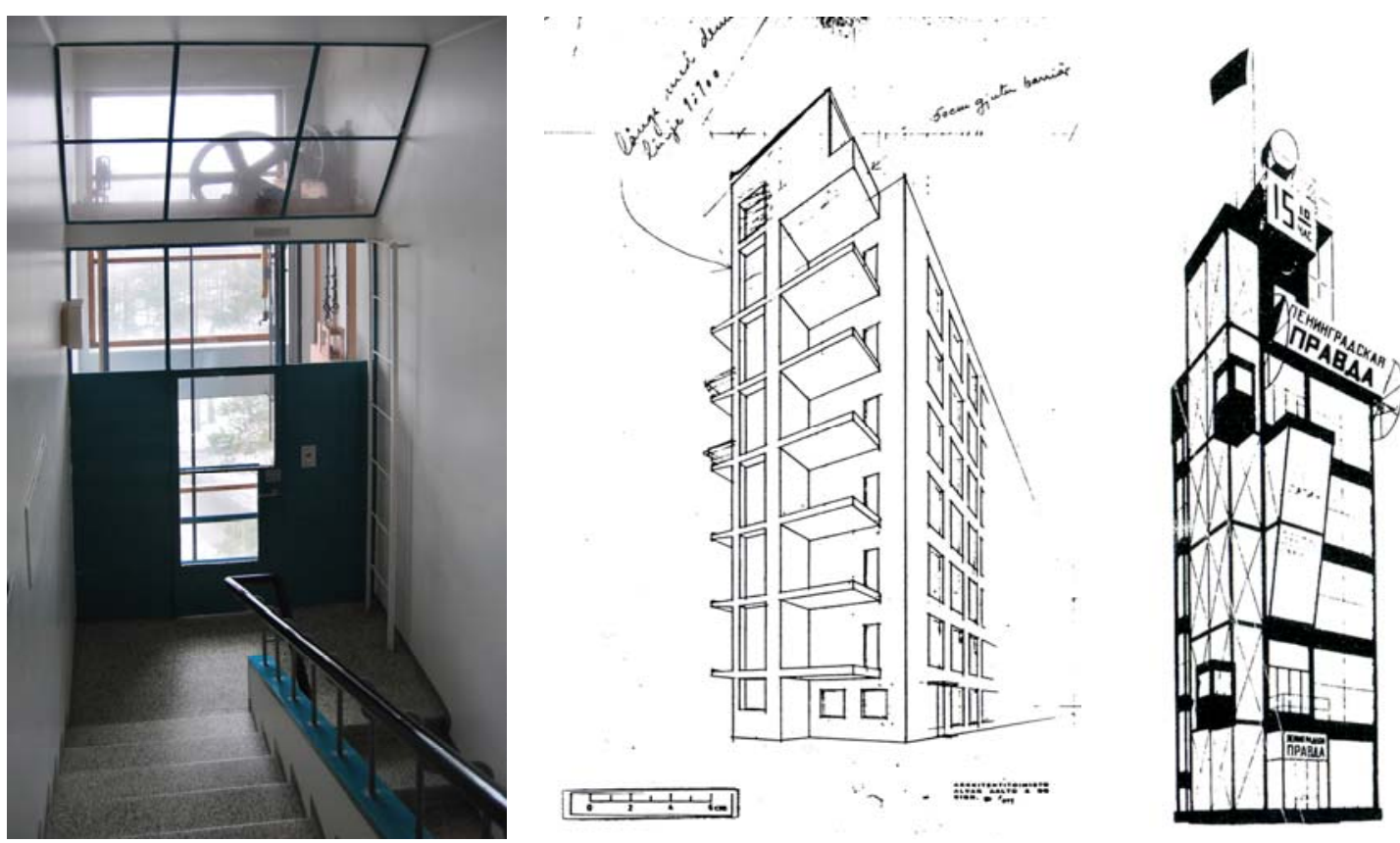

$6.76,6.77$ y 6.78
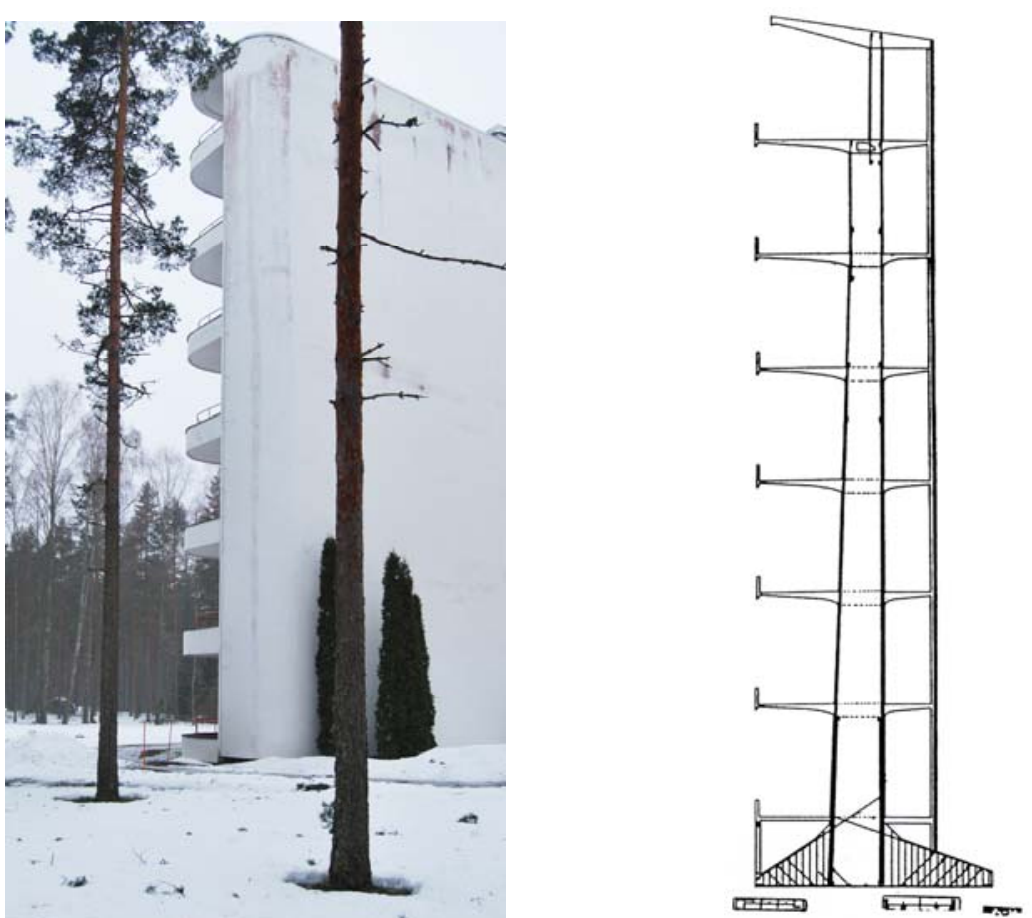

6.79 y 6.80

6.76 A. Aalto. Sanatorio de Paimio, Turku, p. 1928-1932. Ascensor panorámico (fotografía de la autora).

6.77 A. Aalto. Sanatorio de Paimio, Turku, p. 1928-1932. Perspectiva del testero del bloque de habitaciones $(50 / 111)$.

6.78 Hermanos Vesnin. Proyecto del concurso para el periódico Pravda, 1924. Perspectiva.

6.79 A. Aalto. Sanatorio de Paimio, Turku, p. 1928-1932. Perfil de la galería de cura (fotografía de la autora).

6.80 A. Aalto. Sanatorio de Paimio, Turku, p. 1928-1932. Sección de la galería de cura (50/155). 

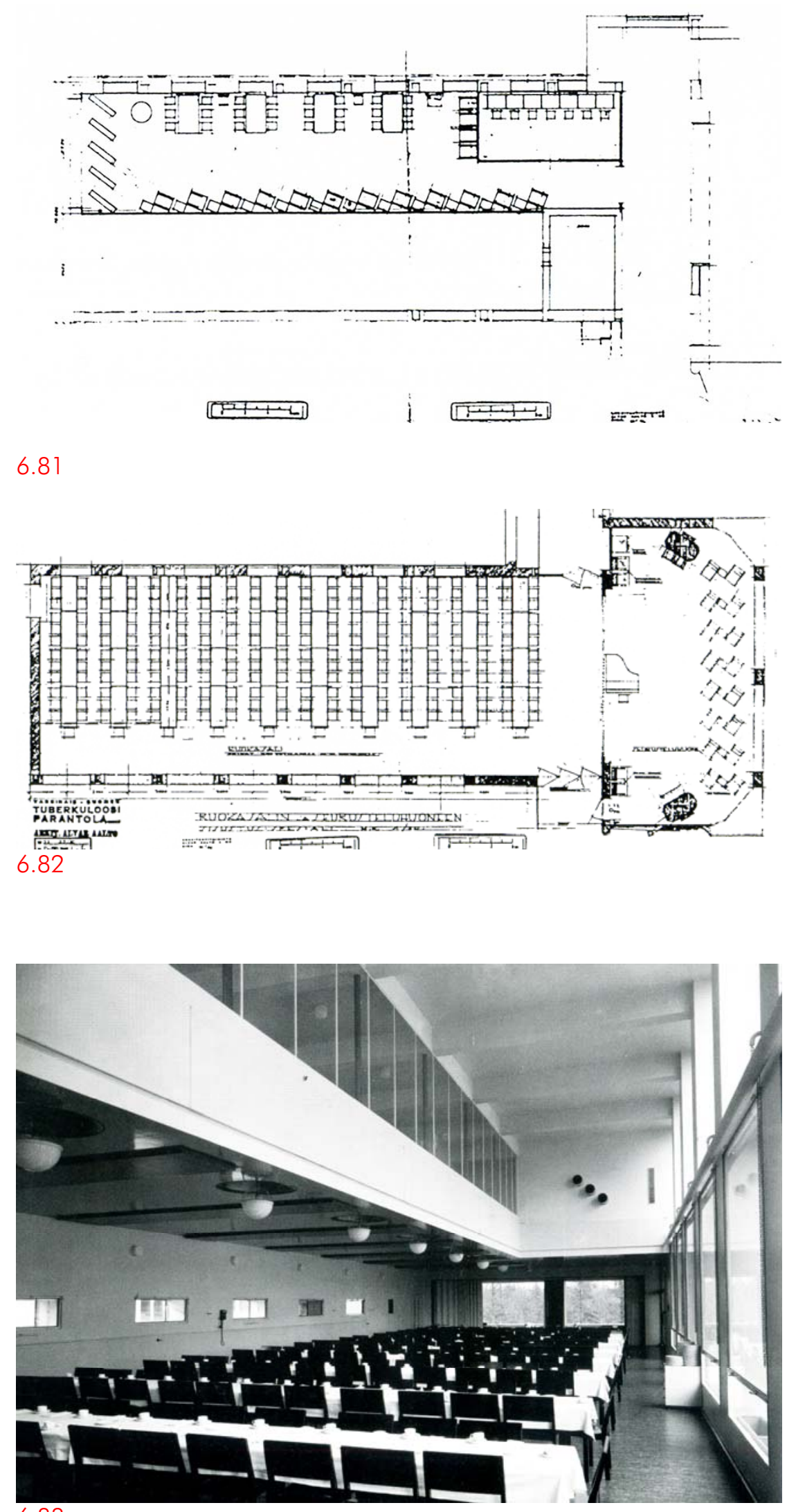

6.83

6.81 A. Aalto. Sanatorio de Paimio, Turku, p. 1928-1932. Planta segunda del bloque de servicios comunes, biblioteca (50/92).

6.82 A. Aalto. Sanatorio de Paimio, Turku, p. 1928-1932. Planta primera del bloque de servicios comunes, comedor, 1932 (50/89).

6.83 A. Aalto. Sanatorio de Paimio, Turku, p. 1928-1932. Comedor. 
hermanos Vesnin, realizado en el año $1924^{67}$ [fig. 6.78]. El ascensor acristalado, pese a estar al principio restringido su uso al personal sanitario, aporta una nueva manera de contemplar el paisaje a través de un desplazamiento en vertical pues, como J.M. Montaner indica: "El funcionalismo orgánico de Aalto (...) pone énfasis en los movimientos y en los procesos humanos de percepción ${ }^{\prime \prime 68}$.

El otro extremo del volumen de habitaciones situado al este se conecta con la galería de cura, un cuerpo rectangular de esquinas redondeadas, cerrado al norte por una pantalla de hormigón totalmente ciega y abierto al sur [fig. 6.79]. En ella la estructura queda vista y se convierte en un elemento compositivo. Las bandejas de hormigón que conforman las terrazas se soportan por una única fila de machones de hormigón que van reduciendo su sección a medida que crece el edificio y disminuyen las cargas. Éstos se separan de la pared norte dejando un paso entre el cerramiento y la estructura, de forma que se compensan los vuelos de los dos frentes de la galería. En sección se parece al perfil de un esbelto árbol con un robusto tronco del que penden las terrazas a modo de ramas horizontales, como sucede en los abetos circundantes [fig. 6.80].

Al proyectar la galería de curas, independiente de las habitaciones, se consigue que éstas puedan orientarse al sureste y que las estancias disfruten de más horas de luz durante la mañana y durante el invierno. Además se evitan así las sombras que la galería en vuelo proyecta sobre la fachada, cuando éstas se arrojan sobre la habitación.

Al otro lado del vestíbulo central, frente al cuerpo de habitaciones, hay un volumen con los servicios comunes. En su planta primera está el comedor acristalado y de doble altura, con una pequeña terraza exterior en el extremo oeste ${ }^{69}$ y una sala de reposo en el extremo contrario, al otro lado del corredor [fig. 6.82]. El comedor es un espacio muy luminoso sobre el que se vuelca la biblioteca, también acristalada pero separada de la fachada para evitar que la incidencia directa de los rayos solares perturbe la lectura, definiendo un quiebro en la sección del comedor que permite la llegada de los rayos solares que atraviesan su fachada hasta las mesas del fondo y no sólo hasta las más próximas a la ventana [fig. 6.81]. Desde ambos espacios, el comedor y la biblioteca orientados al sureste, se ve el acceso para que el enfermo rompa con su monotonía diaria al contemplar el fluir

\footnotetext{
${ }^{67}$ Mateo CLOSA, F. Javier BIURRUN, Alfred LINARES, El sanatorio de Paimio, 1929-1933, Alvar Aalto. La arquitectura entre la naturaleza y la máquina. Servei de Publicacions de la UPC, Barcelona 1991, p.92.

68 Josep María MONTANER, Sistemas arquitectónicos contemporáneos. Editorial Gustavo Gili, Barcelona 2009, p. 83.

${ }^{69}$ La terraza junto al comedor no existe en el proyecto del concurso de 1929 y permite ampliar las vistas al suroeste hacia la vía de acceso al sanatorio.
} 


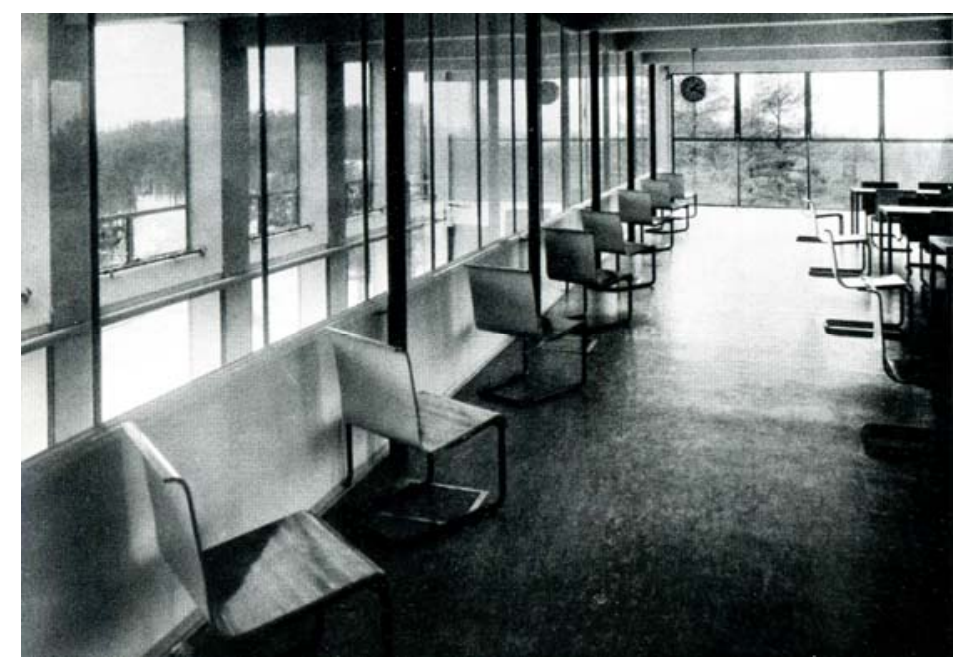

6.84

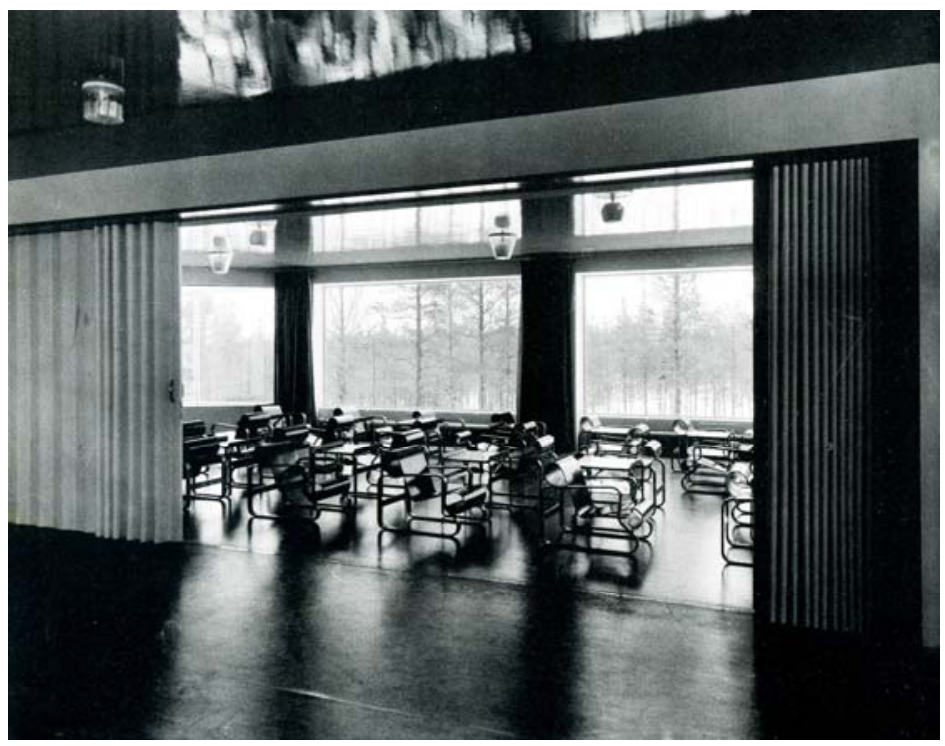

6.85

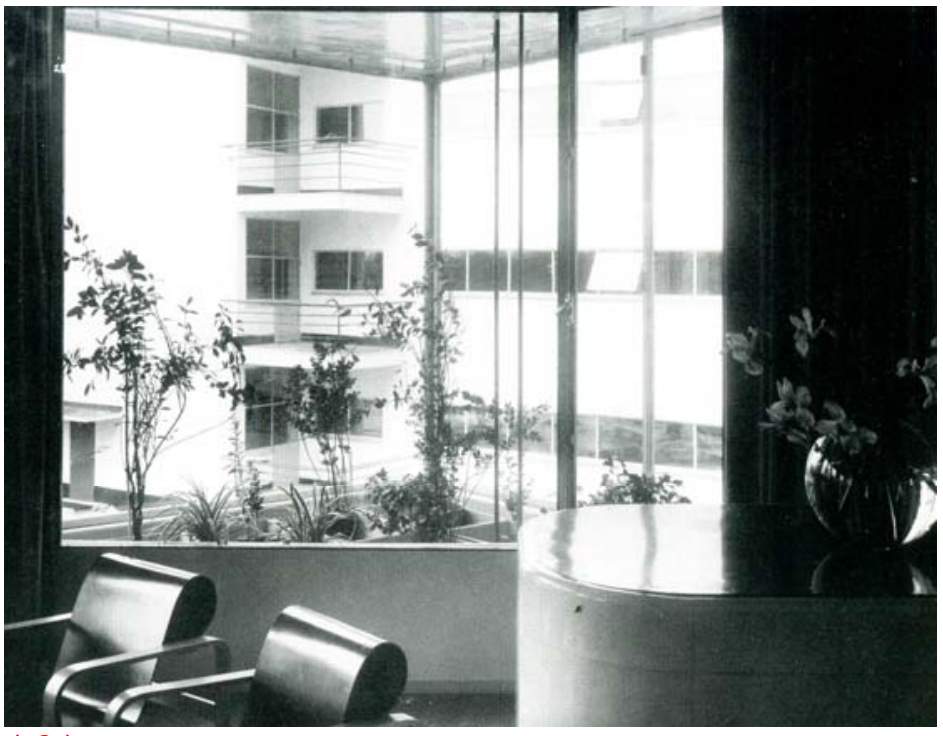

6.86

6.84 A. Aalto. Sanatorio de Paimio, Turku, p. 1928-1932. Biblioteca.

6.85 A. Aalto. Sanatorio de Paimio, Turku, p. 1928-1932. Sala de reposo.

6.86 A. Aalto. Sanatorio de Paimio, Turku, p. 1928-1932. Ventana en esquina de la sala de reposo. 
de los vehículos que acceden y abandonan el centro ${ }^{70}$ [fig. 6.84]. Sobre el acceso al comedor, situado junto a la biblioteca, existe una cabina de proyección que lanza imágenes en la pared del fondo convirtiéndose el comedor en un cine [fig. 6.83].

La sala de reposo se localiza en el extremo contrario a la pared-pantalla, y se independiza del comedor a través de un cerramiento muy ligero que se pliega en acordeón, de manera que ambas estancias pueden formar un único espacio. La sala de reposo está orientada al este y está totalmente acristalada en su frente longitudinal, abierta hacia el paisaje arbolado existente en la parte trasera del Sanatorio [fig. 6.85]. En sus esquinas se incorporan unas ventanas-invernadero triangulares que integran la naturaleza en el interior y amplían aún más las vistas hacia el exterior [fig. 6.86].

Veinticuatro años después de la construcción del Sanatorio de Paimio, en 1957, Aalto revela en una entrevista dada a la revista Casabella que: "El problema crucial en arquitectura no atañe a su perfección formal, sino a la tarea de crear, con medios sencillos un entorno atractivo que armonice con nuestras necesidades biológicas" ${ }^{71}$.

En el Sanatorio Aalto crea un nuevo entorno no sólo artificial, a través del edificio principal del bloque de viviendas del personal y de médicos, incluso de la vivienda del médico jefe construidos entre 1932 y 1933, al que más tarde se añadirán otras edificaciones como la capilla mortuoria o la sauna [fig. 6.87], sino también un nuevo entorno natural, a través del diseño del jardín escalonado que se realiza junto al cuerpo de habitaciones y la galería de cura [fig. 6.88]. Al principio este jardín se crea para practicar la helioterapia en verano y está constituido por una secuencia de plataformas de terreno aterrazadas, paralelas a la galería, rematadas con una serie de estanques circulares que refrescan el ambiente, convirtiéndose el jardín en una continuación de la propia galería ${ }^{72}$. Sea en el Sanatorio o en las viviendas de Aalto "El jardín es parte orgánica de la casa, lo mismo que las habitaciones. (...) La zona ajardinada y la casa forman, en mi opinión, un todo coherente" ${ }^{73}$.

\footnotetext{
70 Esta disposición de las zonas comunes, más próximas a las áreas más vitales del sanatorio, aparece claramente reflejada en la disposición del comedor del Sanatorio de Zonnestraal de J. Duiker.

${ }^{71}$ Alvar AALTO, "Viaje a Italia" ("Journey to Italy" ), Casabella Continuità $\mathrm{n}^{\circ}$ 200, Febrero/Marzo 1954, en Göran SCHILDT (ed.), Alvar Aalto de palabra y por escrito (Alvar Aalto. In his own words, 1997), El Croquis Editorial, Madrid 2000, p.58.

72 Al aumentar el número de plantas del sanatorio, las terrazas-solario naturales dejan de ser necesarias y se convierten en un paseo ajardinado. José María JOVÉ SANDOVAL, Alvar Aalto proyectando con la naturaleza. Universidad de Valladolid, Valladolid 2003, p.261.

${ }^{73}$ Alvar AALTO, "De los escalones de entrada al cuarto de estar" ("Porraskiveltä arkihuoneeseen"), Aitta, 1926, en Göran SCHILDT (ed.), Alvar Aalto de palabra y por escrito (Alvar Aalto. In his own words, 1997), El Croquis Editorial, Madrid 2000, pp.70-71.
} 


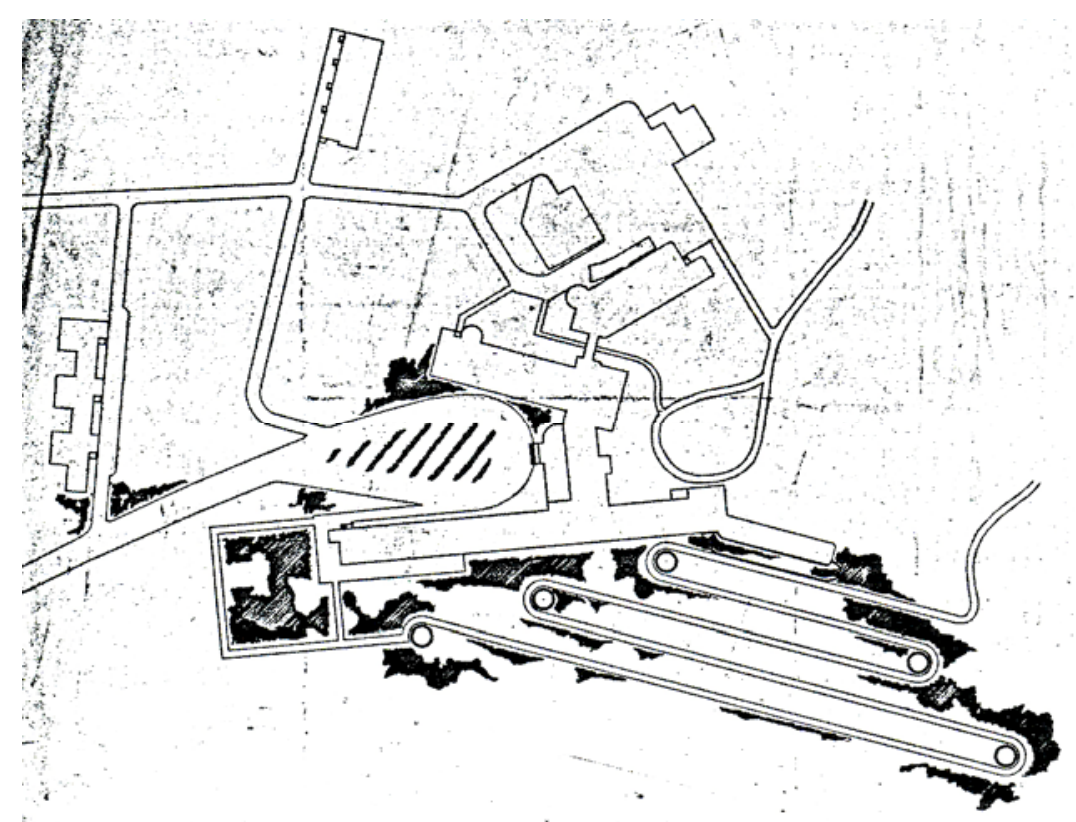

6.87
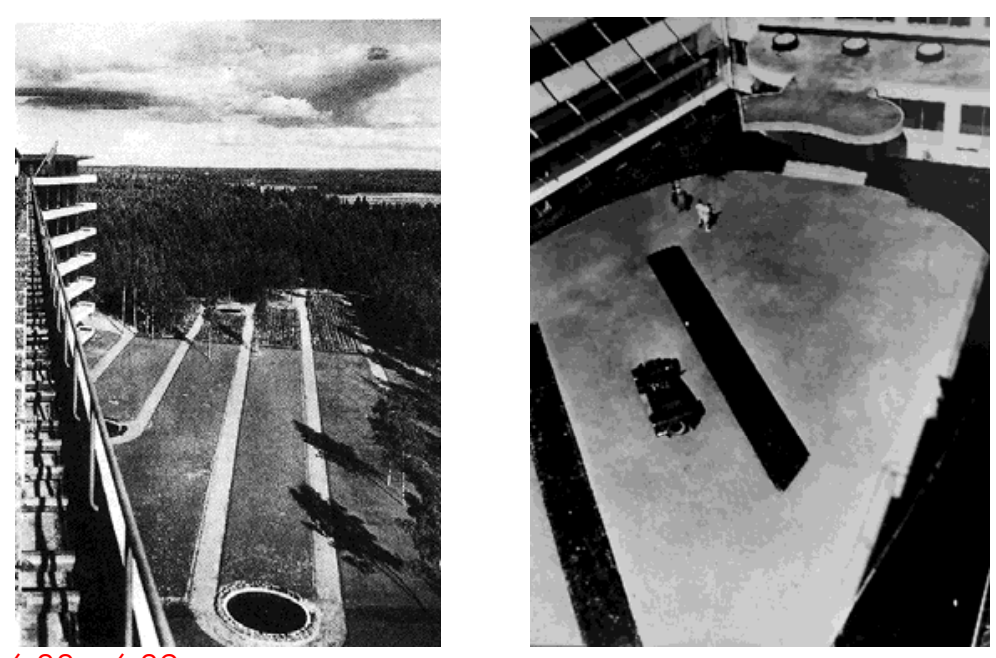

6.88 y 6.89

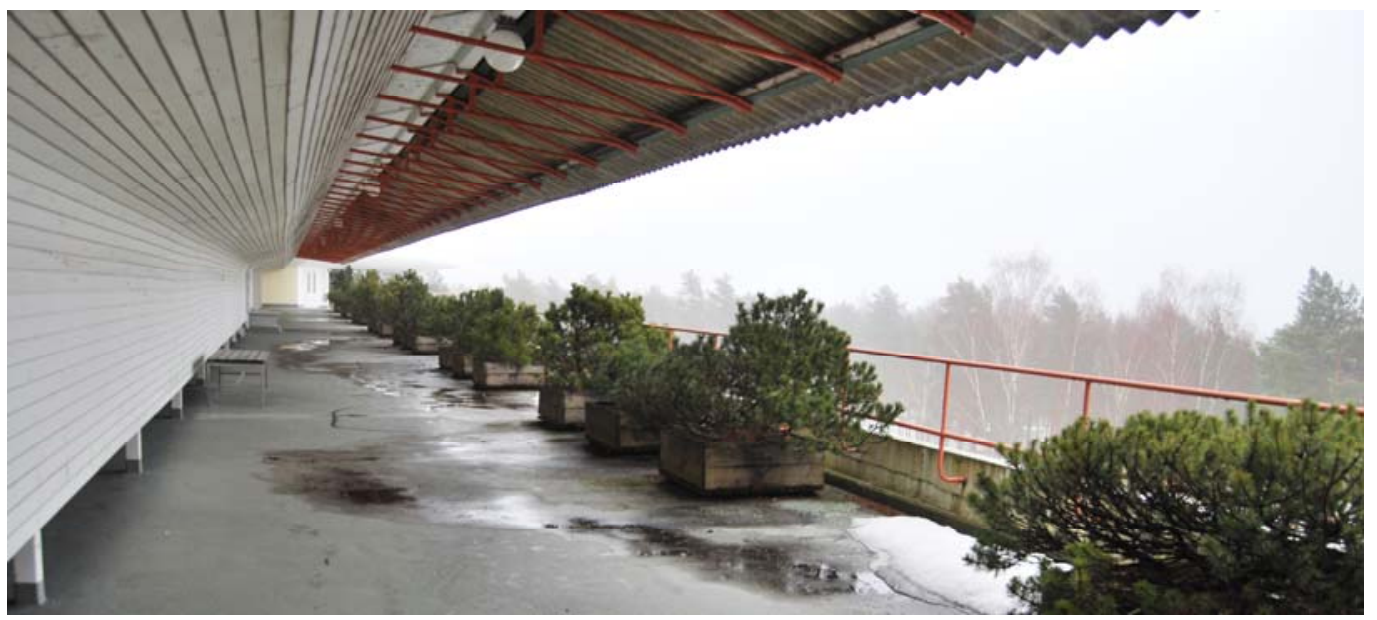

6.87 A. Aalto. Sanatorio de Paimio, Turku, p. 1928-1932. Plano de situación (50/757).

6.88 A. Aalto. Sanatorio de Paimio, Turku, p. 1928-1932. Jardín escalonado.

6.89 A. Aalto. Sanatorio de Paimio, Turku, p. 1928-1932. Jardín de acceso (AAA, AA Mar 263 ).

6.90 A. Aalto. Sanatorio de Paimio, Turku, p. 1928-1932. Cubierta solario (fotografía de la autora). 
Se incluye también un jardín delantero en el recinto principal de acceso al sanatorio, un recurso más que contribuye a hacer el entorno atractivo pues: " $A$ veces, sin embargo, parece que no veamos suficiente naturaleza virgen, y trasplantamos entonces la belleza directamente al umbral de nuestras casas 174 .

El jardín consiste en una serie de macizos de flores formando bandas oblicuas a la fachada principal y paralelas entre sí, que dirigen el recorrido perimetral de los vehículos y delimitan posibles ámbitos de estacionamiento entre ellas [fig. 6.89]. Tanto el jardín del acceso principal como el escalonado de la galería de curas están proyectados para ser contemplados desde lo alto, y en ambos destaca el empleo de las geometrías rectas.

Llama la atención cómo Aalto, que en ciertos elementos de sus edificios traslada, según D. Álvarez Álvarez, las "líneas onduladas, extraídas de una lectura poética y científica del paisaje finlandés ${ }^{\prime \prime 7}$, como se aprecia en el diseño de la silla de reposo del Sanatorio y en otros elementos del mismo, proponga en los jardines de Paimio un estricto rigor geométrico y un carácter mecánico. La analogía expuesta por J.M. Jové Sandoval, sobre la composición del jardín da buena muestra de ello: "una cinta que se pliega apoyando su movimiento en varios estanques circulares (...) una especie de correa que, como en una máquina o en un proyector de films, discurre entre los rodillos que producen su movimiento" ${ }^{\prime \prime 6}$.

A través del trazado geométrico de la vegetación, de la topografía exterior y de la integración de formas orgánicas, e incluso a la presencia de plantas y elementos vegetales en los ambientes interiores, la arquitectura se extiende en el paisaje y el entorno se introduce en el edificio, desdibujando los límites de lo natural y de lo construido. Se observa en la hilera de amplias jardineras plantadas de pequeños abetos en el perímetro de la cubierta solario del cuerpo de habitaciones, que inducen a que el enfermo reclinado en su tumbona aprecie una cierta continuidad entre los abetos de las jardineras y los árboles del bosque que asoman sobre la cubierta, creando la ilusión de estar tumbado fuera del edificio sumergido en una inmensa pradera verde [fig. 6.90].Por otro lado, el contraste entre las formas naturales y las geometrías puras del Sanatorio logra que, como Aalto describe en

\footnotetext{
${ }^{74}$ Alvar AALTO, "La arquitectura en el paisaje de Finlandia Central" ("Keskisuomalainen maiseman rakennustaide"), Sisä-Suomi, 26 de Junio de 1925, en Göran SCHILDT (ed.), Alvar Aalto de palabra y por escrito (Alvar Aalto. In his own words, 1997), El Croquis Editorial, Madrid 2000, p.34.

${ }^{75}$ Darío ÁLVAREZ ÁLVAREZ, El jardín en la arquitectura del siglo XX: Naturaleza artificial en la cultura moderna, Reverté, Barcelona 2007, p. 167.

${ }^{76} J$ José María JOVÉ SANDOVAL, Alvar Aalto proyectando con la naturaleza, Universidad de Valladolid, Valladolid 2003, p. 260.
} 


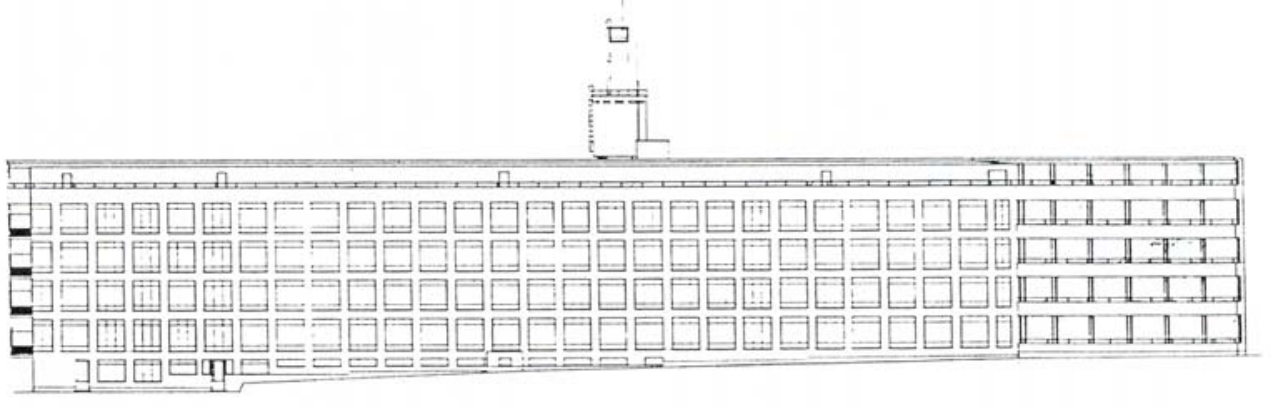

6.91

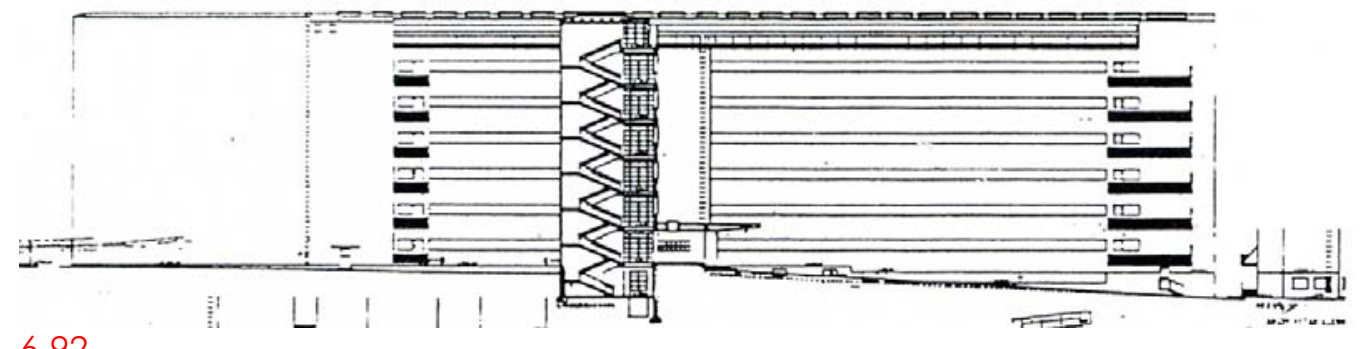

6.92

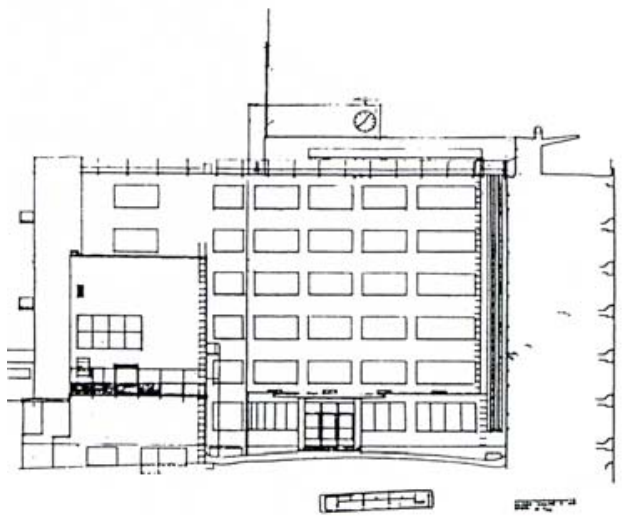

6.93
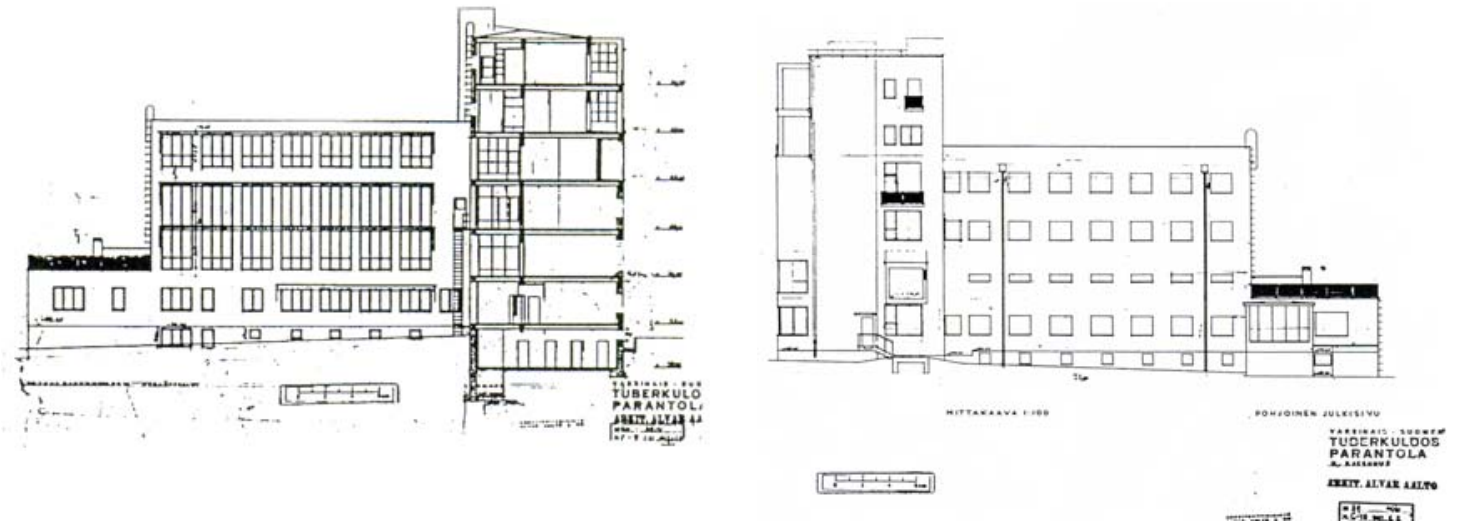

6.94 y 6.95

6.91 A. Aalto. Sanatorio de Paimio, Turku, p. 1928-1932. Frente del bloque de habitaciones, 1930 (50/98).

6.92 A. Aalto. Sanatorio de Paimio, Turku, p. 1928-1932. Espalda del bloque de habitaciones, 1930 (50/95).

6.93 A. Aalto. Sanatorio de Paimio, Turku, p. 1928-1932. Alzado principal (50/106).

6.94 A. Aalto. Sanatorio de Paimio, Turku, p. 1928-1932. Frente del bloque de servicios comunes, 1930 (50/102).

6.95 A. Aalto. Sanatorio de Paimio, Turku, p. 1928-1932. Espalda del bloque de servicios comunes, 1930 (50/103). 
la memoria de 1933, una vez construido éste se convierta en el "factor que caracteriza el paisaje que le rodea ${ }^{1177}$.

A diferencia del proyecto del Sanatorio de Kinkomaa, en Paimio todas las partes del edificio tienen un mismo lenguaje moderno. La pureza de sus volúmenes, la composición horizontal de sus fachadas, la reiteración de los huecos de ventanas y, sobre todo, su refulgente color blanco hacen que, a pesar de la diferencia volumétrica de cada una de sus partes y de la variación del tipo de huecos de sus frentes, todo el edificio se perciba como una misma unidad compacta $^{78}$ y destacada dentro del entorno natural [fig. 6.91- fig. 6.95].

En el alzado del cuerpo de habitaciones construido en 1933 desaparece la ventana en $\mathrm{L}^{79}$, que había sido elegida por Aalto como lema, pero se mantienen las características espaciales descritas a través del mismo. El lema de la ventana en $L$ es en realidad un dibujo en perspectiva del interior de la habitación del enfermo, lo cual muestra la importancia de este espacio, el verdadero hogar del enfermo en el Sanatorio ${ }^{80}$ [fig. 6.96].

A través del lema dibujado se describe una estancia abierta al ambiente exterior, calefactada y ventilada, como se expresa en la representación de la amplia ventana, del radiador y del sistema de apertura de la parte superior de la doble ventana, que permite la continua renovación del aire de la habitación sin generar corrientes. Tratándose de un sanatorio, el lema alude a la helioterapia y a la captación de aire puro que puede penetrar a través de ella, y destaca la importancia de la contemplación del paisaje. En un dibujo posterior de ese mismo espacio con la nueva ventana y el sistema de calefacción propuesto en el proyecto de 1931, Aalto dibuja la visión del paisaje circundante a través de la ventana [fig. 6.97]. Son la percepción física del ambiente exterior desde el interior de la habitación, y su repercusión psicológica y física en el enfermo, los factores que determinan la definición de este espacio arquitectónico. La ventana es la sutil membrana entre el paciente y "los condicionantes biológicos de la vida humana", que según Aalto son: "el aire, la luz y el

\footnotetext{
77 Mateo CLOSA, F. Javier BIURRUN, Alfred LINARES, "Sanatorio de Paimio Memoria", El sanatorio de Paimio, 1929-1933, Alvar Aalto. La arquitectura entre la naturaleza y la máquina. Servei de Publicacions de la UPC, Barcelona 1991, p. 25.

${ }^{78}$ Antón CAPITEL, La arquitectura compuesta por partes. Gustavo Gili, Barcelona 2009, p.167.

${ }^{79} \mathrm{La}$ ventana de la habitación en el proyecto definitivo construido en 1933, es prácticamente cuadrada de 220 × 255 centímetros.

${ }^{80}$ Los lemas propuestos por el resto de finalistas hacen alusiones al sol, enfatizando la importancia de la helioterapia. "Luz", los ganadores del segundo premio y "Ammon-Ra" los del tercero. Mateo CLOSA, F. Javier BIURRUN, Alfred LINARES, "El Concurso" en El sanatorio de Paimio, 1929-1933, Alvar Aalto. La arquitectura entre la naturaleza y la máquina. Servei de Publicacions de la UPC, Barcelona, 1991, pp.20-22.
} 

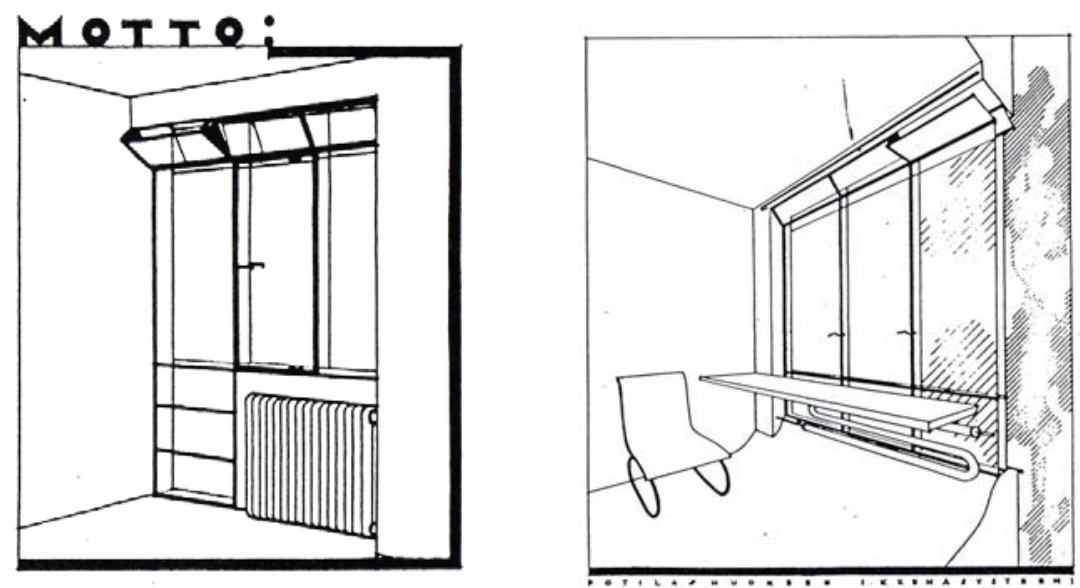

6.96 y 6.97
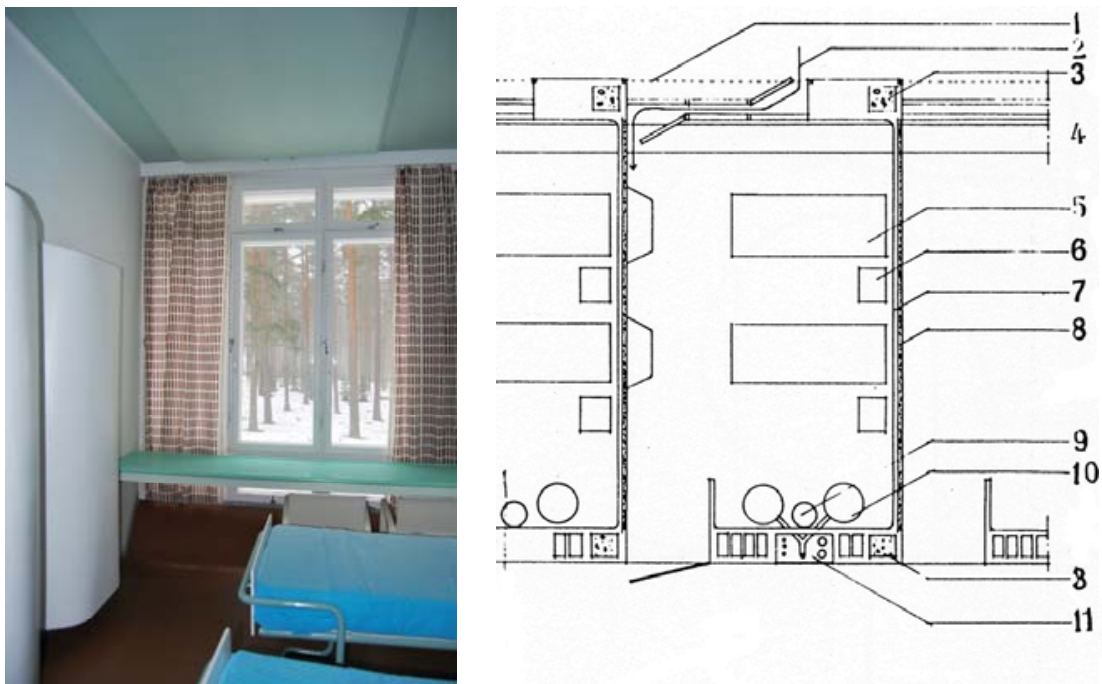

6.98 y 6.99

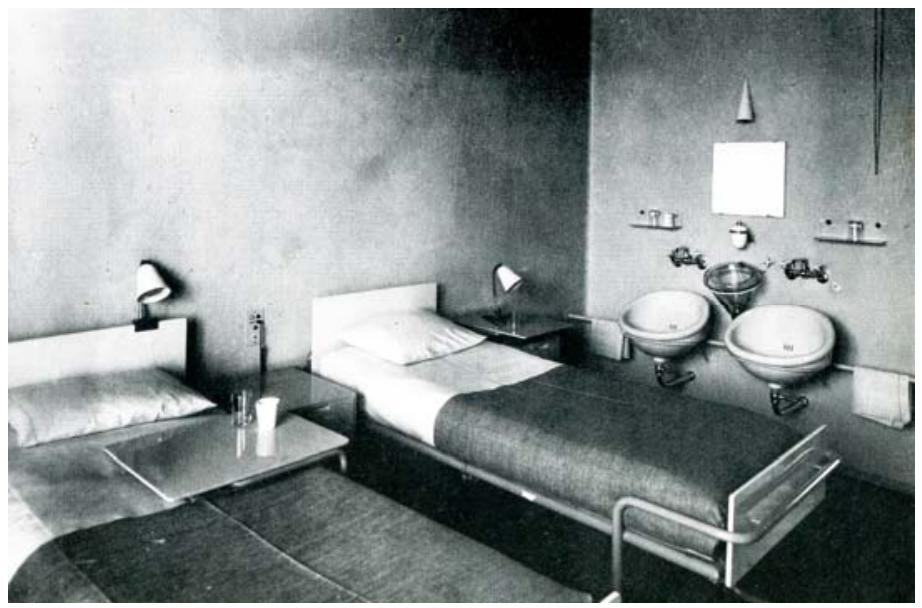

6.100

6.96 A. Aalto. Proyecto del concurso del Sanatorio de Paimio, Turku, 1929. Lema (50/34).

6.97 A. Aalto. Sanatorio de Paimio, Turku, p.1928-1932. Perspectiva de la habitación, 1929 (50/395).

6.98 A. Aalto. Sanatorio de Paimio, Turku, p. 1928-1932. Habitación (fotografía de la autora).

6.99 A. Aalto. Sanatorio de Paimio, Turku, p.1928-1932. Planta de habitación:1. celosía, 2. aire fresco, 3. construcción portante, 4. mesa, 5.cama, 6. mesilla, 7. superficie dura del tabique, 8. superficie blanda del tabique, 9. escupidera, 10. lavabo, 11. unidad de instalaciones. (50/407). 6.100 A. Aalto. Sanatorio de Paimio, Turku, p. 1928-1932. Habitación. 
sol" ${ }^{81}$ entre otros, y el elemento que mejor identifica esta simbiosis.

Para Thomas Mann una simple ventana para un enfermo puede convertirse en una importante fuente de bienestar psicológico por sus constantes cambios [fig. 6.98]:

"Cuando llegaba la mañana, constituía una distracción observar cómo la habitación se iba iluminando y renacía poco a poco de la oscuridad; cómo surgían y se formaban de nuevo los objetos, y cómo se hacía la luz en el exterior, a veces con un resplandor mortecino, otras de un rojo exultante" 82.

De este modo la ventana de la habitación, además del bienestar físico que procura gracias a su orientación solar y a los sistemas de aireación, procura un bienestar psicológico fundamental para el enfermo que debe ser tenido en cuenta, ya que:

"Tan pronto como contemos con los aspectos psicológicos o, mejor dicho, cuando estemos capacitados para hacerlo, habremos ampliado el método racionalista hasta tal grado que será más fácil que antes descartar resultados inhumanos". 83

Esta "humanización" de la arquitectura, característica de una era post-funcionalista erróneamente asociada a un movimiento romántico, ya que, como indica Bruno Zevi, es: "por el contrario, de naturaleza científica: el nacimiento de la psicología moderna "84, comienza a definirse en el Sanatorio de Paimio.

La preocupación constante por el bienestar físico y psicológico del enfermo en el proyecto del Sanatorio, incentiva a investigar sobre las repercusiones psicológicas de la arquitectura, obteniendo una serie de resultados que Aalto más tarde aplica al resto de sus construcciones arquitectónicas. Pues: "Para examinar cómo reaccionan los seres humanos ante las formas y la construcción, resulta útil para nuestro experimento emplear sobre todo personas sensibles, como los pacientes de un sanatorio" 85 .

La habitación del enfermo se convierte en el principal medio de experimentación al ser el espacio arquitectónico más próximo al mismo [fig. 6.99]. En su diseño la arquitectura se

\footnotetext{
${ }^{81}$ Alvar AALTO, "El problema de la vivienda" ("Var bostad som problem"), Domus n 8 8-10, 1930, en Göran SCHILDT (ed.), Alvar Aalto de palabra y por escrito (Alvar Aalto. In his own words, 1997), El Croquis Editorial, Madrid 2000, p.111.

82 Thomas MANN, La Montaña Mágica (Berlín, 1924). Edhasa, Barcelona 2005, p. 291.

${ }^{83}$ Alvar AALTO, "El racionalismo y el hombre" ("Rationalismen och människan"), Jornadas Anuales de la Asociación Sueca de Artesanos, Estocolmo, 9 de mayo de 1935, en Göran SCHILDT (ed.), Alvar Aalto de palabra y por escrito (Alvar Aalto. In his own words, 1997), El Croquis Editorial, Madrid 2000, p. 128.

${ }^{84}$ Bruno ZEVI, Saber ver la arquitectura (Saper vedere l'architettura, 1948). Poseidon, Barcelona 1981, p. 106.

${ }^{85}$ Alvar AALTO, "La Humanización de la Arquitectura" ("The Humanizing of Architecture"), The Techonology Review, Noviembre de 1940, en Göran SCHILDT (ed.), Alvar Aalto de palabra y por escrito (Alvar Aalto. In his own words, 1997), El Croquis Editorial, Madrid 2000, p.143.
} 
adapta a las condiciones particulares del enfermo $y$, en consecuencia, una de las principales consideraciones a tener en cuenta es la particular postura decúbito prono y supino que habitualmente adopta el enfermo en este espacio, motivo por el que:

"la habitación debía ser distinta a una habitación normal. (...) una habitación normal es una habitación pensada para una persona en posición vertical; la habitación del paciente es una habitación que se ha de acoger a una persona en posición horizontal, y los colores, la iluminación, la calefacción, etc., deben ser diseñados teniendo esto en cuenta" ${ }^{\prime \prime 6}$.

Mann se percata de este hecho en varias ocasiones y describe a los enfermos del sanatorio en boca de uno de los personajes de su novela de la siguiente manera: "Settembrini dice que vivimos en horizontal, que somos líneas horizontales. Es uno de sus chistes malos" 87.

A causa de la posición yacente de los enfermos la ventana de la habitación baja casi hasta el suelo, apenas se eleva medio metro sobre el mismo, para aumentar la visión del exterior desde la cama. De la misma manera, la mesa inserta en la ventana es especialmente liviana con el fin de no obstaculizar las vistas.

Como ya se ha mencionado, la habitual posición del enfermo de cúbito supino, hace que cobre una especial importancia el plano del techo de la habitación, al ser la visión frontal del enfermo. En Paimio se pinta en un tono verde apagado casi gris, que contrasta con el amarillo de la escalera principal o el azul cobalto ${ }^{88}$ de algunas puertas, al igual que con la imagen exterior blanca y luminosa del Sanatorio. Esta dualidad amplía las cualidades de la arquitectura, multiplicando en una única edificación, las experiencias que ésta es capaz de transmitir ${ }^{89}$. Dualidad que por otro lado, es habitual en la casas finlandesas, ya que: "La casa finlandesa tiene que tener dos caras: una es la que está en relación directa con el

\footnotetext{
${ }^{86}$ Alvar AALTO, "La Humanización de la Arquitectura" ("The Humanizing of Architecture"), The Techonology Review, Noviembre de 1940, en Göran SCHILDT (ed.), Alvar Aalto de palabra y por escrito (Alvar Aalto. In his own words, 1997), El Croquis Editorial, Madrid 2000, p.144.

${ }^{87}$ Thomas MANN, La Montaña Mágica (Berlín, 1924).Edhasa, Barcelona 2005, p.108.

${ }^{88} \mathrm{El}$ color azul intenso de algunas puertas del sanatorio pasará a ser designado como "azul Paimio".

89 Dualidad que Aalto reconoce en los pabellones de la Exposición Funcionalista de Estocolmo de 1930 realizados por su amigo Gunnar Asplund, donde al igual que en el Sanatorio de Paimio, la vitalidad optimista del exterior contrasta con la quietud del interior. Así los describe en su artículo "La Exposición de Estocolmo de 1930" ("Stockhomsutställningen"), I Abo Underrättelser, 22 de mayo de 1930, II. Arkkitehti, n8, 1930. Publicado en Göran SCHILDT (ed.), Alvar Aalto de palabra y por escrito (Alvar Aalto. In his own words, 1997), El Croquis Editorial, Madrid 2000, p.100.
} 
entorno exterior, y la otra, la faz de invierno, que se evidencia en el diseño del interior tendente a enfatizar el calor de nuestros interiores" 190.

Al diseñar la habitación, estudia cuidadosamente también el sistema de iluminación artificial que aplica. Es consciente de la falta de adecuación de ciertos sistemas habituales como son los plafones opalinos a los que considera "psicológicamente irritantes" 91. Diseña bañadores de pared, situados fuera del ángulo visual del enfermo tumbado en la cama, y también focos móviles que se pueden situar indistintamente colgados del cabecero de la cama o apoyados sobre la mesilla, para ajustar mejor la luz artificial a las necesidades del paciente [fig. 6.100]. La calefacción también se adapta a la posición del enfermo y propone un calefactor que desde el techo irradia calor a los pies de la cama, dejando el cabecero sin calefactar. Atendiendo a otra posible postura proyecta un radiador bajo la ventana que calienta la habitación y los pies del enfermo, sentado a la mesa ubicada junto a ella.

Tampoco olvida el aislamiento acústico de la habitación:

"Para evitar el ruido, una pared de la habitación se hizo absorbente del sonido, y los lavabos -cada paciente de una habitación doble tenía el suyo- fueron especialmente diseñados para que el agua al fluir desde el grifo, golpeara la porcelana según un ángulo muy pequeño" ${ }^{\prime \prime 2}$.

La organización y diseño de la habitación es un ejemplo de la multiplicidad de factores que deben ser tenidos en cuenta en la arquitectura, donde: "participan fenómenos técnicos, físicos y psicológicos, nunca uno de ellos aisladamente. El funcionalismo técnico es correcto solamente si se amplía hasta alcanzar el campo psicológico"193.

Otro aspecto característico de la habitación es su neutralidad. Un ejemplo de ello se halla en el diseño de los armarios de la habitación. Alacenas individuales de formas redondeadas que emergen de la pared a los pies de las camas de los enfermos. Su novedosa geometría implica una pérdida de la identificación formal tradicional,

\footnotetext{
90 Alvar AALTO, "De los escalones de entrada al cuarto de estar" ("Porraskiveltä arkihuoneeseen") Aitta, 1926, en Göran SCHILDT (ed.), Alvar Aalto de palabra y por escrito (Alvar Aalto. In his own words, 1997), El Croquis Editorial, Madrid 2000, p.71.

91 Alvar AALTO, "El racionalismo y el hombre" ("Rationalismen och människan" ), Jornadas Anuales de la Asociación Sueca de Artesanos, Estocolmo, 9 de mayo de 1935, en Göran SCHILDT (ed.), Alvar Aalto de palabra y por escrito (Alvar Aalto. In his own words, 1997), El Croquis Editorial, Madrid 2000, pp.128-129.

92 Alvar AALTO, "La Humanización de la Arquitectura" ("The Humanizing of Architecture"), The Techonology Review, Noviembre de 1940, en Göran SCHILDT (ed.), Alvar Aalto de palabra y por escrito (Alvar Aalto. In his own words, 1997), El Croquis Editorial, Madrid 2000, p.1 45.

93 Alvar AALTO, "La Humanización de la Arquitectura" ("The Humanizing of Architecture"), The Techonology Review, Noviembre de 1940, en Göran SCHILDT (ed.), Alvar Aalto de palabra y por escrito (Alvar Aalto. In his own words, 1997), El Croquis Editorial, Madrid 2000, p.145.
} 

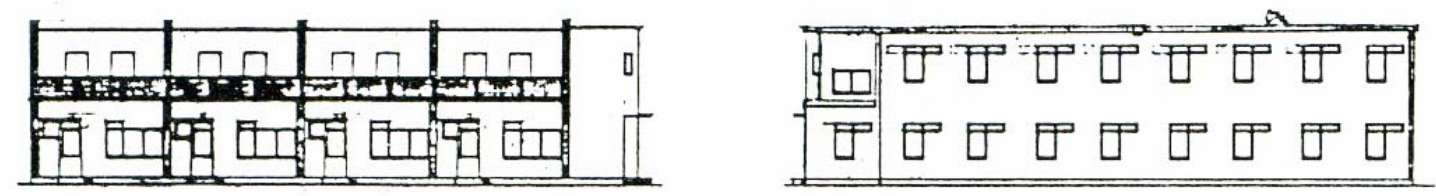

6.101

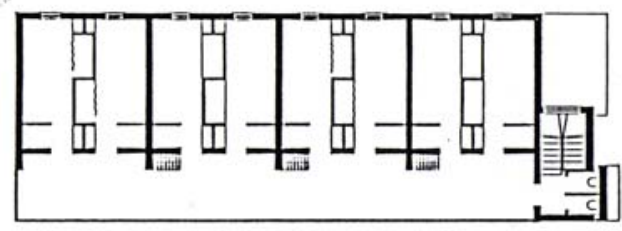

:

planta primera

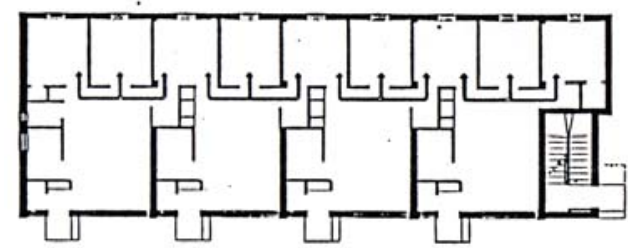

planta baja

6.102 y 6.103
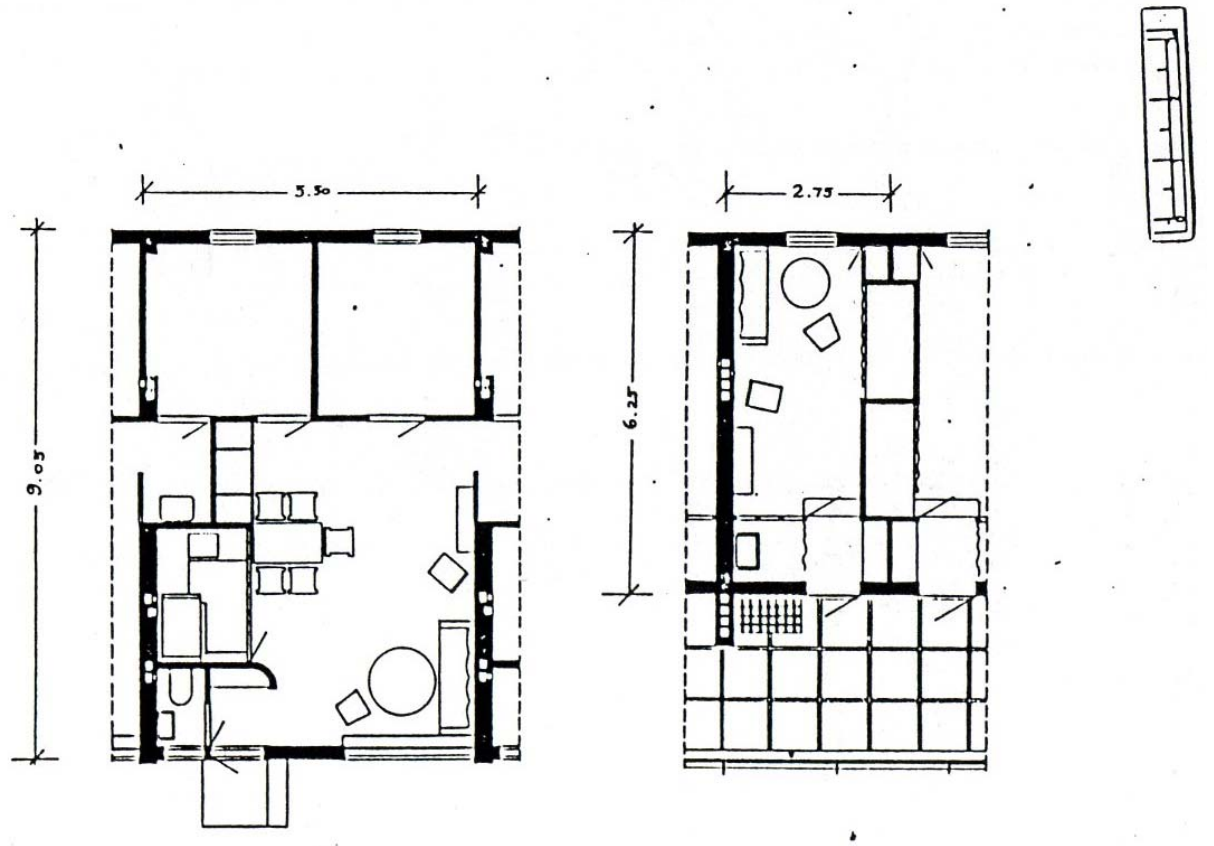

6.104

6.101 A. Aalto. Sanatorio de Paimio, Turku, p.1928-1932. Alzados del bloque de viviendas del personal, 1930 (50/467).

6.102 y 6.103 A. Aalto. Sanatorio de Paimio, Turku, p.1928-1932. Plantas del bloque de viviendas del personal $(50 / 637)$ y perspectiva $(50 / 468)$.

6.104 A. Aalto. Sanatorio de Paimio, Turku, p.1928-1932. Detalle en planta de las viviendas del bloque de viviendas del personal (50/637). 
convirtiendo los armarios en dos pliegues curvos y abstractos sobre un paramento vertical. Los armarios flotan ingrávidos sin tocar el suelo, acentuando su componente plástica, al tiempo que se evita el contacto con el pavimento para facilitar la limpieza del mismo. Constan de un remate superior oblicuo que impide la acumulación de polvo y de flancos curvos que favorecen la limpieza y la circulación por el lateral de la habitación en que se encuentran.

Aunque el diseño en el sanatorio comprende todos los elementos que lo componen, desde las manillas de sus puertas hasta las farolas del jardín, éste carece de adornos superfluos. El aspecto orgánico y funcional, que otorga un cierto grado de neutralidad al conjunto, que hace del ser humano que habita el espacio el protagonista, y su huella sobre la edificación que la convierte en un organismo vivo para Aalto:

"Pero si quiere que bendiga su casa, ésta ha de tener todavía otra cualidad más: Usted debe mostrarse a sí mismo en algún pequeño detalle; en su hogar ha de estar visible deliberadamente, una debilidad, su propia debilidad. Puede ser que aquí se agoten los poderes del arquitecto, pero para mí ninguna creación arquitectónica alcanza la perfección sin ese rasgo, pues entonces no estaría viva" ${ }^{94}$.

Esta actitud arquitectónica se refleja tanto en el diseño aséptico del mobiliario como en la sobriedad y sencillez de las habitaciones de enfermos; espacios mínimos y estandarizados, de unos $5 \mathrm{~m}$. de largo por $3 \mathrm{~m}$. de ancho, que no impone un estilo determinante sino que permiten al individuo que los habita adaptarlos a su personalidad para acabar con la aparente homogeneidad que puede suponer la estandarización.

En el bloque de viviendas de empleados del Sanatorio Antituberculoso de Paimio, proyectadas por Aalto entre 1930 y 1932, son evidentes estas reflexiones sobre la neutralidad y la estandarización [fig. 6.101- fig. 6.05]. Se disponen núcleos servidores fijos que contienen los cuartos húmedos, cocinas, baños y piezas de almacenaje, y se libera el resto de espacios. Se alcanza así el máximo aprovechamiento del espacio y la máxima libertad de uso, como sucede en los apartamentos de la planta primera del bloque. Consta de 8 apartamentos individuales de unos $17 \mathrm{~m}^{2}$ cada uno, a los que se accede a través de un corredor abierto. Todo el conjunto se organiza en una banda paralela a la fachada que contiene los lavabos, el vestíbulo y un armario en cada apartamento, dispuestos para que

\footnotetext{
${ }^{94}$ Alvar AALTO, "De los escalones de entrada al cuarto de estar" ("Porraskiveltä arkihuoneeseen"), Aitta, 1926, en Göran SCHILDT (ed.), Alvar Aalto de palabra y por escrito (Alvar Aalto. In his own words, 1997), El Croquis Editorial, Madrid 2000, p.74.
} 
puedan compartir las canalizaciones. Pegados a los armarios están cuatro piezas transversales. Cada una funciona como un gran muro horadado, de aproximadamente un metro de espesor, que contiene las camas de dos habitaciones contiguas y sus pequeñas cocinas empotradas ubicadas junto a la ventana, separadas por un tabique quebrado [fig. 6.104].

En la planta baja de este mismo bloque de viviendas, Aalto proyecta un sistema flexible de agrupación de espacios que ejemplifica las virtudes de la estandarización:

"Frecuentemente se toma la estandarización por un método que crea homogeneización y esquematismo. Evidentemente eso no es cierto. Las piezas y materiales correctamente estandarizados tienen la propiedad intrínseca de facilitar un número óptimo de combinaciones. Una vez afirmé que el mejor comité de estandarización es la misma naturaleza"95.

La planta baja del bloque de viviendas para empleados [fig. 6.102], consta de un paquete longitudinal de nueve dormitorios consecutivos, y de cuatro bandas perpendiculares en profundidad con los espacios servidores separando los salones de cada una de sus cuatro viviendas. Cada banda consta de vestíbulo, aseo, cocina, un armario y un cuarto con un lavabo con dos posibles accesos, uno a través de una de las habitaciones y otro desde el salón de la vivienda contigua, lo que permite que dicha habitación pueda pertenecer indistintamente a dos viviendas a la vez. Esta distribución espacial hace posible la existencia de viviendas con una, dos o tres habitaciones cada una en función de las necesidades del personal para poder combinar las diversas clases de residencias dentro del mismo bloque [fig. 6.104]. Sólo gracias a esta "variabilidad", a esta capacidad de cambio, se puede lograr la permanencia para Aalto: "un ambiente en permanente renovación implica una forma totalmente independiente de la estructura del objeto" 96.

La estructura de Paimio, a diferencia de Zonnestraal, no define la forma del mismo, "la estructura era un instrumento, no una esencia" ${ }^{97}$, como indica A. Capitel, no sigue un

\footnotetext{
95 Alvar AALTO, "La Influencia de los métodos constructivos y de los materiales en la arquitectura moderna" ("Rakenteitten ja aineitten vaikutus nykyaikaiseen rakennustaiteeseen"), Conferencia pronunciada en las Jornadas Nórdicas de la Construcción; Oslo, 1938, Archivos de Aalto, en Göran SCHILDT (ed.), Alvar Aalto de palabra y por escrito (Alvar Aalto. In his own words, 1997), El Croquis Editorial, Madrid 2000, p.139.

${ }^{96}$ Alvar AALTO, "El racionalismo y el hombre" ("Rationalismen och människan"), Jornadas Anuales de la Asociación Sueca de Artesanos, Estocolmo, 9 de mayo de 1935, en Göran SCHILDT (ed.), Alvar Aalto de palabra y por escrito (Alvar Aalto. In his own words, 1997), El Croquis Editorial, Madrid 2000, p.131.

${ }^{97}$ Antón CAPITEL, La obra de Aalto en Finlandia. Arquitectosdecádiz, Cádiz 2005, p. 25.
} 
único criterio estructural ${ }^{98}$ porque para Aalto el factor determinante de la forma reside en el deseo de permanencia: "la forma no es nada más que voluntad concentrada en la búsqueda de una vida eterna sobre la tierra" ${ }^{\prime 99}$.

El polimorfismo del Sanatorio responde a una estructura formal abierta que permite su crecimiento y su modificación sin alterar su esencia, asegurando así su permanencia en el tiempo. De hecho, entre 1956 y 1958 Aalto incorpora un cuerpo de quirófanos ${ }^{100}$ al Sanatorio sin dañar su identidad formal [fig. 6.105]. La irregularidad de su perímetro y de su perfil tiene parangón con las formas biológicas del primer sanatorio antituberculoso pulmonar donde se aplica la cura de reposo, el Sanatorio de Falkenstein (1874) constituido por la agregación de volúmenes en cadena [fig. 6.106]. La cualidad inconclusa y la diferencia son principios rectores de la naturaleza que Aalto ensalza en su conferencia "La Influencia de los métodos constructivos y de los materiales en la arquitectura moderna" pronunciada en 1938:

"Como oposición a una concepción según la cual las formas establecidas y la homogeneidad de las nuevas (formas) son la única vía hacia una armonía arquitectónica y hacia una técnica de construcción controlada, he querido con todo lo anteriormente dicho, realzar la variación y el crecimiento, semejantes a la vida orgánica natural. Me gustaría decir que al fin y al cabo éste es el único estilo auténtico en arquitectura" ${ }^{101}$.

Los mismos criterios de cambio aplicados al conjunto del sanatorio lo son a la habitación del enfermo:

"Un buen remedio habitual para calmar la tensión del hombre de hoy es cambiar de ambiente -está claro que el entorno más próximo a la persona debe construirse de modo que disponga casi automáticamente de la posibilidad de un cambio (...). La decoración, el monumentalismo, el formalismo, todos estos fenómenos reducen las

${ }^{98}$ En ocasiones Aalto muestra la estructura con intención plástica y en otras la embebe entre los paramentos considerándola un elemento meramente funcional.

99 Alvar AALTO, "El sermón del Abad Coignard", notas manuscritas para una posible conferencia universitaria, 1925, Archivo Aalto, en Göran SCHILDT (ed.), Alvar Aalto de palabra y por escrito (Alvar Aalto. In his own words, 1997), El Croquis Editorial, Madrid 2000, p.76.

${ }^{100}$ Margaretha EHRSTRÖM, Sirkkaliisa JETSONEN, Tommi LINDH, Marica SCHALIN, Mona SCHALIN, Nomination of Paimio Hospital for inclusion in the world heritage list. National Board of Antiquities, Helsinki 2005, p.28.

101 Alvar AALTO, "La Influencia de los métodos constructivos y de los materiales en la arquitectura moderna" ("Rakenteitten ja aineitten vaikutus nykyaikaiseen rakennustaiteeseen"), Conferencia pronunciada en las Jornadas Nórdicas de la Construcción, Oslo, 1938, Archivos de Aalto, en Göran SCHILDT (ed.), Alvar Aalto de palabra y por escrito (Alvar Aalto. In his own words, 1997), El Croquis Editorial, Madrid 2000, pp. 130-140. 

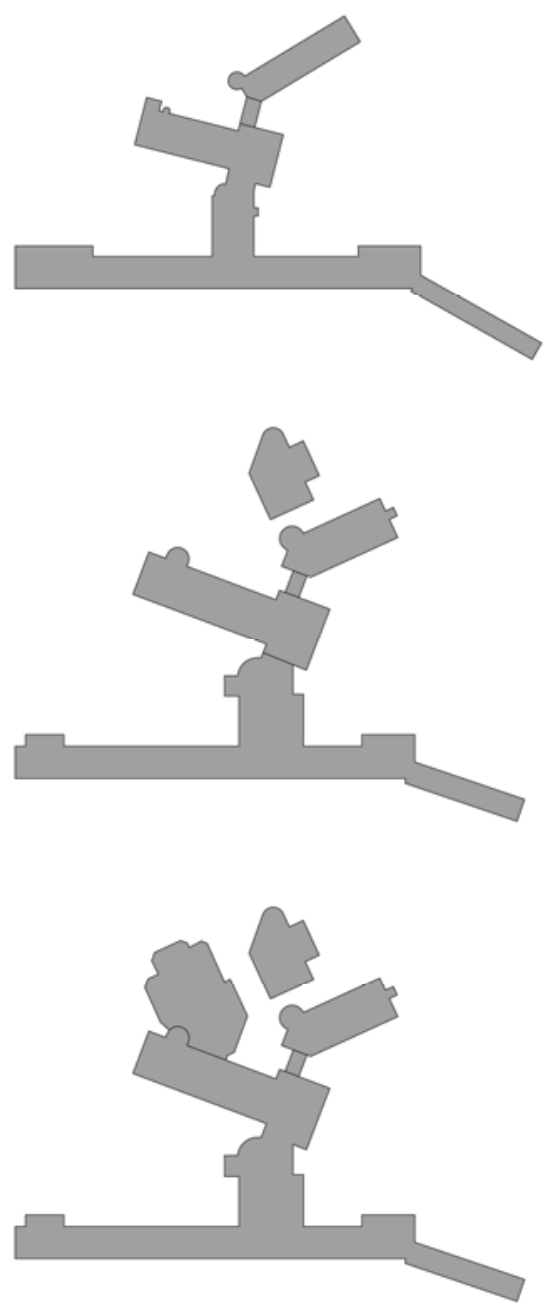

6.105

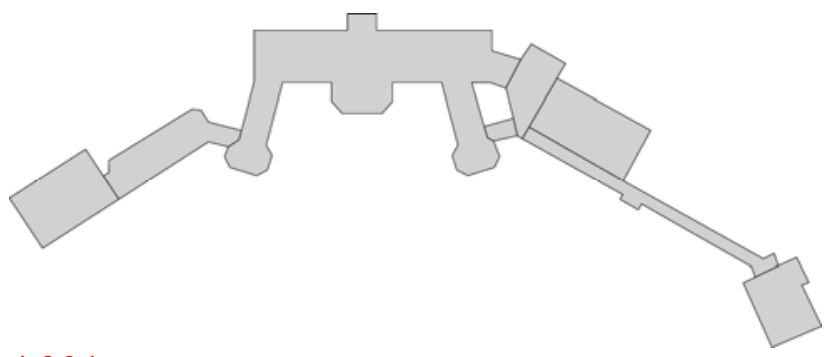

6.106

6.105 A. Aalto. Proyecto del Sanatorio de Paimio, Turku. Plano de situación1929, 1932, 1958 (dibujos de la autora).

6.106 Dr. Dettweiler. Sanatorio de Falkenstein, 1874 (dibujo de la autora). 
posibilidades de generar variaciones" ${ }^{102}$.

La sobriedad y la sencillez existentes en la habitación facilitan su alteración, al igual que la presencia de ciertos elementos móviles como las mesillas compuestas por dos piezas: una cajonera fija y una repisa superior autoportante que se desplaza para convertirse en una mesa que se coloca sobre la cama del enfermo. Elementos que mejoran el bienestar del mismo y que permiten ciertas variaciones en su entorno inmediato para combatir la sempiterna monotonía.

\section{EL PROCESO EVOLUTIVO DE LA ARQUITECTURA EN ALVAR AALTO}

Alvar Aalto entiende la arquitectura ante todo como un proceso:

"la arquitectura no consiste únicamente en unos determinados resultados ya acabados, sino que es, en mucha mayor medida, un proceso evolutivo complejo dentro del cual, gracias a una recíproca acción interna, surgen nuevas soluciones, nuevas formas, nuevos materiales e incesantes cambios en las ideas sobre la construcción" 103 .

Inmejorable ejemplo de constante búsqueda se aprecia en el complejo periplo seguido en la elaboración del proyecto del Sanatorio de Paimio. Se parte de una morfología preconcebida, la del sanatorio compacto de planta en forma de T, y se llega a definir un conjunto polimórfico donde, según lo describe S. Giedion, "las diferentes partes se hallan plenamente integradas como los órganos de un cuerpo, en que cada uno de los cuales posee sus funciones distintas, pero permaneciendo inseparables de los demás ${ }^{\prime 104}$. Gracias a un proceso que dirige el conocimiento de la disciplina heredada hacia una intuición, un proceso en el que se despoja de ataduras establecidas para imbuir una impronta genuina al origen:

"Guiado sólo por el instinto, desprendiéndome de las síntesis arquitectónicas, dibujo composiciones, a veces francamente infantiles, y de esa manera surge, poco a poco,

\footnotetext{
102 Alvar AALTO, "El racionalismo y el hombre" ("Rationalismen och människan" ), Jornadas Anuales de la Asociación Sueca de Artesanos, Estocolmo, 9 de mayo de 1935, en Göran SCHILDT (ed.), Alvar Aalto de palabra y por escrito (Alvar Aalto. In his own words, 1997), El Croquis Editorial, Madrid 2000, p. 131.

103 Alvar AALTO, "La Influencia de los métodos constructivos y de los materiales en la arquitectura moderna" ("Rakenteitten ja aineitten vaikutus nykyaikaiseen rakennustaiteeseen"), Conferencia pronunciada en las Jornadas Nórdicas de la Construcción, Oslo, 1938, Archivos de Aalto, en Göran SCHILDT (ed.), Alvar Aalto de palabra y por escrito (Alvar Aalto. In his own words, 1997), El Croquis Editorial, Madrid 2000, p. 136.

104 Sigfried GIEDION, Espacio tiempo y arquitectura (Cambridge, 1941). Dossat, Madrid 1982, p.611.
} 
desde una base abstracta, la idea principal, una especie de sustancia general que ayuda a armonizar entre sí numerosos problemas parciales y contradictorios" ${ }^{105}$.

Son su carácter, aficiones, viajes, experiencia profesional y personal, así como su conocimiento, destreza y formación los que influyen en su forma de proyectar y acaban por determinar su arquitectura.

En el caso del Sanatorio de Paimio es posible apreciar la influencia de la profesión de agrimensor de su padre, que despierta en él una férrea atención por el territorio ${ }^{106}$ y el entorno, reflejada en la forma de implantar el edificio y en el diseño de una nueva topografía a través del proyecto del jardín escalonado siempre presente desde los primeros bocetos $^{107}$, cuyo perfil revive la belleza de las ciudades sobre las colinas contempladas por Aalto por primera vez durante su viaje a Italia en 1924. Aunque es quizás en otro sanatorio suyo que no llega a ser construido, el Sanatorio antituberculoso de Kälviä proyectado en 1929, en donde la vinculación con el entorno cobra una mayor relevancia.

El Sanatorio de Kälviä, más compacto que Paimio, se localiza en un terreno muy escarpado [fig. 6.107] y consta de un bloque lineal de habitaciones que se escalona en dos niveles de tres y cinco alturas respectivamente, conectado a otros dos volúmenes rectangulares más bajos que contienen los servicios comunes. El volumen del cuerpo de habitaciones se afila y se achaflana en el extremo más próximo al acceso, aumentando su esbeltez, y va creciendo en altura hacia la entrada, rematándose con un escultórico cilindro seccionado, tan sólo esbozado en el proyecto, cuyo perfil también se afila y se remata en punta, remarcando el crecimiento estratificado y ascendente del bloque de habitaciones [fig. 6.108 y fig. 6.109].

A pesar de la imagen funcionalista del Sanatorio de Paimio, en él se pueden apreciar ciertas influencias de las formas de la arquitectura tradicional, muy respetada por Aalto. Éstas se manifiestan en las plazas o patios abiertos generados en los amplios intersticios existentes entre las distintas partes del edificio principal, que tienen vínculos con la arquitectura del país como destaca J.M. Montaner:

105 Alvar AALTO, "La trucha y el torrente de montaña" ("Taimen ja tunturipuro"), Domus, vía Arkkitehti n ${ }^{\circ} 7 / 10,1948$, en Göran SCHILDT (ed.), Alvar Aalto de palabra y por escrito (Alvar Aalto. In his own words, 1997), El Croquis Editorial, Madrid 2000, p. 149.

106 Alvar AALTO, "La mesa blanca" ("Det vita bordet"), Archivo Aalto, en Göran SCHILDT (ed.), Alvar Aalto de palabra y por escrito (Alvar Aalto. In his own words, 1997), El Croquis Editorial, Madrid 2000, p. 16.

107 También pudo influir en la vinculación de su arquitectura con el medio ambiente natural la afición por la práctica de deporte al aire libre. En su juventud había sido cazador, después esquiador y en los veranos un nadador de largas distancias en los lagos finlandeses hasta el final de su días. 
"También la arquitectura urbana finlandesa se ha organizado históricamente en manzanas semiabiertas, con edificios aislados, de formas lógicas y distintas, que siguen las alineaciones de las calles y que van formando un sistema complejo de patios con anexos y almacenes en el interior " 108.

Espacios que ayudan a incorporar el entorno próximo en el edificio y que aparecen también en proyectos anteriores vinculados a la salud como el Hospital Municipal de Alajärvi en Finlandia construido en 1924 [fig. 6.110] o el proyecto para el concurso del Sanatorio de Kinkomaa realizado 1927 [fig. 6.111] donde, como anteriormente se ha dicho, existe una agrupación del programa en cuerpos independientes que se ordenan en torno a espacios semiabiertos, en este caso ortogonales, que ocasionalmente adquieren carácter de plazas. Un sanatorio que es un precedente de Paimio en este tema.

Los proyectos y obras sanitarias realizadas por Aalto al principio de su carrera ${ }^{109}$, le hacen sensibilizarse con la importancia de la salud hasta el punto que en 1930 declara: "Las únicas causas y motivos posibles susceptibles de reemplazar a los antiguos, son consideraciones científicas sobre lo que los hombres y la sociedad precisan para seguir siendo, o más bien, convertirse en un organismo sano" ${ }^{110}$. La sensibilidad hacia la salud, en toda su dimensión, queda patente y cuando tiene entre manos un proyecto específico sobre estos programas utiliza el lenguaje formal moderno de forma indisociable como ocurre en Paimio.

La influencia de ciertas edificaciones de la vanguardia europea como el Sanatorio de Zonnestraal [fig. 6.112] que visita durante su viaje a París realizado poco tiempo antes de elaborar el proyecto es evidente. Presente tanto en la organización radial de su planta como en la enorme chimenea del cuerpo de instalaciones [fig. 6.113], o en la pasarela de conexión que une este volumen con el de los servicios comunes, Zonnestraal sirve de guía a sus reflexiones.

Una vez en París, Aalto y su mujer visitan la Villa Stein-de- Monzie, [fig. 6.114] cuyas franjas horizontales de sus ventanas corridas resultan perfectamente reconocibles en la fachada del

\footnotetext{
108 Josep María MONTANER, Sistemas arquitectónicos contemporáneos. Editorial Gustavo Gili, Barcelona 2009, p. 81

109 Se incluyen otros proyectos relacionados con la salud aunque no sean hospitales, como las residencias de ancianos de Jyväskylä y de Säynätsalo que realiza en el año 1925, o su participación en el concurso para la construcción de un Spa en Pärnu en Estonia en 1927.

110 Alvar Aalto, "El problema de la vivienda" ("Var bostad som problem"), Domus n 8-10, 1930, en Göran SCHILDT (ed.), Alvar Aalto de palabra y por escrito (Alvar Aalto. In his own words, 1997), El Croquis Editorial, Madrid 2000, p. 111.
} 


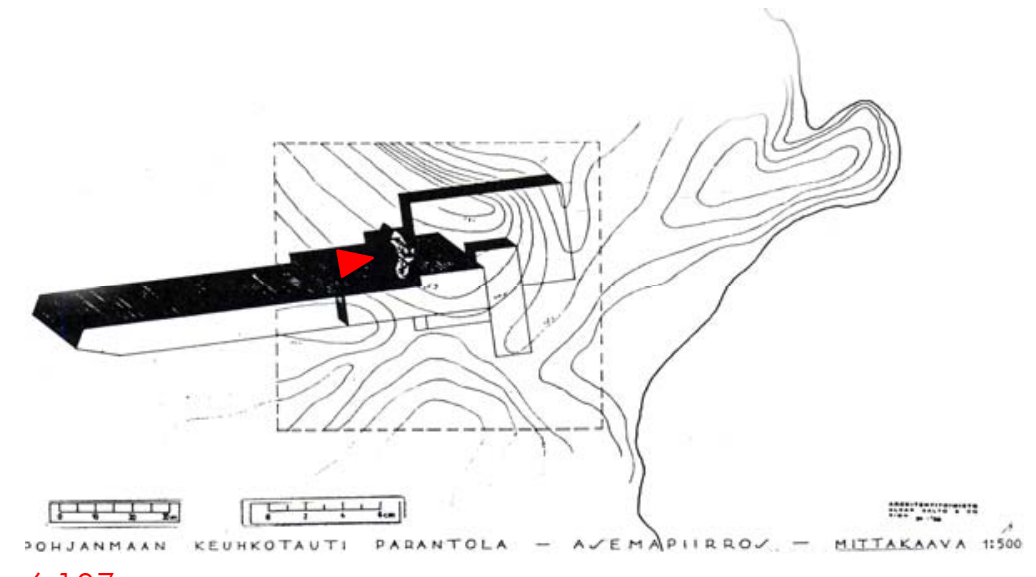

0

6.107

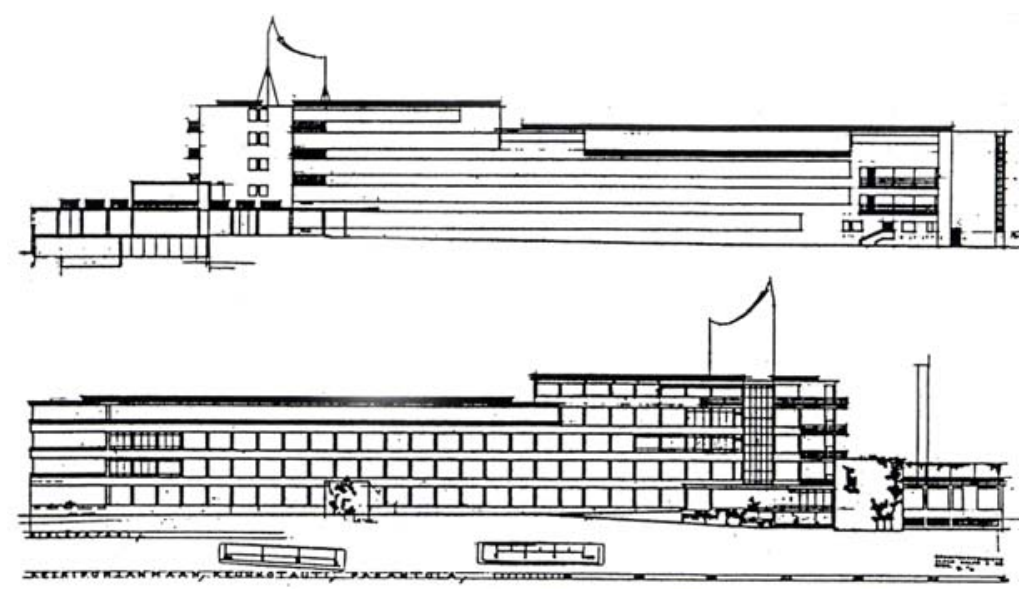

6.108

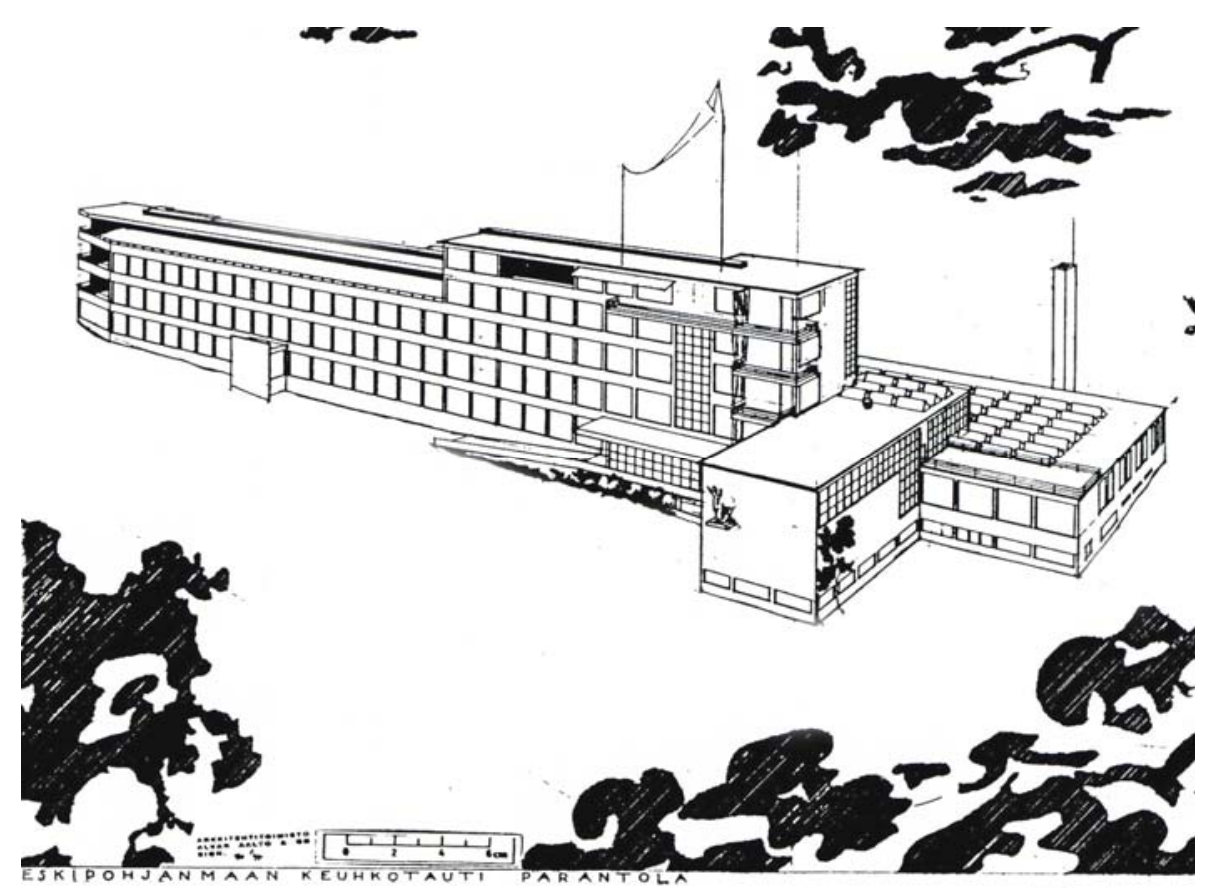

6.109

6.107 A. Aalto. Proyecto del Sanatorio de Kälviä, Kokkola, 1929. Plano de situación (50/38).

6.108 A. Aalto. Proyecto del Sanatorio de Kälviä, Kokkola, 1929. Frentes del bloque de habitaciones (50/46).

6.109 A. Aalto. Proyecto del Sanatorio de Kälviä, Kokkola, 1929. Perspectiva (50/47). 

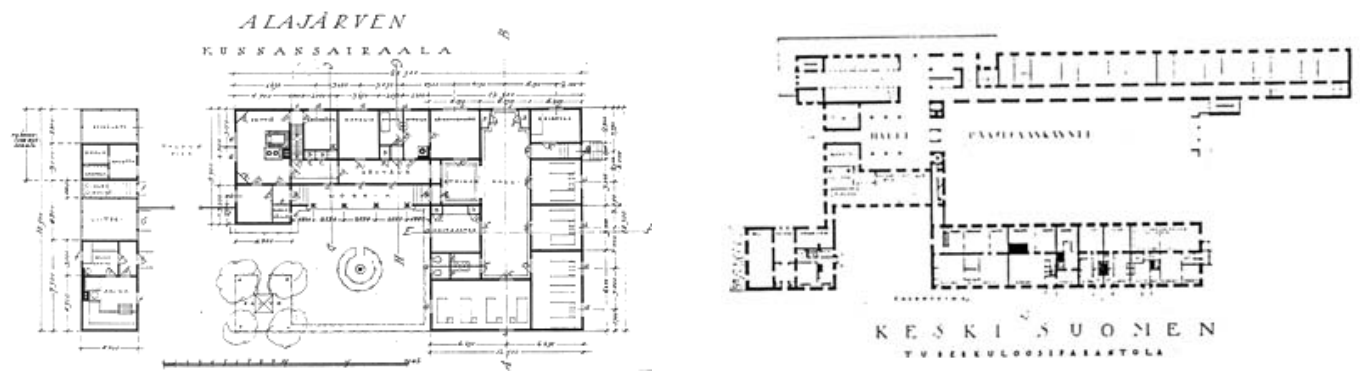

6.110 y 6.111
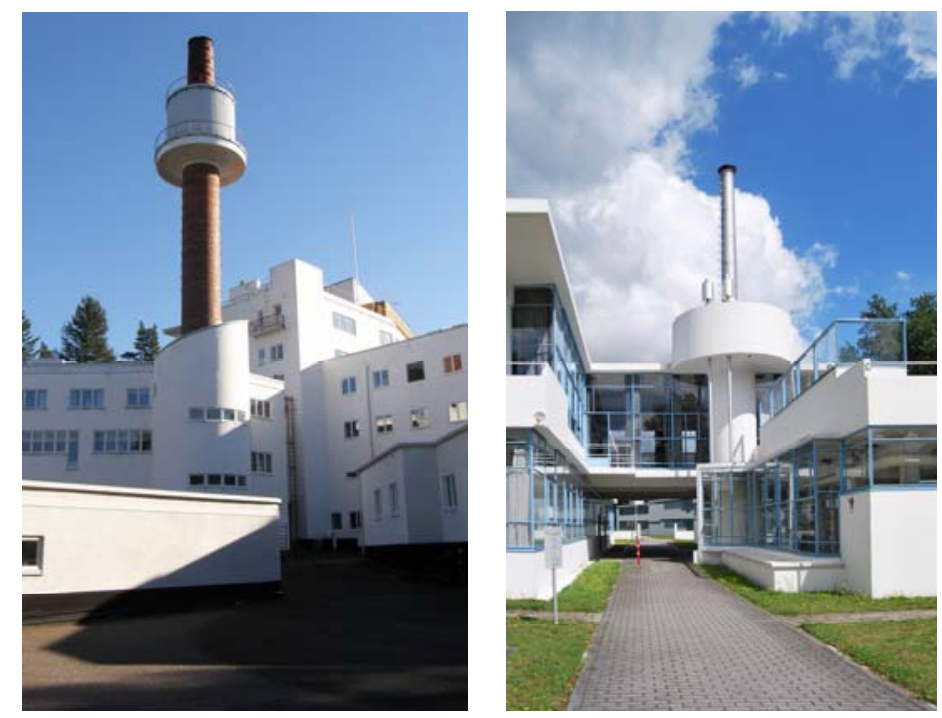

6.112 y 6.113
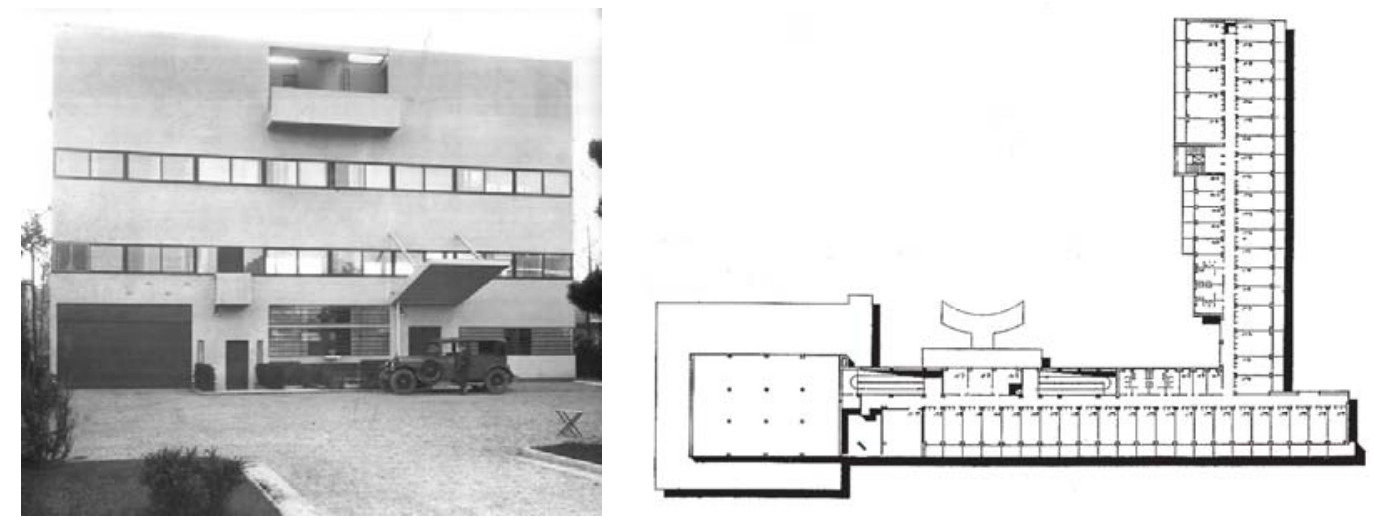

6.114 y 6.115

6.110 A. Aalto. Hospital Municipal de Alajärvi, 1924. Planta baja (50/46).

6.111 A. Aalto. Proyecto del Sanatorio de Kinkomaa, 1927. Planta baja (50/23.3).

6.112 A. Aalto. Sanatorio de Paimio, Turku, p.1928-1932. Frente del bloque de instalaciones (fotografía de la autora).

6.113 J. Duiker. Sanatorio de Zonnestraal, Hilversum, 1926-1928. Fachada principal (fotografía de la autora).

6.114 Le Corbusier. Villa Stein-de- Monzie, Garches, 1926-1927. Fachada principal.

6.115 N. J. Kolli. Proyecto de Casa de Salud del Cáucaso, URSS (publicado en L'Architecture vivante 1933). 

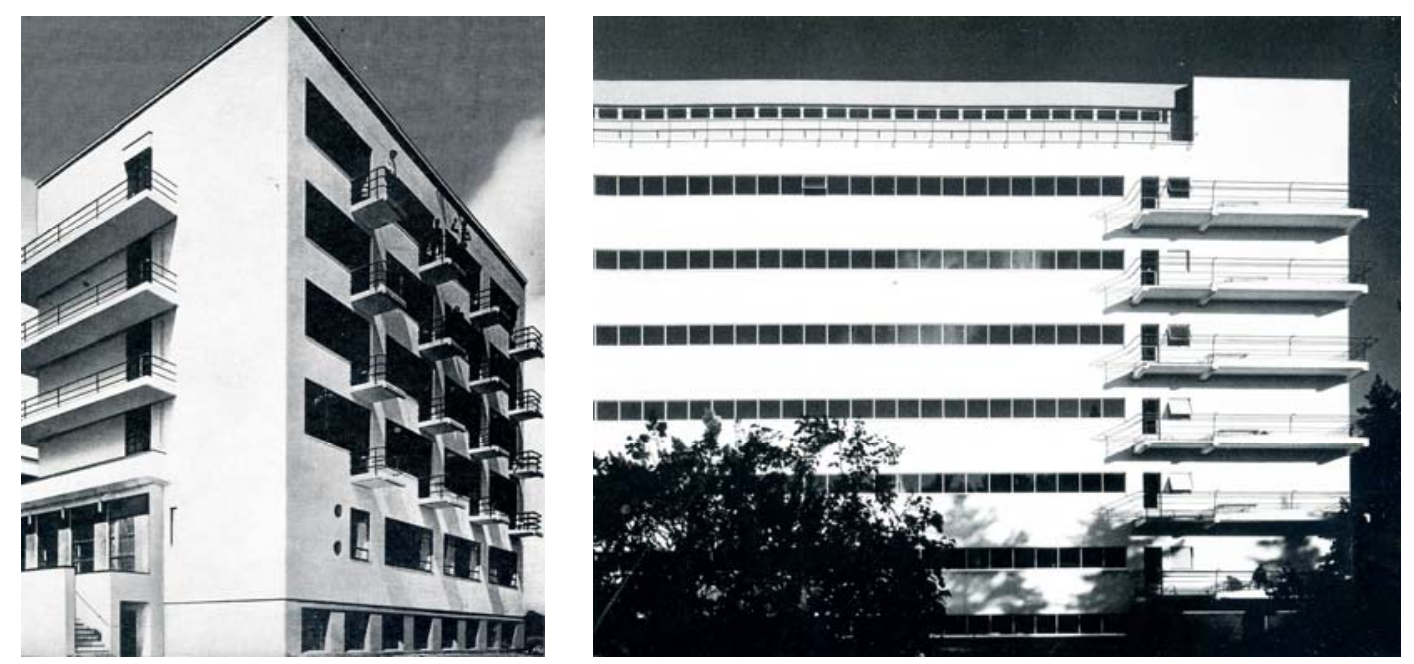

6.116 y 6.117
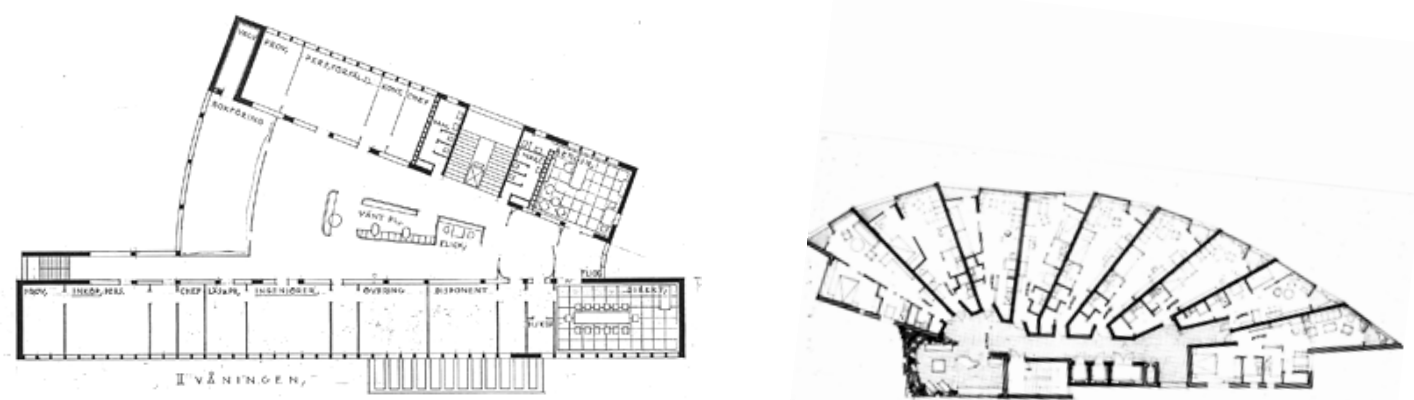

\subsection{8 y 6.119}
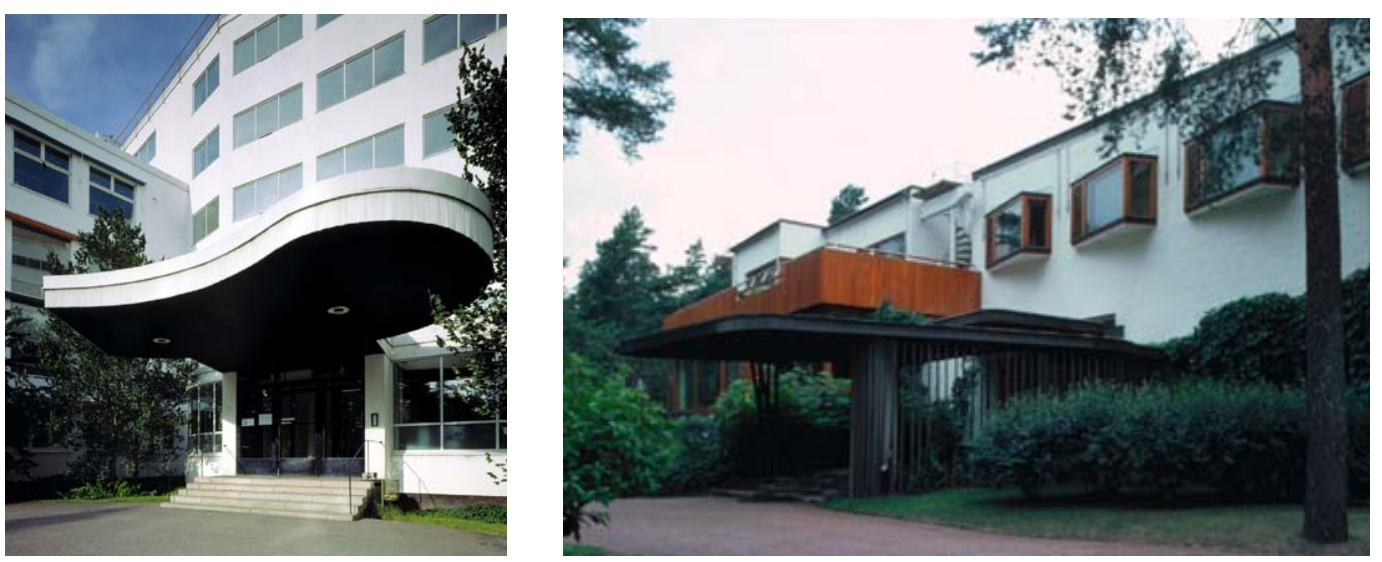

6.120 y 6.121

6.116 W. Gropius. Escuela de la Bauhaus, Dessau, 1925-1926. Vista exterior.

6.117 A. Aalto. Sanatorio de Paimio, Turku, p.1928-1932. Detalle fachada.

6.118 A. Aalto. Proyecto para la sede de la G.A. Serlachius Co., Mänttä-Vilppula, 1929. Planta baja.

6.119 A. Aalto. Torre de "Neve Vahr", Bremen, 1958-1962. Planta tipo.

6.120 A. Aalto. Sanatorio de Paimio, Turku, p.1928-1932. Detalle marquesina.

6.121 A. Aalto. Villa Mairea, Noormarkku, 1938. Detalle marquesina. 
corredor del bloque de habitaciones, ubicado junto al acceso principal ${ }^{111}$. Incluso el mismo recurso utilizado por Le Corbusier para marcar la entrada, a través de una marquesina en vuelo, se reconoce en el acceso diseñado por Aalto para Paimio y también en el del Sanatorio de Käliviä ${ }^{12}$, cuya forma resulta muy similar a la propuesta por el arquitecto N. J. Kolly en su proyecto para la Casa de Salud del Cáucaso, URSS, publicado en L'Architecture vivante (1933) [fig. 6.115].

Aalto sabe de sus obras antes de visitar París, de hecho, en su artículo "De los escalones de entrada al cuarto de estar" publicado en 1926, incorpora una fotografía del pabellón de I'Esprit Nouveau de París (1925) y lo describe como: "Un excelente ejemplo de la unión existente entre el interior de la casa y el jardín. Un hall que bellamente se abre hacia un exterior dominado por árboles, o bien puede ser un jardín construido dentro de la casa o una habitación-jardín" 113.

Lo mismo sucede con la arquitectura alemana que conoce a través de su amigo el arquitecto Sven Markelius, quien en 1927 visita la Weissenhof de Stuttgart y el edificio de la Bauhaus de Gropius ${ }^{114}$ con el que el Sanatorio guarda también una cierta similitud, tanto por la configuración formal del edificio, pues ambos se articulan en partes y definen una forma abierta, como en ciertos elementos del mismo. Las terrazas lineales protegidas por livianas barandillas de la Bauhaus de Dessau [fig. 6.116] también aparecen en Paimio [fig. 6.117], lo mismo que ciertas soluciones acristaladas e incluso las ventanas en $L$ a las que en la Bauhaus se incorpora un pequeño balcón.

Sin embargo, el Sanatorio no sólo recoge las influencias de otras arquitecturas, sino que él mismo se convierte en un referente para otros arquitectos de la época, e incluso para su autor convirtiéndose como indica P. Blundell en: "la obra clave del principio de su madurez $z^{\prime 115}$. Ciertos aspectos expuestos o esbozados en Paimio los retoma y se desarrollan en el resto de sus obras.

El Sanatorio de Kikomaa, seguido del Sanatorio de Paimio, suponen un punto de inflexión

\footnotetext{
${ }^{111}$ En algunas soluciones iniciales del proyecto de Paimio se conciben ciertas formas redondeadas en planta en el cerramiento de los aseos que recuerdan a las adoptadas por Le Corbusier.

112 La marquesina de acceso del Sanatorio de Käliviä presenta la misma geometría en forma de fragmento convexo de anillo que la que inicialmente presenta el Sanatorio de Paimio.

113 Alvar AALTO, "De los escalones de entrada al cuarto de estar" ("Porraskiveltä arkihuoneeseen"), Aitta, 1926, en Göran SCHILDT (ed.), Alvar Aalto de palabra y por escrito (Alvar Aalto. In his own words, 1997), El Croquis Editorial, Madrid 2000, p. 71.

${ }^{114}$ Nicholas RAY, Alvar Aalto. Yale University Press, London 2005. p. 20.

115 Peter BLUNDELL JONES, Modelos de la arquitectura moderna: monografías de edificios ejemplares. Ed. Reverté, Barcelona 2011 , p.143.
} 

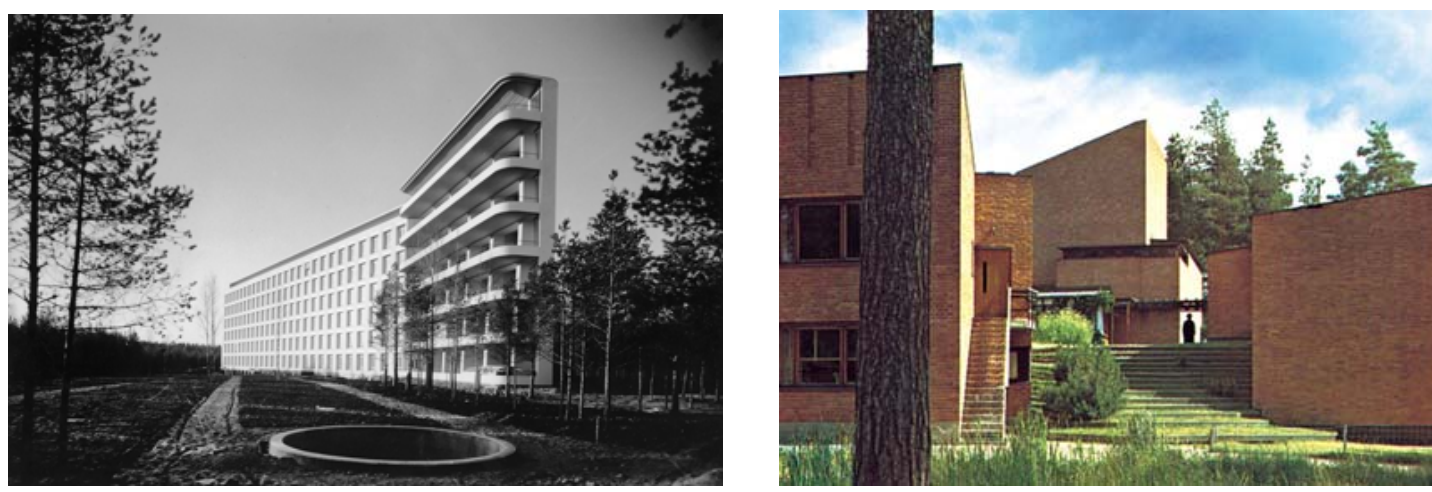

6.122 y 6.123
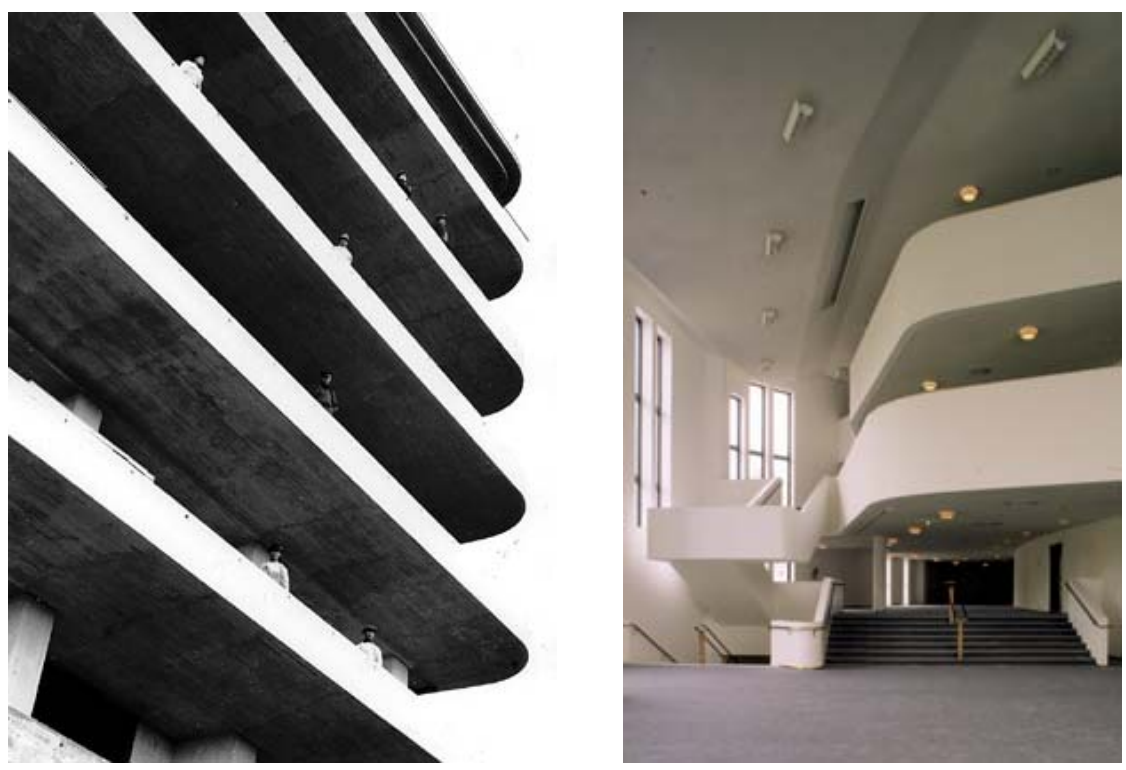

6.124 y 6.125
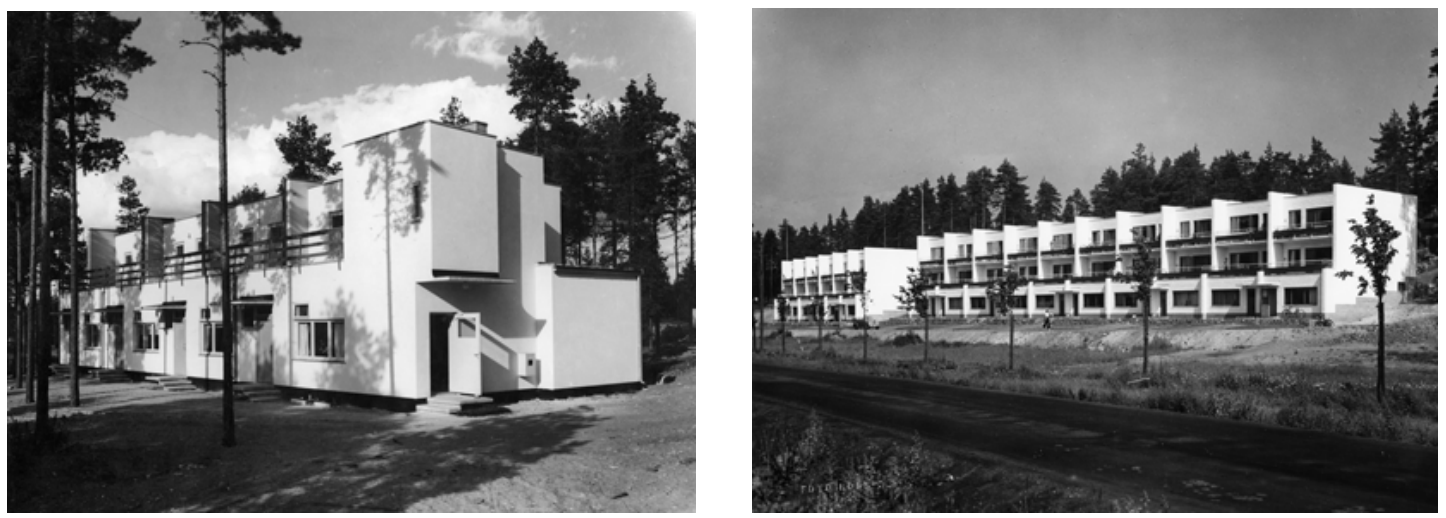

6.126 y 6.127

6.122 A. Aalto. Sanatorio de Paimio, Turku, p.1928-1932. Jardín de la galería de cura.

6.123 A. Aalto. Ayuntamiento de Säynätsalo, 1949-1952. Escalinata vegetal.

6.124 A. Aalto. Sanatorio de Paimio, Turku, p.1928-1932. Galería de cura en construcción.

6.125 A. Aalto. Ópera de Essen, p.1961-1964. Vestíbulo.

6.126 A. Aalto. Sanatorio de Paimio, Turku, p.1928-1932. Bloque de viviendas del personal.

6.127 A. Aalto. Viviendas de empleados fábrica de celulosa de Sunila, Kotka, 1937-1939. 

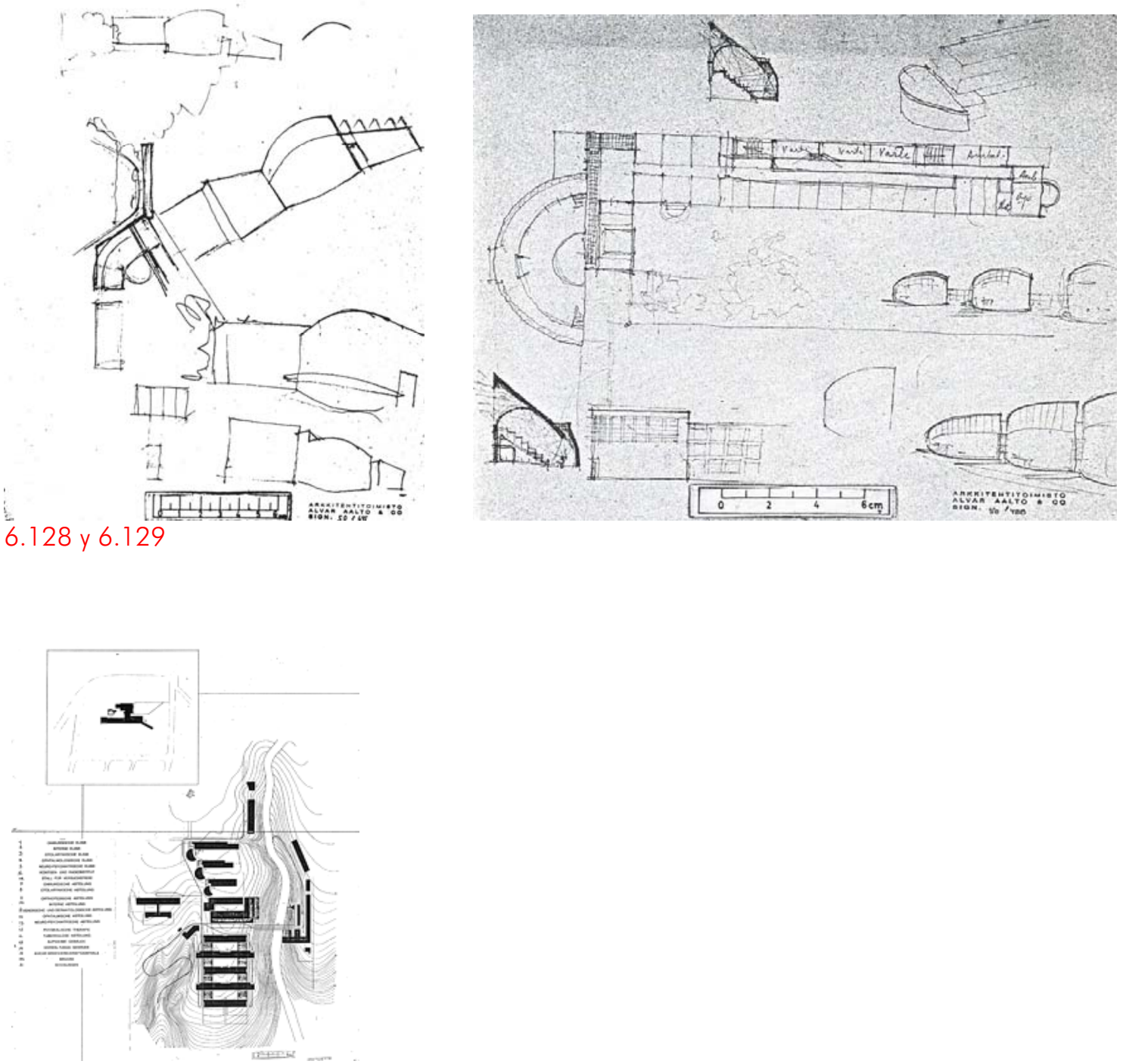

6.130
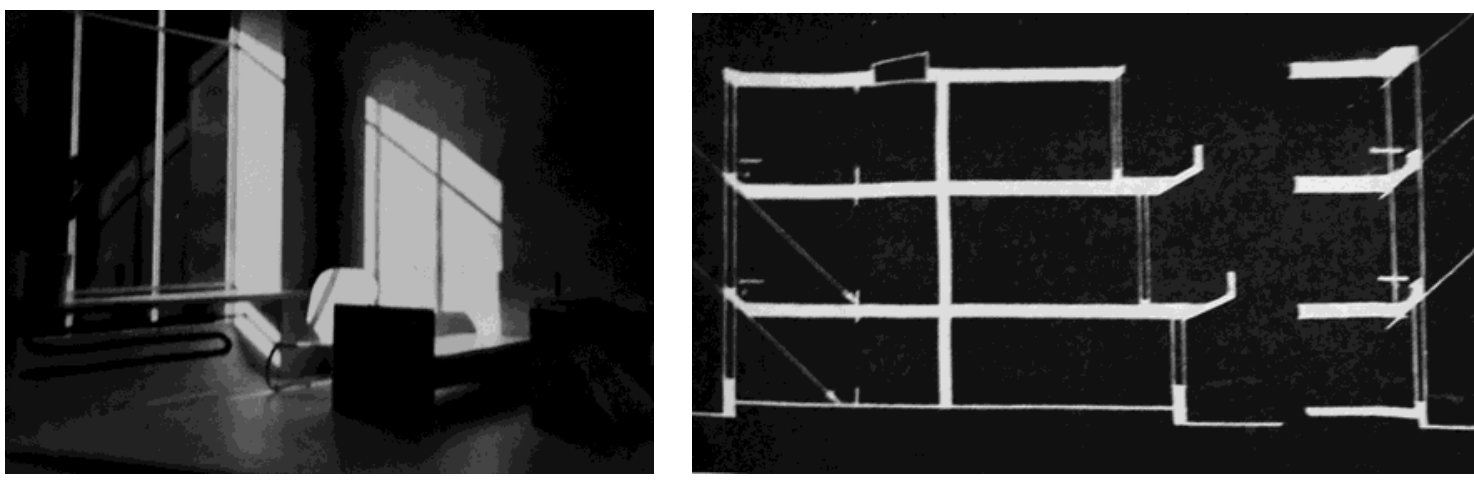

6.131 y 6.132

6.128 A. Aalto. Proyecto del concurso del Sanatorio de Paimio, Turku, 1929. Croquis (50/645).

6.129 A. Aalto. Proyecto del Hospital General de Zagreb, 1931. Croquis (50/488).

6.130 A. Aalto. Proyecto del Hospital General de Zagreb, 1931. Plano de situación.

6.131 A. Aalto. Proyecto del Hospital General de Zagreb, 1931. Maqueta de la habitación (Memoria del concurso del Hospital de Zagreb, AAA).

6.132 A. Aalto. Proyecto del Hospital General de Zagreb, 1931. Sección tipo (Memoria del concurso del Hospital de Zagreb, AAA). 

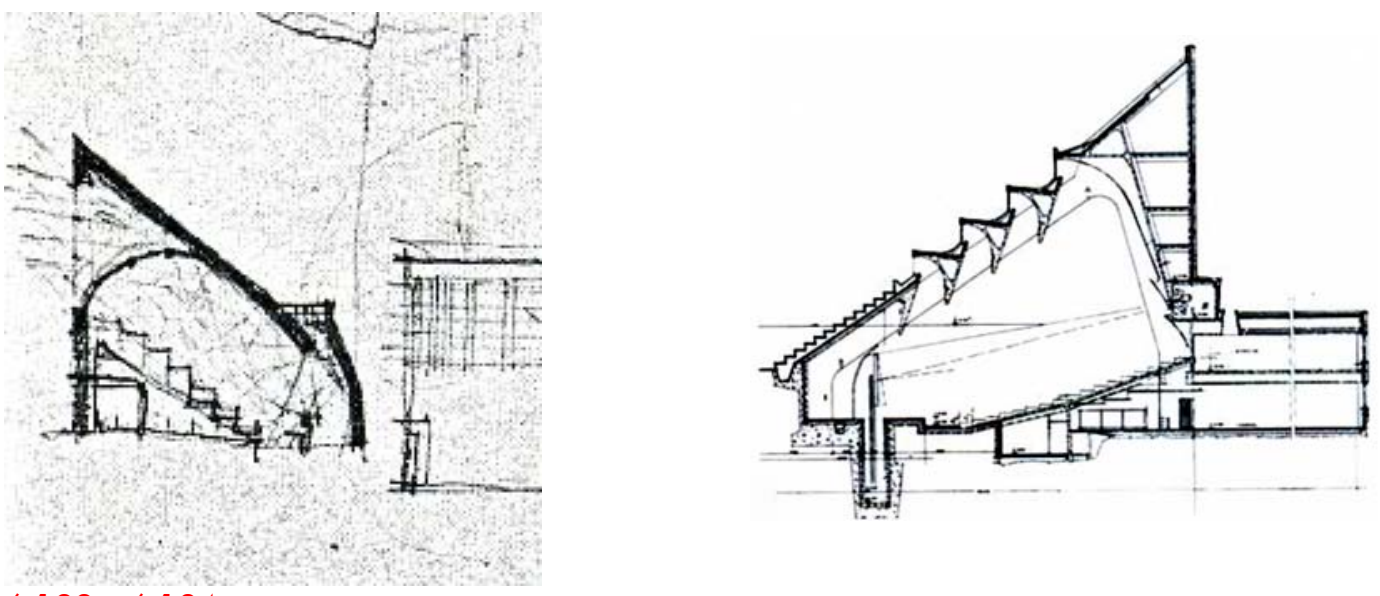

6.133 y 6.134
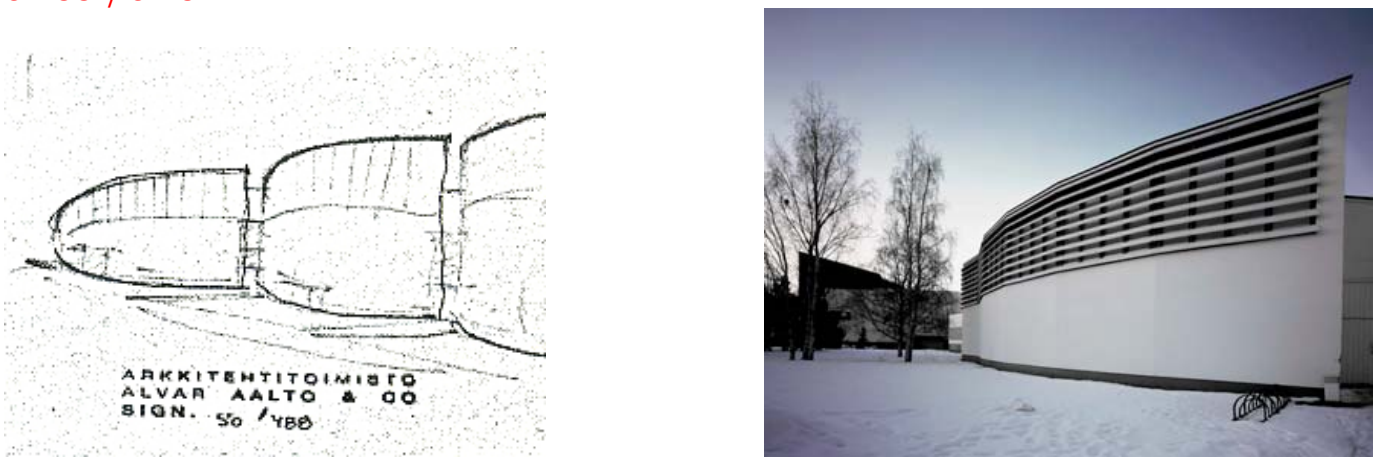

6.135 y 6.136
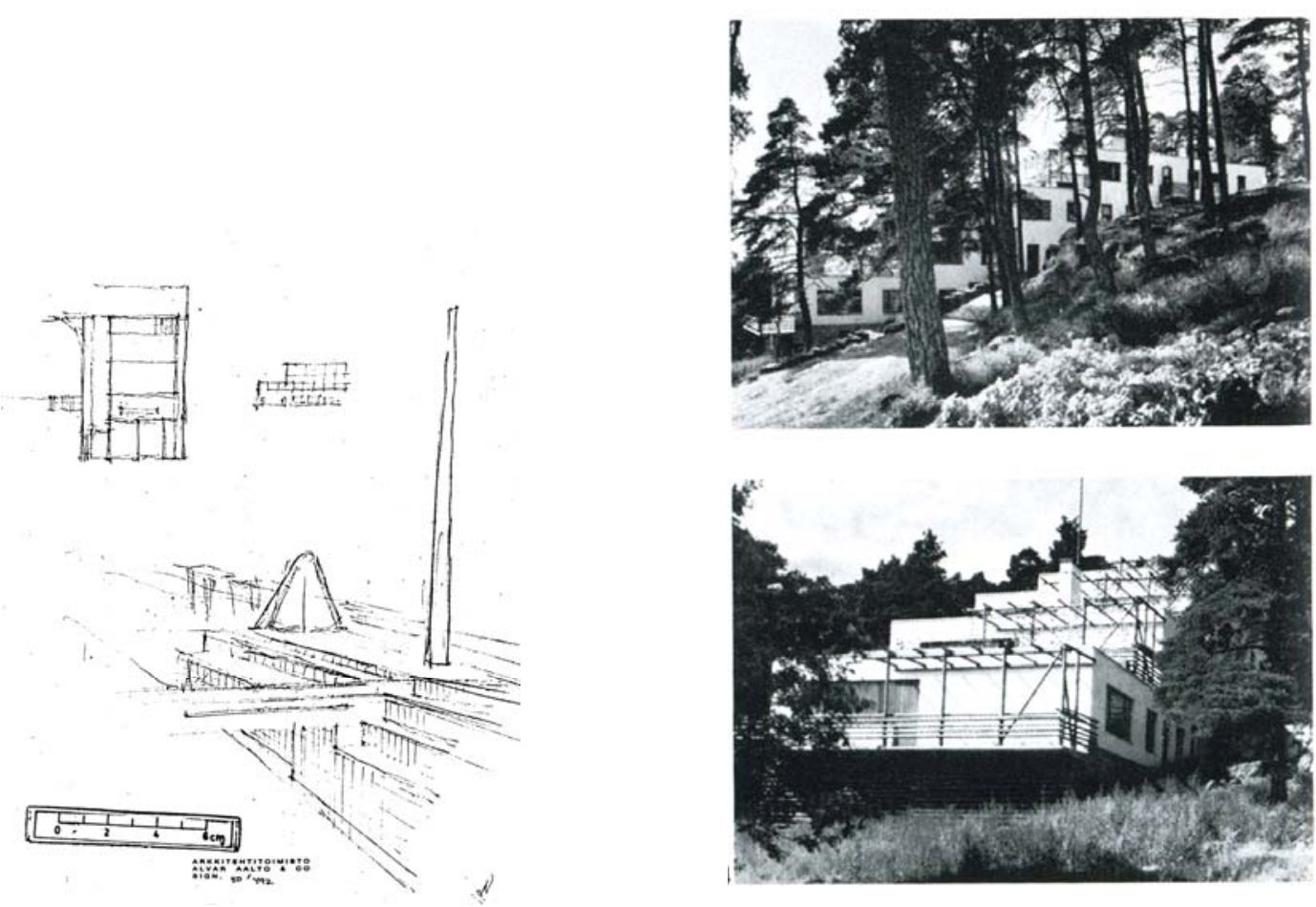

6.137 y 6.138

6.133 A. Aalto. Proyecto del Hospital General de Zagreb, 1931. Sección de auditorio (Fragmento de croquis 50/488).

6.134 A. Aalto. Universidad Politécnica de Otaniemi, Helsinki, 1955-1961. Sección de auditorio. 6.135 A. Aalto. Proyecto del Hospital General de Zagreb, 1931. Perspectiva exterior de los auditorios (Fragmento de croquis 50/488).

6.136 A. Aalto. Biblioteca de Seinäjoky, 1963-1965. Imagen exterior.

6.137 A. Aalto. Proyecto del Hospital General de Zagreb, 1931. Viviendas escalonadas para empleados (50/492).

6.138 A. Aalto. Ciudad residencial de Kauttua, 1937-1940. Imágenes exteriores. 
en su carrera al proponer una arquitectura por partes y una forma abierta inexistente hasta entonces en sus edificaciones; con Paimio se plantea además por primera vez una pérdida de la ortogonalidad y se propone una articulación radial donde la construcción diverge hacia el paisaje. Esta estructuración formal da lugar a crecimientos en abanico que tímidamente comienzan a surgir en el proyecto para la sede de la empresa G.A. Serlachius Co. realizado en 1929 [fig. 6.118] y las torres de viviendas de los años sesenta, como la torre de "Neue Vahr" (1958-1962), construida en Bremen, Alemania [fig. 6.119].

Sucede también que ciertos elementos singulares del Sanatorio de Paimio son posteriormente reinterpretados, como la marquesina curvilínea de la entrada que reaparece a modo de porche en la Villa Mairea (1938) [fig. 6.120 y fig. 6.121]; la creación de una nueva topografía a través del jardín escalonado junto a la galería de cura presente con mayor rotundidad en el Ayuntamiento de Säynätsalo (1949-1952) o el de Seinäjoki (19581965) [fig. 6.122 y fig. 6. 123]; al igual que la galería de cura, cuya reiteración de bandejas horizontales con los bordes redondeados alcanza una mayor sofisticación al adoptar formas más libres y orgánicas en los palcos de la Ópera de Essen, Alemania, proyectada entre 1961 y $1964^{116}$ [fig. 6.124 y fig. 6.125].

Las mismas reflexiones sobre la compactación de los espacios servidores y la liberación de los servidos de las viviendas del personal del Sanatorio existen en sus proyectos posteriores de viviendas colectivas, como en los bloques para los trabajadores de la fábrica de celulosa de Sunila (1937-1939) [fig. 6.126 y fig. 6.127]. Incluso ciertas ideas desarrolladas durante el proceso de proyecto del sanatorio que fueron finalmente rechazadas serán retomadas en otros proyectos suyos. Así, la propuesta de Aalto de crear un vestíbulo circular independiente que se despega del edificio es reutilizada en los auditorios circulares de los pabellones de otro proyecto hospitalario suyo, el Hospital de Zagreb [fig. 6.128 y fig. 6. 129].

En 1931 se celebra en Zagreb, Croacia, un concurso para la construcción del Hospital General. Aalto propone para el concurso un hospital de pabellones independientes conectados entre sí a través de pasarelas y puentes, puesto que se implanta en un terreno en pendiente. El conjunto responde a un programa muy complejo con dependencias de psiquiatría, de medicina interna, etc. e incluso un sanatorio antituberculoso. Aalto parte del Sanatorio de Paimio para proyectar el sanatorio del Hospital General de Zagreb y lo

\footnotetext{
116 También las formas cilíndricas y los recorridos en espiral de la chimenea del Sanatorio se ven de nuevo en la propuesta de Aalto para el concurso del mausoleo de Cristóbal Colón en Santo Domingo (1928-1929), con un faro cilíndrico de diecisiete plantas de altura recorrido perimetralmente por una rampa helicoidal.
} 
reproduce con una disposición más ortogonal y con un número menor de partes [fig. 6.130]. Utiliza la fotografía de un maqueta del interior de la habitación casi idéntica a la del Sanatorio de Paimio [fig. 6.131] para explicar cómo va a ser, en la que se ha perfeccionado el sistema de captación de luz, pues no sólo inclina el suelo junto a la ventana, como hace en Paimio para facilitar su limpieza, sino que también inclina el techo para lograr una mayor captación de los rayos solares, como explica en una pequeña sección que acompaña a la memoria [fig. 6.132].

El diseño de los auditorios circulares de los pabellones del Hospital de Zagreb, según Göran Schildt "anuncian dramáticamente el edificio principal de la Universidad Politécnica de Helsinki en Otaniemi, de $1967^{\prime \prime 17}$, directamente apreciable al comparar las secciones de ambos proyectos [fig. 6.133 y fig. 6. 134]; lo mismo se observa sobre ciertas disposiciones formales creadas por la concatenación de las geometrías curvas de los tres auditorios de los distintos pabellones paralelos entre sí, esbozadas en las vistas generales de los croquis del proyecto, se materializan en construcciones más tardías como en la Biblioteca de Seinäjoki proyectada en 1963 [fig. 6.135 y fig. 6. 136].

En el Hospital General de Zagreb se utiliza la sección escalonada también para un bloque de diez pisos con las viviendas del personal que se anticipa al proyectado para la Ciudad residencial de Kauttua entre 1937 y 1940 [fig. 6.137 y fig. 6. 138], también escalonado y con terrazas $^{118}$.

La presencia de ciertos elementos y estructuras formales recurrentes confirman una continuidad en la arquitectura de Aalto que permite entender su proceso evolutivo e interpretar su carrera en claves tipológicas como propone R. Moneo en su conferencia "Principios tipológicos de Alvar Aalto", pronunciada en la Escuela de Arquitectura de Barcelona en Febrero de $1981^{119}$.

Moneo expone que las ideas y formas del primer período moderno de Aalto, en el que destacan las obras del Sanatorio de Paimio y la Biblioteca de Viipuri, serán retomadas más tarde, y llega a advertir que en los años 60 la matriz tipológica es una constante en su hacer: "es su clara conciencia de cómo aplicar el concepto de estructuración tipológica el

117 Göran SCHILDT, Alvar Aalto. Obra completa: arquitectura, arte y diseño. Editorial Gustavo Gili, S.A., Barcelona 1996, p. 69.

118 Después del proyecto del Hospital de Zagreg Aalto participó en varios concursos de centros hospitalarios de menor envergadura como: el concurso de ordenación del Conjunto Hospitalario de Kivelä (1950), en Helsinki, y el concurso para el Hospital Glostrup (1951) en Copenhague, Dinamarca, cuyos proyectos no llegaron a ser construidos.

119 Según las definiciones de tipo descritas por Rafael Moneo en su artículo "On Typology", Oppositions n¹3, 1978. 
que le permite responder, con tanta rapidez y seguridad, a los encargos que a su estudio vienen confiados' ${ }^{\prime 20}$.

Hay que entender que la estructuración tipológica no se refiere a la mímesis de soluciones anteriormente adoptadas, sino a la variación y a la mejora de las mismas, en un proceso continuo de constante evolución que ratifica la aseveración de C. Martí Arís: "toda verdadera arquitectura posee una matriz tipológica, ya sea patente o solapada, que puede rastrearse como una especie de etimología de la forma"121.

120 Rafael MONEO, conferencia no publicada con título: "Principios tipológicos de Alvar Aalto", Escuela de Arquitectura de Barcelona, Febrero 1981. Reproducida parcialmente en los vídeos de la // Setmana Cultural (1981) Alvar Aalto: i la difussió del Moviment Modern dentro del ciclo Conferències Setmana Cultural ETSAB 1980-1990.

${ }^{121}$ Carlos MARTÍ ARÍS, Las variaciones de la identidad. Ensayos sobre el tipo en arquitectura. Serbal, Barcelona 1993, p. 191. 
III. HACIA UNA ARQUITECURA TERAPÉUTICA

CAPÍTULO 7

ESPACIOS PARA MORIR Y ESPACIOS PARA VIVIR

SANATORIOS, BUQUES INSIGNIA DE LA VANGUARDIA ARQUITECTÓNICA

LA RESIDENCIA MODERNA COMO MÁQUINA DE SANAR

EL URBANISMO HIGIENISTA Y LA CIUDAD SANATORIO

ARQUITECTURA Y PATRIMONIO DE LA SALUD 


\section{SANATORIOS, BUQUES INSIGNIA DE LA VANGUARDIA ARQUITECTÓNICA}

Nada más concluir la Primera Guerra Mundial, a causa de las necesidades de la población, la arquitectura con un mayor carácter social como la vinculada a la construcción de hospitales, encargada de proteger la salud pública, cobra un especial protagonismo.

Hasta entonces: "la arquitectura hospitalaria era coto de la ciencia, y había que ir a su encuentro" ${ }^{\prime 1}$. La importancia que en la concepción de la arquitectura sanitaria tienen los procedimientos clínicos y terapéuticos provoca un distanciamiento entre el arquitecto y el hospital, asumiéndose la supremacía del médico en la configuración del mismo. No es extraño que esta postura sea defendida en el campo de la medicina; así, Cano de León, miembro de la Sociedad Española de Higiene, expone a finales del siglo XIX:

"No es competencia del ingeniero estudiar cuáles son las condiciones higiénicas de los hospitales, cuál debe ser su capacidad y la distribución de sus distintas dependencias. Todo eso pertenece al médico. Correspóndele al ingeniero ser auxiliar del higienista, el ejecutor de sus ideas, el que lleve a la práctica el pensamiento que aquel ha concebido" ${ }^{2}$.

Postura que en el período de entreguerras se va a ver refrendada también por el campo de la arquitectura: "A la arquitectura no le tiene que extrañar ser sometida a otra autoridad, en ocasiones particulares en las que la ciencia interviene, tratando asuntos que se encuentran por encima de ella misma "3, afirma Jan Badovici.

Es en torno a los años treinta cuando estas edificaciones se convierten en unas de los más interesantes para ciertos arquitectos de la época, quienes consideran que: "Si a una cosa cabe dedicar los modernos principios de la construcción, el espiritu renovador de la arquitectura, es a edificios de esta índole "4, como publica en 1933 la revista A.C. Documentos de Actividad Contemporánea refiriéndose a los hospitales; actitud que se

\footnotetext{
' Antonio PIZZA, José M. ROVIRA, GATCPAC 1928-1939. Una nueva arquitectura para una nueva ciudad. Colegio de arquitectos de Cataluña. Barcelona 2006, p. 194.

${ }^{2}$ Mercedes INSUA CABANAS, Arquitectura hospitalaria gallega de pabellones. Universidad de La Coruña, La Coruña 2002, p. 141.

3 Jean BADOVICl, "Architectura Hospitalière" en L'architectura Vivante Otoño-Invierno 1933. № 41 42, p. 5. Ricardo MARCO FRAILE, Carlos BUIL GUALLAR (coor.) L'architectura Vivante: el documento arquitectónico del movimiento. Colegio Oficial de Arquitectos de Aragón, Zaragoza 2004.

${ }^{4}$ AA.W. "Un fallo lamentable. El concurso de anteproyectos para el nuevo hospital de San Sabastián" en AC Documentos de Actividad Contemporánea, n 11, 1933, p.39. Belén GARCÍA-QUIÑONES (coord.), AC Publicación del GATEPAC. Fundación Caja de Arquitectos. Barcelona 2005, p. 571.
} 

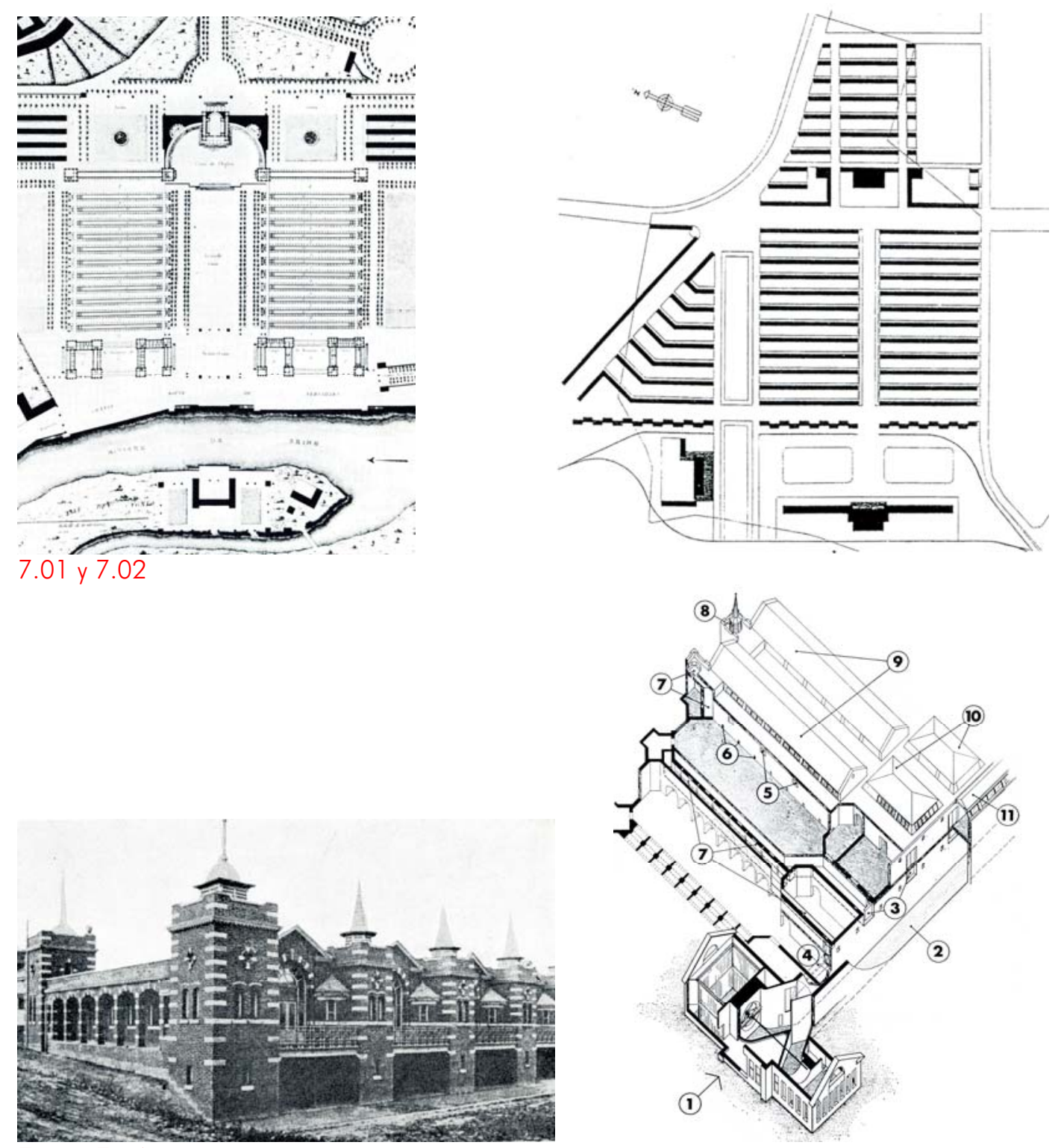

7.03 y 7.04
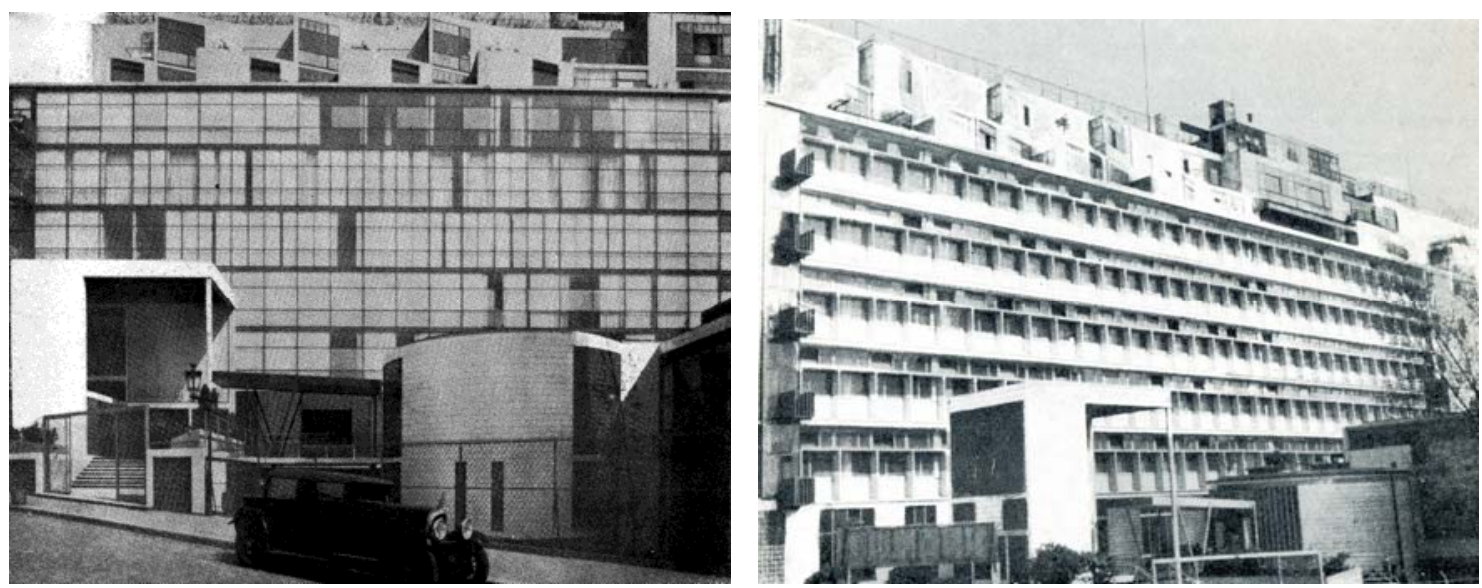

7.05 y 7.06

7.01 J. B. Le Roy. Proyecto para el nuevo Hôtel-Dieu, París, 1787.

7.02 Hinsch y Deimling. Siedlung Haselhort, Berlín, 1929.

7.03 y 7.04 Henman y Cooper. Royal Victoria Hospital, Belfast, 1903. Vista exterior y sistema de ventilación y climatización, perspectiva seccionada.

7.05 y 7.06 Le Corbusier. Cité Refuge, París, 1933. Vista de la fachada original y de la reformada. 
reafirma en la aparición de una serie de artículos y publicaciones especiales sobre el tema ${ }^{5}$.

El hospital aúna desde su desarrollo en el siglo XVIII ciencia y arquitectura, pero es el ideal de la máquina de funcionamiento perfecto el que va a inocularse en su base hasta convertirse en una de sus premisas fundamentales.

Con motivo de la construcción del nuevo Hôtel-Dieu de París el físico francés Jean Baptiste Le Roy describe su propuesta de hospital como una "máquina de curar" ${ }^{\prime \prime}$. Se aplica así por primera vez en 1773 el concepto de "herramienta eficiente" a la arquitectura, casi dos siglos antes de que Le Corbusier definiera en su libro Vers une architecture (1923), la casa como una "máquina de habitar" :

"Si se arrancan del corazón y del espíritu los conceptos inmóviles de la casa y se enfoca la cuestión desde el punto de vista crítico y objetivo, se llegará a la casaherramienta, a la casa accesible a todos, sana, incomparablemente más sana que la antigua (moralmente también) y bella, con la estética de las herramientas de trabajo que acompañan nuestra existencia ${ }^{18}$.

Esta vinculación a la salud y a la ciencia presente en la arquitectura sanitaria facilita los traspasos formales del hospital a las nuevas viviendas modernas; y así, al igual que en su día las arquitecturas palaciegas sirven de referencia a la arquitectura hospitalaria, ahora son las formas y las organizaciones hospitalarias las que se trasladan a la arquitectura residencial. C. Martí Arís argumenta en su libro Las formas de la residencia en la ciudad moderna, cómo la disposición en planta de los idénticos pabellones independientes y ventilados, perfectamente alineados y paralelos entre sí, del proyecto para el nuevo HôtelDieu de París realizado por Le Roy [fig.7.01], sirve de inspiración a los bloques lineales de vivienda colectiva de las Siedlungen berlinesas, en concreto a la Siedlung Berlín-Haselhort,

\footnotetext{
5 Como los artículos: SCHACHNER, Benno; "Idées directrices pour la construction d'un Hôpital" (Baumeister, 9 oct. 1931), L'Architecture vivante n 41,1933, pp. 18-22; "La Central médica de Nueva York", Arquitectura n 119, Sociedad Central de Arquitectos,1929, pp. 141-144; o "Concurso de anteproyectos de un Hospital en San Sebastián", Arquitectura n' 1, Colegio Oficial de Arquitectos, 1934, pp. 1-2; y "Primer Congreso Nacional de Sanidad", Arquitectura n 4, Colegio Oficial de Arquitectos, Madrid, 1934, pp. 75-82; entre otros.

"Son muchos los libros de arquitectura hospitalaria que analizan el concepto de "máquina de curar" pero, cabe destacar entre todos ellos, la obra de Michel Foucault escrita junto a Blandine Barret Kriegel, Anne Thalamy, François Beguin y Bruno Fortier: Les Machines à guérir: aux origines de l'hôpital moderne. Pierre Mardaga, Bruxelles, 1979.

${ }^{7}$ LE CORBUSIER, Hacia una Arquitectura (1923). Poseidon, Barcelona 1978, p.73.

8 Kenneth FRAMPTON, Historia crítica de la arquitectura moderna (1980). Editorial Gustavo Gili, Barcelona 2009, p. 154.
} 
proyectada por Hinsch y Deimling en $1929^{9}$ [fig.7.02].

Sin embargo, la modernidad tecnológica aplicada en la concepción del hospital no concuerda con su estética. El Royal Victoria Hospital de Belfast, Irlanda, construido en 1903 por los arquitectos Henman y Cooper, considerado por Reyner Banham como un edificio "extremadamente 'moderno'"10 por el particular uso de la tecnología que en él se propone, al ser el primero con aire acondicionado aplicado al confort humano, muestra aún un estilo clasicista $^{11}$ [fig.7.03].

El aprovechamiento de la tecnología para procurar bienestar presente en este hospital, presidirá la nueva arquitectura del siglo XX; ya que la tecnología no fue el motor del advenimiento del Movimiento Moderno, fue su veterano acompañante, como Marcel Brever detecta en 1934: "El origen del Movimiento Moderno no fue tecnológico, pues la tecnología ya se había desarrollado mucho tiempo atrás... Lo que hizo la nueva arquitectura fue civilizar la tecnología" ${ }^{\prime 2}$.

Los arquitectos del Royal Victoria Hospital, influidos por la industria naviera desarrollada en Belfast donde se fabrican los sistemas de ventilación forzada de los buques, proponen la creación de un conjunto de salas yuxtapuestas y sin ventanas iluminadas a través de lucernarios donde, para evitar la contaminación ambiental de la ciudad, se instala un sistema de aire acondicionado que recorre todo el hospital. El sistema dispone de una enorme sala de máquinas con un gran ventilador donde el aire se purifica, se humedece y se calienta o se enfría para mantener así unas perfectas condiciones de higiene y confort en el interior de las salas de enfermos [fig.7.04].

Este hospital se adelanta al concepto de "respiration exacte" (respiración exacta) desarrollado por Le Corbusier en 1930, gracias al cual se lograrían construir viviendas para cualquier lugar: "Cada país construye casas para su propio clima. En esta época de penetración internacional de las técnicas científicas, yo propongo: un solo edificio para

\footnotetext{
9 Carlos MARTí ARÍS, Las formas de la residencia en la ciudad moderna (1991). Universidad Politécnica de Cataluña, Barcelona 2000, p. 45.

${ }^{10}$ Reyner BANHAM, La arquitectura del entorno bien climatizado (1969). Infinito, Bueno Aires 1975, p.88.

${ }^{11}$ Reyner Banham critica la falta de reconocimiento por parte de los historiadores del funcionalismo del Royal Victoria Hospital de Belfast, precursor, en su opinión, de las obras diseñadas por Walter Gropius. Indica que probablemente no aparece recogido en la obra de Pevsner Pioneros del Movimiento Moderno por su apariencia clasicista.

12 Reyner BANHAM, La arquitectura del entorno bien climatizado (1969). Infinito, Bueno Aires 1975, p.88.
} 
todas las naciones y climas, la casa con 'respiración exacta' ${ }^{\prime \prime 13}$.

Tres años más tarde y trascurridos treinta desde que se construyó el Royal Victoria Hospital de Belfast, Le Corbusier aplica el sistema de ventilación forzada con sus muros neutralizantes de vidrio en el Centrosoyuz y en la Cité Refuge [fig.7.05]:

"Habíamos estado buscando una oportunidad, y ella llegó: el hogar Cité de Refuge para el Ejército de Salvación. (...) Mil metros cuadrados de pared vidriada iluminan cada cuarto de piso a techo, de pared a pared (...), el vidrio estaba sellado herméticamente, porque el aire filtrado y caliente circula constantemente en el interior, controlado por los calefactores y ventiladores ${ }^{\prime 14}$.

Al margen del conflicto bélico que originó la destrucción de la fachada de vidrio, el sistema aplicado fue un fracaso y optó por mecanismos pasivos de ventilación en su reconstrucción, incorporando ventanas y brisoleil en la fachada original, dado el exceso de calor acumulado en su interior durante el verano [fig.7.06].

Más allá de que la arquitectura moderna se apodere de la tecnología desarrollada en la arquitectura hospitalaria, los mismos métodos justificativos basados en procedimientos científicos presentes a principios del siglo XX en la construcción del hospital serán utilizados más tarde por los arquitectos modernos.

Le Corbusier para explicar uno de sus famosos "cinco puntos" recogidos en el libro Zwei Wohnhauser von Le Corbusier und Pierre Jeanneret (1927), la fenêtre en longueur, ventana alargada, emplea esbozos de gráficas de intensidad lumínica para demostrar sus ventajas ${ }^{15}$ [fig.7.07], método que ya había sido utilizado con bastante más rigor por los doctores Albert J. Oschner y Meyer J. Sturm para la justificación de un uso u otro de ventana, en función de la orientación del edificio en su libro The organization, construction and management of hospitals publicado en $1907^{16}$ [fig.7.08].

Del mismo modo, los esquemas de A. J. Oschner y M. J. Sturm presentes en su libro sobre la ocupación en planta de un hospital de 500 camas repartidas, bien en único edificio compacto de varias alturas o bien en varios pabellones más bajos, son utilizados para explicar de forma gráfica la conveniencia de construir hospitales en altura, ya que logran

\footnotetext{
${ }^{13}$ LE CORBUSIER, Précisions sur un état présent de l'architecture et de l'urbanisme. Crés, Paris 1930, p.64.

${ }^{14}$ LE CORBUSIER, Quand les Cathédrales étaient Blanches. Librairie Plon, Paris 1937, pp. 25-26.

${ }^{15}$ Willy BOESIGER (ed.), Le Corbusier et Pierre Jeanneret: OEuvre Complète, vol. 1, 1910-1929. Les Editions d'Architecture, Zurich 1973, p.129.

16 Albert J. OCHSNER y Meyer J. STURM, The organization, construction and management of hospitals, Cleveland Press, Chicago 1907, pp. 128-131.
} 

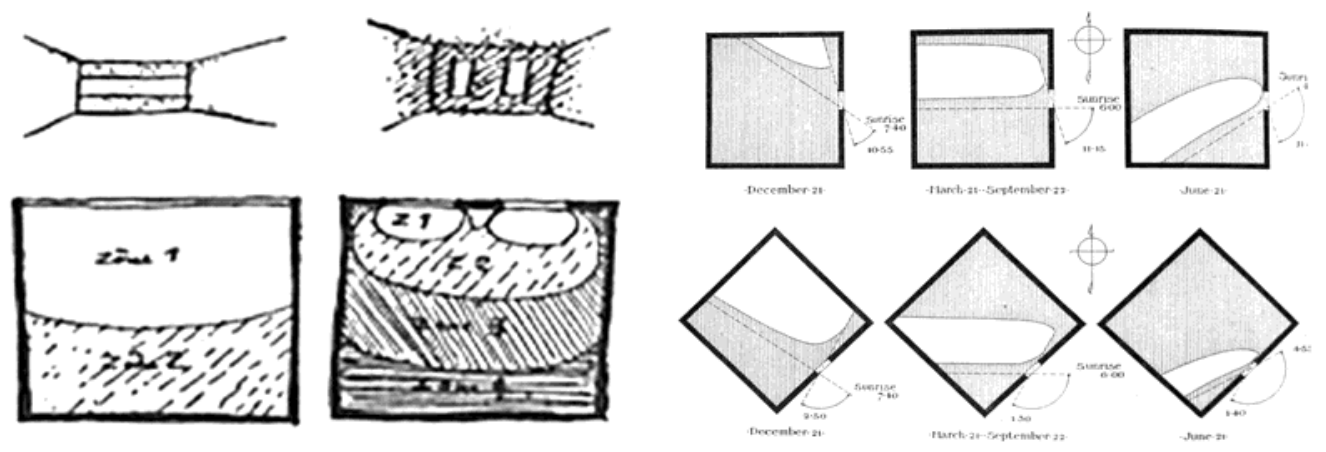

7.07 y 7.08
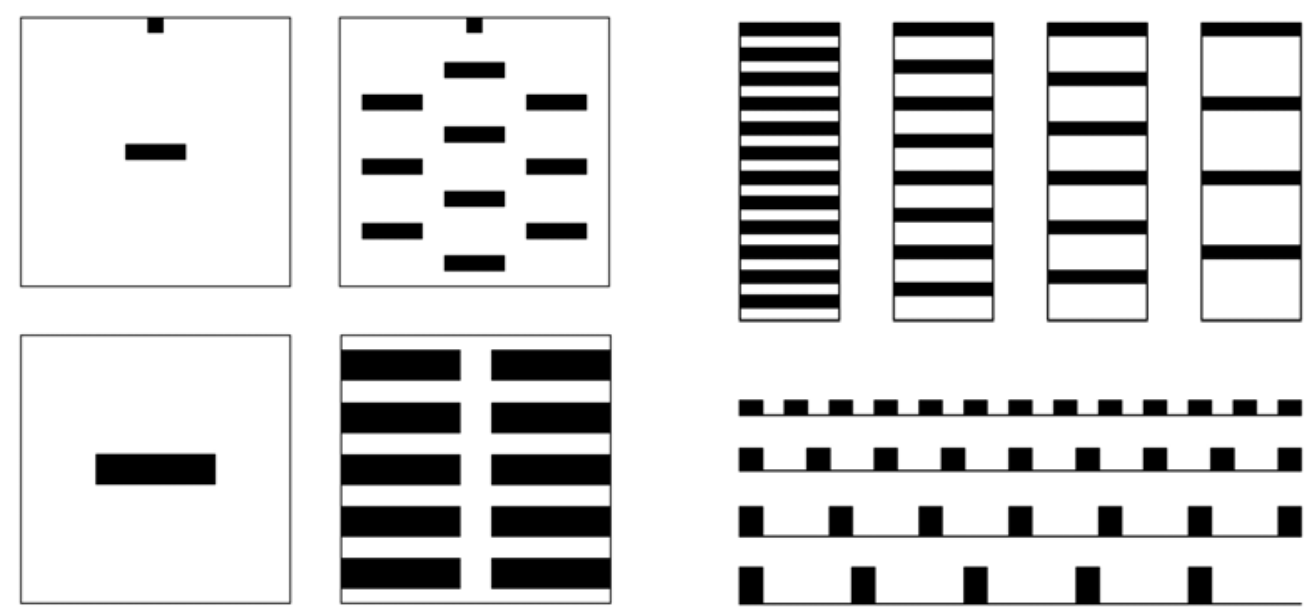

7.09 y 7.10

7.07 Le Corbusier. Fenêtre en longueur, 1927. Bocetos de intensidad lumínica.

7.08 A. J. Oschner y M. J. Sturm. Estudios de iluminación aplicados a la construcción de hospitales, 1907.

7.09 A. J. Oschner y M. J. Sturm. Esquemas explicativos de las ventajas de la construcción de hospitales en altura, 1907 (dibujos de la autora).

7.10 W. Gropius. Esquemas explicativos de las ventajas de la construcción de viviendas en altura, 1930 (dibujos de la autora). 
liberar más espacio a su alrededor favoreciendo la ventilación e iluminación del edificio [fig.7.09]. Este procedimiento antecede tanto en el discurso argumental como en el método gráfico empleado para su explicación al que más tarde utiliza Walter Gropius en el III CIAM celebrado en Bruselas en 1930 para explicar las ventajas de la construcción de bloques de vivienda colectiva desarrollados en altura durante su ponencia "¿̇Edificación baja, media o alta?"17 [fig.7.10] inspirados, como ya se ha comentado anteriormente, en los realizados por J. Duiker ${ }^{18}$.

Sin embargo, las aportaciones del hospital a la arquitectura moderna no sólo son técnicas. La medicina y las ciencias vinculadas a ella, como la fisiología, también influyen en los arquitectos del Movimiento Moderno estableciéndose una serie de analogías conceptuales. Le Corbusier en su libro Précisions sur un état présent de l'architecture et de l'urbanisme, expresa en términos anatómicos su concepto de planta libre, al indicar que las casas deben estar constituidas por "órganos rígidos", la estructura, y por "órganos blandos", las particiones interiores, debiendo ser totalmente independientes unos de otros ${ }^{19}$ [fig.7.11]. En el mismo libro vincula el sistema circulatorio y el sistema de climatización de un edificio, parangonando la fisiología humana con el funcionamiento de la instalación de ventilación: "Este régimen de $18{ }^{\circ} \mathrm{C}$ será el sistema arterial, y también proveo de un sistema venoso por medio de un segundo ventilador que introduce la misma cantidad de aire, y establece así un circuito cerrado" ${ }^{20}$. Probablemente estas analogías proceden de la influencia de su amigo el Dr. Winter quien en su artículo Le Corps Nouveau, publicado en el $n^{\circ} 15$ de L'Esprit Nouveau afirma: "i la fisiología lo es todo !"21.

La aproximación a la fisiología de la arquitectura de Le Corbusier no es sólo conceptual o verbal, también es formal, como muestra su proyecto para el Hôpital de Flers realizado en 1956. Su planta de situación para este hospital, donde aparecen representados tanto los viales de acceso como las formas de las cubiertas del edificio, recuerda a la anatomía de

\footnotetext{
17 Carlos MARTí ARÍS, Las formas de la residencia en la ciudad (Barcelona, 1991). Universidad Politécnica de Cataluña, Barcelona 2000, p. 37.

${ }^{18}$ Ver el apartado: "La economía espiritual y el estilo higiénico de Duiker" del Capítulo5 La escisión higiénica de las partes: El sanatorio de pabellones de Zonnestraal, Johannes Duiker, de esta Tesis doctoral.

19 LE CORBUSIER, Précisions sur un état présent de l'architecture et de l'urbanisme. Crés, Paris 1930, pp.123-124.

${ }^{20}$ LE CORBUSIER, Précisions sur un état présent de l'architecture et de l'urbanisme. Crés, Paris 1930, p.65.

${ }^{21}$ Dr. WINTER, "Le corps nouveau" (L'Esprit Nouveau n¹5, 1922, p. 1755) en Reyner BANHAM, La arquitectura del entorno bien climatizado (1969). Infinito, Bueno Aires 1975, p.158.
} 


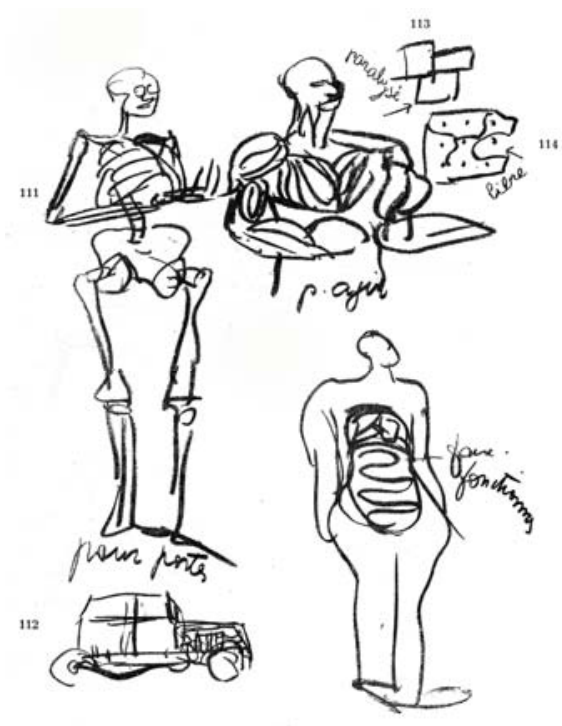

7.11
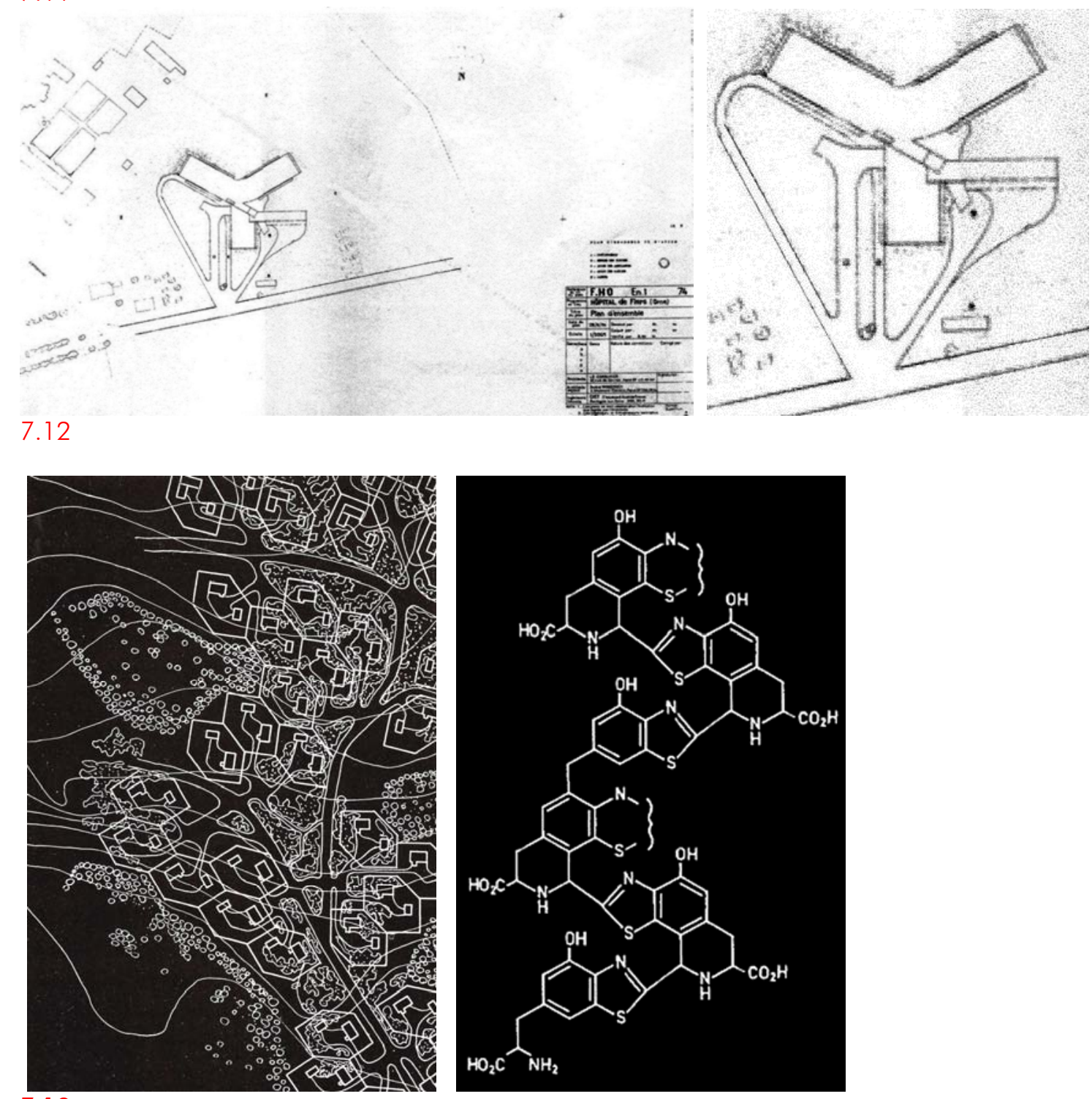

7.13

7.11 Le Corbusier. Illustration de la conferencia "Le Plan de la maison moderne", c. 1930.

7.12 Le Corbusier y Wogenscy. Proyecto del Hôpital de Flers, L'Orne, F.HO 1956 (FLC I 2(9)42).

7.13 A. Aalto. Proyecto de barrio residencial del plan de reconstrucción de la ciudad de Rovaniemi, 1944-46. Montage paralelo de la autora sobre la estructura biológica de la ciudad. 
un corazón [fig.7.12], mientras que la geometría del vestíbulo de acceso, imita a la forma de un estómago 22 .

Estas analogías médicas también se observan entre la célula y la habitación, si bien la vinculación entre la arquitectura y la biología en este término resulta biunívoca, ya que en griego célula, kutos, se refiere a una cavidad como el útero del cuerpo humano, y en latín, cellula, a un pequeño compartimento o vivienda ${ }^{23}$; asimismo la analogía de la célula se hace extensible a las concepciones urbanísticas con sus múltiples interpretaciones biológicas. Alvar Aalto en 1932 propone: "la tendencia de las células a agruparse - en eso consiste el principio biológico de la construcción ${ }^{-24}$, sugiriendo una organización de la ciudad por barrios autosuficientes de una determinada dimensión [fig.7.13]. En cambio Le Corbusier, principal redactor de la Carta de Atenas (1942) surgida como fruto de las reflexiones establecidas en el IV CIAM de 1933, en su artículo 88 expone: "Si la célula es el elemento biológico primordial, el hogar, que es el refugio de una familia, es la célula social ${ }^{\prime 25}$ y propone articular la ciudad en unidades de habitación.

Las metáforas médicas presentes en la arquitectura se trasladan también a sus métodos de diagnóstico y especialmente a los aplicados en la cura de la tuberculosis. Las radiografías contribuyen a un cambio en la percepción de la realidad que influye en la arquitectura, según la certera interpretación que la arquitecta e historiadora Beatriz Colomina realiza en el capítulo "Arquitectura de rayos X" de su libro La Domesticidad en Guerra (2006), donde indica que: "El desarrollo de los rayos X coincide con el de la casa moderna. Exactamente en el mismo momento en que los rayos $X$ exhiben el interior del cuerpo al ojo público, la casa moderna exhibe su interior ${ }^{\prime 26}$.

Gracias a las campañas de lucha contra la tuberculosis, las imágenes proporcionadas por los aparatos de rayos $X$ se popularizan durante la primera mitad del siglo $X X$, época

\footnotetext{
${ }^{22}$ Esta apropiación anatómica apreciable en la arquitectura de Le Corbusier, asociada a diversos programas no sólo al hospitalario como se aprecia en el proyecto del Centro de Cálculo Electrónico Olivetti (1961-1964), un edificio constituido por una serie de piezas conectadas entre sí, muchas de ellas con forma de vísceras, cuya imagen volumétrica asemeja a la reconstrucción anatómica de ciertos órganos internos de un ser vivo como se muestra en sus maquetas, además en las plantas donde, a causa del grafismo empleado en las representación, ciertas salas parecen mitocondrias.

${ }^{23}$ Jaen-Pierre CHUPIN, Analogie et Théorie en Architecture. De la vie, da la ville et de la conception, même. Infolio, Genève 2010, p.103.

${ }^{24}$ Alvar AALTO, "Geografía del problema de la vivienda" ("Arkitektur och samhälle"), Prisma, 1932, en Göran SCHILDT (edit.), Alvar Aalto de palabra y por escrito (Alvar Aalto. In his own words, 1997), El Croquis Editorial, Madrid 2000, p.123.

${ }^{25}$ Jaen-Pierre CHUPIN, Analogie et Théorie en Architecture. De la vie, da la ville et de la conception, même. Infolio, Genève 2010, p.100.

${ }^{26}$ Beatriz COLOMINA, La domesticidad en guerra. Actar, Barcelona 2006, p.146.
} 


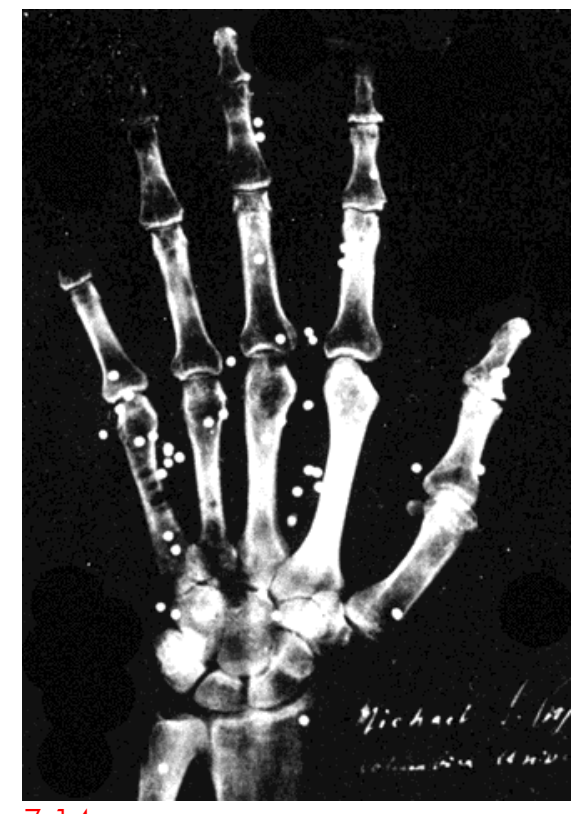

7.14

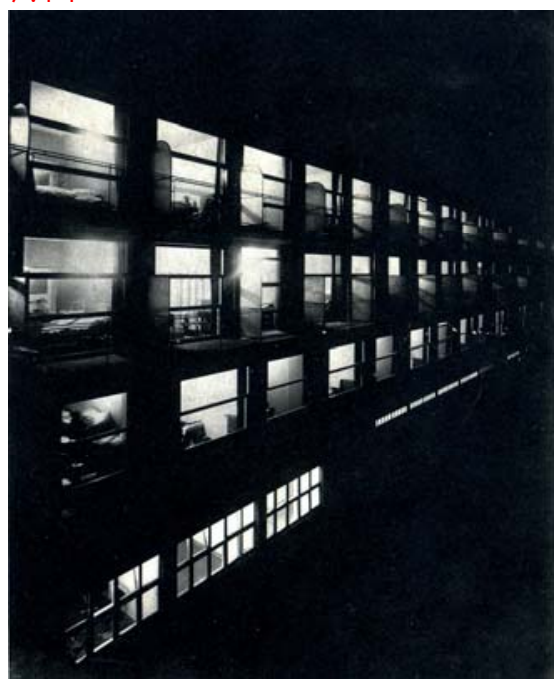

7.15 y 7.16

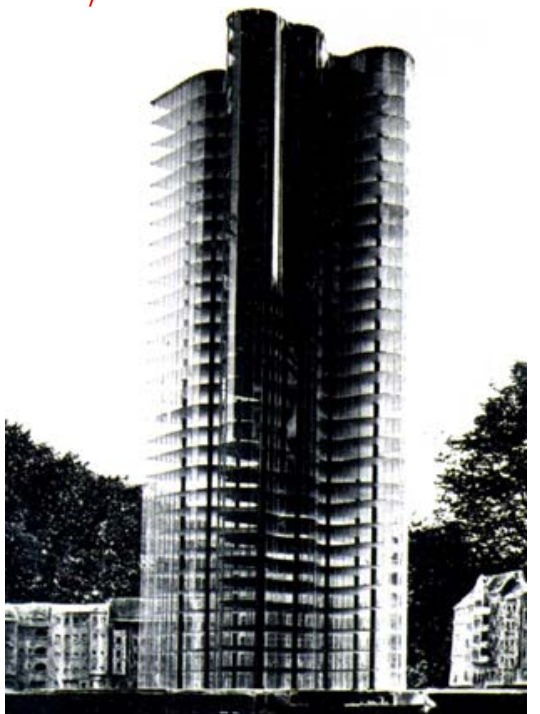

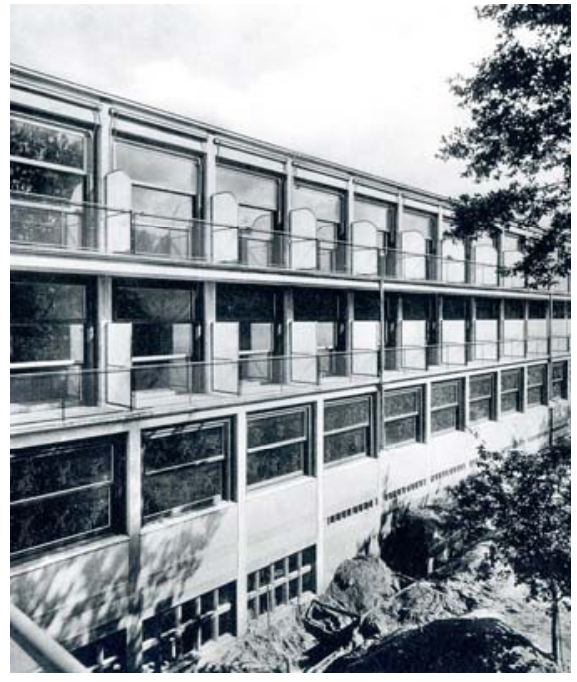

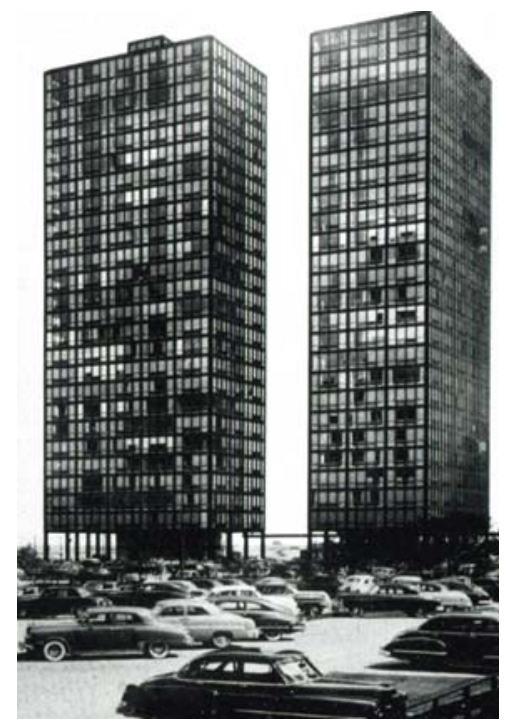

7.17 y 7.18

7.14 Michael Pupin. Radiografía, Febrero 1896.

7.15 y 7.16 Otto Bartning. Hospital de la Cruz Roja de Berlín, 1930-1931. Vista nocturna y diurna.

7.17 Mies van der Rohe. Maqueta de rascacielos de cristal, 1922.

7.18 Mies van der Rohe. Apartamentos 860-880 Lake Shore Drive, Chicago, 1948-1951. 
en la que se llega a someter al menos a una radiografía anual a toda la población ${ }^{27}[$ fig.7.14].

En las radiografías la piel se vuelve transparente y muestra el esqueleto, al igual que en la arquitectura acristalada de las vanguardias centroeuropeas de 1920, donde los cerramientos de los edificios pierden su masa y su función estructural, para convertirse en paños ligeros de vidrio transparente que dejan ver su esqueleto, es decir, la estructura interior que sustenta y da forma al edificio.

Esta visión conjunta del interior y del exterior al unísono, producida gracias al empleo del vidrio, así como la distorsión abstracta de la realidad que los reflejos de dicho material producen, es defendida por la "Neve Sachlichkeit" o Nueva Objetividad. Tal postura procede de una corriente pictórica alemana surgida tras la Primera Guerra Mundial y que se designa con el mismo nombre, en cuyas obras se plasma tanto la apariencia como la esencia de la realidad social del momento ${ }^{28}$. Pero, bajo la perspectiva propuesta por Colomina, esta visión puede no sólo guardar relación con el arte sino también con la tuberculosis $y$, en concreto, con la percepción a través de los aparatos de rayos $X$.

La arquitecta e historiadora catalana advierte de cómo proliferan durante los años 20 las fotografías nocturnas de los edificios acristalados y las imágenes en blanco y negro muy contrastadas de maquetas de proyectos de arquitectura, que fuerzan aún más su vinculación a los rayos X, llegando a afirmar que:"Los libros de arquitectura moderna parecen colecciones de radiografías de tórax" ${ }^{29}$ [fig.7.15 y fig.7.16].

Relaciona también con esta visión de los rayos X la arquitectura de Mies van der Rohe que él describe en términos de "piel y huesos", siendo la "piel" la membrana autoportante que constituye la fachada, un cerramiento terso, ligero y continuo, cada vez más complejo y tecnológico, que sustituye al tradicional sistema murario, como el cerramiento propuesto en su proyecto teórico de rascacielos de cristal (1922) [fig.7.17], y en los apartamentos de Chicago (1948-1950) de Lake Shore Drive [fig.7.18].

De este modo, junto a la influencia del hospital general y de la medicina en la arquitectura moderna, destaca por su especial importancia la repercusión del sanatorio antituberculoso,

${ }^{27}$ Documentales del NO-DO En estos años de Paz (1949) dirigido por Alberto Reig Gozalbes, Filmoteca Nacional, Madrid.

28 Kenneth FRAMPTON, Historia crítica de la arquitectura moderna (London, 1980). Editorial Gustavo Gili, Barcelona 2009, p. 132.

${ }^{29}$ Beatriz COLOMINA, La domesticidad en guerra. Actar, Barcelona 2006, p. 149. 


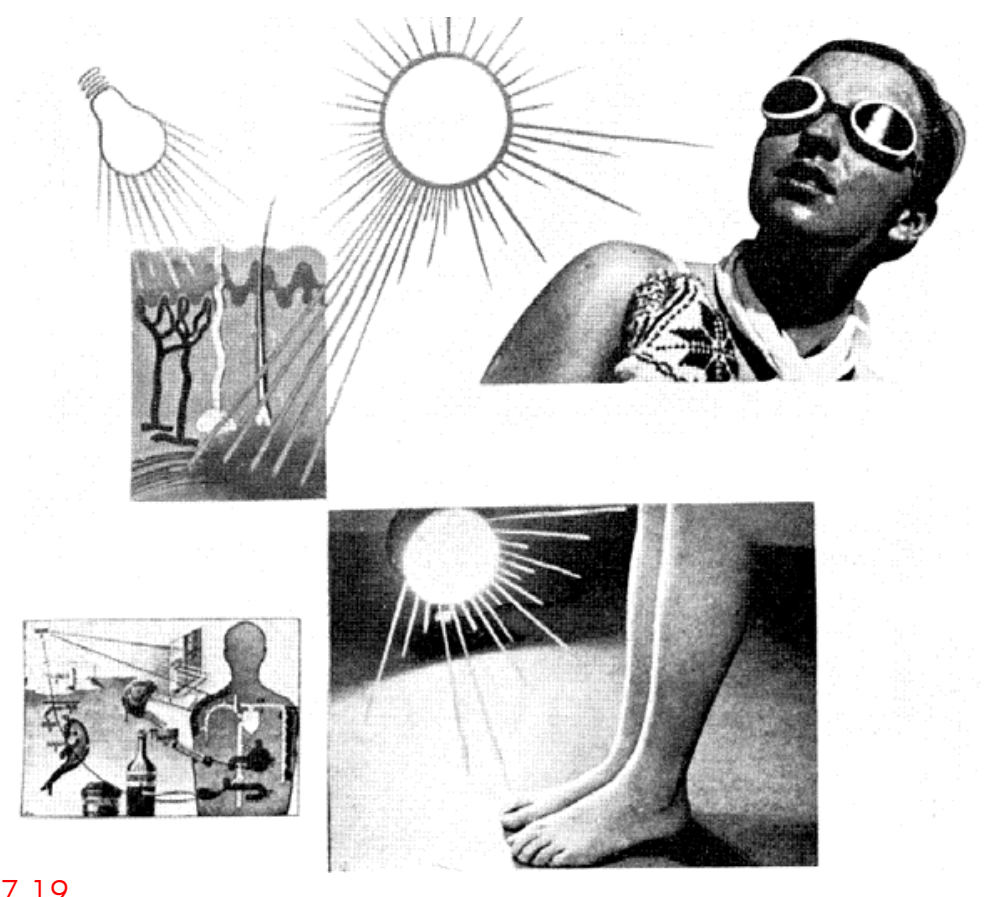

7.19

\section{L'AMBIENT FORMA L'INDIVIDU}

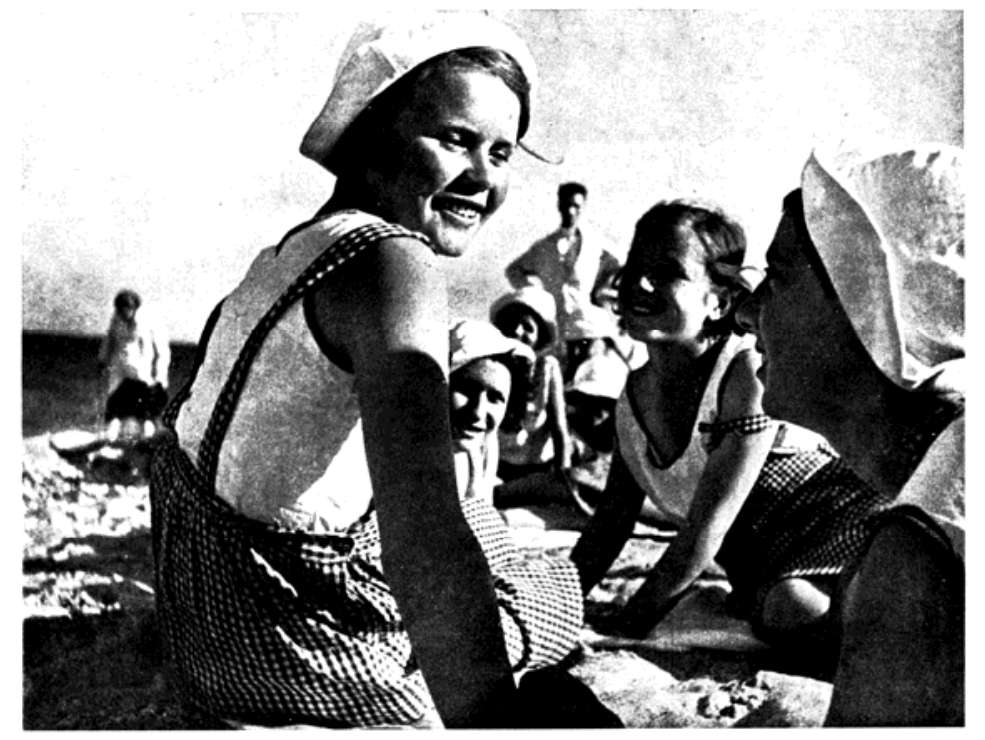

Cal treballar per la formació immediata d'una generació físicament i mentalment sana, en un ambient d'aire, sol, llum i optimisme

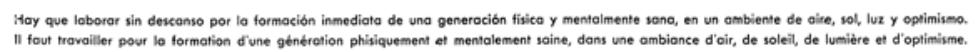
10

7.19 AC Documentos de Actividad Contemporánea, n²2, 1936. 7.20 AC Documentos de Actividad Contemporánea, nº 25, 1937. 
tanto es así que para Colomina: "La arquitectura moderna no puede entenderse al margen de la tuberculosis" $"$.

Los tisiólogos de principios del siglo XX confían en la helioterapia; así el doctor Lovis Landouzy, conocido como el Napoleón de la tuberculosis, exige en 1903 más luz en las viviendas al afirmar que: "donde el sol no entra, entra el médico"31. La insistencia en este principio terapéutico acaba convirtiéndolo en un precepto arquitectónico y en una costumbre social ${ }^{32}$; de este modo, la arquitectura terapéutica vinculada al sanatorio antituberculoso se hace extensiva a todos los programas arquitectónicos.

Las recomendaciones de estos tisiólogos abundan en las publicaciones de arquitectura, así en el $n^{\circ} 22$ de la revista A.C. Documentos de Actividad Contemporánea (1936) podemos leer, acompañado de un cartel explicativo [fig.7.19], una explícita justificación terapéutica:

"Los rayos calurosos del sol penetran a través de los músculos, dando por resultado una perfecta circulación de la sangre. Los rayos ultravioletas se transforman, al actuar sobre la epidermis, en energía química y producen elementos importantísimos para la vida (vitaminas) ${ }^{\prime \prime 3}$.

A principios de los años veinte es el Dr. Winter, un defensor de la helioterapia y del ejercicio físico, quien a través de sus artículos publicados en la revista L'Esprit Nouveau editada por Le Corbusier y Amedée Ozenfant entre 1920 y 1926, difunde la importancia del sol para la salud. Para Winter: "El cuerpo reaparecerá desnudo a la luz del sol, purificado, musculoso, flexible" ${ }^{34}$; lenguaje que para Reyner Banham no es más que una traslación de la medicina a la arquitectura:

"El eco es casi demasiado obvio; sustitúyase la palabra 'cuerpo' por arquitectura, y esto podría ser el lenguaje de Le Corbusier. El nuevo cuerpo debía ser, según parece, el magistral, correcto y magnífico juego de músculos, integrado por la luz"35.

\footnotetext{
${ }^{30}$ Beatriz COLOMINA, La domesticidad en guerra. Actar, Barcelona 2006, p.154.

${ }^{31}$ Jean-Bernard CREMNITZER, Architecture et Santé. Le temps du sanatorium en France et en Europe. A. et J. Picard, Paris 2005, p. 15.

32 Tomar el sol se convierte en una moda, ya que incluso personajes de la alta costura como Coco Chanel lo recomiendan. Margaret CAMPBELL, "What Tuberculosis did for Modernism:The Influence of a Curative Environment on Modernist Design and Architecture" en Medical History n ${ }^{\circ} 49,2005$, p. 464.

33 "La evolución del baño a través del tiempo" en $A C$ Documentos de Actividad Contemporánea, $\mathrm{n}^{\circ}$ 22,1936, p.12. Belén GARCÍA-QUIÑONES (coord.), AC Publicación del GATEPAC. Fundación Caja de Arquitectos. Barcelona 2005, p. 1124.

${ }^{34}$ Dr. WINTER, "Le corps nouveau" (L'Esprit Nouveau n¹5, 1922, p. 1755) en Reyner BANHAM, La arquitectura del entorno bien climatizado (1969). Infinito, Bueno Aires 1975, p.158.

35 Reyner BANHAM, La arquitectura del entorno bien climatizado (The architecture of well-tempered environment, 1969). Infinito, Buenos Aires 1975, p.158.
} 
Ambos, cuerpo y edificio, deben mostrar el mismo aspecto saludable.

La importancia del sol, de la higiene y el ejercicio impregnan las teorías arquitectónicas de Le Corbusier quien en su "Manual de la vivienda" publicado en Vers une Architecture en 1923, hace una exhortación a la sociedad para que la nueva vivienda atienda a estas cuestiones:

"Exigid un cuarto de baño a pleno sol, una de las habitaciones mayores de la casa, el antiguo salón por ejemplo. Una pared llena de ventanas que, si es posible, den sobre una terraza para tomar el sol; lavabos de porcelana, bañera, duchas, aparatos de gimnasia" ${ }^{\prime \prime 3}$.

Además de la helioterapia, las terapias ambientales y de aire puro aplicadas a la cura de la tuberculosis, pasan a protagonizar también los postulados del urbanismo moderno, así en la mencionada Carta de Atenas se establece que:

"El urbanismo tiene cuatro funciones principales, que son: en primer lugar, garantizar alojamientos sanos a los hombres, es decir, lugares en los cuales el espacio, el aire puro y el sol, esas tres condiciones esenciales de la naturaleza, estén garantizados con largueza ${ }^{\prime \prime 3}$.

La misma confianza en la cura a través de la vida al aire libre en un medio natural, que lleva a implantar los sanatorios antituberculosos pulmonares en lugares alejados de las ciudades, en ambientes naturales de clima seco, dentro de grandes parcelas rodeadas de jardines y parques, se hace patente y se amplía cuando Siegfried Giedion sostiene en su libro La mecanización toma el mando (1948): "El cuerpo humano requiere equilibrio entre su medio ambiente orgánico y sus entornos artificiales. Separado de la tierra y del crecimiento, nunca alcanzará el equilibrio necesario para la vida" ${ }^{\prime 38}$.

Los arquitectos del período de entreguerras promueven la vida en entornos naturales y crean una arquitectura en lugares más saludables, propicios para la gestación de una nueva sociedad. Consideran que: "El ambiente contribuye a la formación del individuo. Debemos trabajar para la formación de una generación físicamente y mentalmente sana, en

${ }^{36}$ LE CORBUSIER, Hacia una Arquitectura (Vers une architecture, 1923). Poseidon, Barcelona 1978, p.96.

${ }^{37}$ LE CORBUSIER, Principios de urbanismo: La carta de Atenas (La charte d'Athénes, 1941). Ariel, Esplugues de Llobregat 1979, p.119.

38 Siegfried GIEDION, La mecanización toma el mando (Mechanization takes command. A contribution to anonimus history, 1948). Gustavo Gili, Barcelona 1978, p.18. 
un ambiente de aire, sol, luz y optimismo ${ }^{\prime \prime 39}$, como proclama un eslogan publicado en el año 1937 en la revista $A . C$. [fig.7.20].

Para poder curar la tuberculosis, convertida a principios del siglo XX en una pandemia que afecta especialmente a las clases más desfavorecidas, es preciso vivir en un ambiente saludable; por ello el Dr. Raoul Brunon, director del Colegio de Médicos de Ruan, declara en «Le Bulletin Médical» de 1901 que "para organizar un sanatorio, no es absolutamente necesario la construcción de un edificio especial, (...) para los tuberculosos indigentes no construyáis más sanatorios, cread uno por todas partes ${ }^{140}$; incitando a arquitectos y urbanistas a que mejoren las condiciones de habitabilidad en la casa y la ciudad con el fin de mejorar la salud e impedir la enfermedad.

Estos deseos médicos se convierten en propósitos arquitectónicos, y la arquitectura pasa a ser una medida profiláctica. A esta línea se adscriben proyectos como el Concurso para la Ciudad Verde de Moscú de 1930 de la que Moisei Ginzburg dice:

"Cuando el hombre enferma puede ser curado con las medicinas adecuadas. Sin embargo, hubiese sido mucho mejor para él y menos costoso evitar directamente que se produjese la enfermedad. En esto consiste precisamente la medicina socialista: en la profilaxis. Cuando la ciudad es sucia, o sea cuando la ciudad es ciudad, con todos sus atributos: ruidos, polvo, falta de luz, de aire, de sol, etc., se recurre a la medicina: casas y pequeñas villas en el campo, balnearios, ciudades de reposo, ciudades verdes. Todo esto es medicina, medicina que se hace necesaria cuando existe una ciudad y nosotros no podemos evitarlo"41.

Arquitectos de otras latitudes se aproximan también a esta línea. Richard Neutra llega a considerar a la arquitectura como: "una rama importante de la medicina preventiva, un arte intuitivo con una etiqueta científica, como 'Arte Médico' "42. La repercusión que la arquitectura tiene en la salud y el bienestar particular de cada ser humano trasforma a sus creadores en importantes artífices de la consecución del cometido de la mejora de la salud.

39 "L'Ambient forma l'individu" en AC Documentos de Actividad Contemporánea, n 25, 1937, p.10. Belén GARCÍA-QUIÑONES (coord.), AC Publicación del GATEPAC. Fundación Caja de Arquitectos. Barcelona 2005, p. 1208.

40 Jean-Bernard Cremnitzer, Architecture et Santé. Le temps du sanatorium en France et en Europe. A. et J. Picard, Paris 2005, p.22.

${ }^{41}$ Paolo CECCARELLI, La construcción de la ciudad soviética (Barcelona, 1970). Gustavo Gili, Barcelona 1972, p. 235.

${ }^{42}$ Richard NEUTRA, Vida y Forma (New York, 1962). Marymar, Buenos Aires 1972, pp. 59-65. 

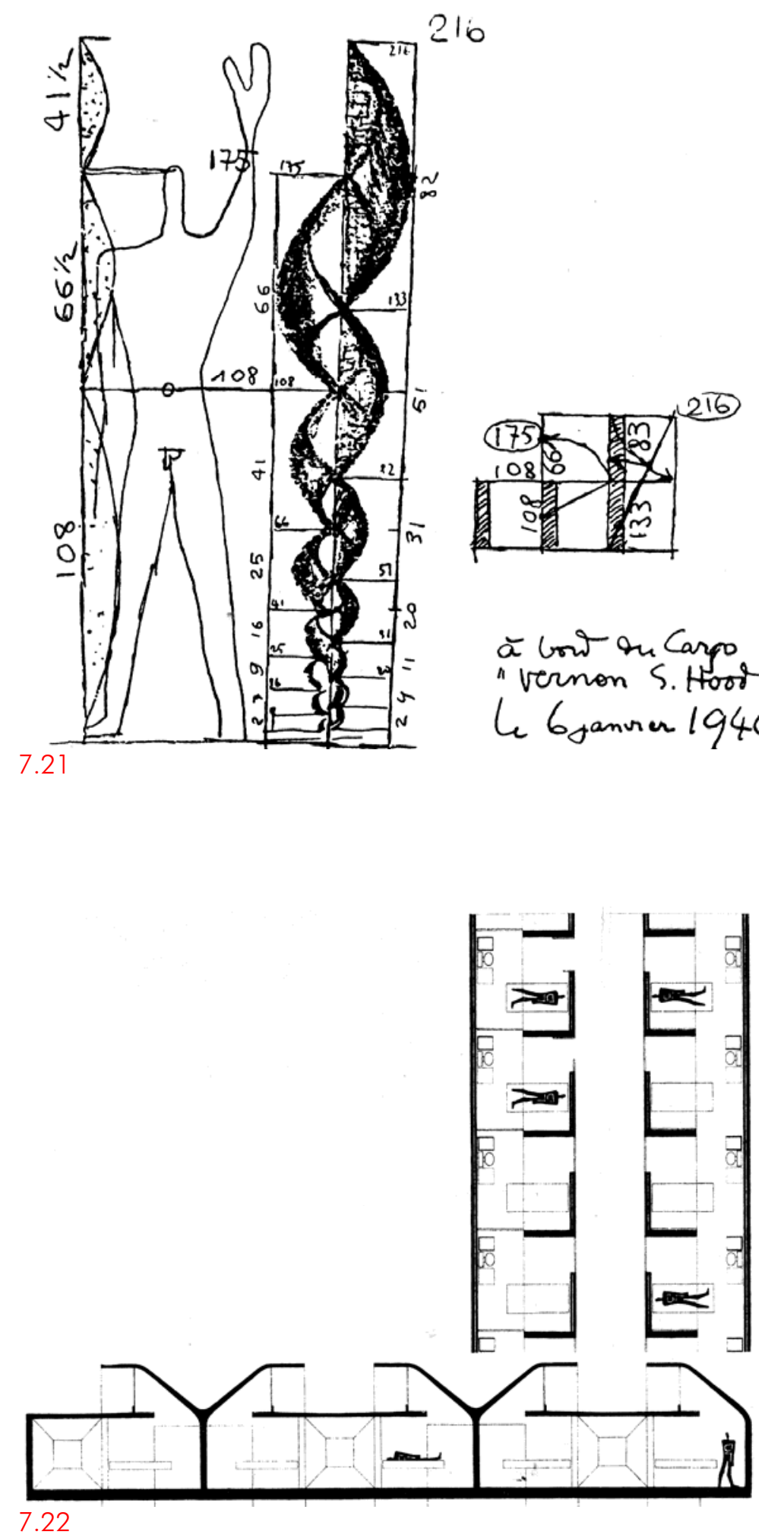

7.21 Le Corbusier. Modulor, 1946.

7.22 Le Corbusier. Hospital de Venecia, 1965. 
Richard Neutra, en su libro Vida y Forma, explica:

"El arquitecto también puede convertirse en destacado clínico, si identifica en ciertos rastros las pruebas que le interesan. (...) Su conocimiento de las personalidades humanas y los procesos fisiológicos, su relación de empatía con los clientes y su percepción de la profundidad oculta de estos últimos le permitirán formular una predicción arquitectónica más exacta de una vida que les ha sido confiada con tanta esperanza y sentimiento. Por consiguiente, es posible que esté elaborando una profecía práctica y preparando un futuro prolongado y más feliz. Todo lo cual exige algo más que el simple conocimiento de la madera, el cemento o la baldosa de vinilo" ${ }^{\prime \prime 3}$.

La misma importancia que el bienestar psicológico tiene en la cura de la tuberculosis también se aprecia en la arquitectura del sanatorio en particular, y en la arquitectura moderna en general, restableciéndose el necesario equilibrio entre pensamiento y sentimiento que la extrema eficiencia de la llamada "Era de la máquina" había logrado desestabilizar" ${ }^{44}$. Para Alvar Aalto "El funcionalismo técnico es correcto solamente si se amplía hasta alcanzar incluso el campo psicológico. Ésta es la única forma de humanizar la arquitectura " ${ }^{45}$. Al arquitecto se le requiere no sólo un conocimiento extenso de la medicina, sino también de aquellas otras disciplinas que favorezcan la mejora de la residencia incluido el mobiliario.

La humanización de la arquitectura que se formaliza en el sanatorio, dadas las especiales condiciones del enfermo, con la creación de una arquitectura "ad hoc" abarca desde el diseño de un sistema de climatización adecuado a la posición del enfermo supino hasta el de un mobiliario específico, como los muebles de reposo. El propio Le Corbusier, que había planteado una arquitectura hecha a la medida del hombre a través de El Modulor ${ }^{46}$ : "un aparato de medida fundado en la estatura humana y en la Matemática" ${ }^{147}$, pensado desde

\footnotetext{
${ }^{43}$ Richard NEUTRA, Vida y Forma (New York, 1962). Marymar, Buenos Aires 1972, pp. 62-63.

${ }^{44}$ Siegfried GIEDION, La mecanización toma el mando (Mechanization takes command. A contribution to anonimus history, 1948). Gustavo Gili, Barcelona 1978, p.19.

${ }^{45}$ Alvar AALTO, "La Humanización de la Arquitectura" en The Techonology 1940, en Göran SCHILDT (edit.), Alvar Aalto de palabra y por escrito (Alvar Aalto. In his own words, 1997), El Croquis Editorial, Madrid 2000, p. 145.

${ }^{46}$ Le Corbusier entre 1942 y 1943 comienza a investigar sobre un nuevo sistema de medida que tiene como referencia el cuerpo humano, pero El Modulor no fue patentado como invento hasta 1946 y publicado como libro-objeto en 1949, ampliado con un segundo volumen en 1955.

${ }^{47}$ LE CORBUSIER. El Modulor (Le Modulor/Modulor 2. De Le Corbusier. 1949-1955). Fondation Le Corbusier, Paris 2005, p.75.
} 

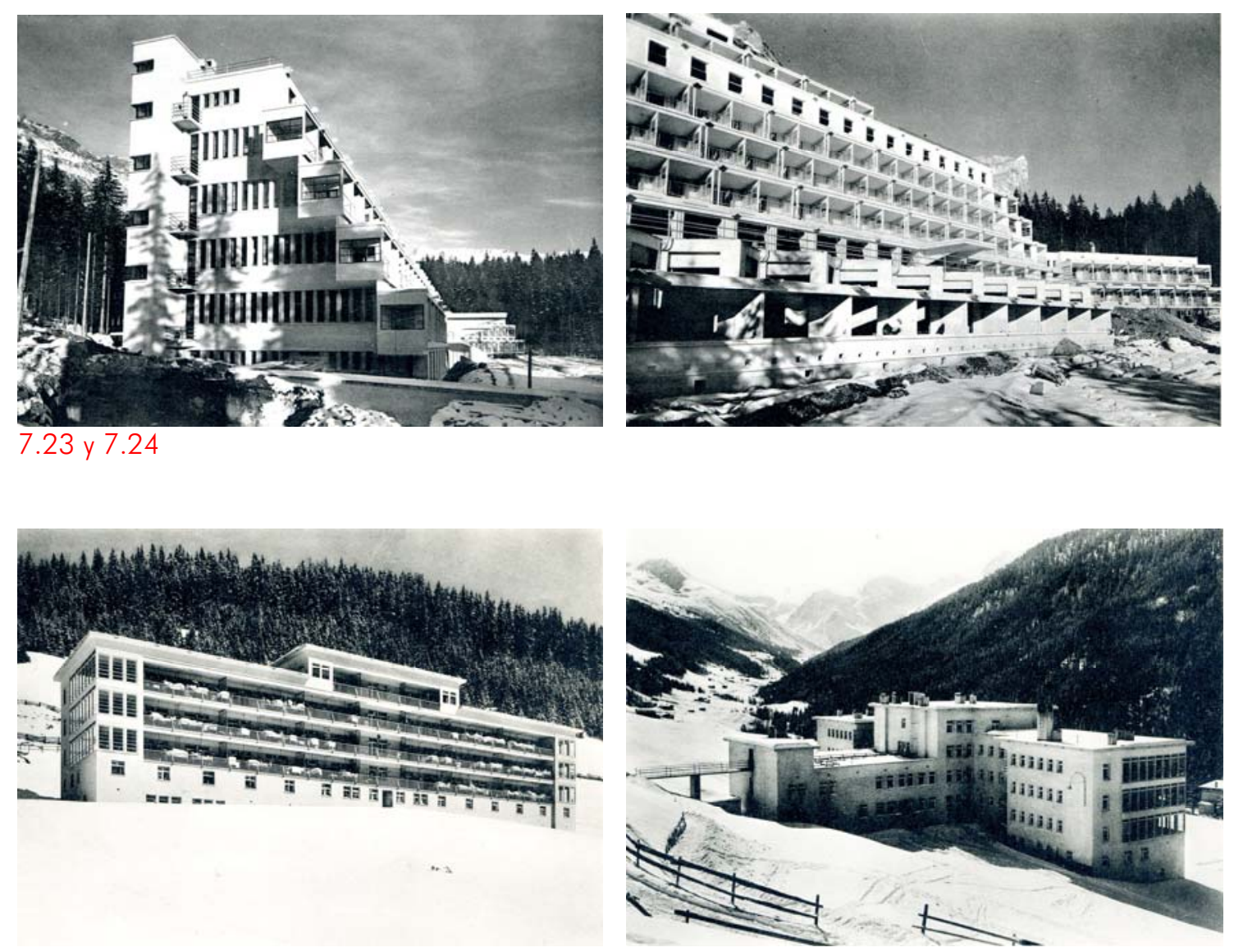

ainsi: sur trois mètres de hauteur à partir de la gouttière, la tuile était enlevir

et remplacée par du zine ou du fer blanc.

J'en conelus: depuis des siécles un comble traditionnel supporte normale-

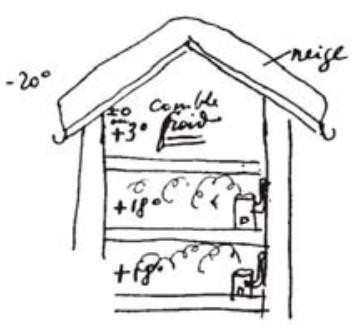

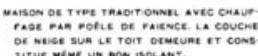

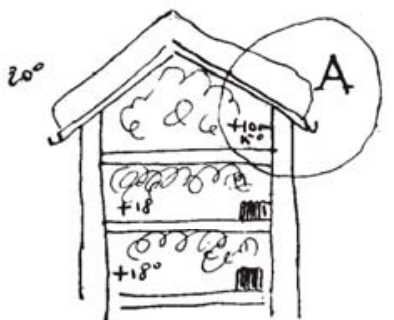

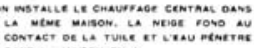

ment lhiver avee sa couche de neige, tant que la maison est chaufféc avec des poéles. Dés l'instant où le chauffage central est installé, le comble traditionnel

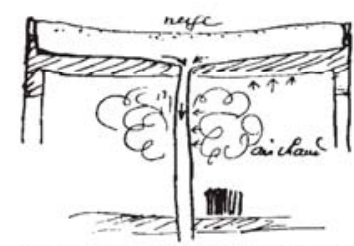

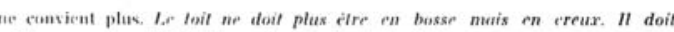

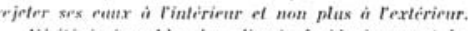

irite irricusable: los climals fraids imposent la suppression da comble.

7.23 y 7.24 P. Abraham y H. Le Mème. Sanatorio Guébriant, Alta Saboya, 1930-1933. Vista lateral y de las habitaciones.

7.25 y 7.26 R. Gaberel. Sanatorio popular suizo Clavadel, Davos, 1930-1932. Vista de las habitaciones y de las zonas comunes.

7.27 Le Corbusier, L'Architecture Vivante n 17-18, 1927. 
la vertical de un "hombre-con-el-brazo-levantado" erguido y fuerte [fig.7.21], en el último proyecto de su vida, el Hospital de Venecia, pasa a ser remplazado por un modulor tumbado que representa al enfermo tendido en la cama [fig.7.22].

Son las especiales condiciones terapéuticas las que acaban por definir la configuración del espacio interior y la imagen exterior del sanatorio antituberculoso pulmonar caracterizado por su cubierta-solario y por sus galerías de cura las que otorgan a la fachada sur una gran profundidad cobrando una apariencia tridimensional; donde la necesaria captación de luz y aire puro, y la disposición en hilera de las idénticas habitaciones, provocan una reiteración constante de elementos que dan al edificio una gran regularidad.

La galería de cura, un elemento crucial para la terapia que otorga a un espacio exterior un uso estancial vinculado al interior de la habitación, propone una alteración de los límites de la edificación que representa una de las claves de la arquitectura del Movimiento Moderno que Le Corbusier resume en la ambigua frase: "Le dehors est tovjours un dedans"148, el exterior es siempre un interior, y ejemplifica en el diseño de sus cubiertas-jardín. Cubiertas planas que, por otro lado, Margaret Campbell en su artículo "What Tuberculosis did for Modernism: The Influence of a Curative Environment on Modernist Design and Architecture" (2005), vincula con la arquitectura del sanatorio y con las soluciones constructivas de cubierta de los edificios de Davos o Davoserflachedach ${ }^{49}$ [fig.7.25 y fig.7.26]. Campbell expone en su artículo cómo, según el historiador Erwin Poeschel, este sistema de cubierta plana surge por primera vez en Davos alrededor de 1851 gracias a Samuel Haussler, con el fin de evitar que en primavera se desprendieran bloques de hielo de los aleros de los edificios; y cómo Le Corbusier reproduce gráficamente en sus cuadernos ${ }^{50}$ el sistema de Samuel Haussler que será posteriormente publicado en varias revistas de arquitectura ${ }^{51}$, manifestando su interés por dicha solución [fig.7.27]. La cubierta plana en los sanatorios de Davos, que Le Corbusier debía conocer dado su origen suizo, tuvo además un aprovechamiento terapéutico al ser utilizadas como terrazas solárium, tal y como Sigfried Giedion explica en 1929 en su libro Befreites Wohnen. Licht, Luft, Öffnung, (Vivienda

\footnotetext{
${ }^{48}$ Beatriz COLOMINA, La domesticidad en guerra. Actar, Barcelona 2006, p. 298.

${ }^{49}$ Margaret CAMPBELL, "What Tuberculosis did for Modernism: The Influence of a Curative Environment on Modernist Design and Architecture" en Medical History n ${ }^{\circ}$ 49, 2005, p. 471.

${ }^{50}$ Dibujos que son publicados en la revista L'Architecture Vivante $n^{\circ} 17-18,1927$.

${ }^{51}$ Erwin POESCHEL, "Das Flache Dach im Davos", Das Werk, Zurich, 1928, pp. 102-109; "Das Flache Dach im Hochgebirge", Der Baumeister, 1931, pp. 38-44.
} 
liberadora. Luz, aire y apertura) ${ }^{52}$ y como Le Corbusier propone en las cubiertas-jardín de sus viviendas.

Otro condicionante terapéutico del sanatorio y de la arquitectura hospitalaria en general es la higiene, factor que resulta determinante también en la definición de la imagen del mismo. Según el tisiólogo Karl Turban: "los muros deben de ser lisos, sin cavidades, para no albergar miasmas ni bacilos ${ }^{\prime \prime 5}$

Así, las características formales del sanatorio se convierten en un modelo ejemplar del llamado Estilo Internacional, cuyos fundamentos son descritos por Henry-Russell Hitchcock y Philip Johnson en El Estilo Internacional: Arquitectura desde 1922 :

"En primer lugar, existe una nueva concepción de la arquitectura como volumen más que como masa. En segundo lugar, la regularidad sustituye a la simetría axial como medio fundamental para ordenar el diseño. Estos dos principios, unidos a un tercero que proscribe la decoración aplicada arbitraria, son los que caracterizan la producción del Estilo Internacional "54.

La relación entre la arquitectura sanitaria y la de las vanguardias es tan estrecha, que hasta el color blanco característico de la higiene del sanatorio y del hospital va a ser defendido por los arquitectos para cualquier arquitectura como apariencia verdadera. Le Corbusier describe este valor moral del blanco:

"Si la casa es completamente blanca, la forma de las cosas se recorta sin posibilidad de error (...). Ponga aquí cualquier cosa deshonesta o de mal gusto y le chocará inmediatamente al ojo. Es más bien una radiografía de la belleza, un tribunal de apelación permanentemente en juicio. Es el ojo de la verdad"55.

La arquitectura del sanatorio antituberculoso pulmonar se convierte en síntesis y emblema del período de entreguerras, y sus características se van a trasladar a la vivienda moderna y al resto de programas sentando así las bases de la nueva arquitectura científica y racional característica de esta época.

\footnotetext{
${ }^{52}$ Sigfried GIEDION, Befreites Wohnen. Licht, luft und Öffnung. Orell Füssli, Zurich, 1929, imagines 65-68.

${ }^{53}$ Dave LÜTHI, "1870-1950 Le sanatorium en Suisse. Du kurhaus à la clinique de pneumologie", en TOULIER, Bernard y CREMNITZER, Jean-Bernard (dirs.) Histoire et Réhabilitation des Sanatoriums en Europe. Docomomo International, Paris 2008, p.44.

${ }^{54}$ Henry-Russell HITCHCOCK, Philip JOHNSON, El Estilo Internacional: Arquitectura desde 1922 (The international style. Architetture since 1922,1932). Colegio Oficial de Aparejadores y Arquitectos Técnicos de Murcia, Murcia 1984, p. 32.

${ }^{55}$ Le Corbusier L'art decoratif d'aujourd'hui 1925.
} 


\section{LA RESIDENCIA MODERNA COMO MÁQUINA DE SANAR}

Gabriel Guevrékian resume en su libro Hôtels et Sanatoria (1930) el origen del sanatorio:

"Los sanatorios son la síntesis del hotel de vacaciones y del hospital; donde todas las invenciones, relacionadas con la medicina, con la cirugía, con la arquitectura, el acondicionamiento interior, alcanzan grados de extrema perfección $n^{\prime 56}$.

La vinculación con el hotel y, por ende, con el ámbito residencial resulta evidente al analizar los orígenes del sanatorio a partir de los Kurhaus germano-suizos, así como las más tardías Maison de Santé o Casas de Reposo, establecimientos hoteleros vinculados al turismo de la salud. Un ejemplo importante de Maison de Santé es La Morava, en Tatranská Lomnica, Eslovaquia (1930-1933), obra de los arquitectos Bohuslav Fush y Karl Ernstberger. Su imagen exterior y organización funcional coincide con la de un sanatorio, al estar constituida por un bloque lineal que alberga las habitaciones con terrazas individuales y de otro volumen que contiene amplios solarios y zonas comunes; sin embargo, a diferencia de los sanatorios, las habitaciones se orientan indistintamente al este y al oeste y, por supuesto, el edificio carece de servicios médicos especializados [fig.7.28 y fig.7.29].

Es probablemente André Lurçat, proyectista y constructor tanto de hoteles como de hospitales, uno de los arquitectos que mejor establece el enlace entre la arquitectura de la residencia y la del sanatorio. El Hotel Norte-Sur de Calvi, Córcega (1929-1930), recogido en la publicación de Henry-Russell Hitchcock y Philip Johnson, El Estilo Internacional: Arquitectura desde 1922, es un hotel con forma de prisma recto orientado hacia el paisaje en donde cada habitación constituye una célula independiente muy abierta, con un balcón individual y un pequeño baño ventilado [fig.7.30]. En él se muestran las reflexiones planteadas anteriormente en el proyecto del Sanatorio de Durtol (1929), al ser la organización lineal y la unidad de habitación del hotel una variación tipológica de su proyecto para el sanatorio [fig.7.31]. Sanatorio que por otro lado, como reconoce Lurçat, guarda una gran vinculación con el ámbito residencial y en concreto con su proyecto para

56 Jean-Bernard CREMNITZER, Architecture et Santé. Les temps du sanatorium en France et en Europe. A. et J. Picard, Paris 2005, p.130. 

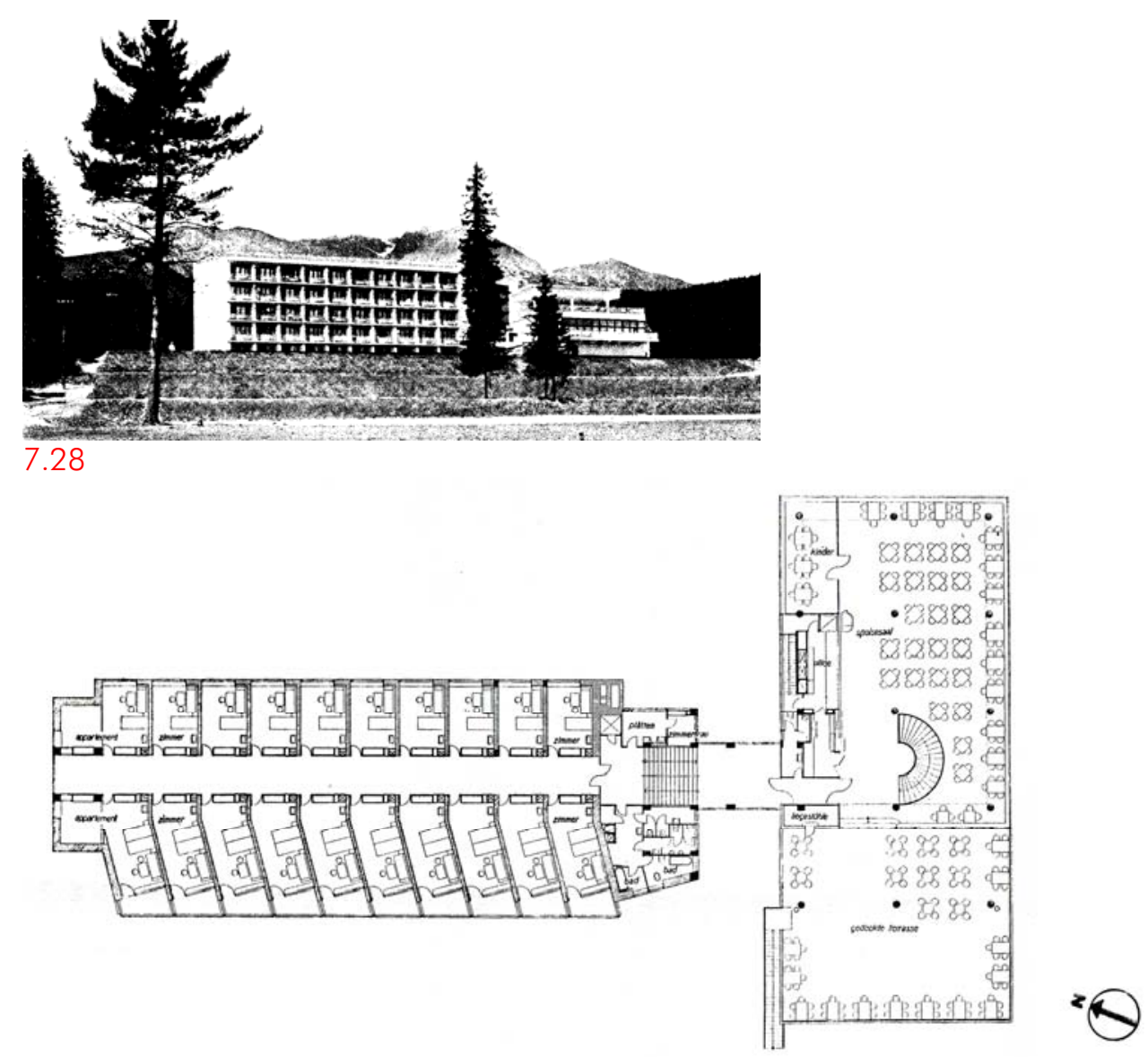

7.29
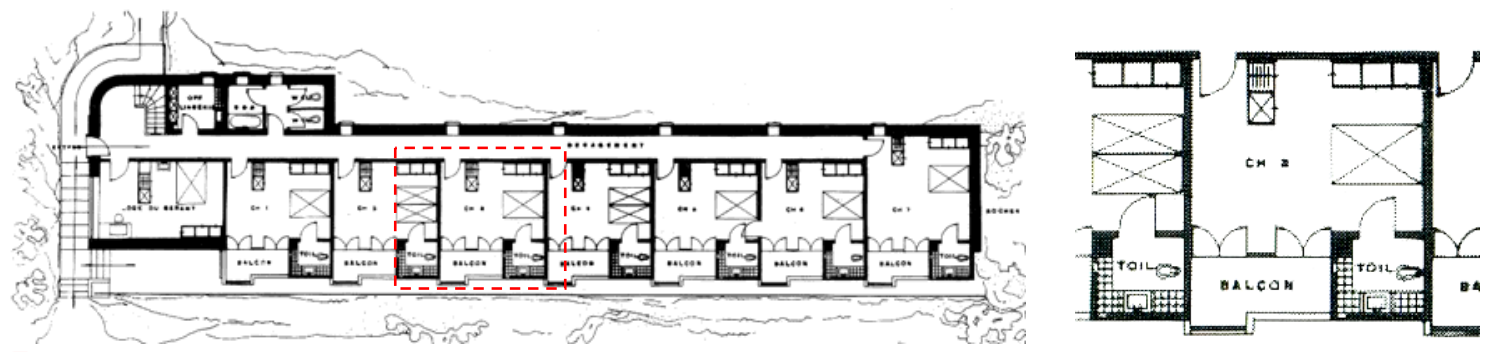

7.30
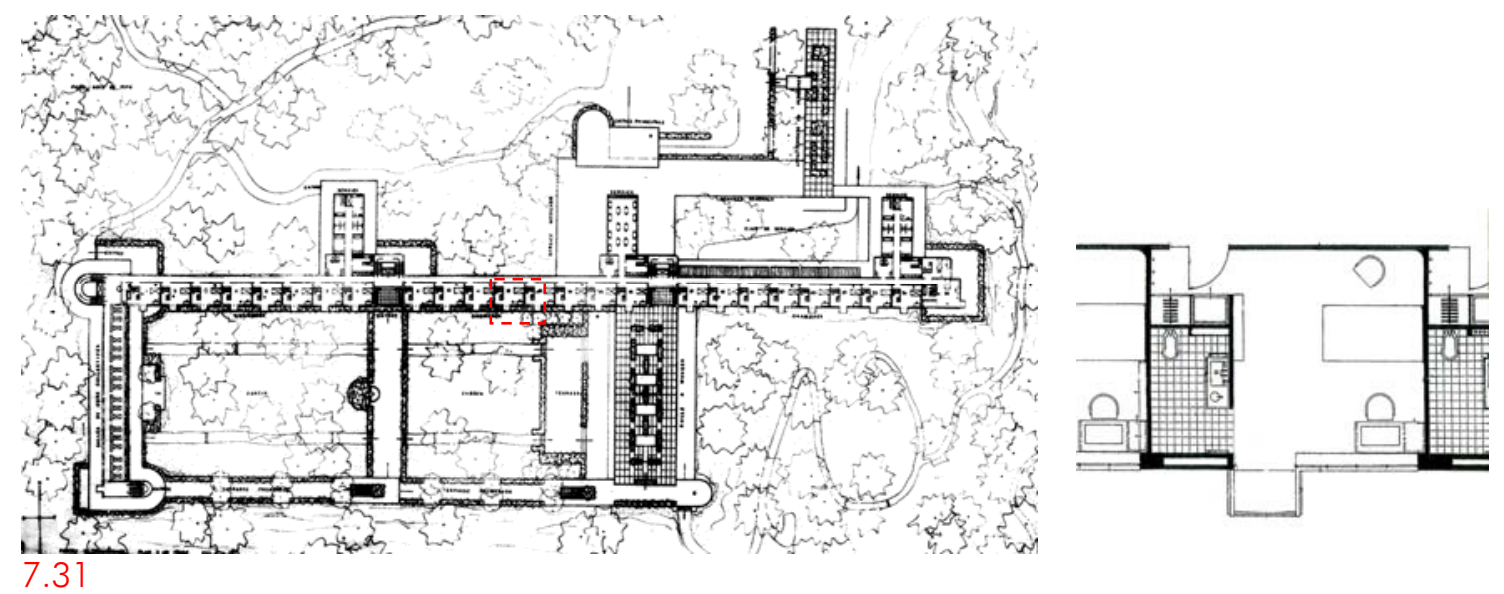

7.28 y 7.29 B. Fush y K. Ernstberger. Maison de Santé La Morava, Eslovaquia, 1930-1933.

7.30 A. Lurçat. Hotel Norte-Sur, Córcega, 1929-1930. Planta.

7.31 A. Lurçat. Proyecto del Sanatorio de Durtol, 1929. Planta. 
el Plage-Hôtel (1929) ${ }^{57}$, mostrando la imbricación existente en su obra entre los dos programas arquitectónicos: el hotelero y el sanatorial.

Sus habitaciones, tanto las del Hotel Norte-Sur como las del Sanatorio de Durtol, son un ejemplo de Existenzminimum en el sentido expresado por Walter Gropius en su ponencia "Las bases sociológicas de la vivienda mínima (para la población obrera de la ciudad)", presentada en el II Congreso de los CIAM celebrado en Frankfurt en 1929, donde parafraseando al Dr. Paul Volger aclara el concepto de vivienda mínima: "se refiere al mínimo elemental de espacio, aire, luz, calor que necesita cada hombre para no sufrir ningún impedimento por su vivienda en el desarrollo normal de sus funciones vitales, o sea, un 'minimun vivendi' y no a un 'modus non moredi'"158, a lo que añade la trascendencia que las teorías médicas tienen en la arquitectura moderna: "Von Drigalski, Paul Volger y otros higienistas se dieron cuenta que el hombre-teniendo las mejores condiciones de ventilación e iluminación solar posibles- desde el punto de vista biológico, necesita muy poco espacio para vivir sobre todo cuando este espacio está bien organizado" ${ }^{\prime \prime 9}$.

Este planteamiento se manifiesta en las pequeñas habitaciones de los sanatorios perfectamente iluminadas y ventiladas, tanto es así que una semana antes de la celebración del congreso Sigfried Giedion publica su libro Befreites Wohnen. Licht, Luft, Öffnung, (1929); donde emplea una fotografía de la habitación del Sanatorio de Waiblingen (19261928), obra de Richard Döcker, para explicar cómo debe ser la vivienda moderna ${ }^{60}$.

Por otro lado, a medida que avanza la medicina, en la terapia sanatorial cobra cada vez más importancia la aplicación de métodos quirúrgicos, de pruebas de diagnóstico y análisis clínico, llevadas a cabo en espacios específicos ubicados dentro del sanatorio. Al mismo tiempo el hospital general pasa a adoptar configuraciones en forma de bloques compactos desarrollados en altura que hacen que, a mediados del mismo siglo XX, las estructuras

\footnotetext{
${ }^{57}$ Ver: "La metamorfosis del tipo arquitectónico: el proyecto del sanatorio de Paimio" del capítulo 6: "La agrupación biológica de las partes: el sanatorio polimórfico de Paimio, Alvar Aalto" de esta Tesis doctoral.

${ }^{58}$ Carlos SAMBRICIO, L'Habitation Minimum (1933). Colegio Oficial de Arquitectos de Aragón, Zaragoza 1997, p.73.

59 Carlos SAMBRICIO, L'Habitation Minimum (1933). Colegio Oficial de Arquitectos de Aragón, Zaragoza 1997, p.73.

60 En el libro Befreites Wohnen. Licht, Luff, Öffnung, se publican además de la imagen de la habitación del sanatorio de Waiblingen de R. Döcker (imagen 5) varias del exterior del edificio (imágenes 57 y 58), también del Sanatorio de Zonnestral de Duiker y Bijvoet (imágenes 59-62) y de las galerías de cura de varios sanatorios de Davos (imágenes 63-65). Sigfried GIEDION, Befreites Wohnen. Licht, luft und Öffnung. Orell Füssli, Zurich, 1929.
} 

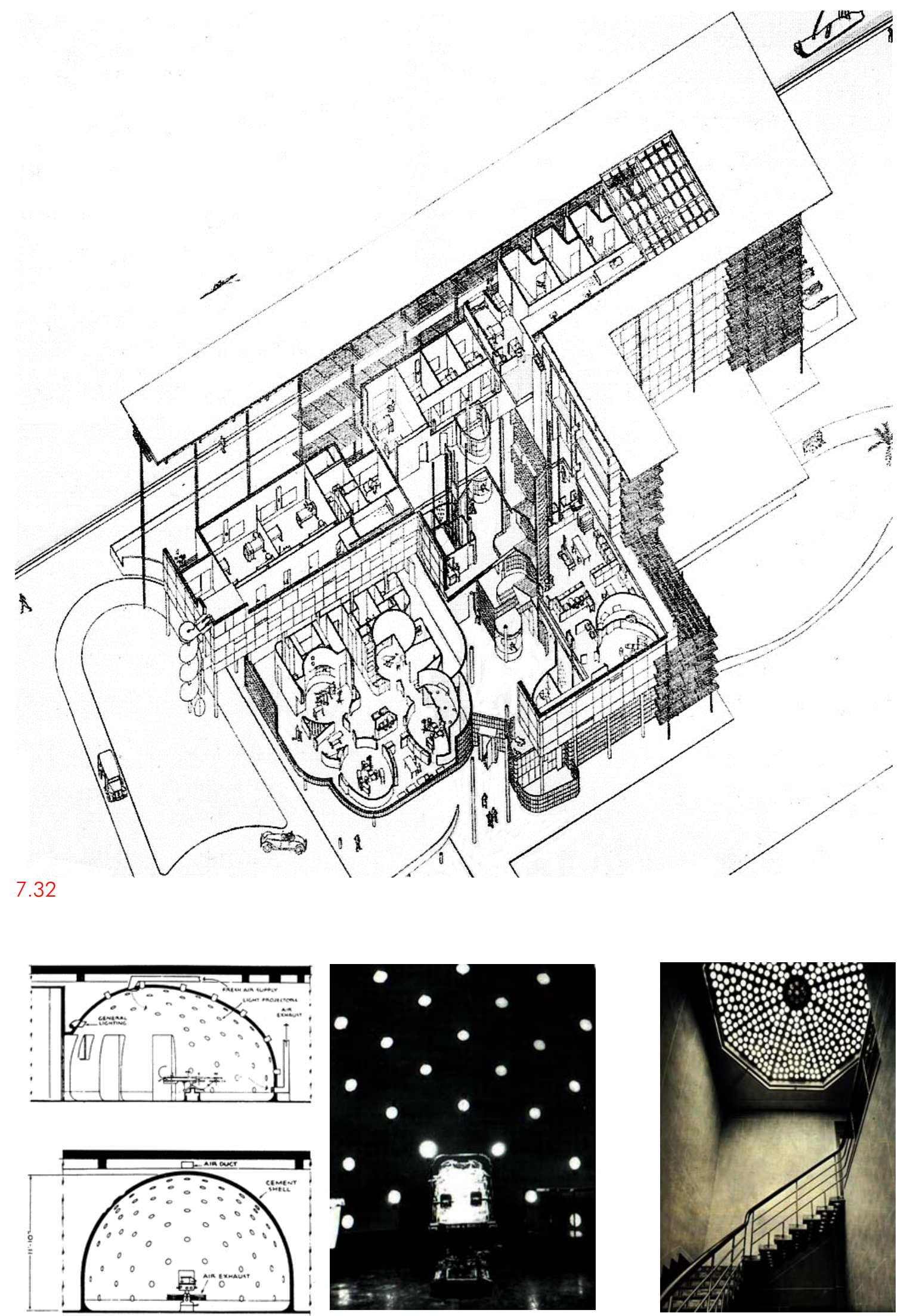

$7.33,7.34$ y 7.35

7.32 P. Nelson. Pabellón de cirugía de Ismailía, Egipto, 1934.

7.33 P. Nelson. Sección del quirófano del Pabellón de cirugía de Ismailía, Egipto, 1934.

7.34 P. Nelson. Quirófano deHospital Franco-Americano de Saint-Lô,1934.

7.35 Pol Abraham. Casa del Dr. Thoyer-Rozat en Louveciennes, Yvelines, 1926-1929. 
formales específicas del sanatorio implantado en un entorno natural y las del hospital general de la ciudad se aproximen entre sí.

Un ejemplo de hospital urbano es el Pabellón de cirugía de Ismailía (1934) en Suez, Egipto, construido por Paul Nelson [fig.7.32]. Tiene una planta en forma de $T$ con un bloque longitudinal con las habitaciones y un cuerpo transversal con los servicios comunes al que se le adosa en planta baja un pabellón con quirófanos. Éstos disponen de una peculiar sección ovoide, perforada en toda la superficie de la cúpula por numerosos puntos que permiten obtener una luz sin sombras idónea para un quirófano [fig.7.33 y fig.7.34]. Pol Abraham, constructor de numerosos sanatorios, ya había planteado anteriormente una solución similar en la casa del Dr. Thoyer-Rozat en Louveciennes, Yvelines, Francia, (19261929). En ella construye una "escalera de vidrio" con los peldaños de hormigón perforados por seis cilindros de vidrio cada uno y una cúpula octogonal completamente troquelada por una gran cantidad de cilindros de cristal que emiten una luz uniforme y difusa. Una muestra más de los traspasos entre la arquitectura doméstica y la hospitalaria, incluso en sus elementos más específicos ${ }^{61}$ [fig.7.35].

Volviendo a retomar la estrecha relación entre la arquitectura del sanatorio y la del hospital general, ciertos elementos terapéutica-arquitectónicos del sanatorio, como son las galerías de cura dispuestas en vertical o escalonadas, también están presentes en el hospital general. Se aprecia en las terrazas escalonadas del frente de habitaciones del Hospital de Dresde, Alemania, proyectado por Paul Wolf [fig.7.36], o en los balcones corridos y en los frentes acristalados de otro hospital alemán, el de Freiberg [fig.7.37].

Sin embargo, estos elementos no sólo están presentes en el hospital; como hemos visto, el viaje de ida del hotel hacia el sanatorio, lo es también de vuelta del sanatorio hacia la vivienda. En la arquitectura residencial se desarrolla una preocupación por la salud y el bienestar que trae consigo la incorporación de azoteas-solarios, grandes ventanales, balcones y terrazas; convirtiéndose las nuevas viviendas, de un blanco inmaculado, en auténticas "máquinas de sanar".

\footnotetext{
${ }^{61}$ Al parecer fueron las cúpulas de los baños árabes de Ismailía los que inspiran a Paul Nelson para construir su quirófano, aunque cabe la posibilidad de que conociese la cúpula de la escalera de vidrio de Pol Abraham difundida por Bruno Taut en su artículo "L'escalier de verre" publicado en Die Neve Baukunst. P. Abraham vuelve a repetir la cúpula en las viviendas del Boulevard Raspail (19301931). AA.W., Pol Abraham Architect 1891-1966. Collection Centre Pompidou, Musée National d'Art Moderne, Paris, 2005, p. 76.
} 

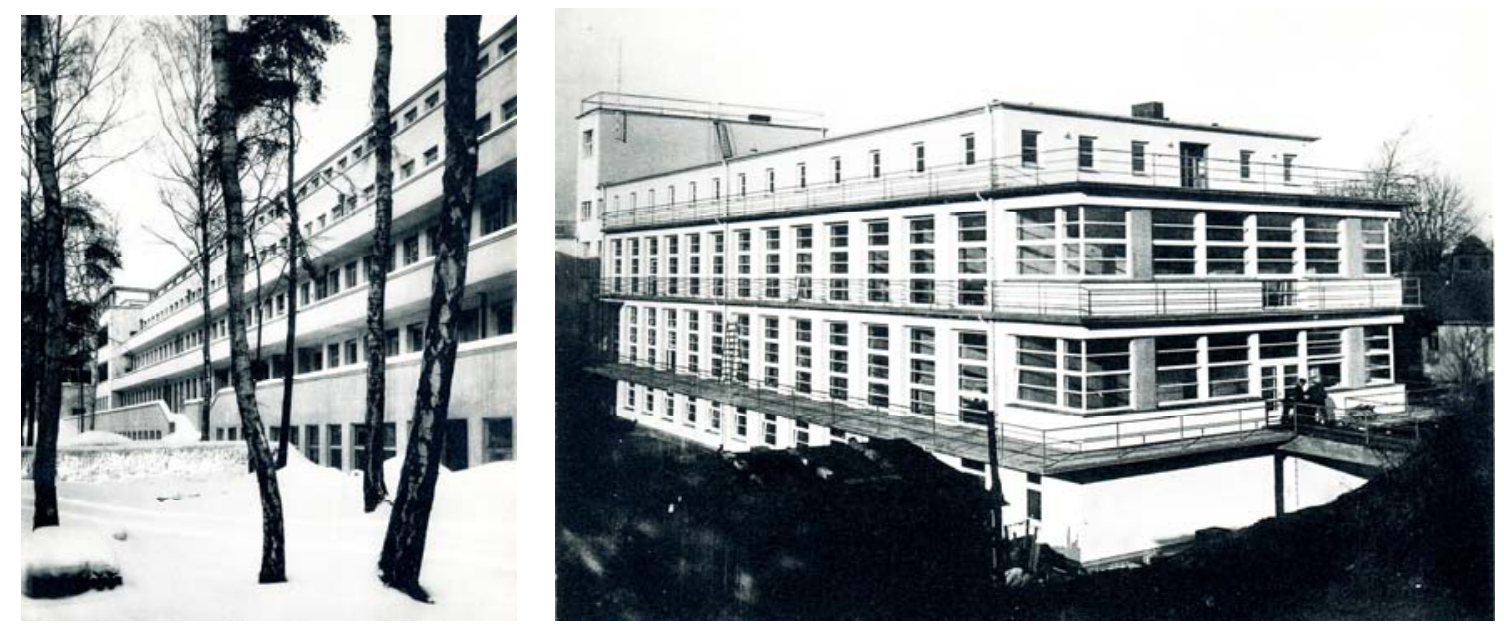

7.36 y 7.37
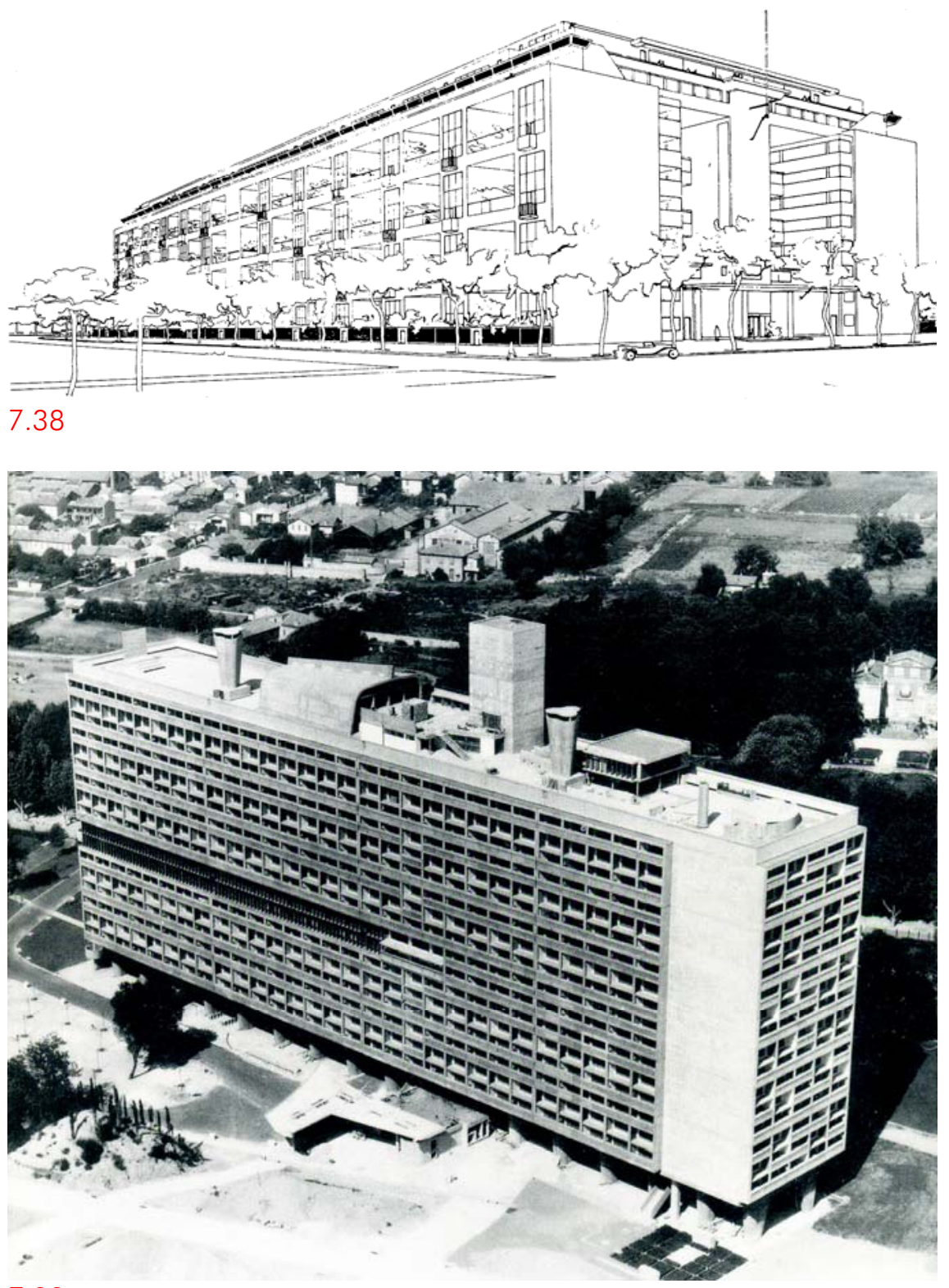

7.39

7.36 Paul Wolf. Hospital de Dresde, Alemania, 1926-1928.

7.37 Dr. Salzmann, Hospital de Freiberg, Alemania, ca.1930.

7.38 Le Corbusier. Proyecto de Inmueble-villa, 1922.

7.39 Le Corbusier. Unité d'habitation, Marsella, 1945-1952. 
En la lucha antituberculosa la helioterapia marcha a la par de la inseparable compañía del higienismo. En el Primer Congreso Internacional de Higiene celebrado en París en 1878, el arquitecto Emile Trélat, Presidente de la Société de Médecine Publique et d'Hygiène Professionelle, presenta la ponencia "Cités ouvrières, maisons ouvrières" donde expone los problemas de salubridad de la vivienda obrera y demuestra estadísticamente cómo la tasa de infección por tuberculosis disminuye entre los trabajadores realojados en viviendas "higiénicas"62. Propone crear nuevos tipos de vivienda social que atiendan a estas teorías higienistas, las mismas que inspiraron al sanatorio, trasladando así las características arquitectónicas de las edificaciones terapéuticas a toda la población, sana o enferma.

En esos tiempos, los concursos de vivienda social o "à bon marché", como el promovido por la Fundación Rothschild celebrado en París en 1905, participan arquitectos concienciados de las necesidades sociales como Tony Garnier ${ }^{63}$, quien propone el establecimiento de una "Ley de higiene" que rija la construcción de la vivienda social para la que establece tres requisitos fundamentales:

"Los dormitorios deberán tener como mínimo una ventana orientada al mediodía.

Quedan prohibidos los patios de luces. Todos los espacios cerrados aunque sean pequeños deberán tener una ventana ${ }^{\prime 64}$.

Garnier muestra una especial inquietud no sólo por las condiciones de iluminación y ventilación, sino también por la captación de los rayos solares, al imponer la orientación sur en los dormitorios.

La preocupación por la orientación al mediodía traspasa fronteras y prevalece en las viviendas alemanas de los años 30 a través de Ordenanzas Municipales, como sucede en Berlín donde, según el apartado $5^{\circ}$ del capítulo 26: "Toda vivienda tendrá por lo menos una habitación soleada. Queda prohibida toda vivienda orientada únicamente al norte"65.

La búsqueda del sol y el aire puro en las viviendas sociales se hace cada vez más patente en las propuestas de los arquitectos del Movimiento Moderno, como en el planteamiento de Le Corbusier en su inmueble-villa proyectado en 1922 [fig.7.38], un bloque lineal cerrado

62 Margaret CAMPBELL, "What Tuberculosis did for Modernism: The Influence of a Curative Environment on Modernist Design and Architecture", en Medical History n ${ }^{\circ}$ 49, 2005, p. 466.

${ }^{63}$ Tony Garnier no gana el concurso, ya que el primer premio lo obtiene un equipo de arquitectos del que es miembro Adolphe Auguste Rey, pero su propuesta es reconocida como la precursora de la solución final. Allain GUIHEUX, Olivier CINQUALBRE, Tony Garnier L'oeuvre complète. Centre Georges Pompidou. Paris 1989, p. 80.

64 Allain GUIHEUX, Olivier CINQUALBRE, Tony Garnier L'oeuvre complète. Centre Georges Pompidou. Paris 1989, p. 81.

65 "Soleamiento de las construcciones", en AC Documentos de Actividad Contemporánea n8, 1932, pp.37- 38. Belén GARCÍA-QUIÑONES (coord.), AC Publicación del GATEPAC. Fundación Caja de Arquitectos. Barcelona 2005, pp. 409-410. 
con forma de anillo rectangular ${ }^{66}$, compuesto por cinco plantas de apartamentos cada uno desarrollado en dos alturas y con una profunda terraza con jardín ${ }^{67}$. En ellos propone una nueva forma de vida próxima a la de un hotel y a la de un sanatorio, como describe Le Corbusier en Vers une architecture:

"Gran casa de alquiler... Una organización hotelera se ocupa de los servicios comunes del inmueble... Una amplia cocina alimenta a las villas o un restaurante común... Constituyen un universo arquitectónico cerrado y autosuficiente, con todo lo que el hombre puede necesitar ${ }^{\prime 68}$.

La idea se materializa, aunque con ciertas diferencias, años más tarde con la construcción de la Unité d'habitation de Marsella (1945-1952) un bloque de apartamentos higiénicos y autosuficientes con capacidad para 1.600 personas que, aunque no están dotados de los servicios hoteleros, dentro del bloque existen también una serie de habitaciones de hotel. Su mayor audacia según S. Giedion "reside en su indumentaria social "69, obtenida al incorporar la zona comercial con sus tiendas, cafeterías, talleres de planchado, peluquerías, etc., en su interior, ubicadas en una planta intermedia del edificio [fig.7.39]. La "Unidad de Habitación" dispone de una guardería en la planta 16 y de una terraza en la azotea con una piscina para niños, una área semicubierta para hacer gimnasia y un ámbito de actividades sociales para adultos. Todas las viviendas tienen alguna de las estancias orientadas al sur y poseen los frentes acristalados protegidos con brisoleil y con balcones, éstos funcionan como una extensión de los salones a modo de cubierta-jardín para favorecer la vida al aire libre. Le Corbusier la describe como: "la primera manifestación de un entorno adecuado para la vida moderna "70 y en su libro L'Unite d'Habitation de Marseille (1950) comenta: "los efectos del sol físicos y morales, han sido demasiado descuidados en los últimos tiempos. Los resultados de esa negligencia pueden verse en

66 Josefina GONZÁLEZ CUBERO, "La paradoja de los inmuebles villa" (2009), en Alexandra TREVISAN, Josefina GONZÁLEZ CUBERO, Pedro VIEIRA DE ALMEIDA (ed.), Ler Le Corbusier. Porto, CEAA, 2012.

${ }^{67}$ En 1925 Le Corbusier proyecta en Pessac, cerca de Burdeos, una serie de bloques de viviendas à redens que designa con la metáfora pulmonar: "lotisement Alvéoles". Se trata de una propuesta similar a los inmuebles-villas de 1922, salvo que ahora las terrazas con los jardines perforan por completo la fachada.

${ }^{68}$ LE CORBUSIER, Hacia una Arquitectura (Vers une architecture, 1923). Poseidon, Barcelona 1978, p. 206.

${ }^{69}$ Sigfried GIEDION, Espacio tiempo y arquitectura (Space, time and architecture, 1941). Dossat, Madrid 1982, p.564.

${ }^{70}$ Carta de Le Corbusier a Claudio M. Petit, Ministro de Reconstrucción y Urbanismo, con motivo de la entrega de la Unidad de Habitación de Marsella el 14 de octubre de 1952 (FLC E2-14 479-499) 
cementerios y sanatorios ${ }^{\prime \prime 1}$, responsabilizando a los arquitectos de la mala salud de la población.

La transposición de la arquitectura del sanatorio al ámbito residencial se manifiesta también en los proyectos de viviendas de Henri Sauvage, que siguen los esquemas de los sanatorios escalonados propuestos por el Dr. Sarason, divulgados a principios del siglo XX en Francia por el Dr. Camille Savoire a través de conferencias y publicaciones ${ }^{72}$. Curiosamente la primera aplicación constructiva del esquema de Sarason no responde a una edificación hospitalaria sino residencial ${ }^{73}$. Son Henri Sauvage junto a Charles Sarazin quienes entre 1908 y 1909 proponen las primeras soluciones de viviendas sociales escalonadas para el Boulevard de L'Hôpital de París que no llegan a ser construidas [fig.7.40]. La confianza en esta solución les lleva a patentar el sistema constructivo en la Oficina Nacional de la Propiedad Industrial de París en 1912, donde explican las ventajas de soleamiento y ventilación de su aplicación a las viviendas construidas en ambos frentes de una misma calle [fig.7.41]. En julio de ese mismo año se concede la patente, pocos días después de que su propuesta sea construida en el bloque de viviendas escalonado de la Rue Vavin en París [fig.7.42 y fig.7.43]. Este edificio consiste en un bloque lineal con un único frente escalonado que se ve duplicado en el ulterior proyecto de viviendas sociales realizado por ambos en la Rue Amiraux de París (1922-1923) con un perfil piramidal y en planta baja una amplia piscina para la comunidad [fig.7.44 y fig. 7.45]. Estos proyectos resultan muy similares al del Hotel Grand Babilon de Viena [fig.7.46] con dos frentes escalonados, realizado por Adolf Loos en 1923, y a su proyecto de bloques de viviendas aterrazados propuestos para la Inzerdorferstrasse de Viena ese mismo año [fig.7.47], una muestra de la preocupación generalizada por mejorar la condiciones higiénicas en las residencias.

Diez años más tarde, en 1933, Le Corbusier propondrá la construcción de varios bloques de viviendas escalonados por un único frente en Oued Ouchaia en Argelia, el Lotissement Durand que no llega a ser construido, cuya sección es similar a varios proyectos de sanatorios que tampoco se llegaron a construir: la Maison de Santé Minimum de Paul Nelson (1932) [fig.7.48] y el sanatorio para 1.100 camas de Marcel Brever y Hassenpflug (1930), puede que a causa de la complejidad estructural que encierra su sección.

\footnotetext{
${ }^{71}$ Le Corbusier, The Marseille block (L'Unite d'Habitation de Marseille, 1950). Harville Press, London 1953, p. 21.

72 François LOYER, Hélène GUÉNÉ, Henri Sauvage. Les immeubles a gradins. Mardaga, Liège Bruxelles 1987, p.35.

73 François LOYER, Hélène GUÉNÉ, Henri Sauvage. Les immeubles a gradins. Mardaga, Liège Bruxelles 1987, p.36.
} 


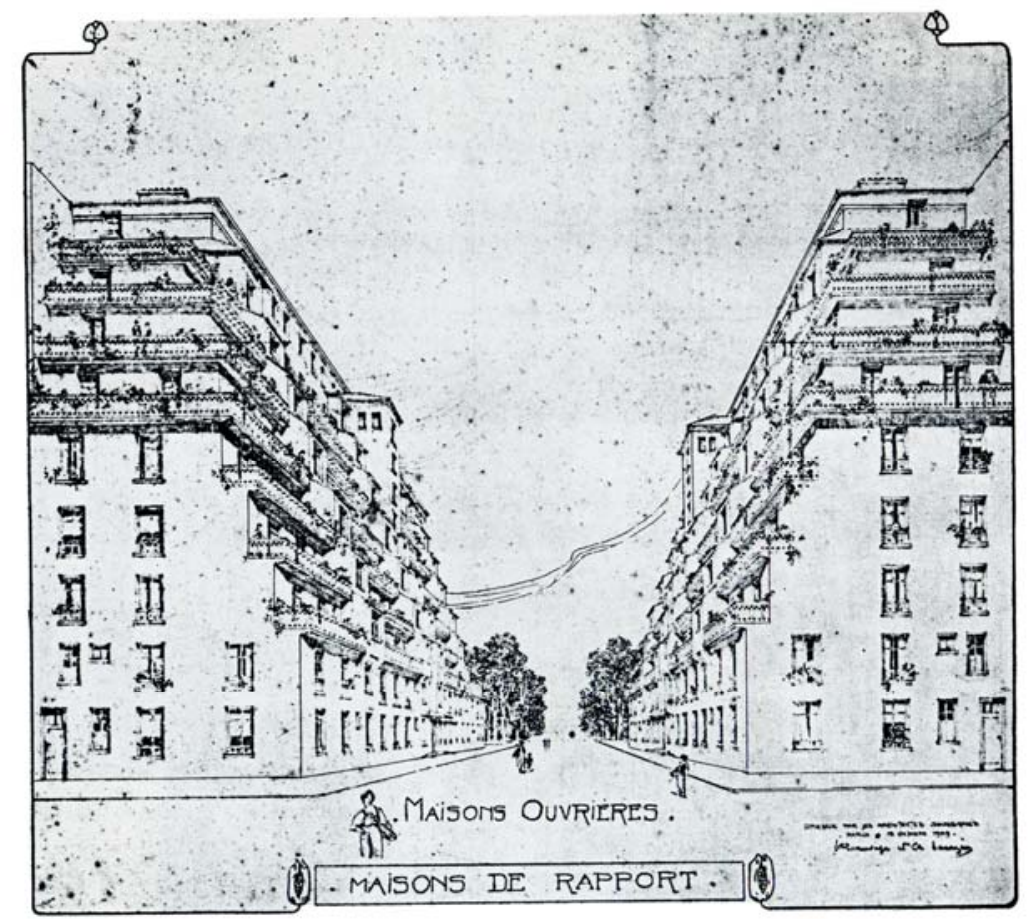

7.40
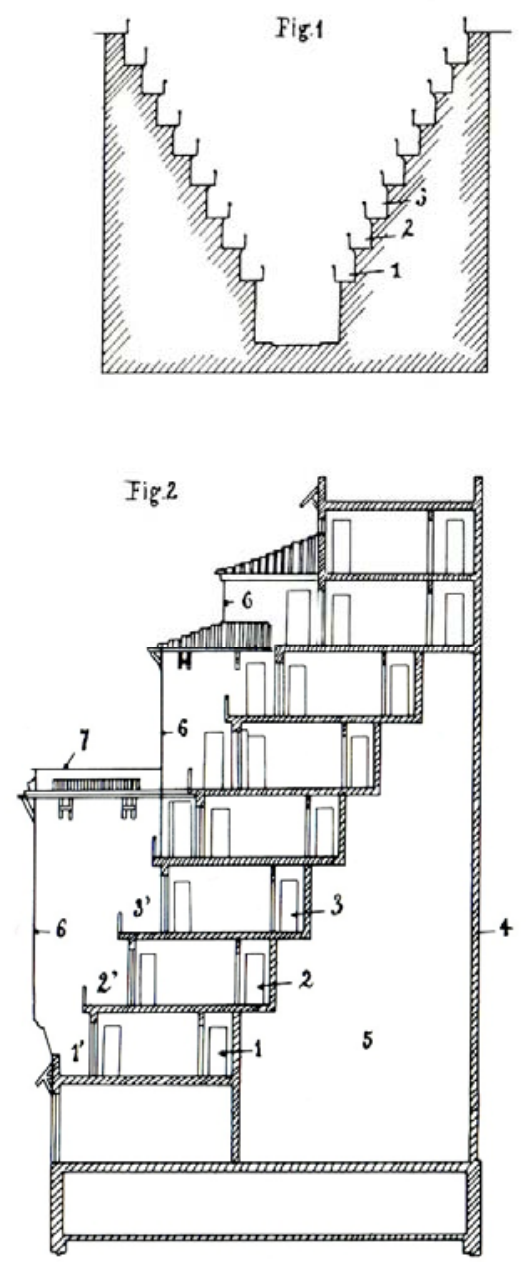

7.40 H. Sauvage y C. Sarazin. Viviendas sociales Boulevard de L'Hôpital, París, 1908-1909.

$7.41 \mathrm{H}$. Sauvage y C. Sarazin. Esquemas de la patente del sistema escalonado, París, 1912. 


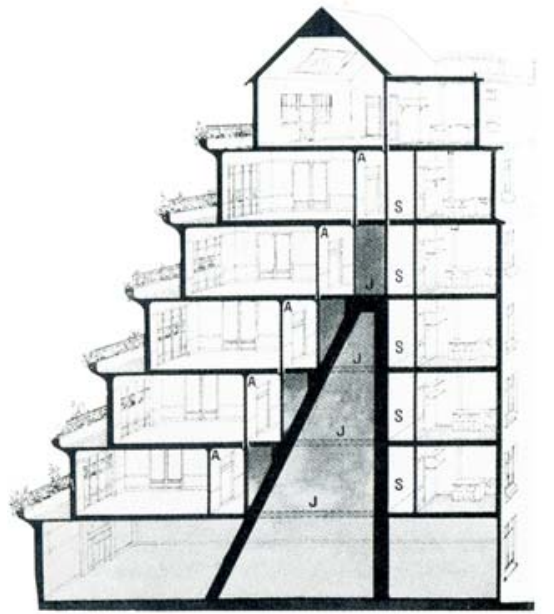

7.42 y 7.43

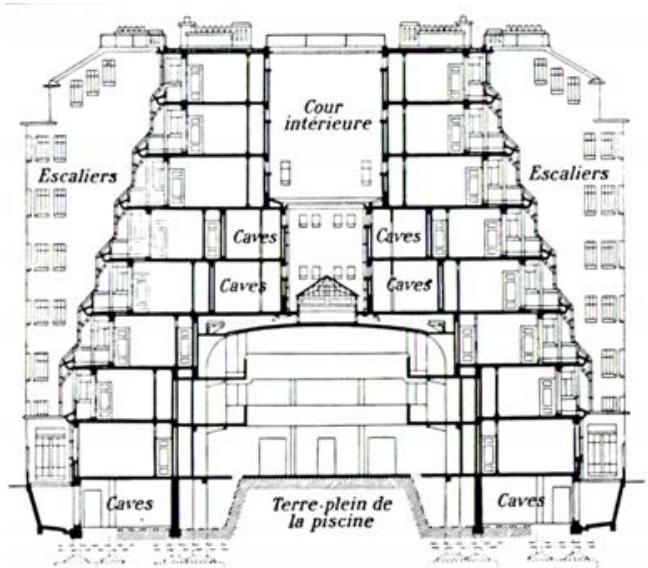

7.44 y 7.45
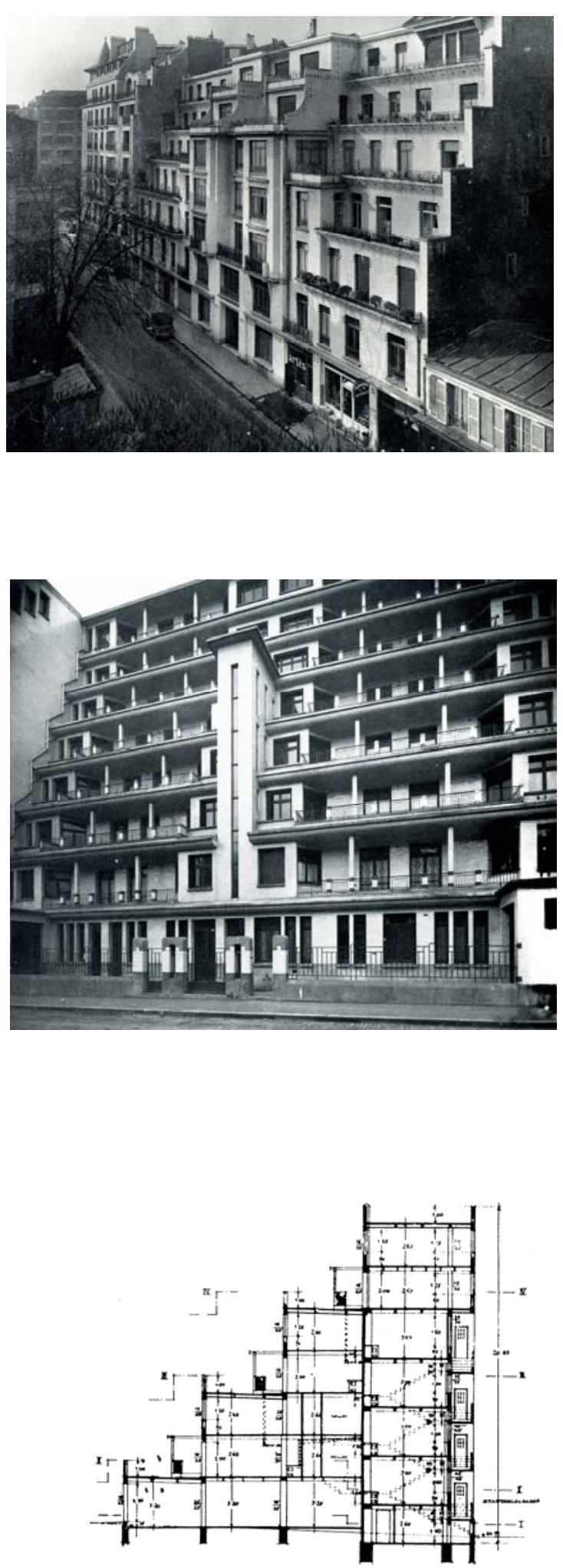

7.42 y 7.43 H. Sauvage y C. Sarazin. Viviendas Rue Vavin, París, 1912. Sección tipo y vista exterior. 7.44 y 7.45 H. Sauvage y C. Sarazin. Viviendas Rue Amiraux, París, 1922-1923. Sección tipo y vista exterior.

7.46 A. Loos. Proyecto de Hotel Grand Babilon, Viena, 1923.

7.47 A. Loos. Proyecto de viviendas en la Inzerdorferstrasse, Viena, 1923. 

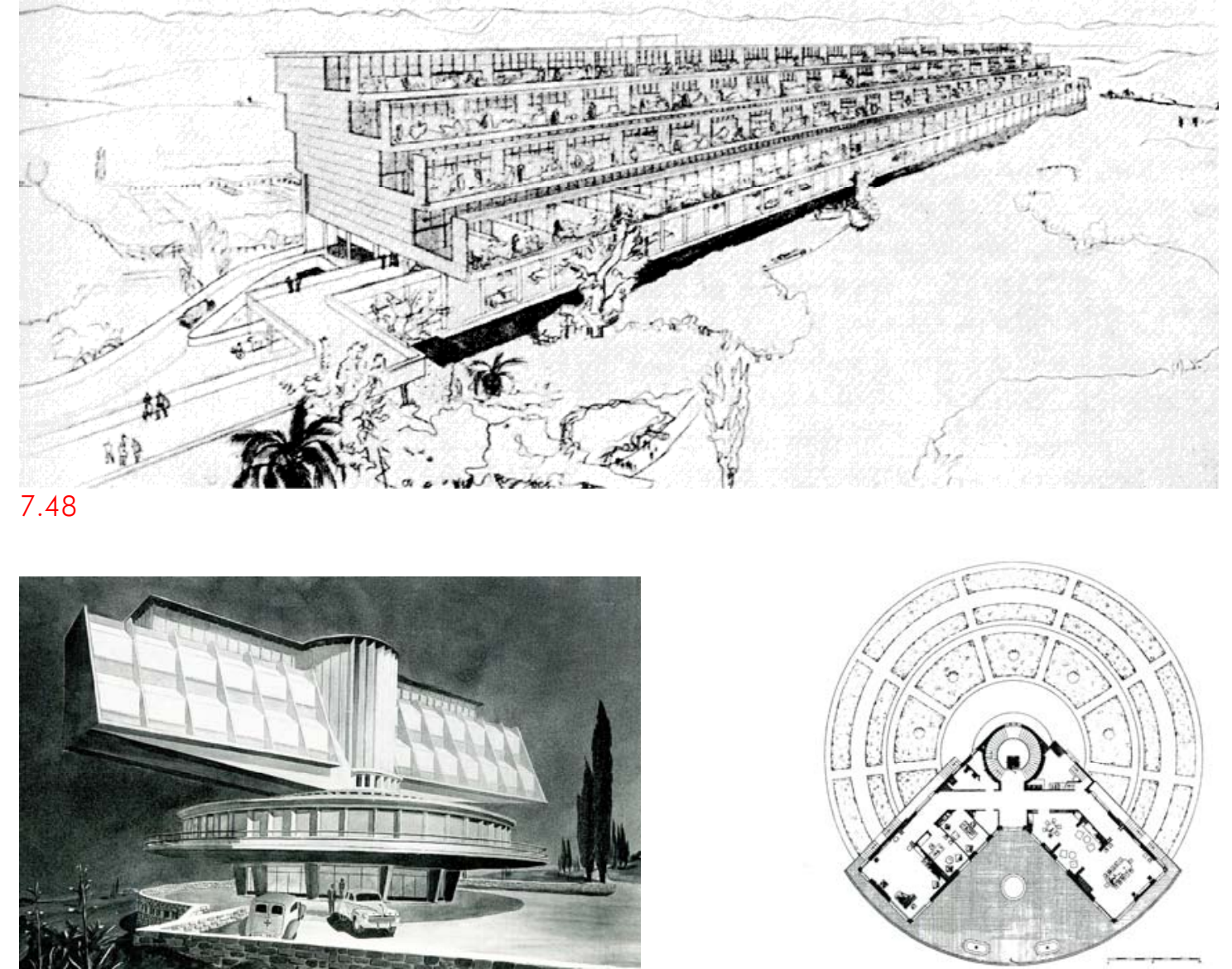

7.49 y 7.50
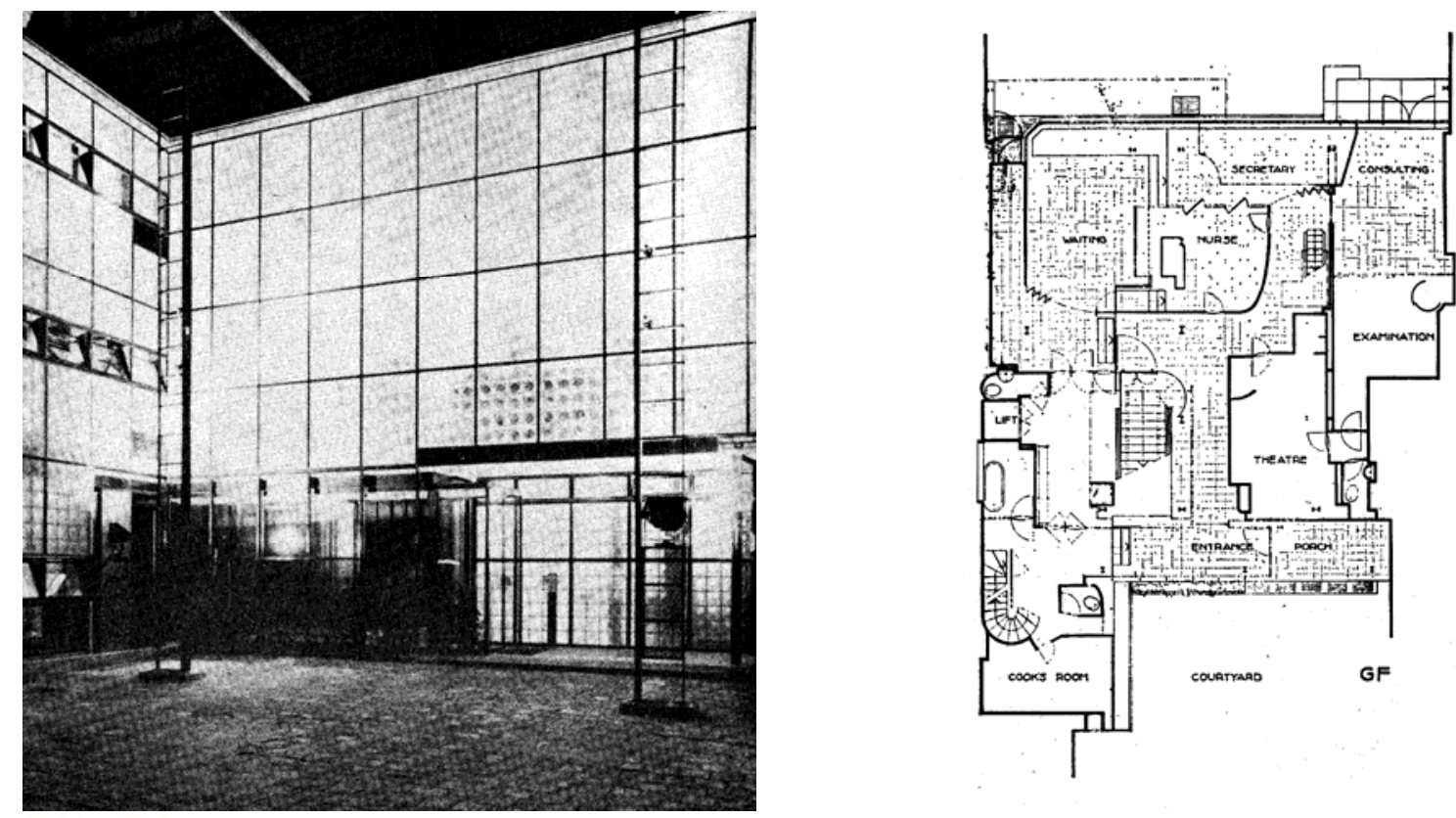

7.51 y 7.52

7.48 Le Corbusier. Lotissement Durand, Oued Ouchaia,1933.

7.49 F. Ottin. Proyecto de sanatorio solárium, École des Beux-arts, París.

7.50 E. Fagivoli. Villa Girasole, Marcellise, 1935.

7.51 y 7.52 P. Chareau y B. Bijvoet. Casa del Dr. Dalsace o La Maison de Verre, París, 1928-1931. Vista exterior y planta baja (clínica). 
Por otro lado, los sanatorios más complicados y experimentales como son los mecánicos de soleamiento giratorios ideados por el Dr. J. Saidman tuvieron también su repercusión, aunque de forma más marginal, en el ámbito residencial [fig.7.49]. En 1935 el arquitecto Ettore Fagivoli construye la Villa Girasole en Marcellise, Italia, propiedad del ingeniero ferroviario Angelo Invernizzi, quien se construye una vivienda unifamiliar soportada sobre unos raíles circulares, como los de los depósitos de las locomotoras, de manera que la casa pueda rotar para captar durante el día la mayor cantidad posible de sol [fig.7.50].

En este período de entreguerras, la estética maquinista convive con la preocupación por la salud y por la higiene como se aprecia en la casa del Dr. Dalsace de París (1928-1931) obra de Pierre Chareau y Bernard Bijvoet conocida como La Maison de Verre por su gran fachada principal construida con ladrillos de vidrio translúcido. Es una casa y una clínica a la vez, porque en planta baja se encuentra la consulta de ginecología del Dr. Dalsace y en las dos superiores se desarrolla su vivienda, ambas con la misma estética aséptica e industrial [fig.7.51 y fig.7.52]. La luz baña los amplios espacios de la misma, llena de mecanismos móviles como escaleras retráctiles, paneles deslizantes, un ascensor, etc., donde la estructura de acero y los conductos tubulares de la instalación eléctrica quedan vistos. Una casa en la que la afirmación de Robert Musil en su obra El hombre sin atributos, se hace realidad: "El hombre moderno nace en la clínica y mure en el hospital, ¿̇debe vivir también como en una clínica? Así precisamente lo exigía un arquitecto vanguardista" $" 74$.

Las viviendas modernas de los médicos, dada la particular vinculación del cliente con la salud, dan buena muestra de la influencia de la arquitectura del sanatorio en la arquitectura residencial, como sucede en la casa del Dr. Philip Lovell, construida en Los Ángeles, California, por Richard Neutra (1927-1929), conocida con el sobrenombre de Health House, Casa de la Salud [fig.7.53]. Muy acristalada y abierta, con sendas terrazas pensadas para dormir a la intemperie, tomar el sol y practicar ejercicio, es una casa con la que se emparentan la Villa Stein-de-Monzie en Garches, Les Terrasses (1926-1927) de Le Corbusier [fig.7.54], la Casa Tugendhat ${ }^{75}$ en Brno (1929-1930) de Mies van der Rohe [fig.7.55] y otras muchas viviendas del período de entreguerras [fig.7.56].

\footnotetext{
${ }^{74}$ Robert MUSIL, El hombres sin atributos Libro primero (Libro 1-1933, Libro 2-1943). Austral, Barcelona 2012, p.22. Título original Der Mann ohne Eigenschaften, escrito entre 1920 y 1942.

${ }^{75}$ La casa Tugendhat será utilizada como gimnasio para niños minusválidos durante la guerra. Beatriz COLOMINA, La domesticidad en guerra. Actar, Barcelona 2006, p. 155.
} 

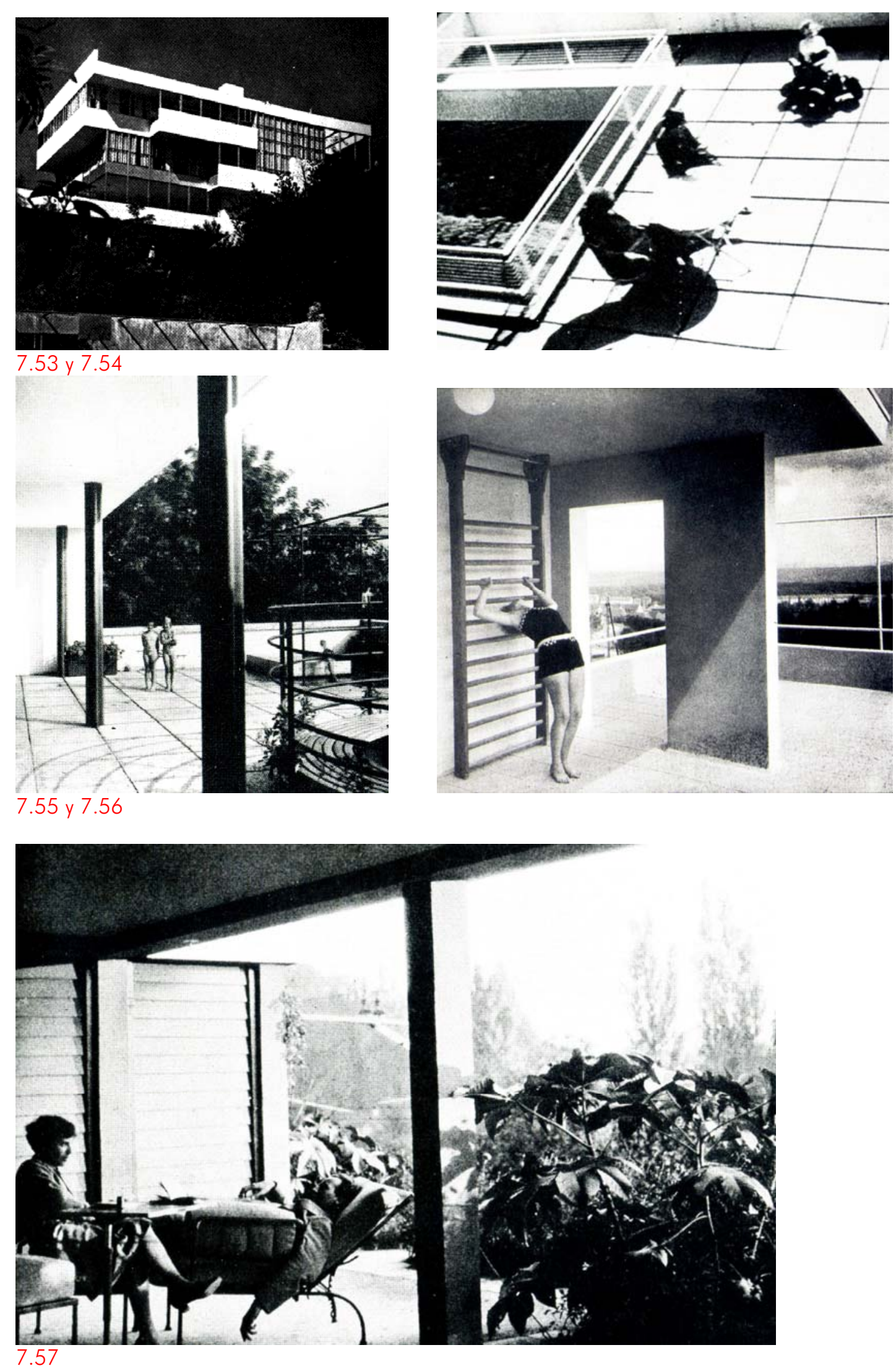

7.53 R. Neutra. Casa del Dr. Philip Lovell, Health House, Los Ángeles, 1927-1929.

7.54 Le Corbusier. Villa Stein-de-Monzie, Les Terrasses, Garches, 1926-1927. Imagen de la películo L'Architecture d'aujourd'hui, 1929 de Pierre Chenal.

7.55 Mies van der Rohe. Casa Tugendhat, Borneo, 1929-1930. Con los niños Tugendhat al fondo.

7.56 R. Döcker. Weissenhofsiedlung, Stuttutgart, 1926-1927. Terrasen Typ 1929.

7.57 M. Haefeli. Casa en Zurich, 1928. Con convaleciente de tuberculosis en la terraza. Befreistes Wohnen: Licht, Luft, Oeffnung, 1929. 
Las residencias de las vanguardias arquitectónicas, creadas para mantener y mejorar la salud en el hogar con su orientación, higiene, amplias terrazas y azoteas-solarios al aire libre son, gracias a la autoridad del sanatorio, máquinas de salud social. La aspiración de alcanzar una vivienda saludable se logra, e incluso se supera al transformarse ésta en un auténtico sanatorio doméstico, como en la casa de M. Haefeli en Zurich de 1928, que se difunde con fotografías en las que aparece un convaleciente de tuberculosis [fig.7.57]. Si el origen del sanatorio surgió de las carencias de la medicina y la arquitectura, con su progreso también serán ellas la causa de su declive, esta es la paradoja del sanatorio.

\section{EL URBANISMO HIGIENISTA Y LA CIUDAD SANATORIO}

Después de la Primera Guerra Mundial aumentan la pobreza y la carencia de higiene en las ciudades, en consecuencia, la cantidad de enfermos y de muertos por tuberculosis pulmonar crece considerablemente. Esta circunstancia lleva a las autoridades a poner en marcha planes estratégicos de lucha contra la tuberculosis que hacen que los sanatorios antituberculosos pulmonares proliferen por toda Europa.

Se llegan a construir hasta sanatorios de enormes dimensiones que contrarían las recomendaciones médicas. Su gigantismo responde tanto a necesidades económicas, para rentabilizar al máximo las instalaciones, como propagandísticas de los regímenes políticos y de las instituciones sanitarias, siendo los arquitectos los encargados de tan importante empresa quienes toman prestado las soluciones anti-urbanas planeadas con anterioridad por franceses y alemanes.

A principios del XIX en Francia, ante la impotencia de no poder mejorar las condiciones de salubridad de la vivienda de la clase obrera, Charles Fourier con su teoría de la "Armonía Universal" opta por construir unos edificios unitarios para este colectivo que denomina "falansterios", conocidos también como "palacios solidarios" o "societarios" [fig.7.57]. Grandes edificios con capacidad para unas 3.500 personas cada uno, donde conviven las familias obreras constituyendo una nueva sociedad con sus propias reglas.

Años más tarde ante la persistencia de los mismos problemas higiénicos y sociales, surge en Alemania, el movimiento denominado "Lebensreform", caracterizado por el odio hacia la gran ciudad moderna. Se trata de una cultura desarrollada durante la segunda mitad del siglo XIX y principios del XX, promovida por pensadores como H.G. Riehl y arquitectos como 


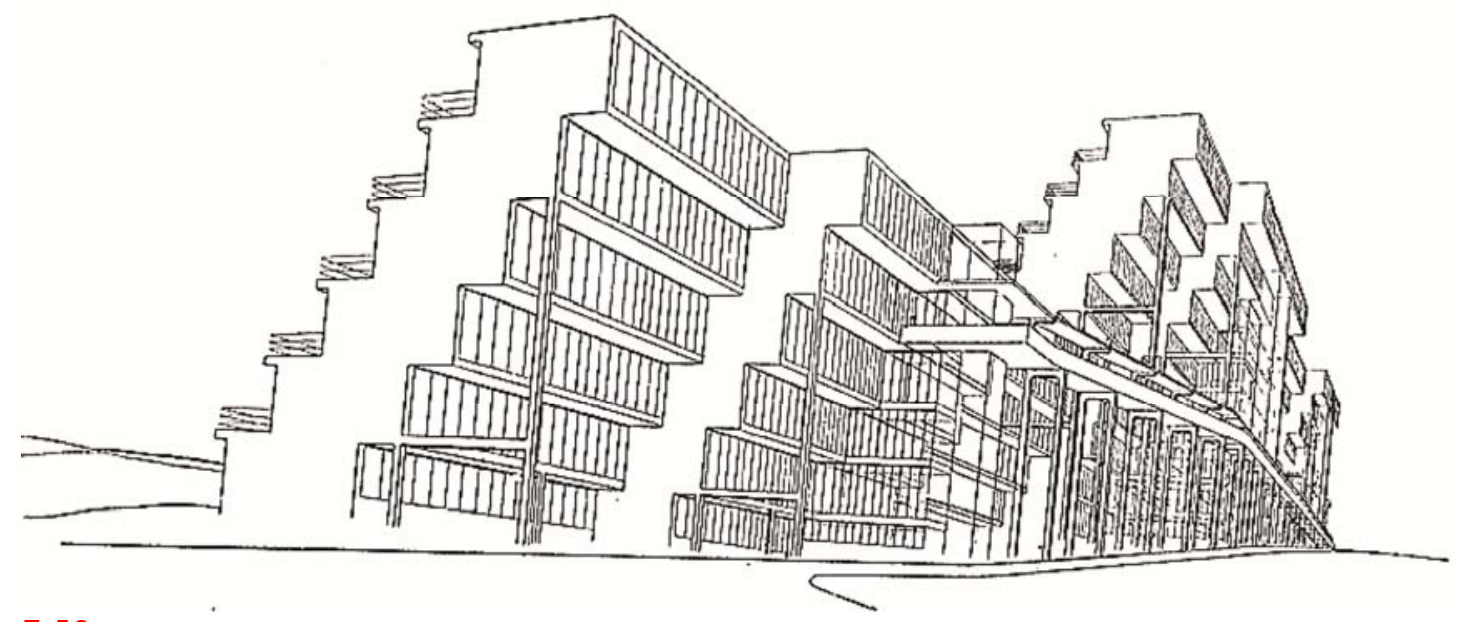

\subsection{8}
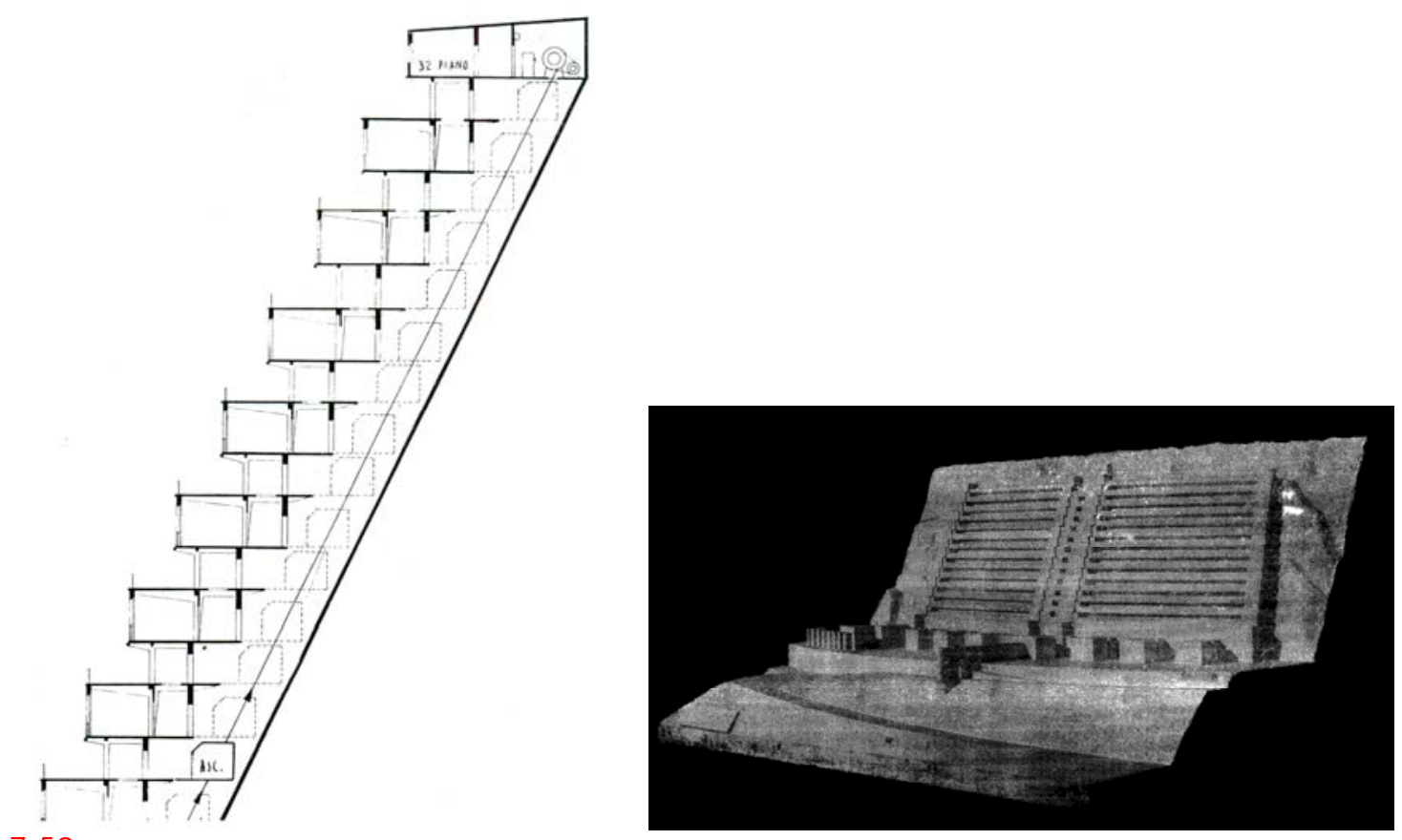

7.59
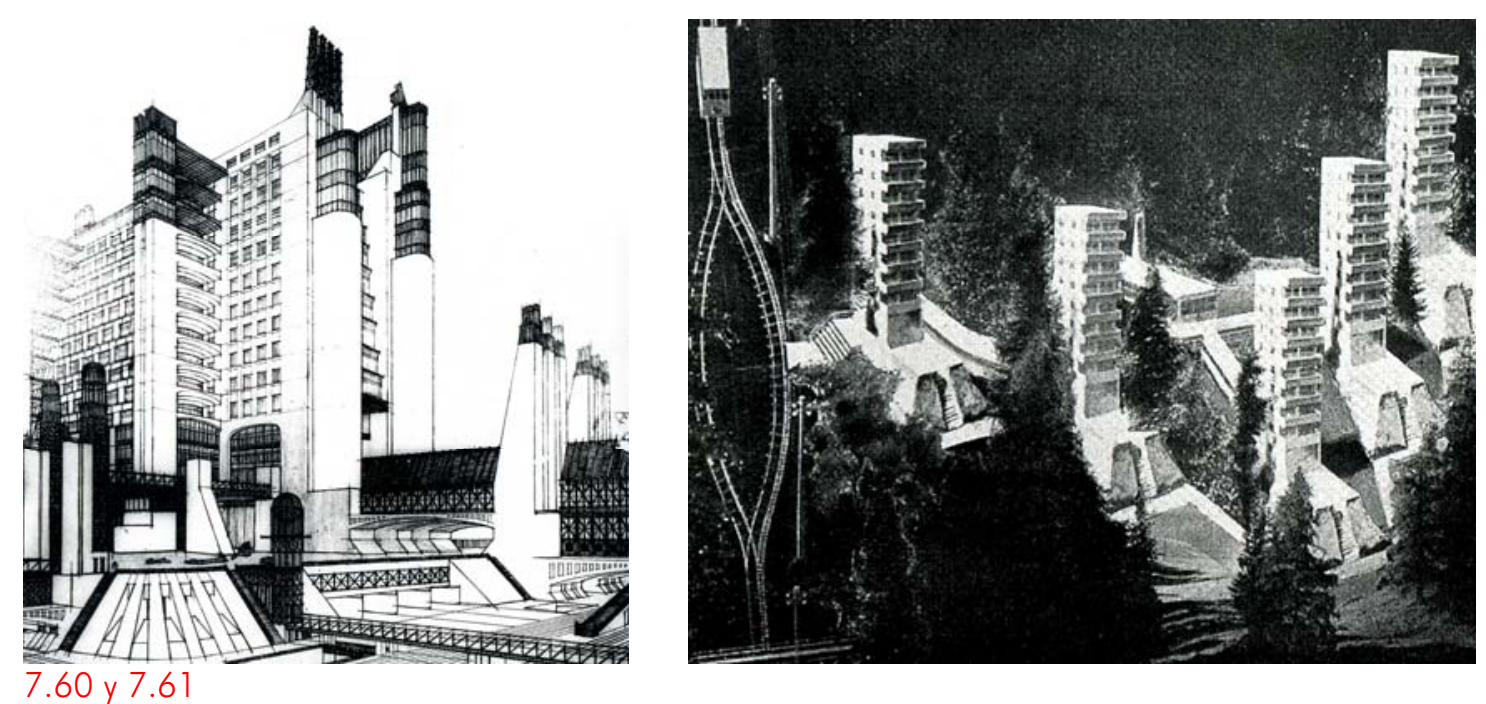

7.58 Marcel Brever y Hassenpflug. Proyecto de Sanatorio con 1.100 camas, Elberfeld, 1928-1929.

7.59 N. Visontaï. Proyecto de Sanatorio en los Alpes italianos,ca. 1934.

7.60 Sant'Elia. Casa escalonada para la Cittá Nuova, 1914.

7.61 Neidhardt. Proyecto de sanatorio vertical en Davos. 
Heinrich Tessenow que tratan de crear nuevas sociedades fuera de la gran ciudad, donde impere la higiene, la salud y el contacto con la naturaleza.

Estos planteamientos coinciden con las teorías terapéuticas de los sanatorios antituberculosos y provocan un cambio social que favorece la aparición de los mismos y su posterior crecimiento. El sanatorio pasa a ser concebido como un gran "palacio de la salud" que concentra a una población enferma, afín a un "falansterio". Se ubica fuera de las urbes contaminadas y en él se desarrollan nuevas formas de vida opuestas a las de la ciudad industrial, con rutinas higiénico-sanitarias establecidas y criterios temporales insólitos en comparación con el ritmo de la vida en la urbe; son lugares donde el mayor logro e interés humano reside en alcanzar la salud.

Surgen sanatorios de grandes proporciones ante la demanda constante de cura. Son concebidos como una ciudad desarrollada en altura, donde, como en tantas obras residenciales del Movimiento Moderno: "La casa es, pues, una metonimia de la ciudad entera "76, en palabras de Carlos Martí Arís. Con sus calles -los pasillos interiores y las galerías exteriores-, sus células residenciales- las habitaciones- y sus áreas de reunión -las salas comunes-.

La constante necesidad de un alojamiento multitudinario trae consigo el desarrollo de ciertos proyectos utópicos como el Sanatorio Hospital de Elberfeld de los arquitectos Marcel Brever y Hassenpflug (1928-1929) con capacidad para 1100 enfermos. Se trata de un gran bloque lineal escalonado ubicado en un terreno en pendiente, por lo que su altura total oscila entre las seis y las doce plantas. El edificio está soportado por un sistema estructural a base de pilares y vigas que quedan vistos en la fachada norte de los que penden los elementos de comunicación vertical, rampas y ascensores exentos al edificio que se muestran al exterior [fig.7.58]. Estos proyectos utópicos de ciudades sanatorio se aproximan a las descripciones futuristas de Sant'Elia contenidos en Messaggio (1914) [fig.7.60]:

"Tenemos que inventar y fabricar ex novo la ciudad moderna, semejante a una inmensa obra tumultuosa, ágil, móvil, dinámica en todas sus partes; y también la casa moderna, semejante a una máquina gigantesca. Los ascensores no deben agazaparse como tenias solitarias en el hueco de las escaleras, sino que las escaleras, convertidas en algo inútil, deben ser abolidas, y los ascensores deben

\footnotetext{
${ }^{76}$ Carlos MARTí ARÍS, Carlos, Las formas de la residencia en la ciudad moderna (Barcelona, 1991).
} Universidad Politécnica de Cataluña, Barcelona 2000, p. 46. 

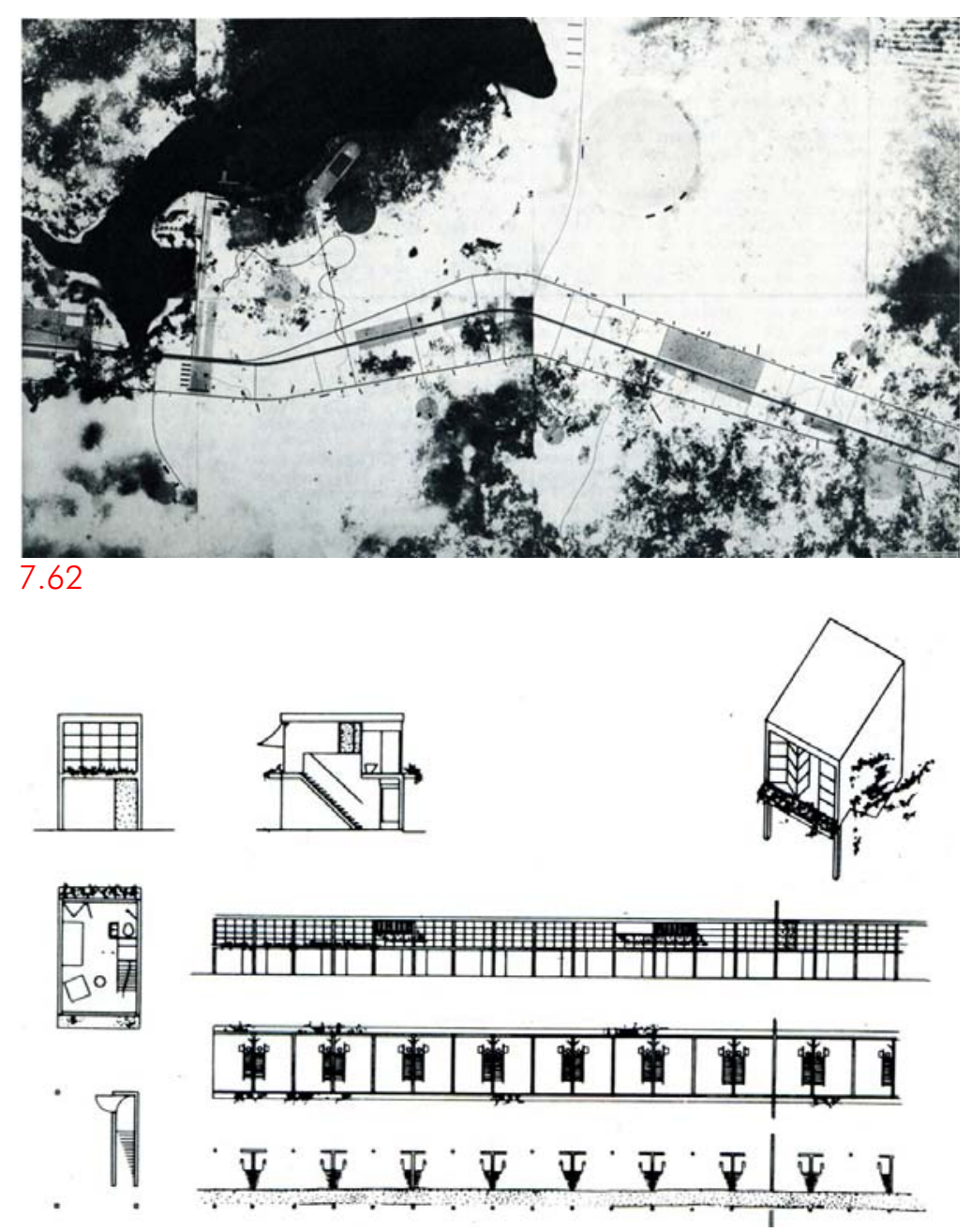

7.63
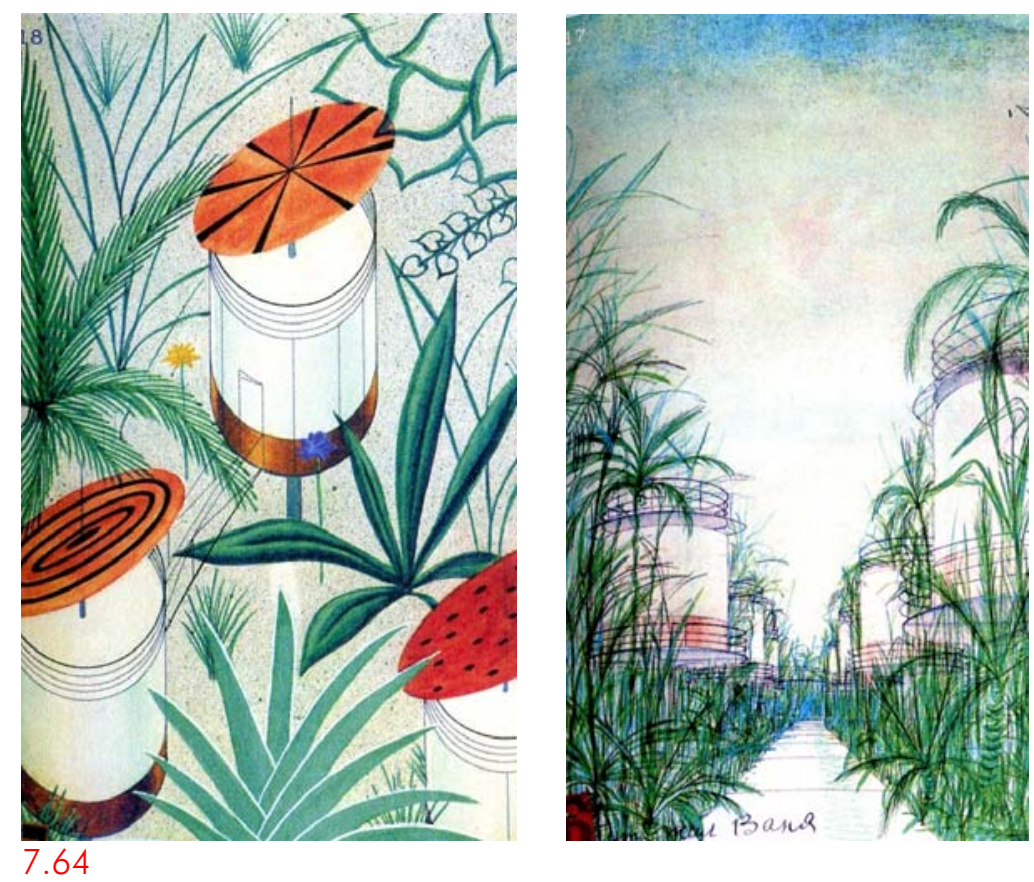

7.62 M. Ginzburg. Proyecto de la Ciudad Verde, Moscú, 1930. Plano de situación.

7.63 M. Ginzburg. Proyecto de la Ciudad Verde, Moscú, 1930. Viviendas individuales.

7.64 N. B. Sokolov. Proyecto de complejo hotelero, 1928. 
trepar, como serpientes de hierro y vidrio, a lo largo de las fachadas. La casa de hormigón, de vidrio, de hierro, sin pintura y sin escultura, rica solamente por la belleza congénita de sus líneas y sus relieves, extraordinariamente fea en su mecánica simple, tan alta y tan ancha como sea necesario, y no como esté prescrito por las leyes municipales" $" 77$.

Se llegan a proyectar hasta sanatorios escalonados con un gran desarrollo en vertical adheridos a las laderas de las montañas, como el sanatorio de los Alpes italianos proyectado por el arquitecto Nicolas $\mathrm{Visontai}^{78}$, con capacidad para 1.250 camas distribuidas en 32 plantas que se comunican por 6 ascensores y 4 montacargas. Cada planta se apoya sobre la inclinada falda de una montaña, asomando en vuelo sobre la misma, mientras que las galerías de cura se intercalan en la edificación sobre las cubiertas de las plantas de habitaciones, remarcando su posición volada [fig.7.59]. Se proyectan también ciudades-sanatorio verticales constituidas por varias torres, como las diseñadas por Neidhardt en Davos. Consta de cinco torres de base cuadrada y de unas nueve plantas de altura, insertadas en medio de la naturaleza aunque como los proyectos anteriores, no llegan nunca a ser construidas [fig.7.61].

Más fructíferos serán los resultados de las proposiciones de ciudades sanatorio que retoman las teorías higienistas de finales del siglo XIX. La ciudad de Hygeia descrita por el Dr. Benjamin Ward Richardson en 1876 en su libro Hygeia: A city of Health es una de ellas. Una salubre ciudad teórica diseñada para reducir en gran medida las enfermedades de la época.

Se trata de una "ciudad ideal", perfectamente equipada para la cultura, el descanso y la salud, dotada de bibliotecas, gimnasios, piscinas, baños turcos, etc. Una ciudad en la que no se consume ni tabaco y ni alcohol; silenciosa, ya que el tráfico pesado es soterrado y están prohibidos los talleres profesionales en las casas; higiénica, con lavanderías públicas donde son desinfectadas las ropas de sus ciudadanos, y con viviendas construidas con materiales antibacterianos. En ella las casas carecen de sótanos insalubres y las cocinas se ubicaban en la planta superior para evitar olores desagradables. Es una ciudad diseñada desde la preocupación por el confort y el bienestar, donde todas las viviendas de más de dos plantas tienen ascensor y donde el dormitorio, regenerador del descanso diario, es una

\footnotetext{
${ }^{77}$ Kenneth FRAMPTON, Historia crítica de la arquitectura moderna (London, 1980). Editorial Gustavo Gili, Barcelona 2009, p. 89.

78"Projet d'un sanatorium dans les Alpes italiennes", L'Architecture d'Aujourd'hui, n 9, 1934, p.78.
} 


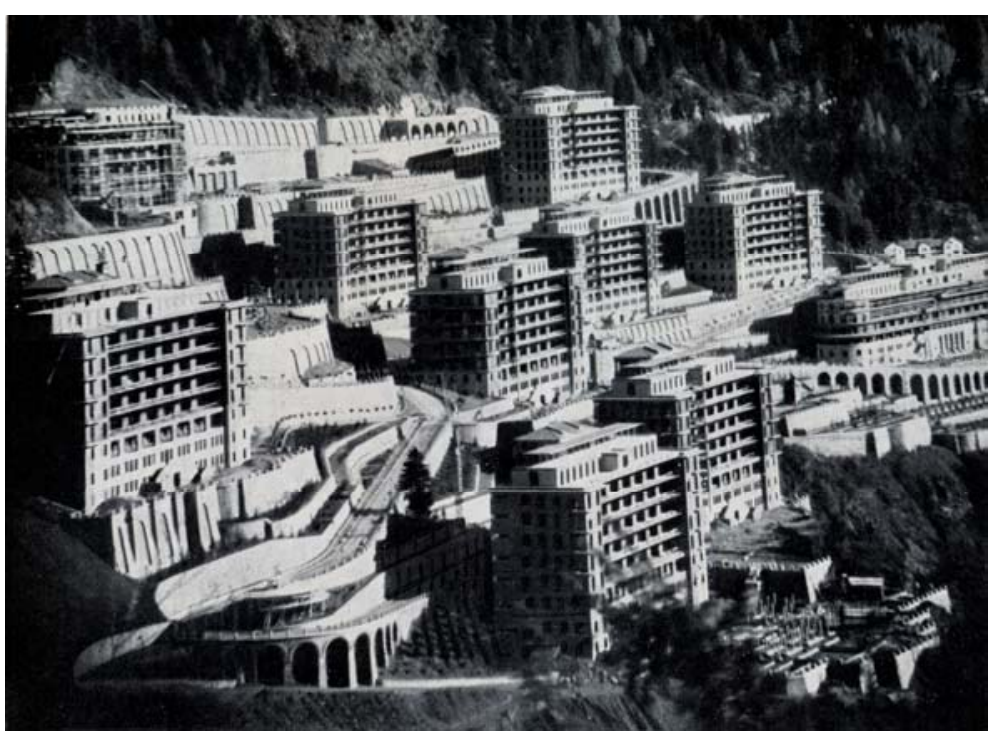

7.65

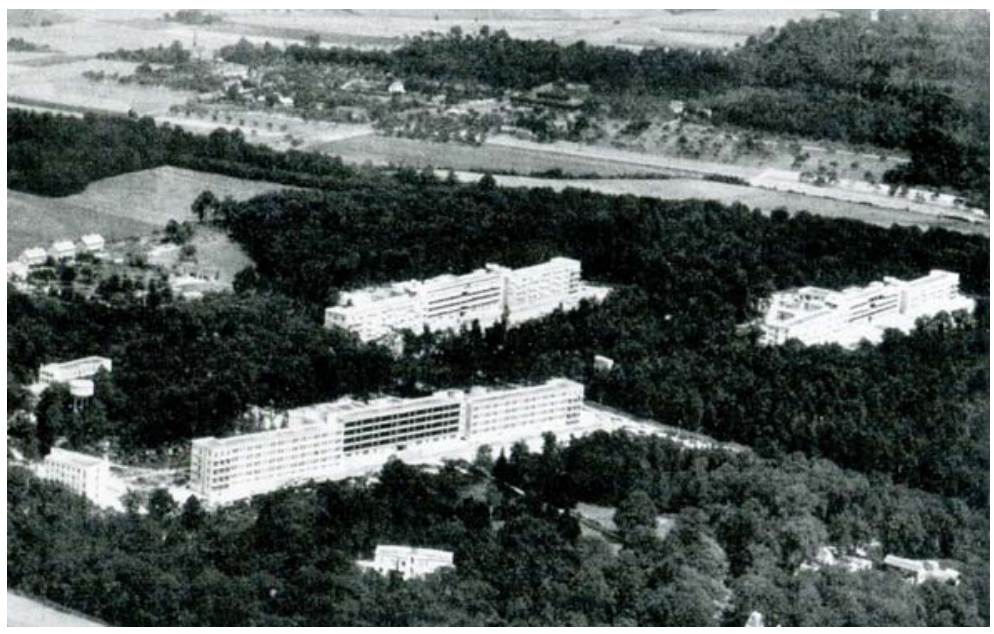

7.66

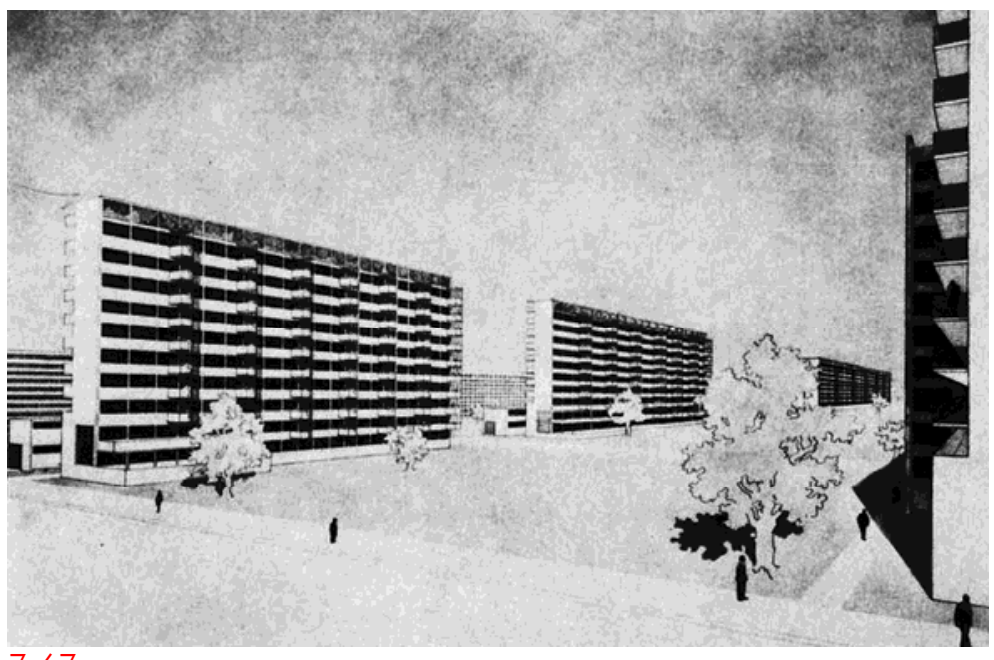

7.67

7.65 Istituto Nazionale Fascista della Previdenza Ciudad Sanatorial de Sondalo, 1932.

7.66 M. Favier, A. Thiers y J. Bardin . Sanatorio femenino de Arnières, c. 1930.

7.67 Walter Gropius. Proyecto de viviendas en altura en Acier, 1931. 
de las estancias más cuidadas en las viviendas. Una ciudad donde se buscaba el contacto con la naturaleza, por ello las casas disponen de "cubiertas-jardín" y se rodean de vegetación, en la cual los edificios públicos se implantan en las áreas verdes de la ciudad.

La preocupación por la salud en Hygeia se constata por la construcción de una gran cantidad de pequeños hospitales distribuidos de forma equidistante dentro de la misma y el abandono del tradicional gran hospital: "La vieja idea de almacén de enfermos de la mayor escala posible, que conviente en el orgullo de la institución los cientos de camas que contiene, se abandona aquí"79. Cuenta con centrales generadoras de agua destilada y de ozono, según recomiendan los médicos, porque éstos participan activamente en las labores de organización y el desarrollo de la misma.

El fin principal de Hygeia es acabar con la enfermedad, al igual que las primeras colonias sanatoriales desarrolladas en Inglaterra, y que ciertas propuestas urbanísticas como la ya comentada Villa Verte de Moscú que pretende ser un "inmenso sanatorio proletario"80. La Ciudad Verde o Ciudad de Reposo propuesta por Moisei Ginzburg alrededor de $1930^{81}$ se basa en el contacto del hombre con la naturaleza como medio para recuperar las fuerzas perdidas y conservar la salud. Ginzburg propone transformar Moscú en un gran parque orientado a la cultura y al descanso y construir una "ciudad lineal" constituida por franjas de viviendas continuas, paralelas a los viales y separadas de éstos unos 200 ó 250 metros. Dentro de cada franja, cada vivienda es una célula individual de 12 metros cuadrados, bien iluminada y ventilada, y totalmente inmersa en la naturaleza ${ }^{82}$ [fig.7.62 y fig. 7.63]. Esta solución de viviendas higiénicas independientes recuerda a las cabinas diseñadas por Nikolai B. Sokolov en $1928^{83}$ para un complejo hotelero [fig.7.64], cuya concepción sigue los mismos criterios "desurbanistas" que la Ciudad Verde de Ginzburg y la misma preocupación por el bienestar y por la salud que se persigue en el diseño de cada una de las habitaciones del sanatorio.

La Ciudad Verde dispone de comedores, de áreas deportivas y de descanso comunes para los trabajadores, pues en ella se quiere una colectivización de la sociedad como la ya

\footnotetext{
${ }^{79}$ Benjamin Ward RICHARDSON, Hygeia: A City of Health (1876). Dodo Press, 2008, pp. 11-33.

80 Jean-Louis COHEN, Le Corbusier et La Mystique de I'URSS. Théories et Projets pour Moscou 1928-1936. Pierre Mardaga Éditeur, Lieja 1987, p. 163.

81 Paolo CECCARELLI, La construcción de la ciudad soviética (1970). Editorial Gustavo Gili, Barcelona 1972, pp. 248-260.

${ }^{82}$ La Ciudad Verde de Moscú sirvió de referente a la Ciudad de Reposo de Barcelona proyectada por José Luis Sert y el GATCPAC, alrededor de 1932.

${ }^{83}$ Ivan NEVZGODIN, "Revolutionizing Hospital Architecture: Experiments in the Soviet Union", en Cor WAGENAAR (ed.), The Architecture of Hospitals, NAi Publishers, Rotterdam 2006, p.50.
} 
propuesta por M. Ginzburg en la "Casa Comuna" Narkonfim construida en Moscú en 1930. Colectivización que precisa del establecimiento de un estricto orden en los hábitos de la sociedad pues, como afirma Le Corbusier: "Donde reina el orden nace el bienestar" ${ }^{84}$, quien considera que la Ciudad Verde de Moscú debe contar: "con un orden de funcionamiento tan preciso como los reglamentos de los trabajadores ${ }^{115}$. Para conseguirlo es necesario lograr que el conjunto de la sociedad se comporte como un grupo adiestrado y no como una suma de individuos y que el bien común impere por encima de los intereses individuales. Este logro se obtiene en las comunidades de enfermos sometidos a un régimen sanatorial, perteneciente a las llamadas "instituciones totales", pero no entre individuos sanos y libres como son los ciudadanos del siglo XX.

La vida en los enormes sanatorios como la Ciudad Sanatorial de Sondalo en Italia, conocida como Ciudad Sanatorial Morelli, construida por el Istituto Nazionale Fascista della Previdenza Sociale a partir de $1932^{86}$ [fig.7.65], es un ejemplo de los modos de vida ordenada y racional que los arquitectos quieren imponer a la sociedad moderna. Este gran complejo alberga a unos 3.000 enfermos de tuberculosis distribuidos en idénticos "pabellones-tipo" autónomos, de ocho plantas de altura cada uno. Constituye un recinto compacto y regular, pese a estar constituido por construcciones aisladas, gracias a su elevada densidad, consecuencia de la altura de sus edificaciones y a la idéntica repetición de las mismas, que dan al conjunto una gran uniformidad.

Pero no sólo las formas de vida de estas ciudades sanatorio coinciden con las que se desean imponer en la ciudad moderna, también su arquitectura. La imagen de los bloques residenciales de la Ciudad Sanatorial de Sondalo sintoniza con la del Sanatorio femenino de Arnières en Francia. Este último está constituido por tres grandes pabellones lineales con planta en forma de $T$, debidamente distanciados y paralelos entre sí y fue construido por los arquitectos M. Favier, A. Thiers y J. Bardin alrededor de los años 30 [fig.7.66]. Arnières y Sondalo formados por la reiteración de bloques lineales sumergidos en grandes espacios verdes aparecen como la avanzadilla de la ciudad moderna descrita por Walter Gropius en el III CIAM celebrado en Bruselas en 1930; quien propone, como ya había hecho Hilberseimer en su Ciudad Vertical (1924), la creación de zonas residenciales con bloques

\footnotetext{
${ }^{84}$ LE CORBUSIER, Hacia una Arquitectura (Vers une architecture, 1923). Poseidon, Barcelona 1978, p.39.

85 Jean-Louis COHEN, Le Corbusier et La Mystique de I'URSS. Théories et Projets pour Moscou 1928-1936. Pierre Mardaga Éditeur, Lieja 1987, p. 288.

86 Bruno MORETTI, Franco MORETTI, Ospedali. Seconda Edizione notevolmente ampliata. Ulrico Hoepli Editore, Milano 1940, pp. 276-279.
} 
de viviendas desarrollados en altura sujetos a un límite de densidad que garantice la incorporación de extensiones naturales en las urbes [fig.7.67]. Estos bloques:

"En lugar de dar a corredores libres de 20 metros de anchura, las ventanas miran a zonas verdes arboladas de 100 metros de anchura que ayudan a purificar el aire y ofrecen amplios espacios para los juegos de los niños. Así penetra la naturaleza en la metrópoli, así la ciudad puede ofrecer nuevas atracciones a los habitantes "87.

Gropius aprecia en los bloques lineales de viviendas, casi idénticos a los volúmenes residenciales de los sanatorios salvo por su orientación ya que recomienda que sus fachadas se obran hacia el este o el oeste en vez de al mediodía, una serie de ventajas sobre los edificios continuos à redents: "que todas las habitaciones pueden tener la misma orientación, que la ventilación de las hileras no está obstaculizada por bloques transversales, y que desaparecen las habitaciones en esquinas, que sólo se pueden ventilar poco y mal"88. De hecho Le Corbusier también abandonará este sistema para adoptar en la Unidad de habitación la organización en forma de bloque lineal, como explica J. González Cubero: "Del desdoblamiento de edificio à redent en sus tramos dobles, los de dos crujías, va a resultar, como consecuencia de esta fragmentación, la Unité d'habitation 1189.

De este modo, la forma de la residencia y de la ciudad modernas que responden a un intento de mejora de las condiciones de ventilación, soleamiento y vegetación de las metrópolis, coinciden con las de la ciudad sanatorio, una urbe higiénica y vertical inmersa en la vegetación, donde el perfil ortogonal de los bloques de sus sanatorios contrasta con las formas onduladas de la naturaleza que los circunda.

\section{ARQUITECTURA Y PATRIMONIO DE LA SALUD}

El avance de la quimioterapia aplicada a la tuberculosis lleva consigo la aparición de antibióticos eficaces capaces de acabar con la enfermedad, este hecho sumado al desarrollo de la vacuna obligatoria contra la tuberculosis la B.C.G., Bacilo Calmette Guerin, y a los nuevos métodos para el diagnóstico, logran disminuir considerablemente el índice de mortandad de la tuberculosis y hacen que a partir de 1950 dejen de ser

${ }^{87}$ Carlo AYMONINO, La vivienda racional. Ponencias de los congresos CIAM 1929-1930. Gustavo Gili, Barcelona, 1973, pp. 227 y 228.

${ }^{88}$ Carlo AYMONINO, La vivienda racional. Ponencias de los congresos CIAM 1929-1930. Gustavo Gili, Barcelona, 1973, pp. 226.

89 Josefina GONZÁLEZ CUBERO, Le Corbusier. El proyecto de la ciudad moderna. Tesis doctoral inédita, Departamento de Teoría de la Arquitectura y Proyectos Arquitectónicos, E.T.S. de Arquitectura Universidad de Valladolid, 1996, p. 259. 

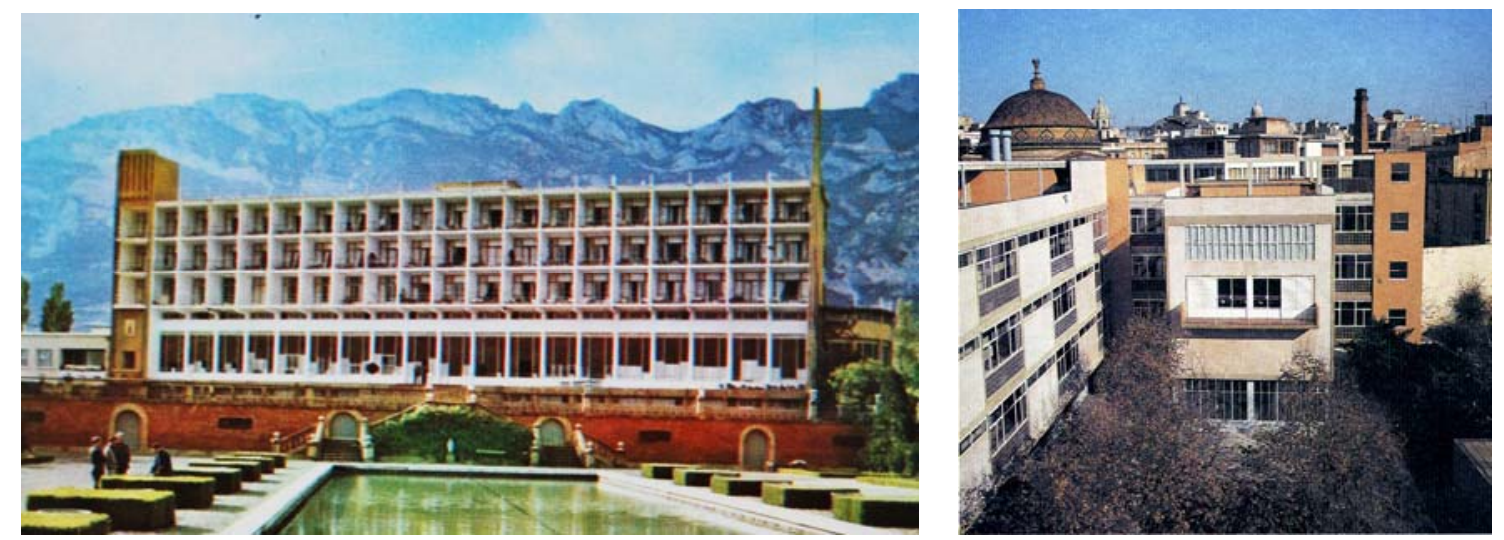

7.68 y 7.69
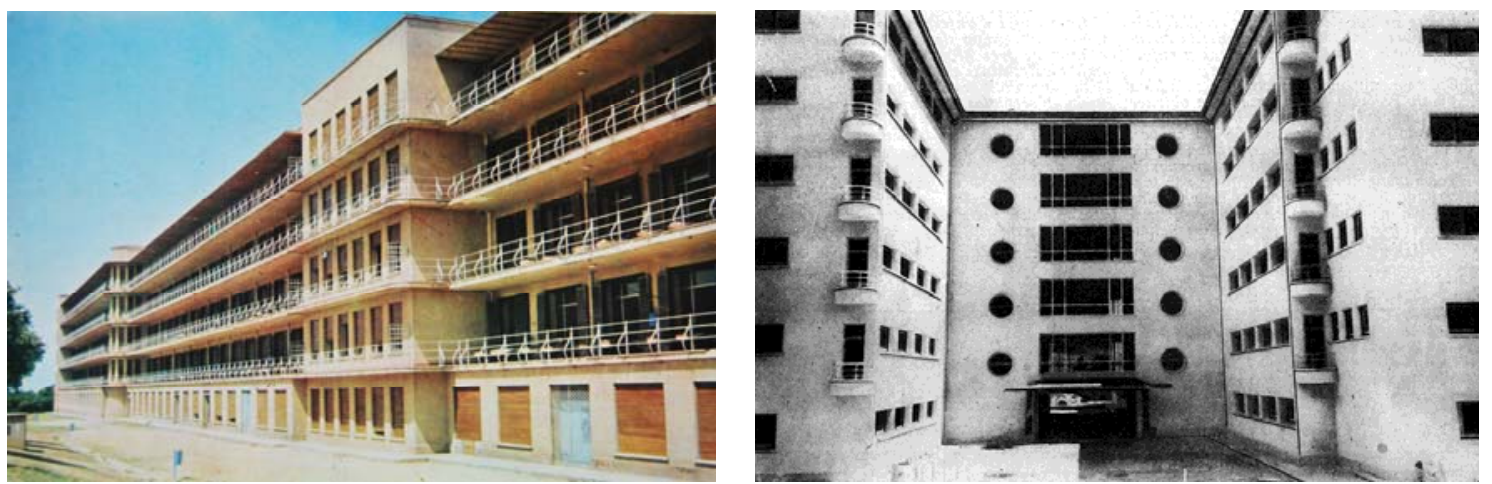

7.70 y 7.71

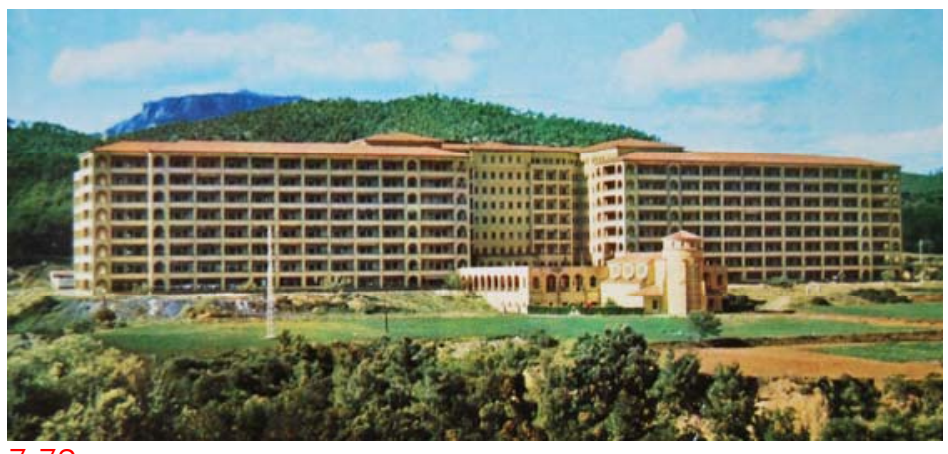

7.72

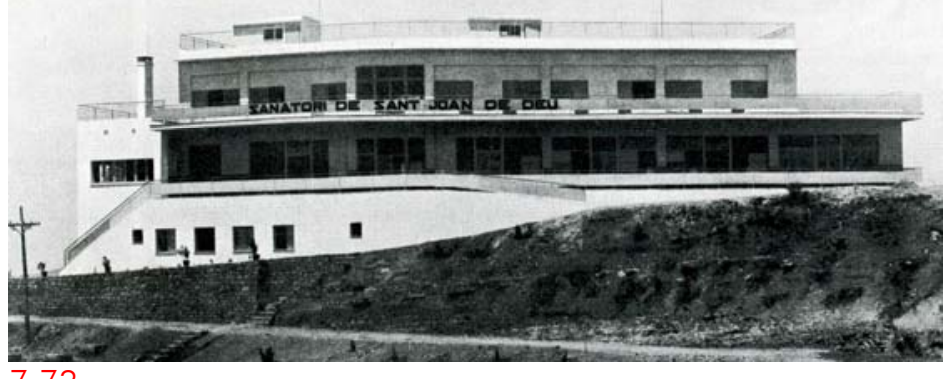

7.73

7.68 P. Zabalo. Sanatorio Antituberculoso de Leza, Álava, 1934-1935.

7.69 Subirana, Sert y Torres Clavé. Dispensario Antituberculoso de Barcelona, 1933-1937.

7.70 R. Bergamín. Sanatorio Antituberculoso de los Montalvos, 1934-1948.

7.71 E. Aguinaga. Sanatorio del Generalísimo Franco, Bilbao, 1944.

7.72 E. Ripollés. Ciudad Sanatorial de Tarrasa, 1944-1952.

7.73 Rodríguez Arias. Sanatorio San Juan de Dios, Manresa, 1932. 
indispensables los sanatorios para la cura de esta enfermedad, pasando a ser tratados los enfermos de tuberculosis en el hospital general ${ }^{90}$.

Paulatinamente los sanatorios antituberculosos pulmonares son abandonados con su consecuente deterioro arquitectónico. A este deterioro también contribuyen ciertos fallos técnicos, provocados por el propio carácter experimental del sanatorio que trae consigo el empleo de materiales y sistemas constructivos desconocidos; factor que aunado a los principios de economía de medios y ahorro en la construcción, que primaba en las instituciones sanatoriales públicas, propician la precoz decadencia de algunas de estas construcciones. Los escasos conocimientos geológicos tampoco ayudaron a la permanencia del sanatorio y, en ocasiones, la elección de lugares inapropiados para la localización de los mismos acabó en tragedia, como sucedió en el Sanatorio de Roc des Fiz en el Plateau d'Assy que fue sepultado por una avalancha de lodo.

Sin embargo, la causa fundamental de su devaluación arquitectónica se debe a la falta de respeto por su valor patrimonial, demostrada en las reformas y obras de mantenimiento ejecutadas en ellos. Hay que tener en cuenta que los sanatorios construidos entre 1920 y 1930 representan el más grande programa de salud jamás llevado a cabo ${ }^{91}$. El sanatorio se populariza al multiplicar su presencia por doquier en diversas latitudes europeas, gracias a las campañas de lucha antituberculosa que utilizan su imagen en sellos, películas ${ }^{92}$, anuncios, etc., hecho que contribuye a que el sanatorio antituberculoso se convierta en un icono de la arquitectura moderna.

En España en el año 1954, momento en el que se pone fin al "Plan de construcción de sanatorios" del Patronato Nacional Antituberculoso, se contaba con un total de 68 sanatorios y 180 dispensarios pertenecientes al Estado, a los que se debía asignar un nuevo uso $^{93}$. De entre estas edificaciones destacan por su valor arquitectónico, el Sanatorio Antituberculoso de Leza (1934-1935), inspirado en el sanatorio de la Fuenfría de Madrid ${ }^{94}$, construido en Álava por Pablo Zabalo. Consiste en un bloque lineal asimétrico cuya

${ }^{90}$ El hospital de Saint-Lô de Normandía, proyectado por Paul Nelson (1948-1956), integra en su séptima y octava plantas habitaciones para tuberculosos dotadas de galerías de cura, en previsión de la futura absorción por parte del hospital general del programa sanatorial.

${ }^{91}$ TOULIER, Bernard, CREMNITZER, Jean-Bernard (dirs.) Histoire et Réhabilitation des Sanatoriums en Europe. Docomomo International, Paris 2008, p. 0.

92 Como se aprecia en los documentales del NO-DO consultados en la Filmoteca Nacional: En estos años de Paz (1949) dirigido por Alberto Reig Gozalbes, y Vidas Salvadas (1949) Revista Imágenes n 226.

${ }^{93}$ Alberto PIELTÁIN, Arquitectura para la Sanidad Pública en España 1942-1977. Instituto Nacional de Gestión Sanitaria, Madrid 2007, p. 35.

94 José Luis JUAN FONSECA, Historia del sanatorio de Leza (1935-1983). Tesis doctoral inédita, Facultad de Medicina de la Universidad de Salamanca, 1986, pp. 12-13. 
organización se aleja de la característica planta en forma de T, aproximándose más a los hospitales tipo torre y base. Su cerramiento del frente de habitaciones mediante paños completos de vidrio es una de sus peculiaridades arquitectónicas más importantes y describen un cambio en los métodos constructivos habituales aplicados en la construcción de sanatorios en España. Delante de este frente, se ubica una serie de profundas terrazas individuales cerradas lateralmente, cuyos flancos actúan de brisoleily definen una marcada cuadrícula característica del sanatorio de Leza [fig.7.68].

Cabe destacar también el Dispensario Antituberculoso de Barcelona (1933-1937) obra de Subirana, Sert y Torres Clavé, articulado en forma de L. Un edificio muy heterogéneo que rompe con los cánones arquitectónicos de la época, tanto por su irregularidad volumétrica como por la desigualdad de sus fachadas ${ }^{95}$ [fig.7.69].

Estas dos obras junto con el gran Sanatorio Antituberculoso de los Montalvos (1934-1948), Salamanca, de Rafael Bergamín, paradigma del sanatorio con planta en forma de T impuesto por el Patronato Antituberculoso por todo el territorio nacional [fig.7.70], son los tres únicos edificios españoles vinculados a la cura de la tuberculosis recogidos en el registro del Docomomo Ibérico.

Sin embargo, existen también otros de gran interés arquitectónico como el Sanatorio del Generalísimo Franco de Bilbao (1944) [fig.7.71], un sanatorio con planta en forma de doble T asimétrica, que toma como referente el Sanatorio de Paimio, según reconoce su autor Eugenio Aguinaga, quien considera que la construcción de sanatorios "constituye una de las más atractivas misiones que un arquitecto pueda recibir, por ser un compendio casi completo en un solo edificio de la casi totalidad de actividades básicas de nuestra civilización $n^{\prime \prime 6}$.

Resultan también importantes la inmensa Ciudad Sanatorial de Tarrasa (1952), posiblemente el sanatorio compacto más grande de Europa [fig.72], o el Sanatorio de San Juan de Dios (1932) de tan sólo 35 camas, construido en Manresa por Rodríguez Arias, el único sanatorio que llega a trascender al panorama arquitectónico internacional de la

\footnotetext{
${ }^{95}$ Antonio PIZZA, Dispensario Antituberculoso de Barcelona, 1933-1937: J. LI. Sert, J. B. Subirana y

J. Torres Clavé. Colegio de Arquitectos de Almería, Almería 1993, pp. 39-51.

96 Eugenio AGUINAGA, "Ideas generales a tener en cuenta en la construcción de sanatorios antituberculosos de la beneficencia y su aplicación en el caso del sanatorio del Generalísimo Franco, de Bilbao, por el arquitecto Eugenio Aguinaga", en Revista Nacional de Arquitectura, $n^{\circ}$ 126, Madrid, 1952, pp. 32.
} 
época ${ }^{97}$, con una amplia terraza que le otorga una particular estética naval [fig.7.73]. Esta lista puede ampliarse con otros tantos sanatorios como el Sanatorio de Nuestra Señora de las Mercedes en San Sebastián [fig.7.74], el Sanatorio Víctor Tapia en Vizcaya [fig.7.75], el Sanatorio del Tomillar en Sevilla [fig.7.76], el Sanatorio de Ofra en Santa Cruz de Tenerife [fig.7.77], el Sanatorio de Viana en Valladolid [fig.7.78], el Sanatorio de Los Llanos en Albacete [fig.7.79], etc., que al igual que aquellos tres destacados constituyen una importante muestra de la arquitectura racionalista realizada en nuestro país.

Estos sanatorios, como los del resto de Europa, han experimentado hasta nuestros días, numerosas actuaciones de conservación, inadecuadas en muchos casos, que se pueden clasificar en tres categorías:

Remodelación constante para lograr la supervivencia.

Reconversión respetuosa proporcionando al sanatorio un nuevo uso.

Restauración formal y conversión del sanatorio en monumento.

El estudio de estas estrategias de conservación nos permite conocer el éxito obtenido en cada caso, y nos ayudan a fijar las posibles líneas de actuación a seguir en la salvaguarda de nuestro patrimonio.

En un primer momento, alrededor de los años 70, los sanatorios antituberculosos son transformados en hospitales de enfermedades del tórax, después amplían el espectro de afecciones y pasan a atender a enfermos cardiovasculares, para terminar convirtiéndose en la mayoría de los casos en hospitales generales vinculados a otros centros más nuevos y mejor equipados ubicados en la ciudad.

Esta adaptación del sanatorio antituberculoso pulmonar en hospital general resulta complicada, tanto por su localización, ya que su distanciamiento de los núcleos de población dificulta este uso, como por su configuración arquitectónica, pues su geometría estrecha y alargada del bloque lineal hace difícil incluir ciertos equipamientos médicos en su interior. Aun así, existen ejemplos de una buena adaptación del sanatorio al hospital como sucede en el del Sanatorio de Paimio, edificio institucional que junto con la Bauhaus y la Sociedad de las Naciones de Ginebra, están: "inseparablemente unidos al resurgimiento de la arquitectura contemporánea ${ }^{198}$, según Sigfried Giedion. Paimio fue transformado en

\footnotetext{
${ }^{97}$ El Sanatorio de San Juan de Dios es el único sanatorio español que aparece recogido en la revista L'Architecture d'Aujourd'hui n9, 1934, dedicado a hospitales, puede que a causa de su previa publicación en la revista AC Documentos de Actividad Contemporánea, n6, 1932.

${ }^{98}$ Sigfried GIEDION, Espacio tiempo y arquitectura (Space, time and architecture, 1941). Dossat, Madrid 1982, p.607.
} 

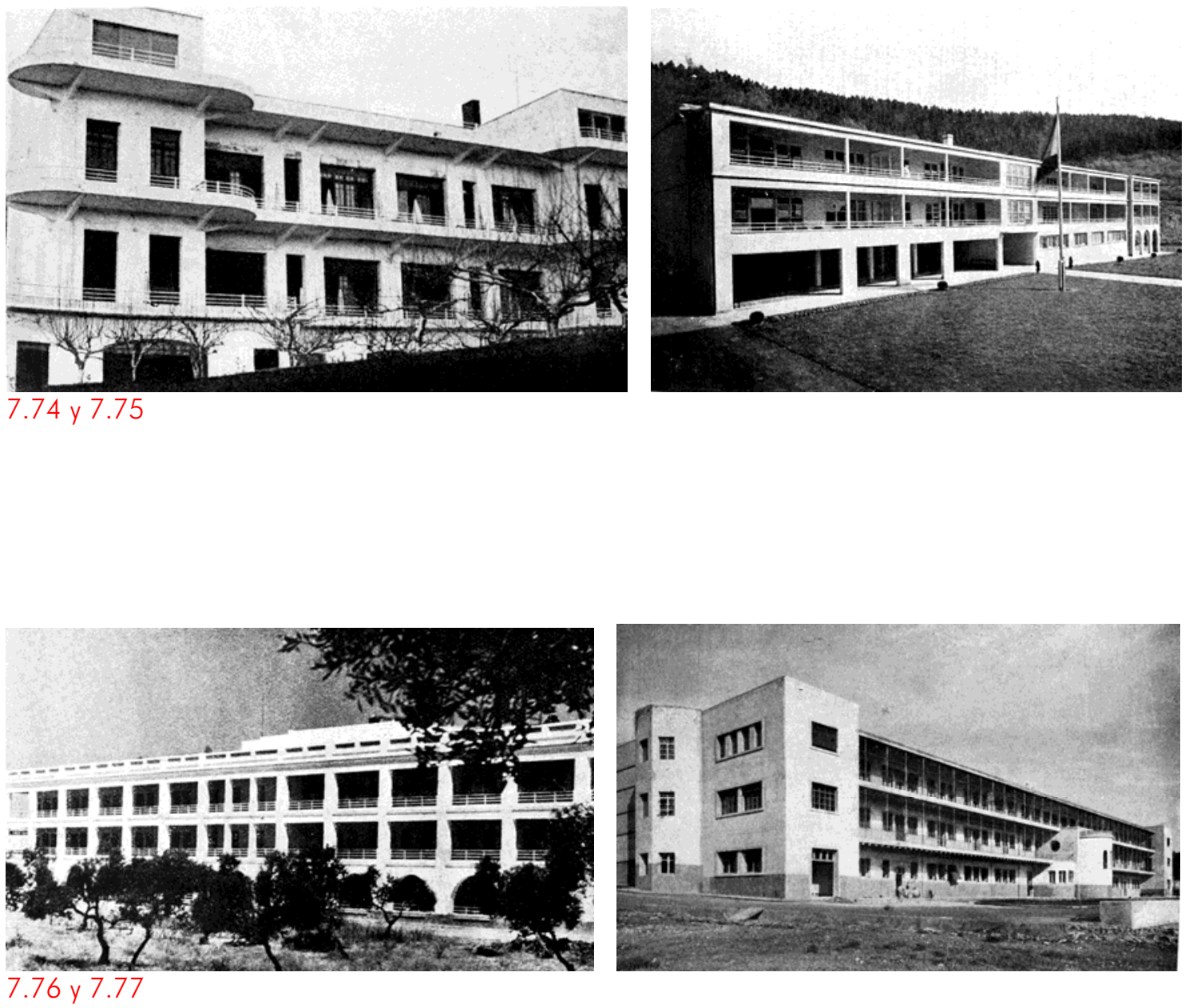

7.76 y 7.77
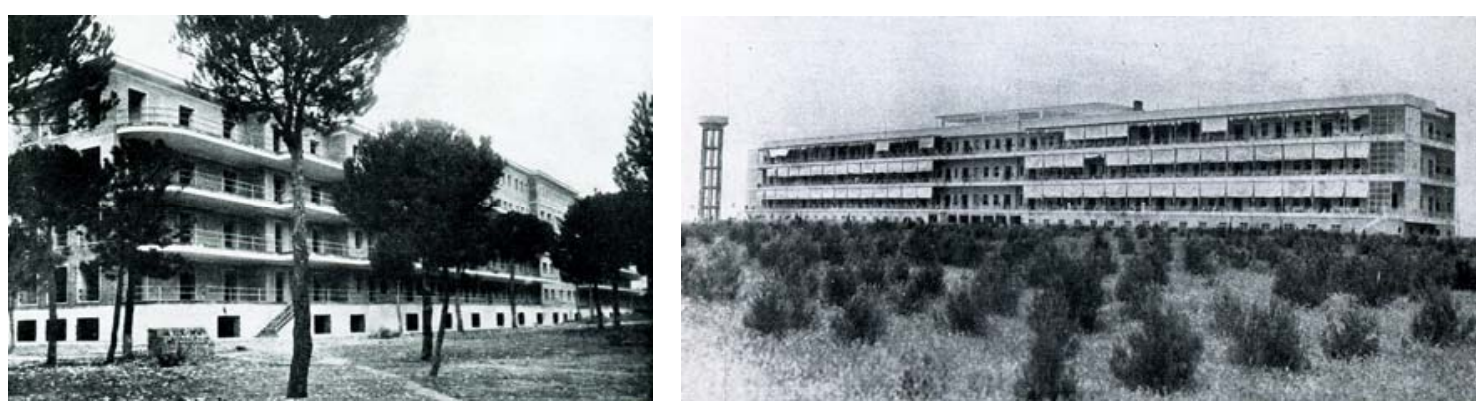

7.78 y 7.79

7.74 Sanatorio de Nuestra Señora de las Mercedes, San Sebastián.

7.75 Sanatorio Víctor Tapia, Vizcaya.

7.76 Sanatorio del Tomillar, Sevilla.

7.77 Sanatorio de Ofra, Santa Cruz de Tenerife.

7.78 Sanatorio de Viana, Valladolid.

7.79 Sanatorio de Los Llanos, Albacete. 

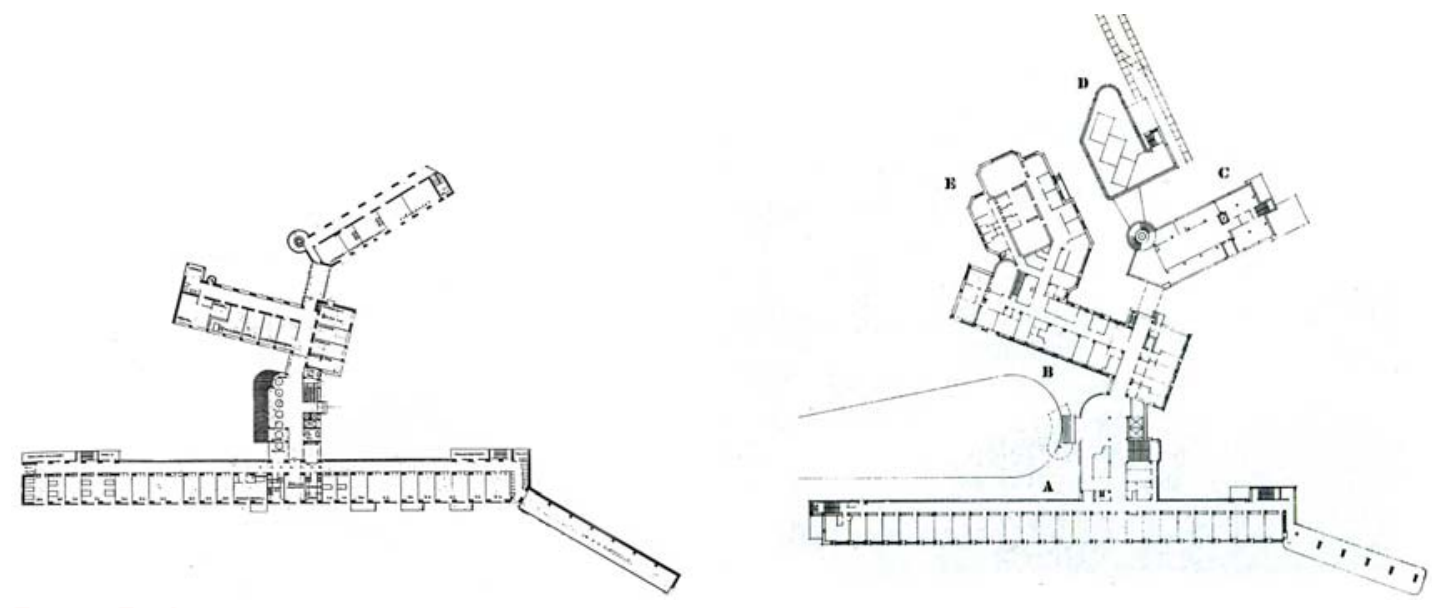

\subsection{0 y 7.81}
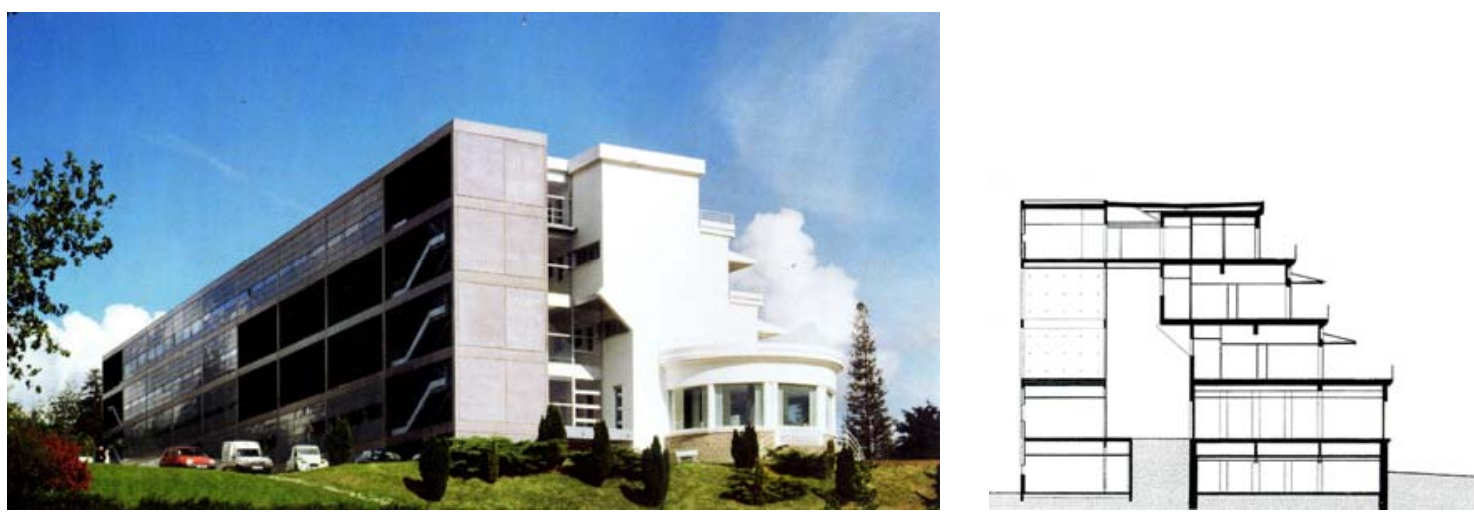

7.82 y 7.83

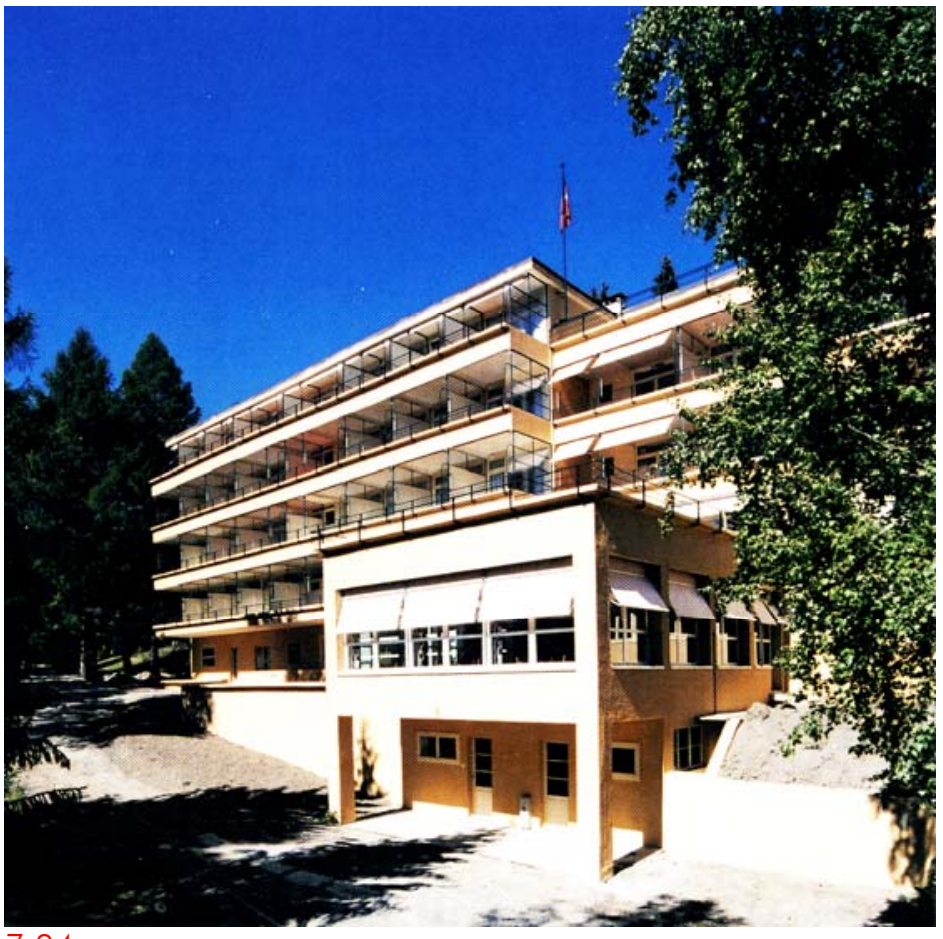

7.84

7.80 y 7.81 Sanatorio de Paimio. Proyecto original y proyecto actual.

7.82 y 7.83. Sanatorio Bodiffé-en-Plémet. Estado actual. Vista exterior y sección.

7.84 Sanatorio de Bella-Lui. Vista estado actual. 


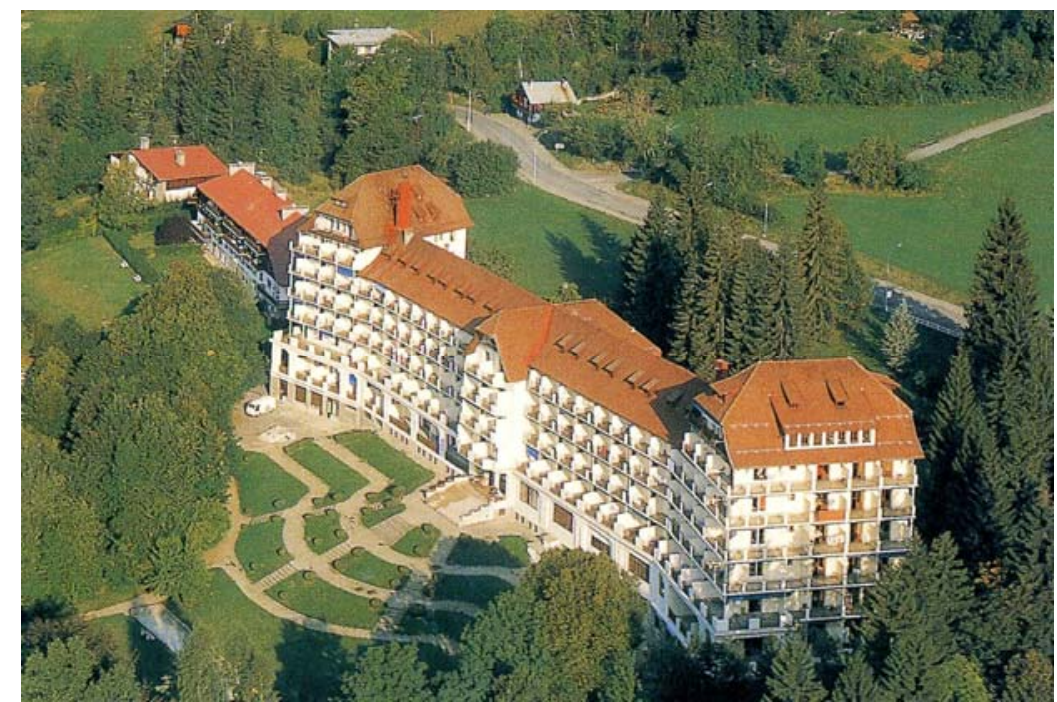

7.85

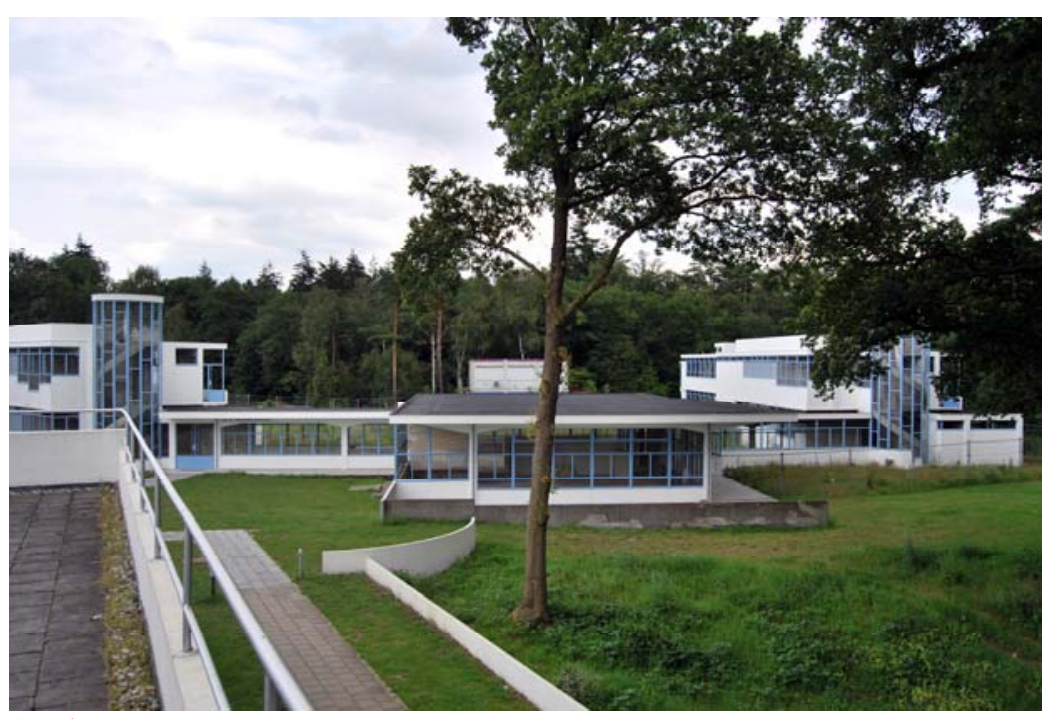

7.86

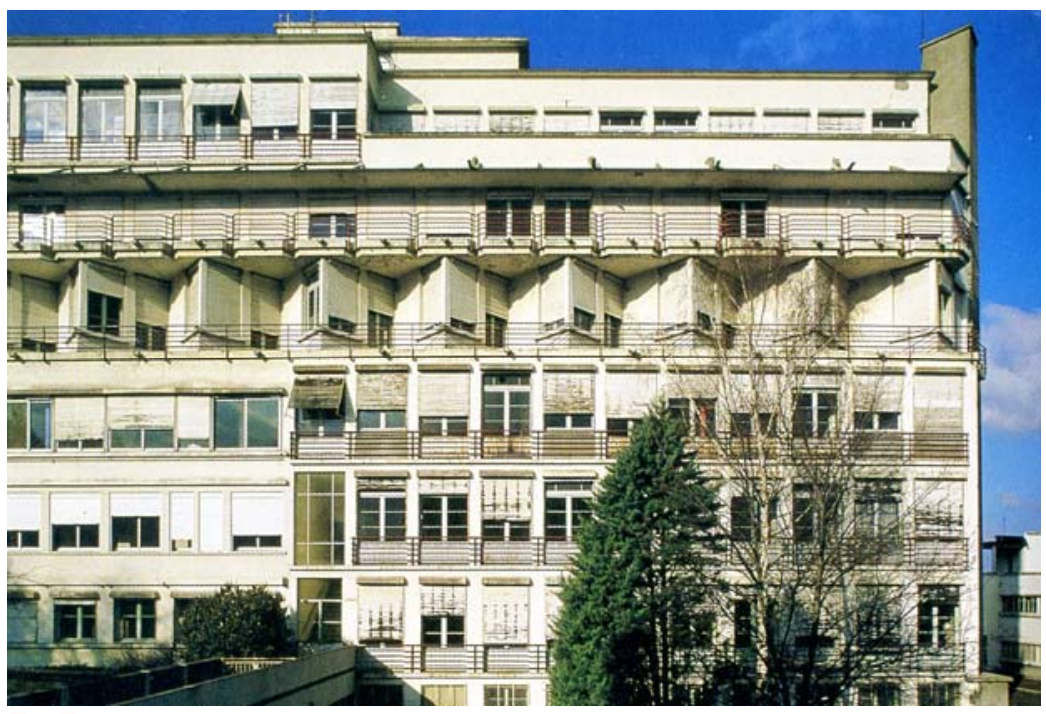

7.85 Hotel Mont-Blanc, Leysin. Estado actual.

7.86 Sanatorio de Zonnestraal, Hilversum. Estado actual (fotografía de la autora).

7.87 Sanatorio Sabourin, Clermont-Ferrant. Estado actual. 
1998 en hospital general, demostrando que las reconversiones arquitectónicas respetuosas con el proyecto original, no conllevan la pérdida de su valor arquitectónico; de hecho en la actualidad este edificio está nominado para entrar en la lista de Patrimonio Mundial de la UNESCO. En el caso de Paimio, la propia configuración del sanatorio constituida por diferentes partes conectadas entre sí, facilita su alteración formal obteniendo un resultado coherente en su conjunto [fig.7.80 y fig.7.81]. La capacidad de adaptación de este sanatorio articulado y polimórfico a hospital general y la calidad arquitectónica que hoy mantiene el edificio debería ser tenida en cuenta no sólo en la conservación de los sanatorios de características similares, sino también en la construcción de los nuevos hospitales, sujetos a una constante remodelación por el avance de la ciencia aplicada a sus técnicas de diagnóstico y terapéuticas.

Respecto a los métodos de conservación mediante una reconversión más respetuosa a través de la búsqueda de un nuevo uso más afín a las características del sanatorio, hay que tener en cuenta que por sus particularidades arquitectónicas y por su localización estos edificios se adaptan mejor a los programas vinculados a hospitales especializados para enfermos de larga duración, como los geriátricos o los centros de rehabilitación. El sanatorio bretón de Bodiffé-en-Plémet construido en 1935, es un ejemplo de transformación de sanatorio en centro de readaptación funcional. En su reconversión se añade un nuevo bloque de servicios comunes al sanatorio que rompe cuidadosamente con la arquitectura del mismo, diferenciándose claramente la ampliación del edificio original, pero manteniendo la misma composición volumétrica [fig.7.82 y fig. 7.83].

Otro destino históricamente afín al sanatorio antituberculoso es el hotelero, por lo que resulta sencillo la reconversión del sanatorio hacia programas residenciales de uso temporal, como colonias de vacaciones y hoteles, permitiendo un cambio de uso sin apenas alterar la arquitectura. Es el caso del Sanatorio de Bella-Lui (1928-1932) en Montana, Suiza, obra de Rudolf Steiger y su esposa Flora Steiger-Crawford, considerado como uno de los edificios que marcaron el comienzo de la modernidad en ese país ${ }^{99}$, rehabilitado como hotel en 2005 por Alfredo Orlando Pin. [fig.7.84].

Existen también numerosos ejemplos de edificaciones que han sufrido una doble transformación en las regiones alpinas. Hoteles como el Mont-Blanc o el Chamois de

\footnotetext{
99 Sigfried GIEDION, "Sanatorium Bella-Lui, Montana -Wallis, 1929-1930" en Bauwelt, 1931, p.4346. Citado en: Dave LÜTHI, "1870-1950 Le sanatorium en Suisse. Du kurhaus à la clinique de pneumologie", en TOULIER, Bernard, CREMNITZER, Jean-Bernard (dirs.) Histoire et Réhabilitation des Sanatoriums en Europe. Docomomo International, Paris 2008, p.47.
} 
Leysin, que en su momento fueron convertidos en sanatorios, han pasado años más tarde a recuperar su uso original [fig.7.85].

La obra de rehabilitación del Sanatorio de Zonnestraal, transformado en hospital polivalente en el año 2003 por Wessel De Jonge, miembro fundador del Docomomo Internacional, es un ejemplo excepcional de los pocos procesos de restauración formal que han elevado al sanatorio a la categoría de monumento.

El objetivo de la reconversión consiste en la recuperación de la construcción original, prácticamente irreconocible en el momento de la restauración, adaptándola a las necesidades de confort actuales. Para lograrlo, se lleva una minuciosa labor de documentación e investigación, llegando incluso a crear ex profeso materiales que imitan a los originales [fig.7.86].

La restauración de Zonnestraal es un referente en la conservación y respeto al patrimonio de los sanatorios antituberculosos, que ha sido capaz de fomentar otras iniciativas como la llevada a cabo en Francia en el Sanatorio Sabourin en Clermont-Ferrant, que ha pasado a ser considerado monumento histórico, garantizándose así su protección y permanencia ${ }^{100}$ [fig.7.87].

También en España, con motivo de la celebración del Día Mundial de la Arquitectura, los Colegios de Arquitectos colocaron el 1 de Octubre de 2012 una serie de placas informativas en los 64 edificios españoles considerados por la Fundación Docomomo Ibérico los más significativos del Movimiento Moderno, entre los que se encontraban el Sanatorio de Leza y el importante Sanatorio de Los Montalvos, una puesta en valor que supone el primer paso para la protección de este patrimonio.

Poco a poco se empieza a reconocer la transcendencia del sanatorio antituberculoso pulmonar, tanto por su repercusión en la medicina como en la arquitectura del Movimiento Moderno, convirtiéndose en un icono del período de entreguerras, ya que, como J.B. Cremnitzer describe: "El sanatorio es una lección de arquitectura inscrita en un momento de cambio decisivo de la historia social y médica del siglo XX"101.

\footnotetext{
100 Está previsto que el Sanatorio Sabourin pase a convertirse en la Escuela de Arquitectura de Clermont-Ferrant.

101 Jean-Bernard CREMNITZER, Architecture et Santé. Le temps du sanatorium en France et en Europe. A. et J. Picard, Paris 2005, p.146.
} 
En conclusión,

este trabajo de investigación quiere formar parte de los estudios realizados o por venir en torno al sanatorio antituberculoso pulmonar para poder actuar sobre el extenso patrimonio nacional existente, en la línea de los trabajos internacionales que han permitido valorar y preservar los sanatorios europeos, en aras de conservar la identidad de los edificios con un uso sanitario general $u$ otros afines 0 , por lo menos, quiere contribuir a mantener el recuerdo de aquellos sanatorios ya desaparecidos.

Sólo si se reconoce el valor de monumento de los sanatorios antituberculosos y éstos se protegen, antes de que se desvirtúe por completo su estado original o desaparezca su presencia, podrán surgir las vías que concilien un uso respetuoso, atendiendo a su idiosincrasia, con un mantenimiento digno de estos importantes edificios terapéuticos, concebidos para sanar a través de sus muros. 


\section{FUENTES}

\section{BIBLIOGRAFÍA}

1. GENERAL

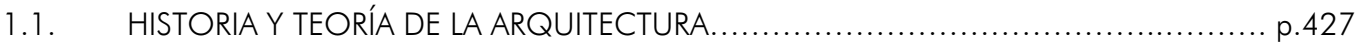

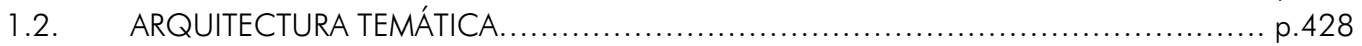

1.3. MONOGRAFÍAS DE AUTORES Y PROYECTOS NACIONALES .............................. p.431

1.4. MONOGRAFÍAS DE AUTORES Y PROYECTOS INTERNACIONALES..................... p.432

2. ESPECÍFICA

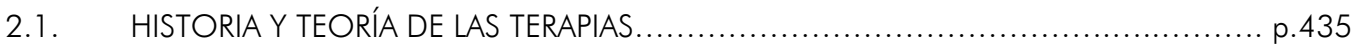

2.2. ARQUITECTURA HOSPITALARIA GENERAL ...................................... p. 437

2.3. MONOGRAFÍAS DE HOSPITALES Y SANATORIOS NACIONALES........................ p.441

2.4. MONOGRAFÍAS DE HOSPITALES Y SANATORIOS INTERNACIONALES.................. p.442

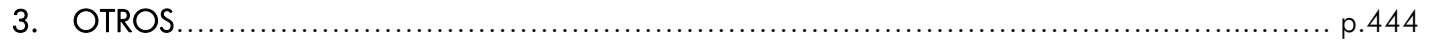

\section{ARCHIVOS}

1. ARCHIVOS CONSULTADOS................................................................ p.445

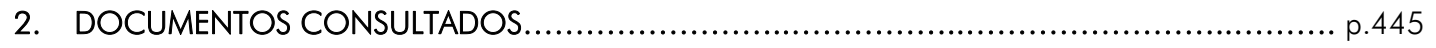




\section{BIBLIOGRAFÍA}

\section{GENERAL}

\subsection{HISTORIA Y TEORÍA DE LA ARQUITECTURA}

Libros:

BANHAM, Reyner; La arquitectura del entorno bien climatizado (The architecture of well-tempered environment, 1969). Infinito, Bueno Aires 1975.

BANHAM, Reyner; Teoría y Diseño arquitectónico en la era de la máquina (Theory and Design in the First Machine Age, 1960). Ediciones Nueva Visión, Buenos Aires, 1971.

BEHNE, Adolf; 1923 La construcción funcional moderna (Der moderne Zweckbau, 1926). Ediciones del Serbal, Barcelona, 1994.

BENEVOLO, Leonardo; Historia de la arquitectura moderna (Storia dell'architettura moderna, 1960). Editorial Gustavo Gili, Barcelona, 2010

BLUNDELL JONES, Peter; Modelos de la Arquitectura Moderna (Modern architecture through case studies, 2002). Editorial Reverté, Barcelona, 2011.

CANIGGIA, Gianfranco; Struttura dello spazio antrópico. Alinea, Firenze, 1984.

CAPITEL, Antón; La arquitectura compuesta por partes. Editorial Gustavo Gili, Barcelona 2009.

CAPITEL, Antón; Lecciones de arquitectura moderna. Nobuko, Buenos Aires, 2008.

CHUPIN, Jaen-Pierre; Analogie et Théorie en Architecture. De la vie, da la ville et de la conception, même. Infolio, Genève, 2010.

COLLINS, Peter; Los ideales de la arquitectura moderna; su evolución (1750-1950) (Changing Ideales in Modern Architecture, 1965). Editorial Gustavo Gili, Barcelona, 1981.

COLQUHOUN, Alan; Arquitectura moderna y cambio histórico. Ensayos: 1962-1976 (Meaning and Change in Architecture). Editorial Gustavo Gili, Barcelona, 1978.

COLQUHOUN, Alan; La Arquitectura moderna una historia desapasionada. Editorial Gustavo Gili, Barcelona, 2005.

COLQUHOUN, Alan; Modernidad y tradición clásica (Modernity and the classical tradition,1989) Júcar Universidad, Madrid, 1991.

FRAMPTON, Kenneth; Historia crítica de la arquitectura moderna (Modern Architecture: A Critical History, 1980). Editorial Gustavo Gili, Barcelona, 2009.

GIEDION, Siegfried; La mecanización toma el mando (Mechanization takes command. A contribution to anonimus history, 1948). Gustavo Gili Editorial, Barcelona, 1978.

GIEDION, Sigfried; Befreites Wohnen. Licht, luft und Öffnung. Orell Füssli, Zurich, 1929.

GIEDION, Sigfried; Espacio, tiempo y arquitectura (Space, time and architecture, 1941). Editorial Dossat, Madrid, 1982.

HITCHCOCK, Henry-Russell/JOHNSON, Philip; El Estilo Internacional: Arquitectura desde 1922 (The international style. Architetture since 1922, 1932). Colegio Oficial de Aparejadores y Arquitectos Técnicos de Murcia, Murcia, 1984.

LE CORBUSIER; Hacia una Arquitectura (Vers une architecture,1923). Poseidon, Barcelona 1978.

LE CORBUSIER; Précisions sur un état présent de l'architecture et de l'urbanisme. Crés, Paris, 1930.

LE CORBUSIER; Principios de urbanismo. La carta de Atenas (La charte d'Athénes, 1941). Ariel, Esplugues de Llobregat 1979.

LE CORBUSIER; Quand les Cathédrales étaient Blanches. Librairie Plon, Paris, 1937.

LE CORBUSIER; El Modulor (Le Modulor / Modulor 2. De Le Corbusier. 1949-1955). Fondation Le Corbusier, Paris, 2005.

MARCHÁN FIZ Simón, La Arquitectura del siglo XX. Textos. Ediciones Alberto Corazón, Madrid, 1974. 
MARTí ARÍS, Carlos; Las variaciones de la identidad. Ensayo sobre el tipo en arquitectura. Ediciones del Serbal, Barcelona, 1993.

MARTíN HeRNÁNDEZ, Manuel Jesús; La tipología en Arquitectura. Tesis Doctoral inédita, Universidad de Las Palmas, Escuela Técnica Superior de Arquitectura, Las Palmas, 1984.

MONEO, Rafael/CORTÉS, Juan Antonio; Sobre el concepto de tipo en Arquitectura. Catedra de Composición. Escuela Técnica Superior de Arquitectura, Madrid, 1984.

MONEO, Rafael; La solitudine degli edifici e altri scritti. Questioni in torno all'Architettura. Umberto Allemandi, Torino, 1999.

MONTANER, Josep Maria; Arquitectura y crítica (1999). Editorial Gustavo Gili, Barcelona, 2010.

MONTANER, Josep Maria; La modernidad superada. Ensayos sobre arquitectura contemporánea (1997). Editorial Gustavo Gili, Barcelona, 2011.

MONTANER, Josep Maria; Sistemas arquitectónicos contemporáneos (2008). Editorial Gustavo Gili, Barcelona, 2009.

MURATORI, Saverio; Studi per una operante Storia Urbana di Venezia. Istituto Poligrafico dello Stato, Roma, 1990.

NEUTRA, Richard; Vida y Forma (New York, 1962). Marymar, Buenos Aires, 1972.

NORBERG-SCHULZ, Christian; Existencia, espacio y arquitectura (Existence, Space and Architecture, 1971). Editorial Blume, Barcelona, 1975

NORBERG-SCHULZ, Christian; Los principios de la arquitectura Moderna (Principles of Modern Architecture, 2000). Editorial Reverté, Barcelona, 2005.

PEVSNER, Nikolaus; Historia de las tipologías arquitectónicas (A History of Building Types, 1976). Editorial Gustavo Gili, Barcelona, 1979

REBECCHINI, Marcello; /l fondamento tipologico dell'architettura. Bulzoni, Roma, 1978.

RODRÍGUEZ LLERA, Ramón; Breve historia de la arquitectura. Libsa, Madrid, 2006.

ROWE, Colin; Manierismo y arquitectura moderna y otros ensayos. Editorial Gustavo Gili, Barcelona, 1978.

RYBCZYNSKI, Wirtold; La Casa, Historia de una idea (1989). Nerea, San Sebastián, 2006.

SEGRE, Roberto; Historia de la arquitectura y del urbanismo. Países desarrollados. Siglo XIX y XX. Instituto de Estudios de Administración Local, Madrid, 1985.

SICA, Paolo; Historia del urbanismo: El siglo XX. Instituto de Estudios de Administración Local, Madrid, 1981.

WRIGHT, Frank Lloyd; The Natural House. Horizont Press, New York, 1954.

ZEVI, Bruno; Historia de la arquitectura moderna (Storia dell'architettura moderna, 1950). Editorial Poseidon, Barcelona, 1980.

ZEVI, Bruno; Saber ver la arquitectura (Saper vedere l'architettura, 1948). Poseidon, Barcelona, 1981.

\section{Artículos de revistas y capítulos de libros:}

MONEO, Rafael; "A vueltas con la Metodología" en Arquitectura n 82, Colegio Oficial de Arquitectos, Madrid, 1965, pp. 9 14.

MONEO, Rafael; "Sobre un intento de reforma didáctica" en Arquitectura $n^{\circ}$ 61, Colegio Oficial de Arquitectos, Madrid, 1964, pp. 43-54.

\subsection{ARQUITECTURA TEMÁTICA}

Libros:

AA.W.; Arquitectura y desarrollo urbano. Comunidad de Madrid, zona oeste. Tomo VI. Colegio Oficial de Arquitectos de Madrid, Consejería de Política Territorial, Dirección General de Arquitectura, Madrid, 1991.

AA.V.; Arquitectura y desarrollo urbano. Comunidad de Madrid, zona oeste. Tomo V. Colegio Oficial de Arquitectos de Madrid, Consejería de Política Territorial, Dirección General de Arquitectura, Madrid, 1991.

AA.V.; Functional architecture : the international style 1925-1940. Benedikt Taschen, Köln, 1990.

AA.W.; Nederlandse architectuur 1893-1918. Architectura. Architectuur Museum, Amsterdam, 1975. 
AYMONINO, Carlo; La vivienda racional. Ponencias de los congresos CIAM 1929-1930. Gustavo Gili, Barcelona, 1973.

ALTÉS BUSTELO, José (ed.); Arquitectura Moderna en Salamanca. Colegio de Arquitectos de León, Delegación en Salamanca, Salamanca, 1998.

ÁlVAREZ ÁlVAREZ, Darío; El jardín en la arquitectura del siglo XX: Naturaleza artificial en la cultura moderna. Editorial Reverté, Barcelona, 2007.

BARBIERI, Umberto S./DUIN, Leen van/JONG, Jaap de/WESEMAEL, Pieter van/WILMS FLOET, Willemiin; $A$ hundred years of Dutch architecture 1901-2000: trends highlights. NAi Publishers, Rotterdam, 2003.

BARREIRO PEREIRA, Paloma; Casas baratas: la vivienda social en Madrid, 1900-1939. Colegio Oficial de Arquitectos de Madrid, Madrid 1992.

BENEVOlO, Leonardo/MElogranI, Carlo/LONGO, Tommaso Giura; La Proyectación de la Ciudad Moderna (Roma Bari, 1977). Editorial Gustavo Gili, Barcelona, 2000.

BERGAMÍN, Rafael; 20 años en Caracas, 1938-1958. Gráficas Reunidas, Madrid, 1959.

BONET CORREA, Yago; La arquitectura del humo. Cuadernos do seminario de Sargadelos no 61. Ediciós do Castro, A Coruña, 1994.

CAPITEL, Antón/WANG, Wilfried (dirs.); Arquitectura del siglo XX, España . Tanais, Sevilla, 2000.

CASTILLO CÁCERES, Fernando; Madrid y el Arte Nuevo (1925-1936) Vanguardia y Arquitectura. La Librería, Madrid, 2011.

CECCARELLI, Paolo; La construcción de la ciudad soviética (Barcelona, 1970). Gustavo Gili, Barcelona, 1972.

CHABOT, Georges; Las ciudades. Editorial Labor, Barcelona, 1972.

COHEN, Jean-Louis; Le Corbusier et La Mystique de I'URSS. Théories et Projets pour Moscou 1928-1936. Pierre Mardaga Éditeur, Lieja, 1987.

COHEN, Jean-Louis /MICHELIS, Marco de/TAFURI, Manfredo; URSS 1917-1978. La cittá, L'architettura. Officina Edizioni, Roma, 1979.

COLOMINA, Beatriz; Doble exposición: arquitectura a través del arte. Akal, Badrid, 2006.

COLOMINA, Beatriz; La Domesticidad en Guerra. Actar, Barcelona, 2006.

CORTÉS, Juan Antonio; El racionalismo madrileño. Colegio Oficial de Arquitectos de Madrid, 1992.

DA ROCHA ARANDA, Óscar; El modernismo en la arquitectura madrileña: Génesis y desarrollo de una opción ecléctica. CSIC, Instituto de Historia, Madrid, 2009.

DIÉGUEZ PATAO, Sofía; La generación del 25. Primera Arquitectura Moderna en Madrid. Cuadernos de Arte Cátedra, Madrid, 1997.

DÖCKER, Richard; Terrasen typ. Krankenhaus, Erholungsheim, hotel, Bürohaus, Einfamiliënhaus Siedlungshaus, Miethaus und die Stadt. Akademischer verlag Fritz Wedekind \& Co, Stuttgart, 1929.

FANELLI, Giovanni; Architettura moderna in Olanda: 1900-1940. Marchi \& Bertolli, Firenze, 1968.

GARCÍA GARCÍA, Rafael; Arquitectura moderna en los Paises Bajos, 1920-1945. Akal, Madrid, 2010.

GARCÍA-QUIÑONES, Belén (coor.); AC Documentos de Actividad Contemporánea. Publicados por el GATEPAC entre 19371937. Fundación Caja de Arquitectos, Barcelona, 2005.

GARRIDO, Henry Vicente (dir.); Arquitecturas desplazadas. Arquitecturas del exilio español. Ministerio de Vivienda, Madrid, 2007.

GONZÁLEZ FRAILE, Eduardo; Ayer y hoy en nuestras ciudades. 2. Junta de Castilla y León, Consejería de Fomento, Valladolid, 2000.

GONZÁLEZ FRAILE, Eduardo/ PÉREZ GIL, Javier (coord.); El sueño de Gunzo : Sahagún y Cluny, historia y restauración arquitectónica. Junta de Castilla y León, Salamanca, 2010.

LANDROVE, Susana (ed.); Equipamientos I. Lugares públicos y nuevos programas, 1925-1965. Registro Docomomo Ibérico. Fundación Caja de Arquitectos, Fundación DOCOMOMO Ibérico, Barcelona, 2010.

MARCHÁN FIZ, Simón; La metáfora del cristal en las artes y en la arquitectura. Ediciones Siruela, Madrid, 2008. 
MARCO FRAILE, Ricardo/BUIL GUALLAR, Carlos (coors.); L'Architecture vivante. El documento del movimiento moderno. Revista editada por Albert Morancé 1923- 1933. Colegio Oficial de Arquitectos de Aragón, Zaragoza, 2004.

MARQUĖS SUREDA, Salomó/MARTíN FRECHILLA, Juan José; La labor educativa de los exiliados españoles en Venezuela. Fondo Editorial de Humanidades y Educación Universidad Central de Venezuela, Caracas, 2002.

MARTÍ ARÍS, Carlos (ed.); Las formas de la residencia en la ciudad moderna. Vivienda y ciudad en la Europa de entreguerras (1991).Ediciones Universidad Politécnica de Cataluña, Barcelona, 2000.

MATTIE, Erik/DERWIG, Jan; Functionalism in the Netherlands. Architectura \& Natura, Amsterdam, 1995.

MÜLLER, Dorothee; Klassiker des modernen Möbeldesigns. Otto Wagner, Adolf Loos, Josef Hoffmann. Keyser, München, 1980.

MUTHESIUS, Hermann; The English House (Das englische Haus. Wasmuth, 1904). Crosby Lockwood Staples, London, 1979.

PAAVILAINEN, Simo (ed.); Clasicismo Nórdico 1910-1930. Servicio de publicaciones Secretaría General Técnica Ministerio de Obras Públicas y Urbanismo, Madrid, 1983.

PIZZA, Antonio/ROVIRA GIMENO, Josep Maria; G.A.T.C.P.A.C. 1928-1939, Una nueva arquitectura para una nueva ciudad. Colegio de Arquitectos de Cataluña, Barcelona, 2006.

RAMÍREZ, Juan Antonio; Edificios-cuerpo. Ediciones Siruela, Madrid, 2003.

REY, Augustin; Le science des plans de villes: ses applications a la constrction, a l'extension, e l'hygiène. Orientation solaire des habitations, par A. Augustin Rey, Justin Pidoux, Charles Barde. Payot, Lausanne, 1928.

RODRÍGUEZ LLERA, Ramón; Japón en Occidente. Arquitecturas y paisajes del imaginario japonés del exotismo a la modernidad. Secretariado de Publicaciones e Intercambio Editorial de la Universidad de Valladolid, Valladolid, 2012.

RIVERA, David; Dios está en los detalles. La restauración de la arquitectura del Movimiento Moderno. General de Ediciones de Arquitectura, Valencia, 2012.

SAMBRICIO, Carlos (int.); L'habitation minimum (Julius Hoffmann, 1933).Colegio Oficial de Arquitectos de Aragón, Zaragoza, 1997.

SANZ ESQUIDE, José Ángel; La tradición de lo nuevo en el País Vasco. La Arquitectura de los años 30 . Tesis doctoral de la Universidad Politécnica de Cataluña, Barcelona, 1988.

SHARP, Dennis/COOKE, Catherine; Docomomo. The Modern Movement in Architecture. Selections for the Docomomo Registers. 010 Publishers, Rotterdam, 2000.

UCHA DONATE, Rodolfo; Cincuenta años de Arquitectura Española / (1900-1950). Adir Editores, Madrid, 1980.

URRUTIA NÚÑEZ, Ángel; Arquitectura moderna: el GATEPAC, Cuadernos de Arte Español n¹9. Editorial Historia 16, Barcelona, 1991

VEEN, Henk van der; Watertorens in Nederlands. Uitgeverij 010, Rotterdam, 1989.

\section{Artículos de revistas y capítulos de libros:}

"Allemagne", L'Architecture d'Aujourd'hui n6, 1932, pp. 98-99.

"El Barrio Chino de Barcelona (Distrito V)", A.C. Documentos de Actividad Contemporánea n 6, 1932, pp.31-33.

"El IV Congreso del C.I.R.P.A.C. (del 29 de julio al15 agosto de 1933)", A.C. Documentos de Actividad Contemporánea n” 11,1933, pp. 15-18.

"International Section: Finland", Architectural Forum, sept.1935, pp. 171-186.

"L'ambient forma l'individu", AC Documents d'activitat contemporánia n²5,1937, pp. 4-11.

"La Ciudad de reposo que necesita Barcelona", A.C. Documentos de Actividad Contemporánea n 7, 1932, pp. 27-31.

"La necesidad de la vida al aire libre", A.C. Documentos de Actividad Contemporánea n 7, 1932, p.7.

"Soleamiento de las construcciones", A.C. Documentos de Actividad Contemporánea n 8, 1932, pp. 36-40.

ALMAGRO SAN MARTíN, Melchor; "¿̇Qué estilo arquitectónico se adapta mejor al carácter de Madrid? ", Revista Nacional de Arquitectura $\mathrm{n}^{\circ}$ 15, Ministerio del Gobernación, Dirección general de Arquitectura, Madrid, 1943, pp. $105-106$.

ARMESTO, Antonio; "La economía espiritual en arquitectura: una cuestión de termodinámica", 2 C Construcción de la ciudad. La línea dura. El ala radical del racionalismo 1924-32, n²22, abril 1985, pp. 94-95. 
BADOVICl, Jean; "L'Exposition Internationale du Batiment, A Berlin, 1931", L'Architecture vivante, automne \& hiver $\mathrm{n}^{\circ} 33-34$, Paris, 1931, pp. 21-34.

BJAZIC KLARIN, Tamara; "Zagreb Group-Foundation and Public Activities in Croatian Cultural Context", Prostor n¹3, 2005, pp. $41-53$.

CAPILLA-RONCERO, Ignacio/RAMOS-CARRANZA, Amadeo/SÁNCHEZ-CID-ENDÉRIZ, José lgnacio; "Club Pineda 1961", en Equipamientos //. Ocio, deporte, comercio, transporte y turismo. Registro DOCOMOMO Ibérico, 1925-1965. Fundación Caja de Arquitectos, Barcelona, 2011 , p.53.

CAPILLA-RONCERO, Ignacio/RAMOS-CARRANZA, Amadeo/SÁNCHEZ-CID-ENDÉRIZ, José Ignacio; "Instituto de Anatomía 1932-1935", en Equipamientos I. Lugares públicos y nuevos programas. Registro DOCOMOMO Ibérico. Fundación Caja de Arquitectos, Barcelona, 2010, p. 40.

CAPILLA-RONCERO, Ignacio; RAMOS-CARRANZA, Amadeo/SÁNCHEZ-CID-ENDÉRIZ, José Ignacio; "Pueblo de Colonización de la Vereda, 1963", en La vivienda moderna. Registro DOCOMOMO Ibérico, 1925-1965. Fundación Caja de Arquitectos, Barcelona, 2009, p. 69.

CAPILLA-RONCERO, Ignacio/RAMOS-CARRANZA, Amadeo/SÁNCHEZ-CID-ENDÉRIZ, José Ignacio; "Pueblo de Colonización de Esquivel, 1952-1963", en La vivienda moderna. Registro DOCOMOMO Ibérico, 1925-1965. Fundación Caja de Arquitectos, Barcelona, 2009, p. 58.

GALLO, Emmanuelle; "Modernismo, arquitectura y calefacción. Innovaciones en Francia, 1900-1939", RE: Revista de edificación $\mathrm{n}^{\circ} 36-37,2007, \mathrm{pp} .119-125$.

GARCÍA GARCÍA, Rafael; "I10 una revista de vanguardia", Cuadernos de notas n¹0, Madrid, 2004, pp. 3-51.

GONZÁLEZ CASAS, Lorenzo; "Urbanismo y patrimonio. La conservación de los centros históricos", en Premio nacional de investigación en vivienda 2001.Caracas: Ministerio de infraestructura, Consejo Nacional de la Vivienda, 2002, pp. 131-295.

GONZÁlEZ CUBERO, Josefina; "La 'Promenade Architecturale' y la ciudad”, Anales de arquitectura n 3, 1991, pp. 89-102.

GONZÁLEZ FRAILE, Eduardo; "El material: contenido intelectual y abstracto”, en IGLESIAS GIL José Manuel, Actas de los XII Cursos Monográficos sobre el Patrimonio Histórico (Reinosa, julio-agosto 2001), 2002, pp. $101-124$.

GUERRAND, Roger-Henri; "Sobre los orígenes del movimiento de las ciudades-jardines en Europa", Ciudades n6, 20002001, pp. 17-20.

LAHUERTA, Juan José; "Ex quo symetria efficitur", L'Architecture vivante: el documento arquitectónico del movimiento moderno. Colegio Oficial de Arquitectos de Aragón, Zaragoza, 2004.

LE CORBUSIER; "Rapport sur le parcellement du sol des villes. Troisième Congrès International D'Architecture Moderne a Bruxelles", L'Architecture vivante, printemps \& été n $31-32$, Paris, 1931, pp. 17-22.

MIKKOLA, Kirmo; "Funktionalismin ideologia", Arkkitehti 1/1978, pp. 46-52.

NEDER, Fernando; "Habiter, vite!", Faces, Journal d'architecture n 57, hiver 2004-2005, pp. 23-25.

PÉREZ MAÑOSAS, Antonio; "Modernos Radicales Holandeses", 2 C Construcción de la ciudad. La línea dura. El ala radical del racionalismo 1924-32, $\mathrm{n}^{\circ} 22$, abril 1985, pp. 62-69.

POSENER, Julius; "L'Expositio: Soleil, Air, Maison pour tous. Berlin, été 1932", L'Architecture d'Aujourd'hui n 6, 1932, pp. $25-27$.

RAMOS-CARRANZA, Amadeo; "Viviendo en la ciudad", Proyecto, Progreso y Arquitectura n 5, 2011 , pp. $12-15$.

RAMOS-CARRANZA, Amadeo; "Compartir y debatir en arquitectura", Proyecto, Progreso y Arquitectura n 1, 2010, pp. 1113.

\subsection{MONOGRAFÍAS DE AUTORES Y PROYECTOS NACIONALES}

Libros:

ABRIL, Manuel; Arquitectura contemporánea en España Tomo II. Los arquitectos Blanco-Soler y Bergamín. Ediciones de Arquitectura y de Urbanización Edarba, Madrid, 1933.

AURREKOETXEA, Josu; Aguinaga, obras. Colegio Oficial de Arquitectos Vasco Navarros, Bilbao, 1992.

ROVIRA, Josep Maria; José Luis Sert 1901-1983. Electa, Milano, 2000.

Artículos de revistas y capítulos de libros: 
"Barriada de casas económicas 'El Viso', Madrid", Nuevas Formas n 4, 1934, pp. 180-189.

"Bergamín y Blanco Soler (arquitectos del racionalismo español)", Nueva Forma n 33, 1968, p. 94-98.

"Casa del Marqués de Villora en Madrid", Arquitectura n 113, Sociedad Central de Arquitectos, 1928, pp. $282-288$.

"Casa del Sr. Bergua Oliván, en Zaragoza" en Arquitectura n 166, Colegio Oficial de Arquitectos de Madrid, 1933, pp. 5961.

"Casa en Madrid", Nueva Forma n 68, 1971, pp. 38.

"Casa para el Marqués de Villora, Madrid", Hogar y Arquitectura n 70, 1967, pp. 44-45.

"Casa particular en la calle de Joaquín Costa, Madrid", Viviendas, revista del hogarn 23 febrero, 1934, pp. 6-19.

"El Concurso de La Tabacalera", Arquitectura n 80, Sociedad Central de Arquitectos, 1925, pp. 315-316.

"Interiores de una vivienda particular en Madrid", Nuevas Formas n², 1934, pp. 97-101.

"La Colonia-Residencia en la Barriada del Hipódromo. Madrid", Viviendas, revista del hogar n 8 febrero, 1933 , pp. 6-23.

"La Vivienda del arquitecto R. Bergamín, en la Colonia 'Residencia", Viviendas, revista del hogar n 8 febrero, 1933, pp. 1620.

"Proyecto de ordenación de la zona de San Francisco-Puerta de Toledo, 1962- Madrid", Hogar y Arquitectura n 42, 1962, pp. 34-36.

"Rafael Bergamín", Conarquitectura n 10, Conarquitectura Ediciones, 2004, pp. 89-90.

"Residencia del Amo", Arquitectura n 144, Sociedad Central de Arquitectos, 1931, pp. 158-163.

"Tiendas nuevas en Madrid: camisería de lujo Regent. La tienda de automóviles Euskalduna", Arquitectura n 99 , Sociedad Central de Arquitectos, 1927, pp. 255-264

"Una Casa 'fin de semana' en las cercanías de Madrid", Nuevas Formas n 1, 1934, pp. 32-34.

AMANN, Eduardo; "Paseo por "El Viso" madrileño del brazo de Bergamín", El Inmueble n 2, marzo 1966, pp. 17-20.

AMAT, Rafael; "Colonia El Viso-Madrid 1934", Arquitectura n 204, Colegio Oficial de Arquitectos de Madrid, 1977, pp. 5056.

AMÓN, Santiago; "Proyecto de urbanización de la zona de San Francisco (Madrid), 1962", Nueva Forma n 65, 1971, pp. $21-22$.

BEHRENDT, Walter C.; "Obras del arquitecto D. Amós Salvador", Arquitectura n 110, Sociedad Central de Arquitectos, Madrid, 1928, pp. 191-196.

BERGAMíN, Rafael; "El Viso, un poco de historia", Arquitectura n 101, Colegio Oficial de Arquitectos de Madrid, 1967, pp. 22-34.

BERGAMÍN, Rafael; "Exposición de Artes Decorativas de París, impresiones de un turista", Arquitectura n 78, Sociedad Central de Arquitectos, 1925, pp. 236-239.

BLANCO SOLER, Luis; "Colonia Infantil en Marbella (Madrid)", Revista Nacional de Arquitectura $\mathrm{n}^{\circ} 2$, Ministerio del Gobernación, Dirección general de Arquitectura, Madrid, 1941, pp. 42-48.

CASTRO ARINES, José; "Rafael Bergamín y su arquitectura madrileña", Temas de Arquitectura y Urbanismo n 138,1970 , pp. 1 -3.

FLORES, Carlos, "1927: primera arquitectura moderna en España. Mesa redonda con Rafael Bergamín, Fernando García Mercadal y Casto Fernández-Shaw", Hogar y Arquitectura n 70, mayo-junio 1967, pp. 39-56.

HIGUERAS DÍAZ, Fernando; "Concurso Plan de Ordenación de la calle San Francisco-Puerta de Toledo. Primer premio del Ayuntamiento de Madrid", en Madrid no construido, imágenes arquitectónicas de la ciudad prometida. Colegio Oficial de Arquitectos de Madrid, Madrid, 1986, pp. 228-231.

SAN ANTONIO GÓMEZ, Carlos; "La Colonia el Viso", en Un siglo de vivienda social: 1903-2003. Ministerio de Fomento, Madrid, 2003, pp. 94-95.

TORRES BALBÁS, Leopoldo; "El Concurso de proyectos de la Sociedad Central. Arquitectura española contemporánea", Arquitectura $\mathrm{n}^{\circ}$ 12, Sociedad Central de Arquitectos, 1919, pp. 103-105. 


\subsection{MONOGRAFÍAS DE AUTORES Y PROYECTOS INTERNACIONALES}

Libros:

AA. W.; Alvar Aalto. A nuestra medida. Museo Nacional de Artes decorativas, Madrid, 2009.

AA.W.; Alvar Aalto. Architect 1898-1976, The Alvar Aalto Fundation, Tempere, 1999.

AA.W.; Pol Abraham Architect 1891-1966. Collection Centre Pompidou, Musée National d'Art Moderne, Paris, 2005.

AALTO, Alvar; The architectural drawings of Alvar Aalto, 1917-1939 Vol.3, Viipuri City Library, Turun Sanomat Building, and Other Buildings and Projects 1927-1929. Garland, New York, London, 1994.

AALTO, Alvar; The architectural drawings of Alvar Aalto, 1917-1939 Vol.4, Paimio Tuberculosis Sanatorium, City of Turku 700th Anniversary Exhibition, Standard Furniture, and other buildings and projects 1929-1930. Garland, New York, London, 1994.

AALTO, Alvar; The architectural drawings of Alvar Aalto, 1917-1939 Vol.5, Helsinki Stadium, Zagreb Central Hspital and Other Buildings and Projects, 1930-1932.Garland, New York, London, 1994.

ÁlvareZ ÁlVAREZ, Darío; O Parque do Capitólio de Chandigarh. Centro de Estudios Arnaldo Araújo, Porto, 2009.

BARONI, Danielle; Josef Hoffman e la Wiener Werkstätte. Electa, Milano, 1981.

BAYÓN, Mariano; Arquitecturas ausentes del siglo XX: Duiker Interior del Cineac de Ámsterdam 1934. Editorial Rueda, Madrid, 2004.

BILL, Max (ed.); Le Corbusier. Oeuvre Complète. Volumen 3. 1934-1938. Les Editions d'Architecture, Zurich, 1970.

BJAZIC KLARIN, Tamara; Ernest Weissmann: arhitektonsko dielo 1926-1939. Tesis doctoral inédita de la Facultad de Artes de la Universidad de Zagreb, Zagreb, 2011.

BOESIGER, W./ STONOROV, O. (ed.); Le Corbusier. Oeuvre Complète. Volumen 1. 1910-1929. Les Editions d'Architecture, Zurich, 1970.

BULLHORST, Rainer/HARMELEN, Kees van/JAGER, Ida; Duiker in Den Haag. Gemeente den Haag, Den Haag, 1999.

CAPITEL, Antón; La obra de Aalto en Finlandia. Arquitectosdecádiz, Cádiz, 2005.

CLAUZIER, Robert; Le Mont-Dore et Bourboule. Stations Thermales et Hivernales. Projet de Thèse Institut d'Urbanisme de L'Université de Paris, 1948.

CLEMENT, Jules; Projet de Relevement et de mise en valeur de la Cité Thermale Spa. Projet de Thèse Institut d'Urbanisme de L'Université de Paris, 1951.

COHEN, Jean-Louis; André Lurçat. 1894 -1970 autocritica di un maestro moderno (1995). Electra, Milano, 1998.

CROSET, P.A (ed.); Alvar Aalto, Visioni urbane. Skira, Ginevra-Milano, 1998.

DESCOUTURES, Jean; Aménagemen et extension d'une Station Thermale du Bassin de Vichy Bellerive-sur-Allier. Projet de Thèse Institut d'Urbanisme de L'Université de Paris, 1927.

DUIKER, Jan; B. Bijvoet und J. Duiker 1890-1935: Wegleitung zur Ausstellung und der eidgenössice Hochschule Zürich von 27 Oktober bis 17 November 1977. Eidgenössische Technische Hochschule, Zürich, 1977.

EVENO, Claude (ed.); Tony Garnier. Centre Georges Pompidou, Paris, 1989.

FERNÁNDEZ ALBA, A.; (ed.), Alvar Aalto, Visiones urbanas. Fundación ICO, Madrid, 1999.

FLEIG, Karl; Alvar Aalto, obras y proyectos (Basel, 1974). Editorial Gustavo Gili, Barcelona, 1998.

GARCÍA RIOS, Ismael; Alvar Aalto y Erik Bryggman. La aparición del Funcionalismo en Finlandia. Instituto Iberoamericano de Finlandia, Madrid, 1998.

GONZÁlEZ CUBERO, Josefina; Le Corbusier. El proyecto de la ciudad moderna. Tesis inédita del Dpto. de Teoría de la Arquitectura y Proyectos Arquitectónicos de la E.T.S. de Arquitectura de la Universidad de Valladolid, Valladolid, 1996.

GROPIUS, Walter; The Walter Gropius Archive: an illustrated catalogue of the drawings, prints, and photographs in the Walter Gropius Archive at the Busch-Reisinger Museum, Harvard University. 2, [Archivo Gropius números 42-76] Winfried Nerdinger (ed.). Garland, New York, 1990. 
GROPIUS, Walter; The Walter Gropius Archive: an illustrated catalogue of the drawings, prints, and photographs in the Walter Gropius Archive at the Busch-Reisinger Museum, Harvard University. 3, [Archivo Gropius números 77-117] Winfried Nerdinger (ed.). Garland, New York, 1990.

GUIHEUX, Allain; CINQUALBRE, Olivier; Tony Garnier L'oeuvre complète. Centre Goerges Pompidou. Paris, 1989.

JOVÉ SANDOVAL, José María; Alvar Aalto proyectando con la naturaleza. Universidad de Valladolid, Valladolid, 2003.

KÄRKKÄINEN, Maija (ed.); The 5th international Alvar Aalto Symposium. Functionalism-Utopia or the way forward?. Alvar Aalto Symposium, Jyväskylä, 1992.

LE CORBUSIER, Urbanisme, Algiers and Other Buildings and Projects, 1930-1933. Garland Publishing, New York, 1983.

LE CORBUSIER; Le Corbusier Buildings and Projects, 1933-1937. Garland Publishing, New York, 1983.

LE CORBUSIER; Le Corbusier et Pierre Jeanneret. Oeuvre Complète. Volumen 2. 1929-1934. Les Editions d'Architecture, Zurich, 1970.

LE CORBUSIER; The Marseille block (L'Unite d'Habitation de Marseille, 1950). Harville Press, London, 1953.

LOYER, François/GUÉNÉ, Hélène; Henri Sauvage. Les immeubles a gradins. Mardaga, Liège, Bruxelles, 1987.

MARSTON FITCH, James (pro.); Ludwig Mies van der Rohe. Escritos, Diálogos y Discursos. Colegio Oficial de Aparejadores y Arquitectos Técnicos de la región de Murcia, Murcia, 2005.

MICHALITSIANOS, Georges; Vouliaghmeni Cité Balnéaire et thermale. Projet de Thèse Institut d'Urbanisme de L'Université de Paris, 1934.

MOLEMA, Jan/BAK, Peter; Jan Gerko Wiebenga. Apostel van het Nieuwe Bouwen. Uitgeverij 010, Rotterdam, 1987.

MOLEMA, Jan; Duiker, arquitecto de una nueva era. Constructor en estuco y acero. Equipo de trabajo Duiker, TH Delft, Delft, 1986.

MOLEMA, Jan; J. Duiker bouwkundig ingenieur. Constructeur in stuc en staal. Stichting Bouw, Rotterdam, 1982.

MOLEMA, Jan; Jan Duiker, obras y proyectos (Rotterdam, 1989). Editorial Gustavo Gili, Barcelona, 1996.

MONTEYS, Xavier; Le Corbusier, obras y proyectos. Editorial Gustavo Gili, Barcelona, 2005.

MONTEYS, Xavier; La gran máquina: la ciudad en Le Corbusier. Colegio Oficial de Arquitectos de Cataluña, Demarcación de Barcelona, Barcelona, 1996.

OUD, Jacobus Johannes Pieter; Architettura olandese, Jacobus Johannes Pieter Oud. Franco Angeli, Milano, 1981.

PEARSON, Paul David; Alvar Aalto and the international style (1978). Mitchell, London, 1989.

POLANO, Sergio; Hendrik Petrus Berlage. Opera Completa. Electra, Milan, 1987.

PROBST, Hartmut; Walter Gropius. Der Architekt und Pädagoge. Verlag für Bauwesen, Berlin, 1986.

RAY, Nicholas; A/var Aalto. Yale University Press, London, 2005.

RAYMOND, Jean; Station Balnéaire. Projet de Thèse Institut d'Urbanisme de L'Université de Paris, 1931.

RINCÓN BORREGO, Iván; Sverre Fehn. La forma natural de construir. Tesis inédita del Dpto. de Teoría de la Arquitectura y Proyectos Arquitectónicos de la E.T.S. de Arquitectura de la Universidad de Valladolid, Valladolid, 2010.

SCHILDT, Göran (ed.); Alvar Aalto de palabra y por escrito (Alvar Aalto. In his own words, 1997). El Croquis Editorial, Madrid, 2000.

SCHILDT, Göran; Alvar Aalto The Decisive Years, Rizzoli International Publications, New York, 1986.

SCHILDT, Göran; Alvar Aalto. His life. Alvar Aalto Museum, Jyväskylä, 2007.

SCHILDT, Göran; Alvar Aalto. Obra completa: arquitectura, arte y diseño. Editorial Gustavo Gili, S.A., Barcelona, 1996.

SINGELENBERG, Pieter; H.P. Berlage. Idea and Style. Haentjens Dekker \& Gumbert, Utrecht, 1972.

VELASCO, Hernando; Projet de Station Balnéaire a Punta-Basan Colombie. Projet de Thèse Institut d'Urbanisme de L'Université de Paris, 1930.

WRIGHT, Frank Lloyd; Frank Lloyd Wright. Early visions. Gramercy Books, New York, 1995.

Artículos de revistas y capítulos de libros: 
"Casa de la Salud. San Francisco de California.-Arquitecto: Richard J. Neutra", A.C. Documentos de Actividad Contemporánea n 6, 1932, pp. 39-40.

"De Openluchtschool voor het gezonde kind aan de Cliostraat in Amsterdam" en Zonnestaal n 2, MOLEMA Jan, "El nacimiento de Zonnestraal", Cuaderno de Notas n¹3, 2010, pp. 49-57.

"Ontwerp van twaalf huurhuizen aan de van aerssenstraat te's-Gravenhage", Vademecum der Bouwvakken, 4 Januari 1917, pp. $1-6$.

"Rafael Bergamín, De la 'gran borrasca' y el exilio a la evanescente figura del arquitecto en Venezuela", Entre rayas, la revista de Arquitectura, n 84, Caracas, 2010, pp. 44-51.

ALBERTS C.A./JELLES. E.J.; Duiker 1890-1935. (Recopilación de los números 5 y 6 del volumen 22 de la revista Forum) 1978.

CIUCCI, Giorgio; "Le Corbusier y Wright en la URSS", en W.AA. Socialismo, ciudad y arquitectura URSS 1977-1937. La aportación de los Arquitectos Europeos (Roma, 1971). Alberto Corazón Editor, Madrid, 1973, pp. 171-191.

CROSAS, Josep; "Le Corbusier y las razones del deporte", en Massilia: anuario de estudios lecorbusierianos, Fundación Caja de Arquitectos, Barcelona, 2004, pp. 106-111.

GARCÍA GARCÍA, Rafael; "Equilibrio y economía edificios de la segunda etapa de Duiker", Cuadernos de notas n4, Madrid, 1995, pp. 53-76.

GARCÍA GARCÍA, Rafael; "Funcionalismo en evolución. Hotel Gooiland y edificios de la segunda etapa de Duiker", Cuadernos de notas n6, Madrid, 1995, pp. 37-58.

GARCÍA GARCÍA, Rafael; “Jan Duiker 1890-1935. Esbozo de una vida truncada”, Cuadernos de notas n¹0, Madrid, 2004, pp. $75-100$.

GARCÍA GARCÍA, Rafael; "Tres artículos de Duiker", Cuadernos de notas n³, Madrid, 1995, pp. 33-48.

GONZÁLEZ CUBERO, Josefina; "Hilos de teatro: La puesta en escena del Palacio de los Soviets de Le Corbusier, 1931", en Proyecto, progreso, arquitectura $n^{\circ} 7$, nov. 2012, pp. 68-90.

GONZÁLEZ CUBERO, Josefina; "La arquitectura del suelo. Las casas Jaoul en Neuilly-sur-Seinemore", en Massilia: anuario de estudios lecorbusierianos, Fundación Caja de Arquitectos, Barcelona, 2003, pp. 162-177.

GONZÁLEZ CUBERO, Josefina; "La paradoja de los Inmuebles-villas" (2009), en Alexandra TREVISAN, Josefina GONZÁLEZ CUBERO, Pedro VIEIRA DE ALMEIDA (ed.), Ler Le Corbusier. Porto, CEAA, 2012.

GONZÁLEZ CUBERO, Josefina; "Los conflictos de la casa-patio: La Casa Sert (1958) en Cambridge", en 4 Centenarios: Luis Barragán, José Luis Sert, Ärne Jacobsen, Marcel Brever. Ed. Universidad de Valladolid, Valladolid, 2002, pp. 39-75.

GONZÁLEZ CUBERO, Josefina; "Sesión continua. 'Nómadas en el jardín', Ville contemporaine y Ville radieuse" en Massilia: anvario de estudios lecorbusierianos, Fundación Caja de Arquitectos, Barcelona, 2004, pp. 69-95.

MARSTON FITCH, James; "Mies van der Rohe y sus viviendas platónicas", en Escritos, diálogos y discursos, Colección Arquitectura $n^{\circ}$ 1, Colegio Oficial de Aparejadores y Arquitectos Técnicos de la región de Murcia, Murcia, 2005

MOLEMA, J. /JONGE, W.; "Johannes Duiker", The Architectural Reviewn¹055, 1985, pp. 48-55.

PORPHYRIOS, Demetri; "Heterotopia: A Study in the Ordering Sensibility of the Work of Alvar Aalto", en D. DUNSTER (ed.) Architectural Monographs n 4. Alvar Aalto. Academy Editions, London, 1978.

RUILOBA QUECEDO, Cecilia/GONZÁLEZ CUBERO, Josefina; "The healthy city: Alvar Aalto, acting in the present while looking to the future and remembering the past", en Proceedings International Conference Inhabiting the future ... After Copenhagen. Clean Edizioni. Università degli Studi di Napoli Federico II, Napoli, 2010, pp. 419-429.

STAM, M.A.; "Op zoek naar een ABC van het bouwen I", Bouwbedrijf n¹0, 1926, pp. 78-79.

WILS, J.; "Verbouwing apotheek te Zandvoort Architecten Irs. Duiker en Bijvoet", Het Bouwbedrijf n¹2, 1926, pp. 388-389.

\section{Documentos audiovisuales:}

MONEO, Rafael; conferencia inédita: "Principios tipológicos de Alvar Aalto", Escuela de Arquitectura de Barcelona, Febrero 1981. Reproducida en los vídeos de la // Setmana Cultural (1981) Alvar Aalto: i la difussió del Moviment Modern dentro del ciclo Conferències Setmana Cultural ETSAB 1980-1990.

\section{ESPECÍFICA}




\subsection{HISTORIA Y TEORÍA DE LAS TERAPIAS}

Libros:

AA. W.; Informe Técnico al Proyecto de Organización Sanatorial. Patronato Nacional Antituberculoso, Madrid, 1945.

AA. W.; La Sanidad en la República, dos años de gestión. Ministerio de la Gobernación, Madrid 1933.

AA.W.; La Higiene Hospitalaria en la obra de Benito Bails. Faculta de Medicina de la Universidad de Granada, Granada 1978.

AA.W.; La tuberculosis en España: resultados del Proyecto Multicéntrico de Investigación sobre tuberculosis (PMIT). Instituto de Salud Carlos III, Madrid, 1999.

AA.W.; Lucha Oficial contra la Tuberculosis. Campaña de 1924 a 1925. Año Primero. Real Patronato Antituberculoso de España, Madrid, 1925.

AA.W.; Lucha Oficial contra la Tuberculosis. Campaña de 1925 a 1926. Año Segundo. Real Patronato Antituberculoso de España, Madrid, 1926.

AA.W.; Lucha Oficial contra la Tuberculosis. Campaña de 1926 a 1927. Año Tercero. Real Patronato Antituberculoso de España, Madrid, 1927.

BENÍTEZ FRANCO, Bartolomé; Información sobre la Lucha Antituberculosa en España y Memoria correspondiente al año 1944. Patronato Nacional Antituberculoso, Madrid, 1945.

BLANCO RODRÍGUEZ, Francisco; Patronato Nacional Antituberculoso y Enfermedades del Tórax. Memoria-bienio 1955 1956. Patronato Nacional Antituberculoso y Enfermedades del Tórax, Madrid, 1957.

BLANCO RODRÍGUEZ Francisco; Patronato Nacional Antituberculoso y Enfermedades del Tórax. Memoria-bienio $1957-$ 1958. Patronato Nacional Antituberculoso y Enfermedades del Tórax, Madrid, 1960.

BLANCO RODRÍGUeZ, Francisco; Patronato Nacional Antituberculoso y Enfermedades del Tórax. Memorias 1962-19631964. Patronato Nacional Antituberculoso y Enfermedades del Tórax, Madrid, 1964.

CODINA CASTELLVÍ, José; Conferencias de divulgación antifuberculosa dadas en el Real Sanatorio "Victoria Eugenia" de Valdelatas. Fernando Fé, Madrid, 1920.

DUIKER J. /BIJVOET B. /SAJET B.H.; Rapport betreffende een onderzoek, inzake de tuberculosebestrijding en de verpleging in sanatoria. Diamantbew. K.S.F., Amsterdam, 1922.

EDOM, Achille; Tuberculose et sanatoriums flottants. Wellhoff et Roche, Paris, 1906.

FORNIELES, Francisco; Patronato Nacional Antituberculoso. Memoria-bienio 1955-1956. Patronato Nacional Antituberculoso, Madrid, 1956.

GARCÍA SÁNCHEZ, Enrique/GARCÍA SÁNCHEZ, José Elias; Infección y cine [CD-ROM]. Ediciones Universidad de Salamanca, Salamanca, 2005

KNOPF, Sigard Adolphus; Les Sanatoria. Traitement et prophylaxie de la phtisie pulmonaire (1895). Georges Carré et C. Naud, Paris, 1900.

MILLER, James Alexander/WAILGREN, Arvid; Pulmonary tuberculosis in adults and children. T. Nelson, New York, 1939.

MOLERO MESA, Jorge; Estudios médicosociales sobre la tuberculosis en la España de la Restauración. Ministerio de Sanidad y Consumo, Madrid, 1987.

NAVARro GarCíA, Ramón (pro.); Catálogo Museo de Sanidad e Higiene Pública. Ministerio de Sanidad y Consumo, Instituto de Salud Carlos III, Madrid, 2007.

NAVARRO GARCÍA, Ramón; Análisis de la Sanidad en España a lo largo del siglo XX. Ministerio de Sanidad y Consumo, Instituto de Salud Carlos III, Madrid, 2002.

NAVARRO GARCÍA, Ramón; Historia de las Instituciones Sanitarias Nacionales. Ministerio de Sanidad y Consumo, Instituto de Salud Carlos III, Madrid, 2001.

NAVARRO GUtierREZ, Julián; Sanatorios Antituberculosos. Manuscrito sin datar.CA-2808, Fondos de la Biblioteca del Colegio Oficial de Arquitectos de Madrid.

ORIOL ANGUerA, J. / ORIOL ANGUeRA, A.; Historia de la Tuberculosis. Ensayos de Fisiología colectiva. Salvat Editores, Barcelona, Buenos Aires, 1944. 
PALANCA, José A. (prol.); Labor del Patronato Nacional Antituberculoso durante el último decenio. Patronato Nacional Antituberculoso, Madrid, 1946.

PULIDO FERNÁNDEZ, Ángel; La tuberculosis y su profilaxis social. Instituto Nacional de Previsión, Madrid, 1916.

RICHARDSON, Benjamin Ward; Hygeia: A City of Health (1876). Dodo Press, 2008.

SMITH, Francis Barrymore; The Retreat of Tuberculosis 1850-1950. Croom Helm, New York, 1988.

TURÉGANO, José F.; Patronato Nacional Antituberculoso. Dos años de labor 1951-1952. Patronato Nacional Antituberculoso, Madrid, 1953.

VERDES MONTENEGRO, José; Estudios sobre tuberculosis. Real Dispensario Antituberculoso de María Cristina, Madrid, 1910.

\section{Artículos de revistas y capítulos de libros:}

ALCALDE GONZÁLEZ, Rafael; "La introducción y el desarrollo del Higienismo en España durante el siglo XIX. Precursores, continuadores y marco legal de un proyecto científico y social", Scripta Nova. Revista Electrónica de Geografía y Ciencias Sociales $n^{\circ}$ 50, Universidad de Barcelona, 15 de octubre de 1999.

BLANCO SOLER, Carlos; "Comentarios de un médico", Arquitectura n 19, Colegio Oficial de Arquitectos de Madrid, Madrid, 1960, pp. 3-6.

BURGOS DE PABLOS, Abilio; "Apuntes para el estudio de la tuberculosis en Palencia, en España y en el Mundo (1)", publicaciones de la Institución Tello Téllez de Meneses n49, Palencia, 1983.

BURGOS DE PABLOS, Abilio; "Contribución al estudio de la epidemiología de la tuberculosis en Castilla y León", Publicaciones de la Institución Tello Téllez de Meneses n52, Palencia, 1985.

GARCÍA-SÁNCHEZ, José Elias / FRESNADILLO, María José /GARCÍA-SÁNCHEZ, Enrique; "El cine en la docencia de las enfermedades infecciosas y la microbiología clínica" en Enfermedades Infecciosas y Microbiología Clínica n²0, 2002, pp.403-406.

HOBDAY, Richard A.; "Sunlight Therapy and Solar Architecture", Medical History, n42, 1997, pp. 455-472.

KNOPF, Adolphus S.; "The centenary of Brehmer's birth", The American review of tuberculosis, vol. 13, august 1926, pp. 207210.

MOLERO MESA, Jorge; "Enfermedad y previsión social en España durante el primer franquismo (1936-1951). El frustrado seguro obligatorio contra la tuberculosis", Dynamis Acta Hispanica ad Medicinae Scientiarumque Historiam Illustrandam vol. 14, 1994, pp. 199-225.

MOLERO MESA, Jorge; "i Dinero para la cruz de la vida !. Tuberculosis, beneficencia y clase obrera en el Madrid de la Restauración", Historia Socia/n³9, 2001, pp. 31-48.

SAURET, Jesús; "La cura sanatorial de la tuberculosis", Historia de las Enfermedades Emergentes, v.3, n.4, Barcelona, 2001, pp. 120-153.

\section{Revistas:}

GONZÁleZ DE PABLO A. / MARTíNEZ PÉREZ J. (coor.); Historia de los hospitales. Revista El Médico. Insalud, Dirección provincial de Madrid.

Revista Española de Tuberculosis. Archivos Nacionales de enfermedades del tórax. Patronato Nacional Antituberculosos (1930-1961).

The World's Health, a monthly review. The league of Red Cross Societies, Paris.

\section{Documentos audiovisuales:}

"Sólo una noticia un millón de vacunas" NODO(1966)

"Veinte años de paz" NODO (1959). José López Clemente (dir.)

\subsection{ARQUITECTURA HOSPITALARIA GENERAL}

Libros: 
AA. W; British Sanatoria for the open-air treatment of tuberculosis. West London Medical Journal, Jhon Bale, Sons \& Danielsson, London 1899.

ADAMAS, Annamarie; Medicine by Design. The architect and the modern hospital, 1893-1943. University of Minnesota Press, Minneapolis, 2008.

ADAMS, Annmaie; Corpus Sanum in Domo Sano. The Architecture of the Domestic Sanitation Movement 1870-1914. Centre Canadian d'Architecture, Montréal, 1991.

ÁLVAREZ-SIERRA, José; Los hospitales de Madrid de ayer y hoy. Publicaciones de la Beneficencia Municipal, Madrid, 1952.

BARDÓN ARTACHO, Javier (ed.); Centros de salud. Munilla-leria, Madrid, 2003.

BERL, Léopold; Importance de L'aménagement architectural dans le rendement thérapeutique d'un sanatorium. Thèse pour le Doctorat en Mèdecine, Faculté de Médecine de Paris, Paris, 1936.

BINET, Jacques-Louis; Les architects de la médecine. Les éditions de l'imprimeur, Besançon, 1996.

BROTO, Carles; Hospitales y centros de salud. Links Internacional, Barcelona, 2009.

CARRÉ, Dominique (ed.); Patrimoine hospitalier. Un parcours à travers /'Europe. Monum editions du patrimoine, Paris, 2001.

CARRINGTON, Thomas Spees; Tuberculosis Hospital and Sanatorium construction. The National Association for the Study and Prevention of Tuberculosis, New York, 1912.

CARRINGTON, Thomas Spees; Fresh Air and How to use it. The National Association for the Study and Prevention of Tuberculosis, New York, 1912.

CODINA SUQUÉ, José; Preventorios, Dispensarios y Sanatorios antituberculosos. Modificaciones ventajosas susceptibles de adaptarse para que Ilenen sus humanitarios fines. Sociedad Española de Higiene, Madrid, 1933.

COX, Anthony/GROVES, Philip; Ospedali e strutture sanitarie (Hospitals \& Health Care Facilities, Oxford, 1990). Dario Flaccovio Editore, Palermo, 1995.

CREMNITZER, Jean-Bernard; Architecture et Santé : Les temps du sanatorium en France et en Europe. Éditions A. et J. Picard, Paris, 2005.

DALL'OLIO, Lorenzo; L'architettura degli edifice per la Sanitá. Officina Edizioni, Roma, 2000.

FOUCAULT, Michel; Les machines à guérir : aux origines de l'hôpital moderne. Pierre Mardaga, Bruxelles, 1979.

GIL NEBOT, Leopoldo; Cuarenta años de arquitectura hospitalaria. T6 Ediciones, Pamplona 1998.

GROBER, Julius; Das deutsche Krankenhaus: Handbuch für Bau, Einrichtung und Betrieb der Krankenanstalten, Ausgabe 3. Gustav Fischer, Jena, 1932.

IGLESIAS PICAZO, Pedro; La habitación del enfermo. Ciencia y arquitectura en los hospitales del Movimiento Moderno. Arquia/tesis n³2 Fundación Caja de Arquitectos, Barcelona, 2011.

INSUA CABANAS, Mercedes; Arquitectura hospitalaria gallega de pabellones. Universidad de La Coruña, La Coruña, 2002.

ISASI, J. F. /PANIAGUA, J. L. /PIELTÁIN, A.; Hospitales. La arquitectura del Insalud. 1986-2000. Insalud, Madrid, 2000.

ISASI, Justo (ed.); La arquitectura del hospital. Ac Rry:Alfonso Casares Ávila. Reinaldo Ruiz Yebenes 1968-2008. Ediciones Díaz de Santos, Madrid, 2008.

JAMES, W. Paul; Hospitals. Design and development. Architectural Press, London, 1986.

KRAUEL, Jacobo; Complejos hospitalarios. Linksbooks, Barcelona, 2010.

LABASSE, Jean; La ciudad y el hospital: geografía hospitalaria. Instituto de Estudios de la Administración Local, Madrid, 1982.

LABRYGA, Franz; Instalaciones sanitarias modernas (1977). Hospitales. Gustavo Gili, México, 1981.

LEISTIKOW, Dankwart; Edificios hospitalarios en Europa durante diez siglos. C. H. Boeringer Sohn, Ingelheim am Rehein, Germany, 1967.

LEVI, Ettori; Utilizzazione ed adattamento delle Case Popolari per la Lotta Antitubercolare. Istituto Italiano d'Igiene Previdenza ed Assistenza Sociale, Roma, 1921.

MEUSER, Philipp (ed.); Medical practices. Construction and design manual. DOM, Berlin, 2010.

MORETTI, Bruno/MORETTI Franco; Ospedali. Seconda Edizione notevolmente ampliata. Ulrico Hoepli Editore, Milano, 1940. 
MORETTI, Bruno; Ospedali. Ulrico Hoepli, Milano, 1935.

MOSSE, Rudolf; Bäder-Almanach. Reports of Spas, Climatic Stations and Sanatoria (1910). Published by Rudolf Mosse, Berlin, 1912.

OCHSNER, A. J. / STURM A. /MEYER J.; The Organization, Construction and Management of Hospitals. Cleveland Press, Chicago, 1907.

PERONA LARRAZ, José Luis; Historia Hospitalaria de la Vía de la Plata. Junta de Castilla y León, Consejería de Sanidad, Valladolid, 2009.

PIELTÁIN, Alberto; Arquitectura para la Sanidad Pública en España 1942-1977. Instituto Nacional de Gestión Sanitaria, Madrid, 2007.

POULAIN, Roger; Hôpitaux Sanatoria. Vincent Fréal, Paris, 1932.

REDSTONE, Louis G.; Hospitals and health care facilities. MacGraw-Hill, New York, 1978.

RIBOULET, Pierre ; Naissance d'un hospital. Les Editions de l'imprimeur, Besançon, 1996.

RUFENACHT, Walters Frederick; Sanatoria for consumptives in various parts of the world. Swan Sonnenschein, London, 1899.

TAVARES, André; Arquitectura Antituberculose. Trocas e tráficos na construção terapéutica entre Portugal e Suiça. Faculdade de Arquitectura da Universidade do Porto, Porto, 2005.

TOLLET, Casimir; Les Hôpitaux modernes XIX ${ }^{\text {me }}$ siècle. Paris, 1894.

TOULIER, Bernard/CREMNITZER, Jean-Bernard; Histoire et Réhabilitation des Sanatoriums en Europe, Les réseaux de la modernité au XXe siècle/1. Docomomo International, Paris, 2008.

VALLEJO FLOREZ, José Luis; Hospitales de Enfermedades del Tórax: presente y futuro. Real Academia de Medicina y Cirugía de Asturias y León, Madrid, 1981.

WAGENAAR, Cor (ed.); The Architecture of Hospitals. NAi Publishers, Rotterdam, 2006.

WOLFSOHN, Robert; Les villages de tuberculeux en Angleterre (Papworth, Preston Hall, Barrowmore Hall). Thèse pour le Doctorat en Médecine, Faculté de Médecine de Paris, Paris, 1924.

YAÑEZ, Enrique; Hospitales de Seguridad Social. Editorial Limusa, México D.F., 1986.

ZAVALA LAFORA, Juan; La evolución de las ideas para la construcción de Hospitales. El Hospital "En Bloque". Publicaciones del Instituto Nacional de Previsión, Madrid, 1947.

\section{Artículos de revistas y capítulos de libros:}

"Algunos hospitales modernos", Arquitectura n 35, Sociedad Central de Arquitectos, Madrid, 1922, pp.105-117.

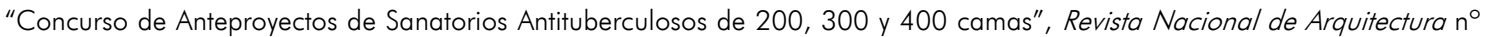
15, Ministerio del Gobernación, Dirección general de Arquitectura, Madrid, 1943, pp. 122-156.

"Primer Congreso Nacional de Sanidad. Asociación de ingenieros y arquitectos sanitarios", Arquitectura $n^{\circ} 4$, Colegio Oficial de Arquitectos, Madrid, 1934, pp. 75-82.

AZCONA, Siro; "Servicios de un hospital", Arquitectura n 19, Colegio Oficial de Arquitectos de Madrid, Madrid, 1960, pp. 7-11.

BADOVICl, Jean; "L'Architecture Hospitalière", L'Architecture vivante, automne nº 41, Paris, 1933, pp. 5-7.

CAMPBELL, Margaret; "What Tuberculosis did for Modernism: The Influence of a Curative Environment on Modernist Design and Architecture", Medical History, n49, 2005, pp. 463-488.

CAVESTANY, Fernando; "Hospitales. Generalidades históricas", Arquitectura n 19, Colegio Oficial de Arquitectos de Madrid, Madrid, 1960, pp. 46-48.

CHÂTELET, Anne-Marie; "1860-1902 La naissance du sanatorium en Europe", en Histoire et Réhabilitation des Sanatoriums en Europe, Les réseaux de la modernité au XXe siècle/7. Docomomo International, Paris, 2008, pp. 17-24.

GARCÍA GUERETA, Ricardo; "De Arquitectura Sanitaria", Arquitectura n 3, Sociedad Central de Arquitectos, Madrid, 1918, pp. 45-47.

GARCÍA GUERETA, Ricardo; "La hospitalización de los enfermos infecciosos", Arquitectura n 9, Sociedad Central de Arquitectos, Madrid, 1919, pp. 1-6. 
GARCÍA GUERETA, Ricardo; "La hospitalización de los enfermos infecciosos", Arquitectura n 10, Sociedad Central de Arquitectos, Madrid, 1919, pp. 29-32.

GARCÍA GUERETA, Ricardo; "La hospitalización de los enfermos infecciosos", Arquitectura n” 11, Sociedad Central de Arquitectos, Madrid, 1919, pp. 53-62.

GARCÍA GUERETA, Ricardo; "La hospitalización de los enfermos infecciosos", Arquitectura n 12, Sociedad Central de Arquitectos, Madrid, 1919, pp. 81-89

GARCÍA GUERETA, Ricardo; "Los sanatorios para niños pretuberculosos", Arquitectura n 5, Sociedad Central de Arquitectos, Madrid, 1918, pp.126-130.

LAPRADE, Albert; "Hôpitaux", L'Architecture d'Aujourd'huin n'9, 1934, pp. 5-7.

LÜTHI, Dave; "1870-1950 Le sanatorium en Suisse. Du Kurhaus à la clinique pneumologie", en Histoire et Réhabilitation des Sanatoriums en Europe, Les réseaux de la modernité au XXe siècle/1. Docomomo International, Paris, 2008, pp. 42-49.

MOLERO MESA, Jorge; "Los sanatorios para tuberculosos", Historia de los hospitales. Revista El Médico. Insalud, Dirección provincial de Madrid, pp. 325-334.

NEVZGODIN, Ivan; "Revolutionizing Hospital Architecture: Experiments in the Soviet Union", en Cor WAGENAAR (ed.), The Architecture of Hospitals, NAi Publishers, Rotterdam, 2006, pp.42-57.

PALANCA, José Alberto; "Ingenieros, Arquitectos y Sanidad", Revista Nacional de Arquitectura n 2, Ministerio de la Gobernación, Dirección General de Arquitectura, Madrid, 1941, pp. 1-2.

PANIAGUA, José León; "La Arquitectura de la Medicina”, A\&V Salud Naciona/n49, sept.-oct., 1994, pp. 3-4.

PESET, José Luis; "El hospital en el mundo contemporáneo (y III)", Historia de los hospitales. Revista El Médico. Insalud, Dirección provincial de Madrid, pp. 213-218.

POSENER, Julius; "Tendances dans la construction hospitalière", L'Architecture d'Aujourd'hui n 9, 1934, pp. 8-10.

PRASAD, Sunand; "Typology quarterly hospitals", The Architectural Review, n 1383, may 2012, pp. 67-79.

RAMOS, Fernando; "L'indépendance du plateau technique. Essai de perspective hospitalière les temps nouveaux", Faces, Journal d'architecture ${ }^{\circ}$ 57, hiver 2004-2005, pp. 18-22.

RUILOBA QUECEDO, Cecilia; "Ciencia, Paisaje y Arquitectura. El Patrimonio de los Sanatorios Antituberculosos", en CAH 20thC, International Conference Intervention Approaches for the 20th Century Architectural Heritage. E.T.S. de Arquitectura de la Universidad Politécnica de Madrid, Madrid, 2011.

RUILOBA QUECEDO, Cecilia; "La ciudad de la salud: Los sanatorios antituberculosos", Ciudades n" 14. "Instituto de Urbanística de la Universidad de Valladolid, Valladolid, 2011 , pp. 213-232.

RUILOBA QUECEDO, Cecilia; "Medicine and Modern Architecture", en Proceedings ICAR 2012: (RE) Writing History International Conference on Architectural Research. "Ion Mincu" University Publishing House Bucharest, Bucharest, 2012.

RUILOBA QUECEDO, Cecilia; "The Architecture of the inter-war years and tuberculosis sanatoria: Light, Air and Openness", en Proceedings ICAR 2012: (RE) Writing History International Conference on Architectural Research. "Ion Mincu" University Publishing House Bucharest, Bucharest, 2012.

SCHACHNER, Benno; "Idées directrices pour la construction d'un Hôpital" (Baumeister, 9 oct. 1931), L'Architecture vivante, automne $\mathrm{n}^{\circ} 41$, Paris, 1933, pp. 18-22.

TOULIER, Bernard; "Les sanatoriums en Europa. Architecture éphémère et reconversión", en Histoire et Réhabilitation des Sanatoriums en Europe, Les réseaux de la modernité au XXe siècle/1. Docomomo International, Paris, 2008, pp. 7-16.

UDOVICKI-SLEB, Danilo; "Les constructivistes face à Staline. Sanatoriums méconnus des années 1930 de Moscou au Caucase", en Histoire et Réhabilitation des Sanatoriums en Europe, Les réseaux de la modernité au XXe siècle/1. Docomomo International, Paris, 2008, pp. 50-59.

\section{Revistas:}

Arquitectura $\mathrm{n}^{\circ}$ 19, Colegio Oficial de Arquitectos de Madrid, Madrid, 1960.

Faces, Journal d'architecture, Hospitalité n 57, hiver 2004-2005.

L'Architecture d'Aujourd'huin ${ }^{\circ}$ 9, 1934

L'Architecture vivante, Architecture Hospitalière automne $n^{\circ} 41,1933$.

Summa: revista de arquitectura, tecnología y diseño, Arquitectura para la salud 2, n 108, Buenos Aires, enero 1997. 


\section{Documentos audiovisuales:}

"En estos años de paz" NODO (1949). Alberto Reig Gozalbes (dir.)

"La Reina Fabiola visita los Centros Sanitarios Belgas" NODO (1961)

"Residencias Sanitarias y Ambulatorios de la Seguridad Social" NODO (1957)

Revista Imágenes $n^{\circ} 226$ (1949)

Revista Imágenes $\mathrm{n}^{\circ} 487$ (1954)

\subsection{MONOGRAFÍAS DE HOSPITALES Y SANATORIOS NACIONALES}

Libros:

AA. W.; La Fuenfría. Memorias médica y administrativa 1951-1955. Ministerio de Trabajo, Servicio de mutualidades laborales, Madrid, 1955.

AA.W.; Colonia Antituberculosa de Torre Bonica. Asistencia en departamentos familiares. Caja de Pensiones para la vejez y de ahorros, Barcelona.

AA.W.; Colonia social Antituberculosa de Torre Bonica. Caja de Pensiones para la vejez y de ahorros, Barcelona, 1925.

AA.W.; Sanatorio Marítimo de Plencia. Caja de Ahorros Vizcaina, Bilbao.

AREILZA, Enrique; El Sanatorio de Górliz. Diputación de Vizcaya, Bilbao, 1921.

BOZAL URZAY, V.; Memoria del Dispensario y Sanatorio antituberculoso Monte "El Viejo" de Palencia. Patronato Nacional Antituberculoso.

HOYO ALGAR, José; Hospital del Rey. Dirección General de Sanidad, Madrid, 1942.

JUAN FONSECA; José Luis, Historia del Sanatorio de Leza (1935-1983). Tesis doctoral inédita del Dpto. de historia de la Medicina de la Facultad de Medicina de la Universidad de Salamanca, Salamanca, 1986.

MARTINEZ RODRIGUEZ, Eugenio; Memoria de las expediciones de colonias infantiles veraniegas al Sanatorio Marítimo Nacional de Oza, La Coruña, creadas y mantenidas por el establecimiento. Madrid, 1929.

MEDINA ALARCÓN, Antonio; Historia del sanatorio de "Los Montalvos" (1935-1986), Tesis inédita del Dpto. de Psiquiatría, Psicología Médica, Medicina Legal e Historia de la Medicina. Facultad de Medicina de la Universidad de Salamanca, Salamanca, 1992.

MEDINA ALARCÓN, Antonio; Modos de vida en los sanatorios antituberculosos europeos. El sanatorio antituberculoso de "Los Montalvos" en Salamanca. Tesina inédita del Instituto de Estudios Europeos y derechos Humanos "Benedictus s Nursia-Rene Cassin", Universidad Pontificioa de Salamanca, Salamanca, 1994.

MONTAÑÉS, Pablo; Trabajos del sanatorio Nacional de Fontilles. Suc. Such Serra y Cía, Alicante, 1934.

PIZZA, Antonio; Dispensario antituberculoso de Barcelona, 1933-1937. J. LI. Sert, J.B. Subirana y J. Torres Clavé. Colegio de Arquitectos de Almería, Almería, 1993.

\section{Artículos de revistas y capítulos de libros:}

"Concurso de anteproyectos de un Hospital en San Sebastián", Arquitectura n 1, Colegio Oficial de Arquitectos, Madrid, 1934, pp. 1-2.

"Sanatorio en Fuenfría", Arquitectura n 16, Sociedad Central de Arquitectos, Madrid, 1926, pp. 93-99.

"Sanatorios Lago en el Guadarrama (Madrid)", Arquitectura n 119, Sociedad Central de Arquitectos, Madrid, 1929, pp. 132134.

"Sanatorium a Waiblingen 1928 ", L'Architecture vivante, automne \& hiver n 25-26, Paris, 1929, pp.1-3.

"Un fallo lamentable. El concurso de anteproyectos para el nuevo Hospital de San Sebastián", A. C. Documentos de Actividad Contemporánea $\mathrm{n}^{\circ} 11,1933$, p. 39.

AGUINAGA, Eugenio M.; "Ideas generales a tener en cuenta en la construcción de Sanatorios Antituberculosos de Beneficencia y su ampliación en el caso del sanatorio del General Franco, de Bilbao, por el arquitecto Eugenio Aguinaga", Revista Nacional de Arquitectura n ${ }^{\circ}$ 126, Consejo Superior del Colegios de Arquitectos de España, Madrid, 1952, pp. 32-50. 
AGUINAGA, Eugenio M.; "Nueva cocina del Grupo Sanatorial de Santa Marina - Bilbao", Revista Nacional de Arquitectura n 100, Ministerio del Gobernación, Dirección general de Arquitectura, Madrid, 1950, pp.176-178.

AGUINAGA, Eugenio M.; "Proyecto del Sanatorio Antituberculoso 'Generalísimo Franco' ", Revista Nacional de Arquitectura n” 33, Ministerio del Gobernación, Dirección general de Arquitectura, Madrid, 1944, pp. 312-323.

BERGAMÍN, Rafael; "Sanatorio de 'La Solana", Cortijos y rascacielos: casas de campo, arquitectura, decoración n” 17,1934 , pp. 22-24.

BOTELLA, Aurelio; "Obras de reparación y ampliación del Sanatorio de Alcohete (Guadalajara)", Revista Nacional de Arquitectura n 33, Ministerio del Gobernación, Dirección general de Arquitectura, Madrid, 1944, pp. $324-329$.

BOTELLA, Aurelio; "Sanatorio de Valdelatas (Madrid). Obras de adaptación y terminación del pabellón quirúrgico", Revista Nacional de Arquitectura n 33, Ministerio del Gobernación, Dirección general de Arquitectura, Madrid, 1944, pp. $329-336$.

CELA, Camilo José; "El Real Sanatorio del Guadarrama", ABC Madrid, 25 de feb. 1995, p.13.

FERNÁNDEZ COCHÓN, R.; "Sanatorio Antituberculoso en el Rebullón (Pontevedra)", Revista Nacional de Arquitectura n 2 , Ministerio del Gobernación, Dirección general de Arquitectura, Madrid, 1941, pp. 3-6.

GONZÁLEZ CUBERO, Josefina; "Arquitectura hospitalaria de Rafael Bergamín: El Sanatorio de los Montalvos", en José ALTÉS BUSTELO (ed.), Arquitectura Moderna en Salamanca. Colegio de Arquitectos de León, Delegación en Salamanca, Salamanca, 1998, pp. 33-42.

HERNÁNDEZ BRIZ, Baltasar; "Pabellón de Oncología de la Beneficencia Provincial (Madrid)", Arquitectura n 119, Sociedad Central de Arquitectos, Madrid, 1929, pp. 135-140.

MONTEYS, Xavier; "Una actitud de modernidad. A propósito del Hospital de Sert y Torres Clavé", 2C Construcción de la ciudad. Josep Torres Clavé arquitecto y revolucionario, n 15-16, mayo 1980, pp. 58-61.

RIPOLLÉS PALACIOS, Ernesto; "Proyecto de Sanatorio Antituberculoso en Tarrasa (Barcelona)", Revista Nacional de Arquitectura ${ }^{\circ}$ 33, Ministerio del Gobernación, Dirección general de Arquitectura, Madrid, 1944, pp. $337-342$.

RODRÍGUEZ ARIAS, Germán; "Sanatorio de S. Juan de Dios (Manresa)", A.C. Documentos de Actividad Contemporánea n” 6, 1932, pp.22-24.

SÁNCHEZ QUINTEIRO, Cristina/MARTÍNEZ GARCÍA, Luis/DÍAZ VÁZQUEZ, Beatriz; “El sanatorio marítimo nacional de Oza. Estudio de siete fondos documentales", en Boletín de la ANABAD, Tomo 41, n¹, 1991, pp. 7-20.

\section{Revistas:}

Revista Nacional de Arquitectura $\mathrm{n}^{\circ}$ 33. Ministerio del Gobernación, Dirección general de Arquitectura, Madrid, 1944.

\section{Documentos audiovisuales:}

"Franco inaugura en Palencia una Residencia Sanitaria y un Colegio" NODO (1954)

"Hospital de San Rafael" (1964) Cortometraje 16 mm. Rafael Enriquez (dir.)

"Residencia Sanitaria de la Seguridad Social y nuevas viviendas en Sevilla" NODO(1954)

\subsection{MONOGRAFÍAS DE HOSPITALES Y SANATORIOS INTERNACIONALES}

Libros:

AA.W.; Istituto e Ospedale Sanatoriale "Benito Mussolini". Istituto Nazionale Fascista della Previdenza Sociale, Roma, 1934.

AALTO, Alvar; SUKKINEN M.M., KAIKAS I. (eds.), Varsinais-Suomen Tuberkuloosiparantola. Artek, 1934.

AALTO, Alvar; Tuberkuloosiparantola, Paimio. Tuberculosis Sanatorium. Alvar Aalto Museo, Jyväskylä, 2004.

BACK, Aimée; A space of their own: the servants'house by J. Duiker at Zonnestraal sanatorium. Uitgeverii 010 , Rotterdam, 1996.

BONESIO, Luisa/CURTO, Davide; // Villaggio Morelli. Diabasis, Reggio Emilia, 2011.

CLOSA, Mateo/BIURRUN, F. Javier/LINARES, Alfred; El sanatorio de Paimio, 1929-1933, Alvar Aalto. La arquitectura entre la naturaleza y la máquina. Servei de Publicacions de la UPC, Barcelona, 1991.

EHRSTRÖM, Margaretha/JETSONEN, Sirkkaliisa/LINDH, Tommi (ed.); Nomination of Paimio Hospital for inclusion in the world heritage list. National Board of Antiquities, Helsinki, 2005. 
GOEHRS; Organisation et Fonctionnement d'une Station pour enfants tuberculeux au Grand Sanatorium d'Aubure. Institut d'Assurance Sociale d'Alsace et de Lorraine, Strasbourg, 1928.

HEIKINHEIMO, Marianna; Keski-Suomen parantola. Rakennushistoriallinen selvitys. Arkkitehtitoimisto Ark-byroo, Helsinki, 2009.

HEIKINHEIMO, Marianna; Paimio Sairaalan. Rakennushistoriallinen selvitys. Arkkitehtitoimisto HNP, Helsinki, 2000.

IDSINGA, Ton; Zonnestraal. Een nieuwe tijd lag in het verschiet. Uitgeverij De Arbeiderspers Stichting Wonen, Amsterdam, 1986.

MILELLI, Gabriele; Zonnestraal. // sanatorio de Hilversum. Universale di architettura, Torino, 2000.

O'BYRNE OROZCO, María Cecilia; El proyecto para el hospital de Venecia de Le Corbusier. Tesis doctoral del Dpto. de Proyectos Arquitectónicos de la Universidad Politécnica de Cataluña, Barcelona, 2007.

PETRILLI, Amedeo; /l testamento di Le Corbusier: il progetto per l'Ospedale di Venezia. Marsilio, Venezia, 1999.

VLIET, P.G. van de; Een halve eeuw de sterken voor de zwakken .1928 Zonnestraal 1978. Van Proosdii, Hilversum, 1978.

WEISSMANN, Ernest; Sanatorij Tuberkuloze kosti i Zglobova. Zaklada Tiskare Narodnih Novina u Zagreb, Zagreb, 1930.

ZOETBROOD, Ronald; Jan Duiker en het sanatorium Zonnestraal. Van Gennep, Amsterdam, 1984.

\section{Artículos de revistas y capítulos de libros:}

"Amerikaansche ziekenhuizen", Vademecum der Bouwvakken , 22 june 1916, pp. 1-4.

"La Central médica de Nueva York", Arquitectura n 119, Sociedad Central de Arquitectos, Madrid, 1929, pp. $141-144$.

"Finland and England", Architect's Journa/n 9, nov. 1933, p.73.

"Sanatorio antituberculoso, Paimio 1929-1932", AV Monografías, Arquitectura Viva n66, 1997, pp. 32-39.

"Sanatorium, Paimio, Finlande", L'Architecture Vivante, autumn n45, 1933, pp. 25-26.

"Tävlan om tuberkulossanatorium för egentliga Finland", Arkkitehti 3/1929, pp. 42-46.

"Tuberculosis Sanatorium, Paimio, Finland. Alvar Aalto architect", Architectural Record, July 1934, pp.12-19.

"Tuberculosis Sanatorium, Paimio, Finland. Alvar Aalto architect", Architectural Record n 231, 1956, pp. 163.

AALTO, Alvar; "Paimio parantolan Asuinrakennuksia", Arkkitehti 1/1934, pp. 83-84.

AALTO, Alvar; "Varsinais-Suomen tuberkuloosiparantola. Paimion sairaala", Arkkitehti 6/1933, pp. 79-90.

BERGDOLL Barry, "Zonnestraal as icon of the Modern Movement. A short history of reception", en Paul MEURS, Mare-Thérèse VAN THOOR (ed.), Zonnestraal, the history and restoration of modern monument. NAi, Rotterdam, 2010, p.10-13.

BIJVOET, B./DUIKER, J. ; “Een diensbodenhuisje op "Zonnestraal" te Hilversum", De 8 en Opbouw, 1932, pp. 219-220.

BJAZIC KLARIN, Tamara; "Competition for Railway Hospital in Zagreb - A Scandal between the Wars", Prostor $\mathrm{n}^{\circ} 14,2006$, pp.64-74.

BLUNDELL JONES, Peter ; "Jan Duiker Sanatorio Zonnestraal. Hilversum, 1926", en BLUNDELL JONES Peter Modelos de la Arquitectura Moderna (Modern architecture through case studies, 2002). Editorial Reverté, Barcelona, 2011, pp. 127-144.

CACHORRO FERNÁNDEZ, Emilio; "Colonia helioterápica en Legnano, 1937-38. Desafío racionalista de BBPR a la arquitectura del régimen", en Proyecto, progreso, arquitectura n7, nov. 2012, pp. 90-103.

DETTINGMEIJER, R.; “Eén Zonnestraal maakt nog geen lente ", Archis n4,1994, pp. 7-8.

HAHL, Nils Gustav; "Alvar Aallon parantola Paimio", Domus n²4, 1933, pp. 63-67.

IDSINGA, Ton; "In their own hands. A social and medical history of Zonnestraal", en Paul MEURS, Mare-Thérèse VAN THOOR (ed.), Zonnestraal, the history and restoration of modern monument. NAi, Rotterdam, 2010, pp. 50-62.

JONGE, Wessel de; "Zonnestraal. Restauration d'une architecture transitoire", en Jean-Bernard CREMNITZER, Bernard TOULIER, Histoire et Réhabilitation des Sanatoriums en Europe, Les réseaux de la modernité au XX e siècle/I. Docomomo International, Paris, 2008, pp.61-70.

JONGE, Wessel de; "Nieuwe Bouwen in practice", en Paul MEURS, Mare-Thérèse VAN THOOR (ed.), Zonnestraal, the history and restoration of modern monument. NAi, Rotterdam, 2010, pp.110-119. 
JONGE, Wessel de; MEURS, Paul; "The Zonnestraal Aftercare Colony. Design and Buildings", en Paul MEURS, Mare-Thérèse VAN THOOR (ed.), Zonnestraal, the history and restoration of modern monument. NAi, Rotterdam, 2010, pp.77-87.

KLINGEREN, F.; van, "Zonnestraal is best te redden", Bouw n48, 1971, pp. 1742-1743.

KOENDERS, Annette; "Centuries-old landscape. History of the design of the Zonnestraal Estate", en Paul MEURS, MareThérèse VAN THOOR (ed.), Zonnestraal, the history and restoration of modern monument. NAi, Rotterdam, 2010, pp. 66-71.

LAlHO Ola, "Paimio Hospital: repairs and modifications", Arkkitehti 3/2009, pp. 28-35.

MARTíNEZ DE GUEREÑU ELORZA, Laura; "Johannes Duiker, Sanatorio de Zonnestraal en Hilversum, 1925", en Laura MARTÍNEZ DE GUEREÑU ELORZA, Construir la abstracción: Actitud y estrategia del proyecto moderno. Tesis doctoral inédita del Dpto. de Proyectos de la Escuela Técnica Superior de Arquitectura de la Universidad de Navarra, 2006, pp. 57-107.

MOLEMA, Jan; "The Zonnestraal commission", en Paul MEURS, Mare-Thérèse VAN THOOR (ed.), Zonnestraal, the history and restoration of modern monument. NAi, Rotterdam, 2010, pp.62-66.

MORTON SHAND, Philip; "A Tuberculosis Sanatorium in Finland", Architectural Reviewn442, sept. 1933, pp. 85-90.

RUILOBA QUECEDO, Cecilia; "La influencia de las Ciencias de la Salud en la Arquitectura del Movimiento Moderno. El Sanatorio Antituberculoso de Paimio.", en Encontros do CEAA / 7 Apropriações do Movimento Moderno. Livro de Actas. Centro de Estudios Arnaldo Araúio, Escola Superior Artística do Porto, Porto, 2012, pp. 295-311.

SMITHSON, P. /DUIKER, J. /JELLES, E.J., “'Zonnestraal' sanatorium te Hilversum”, Forum vol.16, 1962, pp. 1- 40.

STEUR, A.J. van der, "Zonnestraal", Bouwkundig Weekbladn49,1928, pp. 225-231.

TUYNMAN, G.W.; “Drie generaties over Zonnestraal”, Bouwkundig Weekblad, 1962, pp. 137-140.

VARRIER-JONES, P.C.; "Papworth. The first Village Settlement for the Tuberculous", The World's Health, a monthly review. The league of Red Cross Societies, Paris, august 1924, pp. 237-240.

\section{OTROS}

\section{Libros:}

ALBERTI, Rafael; Marinero en fierra (1945). Editorial Losada, Buenos Aires, 1990.

ARNHEIM, Rudolf; El poder del centro. Estudio sobre la composición en las artes visuales. (The Power of the Center-A Study of Composition in the Visual Arts, 1982). Alianza Editorial, Madrid, 1998.

CELA, Camilo José; Pabellón de reposo (1943). Destino, Barcelona, 2011.

DERRUAU, Max; Geografía Humana París (1976). Editorial Vicens Vives, Barcelona, 1983. (ed. orig.

FOUCAULT, Michel; Las palabras y las cosas. Una arqueología de las ciencias humanas (1966). Siglo XXI editores, Madrid, 2010.

GEORGE, Pierre; Geografía Urbana (Paris. 1961). Editorial Ariel, Barcelona, 1977.

GONZÁLEZ CUBERO, Josefina; Proyecto docente. Dpto. de Teoría de la Arquitectura y Proyectos Arquitectónicos de la E.T.S. de Arquitectura de la Universidad de Valladolid, Valladolid, 1996 (inédito).

GUILLÉN, Mauro F.; La disciplinada belleza de lo mecánico. El taylorismo de la arquitectura modernista (The Taylorized Beauły of the Mechanical, 2006). Editorial Modus Laborandi, Madrid, 2009.

JIMÉNEZ-BLANCO, María Dolores; La Guía del Prado. Museo Nacional del Prado, Madrid, 2009.

KROEBER, Alfred L.; Antrpology. Race, language, cultura, psycology, prehistory (London, 1923). Harcourt, New York, 1948.

MANN, Thomas; La Montaña Mágica (Der Zauberberg, 1924). Edhasa, Barcelona, 2005.

MUMFORD, Lewis; Técnica y civilización (1934). Alianza, Madrid, 1982.

MUSIL, Robert; El hombres sin atributos Libro primero (Der Mann ohne Eigenschaften, 1933). Austral, Barcelona, 2012.

TOBE, Anne; Le Plateau d'Assy, montagne magique, l'art inspiré. Reflex Graphic, Paris, 2007. 


\section{ARCHIVOS}

\section{ARCHIVOS CONSULTADOS}

Alvar Aalto Museo, Jyväskylä. AAA.

Archivo del Ministerio de Sanida, Madrid. AMS.

Archivo del Ministerio del Interior, Madrid. AMI.

Archivo General de la Administración, Alcalá de Henares. AGA.

Archivo Histórico Colegio Oficial de Arquitectos de Madrid, Madrid. AHCOAM.

Archivo Histórico Provincial, Madrid. AHPM.

Archivo Histórico Provincial, Valladolid. AHPVA.

Archivos del Instituto General de Sanidad, Madrid. INGESA.

Arxiu Històric Collegi d'Arquitectes de Catalunya, Barcelona. AHCOAC.

Filmoteca Nacional, Madrid. AFN.

Fondation Le Corbusier, París. FLC.

Instituto de Salud Carlos III, Madrid. ISCIII.

Internationaal Instituut voor Sociale Geschiedenis, Ámsterdam. IISG.

Nederlands Architectuurinstituut, Róterdam. NAi.

\section{DOCUMENTOS CONSULTADOS}

\subsection{ALVAR AALTO MUSEO}

Documentación gráfica:

Paimio Parantola (50 24 - 50 1094)

Documentación fotográfica:

Paimio Parantola

\begin{tabular}{|c|c|c|c|}
\hline AAA100266 & AAMaad 328 & AAMav 4531 & AAMav $796-829$ \\
\hline AAA107546 & AAMar 116 & AAMav 4671 & AAMav $836-841$ \\
\hline AAA107801-107805 & AAMar 143 & AAMav 4672 & AAMav 842 - 855 \\
\hline AAA109395 & AAMar $241-245$ & AAMav 4715a & AAMdv 893 \\
\hline AAA109396 & AAMar $251-254$ & AAMav 4715b & AAMdv 894 \\
\hline AAA109469 & AAMar $261-268$ & AAMav $4715 c$ & AAML 1106 \\
\hline AAA109470 & AAMar 2629 - 2647 & AAMav 4716 & AAMI 1107 \\
\hline AAA109471 & AAMar 2648 - 2656 & AAMav 4717 & AAML 1108 \\
\hline AAA109472 - 109478 & AAMar 267 & AAMav 4881- 4885 & AAML $111-118$ \\
\hline AAA109668 - 109685 & AAMar $269-2628$ & AAMav $505-513$ & AAML $1161-1187$ \\
\hline AAA109956 & AAMar $271-274$ & AAMav 5239 - 5391 & AAML $1696-1710$ \\
\hline AAA1 10247 & AAMar 90 & AAMav 5250 & AAML 1792 - 1794 \\
\hline AAA 110248 & AAMarkk 172 -17 10 & AAMav 5251- 5254 & AAML 1922 - 1935 \\
\hline AAA1 10297 & AAMarkk $181-188$ & AAMav 5282 & AAML 1925 \\
\hline AAA1 10881 & AAMav $2116-2122$ & AAMav 5289 & AAML 1928 \\
\hline AAA1 10882 & AAMav 2134 & AAMav 5293 & AAML 1936 - 1941 \\
\hline
\end{tabular}




\begin{tabular}{|c|c|c|c|}
\hline AAA50 003013 & AAMav $230-232$ & AAMav 5306 & AAML $2161-2163$ \\
\hline AAA50 003036 & AAMav $3205-3209$ & AAMav 5307 & AAML $2164-2169$ \\
\hline AAA50 003037 & AAMav 3210 & AAMav 5317 & AAML $2202-2236$ \\
\hline AAA50 003 040- 50003523 & AAMav $363-373$ & AAMav $5332-5340$ & AAML 335 - 348 \\
\hline AAAav 365 & AAMav $4111-4126$ & AAMav $5392-5423$ & AAML 349 A \\
\hline AAAav 369 & AAMav 4257 - 4294 & AAMav 590 & AAML 351 \\
\hline AAMaad 327 & AAMav $4526-4530$ & AAMav 78 & AAML 771 - 776 \\
\hline
\end{tabular}

Otros documentos sin catalogar:

Caja: PAIMIO

Caja: Paimio Parantola Dokumentit I

Caja: Paimio Parantola Dokumentit II

Memoria del concurso del Hospital de Zagreb, 1931.

\subsection{INSTITUTO DE SALUD CARLOS III}

\section{Documentación gráfica sin catalogar:}

\begin{tabular}{|c|c|c|}
\hline Albacete & Sanatorio de Los Llanos. & $\begin{array}{l}\text { R-1974. Diego de Reina y Francisco Fuster. } \\
\text { R-1975. Diego de Reina y Francisco Fuster }\end{array}$ \\
\hline Barcelona & Ciudad Sanatorial de Tarrasa. & $\begin{array}{l}\text { R-1976. Diego de Reina y Francisco Fuster. } \\
\text { R-1976. Diego de Reina y Francisco Fuster. }\end{array}$ \\
\hline Castellón & Sanatorio La Magdalena. & $\begin{array}{l}\text { R-1981. Joaquín Puig Amat. } \\
\text { R-1974. Diego de Reina y Francisco Fuster. } \\
\text { R-1977. Diego de Reina y Francisco Fuster. } \\
\text { R-1979. Francisco Fuster. }\end{array}$ \\
\hline Córdoba & Sanatorio de Los Morales. & $\begin{array}{l}\text { R-1981. Francisco Fuster. } \\
\text { R-1975. Diego de Reina y Francisco Fuster. }\end{array}$ \\
\hline Gran Canaria & Sanatorio de El Sabinal en Las Palmas. & R-1976. Diego de Reina y Francisco Fuster. \\
\hline Guadalajara & Sanatorio Psiquiátrico de Alcohete & R-1971. J. Domínguez Aguado. \\
\hline Huelva & Sanatorio General Camilo Alonso Vega. & $\begin{array}{l}\text { R-1977. Diego de Reina y Francisco Fuster. } \\
\text { R-1975. Diego de Reina y Francisco Fuster. }\end{array}$ \\
\hline Jaén & Sanatorio El Neveral. & R-1977. Diego de Reina y Francisco Fuster. \\
\hline La Coruña & Sanatorio Doctor Novoa Santos en El Ferrol. & R-1976. Diego de Reina y Francisco Fuster. \\
\hline León & Sanatorio de Monte San Isidro. & $\begin{array}{l}\text { R-1976. Diego de Reina y Francisco Fuster. } \\
\text { R-1974. Diego de Reina y Francisco Fuster. }\end{array}$ \\
\hline Logroño & Sanatorio de San Pedro. & $\begin{array}{l}\text { R-1979. Francisco Fuster. } \\
\text { R-1974. Diego de Reina y Francisco Fuster. }\end{array}$ \\
\hline Lugo & Sanatorio de Calde. & R-1985. José M. Bernardez Matovelle. \\
\hline Madrid & Hospital del Rey & R-1973. Ing. Jose Ignacio Bascan. \\
\hline Madrid & Hospital del Niño Jesús & $\begin{array}{l}\text { R-1972. Aurelio Botella Clarella. } \\
\text { R-1978. Diego de Reina y Francisco Fuster. }\end{array}$ \\
\hline Madrid & Hospital de Enfermedades del Tórax Cantoblanco. & R-1981. Francisco Fuster y Julita Sevilla. \\
\hline Madrid & Sanatorio de la Barraca & R-1970. Sebastián Vilata Valls. \\
\hline Madrid & Sanatorio de Helios en Guadarrama. & R-1977. Diego de Reina y Francisco Fuster. \\
\hline Málaga & Sanatorio Marítimo de Torremolinos. & $\begin{array}{l}\text { R-1975. Diego de Reina y Francisco Fuster. } \\
\text { R-1977. Diego de Reina y Francisco Fuster. }\end{array}$ \\
\hline Málaga & Sanatorio de Campanillas. & R-1979. Diego de Reina y Francisco Fuster. \\
\hline
\end{tabular}




$\begin{array}{ll}\text { Orense } & \text { Sanatorio Santo Cristo de El Piñor. } \\ \text { Oviedo } & \text { Sanatorio Monte del Naranco. } \\ \text { Salamanca } & \text { Sanatorio Martinez Anido. } \\ & \\ \text { Sevilla } & \text { Sanatorio de Dos Hermanas El Tomillar. } \\ \text { Tenerife } & \text { Sanatorio de Ofra de Santa Cruz de Tenerife. } \\ \text { Teruel } & \text { Instituto médico Pedagógico El Pinar } \\ \text { Valencia } & \text { Sanatorio Doctor Moliner en Porta Coeli. } \\ \text { Vizcaya } & \text { Sanatorio infantil Víctor Tapia en Bilbao. } \\ \text { Vizcaya } & \text { Sanatorio Generalísimo Franco en Bilbao. } \\ \text { Vizcaya } & \text { Sanatorio Santa Marina en Bilbao. } \\ \text { Zaragoza } & \text { Sanatorio Royo Villanova. }\end{array}$

\section{Documentación fotográfica sin catalogar:}

$\begin{array}{ll}\text { Álava } & \text { Sanatorio de Leza. } \\ \text { Albacete } & \text { Sanatorio de Los Llanos. } \\ \text { Almería } & \text { Preventorio de Almería } \\ \text { Almería } & \text { Preventorio Infantil de Bussot. } \\ \text { Baleares } & \text { Sanatorio Juan March. } \\ \text { Barcelona } & \text { Ciudad Sanatorial de Tarrasa. } \\ \text { Burgos } & \text { Sanatorio de Fuentes Bermejas. } \\ \text { Cádiz } & \text { Sanatorio de Puerto Real. } \\ \text { Castellón } & \text { Sanatorio La Magdalena. } \\ \text { Córdoba } & \text { Sanatorio de Los Morales. } \\ \text { G. Canaria } & \text { Sanatorio de El Sabinal en Las Palmas. } \\ \text { Guipúzcoa } & \text { Grupo Sanatorial de Amara. } \\ \text { Huelva } & \text { Sanatorio General Camilo Alonso Vega. } \\ \text { Huesca } & \text { Sanatorio de Boltaña. } \\ \text { Jaén } & \text { Sanatorio El Neveral. } \\ \text { La Coruña } & \text { Sanatorio Marítimo de Oza. } \\ \text { La Coruña } & \text { Sanatorio Doctor Gil Casares Santiago. } \\ \text { La Coruña } & \text { Sanatorio Doctor Novoa Santos El Ferrol. } \\ \text { León } & \text { Sanatorio de Monte San Isidro. } \\ \text { Logroño } & \text { Sanatorio de San Pedro. } \\ \text { Lugo } & \text { Sanatorio de Calde. } \\ \text { Madrid } & \text { Preventorio Infantil Doctor Murillo Guadarrama. } \\ \text { Madrid } & \text { Sanatorio de Valdelatas. } \\ \text { Sanatorio de la Fuenfría. }\end{array}$

R-1974. Diego de Reina y Francisco Fuster.

R-1978. Diego de Reina y Francisco Fuster.

R-1976. Diego de Reina y Francisco Fuster.

R-1979. Diego de Reina y Francisco Fuster.

R-1981. Francisco Fuster y Julita Sevilla.

R-1979. Diego de Reina y Francisco Fuster.

R-1975. Diego de Reina y Francisco Fuster.

R-1976. Guillermo Ballester.

R-1977. Diego de Reina y Francisco Fuster.

R-1979. Diego de Reina.

R-1977. Diego de Reina y Francisco Fuster.

R-1971. J. Domínguez Aguado.

R-1979. Julita Sevilla Gómez.

R-1978. Francisco Fuster.

R-1977. Diego de Reina y Francisco Fuster.

R-1977. Diego de Reina y Francisco Fuster.

R-1977. Diego de Reina y Francisco Fuster.

R-1976. Diego de Reina y Francisco Fuster.

$\begin{array}{ll}\text { Madrid } & \text { Sanatorio de El Escorial. } \\ \text { Madrid } & \text { Escuela Nacional de Tisiología. } \\ \text { Madrid } & \text { Centro de Colapsoterapia. } \\ \text { Madrid } & \text { Sanatorio de Lago en Guadarrama. } \\ \text { Madrid } & \text { Sanatorio de lturralde. } \\ \text { Málaga } & \text { Sanatorio Marítimo de Torremolinos. } \\ \text { Málaga } & \text { Sanatorio de Campanillas. } \\ \text { Orense } & \text { Sanatorio Santo Cristo de El Piñor. } \\ \text { Oviedo } & \text { Sanatorio Monte del Naranco. } \\ \text { Salamanca } & \text { Sanatorio Martinez Anido. } \\ \text { Santander } & \text { Sanatorio de Liencres. } \\ \text { Santander } & \text { Sanatorio marítimo Víctor Mena. } \\ \text { Segovia } & \text { Sanatorio infantil San Rafael. } \\ \text { Sevilla } & \text { Sanatorio de Dos Hermanas El Tomillar. } \\ \text { Tarragona } & \text { Preventorio La Sabinosa. } \\ \text { Tenerife } & \text { Sanatorio de Ofra de Santa Cruz. } \\ \text { Tenerife } & \text { Preventorio Esperanza de Santa Cruz. } \\ \text { Toledo } & \text { Sanatorio de Toledo. } \\ \text { Valencia } & \text { Sanatorio Doctor Molineren Porta Coeli. } \\ \text { Valencia } & \text { Sanatorio La Malvarosa. } \\ \text { Vizcaya } & \text { Sanatorio infantil Víctor Tapia en Bilbao. } \\ \text { Vizcaya } & \text { Sanatorio Generalísimo Franco Bilbao. } \\ \text { Sanatorio Santa Marina en Bilbao. } \\ \text { Sano Royo Villanova. }\end{array}$

\subsection{FONDATION LE CORBUSIER}

\section{Documentación:}




$\begin{array}{lll}\text { Bloc hydrominéral (urbanisme)-Egleton (France) } 1952 & 11-11 & (187-189) \\ \text { Centre pour tuberculeux- Haut var (France) } 1952 & 11-11 & (185-186) \\ \text { Centre pour tuberculeux- Villars de Lans (France) } 1948 & 11-11 & (77-80) \\ \text { Health city, New York (Etats-Unis) } 1936 & 11-11 & (241-289) \\ \text { Hôpital-Flers (France) } 1956 & 12-9 & (1-39 / 81-87 / 40 / 41 / 42-50) \\ \text { Hôpital-Limous (France) } 1959 & 12-8 & (219-220) \\ \text { Hôpital Venise (Italie) } 1964 & 12-20 & (1-323) \\ \text { Hôpital (La Reunion) sans date } & 11-11 & (49-50) \\ \text { Hôpital (Surinam) 1950 } & 11-11 & (179-184) \\ \text { Hôpital de la charité-Marseile (France) } 1953 & 11-19 & (77-79) \\ \text { Hospice-Montreuil-sur-Aisne (France) } 1950 & 11-11 & (81-95) \\ \text { Sanatorium-Leysin (Suisse) 1950 } & 11-11 & (97-143) \\ \text { Winter Docteur, Hôpital (Sans Lieu) } 1928 & \cup 2-9 & (86-88)\end{array}$

\subsection{INTERNATIONAAL INSTTITUUT VOOR SOCIALE GESCHIEDENIS}

\section{Documentación:}

Archief Zonnestraal (Hilversum)

CAJA 01: Ingekomen en kopieën van vitgaande stukken betreffende de oprichting en de eerste jaren van 'Zonnestraal'. Met notulen van vergaderingen en statuten. 1923-1932.

CARPETA $1^{\circ}$

CARPETA $1^{\mathrm{b}}$

CARPETA $1^{\circ}$

CAJA 02: Stukken betreffende de voorbereiding en de stichting van 'Zonnestraal'. Met statuten, notulen van de vergaderingen van de studiecommissie inzake de exploitatie van het landgoed 'Zonnestraal', rapporten, begrotingen e.d. 1924-1934.

CAJA 40: Stukken betreffende de eerste bouw en inrichting. 1926-1929, 1931.

CARPETA $401926-1927$

CARPETA $40 \quad 1926-1929$

CARPETA $40^{\bar{a}} 1926-1927$

CARPETA $40^{\mathrm{b}}{ }^{-} 1926-1927$

CAJA 41: Stukken betreffende de bouw en inrichting van Paviljoen II en van het koepelhuis. 1930-1933. 2 mappen.

CARPETA 41 1.Bouwo en inrichting 1930-1933 (C41_01)

CARPETA 41 ${ }^{\mathrm{b}}$ BBouwo en inrichting 1930-1933 (C41_02/C41_03 90/C41_04 81)

CAJA 42: Stukken betreffende de bouw en inrichting van het dienstgebouw en de kantine. 1931-1933. 1 map.

CAJA 43: Dossier inzake de verbouw van 11 percelen tot 22 woningen ("Zonnepark"). 1946-1949. 2 mappen.

CARPETA 43_Bouwo en inrichting-Dunstbodehuis en kantina 1931-1933

CARPETA $43^{\circ}$ Bouwo en inrichting- 1946-1949

CARPETA $43^{\mathrm{b}}$

CAJA 64: Bouwtekeningen. 1 doos.

CARPETA 64 ${ }^{\circ}$ Bouwtechningen Bijvoet \& Duiker 1926-1931

CARPETA $64^{\mathrm{b}}$ Hartman \& Hooghlaan 1960

CARPETA $64^{-}$Vos \& Heijermans 1968-1971

CARPETA 64 ${ }^{-}$De Reus 1975

CAJA 69: Gastenboek. z.d. 1 deel.

CAJA 70: Naamlijst van de bezoekers van 'Zonnestraal'. 1928-1940, 1949-1960. 1 deel.

\subsection{NEDERLANDS ARCHITECTUURINSTITUUT}

\section{Documentación gráfica:}

Bijlage III (inventarisnummer $11-41$ ) ZONNESTRAAL, HILVERSUM (1-238) 


\section{PROCEDENCIA DE LAS IMÁGENES}

\section{CAPÍTULO 1}

1.011 .061 .101 .141 .251 .35

Cecilia Ruiloba Quecedo

1.021 .051 .121 .131 .261 .271 .291 .301 .311 .321 .411 .42

ISASI, J. F. / PANIAGUA, J. L. /PIELTÁIN, A.; Hospitales. La arquitectura del Insalud. 1986-2000. Insalud, Madrid, 2000.

1.031 .041 .071 .081 .091 .111 .151 .201 .281 .331 .34

INSUA CABANAS, Mercedes; Arquitectura hospitalaria gallega de pabellones. Universidad de La Coruña, La Coruña, 2002.

1.161 .171 .181 .191 .211 .221 .231 .24

FOUCAULT, Michel; Les machines à guérir (aux origines de i'hôpital moderne). Pierre Mardaga, Bruxelles, 1979.

1.36

CARRÉ, Dominique (ed.); Patrimoine hospitalier. Un parcours à travers l'Europe. Monum editions du patrimoine, Paris, 2001.

1.37

TOLLET, Casimir; Les Hôpitaux modernes XIX me siècle. Paris, 1894.

1.38

CREMNITZER, Jean-Bernard; Architecture et Santé : Les temps du sanatorium en France et en Europe. Éditions A. et J. Picard, Paris, 2005.

1.39

CARRÉ, Dominique (ed.); Patrimoine hospitalier. Un parcours à travers l'Europe. Monum editions du patrimoine, Paris, 2001.

1.40

AA.V.; Pol Abraham Architect 1891-1966. Collection Centre Pompidou, Musée National d'Art Moderne, Paris, 2005.

1.43

O'BYRNE OROZCO, María Cecilia; El proyecto para el hospital de Venecia de Le Corbusier. Tesis doctoral del Dpto. de Proyectos Arquitectónicos de la Universidad Politécnica de Cataluña, Barcelona, 2007.

\section{CAPÍTULO 2}

2.012 .042 .062 .072 .212 .242 .252 .282 .292 .422 .432 .44

Internet.

2.022 .182 .202 .30

TOULIER, Bernard/CREMNITZER, Jean-Bernard; Histoire et Réhabilitation des Sanatoriums en Europe, Les réseaux de la modernité au XXe siècle/l. Docomomo International, Paris, 2008.

2.032 .162 .172 .192 .222 .232 .262 .272 .312 .322 .392 .402 .412 .462 .47

CREMNITZER, Jean-Bernard; Architecture et Santé : Les temps du sanatorium en France et en Europe. Éditions A. et J. Picard, Paris, 2005.

2.052 .102 .122 .142 .15

RUFENACHT WALTERS, Frederick; Sanatoria for Consumptives in various parts of the world. Swan Sonnenschein, London, 1899.

2.08

Josefina González Cubero

2.092 .112 .13

KNOPF, Sigard Adolphus; Les Sanatoria. Traitement et prophylaxie de la phtisie pulmonaire (1895). Georges Carré et C. Naud, Paris, 1900.

2.33

GUIHEUX, Allain/CINQUALBRE, Olivier; Tony Garnier L'oeuvre complète. Centre Goerges Pompidou. Paris, 1989.

2.342 .352 .36

DÖCKER, Richard; Terrasen typ. Krankenhaus, Erholungsheim, hotel, Bürohaus, Einfamiliënhaus Siedlungshaus, Miethaus und die Stadt. Akademischer verlag Fritz Wedekind \& Co, Stuttgart, 1929. 
BADOVICl, Jean; L'Architecture vivante, automne \& hiver n 33-34, Paris, 1931.

2.38

CARRINGTON, Thomas Spees; Fresh Air and How to use it. The National Association for the Study and Prevention of Tuberculosis, New York, 1912.

2.45

WOLFSOHN, Robert; Les villages de tuberculeux en Angleterre (Papworth, Preston Hall, Barrowmore Hall). Thèse pour le Doctorat en Médecine, Faculté de Médecine de Paris, Paris, 1924.

\section{CAPÍTULO 3}

3.013 .023 .283 .293 .303 .313 .323 .33

Internet

3.023 .143 .153 .163 .183 .19

CREMNITZER, Jean-Bernard; Architecture et Santé : Les temps du sanatorium en France et en Europe. Éditions A. et J. Picard, Paris, 2005.

3.03

COHEN, Jean-Louis; André Lurçat. 1894-1970 autocritica di un maestro moderno (1995). Electra, Milano, 1998.

3.043 .05

IGLESIAS PICAZO, Pedro; La habitación del enfermo. Ciencia y arquitectura en los hospitales del Movimiento Moderno. Arquia/tesis n³2 Fundación Caja de Arquitectos, Barcelona, 2011.

\subsection{3 .073 .083 .09}

DÖCKER, Richard; Terrasen typ. Krankenhaus, Erholungsheim, hotel, Bürohaus, Einfamiliënhaus Siedlungshaus, Miethaus und die Stadt. Akademischer verlag Fritz Wedekind \& Co, Stuttgart, 1929.

3.103 .113 .123 .13

CARRINGTON, Thomas Spees; Tuberculosis Hospital and Sanatorium construction. The National Association for the Study and Prevention of Tuberculosis, New York, 1912.

3.17 3.35 3.36 3.373.38

AA.V.; Pol Abraham Architect 1891- 1966. Collection Centre Pompidou, Musée National d'Art Moderne, Paris, 2005.

3.203 .213 .223 .233 .26

Cecilia Ruiloba Quecedo

3.24

MÜLLER, Dorothee; Klassiker des modernen Möbeldesigns. Otto Wagner, Adolf Loos, Josef Hoffmann. Keyser, München, 1980.

3.25

BARONI, Danielle; Josef Hoffman e la Wiener Werkstätte. Electa, Milano, 1981.

3.27

AALTO, Alvar; The architectural drawings of Alvar Aalto, 1917-1939 Vol.4, Paimio Tuberculosis Sanatorium, City of Turku 700th Anniversary Exhibition, Standard Furniture, and other buildings and projects 1929-1930. Garland, New York, London, 1994.

3.34

AA. W.; Alvar Aalto. A nuestra medida. Museo Nacional de Artes decorativas, Madrid, 2009.

\section{CAPÍTULO 4}

4.01

Hogar y Arquitectura $\mathrm{n}^{\circ}$ 70, mayo-junio 1967

4.02

Arquitectura n 12, Sociedad Central de Arquitectos, 1919.

4.03

Arquitectura $\mathrm{n}^{\circ}$ 80, Sociedad Central de Arquitectos, 1925.

4.044 .054 .064 .554 .684 .694 .894 .114

Internet 
4.074 .08

Arquitectura n 99, Sociedad Central de Arquitectos, 1927.

4.09

CORTÉS, Juan Antonio; El racionalismo madrileño. Colegio Oficial de Arquitectos de Madrid, 1992.

4.10 4.14 4.16 4.22 4.30 4.374.394.464.66 4.774.784.884.94 4.107

Cecilia Ruiloba Quecedo

4.114 .124 .13

Arquitectura $\mathrm{n}^{\circ} 113$, Sociedad Central de Arquitectos, 1928.

4.154 .174 .184 .19

Viviendas, revista del hogar $\mathrm{n}^{\circ} 8$ febrero, 1933

4.20

MUTHESIUS, Hermann; The English House (Das englische Haus. Wasmuth, 1904). Crosby Lockwood Staples, London, 1979.

4.21

Arquitectura n 101, Colegio Oficial de Arquitectos de Madrid, 1967.

4.23

Arquitectura $\mathrm{n}^{\circ}$ 204, Colegio Oficial de Arquitectos de Madrid, 1977.

4.244 .25

Arquitectura n 166, Colegio Oficial de Arquitectos de Madrid, 1933.

4.264 .27

Nuevas Formas $\mathrm{n}^{\circ} 1,1934$

4.284 .29

Viviendas, revista del hogar $\mathrm{n}^{\circ} 23$ febrero, 1934

4.314 .334 .344 .354 .384 .474 .484 .494 .50

AA.V.; Arquitectura y desarrollo urbano. Comunidad de Madrid, zona oeste. Tomo V. Colegio Oficial de Arquitectos de Madrid, Consejería de Política Territorial, Dirección General de Arquitectura, Madrid, 1991.

4.32

Cortijos y rascacielos: casas de campo, arquitectura, decoración n $n^{\circ}$ 17, 1934.

4.404 .41

Arquitectura n 1, Colegio Oficial de Arquitectos, Madrid, 1934

4.424 .434 .444 .45

MORETTI, Bruno; Ospedali. Ulrico Hoepli, Milano, 1935.

4.514 .52

PIZZA, Antonio/ROVIRA GIMENO, Josep Maria; G.A.T.C.P.A.C. 1928-1939, Una nueva arquitectura para una nueva ciudad. Colegio de Arquitectos de Cataluña, Barcelona, 2006.

4.534 .54

2C Construcción de la ciudad. Josep Torres Clavé arquitecto y revolucionario, n 15-16, mayo 1980.

4.564 .57

IGLESIAS PICAZO, Pedro; La habitación del enfermo. Ciencia y arquitectura en los hospitales del Movimiento Moderno. Fundación Caja de Arquitectos, Barcelona, 2011.

4.584 .594 .604 .614 .624 .634 .64

WEISSMANN, Ernest; Sanatorii Tuberkuloze kosti i Zglobova. Zaklada Tiskare Narodnih Novina u Zagreb, Zagreb, 1930.

4.65

$L^{\prime}$ Architecture vivante, automne $\mathrm{n}^{\circ} 41$, Paris, 1933

4.674 .794 .804 .814 .824 .834 .844 .854 .864 .874 .904 .914 .924 .934 .1014 .1024 .1034 .1044 .1054 .106

Cátedra de Elementos de Composición. Dpto. Tería de la Arquitectura y Proyectos arquitectónicos. E.T.S. de Arquitectura de la Universidad de Valladolid.

4.704 .714 .724 .734 .74

Archio General de la Administración, AGA.

4.754 .764 .1104 .121 
ALTÉS BUSTELO, José (ed.); Arquitectura Moderna en Salamanca. Colegio de Arquitectos de León, Delegación en Salamanca, Salamanca, 1998.

4.95

Summa: revista de arquitectura, tecnología y diseño, Arquitectura para la salud 2, n 108, Buenos Aires, enero 1997.

4.96

AA.V.; Functional architecture : the international style 1925-1940. Benedikt Taschen, Köln, 1990.

4.97

L'Architecture d'Aujourd'huin n6, 1932.

4.984 .994 .100

POULAIN Roger, Hôpitaux Sanatoria. Vincent Fréal, Paris, 1932.

4.108

Hogar y Arquitectura $\mathrm{n}^{\circ}$ 42, 1962.

4.1094.111

GUIHEUX, Allain /CINQUALBRE, Olivier; Tony Garnier L'oeuvre complète. Centre Goerges Pompidou. Paris, 1989.

4.110

AALTO, Alvar; The architectural drawings of Alvar Aalto, 1917-1939 Vol.4, Paimio Tuberculosis Sanatorium, City of Turku 700th Anniversary Exhibition, Standard Furniture, and other buildings and projects 1929-1930. Garland, New York, London, 1994.

4.1124 .1154 .116

TAVARES, André; Arquitectura Antituberculose. Trocas e tráficos na construção terapéutica entre Portugal e Suiça. Faculdade de Arquitectura da Universidade do Porto, Porto, 2005.

4.113

Arquitectura n ${ }^{\circ} 1$ 19, Sociedad Central de Arquitectos, Madrid, 1929.

4.117

AA. V.; Informe Técnico al Proyecto de Organización Sanatorial. Patronato Nacional Antituberculoso, Madrid, 1945.

4.1184 .119

COHEN Jean-Louis, André Lurçat.1894-1970 autocritica di un maestro moderno (1995). Electra, Milano, 1998.

4.120

Revista Nacional de Arquitectura n 15, Ministerio del Gobernación, Dirección general de Arquitectura, Madrid, 1943.

\section{CAPÍTULO 5}

5.01

VLIET, P.G. van de; Een halve eeuw de sterken voor de zwakken .1928 Zonnestraal 1978. Van Proosdii, Hilversum, 1978.

5.025 .045 .135 .145 .175 .185 .315 .325 .345 .465 .655 .695 .705 .905 .1025 .1035 .1045 .1055 .1095 .1175 .118

5.1215 .1225 .1255 .1265 .1295 .1305 .1315 .1385 .1445 .1485 .1505 .1585 .1605 .1615 .1625 .1635 .1645 .165

Paul, MEURS/Mare-Thérèse, VAN THOOR; (ed.), Zonnestraal, the history and restoration of modern monument. NAi, Rotterdam, 2010.

5.03 5.35 5.36 5.45 5.49 5.50 5.515.535.55 5.91 5.92 5.1335.135

Archivo Internationaal Instituut voor Sociale Geschiedenis, Ámsterdam, IISG.

5.055 .065 .935 .985 .995 .1005 .1015 .1105 .1675 .168

IDSINGA, Ton; Zonnestraal. Een nieuwe tijd lag in het verschiet. Uitgeverii De Arbeiderspers Stichting Wonen, Amsterdam, 1986.

5.07

MOLEMA, Jan; Duiker, arquitecto de una nueva era. Constructor en estuco y acero. Equipo de trabajo Duiker, TH Delft, Delft, 1986.

5.08

RODRÍGUEZ LLERA, Ramón; Japón en Occidente. Arquitecturas y paisajes del imaginario japonés del exotismo a la modernidad. Secretariado de Publicaciones e Intercambio Editorial de la Universidad de Valladolid, Valladolid, 2012.

5.095 .172

MOLEMA, Jan; Jan Duiker, obras y proyectos (Rotterdam, 1989). Editorial Gustavo Gili, Barcelona, 1996.

5.105 .195 .295 .335 .545 .565 .1565 .170 
Internet.

5.115 .125 .165 .205 .255 .445 .525 .575 .585 .595 .605 .615 .625 .635 .955 .1075 .1085 .1115 .1125 .1155 .119 5.1205 .1235 .1245 .1325 .1345 .1365 .1395 .1405 .1415 .1425 .1435 .1455 .1465 .1475 .1515 .1525 .1535 .154 5.1555 .1575 .166

Cecilia Ruiloba Quecedo.

5.155 .17

Vademecum der Bouwrakken, 22 june 1916

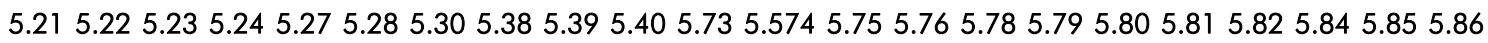
5.875 .885 .945 .975 .1495 .1595 .173

MOLEMA, Jan; J. Duiker bouwkundig ingenieur. Constructeur in stuc en staal. Stichting Bouw, Rotterdam, 1982.

5.26 5.65 5.66 5.67 5.68 5.715.725.775.895.1695.175 5.1765.1775.1785.1795.180

ALBERTS, C.A./JELLES, E.J. ; Duiker 1890-1935. (Recopilación de los números 5 y 6 del volumen 22 de la revista Forum) 1978.

5.375 .415 .425 .435 .96

MOLEMA, Jan; Duiker, arquitecto de una nueva era. Constructor en estuco y acero. Equipo de trabajo Duiker, TH Delft, Delft, 1986.

5.475 .485 .171

BULLHORST, Rainer/HARMELEN, Kees van/JAGER, Ida; Duiker in Den Haag. Gemeente den Haag, Den Haag, 1999.

5.84

The World's Health, a monthly review. The league of Red Cross Societies, Paris, august 1924.

5.106

MATTIE, Erik/DERWIG, Jan; Functionalism in the Netherlands. Architectura \& Natura, Amsterdam, 1995.

5.114

GIEDION, Sigfried; Espacio, tiempo y arquitectura (Space, time and architecture, 1941). Editorial Dossat, Madrid, 1982.

5.116

Het Bouwbedrijf $\mathrm{n}^{\circ} 12,1926$.

5.1275 .128

MOLEMA, Jan, Jan Duiker; obras y proyectos (Rotterdam, 1989). Editorial Gustavo Gili, Barcelona, 1996.

5.137

Archivo Nederlands Architectuurinstituut, Róterdam. NAi.

5.174

IGLESIAS PICAZO, Pedro; La habitación del enfermo. Ciencia y arquitectura en los hospitales del Movimiento Moderno. Fundación Caja de Arquitectos, Barcelona, 2011.

5.1815 .182

OUD, Jacobus Johannes Pieter; Architettura olandese, Jacobus Johannes Pieter Oud. Franco Angeli, Milano, 1981.

5.1835 .184

AA.V.; Pol Abraham Architect 1891-1966. Collection Centre Pompidou, Musée National d'Art Moderne, Paris, 2005.

5.185

CREMNITZER, Jean-Bernard ; Architecture et Santé : Les temps du sanatorium en France et en Europe. Éditions A. et J. Picard, Paris, 2005.

5.186

Archivo Alvar Aalto Museo, Jyväskylä. AAA.

5.1875 .188

COLOMINA, Beatriz; La Domesticidad en Guerra. Actar, Barcelona, 2006.

\section{CAPÍTULO 6}

6.016 .026 .036 .056 .066 .076 .086 .106 .116 .111

AALTO, Alvar; The architectural drawings of Alvar Aalto, 1917-1939 Vol.3, Viipuri City Library, Turun Sanomat Building, and Other Buildings and Projects 1927-1929. Garland, New York, London, 1994.

6.046 .096 .136 .726 .766 .796 .906 .986 .1056 .1066 .1126 .113

Cecilia Ruiloba Quecedo 
6.12

JIMÉNEZ-BLANCO, María Dolores; La Guía del Prado. Museo Nacional del Prado, Madrid, 2009.

6.146 .156 .16

COHEN, Jean-Louis; André Lurçat. $1894-1970$ autocritica di un maestro moderno (1995). Electra, Milano, 1998.

6.176 .18

POULAIN, Roger; Hôpitaux Sanatoria. Vincent Fréal, Paris, 1932.

6.196 .706 .716 .896 .1226 .1246 .1276 .1316 .132

Archivo Alvar Aalto Museo, Jyväskylä. AAA.

6.20 6 .21 6.25 6.26 6.27 6.28 6.29 6.30 6.31 6.32 6.33 6.34 6.35 6.36 6.37 6.38 6.39 6.40 6.41 6.42 6.43 6.44 6.45 6.466 .476 .486 .496 .506 .516 .526 .536 .556 .596 .616 .626 .636 .646 .656 .666 .676 .686 .696 .736 .746 .776 .80 6.816 .826 .876 .916 .926 .936 .946 .956 .966 .976 .996 .1016 .1026 .1036 .1046 .1076 .1086 .1096 .128

AALTO, Alvar; The architectural drawings of Alvar Aalto, 1917-1939 Vol.4, Paimio Tuberculosis Sanatorium, City of Turku 700th Anniversary Exhibition, Standard Furniture, and other buildings and projects 1929-1930. Garland, New York, London, 1994.

6.226 .236 .24

CLOSA, Mateo/BIURRUN, F. Javier/LINARES, Alfred; El sanatorio de Paimio, 1929-1933, Alvar Aalto. La arquitectura entre la naturaleza y la máquina. Servei de Publicacions de la UPC, Barcelona, 1991.

6.546 .57

ISASI, J. F./ PANIAGUA, J. L./ PIELTÁIN A.; Hospitales. La arquitectura del Insalud. 1986-2000. Insalud, Madrid, 2000.

6.56

INSUA CABANAS, Mercedes; Arquitectura hospitalaria gallega de pabellones. Universidad de La Coruña, La Coruña, 2002.

6.58

Paul, MEURS/Mare-Térèse, VAN THOOR (ed.); Zonnestraal, the history and restoration of modern monument. NAi, Rotterdam, 2010.

6.60

MARTí ARÍS, Carlos; Las variaciones de la identidad. Ensayo sobre el tipo en arquitectura. Ediciones del Serbal, Barcelona, 1993.

6.756 .836 .846 .856 .866 .1006 .1176 .126

AALTO, Alvar; Tuberkuloosiparantola, Paimio. Tuberculosis Sanatorium. Alvar Aalto Museo, Jyväskylä, 2004.

6.78

FRAMPTON, Kenneth; Historia crítica de la arquitectura moderna (Modern Architecture: A Critical History, 1980). Editorial Gustavo Gili, Barcelona, 2009.

6.88

JOVÉ SANDOVAL, José María; Alvar Aalto proyectando con la naturaleza. Universidad de Valladolid, Valladolid, 2003.

6.109 6.1146.1186.1196.1206.1216.1236.1256.1306.136

Internet

6.115

L'Architecture vivante, autumn n45, 1933.

6.116

PROBST, Hartmut; Walter Gropius. Der Architekt und Pädagoge. Verlag für Bauwesen, Berlin, 1986.

6.1296 .1336 .1356 .137

AALTO, Alvar; The architectural drawings of Alvar Aalto, 1917-1939 Vol.5, Helsinki Stadium, Zagreb Central Hspital and Other Buildings and Projects, 1930-1932.Garland, New York, London, 1994.

6.1346 .138

SCHILDT, Göran; Alvar Aalto. Obra completa: arquitectura, arte y diseño. Editorial Gustavo Gili, S.A., Barcelona, 1996.

\section{CAPÍTULO 7}

7.017 .027 .47

MARTÍ ARÍS, Carlos (ed.); Las formas de la residencia en la ciudad moderna. Vivienda y ciudad en la Europa de entreguerras (1991).Ediciones Universidad Politécnica de Cataluña, Barcelona, 2000.

7.037 .047 .057 .067 .517 .52 
BANHAM, Reyner; La arquitectura del entorno bien climatizado (The architecture of well-tempered environment, 1969). Infinito, Bueno Aires 1975.

7.07

BOESIGER, W./STONOROV, O. (ed.); Le Corbusier. Oeuvre Complète. Volumen 1. 1910-1929. Les Editions d'Architecture, Zurich, 1970.

7.08

OCHSNER, A. J. / STURM A. /MEYER J.; The Organization, Construction and Management of Hospitals. Cleveland Press, Chicago, 1907.

7.097.107.86

Cecilia Ruiloba Quecedo

7.11

LE CORBUSIER; Précisions sur un état présent de l'architecture et de l'urbanisme. Crés, Paris, 1930.

7.12

O'BYRNE OROZCO, María Cecilia; El proyecto para el hospital de Venecia de Le Corbusier. Tesis doctoral del Dpto. de Proyectos Arquitectónicos de la Universidad Politécnica de Cataluña, Barcelona, 2007.

7.13

CROSET, P.A (ed.); Alvar Aalto, Visioni urbane. Skira, Ginevra-Milano, 1998.

7.14 7.17 7.18 7.53 7.54 7.55 7.56 7.57

COLOMINA, Beatriz; La Domesticidad en Guerra. Actar, Barcelona, 2006.

7.157 .167 .237 .247 .257 .267 .317 .367 .37

POULAIN, Roger; Hôpitaux Sanatoria. Vincent Fréal, Paris, 1932.

7.197 .20

GARCÍA-QUIÑONES, Belén (coor.); AC Documentos de Actividad Contemporánea. Publicados por el GATEPAC entre 1937 1937. Fundación Caja de Arquitectos, Barcelona, 2005.

7.217 .22

PETRILLI, Amedeo; /l testamento di Le Corbusier: il progetto per l'Ospedale di Venezia. Marsilio, Venezia, 1999.

7.277 .67

MARCO FRAILE, Ricardo/BUIL GUALLAR, Carlos (coors.); L'Architecture vivante. El documento del movimiento moderno. Revista editada por Albert Morancé 1923- 1933. Colegio Oficial de Arquitectos de Aragón, Zaragoza, 2004.

7.287 .297 .657 .66

MORETTI, Bruno; Ospedali. Ulrico Hoepli, Milano, 1935.

7.30

HITCHCOCK, Henry-Russell/JOHNSON, Philip; El Estilo Internacional: Arquitectura desde 1922 (The international style. Architetture since 1922, 1932). Colegio Oficial de Aparejadores y Arquitectos Técnicos de Murcia, Murcia, 1984.

7.32 7.33 7.34 7.46

IGLESIAS PICAZO, Pedro; La habitación del enfermo. Ciencia y arquitectura en los hospitales del Movimiento Moderno. Arquia/tesis n³2 Fundación Caja de Arquitectos, Barcelona, 2011.

7.35

AA.W.; Pol Abraham Architect 1891-1966. Collection Centre Pompidou, Musée National d'Art Moderne, Paris, 2005.

7.387 .39

MONTEYS, Xavier; Le Corbusier, obras y proyectos. Editorial Gustavo Gili, Barcelona, 2005.

7.407 .417 .427 .437 .447 .45

LOYER, François/GUÉNÉ, Hélène; Henri Sauvage. Les immeubles a gradins. Mardaga, Liège, Bruxelles, 1987.

7.487 .497 .507 .61

CREMNITZER, Jean-Bernard; Architecture et Santé : Les temps du sanatorium en France et en Europe. Éditions A. et J. Picard, Paris, 2005

7.58

MARCO FRAILE, Ricardo/BUIL GUALLAR, Carlos (coors.); L'Architecture vivante. El documento del movimiento moderno. Revista editada por Albert Morancé 1923-1933. Colegio Oficial de Arquitectos de Aragón, Zaragoza, 2004.

7.59

L'Architecture d'Aujourd'huin n'9, 1934.

7.60 
FRAMPTON, Kenneth; Historia crítica de la arquitectura moderna (Modern Architecture: A Critical History, 1980). Editorial Gustavo Gili, Barcelona, 2009.

7.62

BENEVOLO, Leonardo/MElOGRANI, Carlo/LONGO, Tommaso Giura; La Proyectación de la Ciudad Moderna (Roma Bari, 1977). Editorial Gustavo Gili, Barcelona, 2000.

7.63

COHEN, Jean-Louis /MICHELIS, Marco de/TAFURI, Manfredo; URSS 1917-1978. La cittá, L'architettura. Officina Edizioni, Roma, 1979.

7.64

WAGENAAR, Cor (ed.); The Architecture of Hospitals. NAi Publishers, Rotterdam, 2006.

7.687 .707 .72

Museo de Sanida e Higiene. Instituto de Salud Carlos III.

7.69

PIZZA, Antonio; Dispensario antituberculoso de Barcelona, 1933-1937. J. LI. Sert, J.B. Subirana y J. Torres Clavé. Colegio de Arquitectos de Almería, Almería, 1993.

7.71

COHEN, Jean-Louis /MICHELIS, Marco de/TAFURI, Manfredo; URSS 1917-1978. La cittá, L'architettura. Officina Edizioni, Roma, 1979.

7.64

WAGENAAR, Cor (ed.); The Architecture of Hospitals. NAi Publishers, Rotterdam, 2006.

7.687 .707 .72

Museo de Sanida e Higiene. Instituto de Salud Carlos III.

7.71

Revista Nacional de Arquitectura n 33, Ministerio del Gobernación, Dirección general de Arquitectura, Madrid, 1944.

7.74 7.75 7.76 7.77 7.78 7.79

PALANCA, José A. (prol.); Labor del Patronato Nacional Antituberculoso durante el último decenio. Patronato Nacional Antituberculoso, Madrid, 1946.

7.80

AALTO, Alvar; The architectural drawings of Alvar Aalto, 1917-1939 Vol.4, Paimio Tuberculosis Sanatorium, City of Turku 700th Anniversary Exhibition, Standard Furniture, and other buildings and projects 1929-1930. Garland, New York, London, 1994.

7.81

FLEIG, Karl; Alvar Aalto, obras y proyectos (Basel, 1974). Editorial Gustavo Gili, Barcelona, 1998.

7.827 .837 .847 .857 .87

CREMNITZER, Jean-Bernard; Architecture et Santé : Les temps du sanatorium en France et en Europe. Éditions A. et J. Picard, Paris, 2005. 